\title{
Elements \\ of Structural Syntax
}

\section{Lucien Tesnière}

Translated by

Timothy Osborne and Sylvain Kahane

John Benjamins Publishing Company 
Elements of Structural Syntax 



\section{Elements of \\ Structural Syntax \\ Lucien Tesnière}

Translated by

Timothy Osborne

Zhejiang University

Sylvain Kahane

Université Paris Ouest Nanterre

John Benjamins Publishing Company

Amsterdam/Philadelphia 
The paper used in this publication meets the minimum requirements of the American National Standard for Information Sciences - Permanence of Paper for Printed Library Materials, ANSI z39.48-1984.

\section{Library of Congress Cataloging-in-Publication Data}

Tesnière, Lucien, 1893-1954.

[Éléments de syntaxe structurale English]

Elements of structural syntax / Lucien Tesnière ; translated by Timothy Osborne and Sylvain

Kahane.

p. $\mathrm{cm}$

Previously published by Paris : C. Klincksieck, 1965.

Includes bibliographical references and index.

1. ammar, Comparative and general--Syntax. 2. Structural linguistics. I. Osborne,

Timothy John, translator. II. Kahane, Sylvain, translator. III. Title.

P291.T413

2015

$415-$-dc23

2014021968

ISBN 9789027212122 (Hb; alk. paper)

ISBN 9789027269997 (Eb)

An electronic version of this book is freely available, thanks to the support of libraries working with Knowledge Unlatched. $\mathrm{KU}$ is a collaborative initiative designed to make high quality books Open Access for the public good. The Open Access ISBN for this book is 9789027269997.

(C) 2015 - John Benjamins B.V.

This e-book is licensed under a Creative Commons CC BY-NC-ND license. To view a copy of this license, visit https://creativecommons.org/licenses/by-nc-nd/4.0/. For any use beyond this license, please contact the publisher.

John Benjamins Publishing Company · https://benjamins.com 


\section{Author's dedication}

A mes enfants, Michel, Bernard et Yveline Tesnière, je dédie ce livre dont leurs curiosités d'élèves de sixième A ont hâté la maturation.

'To my children, Michel, Bernard and Yveline Tesnière, students at the sixth grade level, I dedicate this book, the development of which has been promoted by their curiosities.'

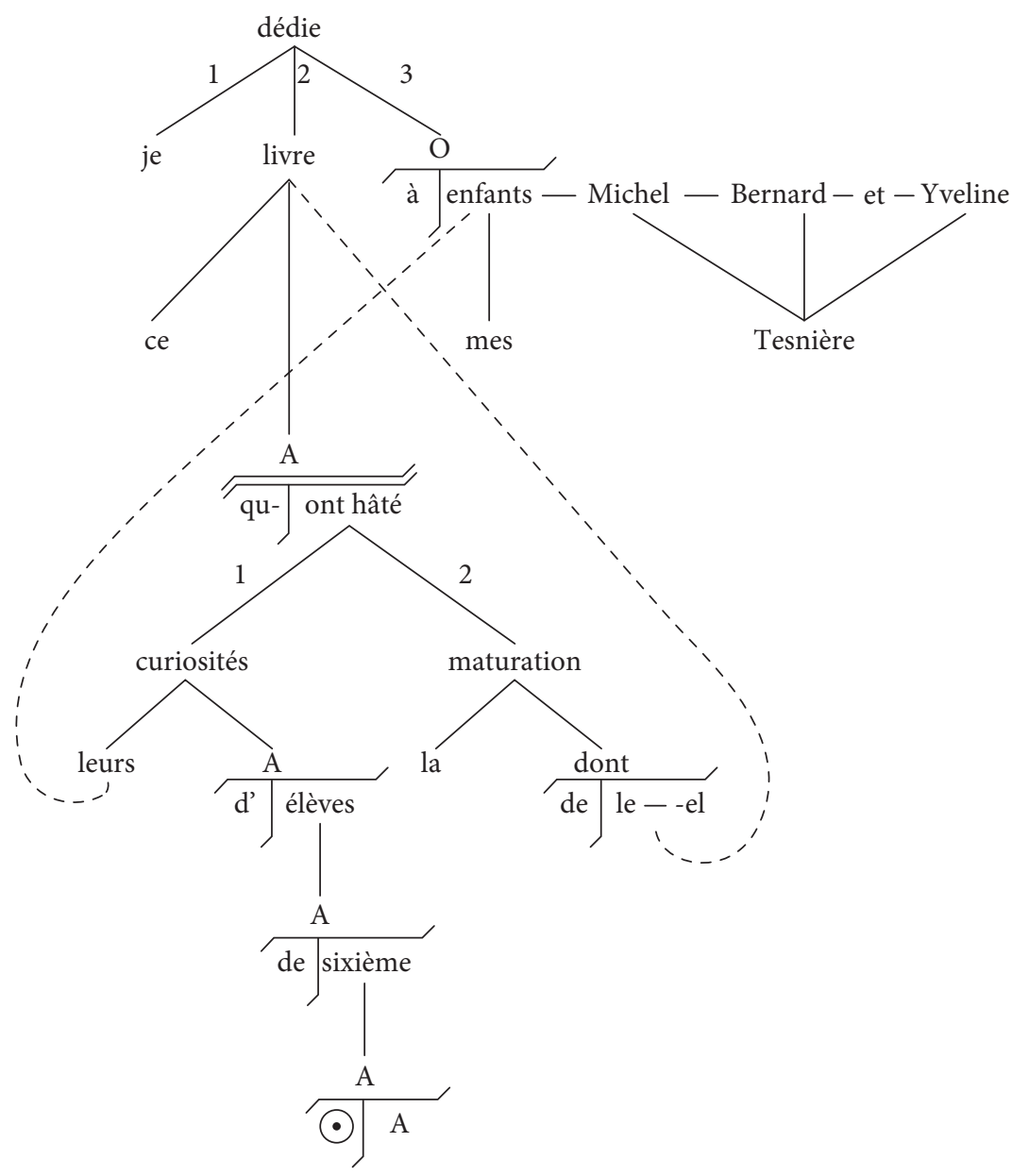




\section{Translators' acknowledgements and dedication}

We translators extend our great thanks to all those who have helped make this translation of Tesnière's Éléments a reality. The following linguists helped check the data from various languages as well as the related content: Yuri Bizzoni, Igor Mel'čuk, Özlem Çetinoğlu, Nicolas Mazziotta, Vered Silber-Varod, András Imrényi, Mikel L. Forcada, Federico Sangati, Dina El Kassas, Junying Liang, Jarmila Panevova. The following linguists provided helpful commentary and information concerning our translators' introduction: Richard Hudson, Kim Gerdes, Thomas Groß, Daniel Maxwell, Nicolas Mazziota, and Marie-Hélène Tesnière. Rachel Bawden receives special thanks for the tremendous scrutiny she devoted to the content and language in the first half of the volume. Finally, our thanks also extend to the team at John Benjamins publishing for taking on and supporting the project, as well as for the patience exercised when confronted with the difficult and tedious typesetting.

We would like to dedicate this translation to the dependency grammar (DG) community in general. We hope the volume helps motivate further investigations into the nature of dependencies.

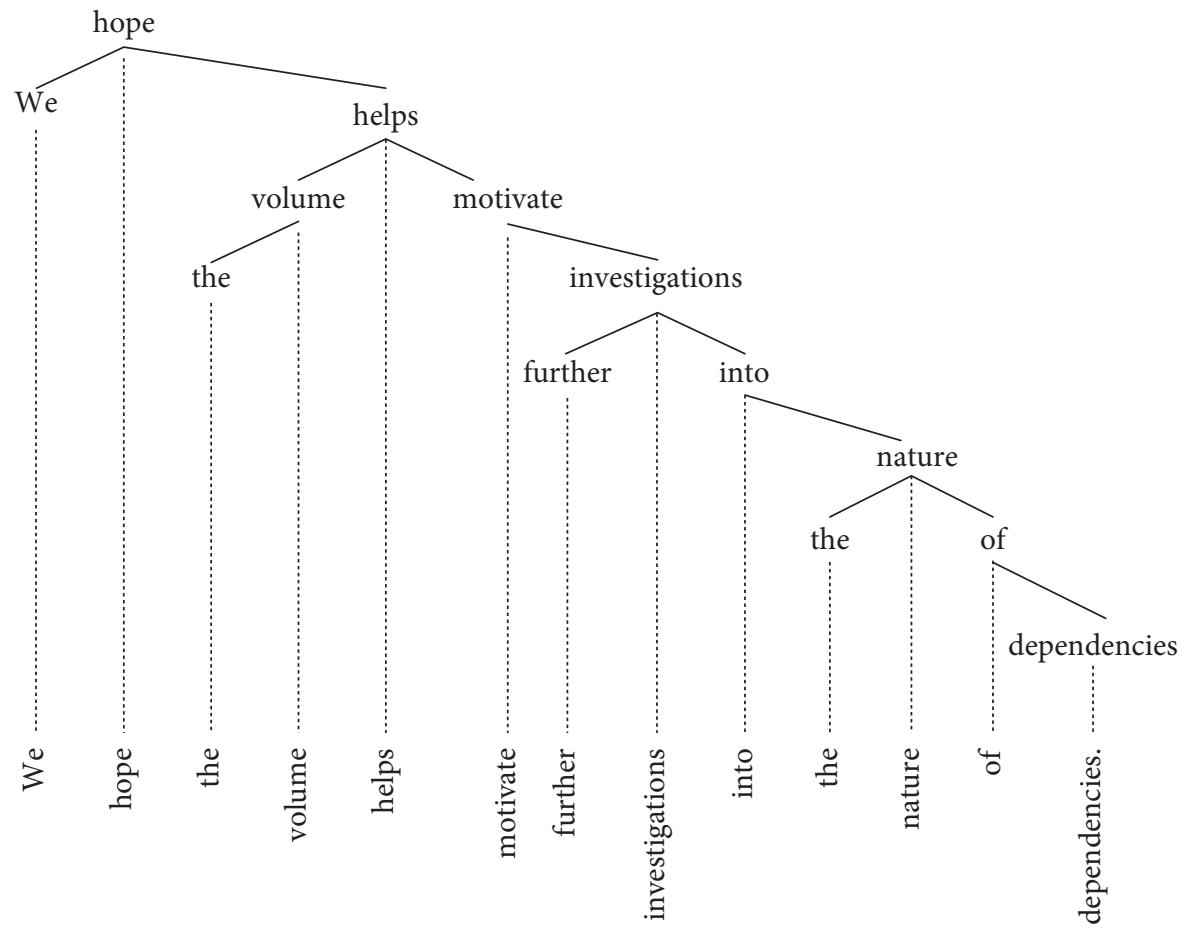




\section{Table of contents}

List of stemmas

XVII

Translators' Introduction

XXIX

Forewords

LXXV

Preface to the first original edition

LXXVII

Preface to the second original edition

LXXXI

PART I. The connection

BOоK A. Preamble

I. Structure

Chapter 1 . The connection 3

Chapter 2. Hierarchy of connections 5

Chapter 3. Node and stemma 6

Chapter 4. Structural order 9

Chapter 5. The spoken chain 10

Chapter 6. Structural and linear order $\mathbf{1 1}$
a) Order

Chapter 7. Antinomy between structural and linear order 13

Chapter 8. Direction of linearization 15

Chapter 9. Strict order 17

b) Adherence

Chapter 10. The word $\mathbf{1 8}$

Chapter 11. Agglutination 20

c) Classification

Chapter 12. Classification of languages $\mathbf{2 1}$

Chapter 13. Humboldt's historical and typological classification $\mathbf{2 3}$

Chapter 14. Classification according to the direction of linearization $\quad 25$

II. Form

Chapter 15. Syntax and morphology 27

Chapter 16. Morphological markers $\mathbf{2 8}$

Chapter 17. The zero marker 29

Chapter 18. The introspective method 30

III. Function

Chapter 19. Structure and function 32

IV. Meaning

Chapter 20. Distinguishing between structure and meaning 33

Chapter 21. Relationships of structure and meaning 35

Chapter 22. The nucleus 38 
Chapter 23. The dissociated nucleus 40

Chapter 24. Categories 41

Chapter 25. Categories and functions 42

Chapter 26. Static and dynamic order 43

V. Types of words

Chapter 27. Traditional types of words 44

Chapter 28. Full and empty words 46

Chapter 29. Constitutive and subsidiary words 48

Chapter 30. Variable and invariable words $\mathbf{5 1}$

Chapter 31. Full words 52

Chapter 32. Types of full words 54

Chapter 33. Symbols and the virtual sentence 56

Chapter 34. The noun 59

Chapter 35. The adjective 61

Chapter 36. The verb 64

Chapter 37. The adverb 67

Chapter 38. Empty words 73

Chapter 39. Junctives 74

Chapter 40. Translatives 75

Chapter 41. Indices 76

Chapter 42. Anaphoric connection 78

Chapter 43. Anaphors 83

Chapter 44 . The method of composite words 85

VI. Types of sentences

Chapter 45. Sentence words $\mathbf{8 8}$

Chapter 46. Classification of sentence words 91

Chapter 47. Types of sentences 94

воок в. Structure of the simple sentence

I. Verbal node

Chapter 48. The verbal node 97

Chapter 49. Subject and predicate 98

a) Actants

Chapter 50. Actants 100

Chapter 51. Types of actants 102

Chapter 52. Types of actants across languages 106

Chapter 53. Personal nouns 109

Chapter 54. Gender of personal nouns $\mathbf{1 1 2}$

Chapter 55. Number in personal nouns $\mathbf{1 1 5}$ 
b) Circumstants

Chapter 56. Circumstants $\mathbf{1 1 8}$

Chapter 57. The dividing line between actants and circumstants 121

c) Direct subordinates of the verb

Chapter 58. The structure of the verbal node in German $\quad 122$

Chapter 59. Indices $\mathbf{1 2 5}$

Chapter 60. Oblique personal indices $\mathbf{1 2 8}$

Chapter 61. Indices and conjugations $\mathbf{1 3 2}$

Chapter 62. Object conjugation 135

II. Nominal node

Chapter 63. The attributive adjective 139

Chapter 64. The attributive adjective in mitigated languages $\mathbf{1 4 2}$

Chapter 65. Non-adjectival attributes $\mathbf{1 4 5}$

Chapter 66. The predicative adjective $\mathbf{1 5 0}$

Chapter 67. Sentences with 'be' 154

Chapter 68. Predicates of the second and third actants 157

Chapter 69. The apposition 159

Chapter 70. The adjective in apposition 162

Chapter 71. The apostrophe 165

Chapter 72. The projection of actants 169

Chapter 73. The nominal sentence $\mathbf{1 7 4}$

III. Adjectival node

Chapter 74. The adjectival node 179

Chapter 75. The adjectival sentence $\mathbf{1 8 3}$

IV. Adverbial node

Chapter 76. The adverbial node $\mathbf{1 8 4}$

Chapter 77. The adverbial sentence 186

воок с. Question and negation

Chapter 78. Question and negation 191

Chapter 79. Nuclear interrogative 192

Chapter 80. General interrogative words 194

Chapter 81. Reinforced interrogative words in French 198

Chapter 82. Binuclear interrogatives 201

Chapter 83. Connective interrogatives 203

Chapter 84. The marker of connective interrogatives 206

Chapter 85. Responses to connective interrogatives 210

Chapter 86. Exclamatives 215

Chapter 87. Nuclear negation $\mathbf{2 1 7}$ 
Chapter 88. Connective negations $\mathbf{2 1 8}$

Chapter 89. Anticipating negation 221

Chapter 90. Agreement of junctives with negation $\mathbf{2 2 2}$

Chapter 91. Double-trigger negation in French 224

Chapter 92. The French discordantial 224

Chapter 93. French forclusives $\mathbf{2 2 7}$

Chapter 94. Extension and evolution of double-trigger negation 229

Chapter 95. Double negation $\mathbf{2 3 2}$

Chapter 96. Permeable negation 235

BOoK D. Valency

Chapter 97. Valency and voice 239

Chapter 98. Avalent verbs $\mathbf{2 4 0}$

Chapter 99. Monovalent verbs 241

Chapter 100. Transitive verbs 243

Chapter 101. The active diathesis 244

Chapter 102. The passive diathesis $\mathbf{2 4 5}$

Chapter 103. The reflexive diathesis $\mathbf{2 4 8}$

Chapter 104. The reflexive possessive adjective 253

Chapter 105. The reciprocal diathesis $\mathbf{2 5 5}$

Chapter 106. Trivalent verbs 256

Chapter 107. Variation in the number of actants $\mathbf{2 6 0}$

Chapter 108. The causative diathesis, the new actant 261

Chapter 109. Causative and passive 264

Chapter 110. Causative and reflexive in French 265

Chapter 111. New valency 267

Chapter 112. Analytical markers of new valency 268

Chapter 113. Synthetic markers of new valency 269

Chapter 114. New valency with a zero marker 273

Chapter 115. The recessive diathesis with a reflexive marker $\quad 274$

Chapter 116. The recessive diathesis with a passive marker $\quad \mathbf{2 7 8}$

Chapter 117. The recessive diathesis with a zero marker 279

Chapter 118. Different degrees of the recessive $\mathbf{2 8 0}$

Chapter 119. Causative and recessive in French 283

BOOK E. Metataxis

Chapter 120. Metataxis $\mathbf{2 8 5}$

Chapter 121. Simple metataxis $\mathbf{2 8 6}$

Chapter 122. Inversion of actants $\mathbf{2 8 8}$

Chapter 123. Double inversion of actants $\quad \mathbf{2 8 9}$

Chapter 124. Inversion of actants and circumstants 292 
Chapter 125. Metataxis and the passive 294

Chapter 126. Metataxis and causatives 295

Chapter 127. Metataxis and anti-causative 300

Chapter 128. Semantic reversal of nodes connected vertically 301

Chapter 129. Change of the structural center 304

Chapter 130. Resultative adverbs 310

Chapter 131. Movement and displacement 311

Chapter 132. Change of the structural center via subordination 313

Chapter 133. Parataxis and hypotaxis 316

PART II. Junction

Chapter 134. Complications of the simple sentence 325

Chapter 135. Duplication and junction 326

Chapter 136. Graphic representations 328

Chapter 137. Junction without a junctive 329

Chapter 138. Linear varieties of junctives 332

Chapter 139. Semantic varieties of junctives 334

Chapter 140. Antinomic junctives 334

Chapter 141. Dialectic junctives 338

Chapter 142. Justificational junctives 339

Chapter 143. Structural variety of junction 341

Chapter 144. Plexus 344

Chapter 145. Bifid sentences 349

Chapter 146: Double bifidity 352

Chapter 147. Sentences with comparison 354

Chapter 148. Sentences with a comparative 356

Chapter 149. Anaphoric junction 358

Chapter 150. Connective junction 360

PART III. Transfer

воок A. Introduction

I. Theory

Chapter 151. The theory of transfer 365

Chapter 152. The mechanism of transfer 368

Chapter 153. The role and importance of transfer 369

Chapter 154. The terminology of transfer $\mathbf{3 7 0}$

Chapter 155. The graphic representation of transfer 371

Chapter 156. Transfer in stemmas 373

Chapter 157. Translative and nucleus 375 
Chapter 158. The life and evolution of transfer 376

Chapter 159. The survival of transfer 379

Chapter 160. Markers of transfer 381

Chapter 161. The agglutination of translatives $\quad 382$

Chapter 162. Transfer without a marker 384

Chapter 163. Transfer and linguists 385

II. Varieties

Chapter 164. Varieties of transfer in stemmas 389

Chapter 165. Nuclear varieties of transfer 391

Chapter 166. Formal transfer 393

Chapter 167. Categorical varieties of transfer 396

Chapter 168. Attenuated transfer 398

Chapter 169. Indices 400

Chapter 170. The auxiliary verb $\mathbf{4 0 2}$

Chapter 171. Empty preverbs 403

Chapter 172. Functional varieties of transfer 405

Chapter 173. Semantic varieties of transfer 406

Chapter 174. Derivation 407

Chapter 175. Composition 409

III. Classification

Chapter 176. Classification of the facts of transfer $\quad \mathbf{4 1 2}$

воок в. First-degree transfer, simple transfer

Chapter 177. Transfer of a specific adjective to a noun $(\mathrm{A}>\mathrm{O}) \quad 415$

Chapter 178. Transfer of a general adjective to a noun $(A>O) \quad 418$

Chapter 179. Transfer of an adverb to a noun $(\mathrm{E}>\mathrm{O}) \quad 420$

Chapter 180. The infinitive 421

Chapter 181. The evolution of the infinitive 423

Chapter 182. The infinitive clause $\mathbf{4 2 4}$

Chapter 183. Inferior connections to the infinitive 427

Chapter 184. Superior connections of the infinitive $\quad 429$

Chapter 185. Infinitives and diathesis 431

Chapter 186. Infinitives and mood 433

Chapter 187. Infinitives and temporal categories 435

Chapter 188. Infinitive and person 437

Chapter 189. Infinitives and number 440

Chapter 190. Infinitives and extension 441

Chapter 191. I > O transfer without an infinitive 442

Chapter 192. Transfer of a noun to a descriptive adjective (O > A) 444

Chapter 193. Transer of a noun to an adjective of color or material 447

Chapter 194. Transfer of a noun to an adjective $(\mathrm{O}>\mathrm{A}) \quad 449$ 
Chapter 195. Transfer of a noun to an adjective of quiddity 452

Chapter 196. Inverse sustantival and adjectival transfer 455

Chapter 197. Transfer of an adverb to an adjective (E > A) 457

Chapter 198. The participle 458

Chapter 199. The participle clause 461

Chapter 200. Evolution of the participle 463

Chapter 201. Transfer of a noun to an adverb $(\mathrm{O}>\mathrm{E}) \quad 467$

Chapter 202. Transfer of a noun to an adverb $(\mathrm{O}>\mathrm{E})$ by case 469

Chapter 203. Transfer of a noun to an adverb $(\mathrm{O}>\mathrm{E})$ without a marker 472

Chapter 204. Transvaluation 473

Chapter 205. Transfer of an adjective to an adverb (A > E) 476

Chapter 206. Transfer of a verb to an adverb, the gerundive 479

Chapter 207. Simple transfer to a verb 479

Chapter 208. Simple subcategory transfers $(A>A)$ and $(E>E) \quad 480$

воок с. First-degree transfer, multiple transfer

I. Double transfer

Chapter 209. Double transfer 483

Chapter 210. Classification of double transfer $\quad 484$

Chapter 211. Double $\mathrm{O}>\mathrm{A}>\mathrm{O}$ transfer with a double marker 486

Chapter 212. Double $\mathrm{O}>\mathrm{A}>\mathrm{O}$ transfer $\quad 488$

Chapter 213. Nouns denoting ships 491

Chapter 214. Inverse transfer $\mathrm{O}>\mathrm{A}>\mathrm{O} \quad 492$

Chapter 215. Double $\mathrm{O}>\mathrm{A}>\mathrm{O}$ transfer with the second transfer unmarked 494

Chapter 216. Nominal double transfer ending with the last transfer A > O 495

Chapter 217. Double I $>$ A $>$ O transfer 496

Chapter 218. Double transfer with the second transfer as $\mathrm{E}>\mathrm{O} \quad \mathbf{5 0 2}$

Chapter 219. Double transfer with the second transfer as $\mathrm{O}>\mathrm{A} \quad 503$

Chapter 220. Double $\mathrm{O}>\mathrm{E}>\mathrm{A}$ transfer 505

Chapter 221. Double I $>\mathrm{O}>$ A transfer 507

Chapter 222. Double transfer according to the formula

$$
\mathrm{A}>\mathrm{O}>\mathrm{E} \text { or } \mathrm{E}>\mathrm{O}>\mathrm{E} \quad 509
$$

Chapter 223. Double I $>\mathrm{O}>$ E transfer 510

Chapter 224. Double transfer with the second transfer as A > E or E > E 514

Chapter 225. Double transfer where the second transfer is verbal 519

Chapter 226. Nuclear elliptical transfer $\mathbf{5 2 2}$

Chapter 227. Connective elliptical transfer $\quad \mathbf{5 2 5}$

II. Triple transfer

Chapter 228. Triple transfer $\mathbf{5 2 8}$

Chapter 229. Triple transfer ending with O 529

Chapter 230. Triple transfer ending with A 533 
Chapter 231. Triple transfer ending with E 536

Chapter 232. Triple transfer ending with I 540

III. Quadruple transfer

Chapter 233. Quadruple transfer ending with $\mathrm{O} \quad 542$

Chapter 234. Quadruble transfer ending with A 543

Chapter 235. Quadruple transfer ending with E or I 546

IV. Quintuple, sextuple, and septuple transfer

Chapter 236. Quintuple transfer 546

Chapter 237. Sextuple transfer 548

Chapter 238. Septuple transfer 549

воок D. Second degree transfer, simple transfer

Chapter 239. Second degree transfer 551

Chapter 240. Correlation 552

Chapter 241. I $>>$ O transfer 553

Chapter 242. The marker of I $>>$ O transfer 556

Chapter 243. Connective indirect interrogatives 561

Chapter 244. Nuclear indirect interrogatives 564

Chapter 245. I $>>$ A transfer 565

Chapter 246. The marker of I >> A transfer 569

Chapter 247. The translative element of the personal pronoun $\quad 572$

Chapter 248. The anaphoric element in the personal pronoun 574

Chapter 249. Agreement of the anaphoric element 578

Chapter 250. Disjunction of the translative and anaphoric element 580

Chapter 251. Syntactic disjunction of the agglutinated relative pronoun 584

Chapter 252. The antecedent of the relative clause $\quad 587$

Chapter 253. Participle agreement 589

Chapter 254. I >> E transfer 593

Chapter 255. Circumstantials of time and place 595

Chapter 256. Causal clauses $\mathbf{6 0 0}$

Chapter 257. Conditional sentences 603

Chapter 258. The conditioning clause 606

Chapter 259. Hypothetical sentences $\mathbf{6 1 0}$

Chapter 260. Concessive clauses 614

Chapter 261. Consecutive clauses 616

Chapter 262. Final clauses 617

Chapter 263. Modal clauses $\mathbf{6 2 0}$

Chapter 264. Quantity clauses $\mathbf{6 2 2}$

Chapter 265. Generalized indeterminate clauses $\quad \mathbf{6 2 3}$

Chapter 266. Structural and semantic aspects of subordinate clauses $\quad \mathbf{6 2 7}$

Chapter 267. Advancement of the subordinate clause $\mathbf{6 3 0}$ 
BOок E. Second-degree transfer, multiple transfer

Chapter 268. Multiple transfer $\mathbf{6 3 3}$

Chapter 269. Double transfer 633

Chapter 270. Triple transfer 638

Chapter 271. Quadruple, quintuple, and sextuple transfer $\mathbf{6 4 2}$

BOoK F. Applications

Chapter 272. The complete stemma 645

Chapter 273. Using the stemma for the study of style $\mathbf{6 4 8}$

Chapter 274. Rhetorical sentences 649

Chapter 275. Short sentences $\mathbf{6 5 0}$

Chapter 276. Pedagogical directions $\mathbf{6 7 0}$

Chapter 277. The program for the study of structural syntax $\quad 674$

Chapter 278. Conclusion 677

Index of terms $\mathbf{6 8 1}$

Index of languages $\quad 691$

Index of linguists $\quad 695$

Index of citations 697 



\section{List of stemmas}

1. Alfred speaks (Alfred parle). 6

2. My friend speaks (Mon ami parle). 6

3. My old friend sings this lovely song (Mon vieil ami chante cette jolie chanson). 7

4. This lovely song charms my old friend (Cette jolie chanson charme mon vieil ami). 7

5. My old friend sings this very lovely song (Mon vieil ami chante cette fort jolie chanson). 7

6. Alfred hits Bernard (Alfred frappe Bernard). 7

7. Bifurcation 9

8. Double bifurcation 9

9. The small streams make the big rivers (Les petits ruisseaux font les grandes rivières). $\mathbf{1 2}$

10. This work concerns Louis XIV (Cet ouvrage concerne Louis XIV). 12

11. Tantae molis erat Romanam condere gentem. 13

12. cheval blanc $\mathbf{1 6}$

13. white horse $\mathbf{1 6}$

14. un chemin montant, sablonneux, malaisé $\mathbf{1 6}$

15. le cheval blanc $\mathbf{1 6}$

16. wayyibräà élōhìm 'et hā 'ādām $\mathbf{1 8}$

17. Kaya mektubunu aldı $\mathbf{1 8}$

18. your young brother (votre jeune frère) 30

19. Le signal vert indique la voie libre. 34

20. Le silence vertébral indispose la voile licite. 34

21. small streams (petits ruisseaux) 36

22. small streams (petits ruisseaux, structural dependency) 36

23. small streams (petits ruisseaux, semantic dependency) 36

24. le livre d'Alfred 37

25. small streams (dashed connection line) 37

26. Alfred speaks. (Alfred parle, nucleus). 39

27. Alfred has arrived (Alfred est arrivé, nucleus). 39

28. Alfred is big (Alfred est grand, nucleus) 39

29. Ni fu-tśhin ču tsai ni-men ti fang-tse li mo? 47

30. Does your father live in your house? (Ton père habite-t-il dans votre maison?, nucleus) 47

31. The horses ate the hay (Les chevaux mangèrent le foin). 47

32. le livre d'Alfred (nucleus) 49

33. Il regarde le livre d'Alfred (nucleus).

34. Il aime les roses (nucleus). 51 
35. Il amat illas rosas. $\quad \mathbf{5 1}$

36. bona mente 51

37. bonne-ment (nucleus) 51

38. Personne n'a rien vu. 53

39. Hier Alfred a oublié son chapeau. 54

40. On oublie toujours quelque chose. 54

41. a light dinner (un dîner léger) 56

42. He dines lightly (Il dîne légèrement). 56

43. Your young cousin sings delightfully (Votre jeune cousine chante délicieusement, real). 57

44. A O A I E (Votre jeune cousine chante délicieusement, virtual). 57

45. This old witch squints terribly (Cette vieille sorcière louche affreusement, real). $\quad 58$

46. A O A I E (Cette vieille sorcière louche affreusement, virtual). $\quad 58$

47. A O I (Alfred parle bien, virtual) 58

48. Alfred speaks well. 58

49. Alfred spricht gut. 58

50. Aulus bene loquitur. 58

51. čej èto dom? 63

52. À qui est cette maison? 63

53. Ci-gît Biron. 65

54. L'arbre est vert. 65

55. Arbor viret. 65

56. Der Baum grünt. 65

57. Alfred est debout. 65

58. Aulus stat. 65

59. Alfred steht. 65

60. Tamet' tehousi. 65

61. tamet tehousit 65

62. O I O O (Humans fear poverty and death, virtual) 73

63. Humans fear poverty and death (Les hommes craignent la misère et la mort). 73

64. A O (the blue of Prussia, virtual) 73

65. the blue of Prussia (le bleu de Prusse, virtual) 73

66. Alfred loves his father (Alfred aime son père). $\quad 78$

67. Vous remettrez la valise de ma tante à son mari et sa clef à leur fils. $\mathbf{8 2}$

68. Alfred calls his dog (Alfred siffle son chien). 85

69. Voici votre chapeau. 91

70. Do you have your book? - Yes (Avez-vous votre livre? - Oui). 91

71. six strong horses (six forts chevaux) 94

72. extremely young (extrêmement jeune) 94

73. relatively quickly (relativement vite) 94 
74. Le stupide XIXe siècle 95

75. Ouvert la nuit 95

76. À la recherche du temps perdu 95

77. Alfred gives the book to Charles (Alfred donne le livre à Charles). 97

78. Alfred always sticks his nose everywhere (Alfred fourre tourjours son nez partout). 97

79. Alfred speaks slowly (Alfred parle lentement). 99

80. Filius amat patrem. 99

81. Your young friend knows my young cousin (Votre jeune ami connaît mon jeune cousin). 99

82. A O A A O I A (virtual stemma of the preceding example) 99

83. Your young friend knows my young cousin (Votre jeune ami connaît mon jeune cousin). 99

84. A O A I A O A (virtual stemma of the preceding example) 99

85. Filius amat patrem. 100

86. Pater amatur a filio. $\mathbf{1 0 0}$

87. Filius amat patrem. 100

88. Pater amatur a filio. $\mathbf{1 0 0}$

89. Pluit. 101

90. Il pleut. 101

91. Alfred falls (Alfred tombe). 101

92. Alfred and Antoine fall (Alfred et Antoine tombent). 101

93. Alfred and Antoine fall $=$ Alfred falls + Antoine falls $($ Alfred tombe + Antoine tombe $=$ Alfred et Antoine tombent). $\quad 101$

94. Alfred can give the book to Charles (Alfred peut donner le livre à Charles). $\quad 102$

95. Bernard is hit by Alfred (Bernard est frappé par Alfred). 104

96. The book is given to Charles by Alfred (Le livre est donné par Alfred à Charles). 104

97. Alfred is speaking. 106

98. Ho Alexandros legei. 106

99. Aulus loquitur. 106

100. Gizona ona da. 106

101. Gizonak erraiten du. 106

102. Kac'man cigni dacera. 107

103. Alfred is striking Bernard. 107

104. Barē sìt bārā' ělōhìm 'et haššāmayim wa 'et hā 'āres. 107

105. Petrul frapǔ pe Gianul. 107

106. Quién no ha visto a Sevilla? 107

107. Tòn patéra kharizei ho uhiós. 108

108. Der Sohn liebt den Vater. 108

109. Syn ljubit otca. $\mathbf{1 0 8}$ 
110. Bernhard wird von Alfred geschlagen. 108

111. Grob nesom tavariščami. 108

112. Homines cupiditate ducuntur. $\mathbf{1 0 8}$

113. Wayyō'mer élōhìm 'el-'abrāhām 108

114. Ho Aléxandros dídōsi to biblíon tōi Gabriēl. 108

115. Aulus dat librum Caio. 109

116. Der Alfred gibt dem Karl das Buch. 109

117. Anton daët knigu Gavrile. 109

118. Alfred is departing tomorrow at noon (Alfred part demain à midi). $\quad \mathbf{1 1 8}$

119. Parla sempre. $\mathbf{1 1 8}$

120. Tha čhang šsuo. $\mathbf{1 1 8}$

121. Je l'estime naturellement toujours beaucoup. 119

122. On le voit toujours beaucoup partout. 119

123. Alfred passera rapidement là-bas demain. $\quad 119$

124. On aime naturellement toujours beaucoup ses parents. 119

125. Marie vous rendra sûrement votre livre demain. $\mathbf{1 2 0}$

126. Peut-être connaissez-vous déjà mon nom. 120

127. Toujours la tyrannie a d'heureuses prémisses. 120

128. Un traître ne doit jamais être imité. $\quad 120$

129. Fourquet's figure of a key ring $\mathbf{1 2 3}$

130. Alfred vous en remercie beaucoup. 127

131. J'en remercie la Providence. $\mathbf{1 2 7}$

132. your young cousin (votre jeune cousine) $\mathbf{1 4 0}$

133. Your young cousin sings a song (Votre jeune cousine chante une chanson). $\mathbf{1 4 0}$

134. Everyone admires your young cousin (Chacun admire votre jeune cousine). $\mathbf{1 4 0}$

135. Alfred gives a book to your young cousin (Alfred donne un livre à votre jeune cousine). $\mathbf{1 4 0}$

136. your pretty little white cat (votre joli petit chat blanc) $\mathbf{1 4 0}$

137. a magnificent book (un livre magnifique) $\mathbf{1 4 1}$

138. Your young cousin gave a magnificent book to my poor nephew (Votre jeune cousine donne à mon pauvre neveu un livre magnifique). $\quad \mathbf{1 4 1}$

139. un livre de raison $\mathbf{1 4 6}$

140. le train de Paris $\mathbf{1 4 6}$

141. la Tour Eiffel $\mathbf{1 4 6}$

142. le boulevard Gambetta $\mathbf{1 4 6}$

143. le dîner Durand $\mathbf{1 4 6}$

144. l'affaire Dreyfus $\mathbf{1 4 6}$

145. ein Glas Bier 147

146. a glass of beer (un verre de bière) 147

147. the man who writes (l'homme qui écrit) $\mathbf{1 5 0}$ 
148. the man who you see (l'homme que vous voyez) $\mathbf{1 5 0}$

149. the red car that you saw yesterday (l'auto rouge que vous avez vue hier) $\mathbf{1 5 0}$

150. Kiv bur. 151

151. Dom nov $\mathbf{1 5 1}$

152. bur kiv $\mathbf{1 5 1}$

153. novyj dom 151

154. Pántōn métron ánthrōpos $\mathbf{1 5 2}$

155. Triste lupus stabulis. $\mathbf{1 5 2}$

156. The house is new (La maison est neuve). 156

157. The house is new (La maison est neuve, dissociated nucleus). 156

158. Pour vivre heureux, vivons caché. $\mathbf{1 5 6}$

159. Je t'aimais inconstant, qu'aurais-je fait fidèle. $\mathbf{1 5 7}$

160. Cicero erat consul. $\quad \mathbf{1 5 8}$

161. Romani creaverunt Ciceronem consulem. $\quad 158$

162. J'appelle un chat un chat. $\mathbf{1 5 8}$

163. Romani Ciceronem consulem creaverunt. 159

164. Otioso mihi esse non licet. 159

165. Louis XIV protected the letters and the arts (Louis XIV, roi de France, protégea les lettres et les arts). $\quad \mathbf{1 6 0}$

166. A remarkable orator, Atticus was a mediocre writer (Orateur remarquable, Atticus était un écrivain mediocre). 161

167. Mortuus est pauper. 165

168. Amo te, Domine. 165

169. Amo vos, fratres mei. 165

170. Prends un siège, Cinna. 166

171. Le loup, il a mangé l'agneau. (projection of actants) $\mathbf{1 7 0}$

172. Le loup, il a mangé l'agneau. $\mathbf{1 7 0}$

173. Toi, tu chanteras; moi, je danserai. 171

174. Schema (summarizes the connections explored in Chapter 72) 174

175. un livre extrêmement joli 179

176. un très beau livre $\mathbf{1 7 9}$

177. Ce livre est très beau. $\mathbf{1 7 9}$

178. Ce livre me plait beaucoup. 179

179. ici-bas $\mathbf{1 8 5}$

180. ci-après $\mathbf{1 8 5}$

181. Il m'a reçu fort aimablement. $\mathbf{1 8 5}$

182. Il marche extrêmement vite. $\mathbf{1 8 5}$

183. Cela se fait relativement très facilement. $\quad \mathbf{1 8 5}$

184. une facilité relative $\mathbf{1 8 5}$

185. relativement facile $\mathbf{1 8 5}$ 
186. relativement facilement $\mathbf{1 8 5}$

187. plus grand que Bernard $\mathbf{1 8 6}$

188. Alfred is singing a song (Alfred chante une chanson). 193

189. ? is singing (? chante). 193

190. Which book is Alfred reading? (Quel livre lit Alfred?). 195

191. Alfred is reading the red book (Alfred lit le livre rouge). 195

192. En quoi faisant obtiendrais-je tel résultat? 195

193. Ti pathōn sautòn es toùs tēs Aítnēs kratēras enébales? 195

194. Who is singing a song? (Qui chante une chanson?). 198

195. Qui est-ce qui chante une chanson? 198

196. Table of interrogatives 199

197. Table of relatives 199

198. Table of relative interrogatives 199

199. Table of Arabic chasse-croisé 200

200. Table of composed interrgatives 200

201. Alfred chante-t-(il)? 205

202. Venietne Aulus? 209

203. Aulusne veniet? 209

204. Alfred does not sing. $\quad 218$

205. Schema: Alfred ne chante pas (discordantial and forclusive). 225

206. Alfred gives to the poor (Alfred donne aux pauvres). 240

207. Alfred gives a hand (Alfred donne la main). 240

208. Alfred sleeps (Alfred dort). $\mathbf{2 4 2}$

209. Alfred kills himself (Alfred se tue). $\mathbf{2 4 2}$

210. Alfred and Bernard kill each other (Alfred et Bernard s'entretuent). 242

211. Me adsum qui feci (unexpressed action, unexpressed first actant). 245

212. Antonius a Burrho verberatur. 245

213. Le maître aime son élève, mais déteste ses défauts (Latin type eius vitia). 255

214. Le maître aime son élève, mais déteste ses défauts (Latin type sua vitia). 255

215. Alfred et Bernard se frappent l'un l'autre. 256

216. cum... multa crudeliter... fecisset. 287

217. après de nombreux actes de cruauté $\mathbf{2 8 7}$

218. Tela milites deficiunt. $\mathbf{2 8 8}$

219. Les traits font défaut aux soldats. $\quad \mathbf{2 8 8}$

220. I miss you. 290

221. Vous me manquez. 290

222. Die grosse Gefahr entmutigte ihn nicht. 302

223. La grandeur du danger ne le décourageait pas. 302

224. Antonius modo profectus est. 306

225. Antoine vient de partir. 306 
226. Er ist bekanntlich schon tot. 308

227. On sait qu'il est déjà mort. 308

228. Décidément, cet homme est fou. 309

229. Après mûr examen il est certain que cet homme est fou. 309

230. Anton schwimmt über den Fluss. 313

231. Antoine traverse le fleuve en nageant. 313

232. Mit knapper Not entging er seinen Feinden. 314

233. Il eut bien de la peine à échapper à ses ennemis. 314

234. Uže ja c trudom različal otdalennye predmety. 315

235. J'avais déjà de la peine à distinguer les objets éloignés. 315

236. Anton schlägt Bernhard. 315

237. C'est Antoine que frappe Bernard. 315

238. orare atque obsecrare 318

239. request insistently (prier intamment) 318

240. divellere ac distrahere 319

241. violently separate (séparer violemment) 319

242. spectator et testis $\mathbf{3 2 0}$

243. un témoin oculaire 320

244. moderatio et sapientia 320

245. Sensible moderation (une sage modération) 320

246. jemandem etwas zur Unterschrift vorlegen 322

247. soumettre quelque chose à la signature de quelqu'un $\mathbf{3 2 2}$

248. Alfred and Bernard fall (Alfred et Bernard tombent). $\quad 328$

249. Alfred and Bernard fall (Alfred et Bernard tombent, with nucleus circles). $\quad 328$

250. Alfred and Bernard love their parents (Alfred et Bernard aiment leurs parents). 342

251. Alfred loves his father and his mother (Alfred aime son père et sa mere). 342

252. a fat and stout cat (un chat gras et dodu) 343

253. Toute sa personne velue représentait un ours, mais un ours mal léché. 343

254. The children laugh and sing (Les enfants rient et chantent). 343

255. Alfred buys new books and folders (Alfred achète des livres et des cahiers neuf). 343

256. The boys and the girls collect buttercups and daisies (Les garcons et les fillettes cueillent des renoncules et des pâquerettes). 343

257. These children give books and folders friends and poor schoolmates (Ces enfants donnent des livres et des cahiers neufs à leurs amis et à leurs camarades pauvres). 344

258. Alfred and Bernard work and Charles sings and laughs (Alfred et Bernard travaillent et Charles chante et rit). 344

259. The children love and honor their parents (Les enfants aiment et honorent leurs parents). 345 
260. The parents buy and give books to the children (Les parents achètent et donnent des livres aux enfants). 345

261. Alfred and Bernard play and laugh (Alfred et Bernard jouent et rient). 346

262. Alfred and Bernarnd love and honor their parents (Alfred et Bernard aiment et honorent leurs parents). 346

263. The children love and honor their father and their mother (Les enfants aiment et honorent leur père et leur mere). 346

264. Alfred and Bernard love and honor their father and their mother (Alfred et Bernard aiment et honorent leur père et leur mère). 347

265. The father and the mother buy and give the books and folders to Alfred and to Bernard (Le père et la mere achètent et donnent des livres et des cahiers à Alfred et à Bernard). 348

266. The teachers, the pedagogues, and the educators give, repeat, and trot out opinions, advice, and warnings to schoolchildren, pupils, and students (Les maîtres, les pedagogues et les éducateurs donnent, répètent et ressassent des avis, des conseils et des avertissement aux écoliers aux collégiens et aux lycéens). 348

267. Raton extracts and Bertrand eats the chestnuts (Raton tire et Bertrand croque les marrons). 350

268. Raton and Bertrand extract and eat the chestnuts (Raton et Bertrand tirent et croquent les marrons). 350

269. Le crime fait la honte et non pas l'échafaud. 351

270. Alfred loves cake and detests punishment (Alfred adore le gâteaux et déteste les punitions). 351

271. Alfred loves roses, not thorns (Alfred aime les roses, non les épines). 352

272. Il est bon de parler et meilleur de se taire. 352

273. L'un portrait sa cuirasse, l'autre son bouclier. 353

274. Alfred sleeps like a baby (Alfred frappe comme un sourd). 355

275. Alfred loves Bernard like a brother (as a brother loves Bernard) (Alfred aime Bernard comme un frère). 355

276. Alfred loves Bernard like a brother (like he loves a brother) (Alfred aime Bernard comme un frère). 355

277. le train de Paris 367

278. la gare de Sceaux 367

279. interné de la Résistance 367

280. interné de la Gestapo 367

281. the book of my friend (le livre de mon ami) 373

282. Write in the book of your friend (Écrivez dans le livre de votre ami). 374

283. le livre d'Alfred 374

284. un livre de raison 374

285. le train de Paris 374 
286. liber Petri 375

287. le livre de Pierre 375

288. a prince loved by the gods (un prince aimé de dieux) $\quad 378$

289. A O (une mer méditerranée, virtual) 380

290. a striking example (un exemple frappant) 383

291. illustre rejeton d'un prince aimé des dieux 383

292. liber Petri 383

293. Representation of a cascade structure of $\mathrm{O}>\mathrm{A}$ transfers 390

294. the cousin of the son of the wife of my uncle (le cousin du fils de la femme de mon oncle) 390

295. Type A $>$ O, inverse transfer 390

296. the three small boys (les trois petits garcons) 401

297. Moi, je danserai. 401

298. O > A (l'Aurore au doigts de rose) 411

299. O (la rose, flower) $>$ A (rose, adjective) 411

300. La mauvaise monnaie chase la bonne. 415

301. un plat plat 417

302. une bonne nouvelle 417

303. une nouvelle bonne 417

304. lequel 419

305. peu d'eau 421

306. Deus est sanctus. 425

307. Credo Deum esse sanctum. 425

308. Fateor me esse Atheniensem. 439

309. Homologō eînai Athēnaîos. 439

310. un poète de genie 445

311. un roi de bonn(e) aire 445

312. la tour Eiffel 446

313. la ville de Paris 453

314. un imbécile de marmiton 457

315. Où sont les neiges d'antan? 457

316. Alfred lives in Montpellier (Alfred habite à Montpellier). 469

317. Venit Romam. 469

318. rapport à Bernard (before transevaluation) 474

319. rapport à Bernard (after transevaluation) 474

320. excepté(s) les enfants 474

321. excepté les enfants 474

322. dans le vif $\mathbf{4 8 4}$

323. une dinde 487

324. celui de Bernard 487 
325. La meilleure leçon est celle des exemples. 488

326. un bâton de rouge 504

327. un drôle d'amoureux (virtual) 504

328. un homme de bien $\mathbf{5 0 4}$

329. grenouilles aussitôt de sauter dans les ondes $\mathbf{5 0 8}$

330. E A I 515

331. puer egregia indole 523

332. puer egregiae indolis $\mathbf{5 2 3}$

333. die Liebe zum Ruhm 524

334. l'amour de la gloire $\mathbf{5 2 4}$

335. Quorum in numero tu certe fuisses. 524

336. Quo in numero tu certe fuisses. 524

337. à cause de la guerre 525

338. Habitat ad aedem Castoris. 527

339. Interest ${ }^{*}$ (causa) regis. $\quad 527$

340. La difficulté fut d'attacher le grelot. 541

341. une âme de sans-culotte 544

342. Les beautés du monde d'ici-bas me donnent par avance une idée des joies de celui de l'au-delà. 550

343. Ad quos cum Caesar nuntios misisset, qui postularent eos, qui sibi Galliaeque bellum intulissent, sibi dederent, responderunt. 567

344. Die die die, die die Bäume beschädigen, anzeigen, werden belohnt. 568

345. l'homme qui écrit 571

346. l'homme qui écrit 571

347. Est enim in manibus laudatio, quam cum legimus, quem philosophum non contemnimus? 585

348. Schema: Est enim in manibus laudatio, quam cum legimus, quem philosophum non contemnimus? 585

349. la femme que j'ai vue peindre 592

350. la femme que j'ai vu peindre 592

351. les blés que nous avons vu semer 592

352. ceux que nous avons vus germer 592

353. Qui est-ce qui chante? 630

354. La cigale, ayant chanté tout l'été... (La Fontaine, La cigale et la fouemi) 655

355. Le vase où... (Sully Prudhomme, Le vase brisé) 657

356. Ithi dé kai... (Palto, Ion). 659

357. Ergo apud... (Tacitus, Dialogue of orators). 661

358. De même qu'on voit un grand fleuve... (Bossuet, Panégyrique de Saint Paul) 662

359. L'autre jour, au fond d'un vallon... (Voltaire). 651

360. Source délicieuse, en misères féconde... (Comeille, Polyeucte). 663 
361. Percé jusque au fond du cœur... (Comeille, Le Cid). 665

362. Le jour n'est pas plus pur que... (Racine, Phèdre). 653

363. Oui, je viens dans son temple adorer l'Eternel... (Racine, Athalie) 666

364. Promettez sur ce livre, et devant des témoins... (Racine, Athalie). 667

365. Tout reposait dans Ur... (Victor Hugo, Booz endormi). 668

366. J'aime à regarder de ma fenêtre (Anatole France, Le crime de Sylvestre Bonnard). 670 



\title{
Translators' Introduction
}

\author{
Sylvain Kahane \& Timothy Osborne
}

\section{Why now?}

The appearance of this translation occurs sixty years after Lucien Tesnière's death and fiftyfive years after the original publication of his Eléments (the term we use to refer to the French original of this translation). Given the tremendous developments in the field of syntax in the decades since, the question arises as to why now: why a translation of a work that appeared decades ago and that must certainly be outdated in its view of the theory of syntactic structure? There are of course a number of considerations that make up the answer to this question. Above all, Tesnière's theory is generally taken to be the starting point for our modern understanding of dependency syntax and dependency grammar (DG), and with the upsurge in interest in DG in recent years - coming mainly from the use of dependency as the basis for parsing natural languages in the field of computational linguistics - a fresh look at Tesnière's theory of syntax is warranted.

Tesnière died in 1954, and his Éléments appeared first five years later in 1959. Noam Chomsky's Syntactic Structures appeared in 1957, and from that point on, the study of syntax has been greatly influenced by Chomsky's ideas. While some took note of Tesnière's Éléments, the impact of Chomsky's works has certainly overshadowed all other developments in the field of syntax on the international stage. Tesnière died at the relatively young age of 61, and in the later years of his life, he was not healthy, a situation that slowed the work toward the publication of his Éléments. The fact that Tesnière was no longer alive when his ideas were being received and evaluated in the 1960s and that at that time Chomsky's ideas were taking full hold of the syntax world helps explain the reduced awareness of Tesnière's contribution to the field. Given Chomsky's tremendous influence, it was easy to overlook Tesnière's work. ${ }^{1}$

Tesnière was a Frenchman writing in French. Since the Second World War, the influence of English (as the international language) on academia and linguistics cannot be underestimated. For a theory of language to gain a large audience, access to that theory has to be available in English. Tesnière's Éléments is a massive work, 670 pages, and it

1. For instance, the French linguist M. Arrivé (1969), discussing whether Tesnière's syntax was transformational, writes: "For the linguist of today, Tesnière's theory is only of historical interest [...] Devised in relative solitude, the essential concepts of structural syntax are far removed from the trends in linguistics of the time" [translated from the French]. Cf. also Kabano (2000). 
contains examples from dozens of languages. It relies particularly heavily on data from Latin, ancient Greek, German, and Russian, whereby Tesnière employed the Greek alphabet for the Greek examples and the Cyrillic alphabet for the Russian examples; this practice probably reduced the accessibility of the work to a general audience. Further, Tesnière often provided examples taken from classical French literature to illustrate many of the points he was making. These examples can be difficult to understand, even for native speakers of French. To increase the accessibility of the translation in these areas, we have transliterated the Greek and Russian examples to the Roman alphabets and we have modernized the transliteration of the Chinese, Arabic and Hebrew examples. We have also added many literal translations, and at times we include a comment to help explain the point at hand.

Tesnière's main contribution to the study of syntax is indisputably the concept of dependency and the use of a dependency tree, i.e. a stemma, as the backbone of what he calls the structural order, that is, the hierarchical part of the syntactic representation, as opposed to the linear order. Tesnière was not the first linguist to draw dependency structures (see Coseriu 1980 and Rousseau 1995); certain aspects of his theory of syntax, such as verb centrality, overlap with the pioneering work of Jespersen (1924, 1937). But Tesnière was the first one to elaborate a complete linguistic theory based on the dependency concept and to propose dependency-based representations for the main constructions in numerous and varied languages. Tesnière devoted much effort to discussing the adequacy of dependency as the organizational principle underlying numerous phenomena. He augmented his dependency-based representations in several ways, introducing many additional concepts, such as a contrast between vertical and horizontal links for coordination (Chapter 134-150), apposition (Chapter 69), and dislocation (Chapter 72), special devices for transfer (Chapters 151-271), "weighted" dependencies (Chapter 169), and even dependencies between dependencies for scope phenomena (Chapters 65 and 68).

While dependency is the most profound concept that Tesnière introduced and built on, his contribution to the field of syntax is acknowledged in one specific area above all, regarding the concept of valency (Chapters 97-133). Most modern theories of syntax acknowledge and build on the notion of verb valency, and this is true even for theories that posit phrase structure - in a certain sense, phrase structure is the opposite of what Tesnière understood syntactic structure to be. The distinction between head-initial and head-final structures and languages (Chapters 28-32) is a second area where Tesnière's contribution to our modern understanding of syntax has been great, yet Tesnière rarely receives the credit he is due for his work in this area. With the appearance of this volume, we hope that Tesnière's influence on these and other areas of our modern understanding of syntactic structures can be fully appreciated.

Beyond the two areas just mentioned, the Éléments contain lesser known concepts and ideas that deserve more evaluation than they have heretofore received. This is particularly true of the theory of junction (Fr. jonction), Part II of the Éléments, and the theory 
of transfer (Fr. translation), Part III of the Éléments. In his relatively short discussion of coordination (35 pages, Chapters 134-150), which he gathers under the term junction, Tesnière produces an insightful analysis of particular mechanisms associated with coordinate structures, such as gapping and right node raising (RNR). These mechanisms were then later identified and explored in the 1970s. The fact that Tesnière had already insightfully examined these phenomena was overlooked. The theory of transfer (Chapters 151-271) is Tesnière's effort to reduce the number of word categories of content words to a bare minimum; he posited just four (nouns, verbs, adjectives, and adverbs). He also identified two categories of function words, junctives and translatives. The role of translatives is to transfer content words of one category to content words of another. Tesnière devotes 270 pages to the theory of transfer, developing the concept in great detail and producing examples of many possible types of transfer. This area of his theory merits more scrutiny than it has heretofore received, since it is a unique contribution to how humans employ language productively, multiplying the number of possible utterances to infinity.

The rest of this introduction considers the author who produced the Éléments (biographical information about Tesnière), the genesis of the book from 1932 to 1959, some of the main ideas in the œuvre, and the impact of the œuvre, i.e. the development of syntactic theory that takes the Éléments as its starting point. The greater goal here is to further increase the accessibility of Tesnière's theory beyond what the translation alone would provide.

\section{The author ${ }^{2}$}

Lucien Tesnière was born on May 13, 1893 in Mont-Saint-Aignan, a village that is now part of the suburb of Rouen, the main city of Normandy on the north-west of Paris on the Seine. His father was a notary and his mother was interested in the fine arts and practiced sculpture. From his mother he may have inherited "the creative instinct that motivates one to seek explanation further afield than conventional wisdom general goes

2. The present biography is mainly based on a résumé written by Tesnière himself for his application to the Université de Montpellier in 1937 (Tesnière 1937), a report on his activity probably written two years later (Tesnière 1939), and a necrology written by the egyptologist François Daumas (1957), who was his friend and colleague in Montpellier. We have also used his personal notes and letters found in the Fonds Tesnière from the Bibliothèque National de France (BNF) (reference NAF 28026, Boxes 1 to 69), as well as material from his granddaughter Marie-Hélène Tesnière (Tesnière 1995), who prepared the Fonds and has provided us with additional materials. Two other biographies of Tesnière have also been consulted: the preface of Madray-Lesigne and Richard-Zappella (1995) and the communication of the montpellierian grammarian Teddy Arnavielle (1995). 
as well as the desire to be engaged on the path of research" [translated from the French] (Daumas 1957).

He studied in Rouen and passed his baccalauréat Latin-Grec in 1910. He was 17. Attracted by the study of languages, he spent the next year in England to learn English and four months in Florence to learn Italian. He already knew German because he had studied it at school and spent several holidays in Germany, where he visited the German housekeeper who had worked for his parents since he was a small boy.

He entered at Sorbonne University in 1912 and graduated (licence-ès-lettres) in 1913 in German, with English as a second major and Old Norse as a minor. In 1913-1914, he continued his studies in Germany and Austria. At the University of Leipzig, he worked on Gothic, Old High German, Middle High German, Old Norse, and at that time he also received his first initiation in the Slavic languages. In Vienna, he took advantage of the numerous Yugoslavian students to learn Croatian. Still a student at Sorbonne, he presented a master's thesis written in German on the German mythologist Wilhelm Mannhardt in June of 1914.

He was 21 when WWI started. He was mobilized on August 12th and sent to the front on October 15th. Becoming a prisoner of war on the 16th of February 1915, he was interned in the camp at Merseburg with 4000 other prisoners from all nationalities. During his 40 months of captivity, he studied Hebrew and read the bible, he learned Russian, Low Breton, Latvian, Hungarian and some elements of Dutch and Finnish, and became friends with the hellenist Mario Meunier. During these years he worked for the German authorities as a French-English-Russian-Italian-German interpreter and practiced these languages every day. Tesnière had a very good ear: he was not only a polyglot, but also a remarkable musician, playing the piano and the zither.

Back in Paris in 1918, he worked at the Foreign Press Service, starting at the Englishspeaking press, then the German press, and finally he was asked to start a Yugoslavian section. In October of 1919, he was received to the agrégation (the top-level competitive examination for recruiting teachers) of German.

He spent the year 1919-1920 studying Russian at the École des Langues Orientales and linguistics at the Sorbonne with Joseph Vendryes and at the Collège de France with Antoine Meillet, who was the most prominent French linguist at this time. Meillet became his thesis supervisor. At the end of the school year, he was nominated GermanSlovene interpreter for the French delegation of the international commission on Carinthian Plebiscite. ${ }^{3}$ He was then invited as a lecturer to the University of Lubjana (now the capital of Slovenia), which at that time was part of the Kingdom of Yugoslavia. He

3. The voters of the north and west area of Carinthia decided on the 10th of October, 1920 to become part of the newly founded First Austrian Republic. 
stayed there four years and founded and ran the French Institute. Working on the dual in Slovene, he accumulated a large amount of various data, whereby he accorded as much attention to spoken data as to the written word. For instance he studied "lonely hearts" advertisements, which focused on girls looking for a husband, seeking to discover how they imagine their future life à deux (Fourquet 1996). He thus developed an Atlas of the dual forms in Slovene according to the "geographic method" of Gilliéron. The dual in Slovene was disappearing, but contrary to what was expected according dogma in IndoEuropean studies at the time, Tesnière showed that there was no correlation between the social level of the speakers and the use of the dual and that the dual could be disappearing in a rural area while still alive in a more industrial area. The cause was elsewhere, partly in the state of the phonological system. His thesis, entitled Les formes du duel en slovène [Forms of dual in Slovene], was defended in May 1925 and received the Volney prize of the Académie française in 1926. He also produced a translation of the poems of Oton Župančič in French (Tesnière 1931), considering that "a good linguist must know to be a good translator" (Tesnière 1939).

In January 1921, Lucien Tesnière married Jeanne Roulier in Zagreb; she often participated in his reasearch. Tesnière fathered three children, each of whom excelled in academia (Daumas 1957).

In February 1924, Tesnière became associate professor of Slavic language and literature at the University of Strasbourg (the capital of Alsace on the border to Germany), where he taught Russian and Old Slavic. He took scientific missions to Russia $(1926,1929,1936)$ and Czechoslovakia $(1927,1928)$, where he learned Czech and the rudiments of Slovakian. In 1929 he officially started a big project, an atlas of the Slavic languages with Meillet; he was also involved in statistical studies of Alsacian at the time. His Petite Grammaire russe was published in 1934.

One hour per week he taught French to Slavic speakers at the Institut d'Etude Française modernes de la Faculté: "Instructing foreigners is, due to the continual comparisons that it imposes across French and idioms with different structures, an excellent way to increase general linguistic knowledge" (Tesnière 1939). At this time he was above all working on his Grammaire du français pour étrangers (1200 pages). In the introduction to this unpublished work - the reason it was unpublished is explained below in Section 3 - Tesnière wrote with humor and insight:

"A Frenchman can produce a good descriptive and synchronic grammar of the Patagonian language because it is not his mother tongue and does not descend from Latin, simply stated, because he views it from the outside, without being troubled by the fancies of Patagonian grammarians. Conversely, in order to produce a good descriptive and synchronic grammar of French, no one is in a better position to do that than a Patagonian who is ignorant of the body of literature produced by French grammarians and who has only the language in front of him to describe. Concerning 
the current grammar, the author can claim only one merit, i.e. that of imposing on himself the perspective of a Patagonian throughout the exposé."

(Fonds Tesnière, Box 33) ${ }^{4}$

In 1934, Tesnière published his famous Comment construire une syntaxe ?'How to build a syntax?'. This work would become very well known.

Tesnière was promoted to professor of grammaire comparée at the University of Montpellier (in the south of France) in 1937. Besides his courses on comparative grammar, he taught structural syntax and saw the transformation of his position into a chair of linguistics. He also continued to teach Russian voluntarily and directed the Institut des Étudiants Étrangers 'Foreign Student Institute. One of its former students states that Tesnière was "...authentic, a great scholar", who the student remembers "standing in front of his chair, talkative, jovial, often joking and paradoxical, speaking clearly and brilliantly. He seemed to teach only what he himself had discovered" (Arnavielle 1995).

Tesnière worked as a cryptography officer for the Military Intelligence, the so-called Deuxième Bureau, during WWII. He became very sick starting in 1947 and his health remained poor until he died on December 6th, 1954, without having published his Eléments. He also left an unpublished Petite grammaire allemande (300 pages), which he had completed in 1953.

The Éléments were published posthumously in 1959 due to the constant efforts of his wife Jeanne and the help of colleagues and friends like Jean Fourquet, who wrote the preface to the volume. Due to the success of the book, a second, corrected edition appeared in 1966.

\section{Genesis of the Éléments}

After completing his doctoral thesis, Tesnière planned to write a precise introduction to general linguistics. He left many notes for a book called Glottologie, lit. 'study of language' (Fonds Tesnière, Box 31-32), the first part of which, about semantics, was called Noétique, where a noeme is a signifying unit (Box 33). In a notebook (entitled Glottologie, Box 57), Tesnière wrote:

"The necessary consequence of this uniquely material interpretation of the facts of language has been that one has studied the material aspects of language almost exclusively, that is, phonetics and the concrete side of morphology. As a consequence, syntax, which in my view is part of morphology, and semantics, which is the study of immaterial meaning, i.e. two areas that constitute the spirit of language, have hardly been studied."

4. All citations of Tesnière have been translated from French. 
We see in this passage that Tesnière was still under the influence of his primary advisor at the time, Antoine Meillet, who "did not believe in the autonomy of syntax" (Chapter 15, \$9).

In a letter dated January 29, 1929 (Box 41), Tesnière's friend Fernand Mossé invited Tesnière to write a grammar of French for foreigners for the publisher Didier. ${ }^{5}$ Immediately thereafter Tesnière stopped his previous book projects and buried himself in his Grammaire française pour étrangers 'French grammar for foreigners', which was never published, although he left an unpublished manuscript of more than 1200 pages: Part I on semantics (which must be the Noétique of his Glottologie), Part II on phonetics (192 pages, Box 37), Part. III on orthography (untitled Graphie; 652 pages, Box 37), where he studies every spelling of every possible syllable of French), and Part IV on morphology (375 pages, Box 38). In a letter to Charles Bally dated March 17, 1934 (Box 49), Tesnière wrote:

"I have been working on a French grammar for two years; it is the fruit of 14 years of French language instruction to foreigners. The sections on phonetics and morphology are entirely drafted. Concerning the syntax, I have only planned out some large sections, such as, for example, the tense system, which I wrote a short article about a few years ago and should have sent to you. The abundance of diverse materials has been preventing me from summarizing these scattered elements. I have not yet seen how to integrate everything into an organic whole. I have therefore put my French syntax aside for the time being; the material has been assembled but is not yet organized. And I have devoted myself to producing a small grammar of Russian, hoping to more easily master the much less extensive material."

The Petite grammaire russe was indeed published in 1934 by Didier.

In 1932 Tesnière had a revelation that he describes in letters to Fernand Mossé dated June 23 and July 7 (Box 42):

"Yesterday I was examining a baccalauréat test of Latin-French translation. In seeing the poor candidates get caught up in the complexity of a sentence, I thought of one of my ideas about structure that had been in my head for a few years, but that I had not been able to completely discern. After two or three failed attempts, I finally succeeded at giving the structure a concrete form. Attached is a copy of my insight. It is of great importance for me; it is the key to my view of sentence structure. [...] I have now obtained the key to the all-important distinction between subordination and coordination, which are the two great architectural processes of the sentence. I add: a verbal sentence is one in which everything gravitates around the verb. A nominal sentence is one in which everything gravitates around a noun. In the Russian Dom nov 'The house is new', the center is nov (dom $\rightarrow$ nov). In contrast, in novy dom 'new

5. Fernand Mossé (1892-1956) was the scientific confident of Tesnière; they exchanged several very interesting letters (see below). Mossé was a specialist of Germanic languages and literature and became professor at the Collège de France in 1949. They met after WWI during their studies at Sorbonne. 
house' the center is dom (novy $\rightarrow$ dom). I explain the inversion of the word order, a general fact in the Asian languages, by the persistence of the direction indicated with the arrow; it is the principle around which everything is organized. At last this move solves the problem I had with the type He speaks quickly becoming a quick speech. The passage of the verb to a noun causes the adverb to change to an adjective [...] According to all this, you see the importance of this point of view for my syntax. I will first take the central sun with all its modalities of time, mood, etc. Then I will successively examine the different types of vassals in sentences that are more and more complicated. I have the impression that I have found a way forward that will permit me to construct a new syntax."

(June 23, 1932)

"I am in the process of revisiting all my notions of syntax from this point of view. Many things have become clear, and I have the impression that I now have the crux of syntax, or something that is very close to it. In any case, I will organize my entire grammar of French around this notion. Evidently, as you stated, this will take me far afield. But that is not an objection, quite to the contrary."

(July 7, 1932)

In May 1934, Tesnière published his paper Comment construire une syntaxe?, in which he presents the outline of his syntax. This outline contained verb centrality, the distinction between actants (called actors here) and circumstants, the stemma, the beginning of the distinction between connection and junction, his classification of parts of speech, including sentence words, and transfer involving the notions of source, target, and translative, and the distinction between first and second-degree transfer. It is worth noting that Tesniere's stemma at this point was still "gravitational", with the main verb at the center, like the sun at the center of the solar system.

A first draft of the beginning of the Éléments was complete in 1936, and in 1938 the 47 chapters of eventual Book A were achieved (Fonds Tesnière, Box 39). In particular, Tesnière had undertaken a wide typological study of word order, classifying around 190 languages from all around the world. He built huge arrays with languages on lines indicating the following constructions: noun-genitive, noun-possessive, verb-subject (nominal vs. pronominal), verb-object, noun-adjective, prefix vs. suffix vs. infix, preposition vs. postposition. In each case, he indicated whether the governor appears before or after the dependent using an upward or downward arrow. This work is summarized in Chapter 14 of the Eléments.

Convinced that his structural syntax was appropriate for teaching grammar at primary school, Tesnière started collaboration with the Ecole Normale d'Institutrice in Montpellier. The first step was to instruct the teachers on producing stemmas, so that they could then use them with the children. The experience was very positive; there were many enthusiastic reports from the teachers to the regional education authority. The experience was repeated each year until 1943. May 13, 1943, Tesnière wrote to Mossé:

"The method has been adopted in the Languedoc-Roussillon region [area of Montpellier], and it has now become a question of adopting it for all of France, in the Youth department of course. All this is undoubtedly the consequence, direct or 
indirect, of the first experiences that I have been collecting here for a few years now due to the involvement of Drouin. There is reason to believe that there is real success, since the system has been instituted now a few times. This has permitted me to obtain a basis in primary education, which is more flexible than secondary education and less interested personally than higher education. I will of course require every guarantee for when, in a year or two, I am in a position to present my book to the public; the system my book presents will be more advanced, but at the same time less compact, and as a consequence less clear, than the brochure."

The brochure in question was printed in December 1943 in Montpellier: it is a document of 59 pages entitled Cours de syntaxe structurale (Résumé aide-mémoire), with mention "résumé du cours donné aux moniteurs des centres d'apprentissages de la région BasLanguedoc-Roussillon" 'abstract of the course given to the students of the learning centers of the Bas-Languedoc-Roussillon area. This course was published 10 years later, in 1953, by Klincksieck under the name Esquisse d'une syntaxe structurale. It is the same text, with some minor changes (Pierre and Paul become Alfred and Bernard) and the suppression of the last chapter entitled Indications pédagogiques - Programme 'Pedagogical information Program', which corresponds to Chapter 277 of the Éléments.

As stated in the letter to Mossé, the redaction of the Eléments was nearly achieved as early as 1943. Tesnière's files (Boxes 46-48) contain typed drafts of the book with minor corrections. The actual version of the Élements that was published is the last typed draft. It contains some hand-written corrections which were not taken into account in the published edition, in particular the Russian and Greek examples had been transliterated to the Roman alphabet, as we have done here in our English translation. Tesnière also planned to reduce the outline of the book, collapsing the chapters by 2 or 3 in order to obtain only about a hundred chapters, instead of 278.

\section{Main ideas}

Tesnière's Éléments develops a number of concepts that have become mainstays for most modern theories of syntax. The following subsections briefly consider some of Tesnière's contributions, touching on 9 main aspects of the theory of syntax presented in the book: (1) connections, (2) verb centrality, (3) stratification, (4) stemmas and trees, (5) ordering and language typology, (6) nodes and nuclei, (7) valency, actants vs. circumstants, and metataxis, (8) junction, and (9) transfer. Our intent is merely to draw attention to some areas where we believe Tesnière's contribution to the study of syntax (and linguistics in general) has been greatest. During the discussion, we continue to cite the relevant passages using a specific convention: first chapter, then paragraph, e.g. Chapter $49, \$ 6$. This practice allows one to immediately find the relevant content at the same time that it maintains consistency across the two original French editions of the book (1959 and 1966) and the translations of the book in other languages (German, Italian, Spanish, Russian). 


\subsection{Connections}

Tesnière begins his Éléments with the insight that morphological units (words) are not the only elements that make up sentences. A two-word sentence such as Alfred speaks consists of more than just the two words Alfred and speaks; it also contains the connection that links the two and makes them into a whole (Chapter $1, \$ 4$ ). The connection establishes a dependency (Chapter 2, \$1), whereby the one word, speaks, is superior over the other, Alfred. Tesnière calls the superior word the governor, and the inferior word its subordinate (instead of dependent, which is commonly used today). The governor governs its subordinates (Chapter 2, \$3). The connection construed in this manner is equivalent to what modern syntax calls a dependency.

For Tesnière the concept of connections was novel. He pointed out that traditional grammars focused much more on concrete forms, i.e. on morphology, than on the combinatorial properties of these forms. He also viewed morphology's influence on the study of syntax as detrimental, since an understanding of syntax demands much more than just the knowledge of the fixed inflection paradigms associated most with the study of classical languages. It demands insights into the role that connections play in grouping words together and thus enabling the conveyance of meaning. Tesnière took the inspiration for his connections in part from Wilhelm von Humboldt's concept of innere Sprachform 'inner speech form. The innere Sprachform of a sentence is its syntactic and semantic organization (Chapter 15, \$3). Morphology is the study of concrete forms that one can see in writing and hear in speech directly, whereas syntax is the study of the interior form of sentences in terms of connections (Chapter 15, \$4ff.). The connections are abstract, and due to this abstractness, the study of syntax is necessarily different from the study of the concrete forms of morphology; it relies heavily on the introspective method (Chapter 17, \$9).

Since each connection involves a governor and a subordinate, it is directed. Connections are therefore directed links between syntactic elements (words). The convention Tesnière employed was a simple vertical line, e.g.

(1)

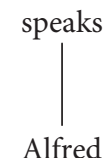

\section{Stemma 1}

This representation shows the three essential units that make up the sentence Alfred speaks. The word speaks is governor over its subordinate Alfred. The connection is depicted by the vertical line connecting the two. The result is a sentence diagram, which Tesnière called a stemma (see Section 4.4 below). In current terminology, a stemma is a tree-like representation that shows the totality of elements of a phrase or sentence and all the dependencies that link those elements into a single structure. 
The connection, as represented with an (at times slanted) vertical line, was not the only type of link that Tesnière posited. His analysis of junction (coordination) and apposition necessitated further link types, ones that are represented with horizontal lines (Chapter 136, $\$ 3$ ), and when he presents his understanding of transfer, he augments the graphic representations further with T-schemas (Chapter 144, \$7). Given these additions, Tesnière's stemma is not a pure dependency tree. While the connection is the central concept for Tesnière's vision of syntax, it alone was not sufficient to capture the varied types of syntactic structures that Tesnière identified.

\subsection{Verb centrality}

As established above, one of Tesnière's profound insights about the nature of syntactic structures concerns the initial grouping of words at the clause level. Tesnière rejected the subject-predicate division that dominated the understanding of syntax at his time and that is still prominent today in phrase structure grammars. He rejected the initial division of the clause into a subject NP and a predicate VP. He argued that this division stems from term logic as associated with Aristotle and that it belongs in logic, not in linguistics. $\mathrm{He}$ writes:

"Founded on the principles of logic, traditional grammar strives to find the logical opposition between subject and predicate in the sentence, the subject being that about which something is said and the predicate being what is said about it. Hence in the sentence Alfred speaks slowly, the subject would be Alfred, and the predicate speaks slowly, which corresponds to Stemma 79. One can acknowledge that this conception of the sentence is merely a remnant that has not yet been entirely eliminated. This remnant stems from the epoch that extends from Aristotle to Port-Royal, when all grammar was founded on logic. Indeed, all arguments that can be invoked against the concept of the verbal node and in favor of the opposition between subject and predicate come a priori from formal logic, which has nothing to do with linguistics." (Chapter 49, \$2-5)

In place of the binary division of traditional grammar, Tesnière positioned the verb as the root of all clause structure. In so doing, he took the subject and object noun phrases to be equi-level dependents of the verb.

The traditional analysis and the analysis that Tesnière chose instead are shown here using an example from English, Alfred speaks slowly, and an example from Latin, Filius amat patrem '(The) son loves (the) father':

(2)

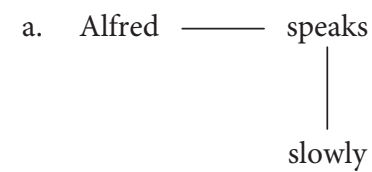

b.

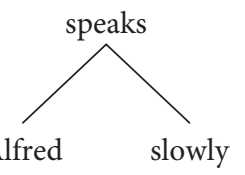




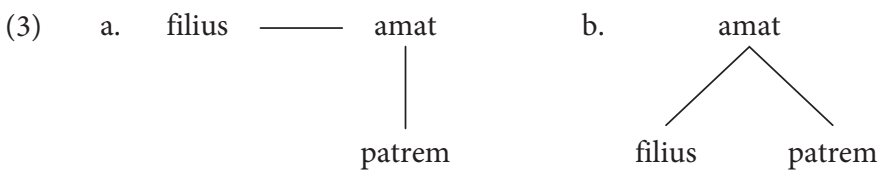

The traditional binary division into subject and predicate is illustrated with the a-examples on the left (from Stemma 79), and the verb-as-root analysis that Tesnière assumed instead are shown with the b-examples on the right (from Stemma 80). Tesnière motivated the analyses in (2b) and (3b) via syntactic and morphological considerations involving case forms and inflectional endings, including the active-passive diathesis. More generally, standard permutation and substitution constituency tests support Tesnière's stance in this area, since these tests fail to identify finite VPs such as speaks slowly as constituents (see Osborne et al. 2011: 323f.).

While others also rejected the subject-predicate division, Tesnière was one of the first in modern linguistics to clearly replace this division with verb centrality. He did this in a manner that left no room for doubt about the underlying approach to syntax he was pursuing: his stemmas clearly position the main verb as the root of the structure. As established above, we know from the letters Tesnière wrote to Mossé that he became convinced of verb centrality in 1932. In the letter from July 7, 1932 (see Section 3), Tesnière produced the following answer to a letter Mossé had sent him containing a Reed-Kellogg diagram: ${ }^{6}$

"I believe that there is something extra in my conception. The English author groups an entire part of the sentence around the subject and the other part around the predicate, conserving a dualism in the sentence that I reject. I never really liked the distinction between subject and predicate. What characterizes my new conception is its universality. Thus the subject also depends on the verb. Isolating a predicate involves acknowledging that the link from the subject to the verb is looser, or of a different sort, than the link from the verb to its other determiners."

He adds:

"Peter (1) hits (0) Paul (1). The (3) young (2) boy (1) that your (4) brother (3) has (2) met recently has (0) hit Paul, etc. Your (4) is further removed from the center than brother (3). I indicate the relation with an arrow that always points in the direction of the center (0)."

The notations Tesnière uses here suggest that he could have been influenced by Otto Jespersen, who had written the following in The philosophy of Language (1924, Chapter VII, p. 96-97):

6. Alonzo Reed and Brainerd Kellogg (Work on English Grammar and Composition, Clark and Maynard, 1878) proposed a method for teaching English based on diagrams, which is sometimes still used in North America. The letter to Mossé was archived by Tesnière with a Reed-Kellogg diagram of the sentence In between the planks which formed the bridge lay the case which he was seeking, with the reference to Isabel Fry, A key to language, 1925. 
"This chief word is defined (qualified, modified) by another word, which in its turn may be defined (qualified, modified) by a third word, etc. We are thus led to establish different "ranks" of words according to their mutual relations as defined or defining. In the combination extremely hot weather, the last word weather, which is evidently the chief idea, may be called primary; hot, which defines weather, secondary, and extremely, which defines hot, tertiary. [...] In a nice young lady the words $a$, nice, and young equally define lady; compare also much (III) good (II) white (II) wine (I) with very (III) good (II) wine (I)."

The similarity between these statements and Tesnière's understanding of connections should be apparent. Tesnière did not, however, credit Jespersen for the idea - Jespersen is not quoted in the Éléments at all. We know, though, that Tesnière was aware of Jespersen's work. In a letter to J. Damourette dated January 18, 1936 (Box 69), Tesnière wrote:

"Thus the idea of the verbal node that we share and that one finds in Jespersen's work is now an objective truth for me, which it was not at first."7

\subsection{Stratification}

Tesnière may have been the first linguist to propose various levels of organization, thus advocating a stratified model of language. At the very beginning of his Éléments, he posits a distinction between structural and linear order. Tesnière contrasts the two-dimensional syntactic representation (Chapter 4) with the one-dimensional spoken chain (Chapter 5). Language is described as the correspondence between the two ordering dimensions. He writes: "speaking a language involves transforming structural order to linear order, and conversely, understanding a language involves transforming linear order to structural order" (Chapter 6, \$4). The synthesis direction (the speaker's perspective, the direction from structural order to linear order) is privileged insofar as word order is explored in terms of linearization. Tesnière states: "When two words are structurally connected, there are two ways to place them in a linear sequence, according to which of the two is placed before the other" (Chapter $8, \$ 1$ ). Tesnière's stratification and emphasis on synthesis have been defended by Mel'čuk (1988) in the Meaning-Text theory and its seven levels of representation.

7. Verb centrality remains rather unclear in Jespersen's work. While Jespersen attributed the rank 1 to the object, like to the subject, he never introduced a rank 0 for the verb (unlike what Tesnière does in his letter to Mossé) and Jespersen called it the theory of three ranks. Jespersen himself could have been inspired by other authors. Imrényi (2013) gives the following citation from a book from 1863 by the Hungarian linguist Brassai: "Sitting at the beginning, middle, or end of the sentence, wherever it pleases him, is the monarch, the verb, related by meaningful bonds to its vassals, the dependents. [...] The rule of the verb is no dictatorship, and its vassals are no slaves but have lawful relations to their lord and to one another; they each possess a degree of autonomy and a certain rank, with a feudalism whose slogan, just as in history, is nulle terre sans seigneur 'no land without a lord' [translated from Hungarian by Imrényi]. 
The synthesis direction is also affirmed in the terminology proposed by Tesnière for the components of the linguistic sign. Instead of Saussure's signified and signifier, Tesnière prefers exprimende and expressed, reversing Saussure's terms: "When we speak, our intent is not to find meaning afterwards in a pre-existing string of phonemes, but rather to give an easily transmissible form to a thought that precedes the form and which is its sole raison d'être" (Chapter 16, \$4).

Although Tesnière does not clearly separate a semantic level from the syntactic level, he does make some interesting remarks in this area. He makes a point similar to the one associated with Chomsky's famous sentence Colorless green ideas sleep furiously (Chomsky 1957, 3 years after Tesnière's death). Tesnière wrote:

"The structural plane and the semantic plane are thus entirely independent of each other from a theoretic point of view. The best proof of this fact is that a sentence can be semantically absurd and at the same time syntactically perfectly correct. Take the meaningful sentence Le signal vert indique la voie libre 'A green light indicates right of way', lit. 'The green light indicates the open road'. If I replace all the words charged with meaning by the words of the same type that immediately follow them in alphabetic order in the dictionary, I obtain the sentence Le silence vertébral indispose la voile licite, lit. 'The vertebral silence antagonizes the lawful sail', the structure of which remains intact, but which makes no sense whatsoever.” (Chapter 20, \$16)

\subsection{Stemmas and dependency trees}

Tesnière included 366 stemmas in the Élements, and these stemmas are perhaps the most distinctive association that one has with his syntax. A stemma is a tree-like diagram that shows the dependency structure of phrases, clauses, sentences, and even texts, e.g.

(4)

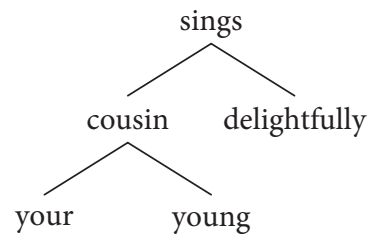

Stemma 43

Most of the stemmas in the book are of simple phrases, but some extensive stemmas (which even span paragraphs) are included in Part II (on junction) and toward the end of the book (Chapter 275). These more extensive stemmas include all the features of Tesnière's analysis (including junction, transfer, and anaphora), the result being quite complex visual representations of sentence structure (see Stemmas 354-366). Worth noting in this area is that some aspects of Tesniére's stemmatic representations have (with few exceptions) not been adopted by other DGs. This is true in particular of Tesnière's analysis of transfer (see below). This may be due to the fact that when transfer is incorporated into 
the stemmatic analyses, the resulting diagrams become quite complex, so complex that the insights gained by stemmatic analysis are, arguably, obscured.

While Tesnière was certainly exposed to various diagramming schemes for representing sentence structure - he mentions one in the footnote of Chapter $3, \$ 9$ and in his letters to Mossé in 1932 - his stemmas deviated from many precedents in a major way: they clearly show the verb as the root of all clause structure and thus reject the binary division of the clause into subject and predicate, as discussed above. In his first representations (Tesnière 1934), the verb was even put "in the center of the figure like the sun in the center of the solar system" (see the excerpt from the letter to Mossé in Section 3 above). And when one compares Tesnière's stemmas to modern trees associated with phrase structure grammars, one sees that most of the stemmas are minimal and easy to produce, containing relatively few nodes and edges. This aspect of Tesnière's stemmas is actually true of most dependency-based tree diagrams; they are simple compared to their phrase structure counterparts because they lack the additional groupings that constituency necessitates.

This point is now is illustrated with two modern trees of the same sentence; the first is dependency-based and the second is constituency-based:
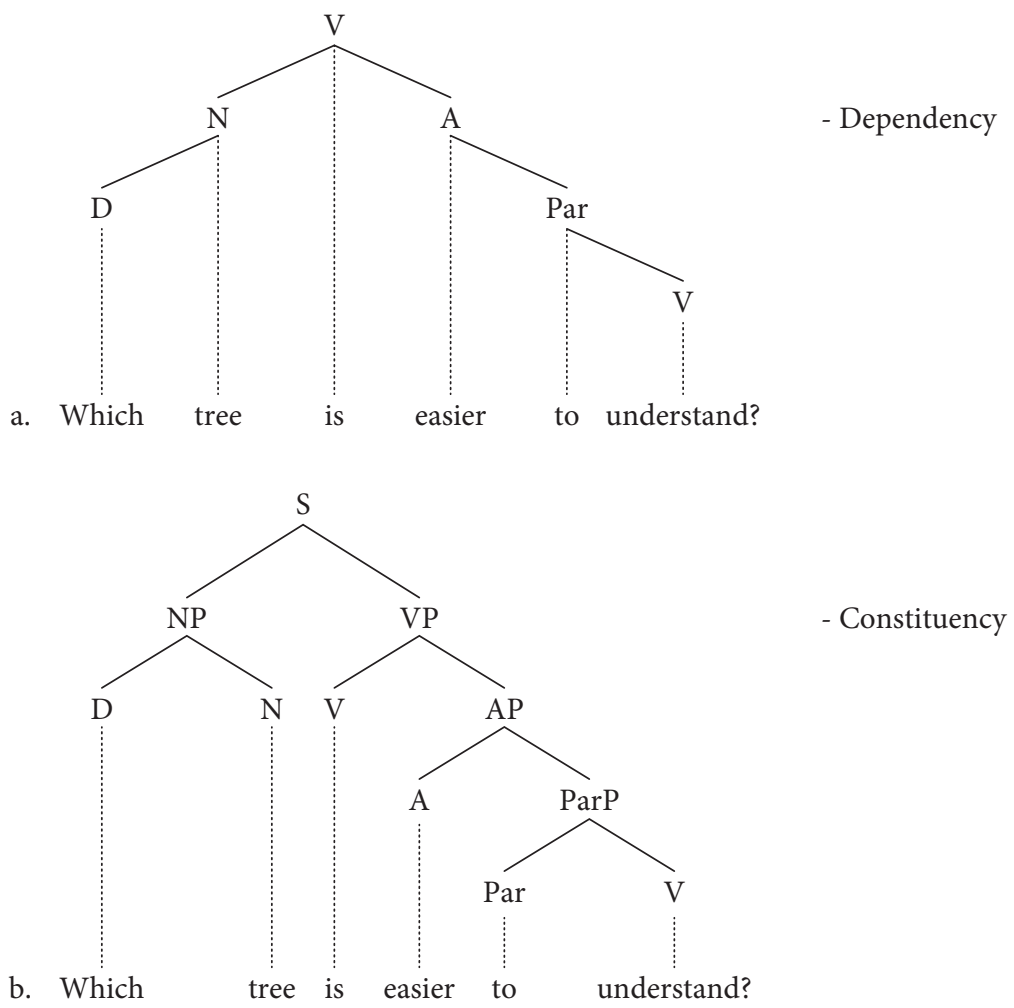
The trees are similar insofar as they both encode actual word order and they both use category labels on the nodes in the tree ( $\mathrm{A}$ = adjective, $\mathrm{D}=$ determiner, $\mathrm{N}=$ noun, $\mathrm{Par}=$ particle, $\mathrm{S}=$ sentence, $\mathrm{V}=$ Verb, $\ldots \mathrm{P}=\ldots$ phrase). However, the dependency tree is much simpler than the constituency tree. The dependency tree contains just six nodes (= number of words) and five edges, whereas the constituency tree contains eleven nodes and nine edges. The simplicity that we see in this dependency tree is certainly also visible in most of Tesnière's stemmas. As stated above, Tesnière's stemmas become more complex when they are augmented to accommodate further aspects of syntactic structures, such as junction and transfer. These areas are discussed below.

\subsection{Ordering and language typology}

Another one of Tesnière's contributions concerns our understanding of language typology. Tesnière distinguished between between centrifugal (head-initial) and centripetal (headfinal) structures and languages (Chapter 13). A given syntactic structure is centrifugal if the head of the structure appears on the left, or centripetal if the head of the structure appears on the right (Chapter 8, §5-7).

(6)

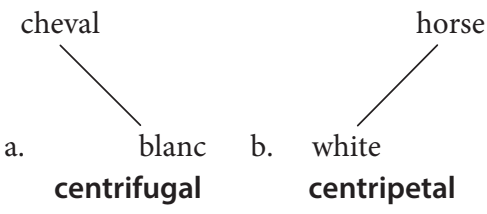

The French noun phrase cheval blanc illustrates a centrifugal structure, whereas the English equivalent thereof, white horse, is centripetal. Worth noting is the fact that Tesnière did not actually produce stemmas like these here to illustrate the distinction. His stemmas intentionally do not encode linear order, since he was clear about his view that structural order (vertical dimension) precedes linear order (horizontal dimension), as mentioned above in Section 4.3.

Tesnière classified languages and language families according to whether their structures are more centrifugal or centripetal, and he provides a table showing his classification (Chapter 14, \$6). From his notes we know that he studied almost 200 languages in this regard (Section 3 above). The Semitic languages (e.g. Hebrew and Arabic) are, for instance, classified as centrifugal, and the Ural-Altaic languages (e.g. Japanese and Korean) as centripetal. The structures of many languages are not strictly head-initial or head-final, but rather they are mitigated (Chapter 9, $\$ 2$ ), meaning that they combine some measure of both centrifugal and centripetal structures. Tesnière classified French as mitigated centrifugal, meaning that it contains more centrifugal than centripetal structures, and he classified English as mitigated centripetal, indicating that it contains more centripetal structures 
than centrifugal ones. We can remark that most modern typologies would disagree with Tesnière's classification of English, since English is widely seen as more head-initial than head-final (even though it has more head-final structures than French).

\subsection{Nodes and nuclei}

Tesnière distinguishes between nodes (Fr. nœuds) and nuclei (Fr. nucléus). He first defines the node to be what modern theories of syntax take to be a phrase/constituent:

"We define a node as a set consisting of a governor and all of the subordinates that are directly or indirectly dependent on the governor and that the governor in a sense links together into a bundle."

(Chapter 3, \$3)

However, he later uses the term node to mean just 'vertex'. For instance when he compares the node notion to the nucleus, he writes: "The node is nothing more than a geometric point, whereas the nucleus is a collection of multiple points,..." (Chapter $22, \$ 12$ ), and indeed most of the time he seems to mean 'vertex' rather than phrase or constituent when he writes "nœud". His inconsistent use of the term is a source of confusion, and it may have contributed to the fallacious assumption that dependency grammars do not acknowledge phrases. Dependency grammars of course do acknowledge phrases, a phrase being a complete subtree consisting of two or more words.

Tesnière defined the nucleus as

"...the set which joins together, in addition to the structural node itself, all the other elements for which the node is the structural support, starting with the semantic elements."

(Chapter 22, \$5)

A nucleus plays two roles insofar as it is both a syntactic as well as a semantic unit. This can be illustrated using the following two sentences:

(7) a. Alfred arrived.

b. Alfred has arrived.

Sentence (7a) contains two words, two nodes, and two nuclei. Each of the two words Alfred and arrived represents a nucleus occupying a node. Sentence (7b), in contrast, contains three words but still only two nuclei - whether it should be construed as containing two, three, or four nodes is not clear. ${ }^{8}$ The auxiliary verb has alone constitutes a nucleus

8. Tesnière's statements about the node vs. nucleus distinction are not clear. Given that "the node is nothing more than a geometric point, whereas the nucleus is a group of several points", one might assume that a nucleus consisting of has arrived contains two nodes, one corresponding to each word. In the immediately preceding paragraph, however, Tesnière writes: "The node is merely 
structurally but not semantically, and the main verb arrived constitutes a nucleus semantically but not structurally. The two together, however, do constitute a nucleus insofar as each contributes one necessary part of a nucleus. Many content words alone fulfill both a structural and a semantic role, which means they alone qualify as both a node and a nucleus, as with each of Alfred and arrived in (7a). Other nuclei, in contrast, consist of two or more elements, as with has and arrived in (7b). Tesnière called the latter type of nucleus dissociated (Chapter 23, \$8); has arrived is a dissociated nucleus.

When Tesnière wanted to show the presence of nuclei in his stemmas, he employed a bubble convention. He enclosed the nucleus in a bubble, e.g.

(8)

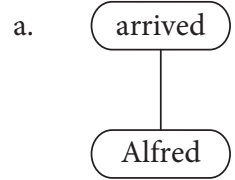

b.

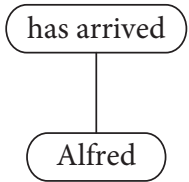

The auxiliary verb has fulfills a syntactic function in establishing the presence of the nucleus syntactically, whereas the full verb arrived fulfills a semantic function in establishing the presence of the nucleus semantically. Note that Tesnière employed the nucleus circle in his stemmas only when the point at hand required that he do so (see Chapter 22, \$17). Otherwise he preferred to keep his stemmas as simple as possible.

When Tesnière discusses interrogative sentences, he points out that nuclei can be identified by forming questions. He remarks that each nucleus in a given sentence can be questioned in one way or another (Chapter 79, \$3), e.g. Who arrived?, What did Alfred $d o$ ?, and he stated the distinction between wh-questions, which focus on a nucleus (and which he therefore called nuclear interrogatives, Chapter 79-82), and the yes-no questions, which focus on the connections (and which he therefore called connective interrogatives, Chapter 83-85). Tesnière makes a similar point concerning negative words, which can negate nuclei as well as connections (Chapter 87-88).

Concerning relative pronouns, Tesnière remarked that they play a double role, as a pronoun inside the relative clause and as the complementizer of the clause (that is, as a translative of a verb to an adjective, Chapter $246, \$ 11$ ). As a consequence, Tesnière grants relative pronouns a double position in the stemma. This very innovative analysis can be compared to later analyses in generative grammar where wh-words were moved from a position inside the clause to the complementizer position.

the material expression of the nodal function of the nucleus" (Chapter 22, \$10). This statement suggests that there can be only one node per nucleus. On this interpretation then, the nucleus consisting of has arrived is both just one nucleus and one node, despite the fact that it contains two words. We translators think that this latter interpretation, i.e. one node per nucleus, is more defensible in part based on other distinctions that Tesnière draws later in the book. 


\subsection{Valency, actants vs. circumstants, and metataxis}

Tesnière concept of valency is arguably his most known contribution to the field of syntax. He noticed that there are many regularities across languages concerning how verbs combine with nouns and other syntactic units. The semantics of a given verb tend to be predictive of the number of nouns with which it can combine. Tesnière expresses the valency metaphor as follows:

"The verb may therefore be compared to a sort of atom, susceptible to attracting a
greater or lesser number of actants, according to the number of bonds the verb has
available to keep them as dependents. The number of bonds a verb has constitutes
what we call the verb's valency."
(Chapter 97, §3)

A given verb attracts one or more actants $(\approx$ arguments) to form a clause in a manner similar to how a given atom attracts other atoms to form a molecule - see Jespersen (1937) for a similar insight and use of chemistry-based notations for syntactic structure. The vividness of this metaphor helps explain the fact that the concept has become a mainstay for dependency- and constituency-based theories of syntax alike.

The valency notion overlaps of course with other notions that have been used to express the combinatorial properties of verbs and other lexical items, e.g. transitivity. According to Tesnière, a verb's valency falls into one of four categories: a given verb is underlyingly avalent (It rained), monovalent (Alfred slept), divalent (Alfred saw Bernard), or trivalent (Alfred gave Bernard a pen). Verb valency serves as the basis for the exploration of diathesis (Chapter $100, \$ 3$ ), a notion similar to grammatical voice. Tesnière posits a number of diathesis types (active, passive, reflexive, reciprocal, causative, recessive).

Valency and diathesis are aspects associated with the actants that verbs demand; they do not concern the circumstants that can appear with verbs. Tesnière's actant vs. circumstant distinction is of course mostly synonymous with the more modern argument vs. adjunct terminology (although Tesnière viewed every prepositional phrase as a circumstant (Chapter 57, \$5-7) - see Lazard (1995) for a critical discussion. Actants (arguments) are necessary to complete the meaning of a given full verb, whereas circumstants (adjuncts) represent additional optional information, that is, information that is not essential to completing the meaning of the verb. The number and types of actants that can appear with a given verb are strictly limited, whereas the number of circumstants that a verb can take is theoretically unlimited. Concerning types of actants, Tesnière acknowledged first actants (subjects), second actants (first objects), and third actants (second objects) (Chapter 51, §3). Concerning types of circumstants, he classified circumstants in the standard way, that is, according to the semantic content that they contribute to the clauses in which they appear (temporal, locative, causal, final, manner, etc.) (Chapter 37).

The distinctions between types of actants and between actants and circumstants is important for Tesnière's concept of metataxis (Part I, Book E, Chapter 120-133). Metataxis concerns the theory of translation. The polyglot Tesnière worked as an interpreter and 
translator (see Section 2 above) and was hence very cognizant of the changes that occur in syntax when translating or interpreting from one language to another. Tesnière's theory of metataxis has helped motivate works that model paraphrasing, translation, and machine translation (Schubert 1987, Mel'čuk 1988). Tesnière presents many examples of mismatches in actant structure across languages; some of these have been cited often, such as specific actant conversions (e.g. En. I miss you $\leftrightarrow$ Fr. Vous me manquez, Chapter 123), the equivalence of these conversions with the active-passive alternation (Chapter 125), the inversion of dependency direction (En. I like to read $\leftrightarrow$ Ger. Ich lese gern, Chapter 129), and the distinction between manner-incorporating and path-incorporating motion verbs expressed later by Talmy (1974), 15 years after the appearance of Tesnière's Éléments (e.g. En. Antoine swam across the river $\leftrightarrow$ Fr. Antoine traverse la rivière à la nage, Chapter 131, \$14).

\subsection{Junction}

Tesnière considered coordination, as well as apposition (Chapter 69), to be orthogonal to connections (that is, to subordination). Tesnière's analysis of coordination, which he called junction (Fr. jonction), was ahead of its time, for Tesnière identified aspects of coordination that would not be explored by linguists in the English-speaking world until decades later, as mentioned above in the introduction. His analysis of junction was comparatively brief, just 35 pages (Part II, Chapter 134-50). Despite the brevity, Tesnière sheds much light on complex traits of coordinate structures. Junction is a powerful tool that increases the ability of language to express content efficiently. At a semantic level, junction sums simple sentences. A sentence such as Alfred and Bernard arrived yesterday is a much more economical way to express the content that is contained in the two separate clauses Alfred arrived yesterday, and Bernard arrived yesterday (Chapter 135, \$4).

Tesnière viewed junction as fundamentally distinct from subordination. The connections that constitute relationships of subordination are represented in stemmas in terms of vertical lines between words. Junction, in contrast, joins like syntactic units using horizontal lines, e.g.

$$
\text { Alfred — and — Bernard }
$$

(Chapter 136, \$3)

The joined units are placed equi-level, and the coordinator, which Tesnière called a junctive (Fr. jonctif), is placed between them on the same level. By placing the conjuncts equi-level in this manner, Tesnière was locating junction in the horizontal dimension, whereas connections reside in the vertical dimension. The distinction between subordination and coordination is hence established in a principled manner that appeals to intuition. Subordination is a principle of organization that exists in the vertical dimension, whereas coordination is the principle of organization that exists in the horizontal dimension. 
Tesnière distinguished between instances of total junction and partial junction (Chapter $145, \$ 1$ ). Junction is total when the conjuncts share all their dependents and/or heads, and partial when some head or dependent is not shared. Concerning total junction, Tesnière used the terminology of heraldry to designate three basic types: coped, shod, and dressed, e.g.

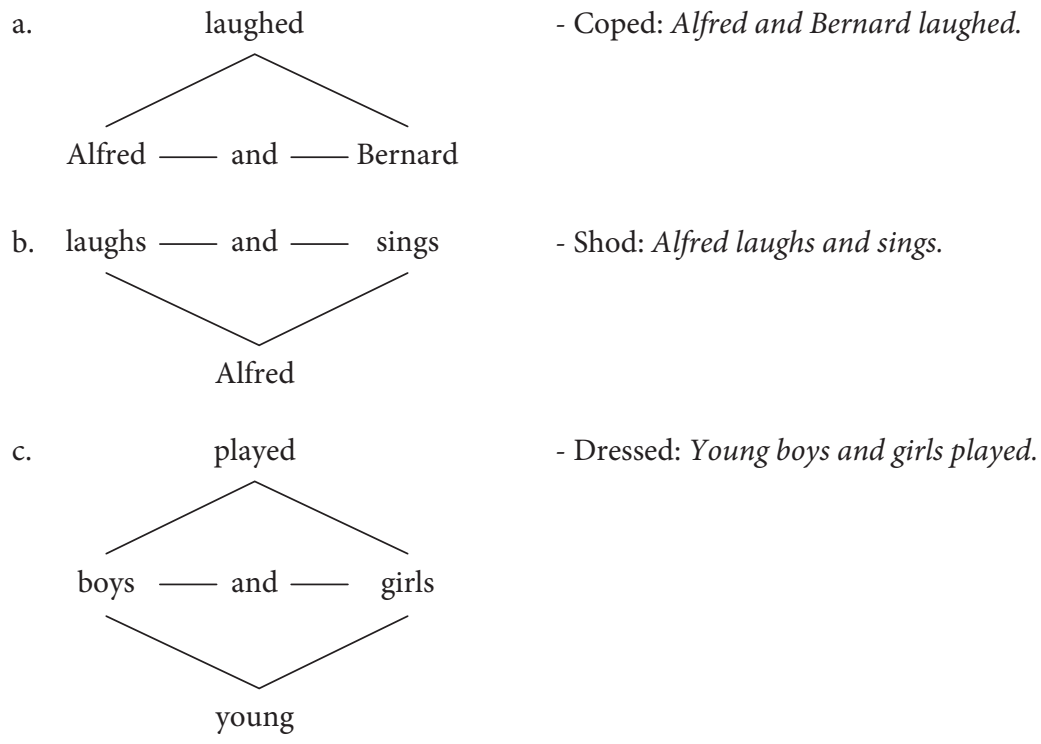

A coped coordinate structure has the joined units sharing a governor; a shod coordinate structure has the joined units sharing a dependent; and a dressed coordinate structure has both a shared governor and a shared dependent. The shapes that these types of coordinate structures take on in the stemma is that of a triangle (coped, shod) or diamond (dressed) the triangle and diamond terms being recommended in Chapter 257 for teaching coordination in schools.

Partial coordinate structures are unlike total structures insofar as they are asymmetric in one sense or another. Tesnière used the term bifid from botany to denote these structures because they have a shape that is similar to the shape of certain leaves of plants and trees (Chapter 145, \$5). He also acknowledged three different types of bifid coordinate structures, and he employed terms borrowed from biology to denote these types. He distinguished between bifid coordinate structures that are either anadidymic, catadidymic, or anacatadidymic, e.g.

a.

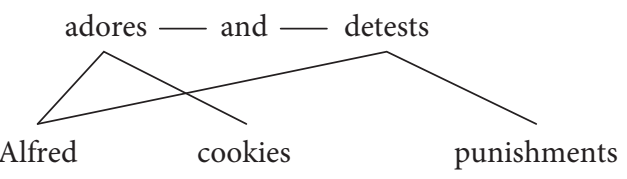

- Anadidymic

Alfred adores cookies and detests punishments. 
b.

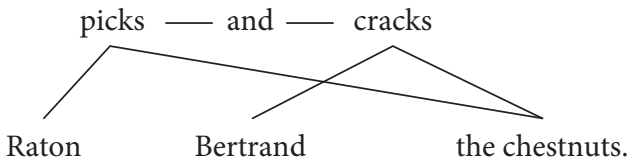

c.

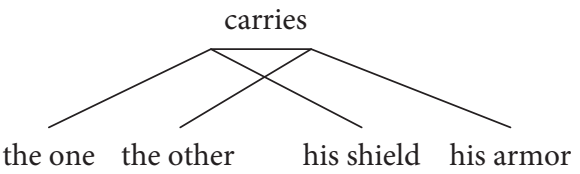

- Catadidymic

Raton picks and Bertrand cracks the chestnuts.

- Anacatadidymic

The one carries his shield and the other his armor.

The joined strings in examples (11a) and (11b) present a non-symmetric shape in the stemma insofar as there is at least one part that is not "shared" by the joined strings. An anadidymic coordinate structure has a shared first actant, Alfred in (11a), but the second actants are not shared, cookies and punishments in (11a). Catadidymic coordinate structure have a shared second actant, the chestnuts in (11b), but the first actants are not shared, Raton and Bertrand in (11b). An anacatadidymic coordinate structure, in contrast, has a shared head, carries in (11c), but the first and second actants are not shared.

Anadidymic junction is common and is called VP coordination when it involves verbs. Catadidymic and anacatadidymic junction occur comparatively rarely, and when they do occur, they are marked. Modern syntax denotes catadidymic junction as right node raising (RNR) and anacatadidymic junction as gapping. Note that Tesnière did not consider multiconstituent coordination, e.g. Charles gave Alfred a pen and Bernard a sheet of paper, which would have been problematic for his representations.

RNR and gapping were not explored in English-language linguistic circles until the 1970s (Ross 1970; Jackendoff 1972; Postal 1974), almost two decades after the appearance of Tesnière's Éléments. The fact that Tesnière had already identified and named these mechanisms was overlooked, for his work was not cited at the time. Tesnière also analyzed comparative constructions in terms of junction (Chapter 148). The parallel between coordination and comparatives was not acknowledged and explored by others until the early 1980s (Pinkham 1982). While Tesnière's analysis of these phenomena was insightful, the nomenclature he employed did not promote the accessibility of his account. For most, terms such as anadidymic and catadidymic do not evoke associations that promote understanding. Perhaps his poor choice of terminology is part of the reason why his contribution to our understanding of coordination was overlooked.

\subsection{Transfer}

Tesnière's theory of transfer (Fr. translation) is perhaps the least known but most innovative component of his approach to syntax. He spent much energy developing this subtheory, devoting 270 pages of his Éléments to it (Part III, Chapter 151-271). Transfer is the tool that 
allows a unit of one syntactic category to occupy a position usually devoted to a unit of another syntactic category. A typical example is the transfer of a noun to an adjective by the preposition of, as in a linguist of France, where the noun France (the source of the transfer) has been transferred to of France (the target), which can modify the noun linguist, something that is typically done by an adjective. It is worth noting that transfer is a syntactic device and must not be confused with morphological derivation. In a French linguist, French is an adjective derived from the noun France; it can be modified by an adverb just like any adjective (a very French linguist), while in a linguist of France, France remains a noun, but occupies an adjectival position. Tesnière nevertheless included derivation in transfer as fixed transfer (see below).

The observation that a word of one syntactic category can appear in a position that is usually devoted to another category preceded Tesnière; it appears in the works of Otto Jespersen in terms of his theory of rank. Jespersen wrote:

"There are two series which to some extent, but only to some extent, run parallel; I call them $\alpha$ and $\beta$. In $\alpha$ we have separate classes of words (parts of speech), in $\beta$ separate ranks, thus

\begin{tabular}{lll}
\cline { 1 - 2 } S. Word-classes & & ß. Ranks \\
Substantives & & Primaries (1) \\
Adjectives & & Secondaries (2) \\
Adverbs & Tertiaries (3)
\end{tabular}

[...] In the easiest and simplest cases, the two series cover one another, thus

$\begin{array}{lll}\text { terribly } & \text { cold } & \text { weather } \\ \alpha . \text { adverb } & \text { adjective } & \text { substantive } \\ \beta \text {. tertiary } & \text { secondary } & \text { primary. }\end{array}$

But this simple parallelism does not always hold good. Both substantives and adverbs may under certain circumstances be secondaries; adjectives and adverbs are sometimes primaries; one and the same combination of words, even a whole clause, can be used in each of the three ranks."

(Analytic syntax, 1937: Section 31.1,

p. 109-110)

This citation is from Jespersen's last book, but the theory he was presenting had been established since 1913, and it was presented completely in 1924 in The Philosophy of language. As shown in Section 3 above, we know from his letters that Tesnière read Jespersen's book, although he never cites Jespersen in his Eléments.

It is possible to transfer a verb to a noun, a noun to a verb, an adjective to a verb, a verb to an adjective, a noun to an adverb, etc. Like junction, transfer is a tool of great productive potential that natural languages employ to create more varied sentences. Sentences that contain transfer are no longer simple, but rather they are complex. Transfer helps explain how it is possible for humans to produce an infinite number of distinct utterances. Due to transfer language structure is recursive and a clause can be embedded in another clause, or in Tesnière's terms, one verb can be subordinated to another. 
The distinction between content and function words was central to Tesnière's understanding. He posited just four basic categories of content words: verbs (I), nouns (O), adverbs (E), and adjectives (A). The abbreviations I, O, E, and A correspond to the last letter of the Esperanto designations of these categories (Chapter 33, \$3). Tesnière classified many function words as translatives (Fr. translatifs). The purpose of a translative is to serve as a marker of transfer. Translatives transfer content words across syntactic categories. More precisely, they allow a word of one category to occupy a syntactic position that is generally associated with a word of another category.

Prepositions, subordinators (subordinating conjunctions), auxiliary verbs, and articles are or can be translatives. Typical translatives are semantically empty words like of. All other words that lack semantic content can be or are considered as translatives. Typical prepositions are translatives that transfer nouns to adjectives or adverbs, e.g.

(12) a. the book on the shelf

b. The book stands on the shelf.

The preposition on in (12a) transfers the noun shelf to an adjective, because on the shelf modifies the noun book like an adjective would (big book, interesting book). The preposition on in (12b) transfers the noun shelf to an adverb because on the shelf modifies the verb stands like an adverb would (The book stands there, The book stands lonely). A typical subordinator transfers a verb to a noun, adjective, or adverb

(13) a. He stated that it happened.

b. the statement that it happened

c. He stated that before it happened.

The subordinator that in (13a) transfers the verb happened to a noun because as the object of stated, that it happened serves like a noun would (He stated many things); the subordinator that in (13b) transfers the verb happened to an adjective because that it happened modifies the noun statement like an adjective would (the first statement); and the subordinator before in (13c) transfers the verb happened to an adverb, because before it happened modifies the verb stated like an adverb would (He stated that repeatedly).

Tesnière also distinguishes between transfer with an analytical marker, that is, a separate word like the preposition of as in (14a) or the subordinator that as in (15a) and transfer with a synthetic marker, that is, an affix, such as case markers as in (14b) (Chapter 168, $172)$ or gerundive as in $(15 b):^{9}$

9. At times, however, transfer occurs in the absence of a marker. Tesnière states, for example, that color nouns are often transferred to adjectives without a marker, e.g. an orange (to eat) vs. an orange shirt (Chapter 162, \$2). He identifies marker-less transfer in his stemmas with the symbol $\odot$ (Chapter 17, $\$ 1$ and Stemma 358). 
(14) a. the book of Peter

b. Lat. Petri liber 'Peter's book'

(15) a. I expect that Peter is coming.

b. I expect Peter's coming.

A key trait of the transfer schema is that it accommodates the fact that words that are transferred from a source category to a target category continue to behave as the source category with respect to their dependents. For instance, a verb transferred to a noun or adjective remains a verb with respect to its dependents. If a transitive verb is transferred, its direct object remains a direct object as in (16a), and this is true even in the case of synthetic transfer as in (16b):

(16) a. I am pleased that Peter achieved that.

b. I am pleased with Peter's achieving that.

Forms like coming or achieving are words which are neither verbs nor nouns singularly, but rather they are nouns with respect to their governor and verbs with respect to their dependents.

These instances of transfer contrast with the derivation of the verb achieve in the noun achievement. The latter is a true noun and its dependents must be adjectives. It can no longer bear a direct object and its actant must be transferred to an adjective by the preposition of:

(17) I like Peter's achievement of that.

Nevertheless, Tesnière includes derivation as a special type of transfer that he calls fixed transfer (Chapter 174). His analysis in this area was motivated by diachronic considerations, because instances of free transfer tend to evolve in derivation. For instance, the verb interest can be translated to an adjective by the suffix -ing: in this case it can still bear its direct object as in (18a). But this form has also become a true adjective in modern English, since it can take a typical adjective modifier as in (18b):

(18) a. a problem interesting me

b. a very interesting problem

The frontier between derivation and free transfer is certainly permeable, but by failing to clearly separate these two phenomena, Tesnière introduced a certain confusion, and this confusion could explain why transfer has to date not been recognized as an insightful way to address the combinatory potential of lexical items.

Tesnière does not consider the relation between a translative and the source as a connection. The relation is symmetric and not hierarchized; the translative and the source are placed equi-level. The two words together form a nucleus and the connection between the governor of the instance of transfer is attributed to the target as a whole. The transfer schema is 
represented using a large $\mathrm{T}$ of a sort: the translative and content word are placed underneath the horizontal line, and they are separated by the vertical dividing line. The category that the content word becomes is usually indicated on top of the horizontal dividing line, e.g
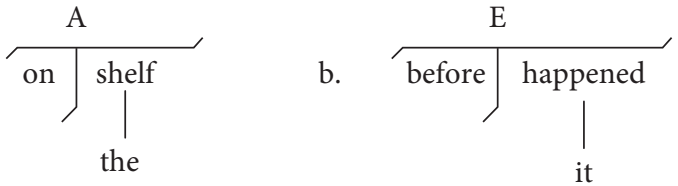

Schema (19a) shows that the translative on transfers the noun shelf to an adjective (A), and schema (19b) shows that the translative before transfers the verb happened to an adverb (E). Tesnière's transfer schema cannot be interpreted as pure dependency, because the nucleus that occupies a syntactic position (a node in Tesnière's terms) is itself the combination of a translative and a source. Moreover this combination, although asymmetric, is not hierarchized: neither the source, nor the translative depends on the other element. ${ }^{10}$ This point will be developed below in Sections 4.9.1 and 4.9.2.

Tesnière distinguishes between transfer of a verbal lexeme, which he calls first-degree transfer of verb, and transfer of a finite verb, which he calls second-degree transfer of verb. To show the presence of second-degree transfer, he employed a T schema with a double horizontal line (Chapter 239, \$15). The typical first-degree translative of a verb to a noun is the infinitive (Alfred espère chanter 'Alfred hopes to sing'), while the typical translative for second-degree transfer is a subordinating conjunction (Alfred espère que Bernard chante 'Alfred hopes that Bernard sings').

In addition to the distinction concerning the degree of transfer (first degree vs. second degree), Tesnière sees transfer occurring repeatedly within one and the same nucleus. He classifies transfer within the nucleus according to the number of times it occurs. $\mathrm{He}$ acknowledges instances of simple, double, triple, quadruple, quintuple, sextuple, and septuple transfer. An instance of quintuple transfer, for instance, has five occurrences of transfer within a single nucleus. Tesnière provides numerous examples of each of these types of transfer on page after page. As Jean Fourquet notes in the preface to the first edition of the Eléments (1959), Tesnière seemed to take pleasure in identifying and describing the sequences of transfer.

\subsubsection{The transfer schema as constituency}

There is controversy about how Tesnière's transfer schema and thus his theory of transfer in general should be interpreted. We translators are in disagreement concerning

10. It can be noted that sources govern their translatives in Tesnière (1934), while Tesnière seems to be more inclined to treat translatives as heads in his Éléments (cf. Stemma 157, Chapter 67 and Stemma 177, Chapter 74). 
the best interpretation of the schema. While we agree that the schema cannot be interpreted in terms of pure dependency, we disagree about whether or not it should be interpreted as constituency. Due to our disagreement, this section and the next one present two competing interpretations of the transfer schema. This section presents the arguments for an analysis that views the transfer schema as a manifestation of constituency, representing the opinions of Timothy Osborne, and the next section presents the arguments for an analysis of the schema as dependency, representing the opinions of Sylvain Kahane.

The distinction between dependency- and constituency-based grammars is pronounced for most dependency grammarians, and when constituency grammarians are aware of the distinction, it is also pronounced for them. However, producing clear definitional statements that capture the core distinction between dependency and constituency and that receive widespread support from linguists working in the field is not easy to do. Nevertheless, one means of narrowing in on the core distinction is to focus on the number of groupings (i.e. nodes) in the syntactic structures that one assumes. The following trees show the dependency vs. constituency distinction at a basic level:

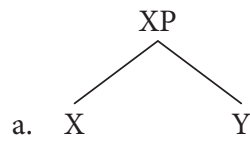

Headed Endocentric b. $\mathrm{X}$

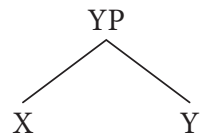

Headed

Endocentric

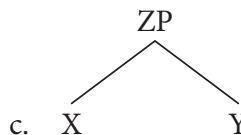

Non-headed

Exocentric
- Constituency

$\varnothing$
(21)

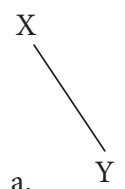

Headed b. $\mathrm{X}$

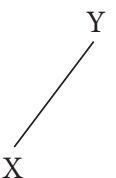

Headed c.

-Dependency

The constituency trees $(20 \mathrm{a}-\mathrm{c})$ show three different ways that a sequence consisting of two elements, $\mathrm{X}$ and $\mathrm{Y}$, might be organized structurally in terms of constituency. One can assume that $X$ is head over $Y(20 a)$, that $Y$ is head over $X(20 b)$, or that neither is head over the other (20c). Headed constituency structures like (20a-b) are sometimes called endocentric, and non-headed structures like (20c) are sometimes called exocentric (Bloomfield 1933). Dependency, in contrast, is incapable of acknowledging headless structures, hence there is no dependency analysis that corresponds to the constituency analysis in (20c). However, like the constituency-based structure in (20a), the dependency-based analysis in (21a) identifies X as head over Y, and like the constituency-based analysis in (20b), the dependency-based analysis in (21b) shows $\mathrm{Y}$ as head over $\mathrm{X}$.

Focusing on the number of nodes present in these trees, the constituency trees assume three nodes each time, whereas the dependency trees assume just two. This insight 
points to the/a primary difference between dependency- and constituency-based structures. Dependency is a one-to-one ratio: for every element that one has in the utterance at hand, there is exactly one node in the syntactic structure that corresponds to that element. Constituency, in contrast, is a one-to-one-or-more ratio; for every element in the utterance at hand, there is at least one node in the structure that corresponds to that element, and often there is more than one. ${ }^{11}$ Thus one can usually distinguish between dependency and constituency tree diagrams by simply counting the number of elements and nodes.

If this means of construing the dependency vs. constituency distinction is on the right track, then Tesnière's transfer schema is more constituency-like than dependency-like. It is more constituency-like because it allows one to acknowledge more nodes than words. The diagram (22a) is a basic example of transfer using Tesnière's transfer schema, and (22b) is a rendition thereof using modern conventions for producing tree diagrams:

a.

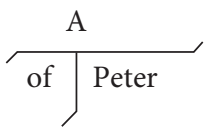

b.

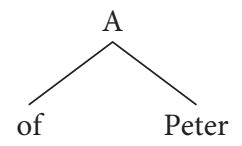

Tesnière's transfer schema in (22a) shows that the translative of transfers the noun Peter to an adjective. Similarly, the modern rendition of the transfer schema in (22b) shows that the phrase of Peter has the status of an adjective (A). There are two things to note about (22b): there are three nodes but just two actual elements and the structure is not headed (i.e. it is exocentric), because neither is of, a preposition, nor is Peter, a noun, head over the other, but rather the entirety has the category status of an adjective. These two characteristics are traits of constituency, not of dependency, as demonstrated with the examples (20-21). In short then, the transfer schema is constituency-based.

This situation is paradoxical, since Tesnière is widely credited as the father of modern dependency grammars. The insight that he was in fact frequently employing a form of constituency to render his syntactic structures is surprising. Nevertheless, if the transfer schema is indeed a form of constituency, then Tesnière was employing constituency quite frequently. The following diagrams of the French phrase le cousin de le fils de la femme de mon oncle 'the cousin of the son of the wife of my uncle' illustrate the analysis further:

11. The complete definitions of dependency and constituency favored here are as follows:

\section{Dependency}

A one-to-one ratio (elements to nodes) resulting in headed syntactic structures;

\section{Constituency}

A one-to-one-or-more ratio (elements to nodes) resulting in syntactic structures that may or may not be headed. 
(23)

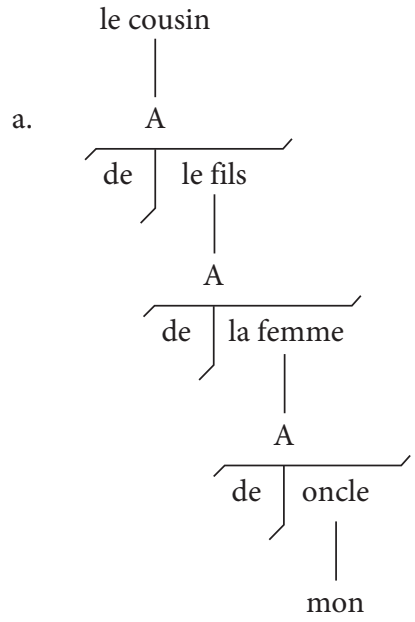

le cousin

b.

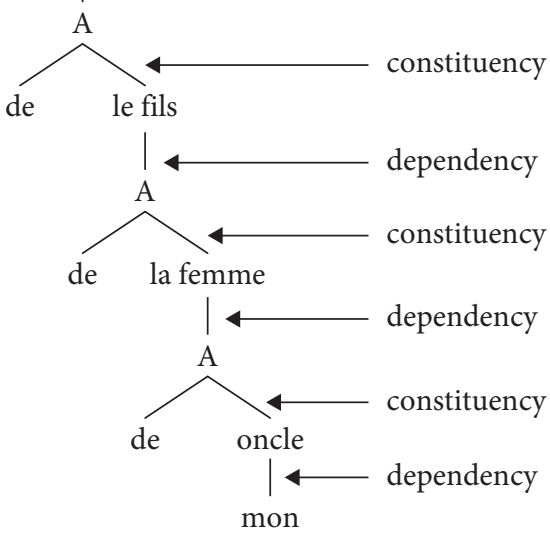

The diagram (23a) is Tesnière's Stemma 294. It contains three instances of transfer. The tree (23b) is the modern rendition thereof. Each of the three instances of transfer is an occurrence of constituency. The result is a tree diagram that is a clear hybrid, combining both dependency and constituency.

An examination of the full stemmas at the end of the book (Stemmas 354-366) reveals just how frequently the transfer schema appears in the stemmatic representations. Stemma 364, for example, contains 17 instances of transfer. These observations lead to the conclusion that Tesnière's theory of syntax is not a pure dependency grammar, but rather it is a hybrid that makes frequent use of both dependency and constituency.

\subsubsection{The transfer schema as dependency}

We have seen that the combination of two elements can be represented in two ways:

- the combination of the elements $\mathrm{X}$ and $\mathrm{Y}$ can be described in terms of constituency: in this case, we do not really represent the combination of $\mathrm{X}$ and $\mathrm{Y}$ but rather the partwhole relations between $\mathrm{X}$ or $\mathrm{Y}$ and the phrase XP (or YP) that they form;

- the combination of the elements X and Y can be described in terms of dependency: in this case, we explicitly represent the combination of $\mathrm{X}$ and $\mathrm{Y}$ by an edge between $\mathrm{X}$ and $\mathrm{Y}$.

The dependency-based representation is regular when the combination of $\mathrm{X}$ and $\mathrm{Y}$ is endocentric: in this case one of the two elements, for instance $\mathrm{X}$, is the head of the phrase $\mathrm{XP}$ they form and $\mathrm{X}$ governs $\mathrm{Y}$. This is the origin of the term dependency: $\mathrm{Y}$ depends on $\mathrm{X}$ in this case. The usual convention is to place the governor on the topmost position and the edge between the two elements is more or less vertical. Such an edge is called a dependency. 
The dependency representation is less evident when the combination of $\mathrm{X}$ and $\mathrm{Y}$ is exocentric, that is, when neither of the elements dominates the other. The combination of $\mathrm{X}$ and $\mathrm{Y}$ can still be represented by an edge, but a convention is needed that does not favor either of the two elements. Usually the convention employed places $\mathrm{X}$ and $\mathrm{Y}$ equi-level and links them with a horizontal edge (see also Kahane 1997 for a formalization in terms of "bubble trees").

(20)

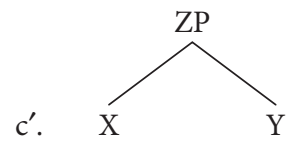

Constituency-based
(21)

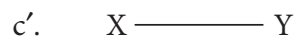

Dependency-based

As established above in Section 4.8, Tensière uses the horizontal edge shown in (21c') for his account of coordinate structures. The phrase Alfred and Bernard is represented as a symmetric combination of Alfred and Bernard: ${ }^{12}$

Alfred — Bernard

But such a representation becomes problematic when one considers the governor of a coordinate structure in a case such as Alfred and Bernard fell.

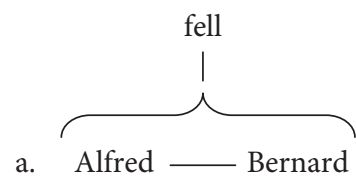

b. Alfred
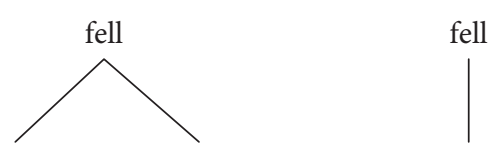

b. Alfred — Bernard

c. Alfred

Bernard

The representation (25a) is used in Stemma 63 and could be interpreted as a constituencybased representation (see Section 4.9.1) because the vertical edge (i.e. the dependency) is connected to a brace, which is an extra object. But Tesnière only uses the graphic convention of (25a) once, in Chapter 38; thereafter he adopts the representation in (25b) where the dependency is split into two edges, one for each conjunct. A third representation is possible, one that Tesnière did not use for junction: in (25c) the vertical edge is directly related to the horizontal edge. Such a structure, called a polygraph, is exploited in Kahane and Mazziotta (in preparation): in a graph edges are between words; in a polygraph you can have edges between a node and an edge. In some sense, the edge acts as a "node", but it is nevertheless an edge, and there is no extra-node.

12. The position of the junctive and is a real problem for Tesnière. In his 1934 paper he placed the junctive above the edge, as a marker of the edge, that is, a marker of the combination. In his Élements, he places the junctor between the conjuncts, cutting the edge in two parts, but he specifies that the junctor is extra-nuclear and does not occupy a node (see Stemmas 62, 63 and 249 and Chapter 136, \$6). We do not represent and here for the sake of simplicity. 
Interestingly, Tesnière explicitly uses a polygraph for the representation of scope effects. He produces the stemma shown in (26a) for red cars that you saw yesterday (Stemma 149); he explains that that you saw yesterday determines red cars rather than cars alone. This stemma is nevertheless dependency-based in the sense that the two combinations (combination A between cars and red and combination B between red cars and that you saw yesterday) are represented by edges, without any extra-node. We can convert (26a) into the constituency-based representation (26b) by "reifying" each edge, that is converting it into a node and two part-whole relations: as shown in (20) and (21), a dependency-based representation can be converted into a constituency-based representation by adding a node for the combination and representing the relation between the combination and the combined elements by part-whole relations.

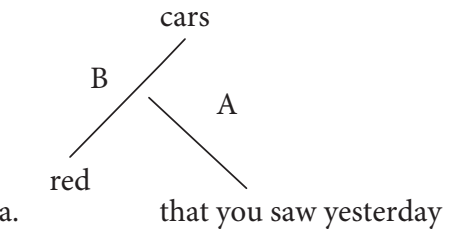

Dependency-based



b. red

cars that you saw yesterday

Constituency-based

The two representations in (26) say exactly the same thing; they say that cars combines first with red and thereafter with that you saw yesterday. In a pure dependency representation, the combinations would not be ordered and both edges A and B would be equi-level. In other words, the dependency tree for (26) (not shown here) would not specify in which order cars combines with its dependents.

Now if we examine Stemma 294, reproduced as (23a) above, we see that for each transfer, the translative and the source are placed equi-level with a T-like symbol between them and a category name (A for adjective) on top of the $\mathrm{T}$ :

$$
\frac{A}{\text { de }{ }_{\text {oncle }}}
$$

This special graphic convention indicates that the translative de combines with the source oncle in a special way, which Tesnière does not want to represent with a vertical line (i.e. a dependency). He places the two elements equi-level, which means that he considers the combination of de and oncle to be exocentric. The label A indicates that their combination behaves as an adjective. He cannot use a horizontal line for representing the transfer combination for two reasons: first he has already used this graphic convention for junction; second, transfer is recursive. Indeed an instance of transfer can apply to the result of a preceding instance of transfer, which would be difficult to represent with a horizontal line (see the dependency-based representation of double transfer in (27b), adapted from 
Stemma 234). In order to show the dependency-based interpretation of Stemma 294, we propose representing the $\mathrm{T}$ combination by a horizontal curved line:

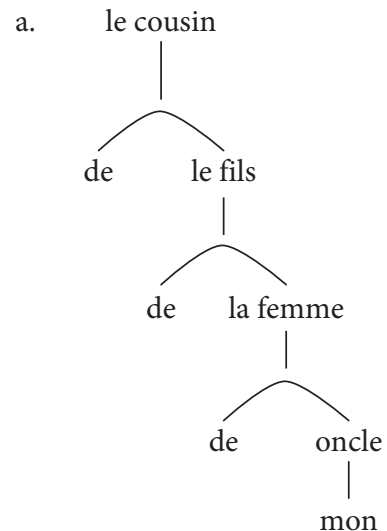

b.

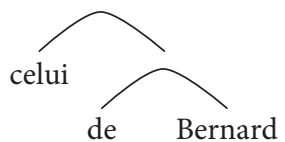

Tesnière's use of the term node (Fr. nœud) is important for the interpretation of these graphs. Tesnière viewed the node as a particular kind of structural position. One could say a "nodal position" rather than a node. Tesnière explains that in case of transfer, neither the source, nor the translative occupy the nodal position, but their combination does. This combination is represented by an edge in a dependency-based representation. Therefore, if we interpret the stemma as a dependency-based representation, it is the edge that occupies the nodal position.

As demonstrated in this section and the previous one, how Tesnière's Stemma 294 should be interpreted is debatable. Tesnière did not formalize the stemma completely. The lack of formalization allows for more flexibility of interpretation.

\section{Dependency after Tesnière}

DG as it is understood by many today differs in certain ways from the theory of syntax that Tesnière presented in his Eléments. It is interesting and instructive in this regard to consider which of Tesnière's ideas did and did not take hold, and furthermore, which aspects of our modern understanding of DG were and were not present in Tesnière's oeuvre. When evaluating the impact of Tesnière's contribution on the later development of DG, it is important to keep in mind that Tesnière himself was not aware of the distinction between dependency and constituency. That distinction was first established in the 1960s during the reception of Tesnière's ideas. Hence Tesnière did not set out to produce a DG, and we can only speculate about how he might judge the merits 
of dependency and constituency were he alive today. Dependency has developed into an entire subfield of the study of grammar, known as dependency linguistics. Within this subfield, further divisions can be acknowledged, e.g. dependency syntax, formal dependency grammars, and dependency parsing (cf. Gerdes, Hajičová \& Wanner 2011, 2013).

The following subsections briefly consider some aspects of most modern DGs that were not addressed or assumed in Tesnière's Éléments.

\subsection{Characterization of dependency}

Tesnière did not produce a falsifiable definition of dependency. His approach was, rather, mentalist. He motivated one of his primary concepts, the connection (see Section 4.1 above) as follows: "The mind perceives connections between a word and its neighbors" (Chapter 1, $\$ 3$ ). While he described the structural order of many constructions in a coherent way, he did not provide criteria that could allow us to falsify his choices. For instance, prepositions could have been dealt with as transitive adverbs (that is, as adverbs with direct objects as in Mel'čuk 1988) rather than as translatives, but we have no means to validate one choice over the other under Tesnière's framework.

This aspect of Tesnière's system stands in contrast to DGs that have followed the Éléments, and it is also unlike the efforts of constituency grammars to identify constituents using constituency tests, these tests shedding light on the segments that should or should not count as phrases and as constituents in general (Bloomfield 1933; Harris 1951; Hockett 1958). Indeed, one way to define dependency structure is to base its construction on a constituency structure: one need merely decide for each constituent which word is its head, that is, one need merely discern which word controls the distribution of that constituent (Bloomfield 1933; Zwicky 1985). A word $y$ depends on a word $x$ if and only if $y$ heads a phrase which is an immediate constituent of the phrase headed by $x$ (Lecerf 1961).

Another means of filling the hole that Tesnière left concerning how dependency is defined is to work with combinations of two-words. Given a two-word utterance or prosodic unit, one can safely assume that they are linked by a dependency (Garde 1974, Melčuk 1988). To decide which of the two governs the other, one need then simply discern which determines the distribution of the two together. The governor is the word that determines the environments in which the two together can appear. In fact the word notion is not necessary to define dependency: as soon as two syntactic units combine, one can posit a dependency between them, whereby the dependency structure is the set of dependencies between the most granular syntactic units (Gerdes \& Kahane 2013). 
In addition to a lack of a falsifiable definition of dependency in general, Tesnière mostly overlooked the distinction between dependency types. While he did acknowledge the difference between semantic and syntactic connections, his discussion of the distinction was brief (Chapter 21f.), and he did not acknowledge aspects of semantic dependencies that many modern DGs take for granted. He remarked that syntactic dependencies generally correspond to semantic dependencies:

“...in the phrase The small streams make the big rivers, small depends on streams, and so the meaning of small bears on that of streams, and I understand that the smallness is a quality of the streams. [...] The semantic impact is thus exercised in the opposing direction to the structural connections."

(Chapter 21, \$4, 7)

Tesnière did not recognize that semantic dependencies can sometimes point in the same direction as syntactic dependencies and sometimes in the opposite direction (Mel'cuk 1988), e.g. the stone freezes vs. the frozen stone: in both cases the meaning 'freeze' is predicated of 'stone', so 'stone' semantically depends on 'freeze', whereas stone syntactically depends on freezes, but it governs frozen.

Tesnière noted that mismatches between syntactic and semantic dependencies are possible, which motivated him to introduce the notion of nucleus:

“...if there are semantic connections that are distinct from structural connections, it is because in the positions where they are joined there are semantic centers distinct from the structural centers."

(Chapter 22, \$2)

But he did not see that some mismatches are more complex, like in cases of so-called tough-movement: a book easy to read. Here a book is the semantic argument of read, but there is no corresponding syntactic dependency connecting the two: in surface syntax, to read depends on easy, which depends on book.

Dependency-based semantic representations have been around since the late 1960s under the names tectogrammatical trees (Sgall 1967; Böhmová et al. 2003), semantic networks (Žolkovskij and Meľčuk 1967, Melčuk 1988), and conceptual graphs (Schank 1969; Sowa 1976).

\subsection{Grammatical functions}

In modern linguistics, the notion of syntactic dependency is attached to the notion of grammatical function (subject, object, oblique, etc.). Grammatical functions are essential in dependency-based approaches because their presence is the only way to distinguish between the various roles that dependents play vis-à-vis their common governor. This contrasts DGs with Chomskyan phrase structure approaches, which derive the grammatical functions from the syntactic configuration instead of viewing them as primitives of 
the syntax. ${ }^{13}$ Nevertheless, the main post-generativist models, LFG (Lexical-Functional Grammar, Bresnan 2001) and HPSG (Head-Driven Phrase Structure Grammar, Pollard \& Sag 1994), have reintroduced grammatical functions as primitives, and thus have something important in common with DGs, all of which have always taken the grammatical functions to be primitives of the theory. ${ }^{14}$

However, the grammatical functions do not play a large role in Tesnière's syntax, unlike in other DGs where their importance is elevated. For instance functional transfer is just sketched in the Éléments (Chapter 72), although it is perhaps as important as categorical transfer (Lemaréchal 1989). Tesnière posits just three actantial grammatical functions, which he calls the first, the second, and the third actant; the other dependents of the verb are circumstants - see Section 4.7 above. While some frameworks also posit just a small set of grammatical functions, e.g. Lexical Functional Grammar (see also the deep syntactic functions of Mel'čuk 1988), most DGs assume dozens of grammatical functions: two elements have the same grammatical function only if they have the same syntactic properties, that is, the same kind of markers, the same linear position, the same agreement properties, and the same distribution. Several sets of grammatical functions have been proposed for formal DGs, parsers, and treebanks. For English, see for instance Mel'čuk and Pertsov (1987), Johnson and Fillmore (2000), or De Marneffe and Manning (2008).

\subsection{Projectivity}

A key concept that is not present in the Éléments but that is central to how dependency syntax understands word order is projectivity. Projectivity is the basis for identifying and defining long-distance dependencies, also known as discontinuities. The concept of projectivity was first defined by Lecerf $(1960,1961)$, shortly after his reading of the Éléments. When employing dependency trees like examples (28a-b) below, the projectivity concept is easily illustrated. A tree that contains no crossing lines is projective, whereas a dependency tree that contains crossing lines is non-projective; it contains a projectivity violation. These points are illustrated with an example of wh-fronting:

13. In X-bar syntax, the subject and the object are distinguished by their position in the phrase structure tree: the object is the NP under VP, while the subject is the NP under IP/TP, the projection of the verbal inflection.

14. The grammatical functions are primitives of functional structure (f-structure) in LFG - as opposed to of constituent structure (c-structure). This fact has motivated some to point to similarities across dependency-based representations and the f-structures of LFG in general (see for instance Broeker 1998 and Owczarzak et al. 2007). 
(28)

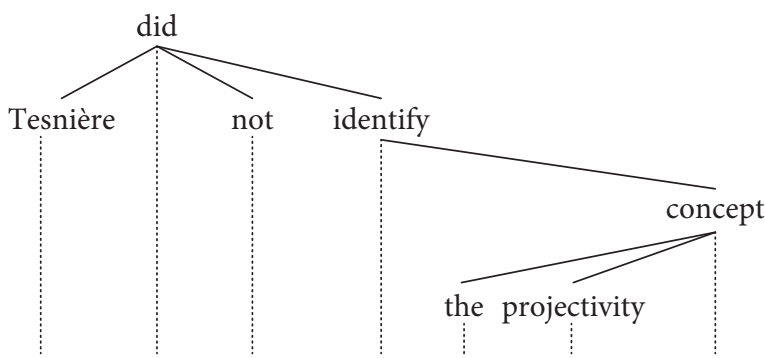

- Projective tree

a. Tesnière did not identify the projectivity concept.

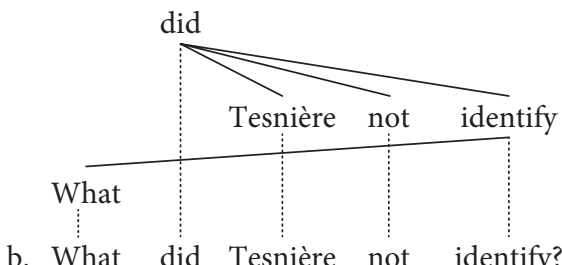

- Non-projective tree

Tree (28a) is projective because there are no crossing lines, whereas tree (28b) contains a projectivity violation due to the fact that the dependency edge connecting the fronted wh-word what to its governor identify crosses three of the vertical projection lines. The tree structures of most if not all discontinuity types (wh-fronting, topicalization, scrambling, extraposition) contain crossing lines in this manner, a fact that makes discontinuities easy to identify.

The projectivity principle has been explored in great depth by numerous theoretical and computational linguists. Tesnière, however, hardly acknowledged the phenomena and issues linked to projectivity. As discussed above, Tesnière separated linear order from hierarchical order, whereby he focused much more on the latter than the former. His stemmas are mostly unordered in the horizontal dimension, which means they largely ignore actual word order. Tesnière's emphasis on hierarchical order certainly influenced the development of many DGs, in part because it left the impression that DG has little to say about word order. Many modern DGs focus intently on word order, however, and when they do so, they inevitably begin their accounts with the principle of projectivity.

\subsection{Function words}

Despite the insightfulness of Tesnière's theory of transfer, the transfer schema he employed has not been adopted by most DGs. ${ }^{15}$ The reason for this may have to do with the particular

15. Taking a quick look at the dependency trees produced in the DG literature reveals that DGs almost unanimously take most function words as heads over content words (e.g. Mel'čuk 1988; 
hierarchical analysis that transfer entails, since it does not grant translatives (auxiliary verbs, prepositions, subordinators) autonomy, but rather their status is secondary insofar as they are function words and hence alone cannot be constitutive of a nucleus. The issue can be reduced to basic assumptions about the hierarchical status of many function words. If one adopts a purely dependency-based approach to syntax, one has to grant function words node status.

The following representations illustrate some possibilities for the analysis of the function word has in the sentence Tom has departed:

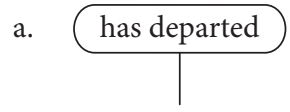

Tom b.

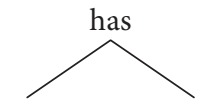

Tom departed

c.

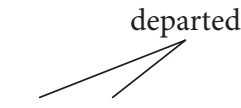

Tom has

The analysis in (29a) is what Tesnière proposed in Part I of the Éléments (Chapter 23, Stemmas 27 and 28). The auxiliary verb has is enclosed in a nucleus circle with the full verb departed. The two together qualify as a dissociated nucleus, which means that neither alone is granted the status of a nucleus. In contrast to Tesnière's analysis in (29a), the analyses in (29b) and (29c) grant the auxiliary verb autonomy, since in each case, there are three distinct nodes shown. The analysis shown in (29b) is closest to what most modern DGs assume, and it corresponds to what many modern phrase structure grammars assume insofar as it shows the auxiliary verb as head over the full verb. The important thing to acknowledge in this regard concerns Tesnière's analysis of the function word, i.e. the auxiliary verb. He did not grant it syntactic autonomy.

In Part III of the Éléments, Tesnière reinterprets dissociated nuclei in terms of the transfer schema (Chapter 155ff.). Tesnière's analysis of function words using the transfer schema is illustrated here with three examples, each of which is shown first according to Tesnière's analysis, and then according to what many modern DGs assume:

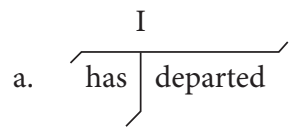

b.
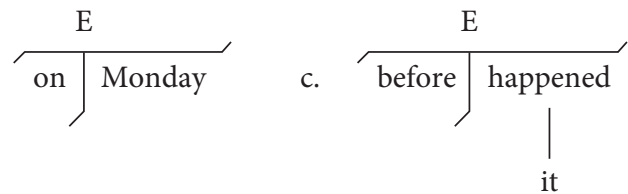

Starosta 1988; Engel 1994; Jung 1994; Eroms 2000; Hudson 1984, 1990, Osborne \& Groß 2012, among many others). There is, however, one prominent exception to this rule. Richard Hudson has argued for determiners as heads (e.g. Hudson 1984:90-92). The majority of DGs, in contrast, continue to assume the traditional NP analysis of noun phrases (noun as head). 
(31)

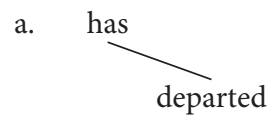

b.

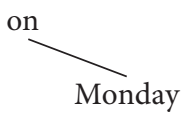

c. before

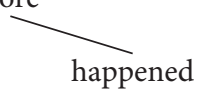

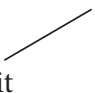

In examples $(30 \mathrm{a}-\mathrm{c})$, the semantically impoverished function word is viewed as a translative and placed equi-level with the content word. The more modern analyses in $(31 \mathrm{a}-\mathrm{c})$, in contrast, take the function word to be head over the content word. The modern approach is motivated in various ways, for instance by the results of permutation and proform-substitution tests. These tests identify the function word as head over the content word.

In sum, Tesnière's hierarchical analysis of many function words in terms of dissociated nuclei and the transfer schema has not survived into later DGs for the most part. Most modern analyses prefer to position the function word as head over the content word. ${ }^{16}$

\subsection{Formalizing valency}

Tesnière had great intuitions, but most of the notions he introduced were not formalized. He did not produce a falsifiable definition of dependency as discussed above, and he did not formalize the concept of valency. Concerning the latter, one can note that there were efforts to erect a concept of valency in formal terms before the appearance of the Eléments and thus before Tesnière used the valency metaphor to denote the combinatory potential of verbs. Extending the pioneering work of Ajduckiewicz (1935), an early implementation of the valency concept can be acknowledged in the tradition of categorial grammar. A monovalent verb form like slept is encoded as $\mathrm{N} \backslash \mathrm{S}$ ("N under S"); slept forms a sentence S if we combine it with a noun $\mathrm{N}$ on the left:

$$
\begin{aligned}
& \text { Alfred slept } \\
& \mathrm{N} \quad \mathrm{N} \backslash \mathrm{S}=\mathrm{S}
\end{aligned}
$$

The combination of $\mathrm{N}$ and $\mathrm{N} \backslash \mathrm{S}$ reduces to $\mathrm{S}$ like the product of $3 / 5$ and 5 reduces to 3 . A bivalent verb form like hit can be encoded as $\mathrm{N} \backslash \mathrm{S} / \mathrm{N}$, which means that hit forms a sentence if it combines with one noun on the right and one noun on the left. It should be apparent

16. See nevertheless Croft (1996), among others, who argues "that there is a case for headhood for both the "content word" (e.g. N in NP, V in a clause) and the relevant "functional category" (e.g. Det in NP, AUX/INFL in a clause)." 
that the concept of valency is present in this approach, since the combinatory potential of verbs and other lexical items is an inherent, inseparable trait of those items. ${ }^{17}$

Another noteworthy attempt to formalize aspects of dependency can be acknowledged in the tradition of Tree Adjoining Grammar (TAG), following the work of Joshi (1987). An elementary tree describing a part of the dependency tree and a whole tree is obtained by combining elementary trees. The following rules, which are consistent with the conventions proposed by Nasr (1995) allow one to obtain the dependency tree of (33):

Alfred often plays big drums.
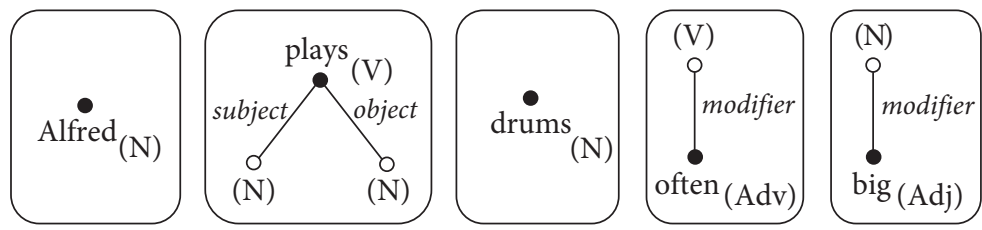

Each rule corresponds to a word and describes its valency: The white nodes indicate valency slots and must unify with black nodes with compatible labels. For instance the second rule, the elementary tree for plays indicates that plays is a verb and that it requires two dependents, both being nouns, one is its subject and the other is its object. The elementary tree for often indicates that it is an adverb that must be adjoined to a verb that it will modify. The six rules can combine to produce the following dependency tree:

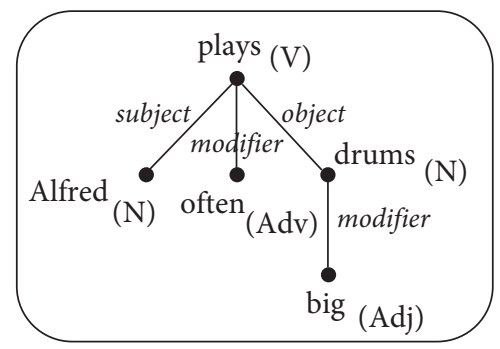

Of course the goal of a linguistic model is not only to generate dependency trees, as shown in this simple DG. The goal of a linguistic model is to be able to associate to every text its possible meanings and conversely to associate every meaning to all the texts that can express it. This program is present in the Éléments (cf. Section 4.3 above), as it was in the Cours de linguistique générale of Ferdinand de Saussure (1916). It was formalized during the 1960s by the Pragians and their Functional Generative Description (Sgall 1967;

17. While the concept of valency is present in early works associated with the tradition of categorial grammar - see for instance Bar-Hillel (1953) - the framework of categorial grammar as it is commonly understood is seen by most syntacticians as being constituency-based. 
Sgall et al. 1987) and the Russian and their Meaning-Text Theory (Žolkovskij \& Mel'cuk 1967, Mel'čuk 1988). Among the most influent dependency-based linguistic models, Word Grammar (Hudson 1984, 2007) must be mentioned.

\subsection{Automated text processing}

Another area in which DG has developed far beyond Tesniere's ideas and efforts concerns the use of dependency as the principle underlying automated text processing, i.e. for computational applications such as computer-aided translation. Tesniere was likely not aware of the potential of his theory in this area, because serious efforts toward automated text processing did not got started until shortly after his death. Hays (1960, 1964) was the first to formalize dependency grammar, his goal being to use dependency for automated text processing. Hays' work was directly inspired by the rewriting systems of Chomsky (1957). Gaifman (1965) showed that Hays' formalism was equivalent to Chomsky's context-free grammar, as well as to the categorial grammar of Bar-Hillel (1953).

But the potential of dependency as the basis for automated text processing did not really come into focus until the 1990s. The first efficient dependency-based parser was the Link Grammar parser of Sleator and Temperley (1993). In the 2000s, dependency parsing has really boomed, becoming more popular than constituency-based parsing. Among the most popular tools are the MaltParser (Nivre et al. 2007) and MATE (Bohnet 2010), as well as constituency-based parsers that convert the parse into a dependency tree, like the Stanford parser (De Marneffe et al. 2006). Several techniques for dependency parsing are presented in Kübler et al. (2009).

Parallel to dependency parsing, dependency treebanks have been developed for testing and training the dependency parsers, as well as for purely theoretical purposes. A treebank is an electronic text consisting of syntax trees that are assigned to the sentences of the text. The first treebank, the Penn Treebank (Marcus et al. 1993), was constituencybased, but dependency treebanks are now more widespread. The best-known of these is the Prague Dependency Treebank (Hajič 1998), which was first created for Czech, but that now includes an English section as well.

One of the advantages of dependency parsers for natural language parsing (NLP) it that the parses can be easily encoded in a table, like the CoNLL format (Nilsson et al. 2007), which has now become a standard. Each word is on a different level and receives an identifier (first column). Its governor is identified by its identifier (fourth column). Other information can be encoded in other columns, like here the part of speech (third column) and the grammatical function (fifth column). The analysis in the table is for the sentence Alfred often plays big drums. 


\begin{tabular}{lllcl}
\hline ID & Word & POS & Governor & Function \\
\hline 1 & Alfred & N & 3 & subject \\
2 & often & Adv & 3 & modifier \\
3 & plays & V & 0 & root \\
4 & big & Adj & 5 & modifier \\
5 & drums & N & 3 & object \\
\hline
\end{tabular}

\section{Outlook}

The influence and reach of dependency as a concept upon which theories of syntax can be developed and syntactic phenomena explored is expanding at present. The upsurge in interest appears to have one or two main sources. Above all, the simplicity and hence practicality of dependency is increasingly acknowledged in the field of computational linguistics, as just stated in the previous section. It is likely that this trend toward dependency in computational circles will continue to grow stronger as more linguists become aware of its potential.

Tesnière was very interested in the pedagogical potential of his syntax. He viewed the practices of grammar instruction in the schools of his day as deficient in more ways than one. He judged much of the grammar terminology to be inaccurate and at times contradictory, and as a remedy to this unfortunate situation, he was interested in seeing his system supplement and eventually replace the faulty practices of grammar instruction of his time. He actually received the opportunity in the late 1930s to see the pedagogical value of his system tested in classrooms in the Montpellier area, as discussed above in Section 3. Apparently, the children were quite capable of learning and employing the stemmatic analysis of simple sentences (see Chapter 276). Unfortunately however, the potential of stemmatic analysis for pedagogical applications does not seem to have been realized, since Tesnière's stemmas did not catch on more widely in French schools.

This is a regrettable situation, since the ease with which one can produce analyses of basic sentences using dependency is difficult to overlook. We translators see great potential in this area. This potential is particularly evident when one considers the approach to teaching sentence grammar that has been widely employed in the past and is still employed by some today in middle schools in North America, i.e. Reed-Kellogg sentence diagrams. ${ }^{18}$ Our sense of the Reed-Kellogg diagrams is that they are more complex and difficult to

18. Concerning the Reed-Kellogg system for diagramming sentences, see note 6 above. 
master than Tesnière's basic stemmas, mainly because the Reed-Kellogg system arguably maintains a measure of constituency in the form of the initial subject-predicate division. The basic stemmas of the sort Tesnière employed would be easier for young minds to understand and employ than the mixed diagrams of the Reed-Kellogg system. Pedagogical approaches to teaching sentence grammar can then benefit from this simplicity. Insights into the nature of syntax and grammar can and should become more accessible to both young and old.

Beyond computational and pedagogical applications, the potential of dependency to serve as the basis of more or less formalized theories of syntax and grammar is well established. The works of prominent linguists such as Richard Hudson in the framework of Word Grammar (Hudson 1984, 2007) and Igor Melčuk in the framework of Meaning-Text Theory (Mel'čuk 1988) have demonstrated that comprehensive and detailed approaches to the study of syntax can be mostly or entirely dependency-based. Indeed, we believe that the academic study of syntax can benefit greatly from the increasing awareness of the alternative that dependency-based approaches to the theory of syntax and grammar offer. It is in this respect that we have been motivated to translate Tesnière's main oeuvre to English. The tremendous breadth of syntactic phenomena Tesnière explores in numerous languages and the insightful analyses of these phenomena that he offers can now serve as inspiration to all those established and aspiring linguists for whom Tesnière's ideas were previously largely inaccessible due to the language barrier.

\section{Literature}

Ajdukiewicz, K. 1935. Die syntaktische Konnexität. Studia Philosophica 1, 1-27.

Arnavielle, T. 1995. Lucien Tesnière à Montpellier. In Madray-Lesigne and Richard-Zappella (1995), 83-86.

Arrivé, M. 1969. Les éléments de syntaxe structurale de Lucien Tesnière. Langue française 1, 36-40. Bar-Hillel, Y. 1953. A quasi-arithmetical notation for syntactic description. Language 29, 1, 47-58. Bloomfield, L. 1933. Language. New York.

Böhmová, A., J. Hajič, E. Hajičová, and B. Hladká 2003. The Prague Dependency Treebank. In A. Abeillé (ed.) Treebanks: Building and Using Parsed Corpora, pp. 103-127. Netherlands: Springer. Bohnet, B. 2010. Very high accuracy and fast dependency parsing is not a contradiction. In Proceedings of the 23rd International Conference on Computational Linguistics (Coling), pp. 89-97.

Brassai, S. 1860-1863 [2011]. A magyar mondat. [The Hungarian sentence.] Edited by Elekfi L. and Kiefer F., Budapest: Tinta.

Bresnan, J. 2001. Lexical-Functional Syntax. Blackwell.

Bröker, N. 1998. The formation of comparative clauses in French and English. University of Stuttgart. arXiv:cmp.I/9807009.

Chomsky, N. 1957. Syntactic Structure. Cambridge: MIT Press.

Coseriu, E. 1980. Un précurseur méconnu de la syntaxe structurale : H. Titkin, Recherches de linguistique: Hommages à Maurice Leroy, Editions de l'Université de Bruxelles, 48-62. 
Croft, W. 1996. What's a head?. In J. Rooryck and L. Zaring (eds.), Phrase Structure and the Lexicon, 35-75. Dordrecht: Kluwer.

Daumas, F. 1957. Lucien Tesnière (1893-1954). Jalons biographiques, Orbis - Bulletin International de Documentation Linguistique 6, 1, Louvain, 253-258.

De Marneffe, M.C., B. MacCartney, and C. Manning 2006. Generating typed dependency parses from phrase structure parses. In Proceedings of LREC, 449-454.

De Marneffe, M.C. and C. Manning 2008. Stanford typed dependencies manual. http://nlp.stanford. edu/downloads/dependencies_manual.pdf.

Engel, U. 1994. Syntax der deutschen Gegenwartssprache, 3rd revised edition. Berlin : Erich Schmidt Verlag.

Eroms, H.-W. 2000. Syntax der deutschen Sprache. Berlin: Walter de Gruyter.

Fourquet, J. 1996. Ce que je dois à Lucien Tesnière. In Gréciano and Schumacher (1996), 1-6.

Gaifman, H. 1965. Dependency systems and phrase-structure systems, Information and Control 18, 304-337. Rand Corporation (1961), RM-2315.

Garde, P. 1977. Ordre linéaire et dépendance syntaxique: Contribution à une typologie. Bulletin de la Société Linguistique de Paris 72, 1, 1-26.

Gerdes, K., E. Hajičová, and L. Wanner (eds.), 2011. Proceedings of the first international conference on Dependency Linguistics (DepLing), Barcelona.

Gerdes, K., E. Hajičová E., and L. Wanner (eds.) 2013. Proceedings of the second international conference on Dependency Linguistics (DepLing), Prague.

Gerdes, K. and S. Kahane 2013. Defining dependency (and constituency). In K. Gerdes, E. Hajičová, and L. Wanner (eds.), Computational Dependency Linguistics, IOS Press.

Gosselin, L. 1995. Connexion structurale et incidence sémantique : le cas des circonstant. In MadrayLesigne and Richard-Zappella (1995), 137-142.

Gréciano, G. and H. Schumacher (eds.) 1996. Lucien Tesnière - Syntaxe structurale et opérations mentales (Proceedings of the German-French colloquium for the 100th anniversary of his birthday, Strasbourg, 1993). Tübingen: Max Niemeyer Verlag.

Hajič, J. 1998. Building a syntactically annotated corpus: The Prague Dependency Treebank. In E. Hajičová (ed.), Issues of Valency and Meaning. Studies in Honour of Jarmila Panevová, Karolinum, Charles University Press, Prague, Czech Republic,106-132.

Hays, D. 1960. Grouping and dependency theories. Technical report RM-2646, Rand Corporation. Hays, D. 1964. Dependency theory: A formalism and some observations. Language 40, 4, 511-525.

Harris, Z.S. 1951. Methods in Structural Linguistics. Chicago University Press.

Hockett, C.F. 1958. A Course in Modern Linguistics. New York: The Macmillan Company.

Hudson, R. 1984. Word Grammar. Oxford: Blackwell.

Hudson, R. 1990. An English Word Grammar. Oxford: Basil Blackwell.

Hudson, R. 2007. Language Networks: The New Word Grammar. Oxford University Press.

Imrényi, A. 2013. Constituency or dependency? Notes on Sámuel Brassai's syntactic model of Hungarian. In P. Szigetvári (ed.), VLlxx. Papers Presented to László Varga on his 70th Birthday. ELTE: Department of English Linguistics, 167-182.

Jackendoff, R. 1972. Gapping and related rules. Linguistic Inquiry 2, 21-35.

Jespersen, O. 1924. Philosophy of Grammar. New York: Henry Holt and Company.

Jespersen, O. 1937 [1984]. Analytic Syntax. University of Chicago Press.

Johnson, C. and C. J. Fillmore 2000. The FrameNet tagset for frame-semantic and syntactic coding of predicate-argument structure. Proceedings of the first North American chapter of the Association for Computational Linguistics conference. Association for Computational Linguistics, 56-62. 
Joshi, A.K. 1987 An introduction to Tree Adjoining Grammars. In A. Manaster-Ramer (ed.), Mathematics of Language, John Benjamins, Amsterdam, 87-115.

Jung, W.-Y. 1994. Syntaktische Relationen im Rahmen der Dependenzgrammatik. Hamburg: Buske. Kabano, A. 2000. Le destin de la théorie syntaxique de Lucien Tesnière (1893-1954). Historiographia linguistica 27, 1, 103-126.

Kahane, S. 1997. Bubble trees and syntactic representations. Proceedings of the 5th Meeting of the Mathematics of Language (MOL). Association for Computational Linguistics, 70-76.

Kahane, S. and N. Mazziotta. (in preparation) Syntactic polygraphs: A common representation for constituency and dependency.

Kaplan, R.M. and J. Bresnan 1982. Lexical-functional grammar: A formal system for grammatical representation. Formal Issues in Lexical-Functional Grammar, 29-130.

Kübler S., R. McDonald, and J. Nivre 2009, Dependency parsing, Synthesis Lectures on Human Language Technologies.

Lascarides, A. and N. Asher 1991. Discourse relations and defeasible knowledge. Proceedings of the 29th annual meeting on Association for Computational Linguistics, Association for Computational Linguistics, 55-62.

Lazard, G. 1995. La définition des actants. In Madray-Lesigne and Richard-Zappella (1995), 151-158.

Lecerf, Y. 1960. Programme des conflits, modèle des conflits. Bulletin bimestriel de l'ATALA 1, 4, $11-18$.

Lecerf, Y. 1961. Une représentation algébrique de la structure des phrases dans diverses langues naturelles, Compte Rendu de l'Académie des Sciences de Paris 252, 232-234.

Lemaréchal, A. 1989. Les parties du discours. Paris: PUF.

Madray-Lesigne, F. and J. Richard-Zappella 1995. Lucien Tesnière aujourd'hui, (Proceedings of the international colloquium, Rouen, 1992), Editions Peeters, Louvain-Paris.

Marcus, M.P., M. A. Marcinkiewicz, and B. Santorini 1993. Building a large annotated corpus of English: The Penn Treebank. Computational linguistics 19, 2, 313-330.

Mel'čuk, I. 1988. Dependency Syntax: Theory and Practice. Albany: State University of New York Press.

Mel'čuk, I. and N. Pertsov 1987. Surface Syntax of English: A formal Model within the Meaning-Text Framework. Benjamins.

Nasr, A. 1995. A formalism and a parser for lexicalised dependency grammars. Proceedings of the 4th International Workshop on Parsing Technologies (IWPT). State University of NY Press.

Nilsson, J., S. Riedel, and D. Yuret 2007. The CoNLL 2007 shared task on dependency parsing. In Proceedings of the CoNLL Shared Task Session of EMNLP-CoNLL, 915-932.

Nivre, J., J. Hall, J. Nilsson, A. Chanev, G. Eryigit, S. Kübler, S. Marinov, and E. Marsi 2007. MaltParser: A language-independent system for data-driven dependency parsing. Natural Language Engineering 13, 2, 95-135.

Osborne, T., M. Putnam, and T. Groß 2011. Bare phrase structure, label-less trees, and specifier-less syntax: Is Minimalism becoming a dependency grammar? The Linguistic Review 28, 315-364.

Osborne, T. and T. Groß 2012. Constructions are catenae: Construction Grammar meets dependency grammar. Cognitive Linguistics 23, 1, 165-216.

Owczarak, K., J. van Genabith, and A. Way 2007. Evaluating machine translation with LFG dependencies. Machine Translation 21, 95-119.

Pinkham, J. 1982. The Formation of Comparative Clauses in French and English. Doctoral dissertation, Harvard University.

Pollard, C. and I. Sag 1994. Head-Driven Phrase Structure Grammar. University of Chicago Press. 
Postal, P. 1974. On Raising: One Rule of English Grammar and Its Theoretical Implications. Cambridge, MA: The MIT Press.

Reed, A. and B. Kellogg 1877. Higher Lessons in English: A Work on English Grammar and Composition. Clark and Maynard.

Ross, J. 1970. Gapping and the order of constituents. In M. Bierwisch and K. E. Heidolph (eds.), Progress in Linguistics: A Collection of Papers. The Hague: Mouton.

Rousseau, A. 1995. Le graphe de Tesnière : origines et originalités. In Madray-Lesigne and RichardZappella, 75-82.

Schank, R. 1969. Conceptual dependency as a framework for linguistic analysis. Linguistics 49, 28-50.

Schubert, K. 1987. Metataxis: Contrastive Dependency Syntax for Machine Translation. Dordrecht: Foris,

Sgall, P. 1967. Generativní popis jazyka a česká deklinace [Generative description of language and Czech declension]. Prague: Academia.

Sgall, P., E. Hajicová, and J. Panevová 1986. The Meaning of the Sentence in its Semantic and Pragmatic Aspects. Springer.

Sleator, D. and D. Temperley 1993. Parsing English with a Link Grammar. Third International Workshop on Parsing Technologies, Carnegie Mellon Univ. Comp. Sc. Techn. Report CMU-CS-91-196, 1991.

Sowa, J. 1976. Conceptual graphs for a database interface. IBM Journal of Research and Development, vol. 20, 4, 336-357.

Starosta, S. 1988. The Case for Lexicase: An Outline of Lexicase Grammatical Theory. New York: Pinter Publishers.

Tesnière, L. 1931. Oton Joupantchitch, Poète slovène, l'homme et l'œuvre. Paris.

Tesnière, L. 1934. Comment construire une syntaxe. Bulletin de la Faculté des Lettres de Strasbourg, 7, $12^{\text {ème }}$ année, 219-229.

Tesnière, L. 1937. Curriculum vitae de Monsieur Tesnière, reprinted in Madray-Lesigne and Richard-Zappella (1995), 410-412.

Tesnière, L. 1939. Eléments d'un rapport sur l'activité scientifique de Monsieur Tesnière, reprinted in Madray-Lesigne and Richard-Zappella (1995), 405-409.

Tesnière, L. 1953. Esquisse d'une syntaxe structurale. Paris: Klincksieck.

Tesnière, L. 1959. Éléments de syntaxe structurale. Paris: Kincksieck.

Tesnière, L. 1966. Éléments de syntaxe structurale, 2nd edition. Paris: Klincksieck

Tesnière, M.-H. 1996. Le fonds Lucien Tesnière à la Bibliothèque national de France. In Gréciano and Schumacher (eds) 1996, 7-14.

Žolkovskij A. and I. Mel'čuk 1967. O semantičeskom sinteze [On the semantic synthesis (of texts)], Problemy Kybernetiki [Problems of Cybernetics] 19, 177-238. [Fr. transl.: Sur la synthèse sémantique (de textes),1970, T.A. Information 2, 1-85.]

Zwicky, A. 1985. Heads. Journal of Linguistics 21, 1, 1-29. 



\section{Foreword to the 1st edition (1959)}

Lucien Tesnière worked for a very long time on his Éléments de syntaxe structurale. He had already prepared an initial draft of it as early as 1939. He continued working on it until 1950, but without the help of new foreign publications that started to become available only after sickness had already slowed his work considerably. In the end, the book appears many years after his death (December 6, 1954), as is appropriate for the memory of the maestro. However, during proofing the references have been checked and if need be, corrected. As new editions of the cited books have appeared, they have been added to the references, and if it seemed necessary, a few brief notes have been added, these notes always appearing in square brackets as a means of distinguishing them from the references in the original manuscript. Rare modifications have occurred, in particular when an obvious imperfection was identified that Tesnière himself would have corrected. Finally, all the cited languages have been reviewed by specialists of each of them, which has permitted more confident corrections. It is not possible to credit all those who have been solicited for help concerning the one or the other passage, for these people are too numerous. However, one cannot pass over in silence the following people, who have graciously donated their time to improve the appearance of the work: Mrs. A. Matignon, Mr. E. Bachellery, L. Bazin, P. Demiéville, H. Guitton, R. Lafon, P. Meile, J. Perrot, A. Vaillant, M. Vey. These people, as well as all the others who have not been named, all receive our gratitude for the care they have produced in correcting the proofs or stemmas.

This work would not have appeared without the devotion of the friends who were most intimately connected to the author: Mr. J. Fourquet and F. Daumas.*

Thus although one cannot ignore the imperfections that remain and that the author himself would have corrected, the work is closer to the more perfect form that Lucien Tesnière dreamed of giving it.

\section{Foreword to the 2 nd edition (1965)}

The second edition of this work has benefited from the remarks and corrections of a number of friends and students of L. Tesnière, in particular Mr. J. Fourquet, P. Garde, J. Perrot, and E. Richer, to whom we express our great gratitude.

${ }^{*}$ Mr. F. Daumas has reviewed all the galleys from one end to the other. The brief additions in square brackets in the notes and the addenda are due to him. [Translators' note: They are marked as "First editors' notes" in this translation.] 



\section{Preface to the first original edition}

Lucien Tesnière, driven by a vocation in linguistics that overcame all obstacles put in front of him by his family, focused on two great novelties that would transform linguistics: dialectology and structuralism.

With his studies on the disappearance of dual number in Slovenian, Tesnière presented the first great application of geographic methods in linguistics in the Slavic domain (1925).

When Tesnière gave his article Comment construire une syntaxe 'How to construct a syntax' to the Bulletin de la Faculté des Lettres de Strasbourg in 1934, he was outlining a method of delimiting the structure of the utterance in every language.

Tesnière devoted the last 20 years of his life to the application of this method to a large number of languages and above all, to French. He poured his entire personality into the enterprise. He was striving to fully realize Meillet's desideratum that the modern linguist should seek active and comprehensive possession of living languages in the domain in which he works.

He reproduced his own experience for the students to whom he taught Slavic languages and the foreign students to whom he taught French: to learn morphology and a syntax that is reduced to the listing of grammatical constraints is to remain at the threshold of the birth of expression according to the structures particular to a given language, without ever crossing that threshold.

What he created was a method of analysis that every country could apply to its national language in order to understand how it functions. The experience acquired through this practice could be transported to the teaching of foreign languages. One could cast light on the structures peculiar to a given language using this method.

The very long time that it took Tesnière to achieve his great work is certainly explained in part by the serious health difficulties that slowed his work in his last years. But there was also another, more important reason: his desire to found a general syntax, to establish an analysis universally applicable to all the languages that he knew and to others as well. In this respect, he deplored not having included languages in his work of a sort that are profoundly different from the European languages.

For at least one language, French, Tesnière wanted to overlook no aspect; every grammatical fact was to rest on one of the simple principles with which he was operating, or on a combination of these principles. He held to the goal of providing an integrated grammatical analysis - without holes - of a literary text of the most idiomatic sort, a fable by La Fontaine. 
Reconstructing the entire grammar of a great literary language starting from zero is only possible by way of a long exploratory effort through many details. This exploration occupied all of Tesnière's thoughts in his final years.

Finally, part of the internal logic of his enterprise was to prove the pedagogical applicability of the new grammatical analysis by way of experiment.

He got the opportunity to test his theory at a school for primary school teachers in Montpellier. The children of the appended school easily learned to decompose sentences according to the stemmatic schemas that one finds in the first part of the Syntaxe structurale.

While Tesnière was endeavoring to realize his work, structural linguistics was developing around him in another direction, in terms of theoretical constructions. Tesnière did not ignore these developments, although in the end he could no longer follow them in detail. It appears that he did not want to put pure analysis ahead of practical analysis. For Tesnière, the pedagogical practice of his day was based on confused and inadequate notions, which rendered it ineffectual; the application of the simplest structural principles would suffice to correct the distressful situation.

Tesnière was therefore long isolated in his urgent and detailed efforts to renew the practice of teaching French using a method that would also be applicable to the other main European languages.

The fact that five years after his death, German-speaking educators and linguists proclaim the necessity today for this new method is telling. One now wants to build a bridge between the scientific theory of language and the instruction of grammar, abandoned to empiricism until now.

Theoreticians might object that there is no need to rush to practice until after the pure science has been firmly established and elaborated. In reality the constant interaction between the classification of various and numerous concrete facts and the theory, the testing of central notions in practice, is essential and is overlooked by some schools of "pure" analysis. One of the strengths of American structuralism, and one of the reasons for its dynamism, is that it has accumulated experience through the description of linguistic facts of native American languages, and it has done so while allowing the reciprocal interaction of practice and theory.

On the other hand, one cannot easily go from pure theory to efficient practice, which is founded on simple solutions to numerous small and specific problems. As an example, take the application to French of the method of the Copenhagen school around K. Togeby; as rich in insights as this method is, it ceases at the point where the foundation of a complete method of instruction would start. 
In other respects, a risk, which such efforts to implement the pure analysis did not escape, is to transpose the facts of a language into the theory's terminology and to represent them with its symbols while remaining hampered by the inadequate analyses that education has left in our mind - (for instance the analysis of verbal forms in French remains shackled by a false division of inflected form in -ait into "indicative" forms and "conditional" forms). ${ }^{19}$ All in all, Tesnière focused his efforts on the middle region, where scientific attitude and all its implications of rigor and critical control as well as attentive observation of the multiplicity of concrete facts come together.

For the theoretician who endeavors to demonstrate the scientific value of the notions that he is elaborating by way of the complete processing of a given language, the study of Tesnière's work will deliver pertinent and useful insights, even if one is working with another terminology and another system of notions than those elaborated by Tesnière. Tesnière did not hesitate to integrate the analyses of others into his edifice, for instance those of of Damourette and Pichon.

Conversely, as soon as the practitioner "battling with the analysis of a determined literary text" becomes discontent with the explications (or lack thereof) of traditional grammar, which is more or less normative and based on logic, Tesnière's analyses will be a goldmine of insights.

In my attempt to situate and characterize Tesnière's structural syntax, I find that again, his temperament led him to focus on the middle region, where syntagmatics and semantics meet.

Tesnière's central syntactic idea is a notion that one imperfectly names with the term word classes. He was not interested in the parts of speech in the traditional sense, which were considered identifiable types based on their form. He was interested, rather, in the fact that expressing information about an event by using a verb and phrases in nominal (subject, object) and adverbial (time, place) function implies a conceptual activity first, an activity involving ideas of a process, active and non-active participants in the process, and circumstances surrounding the action.

Tesnière broached these problems with the concept of the connection, which implies linked terms, one of which is the [root] node of a phrase (verbal node, nominal node) and the other of which is at the other end of the connection link and is already a bearer of qualities that allow it to form a connection with such a node.

19. Translators' note: French uses the same ending for the so-called imperfect il chantait 'he was singing' and conditional il chanterait 'he would sing. There has been much debate about whether the conditional is a tense of indicative mood or a separate mood in its own right. 
Tesnière generalized a notion that one had perceived only in the most glaring cases: a relative clause takes on a qualitative or determinative function similar to the function fulfilled by an adjective (the attributive function). The classification of the facts of transfer and of the "operators" of transfer (the relative pronoun or adverb in the case of transfer from a verbal phrase to a modifier of a noun) is one of the most original aspects of the present work. One senses how Tesnière took pleasure in analyzing the sequence of transfers that permits a servant to say: Mademoiselle sera d'un comme il faut 'Ms. will be upstanding', lit. 'Ms. will be of an as it must' (cf. Chapter 271).

Considered in this light, Tesnière's structuralism is not formalistic.

To unravel/untangle a sentence in a text in the form of a stemma that has the verb as its [root] node and that shows the connections, and to acknowledge it as an entity with both actants and circumstants, these acts, for the primary school student, involve perceiving the articulation of a real-life experience with linguistic structure; the event is structured with the goal of expressing the event using language.

As a practitioner, one cannot always agree with the choices Tesnière made for his nomenclature, or with the graphic representations that he proposed; all practice implies options of presentation, and as a theoretician, one might prefer to attack the problems in a different order and to operate with different abstractions. Nevertheless, the result of 20 years of intense effort of a vigorous linguist to methodologically analyze a tremendous number of linguistic facts with Cartesian freedom can hardly be ignored.

From time with the manuscript, I have taken an enrichment that I can compare only with the reading of Bally's book, Linguistique générale et linguistique française, which has appeared in more than one edition (in fact Bally's work is a general synthesis constructed on the basis of French and German, that is, on a base that is less extensive than that of Tesniere's work).

I think Tesnière's Syntaxe structurale generates interest through the richness of "illuminating" insights that one finds on page after page.

Tesnière's work will even perhaps be discretely looted, in order to update manuals, by the authors who find ingenious and pertinent formulations in the book. Tesnière would certainly readily forgive these authors due to the pleasure of seeing the results of his tireless investigations of pertinent facts pass into practice.

The work has also overcome the obstacles encountered during the efforts to bring it to publication (these obstacles were mastered by the tenacity of Madame Tesnière and some disciples and friends of the linguist). One of these obstacles is the fact that Tesnière pursued only a pure analysis of what he believed necessary, in order to focus more on the basic problems that concerned the teaching of grammar. Further, he remained outside of the relevant debates revolving around theoretical structuralism (without ignoring them), 
while at the same time he demanded the same revolutionary leap of faith associated with the structuralist schools, faith in the superiority of rational attitude as opposed to purely empirical practice.

Structural syntax falls within the current efforts to renew the teaching of grammar, these efforts having taken hold in English and more recently in German. The movement is developing rapidly at present, a fact that is evident in the founding of the Scottish school for the formation of teachers of living languages under the direction of the dialectologist and structuralist Catford, and it is evident in the offer made to Hans Glinz, the author of Die innere Form des Deutschen, to direct the Pedagogical Institute.

It is not without some bitterness that we ponder what the state of language pedagogy in France would be like now [in 1959] had the direction of an Institute of Applied Linguistics like the one in Edinburgh been given to Tesnière 25 years ago in 1934.

J. Fourquet, Professor at Sorbonne University, 1959

\section{Preface to the second original edition}

A new edition of Tesnière's book has become necessary, six years after the first edition.

I did not at all share the skepticism expressed by some that the book would have only a few dozen readers, but I also did not expect that the first edition would be sold out in such a short time.

I expected that converging developments in Europe and America toward a rigorous theory of linguistic structures would motivate many to discover the relevance of Tesnière's ideas, that language instruction could not remain ignorant of progress in basic linguistics, and that at the moment when practical problems arose from this progress, the solutions proposed by Tesnière would be welcomed.

As remarkable as the current acceleration of these two movements is, the diffusion of Tesnière's syntax would have perhaps only just begun if another trend had not appeared that I did not foresee: the appearance of machine translation and information retrieval with the help of electronic processors. Mathematical circles, which are free from the resistance that slowed the pace of Tesnière's work, have had to establish a program of rigorous linguistic analysis. These circles have found suggestions in Tesnière's work that are immediately useful to their efforts. Tesnière's book has been read at Euratom and C.E.T.A in Paris and Grenoble. When these circles discuss the Tesnière-Hays graphs and compare them to those of Chomsky-Harris, it is apparent that the Eléments de syntaxe structurale, or at least the central theses therein, is among universally recognized works. 
A new era is beginning, one in which researchers who were previously separated according to their initial field of expertise - mathematics, psychology, philology - are coming closer together and contributing to the edification of a unique type of linguistics. This is a period in which many are thinking about the first difficulties encountered with computers and in which they are striving to expand on the notions of the base. The extent to which Tesnière's ideas address central aspects of these endeavors is now evident. Among the fruitful ideas that have recently been presented as new, more than one of them was already present in Tesnière's book.

For those who strive to read Tesnière's book attentively and with reflection, the Eléments de syntaxe structurale remains a fundamental work, a goldmine in which there are many discoveries yet to be made.

J. Fourquet, Professor at Sorbonne University, 1965 
PART I

\section{The connection}





\section{BOOK A}

\section{Preamble}

\section{Chapter 1. The connection}

$\$ 1$ The object of structural syntax is the study of the sentence. When German linguists had to translate the word syntax into their language, they could find no better word than Satzlehre 'science of the sentence'.

$\$ 2$ The sentence is an organized set, the constituent elements of which are the words. ${ }^{1,2}$

$\$ 3$ Each word in a sentence is not isolated as it is in the dictionary. ${ }^{3}$ The mind perceives connections between a word and its neighbors. The totality of these connections forms the scaffold of the sentence.

$\$ 4$ These connections are not indicated by anything. But it is absolutely crucial that they be perceived by the mind; without them the sentence would not be intelligible. When I say Alfred speaks (Stemma 1), I do not intend to say, on the one hand, "There is a man who is called Alfred" and, on the other hand, "Someone speaks"; rather I intend to say all at once that "Alfred performs the act of speaking" and "The one who speaks is Alfred".

$\$ 5$ As a result, a sentence of the type Alfred speaks is not composed of just the two elements, Alfred and speaks, but rather of three elements, the first being Alfred, the second speaks, and the third the connection that unites them - without which there would be no sentence. To say that a sentence of the type Alfred speaks consists of only two elements is to analyze it in a superficial manner, purely morphologically, while neglecting the essential aspect that is the syntactic link.

1. Grammarians have tried several times to shine light on the notion of the sentence by employing the term clause (Fr. proposition), borrowed from logic (cf. Chapter 20, \$18). This unfortunate effort does not seem to have satisfied them - see O. Bloch: "The authors cannot even agree as to what should be understood by the term clause" (cf. Bulletin de la Société de linguistique de Paris, 1936, 37: 3, p. 90).

2. Needless to say, we do not share the point of view of A. Sauvageot, who throws in the towel, saying: "A definition of the sentence is of no interest from the point of view of syntax. At best, it can be considered an outcome rather than a point of departure" (cf. Bulletin de la Société de linguistique de Paris, 1936, 37: 3, p. 162).

3. It is moreover by way of pure abstraction that we isolate the word from the sentence, the latter being the natural environment in which the word resides, like a fish in water. That is why the dictionary - which is the result of work that involves taking segments of linguistic reality and separating them from their natural habitat - is inevitably a dead entity. 
$\$ 6$ It works the same way in chemistry, where the combination of chloride $\mathrm{Cl}$ and sodium $\mathrm{Na}$ produces a compound, sodium chloride $\mathrm{NaCl}$, or table salt, which is a completely different substance and presents totally different characteristics from chloride $\mathrm{Cl}$ on the one hand and sodium $\mathrm{Na}$ on the other hand.

$\$ 7$ The connection is indispensable for the expression of thought. Without the connection, we would not be in a position to express a single continuous thought and we would only be capable of producing a succession of isolated images and ideas, with nothing linking them together. ${ }^{4}$

$\$ 8$ It is therefore the connection that gives the sentence its organic and living character and that is, in a sense, its vital principle.

$\$ 9$ To construct a sentence is to breathe life into an amorphous mass of words, establishing a set of connections between them.

$\$ 10$ Conversely, understanding a sentence involves seizing upon the set of connections that unite the various words.

$\$ 11$ The connection is thus at the foundation of structural syntax. One cannot emphasize enough its importance.

4. Such is the normal development of the mental activity of an infant, whose reasoning is less developed than that of an adult. But the images the infant has are livelier. There is, however, no logical bond that constitutes a proper utterance or thought.

This is what has been magnificently illustrated by the Slovene poet Oton Župančič in one of the best pieces of poetry for kids, The Turk (Lucien Tesnière, Oton Joupantchitch, poète slovène, 1931, p. 335). The beginning of the poem presents a succession of images, pleasing to a child's imagination, but without logical links:

\begin{tabular}{ll}
\hline Comme c'est long, un nez de Turc & How long it is, the nose of a Turk \\
C'est couvert de grosses verrues! & It is covered with big warts! \\
Sabots de Turc, la pointe en l'air & Clogs of a Turk, tips point upward \\
Comme une barque sur la Save! & Like a small fishing boat on the Save! \\
Ou un fez, un fez de Turc - & Or a fez, the fez of a Turk - \\
Une vraie fleur de coquelicot! & A true poppy flower! \\
Et une belle ceinture de Turc, & And the lovely belt of a Turk \\
Aux couleurs d'arc-en-ciel & With rainbow colors \\
Turc, donne-moi ton fez, & Turk, give me your fez, \\
Ton beau fez et ta ceinture - & Your lovely fez and your belt - \\
Garde ton nez et les sabots, & Keep your nose and your clogs, \\
C'est ta gloire et ton honneur! & They are your glory and your honour! \\
\hline
\end{tabular}

The same is true of dreams, where one passes from one image to another according to inconsequential associations, which on the whole have neither head nor tail. 
\$12 Thus it is the notion of connection that is expressed by the name syntax itself, in Greek 'setting in order, arrangement'. And it is equally to this notion, which is most often purely interior, that Humboldt's innere Sprachform 'interior form of language' corresponds. ${ }^{5,6}$

$\$ 13$ For greater clarity, we represent graphically the connection between words by lines that we call connection lines (Stemma 1).

\section{Chapter 2. Hierarchy of connections}

Sovereign law is subordination and dependency. (Vauvenargues)

$\$ 1$ Structural connections establish dependency relations between words. In principle, each connection unites a superior term and an inferior term.

$\$ 2$ The superior term is called the governor, and the inferior term the subordinate. Thus in the sentence Alfred speaks (Stemma 1), speaks is the governor and Alfred is the subordinate.

$\$ 3$ We say that the subordinate depends on the governor and that the governor governs the subordinate. Thus in the sentence Alfred speaks (Stemma 1), Alfred depends on speaks, and speaks governs Alfred.

5. Despite the fact that for more than a century, the seminal concept of innere Sprachform 'inner language/linguistic form' has been known, linguistics has learned nothing from it. This unfortunate situation is due to the fact that linguistics, under the influence of morphologists, has established, as its Euclidian postulate, that it would be concerned only with facts of language perceivable in terms of concrete form, that is, with facts that have an exterior form. This postulate has amounted to the a priori negation of the notion of innere Sprachform, since innere Sprachform is by definition interior to language.

6. Wilhelm von Humboldt was a first-class linguist, with the intuitions of a genius. Modern linguistics is far removed from fully acknowledging his contribution, while it praises to the skies Franz Bopp, father of Comparative Grammar. Antoine Meillet judged that this evaluation was justified, which seems at least paradoxical, if we think of the relative importance attributed to these two thinkers. People studying the history of ideas got this right; they do not hesitate to see Humboldt, friend of Friedrich Schiller and Goethe, as a mind far superior to that of Bopp, who never rose beyond the level of a good specialized technician. A scholar aware of the evolution of German thought in 19th century will be rightly amazed at the fact that linguists were not sensible to this bizarre distribution of estimation: Humboldt, a universal and highly cultivated mind, armed, in particular, with the deepest general scientific culture, is ranked after Bopp, a simple technician of Comparative Grammar, who rarely even receives a mention by the history of German thought. One day linguistics will be obliged to do full justice to W. Humboldt, whom Goethe himself admitted into his intellectual circle and who was of a completely different caliber from that of Bopp (see J. Vendryes, La comparaison en linguistique, Bulletin de la Société de linguistique de Paris, 42:1, p. 7). 
$\$ 4$ A word can be both subordinate to a superior word and governor of an inferior word. Thus in the sentence $M y$ friend speaks (Stemma 2), friend is both the subordinate of speaks and the governor of $m y$.

$\$ 5$ The set of words of a sentence constitutes a veritable hierarchy. Thus in the sentence My friend speaks (Stemma 2), my depends on friend, which depends in turn on speaks, and conversely, speaks governs friend, which in turn governs my.

$\$ 6$ The study of the sentence, which is the very subject of structural syntax (Chapter 1 , $\$ 1$ ), is essentially the study of its structure, which is nothing more than the hierarchy of its connections.

$\$ 7$ The connection line is vertical (Stemmas 1 and 2 ), since it symbolizes the connection between a superior term and an inferior term.

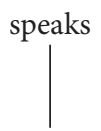

Alfred

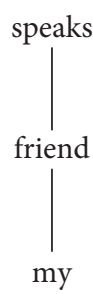

Stemma 1

\section{Chapter 3. Node and stemma}

$\$ 1$ In principle, a subordinate can only depend on a sole governor. ${ }^{7}$ A governor, in contrast, can govern multiple subordinates, for example My old friend sings this lovely song (Stemma 3).

\$2 Every governor that governs one or more subordinates forms what we call a node. ${ }^{8}$

$\$ 3$ Thus, we define a node as a set consisting of a governor and all of the subordinates that are directly or indirectly dependent on the governor and that the governor in a sense links together into a bundle.

7. Except in the case of duplication, which will be considered later (Chapter 135).

8. Translator's note: Tesnière uses the term node (noud) variably. It can mean both 'vertex' (in a graph) or 'subtree' (i.e. 'constituent' in modern linguistics). We translate nœud consistently with node. One should be aware in this area that Tesnière did not employ the term consistently. Here he defines the node as a subtree, that is, as a constituent rooted by its vertex. In general however, Tesnière appears to prefer the meaning 'vertex', which is consistent with the modern use of the term node. See the note in Chapter $22, \$ 12$. 
$\$ 4$ From the preceding definition, it follows that each subordinate shares the fate of its governor. Consider, for example, the sentence My old friend sings this lovely song (Stemma 3). If I reverse the order of elements to This lovely song charms my old friend (Stemma 4), the noun friend, in changing from subject to object, takes with it the adjectives $m y$ and old, which depend on it.

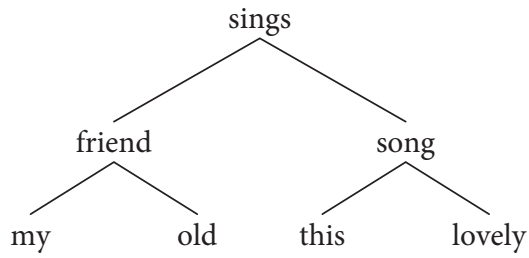

Stemma 3

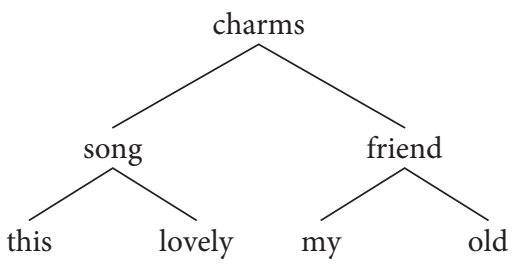

Stemma 4

$\$ 5$ Just like connections (Chapter $2, \$ 4$ ), nodes can be superimposed. There is therefore a hierarchy of nodes, just as there is a hierarchy of connections. Take for example the sentence My old friend sings this very lovely song (Stemma 5): the node lovely depends on the node of song.

$\$ 6$ The node formed by the governor that governs all the subordinates of a sentence is the node of nodes, or the central node. It is at the center of the sentence and ensures its structural unity by tying the diverse elements into a single bundle. It can be identified with a sentence.

$\$ 7$ The node of nodes is generally verbal, as is evident from the examples produced thus far. But nothing prevents a sentence from having a noun as its central node, or an adjective, or an adverb. These cases are frequent in colloquial speech and in titles of literary works (Chapter 47, \$12).

$\$ 8$ Since the inferior connections can be numerous, we are obliged to cheat in the graphic representation by using slanted instead of vertical lines. (Stemmas 3, 4, 5, and 6).

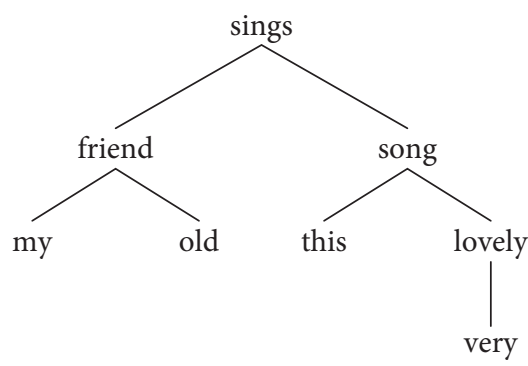

Stemma 5

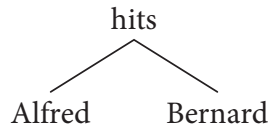

Stemma 6 
$\$ 9$ The set of connection lines constitutes a stemma. ${ }^{9}$ The stemma clearly shows the hierarchy of connections; it presents the various nodes that join connections into groups schematically, and therefore, visually manifests the structure of the sentence.

$\$ 10$ The stemma is thus a visual representation of an abstract notion: the structural schema of the sentence.

\$11 The stemma therefore comes to represent the activity of speaking. This activity was referred to simply as speech (parole), and it stands in opposition to the result of speaking such that it appears in a tangible and immutable form which is imposed on a given linguistic community and for which it is usual to reserve the name of language (langue). This opposition was explicitly identified by Wilhelm von Humboldt (cf. Chapter $1, \$ 12$, note 7 ), who had the ingenius intuition about the fundamental difference between the two entities, which he denoted with the two Greek words ergon 'language' (langue) and energeia 'speech' (parole).

$\$ 12$ The stemma is a response to the concern that experienced teachers of traditional grammar express when they first invite students to construct the sentences they encounter, be it in Latin or in a living language. Everyone knows that an incorrectly constructed sentence is subject to misinterpretation.

$\$ 13$ Generally speaking, such concrete representations of abstract notions are quite popular in teaching. One can foresee the day when every analysis, grammatical as well as logical, will be replaced by a single analysis, the stemmatic analysis (cf. Chapter 276, \$22).

9. I first got the idea for the stemma in June 1932. The first stemmas that I published appeared in my article Comment construire une syntaxe 'How to construct a syntax', written in 1933 and published in the Bulletin de la Faculté des Lettres de Strasbourg in May-June 1934. In 1935 I started to utilize the stemmas in my private tutoring, and in 1936 in my public teaching in Strasbourg.

Sent on a scientific mission to the USSR in 1936 and having bought some Russian grammars there, I had the joy of discovering that the idea for the stemma had germinated there independently. The earliest grammar with stemmas that I found was that of Ušakov, Smirnova, and Ščeptova, Učebnaja kniga po ruskomu jazyku 'Manual of Russian', Moscow-Leningrad, Gosizdat, 1929, 3rd part, pp. 6-7, and 4th part, p. 5. I was told that MM. C. Barxudarov and Princip, students of Prof. L. Ščerba, had utilized the stemma from 1930. And I found stemmas again in The Grammar of Krjučkov and Svetliev, Moscow, 1936, pp. 6 and 7.

One should note that while the fundamental idea is the same, the details of application are different. Russian linguists express the opposition between the subject and the predicate in their stemmas, a conception of the sentence that I take for grammatically erroneous (see below, Chapter $49, \$ 2 \mathrm{ff}$.). Therefore the stemma appears, at least in the grammars I know and have just quoted, only in a very fleeting and transient way, as the demonstration of a principle. It seems to me that these Russian authors have neither recognized the practicality, which seems obvious to me, nor foreseen all the developments to which the stemma can lead. 
$\$ 14$ Given the nature of stemmas, one can see that it is always easier to construct them from the bottom upwards. If they are constructed from the top down, one risks being left with too little room width-wise and a graphic representation that becomes entangled because one did not allow for enough space. ${ }^{10}$

\section{Chapter 4. Structural order}

$\$ 1$ The structural order of words is the order by which the connections are established.

$\$ 2$ Yet the connections are numerous, since each governor can govern several subordinates. The result is that structural order has multiple dimensions.

\$3 The stemma, which is the graphical expression of structural order, obeys the same law. It must also exist in multiple dimensions. But it can in fact be reduced to two dimensions. $\$ 4$ Indeed, we have seen (Chapter $3, \$ 1$ and Chapter $4, \$ 2$ ) that a single governor can govern multiple subordinates, without the opposite being the case. This particularity conditions the form of stemmas, which can be seen as analogous to that of a genealogical table with a single supreme ancestor (the central node of the sentence) and many inferior ancestors (Stemmas 7 and 8). Yet such a representation does not require more than two dimensions.

$\$ 5$ But the other aspect of the stemma is such that it can be drawn on a plane (a piece of paper, a slate, a chalkboard). A plane has by definition only two dimensions. Therefore the stemma can only be represented graphically if it has at most two dimensions.

$\$ 6$ The number of dimensions in the stemma is thus a minimum of two from the point of view of the structural order that it represents, and a maximum of two from the point of view of the graphical possibilities to which it is tied. The stemma will therefore necessarily have two dimensions.

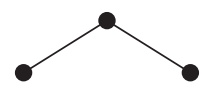

Stemma 7

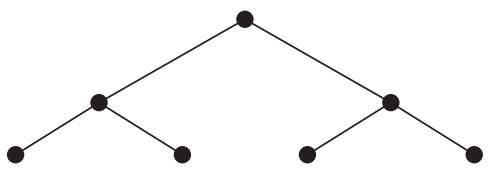

Stemma 8

10. Translator's note: We have translated this paragraph true to the French original. We do not understand what Tesnière meant, however, since regardless of whether one constructs the stemmas top down or bottom up, one will be confronted with the same challenge of allowing for enough space either above or below the starting point. 


\section{Chapter 5. The spoken chain}

\$1 The raw material of speech is the sequence of sounds or phonemes that we perceive by hearing. We give this sequence the name spoken chain. ${ }^{11}$

\$2 The spoken chain is the immediate result of speech. In its natural form or in its written notation, it is what provides the basic empirical realities, the observation of which is thus the source of all linguistic speculation.

$\$ 3$ The spoken chain is one-dimensional. It is presented like a line. That is its essential trait.

$\$ 4$ The linear character of the spoken chain is tied to the fact that we speak in time, which is one-dimensional. Indeed, the phonemes or groups of phonemes, which are the signs for the ideas we want to express, cannot occur simultaneously. I cannot articulate $a$ and $b$ at the same time. The one must precede the other: $a b$ or $b a$. We are thus obliged to string the phonemes together successively on a timeline. Moreover, is a discourse not measured by the length of its duration?

$\$ 5$ The linear character of the spoken chain does not appear straight away. In a language that we know, we involuntarily associate with the sounds of the spoken chain a meaning that catches our attention and masks the true nature of the chain. Matters are completely different in a language that we do not know, since we experience the spoken chain in its elementary, purely acoustic state, and independently of its entire semantic superstructure. Its linear character stands out with clarity. To convince oneself of this fact, one has only to listen to a discourse in an unknown language.

$\$ 6$ The linear character of the spoken chain is automatically transposed into the written notations for speech, where it constitutes an everyday elementary observation of reality. Writing has a linear form. An entire book is nothing more from beginning to end than a single line that is cut up into small sections in order to accommodate the physical reality of pages. Therefore the line, which is one-dimensional, presents itself in page units, the page being a two-dimensional surface. Divided in the same fashion, the two-dimensional page presents itself in a three-dimensional volume. ${ }^{12}$ One finds this same line in the microscopic grooves that the spoken word scratches into a phonographic disk. And finally, if the telegraph and the telephone use lines to carry speech or writing to a distance, this is only possible because speech itself is presented as a line.

11. The notion of the spoken chain (chain of sounds, chain of heard speech, acoustic chain, phonetic chain) is one of the most profound and seminal concepts presented by Ferdinand de Saussure. See his Cours de Linguistique générale, published by Bally and Sechehaye, pp. 65-67 and 79ff.

12. The matter here is not one of a simple word play of no real consequence. If one gets to the bottom of the matter, one sees that it was precisely because they unrolled (Lat. voluo 'roll') papyrus, which was in the form of a scroll, that the Romans made it a volumen 'volume'. 
\$7 Moreover the linear nature of discourse has been noticed many times, in particular by Lessing, who, in his celebrated book Laocoon: or, The limits of Poetry and Painting, traces the limits between these two art forms. He says that "sequence is the domain of the poet, whereas space is the domain of the painter" (Laocoon, Chapter 18).

$\$ 8$ We refer to the order by which words come to be arranged in a spoken chain as linear. ${ }^{13}$ Linear order exists in one dimension, just like the spoken chain.

$\$ 9$ We say that two words that follow each other in the spoken chain constitute a sequence. Thus in the sentence My old friend sings a lovely song, the words sings and $a$ are in sequence.

$\$ 10$ A word of the spoken chain cannot be in sequence with more than two other words, with the word that immediately precedes it and with the word that immediately follows it. Take for example the sentence My old friend sings a lovely song, the word $a$ is in sequence with sings, which precedes it, and with lovely, which follows it, but it cannot be in sequence with a third word.

$\$ 11$ The spoken chain is not only one-dimensional (cf. \$3), but it is also uni-directional, for it is, as we have seen (cf. \$4), a function of time and is therefore inherently uni-directional. $\$ 12$ The spoken chain is therefore irreversible like time. Just as one cannot reverse the flow of time, one cannot speak in reverse. A discourse in a known language that is played backwards using a phonographic disk or by any other mechanical method becomes completely incomprehensible: Enil tsal eht gnidaer morf srucco taht nossel eht redisnoc ot seciffus ti fleseno ecnivnoc ot. ${ }^{14}$

\section{Chapter 6. Structural and linear order}

$\$ 1$ All structural syntax rests on the relationships that exist between structural and linear order.

\$2 Constructing or establishing the stemma of a sentence involves transforming linear order to structural order. Take for example the sentence The small streams make the big rivers. When I transform linear order into structural order, I obtain Stemma 9:

13. Linear order seems to have nothing in common with what M. Marr calls linear language (cf. the minutes of Marcel Cohen, Bulletin de la Société de Linguistique de Paris, 40, p. 11) and which is nothing other than, it appears, language in gestures. The illustrious Russian linguist seems to mean that the linear character of language is manifest in the extraneous and superficial movements of arms and hands that trace a concrete line in space. He has not recognized that articulated language, which stands in opposition to his linear language, is also essentially linear and that its inner form, which is the abstract basis for the spoken chain, also exists in a single dimension.

14. To be read in reverse. 


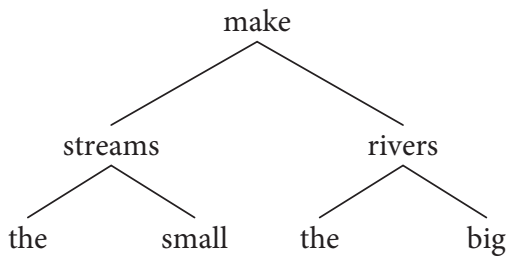

STRUCTURAL ORDER

Stemma 9

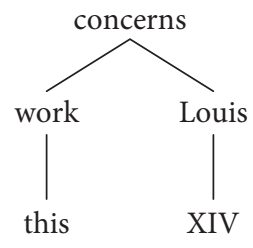

Stemma 10

$\$ 3$ Conversely, transposing a stemma, or transforming it into a sentence, is the act of switching from structural order to linear order by arranging the words in the spoken chain. ${ }^{15}$ Take for example Stemma 9; if I read it in linear order, I obtain the sentence The small streams make the big rivers.

The small streams make the big rivers.

LINEAR ORDER

$\$ 4$ From this point of view, we can say - acknowledging our definition above (Chapter 1, $\$ 9$ and 10) and making it more precise - that speaking a language involves transforming structural order to linear order, and conversely, understanding a language involves transforming linear order to structural order.

$\$ 5$ The fundamental principle of transforming structural order to linear order involves changing the connections of structural order into the sequences of linear order. This transformation occurs in such a manner that the elements connected in structural order become immediate neighbors in the spoken chain.

$\$ 6$ The effort necessary to overcome the difficulties encountered when transforming structural order to linear order is the profound cause of energeia, which was so well recognized by Wilhelm von Humboldt (Chapter 3, \$11).

$\$ 7$ Thus in the English sentence This work concerns Louis XIV (Stemma 10), all the structural connections have been transformed to linear sequences:

A. There is the connection between the governor work and its subordinate this, whereby the word work immediately follows the word this.

B. There is the connection between the governor concerns and its subordinate work, whereby the word concerns immediately follows the word work.

15. Transforming a stemma into a sentence corresponds quite exactly, technical questions aside, to the operation that radio technicians call putting into wave. 
C. There is the connection between the governor concerns and its subordinate Louis, whereby the word concerns immediately precedes the word Louis.

D. There is the connection between the governor Louis and its subordinate XIV, whereby the word Louis immediately precedes the word XIV.

$\$ 8$ The switch from structural order to linear order has the effect of flattening the structure to a laminate. In a sense, the linear string is a structure that has been wiredrawn and laminated.

$\$ 9$ The transformation of structural order to linear order is often facilitated by grammatical agreement, which involves marking connected words with the signs that convey agreement. Agreement greatly aids comprehension of the sentence by facilitating the establishment of connections. Take for example Vergil's verse Tantae molis erat Romanam condere gentem 'It was such a massive task to establish the Roman race' (Aeneid I-33): a connection is easily established between tantae 'such' and molis 'heap, job', because the two words have the form of the genitive feminine singular (Stemma 11).

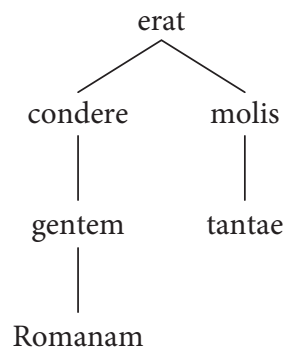

Stemma 11

\$10 One must not lose sight of the fact that syntactically, the true sentence is the structural sentence, for which the linear sentence is only an image projected onto the spoken chain, with all the disavantages associated with flatness.

\section{Chapter 7. Antinomy between structural and linear order}

\$1 The possibility that a term has, in addition to its unique superior connection, two or more inferior connections (Chapter $3, \$ 1$ ) contradicts the impossibility of a word in the spoken chain having more than two neighbors (Chapter $5, \$ 10$ ). In other words, every structural node is susceptible to creating bifurcations, trifurcations, etc. that are incompatible with linear order.

$\$ 2$ Hence in the sentence The small streams make the big rivers (Stemma 9), the term streams forms a node with three structural connections (the first is make with streams, the 
second is streams with the, and the third is streams with small), which together result in only two linear sequences: small streams and streams make.

$\$ 3$ There is therefore a contradiction between structural order, which has multiple dimensions (that are reduced to two in a stemma), and linear order, which has but a single dimension. This contradiction is "the quadrat of a circle" of language. The solution to the contradiction is the sine qua non of speech.

$\$ 4$ The contradiction between structural and linear order can only be resolved by sacrificing at least one linear sequence. Therefore in the sequence above, one must refrain from attempting to transform the connection between streams and the into the immediate linear sequence the streams or streams the. The sequence must be mediated: the small streams.

$\$ 5$ Taking up our definition above once again (Chapter $1, \$ 9-10$ ), we can now precisely state that to speak a language is to know which structural connections can be sacrificed by transforming structural order to linear order and conversely, to understand a language is to know which structural connections are not expressed by the sequences and must be restored by transforming linear order into structural order.

$\$ 6$ In reestablishing the structural connections that are not expressed by the sequences, the role of grammatical agreement (Chapter 6, \$9) is crucial. Thus in Vergil's verse Tantae molis erat Romanam condere gentem 'It was such a massive task to establish the Roman race' (Stemma 11), the connection is easily established between Romanam and gentem even though these two words are not in sequence in the spoken chain - because both are marked as accusative feminine singular.

$\$ 7$ Grammatical agreement permits disruption of sequences without endangering comprehension of the sentence. The result of this is that the richer a language is in terms of its possibilities for agreement, the greater its ability to interrupt linear sequences, and conversely, the fewer markers of grammatical agreement a language has, the less freedom it has to interrupt linear sequences.

$\$ 8$ Certain languages push the liberty so far as to make the most of the richness of their agreement procedures by breaking up sequences entirely, and they thus do not need syntax at all. One says therefore that linear order is broken. Broken order is frequent in poetical Latin. Take again Vergil's sentence Tantae molis erat Romanam condere gentem: the sequence corresponding to the connection between Romanam and gentem (Stemma 11) is sacrificed in the spoken chain. But from the point of view of Latin syntax, nothing requires this sacrifice to occur. It is perfectly possible to say Tantae molis erat Romanam gentem condere, but the verse would have been false. The broken order fulfils a metrical constraint.

$\$ 9$ The optional rupture of linear sequences occurs mainly due to metrical or stylistic considerations. It is never forced by typological necessity or proper syntax. 


\section{Chapter 8. Direction of linearization ${ }^{16}$}

$\$ 1$ When two words are structurally connected, there are two ways to place them in a linear sequence, according to which of the two is placed before the other.

\$2 In the one case, the governor is spoken first and the subordinate second. This happens for instance in the French phrase cheval blanc 'white horse' (Stemma 12).

$\$ 3$ In the other case, the subordinate is spoken first and the governor second. This happens with the English phrase white horse (Stemma 13).

$\$ 4$ In the first case (cheval blanc), we say that there is descending or centrifugal order because to place the terms in the spoken chain (linear order), one reads the stemma (structural order) top down, that is, moving away from the central node.

$\$ 5$ Conversely in the second case (white horse), we say that there is climbing or centripetal order because to place the terms in the spoken chain (linear order), one reads the stemma (structural order) bottom up, that is, moving toward the central node. ${ }^{17}$

$\$ 6$ From this point of view, one acknowledges that different languages behave in different ways.

$\$ 7$ Some languages have a preference for descending or centrifugal order. We call them descending or centrifugal languages. French, for example, is a centrifugal language ( $\$ 2$ and Stemma 12).

$\$ 8$ Other languages have a preference for climbing or centripetal order. We call them climbing or centripetal languages. English, for example, is a centripetal language ( $\$ 3$ and Stemma 13). ${ }^{18}$

$\$ 9$ The linearization of the sequence becomes very important as soon as one begins translating from a centrifugal language to a centripetal one, and vice versa.

$\$ 10$ The relevant rule (centrifugal $\rightarrow$ centripetal) is thus as follows: Reverse the order of the vertical reading but respect the order of the horizontal reading.

$\$ 11$ Take for example the parts of the French sentence un chemin, montant, sablonneux malaisé 'a steep sandy difficult path' (La Fontaine, Fables, VII-9), where the sequences are

16. Translator's note: Tesnière uses the ambiguous term relevé linéaire, where faire un relevé means 'to list, to note down'. But relévé is also the past participle of relever 'to stand up, pick up'. We prefer to use the unambiguous term linearization, which is commonly used in dependency grammar today.

17. Cf. H. About: Latin syntax has an ascending march, the opposite of the descending gait of French. The determined precedes the determiner (Bulletin de la Faculté des Lettres de Strasbourg, XIII: 3, January 1935, p. 108).

18. Translator's note: Tesnière's claim here, i.e. that English is more centripetal (head-final) than centrifugal (head-initial), is contrary to the stance of most work in modern syntax. English is widely acknowledged to be more head-initial than head-final. 
centrifugal (Stemma 14). If we want to translate this sentence into a centripetal language like German, we will have to invert the order of the governor chemin 'path' and the set of three subordinates montant 'steep', sablonneux 'sandy', malaisé 'difficult', which results in ein steiler, sandiger, schwieriger Weg. But we have to leave the three subordinates montant, sablonneux, malaisé in the same order steiler, sandiger, schwieriger, since they are coordinated, that is, horizontally linked.

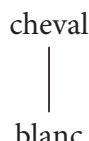

blanc

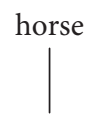

white

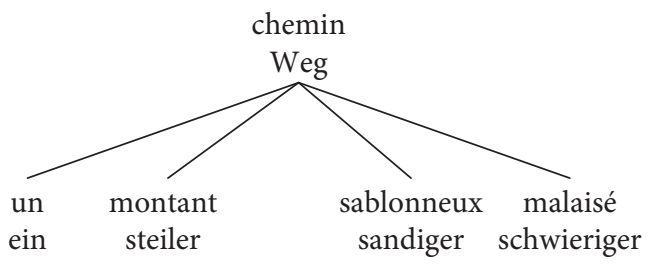

Stemma 14

Stemma 12 Stemma 13

$\$ 12$ One sometimes observes a linear order that is the inverse of what language typology suggests it should be. One is dealing in such cases with an intentional violation of the norm, the intention being to grab the listener or reader's attention in order to generate the impression of archaic and poetic language (poetic license). This order can be called stylistic order.

Enfant, voici des boufs qui passent, 'Child, here are the passing oxen,
$\begin{array}{ll}\text { Cachez vos rouges tablier. } & \text { Hide your overalls red.' }\end{array}$

(V. Hugo, Odes et Ballades, La légende de la Nonne 'Odes and Ballads, The legend of the Nun')

Poetic style (a normally prenominal adjective follows its noun in German): Röslein, Röslein, Röslein rot 'Little rose, little rose, little rose red' (Goethe, Röslein rot); style destined to strike the hearer (a sentence starts with a verb rather than having it in its middle): Restait cette redoutable infanterie de l'armée d'Espagne 'Was staying this formidable infantry of the army of Spain' (Bossuet).

$\$ 13$ Confusing stylistic order with normal linear order is at the base of one of the most ingrained and harmful pedagogical practices. It is insane to teach the pleasing verse of Ger. Ich weiss nicht was soll es bedeuten... 'I don't know what should it mean' (Heine, Die Lorelei, Heimkehr, 2) to pupils who have not yet been exposed to the mechanisms of constructing German sentences. ${ }^{19}$

19. Lucien Tesnière, Une survivance pédagogique, l'inversion et le rejet dans la construction de la phrase allemande 'A pedagogical remnant, inversion and its rejection in the construction of the German sentence', Les Langue modernes, March-April 1947, pp. 151-152. 


\section{Chapter 9. Strict order}

$\$ 1$ The tendency of a language to prefer centrifugal or centripetal order can be more or less marked. We say that a given language has strict or mitigated centrifugal or centripetal order.

\$2 We acknowledge that a language presents a mitigated character when neither of the two orders, centrifugal or centripetal, completely blocks the other and that the two coexist to an extent. This is the case, for example, for French, where the phrase le cheval blanc 'the white horse' contains both centripetal (le cheval) and centrifugal (cheval blanc) order (Stemma 15).

$\$ 3$ Conversely, we acknowledge that a language is strict when the one order, centrifugal or centripetal, blocks the other entirely.

$\$ 4$ In the strictest languages, the tendency to prefer centrifugal or centripetal order can go so far as to conflict with the principal of sequence (Chapter $6, \S 5$ ).

$\$ 5$ Indeed, as soon as structural order presents a bifurcation (Chapter $7, \$ 1$ ), it is only possible to transpose the two connections to linear sequences under the condition that one of them appears in centrifugal order and the other in centripetal order.

$\$ 6$ But as soon as one wishes to put both connections in the same order, be it centrifugal or centripetal, one is forced to sacrifice one of the two sequences (Chapter $7, \$ 4$ ). For this reason, the tendency for strict centrifugal or centripetal order leads necessarily to broken order (Chapter $7, \$ 8$ ).

$\$ 7$ Take for example the French sentence Alfred frappe Bernard 'Alfred hits Bernard'; it contains a structural bifurcation. But since French is a mitigated centrifugal language, centripetal order is not excluded, and the two structural connections can both be placed in linear sequence. One therefore puts the first connection in centripetal order (Alfred frappe) and the second in centrifugal order (frappe Bernard).

$\$ 8$ Now take a strictly centrifugal language like Ancient Hebrew, the linear reading of the structural order tends to take on entirely centrifugal order: wayyibrrā' élōhìm 'ét hā 'ādām 'and God created man' (Genesis, I, 27). At the connection of the governor (wa)yyibrāa' and the subordinate 'ét hà ' 'âdām, there is no immediate linear sequence (Stemma 16). In languages of this type, the sentence begins with the sentence node, that is, with the verb.

$\$ 9$ Take the opposite case, a strictly centripetal language like Turkish. Changing linear order to structural order results in an entirely centripetal structure: Kaya mektubunu aldı 'Peter takes his book'. One sees that there is no immediate linear sequence corresponding to the connection between the governor ald ' take' and the subordinate Kaya 'Peter' (Stemma 17). In languages of this type, the sentence ends with the sentence node, that is, with the verb. 


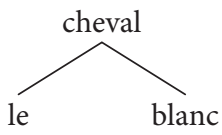

Stemma 15

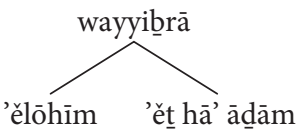

Stemma 16

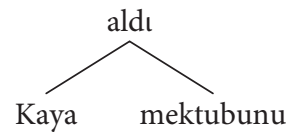

Stemma 17

\section{Chapter 10. The word}

\$1 Simple as it may seem, the definition of the word is most delicate for the linguist. ${ }^{20}$

\$2 Perhaps too often one starts with the concept of the word and proceeds to the concept of the sentence, instead of starting with the concept of the sentence and proceeding to the concept of the word. Indeed, one could not define the sentence with the word as the starting point, but rather one must start with the sentence and proceed to the word, for the notion of the sentence logically precedes the notion of the word (Chapter $1, \S 1$, 2, and 3).

$\$ 3$ Since the sentence appears in linear order in the spoken chain, the word can be defined as nothing more than a segment of this chain.

$\$ 4$ And yet a linear segment is a portion of a line between two points. Likewise, a word is a portion of the spoken chain that extends between two breaks. In other words, one cannot define the word in isolation, but rather only in terms of the breaks that mark where it begins and ends.

\$5 The breaks vary in character. We learn about the character of words from these variations.

$\$ 6$ First, the breaks are partial, that is, they only cut into the spoken chain without ever completely severing it. If things were otherwise, the discourse thread would be interrupted and the words would follow each other without a link between them. Yet a word is never completely isolated in discourse.

$\$ 7$ Second, the breaks are variable. In other words, the cuts that they make in the spoken chain do not all have equal depth. Thus in the La Fontaine's verse La raison $d u$ plus fort est toujours la meilleure 'The reason of the strongest is always the best, The strongest is always right' (Fables, I, 10), the break that separates $d u$ from plus fort is deeper than the break that separates plus from fort; furthermore, the break that separates raison from $d u$ plus fort is even deeper; and the break that separates raison $d u$ plus fort from est is yet still deeper. If the breaks are indicated with a vertical slash in such a manner that the

20. V. Vendryes, Le Langage, pp. 62-105. 
more slashes, the deeper the break, one obtains the following sequence: raison $\|\mid d u\|$ plus | fort |||| est...

$\$ 8$ Third, the breaks do not have absolute value, just relative value. That is to say, one cannot measure the depth of a break in isolation, but rather only in relation to other breaks. Take the verse of Victor Hugo:

Mon âme aux mille voix, que le Dieu que j'adore 'My soul with a thousand voices that the God (that) I love

Mit au centre de tout comme un écho sonore. Put in the center of everything like a ringing echo'

(Feuilles d'automne: Ce siècle avait deux ans

'Leaves of Autumn: This century was two years old')

The group que le Dieu que j'adore mit au centre de tout comme un écho sonore 'that the God that I love put in the center of everything like a ringing echo' is subordinate to âme 'soul' to the same extent as que j'adore 'that I love' is subordinate to Dieu 'God'. And yet despite this natural identity, we cannot attribute the same value to the break that precedes each of the two que 'that'. The first, which separates off the entire group que le Dieu que j'adore mit au centre de tout comme un écho sonore, is evidently stronger than the second, which separates off only que j'adore, which is just a part of this group. We have: Mon âme aux mille voix, \| que le Dieu | que j'adore | Mit au centre de tout comme un écho sonore!

$\$ 9$ Supposing now that the sentence includes an additional relative clause - take for example Mon âme aux mille voix, que le Dieu, que ma mere, que j’adorais, m’apprit à vénérer, mit au centre de tout comme un écho sonore 'My soul with a thousand voices that the God, that my mother, that I loved, taught me to venerate, put in the center of everything like a ringing echo' - we have, for the same reason, three breaks with different values: Mon âme aux mille voix, ||| que le Dieu, || que ma mère, | que j'adorais, | m’apprit à vénérer, || mit au centre de tout comme un écho sonore. The number of breaks of this nature can, at least theoretically, increase to infinity, and in so doing, these breaks take on an infinite number of values. The attempt to measure these breaks in terms of an absolute criterion would be in vain; they can be assessed only in relation to each other.

$\$ 10$ In other words, a hierarchy of breaks corresponds to the hierarchy of connections (Chapter 2, \$6) and nodes (Chapter 3, \$5).

$\$ 11$ The result is that the breaks that delimit the word in the spoken chain are not only imprecise and unspecified, but also unspecifiable, and as a consequence, the notion of the word is essentially elusive.

$\$ 12$ It is also remarkable that in many texts and ancient inscriptions, scribes and engravers did not in fact separate the words. That is not surprising if one considers the difficulty, given only simple auditory cues, in spotting the breaks between the words of a language that one does not know or knows poorly (Chapter $5, \S 5$ ). 
$\$ 13$ The ungraspable character of the word concept appears in its full light in the uncertainties of orthography, which has proven incapable of consistently marking the breaks between words.

$\$ 14$ Sometimes orthography draws a distinction where there is none: chou-rave $\neq$ betterave cabbage-radish 'kohlrabi' vs. beet-radish 'beet', sous-nappe $\neq$ soucoupe sub-tablecloth 'undercloth' vs. sub-cup 'saucer', plat-bord $\neq$ plafond flat-edge 'gunwale' vs. flat-bottom 'ceiling', poule d'Inde $\neq$ dinde 'hen of India' vs. 'turkey', d'or $\neq$ dorer 'of gold' vs. 'gild', si oui $\neq$ sinon 'if yes' vs. 'if no, if not, otherwise', bon Dieu $\neq$ bondieuserie 'good Lord' vs. 'religious trinket', bonne femme $\neq$ bonhomme good woman 'woman (pejorative)' vs. good man 'guy', moyen âge $\neq$ moyen-âgeux 'Middle Ages' vs. 'medieval', fleur de lis $\neq$ fleurdelisé 'flower of lily' vs. 'fleurty (cross)'.

$\$ 15$ Sometimes, in contrast, orthography does not draw a distinction where there is one: de bonnes femmes 'good women' = des bonnes femmes 'women (pejorative)' (in comparison de bons hommes 'good men' $\neq$ des bonshommes 'guys'), de jeunes filles 'young girls' = des jeunes filles 'girls'; Ger. Der Schiffer will uns nicht übersetzen 'the ferryman does not want to take us to the other side' = Der Dolmetscher will diesen Brief nicht übersetzen 'The interpreter does not want to translate this letter' (in comparison to the indicative Der Schiffer setzt uns über 'The ferry man is taking us to the other side' $\neq$ Der Dolmetscher übersetzt den Brief 'The interpreter is translating the letter').

\section{Chapter 11. Agglutination}

\$1 One observes that in the course of the history of languages, the depth of the breaks that separate words is consistently diminishing, never increasing.

$\$ 2$ The result of this tendency is that two words in contact in the spoken chain tend to bond together with increasing strength.

$\$ 3$ The conclusion of this process is the complete disappearance of the break and as a result, the cementing of the two words is so complete that the break disappears.

$\$ 4$ We give this historical process the name agglutination.

$\$ 5$ We refer to those words in the process of losing their autonomy as agglutinated. Composite words (Fr. cerf-volant, lit. flying-stag 'kite'), compound tenses (Fr. (Nous) avons chanté '(We) have sung') and verbs in composition with a preverb (Fr. prédominer 'predominate') are agglutinated to varying degrees.

$\$ 6$ Conversely, we refer to those words that are unaffected by agglutination and that hence completely conserve their independence as autonomous. Hence simple tensed forms (e.g. Fr. (nous) chantons '(we) sing') are autonomous words.

$\$ 7$ Agglutination does not occur randomly. It is subject to well-defined conditions, the principle ones being the following. 
$\$ 8$ First, in order for agglutination to occur, it is of course necessary that the relevant words find themselves in sequence in the spoken chain.

$\$ 9$ Second, this sequence must also correspond to a structural connection (Fr. plafond 'ceiling' < * plat fond 'flat bottom'; maintenir 'maintain' < *main tenir 'hand hold'; Eng. someone $<{ }^{*}$ some one; away $<{ }^{*}$ a way, outside $<{ }^{*}$ out side). Two words that are in linear sequence by chance - without a structural connection between them - would not be susceptible to agglutination. Thus Fr. mit au 'put in' in the example used above (Chapter 10, $\$ 8$ ) has no chance of agglutinating to ${ }^{*}$ mitau.

$\$ 10$ Third, the sequence and the connection that it expresses must have a certain frequency. Two words that are in connection and in sequence in an exceptional manner are not susceptible to agglutination.

$\$ 11$ There are many degrees of agglutination, depending upon whether the process is more or less advanced. From this point of view, we say that agglutination is loose when it is not yet advanced, and in contrast, it is narrow when it is very advanced.

$\$ 12$ But one cannot give a rigorous value to these terms, since agglutination is essentially progressive and it is impossible to measure the degree with precision at a given moment. The degrees of agglutination are also infinite in number, just like the values of the breaks to which they correspond (Chapter 10, \$9).

$\$ 13$ One can only determine the relative value of different degrees of agglutination, the one in relation to the other, just as with the breaks (Chapter 10, \$9). Therefore agglutination is looser in bas-fond 'low-bottom, shoal, dregs', which stands in opposition to hautfond 'high-bottom, shallows', than in tréfond 'innermost', where one senses still more the value of -fond 'bottom', but where one no longer gives to tré- a value that is precise, and more narrow than plafond 'ceiling', from which the derived plafonner 'put a ceiling on' (and not ${ }^{*}$ plafonder) seems to indicate that the process is complete and that we are now in the presence of a new word.

$\$ 14$ Orthography has, at least in French, two means at its disposal for marking the degree of agglutination. One can unite the two agglutinated words with a hyphen (bas-fond 'shoal') or one can write them as a single word (tréfond 'innermost'). But we have seen (Chapter 10, $\$ 13,14$, and 15) how difficult it is to utilize these two means in a consistent way.

\section{Chapter 12. Classification of languages}

\$1 There are two ways of classifying languages, depending upon whether they are considered from a diachronic or synchronic point of view.

$\$ 2$ The diachronic (or historical) point of view involves the history of languages. It gives rise to a genealogical classification that is based on communities of origin. 
$\$ 3$ The synchronic point of view involves the character of languages. It gives rise to a typological classification that is based on communities of structure.

$\$ 4$ The diachronic point of view allows one to take into account the kinship of languages. Two languages are reputedly in a kinship relation when they have taken on two distinct forms after having followed distinct evolutionary paths, departing from one and the same parent language. Expressed differently, kinship implicates a community of origin.

$\$ 5$ Bearing in mind that the term kinship has a precise meaning and is well defined, it would be inappropriate to also use it to designate the community of structure, for which we reserve the term affinity, which is no less precise.

$\$ 6$ Kinship does not exclude affinity. Two related languages can present an affinity for each other. One acknowledges in effect that a community of origin can cause a community of structure. Thus French and Italian, related languages, have an affinity for each other, since they are both forms of modern-day Latin.

$\$ 7$ But kinship and affinity do not necessarily go hand in hand.

$\$ 8$ Thus two languages can be related without having an affinity for each other. Such is the case for French and Russian, which are related languages since they are both forms of Indo-European, but which do not have an affinity for each other because they have strongly diverging types of structures.

$\$ 9$ Conversely, two languages can have an affinity for each other without being related in any way. Such is the case for languages like Armenian and Georgian, which demonstrate striking resemblances, especially with respect to phonetics, but are not related to each other to any degree, since Armenian is a form evolved from Indo-European, whereas Georgian is a Caucasian language.

$\$ 10$ A group of related languages constitutes a family of languages. It is appropriate in this area to associate the word "family" with its precise historical and genealogical meaning and to apply this word only to a group of languages that share the same origin. The Indo-European languages constitute a family, because they are all forms of the same earlier language, common Indo-European, and they have arisen through time and under varying circumstances.

$\$ 11$ Since the term family has a precise and clearly defined meaning, it would be methodologically poor to expect it to clearly denote the sets of languages that present an affinity for each other $(\$ 5)$. We therefore reserve for this group the term type, which is no less precise. Thus the Ural-Altaic languages constitute a type of language characterized by a certain number of communal traits, none of which prove a communal origin; there is no Ural-Altaic community. It is therefore inappropriate to speak of a Ural-Altaic family of languages, as has too often been done. There is merely a UralAltaic type. 


\section{Chapter 13. Humboldt's historical and typological classification}

\$1 The historical and genealogical classification of languages is in general that of linguists linked to the neo-grammarian school. ${ }^{21}$ These linguists even grant this classification an exclusive value that is not without intransigence with respect to other modes of classification. ${ }^{22}$

$\$ 2$ The typological classification of languages was developed by the linguists Friedrich Schlegel ${ }^{23}$ and Wilhelm von Humboldt, ${ }^{24}$ from the German romantic school. Bopp and Pott adopted this classification in its entirety.

$\$ 3$ The typological classification of Schlegel and Wilhelm von Humboldt ${ }^{25}$ is based on the degree of fusion and interpenetration of formal elements (our modern semantemes) and on the material elements (our modern morphemes) of the sentence.

$\$ 4$ From this point of view, Schlegel and von Humboldt partitioned the totality of the world's languages into three broad types: isolating languages, agglutinating languages, and inflectional languages. ${ }^{26}$

21. The first neo-grammarian work to appear was from Friedrich Müller, Grundriss der Sprachwissenschaft, 1876-1885.

22. "The sole linguistic classification that has value and utility is the genealogical classification, which is founded on the history of languages" (Meillet, Les langues du Monde, 1924, pursued by Marouzeau, Lexique de la terminologie linguistique, 1933, p. 48). [One can note that in the second edition of Les langues $d u$ Monde, Paris 1952, the introduction by Meillet no longer appears; it must be sought in volume II of Linguistique historique et linguistique générale, Paris 1938, pp. 53ff. On the other hand, the grouping of languages in this new edition seems less based on geography than on history, as was the case in the first edition.

In the second edition of Lexique de la terminologie linguistique, Paris 1943, M. Marouzeau adds: "The progress of functional and structural linguistics now permits us to envisage and undertake a synchronic classification of languages" (p.48-49). The movement that has occurred since 1933, the date of the first edition of this book, is clear to see.]

23. Über die Sprache und Weisheit der Indier, 1808.

24. Über die Verschiedenheit des menschlichen Sprachbaues und ihren Einfluss auf die geistige Entwickelung des Menschengeschlechts, 1835, preface of Über die Kawissprache auf der Insel Java, 1836.

25. Cf. above, Chapter $1, \$ 12$.

26. This classification, although essentially typological, is not without historical conceit, because in the spirit of those who proposed it, the isolating, agglutinating, and inflectional types constituted three successive stages, three phases, the claim being that all languages pass successively through these stages in the course of their evolution. 
$\$ 5$ In isolating languages (Sino-Tibetan, Vietnamese), formal elements and material elements remain separate and form distinct words. Thus in Chinese lai le 'came', the word lai, which expresses the idea 'come', is clearly separate from the word le, which expresses the notion of past time.

$\$ 6$ In the agglutinating languages ${ }^{27}$ (Malayo-Polynesian, Dravidian, Ural-Altaic, Bantu, etc...), formal and material elements are joined in a single word, but without being altered, in such a manner that they remain easily recognizable. Thus in the Turkish word geldi 'came', the analysis easily discerns the stem gel-, which expresses the idea of 'come', and the suffix - $d i$, which expresses the notion of past time.

$\$ 7$ Finally in the inflectional languages (Indo-European, Semitic), formal and material elements are so well joined together, so entirely amalgamated, and in addition, so profoundly altered that they resist any analysis. Thus the Eng. came expresses the idea of 'come' and the notion of past time all at once, without distinguishing between those elements of the word that express the one idea and those that express the other.

$\$ 8$ Humboldt, Pott, and Steinthal have likewise posited a fourth type, that of polysynthetic languages (holophrastic, incorporating). In this type of language, agglutination has gone so far that it includes the totality of the elements of the sentence. The sentence tends to be nothing more than one immense agglutinated word, a little like the French word kekseksa for qu'est-ce que c'est que ça 'what is it that that is.'. ${ }^{28}$

$\$ 9$ Humboldt's typological classification, after having been favored for a long time, was vigorously attacked by the neo-grammarians, who denied it any measure of value. ${ }^{29}$

$\$ 10$ The defect of Humboldt's classification is not that it is typological, but that it has not retained a typological character, a typological character serving best as the point of departure for a rational classification.

$\$ 11$ Indeed, Humboldt's classification is based on the degree of fusion, that is, on the degree of agglutination of the elements to each other. Yet we have seen (Chapter 11, \$12) that, since agglutination is progressive, it is impossible to measure the degree with precision at

27. One has also proposed to call these languages grouping (groupant), cf. J. Przyluski "La Plasticité des mots et la cohesion du discours", Journal de Psychologie 1934, 7-8, pp. 583f.

28. Keksekça is placed in the mouth of Gavroche by V. Hugo (Les Misérables, 4, 6, 1), who judges it appropriate to warn his readers that it is not "a Russian or Polish word, or one of those savage calls that the Yoways and the Botcudos call out to each other from one side of a river to the other through the solitude", but rather it is "a word that they say to each other daily".

29. "The overly famous classification of languages as isolating, agglutinating, and inflectional cannot be pursued with stringency, and to the extent that it can be formulated, it is neither scientific nor is it practical” (Meillet, Les langues du monde, p. 1). See also above $\$ 1$ and note 23. 
a given moment. Any classification founded on the degree of agglutination is thus condemned to conflict with this impossibility.

$\$ 12$ In this way, Khasi, a language spoken in south Assam, is an intermediate type between isolating and agglutinating. Its intermediate status is so pronounced that there is no reason to place it more in one category than in another. ${ }^{30}$

$\$ 13$ We have seen above (Chapter 11) that agglutination is a general phenomenon common to all languages. It therefore cannot be characterized as being more of one linguistic type than of another. All languages practice agglutination to varying degrees, and that is why Wilhelm von Humboldt himself was led to place the majority of human languages in the agglutinating category.

\section{Chapter 14. Classification according to the direction of linearization}

$\$ 1$ If the degree of agglutination does not provide a criterion for a satisfactory typological classification, the same is not true for the direction of linearization, which has the advantage of giving a convenient criterion for the facts (cf. also Chapter $63, \$ 12 \mathrm{ff}$.).

$\$ 2$ Indeed, linearization can occur only in one sense or in the opposing sense. There is no intermediate possibility. And if it is true that the two types can coexist in the same language (Chapter $9, \$ 2$ ), it is nevertheless quite rare that one of the two does not prevail over the other.

$\$ 3$ The typological classification according to the direction of linearization has been applied by Steinthal to a certain extent, and more recently by P.W. Schmidt. ${ }^{31}$ It is contained implicitly in the doctrines of the Prague school of phonology. Since it is based on a trait of structure, it is most pertinent for structural syntax, and as a consequence, we adopt this classification here. In so doing, we guard against excluding the genealogical classification, for which there is no dispute about the legitimacy of the historical point of view.

$\$ 4$ We classify languages as centrifugal or centripetal (Chapter $8, \$ 7$ and 8 ), and we distinguish those of strict and those of mitigated character.

$\$ 5$ In this regard, we arrive all told at the following classification, where we begin with the languages that are most centrifugal and end with those that are most centripetal.

$\$ 6$ Typological classification of languages according to the nature of linearization.

30. V. Hovelacque, La Langue khasia étudiée sous le rapport de l'évolution des formes, 1880, and La Linguistique, 4, pp. 58-59 and 63-65.

31. See Die Sprachfamilien und Sprachenkriese der Erde, Heidelberg, 1926, in particular, pp. 381ff. 


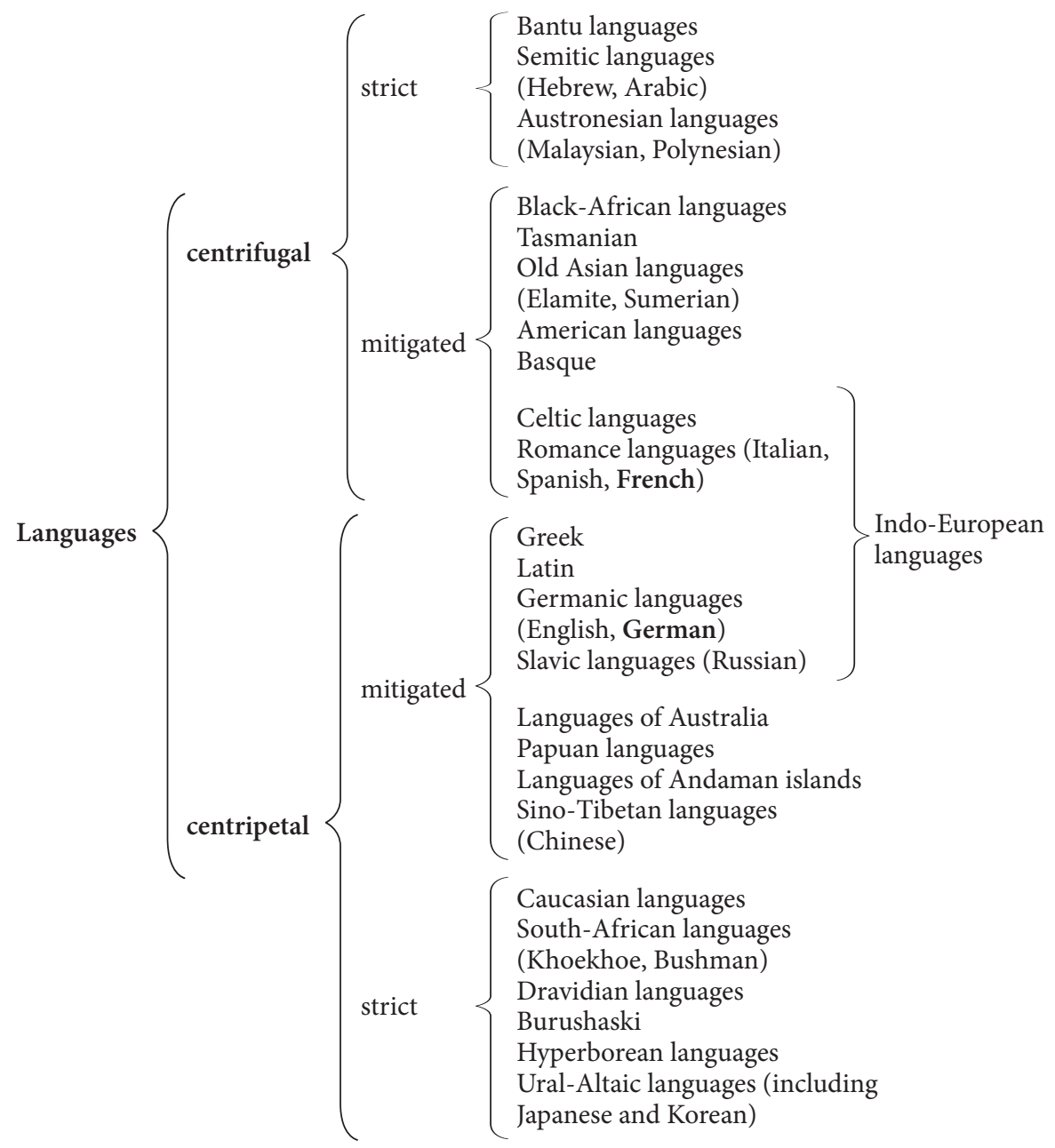

\$7 The typological opposition between French (centrifugal) and German (centripetal) is noteworthy. Also noteworthy is the fact that French (centrifugal) and Latin (centripetal), although historically and genetically related (since French descends from Latin), are typologically very different.

$\$ 8$ Moreover, one can acknowledge a characteristic geographical distribution. The centrifugal languages occupy the greatest part of Africa (with the exception of the extreme south) and Oceania. In contrast, the centripetal languages occupy the greatest part of Asia. It would be strange to have such a clear distribution by simple chance. 


\section{Chapter 15. Syntax and morphology}

$\$ 1$ Once assigned linear order on the spoken chain, the structural schema of the sentence is ready to receive the phonetic clothing that gives it its exterior form.

$\$ 2$ But this exterior form, which is a perceivable element destined to strike our auditory sense, merges neither with the structural schema nor with the linear schema from which it stems. These are abstract elements that differ profoundly from the concrete nature of the exterior form.

$\$ 3$ In the face of the exterior form of the sentence, the structural schema and the semantic schema constitute a veritable interior form. Concerning this form, Wilhelm von Humboldt had an ingenious intuition, to which he gave the well-chosen name innere Sprachform 'inner speech form' (Chapter $1, \$ 12$ and note 7 ).

$\$ 4$ All those who have learned a foreign language know the pressure that the inner form of a language can exert on a speaker. It is a force from which they cannot escape, a veritable categorical imperative of grammar.

$\$ 5$ The study of the exterior of the sentence is the focus of morphology. The study of its interior form is the focus of syntax.

$\$ 6$ Syntax is therefore quite distinct from morphology; it is independent from it. It has its own law. It is autonomous.

\$7 The autonomy of syntax is far from being generally acknowledged. Ever since the practice advocated by Bopp ${ }^{32}$ replaced Humboldt's work due to the influence of the ideas that were dominant in the 19th century, comparative grammar has been employed almost exclusively in the fields of phonetics and morphology. The majority of manuals written by the neo-grammarians in those times even show an undisguised preference for dating the works of Bopp, which were themselves quite remarkable, as year one of linguistics.

$\$ 8$ Since Bopp, syntax has been consistently treated as the poor relative. When by chance one decides to not pass over the subject in silence, the only option is to impose a morphological straightjacket on it. The majority of syntaxes that have been published in the last century are thus merely morphological syntaxes.

$\$ 9$ A. Meillet, one of the last and best known representatives of the neo-grammarian school, did not believe in the autonomy of syntax. "A language", he wrote, "is defined by three things, a phonetic system, a morphological system, and a vocabulary, in other words, by a manner of pronunciation, by a grammar, and by a certain manner of describing

32. Creator of comparative grammar, cf. above, Chapter $1, \$ 12$ and note 7 . 
meaning." ${ }^{33}$ One can see that this conception grants no position to proper syntax, which Meillet viewed as merely the study of employing forms.

\$10 The belief in the morphological character of syntax is so strongly anchored in the spirit of Meillet and the majority of his students that they have purely and simply appropriated the terminology of syntax, without realizing that they were thus stealing something essential to the syntacticians. Without it, it becomes difficult for them to discuss syntax in a really syntactic way, because morphologists contrive to give every syntactic term a morphological sense.

$\$ 11$ For instance, they decreed that the term iterative applied in Slavic languages to a kind of verb not having a given meaning but a given form. They thus confiscated the term for their advantage even if it meant rejecting it contemptuously when they realized that these verbs are in fact derived imperfectives. This did not prevent them from being immodest about this beautiful "discovery".

$\$ 12$ The credit for having rehabilitated the interior form of language in the face of morphology is due to Charles Bally, whose Précis de stylistique (Geneva, 1905) marks a historical turning point in the history of language. For Bally, linguistics "is based on the observation of what passes into the mind of a speaker at the moment when he expresses what he thinks" ${ }^{34}$

$\$ 13$ The same general tendency to liberate syntax from morphology is found in F. Brunot's book La pensée et la langue (see above, Chapter 20,\$20) and, more recently, in the works of A. Juret ${ }^{35}$ and V. Brøndal, ${ }^{36}$ who are staunch advocates of the autonomy of syntax. Among the books inspired by this spirit is the Greek syntax of Jean Humbert. ${ }^{37}$

\section{Chapter 16. Morphological markers}

\$1 We give the name exprimende (Fr. exprimende) to the thought and to the structural and linear schema which correspond to it on the linguistic plane, and the name expressed form (Fr. exprimé) to the phonetic clothing that gives it a perceivable form.

33. Linguistique historique et linguistique générale, Vol. I, pp. 83-84.

34. Traité de sylistique française, Geneva, 1909, I, pp. 83-84.

35. Système de la syntaxe latine, Strasbourg, 1926.

36. Morfologi og Syntax, program from the University of Copenhagen, November 1932, French review with the title L'autonomie de la syntaxe, in the Journal de Psychologie 1933, number 1-4, pp. 217-224.

37. Jean Humbert, Syntaxe grecque, Paris, Klincksieck, 1945; [2nd revised ed., Paris, 1954.] 
\$2 The meaning or signification of a given element of the spoken chain is the relationship of the expressed form to the exprimende. Indeed, the exprimende is the meaning of the expressed form.

$\$ 3$ The notion of meaning can only enable a definition of the expressed form in terms of the exprimende. It thus implies the primacy of the expressed form over the exprimende, that is, of morphology over syntax.

$\$ 4$ Yet this primacy cannot be acknowledged. Indeed, syntax precedes morphology. When we speak, our intent is not to find meaning afterwards in a pre-existing string of phonemes, but rather to give an easily transmissible form to a thought that precedes the form and which is its sole raison d'etre. In other words, the telegraph is there to transmit messages; the messages are not there to make the telegraph function.

\$5 The primacy of syntax obliges us to adopt a term into our terminology that is the inverse of meaning. We arrive at the term marker (or morphological marker).

$\$ 6$ The marker will no longer express the relationship of the expressed form to the exprimende $(\$ 2)$, but rather the relationship of the exprimende to the expressed form. And we say that the expressed form is the marker of the exprimende.

$\$ 7$ The result of this is that morphology is essentially and uniquely the study of markers.

$\$ 8$ The markers differ among each other in three ways: in their nature, their order, and their adherence.

$\$ 9$ The nature of markers is the phonetic clothing that constitutes them.

$\$ 10$ The order of markers is their successive appearance in the spoken chain. It is therefore only a morphological reflex of linear order (Chapter 8).

$\$ 11$ Finally, the adherence of markers is the degree of cohesion that binds together those among them that are in sequence in the spoken chain. Adherence is thus the inverse function of the depth of breaks (Chapter 10, $\$ 4 \mathrm{ff}$.).

$\$ 12$ Connections do not have markers, but they are no less present, since they must be perceived by the mind, a necessity for the understanding of a sentence. (Chapter $1, \$ 4$ ).

\section{Chapter 17. The zero marker}

\$1 It is certainly not the case that all syntactic facts are marked morphologically. On the contrary, it can often be seen that undeniable syntactic facts are not indicated on the morphological plane by any marker. In such a case we say that they are without markers, or equally that they have a zero marker, which we show, where necessary, with the symbol $\odot$ in stemmas (cf. Stemma 358).

\$2 Therefore most often, connections do not have markers. When I say your young brother (Stemma 18), I intend for there to be a connection between your and brother. But 
no marker - not even a sequence or an agreement - indicates this connection on the morphological plane.

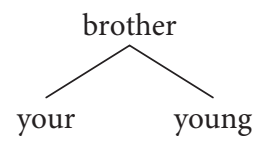

Stemma 18

$\$ 3$ The existence of syntactic facts without markers, i.e. an exprimende without an expressed form, suffices to show the weakness of all morphological syntax (Chapter $1, \$ 5$ ).

$\$ 4$ Viewing syntax as no more than the science of employing forms is the same as wanting to acknowledge the facts of syntax only to the extent that they have morphological markers, and consequently to condemn oneself to ignoring every fact that is not marked (Chapter 162, \$6).

$\$ 5$ This means that a purely morphological understanding of syntax is necessarily incomplete and gives no more than an impoverished reflection of reality.

$\$ 6$ It can also be seen that with similarly incomplete material, it is impossible to construct the syntactic system or even to acknowledge the existence of this system.

$\$ 7$ The economy of a syntactic system can show itself only to those who know the totality of its constituent elements and who seek to discover the internal law of their layout.

$\$ 8$ The result of this is that the study of syntax is only possible under the condition that the deficiencies of morphological material are filled in by the direct knowledge of true syntactic material. When exterior means of information are lacking, it is necessary to appeal to interior means of information.

\$9 The very conditions under which syntactic facts turn up therefore impose on us an at least partial usage of the introspective method. Indeed, the activity of speaking at the syntactic plane can be analyzed only by introspection.

$\$ 10$ This is why introspection is destined to become one of the main pieces of the investigative method for discovering facts of syntax.

\section{Chapter 18. The introspective method}

\$1 The introspective method goes too much against received habits in linguistics and the traditions inherited from the 19th century to be employed without evoking objections and criticisms.

\$2 This method can be accused in particular of being difficult to employ due to its subjective and consequently dangerous character. 
$\$ 3$ It is true that the introspective method is difficult to employ in syntax. But has the difficulty of a task ever been a valid reason not to undertake it?

$\$ 4$ The introspective method will be criticized for its subjective character, for it appeals to intuition.

$\$ 5$ In this area, the grievance is even more questionable. The introspective method does indeed appeal to intuition. But it also appeals to internal experience. In this respect, it is an experimental method and as a consequence, it is objective.

$\$ 6$ The introspective method is also objective because it bears on facts. Of course these facts are abstract, but not only concrete facts exist. It is even possible to say that in syntax, all facts are abstract, since after all it is only their markers that are concrete. And there is almost no other method for reaching purely abstract syntactic facts than that of internal analysis.

$\$ 7$ Finally, the introspective method will see its character reproached as dangerous, and it must be acknowledged that the user may find himself on slippery ground with it.

$\$ 8$ But we will be content to take from this insight the lesson of prudence that it imposes.

$\$ 9$ Above all, it is necessary to employ the method only when it is indispensable. We will therefore appeal to the introspective method only when in the presence of syntactic facts without markers.

$\$ 10$ It is also necessary to limit the conclusions based upon the introspective method to those that it can reasonably deliver. In this way we avoid making the same mistakes as those who, taking phenomena established by introspection as their starting point, claim to arrive at historical conclusions and thus cast discredit on the introspective method.

$\$ 11$ Finally, it is essential to know how to utilize the introspective method judiciously within these limits, that is, it is essential to know how to correctly and methodologically analyze oneself.

$\$ 12$ The introspective method is no more innate than any other technique. Whatever natural disposition there may be for employing the method, it is important to know how to study and work it assiduously in order to fully develop and master it. In short, there is an entire course of education of introspection to be conducted with it.

$\$ 13$ It follows that in principle the introspective method can only be used on the mother tongue of the user. Its use therefore requires that the linguist also be the speaker.

$\$ 14$ Therefore we can only imagine building a comparative syntax when there exist, amongst speakers of the most diverse languages, linguists who are trained and have experience with the introspective method. 
\$15 Practiced in this manner, the introspective method can be a useful contribution to the theory of syntax; it enables the linguist first to seize upon and acknowledge facts of syntax and from there, to study their morphological markers, in accordance with the principle established above (Chapter 16, \$4).

\section{Chapter 19. Structure and function}

\$1 The introspective method seeks to discover the deep raison d'être of words underneath their surface form.

\$2 The method therefore highlights their purpose, that is, the role that they play in the economy and functioning of a given syntactical system.

$\$ 3$ Words can be seen as tools. The design of each of these tools is specific to its use, for which the tool is narrowly adapted.

$\$ 4$ We call the function of words the role that they are assigned in the mechanism of expressing thought.

$\$ 5$ We have seen (Chapter $3, \$ 3$ ) that the governor fulfills the function of linking the different connections to diverse subordinates together into a single group. We call this function the nodal function.

$\$ 6$ We have seen (Chapter $3, \$ 1$ ) that a group never has more than a single governor. The sole superior term of a group never has more than a single function, the nodal function, which remains unchanged at all times.

$\$ 7$ Conversely, we have seen (Chapter $3, \$ 1$ ) that a governor can have numerous subordinates. In such cases, the various subordinates assume different functions with respect to the governor. We will learn about the details of these subordinate functions when we address the study of the sentence (Chapter 48ff.).

$\$ 8$ The economy of a given structural group rests on the judicious arrangement of the functions of each of the group's elements. Structure is possible only in the presence of function. The same is true as in military hierarchy (Chapter $2, \S 5$ ), where each rank fulfills a determined function.

\$9 The result is that structural syntax is simultaneously functional syntax, and it must essentially study the various functions necessary to the life of the sentence.

\$10 Knowing a language involves knowing the different functions that must be present in that language, and knowing how to speak a language involves understanding the handling of the tools that guarantee these functions.

$\$ 11$ From this point of view, functional syntax is immediately useful to the study of modern foreign languages, to the knowledge of these languages, and to their pedagogy. 
$\$ 12$ There is a striking analogy between the concept of functional syntax and the phonology of the Prague school, which aims to discover, beyond the purely physical nature of the phenomena, their ability to be charged with true linguistic functions.

\section{Chapter 20. Distinguishing between structure and meaning}

\$1 Syntax is distinct from morphology, and it is no less distinct from semantics. The structure of a sentence is one thing, and the idea that it expresses and that constitutes its meaning is another. It is therefore necessary to distinguish between the structural plane and the semantic plane.

$\$ 2$ We have so far deliberately overlooked the semantic plane in order to focus on the structural plane, which is the only area that directly concerns structural syntax.

$\$ 3$ But we can nevertheless not completely pass over the semantic plane, since meaning is ultimately the raison d'être of structure, and it is therefore indirectly of interest to the study of structural syntax.

$\$ 4$ The distinction between the structural plane and the semantic plane is of primary importance for good comprehension of structural syntax.

\$5 The structural plane is where the linguistic expression of thought is developed. It pertains to grammar and is intrinsic to it.

$\$ 6$ The semantic plane, in contrast, is the domain specific to thought, leaving all linguistic expression aside. It does not pertain to grammar, to which it is extrinsic, but rather to psychology and logic.

$\$ 7$ It is still necessary to carefully observe the distinction between the real meaning and the meaning expressed by the morphological marker clothing it. It occurs frequently that a given expressed form is subjected to semantic shift, which results in a situation where the expressed form no longer corresponds to the morphological marker clothing it.

$\$ 8$ For example Fr. excessivement is far from expressing the idea avec excès 'with excess', since it is no more than an intensified substitute for the word très 'very'. Many French speakers often say Cette femme est excessivement jolie 'This woman is excessively pretty', although it is evident that it is not possible to have an excess of beauty.

$\$ 9$ Similarly sans doute, lit. 'without doubt' 'probably', practically no longer means that there is no doubt, but on the contrary, that there is some doubt, and is therefore distinguished from sans aucun doute 'without any doubt'. If you ask Fera-t-il beau cet après-midi? 'Is the weather going to be nice this afternoon?' of someone who is knowledgeable about the weather and if this person replies Sans doute 'Perhaps', it would be wise to take your umbrella. 
\$10 Semantic shift is very dangerous for foreigners, who, if they have not been warned, tend to have blind confidence in the expressions for which the morphological marker is now far removed from the original expressed form.

\$11 Many Germanophones believe with complete confidence that Ger. ohne Zweifel 'without a doubt' translates exactly to Fr. sans doute, when it is actually necessary to use Fr. sans aucun doute if the corresponding meaning is to be obtained.

$\$ 12$ There is a closely analogous case in Fr. Je l'espère 'I hope so', which does not in fact express any desire, but rather a reinforced observation, born out of a little satisfaction, of a real fact, in a sentence such as En voilà un de robuste, je l'espère 'Here is a robust one, apparently' (J.-H. Fabre, La science de l'oncle Paul, p. 27).

$\$ 13$ The mental activity that is exercised on the structural plane is subjective and subconscious. It constitutes a deep phenomenon which is elementary and necessary. It eludes all control of human will. It is the very life of speech. It can only be analyzed by intuitively turning in on itself, which is not part of the natural order of things. That is why the average speaker, who speaks quite happily on the subject of grammar, generally has a false conception of it.

$\$ 14$ But it is good that things are this way, since reflection kills life. The sick person who hears himself too much makes the malady worse rather than better. The day when all speakers know how they speak would be the end of all eloquence and conversation. The linguist himself, who is naturally ineloquent, would completely lose the usage of speech if he did not take care to forget his linguistics when he spoke.

$\$ 15$ On the other hand, the mental activity that is exercised on the semantic plane is objective and conscious. It constitutes a superficial and completely contingent phenomenon. The speaker chooses the ideas that he wants to express. If he has any culture, he can even control his mode of expression himself and prefer one word over another.

$\$ 16$ Numerous words have hence been created by an act of conscious and individual will. We have the birth certificate for these words, with the date of appearance and the indication of paternity, for example gaz 'gas' (1648, van Helmont), dolomite 'dolomite' (1792, Bénédict de Saussure), avion 'airplane' (1875), etc...

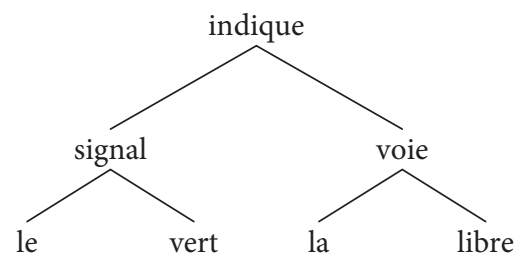

Stemma 19

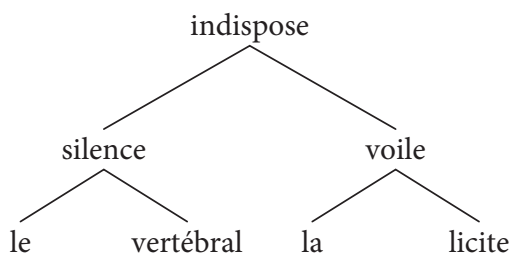

Stemma 20

$\$ 17$ The structural plane and the semantic plane are therefore entirely independent of each other from a theoretic point of view. The best proof is that a sentence can be semantically 
absurd and at the same time syntactically perfectly correct. Take the meaningful sentence Le signal vert indique la voie libre 'The green light indicates right of way', lit. 'The green light indicates the open road' (Stemma 19). If I replace all the words charged with meaning by the words of the same type that immediately follow them in alphabetic order in the dictionary, I obtain the sentence Le silence vertébral indispose la voile licite, lit. 'The vertebral silence antagonizes the lawful sail' (Stemma 20); the structure remains intact, but the sentence now makes no sense whatsoever (see also passim in the works of the futurist and surrealist poets). ${ }^{38}$

$\$ 18$ The result of the independence of the structural and semantic planes is that syntax is completely independent of logic and psychology. Syntax bears on the form of the expression of thought, not on the thought itself, which is its content.

$\$ 19$ This conception of syntax is therefore far from being a simple return to the logical and reasoned grammar that was the trend at the end of the 17th century to the 18th century, from the Grammaire Générale of Port-Royal (1660) to the Grammaire of Condillac (1756).

\$20 But it is also very different from the psychological conception of Wundt ${ }^{39}$ and from the more recent conception of Ferdinand Brunot, who in La Pensée et la Langue (1922), while intending to produce a "Psychology", nonetheless based his account more on aspects of thought than on their modes of expression. ${ }^{40}$

\$21 Since it is distinct from logic and psychology, syntax has to seek its proper decree in itself. It is autonomous.

\section{Chapter 21. Relationships of structure and meaning}

$\$ 1$ We have just seen (Chapter $20, \$ 17 f f$.$) that the structural and semantic planes are inde-$ pendent of each other. But this independence is merely a theoretical construct of the mind. In practice, the two planes are in fact parallel because the structural plane has no other purpose than to render the expression of thought possible, that is, to render the expression of the semantic plane possible. While they are not identical, there is parallelism between the two planes.

38. Translators' note: The point here concerning the nonsensical but grammatical sentence (Le silence vertébral indispose la voile licite) is the same point that Chomsky makes concerning the famous sentence Colorless green ideas sleep furiously (Chomsky 1957, Syntactic structures). Tesnière died in 1954, one year before the appearance of the notion of the semantically nonsensical sentence in Chomsky's 1955 thesis.

39. Völkerpsychologie, I, Die Sprache, 1900.

40. "What I wanted was to present a methodology of the facts of thought, considered and classified in relation to language, and of their corresponding means of expression" (F. Brunot, La Pensée et la Langue, Introduction, p. VII). 
\$2 This parallelism is obvious in the connections. The semantic connections are superimposed onto the structural connections. Take for example the group small streams (Stemma 21). If the word small is connected structurally to streams, this is the case because there is a desire to express a semantic connection between the two; namely the idea of small being applied to the idea of streams.

$\$ 3$ In other words, the parallelism can be described by saying that the structural expresses the semantic.

$\$ 4$ The expression of the semantic by the structural occurs as follows: The meaning of the subordinate pertains to that of the governor upon which it depends. Therefore in the sentence The small streams make the big rivers (Stemma 9), small depends on streams, and so the meaning of small bears on that of streams, and I understand that the smallness is a quality of the streams, not of the rivers. Likewise, big depends on rivers and so the meaning of big bears on that of rivers, and I therefore understand that the bigness is a quality of the rivers, not of the streams.

$\$ 5$ The result of what was stated above (Chapter 2 and Chapter $3, \$ 5$ ) about the hierarchy of connections and nodes is that the structural connections are established from a governor to its subordinates, that is, top down in the stemmatic representation (Stemma 22).

$\$ 6$ In contrast, the result of what was just stated above (Chapter $21, \$ 4$ ) is that semantic impact is exercised from a subordinate to its governor, that is, bottom up in the stemmatic representation (Stemma 23).

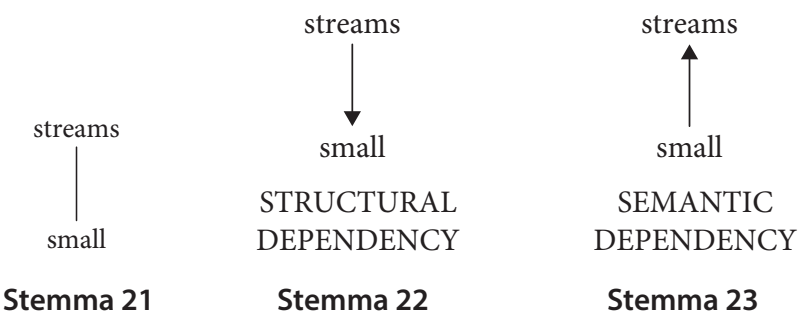

\$7 The semantic impact is thus exercised in the opposing direction to the structural connections. This observation reinforces what has been said previously (Chapter 20, \$4) about the fundamental distinction between semantics and structure (see also Chapter 266, $\$ 10 \mathrm{ff}.)^{41}$

$\$ 8$ The result is that the hierarchical importance of the words (structural plane) is inversely related to their semantic importance (semantic plane). The lower a word is situated in the structural hierarchy, the greater the likelihood that it is essential for the meaning of the

41. The same thing has been observed by G. Galichet, Essai de grammaire psychologique, p. 61. 
sentence - it is as though the role of the governor is merely to support the semantic impact of the subordinate. Therefore the sentence Le signal vert indique la voie libre 'A green light indicates right of way', lit. 'The green light indicates the open road' only takes its full meaning thanks to the words vert and libre, which are subordinates of subordinates and are located at the lowest level of the stemma. If they were to be removed, the sentence would no longer make sense: Le signal indique la voie 'A light indicates a road'. And if they are replaced with other words, the sentence takes on a totally different meaning: Le signal rouge indique la voie fermée 'A red light indicates a closed road'.

$\$ 9$ We characterize semantic connections by saying that the subordinate determines the governor. The subordinate is therefore the determiner, and the governor is the determined. In the preceding sentence, the determiner green determines the governor light. ${ }^{42}$ $\$ 10$ The subordinate can also be said to complete the governor. The subordinate is then the complement of the governor. In the preceding sentence, the complement road completes the verb indicates.

\$11 Although the same structural phenomenon is present in the two preceding cases, traditional grammar gives them different names. Traditional grammar reserves the term complement for certain structures, and the term determiner for other structures. This traditional partitioning of the two terms, while quite routine, does not obey any systematic principal. While rouge 'red' is said to be the determiner of signal 'light' and voie 'way' to be the complement of indique 'indicate', it is nevertheless the case that signal is said to be neither the complement nor the determiner of indique, but rather its subject. And in the phrase le livre de Alfred, lit. 'the book of Alfred', 'Alfred's book' (Stemma 24), Alfred is said to be both the complement and the determiner of book and to receive the traditional name determinative complement, as if every complement was not ipso facto determinative.

$\$ 12$ We represent the semantic connection graphically using a dashed line. Thus in the phrase small streams, we express the semantic connection between small and streams with Stemma 25.

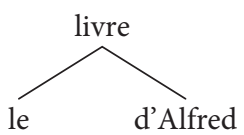

Stemma 24

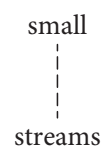

Stemma 25

42. Translator's note: It should be apparent here that Tesnière's determiner is much different from the modern use of the term determiner. The determiner in modern times is a specific class of word. For Tesnière here, in contrast, a determiner is any word that 'determines' another word. 
$\$ 13$ We will of course only make use of the dashed connection line when we are focusing on the semantic connections. When we want to express the structural connection and at the same time the semantic connection parallel to it, we superimpose the dashed line of the semantic connection onto the solid line of the structural connection such that only the latter appears. Stemma 21 simultaneously expresses the semantic connection and the structural connection between small and streams.

$\$ 14$ The result of this is that we foresee no possibility of noting the structural connections to the exclusion of the semantic connections. In practice there is no necessity to do this anyway. Indeed, there is never a structural connection without a semantic connection $(\$ 1)$, whereas there can be semantic connections without structural connections, as we will see further down when we study anaphora (Chapter 42).

\section{Chapter 22. The nucleus}

\$1 The opposition structure vs. semantics is relevant not only to the connections, but also to the centers that they connect.

\$2 Semantic connections are distinct from structural connections, because where they join together, there are semantic centers distinct from the structural centers.

$\$ 3$ The concept of the node, to which we have given a precise structural value (Chapter 3, $\$ 2$ ff.), becomes insufficient to account for the complexity of facts as soon as we introduce the semantic factor.

$\$ 4$ We are led to expand the notion of the node by introducing a broader concept, for which we reserve the name nucleus.

$\$ 5$ We define the nucleus as the set which joins together, in addition to the structural node itself, all the other elements for which the node is the structural support, starting with the semantic elements.

$\$ 6$ We therefore conceive of the nucleus as the seat of a certain number of functions.

$\$ 7$ Amongst these functions, we have already seen the nodal function (Chapter 19, §5), which was the starting point of this exposition.

$\$ 8$ We have also considered the semantic function (Chapter 20), which has completely undone the notion of the node, it being too narrow, thus leading to the notion of the nucleus. $\$ 9$ Finally, we can henceforth expect to see that the nucleus will be the seat of several other functions, above all of the translative function.

$\$ 10$ The concept of the node, which is simple, must not be confused with the concept of the nucleus, which is vaster and more complex.

$\$ 11$ The node is merely the material expression of the nodal function of the nucleus. It is merely a part of the nucleus, which, in addition to the node, contains or can contain a certain number of other elements. 
$\$ 12$ The node is nothing more than a geometric point, whereas the nucleus is a group of several points, or more accurately, the circle or sphere that contains them, i.e. a surface or volume. $^{43}$

$\$ 13$ From this point of view, it could be said that the nucleus is merely the microscopic enlargement of what appeared to us at first (Chapter 3) under the auspices of the simple node.

$\$ 14$ The nucleus is ultimately the elementary syntactic entity, the fundamental material of the structural frame of the sentence; it is in a sense the constitutive cell of the living organism that is the sentence.

\$15 With all the functions for which it is the locus, the nucleus is essentially a root for words. And it is possible to see, in all languages, elements on the verge of agglutinating into a nucleus, which constitutes the center of solidification, around which forms what we call at a later stage of evolution a 'root'. For example the current root commenc- 'start' of Fr. commenc-er 'to start' consists etymologically of prefixes and suffixes, which, as they developed in Latin, gradually agglutinated around the central element $-i$ - of the Latin nucleus $i$-re 'go' (by way of the intermediary of colloquial Lat. ${ }^{*} c o m$-in-i-ti-a-re). It should be noted that the original root represented by Lat. $-i$ - has completely disappeared in the French root commenc-, suffocated by its location between the self-propagating elements, prefixes and suffixes, which have completely squashed it.

$\$ 16$ Since we have been led to compare the nucleus to a circle, we represent it graphically by drawing a circular form around the words that form a nucleus. We call this circle, to which the connections are joined, a nucleus circle (Stemma 26).

$\$ 17$ However, it often seems unnecessary to employ the nucleus circle as often as the connection line in stemmas. We will therefore not force ourselves to mark the nucleus with a circle unless there is a particular reason for wanting to precisely delimit its scope. In the other cases, we will avoid weighing down our stemmas with the nucleus circle, the connection lines sufficing in most cases to indicate the structural economy of the sentence and at the same time to convey the scope of a nucleus. In other words, the use of nucleus circles in the stemmas is optional.

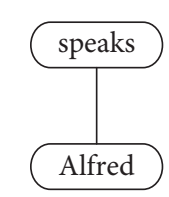

Stemma 26

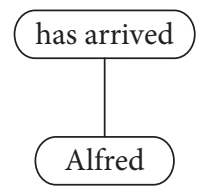

Stemma 27

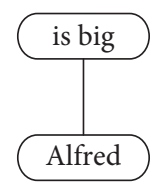

Stemma 28

43. Translator's note: Here we see the other understanding of the French term nœud, which we have chosen to translate with node throughout. A node is now clearly a vertex in the (graphic representation of) sentence structure. It is no longer a subtree. See the note in Chapter $3, \S 2$. 


\section{Chapter 23. The dissociated nucleus}

\$1 Among the diverse functions of the nucleus, there are two that are fundamental, the nodal function and the semantic function.

$\$ 2$ There can be no nucleus without a nodal function, since, as we have seen, (Chapter 22, $\$ 4)$, the very notion of the nucleus is merely an enlargement of the notion of the node that it involves.

$\$ 3$ There can be no nucleus without a semantic function, since, as we have seen, structure only has a reason to exist in semantics (Chapter 20,\$3), and as a consequence, a purely structural nucleus would have no reason to exist (Chapter 21, \$14).

$\$ 4$ The simultaneous presence of a structural node and a semantic node is thus obligatory in a nucleus, and there can be no nucleus unless both of these functions are guaranteed.

$\$ 5$ But each must be fulfilled just once. A nucleus cannot have two structural centers or two semantic centers.

$\$ 6$ We say therefore that if there is a nucleus, it is necessary and sufficient for there to be a structural and a semantic center at the same time.

$\$ 7$ But it is not necessary that the structural function and the semantic function be fulfilled by the same word. They can be dissociated and each fulfilled by a separate word.

$\$ 8$ We say in such cases that we are dealing with a dissociated nucleus.

$\$ 9$ The result of this is that every dissociated nucleus contains at least two words, one that fulfills the structural function and the other that fulfills the semantic function.

\$10 The name morpheme is often given to the word that fulfills the structural function and the name semanteme to the word that fulfills the semantic function.

$\$ 11$ The most striking case of a dissociated nucleus is the so-called compound tenses. ${ }^{44} \mathrm{~A}$ compound tense is a symbiosis composed of two words, one of which is called the auxiliary (Fr. auxiliare), which fulfills the structural function, and the second of which is called the auxiliated (Fr. auxilié), ${ }^{45}$ which fulfills the semantic function.

$\$ 12$ Therefore in the sentence Alfred has arrived, the hightest nucleus contains the two words has and arrived. One of these, has, fulfills the structural function, whereas the other, arrived, fulfills the semantic function (Stemma 27).

$\$ 13$ Another example is provided by the symbiosis of a predicative adjective with the verb $b e$, which has been called a nominal verb.

44. See my article Théorie structurale des temps composés, Mélanges Bally, Geneva, 1939. See also below, Chapter 170.

45. The term auxilié was introduced by Damourette and Pichon in their works. Since it is precise and convenient, it should be adopted into the classroom. 
\$14 Therefore in the sentence Alfred is big, the highest nucleus contains the two elements is and big. One of these, is, fulfills the structural function, whereas the other, big, fulfills the semantic function (Stemma 28).

$\$ 15$ The result is that the concept of the nucleus is quite different from the concept of the word.

$\$ 16$ Sometimes, however, the symbiosis of the two elements, the structural element and the semantic element, may be reflected in the fact that the substantive verb and the predicative adjective are agglutinated into a single form: for example in Turkish, Kitap kırmızıdır 'The book is red'.

$\$ 17$ While the word, a simple segment of the spoken chain (Chapter $10, \$ 3$ ), is the linear unit of the sentence, the nucleus is the structural unit thereof.

\$18 Taking a look back, we now understand why it is so difficult to understand the notion of the word (Chapter $10, \$ 1$ ). The word has no syntactic reality. Syntax can only be practiced insofar as nuclei can be identified behind the words.

\section{Chapter 24. Categories}

\$1 In photogravure, differences in tone present in the original can be captured only by way of a screen applied onto the original, which is to be reproduced. Solid tones, as if passed through a sieve, appear on the photogravure as a series of juxtaposed points which are more or less big depending on whether the original is more or less dark, and which as a whole, although discontinuous, succeed in giving the impression of the continuous tone of the original. This phenomenon can be observed by studying a photogravure under a magnifying glass.

\$2 The role of categories in logic and grammar can be compared to the role of engraving screens.

$\$ 3$ Thought can capture the complexity of the exterior world only by projecting onto this world the screen of a system of general ideas called categories of thought. By way of these categories, the human mind perceives the world within the limits of its own means.

$\$ 4$ In the same way, in linguistics, language can capture thought in turn only by projecting onto it the screen of a system of general notions called grammatical categories. By way of grammatical categories, language represents thought within the limits of its own means.

$\$ 5$ Grammatical categories are often consistent with categories of thought, but this does not mean that they do not belong to an essentially different plane.

$\$ 6$ Categories of thought reside on the psychological and logical plane. Since psychological and logical operations are the foundation of all thought, they are common to all humans, regardless of their language.

$\$ 7$ Grammatical categories are, in contrast, on the linguistic plane. They can therefore vary considerably from one language to another. 
$\$ 8$ Thus in the category of gender, French has masculine and feminine, Slavic has animate and inanimate, German has masculine, feminine, and neuter, Swedish has common gender and neuter gender, etc... Likewise, the category of tense dominates in Latin languages, whereas aspect is essential in Slavic languages.

\$9 The screen of grammatical categories projected by a language onto a thought that the language wants to express never exceeds the absolute minimum necessary to capture the thought.

\$10 A language that has an insufficient inventory of categories at its disposal would not be able to cover reality with a sufficiently tight network and therefore it would not be able to capture and express reality.

$\$ 11$ Conversely, a language that has at its disposal too great a number of categories would be weighed down for no reason.

$\$ 12$ For each language, there is therefore an optimum number of categories. This number is a function of the complexity of the civilization that needs to be expressed and it constitutes an equilibrium that is attained automatically thanks to the mere functioning of the language.

$\$ 13$ This optimum is quantitative, not qualitative. And while each language, to be viable, must remain within its imposed limits, each language is also free to choose the categories that suit it most. This is why categories are so variable from one language to the next.

$\$ 14$ Often consistent with the categories of thought, the grammatical categories have close relations with the semantic plane, even though they remain entirely on the grammatical plane.

\$15 The grammatical categories are the superiors under which the ideas fall into order in each language according to its idiosyncrasies. In this respect, the categories pertain to semantics.

$\$ 16$ But this does not mean that there is no less a principled opposition between the categorical plane and the semantic plane.

$\$ 17$ Indeed, the categorical plane is the locus of general ideas that are likely to serve as classifiers, whereas the semantic plane is the infinite dust of particular ideas.

\section{Chapter 25. Categories and functions}

$\$ 1$ The notions of category (Chapter 24) and function (Chapter 19) are distinct. They stand in opposition to each other in many respects.

$\$ 2$ Categories are static and inert elements. Functions in contrast are dynamic and living.

$\$ 3$ Take for example the sentence Alfred hits Bernard (Stemma 6). If we consider the categories, we observe that Alfred and Bernard belong to the noun category, and hits to the verb category. But if we only consider them from this point of view, these words teach us only that there is a person named Alfred and a person named Bernard and an action of 
hitting. They teach us nothing about the organic bond that unites the three elements when they are isolated in a sentence.

$\$ 4$ If, however, we take their functions into consideration, we observe that Alfred fulfills the function of subject, Bernard that of object, and hits that of the verbal node. From this point of view, everything becomes clear: the connections are established, the inert words become a living organism, and the sentence takes on its meaning.

$\$ 5$ Categories can be compared to artillery pieces that are either arranged in a repository and not currently in use or in a battery and in full action, that is, being used to do what they were made to do.

$\$ 6$ Or the categories can be compared to printing characters that are either lying idle in the typographic frame or ordered in line in the composing stick and aligned in the frame for printing.

\$7 The distinction between categories and functions is confirmed a posteriori by the behavior of different languages with respect to them. As observed by A. Meillet, who illustrated the different nature of categories and functions in his teachings, categories vary considerably across languages, whereas functions always remain more or less identical.

$\$ 8$ On the other hand, we will see further below (Chapter 28) that the distinction between categories and functions is the basis for the typological classification of words.

$\$ 9$ The study of grammatical categories and functions constitutes, as all signs indicate, the two essential divisions of syntax.

$\$ 10$ Static syntax is concerned with the study of categories, and dynamic syntax is dedicated to the study of functions.

$\$ 11$ Since the present study explores only structural syntax, which concerns the functions, the categories will not be considered per se, but only in respect to their interplay with the functions.

\section{Chapter 26. Static and dynamic order}

$\$ 1$ Concerning the classification of facts, a different order corresponds to each of the two essential divisions of syntax.

$\$ 2$ Just as there is a static syntax and a dynamic syntax, the static order and the dynamic order of the elements of language are seen as radically different.

$\$_{3}$ Static order is the logical and systematic order of the classification of language elements in the mind of a speaker, prior to the rendering of sentences. It is the order, for instance, of the paradigms of declension and conjugation in grammar.

$\$ 4$ Dynamic order, in contrast, concerns the organization of static elements in the mind as they are accessed to constitute sentences. It is the order of the interior form of language, 
the order according to which the connections are established (Chapter $4, \$ 1$ ) and the structural outline, which is represented by the stemma, is organized.

$\$ 5$ Dynamic order is thus the same as structural order, the only difference being the point of view. Indeed, just as dynamic order stands in opposition to static order, structural order stands in opposition to linear order (Chapter 6).

$\$ 6$ The distinction between static and dynamic order and between structural and linear order is the basis of all language pedagogy.

$\$ 7$ Static order concerns declensions and conjugations. It is generally the order favored by unrelenting teachers of ancient languages, who emphasize the knowledge of paradigms above all.

$\$ 8$ This method results infallibly in great knowledge of the ancient languages, and makes them essentially dead languages. It is quite evident that it is impossible to learn to organize forms in dynamic order according to the internal scheme of the living sentence by dwelling entirely on the static order of declensions and conjugations, or even less to establish the linear order of the spoken chain in discourse.

$\$ 9$ The teachers of modern languages have understood this state of affairs. They have, as a natural reaction to the desire to conserve the character as living languages, concentrated their pedagogy on linear order, focusing their teachings on the active practice of living and spoken sentences.

\$10 This method, known as the direct method, has overcome some of the drawbacks indicated above, but has entailed others. It has become evident that with this method, the liveliness of discourse often comes at the expense of its correct use. The practice bears too exclusively on the external form of language and necessitates a passive usage in order to gradually create the internal form, without which there can be no correct speech.

$\$ 11$ To summarize, these two opposing methods, each of which has its strong suit, have in common the fact that neither is based on dynamic structural order, which is as unrecognized as syntax itself. The expectation is that the introduction of the structural method and the use of stemmas that it entails will deliver good results in language teaching.

\section{Chapter 27. Traditional types of words}

$\$ 1$ Traditional syntax discerns ten types of words, which it calls parts of speech and which it identifies in most languages to a greater or lesser degree: article, noun, ${ }^{46}$ adjective, pronoun, verb, participle, adverb, preposition, conjunction, and interjection.

46. Translator's note: Tesnière uses the term substantif'noun' rather than nom 'noun', following a usage still enduring at his time. 
\$2 This classification, which rests on vague and sterile empiricism and not on a precise and fertile doctrine, does not stand up to scrutiny.

$\$ 3$ All evidence indicates that a good classification cannot rest simultaneously on multiple characteristics. We must therefore separate essential characteristics from secondary ones, or, to borrow terminology from logic, to distinguish dominant characteristics from subordinate ones. The principle of subordination leads to the establishment of a hierarchy of criteria, the most important of which serves to determine the classes and the second most important of which serves to determine the subclasses, and so on.

$\$ 4$ Yet the traditional classification into ten types of words is founded simultaneously on three criteria: on nature, on function, and on position.

$\$ 5$ Indeed, verb, noun, article, and participle are defined and named according to their nature alone.

$\$ 6$ The pronoun, which substitutes for a noun, the adjective, which accompanies a noun, the adverb, which accompanies a verb, and the conjunction, which relates the words to each other, are defined and named according to their function.

\$7 Finally the preposition, which is placed in front of the noun, and the interjection, which is interjected in discourse, are defined and named according to their position.

$\$ 8$ Deceptive at its core, this classification is inconsistent with usage, since it could lead to the conclusion for example that in Lat. mecum 'with me', the preposition takes a position after the pronoun (cf. Chapter 160, \$6), or that in French the word oui 'yes', which never accompanies a verb, is an adverb.

$\$ 9$ The process of traditional classification of types of words should no longer be practiced for these reasons. J. Vendryes wrote as early as 1921 that "the difficulty in classifying the parts of speech is such that a satisfying classification has not yet been drawn up."

$\$ 10$ Despite the embarrassment of such an inaccurate classification, it is nevertheless possible to do it by describing words that are absent as implicit and other words that one cannot classify as expletives.

$\$ 11$ These two terms are extremely dangerous in every use due to their very convenience, since their only purpose is essentially to mask the incomprehension of grammarians. They enable the explanation of the syntax of any given language, using the syntactic principles of any other language. They should therefore not be used except with extreme caution (Chapter 195, \$9).

$\$ 12$ In fact the language the grammar of which is most often substituted for the grammar of the language being studied is Latin. Indeed, Latin occupies a certain number of key positions in our human society. The study of the arts begins with Latin. It is the base from

47. Le langage, p. 136. 
which grammarians are trained. In particular, missionaries, who are often the first to study exotic languages, are inculcated with Latin starting in the seminary.

$\$ 13$ This substitution is realized by the following mechanism. If by chance the studied language is found to have the same number of word categories as Latin, the syntax of Latin is applied, by definition and most inappropriately! As ill luck would have it, if the language being studied has one fewer type of words than Latin typology, it does not matter, since it is implicit! If the studied language presents a word that is beyond the typology of Latin, the difficulty is no more problematic, for the word is an expletive! Presto! Clear as mud!

\section{Chapter 28. Full and empty words}

\$1 There are two essential types of words, full and empty ones.

\$2 Full words are those that are charged with a semantic function, that is, the form is associated directly with an idea, which it must represent and evoke. Thus Fr. cheval, Ger. Pferd, Eng. horse, Lat. equus, etc... are full words because their form, that is, the phonemes (or the letters) that compose them are sufficient to evoke the idea of a horse.

$\$ 3$ Empty words are those that do not have a semantic function. They are simple grammatical tools. ${ }^{48}$ Their role is to indicate, specify, or transform the category of full words and to regulate the relations between them.

$\$ 4$ Thus Fr. le, Ger. das, Eng. the, etc... are empty words because they alone do not evoke an idea; they serve only to determine the categories of the words cheval (noun, masculine, singular), Pferd (noun, neuter, singular, nominative), horse (noun, singular).

$\$ 5$ What we respectively call full words and empty words are notions that seem quite closely related to the concepts that certain linguists often designate with the terms semanteme and morpheme, although there is far from any consensus among these linguists about these terms (Chapter 23, \$10).

$\$ 6$ The distinction between full and empty words is rigorous only in certain languages, particularly in Chinese. Morevoer it is from Chinese stylistics that the terms full word and empty word are borrowed.

$\$ 7$ Thus in the Chinese sentence Nǐ fù-qīn zhū zaì nǐ mén de fáng-ž̀ li ma? 'Does your father live in your house?' (Stemmas 29 and 30), the words fù-qìn 'father', fáng-ž̀ 'house', and $z h \bar{u}$ 'live' are clearly full, whereas the words de (marker of a determining complement), $z a i$ (locative marker), $l i$ 'in' and $m a$ (interrogative marker) are clearly empty.

48. Damourette and Pichon felicitously call them "struments". Others proposed "mots-charnières", literally hinge words. 


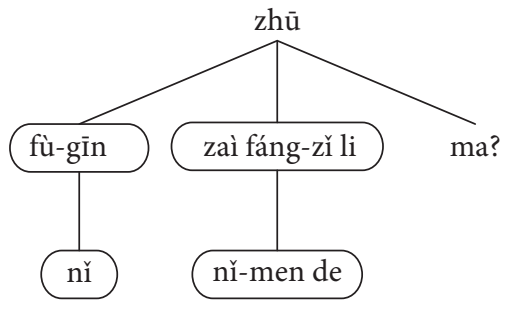

Stemma 29

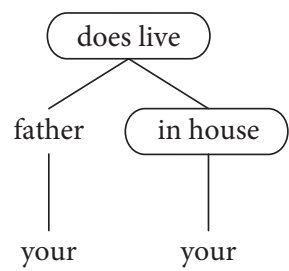

Stemma 30

$\$ 8$ Many languages - above all our European languages, which we take a particular interest in - unite full and empty elements in a single word (Chapter $23, \$ 7$ ). We qualify such words as composite.

$\$ 9$ Thus in the sentence The horses ate the hay (Stemma 31), the words horses and ate are composite, since they have both full elements like horse- and empty elements like -s, and the two elements are both so intimately associated in ate that it is difficult to separate them with precision.

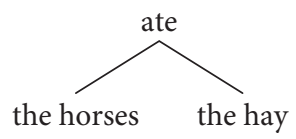

Stemma 31

\$10 It goes without saying that composite words must be considered full words from a syntactic point of view, since they have the semantics inherent to full words (\$2).

$\$ 11$ Telegram style, which in the interest of economy aims to cut out all words that are not absolutely needed for the comprehension of a text, involves retaining the full words and eliminating the empty words.

$\$ 12$ Thus the telegram Arriving Paris tomorrow train eight is easily understood just as I am arriving in Paris tomorrow by train at eight o'clock, in which the empty words carry no meaning in isolation: $I, a m$, in, by, at.

$\$ 13$ In the course of the historical development of a language, full words have a tendency to be emptied of semantic content as they become grammatical tools. Many empty words were once full words, whereas the opposite is never observed, for example Lat. quā $r \bar{e}$ ' what thing, why' > Fr. car 'because'; Lat. illam 'her' > Fr. la 'the (feminine)'; ${ }^{*}$ aug- (cf. Lat. aug-eo 'I increase') > Ger. auch 'also'; ${ }^{\star} m$ e/o $g$ 'can' (cf. Ger. ich mag 'I may') > Lat. magis 'more' > Fr. mais 'but'; Lat. de 'from above' > Fr. de 'of, from'.

$\$ 14$ The ideas expressed by full words can be captured only through the screen of grammatical categories (Chapter 24, $\$ 4$ ). Essentially, full words pertain to categorical syntax.

$\$ 15$ In contrast, empty words only appear as grammatical tools to enable the creation of sentence structure. They essentially pertain to functional syntax. 
\$16 Thus the opposition between full and empty words is merely a reflex of the opposition between static and dynamic syntax (Chapter 25, \$10).

$\$ 17$ Note that it is very difficult to completely empty a full word of its semantic content and to thus perceive it as a word that is completely empty. This difficulty gives occasion to numerous mistranslations.

\$18 In this respect, French prepositions are very often empty, a fact that many speakers of other languages, in particular of Germanic and Slavic languages, have difficulty comprehending. This is made obvious in the following news item which I have taken from a newspaper in Strasbourg. The item: Elle reçut un coup de revolver dans le foie de son fiancé, would be interpreted at first as 'She received a shot in the liver of her fiancé, while the writer, who probably followed the Germanic order of his native dialect, Alsacian, wanted to say 'She received a shot in the liver from her fiancé. A non-Germanic speaker, aware of the preponderant role of the preposition de 'of' as an empty word, would have rather used the unambiguous reverse order of the complements Elle reçut de son fiancé un coup de revolver dans le foie.

$\$ 19$ Similarly, French-speakers have much difficulty separating the Russian adjective svoj, which contains a purely reflexive notion, from the notion of person which is always associated with the corresponding word in French. It suffices to ask a French speaker, regardless of background, to state the meaning of an expression like svoja kareta 'one's own coach' I have had this experience many times. The French speaker being questioned has some difficulty in abandoning the notion of 'his/her/one's coach', or even 'my coach', 'our coach', 'their coach' to correctly understand the meaning 'one's own coach', that is, 'a coach that belongs to one', the one being impersonal (cf. Chapter 103, $\$ 6$ and 11).

\section{Chapter 29. Constitutive and subsidiary words}

\$1 The distinction between constitutive and subsidiary words on the structural plane corresponds to the distinction between full and empty words on the semantic plane.

\$2 We call constitutive every word that is likely to assume a structural function and form a node (Chapter 3, $\$ 2$ and 3). Thus in the phrase le livre d'Alfred (Stemma 24), the words livre and Alfred are constitutive.

$\$ 3$ Conversely, we call subsidiary every word that is not likely to assume a structural function and to form a node. Thus in the preceding phrase, the words the and of are subsidiary.

$\$ 4$ The result of this is that a subsidiary word, since it is not likely to constitute a node on its own, can only appear inside a nucleus where it accompanies a constitutive word which 
is the center of the nucleus. Thus, in the preceding phrase, the subsidiary word $d$ ' appears inside the nucleus the structural center of which is the constitutive word (Stemma 32).

\$5 The fate of every subsidiary word is thus intimately tied to the fate of the constitutive word in the nucleus in which it appears (Chapter $3, \$ 4$ ).

$\$ 6$ Constitutive words are always autonomous, that is, they conserve their full and entire individuality (Chapter 11, \$6). They are thus something on their own and can be found together in sentences without the accompaniment of subsidiary words. Thus in the sentence Alfred hits Bernard (Stemma 6), each of the three words Alfred, hits, and Bernard can exist on its own.

$\$ 7$ In contrast, subsidiary words have no autonomy. They are nothing on their own and cannot appear together in sentences independent from the constitutive words that they accompany. They are veritable satellites of these constitutive words; they form a nucleus with them, and tend to agglutinate to them (Chapter 11, \$5).

$\$ 8$ Thus the article the cannot appear without the noun that it determines, for example the book. Likewise, the French personal index $i l$ 'he/it' cannot appear without the verb the person of which it functions to indicate, for example Il chante 'He sings' or le in Donne-lemoi 'Give it to me. 49

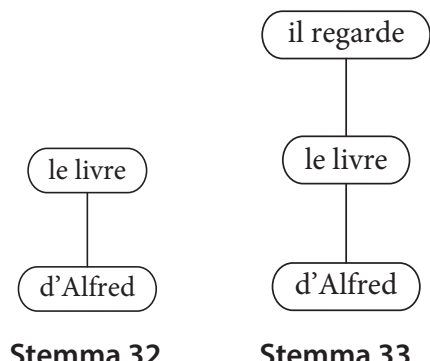

Stemma 32

Stemma 33

$\$ 9$ In other words, constitutive words are the bricks of the sentence, whereas subsidiary words are merely the mortar that serves to assure the cohesive arrangement of the bricks. $\$ 10$ Since they have the ability to appear alone as structural elements of sentences, only constitutive words are qualified to appear alone in stemmas.

49. Translator's note: The French personal indices like $i l$ 'he/it' and le 'him/it' are clitics and have no autonomy. They have the tonic counterpart lui, which can stand alone: Qui vient? Lui/*Il 'Who comes? Him/he'. Contrary to French clitics, the English pronoun he, which can stand alone, is a constitutive word (see $\$ 20$ concerning the corresponding Latin). 
$\$ 11$ Conversely, subsidiary words, not having the ability to appear by themselves as constitutive elements in sentences, cannot appear alone in stemmas. They appear only as the henchmen of full words, and within the same nucleus circle (Chapter 22, \$16).

$\$ 12$ Thus in the French sentence Il regarde le livre d'Alfred 'He sees the book of Alfred' (Stemma 33), the three subsidiary words $i l$, le, and $d e$ (reduced to $d$ ') appear respectively in the same nucleus circle as the constitutive words regarde, livre, and Alfred.

$\$ 13$ The constitutive words are by definition morphemes, since they guarantee a structural function (Chapter 23, \$10).

$\$ 14$ Similarly, but on the semantic plane, the full words are by definition semantemes, since they assure a semantic function (Chapter 23, \$10).

\$15 Most often, constitutive words are simultaneously full words, and vice versa. Thus in the example above, Alfred is both constitutive, since it forms a node, and full, because it is semantically loaded.

\$16 But it can occur that a constitutive word is empty. It then has to be counterbalanced by a subsidiary full word, which means we are in the presence of a dissociated nucleus (Chapter 23, \$7).

$\$ 17$ From a historical point of view, subsidiary words are in general former constitutive words that have gradually lost their autonomy in the course of time. Thus the personal index il 'he/it', which is a subsidiary word, since it cannot appear alone without a verb, is merely the form taken in French by a Latin demonstrative of the type ille 'this', which was an autonomous word. Moreover, the subsidiary personal index $i l$ was still an autonomous personal pronoun in Old French, cf. Ne vus ne il n'i porterez les piez 'Neither you nor he will you go there' (Chanson de Roland, 260), to be compared to Modern Fr. Ni vous ni lui n'y porterez les pieds 'Neither you nor he will go there'.

$\$ 18$ The constitutive word that a subsidiary word accompanies is generally the word on which it depended when it was autonomous. The structural relationship between a constitutive word and a subsidiary word is thus in principle the same as that of a governor to its subordinate. But whereas the connection between the governor and the subordinate implicates a certain distance between the two, this distance is reduced to nil between the constitutive word and the subsidiary word that accompanies it. Subsidiary words are thus in a sense like satellites that are pulled toward the star around which they gravitate. For this reason it is appropriate to represent them within the same nucleus circle, with a connection surviving between them on a purely etymological basis.

$\$ 19$ It can therefore be decided once and for all that the connections contained within a nucleus have only etymological value by definition.

\$20 The profound structural difference between Fr. Il aime les roses 'He adores the roses' and its prototypical ancestral Lat. Ille amat illas rosas 'He adores these roses' can therefore be graphically translated by the difference between the two Stemmas 34 and 35. 


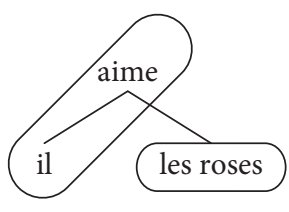

Stemma 34

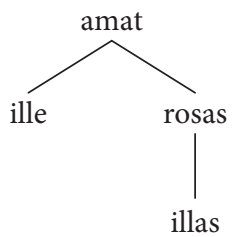

Stemma 35

$\$ 21$ The semantic evolution and genesis of empty words is independent of the structural evolution and genesis of subsidiary words. Hence it can occur that a subordinated full word becomes a constitutive word. In this case, and in contrast to what was observed in the preceding paragraph, the constitutive word that accompanies a subsidiary word is the word that was governed by this subsidiary word when it was autonomous. Such is the case for French manner adverbs, where the subsidiary element -ment stems from the autonomous Latin word mente: bona mente 'in a good mind' > Fr. bonnement 'simply' (Stemmas 36 and 37).

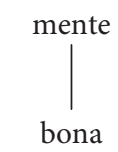

Stemma 36 bonne-ment

Stemma 37

\section{Chapter 30. Variable and invariable words}

\$1 While the distinction between full and empty words is semantic in nature and that between constitutive and subsidiary words is structural in nature, the distinction between variable and invariable words is morphological in nature.

\$2 The latter distinction need not be addressed in an exposé that is devoted to structural syntax.

$\$ 3$ Nevertheless, the study of the relationships between the variability of words and their structural and semantic character is not without interest.

$\$ 4$ Constitutive words are likely to be variable, since the marker of variation is an empty subsidiary element, and they are susceptible to agglutinating with subsidiary elements. Such is the case with Fr. cheval 'horse', pl. chevaux, Eng. horse, pl. horses, Ger. Pferd, pl. Pferde.

$\$ 5$ Since variability is a mere possibility, it is not always exploited, and many constitutive words are invariable. Such is the case with many adverbs: Fr. lentement, Eng. slowly. Such is also the case for adjectives in English: two beautiful books. 
$\$ 6$ In contrast, subsidiary words, since they do not enjoy the autonomy that alone would allow them to agglutinate to other elements, remain invariable in principle, for example Fr. de, Ger. von, Eng. of.

\$7 But if subsidiary words are not capable of agglutinating to other elements in their present state, they were once able to do so at a time when they were autonomous and constitutive. At that time they could be variable, and it can happen that they remain that way even as subsidiary words. The variability of subsidiary words is thus a relic of a past state. Such is the case with the definite article in Fr. le, la, les, or with the personal indices il, elle, ils, elles.

$\$ 8$ The variability of words is thus in close correlation with their structural character, being either constitutive or subsidiary. By contrast, variability is in no way connected to the semantic character of the words, being either full or empty, except of course indirectly in that constitutive words tend to also be full words (Chapter 29, \$15).

$\$ 9$ Full words are often variable, cf. Fr. cheval 'horse', plural chevaux, and empty words invariable, cf. Fr. de 'of'. But the correlation is not obligatory.

$\$ 10$ It is therefore possible to find many full invariable words, Fr. lentement 'slowly', Eng. (two) beautiful (books).

$\$ 11$ Conversely, it is also possible to find empty variable words, for example the empty auxiliary verbs: Fr. être, Ger. sein, Eng. (to) be.

$\$ 12$ It should be noted that the variability of an empty word is not an obstacle to agglutination. Thus in the future Fr. (Je) parlerai 'I will speak', (Tu) parleras 'You will speak', (Il) parlera 'He will speak', the endings - $a i$, - $a s,-a$ are nothing other than the present forms of the verb avoir 'have': (j') $a i,(t u) a s$, (il) $a$. Yet agglutination is complete without them ceasing to be variable.

$\$ 13$ It should also be noted that a full word that appears in its varied form automatically becomes composite because the marker of variation is an empty element that has grammatical value. In languages like Chinese where there are only full words and empty words but no composite words, the full words are by definition always invariable.

\section{Chapter 31. Full words}

$\$ 1$ The full words are, as we have seen (Chapter $28, \$ 2$ ), those words that directly express thought.

\$2 Yet two sorts of ideas can be imagined, particular ideas that represent the objects themselves and general ideas that represent only categories from the framework from which we take particular ideas (Chapter $24, \$ 3$ and 17).

$\$ 3$ Among full words, we distinguish between those that express particular ideas and those that express general ideas. We call the first kind particular full words and the second general full words. 
$\$ 4$ Particular full words simultaneously express particular ideas and general categories that allow these ideas to be captured. They therefore have a strictly semantic content as well as a categorical content. Thus the French word cheval 'horse' simultaneously expresses the idea 'horse' (semantic content) and the category noun (categorical content).

$\$ 5$ General full words, in contrast, express only the general categories that permit them to capture particular ideas, to the exclusion of these very ideas. They hence have categorical content, but no strictly semantic content. Thus the French word quelqu'un 'someone' expresses the noun category, without expressing any particular idea (semantic content).

$\$ 6$ Traditional grammar classifies general full words as indefinite or indeterminate. Thus the French word quelqu'un is generally called an "indefinite pronoun".

$\$ 7$ By way of their indefinite content, general full words often risk being taken for empty words. It is important to guard against this misconception. General full words have many more traits in common with particular full words than with empty words.

$\$ 8$ First of all, general full words can function as the semantic core of a nucleus in the same way as particular full words can. This is the key trait which distinguishes them from empty words.

$\$ 9$ The nature of general full words as semantic centers is evident in the fact that in a nucleus that is not dissociated, they also assume the function of structural centers (Chapter 23, \$6), which indicates that they are both full and constitutive (Chapter 29, \$15).

\$10 Take for example the French sentence Personne n'a rien vu 'Nobody saw anything' (Stemma 38). The two general full words personne and rien are clearly constitutive, since it would be impossible to establish a stemma without acknowledging them as such.

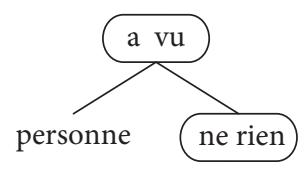

Stemma 38

$\$ 11$ In addition, general full words are similar to particular full words insofar as they survive in telegraph style (Chapter $28, \$ 8$ ). Thus no word can be easily omitted in the French telegram Personne n'a rien acheté 'Nobody bought anything.'

$\$ 12$ The result of this is that particular full words express the real world, whereas general full words express only a virtual semantic copy of particular full words. The French sentence Hier Alfred a oublié son chapeau 'Alfred forgot his hat yesterday' (Stemma 39) expresses a reality. However, the French sentence On oublie toujours quelque chose 'One always forgets something' (Stemma 40) expresses merely a vague generality, which may or may not correspond to reality. 


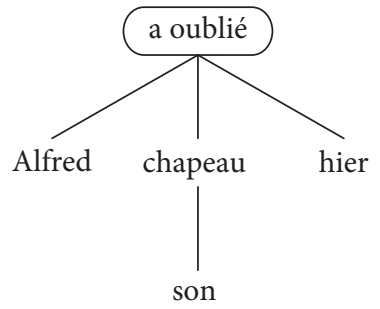

Stemma 39

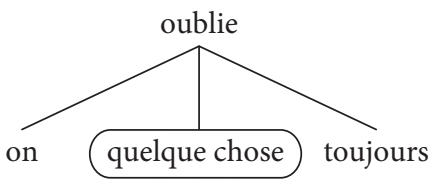

Stemma 40

\section{Chapter 32. Types of full words}

$\$ 1$ We have seen (Chapter 31, 4 and 5) that semantic content appears only in particular full words, whereas categorical content appears in both particular full words and general full words. Categorical content is thus the only content capable of delivering a principle of classification common to all full words, i.e. whether they are particular or general. We therefore classify full words according to their categorical content.

$\$ 2$ A primary division distinguishes between ideas of substance and ideas of process.

$\$ 3$ Substances are the things perceived by the senses and conceived by the mind as endowed with a distinct existence, for example cheval 'horse', table 'table', quelqu'un 'someone'. Full words that express ideas of substance are called nouns.

$\$ 4$ Processes are the states or actions through which substances exist, for example is, sleeps, eats, does, etc. Full words expressing the idea of a process are called verbs.

$\$ 5$ The majority of languages cannot distinguish the notion of process from the notion of substance. They view a process as a substance, and as a consequence, they also view a verb as a noun. Therefore in such languages, he adores is indistinguishable from his adoration, and they adore is indistinguishable from their adoration. In other words, the sentence node is a noun node. The notion of the verb proper seems to exist only in the languages of Europe.

$\$ 6$ The situation is transparent in Hungarian, where the personal indices of the verb are strongly analogous to the possessive suffixes of the noun:

\begin{tabular}{lll}
\hline $\begin{array}{c}\text { Personal indices of the } \\
\text { verb in Hungarian }\end{array}$ & $\begin{array}{c}\text { Possessive suffixes } \\
\text { of the noun in Hungarian }\end{array}$ \\
\hline vár-om 'I await [it]' & kalap-om 'my hat' \\
vár-od 'you await [it]' & kalap-od 'your hat' \\
vár-ja 'he awaits [it]' & kalap-ja 'his hat' \\
\hline
\end{tabular}


$\$ 7$ Likewise in Turkish:

\begin{tabular}{|c|c|c|c|c|}
\hline & \multicolumn{2}{|c|}{$\begin{array}{l}\text { Personal indices of the } \\
\text { verb in Turkish }\end{array}$} & \multicolumn{2}{|c|}{$\begin{array}{l}\text { Possessive suffixes } \\
\text { of the noun in Turkish }\end{array}$} \\
\hline & sever-im & 'I love' & $e v$-im & 'my house' \\
\hline \multirow[t]{3}{*}{ Singular } & sever-sin & 'you love' & $e v$-in & 'your house' \\
\hline & sever & 'he/she/it loves' & $e v-i$ & 'his/her/its house' \\
\hline & sever-iz & 'we love' & $e v$-imiz & 'our house' \\
\hline \multirow[t]{2}{*}{ Plural } & sever-siniz & 'you love' & ev-iniz & 'your house' \\
\hline & sever-ler & 'they love' & ev-leri & 'their house' \\
\hline
\end{tabular}

$\$ 8$ And in Ancient Egyptian:

\begin{tabular}{|c|c|c|c|c|c|}
\hline & & \multicolumn{2}{|c|}{$\begin{array}{l}\text { Personal indices of the } \\
\text { verb in Ancient Egyptian }\end{array}$} & \multicolumn{2}{|c|}{$\begin{array}{l}\text { Possessive suffixes of the } \\
\text { noun in Ancient Egyptian }\end{array}$} \\
\hline & $1 \mathrm{st}$ & $s \underline{d} m-j$ & 'I hear' & $p r-j$ & 'my house' \\
\hline & 2nd masc & $s \underline{d} m-k$ & 'you hear' & $p r-k$ & 'your house' \\
\hline \multirow[t]{4}{*}{ Singular } & 2nd fem. & $s \underline{d m-\underline{t}}$ & 'you hear' & $p r-\underline{t}$ & 'your house' \\
\hline & 3rd masc. & $s \underline{d} m-f$ & 'he hears' & $p r-f$ & 'his house' \\
\hline & 3rd fem. & $s \underline{d m-s}$ & 'she hears' & $p r-s$ & 'her house' \\
\hline & $1 \mathrm{st}$ & $s \underline{d} m-n$ & 'we hear' & $p r-n$ & 'our house' \\
\hline \multirow[t]{2}{*}{ Plural } & 2nd & $s \underline{d} m-\underline{t} n$ & 'you hear' & $p r-\underline{t} n$ & 'your house' \\
\hline & $3 \mathrm{rd}$ & $s \underline{d} m-s n$ & 'they hear' & $p r-s n$ & 'their house' \\
\hline
\end{tabular}

$\$ 9$ Even in Turkish the plural of the verb in the third person is indistinguishable from the noun (without its possessive suffix):

\begin{tabular}{lllll}
\hline & \multicolumn{2}{c}{$\begin{array}{c}\text { Personal indices of the } \\
\text { verb in Turkish }\end{array}$} & Noun in Turkish \\
\hline Singular sever & 'he/she/it loves' & ev & 'house' \\
Plural & sever-ler & 'they love' & ev-ler & 'houses' \\
\hline
\end{tabular}

\$10 A second subdivision distinguishes the concrete notions of substance and process from their abstract attributes; hence there are two new types of full words, one in the domain of substances and the other in the domain of processes.

$\$ 11$ Full words that express the abstract attributes of substances are called adjectives.

$\$ 12$ Full words that express abstract attributes of processes are called adverbs.

$\$ 13$ By nature, the adjective is thus closer to the noun, whereas the adverb is closer to the verb. Therefore the distinction between noun and adjective is elusive in a number 
of languages. The words good, general, new are employed as both nouns and adjectives (Chapter 177, \$12). It would therefore be appropriate to reserve for these words a generic term which covers both noun and adjective.

14., 15., 16., $17 . .^{50}$

\$18 The adverb is to the verb what the adjective is to the noun. The result is that if a noun is transformed into a verb, the adjective must also be transformed into an adverb.

$\$ 19$ Thus a light dinner (Stemma 41) becomes He dines lightly (Stemma 42). Note that in both cases, the stemma has the same form.

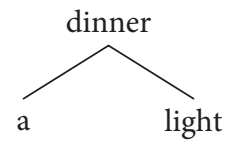

Stemma 41

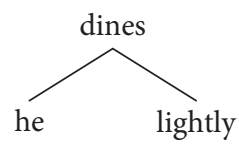

Stemma 42

\$20 The observation taken from this parallelism is a fundamental element of every theory of translation (Chapter 121, \$8).

\$21 The definitive four types of full words are thus noun, adjective, verb, and adverb. ${ }^{51}$ These four elements are the cornerstones of discourse. Their relationships are summarized in the following table, which is the base quadrilateral of full words:

\begin{tabular}{lll}
\hline & Substance & Process \\
\hline Concrete & Noun & Verb \\
Abstract & Adjective & Adverb \\
\hline
\end{tabular}

\section{Chapter 33. Symbols and the virtual sentence}

\$1 It is convenient to represent each type of full word using a symbol that expresses the fundamental nature of the word while avoiding accidental contingencies.

50. Translator's note: Four paragraphs have been suppressed here. Tesnière explains why he chooses the term substantif 'noun' rather than nom 'noun'. He justifies his choice by the fact that he wants to reserve the term nom for the category covering noun and adjective. In the interest of making Tesnière's theory more accessible to a modern audience, we have translated substantif with noun throughout.

51. The author, who has been studying these matters since before 1943 (cf. Cours de Syntax structurale, polycopié, Montpellier, 1943, p. 10), was happy that G. Galichet arrived at the same conclusion in his Essai de grammaire psychologique, 1947, p. 38. 
$\$ 2$ We adopt the following symbolic representations:

\begin{tabular}{ll}
\hline O & Noun \\
A & Adjective \\
I & Verb \\
E & Adverb \\
\hline
\end{tabular}

$\$ 3$ It should be noted that these four letters correspond to the ends of the four corresponding types of words in Esperanto: - $o$ for noun, $-a$ for adjective, $-i$ for infinitive, and $-e$ for adverb.

$\$ 4$ This particularity provides a mnemonic device, Esperanto being more or less a compromise between the different European languages: - $o$ corresponding to the masculine noun of Italian and Spanish and the neuter of Slavic, $-a$ corresponding to the feminine adjective of most Romance and Slavic languages, $-i$ corresponding to the passive infinitive of Latin and to the - $t i$ infinitives in Slavic and - $n i$ infinitives of Hungarian, and -e corresponding to Romance and Slavic adverbs in $-e$.

$\$ 5$ In addition, this system of symbols has the advantage of utilizing the first four vowels of the alphabet, which should be convenient.

$\$ 6$ But it goes without saying that, aside from the purely practical advantage, the adopted system is entirely arbitrary. From a theoretical point of view, any other system would be just as good.

$\$ 7$ If we now replace the types of words with their symbols, the final table of Chapter 32, $\$ 21$ becomes simply:

\section{O I}

A E

$\$ 8$ If, on the other hand, we use the symbols in the stemma instead of the actual words, we obtain a symbolic stemma instead of the word stemma. We give the name real stemma to the latter and the name virtual (or symbolic) stemma to the former.

\$9 Take for example the sentence Your young cousin sings delightfully, which results in the real Stemma 43 and the virtual Stemma 44.

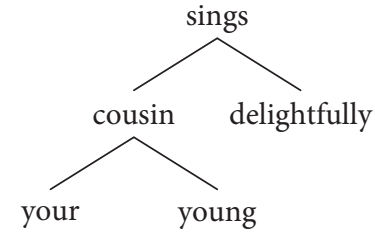

Real stemma

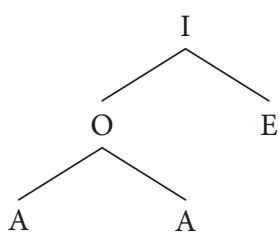

Virtual stemma 
$\$ 10$ The use of these symbols is to grammar what the algebraic method is to calculus. The algebraic method involves representing numbers using letters.

$\$ 11$ The algebraic method permits the generalization of the solutions to problems of quantity by superimposing standard solutions represented by more general formulas onto the infinite multitude of particular solutions. In the same way, the use of symbols will enable generalization of questions of grammar by substituting standard sentences represented by more general formulas in for the infinite multitude of particular sentences.

$\$ 12$ Take for example the sentence This old witch squints terribly; this sentence corresponds to the real Stemma 45 and the virtual Stemma 46:

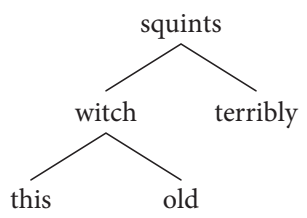

Real stemma

Stemma 45



Virtual stemma

Stemma 46

$\$ 13$ It is easy to see that while the real stemma of this sentence (Stemma 45) is different from the preceding stemma (Stemma 43), the virtual stemma, in contrast, is identical (Stemmas 44 and 46).

$\$ 14$ The preceding example has been chosen intentionally to show that the virtual stemma is not concerned with semantics and retains only structure. Indeed, the two proposed sentences have very different meanings and at the same time they are constructed on the same structural schema.

$\$ 15$ In other words, real stemmas represent real sentences, whereas symbolic stemmas represent virtual sentences.

$\$ 16$ The utility of this practice is that by abstracting away from morphological differences, which are real, the focus turns to typological differences, which are virtual.

$\$ 17$ Thus the English sentence Alfred speaks well (Stemma 48) and the German sentence Alfred spricht gut (Stemma 49), which have the same structure despite the differences in appearance, are represented by the same symbolic stemma (Stemma 47). This stemma is the same as for the Latin sentence Aulus bene loquitur (Stemma 50), which also has the same structure, although the words are organized in a different order in the spoken chain.

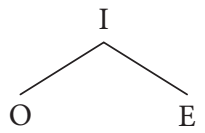

Stemma 47

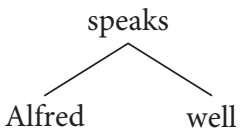

Stemma 48

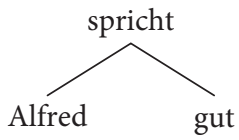

Stemma 49

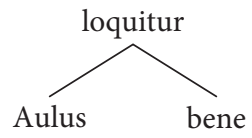

Stemma 50 
$\$ 18$ The symbolic representation of grammatical facts is a way of capturing Humboldt's innere Sprachform 'inner speech form' (Chapter $1, \$ 12$ ), which, in a sense, lies beyond the outer appearance of the sentence.

$\$ 19$ This is the reason why structural syntax is to be associated first and foremost with this method of symbolic representation. It offers the possibility of revealing the deep structural virtuality of sentences behind the multitude of possible realizations.

$\$ 20$ It is immediately possible to envisage the pedagogical applications that are possible with this method. It provides the possibility of freeing the structural types essential to learning from the monotone multitude of particular forms that they can take. The very substance, which is a matter of intelligence, is freed from superficial verbosity, which is a matter of memory alone.

\section{Chapter 34. The noun}

$\$ 1$ Conforming to the definition given above (Chapter $31, \$ 1$ and 2), we distinguish between general nouns (who?, nobody) and particular nouns (horse, Alfred).

$\$ 2$ General nouns are ordinarily designated in traditional grammar with the terms pronoun and indeterminate or indefinite (Chapter $31, \$ 6$ ).

$\$ 3$ We reserve here a precise meaning for the term pronoun: that of an adjective employed in the function of a noun, or, to use the terminology that we propose below (cf. Chapter 152), that of an adjective changed into a noun. Defined in this way, the pronoun is merely one of several particular cases of the very general phenomenon of transfer. Only by studying transfer (Chapter 151ff.) will we be in a position to assign the pronoun an exact position in the economy of the syntactic system.

$\$ 4$ If traditional grammar readily calls general nouns pronouns, it is because the majority of them are simply nominal forms of what are essentially adjectival notions. Moreover, the parallelism between the two types is striking:

\begin{tabular}{lll}
\hline & Pronominal adjectives & Pronominal nouns \\
\hline Interrogative & which & which (one) \\
Demonstrative & this, that & this, that \\
Individual & each & each (one) \\
Indefinite & some & someone \\
Identical & same & the same \\
\hline
\end{tabular}

etc. etc. (Chapter 53, \$3).

$\$ 5$ But there are also pronouns that are true nouns, and it is for these that we reserve the designation general noun. 
$\$ 6$ General nouns are easily recognizable either because they are susceptible to having their own grammatical gender or because there are no adjectives analogous to them.

\$7 Given the first of these characteristics, we can identify the interrogative nouns who? and what?, as well as the negative nouns nobody and nothing. Indeed, who and nobody have a common gender (masculine-feminine), and what? and nothing have inanimate gender (neuter).

$\$ 8$ Given the second of the characteristics mentioned in $\$ 6$, we can identify the personal nouns me, you, him, her, etc... Indeed, no adjective is analogous to them. For this reason, we break from the tradition of calling them personal pronouns (see also Chapter $41, \$ 24$ ). $\$ 9$ As for the terms indeterminate and indefinite (\$2), they have the flaw of applying only to one of the numerous categories of general notions. The tendancy to apply them to all of the categories only occurs because an incapacity to analyze these categories and classify them with even the slightest degree of rigor has led to a vague and imprecise notion of their true nature, for which the designations indeterminate and indefinite are then all too well suited.

$\$ 10$ We hence force ourselves here to reserve the terms indeterminate and indefinite for the words that truly express a vague and indeterminate notion. Such is the case for the indeterminate nouns, e.g. something, someone.

$\$ 11$ As for the detailed analysis of the general categories, it pertains to categorical syntax and not to structural syntax. However, we will examine the general categories in the following pages insofar as doing so is indispensable for good comprehension of the facts of structural syntax.

\$12 Particular nouns can be divided into common nouns and proper nouns according to their extension and intension, ${ }^{52}$ which vary in an inverse manner to each other.

$\$ 13$ Proper nouns have the most limited extension, since they apply to individuals, but at the same time, their intension is vast, since these individuals have an infinite number of qualities, e.g. Alfred.

$\$ 14$ Common nouns have a larger extension, since as their name indicates, they are common to smaller or larger groups of individuals. At the same time, they have an intension that is less vast, since these groups have a lesser number of qualities in common, e.g. horse. $\$ 15$ Common nouns serve in practice to designate or "name" the entities that surround us. They are sometimes called appellatives, which has the drawback that it can also be applied to proper nouns.

52. For the technical meaning of these terms, we refer the reader to manuals of logic. Translator's remark: Tesnière actually uses the less technical term comprehension rather than intension. The extension of a set is defined as the list of elements that have the relevant property, whereas the intension of a set is defined as the property or list of properties that the elements of the set all have. 
$\$ 16$ If we continue to enlarge the extension and to limit the intension of nouns, we depart from the cadre of particular nouns and return to general nouns. General nouns have, by virtue of their generality itself, an extension that is vast, but at the same time their intension is quite limited, since in principle they have but a single quality.

$\$ 17$ Proper nouns, the extension of which is restricted but the intension unlimited, are the opposite of general nouns, the intension of which is restricted but the extension unlimited, whereas common nouns, the extension and the intension of which are intermediate, are situated between the two.

$\$ 18$ Articles, which are empty words serving essentially to indicate the extension of a noun, are ipso facto markers of the noun. They will be qualified as such in the study of empty words (Chapter $41, \$ 21$, cf. also Chapter 177, \$3).

$\$ 19$ The principle varieties of nouns are summarized in the following table:

Nouns $\begin{cases}\text { General } & \begin{cases}\text { Interrogative } & \text { who? } \\ \text { Negative } & \text { nobody } \\ \text { Personal } & \text { me } \\ \text { Indeterminate }\end{cases} \\ \text { Particular } \begin{cases}\text { Common } & \text { someone } \\ \text { Proper } & \text { Alfred }\end{cases} \end{cases}$

\section{Chapter 35. The adjective}

$\$ 1$ As with the nouns, and for the same reason (Chapter $31, \$ 1,2$, and 3 ), we distinguish general adjectives (such, $m y$ ) from specific adjectives (white, old).

$\$ 2$ General adjectives are ordinarily qualified in traditional grammar as indeterminate or indefinite, epithets which have already been discussed (Chapter $34, \$ 9$ and 10).

$\$ 3$ Specific adjectives have a restricted intension, which moreover varies with their semantic complexity. This semantic complexity is minimal in an adjective with simple meaning such as red. It is predictably vaster in an adjective with complex meaning such as vapid.

$\$ 4$ Due to their abstract nature (Chapter $32, \$ 11$ ), on the other hand, adjectives have no extension of their own accord. The idea of white is self-conceived and is independent of its application to a particular concrete case. The absence of extension is what mostly distinguishes the adjective from the noun.

$\$ 5$ But while they have no extension of their own accord, adjectives automatically take on an extension as soon as they determine a noun. In this case, the intension of the adjective is added to that of the noun. The intension of the nominal node is greater than that of the 
noun alone, and the extension of the nominal node, since it varies with an inverse relation, is more restricted than that of the noun. The term red book is applicable to fewer objects than the term book.

$\$ 6$ Since the intension of adjectives is restricted and their extension is null, these two criteria cannot furnish a principle of classification for adjectives as they do for nouns (Chapter 34, \$12).

$\$ 7$ However, we find a principle of classification for adjectives in the very nature of the abstract idea that they express.

$\$ 8$ From this point of view, we distinguish two essential types of adjectives, attributional and relational. ${ }^{53}$

\$9 Attributional adjectives attribute a quality or quantity to the noun that they determine. We therefore divide attributional adjectives into adjectives of quality (red book) and adjectives of quantity (two books).

$\$ 10$ Relational adjectives indicate that the noun that they determine is in a relationship with a person or a temporal or locative circumstance. We therefore divide relational adjectives into personal adjectives ( $m y$ book) and circumstantial adjectives (this book here).

$\$ 11$ Attributional adjectives express archetypical adjectival notions. They are in a sense the most adjectival adjectives.

$\$ 12$ In contrast, relational adjectives indirectly bring into play the idea of the type of word they evoke a relationship with - in addition to the idea of the adjective itself. Thus personal adjectives evoke a nominal idea of person and circumstantial adjectives evoke an adverbial idea of circumstance.

$\$ 13$ All these varieties of adjectives can be classified as either general or particular $(\$ 1-3)$.

$\$ 14$ General adjectives of quality (which?, such, etc.) occur in all the varieties seen above for nouns (Chapter 34, \$4).

$\$ 15$ Specific adjectives of quality are those that traditional grammar ordinarily denotes with the term qualitative adjective. ${ }^{54}$ The main types of specific adjectives of quality are those of quality (good), dimension (big), color ( $r e d)$, and order (or ordinal adjectives (third)).

53. Translators' note: Tesnière used the term adjectif attributif, which cannot be translated with attributive adjective, because attributive adjective translates as adjectif épithète in French. Furthermore, Tesnière used the term adjectif de rapport, literally 'adjective of relationship'. The term adjectif relationnel, which is used in French today, probably came into use later.

54. Translators' note: Tesnière used the term adjectif qualificatif, which is very common in French traditional grammar today and which can also be translated as qualifying adjective. 
$\$ 16$ Adjectives of general quantity (many, Lat. paucus 'few') are quite rare in French, where they are generally replaced by the corresponding adverb-like expression: beaucoup de livres 'many books'; compare: Lat. multi libri, Ger. viele Bücher.

$\$ 17$ Specific adjectives of quantity are those that traditional grammar ordinarily designates as numeral adjectives or cardinal numbers (three books).

$\$ 18$ General personal adjectives indicate a relation with a general personal noun. In this way the general personal adjective my corresponds to the general personal noun me, and the same holds throughout the series.

\begin{tabular}{lll}
\hline & Noun & Adjective \\
\hline 1st singular & I, me & my \\
2nd singular & you & your \\
3rd singular & he, him, she, her, it & his, her, its \\
1st plural & we, us & our \\
2nd plural & you & your \\
3rd plural & they, them & their \\
\hline
\end{tabular}

$\$ 19$ Certain languages, for example Russian, also possess an interrogative personal adjective $\check{c}$ ej 'whose' next to the general interrogative (and relative) noun čto 'what'. This sort of personal adjective is absent from French, and an equivalent form can only be attained by adding the empty word de or à: čej èto dom? lit. 'Whose [is] this house?', (Stemma 51) vs. à qui est cette maison?, lit. 'To whom is this house?' (Stemma 52).

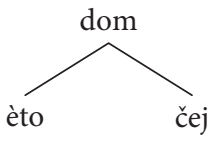

Stemma 51

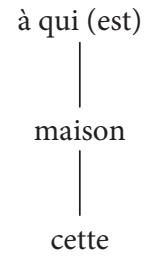

Stemma 52

\$20 Traditional grammar ordinarily denotes the general personal adjective with the term possessive adjective, which does not do justice to the nature of these words because it is too narrow.

$\$ 21$ The possessive adjective does not only express a relation of possession. It is true that we say his dog when talking of the master of the dog. But we also say his master when speaking of the dog, without intending to say that the dog possesses the master. It is a bit too much of a simplification to reduce personal relations to possession alone. 
\$22 Specific personal adjectives are rare in French: cornélien 'cornelian', cartésian 'cartesian'. But they are frequent in a language like Russian, where particular nouns, as with general nouns, have corresponding relational adjectives, which are ordinarily designated as possessive adjectives: Rus. Ivanov dom 'Ivan's house', sestrin dom '[the] sister's house'.

\$23 General circumstantial adjectives indicate a relationship with a general circumstance. These adjectives are rare in French. But they are abundant in German and Russian: Ger. gestrig 'yesterday's', Rus. včerašnij 'yesterday’s', Ger. hiesig 'local', Rus. zdešnij ‘local'.

$\$ 24$ Finally, particular circumstantial adjectives principally indicate a relationship with a particular circumstance. ${ }^{55}$ But since these circumstances are not generally expressed by an adverb but by an adverbial expression, the adjective corresponds not to an adverb, but to a circumstantial expression, the exact nature of which will be explored in the chapter on transfer (Chapter 201, \$4).

$\$ 25$ In this way, the adjective subterranean corresponds to the circumstantial periphrasis below ground. Adjectives of this type are particularly frequent in Russian, where the adjective podmoskoviyj 'in the Moscow area' corresponds to the circumstantial paraphrase nod Moskvoju.

$\$ 26$ The principal varieties of adjectives are summarized in the following table:

\begin{tabular}{|c|c|c|c|}
\hline & & \multicolumn{2}{|c|}{ Adjectives } \\
\hline & & general & specific \\
\hline \multirow[t]{2}{*}{ Attributional } & of quality & such & red (qualitative adj.) \\
\hline & of quantity & many & two (numeral adj.) \\
\hline \multirow[t]{2}{*}{ Relational } & personal & $\begin{array}{l}\text { my } \\
\text { (possessive adjectives) }\end{array}$ & $\begin{array}{l}\text { Rus. Ivanov } \\
\text { (adjectives of affiliation) }\end{array}$ \\
\hline & circumstantial & $\begin{array}{l}\text { this } \\
\text { (demonstrative adjectives) }\end{array}$ & $\begin{array}{l}\text { Ger. morgig } \\
\text { 'tomorrow's' }\end{array}$ \\
\hline
\end{tabular}

\section{Chapter 36. The verb}

$\$ 1$ According to what was said above (Chapter $32, \$ 4)$, verbs express processes.

$\$ 2$ The term process is what A. Meillet employs, using a sufficiently broad name, to denote states and actions.

55. A. Malblanc correctly points to the almost unlimited ability of German to create adjectives as need be (Pour une stylistique comparée du français et de l’allemand, 2nd edition, Paris, §33). Translator's remark: The same is true in English with the derivative -y: hairy, girly, beachy, etc. 
$\$ 3$ We will therefore only explore the term's meaning in relation to the distinction between two essential types of verbs: verbs of state and verbs of action.

$\$ 4$ This distinction appears with particular clarity in certain languages, for example in Basque, where all conjugations come down to two auxiliary verbs, the verb da 'be' for states, and the verb $d u$ 'have' for actions: gizona ona da 'the man is good', gizonari erraiten $d u$ 'he says to the man' ${ }^{56}$

$\$ 5$ Verbs of state are those that express a state, that is, a way of being characterized by a quality or by a position: Ci-gît Biron 'Here lies Biron' (Stemma 53).

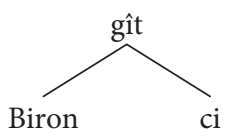

Stemma 53

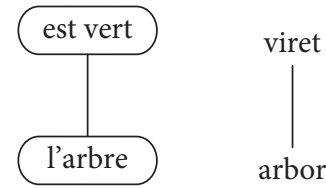

Stemma 54
Stemma 55

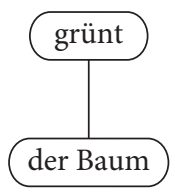

Stemma 56

$\$ 6$ Verbs of state are rare in French, where their position is generally held by dissociated nuclei (Chapter 23, \$1ff.), the structural center of which is the verb être 'be' and the semantic center of which is the adjective (or the adverb) that expresses the quality or the position: L'arbre est vert 'The tree is green', Alfred est debout 'Alfred is standing' (Chapter 23, \$13, and Stemmas 54 and 57).

$\$ 7$ In other languages, simple verbs of state often correspond to these complex nuclei: Lat. Arbor viret 'The tree is turning green', Ger. Der Baum grünt 'The tree is turning green', Lat. Aulus stat 'Alfred is standing', Ger. Alfred steht 'Alfred is standing' (Stemmas 55, 56, 58, and 59).

$\$ 8$ Certain languages like Berber even present a situation that is the exact opposite of French. They do not have adjectives, but rather just verbs of state, and the participle of these verbs functions as an adjective: Tuareg Tamet' tehousi 'The woman is pretty' (Stemma 60 ), tamet tehousit 'a woman (being) pretty' (Stemma 61).

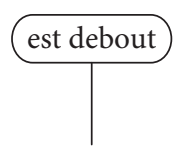

Alfred

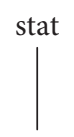

Aulus

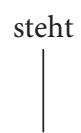

Alfred

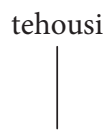

tameț'

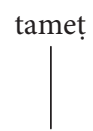

tehousit

Stemma 57

Stemma 58

Stemma 59

Stemma 60

Stemma 61

56. Translator's note: Tesnière is likely oversimplifying the account of verb conjugations in Basque, the use of the two auxiliaries $d a$ and $d u$ not being as clear cut as he claims. 
\$9 The usual practice in our grammar schools, which reserves a privileged position for the verbs be and have, ${ }^{57}$ readily evokes the idea that these two verbs are the two cornerstones of discourse. This idea is inexact. It incorrectly points to what was said above (\$3), namely that the fundamental opposition is not between the idea of the verb be and that of the verb have, but rather between the idea of the verb be and that of the verb do.

S10 As for the verb have, it is a verb of state. It can be defined as the verb be in reverse, to which is added an idea of possession. That is why a number of languages do not have it and render the notion with the verb be: Rus. U menja lošad' 'I have a horse', literally 'By me [is] horse', Latvian Man ir zirgs 'I have a horse', Tuareg Illa r'our i aiis ${ }^{58}$ 'I have a horse', lit. 'A horse is to me', cf. Lat. Est patri meo domus 'My father has a house', lit. 'To my father is house'.

$\$ 11$ Verbs of action are those that express an activity: Alfred hits Bernard, Alfred falls, It is raining.

$\$ 12$ Moreover, a number of verbs of action across languages build on the base verb do/ make/cause (Fr. faire) ${ }^{59}$ This verb is followed by an element that indicates the conducted action: cause a fury, cause a sensation, etc. ${ }^{60}$

$\$ 13$ Therefore the verb faire in French is a verb largely lacking semantic content, and that is why it can serve as a substitute for any other verb: un charmant garcon qui ne fait que sortir du regiment 'a charming fellow who could do nothing other than leave the regiment' (H. Lavedan, Viveurs, act I, p. 76), Si ça continue, je m’en vais te la débarquer comme j'ai fait ce soir de Louise Dubois 'If this keeps up, I will kick her out for you as I did with Louise Dubois' (ibid. Act II, p. 179), (cf. Chapter 43, \$19).

$\$ 14$ The distinction between verbs of state and verbs of action is related to the difference between sensation verbs (the Empfindungsverben 'impression verbs' of German) and verbs of action (the Tatverben 'verbs of action' of German). This distinction must not be confused with that of transitive and intransitive verbs, which we will examine in more detail in the chapter on valency (cf. Chapters 99 and 100).

57. Translator's note: This practice is particularly characteristic of French, where the verbs être 'be' and avoir 'have' are the most irregular verbs with a lot of homophonic forms but varying orthographies (like es '[you] are', est '[it] is', ai '[I] have', ait '[it] have (subjunctive)').

58. [Transcription: Hanoteau, Grammaire de la langue tamachek', 1896, p. 85].

59. When one is dealing with inchoative aspect (cf. Chapter $37, \$ 25$ ), colloquial French readily replaces the base verb faire 'do/make' with the verb piquer 'sting': piquer un laïus 'give a long-winded speech', piquer un roupillon 'have a snooze', piquer une colère 'get angry'.

6o. A. Malblanc remarks quite correctly that in such cases, a group of more concrete verbs in German correspond to the French verb faire: Fr. faire un sacrifice 'make a sacrifice', Ger. ein Opfer bringen 'bring a sacrifice'; Fr. faire merveille 'make wonder', Ger. Wunder wirken 'work wonder'; etc. (cf. Pour une stylistique comparée du français et de l'allemand, Paris, §57). 
\$15 It is true that verbs of state are readily intransitive: Alfred stands; and conversely, verbs of action are readily transitive: Alfred hits Bernard.

$\$ 16$ But the two notions do not overlap, and there are also transitive verbs of state, Alfred has a horse, as well as intransitive verbs of action, Alfred sings.

$\$ 17$ These varying principles associated with verbs are summarized in the following table:

\begin{tabular}{lcc}
\hline & \multicolumn{2}{c}{ Verbs (processes) } \\
\cline { 2 - 3 } & State & Action \\
\hline Intransitive & be, stand & fall \\
Transitive & have & hit \\
\hline
\end{tabular}

\section{Chapter 37. The adverb}

$\$ 1$ As we have seen above (Chapter $32, \$ 12$ ), adverbs express the attributes of processes, that is, the circumstances under which these processes occur.

\$2 These circumstances have the effect of localizing the processes in space and time and marking their relations with other processes.

$\$ 3$ We therefore distinguish between locative adverbs, which are subdivided into locational adverbs and temporal adverbs, and relational adverbs.

$\$ 4$ The opposition between locational and relational adverbs is parallel to the opposition established by philosophers between the world of sensibility and the world of understanding.

$\$ 5$ In each of the three categories of time, place, and relation, four subcategories may be distinguished.

$\$ 6$ In the category of place, the four subcategories correspond to the four questions posed by the Latin adverbs ubi? 'where', quo? 'to where?', unde? 'from where?', and qua? 'by which way?'.

$\$ 7$ Adverbs that indicate where someone is located correspond to the question $u b i$ ? 'where': Ubi es? 'Where are you?' - Hic 'Here'.

$\$ 8$ Adverbs that indicate where someone is going correspond to the Latin question Quo is? 'Where are you going?' - Istuc 'There'.

$\$ 9$ The opposition between the question ubi? 'where' and the question quo? 'to where' is clearly indicated in certain languages: Lat. Ubi es? 'Where are you?' vs. Quo is? 'Where are you going?', Ger. Wo bist du? 'Where are you' vs. Wo gehst du hin? 'Where are you going?'.

$\$ 10$ This opposition is well known to students of Latin, where it is symbolized by the opposition between the syntactic types In urbem ingressus est 'He entered the city' and Ambulat in horto 'He strolls in the garden'. 
\$11 It used to be the custom to express this opposition by saying that in the one case (in urbem ingressus est), there is movement, whereas in the other case (ambulat in horto), there is no movement, or the subject is at rest. Accordingly, beginners were taught that certain Latin prepositions are constructed with the accusative when there is movement and with the ablative when there is no movement.

$\$ 12$ Unfortunately, this manner of formulating the rule in question had a serious weakness; it lacked clarity. The instructor did his utmost to explain that the preposition in takes the accusative in Venit in hortum 'He comes into the garden' because there is movement, and the ablative in Ambulat in horto 'He strolls in the garden' because there is no movement; but this grammatical explanation generally confused young minds, who asked with frustration how it is possible to stroll in a garden without there being movement (Chapter 131, §10).

$\$ 13$ This difficulty with the terminology has been resolved by high school teachers, in particular by teachers of German. Having had the good sense to recognize the inexactitude and absurdity of the traditional terminology, they gave up trying to simply make young students, who are not necessarily entirely lacking in critical analysis, "understand" that it is possible to stroll in a garden without moving. They now advocate that the terms of movement and rest be replaced by those of translocality and intranslocality. These terms are infinitely clearer, and they do not result in the minds of young students being tortured with the discord of two contradictory notions of movement.

$\$ 14$ While Latin (ubi? and quo?) and German (wo? and wohin?) clearly mark the opposition translocal vs. intranslocal, English does not have a specific grammatical marker to distinguish between the two: Where are you?, Where are you going?

$\$ 15$ The adverbs that indicate from the place someone comes from correspond to the question unde? 'from where' in Latin: Unde venis?- Illinc 'From where are you coming From over there'.

\$16 Adverbs that indicate the place by which someone passes correspond to the question qua?: Qua is? - Ea 'Which way are you going? - That way'.

$\$ 17$ In the category of time, the question $u b i$ ? corresponds to the question when?: When did you arrive? - Yesterday.

\$18 The temporal question quo? corresponds to the question until when?: Until when did you sleep? - Until yesterday evening.

$\$ 19$ The temporal question unde? corresponds to the question since when?: Since when have you been sleeping? - Since yesterday evening.

$\$ 20$ The temporal question qua? corresponds to the question how long?: How long did you sleep for? - For a long time.

\$21 In languages where the preceding subcategories are expressed by the verb itself instead of by an adverb, these subcategories are called aspect. This occurs in Russian and in the Slavic languages in general. 
\$22 The aspect corresponding to the question $u b i$ ? is momentary or perfective or aorist aspect, which expresses the time point, which means that the process is situated on a point of the time line: Rus. Ja upal 'I fell'.

\$23 French does not have a procedure available for expressing perfective aspect. This is probably because French, since it normally conceives of all actions as perfective, does not deem it necessary to indicate perfective aspect with a special marker. However, there appears to be a tendency in popular French to indicate perfective aspect with the preverb re-. People often say Rentrez 'Re-enter' (instead of entrez 'enter') to someone invited to enter for the first time: Défense au public de rentrer dans l' atelier 'Public prohibited from entering workshop' (A. Moufflet, Contre le massacre de la langue française 'Against the massacre of French language', I, 1930, p. 17).

$\$ 24$ The aspect corresponding to the question quo? is terminative. Terminative expresses the time line-point, that is, both the duration of a process on the timeline and the point on this line when it stops: Rus. Ja prosnulsja 'I woke up'.

$\$ 25$ The aspect corresponding to the question unde? is inchoative. Inchoative aspect expresses the time point-line, that is, both the point on the timeline when the process began and the duration of the process on the line: Rus. Ja zasnul 'I fell asleep' (Chapter 36, $\$ 12$, note 60 ).

\$26 Finally, the aspect corresponding to the question qua? is imperfective or durative. Imperfective or durative aspect expresses the time-line, that is, the duration of the process on the timeline: Rus. Ja spal 'I slept' (without any limitation on the action, or on its start or end point).

\$27 Aspect is completely absent from French, although a number of French speakers, who are not practiced speakers of a Slavic language like for example Russian and therefore have never used it, do not hesitate to blather about aspect. Therefore certain grammarians assume an imperfective aspect in the French imperfect tense imparfait, which expresses not the duration of the action (cf. Chapter $44, \$ 7$ ), but its habit (cf. Chapter 44, \$13).

$\$ 28$ In fact it is interesting to observe how little French Hellenists sense the value of aspect. In 1847 in the 45th edition of his Méthode pour étudier la langue grecque 'Method for the study of the Greek language', J.-L. Burnouf - who was nevertheless from a generation raised on Greek, quite unlike current generations, and whose works had come to be an authority and who had reached the highest level of academia - did not hesitate to teach (p. 273) with conviction that "the present and the aorist are often interchangeable". From this it can be suspected that he understood the opposition between the present and the aorist not as an opposition of aspect, but as an opposition of tense (conforming to the typology of French).

$\$ 29$ From there we have the following unlikely interlinear translations "by a society of professors and Hellenists” that have poisoned our youth: Gr. Apódos ô katárate, tà porthmeîa, translated to French as $O$ maudit, aie payé le prix du passage, lit. 'O damned, have paid the price of ferrying' (Lucian, Dialog of the Dead, XXII), and a plague of past 
imperative which signify nothing in French, but which clearly show that the translator perceived the aorist of Greek not as perfective aspect, but as past tense.

$\$ 30$ For many modern Hellenists, the notion of perfective aspect is not usual and this gap in their understanding can sometimes be a considerable problem for them when they want to express themselves in Modern Greek, where the notion of aspect from Classic Greek is retained.

$\$ 31$ That is why a former pupil of the School of Athens, today a distinguished Hellenist, told the author that during an excavation, having asked a Greek worker to turn over a newly uncovered stone to see the other face and read the continuation of the inscription written on the first side, he was surprised to see the worker endlessly turn the stone over and over, very intrigued to know what the professor expected to learn from this gyratory movement. It was only then that our Hellenist understood the disadvantage of employing the present imperative (imperfective) where the aorist imperative (perfective) should have been employed.

$\$ 32$ The adverbs déjà 'already' and encore 'still, yet' belong to the category of aspect, but aspect from an affective point of view.

$\$ 33$ From this affective point of view, encore 'still, yet' corresponds to the terminative aspect; it expresses the fact that the process is not yet completed at a point in time when we would have expected it to have been (or when we would have hoped it to have been): Quelle heure est-il? Neuf heures du matin. Le reverend père n' a pas encore assez bu pour être gris 'What time is it? Nine oclock in the morning. The reverend father has not yet drunk enough to be tipsy' (A. About, Le Roi des Montagnes 'The King of the Mountains', V, toward the end).

$\$ 34$ From the same point of view, déjà 'already' corresponds conversely to the inchoative aspect and expresses the fact that the process has already commenced at a point in time when we would not have expected it to, or when we would have hoped it not to: Ils étaient déjà saouls comme des tiques 'They were already as drunk as skunks' (Zola, L' Assommoir, VII).

$\$ 35$ In the category of relation, it seems that adverbs corresponding to the question ubi? 'when, where?' are those that express the very essence of the process, which could be called, using a scholastic term, its quiddity (Chapter $36, \$ 12$ ).

$\$ 36$ Adverbs of quiddity are not present in all languages. They are common in Basque, where they form dissociated nuclei with empty action auxiliaries. These nuclei are analogous to those formed in French by adjectives and auxiliaries of state (cf. Chapter $23, \$ 13$ ): Basque erraiten $d u$ ' (he/she/it) is saying that'.

$\$ 37$ In French, adverbs of quiddity are present first and foremost in child language: faire risette 'to smile', faire coucou ' to wave (to a person)' faire joujou 'to play', faire dodo 'to sleep', and thousands of other expressions (Chapter 36, \$12). In other languages, adverbs of quiddity are confused with infinitives: Eng. I do speak (emphatic), Ger. Die Kinder tun spielen (familiar) 'The kids do play'. 
\$38 Note that in English, it is necessary to say If you want me to do so, and not as in French *If you want me to do it (Si vous voulez que je fasse cela). This demonstrates that the element subordinate to the verb to do is perceived as an adverb of quiddity, and not as a nominal actant. The same adverbial character of the subordinate of to do is found in the common question How do you do?, just as it is in the usual response Very well, which cannot structurally stem from any other sentence than one of the type I do well.

$\$ 39$ Adverbs of relation corresponding to the question quo? 'until when?' are adverbs of purpose or goal, a category to which it is also possible to add adverbs of effect or consequence, e.g. Ger. deswegen 'for that reason', and resultative adverbs (cf. Chapter 130).

$\$ 40$ It is appropriate to take some time to reflect on resultative adverbs, since, while common in languages like German, they are however completely absent from French.

$\$ 41$ In German, the most common type of resultative adverb is what grammarians refer to most inappropriately as separable particles. ${ }^{61}$ These particles are always stressed: Ich schließe die Tür zu 'I am locking the door,' lit. 'I am closing the door (in such a manner that it is) locked', Ich schließe die Tür auf'I am unlocking the door', lit. 'I am closing the door (in such a manner that it is) unlocked' (cf. also Chapter 201, \$10). ${ }^{62}$

$\$ 42$ Resultative adverbs in German are often adverbs of place with translocal meaning (cf. above \$13), Ich gehe hinaus 'I am going outside'.

$\$ 43$ Resultative adverbs in German can be constructed directly with auxiliaries of modality: Ich muss fort 'I have to go', Wo will das hinaus? 'Where is that going?', Lasst ihn herein 'Let him in'.

$\$ 44$ These adverbs can also be constructed with imperative value alone. They can therefore govern adverbial subordinates introduced by the preposition mit 'with' (cf. Chapter 201, $\$ 2$ ), which, in French typology, are semantically equivalent to first actants: Weg mit ihm 'Get him out of here' (cf. also Chapter 116, $\$ 5$ and Chapter 207, \$11).

$\$ 45$ The imperative of the impersonal passive can be expressed in German by the anterior passive participle alone: Aufgepasst! 'Watch out!, Stillgestanden! 'Stand still!' (cf. Chapter 116, \$9).

$\$ 46$ Resultative adverbs often enable a precision of expression in German that can give a French speaker the impression of repetition: ${ }^{63}$ nachäffen 'to ape', lit. 'ape after'.

61. Cf. A. Malblanc, Pour une stylistique comparée du français et de l'allemand, Paris, 1963, \$58-60.

62. Translator' note: Tesnière, who was a Germanist, uses German examples. But of course this is also very common in other Germanic languages, including English. See for instance to turn the light on vs. to turn the light off. But such particles are absent from French and are expressed instead by plain verbs: entrer 'go in', sortir 'go out', traverser 'go across', monter 'go up', descendre 'go down', etc.

63. Cf. Malblanc, Pour une stylistique comparée du français et de l’allemand, \$59. 
$\$ 47$ Finally the predicative adjective of German often has a resultative value (cf. Chapter 205, \$22): freilassen 'to liberate', lit. 'to let free', totschlagen 'to kill', lit. 'strike dead', Alfred tropfte die Kerzen fest 'Alfred melted the candles firm', sich krank lachen 'to laugh oneself sick', sich müde gehen 'to walk oneself tired', sich dick fressen 'to eat oneself fat'.

\$48 Adverbs of relation corresponding to the question unde? 'from where?' are causal adverbs (Ger. deshalb 'for this reason', Lat. ideo 'for this reason'). Adverbs of concession and condition must be added to this category (Fr. sinon 'otherwise').

$\$ 49$ Finally, adverbs of relation corresponding to the question qua? 'how long?' are adverbs of manner (Fr. gentiment 'kindly'). Adverbs of comparison and quantity must be added to this category.

$\$ 50$ The only relational adverbs that are really frequent are manner adverbs. The other types are rare. Most often, relational adverbs are represented by adverbial locutions or by circumstantial clauses, to which we will return in our study of transfer (cf. Chapter 254ff., in particular Chapter 264). These expressions can be considered adverbs the elements of which have completely retained their autonomy.

\$51 Conversely, it can occur that authentic adverbs lose their autonomy in time and agglutinate to the verbs upon which they depend. Such is the case with preverbs: Gr. meta-gráfō 'I change the text/I transcribe', Lat. $\operatorname{tran}(s)$-scribo, Rus. pere-pisyvaju 'I rewrite/I transcribe'.

$\$ 52$ The principle varieties of adverbs are summarized in the following table:

\begin{tabular}{|c|c|c|c|c|c|}
\hline & \multicolumn{5}{|c|}{ Adverbs (circumstances) } \\
\hline & & \multicolumn{3}{|c|}{ Locality (sensitivity) } & \multirow[t]{3}{*}{ Relation (understanding } \\
\hline & & Space & & Time & \\
\hline & & & & Aspect & \\
\hline Point & - & ubi? & when? & $\begin{array}{l}\text { momentary perfective } \\
\text { aorist } \\
\text { Rus. Ja upal 'I fell' }\end{array}$ & $\begin{array}{l}\text { essence, quiddity: } \\
\text { Basque erraiten 'saying, } \\
\text { Fr. dodo 'sleep' }\end{array}$ \\
\hline Line-Point & $-\bullet$ & quo? & until when? & $\begin{array}{l}\text { terminative } \\
\text { Rus. Ja prosnulsja } \\
\text { 'I got up' }\end{array}$ & $\begin{array}{l}\text { goal or end: } \\
\text { Ger. deswegen 'therefore' } \\
\text { effect or consequence }\end{array}$ \\
\hline Point-Line & $\cdot-$ & unde? & from when? & $\begin{array}{l}\text { inchoative } \\
\text { Rus. Ja zasnul } \\
\text { 'I fell asleep' }\end{array}$ & $\begin{array}{l}\text { cause: Lat. ideo } \\
\text { concession } \\
\text { condition: Fr. sinon } \\
\text { 'otherwise' }\end{array}$ \\
\hline Line & - & qua? & how long? & $\begin{array}{l}\text { durative imperfective } \\
\text { Rus. Ja spal 'I slept' }\end{array}$ & $\begin{array}{l}\text { manner: kindly } \\
\text { comparison } \\
\text { quantity }\end{array}$ \\
\hline
\end{tabular}




\section{Chapter 38. Empty words}

$\$ 1$ We have seen that empty words are grammatical tools (Chapter $28, \$ 3$ ) and that as such, they pertain to functional syntax (Chapter $28, \$ 15$ ). We therefore classify them according to the nature of the function that is reserved for them.

$\$ 2$ The functions assured by empty words are of two types. They serve to diversify the structure of the sentence by affecting economy, the first type in terms of quantity and the second in terms of quality.

$\$ 3$ The function that affects the quantitative economy of the sentence is the junctive function, which enables the infinite augmentation of its terms by adding to a given nucleus a theoretically unlimited number of like nuclei.

$\$ 4$ We give the name junctive to the morphological markers of conjunction.

$\$ 5$ Junctives therefore serve to join together full words or the nodes that they form. In the sentence Humans fear poverty and death, the junctive and unites the full word poverty with the full word death to form a single group (Stemmas 62 and 63).

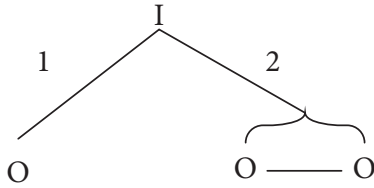

Stemma 62

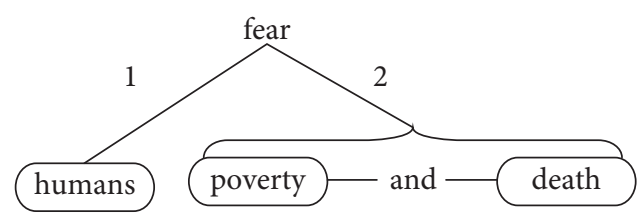

Stemma 63

$\$ 6$ The function that affects the qualitative economy of the sentence is the translative function, which enables the infinite differentiation between the terms of a sentence by transforming every nucleus into a theoretically unlimited variety of nuclei of different natures (i.e. of different categories).

$\$ 7$ We give the name translative to morphological markers of transfer (cf. Chapter 151, \$5).

$\$ 8$ Translatives have the function to transfer the category of full words. Thus in the nominal node le bleu de Prusse, lit. 'the blue of Prussia', le is a translative that transfers the adjective bleu to a noun, and de is a translative that transfers the noun Prusse to an adjective, the group de Prusse acting as an adjective (Stemmas 64 and 65).
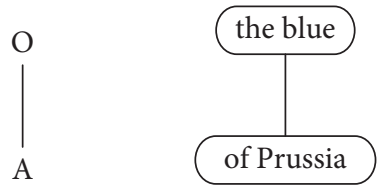
\$9 It makes sense to bring together translatives and indices, the latter being a mere variety of translative and whose characteristics will be studied below (Chapter 41 and 59).

$\$ 10$ The result of this is that there are two essential types of empty words: junctives and translatives.

$\$ 11$ Just as we have adopted capital letters as symbols for full words (cf. Chapter 33 , \$2), we adopt lowercase letters as the symbols for empty words.

\begin{tabular}{ll}
\hline $\mathbf{j}$ & junctive \\
$\mathrm{t}$ & translative \\
\hline
\end{tabular}

$\$ 12$ Most often, empty words are also subsidiary, and vice versa (Chapter $29, \$ 15)$. Thus in the examples above, the junctive $e t$ and the translatives $l e$ and $d e$ are empty because they have no semantic content and subsidiary because they cannot form a node on their own.

$\$ 13$ But it can occur that an empty word is constitutive (Chapter $29, \$ 16$ ). This is the case with auxiliary verbs, which are both empty because they have no semantic content and constitutive because they form a node on their own.

$\$ 14$ Empty words are, as we have seen (Chapter 29, \$17), former full words that have been emptied of their meaning and have become essentially grammatical tools. In other words, they are words that have lost their former concrete meaning and acquired a purely abstract value.

$\$ 15$ Via their abstract nature, empty words are less distant from abstract full words such as adjectives and adverbs than they are from concrete full words such as nouns and verbs (Chapter 32, \$10-12).

$\$ 16$ On the historical plane, empty words are almost always former adjectives or adverbs: Lat. illam 'that' > Fr. la 'the'; Lat. supra 'above' (adverb) > Lat. supra (preposition) > Fr. sur 'on'.

$\$ 17$ But abstract full words, whose affinity with empty words we have just seen (\$15), can be former nouns, in particular the nouns that, thanks to their restricted extension, are closest to adjectives: Lat. homo 'man' > Fr. on 'one' (general personal noun).

\$18 This changeover from concrete to abstract necessarily being the result of a long shift, empty words are definitely the most evolved and are therefore the most humanized and interesting of language.

\section{Chapter 39. Junctives}

$\$ 1$ Junctives are, as we have seen (Chapter $38, \$ 5$ ), empty words the function of which is to unite full words or the nuclei that they form.

\$2 Junctives are therefore in a sense the mortar that binds together nuclei of the same nature (Chapter 29, §9). 
$\$ 3$ The result of this is that, like mortar between bricks, junctives are structurally situated between nuclei but remain outside these nuclei. We say that they are internuclear (Chapter 136, \$7). In addition, we will see that junctives are placed accordingly in the stemmas (Stemmas 63 and 249).

$\$ 4$ The junctive function has been recognized by traditional grammar under the name coordinate conjunction.

$\$ 5$ It is important not to confuse junction with junctive. Junction is a structural phenomenon, whereas a junctive is merely its morphological marker.

$\$ 6$ Since the junctive is a marker of junction, there can be no junctive without junction. Indeed, there would be no reason to morphologically mark a non-existent phenomenon.

$\$ 7$ In contrast, it is possible to have junction without a junctive, that is, the junctive function can appear without the need for a marker: Lat. Veni, vidi, vici 'I came, I saw, I conquered'.

$\$ 8$ Thus the concept of junction is vaster than that of junctive.

$\$ 9$ The study of junctives is therefore inseparable from that of junction, to which we will return for more details. We will examine the classification of the different types of junction, and as a consequence, of junctives as well (cf. Chapter 138ff.).

\section{Chapter 40. Translatives}

$\$ 1$ Translatives are, as we have seen (Chapter $38, \$ 8$ ), empty words the function of which is to transform the category of full words.

$\$ 2$ The result of this is that translatives act directly on full words and as a consequence, on the interior of the nuclei that these words form. We will therefore say that in comparison with junctives, which are internuclear (Chapter 39, \$3), translatives are intranuclear (cf. Chapter 157, \$7). Moreover, we will see that they are placed accordingly in the stemma (Stemma 65 and Chapter 157, \$10).

$\$ 3$ Traditional grammar does not acknowledge the translative function. It only distinguishes between coordinate and subordinate conjunctions.

$\$ 4$ It is not just subordinate conjunctions that should be counted as translatives, but also relative pronouns, prepositions, articles, and auxiliary verbs of traditional grammar, not forgetting empty preverbs and grammatical endings, which are merely agglutinated translatives.

$\$ 5$ It is important not to confuse the notion of transfer with the notion of translative. Transfer is a syntactic phenomenon, whereas a translative is merely a morphological marker (Chapter 39, \$5).

$\$ 6$ Since a translative is a marker of transfer, a translative cannot exist without transfer. Indeed, there would be no reason to mark a non-existing phenomenon morphologically. 
\$7 In contrast, transfer can occur without a translative, that is, transfer can occur without the need for a marker. For instance in the French Tour Eiffel, the word Eiffel, which in reality is a proper noun, is transferred to a relative personal adjective without any morphological marker indicating transfer (Chapter 39, \$7).

$\$ 8$ Thus the notion of transfer is vaster than that of the translative (Chapter $39, \$ 8$ ).

$\$ 9$ The study of translatives is hence inseparable from that of transfer, to which we will return for more details (Chapter 39, \$9). We will consider the different types of transfer and as a result, of translatives as well (Chapter 176).

\section{Chapter 41. Indices}

\$1 It is important to separate indices from translatives, since, while closely similar to translatives, indices do not completely overlap with them.

$\$ 2$ Indices are markers of the indicative function.

$\$ 3$ In contrast to translatives, which transform categories of full words, indices are content to indicate categories without needing to transform them.

$\$ 4$ Take for example the phrase le livre d'Alfred (Stemma 32). The empty word $d^{\prime}$ is a translative, since it transforms the noun Alfred into the group d'Alfred, which has the value of an adjective, whereas the empty word $l e$ is an index, since the word book is already a noun on its own. The article $l e$ is content to indicate the character of a noun without transforming it. \$5 The difference between indices and translatives resides therefore less in the outcome of their nature than in its starting point.

$\$ 6$ In both cases, the outcome, i.e. the category that is reached, is the same. From this point of view, the indicative function overlaps with the translative function.

$\$ 7$ But the starting point is much different in the two cases.

$\$ 8$ In the case of transfer, the initial category, that is the full word's category before transfer, is clearly defined and quite distinct from the category after transfer.

$\$ 9$ Thus in the example above, the word Alfred is clearly a noun before the addition of the translative de turns it into the syntactic equivalent of an adjective.

$\$ 10$ In contrast, in the case of simple indication, either 1) the initial category is not clearly marked or 2) it does not differ from the target category.

$\$ 11$ In the first case, there are many words in English that do not pertain to a specific category in isolation but that are susceptible to becoming either nouns or verbs according to whether they are preceded by the article the or a personal index: the love, I love. ${ }^{64}$

64. Translator's note: Note that Tesnière views the personal pronoun $I$ here as an index, contrary to what one might assume based on the behavior of personal pronouns in English. 
$\$ 12$ We saw the second case in the example in $\$ 4$ above, in which the word book pertains to the noun category before the addition of the index the.

$\$ 13$ Moreover, it is very difficult to draw a clear distinction between translatives and indices. They are essentially two varieties of one and the same type of word. The character of the word is sometimes that of a translative and sometimes that of an index, depending much more on the circumstances of their use than on their inherent nature.

$\$ 14$ Take for example the article the, which evidently plays the role of a translative when it transforms an adjective into a noun, cf. the blue. It merely has a uniquely indexical role when it introduces a word that is a noun in its own right, cf. the book.

$\$ 15$ Take for example the French verb (nous) aim-ons 'we love'. We can consider the final -ons a translative or an index depending on the point of view we take.

$\$ 16$ If we acknowledge that the form (nous) aim-ons is constructed on the primitive form (j) $\operatorname{aim}(e)$ 'I love', we must attribute translative value to the final -ons, since it transforms the first person singular into the first person plural.

$\$ 17$ If, on the contrary, we assume that the form (nous) aim-ons is constructed on the stem aim- (that we find in the forms aim-ais, aim-ai, aim-er, aim-ant, etc.), we must attribute the value of index to the final-ons, since the theme aim-alone expresses neither the category of the first person singular nor that of the first person plural.

\$18 The point of view will differ from one verb to the next according to morphological contingencies. In this way, the final -ons can be seen as having the role of a translative in the case of the verb aimer, where next to the form (nous) aim-ons 'we love', there exists the form (il) aim-(e) 'he loves. The same is not true for the verb aller, where next to the form (nous) allons 'we go', we do not find the form ${ }^{*}(j$ ') alle 'I go', but rather the form (je) vais.

$\$ 19$ The result of this is that the distinction between translative and index is elusive. The passage from one to the other is imperceptible. It is in reality a case of two varieties of word that are extremely closely related. Furthermore, rigorously distinguishing between the two is not hugely important for structural syntax.

\$20 The principle types of indices are, in addition to the various inflectional endings, the article and the personal index.

$\$ 21$ The article functions to indicate the extension of the noun (Chapter 34, \$18). It is therefore the archetypal nominal index: the book.

$\$ 22$ The personal index functions to indicate the person and number in the verb: Fr. $j$ ' aime, tu aimes, il aime 'I/you/he loves'.

$\$ 23$ The personal index is thus the exact syntactic equivalent of the personal endings in a language such as Latin: Fr. j' aime, tu aimes, il aime; ${ }^{65}$ Lat. am-o, am-as, am-at ' $\mathrm{I} / \mathrm{you} / \mathrm{he}$

65. Translator's note: Even if the orthography of $(t u)$ aimes is different from that of $(i l)$ aime, both forms are homophonic and can only be differentiated by the personal index $t u$ vs. $i l$. 
loves. The only difference is that the index is postposed and agglutinated in Latin, whereas it is preposed and autonomous in French (at least in orthography). Forms such as nous aimons 'we love', vous aimez 'you love' bear witness to a former state where French conserved traces of Latin endings.

$\$ 24$ It is therefore necessary to establish a rigorous distinction between the personal indices je, $t u$, il 'I, you, he' and the personal nouns, moi, toi, lui 'me, you, him'. As a consequence, we should refrain from confusing them, as traditional grammar does, under the term personal pronouns (Chapter 34, \$8).

\$25 The personal index is the archetypal verbal index. Indeed, we will see (Chapter 178ff.) that the only truly verbal forms are the personal forms and that the infinitive form, which unfortunately has come to be associated with the verb in most languages, is not a true verbal form.

\section{Chapter 42. Anaphoric connection}

\$1 The anaphoric connection is a supplementary semantic connection, which has no corresponding structural connection.

$\$ 2$ Take for example the sentence Alfred loves his father (Stemma 66); the word his is semantically connected not only to the word father, which it depends on structurally, but also to the word Alfred, of which it is entirely structurally independent.

$\$ 3$ In accordance with what we have said above (Chapters $21, \$ 12-14$ ), we will represent the anaphoric connections graphically in the stemma by a dashed line (Stemma 66), which we call an anaphor line.

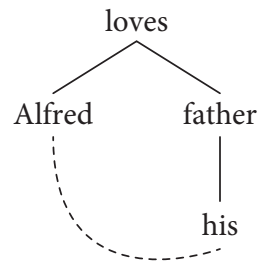

Stemma 66

$\$ 4$ Every anaphoric connection implies two semantic connections, the first doubles the main structural connection and the second is the supplementary semantic connection that constitutes the anaphora.

$\$ 5$ These two connections are not of the same nature.

$\$ 6$ A semantic connection that duplicates a structural connection expresses a relationship of determination. 
\$7 Thus in the example above, the word his expresses that the idea of father is determined by that of Alfred. We are dealing with Alfred's father, and nobody else's.

$\$ 8$ The anaphoric connection, in contrast, expresses an identity and thus constitutes a veritable semantic referral; this is incidentally the etymological meaning of the Greek word anaphora 'reference, referral'.

$\$ 9$ Thus in the example above, the word his expresses the idea of Alfred, to which it refers, since his $=$ he's and he $=$ Alfred .

$\$ 10$ Anaphors are thus empty words in the dictionary, where they are listed separately from any actual anaphoric connection. But they become full words as soon as they appear in a sentence in an anaphoric relation with another word, since the other word supplies it with its meaning.

$\$ 11$ Therefore he does not designate a particular person in the dictionary. ${ }^{66}$ But in the sentence I saw Alfred; he is doing well, it is evident that he designates Alfred, and in the sentence I saw Bernard; he is doing well, the same he now designates Bernard.

$\$ 12$ The anaphoric mechanism is clearly illustrated by the following example:

Salomon: Je me suis dit: Si je montais

la voir, je ne la vois pas assez.

Alice: La, c'est moi?

Salomon: La, c'est vous!
'Salomon: I said to myself: What if I were to go see her? I don't see her enough.

Alice: By her, do you mean me?

Salomon: 'By her, I mean you!'

(Henri Lavedan, Viveurs, III, p. 214)

The last two replies clearly show that what is in question is the anaphoric meaning of $l a$ 'her' (= moi 'me' for Alice, vous 'you' for Salomon = Alice).

$\$ 13$ The full word that appears at the upper end of the anaphoric connection is the one that conveys its semantic value to the empty word situated at the lower end of the connection. This upper word plays an important role in the meaning of the sentence. It is therefore necessary, to avoid any ambiguity, to designate it with a clear and precise term. The term that immediately comes to mind is that of antecedent, which in traditional grammar already designates the full word to which a relative pronoun (cf. Chapter $246, \$ 4-6$ ) is connected anaphorically.

$\$ 14$ Unfortunately, this term has the disadvantage of designating the word in question not according to its nature, which is not even sought out, but according to its position, which

66. Cf. E. Benvéniste: "he" per se designates nothing and nobody specifically (Structure des relations de personnes dans le verbe 'Structure of person relations in the verb', Bulletin de la Société de Linguistique de Paris, 43, 1947, p. 7). 
is subject to all the variation that the linearity of the spoken chain imposes on it. In fact, if the antecedent indeed always precedes the relative pronoun on the spoken chain, the same is not necessarily the case when the lower term on the anaphoric connection is not a relative pronoun. This situation obtains in the following case:

Le bonheur de la femme qu'il aime, quand ce bonheur lui vient d'un rival, est une torture pour un jaloux
'The happiness of the woman he loves, when this happiness comes to her from a rival, is torture for the jealous man'

(A. Dumas, Le vicomte de Bragelonne, Visite domiciliaire, éd. Marescq, Paris, 1853, p. 362)

In this sentence, the anaphor $i l$ 'he' is positioned in front of its antecedent un jaloux 'a jealous man'. This observation suffices to show the absurdity of using a morphological appellation to designate a syntactic reality. Furthermore, for want of a better term, we adopt the term semantic source, which, while lacking other qualities, has the ability to more or less say what it means.

\$15 Anaphoric connections are not limited by clausal or sentential boundaries. They often spill over. Furthermore, an anaphora can effectively establish a semantic connection between two sentences that are not joined by a syntactic connection. The anaphora therefore links a subsequent sentence and a preceding sentence: I saw Alfred; he was doing well (cf. \$11). It is evident that the anaphor he, which is the subject of the second sentence, establishes a semantic connection with Alfred, which is the object of the first sentence.

$\$ 16$ This situation is illustrated with the following passage of the famous poem La cigale et la fourmi 'The cicada and the ant':

\begin{tabular}{ll}
\hline La cigale, ayant chanté & 'The cicada, having sung \\
Tout l'été, & All summer long, \\
Se trouva fort dépourvue & Found herself sorely deprived \\
Quand la bise fut venue: & When the North wind arrived: \\
Pas un seul petit morceau & Not a single morsel \\
De mouche ou de vermisseau. & Of fly or tiny worm \\
Elle alla crier famine & She went to plead famine \\
Chez la fourmi sa voisine, & At the house of the ant her neighbor \\
La priant de lui prêter & Beseeching her to lend to her \\
Quelques grains pour subsister & Some grain to survive \\
Jusqu'à la saison nouvelle. & Until the new season'.
\end{tabular}

(La Fontaine, Fables, I, 1)

The anaphor elle 'she' in the second sentence evidently refers to la cigale 'the cicada' (cf. Stemma 354) of the first sentence, although structurally, the two sentences are completely independent (cf. Chapter 272, \$15).

$\$ 17$ Often, the semantic source of an anaphoric connection is not explicitly expressed. In such a case, we are dealing with a vague anaphoric connection, a sort of riddle to which 
only those who know the language well have the key. It is often only by hypothesis that it is possible to identify the word the anaphor refers to in the mind of the speaker:

\begin{tabular}{|c|c|}
\hline $\begin{array}{l}\text { French la } \\
\text { 'it' }\end{array}$ & $\begin{array}{l}\text { la comprendre 'to understand it' (existence), se la couler douce 'to take } \\
\text { it (existence) easy', la connaître dans les coins 'to know the ropes' lit. 'to } \\
\text { know it in the corners' (the way of managing), l'échapper belle 'to have a } \\
\text { lucky escape' lit. 'escape it beautiful', Il se la pète 'He thinks he's God's gift', } \\
\text { lit. 'He busts it.' }\end{array}$ \\
\hline $\begin{array}{l}\text { French en } \\
\text { 'of it' }\end{array}$ & $\begin{array}{l}\text { ne pas s'en faire 'not to worry' < se faire de la bile 'to produce bile', en } \\
\text { découdre 'to fight', en venir aux mains 'to come to blows', s'en aller 'to leave', } \\
\text { en avoir assez 'to be fed up', en griller une 'to light up' (cigarette), Vous en } \\
\text { êtes? 'Are you taking part?', en pincer pour quelqu'un 'to have a crush on } \\
\text { someone. }\end{array}$ \\
\hline $\begin{array}{l}\text { French } y \\
\text { 'there' }\end{array}$ & $\begin{array}{l}\text { Tu n'y couperas pas 'You won't get out of it', Nous avons joué à cache-cache. } \\
\text { C'est Mlle Hurtrot qui y était... 'We played hide-and-seek. It was Ms. } \\
\text { Hurtrot who was it (the seeker)' (H. de Régnier, Les vacances d'un jeune } \\
\text { homme sage 'The holidays of a wise young man', VI). }\end{array}$ \\
\hline $\begin{array}{l}\text { German es } \\
\text { 'it' }\end{array}$ & $\begin{array}{l}\text { Er hat es leicht 'He has it easy', Ich habe es nicht böse gemeint 'I didn't mean } \\
\text { it maliciously', Ich habe es gut warm 'I have it nicely warm', Ich halte es mit } \\
\text { ihm 'I can keep up with him', Er treibt es zu bunt 'He goes too far', etc. } \\
\text { (A. Malblanc, Pour une stylistique comparée du français et de l'allemand, } \\
\text { 1st edition, 1944, pp. 62-63). }\end{array}$ \\
\hline
\end{tabular}

$\$ 18$ Thus it was on the island Maurice in 1816 that lui 'him' signified Napoleon (then prisoner on Saint Helena) for the Mauritians, who, after the English had taken the island in 1910, feared mentioning him by name. On buvait à "lui”" 'One toasted to "him"' (Las Cases, Mémorial de Sainte-Hélène, V).

$\$ 19$ In popular speech - the type of speech most regularly associated with lewd notions the unexpressed semantic source leaves room for the most unseemly and bawdy interpretations. In this case, the anaphoric connection is deliberately vague.

\begin{tabular}{ll}
$\begin{array}{l}\text { French le } \\
\text { 'it' }\end{array}$ & $\begin{array}{l}\text { L'être ou ne pas l'être (cocu) 'To be or not to be (a cuckold)', parody of } \\
\text { the famous verse of Shakespeare's Hamlet To be or not to be, that is the } \\
\text { question. }\end{array}$ \\
$\begin{array}{l}\text { French en } \\
\text { 'of it' }\end{array}$ & $\begin{array}{l}\text { French title of the translation of the English novel by Hemingway To } \\
\text { have or to have not. }\end{array}$ \\
\hline
\end{tabular}

\$20 It is sometimes a delicate matter to say something concrete about anaphoric meaning when the word to which the anaphor refers is not evident. Such is the case in the refrain of the hymne of Victor Hugo: 
Gloire à notre France éternelle! Gloire à ceux qui sont morts pour elle! Aux martyrs! Aux vaillants! Aux forts! A ceux qu' enflamme leur exemple, Qui veulent place dans le temple Et qui mourront comme ils sont morts
Glory to our eternal France!

Glory to those who have died for her!

To the martyrs, the valiant! To the strong!

To those whom their example inflames

Who want a place in the temple

And who will die as they have died

(Chants du crepuscule 'Songs of the twilight', III)

One must take some time for reflection to understand that ils 'they' in the last verse refers to ceux qui sont morts pour elle 'those who have died for her', les martyrs, les vaillants, et les forts 'the martyrs, the valiant, and the strong', to which the anaphoric connection refers back from leur of leur exemple 'their example', and not to ceux qu' enflamme leur exemple 'those whom their example inflames', to which the anaphor qui 'who' of the last two verses refers.

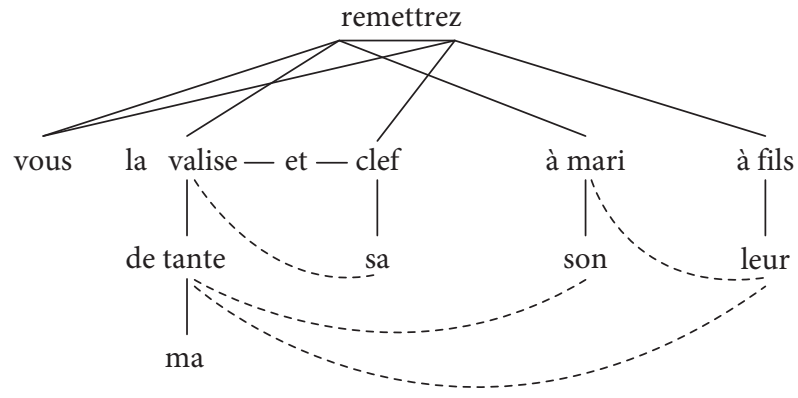

Stemma 67

\$21 Sentences can contain numerous anaphora, and when they do, they are susceptible to confusion. Such is frequently the case when the anaphor is a possessive adjective: Vous remettrez la valise de ma tante à son mari et sa clef à leur fils 'You will return my aunt's suitcase to her husband and her/his/its key to their son' (cf. Stemma 67).

\$22 This is a source of obscurity condemned by French clarity. But of course if the anaphora being criticized from this point of view is the work of a great writer, it is immediately labeled an anacoluthon and its aesthetic value marveled at:

Indomptable taureau, dragon impétueux,

Sa croupe se recourbe en replis tortueux.
'Untamable bull, impetuous dragon,
Its tail curves up in tortuous folds.

(Racine, Phèdre,V-6; cf. also Chapter 252, §5)

Olivier... contemplait le désert de sa vie... Où était l'ardeur de son noviciat, sorti de Saint-Cyr et entrant dans l'armée?
'Olivier...contemplated the emptiness of his life...Where was the ardor of his novitiate, having departed from Saint-Cyr and joining the army?'

(Paul Marguerite, Les Fabrécé, Part One, V) 
\$23 Here it would be appropriate to classify the extensive collection of clumsy and ridiculous anaphora, for example, the following, taken from a notice to passengers in a French train station in 1941: MM. les voyageurs sont priés d'écrire sur leurs colis leur adresse et leur destination 'Passengers are advised to write their address and destination on their packages' - The destination of the packages or of the passengers? (cf. also Chapter 252, \$9).

$\$ 24$ It can be seen from the preceding point that the use of the third person in the visiting card of Mr. and Mrs. Smith addressed to Mr. and Mrs. Wesson becomes a real brainteaser:

Mr. and Mrs. Smith send their best wishes to Mr. and Mrs. Wesson and extend to them their thanks for their lovely invitation, which they are happy to accept. They (?) hope they (?) are doing well ...

This is why sensible people avoid the third person in such a case and get around the difficulty by appealing to the first or second person as quickly as possible: We hope you are doing well, etc.

\$25 The anaphoric connection is a phenomenon that has the effect of adapting the quite rigid hierarchical schema of the structural sentence - in which every subordinate ultimately depends either directly or indirectly on a sole and unique governor - to the necessity of the expression of thought, which presents an infinitely more flexible network of infinitely more varied connections.

\section{Chapter 43. Anaphors}

$\$ 1$ We call a word an anaphor (pl. anaphors) if it appears at the end of both semantic connections of an instance of anaphora. Therefore in the example from the preceding chapter (Chapter 42, \$2), the word his is an anaphor.

$\$ 2$ Anaphoric phenomena appear only in organized sentences; anaphors by themselves have no meaning, i.e. when they are not included in a sentence.

$\$ 3$ In other words, anaphors are empty words on the static plane, but they automatically become full words on the dynamic plane.

$\$ 4$ Thus the anaphor his does not designate a person on its own, and it is only in a sentence like Alfred adores his father that his takes on the meaning Alfred's.

$\$ 5$ Anaphors are thus empty words that are only realized in sentences as full words. They are virtual full words.

$\$ 6$ Anaphors can be compared insightfully to electric lights that only light up when the filament thread is in contact with a source of electricity. A sort of semantic electricity is taken up. In this regard, anaphors can be said to be power point words.

$\$ 7$ Anaphors are classed quite naturally according to the full words they are semantically identified with. 
$\$ 8$ We thus distinguish between the following types of anaphors: nouns, adjectives, verbs, and adverbs.

$\$ 9$ Anaphoric nouns are demonstrative pronouns, 3rd person personal nouns (called personal pronouns), personal pronouns of relation (called possessive pronouns) and circumstantial pronouns of relation (called demonstrative pronouns), and relative pronouns.

$\$ 10$ Possessive pronouns: On voit les maux d' autrui d' un autre ceil que les siens 'One sees the faults of others differently from one's own' (Corneille); Which dress do you prefer, hers or mine?

$\$ 11$ Demonstrative pronouns: Corneille nous assujettit à ses caractères et à ses idées, Racine se conforme aux nôtres, celui-là (Corneille) peint les hommes tels qu'ils devraient être, celuici (Racine) les peint tels qu'ils sont. 'Corneille subjects us to his characters and ideas, Racine conforms to ours, the former (Corneille) depicts people as they should be, the latter (Racine) depicts them as they are' (La Bruyère, Caractères, 1).

$\$ 12$ Relative pronouns:

Le nombre des sages est assez grand qui (= les sages), en observant le cours des astres, et l'art prodigieux qui (= l'art) règne dans la structure des animaux et des végétaux, reconnaissent une main puissante qui (= la main) opère de continuelles merveilles.
'The number of sages is quite high who (= the sages), by observing the course of the stars and the prodigious art which (= the art) exists in the structure of animals and vegetation, recognize a powerful hand which (= the hand) produces continual marvels.'

(Voltaire) (cf. Chapter 246, \$12)

$\$ 13$ Anaphoric adjectives are adjectives of personal relation (called possessive adjectives) and circumstantial relation (called demonstrative adjectives) as well as relative adjectives.

$\$ 14$ Possessive adjective: Alfred loves his (= Alfred's) father.

$\$ 15$ Demonstrative adjectives:

Lorsqu'on représentait à Napoléon une chose comme impossible, il prétendait que ce mot-là (= impossible) n'était pas français.
'When one presented something as impossible to Napoleon, he declared that the (lit. this) word (= impossible) was not French'

(Say)

\section{$\$ 16$ Relative adjective:}

Lequel Hiérome, après plusieurs rebellions, Aurait atteint, frappe, moi sergent, à la joue...
'This (lit. which) Hiérome, after several rebellions, Would have hit me the sergeant on the cheek...'

(Racine, Plaideurs, II, 4) 
$\$ 17$ Note that for nouns as well as for adjectives, we are dealing with words that establish a relation between two terms that are precisely the words to which the anaphors have a semantic connection.

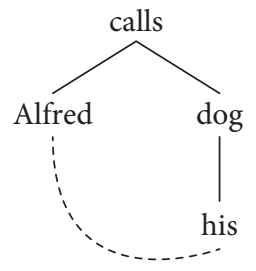

Stemma 68

\$18 In the particular case of so-called possessive pronouns and adjectives (Chapter 35, $\$ \$ 18-20)$, it is evident that every relation of possession presupposes a possessor and a possessed. Thus in the sentence Alfred calls his dog (Stemma 68), the anaphor his is linked by a structural semantic connection to the possessed $d o g$, and by an anaphoric semantic connection to the possessor Alfred.

$\$ 19$ The main anaphoric verb is the verb faire 'do/make' (Chapter 36, \$13): On regarde une femme savant comme on fait (= comme on regarde) une belle arme. 'One views a learned woman as one does (= as one views) a good weapon' (La Bruyère, Caractères, III).

$\$ 20$ The principal anaphoric adverbs are the adverb ainsi 'thus/in this way/as' and its substitute: comme ça 'like that', etc... Le hibou cherche l'obscurité, ainsi (= comme le hibou cherche l'obscurité) le méchant cherche les ténèbres. 'The owl seeks darkness, just as (= as the owl seeks) the villain seeks shadows' (Laveaux).

\section{Chapter 44. The method of composite words}

\$1 The opposition between full words and empty words provides one of the most objective and rigorous procedures for syntactic investigation.

\$2 This procedure finds its simplest application in the words that contain both full and empty elements, that is, in composite words (Chapter $28, \$ 8$ ). Therefore we call this procedure the method of composite words.

$\$ 3$ The method of composite words consists of making the full and empty elements of composite words react to each other. By establishing well-designed operational experiments, it is possible, thanks to accompanying variations and incompatible cases, to utilize the semantic aspects of full elements to define the functions of empty elements.

$\$ 4$ Take for example the attempt to define the limits of the French imperfect (or presentpast). The method of composite words permits us to both demonstrate the falsity of many 
traditional rules taught in grammar books and to test the appropriateness of the rules that we propose to replace them.

$\$ 5$ Most elementary grammars teach in particular that the French imperfect is employed when there is duration or repetition, which has the unavoidable effect of leading Slavic speakers, who possess a category of duration in their imperfect, to say for example in French: Hier il se leva à huit heures 'Yesterday he got up at eight o'clock'(since there is no duration) et se promenait (instead of the perfect se promena) toute la journée 'and he walked the whole way' (since there is duration) or even Il agitait (instead of the perfect agita) la bouteille plusieurs fois 'He shook the bottle several times'(since there is repetition) et l' ouvrit 'and opened it' (since there is no repetition).

$\$ 6$ The method of composite words highlights the falsity of the rules just mentioned.

$\$ 7$ Indeed, take the idea of duration, in which the full word that expresses duration is the verb durer 'last' in French. If the idea of duration is one that leads, in the past, to the use of the imperfect, the verb durer, which expresses duration by definition, cannot express any other past time than the imperfect. Yet even if the verb durer does exist in the imperfect, it also exists in the simple past. It is correct to say La guerre de Cent ans dura (not ${ }^{*}$ durait) en réalité cent seize ans 'The Hundred Years War actually lasted 116 years'. One sees that the empty element $-a$, which is a marker of the simple past, is in no way incompatible with the full element dur-. Therefore it is not the idea of duration that leads to the use of the imperfect. The proposed rule is false.

$\$ 8$ Take now the idea of repetition. The full word that expresses repetition is the verb répéter 'repeat'. If the idea of repetition is also one of those that leads, in the past, to the use of the imperfect, the verb répéter, which expresses repetition by definition, should not be able to appear in any other past tense than the imperfect. Yet while it is true that the verb répéter does exist in the imperfect, it exists just as well in the simple past. It is correct to say Il répéta (and not * répétait) cent fois la même expérience 'He repeated the same experience a hundred times'. The empty element $-a$, which is a marker of the simple past, is in no way incompatible with the full element répét-. It is therefore not the idea of repetition that leads to the use of the imperfect. The proposed rule is false.

$\$ 9$ We have proposed to replace the concepts of duration and repetition with the concepts of habit and concomitance as the factors that necessitate the use of the imperfect and as a consequence, as the determining cause. ${ }^{67}$

\$10 Take for example the idea of habit. The full word that expresses habit is the verbal expression avoir l'habitude 'to be accustomed' (lit.'have the habit'). If the idea of habit is one of those that leads to the use of the imperfect, the expression avoir l'habitude, which

67. See Lucien Tesnière L' emploi des temps en français 'The use of tenses in French', Bulletin de la Faculté des Lettres de Strasbourg, Cours de Vacances 1927, pp. 46ff. 
by definition expresses habit, should not be able to appear in any other past tense than the imperfect. It is correct to say il avait l'habitude de... 'he was accustomed to...', whereas it would be impossible to say il eut l'habitude de... ${ }^{68}$ The empty element eut, which is the marker of the simple past, is incompatible with the full word habitude. Therefore it is the idea of habit that leads to the use of the imperfect. The proposed rule is correct.

$\$ 11$ There are possible objections here, namely that we are dealing with a locution consisting of an empty word and a full word, not consisting of a truly composite word. But the agglutinated or autonomous character of the full and empty elements involved changes absolutely nothing about the principle on which the method works and the method will often apply to completely independent words.

\$12 Moreover, it suffices to go back in time a few centuries in the history of French to find the method of (true) composite words. Indeed, there once existed the French verb souloir $<$ Lat. solere, which expressed the same idea as our modern expression avoir l'habitude 'to be accustomed' in a single word. Let us take up our reasoning with this verb. If the idea of habit is one of those that leads to the use of the imperfect, the verb souloir, which by definition expresses habit, should be capable of appearing in no other tense of the past than the imperfect. However we do find il soulait:

Jean s'en alla comme il était venu, Mangeant le fonds avec le revenu, Tint les trésors chose peu nécessaire. Quant à son temps, bien sut le dispenser, Deux parts en fit, dont il soulait passer L'une à dormir et l'autre à ne rien faire.
'John left as he came,

Consuming capital and revenue, Considering treasure unimportant, As for his time, (he) knew how to spend it, He divided it in two and spent it Sleeping and doing nothing.'

(Fontaine's epitaph for himself)

whereas the old form of the simple past would be impossible. ${ }^{69}$ The empty marker of the simple past is incompatible with the full element of the verb souloir. It is hence precisely the idea of habit that leads to the use of the imperfect. The proposed rule is correct.

68. Translators' note: This form is not impossible when one is speaking about a habit that lasted only a while: Il eut longtemps l'habitude d'aller demander l'hospitalité à ses amis, pour une nuit, un jour, deux, plus ou moins 'He has had the habit for a long time of asking for hospitality from his friends for one night, one day, two, more or less' (Baudelaire, Biographical study of E. Crépet, 1906).

69. This item is attested in Old French under different forms: solt, sot, seult, sieut, siout, suit, suet, which stem from the Latin form ${ }^{*}$ soluit. The result of what has been said above is that while these forms were in usage in Old French, the use of the imperfect was different then from what it is in modern French. The use in Old French approached what it was in Latin, where the perfective solitus sum equally existed. The simple past of the verb souloir seems to have been employed up to the 13th century. It still appears in the 16th century, but in a grammaire (that of Du Guez), not in a text. In the 17 th century, the Dictionnaire de Trévoux stated that souloir "can only appear in the 
$\$ 13$ This is why it would be good to acknowledge a special grammatical category for the notion of habit. This notion is often confused with aspect (Chapter 37, §27); it could be designated with the term custom. ${ }^{70}$

$\$ 14$ Concerning the idea of concomitance, it is not directly expressed by any verb [in French]. The method of composite words does not therefore find its direct application here. Take the French sentence Jésus-Christ est venu surprendre la reine dans le temps que nous la croyions la plus saine, dans le temps qu'elle se croyait la plus heureuse 'Jesus Christ came and surprised the queen at the point in time when we believed her to be the sanest, at the point in time when she believed herself to be the happiest' (Bossuet). Of course it is easy to demonstrate that the use of the imperfect endings -ions of croy-ions and -ait of croy-ait is conditioned by the presence of the locution dans le temps que 'at the time when', which expresses concomitance. And it is easy to establish that the use of the simple past crûmes, crut would be incompatible with this locution. But that is not strictly speaking what defines the method of composite words, which makes it necessary not for the locution dans le temps que, but for the theme croy- of the verb croire 'believe' to be reactive to temporal verbal endings.

$\$ 15$ The method of composite words takes great demonstrative power from its absolute rigor and from its purely objective character. Conforming to what was said above (Chapter 18, §8ff.), the method of composite words must be preferred over the introspective method whenever possible.

\section{Chapter 45. Sentence words}

\$1 If we go over the different parts of speech of traditional grammar, we can observe that there is one part of speech that is outside of the classification into types of word that we have proposed above (Chapter 28ff.), namely interjections.

\$2 If the interjections do not find a place in our classification of types of words, it is because they are in reality not types of words, but rather types of sentences.

$\$ 3$ Indeed, take an interjection such as Fr. ä̈e 'ow'. This interjection suffices alone to express pain and thus constitutes on its own the equivalent of an entire sentence.

imperfect". One reads the same in the Dictionnaire général of Hatzfeld, Darmesteter \& Thomas, s.v. souloir: "Is only found in the imperfect." [Littré (Dictionnaire de la langue française, t. IV): wrote: "Dated term only the imperfect of which survives and is very rarely used".]

70. Translators' note: Tesnière uses an uncommon word, assuétude, which can also be translated by addiction. 
$\$ 4$ Certain interjections can even express states of mind that are so nuanced and so complex that they say more alone than an entire sentence, and long paraphrases are needed to analyze and define their semantic content.

$\$ 5$ Take for example the French interjection parbleu! 'Egad!, Of course!'. It expresses no less than the superb assurance with which the mind exclaims its surprise, when faced with something that it enjoys presenting - not without a certain snobbery - as only too evident: Mais que vas-tu faire de cette horreur (a skinned hand)?, nous écriâmes-nous. Eh parbleu, j'en ferai mon bouton de sonnette pour effrayer mes créanciers. 'But what are you going to do with this horror?, we exclaimed. - Eh!, egad!, I will make a door bell out of it to frighten my creditors' (Guy de Maupassant, La main d'écorché 'The skinned hand'). The semantic analysis of $A$ la bonne heure! 'Well done!' as an expression of approbation, of Allons donc! 'Come on!' as an expression of doubt, and of many other analogous expressions is no less delicate. ${ }^{71}$

$\$ 6$ Since interjections play the same role in speech as entire phrases, we call them sentence words.

$\$ 7$ Sentence words are composite words, since they are the equivalents of sentences and because every sentence contains both full and empty elements.

$\$ 8$ But it would be futile to seek to determine the full and empty elements in a given sentence word. For, with the exception of particularly favorable cases (Fr. voilà 'there it is!' $<$ vois là 'see there'), sentence words resist structural analysis. They are fixed organisms, stereotyped expressions. What such a word signifies, it signifies as a whole, most often without the possibility of discerning an internal organization of a nucleus that would have grammatical structure. In other words, they are structurally un-analyzable.

$\$ 9$ Therefore, grammatically unorganized sentences escape grammar constraints inasmuch as they are frozen as sentence words. Thus the markers of the second and third person plural, which no longer have any real value, can coexist quite well in Fr. Allez, allez, laissons cela tranquille 'Go, go, let's leave that alone' (Denys Amiel, Ma Liberté, p. 11).

$\$ 10$ The more primitive a language, the more it has the chance to be constituted by sentence words that remain syntactically unarticulated. Such is the case in particular with the language of certain great apes, in which it is possible to distinguish up to 18 articulations with different meanings, but which are no more than sentence words without any grammatical organization.

71. See also the study by J. Jeanjaquet on Fr.par exemple 'for example' with exclamative value such as surprise 'well I never!' or irony 'honestly!' in the Mélanges Bally, pp. 439-459. 
$\$ 11$ But while they are not analyzable structurally, they are analyzable semantically. The example from $\$ 5$ shows that it is not impossible to try to analyze the meaning, which is always more or less complex, down to minute details.

$\$ 12$ Since they lack internal structure and are devoid of any grammatical organization, the sentence words appear frozen. Hence they are of no interest to structural syntax.

$\$ 13$ We have seen (Chapter $45, \$ 5$ ) on the other hand that sentence words have most often semantic content that is extremely complex and finely nuanced, which redeems their poverty of structure.

$\$ 14$ Bearers of a semantic charge, sentence words often descend historically from former full words: Ger. Je! < Jesus.

$\$ 15$ As equivalents of entire sentences, sentence words often descend historically from short sentences, or at least from elements of sentences or from groups of words: Fr. oui! < Old Fr. oil < Lat. hoc illum; Fr. non! < Lat. ${ }^{\star}$ ne oinom 'not one'; Fr. palsambleu! < Fr. par le sang (de) Dieu 'by the blood of God'.

$\$ 16$ The tendency to attach an anaphoric pronoun to a demonstrative to turn it into an affirmative sentence word (Lat. hoc illum > Fr. oui) can be found more recently in the tendency to attach a personal index to sentence words of affirmation or negation or vice versa: Middle High German Jâ ër, cf. also the fact signaled by Marcel Cohen at Fressines (near Niort). ${ }^{72}$

$\$ 17$ Like all sentences, sentence words are susceptible to gaining a facultative supplementary addition, which generally appears as an adverb. Thus in the French dialogue Avez-vous terminé? - Non, pas tout à fait 'Have you finished? - No, not exactly', the pas tout à fait at the end clarifies the negative anaphoric sentence word non by correcting its meaning. The same is true of the expression pan dans l'œil 'smack in the eye' where the designation dans l'œil determines the point at which the hit expressed by the sentence word pan 'bang!' occurs, cf. also Rus. Vac v vodu 'Wham in the water'.

$\$ 18$ Conversely, a sentence word, when it is anaphoric, can have only the adverbial value that adjoins to the semantic source of the anaphor, for example in Fr. Nous aimons les roses, non leurs épines 'We like roses, not their thorns', where non expresses the negation of the sentence nous aimons, to which the anaphor refers back.

$\$ 19$ Just as we have presented a symbol for full words (cf. Chapter 33, §2) and a symbol for empty words (cf. Chapter 38,\$11), it is convenient to adopt one for sentence words as well. This symbol will be 9 , the base of which is $I$, the verb symbol, implied by the word sentence by definition.

72. Bulletin de la Société de Linguistique de Paris, 37, 2, 1936, p. XV. 


\section{Chapter 46. Classification of sentence words}

$\$ 1$ By reason of their unanalyzable and fixed character, sentence words do not in principle present any structural variety. They therefore do not lend themselves well to structural classification.

$\$ 2$ At most, a distinction can be established between sentence words according to whether they are structurally complete or incomplete.

$\$ 3$ Complete sentence words are sufficient on their own, that is, they are the equivalents of a complete sentence. Take for example the French word Aïe 'Ow'; it is complete because it is a sentence on its own and suffices to express physical pain without any other element having to adjoin to it to complete the sentence.

$\$ 4$ Incomplete sentence words, in contrast, do not suffice alone, that is, they are not the equivalent of a complete sentence. They constitute only a fragment of a sentence, to which it is necessary to add other elements to obtain a complete sentence.

\$5 Take for example the French sentence Voici votre chapeau! 'Here is your hat' (Stemma 69). The word voici is an incomplete word, because while it is true that it constitutes by itself a large part of the sentence and thus largely corresponds to the definition of the sentence word, it is nevertheless not the equivalent of an entire sentence, since it is necessary to adjoin to it the complement votre chapeau for the sentence to be complete.

$\$ 6$ Anaphoric sentence words have a separate status. Structurally, they are complete and equivalent to entire sentences. But semantically, they are in an anaphoric connection with other sentences and only take on meaning according to these other sentences.

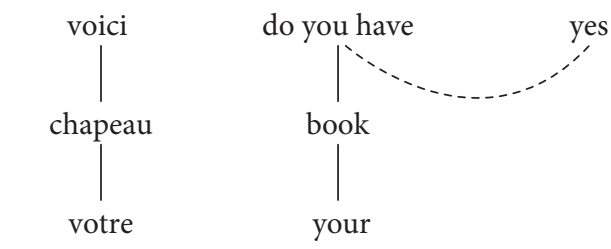

Stemma 69

Stemma 70

$\$ 7$ Take for example the dialogue Do you have your book? - Yes (Stemma 70). The isolated word Yes signifies nothing on its own, and it is only in anaphoric connection with the sentence Do you have your book? that it becomes the equivalent of the sentence I have my book.

$\$ 8$ Anaphoric sentence words are a container of practically unlimited semantic potential, since they take on all the semantic content, which can sometimes be quite substantial, from 
the sentence to which they are anaphorically connected (cf. the preceding example and also Chapter 85, \$7).

\$9 While they lend themselves poorly to structural classification, sentence words are semantically rich by virtue of the wealth of ideas and sentiments that they can express. This richness means that they lend themselves admirably to semantic classification.

$\$ 10$ From this point of view, we can distinguish between logical sentence words and affective sentence words.

$\$ 11$ Logical sentence words are sentence words in which the expressed notion is entirely intellectual, without any affective element. Some are incomplete: Fr. voici, voilà 'here is, there is'. Others are anaphoric: Fr. oui, non, si 'yes, no, yes of course'.

$\$ 12$ Because it has misconstrued the nature of sentence words, traditional grammar generally classifies the logical sentence words oui, non, and si among the adverbs, which is evidently inappropriate, since these words express a process (Chapter 27, \$8).

$\$ 13$ But even if they are not adverbs, the sentence words can be derived from adverbs. Therefore the German sentence word doch 'on the contrary' still has the same form as the junctive doch, which is used as an adverb (Chapter 140, \$8). Likewise, the French sentence word $s i$ 'yes of course' stems from the Latin adverb sīc 'thus', which was once initially an adverb dependent on the anterior participle fait in si fait 'thus done'.

$\$ 14$ Unlike logical sentence words, affective sentence words are full words in which the expressed notion presents a sense that is emotional to varying degrees.

$\$ 15$ As a consequence, affective sentence words correspond exactly to the interjections of traditional grammar.

$\$ 16$ Expressing an attitude of the speaker who is more or less active or passive in relation to the exterior world, affective sentence words are subdivided in turn into three subtypes: imperative, representative, and impulsive.

$\$ 17$ Imperative sentence words express an active attitude that is more or less marked according to the speaker's stance toward the external word. There are three nuances:

First, politeness sentence words, which reduce the imperative attitude to a minimum, and are closest to logical sentence words, e.g. Fr. S'il vous plait! 'Please';

Second, appellative sentence words, in which the imperative attitude is not weakened: Fr. Hep!, Pst! 'Hey!, Shush!';

Third, command sentence words, in which the imperative attitude reaches its maximum, e.g. Chut! 'Hush!'.

\$18 Representative or imitative sentence words express an attitude of equilibrium between the exterior world and the speaker, who is seeking to reproduce by imitation the impression that he himself senses: Pow! Piff! Bang! Boom! 
$\$ 19$ Finally, we have impulsive sentence words, which stand in opposition to imperative sentence words. They express a speaker's more or less passive attitude, that is, a more or less receptive attitude to the exterior world. They are nuanced in three subcategories:

First, sense sentence words, in which the receptive attitude of the speaker reaches its maximum: Fr. Aïe! 'Ow!'.

Second, emotive sentence words, in which the receptive attitude of the speaker is less pronounced: Fr. Oh!, Hélas! 'Oh!, Alas!'.

Third, intellectual sentence words, in which the receptive attitude of the speaker is reduced to a minimum, and completely permeated with intellectual reflection and are therefore closest to logical sentence words: Fr. Dame!, Ouais!, Parbleu! 'My word!, Yeah!, By jove!'.

$\$ 20$ The principal varieties of sentence words are summarized in the following diagram: ${ }^{73}$

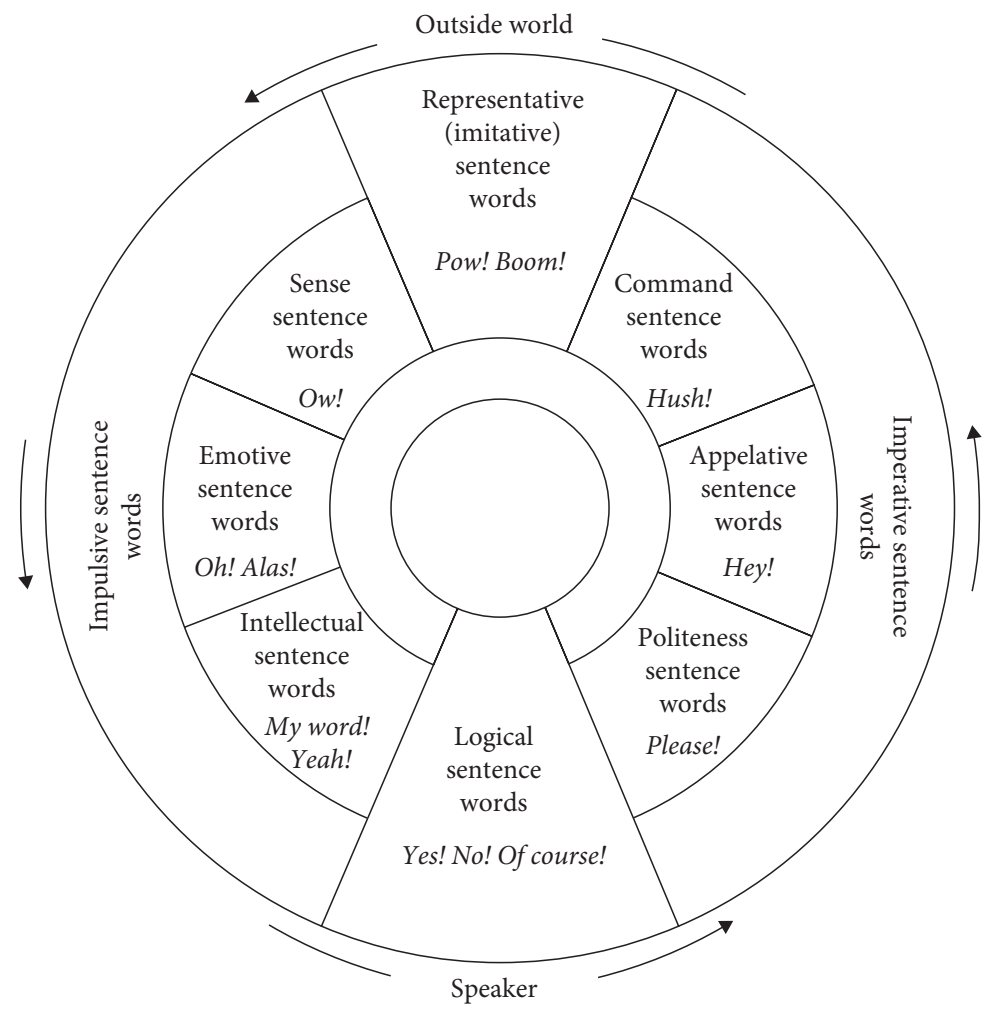

73. For more details, see Lucien Tesnière, Sur la classification des interjections ' ${ }^{\text {On }}$ the classification of interjections', Mélanges P. M. Haškovec, Brno, 1936, pp. 343-352. 


\section{Chapter 47. Types of sentences}

$\$ 1$ Every full word is susceptible to forming a node. We therefore distinguish between as many types of nodes as there are types of full words, namely four: verbal nodes, nominal nodes, adjectival nodes, and adverbial nodes.

\$2 The verbal node has a verb as its center, for example Alfred hits Bernard (Stemma 6).

$\$ 3$ The nominal node has a substantive as its center, for example six strong horses (Stemma 71).

$\$ 4$ The adjectival node has an adjective as its center, for example extremely young (Stemma 72).

\$5 The adverbial node has an adverb as its center, for example relatively quickly (Stemma 73).

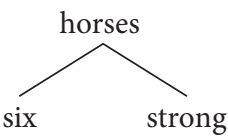

Stemma 71

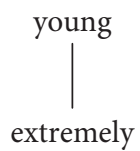

Stemma 72 quick

relatively

Stemma 73

$\$ 6$ We have seen that every sentence is the organization of one or more nodes, and we have given the name central node to the one node that commands all the others (Chapter 3, \$6).

\$7 We classify sentences according to their central node. We therefore distinguish as many types of sentences as there are types of nodes, namely four: the verbal sentence, the nominal sentence, the adjectival sentence, and the adverbial sentence.

$\$ 8$ A verbal sentence is one that has a verbal node as its central node, for example $A$ green light signals an open road (Stemma 19).

$\$ 9$ It should be noted that the sentence words voici, voilà 'here is, there is' (Chapter 46, \$2) are verbal sentences by their etymology vois ici, vois là 'see here, see there', in which it is not difficult to recognize the verb vois 'see'.

$\$ 10$ A nominal sentence has a noun as its central node, for example Fr. Le stupide XIX siècle 'The stupid 19th century', title of a novel by Léon Daudet (Stemma 74). Fr. "Je me fais des resolutions près desquelles les projets du stathouder et ceux du roi d'Espagne sont des jeux d'enfant puis, le jour de la mise à exécution, rien" 'I impose myself resolutions next to which the projects of the stadtholder and those of the king of Spain were child's plays, then, the day of execution, nothing' (A. Dumas, Le Vicomte de Bragelonne: Ce qui se disait sous le chêne royal 'The Vicomte of Bragelonne: What was said under the royal oak'), Lat. Uae victis 'Misfortune to the defeated'. 


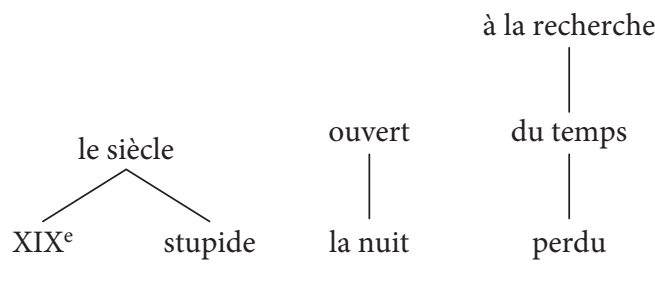

Stemma 74

Stemma 75

Stemma 76

$\$ 11$ An adjectival sentence has an adjective as its central node. The adjective can be replaced by a participle that functions structurally in the same way (see the chapter on transfer), for example Fr. Ouvert la nuit 'Open at night', title of a novel by Paul Morand (Stemma 75), Ger. Frankreich hoch 'Up with France!'

$\$ 12$ An adverbial sentence has an adverb as it central node. The adverb can be replaced by an adverbial locution, which is structurally the same (Chapter 197), for example Fr. A la recherche du temps perdu 'In search of lost time' (title of a set of novels by Marcel Proust, Stemma 76).

$\$ 13$ In languages that distinguish between verbs and nouns - that is, in European languages in general (Chapter $32, \$ 5$ ) - the most frequent sentence is the verbal sentence, then in decreasing frequency, the nominal sentence, the adjectival sentence, and the adverbial sentence. The latter three sentence types are often found in the titles of books as we have just seen $(\$ 10-12)$, and in the scene descriptions of plays, etc. (Chapter 3, \$7).

$\$ 14$ In languages that do not distinguish verbs from nouns, there can clearly be no verbal sentences. The most frequent sentence is therefore the nominal sentence (Chapter 32, \$5).

$\$ 15$ The simple organization of one or more nodes is the basic phenomenon in the structure of a sentence.

$\$ 16$ Other phenomena come to be grafted onto this common base. These phenomena have the effect of complicating the structure of the sentence, and variety is hence multiplied. These phenomena are junction (Chapters 134ff.) and transfer (Chapters 151ff.).

$\$ 17$ We resolve to call simple every sentence that has a normal organization of nodes, uncomplicated by any phenomenon of junction or transfer.

$\$ 18$ Conversely, we agree to call complex every sentence that includes any phenomenon of junction and/or transfer.

$\$ 19$ It is rare that a sentence does not contain at least one instance of junction or transfer. Complex sentences are therefore more numerous than simple sentences.

\$20 Nonetheless, as it is good pedagogical practice to pass from the simple to the complex, we begin our study with the simple sentence. 
$\$ 21$ Our plan is as follows:

\begin{tabular}{lll}
\hline First & Study of the simple sentence & Part I Books B-E \\
Second & Study of junction & Part II \\
Third & Study of transfer & Part III \\
\hline
\end{tabular}




\section{BOOK B}

\section{Structure of the simple sentence}

\section{Chapter 48. The verbal node}

\$1 The verbal node, found at the center of the majority of European languages (Chapter 3, $\$ 7$ and Chapter $32, \$ 5$ ), is a theatrical performance. Like a drama, it obligatorily involves a process and most often actors and circumstances.

\$2 Transferred from the theatre to structural syntax, the process, the actors, and the circumstances become respectively the verb, the actants, and the circumstants.

$\$ 3$ The verb expresses the process. Thus in the sentence Alfred hits Bernard (Stemma 6), the process is expressed by the verb hit.

$\$ 4$ The actants are the beings or things, of whatever sort these might be, that participate in the process, even as simple extras or in the most passive way.

$\$ 5$ Thus in the sentences Alfred gives the book to Charles (Stemma 77), Charles and the book are no less actants than Alfred ((64), although they do not actually act (Chapter 64, $\$ 15)$.

$\$ 6$ Actants are always nouns or the equivalents of nouns. In return, nouns in principle always assume the function of actants in the sentence.

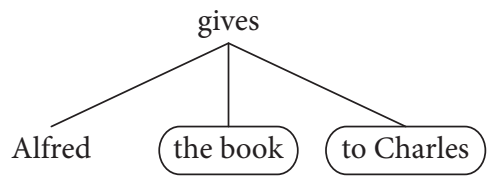

Stemma 77

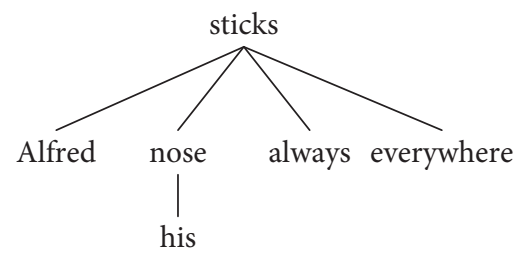

Stemma 78

\$7 Circumstants express the circumstances of time, place, manner, etc. in which the process unravels. Thus in the sentence Alfred always sticks his nose everywhere (Stemma 78), there are two circumstants, one of time (always) and one of place (everywhere).

$\$ 8$ Circumstants are always adverbs (of time, of place, of manner, etc...) or the equivalents of adverbs. In return, adverbs in principle always assume the function of circumstants.

$\$ 9$ We have seen that the verb is at the center of the verbal node (Chapter $47, \$ 2$ ), and as a consequence, it is at the center of the verbal sentence (Chapter $47, \$ 8$ ). It is therefore the governor of the entire verbal sentence. 
$\$ 10$ Some grammarians keen on logic have maintained that every simple sentence has a verb as its central node. Others have argued for the existence of nominal, adjectival, and adverbial sentences to contest the assertion, which results in a seemingly irreconciliale antinomy.

$\$ 11$ The problem is poorly formulated and in terms that are too absolute. In a simple sentence, the central node is not necessarily a verb, but when there is a verb, this verb is always the central node of the sentence.

$\$ 12$ It is therefore misguided that German grammarians (Morhof, 1682, Gottsched, 1730) have baptized the noun as Hauptwort 'main word'. In reality, this designation is better suited to the verb than to the noun.

$\$ 13$ As for actants and circumstants, they are the immediate subordinates of the verb.

$\$ 14$ Graphically, we represent this in stemmas, by placing the actants on the left and the circumstants on the right as much as possible. The sentence Alfred speaks well is represented by Stemma 48.

\$15 The symbolic stemma of the verbal sentence will hence always be of the type shown in Stemma 47.

\section{Chapter 49. Subject and predicate}

\$1 The representation of the verbal sentence as established in the preceding chapter differs considerably from the representation adopted by traditional grammar.

$\$ 2$ Founded on the principles of logic, traditional grammar strives to find the logical opposition between subject and predicate in the sentence, the subject being what is being spoken about and the predicate what is being said.

$\$ 3$ Hence in the sentence Alfred speaks slowly, the subject would be Alfred, and the predicate speaks slowly, which corresponds to Stemma 79.

$\$ 4$ This conception of the sentence is merely a remnant that has not yet been eliminated from the epoch that extends from Aristotle to Port-Royal, when all grammar was founded on logic.

$\$ 5$ Indeed, all arguments that can be invoked against the concept of the verbal node and in favor of the opposition between subject and predicate come a priori from formal logic, which has nothing to do with linguistics.

$\$ 6$ Concerning strictly linguistic observations about the facts of language, the conclusions drawn a posteriori are of a much different nature. There is no purely linguistic fact in any language that suggests the existence of the subject-predicate opposition.

$\$ 7$ Take for example the Latin sentence Filius amat patrem 'The son loves his father' (Stemma 80). The word amat 'loves' here is an agglutinated form of the predicative element $a m a$ - and the subject element $-t$. The break between the subject and the predicate is not 
marked by a word break. In contrast, such a break exists between the elements composed of the subject filius...-t and the predicate ama-...patrem.

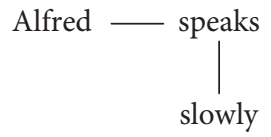

Stemma 79

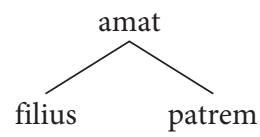

Stemma 80

$\$ 8$ The overlapping of subject and predicate elements does not sit well with the opposition between the two notions, whereas it poses no difficulty for the hypothesis that the verbal node is the central node.

$\$ 9$ Furthermore, it is difficult to place the subject on equal ground with the predicate. The subject often consists of a single word and cannot be fully expressed. The enunciation of the predicate, in contrast, is obligatory and in the majority of cases, the predicate contains many more elements than the subject.

$\$ 10$ The objection formulated in the preceding paragraphs is all the more serious because the predicate can contain elements whose internal nature and structure are entirely comparable to those of the subject.

$\$ 11$ Take for example the sentence Your young friend knows my young cousin (Stemma 81); the element my young cousin is a noun node of the same type as your young friend, as shown by their identical virtual stemmas (Stemma 82). These facts do not suggest that the two should be placed on different levels. But this fatal mistake occurs if one acknowledges the subject-predicate opposition (Stemmas 81 and 82).

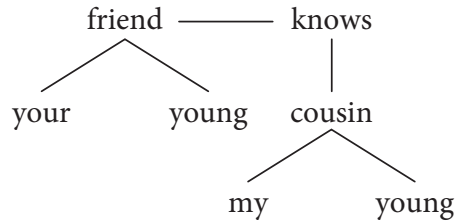

Stemma 81

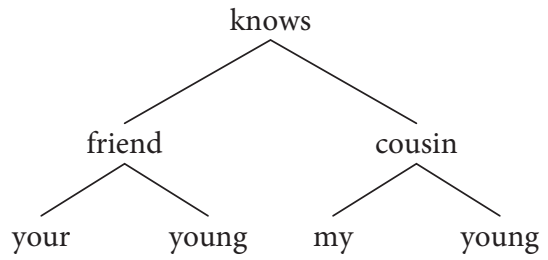

Stemma 83

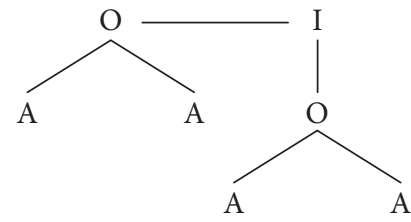

Stemma 82

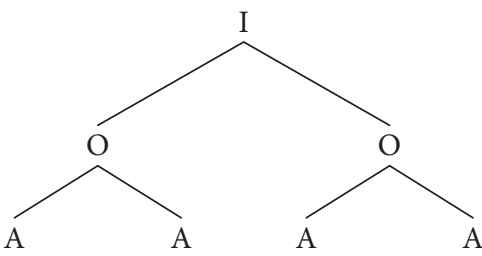

Stemma 84

$\$ 12$ This inconvenience disappears as soon as the verbal node is acknowledged as the central element and the stemmas constructed accordingly. The parallelism between the two noun nodes is reestablished (Stemmas 83 and 84). 
\$13 The subject-predicate opposition prevents the representation of the structural equilibrium in the sentence, since it leads to the isolation of one of the actants as the subject, to the exclusion of the others which are placed within the predicate pell-mell with the verb and all the circumstants. A disproportionate importance is thus accorded to one of the elements in the sentence, which is not justified by any strictly linguistic fact.

$\$ 14$ In particular, the subject-predicate opposition masks the interchangeable character of the actants, which is at the base of the active-passive mechanism.

$\$ 15$ Take the Latin sentence Filius amat patrem 'The son loves the father'. This sentence is rendered in the passive as Pater amatur a filio 'The father is loved by the son' by simple inversion of the actants, the first actant being pater instead of filius, the second being a filio instead of patrem, each remaining on the same level.

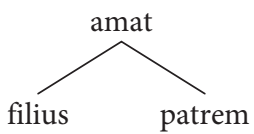

Stemma 85

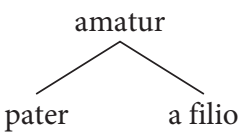

Stemma 86

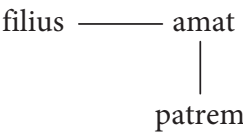

Stemma 87

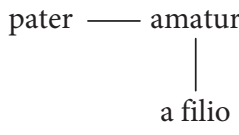

Stemma 88

$\$ 16$ In contrast, the subject-predicate opposition introduces a measure of dissymmetry, each actant being on a different level according to whether or not it is the subject (Stemmas 87 and 88 ).

$\$ 17$ By masking the mechanism of voice, the subject-predicate opposition negates the theory of actants and the valency of verbs.

\$18 In addition, it prevents the illustration of the facts of junction and transfer, which are so clear if the verbal node is central.

$\$ 19$ It is not by accident that traditional grammar has failed to acknowledge these notions. Falsely building on a foundation of pure logic, which has nothing to do with grammar, traditional grammar simply could not acknowledge them.

\$20 Conversely, the development of our conception of the verb as center in the following chapters will be, a posteriori, the best proof of the strong foundation of this conception.

\section{Chapter 50. Actants}

$\$ 1$ We have seen (Chapter $48, \$ 4)$ that actants are persons or things that participate to some degree in the process.

$\$ 2$ Furthermore, we have seen that the actants are in principle always nouns (Chapter 48 , $\$ 6)$ and that they are immediate subordinates of the verb.

$\$ 3$ Actants differ from each other in their nature, which is itself a function of their number in the verbal node. The question concerning the number of actants is therefore of primary interest to the structure of the verbal node. 
$\$ 4$ All verbs do not have the same number of actants. Furthermore, one and the same verb does not always have the same number of actants.

$\$ 5$ There are verbs with no actants, one actant, two actants, and three actants.

$\$ 6$ The verbs without actants express a process that takes place of its own accord, without any participants. This is essentially the case for verbs that denote meteorological phenomena. Thus in the Latin sentence Pluit 'It is raining', the verb Pluit depicts an action (the rain) without an actant. The stemma here is reduced to a simple nucleus (Chapter 22, \$4), since due to the absence of actants, there cannot be a connection between them and the verb (Stemma 89).

$\$ 7$ The French sentences Il pleut, Il neige 'It is raining, It is snowing', where il 'it' appears to be an actant do not provide a legitimate objection, for $i l$ in reality is merely an index of the third person singular and designates neither a person nor a thing capable of participating in any way in the process of raining. Il pleut forms only one nucleus, and the stemma is identical to the preceding one (Stemma 90). Traditional grammar acknowledges this situation by qualifying $i l$ as an apparent subject.

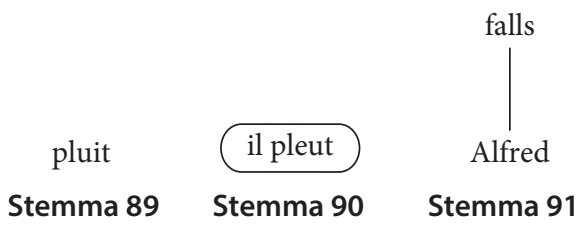

$\$ 8$ Comparing these sentences with a small drama (Chapter $48, \$ 1$ ), we say that in the case of a verb without an actant, the curtain is lifted on a scene where rain or snow is falling, but no actors are present.

$\$ 9$ Verbs with a single actant express a process in which only a single person or thing participates. Thus in the sentence Alfred falls (Stemma 91), Alfred alone participated in the action of falling, and realization of the process did not require the participation of anything other than Alfred.

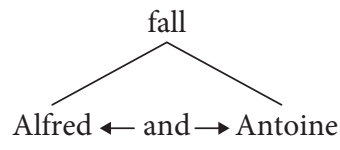

Stemma 92

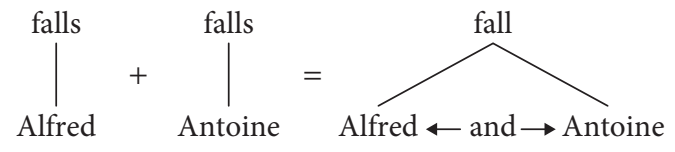

Stemma 93

\$10 Based on the preceding definition, one might object that the verb fall has two actants in a sentence like Alfred and Antoine fall (Stemma 92). That is not the case, however. The same actant is represented more than once. The same role is played by more than one person. In other words, Alfred and Antoine fall = Alfred falls + Antoine falls (Stemma 93). There is a simple phenomenon of duplication (Chapter 135) here. The phenomenon of duplication does not influence the number of actants. 
\$11 Verbs with two actants express a process in which two people or things participate (without duplication of course). Thus in the sentence Alfred hits Bernard, (Stemma 6), there are two actants, the first Alfred, who does the hitting, and the second Bernard, who receives the blows. The process with two actants could not take place without both taking part, each performing its role.

$\$ 12$ Verbs with three actants express a process in which three people or things take part (of course still without duplication). Thus in the sentence Alfred gives the book to Charles (Stemma 77), there are three actants, the first Alfred, who does the giving, the second the book, which is given to Charles, and the third Charles, who receives the book. The process with three actants cannot take place without all three actants taking part, each in its role.

$\$ 13$ With verbs that take three actants, the first and the third actant are in principle persons (Alfred, Charles), and the second is a thing (the book).

$\$ 14$ The introduction of an auxiliary (of mood or tense) does not influence the presence of actants: The organization of actants in the sentence Alfred can give the book to Charles (Stemma 94) does not differ in any way from the sentence Alfred gives the book to Charles (Stemma 77)

$\$ 15$ In the stemmatic representation, one is better off adopting the principle of always placing the first actant to the left of the second actant, and the second actant to the left of the third actant (Stemma 77).

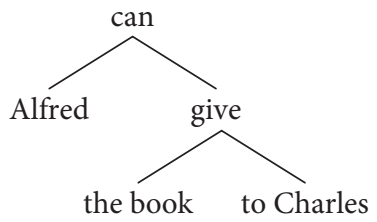

Stemma 94

\section{Chapter 51. Types of actants}

\$1 The various actants do not have the same function with respect to the verb that they are subordinate to.

\$2 From this point of view, we acknowledge as many types of actants as a verb can have, that is three, since there are verbs that take three actants (Chapter $50, \$ 5$ ).

$\$ 3$ We distinguish between the actants based upon numerical ordering: first actant, second actant, and third actant.

$\$ 4$ The ordinal number of actants can never be higher than the number of actants that the verb has. Thus while it is evident that a verb without an actant can have no type of actant, it is no less evident that a verb with just one actant cannot have a second actant, nor a third, and that a verb with two actants cannot have a third actant. 
\$5 Of course a first actant is present in principle in all sentences that have one, two, or three actants; a second actant is present in all sentences that have two or three actants; and a third actant is present in all sentences that have three actants.

$\$ 6$ From a semantic point of view, the first actant is the one that performs the action.

$\$ 7$ The first actant is known in traditional grammar as the subject, a term which we also retain here.

$\$ 8$ Hence in the sentence Alfred speaks (Stemma 1), Alfred is structurally the first actant and the one that performs the action.

$\$ 9$ From a semantic point of view, the second actant is the one that bears the action.

$\$ 10$ The second actant was known at one time in traditional grammar as the direct complement. This designation was replaced by the term object complement (Fr. complément d'objet) in $1910 .^{74}$ We will call it the object, pure and simple.

$\$ 11$ There is reason to observe that while the subject-object distinction ( $\$ 7$ and Stemma 12 ) is motivated from a semantic point of view, there is no structural opposition between the first and the second actant, just a simple distinction.

$\$ 12$ From the structural point of view, the subordinate, be it a first or second actant, is always a complement that completes the governor (Chapter $21, \$ 10$ ) in one way or another. In both cases (subject or object), it is a noun governing all the subordinated elements contained in the group of which it is the center.

$\$ 13$ From this point of view, and to express the matter in traditional terms, one can say without hesitation that the subject is a complement like the others. This seems to be paradoxical at first, although it is easy to demonstrate, assuming that it is made clear that the structural, not the semantic, point of view is what counts.

$\$ 14$ Thus in the sentence Alfred hits Bernard (Stemma 6), Bernard is structurally the second actant and is semantically the object of hits.

74. This is an example of the successive plunderings that have deprived syntax of all terminology to the benefit of morphology (cf. Chapter $15, \$ 10,11$ ). The terms direct complement (expressed by the Latin accusative) and indirect complement (expressed by the Latin dative) designated perfectly clear syntactic notions. These notions became morphological concepts; every complement that appears without a preposition was called direct and every complement that does appear with a preposition was called indirect. This reform, which a few rare grammarians rebelled against with good reason (Cf. A. Moufflet, Contre le massacre de la langue française 'Against the destruction of French language', I, 1930, pp. 202 and 203), was even less necessary since it it is possible to simply say prepositional complement or non-prepositional complement. What is more, it is of doubtful pedagogical virtue for elementary education, for the practice means that children get used to no longer acknowledging the abstract syntactic fact that lies behind the presence or absence of a preposition. This fact alone is the source of true insight that can prepare the young intellect for the study of foreign case languages, be they ancient languages (Greek and Latin) or modern languages (German, Russian, etc.). 
\$15 We have so far defined the second actant from the most frequent situation, that of the active diathesis (Chapter 100, $\$ 3$ ). It now becomes necessary to envisage the case of the passive diathesis, where the action is conceived of in the reverse direction (Stemma 6 and Stemma 95).

$\$ 16$ While the second actant of an active verb is what is acted upon (\$9 and Stemma 6), the second actant of the passive verb is what performs the action: Bernard is hit by Alfred (Stemma 95).

$\$ 17$ From a structural point of view, we distinguish the second passive actant from the second active actant. We refer to the latter simply as the second actant.

\$18 From a semantic point of view, the first passive actant is present in traditional grammar under the name passive complement or agent complement. We give it the name counter-subject, since it stands in opposition to the active subject just as the passive stands in opposition to the active.

$\$ 19$ From the semantic point of view, the third actant is what benefits or takes detriment from the action.

$\$ 20$ In this respect, the third actant was once known in traditional grammar under the name indirect complement, a designation that has recently been replaced $(\$ 10$, note 75$)$ by complement of attribution. ${ }^{75}$

\$21 The third actant is not affected in the least by the exchange of actants and by the change over from active to passive. In both forms of diathesis, the third actant remains unchanged: Alfred gives the book to Charles (Chapter 48, \$5) $\rightarrow$ The book is given to Charles by Alfred (Stemma 96).

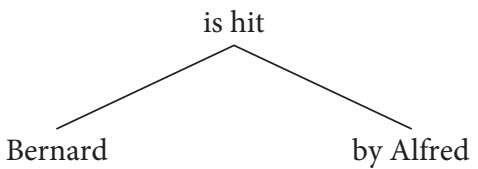

Stemma 95

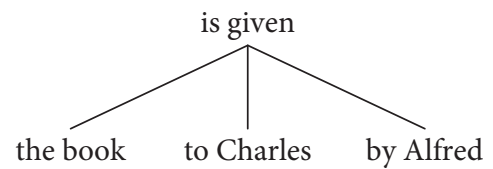

Stemma 96

\$22 The semantic value of the third actant is sometimes wider than what has been defined above in $\$ 16$. Its value easily extends in a general way to a person related to the envisaged process: Lat. Gomphos pervenit, quod est oppidum primum Thessaliae venientibus ab Epiro

75. The term is more or less appropriate. In the French sentence Le préfet accorde une bourse à l'élève 'The headmaster is according a scholarship to the student', it is understood that the élève is the complement of attribution. But it is less clear in the French sentence Le préfet refuse la bourse à l' élève 'The headmaster refuses [to give] the scholarship to the student'. It is also a poor choice to expose the possible risk of confusion between the term attribution and the term attribute (Chapter 66). Moreover, the term attribution has been the target of other criticism (see G. Galichet, Physiologie de la langue française, 1949, pp. 76-77). 
'He is arriving in Gomphes, which is the first city in Thessaly for those coming from Epirus' (Ceasar, De bello Civili, III, 80, 1).

$\$ 23$ In Latin, this semantic value is readily that of the third actant of a past passive verb, which cannot accommodate the complement of the passive because it is by definition perfective and therefore expresses a completed process (cf. \$18). In Latin, the third actant is expressed by the ablative preceded (or not) by $a b$ (cf. Chapter $52, \$ 18$ ) indicating an infectum, which would be absurd since it would imply current participation in a process that is already terminated: Lat. Mihi consilium captum iamdiu est 'For me, the decision was taken a long time ago'.

$\$ 24$ Since actants are always nouns, we will represent them symbolically with the letter O, to which we can add a first index $\left(\mathrm{O}^{\prime}\right)$, second index $\left(\mathrm{O}^{\prime \prime}\right)$, and third index $\left(\mathrm{O}^{\prime \prime \prime}\right)$, according to whether we are dealing with the first, second, or third actant.

$\$ 25$ Concerning the second passive actant (counter subject), since it is the counterpart to the second active actant, we will represent it in the inverse manner, by placing the second index before the $\mathrm{O}($ ("O), pronounced "counter second $\mathrm{O}$ ".

\$26 The characteristics of these diverse types of actants are summarized in the following table:

\begin{tabular}{|c|c|c|c|c|c|c|c|}
\hline \multicolumn{6}{|c|}{ Point of view } & \multicolumn{2}{|c|}{ Representation } \\
\hline \multicolumn{2}{|c|}{ Structural } & \multicolumn{4}{|c|}{ Semantic } & \multirow{4}{*}{ Symbol } & \multirow{4}{*}{ Enunciation } \\
\hline \multirow{3}{*}{ Name } & \multirow{3}{*}{$\begin{array}{c}\text { Character: } \\
\text { appears } \\
\text { in sentences } \\
\text { with }\end{array}$} & \multicolumn{3}{|c|}{ Name } & \multirow{3}{*}{ Character } & & \\
\hline & & \multicolumn{2}{|c|}{ Traditional } & \multirow{2}{*}{$\begin{array}{l}\text { In the } \\
\text { present } \\
\text { work }\end{array}$} & & & \\
\hline & & Old & New & & & & \\
\hline $\begin{array}{l}\text { First } \\
\text { actant }\end{array}$ & $\begin{array}{c}1,2, \\
\text { and } 3 \\
\text { actants }\end{array}$ & \multicolumn{3}{|c|}{ Subject } & $\begin{array}{l}\text { Does the } \\
\text { action }\end{array}$ & $\mathrm{O}^{\prime}$ & $\underset{\text { prime }}{\mathrm{O}}$ \\
\hline $\begin{array}{l}\text { Second } \\
\text { actant } \\
\text { (active) }\end{array}$ & $\begin{array}{l}2 \text { and } 3 \\
\text { actants }\end{array}$ & $\begin{array}{c}\text { Direct } \\
\text { complement }\end{array}$ & $\begin{array}{c}\text { Object } \\
\text { complement }\end{array}$ & Object & $\begin{array}{l}\text { Does the } \\
\text { action } \\
\text { (of the } \\
\text { passive } \\
\text { verb) }\end{array}$ & $\mathrm{O}^{\prime \prime}$ & $\begin{array}{c}\mathrm{O} \\
\text { second }\end{array}$ \\
\hline $\begin{array}{l}\text { Second } \\
\text { actant } \\
\text { (passive) }\end{array}$ & $\begin{array}{l}2 \text { and } 3 \\
\text { actants }\end{array}$ & \multicolumn{2}{|c|}{$\begin{array}{c}\text { Passive } \\
\text { complement } \\
\text { Agent } \\
\text { complement }\end{array}$} & $\begin{array}{l}\text { Counter- } \\
\text { subject }\end{array}$ & $\begin{array}{l}\text { Does the } \\
\text { action } \\
\text { (of the } \\
\text { passive } \\
\text { verb) }\end{array}$ & "O & $\begin{array}{l}\text { O counter } \\
\text { second }\end{array}$ \\
\hline $\begin{array}{l}\text { Third } \\
\text { actant }\end{array}$ & 3 actants & $\begin{array}{c}\text { Indirect } \\
\text { complement }\end{array}$ & $\begin{array}{l}\text { Complement } \\
\text { of attribution }\end{array}$ & & $\begin{array}{c}\text { Action } \\
\text { occurs to its } \\
\text { benefit or } \\
\text { detriment }\end{array}$ & $\mathrm{O}^{\prime \prime \prime}$ & O third \\
\hline
\end{tabular}




\section{Chapter 52. Types of actants across languages}

\$1 For a sentence to be comprehensible, the various actants must be supplied with sufficient distinctive signs to differentiate between them.

\$2 These distinctive signs are either indices (Chapter 41), which are more or less agglutinated forms (prepositions and postpositions, prefixes, suffixes, or endings), or the position of the actants on the spoken chain.

$\$ 3$ Among these diverse processes, different languages make, for each actant, the most varied choices.

$\$ 4$ In languages without case, the first actant is considered as the normal actant and receives no distinct sign whatsoever. This situation is particularly the case of French and English, for example Alfred is speaking (Stemma 97).

$\$ 5$ In languages that have case, the first actant appears in the nominative. This is what takes place in Latin and Greek, for example Gr. Ho Aléxandros légei 'Alexander is speaking', Lat. Aulus loquitur 'Aulus is speaking' (Stemma 98 and Stemma 99).

$\$ 6$ Finally, certain languages of a very archaic sort, such as Basque and the languages of the Caucasus, in particular Georgian, mark the acting character of the first actant very clearly, using an ending.

\$7 In Basque, the subject of verbs of action has an ending that brings out the active character, whereas the subject of verbs of state does not have an ending. One says gizona in the sentence Gizona ona da 'The man is good', but gizonak in the sentence Gizonak erraiten $d u$ 'The man is speaking' (Stemmas 100 and 101).

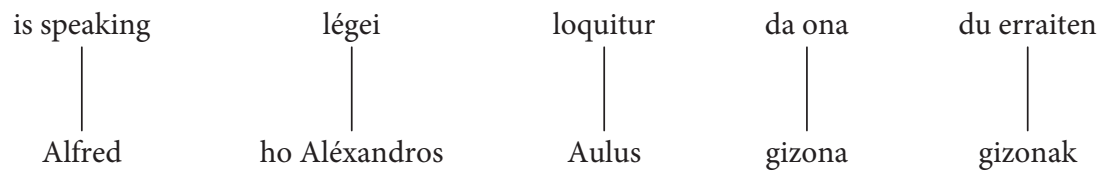

Stemma $97 \quad$ Stemma $98 \quad$ Stemma 99 Stemma $100 \quad$ Stemma 101

$\$ 8$ In Georgian, the same phenomenon only occurs when the verb is in the perfective. The first actant, instead of being in the nominative, is put into a special case, the ergative ${ }^{76}$ or active, indicating its value quite clearly, for example Geor. Kac'man cigni dacera 'The man wrote the book' (Stemma 102).

$\$ 9$ Second actant. In languages without case, in general no index distinguishes the second actant from the first actant. They resort to the position of the actant, a fixed position being

76. Cf. A. Vaillant "L'ergatif indo-européen", Bulletin de la Société de Linguistique de Paris, 37, 1936, pp. 93-108. 
attributed to each actant that bears the subject or object function. This is what happens in French and English, where the position in front of the verb is the position of the subject and the position after the verb is that of the object, for example Fr. Alfred frappe Bernard, Eng. Alfred is striking Bernard (Stemma 103).

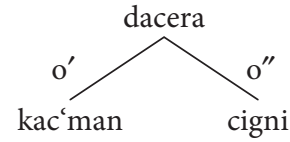

Stemma 102

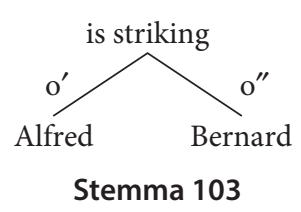

Stemma 103

$\$ 10$ The same is true of Chinese, where simple inversion of the first and second actant

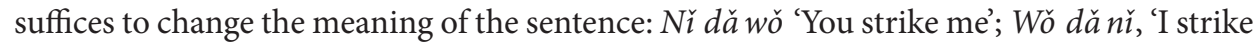
you'.

$\$ 11$ Certain languages without case rely on a preposition to indicate the second actant. This occurs in Ancient Hebrew, Romanian and often in Spanish, for example Heb. Barē 'š̄it bārā' élōhìm 'êt haššāmayim wa 'êt ha 'āreș 'Elohim created the sky and the earth' (Stemma 104); Rom. Petrul frapǔ pe Gianul 'Peter is striking John' (Stemma 105); Sp. Quién no ha visto a Sevilla? 'Who did not see Seville?' (Stemma 106).

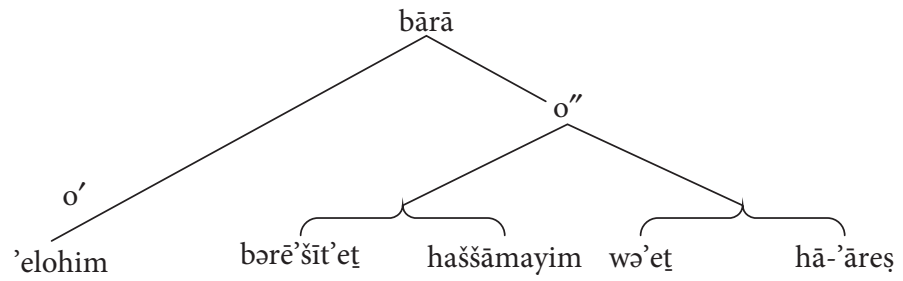

Stemma 104

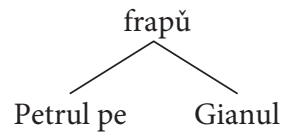

Stemma 105

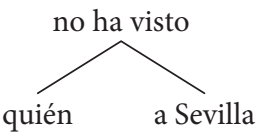

Stemma 106

$\$ 12$ In languages that have case, the second actant appears in the accusative. This is what happens in Greek, Latin, German, and Russian: Gr. Tòn patéra kharízei ho uhiós 'The son loves his father' (Stemma 107); Lat. Filius amat patrem (same meaning) (Stemma 85); Ger. Der Sohn liebt den Vater (same meaning) (Stemma 108), Rus. Syn ljubit otca (same meaning) (Stemma 109). ${ }^{77}$

77. See the very interesting remarks of E. Benvéniste on the original non-distinction of the "nominative-accusative" neuter (cf. Origines de la formation des noms en indo-europeen, p. 95), see also Chapter 52, $\$ 4$. 


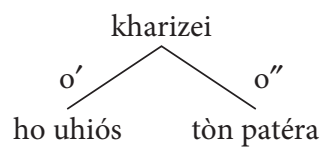

Stemma 107

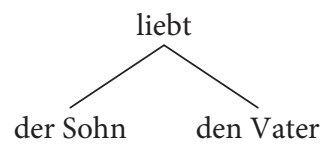

Stemma 108

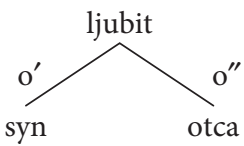

Stemma 109

$\$ 13$ The variety of processes, although very simple, employed by diverse languages to distinguish the second actant is the source of repeated mistakes made by those who are learning a foreign language.

$\$ 14$ The common mistake of French speakers is to forget to put the second actant into the accusative in languages that have case.

$\$ 15$ Slavic speakers make the opposite mistake. Accustomed to their languages that have case, they have great difficulty understanding that the nature of actants is bound to their position and that there is a difference between Alfred hits Bernard or Bernard hits Alfred. Furthermore, as the position of actants in their language has a stylistic value that they incorrectly attempt to render in French (or English), they often end up saying exactly the opposite of what they intended.

$\$ 16$ The second passive actant (Chapter $51, \$ 17 \mathrm{ff}$.) is most often marked by a preposition, even in languages that have case, e.g. Ger. Bernard wird von Alfred geschlagen (Stemma 110) as well as in languages that lack case, e.g. Eng. Bernard is hit by Alfred (Stemma 95).

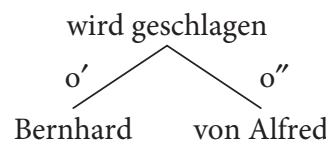

Stemma 110

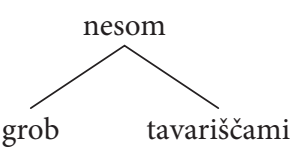

Stemma 111



Stemma 112

$\$ 17$ But some languages with a developed case system rely on the use of a case alone. This occurs in Russian, for example Grob nesom tavariščami 'The coffin is carried by the comrades', which uses the instrumental (Stemma 111).

$\$ 18$ Latin marks the counter subject (Chapter $51, \$ 18$ ) with the preposition $a b$ and the ablative when it is a person, and by the ablative alone when it is a thing, for example Pater amatur a filio 'The father is loved by the son' (Stemma 86), but Homines cupiditate ducuntur 'Men are guided by passion' (Stemma 112).

$\$ 19$ Greek marks the counter subject by the preposition hupó reinforced by the genitive Paideúomai hupò toû didaskálou 'I am instructed by my teacher'.

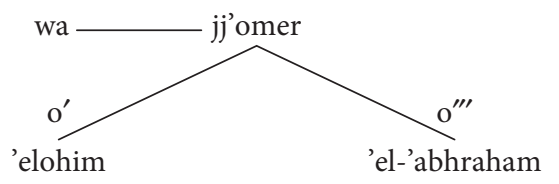

Stemma 113

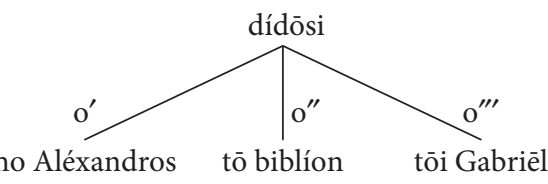

Stemma 114 
\$20 Third actant. In languages without case, the third actant is marked with a preposition: Eng. Alfred gives the book to Charles (Stemma 77), Heb. wayyō'mer 'êlōhìm 'el-äbrāhām šema'! 'and God said unto Abraham: Listen!' (Stemma 113).

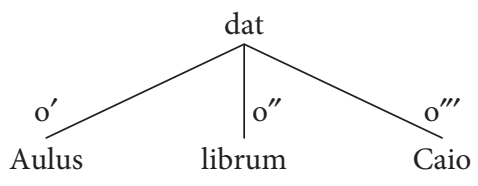

Stemma 115

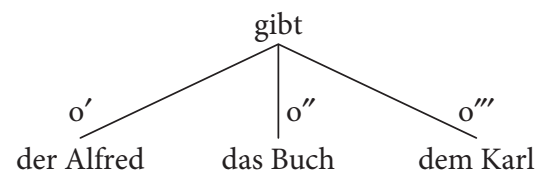

Stemma 116

\$21 In languages with case, the third actant is marked by the dative, for example Gr. Ho Aléxandros dídōsi tò biblion tōi Gabriēl 'Alexander gives the book to Gabriel' (Stemma 114), Lat. Aulus dat librum Caio (same meaning) (Stemma 115), Ger. Der Alfred gibt dem Karl das Buch (same meaning) (Stemma 116), Rus. Anton daët knigu Gavrile (same meaning) (Stemma 117).

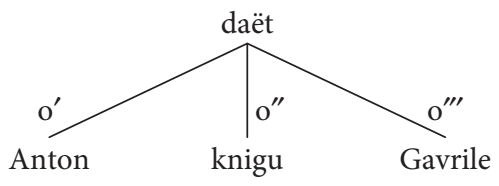

Stemma 117

\section{Chapter 53. Personal nouns}

$\$ 1$ In addition to the nouns examined so far, there exists a category of nouns that are few in number but occur frequently. Instead of designating people and objects by way of their appellation (the father, the book), they designate by way of their grammatical person, that is, in terms of interlocutors: I, you, he.

$\$ 2$ We call these nouns personal nouns. Structurally, they are constructed essentially like true nouns, and in particular, they can be preceded by a preposition: for me, for you, for him, as in for Alfred.

$\$ 3$ Traditional grammar calls these nouns personal pronouns. But this designation has the major drawback that it grants a very special meaning to the term pronoun, which, in all other cases, is applied to the nominal forms of determinative adjectives (Chapter 34, \$4).

$\$ 4$ If the terminology is generalized (Chapter $178, \$ 3$ ), it is clear that a personal noun is not a pronoun, since it is a noun of its own right, and not by nominalization of an adjective.

$\$ 5$ The notion of person should be made more precise. Traditional grammar distinguishes between three persons: first person, the one who speaks, second person, the one to whom one speaks, and third person, the one of whom one speaks. 
$\$ 6$ At first, this classification seems to be perfectly defensible, since it is based on the common observation that the first person is the one who is most directly of interest to the speaker or locutor and the third person is the one who is least directly of interest to the speaker. ${ }^{78}$

\$7 It is for the same reason that the first person trumps the second person, and the second person trumps the third person. Indeed, it is also clear that in general an $I$ (first person) and a you (second person) make a we (first person), and a you (second person) and a he (third person) make a you (second person). ${ }^{79}$

$\$ 8$ But when this situation is examined more closely, the classification appears more psychological than logical, since it rests essentially on the ethical observation that "charity begins at home". It is only human for the speaker to have the tendency to subjectively consider himself as automatically having the right to be the center of interest.

$\$ 9$ Therein lies an example of grammatical boorishness. The example is analogous to the desire for the grammar - which was originally produced by men and not by women - to place the masculine before the feminine, even when the morphological facts suggest that it might be placed after the feminine, as for example in Latin or Greek, where the feminine, which is the first declension, is distinguished from the masculine and neuter, which both belong to the second declension and are thus more appropriately grouped after the feminine.

\$10 Moreover, it is not the case in all languages that grammarians conjugate verbs beginning with the first person. In the Semitic languages (Hebrew, Arabic), the practice is to conjugate the personal forms beginning with the third person, the perfective form of which generally represents the root of the verb, followed by the second person, and finally the first person. The same is true of Sanskrit, where the numbers of the third persons are the opposite of what our European grammarians acknowledged when they based their ideas upon the Greek model.

$\$ 11$ In these conditions and by reason of the imperfection of the terminology based on person numbering, Damourette and Pichon, who distinguish between the locutive (first person), allocutive (second person), and delocutive (third person), have appropriately introduced a terminology that presents the advantage of using terms that indicate characteristics of the designated notions. In so doing, they avoid arbitrary numbering.

$\$ 12$ Damourette and Pichon's terminology has been roundly criticized. It would be easy to reply that, if such a need for new terms was felt, it only occurred because there were new notions to be expressed. However here it is a notion that has already been proposed, but was poorly designated. In any case and although the new terminology is too different from

78. Georges Galichet, Essai de Grammaire Psychologique, p. 102.

79. George Galichet, Essai de Grammaire Psychologique, p. 103, \$12. 
current terminology to be adopted without further ado, it presents a very helpful observation that constitutes undeniable progress, and it would be unfortunate to reject it as a matter of policy (Chapter 91, $\$ 5$ and note 127).

$\$ 13$ But while from this point of view, the terminology of Damourette and Pichon is far from being poor, it is nonetheless susceptible to criticism insofar as the structure of the notion of person on which it is founded does not seem to correspond to reality.

$\$ 14$ This terminology, as psychological as it is, is not confirmed by the majority of languages, which have, on the contrary, a very different and much deeper syntactic structure.

$\$ 15$ This deep syntactic structure has been masterfully brought to our attention by E. Benvéniste in the study that he dedicated to the structure of person relations in the verb (Structure de relations de personne dans le verbe) in the Bulletin de la Société Linguistique de Paris (43, 1947, issue 1, pp. 1-12).

$\$ 16$ By examining corroborating facts from a large number of languages, Benvéniste’s study shows that the ternary character of the psychological structure is based on superficial appearance. In reality, all the facts of language that can be invoked come together to show that there are in fact two binary correlations that are superimposed on each other, that of personality and subjectivity.

$\$ 17$ The personality correlation sees person (first and second person) in opposition to non-person, which Arabic calls $a l-\dot{g} \bar{a}^{\prime} b$ 'the one who is absent'. It is also the form of the verb that Sanskrit grammarians cite, whereas the first person is cited in Greek (cf. above, \$10). Finally, this non-person (third person) has many traits in a number of languages that are similar to those of a noun.

\$18 The subjectivity correlation places the person who is speaking in opposition to the person to whom he is speaking. The opposition to the not-self has the speaker becoming psychologically conscious of his subjective personality, of his self.

$\$ 19$ From this point of view, we immediately see the weak point in the terminology of Damourette and Pichon, which completely fails to recognize the double correlation and in which, on the contrary, it is the locutive (first person) that goes it alone against the allocutive (second person) and the delocutive (third person, both with a prefix).

\$20 Given this state of affairs, the desire is to find a terminology that has the advantage of conserving the strengths of Damourette and Pichon's terminology at the same time as it acknowledges the two correlations highlighted by Benvéniste.

\$21 One could for example knit together the Latin suffix -ive, which was adopted by Damourette and Pichon, and the theme ont-, which, being the present participle of the verb 'be' in Greek, seems particularly suited to signify the essence of person. An opposition between the anontive (third person, the non-person of Benvéniste) and the ontive (first and second person) would first be acknowledged. Then within the ontive, the autoontive (first person) could be distinguished from the antiontive (second person), becoming aware of the notion of "I" through this opposition. 
\$22 Given the numbering differences for person between the Semitic languages, Sanskrit, and our European languages, the summary in the following table is helpful:

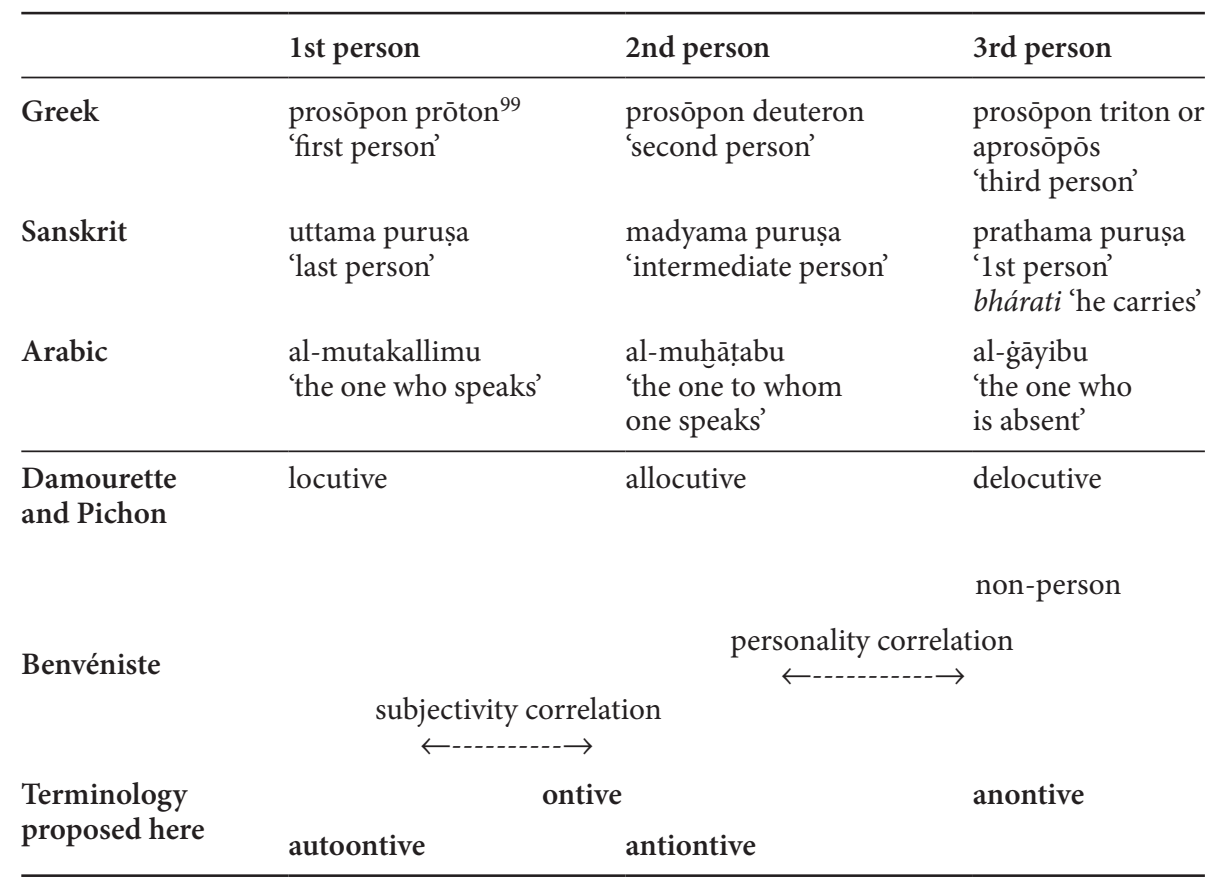

\$23 Like the other nouns, the personal nouns are variable in case (in the languages that have case), in gender, and in number. The variations in gender and number are the most interesting to study here; they are examined below.

\section{Chapter 54. Gender of personal nouns}

$\$ 1$ In French and in the majority of European languages, gender distinctions (masculine, feminine, and potentially neuter) appear almost only in the anontive personal noun: lui 'him', elle 'her', eux 'them (masc.)', elles 'them (fem.)'.

\$2 But there are languages, Semitic and Hamitic for instance, where the personal noun is sensitive not only to the anontive gender distinction, but also to the antiontive and sometimes even to the autoontive: ${ }^{81}$

80. Translators' note: The Greek designations in this first row were added by the editors of the first edition. Tesnière had left the cells blank.

81. Translators' note: The editors of the first edition added the following note at this point: “The Kabyle examples follow A. Basset and A. Picard, Eléments de grammaire berbère, Alger, 1948. 


\begin{tabular}{|c|c|c|c|c|c|c|}
\hline \multirow{2}{*}{$\begin{array}{l}\text { Singular } \\
\text { Gender }\end{array}$} & \multicolumn{2}{|c|}{ Anontive } & \multicolumn{2}{|c|}{ Antiontive } & \multicolumn{2}{|c|}{ Autoontive } \\
\hline & Fem. & Masc. & Fem. & Masc. & Fem. & Masc. \\
\hline Hebrew & $h \bar{\imath}$ & $h \bar{u}^{\prime}$ & 'at & 'attāh & \multicolumn{2}{|c|}{ 'ǎnī 'ānōkñ } \\
\hline Arabic & hiya & huwa & 'anti & 'anta & \multicolumn{2}{|c|}{ 'anà } \\
\hline Kabyle & netță & netța & kem & keěč & \multicolumn{2}{|c|}{ nekk } \\
\hline Tuareg & entat & enta & kem & $k a i$ & \multicolumn{2}{|c|}{ nek } \\
\hline $\begin{array}{l}\text { English } \\
\text { translation }\end{array}$ & 'she/her' & 'he/him' & \multicolumn{2}{|c|}{ 'you' } & \multicolumn{2}{|c|}{ 'I/me' } \\
\hline
\end{tabular}

\begin{tabular}{|c|c|c|c|c|c|c|}
\hline \multirow{2}{*}{$\frac{\text { Plural }}{\text { Gender }}$} & \multicolumn{2}{|c|}{ Anontive } & \multicolumn{2}{|c|}{ Antiontive } & \multicolumn{2}{|c|}{ Autoontive } \\
\hline & Fem. & Masc. & Fem. & Masc. & Fem. & Masc. \\
\hline Hebrew & hèn & hèm & 'atten & 'attem & \multicolumn{2}{|c|}{ 'anāḥnnū } \\
\hline Arabic & hunna & hum & 'antunna & 'antum & \multicolumn{2}{|c|}{ naḥnu } \\
\hline Kabyle & entenetidh & entenidh & kametidh & kaouenidh & nekkenetidh & nekkenidh \\
\hline Khasi & nețțat & netta & $\mathrm{kem}$ & keěč & \multicolumn{2}{|c|}{ nekk } \\
\hline Tuareg & $k a$ & $u$ & $p^{\prime} \bar{a}$ & $m \bar{e}$ & \multicolumn{2}{|c|}{$n \bar{a}$} \\
\hline English & \multicolumn{2}{|c|}{ 'they/them' } & \multicolumn{2}{|c|}{ 'you' } & \multicolumn{2}{|c|}{ 'we/us' } \\
\hline
\end{tabular}

$\$ 3$ In the same languages, the gender distinction exists not only in the personal noun, but also in the verb. ${ }^{82}$

\begin{tabular}{|c|c|c|c|c|c|}
\hline \multirow{2}{*}{$\frac{\text { Plural }}{\text { Gender }}$} & \multicolumn{2}{|c|}{ Anontive } & \multicolumn{2}{|c|}{ Antiontive } & \multirow[t]{2}{*}{ Autoontive } \\
\hline & Fem. & Masc. & Fem. & Masc. & \\
\hline Hebrew & \multicolumn{2}{|c|}{$k \bar{a} t \underline{b} u$} & ktabten & ktabtem & kātabِnū \\
\hline Arabic & katabna & katabū & katabtunna & katabtum & katabnā \\
\hline Kabyle & $-t t$ & $-n$ & $\check{t}-m \check{t}$ & $t-m$ & $-m$ \\
\hline Tuareg & $-n t$ & $-n$ & $t-m t$ & $t-m$ & $-n$ \\
\hline English & \multicolumn{2}{|c|}{ 'they wrote' } & \multicolumn{2}{|c|}{ 'you wrote' } & 'we wrote' \\
\hline
\end{tabular}

Concerning Tuareg, for which there is no recent grammar, we employ the dated transcription of A. Hanoteau, Essai de grammaire de la langue tamachek', Alger, 1896.

82. Evidently the persons of the verb originally stem from personal nouns that agglutinated through time to the verb as they lost their autonomy and in so doing became simple personal affixes (Chapter 55, $\$ 3$ and Chapter $61, \$ 13$ ). But it is from the verbal noun that the gender distinction stems, this distinction extending in the verb to the anontive and the autoontive forms. 
$\$ 4$ Likewise, gender appeared in the preterit of the Slavic languages, which is a former active participle and which, as such, agrees in gender (and number) with the subject, regardless of which person is concerned. Hence one finds a preterit in Serbo-Croatian and Bulgarian that is a compound tense of the present form of the verb 'be' and its participle:

\begin{tabular}{|c|c|c|c|}
\hline \multirow{4}{*}{ Serbo-Croatian } & Fem. & Masc. & \\
\hline & ona je pisala & on je pisao & 'she/he wrote' \\
\hline & ti si pisala & ti si pisao & 'you wrote' \\
\hline & ja sam pisala & ja sam pisao & 'I wrote' \\
\hline
\end{tabular}

\begin{tabular}{|c|c|c|c|}
\hline \multirow{4}{*}{ Bulgarian } & Fem. & Masc. & \\
\hline & tja e pisala & toj e pisal & 'she/he wrote' \\
\hline & ti ci pisala & ti si pisal & 'you wrote' \\
\hline & az s'm pisala & ti si pisal & 'I wrote' \\
\hline
\end{tabular}

\$5 In Czech, the auxiliary is tentatively beginning to disappear from the antiontive and autoontive. ${ }^{83}$ It has completely disappeared from the anontive:

\begin{tabular}{|c|c|c|c|}
\hline \multirow{4}{*}{ Czech } & Feminine & Masculine & \\
\hline & (ona) psal & (on) psal & 'she/he wrote' \\
\hline & $(t y) s$ psala & (ty)s psal & 'you wrote' \\
\hline & (já) (jsem) psala & (já) (jsem) psal & 'I wrote' \\
\hline
\end{tabular}

$\$ 6$ In Russian, where the verb be is never expressed in the present of a nominal sentence (Dom nov 'The house is new'), the same participle, being employed in an attributive function, constitutes the preterit alone, without an auxiliary.

\begin{tabular}{llll}
\hline \multirow{3}{*}{ Russian } & Fem. & Masc. & \\
\cline { 2 - 4 } & ona pisala & on pisal & 'she/he wrote' \\
& typisala & ty pisal & 'you wrote' \\
& ja pisala & ja pisal & 'I wrote' \\
\hline
\end{tabular}

83. V. Mazon, Grammaire Tchèque 3, 1952, \$104, p. 169. 
\$7 In Polish, matters have gone even further. The auxiliary remains as a postposed form, agglutinated to and elided from the antiontiv, where czytałaś evidently represents evolution from the former czytata si. The same explanation is sometimes given for the autoontive. But in this case, the absence of $s$ and of the entire radical in the auxiliary jestem suggests rather that this is an analogous reconstruction:

\begin{tabular}{llll}
\hline \multirow{4}{*}{ Polish } & Fem. & Masc. & \\
\cline { 2 - 4 } & pisała & pisat & 'he/she wrote' \\
& pisałaś & pisałeś & 'you wrote' \\
& pisałam & pisałem & 'I wrote' \\
\hline
\end{tabular}

$\$ 8$ Be that as it may, the forms of the personal endings of the Polish preterit now constitute a veritable conjugation of the preterit, which differs across the masculine and the feminine for the three persons.

\section{Chapter 55. Number in personal nouns}

$\$ 1$ Number variation appears in the personal noun, which is quite natural, since the personal noun is a noun. As with gender variation, number variation also spread to the verb where it must have started with the anontive form, which is the most nominal verb form. The impact of this development is that the plural of the verb in certain languages, for example Turkish (Chapter $32, \$ 9$ ), is exactly the same as that of a noun:

\begin{tabular}{llllll}
\hline \multirow{2}{*}{ Turkish } & \multicolumn{2}{c}{ Noun } & & \multicolumn{2}{c}{ Anontive verb } \\
\cline { 2 - 3 } \cline { 5 - 6 } \cline { 5 - 6 } & Singular & Plural & & Singular & Plural \\
\cline { 2 - 3 } & $\begin{array}{l}\text { ev } \\
\text { 'house' }\end{array}$ & $\begin{array}{l}\text { ev-ler } \\
\text { 'houses' }\end{array}$ & $\begin{array}{l}\text { sever } \\
\text { 'he/she/it loves' }\end{array}$ & $\begin{array}{l}\text { sever-ler } \\
\text { 'they love' }\end{array}$ \\
\hline
\end{tabular}

$\$ 2$ These facts are to be compared with those of Slavic, in particular of Czech and Polish, where the anontive also presents a purely nominal form of the plural, Cz. psali 'they wrote', Pol. pisali, whereas support from the auxiliary grants the antiontive and the autoontive a character that is more essentially verbal.

$\$ 3$ But while everything seems to suggest a nominal origin for the verbal plural, it is not always straightforward when dealing with personal nouns.

$\$ 4$ Indeed, A. Meillet astutely remarked that $I$, being by definition singular, cannot be put in the plural. It is true that they can be he + he or she + she. In the same way, you two 
can be you (sg.) + you (sg.) when one employs the antiontive to address two people. ${ }^{84}$ But it is impossible to say that we is $I+I$. Since there can be no other $I$ besides myself, we is necessarily $I+$ another, that is, $I+$ you (sg.) or $I+$ he/she. Likewise, the antiontive is used to address a sole interlocutor, it is not possible to have you + you, but rather it must be you (pl.) + he, she, or they. It is only by way of an abstraction that is so deep that it departs from reality that it is possible to conceive of a plural form of autoontive $I$ or the antiontive you.

$\$ 5$ Many languages were incapable of producing this effort of abstraction. These languages, instead of having a sole plural corresponding to the singular $I$, have two plurals, a we $=I$ + you, and another $w e=I+h e / s h e$. This is the case in Maori. Or to be more exact, since Maori additionally distinguishes the dual from the plural in the personal pronouns, we = $I+$ you and $w e=I+h e / s h e$ are the dual forms, which do not exclude the plurals $w e=I+$ you or we $=I+$ they. In Maori, there are therefore no fewer than four ways to express the we of English:

\begin{tabular}{lllll}
\hline & Autoontive + antiontive & Singular & =taua 'we' & $I+$ you \\
Maori & Autoontive + antiontive & Plural & = itatou 'we' & $I+$ you guys \\
& Autoontive + anontive & Singular & = mauo 'we' & $I+$ he/she \\
& Autoontive + anontive & Plural & imatou 'we' & $I+$ they \\
\hline
\end{tabular}

$\$ 6$ The terms inclusive and exclusive are used to distinguish between dual forms and plural forms of the personal noun according to whether or not they designate the antiontive, in addition to the autoontive which is implied in both cases. A form of the personal noun (dual or plural) that designates both the autoontive and the antiontive is said to be inclusive. Conversely, a form of the personal noun, dual or plural, that designates both the autoontive and the anontive, to the exclusion of the antiontive, is said to be exclusive.

$\$ 7$ Schmidt's atlas provides a distribution of the world's languages that has the inclusive vs. exclusive distinction. ${ }^{85}$ It can be found in more or less all exotic languages:

Languages that encode the inclusive vs. exclusive distinction

Africa Khoekhoe, Bushman, Somali, Malagasy

Asia Dravidian and Munda languages, Tungusic, Manchu, to which one must add Tibetan

Oceania Malaysian and other Austronesian languages, languages of South-East Australia, to which one must add Papuan

Americas Algonquian, Sioux, and a large part of the Amerindian languages

84. Translators' note: In Modern English, the former plural form you, first used only as a polite form, is now the only possible singular form.

85. P. W. Schmidt, Die Sprachfamilien und Sprachkreise der Erde, Atlas of 14 maps, map 11. 
It should be noted that this large enumeration completely leaves out the languages of Europe - with the exception of certain languages of the Caucuses - as if the phenomenon were absolutely unknown in Europe.

$\$ 8$ And yet the distinction between inclusive and exclusive is so natural that traces can even be found in Europe. The fact that Schmidt did not take account of it indicates that he either ignored it or did not recognize it as such. Hence it is possible that it exists in other regions in addition to the ones shown on Schmidt's map.

$\$ 9$ The languages of Europe to which the previous paragraph alluded are none other than the Romance languages, starting with French, where the attribute autres in nous autres, vous autres indicates exclusivity: nous autres 'we others' (we but not you) as opposed to vous autres 'you others' (you but not us). ${ }^{86}$ It should be noted that this opposition between the autoontive and antiontive overlooks the anontive almost entirely; the analogous expression eux autres 'they others' is encountered only very rarely. ${ }^{87}$

$\$ 10$ In Italian, the forms corresponding to noialtri 'we others', voialtri 'you others', are written as one word, which seems to indicate a more advanced agglutination than in French between the personal noun and the attribute.

$\$ 11$ In Spanish, the development has progressed even further. Not only are nosotros and vosotros agglutinated forms in writing, like in Italien, but these forms have taken on such an extension in use that they have completely eliminated the simple forms nos and vos. The development is so advanced that they are used in every case, so that -otros has totally lost its etymological value of exclusion. The words nosotros, vosotros today represent nothing more than Eng. we, you.

$\$ 12$ The same type of form is encountered in Old Catalan nosaltros, cf. H. Guitter, Grammaire de la langue du “Llibre d'Ave Maria" of Ramon Llull, p. 18, \$50 and p. 79, 13-14.

$\$ 13$ The exclusive forms of this type even seem to be particularly contagious, since they are sporadically encountered even in German. Finck locates them in Goethe's writings: uns andere Laien 'we other secular people'; ${ }^{88}$ and also in Sudermann's writings: Wir anderne wollen wir Hölzer suchen 'The rest of us, we want to seek wood'89

86. Is is evidently from the inclusive personal noun vous autres [vuzot(ь)] that the Creole (of Reunion) zot' 'you.PL' arises by apheresis: Ça que zot' y appelle patois créole 'That that zot' call creole patois' (Georges Fourcade, Z'istoires la caze 'Stories of the house', Tananarive, 5th edition, pp. 3ff.).

87. Cf. however A. Moufflet, Contre le massacre de la langue française, I, 1930, p. 360.

88. Reineke Fuchs VII, 171-173, cf. Finck, Die Haupttypen des Sprachbaus, p. 91.

89. Der Katzensteg, 6. 


\section{Chapter 56. Circumstants}

$\$ 1$ We have seen (Chapter $48, \$ 7$ ) that circumstants express the circumstances in which the process takes place.

\$2 Moreover, the function of circumstants is always assumed by an adverb, or by a group of words that is equivalent to an adverb (Chapter $48, \$ 8$ ). In addition, the grammatical terminology of German designates the adverb with the compound Umstandswort, lit. 'word of circumstance, the first element being Umstand, which signifies circumstance (Lat. circumstantia), of which it is merely a calque (um-= circum, -stand = stantia).

\$3 There are therefore as many types of circumstants as there are types of adverbs: time, place, manner, etc. (Chapter 37).

$\$ 4$ Unlike the number of actants, the number of circumstants is not limited. There can be no circumstants at all, just as there can be an unlimited number of them.

$\$ 5$ However, it is evident that there can only be two circumstants of the same sort as long as they do not exclude each other. Such is the case in the sentence Alfred is departing tomorrow at noon (Stemma 118), with two circumstants of time, tomorrow and at noon, because the circumstant at noon, which expresses the hour, merely makes the circumstant tomorrow, which indicates the day, more precise without contradicting it. On the other hand, the two circumstants sometimes and always cannot depend on the same verbal node, since they assign incompatible temporal conditions.

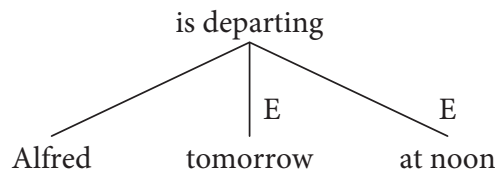

Stemma 118

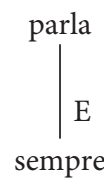

Stemma 119

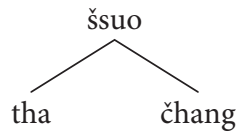

Stemma 120

$\$ 6$ In centrifugal languages (Chapter $14, \$ 4$ ), the circumstant follows the verb it depends on: Fr. Il parle toujours 'He talks all the time', It. Parla sempre (Stemma 119), Breton Eñ a gomz bepred.

\$7 On the contrary, the circumstant in centripetal languages appears in front of the verb that it depends on: Chinese Tă zóng shuō 'He talks all the time' (Stemma 120), Rus. On vsegda govorit, Eng. He always speaks. The same is true of Ukranian, White Russian, Polish, Lithuanian, Latvian, Latin, Romanian, Udmurt, Mari, Chuvash, Komi, Basque, and Armenian. Further: Georgian Is amagad daseirnobda 'He strolls proudly', Romani Kaj tu salas kana joda brošindelas? 'Where did you go when it rained so much?'. 


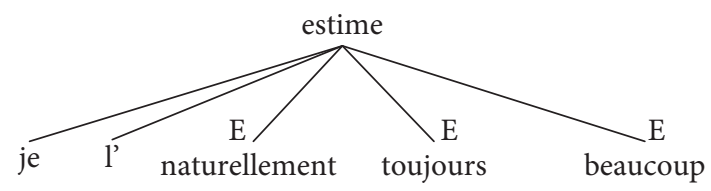

Stemma 121

$\$ 8$ Circumstants tend to appear in a certain order. Thus circumstants of manner are usually placed before those of general time, those of general time before those of quantity, and those of quantity before those of place, and finally, those of place before those of particular time: Fr. Je l'estime naturellement toujours beaucoup 'I naturally always value that a lot', On le voit toujours beaucoup partout 'One always sees him a lot everywhere', Alfred passera rapidement là-bas demain 'Alfred will stop off quickly there tomorrow' (Stemmas $121,122,123)$, Ger. Er ist immer da 'He is always there'.

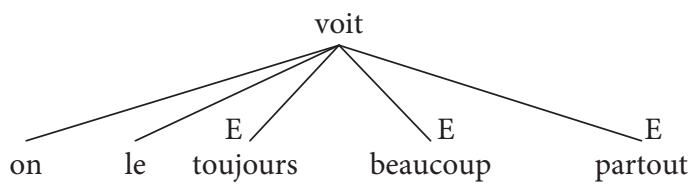

Stemma 122

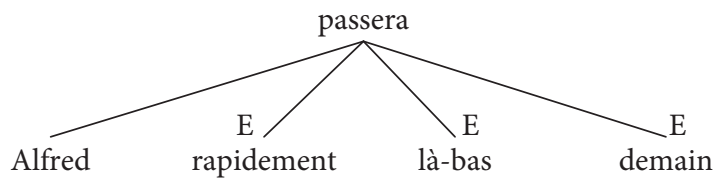

Stemma 123

$\$ 9$ The position of circumstants in relation to actants is generally as follows. They all appear after the first actant, but

1. circumstants of manner, general time, and quantity usually appear after the first actant and before the second actant, the third actant, and the auxiliary verb, whereas

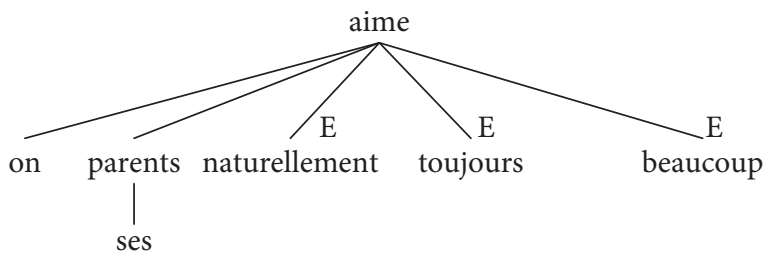

\section{Stemma 124}

2. circumstants of place and particular time ordinarily appear after the second and third actant (and the auxiliary verb that precedes them): On aime naturellement toujours 
beaucoup ses parents 'One always of course loves one's parents much', Marie vous rendra sûrement votre livre demain 'Marie will surely return your book tomorrow', Alfred fourre toujours son nez partout 'Alfred always sticks his nose everywhere'(Stemmas 124, 125, and 78), J'ai naturellement toujours beaucoup aimé mes parents 'I of course also loved my parents a lot', Marie vous aura sûrement rendu votre livre demain 'Marie will surely have returned your book to you tomorrow'

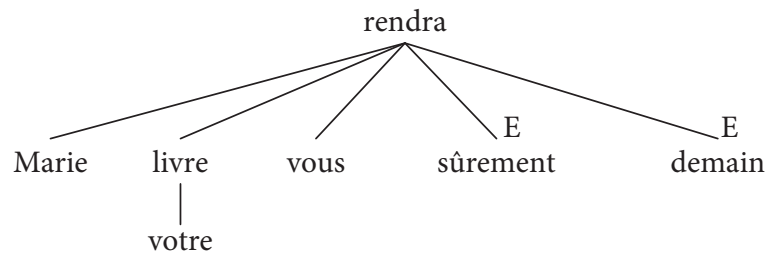

Stemma 125

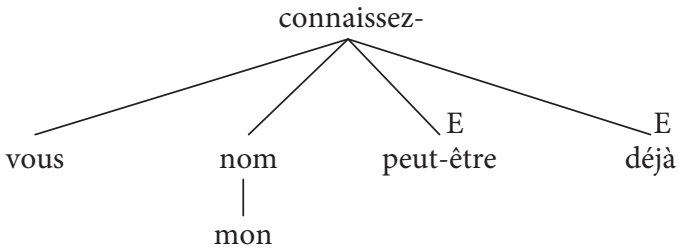

Stemma 126

\$10 The position after the actants is the most natural position for circumstants. But it remains as a matter of course that every circumstant can be removed from its ordinary position and placed in a prominent position, for example at the front of the sentence. Doing so is a matter of style: Peut-être connaissez-vous déja mon nom? 'Perhaps you already know my name?, Toujours la tyrannie a d'heureuses prémisses 'At all times, tyranny has good intentions' (Racine), Un traître jamais ne doit être imité 'Never should a traitor be imitated' (Le Franc de Pompignan) (Stemmas 126, 127, and 128). These two latter sentences are more prominent than La tyrannie a toujours d'heureuses prémisses, and Un traître ne doit jamais être imité, which are more common and leveled.

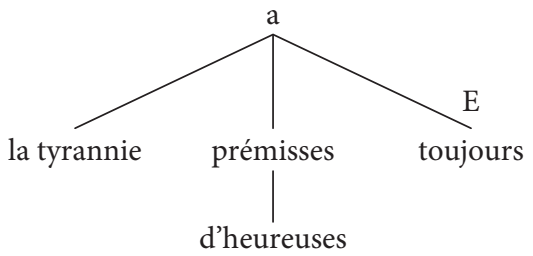

Stemma 127

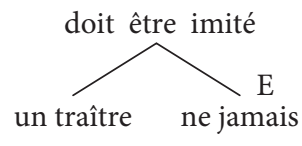

Stemma 128

\$11 It can be seen from the preceding examples that by and large, circumstants appear after actants. For this reason, we always place them in the stemma to the right of the actants (Chapter $48, \S 14$ ), regardless of their real position in the linear sequence. 


\section{Chapter 57. The dividing line between actants and circumstants}

$\$ 1$ At first blush, the dividing line between actants and circumstants is clear. But upon closer inspection, the distinction proves difficult to establish with precision. The actant bearing the highest numeral index - that is, the third actant - shows some characteristics of circumstants. Conversely, certain circumstants share some characteristics with actants, which suggests that a closer examination of the criteria is necessary to distinguish between actants and circumstants.

$\$ 2$ Two such criteria are that of form and that of meaning.

$\$ 3$ From the point of view of form, an actant, being in principle a noun, is self-sufficient as a dependent of the verb, for example Alfred hits Bernard, whereas a circumstant, which is only capable of functioning as an adverb, must in addition, if it is a noun, receive an adverbial marker in the form of a preposition (cf. Chapter 201, \$2), for example Alfred walks with a cane.

$\$ 4$ From the point of view of meaning, an actant stands solidly behind the verb to the point that it is often indispensable for completing the meaning of the verb, for example Alfred hits Bernard. It is difficult to understand Alfred hits without the second actant. On the contrary, circumstants are essentially optional: Alfred walks is sufficient on its own, without the necessity to indicate what he uses to walk, not even if he needs something to help him walk.

$\$ 5$ Furthermore, the third actant and even the second actant, if they are undoubtedly actants by form in a language that possesses a dative and an accusative, approach the circumstants in languages where they are signaled by prepositions: Alfred gave the book to Charles (Chapter 52, \$20 and Stemma 77), Romanian Petrul frapǔ pe Gianul (Chapter 52, $\$ 11$ and Stemma 105).

$\$ 6$ Conversely, certain complements that look like circumstants because they have a preposition are actually actants because their connection to the verb is very tight. The verb seems incomplete without them, e.g. Fr. Alfred change de veste 'Alfred changes his jacket'.

\$7 But de veste cannot be an actant, since it does not fit the definition of the first actant, which performs the action (Chapter 51, \$6), nor that of the second actant, which supports the action (Chapter 51, \$9), and finally, nor that of the third actant, which receives benefit or detriment from the action (Chapter 51, \$19). Not being an actant, it can only be a circumstant. Indeed, de veste expresses one of the circumstances that accompanies and defines the action of changer. Circumstants of this type are therefore adverbs of quiddity (Chapter 37, \$35) in a sense. The sought-after dividing line is therefore located between the third actant and the circumstant of the type de veste.

$\$ 8$ One should note that this division classifies the majority of complements that appear in the dative (for example in Latin) or with the preposition $a$ in French as third actants: plaire à quelqu'un 'be pleasing to someone', nuire à quelqu'un 'be harmful to someone', Lat. nocere 
alicui. These complements can actually be assimilated to the verbs of giving (Chapter 106, \$8): donner du plaisir à quelqu'un 'give pleasure to someone', donner de la nuisance à quelqu'un 'cause someone trouble', porter envie à quelqu'un 'make someone envious'.

$\$ 9$ Conversely, the majority of complements are classified as circumstants when they appear in the genitive (for example in Latin) or with the preposition de in French: dépendre de quelqu'un 'depend on someone', changer de chaussettes 'change socks', se souvenir de quelque chose 'remember something', se tromper de porte 'take the wrong door'.

$\$ 10$ One should note in particular the propensity of verbs of remembering to take a circumstant of this type, for example Fr. Je me souviens de mon enfance 'I remember my childhood', which rubs off, in colloquial French, on Je me rappelle mon enfance 'I remember my childhood' giving the incorrect form Je me rappelle de mon enfance.

\section{Chapter 58. The structure of the verbal node in German}

$\$ 1$ We have seen (Chapter $48, \$ 13$ ) that the immediate subordinates of the verb are actants and circumstants. The construction of the German sentence furnishes us with strong confirmation of this state of affairs.

\$2 The principle of the construction of the German sentence (excluding interrogative or exclamative sentences, and those introduced by a subordinator) is to express at the head of the sentence one of the actants or one of the circumstants directly subordinated to the verb; then the verb, and then the (other) actants and circumstants directly subordinated to the verb. The latter appear in a precise order that will not interest us here. Thus one would construct variations as follows, the different orders carrying nuances but no variations in meaning, strictly speaking:

\begin{tabular}{lllll}
\hline $\mathbf{1}$ & \multicolumn{1}{c}{$\mathbf{2}$} & \multicolumn{1}{c}{3} & \multicolumn{1}{c}{$\mathbf{4}$} & \multicolumn{1}{c}{5} \\
\hline $\begin{array}{l}\text { Mein Sohn } \\
\text { 'My son }\end{array}$ & $\begin{array}{l}\text { besuchte } \\
\text { visited }\end{array}$ & $\begin{array}{l}\text { gestern } \\
\text { yesterday }\end{array}$ & $\begin{array}{l}\text { mit einem Freunde } \\
\text { with a friend }\end{array}$ & $\begin{array}{l}\text { das Museum. } \\
\text { the museum. }\end{array}$ \\
Gestern & besuchte & mein Sohn & mit einem Freunde & das Museum. \\
Mit einem Freunde & besuchte & mein Sohn & gestern & das Museum. \\
Das Museum & besuchte & mein Sohn & gestern & mit einem Freunde. \\
\hline
\end{tabular}

Each of these variants is equally correct. The sole difference between them is that the fronted element is more prominent.

$\$ 3$ Fourquet quite correctly compares this structure to a key ring where the direct dependents of the verb (actants as well as circumstants) are represented by the keys and the verb by the ring that binds the keys together. The German sentence behaves as if one key is held bottom up, with the key ring below, followed by all the other subordinate keys, hanging from the ring (Figure 129). 


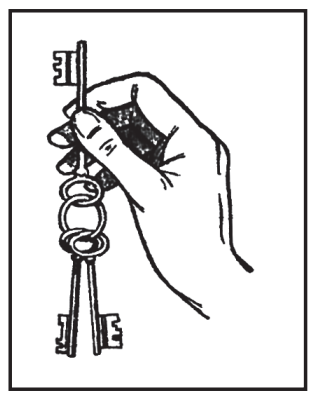

Figure 129

$\$ 4$ This structure leads to the distinction of a certain number of positions in the German sentence and to the observation that the secret of German sentence structure resides above all in the verb's position. In interrogative and exclamative sentences, the verb occupies the first position; it occupies the last position in clauses that are introduced by a subordinator and the second position in all other clauses.

\$5 The conclusion is that word position in German sentences is not relative, as is too often taught with respect to the theory of inversion, which actually confuses matters. It is actually absolute, since the verb does not appear after one word or another, but in a position that is determined by the nature of the clause at hand. This position is fixed and determined in its own right. ${ }^{90}$

$\$ 6$ Regarding the other positions, each subordinate of the verb, be it an actant or a circumstant and however extensive it may be, occupies one position in the clause, and only one. Each of these subordinates of the verb can in turn be a governor and therefore drag along with it all its subordinates. This situation is consistent with the principle formulated above (Chapter $3, \S 4$ ), whereby a governor and all its subordinates occupy just a single position.

\begin{tabular}{|c|c|c|c|}
\hline 1 & 2 & & \\
\hline Alfred & schenkte & mir & ein Buch. \\
\hline Alfred & gave & me & a book \\
\hline
\end{tabular}
2

Mein Vater, der mich sehr gern hat und nie eine Gelegenheit vermisst mir eine schenkte mir ein Freude zu machen, besonders wenn diese zu meiner Erziehung beitragen kann,

'My father, who adores me and never misses an opportunity to make me gave me a happy, especially when the opportunity contributes to my education, Buch book.'

90. For everthing that concerns the structure of the German sentence, see Lucien Tesnière Une survivance pédagogique: l'inversion et le rejet dans la construction de la phrase allemande 'A pedagogical remnant: inversion and rejection in the construction of the German sentence', Les Langues Modernes, ${ }^{0}$ 2, mars-avril 1947, pp. $21 \mathrm{ff}$. 
Whether the noun is alone, as with Alfred, or accompanied by a whole slew of subordinates, as with Vater - which governs not only mein, but also the string of subordinates der mich sehr gern hat und nie eine Gelegenheit vermisst mir eine Freude zu machen, besonders wenn dieselbe zu meiner Erziehung beitragen kann - the whole node occupies a single position.

$\$ 7$ Therefore for a German sentence to be complete, its structure requires that the actants and circumstants be the immediate subordinates of the verb, since each of them, regardless of the node it may be composed of and which it tows with it, always occupies one 'position' in the construction of the German sentence. The German sentence can always be deduced logically in this way, and only in this way, from the structure of the verbal node.

$\$ 8$ Conversely and given its strictness, German sentence structure furnishes - this time not by the deductive method, but by the inductive method - a precise method for investigating the structure of the sentence and the deep essence of types of words.

$\$ 9$ The German sentence can provide useful insights into, for example, the nature of infinitives and participles. Indeed, these two types of words occupy a special position in the German sentence, which is not that of the verb:

\begin{tabular}{lllllll}
\hline \multicolumn{2}{c}{2} & & & & \\
\hline Ich & werde & dieses Buch & morgen & fertig & gelesen & haben. \\
I & will & this book & tomorrow & finished & read & have \\
'I will have finished reading this book tomorrow.' & & \\
\hline
\end{tabular}

In the interrogative structure:

\begin{tabular}{lllllll}
\hline 1 & & & \\
\hline Werde & ich & dieses Buch & morgen & fertig & gelesen & haben? \\
will & I & this book & tomorrow & finished & read & have \\
'Will I have finished reading this book by tomorrow?' & & \\
\hline
\end{tabular}

And in the subordinate clause:

\begin{tabular}{lcccccc}
\hline & & & Last \\
\hline $\begin{array}{l}\text { Du glaubst nicht } \\
\text { You believe not }\end{array}$ that & I & this book & dieses Buch & morgen & gelesen haben & werde. \\
'You do not think that I will have finished reading this book by tomorrow. & read have & will \\
\hline
\end{tabular}

\$10 As can be seen from the preceding examples, the auxiliary werde alone is considered as the verb, since it alone occupies the position of the verb, whereas the auxiliated forms, 
i.e. the participle gelesen and the infinitive haben, are treated as different types of words, since they occupy their own position, which is not the position of the verb. We will see in what follows (Chapter 180 and 198) that this conclusion is confirmed by the analysis of these words.

\section{Chapter 59. Indices}

\$1 The immediate subordinates of the verb, especially the nouns, naturally tend to form a sequence (Chapter $6, \$ 5$ ) with the verb that they depend on, and as a consequence, they are placed as close to it as possible in the spoken chain. Hence in French orthography, the actants can never be separated from the verb by a comma. ${ }^{91}$ It is correct to punctuate without a comma Mon père aime la chasse 'My father loves hunting', whereas it would be incorrect to use a comma as in ${ }^{\star}$ Mon père, aime la chasse or ${ }^{*}$ Mon père aime, la chasse.

$\$ 2$ With this universal gravitation of immediate subordinates of the verb to the verb, it appears that the personal nouns have a tendency even more marked than for other nouns not to distance themselves from the verb.

$\$ 3$ This situation is evident for example in French, where the usual order is Je donne le livre à mon frère 'I give the book to my brother', with a second and a third nominal actant, but if one of these two nouns is replaced with a personal noun, the order is Je le donne à mon frère 'I give it to my brother', Je lui donne le livre 'I give him the book'. In these last two sentences, it can be seen that the personal noun has the priority in terms of proximity to the verb, regardless of whether it is a second or third actant.

$\$ 4$ The situation is no less clear in German, where the sentence Ich gebe meinem Bruder das Buch 'I give my brother the book', can be compared to Ich gebe es meinem Bruder 'I give it to my brother' and Ich gebe ihm das Buch 'I give him the book'.

$\$ 5$ The same is true in English, where it is I give the book to my brother, but I give it to my brother and I give him the book.

$\$ 6$ In certain languages, personal nouns, which gravitate into the immediate vicinity of the verb, tend to lose their autonomy. Phonetically, they lose their accent. Morphologically,

91. To be more precise, they can never be separated from the verb by a single comma, although they can be separated off by two commas that function as a parenthesis, the first opening the parenthesis that the other closes: Mon père, qui a le tempérament sanguin et qui éprouve le besoin de faire beaucoup d'exercice, aime la chasse 'My father, who has a sanguine temperament and feels the need to get a lot of exercise, loves hunting. 
they tend to agglutinate to the verb; they are integrated into the verb as an affix (prefix or suffix). In European languages, this process can be seen in particular in the Romance and the Slavic languages (but not in Russian).

\$7 The forms of the personal nouns that are incorporated into the verb differ from the forms of autonomous personal nouns, since they are treated differently in terms of phonetics due to their atonic nature. In French a clear distinction is encountered between $\mathrm{Il} \mathrm{me} \mathrm{le}$ donne 'He gives it to me' and Donne-le moi 'Give it to me'. In the first case, $m e$ is atonic and treated phonetically as such, whereas in the second case, moi requires the phonetic treatment of an accented syllable.

$\$ 8$ Deprived of their phonetic and morphological autonomy, the personal nouns are increasingly specialized in their role as additives to the verb. In this way subject personal nouns tend to become simple indicators of the person of the verb (Chapter $60, \S 16$ ). We hence call them personal indices. Indeed in the French je parle 'I speak', je serves much less to mark the speaker than to indicate that the verb is autoontive (Chapter $53, \$ 21$ ).

$\$ 9$ The result of this is that it is necessary to formally condemn the term personal pronoun, not only because it is not a pronoun (Chapter $53, \$ 3$ and 4), but also because it has the inconvenience of grouping two types of obviously distinct words under the same banner, the personal noun and the personal index.

\$10 The personal noun is easily recognized, since it always maintains its accent and can appear with a preposition. The form avec moi is used just like avec Alfred, and Il se moque de moi 'He makes fun of me' just like Il se moque d'Alfred 'He makes fun of Alfred'.

$\$ 11$ Conversely, the personal index is recognized insofar as it does not bear any accent and is merely a subsidiary word (Chapter $29, \$ 3$ ), an addition to the verb. Thus in the Fr. je parle, the word je is effectively deprived of autonomy and cannot appear alone. It is not possible to say avec je, only je parle, where je indicates merely that the verb parler is employed as an autoontive. ${ }^{92}$

$\$ 12$ The opposition between the personal noun and the personal index appears clearly when there is insistence on the person indicated by the index. In such a case, the index no

92. It is not necessary to account for formulations of the sort Je, soussigné Jean-Pierre Durand, notaire à Saint-Jean, certifie par les présentes, que... 'I, undersigner Jean-Pierre Durand, notary at Saint-Jean, certify by the present documents, that...' Indeed this form, which is the only case in which the personal index is still employed as a personal noun, is an archaic and isolated occurrence. It is preserved in juristic and administrative jargon, but is no longer alive in productive language. Translator's note: Apart from the previous kind of texts, je 'I' can only be separated from the verb by other clitics: Je le lui donne 'I give him it', but ${ }^{\star} J e$, tu sais, viens seulement demain 'I, you know, am arriving only tomorrow' 
longer suffices and an additional noun must be used, for example Fr. Toi, tu chanteras, moi, je danserai 'You, you will sing, me, I will dance'.

\begin{tabular}{lll}
\hline French & $\begin{array}{l}\text { Il me frappe. } \\
\text { Qui? - Moi }\end{array}$ & $\begin{array}{l}\text { 'He hits me. } \\
\text { Italian }\end{array}$ \\
& $\begin{array}{l}\text { Egli mi tocca. } \\
\text { Chi? - Me. }\end{array}$ & 'He hits me. \\
Spanish & Elmi ama. & 'He loves me. \\
& A quien? - A me. & Who? - Me.' \\
Serbo-Croatian & On me je video. & 'He sees me. \\
& Koga? -Mene. & Who? - Me.' \\
\hline
\end{tabular}

$\$ 13$ Colloquial speech sometimes deletes the subject index or its equivalent. This suppression gives the sentence a careless allure: Fr. Ah, nom de Dieu, Déodat, pour un facteur, êtes un sacré facteur... 'Ah, name of God, Deodat, for a messanger, [you] are a sacred messenger...' (Marcel Aymé, La Jument verte, p. 103). This type of sentence is not a modern innovation. It can be found in Alexandre Dumas: Bonsoir, Grimaud, dit-il, comment va? 'Good evening, Grimaud, he said, how's [it] going?'(Le vicomte de Bragelonne).

$\$ 14$ In English, the same phrase serves as an abbreviation, and is quite common in colloquial language: Here's Mr. Maldon, begs the favour of a word, Sir (Dickens, David Copperfield, I, 16).

\$15 These diverse examples show that, just as in the languages where person is normally indicated by an index, the index can be absent. But in such cases, the verb is always in a form that suffices to indicate the person (êtes, va, begs).

$\$ 16$ In the stemma, the indices retain their status as actants and circumstants, but they are included in the circle drawn around the verbal nucleus: Alfred vous en remercie beaucoup 'Alfred thanks you a lot for that', J'en remercie la Providence 'I thank Providence for that' (Stemmas 130 and 131).

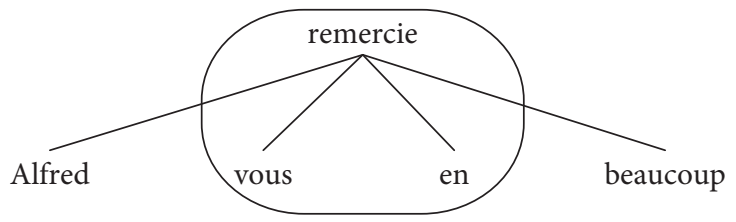

Stemma 130

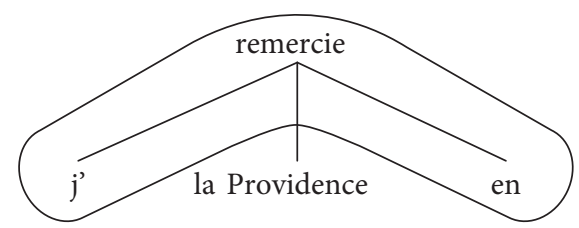

Stemma 131 


\section{Chapter 60. Oblique personal indices}

\$1 While the personal noun as first actant has the tendency to become a simple personal index, it is not alone in doing so. A personal noun as second or third actant can also become a personal index. In such a case, it is not a personal subject index, but rather an oblique personal index. Thus in the Fr. Je le lui donne 'I give it to him', je is a personal index as first actant, whereas le and lui are oblique personal indices, le the personal index of the second actant and lui the personal index of the third actant.

\$2 The oblique masculine personal index can designate an idea contained in a preceding phrase or sentence: Fr. Ce fut ainsi qu'elle mourut un soir du mois d'octobre. Le jour de l'arrivée des grives, comme Isidore le fit observer à son père 'It was thus that she died one evening in the month of October. The day the thrushes arrived, as Isidor remarked to his father' (Murger, Le Sabot rouge, X). The oblique index le anaphorically designates the idea that it was on the day that the thrushes arrived that the heroine died.

$\$ 3$ Oblique personal indices are found in the majority of languages where there are personal subject indices:

\begin{tabular}{ll}
\hline French & Je le vois. \\
Italian & Lo vedo. \\
Breton & Me am eus en ewelet. \\
Serbian & Ja sam ga vidao. \\
\hline
\end{tabular}

$\$ 4$ But it is evident that only the personal index of the first actant is likely to initiate the system of endings and personal prefixes and, as a consequence, of conjugation, since the verb always agrees in person with the first actant.

\$5 The anontive personal index le or $l a$ in front of a vowel is elided in $l$, which tends to be pronounced as a geminate $l l$ ' in colloquial speech and in certain dialects.

$\$ 6$ Despite what A. Moufflet thinks (Contre le massacre de la langue française, 1930, p.16), it is not because of an improbable danger of being confused with gelé 'frozen' that the $l$ ' is generally pronounced as $l l$ ' in $J e ~ l ' a i$ 'I have it'. It is actually because it is the only way of distinguishing between the first actant $i l$ 'he' in the common phrase qui l', which has a contrary meaning to qu'il: l'homme qui l' (colloquially pronounced $l l^{\prime}$ ) a $v u \neq l$ 'homme qu'il a vu. In

\begin{tabular}{ll}
\hline Apprenez que tout flatteur & 'Know that every flatterer, \\
Vit aux dépens de celui qui l'écoute. & Lives at the expense of he who listens to him.'
\end{tabular}

(La Fontaine, Fables, I, 2, Le Corbeau et le Renard

'The crow and the fox', cf. Chapter 271, \$3)

The correct pronunciation of $l$ ' has the serious drawback that it is confused with qu'il, which gives the sentence a diametrically opposed meaning and does not justify the moral 
of the fable. This is the reason why the pronunciation $l l$, while incorrect, has a good chance of being adopted into academic pronunciation, which is less clear due to the ambiguity.

$\$ 7$ The tendency of indices to agglutinate to the verb has the effect of bringing the indices to the same position right in front of the verb in the spoken chain. The result is that they are grouped together in a manner that makes them more or less inseparable, for example, Fr. Vous le lui donnez 'You give it to him', where the three personal indices of the first, second, and third actant congregate immediately in front of the verb. In this manner, they form an inseparable block.

$\$ 8$ The cohesion is particularly strong between the indices of the second and third actants, which are, for example in French, always adjacent to each other in the spoken chain and in the same respective order, whereas the index of the first actant can appear on the other side of the verb, as for example in interrogative sentences, cf. Fr. Le lui donnerez-vous? 'Did you give it to him?', or it can even be completely absent, as is the case with the imperative, cf. Fr. Donnez-le lui! 'Give it to him!'.

$\$ 9$ In the preceding examples, the two oblique personal indices, i.e. the second actant $l e$ and the third actant $l u i$, tend to form an inseparable block le lui (see $\$ 7$ ), be this block placed on the spoken chain immediately before or immediately after the verb: Vous le lui donnez 'You give it to him' and Le lui donnez-vous? 'Do you give it to him?' vs. Donnez-le lui! 'Give it to him!'. We call this block (le lui) the block of oblique indices.

$\$ 10$ Finally, all subordinates introduced by the prepositions $d e$ and $\dot{a}$, which can be actants or circumstants, can be represented by an index. In these cases, the index en takes the place of subordinate phrases that begin with the preposition $d e$, and the index $y$ takes the place of all subordinate phrases that begin with the preposition $\dot{a}$.

$\$ 11$ The index en can be an actant as in Pour avoir de vrais amis, il faut être capable d'en faire et digne d'en avoir 'To have true friends, one has to be capable of making them and worthy of having them' (La Rochefoucauld), where en takes the place of des amis. It can also be a circumstant of place, as in Alfred est à Paris, Bernard en vient, where en stands for de Paris. $\$ 12$ The index $y$ can be an actant, as in C'est lorsque nous sommes éloignés de notre pays que nous sentons surtout l'instinct qui nous y attache 'It is when we are distant from our country that we sense most the instinct that ties us to it' (Chateaubriand), where $y$ signifies à notre pays 'to our country'. It can also be a circumstant of place as in Ce qu'il y a de plus intéressant, c'est la simplicité des mours de la ville de Vevey; on ne m'y connaît que comme peintre, et j'y suis traité pourtant comme à Nancy 'What is more interesting is the simplicity of the customs in the city of Vevey; I am only known as a painter there, and I am yet treated there as in Nancy' (De Boufflers), where both $y$ signify à Vevey.

$\$ 13$ French is becoming more and more resistant to employing the indices en and $y$ when people are involved. In this regard Balzac writes: C'est un jeune homme et il a du cour. Nous ne pourrons jamais nous en emparer à son entrée à Fougères 'He is a young man with courage. We will never be able to get hold of him as he enters Fougères' (Les Chouans). French 
has an ever greater tendency to say: Nous ne pourrons jamais nous emparer de lui à son entrée à Fougères. Likewise, where the dictionary of the Academy specifies C'est un honnête homme, fiez-vous $y$, French has an ever greater tendency to say C'est un honnête homme, fiez-vous à lui 'He is an honest man, trust him'.

$\$ 14$ The indices en and $y$ constitute one of the great originalities of the Latin languages and in particular of French, since they express as much as the subordinates that they replace and that are sometimes very long. In general, foreign speakers of French do not know how to use them and, when a text, even written correctly in French, has been written by a foreign speaker, it is easy to detect due to the total absence of the indices en and $y$, whereas they appear quite naturally under the feather of native French speakers.

\$15 Although they are so intimately associated with the verb that they are practically agglutinated to it, the personal indices continue to be written as separate words in French: Vous le lui donnez 'You give it to him'. But even French orthography acknowledges the agglutination via a hyphen, when the construction causes the inversion of the verb and the indices, so that the indices, which usually appear before the verb, come to appear immediately after it, as in interrogative and imperative sentences: Le lui donnez-vous? 'Are you giving it to him?', Donnez-le lui! 'Give it to him!', Donnez-lui le livre! 'Give him the book!'.

$\$ 16$ In Spanish and in Italian, the oblique personal indices amalgamate to a single word in orthography and, if they follow the verb, also with the verb: It. Lei glielo dà 'You give it to him', Glielo dia! 'Give it to him!', Bisogna darglielo 'It should be given to him'; Sp. escribiéndolo 'writing it', prometiéndoselo 'promising it to him'. For this reason, the grammatical terminology of these languages often calls the personal indices joint personal pronouns.

$\$ 17$ The joint personal pronouns can be agglutinated to a noun to which they are subordinate: It. Comunicare numero riferimento e numero circolare ministeriale esatti specificando ogettole 'Communicate the reference number and the number of the exact ministerial bill by specifying its object'.

\$18 The agglutinated forms are also written with a single word in certain French dialects, as for example in Gascon, where it would be practically impossible to write $m$ alone in a sentence like Dechem droumi! 'Let me sleep!'.

$\$ 19$ The same is true in Breton where there are veritable joint personal pronouns as there are in Italian and Spanish. These personal indices agglutinate to the verb and are written as a single word together with the verb, e.g. - $i$ 'it' in keméret-i 'take it'.

\$20 In the languages where the indices are always written as a single word together with the verb on which they depend, they are called affix pronouns. Such is the case for example in Hebrew, where there is Kätab 'He wrote', but Ktābō 'He wrote it', or in Aramaic, in the celebrated sentence that the Gospel of Matthew and Mark attribute to Jesus as he was dying on the cross: Eli, Eli, lama šabhaqtani 'My God, my God, why have you abandoned me', where the verb šabhaq is followed by the two agglutinated indices - ta- 'you' (first actant) and $-n i$ 'me' (second actant). 
\$21 The affix pronouns exist very rarely in the Germanic languages. However, they can be found in dialects of German, for example in dialects of Alemannic: sagi for sage ich 'say I', bringem for bring ihm 'bring him' (Hebel, Alemanische Gedichte, Preface).

$\$ 22$ This means that the indices, which were originally perfectly autonomous personal nouns, have progressively become simple elements of the verb of which they have come to form a central part of in a number of languages. During this evolution, which has gradually caused them to lose their liberty of position in the sentence, they end up being trapped against the verb, around which they originally gravitated. But it is also evident that they have become immobile in the position that they occupied at the point when agglutination trapped them by robbing them of their original liberty of movement.

\$23 The result from the process described in the preceding paragraphs is that the rules that govern the order of agglutinated indices reflect the mechanism of their construction at a time when they were still autonomous. It is therefore possible to explain certain apparent anomalies, which in reality are merely a remnant of the free play of the original construction of personal nouns. For example, in French, when the index of a second actant coexists with the index of a third actant, the index of the third actant is placed after the index of the second actant, except if it is the autoontive or antiontive plural, in which case the index of the third actant is placed before that of the second actant: Donnez-le moi 'Give it to me', Donnez-la lui 'Give it to him', but Donnez-nous la 'Give it to us', Tenez-vous le pour dit, 'You won't be told again!', lit. 'Take it to you for said'.

$\$ 24$ In modern French, the position of the block of oblique indices (see \$9) is not the same as in the 17th century when it depends on a dependent infinitive of a verb of volition (modal auxiliary: vouloir 'want', pouvoir 'can', devoir 'must'). In the 17th century, the block of oblique indices preceded the verb of volition, whereas nowadays the block appears after the verb of volition but before the infinitive to which it is subordinate:

\begin{tabular}{lll}
\hline 17th century & Je le lui veux donner. & 'I want to give it to him.' \\
Now & Je veux le lui donner. & 'I want to give it to him.' \\
\hline
\end{tabular}

The elements of the block remain frozen together, but the group that they form is no longer fixed to the verb in the same position as it was in the 17th century. This situation proves that the freezing in the 17th century was not yet solid and definitive. After having tended to fix the block to the verb in one position, the block has finally come to be fixed definitively in another position.

\$25 In a conversation, it is easy to determine who the speaker is, and who the listener is. The speaker designates himself by employing the autoontive, and the listener is designated using the antiontive. But it is much more delicate to determine the person who is being spoken about, because the anontive can apply to any third party, person or even thing. That is the reason why anontive nouns and indices are in principle always anaphors (Chapter 43). Thus in the French sentence Je vous assure qu'il est parti 'I assure you that he 
has left', it is naturally understood that je designates the person who is speaking, and vous the person to whom s/he is speaking. But it is impossible for anyone who was not present at the beginning of the conversation and is therefore incapable of knowing the semantic source (Chapter $42, \$ 14$ ) of the anaphoric connection resulting in $i l$ to determine who is being spoken about and to know whether $i l$ is someone who has left or something, for instance a package, that has been sent by mail.

\$26 An oblique personal index can be governed by an incomplete sentence word (Chapter 46, \$2ff.): Me voici, te voici, le voici qui vient, lit. 'Here I am, here you are, here he is who comes. ${ }^{93}$

\section{Chapter 61. Indices and conjugations}

$\$ 1$ We have seen (Chapter $53, \$ 1$ ) that the personal nouns designate people by their grammatical person. Their essential function is thus to designate the person. Moreover, in many languages, especially exotic ones, personal conjugation is uniquely assured by the personal noun of the first actant, whereas the verb itself is invariable. Such is the case, for example, in Chinese and Samoan:

\begin{tabular}{|c|c|c|c|}
\hline \multicolumn{4}{|c|}{ Chinese } \\
\hline \multirow[t]{3}{*}{ Singular } & Anontive & tǎ dă & 'he hits' \\
\hline & Antiontive & $n \check{~}$ dă & 'you hit' \\
\hline & Autoontive & wǒ dă & 'I hit' \\
\hline \multirow[t]{3}{*}{ Plural } & Anontive & tă men dă & 'they hit' \\
\hline & Antiontive & nǐ men dă & 'you hit' \\
\hline & Autoontive & wǒ men dă & 'we hit' \\
\hline \multicolumn{4}{|c|}{ Samoan } \\
\hline \multirow[t]{3}{*}{ Singular } & Anontive & na te alofa & 'he loves' \\
\hline & Antiontive & e te alofa & 'you love' \\
\hline & Autoontive & ou te alofa & 'I love' \\
\hline \multirow[t]{3}{*}{ Plural } & Anontive & latou te alofa & 'they love' \\
\hline & Antiontive & tou te alofa & 'you love' \\
\hline & Autoontive & tatou te alofa & 'we love' \\
\hline
\end{tabular}

93. Translators' note: Fr. voici is the frozen form of vois (i)ci 'see here' and still has some verbal properties. 
$\$ 2$ Insofar as the personal noun of the first actant does not conserve its autonomy but rather becomes a simple atonal index, it no longer serves any other purpose than to mark the person of the verb and to thus assure the personal conjugation. Such is the case for example in Breton and English, where the index alone assures the personal conjugation, called impersonal in Breton, of the verb, whereas the verb itself remains completely invariable:

\begin{tabular}{|c|c|c|c|c|c|}
\hline \multicolumn{6}{|c|}{ Breton } \\
\hline \multirow[t]{3}{*}{ Singular } & \multicolumn{2}{|c|}{ Anontive } & \multicolumn{2}{|c|}{ eñ a gar } & 'he loves' \\
\hline & \multicolumn{2}{|c|}{ Antiontive } & \multicolumn{2}{|c|}{ te a gar } & 'you love' \\
\hline & \multicolumn{2}{|c|}{ Autoontive } & \multicolumn{2}{|c|}{ me a gar } & 'I love' \\
\hline \multirow[t]{3}{*}{ Plural } & \multicolumn{2}{|c|}{ Anontive } & \multicolumn{2}{|c|}{ i a gar } & 'they love' \\
\hline & \multicolumn{2}{|c|}{ Antiontive } & \multicolumn{2}{|c|}{ c'houi a gar } & 'you love' \\
\hline & \multicolumn{2}{|c|}{ Autoontive } & \multicolumn{2}{|c|}{ ni a gar } & 'we love' \\
\hline & \multicolumn{4}{|c|}{ English } & \\
\hline & \multirow[t]{3}{*}{ Singular } & \multicolumn{2}{|c|}{ Anontive } & he loved & \\
\hline & & \multicolumn{2}{|c|}{ Antiontive } & thou loved & \\
\hline & & \multicolumn{2}{|c|}{ Autoontive } & i loved & \\
\hline & \multirow[t]{3}{*}{ Plural } & \multicolumn{2}{|c|}{ Anontive } & they loved & \\
\hline & & \multicolumn{2}{|c|}{ Antiontive } & you loved & \\
\hline & & \multicolumn{2}{|c|}{ Autoontive } & we loved & \\
\hline
\end{tabular}

$\$ 3$ The personal index of the subject thus plays exactly the same role as the personal ending. This situation is evident in the typological comparison of Latin and French:

\begin{tabular}{llll}
\hline & Latin & French & \\
\hline Anontive & am-at & {$[\mathrm{il}-\varepsilon \mathrm{m}]$ il aime } & 'he loves' \\
Antiontive & am- $a$ s & {$[\mathrm{ty}-\varepsilon \mathrm{m}]$ tu aimes } & 'you love' \\
Autoontive & am-o & {$[3-\varepsilon \mathrm{m}] j$ 'aime } & 'I love' \\
\hline
\end{tabular}

This table shows that the French personal indices [il], [ty], and [3], which only function to indicate person, play exactly the same role as the Latin endings -at, -as, -o.

$\$ 4$ Agglutination of the verb to the personal noun of the subject is thus one of the most natural procedures by which languages develop their system of prefixes, affixes, or personal endings, that is, of their conjugation in general. In this way, the Semitic verb seems to have originally formed its perfect by agglutinating a postposed personal index and its imperfect by agglutinating a preposed personal index. This situation is still transparent in 
the majority of Semitic languages. For example in Hebrew, where the masculine singular allocutive personal noun has the form 'attāh 'you', the corresponding verbal forms are $k \bar{a} t a b \underline{t a}$ 'you have written' in the perfect and tiktob 'you will write' in the imperfect.

$\$ 5$ The preceding examples render the glossogenetic hypothesis, which has already been appropriately formulated, immensely probable. According to this hypothesis, personal endings stem from past personal nouns in all languages. This observation grants significant importance to the fact that in a number of languages, verbal endings present more or less striking analogies to the personal nouns. Thus in the Indo-European languages, it is characteristic for the endings of the anontive to be marked by a - $t$, which is identical to the theme - $t$ of the demonstrative. In Latin ama-t, for example, could well be the mere agglutination of the demonstrative to the verb, which has survived as such in Rus. to 'that' and as an article in Gr. tó, cf. Lat. (is) - tud 'that'.

$\$ 6$ The result of all this is that in the Latin phrase Aulus amat 'Aulus loves', the first actant is actually expressed two times, the first time purely etymologically by the ending $-t$, which is the residue of a former personal noun, and a second time by the word Aulus itself, which is the first actant and perceived as such. Saying Aulus amat is a little bit like saying Alfred il aime in French. And so the Latin form amat is employed equally with or without an accompanying overt subject. The form amat 'he loves' and Aulus amat 'Aulus loves' are therefore equally correct.

$\$ 7$ In this respect, speaking of agreement between the verb and first actant amounts to observing that the verb has already incorporated the first actant in a syntactically identical function to the currently existing first actant.

$\$ 8$ As the anontive personal indices become simple verbal endings, they tend to no longer contain an anaphoric link (Chapter $43, \S 9$ ), since they no longer serve to designate an actant. Such is the case for example with the so-called impersonal verbs. Indeed, $i$ in French Il pleut 'It is raining' and es in Ger. Es regnet in no way imply that there is an actant that performs the action of raining, but rather just that the verb designates a meteorological process, since this verb cannot be expressed as an autoontive or an antiontive. Instead, it must be expressed as an anontive as in Lat. Pluit 'It is raining' (Chapter 50, $\$ 6$ and 7, Chapter 98, \$1ff.).

$\$ 9$ This situation also occurs in sentences that contain a so-called apparent subject. This element is in no way an actant, since the true subject is identified further away; it is, rather, merely a grammatical tool serving to indicate that the verb is anontive. Thus in Fr. Il pleut des hallebardes 'It is raining cats and dogs', the one actant is des hallebardes 'halberds', not $i l$, since $i l$ functions merely to indicate that the verb is anontive. Therefore, $i l$, which is singular, cannot designate des hallebardes anaphorically, which is plural (Chapter 99, \$6).

$\$ 10$ Insofar as the personal index of the first actant becomes a simple personal ending and as a consequence loses its semantic value as first actant, it becomes necessary to express the first actant as the real subject, if a true first actant is to be expressed. This situation is evident in the frequent German saying Es lacht der Mai 'The (month of) May laughs' 
(Goethe). The first actant here is der Mai, and not es, which functions merely to indicate that the verb is anontive. And so es, which is neuter, cannot designate der Mai anaphorically because der Mai is masculine.

\$11 The real first actant, instead of being an ordinary noun, can also be a personal noun with full value. This personal noun with full meaning is thus far from performing a double function with the personal index, which has been emptied of meaning. In languages that have a personal index for the first actant, it is necessary to use the personal noun when one intends to emphasize the person of the first actant. The index that has lost its meaning is incapable of performing this role (Chapter $59, \$ 12$ ). This situation occurs in both French and Latin:

\begin{tabular}{llll}
\hline & Latin & French & \\
\hline Anontive & ille amat & lui, il aime & 'he loves' \\
Antiontive & tu amas & toi, tu aimes & 'you love' \\
Autontive & ego amo & moi, j'aime & 'I love' \\
\hline
\end{tabular}

In this table, the French group has exactly the same value as the corresponding Latin group, and it would be a grave mistake to view ego and je as equal and to translate ego amo as j'aime.

$\$ 12$ The index that lacks meaning cannot support the weight of an opposition. In such a case, it is necessary to appeal to the personal noun: Fr. Toi, tu chanteras, moi, je danserai 'You sing, me, I dance' (cf. Chapter 72, \$11 and Chapter 59, \$12).

$\$ 13$ In the preceding paragraphs, we have seen that the personal noun, as it gradually becomes a personal index and then a personal ending, arrives at a point where it furnishes the verb with its elements of personal conjugation. The emergence of the verb, which is not a universal fact of language (Chapter $32 \$ 5$ ), is a result of the agglutination of an action noun and a personal noun. This conclusion confirms the remarks that have already been made about the nominal origin of the verb (Chapter $32, \$ 5$; Chapter $54, \$ 3$, note 83 ; and Chapter 55, §3)..$^{94}$

\section{Chapter 62. Object conjugation}

\$1 We have seen that when personal indices of the subject have progressed to the point where they are completely agglutinated to the verb, they provide the personal endings that constitute conjugation, and it is this agglutination that causes the verb to agree in person, number, and sometimes even in gender with the first actant that depends on it.

94. Cf. Vaillant, Bulletin de la Société de Linguistique de Paris, 37 (1936), p. 104, and Benvéniste, Origine de la formation des noms en indo-européen, p. 173. 
\$2 But it can also occur that the verb agglutinates with the second actant to also make a personal ending. In these forms, the personal ending no longer indicates the person of the first actant, but rather, of course, that of the second actant. A verbal form of this type evidently agrees no longer with the first actant, but with the second actant that depends on it.

$\$ 3$ Agreement between the verb and its object must arise originally from agglutinations of this type. The fact seems rare enough, but a striking example can be found in the object conjugation of Hungarian. ${ }^{95}$

$\$ 4$ Object conjugation in Hungarian occurs in principle when the verb possesses a second actant. The verb látni 'see', next to its single infinitive form, therefore has two forms when it is the singular autoontive form of the present indicative. One form is employed when there is no second actant, and the other when there is a second actant. It is therefore Én látok 'I see', but Én látom a fát 'I see the tree', and also Én látom 'I see it', such that Én látom a fát in reality signifies 'I see it the tree'.

$\$ 5$ In this regard, object conjugation constitutes at times a completely parallel pattern to subject conjugation, for example, in the present of the indicative in Hungarian:

\begin{tabular}{llllll}
\hline & & \multicolumn{2}{l}{ Subject conjugation } & \multicolumn{2}{l}{ Object conjugation } \\
\hline \multirow{2}{*}{ Singular } & Anontive & ö lát & 'he sees' & ö lát-ja & 'he sees it' \\
& Antiontive & te lát-sz & 'you see' & te lát-od & 'you see it' \\
& Autoontive & én lát-ok & 'I see' & én lát-om & 'I see it' \\
\multirow{3}{*}{ Plural } & Anontive & ök lát-nak & 'they see' & ök lát-ják & 'they see it' \\
& Antiontive & ti lát-tok & 'you see' & ti lát-játok & 'you see it' \\
& Autoontive & mi lát-unk & 'we see' & mi lát-juk & 'we see it' \\
\hline
\end{tabular}

$\$ 6$ Note that nothing in the current morphology of Hungarian enables the indication of the agglutination of the personal index of the second actant. The forms of the personal noun and those of the conjugation do not have a common characteristic. In other words, the proof that the endings of the indices are the basis of object agreement is not delivered by morphological observations. Object conjugation is only plausible from a syntactic

95. Translators' note: Tesnière uses the now outdated terms subject conjugation and object conjugation for the Hungarian data. Alternative terms that may be more accurate and widespread nowadays are indefinite conjugation (instead of subject conjugation) and definite conjugation (instead of object conjugation). When the second actant in Hungarian is indefinite, conjugation occurs with the subject, not with the object. "Object conjugation" occurs almost exclusively when the anontive second actant is definite, a fact that Tesnière does not mention. 
point of view, and because, even though no index agglutination is historically provable, it is nevertheless true that in its actual state, the object agreement of Hungarian involves the notion of an incorporated second actant.

$\$ 7$ Hungarian makes use of object conjugation each time a verb has a second actant:

\section{Object conjugation in Hungarian}

a determined noun

Ö lát-ja a fát.

'He sees a tree.'

Ö lát-ja azt a fát.

'He sees this tree.'

a proper noun

Ö lát-ja Ernőt.

'He sees Ernest.'

a demonstrative

Ö lát-ja ezt.

'He sees this.'

pronoun

a complement clause, that is, with a clause that functions as the second actant (Chapter 241, \$6ff.) and is introduced by hogy 'that'

(Chapter 242, \$17)

an anontive

personal noun

a reflexive or reciprocal personal noun of whatever person (not only anontive, but also ontive)
Ö lát-ja, hogy szegény fiú vagy.

'He sees that you are a poor child.'
Ö lát-ja őt.

Ő lát-ja őket.

Ö lát-ja magát.

Én lát-om magamat.

Mi lát-juk egymást.
'He sees him (or her).'

'He sees them,'

'He sees himself'.

'I see myself.'

'We see each other.'

$\$ 8$ Note that, except with the reflexive and reciprocal, object conjugation is employed only with the anontive. For the ontive, Hungarian employs subject conjugation: Ö lát engem 'He sees me'; Ö lát magamat 'He sees only me', lit. 'He sees myself'.

$\$ 9$ Hungarian possesses a special suffix to indicate incorporation of a second antiontive actant into the verb. The suffix -lak (-lek) serves this purpose: Én látlak téged 'I see you ${ }_{\text {SING }}$ '; Én látlak titeket 'I see you ${ }_{\text {PLUR }}$ '.

\$10 While there are great similarities in structure across subject and object conjugation, the former having incorporated the index of a first actant and the latter that of a second actant, there remain considerable differences across the two processes. The verb agrees in number and person with the first actant, whereas with the second actant, the verb agrees only in person, but not in gender or number.

$\$ 11$ For example, Ö lát-ja a fát 'He sees the tree’ presents the same form lát-ja with a second singular actant as with a second plural actant, Ô lát-ja a fákat 'He sees the trees.

$\$ 12$ Likewise, with an anontive second actant, the same form látlak is present with the singular second actant téged as with the plural second actant titeket: Én látlak téged 'I see you $_{\mathrm{SING}}$ ' Én látlak titeket 'I see you $\mathrm{PLUR}^{\text {' }}$ 
\$13 Hence when the anontive second actant is unexpressed, Ö látja can mean 'He sees him (or her)' as well as 'He sees them', and when the antiontive second actant is unexpressed, the sentence Én látlak can mean 'I see you ${ }_{\mathrm{SING}}$ ' as well as 'I see you ${ }_{\mathrm{PLUR}}{ }^{\text {' }}{ }^{96}$

$\$ 14$ In conclusion, object conjugation and the suffix -lak (-lek) provide an interesting and suggestive parallel to conjugation coming, via agglutination, from the index of the first actant, showing that whatever form it takes on, conjugation always seems to stem from agglutination of personal indices to the verb, that is, of elements that were originally nouns.

$\$ 15$ When discussing object conjugation in Hungarian, it is impossible not to address the middle voice, which the similarity of Sanskrit and Greek leads us to attribute to IndoEuropean. Like in Hungarian, it is not possible to detect agglutination of a personal index using morphological analogies, but the meaning of middle forms show that they have incorporated the semantic content of a personal reflexive index.

$\$ 16$ Take the Greek form ahiroûmai 'I take for me', i.e. 'I choose', which is a form of the active ahirō 'I take.' This form indicates that the action, which has been performed by the speaker, has been done for the benefit of the speaker and according to his interest, in such a way that it includes the notion of this speaker and is expressed by the corresponding personal noun. French, which has no middle diathesis, can merely give an idea of this by expressing the personal noun moi in its full form, because in such a case, it cannot use a form reduced to an index or personal ending.

$\$ 17$ In the case of middle diathesis, the index that is incorporated is not that of a first actant nor that of a second actant, and it is not even that of a third actant. It is, rather, that of a circumstant, since the person referenced is not engaged in the capacity of being a person, but rather in the capacity of being a final cause: 'for me'. In the Occitan expression Me la suce o me la manje, l'irange? 'Do I suck it (for me) or do I eat it (for me), the orange?'. The index $m e$ is not a third actant with the meaning 'to me', but rather a circumstant of goal with the meaning 'for me'.

\$18 It should also be noted that a number of these Occitan uses of the middle voice exist precisely for the verbs that are middle in Greek, cf. Me pense que vendràs 'I think you will come', where the verb penser is a middle as is its correspondant in Gr. oiomai.

$\$ 19$ The Occitan expression exists also in Italian, you may hear Me lo merito 'I deserve it', lit. '(I) me-DAT it-ACC earn'.

\$20 When the index of the third actant is an antiontive, it often constitutes a well-known type of expression known as the ethical dative, which is generally interpreted as if the third actant was called to witness the expressed occurrence:

96. Translators' note: Tesnière was incorrect here. Both pairs prefer the singular reading if the second actant is omitted. The plural reading requires the appearance of the second actant. 
Le renard sort du puits, laisse son compagnon

Et vous lui fait un beau sermon

(La Fontaine, Fables, III, 5, Le renard et le bouc)

Philaminte: Vous ne voulez pas,

vous, me la faire sortir

(Molière, Les Femmes savants 'The learned ladies', II, 6)

Prends-moi le bon parti: laisse là tous les livres

(Boileau, Satires, VIII, 179)
'The fox climbs out the well, leaves his companion

And gives him a nice sermon for you.'

'Philaminte: You don't want to get her to leave for me'

'Make the right choice for me: leave all the books there'.

$\$ 21$ The ethical dative can simultaneously have two personal indices of the singular antiontive, the normal form and the polite plural form which is redundant with it, te vous 'you you'.

Avez-vous vu comme je te vous lui ai craché à la figure. (Victor Hugo, Les Misérables, IV, V, 13)

Je te vous lui aurais coupé la margoulette (Victor Hugo, Les Misérables, III, VIII, 20)

Comme je te vous lui flanquerais un bonne sommation respectueuse.

(Victor Hugo, Les Misérables, IV, VIII, 7)
'Have you seen how I spat in his face for you?'

'I would have cut his face for you.'

'How I would treat him to a nice respectable summons for you.'

\section{Chapter 63. The attributive adjective}

$\$ 1$ Just as the verb governs a certain number of subordinates, which are actants and circumstants, these subordinates themselves have different types of subordinates.

$\$ 2$ We have seen (Chapter $48, \$ 6$ ) that actants are generally nouns, be they personal nouns or not. These nouns are therefore structurally the point of confluence of a number of connections, and consequently form a node, known as the nominal node. It is important to understand that the ability of nouns to join connections together to form a node is not a result of the noun's status as a first, second, or third actant, but because of its quality as a noun.

$\$ 3$ If a noun governing a given node is a second instead of a first actant, only the connection above this node is sensitive to the distinction. The connections below the noun are unaffected; these lower connections remain unchanged. In other words, a dependent follows the fate of the noun that it depends on (Chapter $3, \$ 4$ ).

$\$ 4$ Take for example the nominal node your young cousin. The noun cousin governs both the qualitative adjective young and the possessive adjective votre (Stemma 132, cf. Stemma 18). The noun cousin and the two adjectives that it governs and with which it constitutes a nominal node can be a first, second, or third actant without the internal structure being affected by the nature of its superior connections with the verb. It can be a first actant, Your young cousin sings a song (Stemma 133), or a second actant, Everyone admires your young cousin (Stemma 134), or a third actant, Alfred gives a book to your young cousin (Stemma 135). 


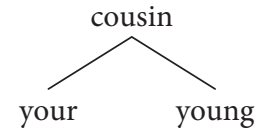

Stemma 132

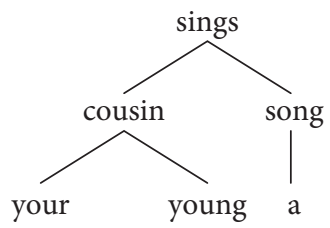

Stemma 133

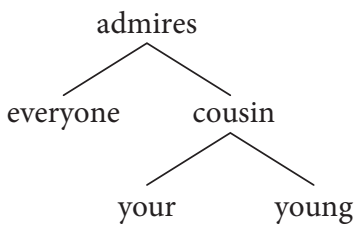

Stemma 134

\$5 Among the subordinates of the noun that make up the nominal node, the most ordinary of these is the attributive adjective, which serves to qualify the noun that it depends on. Thus in the sentence $A$ green light indicates an open road (Stemma 19), green is an attributive adjective that qualifies light. Without this adjective, the sentence would not be meaningful, since the color of the light would be unknown. Likewise, if the adjective green were replaced with the adjective red, the sentence would take on an entirely different meaning and would express a contrary reality, since a red light does not signal an open road, but quite the opposite, a closed one.

$\$ 6$ In principle, an adjective modifies the noun: a green light, a red light, your young cousin.

\$7 While the number of actants of the verb is limited to three, the number of attributes of the noun is unlimited: your pretty little white cat (Stemma 136).

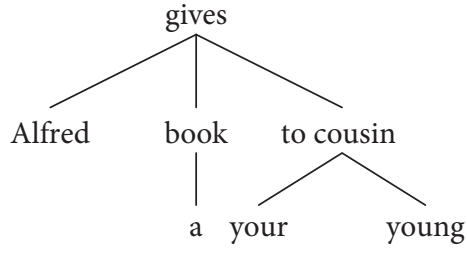

Stemma 135

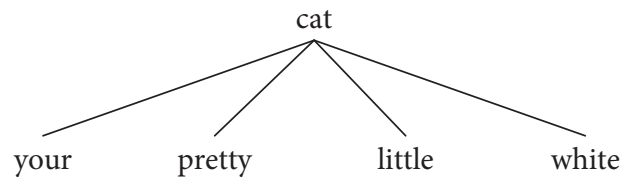

Stemma 136

\$8 In languages that have gender, the connection between a noun and an attributive adjective governed by the noun is marked by agreement. The attributive adjective takes the same gender, number and case as that of the noun it depends on: Fr. un grand arbre 'a big tree', une grande fabrique 'a big factory', Ger. ein großer Baum 'a big tree', ein großes Haus 'a big house', Gr. ho eurùs potamós 'the broad river'.

$\$ 9$ But in English, there is of course no such agreement, since the adjective is always invariable: a big tree, a big factory, a big house.

\$10 Invariability of the adjective is the exception in French: feu mon père 'my late father', feu ma mere 'my late mother'.

$\$ 11$ In a stemma, the connection between a noun and its attributive adjective will in principle be marked by a vertical line: a magnificent book (Stemma 137). In the case of multiple attributive adjectives, the vertical lines must of course be slanted (Chapter 3, \$8). Take for example the sentence Your young cousin gave a magnificent book to my poor nephew, its 
stemma is as follows (Stemma 138). It is necessary to consider that only the vertical aspect of these slanted lines have structural value, whereas the horizontal aspect is uniquely due to the material necessity of the graphic representation, and consequently does not express any structural notion.

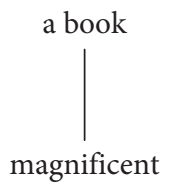

Stemma 137

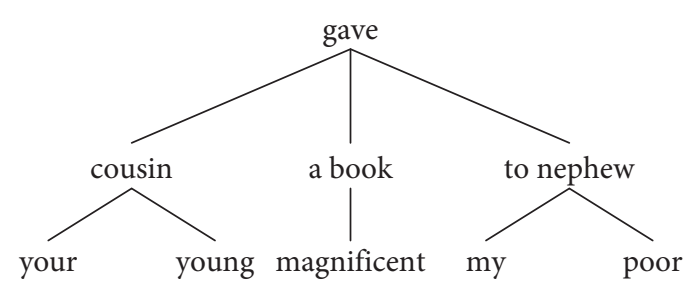

Stemma 138

$\$ 12$ The difference in the direction of the linearization of sentences that have a connection between a noun and an attributive adjective is one of the most striking that there is. In languages where attributive adjectives follow the nouns that they depend on, the linearization is centrifugal (Chapter $14, \S 4$ ), and as a consequence, the determining subordinate follows the determined governor. Conversely, in languages where the attributive adjective precedes the noun that it depends on, the linearization is centripetal, and as a consequence, the determining subordinate precedes the determined governor.

$\$ 13$ In this respect, the following languages are centrifugal:

\begin{tabular}{|c|c|c|}
\hline Bantu & $\begin{array}{l}\text { munu uzo mbi } \\
\text { man this bad }\end{array}$ & 'this bad man' \\
\hline Subiya & $\begin{array}{l}\text { muntu mulotu } \\
\text { man beauty }\end{array}$ & 'a man of beauty' \\
\hline $\begin{array}{l}\text { Ancient } \\
\text { Egyptian }\end{array}$ & $\begin{array}{l}\text { hrw } n f r \\
\text { day beautiful }\end{array}$ & 'a beautiful day' \\
\hline Samoan & $\begin{array}{l}\text { le funafuna pala'ai } \\
\text { the sea_cucumber cowardly }\end{array}$ & 'the cowardly sea cucumber' \\
\hline $\begin{array}{l}\text { Maghrebin } \\
\text { Arabic }\end{array}$ & $\begin{array}{l}\text { al-wādi al-kabīi }{ }^{u} \\
\text { the river the great }\end{array}$ & $\begin{array}{l}\text { 'the great river' } \\
\text { (cf. Sp. Guadalquivir) }\end{array}$ \\
\hline Romanian & $\begin{array}{l}\text { un hom bogat } \\
\text { a man rich }\end{array}$ & 'a rich man' \\
\hline Italian & un uomo ricco & same meaning \\
\hline Spanish & un hombre rico & same meaning \\
\hline Breton & eun den pinvik & $\begin{array}{l}\text { same meaning, also in Celtic, } \\
\text { cf. Bulletin de la Société de } \\
\text { Linguistique de Paris, } \mathrm{n}^{0} 36, \text { p. } 87\end{array}$ \\
\hline Eskimo & $\begin{array}{l}\text { ilu-totak } \\
\text { house old }\end{array}$ & 'old house' \\
\hline Basque & $\begin{array}{l}\text { gizon aberats } \\
\text { man rich }\end{array}$ & 'rich man' \\
\hline
\end{tabular}


$\$ 14$ Conversely, the following languages are centripetal:

\begin{tabular}{lll}
\hline Chinese & $\begin{array}{l}\text { hăo rén } \\
\text { good man } \\
\text { Rorošij čilovek } \\
\text { good man } \\
\text { eğri gemi } \\
\text { curved boat } \\
\text { ein weißes Buch } \\
\text { a white book }\end{array}$ & 'good man' \\
German & 'the good man' & 'curved boat' \\
English & $\begin{array}{l}\text { white book } \\
\text { een wit boek } \\
\text { a white book } \\
\text { turtingas žmogus } \\
\text { rich man } \\
\text { bagats cilvēks } \\
\text { rich man } \\
\text { zeleno carori } \\
\text { green grass } \\
\text { didikac'i } \\
\text { big man } \\
\text { Larust mard } \\
\text { rich man }\end{array}$ & 'a white book' \\
Romani & 'the rich man' \\
Georgian & 'the rich man' \\
Armenian & 'the green grass' \\
\hline
\end{tabular}

The same is true of modern Scandinavian (cf. B.S.L p. 36, p. 87), Finno-Ugric languages (in particular in Komi, Chuvash, Mari, Udmurt), Tatar, Mongolian, and Tungusic languages (cf. B. S. L. p. 36, p. 135)

$\$ 15$ It should be noted that the locality of Hennebont in Lower Brittany seems to have a very old centripetal construction: hen bont 'old bridge', in a region where the native language is still Breton today. The construction is confirmed by the appearance of the adjective hen in other Brythonic languages of every era.

\section{Chapter 64. The attributive adjective in mitigated languages}

$\$ 1$ In mitigated languages ( $\mathrm{cf}$. Chapter $9, \$ 2$ ), it can happen that two orderings of noun and attributive adjective are possible, whereby a difference in meaning is obtained across the two. Such is the case in French: while un homme brave necessarily means 'a brave man', un brave homme means 'a good man'; while une femme bonne means 'a good woman', une bonne femme simply means 'a woman' in a pejorative sense.

\$2 The normal order in French, i.e. the productive order, is centrifugal, since it is possible to say un livre rouge 'a red book', un chien intelligent 'an intelligent dog', whereas it is 
absolutely impossible to say ${ }^{*} u n$ rouge livre, ${ }^{*} u n$ intelligent chien. In these conditions, the normal form is therefore un homme brave, une femme bonne (Chapter 56, \$7).

$\$ 3$ In the case of centripetal order (un brave homme, un bonne femme), the adjective tends to more or less agglutinate to the following noun in such a way that a new noun is formed, which is a veritable composite noun.

$\$ 4$ The tendency towards agglutination is evident in four areas:

1. in orthography in terms of the tendency to use a hyphen, or even to write a single word;

2. in morphology in terms of the tendency to sense an intimate bond between the noun and the adjective, which often results in liaison in pronunciation;

3. in syntax in terms of the use of des instead of $d e$ as the partitive article;

4. in semantics in terms of the tendency for each of the two words to lose its meaning and thus present a new and original meaning together; it is difficult to assign each of the component words a clear compositional meaning.

$\$ 5$ Agglutination can be tracked in orthography, starting from words that remain graphically independent (un brave homme 'a good man', votre jeune cousine 'your young cousin', un petit garcon 'a little boy') to words that take a hyphen (petit-fils 'grand-son', grand-père 'grand-father') all the way to words that are written as a single word (bonhomme 'man', lit. 'good man', plafond 'ceiling', lit. 'flat bottom') (Chapter 11, \$9). The intermediate stages sometimes attest orthographic hesitation. This can be seen in the fact that bonhomme is still written as a single word, but bonne femme as two (Chapter 10, §15). Likewise, grand-père takes a hyphen, whereas grand'mère is deprived of this hyphen in favor of an apostrophe.

$\$ 6$ Liaison is not obligatory between a noun and a following adjective. It is equally acceptable to say un mouvement acceléré 'an accelerated movement' without liaison [õ̃muvmã akseleвe] as well as with liaison [õ̃muvmãtakselese]. But it is obligatory when the reverse order is present. It is impossible to say un bon enfant [oẽbonãfã] 'a good child' without liaison. ${ }^{97}$

97. Translators' note: From a synchronous point of view, it has often been argued that the root of the French adjective is the feminine form and that the final consonant of the masculine form is truncated: une pierre blanche [blãf], un caillou blanc [blã] 'a white stone' (pierre and caillou both mean 'stone', but pierre is feminine and caillou is masculine), une pierre verte [vest], un caillou vert [ves] 'a green stone'. When the final consonant is [n], the vowel is nasalized (bonne [bon] gives bon [bj̃]). When the liaison is required, the final consonant remains and the complete root is used. This is why bon is pronounced [bon] here even when the noun with which it agrees is masculine. 
\$7 This also marks the distinction between un savant allemand 'a German savant', where savant is a noun and allemand an adjective, and un savant Allemand 'a learned German', where liaison suffices to make savant an adjective and Allemand a noun.

$\$ 8$ Likewise, le beau idéal 'ideal beauty' signifies a conception of the beautiful that is ideal, whereas le bel idéal 'beautiful ideal' would signify an ideal that is beautiful. ${ }^{98}$ In English the expression beau-ideal, which is borrowed from French, is attested since 1801, where beau is a noun and ideal an adjective: the beau-ideal of domestic comfort (Charlotte Brontë, Jane Eyre, Chapter XI). However, it can be seen that, due to the centripetal structure of English, English-speakers tend to view ideal as the noun (cf. Oxford Dictionary, beau-ideal).

$\$ 9$ The sequence in which the adjective precedes the noun is sometimes so strongly agglutinated semantically that the two words are treated syntactically as a true noun. It is a known fact that when the adjective precedes the noun, the partitive article des of the plural is replaced with the preposition de. Therefore it is de savoureuses pommes 'tasty apples' yet des pommes savoureuses 'apples that taste good. While jeune is still more or less an adjective in de jeunes filles 'young girls' or de jeunes gens 'young people', who are young women or young men, by contrast the use of des in des jeunes filles and des jeunes gens clearly shows that jeunes filles and jeunes gens are no longer perceived as compound nouns. Une jeune fille 'a young girl, generally a teenager/unmarried female' is a completely different social type from une fille jeune 'a young girl'. A jeune fille could well be aged 50 or even more.

$\$ 10$ Conversely, when a compound group consisting of a noun and an adjective freezes and agglutinates, it does so readily in centripetal order, even when the group was originally centrifugal and it was therefore necessary to reverse the order of the elements. In Old French the term mère-grand existed, but the form grand'mère is the one that has been fixed.

$\$ 11$ Finally, when the adjective precedes the noun, the tendency is for the two to form a single word, with a new meaning, and as a consequence, the original meaning of the adjective is somewhat modified. If the adjective follows the noun, the meaning of the group is the sum of the meaning of the component parts. If on the contrary the adjective precedes the noun, the group that forms takes on a new meaning, which is only vaguely related to the sum of the meanings of the component parts.

$\$ 12$ Take for example the adjective brave 'brave', which is a synonym of courageux 'courageous'. The meaning is intact in the phrase un homme brave 'a brave man', which continues to signify un homme courageux. The meaning is that of the combined parts homme and brave. In contrast, in un brave homme the combination of the words creates a semantically new word for designating the social type of brave homme. This type evokes very complex

98. Translators' note: Although idéal is a masculine noun in French, the form of the adjective 'beautiful' is not beau [bo], but the complete radical, that is, the oral feminine form [bel], which is written as bel in this case rather than as belle (une belle femme'a beautiful woman'). 
qualities: honesty, benevolence, good-natured character, simplicity, etc. but is not necessarily un homme brave.

$\$ 13$ Likewise, un saint homme 'a saint' is an expression infinitely more nuanced than un homme saint 'a holy man'. In le saint homme, there is more leniency, unction, and sanctity than in l'homme saint, which possesses more real virtue. Thus just as un brave homme is not necessarily un homme brave, un saint homme is not necessarily a saint nor a man: un saint homme de chat, as written by La Fontaine (Fables, Le chat, la belette et le petit lapin 'The cat, the weasel and the little rabbit', VII, 16, Chapter 196, 1ff.).

$\$ 14$ The two possibilities for the position of the adjective in French thus furnish a mass of richly nuanced expressions. In un vieil ami 'an old friend', it is the friendship that is old, and the expression is nuanced with tenderness and affection, whereas in un ami vieux 'a friend that is old', the friend himself is old and the expression is more objective and carries less affection.

$\$ 15$ Alfred Sommerfelt wrote in a report (B. S L. 36, p. 87): "It is of significance in Celtic that the verb always appears in first position and the attributive adjective always follows the noun". 99 This judicious remark implies that the structural relationship between a verb and its actants is of the same nature as that between a noun and its adjective, for when one sequence is marked by centrifugal order, so is the other. This situation demonstrates, as suggested above, that the actants are subordinates of the verb, and not vice versa(Chapter 48 , $\$ 9)$.

\$16 This confirmation is important because the relationship between a verb and its actants is not as evident at first as the relationship between a noun and its attributive adjectives.

\section{Chapter 65. Non-adjectival attributes}

$\$ 1$ The role of an attribute is not always played by an adjective in the strict sense of the term. It can also be played by elements that, while clearly not adjectives per se, behave syntactically as adjectives (Chapter $151, \$ 17$ ).

$\$ 2$ The most frequent attributive subordinate of the noun after the adjective is the preposition $d e$ in French (and of in English). We will see below (Chapter 152, \$2-5) under what conditions the noun preceded by de can function like an adjective. It is in this way that we have expressions of the type le livre de Pierre 'Peter's book', un livre de raison 'a book

99. Translator's note: A note was included here addressing the fact that Sommerfelt uses the term attributif instead of the term épithète following the grammatical terminology of Germanic studies. Indeed, the adjectif attributif of French translates to predicative adjective in English, and the adjectif épithète of French translates to attributive adjective in English. This changeover has been performed consistently throughout this translation. 
of reason', le train de Paris 'the Paris train', where the de-phrases all function exactly like adjectives.

\$3 The same process exists in languages that have case, with the difference that the attribute of the noun, instead of being preceded by the preposition de, is put in the genitive, for example: Lat. puer egregiae indolis 'a child of good nature', Rus. čelovek vysokogo rosta 'a man of high stature'.

$\$ 4$ We will represent these phrases in stemmas as if they were really adjectives, since they function like adjectives and since the stemmas are tantamount to functional representations (Stemmas 32, 139, 140, and Chapter 152, \$3).

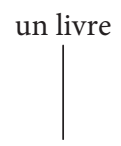

de raison

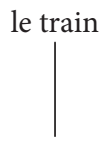

de Paris

\section{Stemma 139 Stemma 140}

\$5 These phrases, beginning with the preposition de, can be represented by the index en (Chapter 60, \$10), for example, in Racine’s verse Nourri dans le sérail, j’en connais les detours 'Nourished/raised in the seraglio, I know the hidden recesses of it' (Bajazet IV; 7, p.1424). In this case, en has an anaphoric connection to sérail 'seraglio'; it stands for $d u$ sérail.

$\$ 6$ The word en is therefore a veritable adjective, since it takes the place of an adjective in syntax. But traditional grammars and dictionaries do not seem to have recognized this aspect of en, which they view as a personal pronoun. This is an error on their behalf that makes it very difficult, if not impossible, to comprehend the true structure of a sentence that contains en.

$\$ 7$ The presence of the preposition $d e$ is not indispensable for the dependent noun to appear as an attribute, as seen in phrases such as Tour Eiffel 'Eiffel tower', le boulevard Gambetta 'Gambetta boulevard', le dîner Durand 'Durand dinner', l'affaire Dreyfus 'Dreyfus affair'. In these expressions, Eiffel, Gambetta, Durand and Dreyfus, which are all evidently nouns since they designate people, function like attributive adjectives, modifying tour, boulevard, dîner, affaire (Stemmas 141, 142, 143, 144).

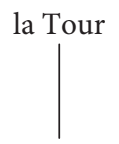

Eiffel

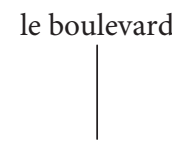

Gambetta

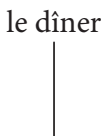

Durand

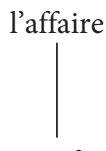

Dreyfus

\section{Stemma $141 \quad$ Stemma $142 \quad$ Stemma $143 \quad$ Stemma 144}

$\$ 8$ In the same manner, a noun in German can serve as, for example, a subordinate of another noun: ein Glass Bier 'a glass of beer' (Stemmas 145 and 146). 


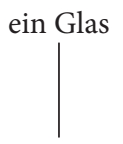

Bier

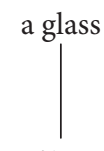

of beer

\section{Stemma 145 Stemma 146}

$\$ 9$ Compound nouns are formed by this process in a large number of languages (Chapter 175, \$1ff.). One of the two nouns retains its syntactic status as governor, and the other assumes the function of an adjective, that is, it plays the subordinate role of an attributive adjective that qualifies the governing noun. Across languages, the noun that functions like an attributive adjective is itself generally constructed like an attributive adjective.

S10 We find centrifugal compound nouns in the following languages:

\begin{tabular}{lll}
\hline Samoan & $\begin{array}{l}\text { itu-taua } \\
\text { party war } \\
\text { reménkēmi } \\
\text { man of Egypt }\end{array}$ & 'war-party' \\
& 'Egyptian' \\
Ancient & $\begin{array}{l}\text { 't-sb', (S. Coptic anzēbe) } \\
\text { room of teaching }\end{array}$ & 'school' \\
\hline
\end{tabular}

$\$ 11$ This order is not common in Greek, in which it can only be expressed by an archaic form or by a substrate. However, the order is attested in words such as:

\begin{tabular}{|c|c|c|}
\hline \multirow{3}{*}{ Greek } & $\begin{array}{l}\text { hippopótamos } \\
\text { horse river }\end{array}$ & 'hippopotomus' \\
\hline & $\begin{array}{l}\text { philánthrōpos } \\
\text { friend man }\end{array}$ & 'philanthropist' \\
\hline & $\begin{array}{l}\text { philósophos } \\
\text { friend wisdom }\end{array}$ & 'philosopher' \\
\hline
\end{tabular}

\$12 The German example Frauenzimmer 'young woman', lit. 'women room', is explained quite differently by a restriction of meaning. The word first designated a room in which the young woman resided, then by way of the reduction of the number of entities denoted, a single woman, then the young woman herself.

$\$ 13$ Centripetal compound nouns are found in the following languages:

\begin{tabular}{lll}
\hline Chinese & $\begin{array}{l}\text { shüfáng } \\
\text { book house }\end{array}$ & 'study' \\
Greek & $\begin{array}{l}\text { hudrophobia } \\
\text { water fear }\end{array}$ & 'fear of water' \\
\hline
\end{tabular}


$\$ 14$ This type is extremely frequent in Greek and is the base of a very large number of modern scientific words:

\begin{tabular}{lll}
\hline Latin & $\begin{array}{l}\text { agricultura } \\
\text { field cultivation }\end{array}$ & 'agriculture' \\
German & $\begin{array}{l}\text { Briefträger } \\
\text { letter carrier }\end{array}$ & 'postman' \\
English & postman & \\
\hline
\end{tabular}

\$15 This English sort of expression has penetrated French, where it even caused a trend at the start of the 20th century. At that time it was a fashion of questionable taste to produce English compositions such as Montpellier's bar and Fouquet's (hotel).

$\$ 16$ German draws a distinction between its compound words that are centripetal and syntactical groups of two nouns that are not compound and that adopt centrifugal order instead. The same elements come to have different meanings according to whether they are compound (centripetal) or merely syntactically juxtaposed (centrifugal). This particularity enables the distinction between different meanings and word plays, such as the one used by Bismark, who enjoyed saying to Frankfurters: Früh morgens ein Bierfass, spät abends ein Fass Bier 'In the early morning a beer barrel, in the late evenings a barrel of beer'. $\$ 17$ It is also in German that the adjectival nature of the subordinate noun is perhaps most evident in compounds, since there can be several of them that qualify the same governing noun (Chapter 63, \$7), for example der Brief- und Paketträger 'the letter and package carrier (the postman)'.

$\$ 18$ Compound nouns are basically of a nature that is semantically, if not syntactically, close to derived forms. It suffices that the syntactic relationship is gradually reversed so that the governing element, which is more important from a structural point of view, loses its prerogative to the benefit of the subordinate element, so that the word becomes a derived form. Take for example:

\begin{tabular}{lll}
\hline Eskimo & $\begin{array}{l}\text { sila-mio } \\
\text { earth resident }\end{array}$ & 'resident of the earth' \\
\hline
\end{tabular}

The element mio is not felt to be the governor of sila, but rather serves as a suffix to produce the derivative form sila-mio, which can be translated as earthling.

$\$ 19$ It is just as common to encounter cases where an autonomous noun utilized as the second part of a compound gradually loses its autonomy to become a simple suffix to the first element of the compound that it originally governed. The change of a personal noun to a suffix brings to mind the progressive change of personal nouns to personal indices and endings of verb conjugation (cf. 174, \$20). 
\$20 The Germanic languages, in particular English and German, furnish good examples of current suffixes that stem from formerly autonomous nouns. Take for example Ger. Gottheit 'divinity'. It is the agglutination of the much older Gothic forms gudis haidus 'manner of being God'. Similarly, the German suffix -tum corresponds to the autonomous Gothic noun dōms 'judgement', and the German suffix -lich corresponds to the Gothic leik 'body', cf. Ger. Leiche 'corpse' (Chapter 174, \$21ff.). Still further, the German suffixes -sam and -haft correspond respectively to the autonomous Gothic adjectives sama 'the same' and hafts 'that comprises' (Lat. captus).

\$21 Finally, the same fate certainly awaits, in a more or less distant future, the German compounds with the second element -mann, such as Kaufmann 'business man' and Seeman 'sailor', where the element -mann seems destined to become quite simply a suffix designating names of professions. ${ }^{100}$

\$22 When creating Esperanto, Doctor Zamenhof exploited this particularity so well that it is often not clear, given a particular word in Esperanto, if the word is a derived or compound form. Zamenhof borrowed from the generic Greek nouns Atrides, Pelopides, Peleides, a generic suffix -id-, which designates relatedness. For example, in addition to the Esperanto words la koko 'the rooster' and la hundo 'the dog', Zamenhof created the derivatives la kokido 'the chick' and la hundido 'the puppy', but at the same time, he employed the suffix -id- as a root in the noun la ido 'the child.' Consequently, the word kokido can be viewed just as well as a derived form, like Fr. coquet from coq 'rooster', or as a compound form 'the child of the rooster'.

\$23 Finally, in addition to the subordinate noun that functions like an attributive adjective, it is necessary to acknowledge the subordinate clause that functions like an attributive adjective, since it too is connected to the noun node. In the phrases the man who writes, the man who you see, etc..., the phrases who writes and who you see serve as attributive modifiers of the man in effect.We can therefore, more or less provisionally, ${ }^{101}$ stemmatize these sentences (Stemmas 147 and 148) like the previous ones (Stemmas 139-146).

$\$ 24$ Not all subordinates depend as closely on the noun as others. Some of them relate to the noun directly, whereas others are related to it more loosely (cf. Chapter 11, \$11-13) and are placed further away. They can be so distant that they seem to depend not on the noun controlling the node but on the node formed by the noun and one of its subordinates. \$25 In order to represent these nuances, which merit a more detailed analysis than can be produced here, it is possible (but not necessary in the standard practice of stemmas)

100. See Charles Bally, Linguistique générale et linguistique française, Paris, 1932, pp. 100, 233, and 311. Concerning formations that are thus at the dividing line between compound and derivation, see also Andvoort, Grammaire descriptive de l'anglais contemporain, translator Bouvet, I.A.C., 1949, $\$ 819$ and 820 .

101. We will see below (Chapter 246, \$9-15) that the stemma containing embedded clauses can be represented in a manner that is more precise, though roughly faithful to the decisions taken here. 
to adopt longer lines for more extended subordinates, and rather than connecting them directly to the node, to connect them to a point along the connection line between the noun and one of its close subordinates. By this process, the phrase the red car that you saw yesterday can be analyzed structurally in such a way that the connection line extending upward from the subordinate clause reaches the connection line connecting red to car. This means that that you saw yesterday is connected not to car but to red car, since what you saw yesterday was not the car, but the red car (Stemma 149).

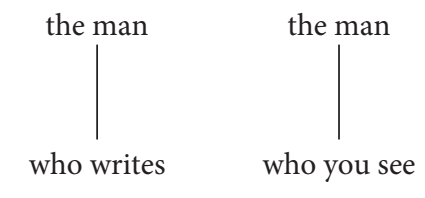

Stemma $147 \quad$ Stemma 148

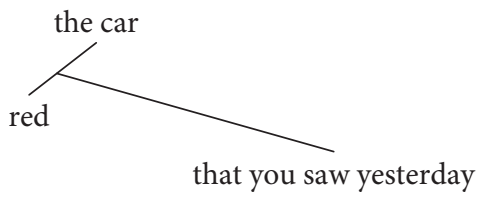

Stemma 149

\section{Chapter 66. The predicative adjective}

\$1 The attributive adjective is not the only type of adjective encountered. Adjectives can also appear in the sentence with the quality of a predicate. In the example the big house, big is an attributive adjective. In contrast, the sentence The house is big has big as a predicative adjective.

\$2 To form a complete sentence, it suffices to pronounce a first actant and its predicate. We reserve the designation predicate sentence for this type of sentence.

$\$ 3$ We have seen (Chapter $63, \$ 14$ ) that in many languages, the attributive adjective is pronounced before the noun that it depends on. Yet we observe that in the same languages, the predicative adjective occupies the opposite position with respect to the verb, that is, it follows the verb. Take for example the Komi bur kiv 'a good tongue.' The same words in the reverse order Kiv bur mean 'The tongue is good'. In other words, the adjective bur 'good' is an attributive adjective if it precedes the noun and a predicative adjective if it follows the noun. This law of position is at the core of the syntax of the majority of Ural-Altaic languages, which occupy almost all of central Asia and Siberia:

\begin{tabular}{|c|c|c|}
\hline Turkish & $\begin{array}{l}\text { Dil iyi } \\
\text { tongue good }\end{array}$ & \\
\hline Tatar & $\begin{array}{l}\text { Til yorš } \\
\text { tongue good }\end{array}$ & \\
\hline Chuvash & $\begin{array}{l}\text { Šelxe laix } \\
\text { tongue good }\end{array}$ & 'The tongue is good. \\
\hline Udmurt & $\begin{array}{l}\text { Kil dzeć } \\
\text { tongue good }\end{array}$ & \\
\hline
\end{tabular}


The phenomenon has even spread into Russian, where novyj dom means 'the new house', and Dom novyj 'The house is new'.

$\$ 4$ The interpretation of these facts is instructive. Should one conclude that these languages, which are centripetal when the adjective is attributive, cease to be centripetal when the adjective is predicative? That would be absurd, for, if the deep structural tendency of the language varied at the same time as the value of the attributive or predicative adjective, it would be impossible to understand this value, since it is based on position. We are forced, then, to admit that the marker of the adjective's value lies with the difference between the two constructions, and whether the adjective precedes or follows the noun determines whether it is attributive or predicative.

$\$ 5$ The opposition between antecedence and subsequence is thus parallel to the opposition between attributive and predicative. In a language that is consistently centripetal, it appears therefore that if the attributive adjective is subordinate to the noun, then the predicative adjective must be its governor.

$\$ 6$ But since the governor of the noun is normally a verb, the conclusion reached is that the predicative adjective plays the same structural role as the verb. In other words, in the Komi and Russian sentences cited above, the words bur 'good' and nov 'new' must be constructed like verbal nodes that the nouns kïv 'tongue' and dom 'house' depend on (Stemma 150 and 151).

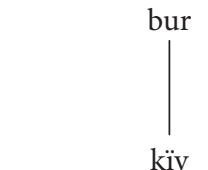

kïv
Kï bur

Stemma 150

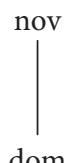

Dom nov

'The tongue is good' 'The house is new'

Stemma 151

$\$ 7$ In these stemmas, the nouns depend on the adjective-verbs, and the structure is exactly the reverse of the structure of attributive adjectives (Stemmas 152 and 153).

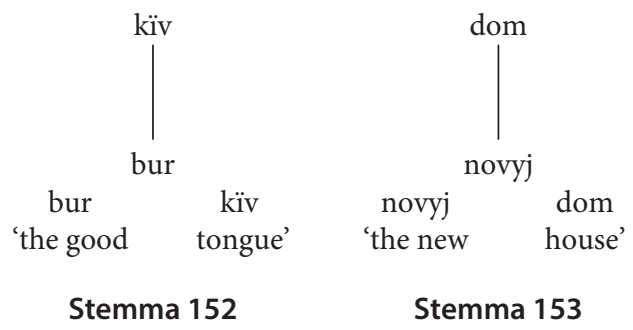

$\$ 8$ Predicate sentences also exist in Latin, where one can say Domus nova 'The house is new', lit. 'House new'. This sentence is of the same sort as the nominal sentence in Latin, as 
inherited from Indo-European. The same is true in Greek: Pántōn métron ánthrōpos 'The man is the measure of all things', (cf. Stemma 154).

$\$ 9$ In the Latin sentence Triste lupus stabulis 'The wolf is a harmful thing for the stables' (Stemma 155), the attribute triste is of course an adjective, but an adjective taken as a noun. The proof of this fact is that it is neuter and does not agree with the first actant.

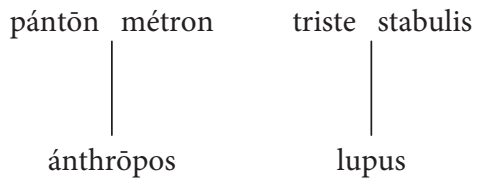

Stemma $154 \quad$ Stemma 155

\$10 In nominal sentences, the adjective plays the role of a predicate, since it expresses a quality that is attributed to the first actant. It is precisely this trait that makes the adjective the structural equivalent of the verb, which is the part of the sentence that governs an action. When I say Domus nova, lit. 'House new', I observe simply the state of newness of the house.

$\$ 11$ In addition to the predicate of a first actant in the nominative, there is a predicate in the instrumental in Russian. There is hence a difference between a nominative and an instrumental predicative adjective. The nominative predicative adjective expresses a permanent intrinsic quality of the first actant, whereas the instrumental expresses a passing and accidental quality thereof. Therefore there is a contrast between Anton byl kučer (nominative) 'Antoine was coachman', and On sidel kučerom (instrumental) 'He was sitting performing the role of coachman'. In the former case, we are dealing with a man whose profession is that of a coachman, and in the latter case, we are dealing with a man who performed the function of coachman on that day, but who was not a coachman by profession.

$\$ 12$ In the examples above, the predicative adjective alone can play the role of a verb without it being necessary to employ the verb être/be as in French and English. This expression without the verb être/be seems normal; it is probably the most frequent way of expressing predicative expressions across languages. Moreover, it is not completely excluded from French, since it appears in sentences of the sort Trois fois quatre douze 'Three times four (is) twelve'. It also occurs in German, e.g. Frankreich hoch! 'Long live France!'.

$\$ 13$ In languages that normally employ the verb 'be' with a predicative adjective (for example French and German), this expression is reserved for exclamative or interrogative sentences: Fr. Votre ami! un as 'Your friend! An ace', Ger. Wer da? 'Who (goes) there?' 
Madame Blandin: ... Nous, des viveurs? Ah! Ah! Des sous-viveurs tout au plus.
'Mrs. Blandin: ...Us pleasure seekers? Ah! Ah! At most sub-pleasure seekers.'

(H. Lavedan, Viveurs, acte IV)

$\$ 14$ Incidentally, most often the usual order of words is reversed, so that the predicative adjective is pronounced before the subject, which gives the utterance a particularly vigorous character: Très joli, votre tableau! 'Very pretty, your painting!', Excellent, votre poulet! 'Excellent, your chicken!' Remarquable, ce livre! 'Remarkable, this book!'

Un des jeunes gens: Gai, le Durand de ce soir, hé! (H. Lavedan, Viveurs, act II)

Heureux qui, comme Ulysse, a fait un beau voyage! (Du Bellay)

Beinheureux les pauvres d'esprit! Translation of Beati paupers spiritu of the Gospel

(Matthew, V, 3).

Ger. Heil Hitler!
'One of the young people: Happy, the Durand of this evening!'

'Happy he who, like Ulysus, has had a good trip!'

'Blessed the poor of wit!'

$\$ 15$ This type of sentence is strongly compatible with a predicate, since it is not strictly speaking, an adjective:

\begin{tabular}{|c|c|c|}
\hline \multirow[t]{2}{*}{ Participle } & $\begin{array}{l}\text { Déchirés les Compactats, enfuie la } \\
\text { dernière chance d'accommodement } \\
\text { entre Rome et la Bohême utraquiste! } \\
\text { (V. L. Tapié, Une église tchèque au XVe } \\
\text { siècle, l'unité des Frères, p. 59) }\end{array}$ & $\begin{array}{l}\text { 'Torn the agreements, run away the } \\
\text { last chance of compromise between } \\
\text { Rome and Utraquist Bohemia' }\end{array}$ \\
\hline & $\begin{array}{l}\text { Toute plissée sa jupe... } \\
\text { (Céline, Mort à credit, p. 21) }\end{array}$ & 'All pleated her skirt...' \\
\hline Noun & $\begin{array}{l}\text { Pas un endroit réservé, mon dos? } \\
\text { (Angry protest of a human billboard at } \\
\text { election time, cf. Le Matin, 27-XII-34) }\end{array}$ & 'Not a reserved spot, my back?' \\
\hline \multirow{3}{*}{$\begin{array}{l}\text { Noun } \\
\text { (third } \\
\text { actant) }\end{array}$} & À moi les gateaux, à toi les pénitences. & 'For me cakes, for you penitence.' \\
\hline & $\grave{A}$ bon chat bon rat. & 'Tit for tat.', lit. 'To good cat good rat'. \\
\hline & À coeur vaillant rien d'impossible. & $\begin{array}{l}\text { 'For brave heart, nothing impossible' } \\
\text { [Jacques Cœur's motto] }\end{array}$ \\
\hline $\begin{array}{l}\text { Temporal } \\
\text { circumstant }\end{array}$ & À demain les affaires sérieuses! & 'Tommorow, serious matters!' \\
\hline $\begin{array}{l}\text { Adverbial } \\
\text { locution }\end{array}$ & $\begin{array}{l}\text { Mais dans quel but cette trappe et cet } \\
\text { escalier? } \\
\text { (Alexandre Dumas, Le Vicomte de } \\
\text { Bragelonne, Visite domiciliaire) }\end{array}$ & $\begin{array}{l}\text { 'But to what end this trap and this } \\
\text { stair?' }\end{array}$ \\
\hline
\end{tabular}




\section{Chapter 67. Sentences with be}

$\$ 1$ In a number of languages, especially European languages, the dominance of the verbal sentence is so strong that it even appears in predicate sentences. The verb that is then chosen as the structural center is usually $b e$, because $b e$ is the verb that most naturally expresses a state. In this respect, we call the verb be a nominal verb. It is hence possible to distinguish two types of sentences with predicative adjectives, the pure predicate sentence, which was examined in the preceding chapter, and the be sentence.

\$2 The be sentence competes with the pure predicate sentence, even in Latin, and it is just as Latin to say Domus est nova 'The house is new' as Domus nova 'House new'.

$\$ 3$ Other languages completely ignore the pure predicate sentence and can only express the predicative adjective by placing the nominal verb in front of it. This sitatuation is true of French, e.g. La langue est bonne 'The tongue is good', and of a large number of other European languages.

\begin{tabular}{ll}
\hline Italian & La lingua è buona. \\
Provençal & La lengo es bona. \\
Occitan & La lenga es bona. \\
Spanish & La lingua es buena. \\
Romanian & Limba este bună. \\
Low Breton & An teod a zo mad. \\
German & Die Zunge ist gut. \\
Flemish & De tong is goed. \\
English & The tongue is good. \\
Latvian & Mele ir laba. \\
Polish & Język jest piękny \\
Ukranian & Jazyk je harnym. \\
White Russian & Jazik ësc' krasivym. \\
Serbo-Croatian & Jeik je dobar. \\
\hline
\end{tabular}

$\$ 4$ The predicative adjective of German often takes on a resultative value (Chapter $37, \$ 47$ ).

\$5 Thus employed, the verb be is sometimes called a copula, since its purpose is to unite the first actant and the predicate. This assumption does not do justice to the facts. The predicate that functions like a verb is structurally in the same position as the nominal verb, so its role is not to unify the nominal first actant and the predicate. It instead joins with the predicate and thus serves to mark the verbal role (Chapter 207, \$8). ${ }^{102}$

102. Concerning the opposition between the nominal verb and the copula, cf. what Vaillant says in the Bulletin de la Société de Linguistique de Paris, p. 37, p. 104. 
$\$ 6$ The result of this is that the nominal verb and the predicate together form a dissociated nucleus (Chapter 23, \$8), in which the nominal verb is the auxiliary, because it assures the structural function, and the predicative adjective is the auxiliated, because it assures the semantic function. In the sentence La langue est bonne, the auxiliary est has the structural role of being the center of the sentence, whereas the auxiliated bonne merely expresses the quality that is assigned to the first actant. Due to the presence of the nominal verb, it is possible to utilize an adjective as the auxiliated, which for that matter does not present any distinction with an attributive adjective.

$\$ 7$ For this reason, a predicative adjective, just like an attributive adjective, agrees in gender, number, and case with the first actant that it governs. ${ }^{103}$

$\$ 8$ The intimate union of the nominal verb with the predicate in a dissociated nucleus is also marked morphologically in certain languages.

$\$ 9$ Thus in ancient Greek, it is clear that a nominal verb employed as an auxiliary is no more than a simple grammatical tool, deprived of its autonomy, that loses its accent, becoming an enclitic: agathós estin 'It is good' (with a sole accent for the nucleus group).

$\$ 10$ Likewise in Georgien, the nominal verb, the form of which is aris 'is', is generally reduced to the atonic form $-a$, which then functions as a veritable suffix: Melani šavi-a 'The ink is black'.

$\$ 11$ In the case where the predicate is supported structurally by the presence of the auxiliary be, the position of the predicate in the stemma coincides with that of the auxiliary verb and the logical thing to do is to produce the stemma of the sentence The house is new by positioning is new in the same hierarchical position (Stemma 156, also Stemmas 151 and 157).

\$12 But this move would have the drawback that it would force two elements into one position. In this regard, it would be better to show the difference graphically between the elements. The drawback would become even more severe if the predicate itself were constituted by multiple elements, since all these elements would have to be put in the same block as the auxiliary. This situation would prevent any graphic rendition and would thus be contrary to the very notion of stemmatic representations. We therefore agree to place the predicates on the same horizontal level as the actant that they govern. As well as being unavoidable, this move does not result in a serious problem, for it is possible, if need be, to enclose the predicate inside the same nucleus circle that contains the auxiliary that supports it structurally (in order not to confuse it with an actant) and then mark the semantic connection between the predicate and the actant that the predicate governs by way of a dashed anaphor line (Chapter $42, \$ 3$ ). In this manner, the underlying connection survives, even though the predicate is graphically removed from the auxiliary where the connection

103. Translators' note: Nevertheless, in German the predicative adjective does not agree with the first actant, as explained in Chapter $70 \$ 7$, although the attributive adjective agrees with its governor. 
line ends (Stemma 157). Further, the structural connection that connects the actant to the nucleus can only reach to the auxiliary verb, which, since it is inside the dissociated nucleus, assumes the structural function entirely.

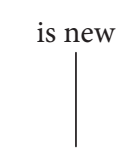

the house

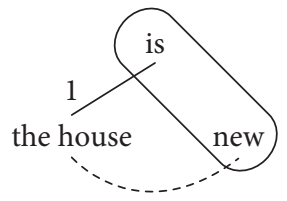

Stemma 157

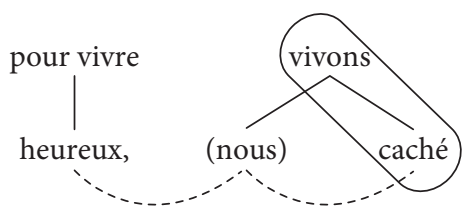

Stemma 158

\$13 In such cases we call the stemma an expanded stemma, in order to indicate that the internal structure of the dissociated nucleus is analyzed graphically in its entire extension and in full detail. We therefore find ourselves faced with two possibilities for rendering the stemmas: abbreviated stemma vs. expanded stemma. Our choice of stemma type will depend on the necessities of the demonstration at hand, and we will use an expanded stemma only in the event that the abbreviated stemma does not sufficiently present the graphic analysis of the point at hand.

\$14 Just as an attributive phrase, instead of being an adjective, can be a noun preceded by the preposition of (Chapter $65, \$ 2$ ), a predicative phrase, instead of being an adjective, can also be a phrase of this kind. Thus in the sentence Alfred is of excessive friendliness, the nominal node excessive friendliness, which is preceded by the preposition of, constitutes the predicate that governs the first actant.

\$15 The same phenomenon can be observed in many languages, for example in Russian: On byl vycokogo rosta 'He was of high stature' (Chapter 65, \$3).

$\$ 16$ Just like the attributive role, the predicative role can be played by a noun that is not preceded by of (Chapter $65, \$ 2)$ : In the kingdom of the blind, the one-eyed are kings. The same in Greek: Hè sophía estin arkhế tês eutukhías 'Wisdom is the beginning of happiness'. $\$ 17$ In addition to the proper nominal verb, there is a certain number of related verbs that are susceptible to combining with a predicate. These verbs are become, remain, seem, count as, etc. The predicate that appears with these verbs expresses a quality of the first actant:

\begin{tabular}{lll}
\hline French & $\begin{array}{l}\text { On devient cuisinier, mais on naît rôtisseur. } \\
\text { (Brillat-Savarin, Physiologie du goût, }\end{array}$ & $\begin{array}{l}\text { 'One becomes a cook, but one is } \\
\text { Aphorisme du professeur, IV) }\end{array}$ \\
Latin & $\begin{array}{l}\text { Cicero creatus est consul. } \\
\text { Ego nominor Leo. }\end{array}$ & 'Cicero was made consul.' \\
German & Das heißt gelogen. & 'I am called Leo.' \\
& & 'That is a lie., \\
& & lit. 'That is called lied.' \\
\hline
\end{tabular}

\$18 Finally, we will see below that the predicate function can be fulfilled by a participle: My plan is stopped, by a personal noun: I become myself again, by an infinitive: Fr. Souffler 
n'est pas jouer 'Huffing is not a real move', lit. 'To huff is not to play', and by an adverb: This man is well (Chapter 177ff.). ${ }^{104}$

$\$ 19$ When an adjective serves as the predicate over a personal noun, this personal noun can still be reduced to the role of an index, or even to the role of an incorporated complement to the verb. In such a case, it will be represented covertly by a virtual node, to which on one side a connection line extends coming from the verb or elsewhere and to which on the other side a dashed anaphor line extends from the predicative adjective: Pour vivre heureux, vivons cachés 'To live well, (we) live secretly' (Stemma 158). ${ }^{105}$

\section{Chapter 68. Predicates of the second and third actants}

\$1 In addition to the predicate over the first actant, the second actant can also have a predicate. The quality expressed by this predicate is not assigned to the first actant, but to the second actant. Such is the case in French in the sentence J'appelle un chat un chat et Rolet un fripon 'I call a spade a spade and Rolet a rascal', lit. 'I call a cat a cat...'(Boileau, Satire I, v. 52), where the quality of 'cat' is assigned to the second actant un chat and the quality of being a rascal to the second actant Rolet. Another example: Je te baptise carpe 'I baptize you a carp', where the quality of being a carp is assigned to the dish denoted by the antiontive personal index te.

$\$ 2$ In Je t'aimais inconstant, qu'aurais-je fait fidèle? 'I loved you fickle, what would I have done (if you had been) faithful' (Racine, Andromaque, IV, 5, see 1365), the predicate inconstant 'fickle' indicates the quality by which the person designated by the personal index $t$ ' 'you' (Pyhrrus) was loved. This famous sentence contains a quite drastic instance of ellipsis, since fidèle 'faithful', although in the second sentence, is also the predicate of $t$ ', which is in the first sentence (Stemma 159).

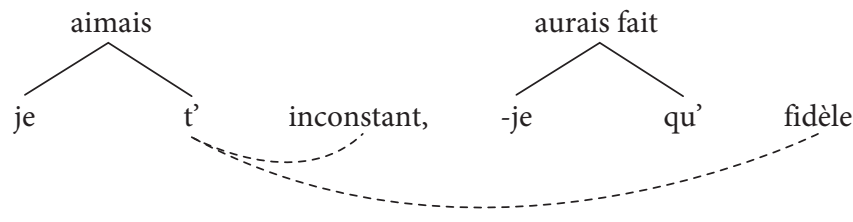

Stemma 159

104. Translators' note: Interestingly however, most adverbs cannot appear as predicative expressions, e.g. * They were happily.

105. Translators' note: vivons 'let's live' is a 1st person (autoontive) plural imperative, so there is no expressed subject. 
\$3 Just as there are verbs that normally co-occur with a predicate over the first actant (Chapter $67, \$ 17$ ), there are certain verbs that co-occur with a predicate over the second actant. Principle examples of such verbs are make, render, take for, call, name, find, e.g. call you responsible, name someone general, find someone quite pale.

$\$ 4$ In languages that have case, the second actant appears in the accusative and its predicate also appears in the accusative: Lat. creare aliquem consulem 'name someone consulACC', appellare aliquem regem 'declare someone king-ACc', Gr. Ahiroûntai auton arkhonta 'They choose him as leader-AcC'.

$\$ 5$ This mechanism is merely a development of the previous one and the relationship between the first actant and the quality assigned to it remains the same. It is only insofar as the first actant becomes the second actant that the quality expressed by the predicate follows it into its new role. In the Lat. Romani creaverunt Ciceronem consulem 'The Romans elected Cicero consul', the relationship between Ciceronem and consulem is the same as between Cicero and consul in Cicero erat consul 'Cicero was consul'. But this relationship, instead of being observed as a simple state, is given as the result of the intervention of the new actant Romani, which takes the position of the first actant, while the former first actant Cicero is relegated with its predicate consul to the role of second actant. This complex relationship is illustrated in the Schemas 160 and 161.

$\$ 6$ The preceding points suggest that in Russian, a predicate over the first actant can, when it denotes a fleeting quality, occur as a predicate over the second actant; it remains in the instrumental and has the same nuance. We therefore have Pëtr byl astronom (nominative) 'Peter was an astronomer', but On nazval svoju cobaku Astronomom (instrumental) 'He had named his dog Astronomer. In the first case, it is a man whose profession is astronomy, whereas in the second case, it is simply a quality assigned to a dog by pleasantry used as a name, but the dog is not really and will never be an astronomer.

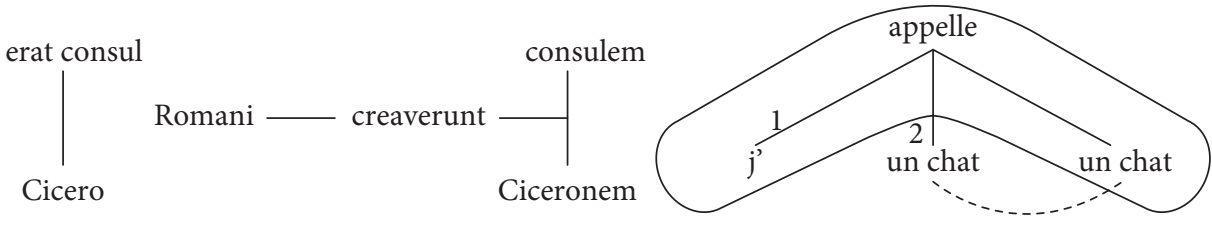

Schema 160

Schema 161

Stemma 162

\$7 Under the same condition, a predicate can express a quality assigned to a third actant. In languages with case, a predicate can appear in the same case as the third actant, that is, in the dative. Take for example Lat. Mihi non licet esse otioso 'One does not allow me to be idle. The predicate otioso is in the dative because the quality that it expesses is assigned to the personal noun mihi, which is also in the dative by virtue of being the third actant of licet. 
$\$ 8$ In stemmas containing a predicate over a second or third actant, it is usual to use the expanded stemma, since it would otherwise be impossible to distinguish the predicate over the second or third actant from a predicate over the first actant. The situation is evident with sentences like J'appelle un chat un chat 'I call a spade a spade'(\$1), Romani Ciceronem consulem creaverunt 'The Romans elected Cicero consul', or Otioso mihi esse non licet 'One does not allow me to be idle' (Stemma 162, 163 and 164).

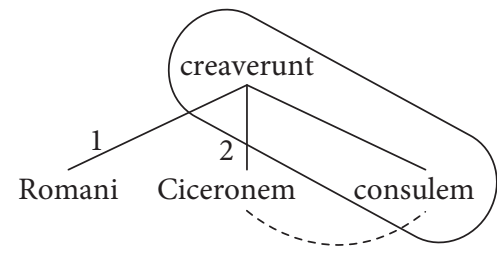

Stemma 163

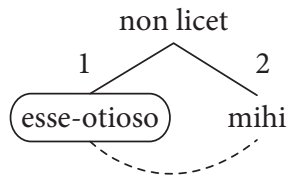

Stemma 164

In the preceding stemmas, we have positioned the predicate to the right of the actant that it governs. For the sake of clarity, we adopt this convention each time it is possible, that is, when a dissociated nucleus is present containing both an auxiliary verb and a full predicate.

$\$ 9$ This arrangement, as in Stemma 163, reproduces the economy of Schema 161 consistently, with the sole difference being that it takes the form of a proper stemma because the verb appears at the top as the structural center of the sentence.

\section{Chapter 69. The apposition}

$\$ 1$ An apposition is a noun that takes part in a noun node. Take the following sentence: Louis XIV, king of France, protected the letters and the arts. The noun king here is said to be in apposition to Louis.

$\$ 2$ The noun in apposition is part of the nominal node associated with the superordinate noun. King is commanded by Louis. Indeed, king has a semantic connection directly to Louis, for which it is merely a hypostasis.

$\$ 3$ As stated, the word king has a connection directly to Louis. It is now appropriate to study the nature of this connection.

$\$ 4$ It was apparent early on that this connection is not vertical (despite Chapter 2, §7). Structurally, one sees that king is on the same plane as Louis. The two nouns are alike, and as a consequence, they should not appear on separate levels. This sentiment is so evident that it inspired the term apposition. The term itself indicates that the two nouns are equilevel; the one is not above or below the other. 
\$5 On the other hand, the apposition is not connected directly to the verb. It does not depend directly on the verb, but rather it is mediated by the noun node. Thus king is not connected directly to protected, but only to Louis, which in turn does have a direct connection to protected.

$\$ 6$ If I say Louis XIV protected the letters and the arts, this certainly implies that the king of France protected the letters and the arts, since Louis XIV was the king of France. This situation does not prevent one from assuming that it was Louis XIV (and not the king of France) to whom I attribute the role of protecting the letters and arts. It is up to my interlocutor to extract the consequence from my words and in doing so, to deduce that, since Louis XIV protected the letters and the arts, it was exactly also the king of France who protected the letters and the arts. But that is not what I said. I am content to establish a connection between Louis and king. From the structural point of view, I indeed want to set Louis and the king equal. But while the two elements are equivalent to each other, that does not force the conclusion that they are identical. Structurally, a specific difference survives between the two: Louis alone is the first actant of protected, whereas king is merely a predicate over Louis.

\$7 From a graphic point of view, we will fix the connection between the noun, the center of the nominal node, and its apposition using a horizontal line. But only the nominal center of the node will receive a connection line reaching to the verb since, as we have seen, the noun in apposition does not have a connection to the verb (Stemma 165).

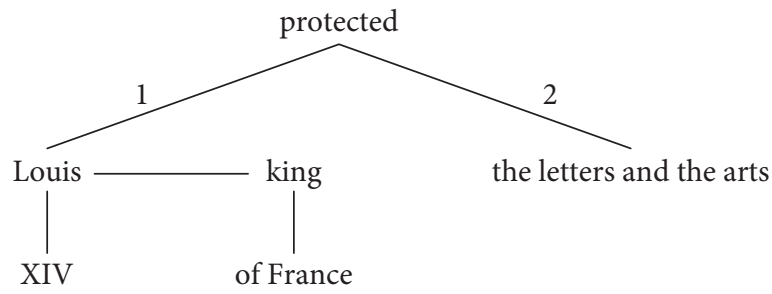

Stemma 165

\$8 This arrangement permits one to make it clear that it was Louis alone who I state to have protected the letters and the arts. The king of France may not have participated in this affirmation at all, a fact that is seen in the horizontal line and mediation of Louis.

$\$ 9$ The apposition is thus fully distinguished on the one hand from an attribute, and on the other hand from a predicate. Both of these elements are vertically connected to the central noun of the nominal node. What this means is that these elements are also connected to the apposition, since the apposition appears on the same horizontal level as the central noun.

$\$ 10$ It is necessary to pay attention, so as to not confuse the apposition, which is attached structurally to an actant, with an apostrophe, which is expressed with the vocative in languages that have case. The topic is discussed in Chapter 71 . 
$\$ 11$ In certain sentences, confusion is possible that leads to a big misinterpretation. The saying Souffre, enclumeau, frappe, marteau 'Suffer, anvil, beat, hammer' would be misunderstood if one considered enclumeau 'anvil' and marteau 'hammer' as apostrophes, as if one ordered the anvil to suffer and the hammer to beat. They are, rather, in apposition to the unexpressed first actant of the imperative verb (Chapter 71, \$11). In this latter, correct interpretation, one understands that the given order is to suffer in the role of an anvil and to beat in the role of a hammer, that is, to be flexible enough to bend when necessary and to take advantage of the situation when possible.

$\$ 12$ The preceding example could thus be glossed in English in the following manner: 'Suffer when (or if) you are the anvil, beat when (or if) you are the hammer. This is where the exact value of the apposition appears, which, since it is not itself an actant, tends to readily take on the light nuance of a circumstant (when, temporal, or if of condition) at the same time that it remains entirely connected horizontally to the noun to which it is in apposition.

\$13 This circumstantial nuance can be variable. Thus in the sentence $A$ remarkable orator, Atticus was a mediocre writer, if the quality of being a mediocre writer is attributed to Atticus by the predicate, this quality stands in contrast to the quality that Atticus receives from the apposition. The latter can even take on the meaning of a concessive circumstant: Although a remarkable orator, Atticus was a mediocre writer.

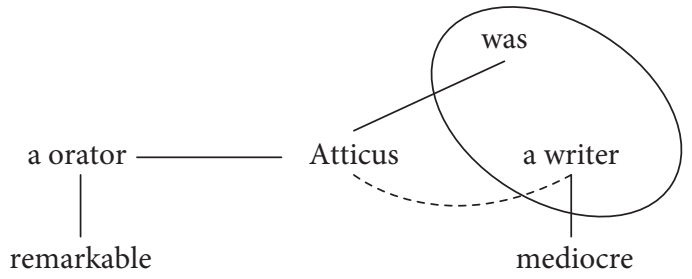

\section{Stemma 166}

$\$ 14$ In languages that have case, the apposition, being attached to the central nominal node by definition and thus playing essentially the same role, appears in the same case: Lat. urbs Roma 'the city of Rome', Hannibal debellavit urbem Romam 'Hannibal destroyed the city of Rome'.

$\$ 15$ Regarding these two examples, we will see below (Chapter 195, \$8) that in the structure of the city of Rome or the city of Paris, the expressions of Rome or of Paris are not appositions like the ones currently being examined, but rather they are attributes.

$\$ 16$ But while the noun in apposition agrees in case with the central noun of the node, it need not agree with it in gender, nor in number. It is not an attributive adjective, but rather a noun, and as such, it has its own gender and number, whereas its function is the same as that of the central nominal node. This is why one says urbs Lugdunum 'the city of Lyon' in 
Latin with the neuter Lugdunum in apposition to the feminine urbs, or urbs Athenae with the plural Athenae in apposition to the singular urbs.

$\$ 17$ In order to bring out the circumstantial nuance of the apposition, it can be expedient, when translating from Latin, to invert the roles and produce a circumstant that one subordinates to the apposition from the center of the former verbal node, Admodum senex suasor legis Cinciae fuit 'It was at an advanced age that he passed the law Cincia' (Cicero, de Senectute, 4, 10).

$\$ 18$ Sometimes it is very difficult to arrive at the translation necessary to render a circumstantial nuance of Latin. It is thus absolutely impossible to translate literally the exclamation attributed by Suetonius to Nero as he was dying: Qualis artifex pereo! (Vita Neronis, 49). The English translation 'Which artist, I am dying!' is not comprehensible. But one can note that all good attempts at translation tend to bring the notion of circumstant into play in one form or another: 'What artist died in me!, Which artist died in my person!'

$\$ 19$ Greek tends to make a sort of apposition from an adjective when it wants to emphasize the quality expressed by the adjective. It suffices for it to substantivize the adjective by means of an article (Chapter $173, \$ 3,4$, and 6) in such a manner that one is in the presence of two veritable nouns, whereby the second is in apposition to the first. Hence to the attributive adjective agathós of ho agathós patếr 'the good father', Greek readily substitutes the adjective nominalized in apposition in ho patếr ho agathós 'the father, the good', where the quality of goodness is expressed with more energy.

\section{Chapter 70. The adjective in apposition}

$\$ 1$ We have seen (Chapter $65, \$ 7$ ) that the role of an attribute, which is normally played by an adjective because the connection is vertical and it is therefore necessary to choose a type of word that can be subordinate to a noun, can also be played by a noun. Conversely, while the role of an apposition is normally played by a noun, an adjective can also take on this role: Lat. Aristides mortuus est pauper 'Aristides died poor', Gr. Autòs êken 'He came himself.

\$2 An adjective in apposition behaves like a noun; it takes on the nuance of a circumstant (locative, temporal, manner):

\section{Latin}

Locative Duobus summis oratoribus, Crasso et Antonio, L. Philippus proximus accedebat (Cicero, Brutus, 47, 173).

Temporal

Manner
Assiduus in oculis fuerat.

Praeceps abiit.
'L. Phillipus was the one who got closest to the two eminent orators Marcus Crassus and Marc Antony'

'He had been constantly in view.

'He departed hastily'. 
\$3 In the examples above, circumstantial character is expressed by an adverb in English, but it can also be expressed by an adverbial expression in the form of a noun (either a personal noun or an infinitive) preceded by a preposition:

\begin{tabular}{lll}
\hline Latin & French & \\
\hline Rediit incolumis. & Il est revenu en bon état. & 'He returned uninjured.' \\
$\begin{array}{l}\text { Haud timidi } \\
\text { resistunt. }\end{array}$ & Ils resistent avec & 'They resist without \\
\hline
\end{tabular}

$\$ 4$ The role of the adjective apposition itself can be taken by a participle:

Etant petit garcon, je lisais son roman. 'Being a small boy, I read his novel, Et je le lis encore, ayant la barbe grise. $\quad$ And I still read it, having a gray beard.'

(La Fontaine, Poésies diverses, VII, Ballade, 15-16)

The translations have the same adverbial character:

\begin{tabular}{ll}
\hline Latin & \\
\hline $\begin{array}{l}\text { Faciam libens. } \\
\text { Diversae duae legiones } \\
\text { proeliabuntur. }\end{array}$ & 'I will do it willingly.' \\
Feci non invitus. & 'Two legions fought separately.' \\
Sapiens nihil facit invitus. & $\begin{array}{l}\text { 'The sage does nothing inspite } \\
\text { of himself.' }\end{array}$ \\
Non rogatus venit. & 'He came without being asked.' \\
\hline
\end{tabular}

$\$ 5$ Greek is particularly fond of expressions containing a participle in apposition:

\begin{tabular}{|c|c|}
\hline Greek & \\
\hline Epaúsato makhómenos. & 'He stopped struggling.' \\
\hline $\begin{array}{l}\text { Élathe ekhthròs ón. } \\
\text { (Xenophon) }\end{array}$ & $\begin{array}{l}\text { 'He did not let it be known } \\
\text { that he was an enemy.', } \\
\text { lit. 'He remained hidden } \\
\text { being an enemy.' }\end{array}$ \\
\hline $\begin{array}{l}\text { Toûton humeîs epîstasthe } \\
\text { hēmâs prodónta. }\end{array}$ & $\begin{array}{l}\text { 'You know that he } \\
\text { betrayed us.' }\end{array}$ \\
\hline $\begin{array}{l}\text { Deíxō ohútō taûta ékhonta. } \\
\text { (Plato) }\end{array}$ & $\begin{array}{l}\text { 'I will show that he is } \\
\text { of that sort.' }\end{array}$ \\
\hline
\end{tabular}

$\$ 6$ In contrast to the noun in apposition, which does not show gender and number agreement, the adjective and the participle in apposition agree with the noun to which they are in apposition not only in case, but in gender and number as well. Accusative: Lat. Eos non 
possum retinere invitos 'I cannot keep them despite them'; dative: Quorum rerum altera mihi vivo nunquam eripietur, altera ne nortuo quidem 'The first (of these passions), one will never take it from me alive, and death will not separate the second from me'.

$\$ 7$ The German adjective in apposition remains invariable. We are therefore dealing with a proper adjective or participle:

Fest gemauert in der Erden, Steht die Form aus Lehm gebrannt.
'Firmly built in the earth

Stands the form of cooked clay.

(Schiller, Das Lied von der Glocken, 1-2)

German shares this particularity with the predicative adjective: Die Form ist in der Erde fest gemauert 'The form is solidly built in the earth'. One can conclude from this observation that in German, the adjective or the participle does not agree with an inferior connection (attribute) or a horizontal connection (apposition), but only with the superior connection: die in der Erde fest gemauerte Form 'the form built firmly into the earth'.

$\$ 8$ When a word is in apposition to a personal noun (cf. Chapter $67, \$ 19$ ), this noun can still be reduced to the role of an index or even incorporated into the verb. In such a case, it is represented covertly by a virtual node, to which a horizontal line reaches from the apposition on the one hand and a vertical connection line reaches coming from the verb on the other hand. This is what happens in a sentence like Mortuus est pauper 'He died poor', where pauper is in apposition to the first actant of mortuus est. This actant is incorporated into the verb and is no longer expressed overtly (Stemma 167).

$\$ 9$ Although the apposition occurs in principle with an actant, it can also appear with a non-actant noun. Expressions of this sort are more or less acceptable by virtue of the nature of the anacolutha that they present:

Voisin de l'une des parties les plus giboyeuses de la forêt et entouré de toutes parts par une agglomeration de bois communaux, la position accidentée de ce hameau en rendait la surveillance plus difficile.

\begin{abstract}
'Neighbor to the most bountiful part of the forest and sourrounded by a conglomeration of communal forest in every direction, the hilly position of this hamelet rendered its surveillance more difficult?.
\end{abstract}

(Murger, Le Sabot rouge, I)

In this example, the appositional nodes governed by the noun voisin 'neighbor' and the participle entouré 'surrounded', which are masculine, can only refer to the masculine noun hameau 'hamelet', which is incorrect, since hameau is itself not an actant, but rather it functions as an attribute qualifying the word position 'position', which is feminine.

$\$ 10$ The anacolutha is even more solid when the apposition does not become an actant, but an idea that is not expressed by a noun: 
D'ailleurs il était question d'améliorer ce service en le logeant plus au large, tout un vaste local sous une des rampes du Rosaire et dont on préparait déjà l'aménagement
'Besides, it was a question of improving the service by accomodating it more in the open, an extensive area which was under one of the slopes of the Rosaire and was already accommodated'

(Zola, Lourdes, IV)

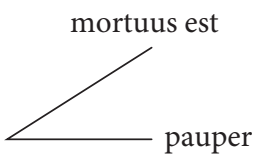

Stemma 167

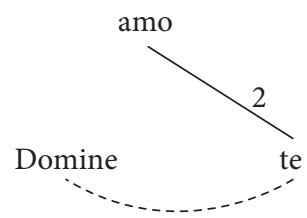

Stemma 168

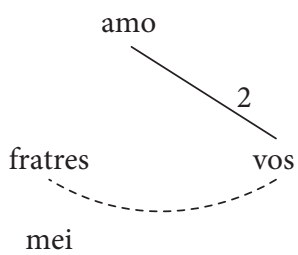

Stemma 169

\section{Chapter 71. The apostrophe}

\$1 The apostrophe is an appellation that the speaker uses to capture the attention of his interlocutor by naming him. Thus in the sentence Nicole, apportez-moi mes pantoufles 'Nicole, bring me my slippers' (Molière, Le Bourgeois Gentilhomme, II, 4), Nicole is an apostrophe because it allows Monsieur Jourdain to call Nicole, or to be more exact, it directs her attention to the order that he is about to give her.

\$2 By way of its appellation and the manner in which it corresponds directly to its purpose, which is to grab attention, the apostrophe is generally placed at the front of the sentence. But it can also be located at the end of the sentence: Prends un siege Cinna 'Take a seat, Cinna' (Corneille, Cinna, V. 1) (cf. Stemma 170). In this case, the appellation is less imperative and corresponds to a more moderate tone.

$\$ 3$ Since it serves to call, the noun of the apostrophe is essentially an antiontive. In languages with case, this antiontive character is marked by a special case, the vocative, e.g. Lat. Domine! 'Lord'.

$\$ 4$ The noun of an apostrophe can serve to capture the attention of someone who is not directly implicated in the process and who as a consequence is expressed by an antive or autoontive node: anontive My God, this country is so beautiful!, autoontive My God, I am so tired!.

$\$ 5$ But as soon as the person called appears as an actant of the verbal node, an automatic anaphoric connection is established between the noun of the apostrophe and this actant, since both designate the same person. 
$\$ 6$ In the case where it is the second actant that is antiontive, an anaphoric connection is established between the word of the apostrophe and the second actant: Lat. Amo te, Domine 'I love you, Lord', Amo vos, fratres mei 'I love you, my brothers' (Stemmas 168 and 169).

\$7 The preceding examples permit one to show clearly the difference that exists between an apostrophe and an apposition. The proof that one is not dealing with an apposition is that in languages that have case, the word of the apostrophe does not appear in the same case as the actant to which it refers, but in the vocative, which corresponds to a structural position that is outside of the verbal node. Thus in the Latin examples above, Domine and fratres mei are vocatives. The singular form of the vocative is different from the nominative form Dominus. The plural form of the vocative is the same as the nominative for fratres, but the form mei is clearly not that of the accusative.

$\$ 8$ If instead of being an apostrophe, the words Domine and fratres mei were in apposition, they would agree with the second actant and thus appear in the accusative: Amo te Dominum, Amo vos fratres meos. But the meaning would be much different: 'I love you as Lord, because you are the Lord' and 'I love you as brothers, because you are my brothers'.

$\$ 9$ In the case where the first actant is antiontive, the matter is less clear, because the vocative borrows from the nominative every time there is no proper form, which generates confusion, but the principle is the same. The apposition to the first actant appears in the nominative, whereas the noun of an apostrophe is vocative, for example in Latin: Quousque tandem, Catilina, abuteris patientia nostra? 'How long, Catilina, will you abuse our patience' (Cicero, In Catilinam, I, 1).

$\$ 10$ But if the verb is in the imperative, since the imperative is inherently antiontive due to the fact that the order that one gives is addressed to the listener, there is necessarily an anaphoric connection between the word of the apostrophe and the first covert actant you of the imperative: Prends un siège, Cinna 'Take a seat, Cinna' (Stemma 170).

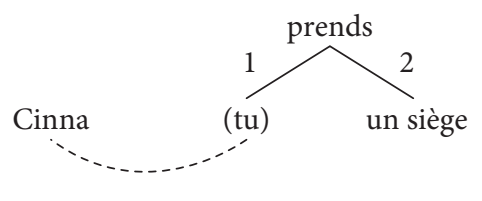

\section{Stemma 170}

$\$ 11$ In this case the apostrophe, which is not a proper actant, behaves structurally as the virtual first actant of an imperative verb.

$\$ 12$ The reason for this is that the person called by the apostrophe using an imperative sentence is the one who would function as the first actant if the same sentence were in the indicative, for example Nicole apporte les pantoufles de Monsieur Jourdain; Cinna s'assied 'Nicole is bringing the slippers of Monsieur Journal; Cinna sits down'. 
\$13 The Latins and Greeks experienced the event so clearly (but very rarely, and only in poetry) that they placed the attribute to the unexpressed first actant in the vocative: ${ }^{106}$ Lat. Venias hodierne 'Come today' (Tibulle, I, 7, 53), Gr. Ólbie, koûre, génoio 'Happy, young man, be' = 'Be happy, young man' (Théocrite, idylls, 17, 66).

$\$ 14$ This is also the reason why the imperative agrees in number with the noun of the apostrophe. If Auguste says prends 'take', he does so because he is addressing Cinna alone. If, in contrast, Allons 'let's go' is plural in the first verse of the Marseillaise Allons, enfants de la Patrie 'Go, children of the Fatherland', that is because the verse is addressed to the children of the Fatherland, which are plural. The case of Nicole, apportez-moi mes pantoufles 'Nicole, bring me my slippers' is isolated, since the plural of apportez is not the plural of agreement, but the plural of politeness.

\$15 Just like the imperative to which it corresponds, the apostrophe takes from the nature of the interjection. The apostrophe is an actant employed with the value of an interjection just like the imperative is employed with the value of an interjection.

$\$ 16$ Similarly, the interjective form of the verb is the imperative and that of the noun is the vocative, which, as we have seen $(\$ 7)$, the languages that have case distinguish from the nominative.

$\$ 17$ The fact that the vocative and imperative have morphological characteristics in common is not merely a matter of chance, for example the $-e$ in Latin and Greek in the theme inflection: Lat. Parce, Domine 'Have pity, Lord', Gr. Lége, o Kúrie 'Speak, Lord'. We are in effect dealing with the same Indo-European form with the suffix ${ }^{*}-e$, but without inflection. It is the bare theme, non-inflected, which answers more closely to the invariable character of the interjection.

$\$ 18$ The interjection is an appellation by definition, a sort of shout that must immediately capture the attention of the person addressed. The core aspect of this call is that it must be immediately evident upon utterance. But since inflection appears at the end of words in Indo-European languages, inflection is of little use in an interjection.

$\$ 19$ This very situation is the reason why in colloquial Russian, a new vocative is arising that is characterized by the apocope of the nominative endings. This new vocative is in addition to the ancient vocative that survives in six clerical words of Slavonic origin.

\begin{tabular}{lll}
\hline Nominative & & Vocative \\
\hline staryxa & 'old woman' & staryx \\
Nikita & 'Nikita' & Nikit \\
Anja & 'Johnny' & $A n '$ \\
Atja & 'Papa' & $A t '$ \\
\hline
\end{tabular}

106. V. Riemann, Syntax latine, edition revised and corrected by Ernout, $\$ 28$, number 2 . 
\$20 The tendency to focus attention on the start of the vocative forms is readily evident in the domain of accents. Thus in Greek, one observes that in cases where the vocative differs from the nominative in intonation, the accent slides forward in the vocative from its position in the nominative:

\begin{tabular}{lll}
\hline Nominative & & Vocative \\
\hline patếr & 'father' & páter \\
anếr & 'man' & áner \\
gastếr & 'stomach' & gáster \\
gunế & 'woman' & gúnai \\
rhếtōr & rhéteur & rhêtor \\
daérr & 'brother-in-law' & dãer \\
daímōn & 'demon' & daîmon \\
despótēs & 'master' & déspota \\
Dēmétēer & 'Demeter' & Démēter \\
authádē & 'sufficient' & aúthades \\
Apóllōn & 'Apollo' & Ápollon \\
thugátēr & 'sister' & thúgater \\
adelphós & 'brother' & ádelphe \\
Poseidón & 'Poseidon' & Póseidon \\
\hline
\end{tabular}

In any case, the accent slides as far forward as it can without breaking any of the complicated laws of accentuation in Greek:

\begin{tabular}{lll}
\hline Nominative & & Vocative \\
\hline Agamémnōn & 'Agamemnon' & Agámemnon \\
eleémōn & 'merciful' & eléénon \\
\hline
\end{tabular}

\$21 The words are rare that do not exploit the possibility to move the accent in the vocative to maximum potential. But even in this case, the direction of the movement is backward all the same:

\begin{tabular}{|c|c|c|}
\hline Nominative & & Vocative \\
\hline basileús & 'king' & 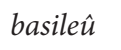 \\
\hline euốdēs & 'odiferous' & euôbes \\
\hline stratiôtēs & 'soldier' & stratiôta \\
\hline
\end{tabular}

$\$ 22$ One finds this reduction in Sanskrit, where the vocative pitār 'god' shows a change of accent in relation to the nominative pitáa and in the accusative pitáram. 
\$23 Finally, the same shift occurs in the feminine plural of certain Serbo-Croatian words: nominative plural žène, vocative plural žëne 'women'. The low accent represents an accent in Serbian that has moved from one syllable and that therefore was otherwise on the final syllable of the word, whereas the double low accent represents a more brief accent that has not changed and that was, therefore, formerly on the first syllable. At this earlier stage, the vocative accent, which was still on the initial syllable, experienced a change in relation to the nominative.

\$24 The diverse works on pre-Indo-European, in particular those of E. Benvéniste, have shown that the alternative e/o/zero seemed to depend on the accent, the full degrees coming from accented forms, the zero degree coming from atonic forms. It is appealing to note that the Indo-European vocative of themes in ${ }^{*}-\bar{a}$ - is also characterized by the zero degree ${ }^{*}-\curvearrowright$ in front of the full degree ${ }^{*}-\bar{a}$ of the nominative, for instance Homerian Greek nominative númphē, vocative númpha, nominative Old Slavic, Czech žena, Serbo-Croatian žèna, Polish glowa - vocative Old Slavic, Czech ženo, Serbo-Croatian žèno, Polish głowo. But the ${ }^{*}-\bar{a}$ of the nominative represents a former ${ }^{*} e \partial_{2}$, the degree $e$ of which reveals an accented vowel in pre-Indo-European, while the ${ }^{*}$ of vocative represents a pre-Indo-European $\partial_{2}$, the zero degree of which reveals a former vowel that falls away because it was atonic. As the last vowel of the word, for it was an ending, the accent was on the previous syllable. The question is whether it would be the trace of a backward movement of the accent in the pre-Indo-European vocative.

\section{Chapter 72. The projection of actants}

$\$ 1$ Actants in certain languages sometimes have such pronounced autonomy that it is difficult to discern whether or not they partake in the verbal node at all. They are no longer related to the verbal node by a proper structural connection per se, but rather by an indirect semantic connection.

$\$ 2$ This is the case for example in French where the expression, which exists in familiar language, is extremely expressive. For example, the sentence Le loup a mangé l'agneau 'The wolf ate the lamb' is readily replaced, notably in the language of children, by the following sentence, which is much more lively and vigorous: Le loup, il a mangé l'agneau, lit. 'The wolf, he ate the lamb'.

$\$_{3}$ In the last sentence of the preceding paragraph, the actant loup 'wolf' belongs to the stemma of the sentence only by virtue of the anaphoric connection that relates it to the personal index $i l$, which is in turn related to the verb. The index has been more or less incorporated into the verb by a structural connection (Stemma 171).

$\$ 4$ While the semantic connection between the verb and the actant loup is thus indirectly assured by the intermediate personal index $i l$, the structural connection in contrast is extremely loose, and the actant has a certain structural autonomy. This autonomy is 
marked in the spoken chain by a pause, represented in orthography by a comma or even by a colon: Le nez de Cléopâtre: s'il eût été plus court, toute la face de la terre aurait changé 'The nose of Cleopatra: if it had been shorter, the entire face of the world would have changed' (Pascal, Pensées, II, 162, ed. Brunschvieg).

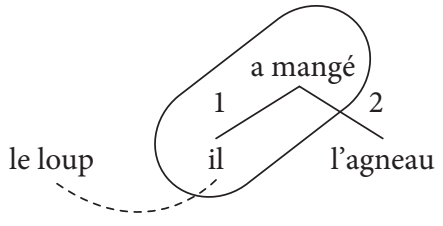

Stemma 171

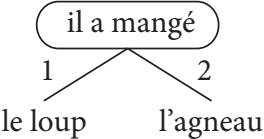

Stemma 172

\$5 Detached from the verb in this manner, the actant is strongly emphasized and appears to be projected outside of the verbal node. That is why we say there is a projection of an actant in such a case.

6.The phenomenon can be presented differently: the index, since it is completely incorporated into the verb, is considered part of the verb's nucleus. The actant loup is then analyzed as the subject dependent of this nucleus (Stemma 172). But this conception has the drawback of not accounting for the phonetic autonomy of the phrase le loup, which is projected away from the verb on the spoken chain.

\$7 The noun that is projected at a distance from the verb is separated from the words of the verbal nucleus. Take for example the sentence Le loup a mangé l'agneau 'The wolf ate the lamb'. If we project le loup, we get Le loup, il a mangé l'agneau 'The wolf, he ate the lamb', where le loup forms a separate group. If, however, we project l'agneau, l'agneau will form a separate group: L'agneau, le loup l'a mangé 'The lamb, the wolf ate her'.

$\$ 8$ The result of this is that the projected actant can appear equally before or after the verbal group. In the preceding examples, the projected actant is placed before the verbal group on the spoken chain, but it could just as well be placed after the verbal group: Il a mangé l'agneau, le loup 'He ate the lamb, the wolf'; Le loup l'a mangé, l'agneau 'The wolf ate her, the lamb' ${ }^{107}$

\$9 Insofar as the actant is projected at a distance from the verbal center and is consequently separated from the verb on the spoken chain, the sequence that expresses this connection with the verb (Chapter $6, \$ 5$ ) is broken. This is why it is indispensable to reestablish the connection, at least semantically, by use of an anaphoric connection. The anaphoric connection is thus the inevitable price to pay for the break in the sequence, and

107. Translators' note: Left and right dislocations are possible in English, but they are much more productive in French, especially in spoken language. 
that is why every actant projection is necessarily accompanied by an anaphoric connection and thus by an anaphor.

$\$ 10$ The anaphor is an anontive personal index in principle, but it can also be a demonstrative pronoun: Ah! C'est un vrai type, ton pére! 'Ah! He's the real thing, your father!', lit. 'Ah! That's a real guy, your father!' (Denys Amiel, Ma Liberté, acte I, p. 10).

$\$ 11$ Concerning the projected actant, it is usually a noun, but it can also be a personal noun: Toi, tu chanteras; moi, je danserai 'You, you will sing; me, I will dance' (Stemma 173). Due to the autonomy of the actant, this construction has the effect of elevating the actant to an extremely pronounced position (Chapter 61, \$12).
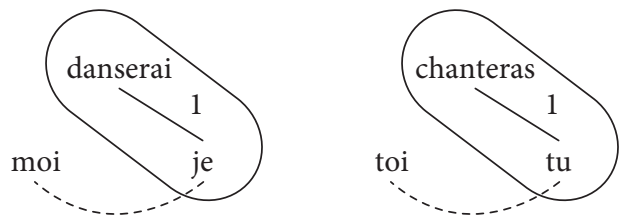

Stemma 173

$\$ 12$ A projected actant can take part in a subordinate clause, in which case it must be entirely separated in the spoken chain from the subordinate clause: Je suis surpris, vous qui voyagez beaucoup, que vous ne le sachiez pas, lit. 'I am surprised, you who travels a lot, that you do not know that' (Jean-Jacques Bernard, Nationale 6, p. 11). It can even be separated from it by the main clause: Vous qui voyagez beaucoup, je suis surprise que vous ne le sachiez pas, lit. 'You who travels a lot, I am surprised that you did not know that'. Or further, it can be projected inside the main clause: Regarde Jean, quelle drôle de tête il a 'Look at John, how funny he looks' (Maupassant, Contes: La Reine Hortense) (cf. Chapter 61, \$12).

$\$ 13$ The projected actant need not be the first actant. It can also be the second or third actant:

Projected second and third actants

\begin{tabular}{lll}
\hline $\begin{array}{l}\text { Second } \\
\text { actant }\end{array}$ & $\begin{array}{l}\text { Mon doigt, l'abeille l'a piqué. } \\
\text { Ma mére, je la vois. } \\
\text { (Meilhac \& Halévy, Carmen, I) }\end{array}$ & $\begin{array}{l}\text { 'My finger, the bee stung it. } \\
\text { My mother, I see her. }\end{array}$ \\
$\begin{array}{l}\text { Third } \\
\text { actant }\end{array}$ & $\begin{array}{l}\text { Mon malheureux cousin, je lui } \\
\text { ai offert un beau livre. }\end{array}$ & $\begin{array}{l}\text { 'My poor cousin, I } \\
\text { offered him a nice book.' }\end{array}$ \\
\hline
\end{tabular}

$\$ 14$ The projection can also concern a circumstant: Là-bas, je n'y vais jamais, lit. 'Over there, I never go there'.

$\$ 15$ But if this circumstant is a noun preceded by a preposition, the noun alone is projected. Thus it is correct to say Paris, j'y vais souvent 'Paris, I go there often', but not $\bar{A}$ Paris, j'y vais souvent 'To Paris, I go there often'. 
\$16 The projection can take place for multiple actants from the same sentence. In such cases, we say that there is a multiple projection. For example, there is a double projection in L'abeille, elle l'a piqué, mon doigt 'The bee, it stung it, my finger'.

$\$ 18$ But it is more difficult to project the two actants on the same side of the verb: L'abeille, mon doigt, elle l'a piqué, lit.'The bee, my finger, it stung it', or even Elle l'a piqué, mon doigt, l'abeille, lit. 'It stung it, my finger, the bee. These latter sentences are clumsy and familiar enough to border on vulgar.

$\$ 19$ The greater the number of projected actants (and circumstants), the more the sentence is lax and familiar: Il la lui a donnée, à Jean, son père, sa moto, 'John's father gave him his mortorbike', lit. 'He gave it to him, to John, his father, his motorike' (from a student in 1936).

\$20 This construction seems to be the very prototype of the sentence in Bantu languages, where it is favored by the large number of genders, known as categories. Many of these languages possess up to twenty of these categories, for example: personal gender, lively gender, neuter gender, organic gender, individual gender, diminutive gender, abstract gender, superficial gender, interior gender, and even the singular and plural of these genders.

\$21 The presence of this gender richness allows these languages to have a great variety of anaphors without risking confusion, since due to the twenty genders that a noun can have, there is relatively little possibility that the three or four actants present will have the same gender. The nouns are represented in the verbal node by an anaphoric index marking function. The anaphor alone indicates, by way of gender agreement, the anaphoric element to which each projected noun is related.

$\$ 22$ Take the Subiya example:

\begin{tabular}{cccccc}
\hline Mulala & in- & zoka & iyo & $i$ & sumpwa. \\
Mulala & ANIMAL & snake this it.ANimaL & was called \\
& \multicolumn{5}{c}{ 'This snake was called Mulala.' } \\
\hline
\end{tabular}

The anaphoric index $i$ - which is the first actant of the verb sumpwa and with which it is in sequence on the spoken chain - has animal gender and therefore refers to the noun zoka, which itself is preceded by the classifier in-, which also shows animal gender. And hence one understands that the first actant of sumpwa is in-zoka.

\$23 The same situation occurs in the following Subiya sentence:

\begin{tabular}{lllllll}
\hline Abo & ba- & kazana & $i$ & $b a$ & mini & manze \\
these.HUM & HUM & girls & it.ANIMAL & they.HUM & ate & all.hum \\
& & & 'It ate all these girls.' & & \\
\hline
\end{tabular}


The center of the sentence is the phrase $i$ ba mini 'it ate them'. The index of the first actant in this phrase, which is of the animal category, refers anaphorically to the noun zoka 'snake', which appears in the preceding sentences and is preceded by the classifier in-, also an animal classifier. This situation indicates by ricochet that the snake is the first actant. The index of the second actant $b a$-, which indicates the human plural category (cf. ba-ntu 'men', plural of $m u-n t u$ 'man'), refers anaphorically to the noun kazana 'young girls', which is preceded by the classifier $b a$-, also a classifier showing human plurality. This situation indicates by ricochet that the index of the second actant represents the young girls. It is by way of this mechanism that one understands that the snake has eaten the young girls, and not the other way round.

$\$ 24$ Take the Tongan sentence Ba-lavu ba-ba-luma ba-ntu 'The lions bit the men', lit. 'The lions, they bit them, the men'. The first actant $b a$ - and the second actant - $b a$ - have the same gender. Despite this situation, there is no confusion for two reasons: 1) because the meaning indicates clearly that it is the lions that bit the men and not the men who bit the lions, and 2) because the first actant precedes the verbal group, whereas the second actant follows it.

$\$ 25$ Hence the projection of actants, which is a highly expressive process in French, seems to be the normal mechanism in a Bantu language such as Subiya.

\$26 The mechanism of Bantu seems to exist in other languages, for example in Chinook, an Amerindian language: ${ }^{108}$

\begin{tabular}{l} 
Tgi génxaute ikanāte tEmewālEma. \\
they it watch the soul the spirits \\
'The spirits watch the soul.' \\
lit. 'They watch it, the soul, the spirits' \\
\hline
\end{tabular}

\$27 The preceding chapters show that the noun node is in turn susceptible to exerting influence by way of the connections that can extend outward from it in all directions. By its inferior connections, it governs attributes; by its superior connection, it is governed by the predicate, by its horizontal connections, it commands appositions, and with its horizontal semantic connections, it commands apostrophes and permits the projection of actants. The set of all these connections is summarized by the following schema:

108. Boas, Handbook of American-Indian Languages, I, p. 647, cited by Benvéniste, "Structure des relations de personne dans le verbe”, Bulletin de la Société de Linguistique de Paris, 43, 1947, p. 7. 


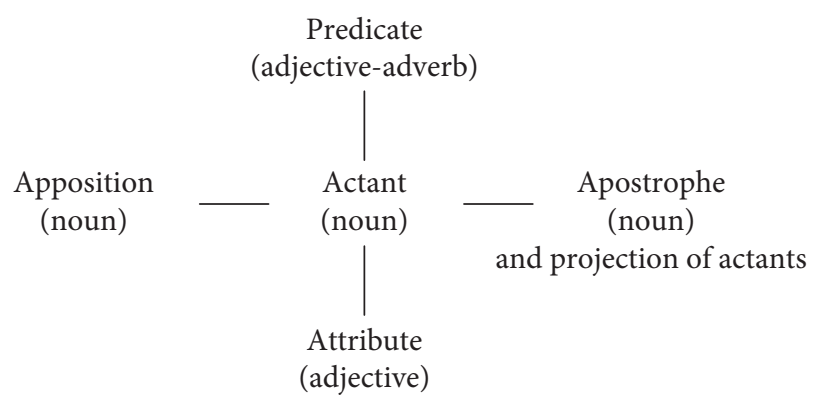

Schema 174

\section{Chapter 73. The nominal sentence}

$\$ 1$ Every noun node alone suffices to constitute a sentence, assuming it is not subordinated to another syntactic unit, e.g. to a verb - if it is subordinated to a verb, it is an actant. But in the absence of a verb, the nominal node alone can establish a sentence that is called a nominal sentence.

\$2 The nominal sentence is particularly apt at expressing a description. To accomplish this, the simple utterance of the noun or nouns designating the persons or objects being described can suffice. Each noun may or may not be accompanied by elements that are subordinate to it and that constitute a nominal node with it.

$\$ 3$ Several nominal sentences can follow each other. Such a sequence constitutes nominal style, which is more lively and more striking than the ordinary sentence. But it should be used sparingly since it is casual, quite invariable and so quickly becomes monotone. Let us give here the beginning of a long description using only nominal sentences:

Pavillons de tous les pays, russes, grecs, suédois, tunisiens, américains... Les navires au ras $d u$ quai, les beauprés arrivant sur la berge comme des rangées de baïonnettes. Au dessous les naïades, les déesses, les saintes vierges et autres sculptures de bois peint qui donnent le nom au vaisseau; tout cela mangé par l'eau de mer, dévoré, ruisselant, moisi... De temps en temps, entre les navires, un morceau de mer, comme une grande moire tachée d'huile... Dans l'enchevêtrement des vergues, des nuées de mouettes faisant de jolies taches sur le ciel bleu, des mousses qui s'appelaient dans toutes les langues $^{128}$
'Flags of every country, Russian, Greek, Swedish, Tunisian, American... The ships level with the quay, the bowsprits pulling up to the bank like rows of bayonets. Below the nymphs, the goddesses, the holy virgins, and other sculptures in painted wood that give the vessel its name; everything eaten by the sea water, consumed, streaming, mouldy... From time to time, between the ships, a piece of sea, like a big moiré stained with oil... In the entanglement of yards, flocks of gulls making pretty stains on the blue sky, ship boys calling to each other in all languages.'

(A. Daudet, Tartarin of Tarascon, first episode, XIV).

109. Translators' note: The example that Tesnière cites here is much longer than just one paragraph. We have reduced the length of the cited passage in the interest of getting to the point. 
$\$ 4$ Due to its casual character, the nominal sentence is particularly well-suited to conversational style, and that is why it is readily employed by dramatic authors:

Madame Blandin: [...] Je me suis faite noceuse enragée, à jet continu, la vie de Saint Guy, du matin au soir et du soir au matin, sans raison, sans but, comme des hystériques ou des fous. Saint Lazare et la Salpêtrière.
'Mrs Blandin: I became a furious reveler, in an endless stream, the life of Saint Guy, from morning to evening and from evening to morning, without reason, like hysterical or mad people. Saint Lazare [prison for women] and la Salpétrière [hospital].'

(H. Lavedan, Viveurs, act IV)

Gustave: Pyjamas ou chemises de nuit... Ravier: Décidément vous ne pensez qu'à dormir... Je pars vingt-quatre heures, le smoking, linge de soirée... et pyjamas de soie.
'Gustave: Pyjamas or night shirts...'

Ravier: You are clearly only thinking about sleeping... I leave for twenty-four hours, the dinner jacket, evening wear... and silk pyjamas.'

(P. Armont \& L. Marchand, Le Valet Maître, Act IV, Scene 4, Petite Illustration Journal of May 7, 1938).

\$5 The noun forming the center of the nominal sentence can appear in negative form:

Salomon: ...On ne se quitte pas, malgré tout, après quatre ans, sans un petit machin.

Madame Blandin: Non mon cher. Pas de petit machin...pas le moindre. Un grand accablement et un bon débarras...
'Salomon: We won't separate, despite everything, after four years, without a little thing. Madame Blandine: No my dear. No little thing...not in the least. Much despondency and good riddance.'

(H. Lavedan, Viveurs, act IV)

$\$ 6$ The nominal sentence is particularly well-suited to titles of literary, artistic, and other works, which are sentences like the others and for which there is no reason to pass over them in silence: Horace, Le Cid (Corneille), Le Misanthrope, Le Bourgeois gentilhomme (Molière), Le Corbeau et le Renard 'The crow and the fox', La cigale et la fourmi 'The cicada and the ant', Le loup et l'agneau 'The wolf and the lamb' (La Fontaine), The Merchant of Venice, The Tempest (Shakespeare).

$\$ 7$ In plays, the nominal sentence is not only used to indicate the title, but also to give scenic indications (characters and scenery).

Un salon. - A gauche, au premier plan, une cheminée; au deuxième, une porte; au troisième, une console. - A droite, ...
'A living room. - On the left, in the foreground, a fireplace; in the middle distance, a door; in the background, a console table. - On the right, ...' 
$\$ 8$ Indicators of this nature can also be encountered at the start of a novel, which gives the narrative a more lively tone: Quatre heures $d u$ soir au mois de septembre 'Four o' clock in the evening in the month of September' (F. Deschamps, Les Petits Poussargues, Chapter 1, Bibliotheque rose).

$\$ 9$ The central noun of the nominal sentence can be accompanied by a third actant:

\begin{tabular}{|c|c|}
\hline À tout seigneur tout honneur. & 'To every lord every honor.' \\
\hline À tout péché miséricorde. & 'To every sin forgiveness.' \\
\hline
\end{tabular}

\$10 Moreover, even though it is a simple noun and dependent on no verb, the central noun of the nominal sentence can be conceived of as a third actant: $\grave{A}$ d'autres! 'A likely story!', lit. 'To others!'.

$\$ 11$ Finally, this same noun can be an infinitive, the infinitive being, as we will see (Chapter 180), the nominal form of the verb: Que faire? 'What to do?'

French Et dire que les vives préoccupations d'une personne non tout-à-fait dépourvue de sens se trouvent parfois sous la dépendance d'une querelle de roquets.

(J.-H. Fabre, Nouveaux souvenirs entomologiques, Chapter 6, Les Odynères)

...Quoi? Toujours, malgré mes remontrances,

Heurter le fondement de toutes les sciences.

(Molière, Les Femmes savantes, II, 6).

Latin Tam nullo consilio gesta esse omnia!

Omnes per urbem discurrere pavidi; alii alios sciscitari; auctorem nuntii requirere.
'And to say that the deep concerns of a person not completely without sense are sometimes subordinate to a quarrel of grouches.'

'What? Every time, despite my reprimands,

Go against the foundation of all the sciences.'

'Did it have to be the case that everything was done without prudence!'

'Everyone ran through the city alarmed; they questioned each other; they sought the author of the news.

\$12 As we have said, the noun that functions as the center of the noun node can be accompanied by various subordinates, for example

\footnotetext{
Attributive

Charles $X$ a soixante treize ans. Il est très grand adjective et très mince. Les cheveux tout blancs.

(L. Verneuil, Vive le Roi, II, 3)

Temporal Après nous le déluge circumstant (Madame de Pompadour).

'Charles $\mathrm{X}$ is seventy-three. He is very tall and very thin. Hair all white.'

'After us the downpour'
} 
Il ne doute pas de l'effet que ses allusions vont produire dans l'esprit du prince, son jeune

Locative parent, à l'esprit si doux, qui règne sur un pays circumstant neutre avec le juste souci de son bonheur et de sa prospérité: Satan sur la montagne.

(L'Officier de réserve, number 7, 1935, p. 106)

Chaque compagnie des autres régiments comptait des piquiers, des mousquetaires et des grenadiers. Les mousquetaires en gris, bleu ou

Manner blanc, ...

circumstant (H. de Régnier, Le Bon Plaisir, Chapter VII).

Fallait voir ses hanches! Un vrai scandale sur pétard. (Céline, Mort à crédit, p. 21)
'He does not doubt the effect that his allusions are going to produce in the prince's mind, his young parent, so gentle, who rules over a neutral country with just concern about its happiness and prosperity: Satan on the mountain.'

'Each company of the other regiments contained pikemen, musketeers and grenadiers. The musketeers in grey, blue, or white...'

'You shoud have seen her hips! That arse was a public scandal', lit. 'A real scandal on buttocks.'

\$13 The subordinate of the noun that functions as a nominal node can be the result of firstdegree transfer (O > E, cf. Chapter 201), e.g. Trêve de plaisanteries! 'Enough of this joking!', lit. 'Truce of jokes' and of second degree (I >> A, cf. Chapter 245), e.g.

Le chat qui la regarde D’un petit air fripon. (Il était une bergère, popular simple round dance, 3rd couplet)

Même le vieux Rabbe, qui est prêt à s'engager, si on veut de lui!

(Roger Martin du Gard, Les Thibault,

Summer 1914,71, p. 226)
'The cat that watches her with mischief.'

'Even the old Rabbe, who is ready to get involved, if he is wanted!'

\$14 Like a normal sentence, a nominal sentence can be interrogative: Le moyen d'apaiser un auteur irrité? 'The way to calm down an irritated author?', Je le plains sans doute, mais quel remède? 'I certainly feel sorry for him, but what cure?'.

$\$ 15$ Similarly, the nominal sentence can be exclamative. As such it is capable of expressing the most diverse sentiments: emotion Ah! Mon vieil ami! 'Ah! My old friend!', exasperation La peste de l'animal! 'Goddammit!', lit. 'Plague of the animal', irony La belle avance! Le beau mérite! Le grand mal! ' What good use!, What good merit!, What great harm!', malicious surprise Et les cadeaux qu'elle se fait donner par les grandes grues qui viennent ici! 'And the gifts that she gets from the tall hookers who come here!' (H. Lavedan, Viveurs, I).

$\$ 16$ The sentiment can be expressed by enormity of the event that provokes amazement, this being denoted by the neuter pronoun ce: Ce qu'elle est gourmande!'What a gourmande she is!' (H. Lavedan, Viveurs, I).

$\$ 17$ The central noun of the nominal sentence can be followed by a determinative complement composed of the preposition de and the infinitive (cf. Chapter 221, \$4): Grenouilles aussitôt de sauter dans les ondes 'Frogs to jump straight into the waves' 
(La Fontaine, Fables, II, 14), Et grenouilles de se plaindre, Et Jupin de leur dire... 'And frogs to complain, And Jupin to say to them:...' (La Fontaine, Fables, III, 4), Occitan E mi dos furo de s'esquiha 'And my two mice to escape' (Frédéric Mistral, Nouvelle prose d'almanach, p. 278).

$\$ 18$ The central noun of the nominal sentence can also be followed by a subordinate relative phrase. This type of sentence is particularly frequent in titles, for instance in the titles of La Fontaine's fables:

\begin{tabular}{|c|c|}
\hline $\begin{array}{l}\text { L’Homme qui rit } \\
\text { (V. Hugo) }\end{array}$ & $\begin{array}{l}\text { 'The laughing man', lit. 'The man } \\
\text { who laughs' }\end{array}$ \\
\hline $\begin{array}{l}\text { La Terre qui meurt } \\
\text { (R. Bazin) }\end{array}$ & $\begin{array}{l}\text { 'The dying earth', } \\
\text { lit. 'The earth that dies' }\end{array}$ \\
\hline $\begin{array}{l}\text { L'Avare qui a perdu son trésor } \\
\text { (La Fontaine, Fables, IV, 20) }\end{array}$ & 'The miser who lost his treasure' \\
\hline $\begin{array}{l}\text { Le Chien qui lâche sa proie pour l'ombre } \\
\text { (La Fontaine, Fables, IV, 17) }\end{array}$ & $\begin{array}{l}\text { 'The dog who releases his prey } \\
\text { for a shadow' }\end{array}$ \\
\hline $\begin{array}{l}\text { Les Grenouilles qui demandent un Roi } \\
\text { (La Fontaine, Fables, III, 4) }\end{array}$ & 'The frogs who demand a king' \\
\hline $\begin{array}{l}\text { Le Chien à qui on a coupé les oreilles } \\
\text { (La Fontaine, Fables, X, 8) }\end{array}$ & 'The dog whose ears were cut off' \\
\hline
\end{tabular}

The relative subordinate, having a verb as its center, can be expanded indefinitely. Some of these titles hence become veritable abbreviated narratives: L'Homme qui court après la fortune et l'Homme qui l'attend dans son lit 'The man who runs after fortune and the man who awaits it in his bed' (La Fontaine, Fables, VII, 12).

\$20 Finally, the central noun of the nominal sentence can be followed by an element of the sentence that is introduced by que 'that/than':

De vrais petits sauvages que mes neveux!

(Mme Chéron de la Bruyère, L’Epée du

Donjon, Chapter 2, Bibliothèque rose)

Rien de plus compliqué qu'un barbare

(Flaubert, A Sainte-Beuve, December 1862)
'My nephews are true little savages!',

lit. 'True little savages that my nephews!'

'Nothing more complicated than a barbarian'

\section{Chapter 74. The adjectival node}

$\$ 1$ As we descend further down the hierarchy of nodes, the number of possible types of subordinates diminishes. For the adjective, practically the only possible subordinate is the adverb. The possibilities for the adjective node are therefore quite restricted. 
$\$ 2$ The normal subordinate of the adjective is hence the adverb, which, in this function, is represented stemmatically below the adjective by a vertical connection line: un livre extrêmement joli 'a very cheerful book' (Stemma 175).

$\$_{3}$ On the spoken chain, the adverb generally appears in front of the adjective that it depends on: Fr. très bon, Ger. sehr gut, Eng. very good, Rus. očen' xorošo. However, in certain langauges with mitigated centrifugal order, the adverb can follow the adjective, for example in the Austronesian languages Maori and Samoan:

\begin{tabular}{llllllr}
\hline & E & tau & hoa & iti & here & rahi \\
Maori & O & my & friend & little & dear & very \\
& O mon très cher petit ami 'O my very dear little friend' \\
& (P. Loti, Mariage de Loti, p. 295). & \\
\hline
\end{tabular}

\begin{tabular}{lll}
\hline \multirow{3}{*}{ Samoan } & tele & lava \\
& big $\quad$ very \\
& 'very big' \\
\hline
\end{tabular}

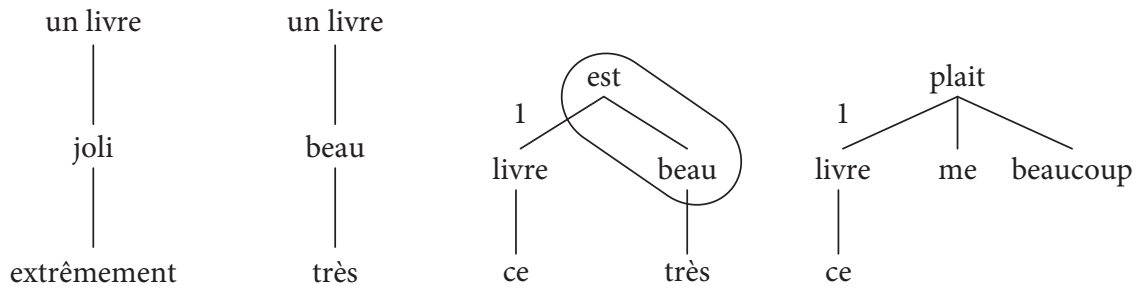

Stemma 175 Stemma $176 \quad$ Stemma 177

Stemma 178

$\$ 4$ Due to its ability to accept adverbs as subordinates, that is, to accept circumstants, the adjective resembles a verb to a certain degree. That is why it can function as a verb, which is, as we have seen, the very definition of a predicative adjective.

$\$ 5$ Unlike the verb, which can govern both actants and circumstants, the adjective can only govern circumstants. It is this difference that, structurally speaking, marks the essential difference between verbs and adjectives. ${ }^{110}$

110. Translators' note: Tesnière's claim here is contrary to modern accounts. Adjectives such as proud, satisified, angry, etc. govern actants, e.g. proud of his children, satisfied with it, angry at them, etc. The actants that adjectives govern are, however, always introduced by a preposition. 
$\$ 6$ It is possible to uncover the trace of this difference in adverbs, although it is rare. Two adverbs with the same meaning, très 'very' and beaucoup 'a lot', are preferably employed with an adjective and a verb, respectively: un très beau livre 'a very pretty book' (Stemma 176), Ce livre est très beau 'This book is very pretty' (Stemma 177), but Ce livre me plaît beaucoup 'This book pleases me a lot' (Stemma 178).

$\$ 7$ In analyzing further the difference between verb and adjective, we find that the verb is essentially the means to express a process, action, or state. Yet it is precisely because it expresses process-actions that it needs to be able to govern actants. In contrast, if it is a verb of state or a predicative adjective, only circumstants are required.

$\$ 8$ A new distinction is imposed according to the nature of the circumstants. All circumstants, regardless of their type, can be called upon to qualify a process. But while spatial circumstants (of location and time) are almost indispensible for determining the conditions of an action or state process in space and time (they therefore often modify predicative adjectives), they cannot occur as modifiers of attributive adjectives because attributive adjectives lack the notion of a process. This is the reason why attributive adjectives have only manner and quantitive adverbs as dependents.

$\$ 9$ What is valid for the adjective is also valid of course for the types of words that can take the place of adjectives in the varying circumstances that we have seen in preceding chapters:

Noun Elle est très grande dame.

Il est très professeur de Sorbonne.

Adverb un monsieur très bien

une dame très comme il faut
'She is very much the great lady',

lit. 'She is very great lady', where très 'very' is a modifier of grande dame 'great lady' and not of grande 'great'.

'He is very much the Sorbonne professor, lit. 'He is very professor of Sorbonne'

'a very decent man', lit. 'a man very well'

'a fine upstanding woman',

lit. 'a woman very as it need be'

\$10 In addition to proper adverbs, adjectives can have dependants that are adverbial formulations introduced by prepositions, the most frequent of which are de and $a$ :

de

'of, from'

capable de 'capable of', différent de 'different from', fier de 'proud of', jaloux de 'jealous of' (Chapter $60, \$ 10$ ), redevable de 'indebted to', susceptible de 'susceptible to'; J'aime trop la valeur pour en être jaloux (La Harpe). 'I like their value too much to be jealous of them'

à sensible à 'sensitive to', apte à 'capable of', enclin à 'inclined to', fidèle à faithful to', 'to' pareil à 'same as', hostile à 'hostile to', propre à 'specific to', contraire à 'contrary to', rebelle à 'rebelious to', semblable à 'similar to', sujet à 'subject to', utile à 'useful for', une salle pleine à craquer 'a room fit to burst', lit. 'a room full to burst' 


\begin{tabular}{ll}
\hline $\begin{array}{l}\text { avec } \\
\text { 'with' }\end{array}$ & compatible avec 'compatible with', incompatible avec 'incompatible with' \\
pour & utile pour 'useful for', bon pour 'good for' \\
'for' & \\
en & riche en miel 'rich in honey', fertile en incidents 'rich in incidents' \\
'in' & célèbre par ses crimes 'famous for his crimes' \\
'bar & \\
sur' & haut sur pattes 'long-legged' \\
\hline
\end{tabular}

\$11 In the languages with case such as Latin and Greek, it is of course case markers that play the role of the French/English prepositions:

\begin{tabular}{llll}
\hline & Accusative & Dative & Ablative \\
\hline Latin & $\begin{array}{l}\text { murus decem pedes altus } \\
\text { 'a wall ten feet high' }\end{array}$ & $\begin{array}{l}\text { utilis 'useful', } \\
\text { par 'equal', } \\
\text { similis 'similar' }\end{array}$ & $\begin{array}{l}\text { dives 'rich', } \\
\text { orbus 'private', } \\
\text { dignus 'worthy' }\end{array}$ \\
Freek mur haut de dix pieds & $\begin{array}{l}\text { hómoios 'similar', } \\
\text { áxios 'full', }\end{array}$ & \\
& áxos 'equal' & \\
\hline
\end{tabular}

\$12 Moreover, the same adjective can have many circumstantial complements, each corresponding to a different notion. Hence Fr. plein 'full' can be constructed both with de and à: plein de blé 'full of wheat' expresses the complement of means, that is, the object of which the sack or the basket is full; plein à craquer, in contrast, expresses a complement of manner, that is, the extent to which the sack is full to the point of bursting.

$\$ 13$ We can see that the multiplicity of possible complements is no more limited than that of circumstants.

$\$ 14$ This can be explained by the fact that most adjectives are former participles (Chapter 36, $\S 8$ ), that is, they were originally verbal forms, and as a consequence, they could contain circumstants. The circumstants that they originally governed when they where verbs have given rise to adverbs, and these adverbs continue to depend on them, even though they have become adjectives.

$\$ 15$ Indeed, take the Lat. latus 'wide' as an example; it is a former past participle ${ }^{*}$ stlatus 'stretched' of a verb denoting 'stretch over. The verb itself no longer survives in Latin, e.g. centum pedes latus strictly speaking means 'stretched over a hundred feet'.

$\$ 16$ Similarly, plenus 'filled' is merely a former anterior participle in -no-, formed on the stem ple-from Lat. im-ple-re, cf. Gr. plếrēs; it therefore signifies 'filled' rather than 'full'. The same is also true of the Fr. plein 'full' which, under its easy-going appearance as an adjective, hides a former participle etymologically. When all is said and done, the French 
construction with de is merely a circumstant that reproduces, at a distance and more or less faithfully, the circumstant that was etymologically that of the verb remplir.

$\$ 17$ All these considerations lead to the insight that if in a number of cases, the adjective can govern circumstants like the verb does, this only occurs because the adjective has developed from an adjectival form of the verb - the participle. In other words, the circumstant remains consistent, whether it depends on a verb or on an attributive adjective.

$\$ 18$ But there is a sort of adverb that is completely different from the others, first by its use, since it can only serve as a circumstant for the adjective, and second by its form, which does not differ from its adjectival form and which, therefore, is also variable. The adverbs in question are those that behave like the French adjectives tout 'all' and grand 'wide' in the expression toute grande ouverte 'entirely wide open', lit. 'all-FEM wide-FEM open-FEM'.

$\$ 19$ Adverbial expressions of this sort are not very common, but they are characteristic of certain French turns of phrases. The main examples are:

1. tout before an adjective: Elle est toute honteuse 'She is very ashamed', la toute bonne 'the very good one', les toutes belles 'the very pretty ones'.

2. tout before a variable adverb: Cette porte est toute grande ouverte 'this door is entirely wide open'.

3. Certain common adjectives which take on an adverbial function in front of another adjective or adjectival equivalent: Elle est arrivée bonne dernière 'She arrived the very last one', lit 'She arrived good last'; une porte grande ouverte 'a wide open door'; un parfait honnête homme 'a perfectly honest man', lit. 'a perfect honest man'.

\$20 What is noteworthy about these expressions is that the word that functions like an adverb behaves morphologically like a true adjective. As an adjective, it agrees in gender and number with the adjective that, as a circumstant, it modifies.

\$21 This state of affairs is difficult to observe with precision in French because the construction has been eviscerated by grammarians, who claim to have applied to it the norms of Latin grammar (Chapter 27, \$12). Having thus established a universal maxime, which is in reality just a principle of Latin grammar, they wanted to render the French adverb invariable just like the Latin adverb. They succeeded in imposing their conception on French orthography every time the adverb tout could seem to be invariable, that is, before a feminine adjective beginning with a vowel or a silent $h$ : Elles sont tout étonnées 'They are really surprised', Elles sont tout heureuses 'They are really happy'.

\$22 But faced with the facts, they were obliged to acknowledge and allow agreement of the adverb with the adjective before a consonant or aspirated $h$ : Elles sonts toutes confuses, toutes honteuses 'They are really confused, really ashamed'. The result of this on French has been grammatical confusion and spelling mistakes, which could have been easily avoided had it been acknowledged that French and Latin are not alike and that variable adverbs 
actually do exist in French. French common sense has in part rejected this negative influence insofar as both toute entière and tout entière, lit. 'all entire', are acceptable today.

\$23 Despite the inopportune influence of grammarians, who do nothing more than sew confusion and disorder on issues that used to be clear and ordered, it is clearly the case that the adverb, far from always being invariable by definition as in Latin, can in fact be quite variable, agreeing with its governing adjective, as is the case sometimes in French.

\section{Chapter 75. The adjectival sentence}

\$1 Contrary to a principle that is still too often taught but that is a flagrant contradiction of fact, the adjectival node, like the nominal node, can alone make up a sentence (Chapter 48, $\$ 10)$. This is the case when there is no higher syntactic unit that is capable of taking on this function, for it is always the highest syntactic element that automatically becomes the center of the sentence, just as it is also the highest rank that takes control over the sentence, which does not necessarily mean that a high rank is required to take command.

$\$ 2$ The sentence composed only of an adjectival node is what we call an adjectival sentence. It is entirely governed by an adjective.

$\$ 3$ Like the nominal sentence, the adjectival sentence is particularly alert and alive, but also casual and amorphous. It is characteristic of a simple style, but does not give an impression of being entirely correct. It is a sentence in shirt-sleeves; it judges its author.

$\$ 4$ The adjectival sentence can be composed completely and entirely of an attribute that is applied to someone expressed in the anontive:

La duchesse de Berry, jeune, vive, ardente et brune, parle avec un très léger accent italien. Elle est la gaîté même. Jolie et sympathique.

(L. Verneuil, Vive le Roi, p. 19)

Blandin: Es-tu enfant! Gentille mais peu sérieuse. (Henri Lavedan, Viveurs, act IV, p. 291)
'The Duchess of Berry, young, lively, fiery and brunette, speaks with a very light Italian accent. She is gaiety incarnate. Pretty and likeable.'

'Blandin: You are a child! Sweet but hardly serious.'

$\$ 5$ The adjective can be replaced by a participle (Chapter $196, \$ 2)$ :

Mme Rémusat: Tiens, Alain! Mais je ne vous savais pas à Annonay! Alain: Débarqué nuitamment.
'Mrs Rémusat: Hello, Alain! But I didn't know you were in Annonay! Alain: Landed in the night.'

(D. Amiel, La Maison Monestier, epilogue, scene 2, Petite Illustration, June 17, 1939) 
$\$ 6$ The adjective sentence can also be made up of an adjective that only serves as an attribute to an idea expressed by a clausal infinitive, whereby the infinitive clause seems to depend on the adjective, although it could also be considered to be the first actant. The adjective would therefore be the "predicate", that is, a predicative adjective. The sentence in both cases is an adjectival sentence: Inutile d'insister davantage 'Pointless to insist any further' (P. Lester \& L. Millot, Les Races humaines, p. 192), Libre à vous d'agir à votre guise 'free to you to do as you like.'

$\$ 7$ Finally, the person of the adjective sentence can be the autoontive; the sentence becomes a simple exclamation followed by a complement, either in the form of a determinative or in the form of a subordinate clause:

\begin{tabular}{|c|c|c|}
\hline \multirow[t]{5}{*}{ Determinative complement } & French & $\begin{array}{l}\text { Pauvre de moi! 'Poor me!', } \\
\text { lit. 'Poor of me } 130\end{array}$ \\
\hline & Occitan & Paure de ieu 'Poor me!' \\
\hline & Gascon & Praube de nous autes! 'Poor us!' \\
\hline & Béarnese & Pauvre d'eux 'Poor them' 131 \\
\hline & Spanish & $\begin{array}{l}\text { Triste de mí! 'Poor me!' } \\
(\text { Chapter } 196, \$ 6)^{132}\end{array}$ \\
\hline Subordinate clause & French & $\begin{array}{l}\text { Imbécile que je suis! } \\
\text { 'Imbecile that I am!' } \\
\text { (Chapter } 249, \$ 15 \text { ) }\end{array}$ \\
\hline
\end{tabular}

\section{Chapter 76. The adverbial node}

\$1 While the adjective can only have an adverb as a subordinate, the adverb, which is situated lower in the hierarchy of nodes, should also obviously not be able take other types of subordinates. Since the adverb is to the verb what the adjective is to the noun, as we have seen (Chapter $32, \$ 18$ ), the adverb shares with the adjective not only the charactistic of being a subordinate by definition, but also the inability to govern anything other than another adverb.

\$2 We have seen an example of an adverb governing another adverb in double adverbs of the sort ici-bas 'down here' and ci-après 'henceforth'. In the first case, the adjective bas 'low'

111. Mme Chéron de la Bruyère, L’Epée du Donjon, Paris, 1903, Hachette, Bibliothèque Rose, pp. 90, 100, 106, 129, 150, 214, 246, 252.

112. Combarnous, Mamette, Montpellier, about 1943, p. 46.

113. P. Laborde, Marivaux et El si de las niñas, Revue des Langues Romanes, vol. LXIX, 1946, p. 142 (Da. Francisca). 
is in reality employed as an adverb of the same type as the preposition après 'after', and it is subordinate to the adverb ici 'here', just as après 'after' is subordinate to the adverb ci 'here' (old form only used in compound today, cf. ici 'here'). The order of the two adverbs is hence centrifugal, as can be seen in the Stemmas 179 and 180.

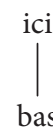

Stemma 179 Stemma 180

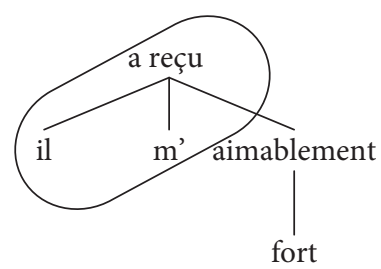

Stemma 181

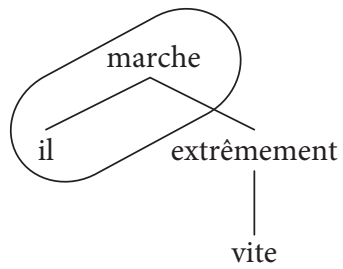

Stemma 182

$\$ 3$ But centripetal order is also very frequent with adverbs in -ment '-ly', or with an adverb of quantity like très 'very' or fort 'most': Il m'a reçu fort aimablement 'He received me most aimably' (Stemma 181), Il marche extrêmement vite 'He walks extremely fast' (Stemma 182).

$\$ 4$ Once descended down the hierarchy of nodes to the level of adverbs, theoretically nothing limits the number of adverbs that can be subordinated to each other. However, a cascade of three subordinated adverbs is quite rare: Cela se fait relativement très facilement 'That is done relatively very easily' (Stemma 183). These expressions are unwieldy because of the weight of the adverbs ending in -ment. Sequences of two adverbs in -ment are practically impossible. It is ugly to say: Cela se fait relativement facilement 'That is done relatively easily?.

$\$ 5$ The adverbs in -ment '-ly' are usually derived from adjectives. The derivational suffix -ment has the effect of lowering them by one level in the hierarchy of nodes. Therefore on one level there is une facilité relative 'relative ease' (Stemma 184), and one level down relativement facile 'relatively easy' (Stemma 185), and another level down relativement facilement 'relatively easily' (Stemma 186). The latter is practically condemned by its extreme weight.

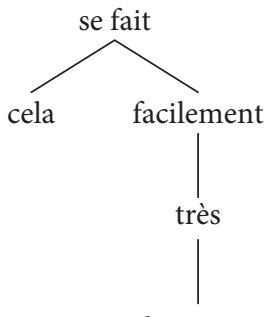

relativement

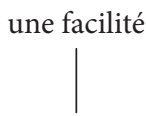

relative

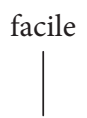

relativement facilement

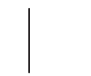

relativement 
The form of the stemmas shows that, while the set of nodes is lowered gradually as they become progressively more adverbial, the positions of governor and subordinate in relation to each other always remain the same hierarchically.

$\$ 6$ If in order to generate adverbs, adjectives that have adverbial groups introduced by prepositions are lowered by one level, these adverbial groups survive as possible complements of adverbs of the type: indépendamment de 'independently of', préférablement à 'preferably to', proportionnellement à 'proportionally to', heureusement pour 'luckily for'. For example, in the sentence (Vous serez rémunéré) proportionnellement à votre travail 'You will be paid proportionally to your work', the word proportionnellement is an adverb that depends on serez rémunéré 'will be paid', and à votre travail 'to your work' is an expression of the adverbial sort that in turn depends on proportionnellement. It is easy to account for this situation by raising the group by one level in the hierarchy: (Votre rémunération sera) proportionnelle à votre travail '(Your pay will be) proportional to your work'.

$\$ 7$ The comparative element of the adjectival node, e.g. plus grand que Bernard 'bigger than Bernard', constitutes (with the complement of the comparative) an adverbial node; it therefore contains one more structural level than the absolutive (Chapter $78, \$ 7$, note 116), as Stemma 187 shows. This situation is normal given that the notion of quantity is added to the simple expression of quality (cf. Chapter $148, \$ 1-4$ ).

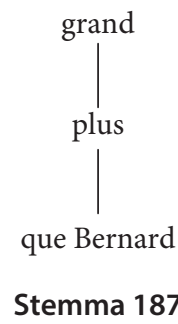

\section{Chapter 77. The adverbial sentence}

\$1 An adverb can form a sentence alone if it is not accompanied by a governor. An adverb can, for instance, be preceded by a noun preceded by $d e$, the noun and de functioning together as an adverb, i.e. as a circumstant: Charles $X$ a soixante-treize ans... Infiniment de majesté, de grâce et de séduction 'Charles $\mathrm{X}$ is seventy-three years old... With infinite majesty, grace and seduction', lit. 'Infinitely of majesty, grace and seduction' (L. Verneuil, Vive le Roi, p. 19).

\$2 The sentence can itself be composed of a noun that is introduced by a preposition, the whole phrase functioning as an adverb: Charles $X$ a soixante-treize ans... En habit mauve brodé, avec le cordon du Saint-Esprit... En uniforme chamarré 'Charles X is seventy-three 
years old... In mauve embroidered clothes, with the cord of the Holy Spirit.... In a richly decorated uniform' (L. Verneuil, Vive le Roi, p. 19).

$\$ 3$ Sentences of this type appear most frequently with the preposition à 'to', which can express 1) the length of time before the next meeting: Au revoir 'Good bye', lit. 'To the see again', A demain 'See you tomorrow', lit. 'Until tomorrow', A l'année prochaine 'See you next year', lit. 'Until the next year'; 2) devoted loyalty: A votre service 'At your service'; 3) a wish or desire: A votre santé 'Cheers', lit. 'To your health' (in a toast), A la gloire de nos alliés 'To the glory of our allies' (on a monument); or 4) manner: A la guerre comme à la guerre 'We'll just have to make the best of things', lit. 'In war as in war'.

$\$ 4$ In certain cases, an expression of the manner in which the action occurs is enough to evoke the action without it being explicitly expressed, but the first actant is indicated as if the action had been expressed by a verb:

Claude: ...Oh! Tu sais, j'ai bien peur que tout le monde ne tire un peuce mois-ci. Janine a des élèves qui ne l'ont pas encore payée, et puis maman a la première échéance de sa dent à pivot. Il n'y a que Nicole. Celle-là, rubis sur l'ongle!
'Claude: Oh, you know, I am quite afraid that everyone will take a little this month. Janine has pupils who have not paid her yet, and then Mom has the first due date of her pivot tooth. There is only Nicole. Her, cash on the nail!

(D. Amiel \& Mrs Monique Amiel-Petry, Famille, act II, scene 5, Petite Illustration, 1, I, 1938)

\$5 The adverbial sentence can be made up of an adverb governing a subordinate clause introduced by que. In such cases, which are frequent in spoken language, the adverb of the governing clause is generally an adverb ending in -ment. This adverb is often heureusement 'luckily':

Blandin: Heureusement que je suis là.

(H. Lavedan, Viveurs, act IV, p. 291).

Alice: ...Heureusement que ta femme aime ce genre de musique.

(D. Amiel, Ma Liberté, act II, p. 16)

Mais heureusement qu'elle a d'autres qualités

(A. Lichtenberger, Petite Madame, p. 34)

Sûrement qu'il s'est trompé.

Certainement que je viendrai!

Dans quel guêpier...

- Si vous voulez m'y suivre.

- Certainement que je vous y suivrai

(A. Dumas, Le Vicomte de Bragelonne,

Montalais et Malicorne)

Mais oui, qu'on peut, certainement, qu'on peut, pourquoi pas. (heard in 1945).
'Luckily, I am here'.

'Luckily, your wife likes this type of music.'

'Luckily however, she has other qualities.'

'Surely he is mistaken.'

'Certainly I will come!'

'In which can of worms...

- If you want to follow me there.

- Certainly I will follow you there.'

'But yes, we can, certainly we can, why not.' 
$\$ 6$ The circumstant acting as a governing clause can itself be an adverbial locution instead of an adverb:

\begin{tabular}{|c|c|}
\hline $\begin{array}{l}\text { Peut-être qu'il viendra. } \\
\text { Sans doute que vous lui avez écrit. } \\
\text { Sans doute que son inquietude cessa, } \\
\text { car il vida son assiette de } \\
\text { ce qu'elle contenait... } \\
\text { (H. de Régnier, Le Bon Plaisir, p. } 31)^{2}\end{array}$ & $\begin{array}{l}\text { 'Perhaps he will come.' } \\
\text { No doubt you wrote to him } \\
\text { Probably his uncertainty ceased, } \\
\text { because he emptied his plate of } \\
\text { everything on it.' }\end{array}$ \\
\hline
\end{tabular}

\$7 The governing adverb can be represented by a noun introduced by a preposition: Avec ce pantalon que tu iras à la messe!, lit. 'With these trousers (that) you will go to mass!' (Marcel Aymé, La Jument Verte, p. 78).

$\$ 8114$

$\$ 9$ The subordinate clause, instead of beginning with que 'that', can be a condition introduced by $s i$ 'if':

Du diable si je devine à quel mobile vous obéissez!

(E. Augier, Lions et Renards, 4, VII)

Du tonnerre si nous remettons jamais les pieds dans votre baraque (Zola, L'Assommoir, Chapter III, towards the end).

A peine s'ils pouvaient se servir de leurs mains (F. Deschamps, Les Petits Poussargues, Bibliothèque rose, XI, in fine).
'I will be in hell before guessing what motive you are obeying', lit. 'The devil if I guess ...'

'The thunder will fall on us before we set foot in your shed, lit. 'The thunder if we never ...'

'They were hardly able to use their hands', lit. 'Hardly if they were able ...'

$\$ 10$ Sentences of this sort, where the governing clause is an adverb, can be found in Greek: Thaumastōs hōs ploúsiós estin 'He is surprisingly rich'.

$\$ 11$ In German, the role of the main clause is played by one of those separable particles that are actually adverbs of movement (cf. Chapter $37, \$ 41, \$ 42, \$ 45$ and $\$ 46$ ):

\begin{tabular}{ll}
\hline Fort! & 'Away!' \\
Herein! & 'Herein!' \\
Hinaus! 'Out!' \\
Weiter! 'Continue!' \\
\hline
\end{tabular}

114. Translators' note: $\$ 8$ has been omitted because the example Tesnière uses is not representative of modern French. 
\$12 Note that the complement of these expressions can be a circumstant, which is generally introduced by the preposition mit 'with': Heraus damit! 'Bring it out!, lit. 'Out with it', Hinaus mit ihm! 'Get him out of here!', lit. 'Out with him!'

$\$ 13$ The adverb that serves as the main clause node can govern a third actant: Ger. Wohl dem, der seiner Väter gern gedenkt 'Good comes to those who remember their ancestors', lit. 'Well those who ....

$\$ 14$ German also frequently employs adverbial sentences where there is a correlation between two adverbs of the same type: Je eher, je lieber 'The sooner, the better', Je länger, je lieber 'The longer, the better', lit. 'Ever longer, ever better'.

$\$ 15$ As always, the role of the adverb can be played by a noun introduced by a preposition: Aus den Augen, aus dem Sinn 'Out of sight, out of mind'. 



\section{Question and negation}

\section{Chapter 78. Question and negation}

$\$ 1$ All the sentences that we have seen so far express an idea as if it is real, without reservation or doubt. But this serene certainness is far from always present. It is often the case that the speaker does not know whether the information put forward is accurate or whether it is known that it is explicitly not accurate.

\$2 In the former case, his thought is no longer at rest, and he is forced to consider whether the proposition in question is exact or not. This hesitation between the alternatives and the necessity for the mind to resolve the issue in order to know where it stands constitute the intellectual mindset of a question.

$\$ 3$ Questions are formulated in language by special turns of phrase called interrogative forms. This is true for every sort of question: they can be internal and addressed to the speaker himself with the desire to find a satisfying answer by internal thought, or they can be external and addressed to an outsider whose answer is expected by the speaker, either with the intention of adopting it without hesitation or, on the contrary, with the intention of viewing it as a mere opinion that can be adopted or rejected after evaluation.

$\$ 4$ Take for example the sentence The factory manager arrived at ten o'clock. This sentence expresses a certain number of facts that are presented as exact. But each of these facts can be placed in doubt, and each possible doubt corresponds to a question:

1) Who has arrived?

2) Which manager has arrived?

3) What did the factory manager do?

4) At what time did the factory manager arrive?

5) Has the factory manager arrived?

$\$ 5$ The fact being put in doubt by of these questions can be accepted as accurate, in which case the answer is limited to confirming it. But it can also occur that the response functions to invalidate the question, in which case the response is negative.

$\$ 6$ For example, the negative responses to the questions above would be:

1) Nobody has arrived.

2) No manager has arrived.

3) The factory manager has not arrived.

4) The factory manager never arrived.

5) No, the factory manager has not arrived. 
$\$ 7$ With respect to these interrogative and negative sentences, it is important to be able to designate clearly those that are neither interrogative nor negative. The term often adopted is positive, but this term is unfortunately ambiguous, since it can be in opposition to interrogative as well as to negative. ${ }^{115}$ We will therefore restrict it to the opposition with negative, and in opposition to the term interrogative, we will employ the term declarative.

$\$ 8$ Our terminology is summarized as follows: declarative vs. interrogative, and positive vs. negative.

\$9 Question and negation do not exclude each other, but they are not entirely on the same plane, since they can interact with each other. An interrogative can be positive or negative; just as negation can be declarative or interrogative:

\begin{tabular}{ll}
\hline $\begin{array}{l}\text { Declarative } \\
\text { and positive }\end{array}$ & The manager has arrived. \\
$\begin{array}{l}\text { Interrogative } \\
\text { and positive }\end{array}$ & Has the manager arrived? \\
$\begin{array}{l}\text { Declarative } \\
\text { and negative }\end{array}$ & The manager has not arrived. \\
$\begin{array}{l}\text { Interrogative } \\
\text { and negative }\end{array}$ & Has the manager not arrived? \\
\hline
\end{tabular}

\$10 It is clear that the combination interrogative plus negative is the form of locution that is most opposed to the combination declarative and positive.

\section{Chapter 79. Nuclear interrogative}

$\$ 1$ Take the declarative sentence Alfred is singing a song. We can observe that, as in the preceding chapter (Chapter $78, \$ 4$ ), each of the elements making up the expression of this idea can be put in question, and as a consequence, can lead to a question. This produces three questions:
1) Who is singing a song?
2) What is Alfred doing?
3) What is Alfred singing?

\$2 What is more, if we produce the stemma of this same sentence (Stemma 188), we observe that the number of nuclei is also three.

115. In a third case, the term positive can be used in opposition to the comparative and superlative. We will propose to replace it in this case with the term absolutive (Chapter $76, \$ 7$ ) in order to indicate the degree of comparison that Quintilian (Inst. Or. IX, 3, 19) called the absolute. 
$\$ 3$ Examining the specifics of these three nuclei and of the three questions shows that if the sentence with three nuclei gives three distinct questions, each nucleus is responsible for one of these questions.

$\$ 4$ If the nucleus Alfred is called into question, it motivates the following question: Who is singing a song?. On the other hand, if it is the nucleus a song that is put in question, the interrogative will be What is Alfred singing? Finally, if the question is put on the nucleus is singing, the question becomes What is Alfred doing?

$\$ 5$ An interrogative relating to the contents of a nucleus in this way is known as a nuclear interrogative. The preceding example shows that each utterance can give as many nuclear interrogatives as it contains nuclei.

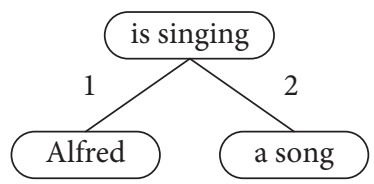

Stemma 188

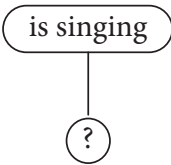

Stemma 189

$\$ 6$ Take for example an interrogative with four nuclei, such as Alfred is giving the book to Bernard. We can easily verify that this sentence can give rise to four nuclear interrogatives, the first relating to Alfred, the second to the book, the third to to Bernard, and the fourth to is giving. It is easy to observe that we can pose the following questions:

1) Who is giving the book to Bernard?

2) What is Alfred giving to Bernard?

3) To whom is Alfred giving the book?

4) What is Alfred doing?

These questions exhaust the possibilities for nuclear interrogatives that the current sentence permits.

$\$ 7$ The mechanism of nuclear interrogatives is very simple. Take the sentence with two nuclei Alfred is speaking (Stemma 26); it can give rise to the nuclear interrogative: Who is speaking? This is what happens when the question is put on the person who is speaking: Is it Alfred? Is it not rather Albert or Antoine? This is what I am not certain about, and what I must found out. I know that someone is speaking, and that there is therefore a nucleus for a first actant, but I do not know whether or not this nucleus should be assigned to Alfred, Albert, or Antoine. The content of the nucleus is therefore a mystery, which is why I pose the question.

$\$ 8$ We can represent this in a stemma by replacing the word Alfred with a question mark (Stemma 189). 
\$9 A nuclear interrogative is constructed with an empty nucleus. It is therefore formed by means of an empty word, which in this case is the interrogative pronoun who?: Who is speaking? This nucleus cannot be replaced by a particular noun, since the first actant is unknown. It is therefore necessary to place a general noun here (Chapter $34, \$ 1 \mathrm{ff}$ ), which serves only to give the nucleus a first actant bearing the interrogative element.

$\$ 10$ The grammatical tool of the nuclear interrogative is thus a general word that we call an interrogative word.

\section{Chapter 80. General interrogative words}

\$1 There exist a fair number of general interrogative words. In principle, there is one per nucleus, and the form varies according to the structural nature of the nucleus.

$\$ 2$ If the nucleus in question contains an actant, the corresponding interrogative will be a general interrogative noun that has the status of an actant. The principal interrogative nominal actants in English are who for people and what for things: Who is singing? What is Alfred singing? What?

$\$ 3$ If the nucleus in question contains a circumstant, the corresponding interrogative word will be a general interrogative adverb that has the status of a circumstant. There are of course as many interrogative adverbial circumstants as there are types of circumstants.

$\begin{array}{ll}\text { Locative } & \text { Where are you?, Where are you going?, } \\ & \text { Where did you pass by? } \\ & \text { When are you coming?, Since when have you been here?, Until } \\ \text { when are you staying?, How long do you plan to stay here? } & \text { Lat. Quousque tandem, Catilina, abutere patientia nostra? } \\ \text { Temporal } & \text { 'How long, Catilina, will you abuse our patience?' } \\ & \text { (Cicero, Catilinearian Orations) } \\ \text { Manner } & \text { How do you do?, Why are you reading this book?, } \\ & \text { For what reason are you writing to Alfred? }\end{array}$

$\$ 4$ In addition, these interrogative words have already been recognized in diverse languages with different purposes, e.g. with a speculative purpose in Scholastic Latin: Cur? Quomodo? Quando? 'Why? How? When?', and with a military purpose in German, where the tetralogy Wer? Wo? Wann? Wie? 'Who? Where? When? How?' is taught to all military recruits as the structure of information that every reconnaissance scout must be capable of acquiring and reporting to a superior.

$\$ 5$ Finally, when the nucleus contains an attributive adjective, the corresponding interrogative will be an interrogative adjective. 
$\$ 6$ The general interrogative adjective is which: Which book is Alfred reading? (Stemma 190), Alfred is reading the red book (Stemma 191).

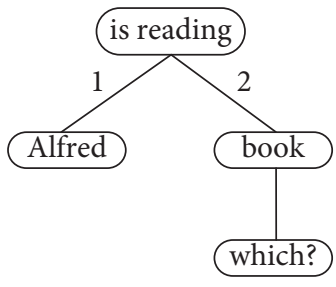

Stemma 190

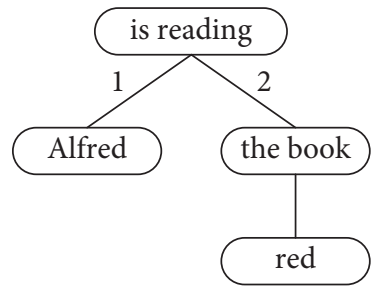

Stemma 191

$\$ 7$ To finish, it is important not to forget that the verbal nucleus, which forms the superior node of the entire sentence, can also furnish a nuclear interrogative. The particular verb is then replaced by the verb do, which stands in for the general word and to which the second actant what is added: What is Alfred doing?

$\$ 8$ We can see in the preceding examples that at least in our European languages, the interrogative word appears at the front of the interrogative sentence (in the spoken chain): Who is giving the book?, Where are you?, When are you coming?, etc.

$\$ 9$ But in the stemma, the interrogative word can be found in any position and in particular, very far from the central node. Experience tells us that that in the latter case, the further away the interrogative word is from the central node, the more difficult it is to construct the sentence. This is because the necessity to place the interrogative word at the front of the interrogative sentence can sometimes result in acrobatic constructions in order to maintain the desired sequence.

$\$ 10$ This is what happens in sentences such as Fr. En quoi faisant obtiendrais-je tel résultat? 'By doing what would I obtain such a result?'

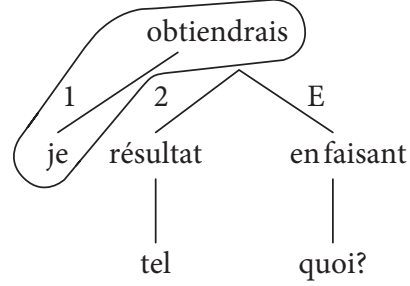

Stemma 192

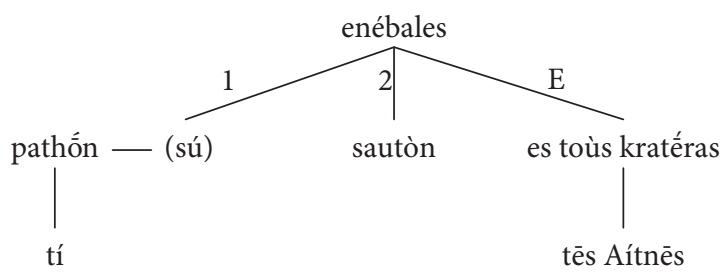

Stemma 193

\$11 Analogous sentences are quite frequent in languages that, like Greek, are in general very free in their use of interrogatives. The frequent use of participles in Greek 
results in the frequent use of interrogatives that are dependent on a node governed by the participle:

\begin{tabular}{|c|c|}
\hline $\begin{array}{l}\text { Interrogatives with } \\
\text { Participles in Greek }\end{array}$ & English \\
\hline Típathốn? & lit. 'Having tested what?', \\
\hline Tí boulómenos? & lit. 'What wanting?' \\
\hline $\begin{array}{l}\text { Tí pathốn sautòn es toùs tēs } \\
\text { Aítnēs kratēras enébales? } \\
\text { (Lucian, Dial. Death. 20, 4) } \\
\text { (Stemma 193) }\end{array}$ & $\begin{array}{l}\text { 'Why did you jump into the } \\
\text { crater of Mount Etna?', } \\
\text { lit. 'Which idea has taken you } \\
\text { to jump... }\end{array}$ \\
\hline $\begin{array}{l}\text { Tí adikètheis hup'emoû } \\
\text { epibouleúeis moi? }\end{array}$ & $\begin{array}{l}\text { 'In what way have I offended } \\
\text { you that you would harm me?', } \\
\text { lit. 'In what having been } \\
\text { offended by me seek you to } \\
\text { harm me?' }\end{array}$ \\
\hline Tí poīon àn nikến láboim? & $\begin{array}{l}\text { 'What must I do to obtain } \\
\text { victory?' }\end{array}$ \\
\hline
\end{tabular}

\$12 This means that the number of nuclear interrogatives that a declarative sentence can give rise to is quite considerable. Take for example the sentence: Yesterday Alfred gave back a hundred francs by mail to Bernard, because he owed him them and in order to clear his debt:

\begin{tabular}{ll}
\hline Question & Answer \\
\hline Who? & - Alfred. \\
What? & - A hundred francs. \\
To whom? & - To Bernard. \\
When? & - Yesterday. \\
By what means? & - By post. \\
What did he do? & - He gave back a hundred \\
& francs to Bernard. \\
To what end? & - In order to clear \\
Why? & his debt. \\
\hline
\end{tabular}

\$13 The skill of a good modern languages teacher is to know how to extract from each declarative phrase all of the nuclear interrogatives that it can give rise to. A good exercise for those who are teaching themselves to speak a foreign language is to take a text and, for each declarative sentence, to pose all the questions that the sentence gives rise to. 
A surprisingly wide variety of questions can be extracted from a text, resulting in an exercise that is quite valuable.

$\$ 14$ While replacing the words contained in each nucleus by the corresponding interrogative word already provides a quite large body of questions, replacing the general interrogative words with suitable particular words in the response gives rise to an infinitely wider variety of responses.

$\$ 15$ Take for example the interrogative word who in the sentence Who is singing? The number of different actants that the response can give is practically infinite. Not only can the response be Alfred or Albert or someone else, but also My father, My mother, My son, or even Caruso or Chaliapine, or some other famous singer. Thus each question can give rise to an extremely large number of responses. Such a proliferation, which begins with a single declarative sentence and via the correct exercises develops a number of questions, can result in an infinitely greater number of responses.

$\$ 16$ The number of particular words is by definition greater than that of general words, and while nuclear interrogatives contain general interrogative words, particular words, on the other hand, contain the responses to these questions. In other words, each general interrogative word can call up an infinite number of particular words as possible responses.

$\$ 17$ Since a nuclear interrogative is formed with an empty nucleus (Chapter $79, \$ 9$ ), a reply has only to fill the nucleus in question: Who is singing? - Alfred is singing.

$\$ 18$ It is not even useful to repeat the entire sentence, and in most cases, especially in everyday conversation, it suffices to answer with just the word that fills the empty nucleus: Who is singing? - Alfred.

$\$ 19$ Concerning the methodology of modern language teaching, the skill of a good teacher lies not only, as we have said (Chapter $80, \$ 13$ ), in knowing how to multiply the number of nuclear interrogatives that can be extracted from a basic declarative sentence, but also in knowing how to multiply each of these nuclear interrogatives by all the responses that can fill the empty nuclei expressed by the questions.

\$20 A nuclear interrogative does not appear in the stemma with a different structure, the structure of the declarative sentence and of the corresponding nuclear interrogative being strictly the same. For example, the declarative sentence Alfred is singing a song (Stemma 188), and the corresponding interrogative Who is singing a song? (Stemma 194) give rise to two identical stemmas.

\$21 The only difference is that the interrogative stemma contains a question mark, which highlights the location of the question and shows that the nucleus is a nuclear interrogative, since it is located inside a nucleus. 


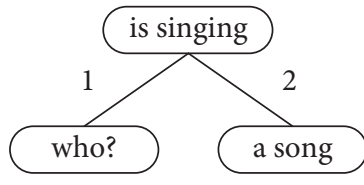

Stemma 194

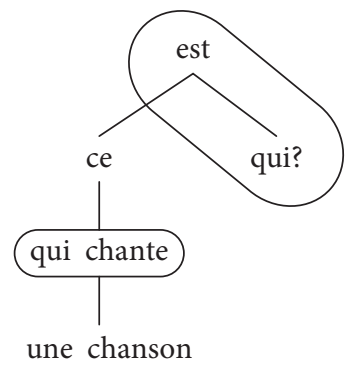

Stemma 195

\section{Chapter 81. Reinforced interrogative words in French}

\$1 In French, there is a means of reinforcing general interrogative words, and consequently the nuclear questions: by placing the general interrogative words in a main clause with the verb être 'be' and placing the body of the question in a subordinate clause dependent on the main clause (Chapter 267, \$2).

\$2 Thus Qui chante? 'Who is singing?' (Stemma 194) becomes the more emphasized Qui est-ce qui chante?, lit. 'Who is it that is singing?' (Stemma 195).

$\$ 3$ This second expression is less formal than the first, but it is more expressive, more common, and more alive.

$\$ 4$ In addition, it is extremely easy to use, since it is formed as if the interrogative word $q u i$ is replaced by the group qui est-ce qui, which is an entirely fixed expression today and which may be viewed as a general interrogative noun on the verge of replacing the interrogative word qui?, thanks to its expressivity. This phrase is almost always sufficient as a replacement for qui in order to obtain an expressive form, without having to change the rest of the sentence: Qui chante une chanson? 'Who is singing a song?', Qui est-ce qui chante une chanson?, lit. 'Who is it that is singing a song?'.

$\$ 5$ In the same way, all general words can develop an alternative expression which is often less correct, but always more expressive:

\begin{tabular}{|c|c|c|c|}
\hline \multicolumn{4}{|l|}{ French } \\
\hline que? quoi? & qu'est-ce que? & 'what?' & lit. 'what is it that?' \\
\hline à qui? & à qui est-ce que? & 'to whom?' & lit. 'to whom is it that?' \\
\hline où? & où est-ce que? & 'where?' & lit. 'where is it that?' \\
\hline quand? & quand est-ce que? & 'when?' & lit. 'when is it that?' \\
\hline pourquoi? & pourquoi est-ce que? & 'why?' & lit. 'why is it that?' \\
\hline comment? & comment est-ce que? & 'how?' & lit. 'how is it that?' \\
\hline
\end{tabular}


$\$ 6$ If the new interrogative words formed in this way by two fixed subordinate elements are greatly favored and are constantly gaining, this is occurring not only because they are more expressive, but also because they are, at least in certain cases, much more clear. This assertion deserves a demonstration.

$\$ 7$ A crucial point that elementary grammars rarely expound on and which present no difficulties for the French (they do not even realize it), but which is problematic for foreigners, is the correct use of qui and que. As an interrogative word, qui 'who' designates people and que 'what' designates things. As relative pronouns, in contrast, qui 'that.NOM' designates the first actant, and que 'that.AcC' the second actant. ${ }^{116}$ This is demonstrated in the table below. For both the interrogatives and the relatives, the two entries help to discern the details of their usage:

\begin{tabular}{|l|l|l|l|l|}
\cline { 2 - 5 } \multicolumn{1}{c|}{} & \multicolumn{2}{c|}{ Interrogative } & \multicolumn{2}{c|}{ Relative } \\
\cline { 2 - 5 } \multicolumn{1}{c|}{} & 1st actant & 2nd actant & 1st actant & 2nd actant \\
\hline People & qui? 'who?' & qui? 'who?' & ..., qui 'that' & ..., que 'that' \\
\hline Things & que? 'what?' & que? 'what?' & ..., qui 'that' & ..., que 'that' \\
\hline
\end{tabular}

Table 196

Table 197

$\$ 8$ It is immediately obvious that the line that separates the use of qui and that of que is horizontal for the interrogatives and vertical for the relative pronouns, in such a way that the value of qui makes a crossover with that of que:

\begin{tabular}{|l|l|l|l|}
\cline { 2 - 3 } \multicolumn{1}{c|}{} & Relative & Interrogative & \multicolumn{1}{c|}{} \\
\hline First actant & ..., qui 'that' & que? 'what' & Things \\
\hline Second actant & ..., que 'that' & qui? 'who' & People \\
\hline
\end{tabular}

Table 198

$\$ 9$ This crossover, which seems at first sight to be a complication, and which is indeed confusing for foreigners, complies with a deep necessity that one encounters in the morphological systems of numerous languages, which, in order to reduce confusion, avoid establishing their systems on parallel planes. Therefore in the Semitic languages (Arabic, Hebrew, etc.), the masculine antiontive of the imperfect has the same form as the feminine anontive, whereas the feminine and masculine anontive have quite different forms. The identity of the forms is

116. Translators' note: Contrary to English, which has wh-relativizers (the girl who is singing) and a that relativizer (the girl that is singing), French has only one set of relativizers. Although all its relativizers are etymologically related to English wh-words, the subject relativizer qui and the object relativizer que function more like that: they do not have a human feature and do not allow piedpiping. On the other hand, the relativizer qui used in à qui (la fille à qui je parle 'the girl to whom I am talking') is necessarily human and is similar to whom. 
established on a diagonal, whereas if they were established vertically between the antiontive and the anontive, either for the feminine or the masculine, ambiguity between these two persons would be unavoidable. This situation is summarized in the following table:

\begin{tabular}{|c|c|c|c|c|c|}
\hline & & & minine & & Masculine \\
\hline \multirow{2}{*}{ Anontive } & Arabic & taqtulu & \multirow{2}{*}{ 'she will kill' } & yaqtulu & \multirow{2}{*}{ 'he will kill/is killing' } \\
\hline & Hebrew & tiqțol & & yiqțol & \\
\hline \multirow{2}{*}{ Antiontive } & Arabic & taqtulina & \multirow{2}{*}{ 'you will kill' } & taqtulu & \multirow{2}{*}{ 'you will kill' } \\
\hline & Hebrew & tiqțali & & tiqtol & \\
\hline
\end{tabular}

Table 199

\$10 Yet interrogatives reinforced by subordination have the effect of simultaneously utilizing the interrogative and relative systems, and in so doing, the two interfere with each other. The two halves of the table of $\$ 7$ can be superimposed. Doing so results in a situation where each cell in the table contains a unique interrogative form, which indicates with precision whether the form concerns a person or a thing and whether it is a primary or secondary actant.

\begin{tabular}{|c|c|c|}
\cline { 2 - 3 } \multicolumn{1}{c|}{} & \multicolumn{2}{c|}{ Interrogative compound words } \\
\cline { 2 - 3 } \multicolumn{1}{c|}{} & 1st actant & 2nd actant \\
\hline People & qui est-ce qui...? 'who.nom' & qui est-ce que...? 'who.Acc' \\
\hline Things & qu'est-ce qui...? 'what.Nom' & qu'est-ce que...? 'what.Acc' \\
\hline
\end{tabular}

Table 200

$\$ 11$ These new compound interrogatives are much more precise than simple interrogatives and their increasing frequency is an enrichment of the language, for they sometimes permit uses that are impossible with simple interrogatives.

$\$ 12$ Take the declarative sentence Alfred frappe Bernard 'Alfred hits Bernard', where each of the two actants has the same form qui? as an interrogative substitute of person. In the sentence Qui frappe Alfred?, it is impossible to know whether qui is the first actant (Lat. Quis verberat Alfredum?) or the second actant (Lat. Quem verberat Alfredus?).

$\$ 13$ If, in contrast, we say Qui est-ce qui frappe Alfred ? 'Who hits Alfred?' in the first case and Qui est-ce que frappe Alfred? 'Who does Alfred hit?' in the second, no doubt is possible concerning the meaning of the question.

$\$ 14$ There is an amusing application of this theory, which highlights the advantage of precision of interrogative nouns composed by subordination. A test in its favor conducted one or two years ago consisted of posing the following questions to the listener: (1) Quel est le roi français qui faisait de la fausse monnaie? 'Who was the French king who made false money?, (2) Quel est le fusil en usage dans l'armée française? 'What is the gun in use in the French army?, and (3) Qui est-ce qui a tué Caïn? 'Who killed Cain?'

The trick here consists in confusing the listener's answers through rhyme. The listener after first responding with Philippe Le Bel to the first question and Le fusil Lebel 'the Lebel 
gun' to the second - rarely fails to respond with Abel to the third question, without realizing that the third question is purposefully the inverse of the first two and that he has been led insidiously to swap the positions of the first actant and second actant, for it is not Abel who killed Cain, but Cain who killed Abel.

$\$ 15$ Yet one day the question was posed to a grammarian, who did not fail to fall head first into the trap that was set. Later reflecting on the matter - and fortunately doing so before it was too late to limit the damage done to his reputation - the grammarian suddenly realized that the third question had been asked in the ambiguous form Qui a tué Cain? This insight enabled him to insist, in bad faith, that he had understood qui as the second actant and therefore that the response Abel was perfectly correct, and it was therefore the author of the test that received the humiliation. Such misfortune would not have befallen him (the author) if he had said qui est-ce qui instead of qui. ${ }^{117}$

\section{Chapter 82. Binuclear interrogatives}

\$1 We have reasoned thus far as if the question could bear on only one of the nuclei of the sentence. This is indeed the case in French.

\$2 But a number of languages - in particular the Germanic languages, the Slavic languages, Greek, and Latin - allow the placement of the interrogative on two nuclei at once. We call these interrogatives binuclear.

$\$ 3$ This is the case in English, where the equivalent of The Bottin (the telephone directory) bears the name Who's who? This expression would not be comprehensible in French, even though it is perfectly logical in itself and even though it is the question corresponding to each line of the directory: Monsieur Dupont est notaire, Monsieur Durand est charcutier 'Mr. Dupont is a notary, Mr. Durand is a pork butcher'; the nucleus Monsieur Dupont and the nucleus est notaire have been emptied of their semantic content, which has been replaced in both cases by the general interrogative qui 'who'.

$\$ 4$ Binuclear interrogatives are even common in Russian. A good example is the following popular saying:

\begin{tabular}{ll}
\hline Byk revët. & 'The bull bellows.' \\
Korova revët. & 'The cow bellows.' \\
A kto kogo bodët? & 'But who deals blows to whom?' \\
Sam čert ne razberët. & 'Even the devil understands nothing.' \\
\hline
\end{tabular}

This saying alludes to a domestic squabble.

117. Translators' note: The point Tesnière is making here is not clear. He may be poking fun at the grammarian with this last sentence, since the question was exactly that, namely Qui est-ce qui... 
\$5 The French translation of a binuclear interrogative poses an almost unsolvable problem, since the binuclear interrogative is absent from French. A practical but inelegant means of overcoming the difficulty is to break the interrogative sentence into two sentences, each containing one of the interrogative nuclei and then translate each sentence accordingly.

$\$ 6$ Binuclear interrogatives are common in Serbo-Croatian, where the expression Gde je što?, lit. 'Where is what?', is a translation of the more idiomatical 'Table of contents'.

$\$ 7$ The same phenomenon is present in Greek, for example in the question: Tínas hupo tínōn ehúpoimen àn meízona euergetēménous hế paîdas hupò gonéōn 'Who would we find showered by more good turns than children are by their parents? From whom have they received more?'

$\$ 8$ The same process is used in Latin in the binuclear Quis quem verberat? 'Who hits whom?'.

$\$ 9$ Even though French, as we have seen in $\$ 5$, does not have binuclear interrogatives, such cases may be found when the following two conditions are met: 1) The nuclear interrogative bears on the causal nucleus by means of the interrogative word pourquoi?; and 2) what was asked was not heard or was not understood by the person questioned, who, turning to the questioner, adds the secondary interrogative nucleus quoi? to the primary interrogative nucleus pourquoi? This secondary interrogative nucleus applies to the rest of the question.

\$10 The question that is expressed in such a case takes on the form Pourquoi quoi? 'Why what?' The elegance of this expression is doubtful, but it is often necessary in conversation, particularly during a telephone conversation where the interlocutors have trouble hearing each other. For example:

\begin{tabular}{ll}
\hline Interrogative: & $\begin{array}{l}\text { Pourquoi ne veux-tu pas aller à Versailles? } \\
\text { 'Why don't you want to go to Versailles?' }\end{array}$ \\
$\begin{array}{l}\text { Counter- } \\
\text { interrogative: }\end{array}$ & \begin{tabular}{l} 
Pourquoi quoi? \\
\hline
\end{tabular} \\
\hline
\end{tabular}

The questioner answers by repeating the misheard or misunderstood question, which then the person questioned can answer.

$\$ 11$ However, even though it bears an uncanny resemblance to a binuclear interrogative, this expression is not really a binuclear interrogative. It is rather a sort of counterclaim, and consequently a mononuclear interrogative that appears on top of a preceding nuclear interrogative. But the questions are neither simultaneous, nor of the same nature, two conditions that must be met in order to have a true binuclear interrogative.

$\$ 12$ Beyond binuclear interrogatives, nothing prevents multinuclear interrogatives. However, there do not seem to be any languages that make use of multinuclear interrogatives. 


\section{Chapter 83. Connective interrogatives}

$\$ 1$ We have seen (Chapter $79, \$ 5$ ) that each declarative sentence gives rise to as many nuclear interrogatives as it has nuclei, because each nucleus can be put into question. This is why in every nuclear interrogative there is at least one nucleus that is semantically empty (and even two in binuclear interrogatives).

$\$ 2$ But for the same declarative sentences, there is a type of question that is entirely different. This special type of question is encountered when all the nuclei are semantically full. Therefore we are пот dealing with a nuclear interrogative, since the question does not fall on a nucleus.

$\$ 3$ Where does the question reside if not in a nucleus? The analysis alone of this new type of question can give us the answer.

$\$ 4$ Take the declarative sentence Alfred is singing a song (Stemma 188), the question that corresponds to this new type of question is as follows: Is Alfred singing a song?

$\$ 5$ It is easy to observe that the nuclei Alfred, is singing, and a song are all full. That is, Alfred is given, a song is given, and the action of singing is also given. What is not given, what is put in question, what is not known, and what we wish to find out is whether the three notions have to be placed end to end, that is, whether there are connections linking them.

$\$ 6$ The question here concerns the connection of full nuclei. For this reason, we will give a totally different name to this type of interrogative, the name connective interrogative.

$\$ 7$ Connective interrogatives are quite different from nuclear interrogatives, and even though the difference is not acknowledged in contemporary grammars, it has already been acknowledged by many authors.

$\$ 8$ A. Juret writes the following sentence in his Syntaxe Latine: ${ }^{118}$ The question pertains "to the determination of a representation" (nuclear interrogative) or "to the point of knowing whether the affirmation is suited to a determined representation" (connective interrogative).

$\$ 9$ The terms nuclear interrogative and connective interrogative, such as they have been defined, seem clearer to us and more appropriate than Juret's more abstract definitions because they constitute a terminology that can be used to easily designate each type of interrogative, but the distinction that they establish is exactly the same as the one defined by Juret.

118. A. Juret, Système de la Syntaxe Latine, Paris-Strasbourg, Belles Lettres, 1926, p. 137. 
\$10 In addition, one finds the same distinction in Le Baut's English method, ${ }^{119}$ in which he distinguishes two types of questions, which he calls particular interrogatives and general interrogatives and which he defines as follows:

$\$ 11$ "A particular interrogative: we call questions that concern only a single term in the sentence particular interrogatives. Example: Where is Peter? The question begins with a specific interrogative word and is in most cases open to an unlimited number of responses" (page 21,\#1). Evidently, this is the nuclear interrogative.

$\$ 12$ "A general interrogative: we call questions that concern the whole sentence general interrogatives. Example: Are you French? In English the question is the result of the inversion of the auxiliary verb and the subject and can only be answered by yes or no, or by the repetition of the auxiliary verb" (p. 22, \#1). Evidently, this is the connective interrogative.

$\$ 13$ It is interesting to note that L. Le Baut arrived at this distinction by a very different method from that of the current author. The current method uses the introspective method to analyze the content of the questions. L. Le Baut, in contrast, has arrived at the distinction by concentrating entirely on a material observation, namely the intonation of the sentence.

$\$ 14$ He distinguishes between two types of intonation of the sentence, type 1 where the sentences ends with descending intonation, and type 2 where the sentence ends with ascending intonation.

\$15 Type 1 (descending intonation) is for assertions and particular interrogatives, for example (Le Baut, p. 21):

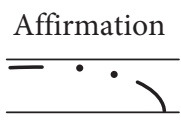

Tom is a boy
Particular interrogative

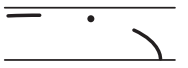

What is Tom?

$\$ 16$ Type 2 (ascending intonation) is for general interrogatives, for example (Le Baut, p. 22):

General interrogatives :

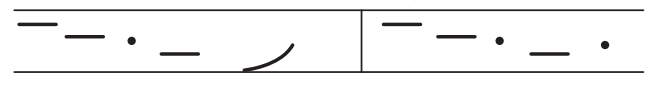

Is Mister Grey French? Is Missis Grey in?

$\$ 17$ In sum, nuclear interrogatives are produced in English with a descending intonation of the sentence, whereas connective interrogatives are produced with an ascending intonation of the sentence. This fundamental opposition, which is very easy to observe in

119. L. Le Baut, agrégé d'anglais, inspecteur d'Académie, Istra's first English book, $1^{\text {re }}$ année d'anglais à l'usage de l'enseignement du second degré (programme de 1938), Paris-Strasbourg, Librairie Istra (around 1938). 
English, corroborates what has been shown about questions and proves that the distinction between nuclear interrogatives and connective interrogatives is not an arbitrary matter, but rather a profound reality that is marked by the very intonation of the sentence.

$\$ 18$ In exploring the nature of the distinction between nuclear and connective interrogatives, it is easy to see that it is based on the same fundamental notions that distinguish between categorical or static syntax and functional or dynamic syntax (Chapter 25, \$10). $\$ 19$ Indeed, nuclear interrogatives bring categories into play, since they make use of interrogative words, which, as we have seen (Chapter $79, \$ 10$ ), differ depending on their category. $\$ 20$ In contrast, connective interrogatives involve only the connection, that is, only the architecture of the sentence, and consequently, the syntactic or functional structure.

\$21 This is why nuclear interrogatives are to some extent categorical questions, whereas connective interrogatives are functional questions.

$\$ 22$ And this is one of the reasons why the current author still used the terms categorical question and functional question in his Russian grammar; those terms seemed more accessible to the public at that time. ${ }^{120}$ I had not yet analyzed the two types of questions precisely and the terms nuclear and connective had not yet been recognized as more appropriate.

\$23 Since L. Le Baut also uses a third terminology, it is helpful, in order to avoid any confusion, to establish the correspondences between the three terminologies:

\begin{tabular}{llll}
\hline & $\begin{array}{l}\text { Present work } \\
(1949)\end{array}$ & $\begin{array}{l}\text { P. Grammaire } \\
\text { Russe (1934) }\end{array}$ & $\begin{array}{l}\text { First English Book } \\
\text { by L. Le Baut } \\
\text { (approx. 1938) }\end{array}$ \\
\hline \multirow{2}{*}{ Interrogative } & $\begin{array}{l}\text { nuclear } \\
\text { connective }\end{array}$ & $\begin{array}{l}\text { categorical } \\
\text { functional }\end{array}$ & $\begin{array}{l}\text { particular } \\
\text { general }\end{array}$ \\
\hline
\end{tabular}

\$24 A connective interrogative appears in the stemma no more than the a nuclear interrogative. In the connective interrogative Alfred chante-t-il? 'Is Alfred singing?', the connective relationships between the nucleus Alfred and chante are exactly the same as in the declarative sentence Alfred chante. But nothing prevents one from representating the interrogative nature of the sentence by way of a question mark, as with the nuclear interrogative above (Chapter 80, \$20). A question mark is placed against the connection line instead of inside a nucleus (Stemma 201).

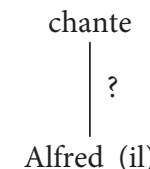

Stemma 201

120. L. Tesnière, Petite Grammaire Russe, Paris, Didier, 1934, pp. 136 and 137. 
\$25 The impossibility of accounting for the nature of the questions that we are now calling connective (as opposed to the nuclear type) without appealing to the notion of a connection confirms the necessity a posteriori to posit this notion, which, as we have already seen, is essential and syntactically unavoidable (cf. Chapter $1, \$ 3 f f$.$) .$

\section{Chapter 84. The marker of connective interrogatives}

$\$ 1$ As we have seen (Chapter $83, \$ 17$ ), the connective interrogative is identified by rising intonation in English. Rising intonation seems to convey the intellectual weight of the connective interrogative.

\$2 Indeed, it is normal that in an ordinary sentence, the tone level, which readily rises at the beginning, progessively lowers towards the end, such that the sentence ends with a low tone. If, however, contrary to this natural tendency, the sentence ends with rising intonation, the listener is left with the impression that something is incomplete, or to use a more familiar expression, that something is "left hanging".

$\$ 3$ Yet this impression corresponds perfectly to the connective interrogative, in which the nuclei are all present but in which they appear in a dispersed, ungainly order, corresponding to a jumbled and incoherent stemma since the connection itself is in question. This is why rising intonation is so well suited to the connective interrogative.

$\$ 4$ But while for this reason the connective interrogative is readily accompanied by ascending intonation in a number of languages, conversely, in many languages, ascending intonation (alone) can express a connective interrogative.

$\$ 5$ This is the case, for example, in French, where at least in everyday speech, pronouncing a declarative sentence with ascending intonation immediately conveys the interrogative. In everyday speech, instead of Alfred est-il venu? 'Has Alfred arrived?' or Est-ce qu'Alfred est venu?, lit. 'Is it that Alfred has arrived?', ${ }^{121}$ it is possible to say Alfred est venu? 'Alfred has arrived?', with rising intonation, turning the sentence into a connective interrogative.

$\$ 6$ The same is true in Russian, where the more correct interrogative form, which is expressed by means of the interrogative particle li, illustrated below, is often replaced in conversational speech by a more familiar form of interrogation, which is principally characterized by rising intonation. It is true that in this case, Russian prefers to preface the question with the coordinator $a$ 'and/but'. This conjunction, which is in the process

121. Translators' note: The status of Fr. est-ce que [zsk] as an interrogative marker will be discussed below (Chapter 84, \$16ff). 
of becoming a true interrogative word, is not one yet and is merely associated in this case with rising intonation, which remains the essential marker of the connective interrogative, for example:

\begin{tabular}{ll}
\hline A vy russkij? & 'Are you Russian?' \\
A Vanja priexal? & 'Has Johnny arrived?' \\
\hline
\end{tabular}

\$7 In addition to rising intonation, there is another marker for connective interrogatives. This marker consists in placing the verb at the beginning of the sentence. This process is common practice in German, where the verb in first position is thus emphasized, which makes the sentence a connective interrogative. For example, faced with the declarative Alfred ist gekommen 'Alfred has come', the connective interrogative form is Ist Alfred gekommen? 'Has Alfred come?'.

$\$ 8$ Placing the verb in first position results in inversion (Chapter $58, \S 5$ ), that is, a swapping of the positions of the verb and the first actant. This inversion, which is merely the result of placing the verb at the front of the sentence, is in and of itself the interrogative marker in other languages, for example: Fr. Parlez-vous français? 'Do you speak French?', Sp. Habla $V^{d}$ español? Analogous expressions can be found in Catalan, Romanian, Dutch, Lithuanian, Armenian, Arabic, Chuvash, and Basque.

$\$ 9$ In French and certain other languages, inversion is tolerated only between the verb and a personal index:

\begin{tabular}{lll}
\hline Antiontive & Parlez-vous français? & lit. 'Speak you French?' \\
Autoontive & Irai-je danser? & 'Will I dance?' \\
Anontive & Est-il venu? & 'Has he come?' \\
\hline
\end{tabular}

But inversion cannot occur with the verb and an autonomous first actant. In French it is not possible to say ${ }^{\star}$ Est Alfred venu? 'Has Alfred come?' as it is in English and in German Ist Alfred gekommen? The question must be expressed by the inversion of the verb and a personal anontive index of the first actant, the latter having an anaphoric connection to the primary nominal actant, which must appear at the beginning of the sentence: Alfred est-il venu?, lit. 'Alfred has he come?' In this expression, Alfred is closely reminiscent of a projected actant (Chapter $72, \$ 1 \mathrm{ff}$.).

$\$ 10$ A third means of marking a connective interrogative is the use of a interrogative word exclusively designed for this use and which precedes the word carrying the interrogative focus in centrifugal languages and follows it in centripetal languages. 
\$11 Centrifugal languages:

\begin{tabular}{lll}
\hline $\begin{array}{l}\text { Latvian } \\
\text { Low Breton }\end{array}$ & $\begin{array}{l}\text { Vai vi šs saka? } \\
\text { Hag heñ a lavar? } \\
\text { Béarnese }\end{array}$ & $\begin{array}{l}\text { 'Did he say...?' } \\
\text { parles seriouzemen? }\end{array}$ \\
$\begin{array}{lll}\text { Russian } \\
\text { (expecting an expected he say...?' } \\
\text { negative answer) }\end{array}$ & $\begin{array}{l}\text { Razve on pridët? } \\
\text { Russian } \\
\begin{array}{l}\text { (with a desired } \\
\text { negative answer) }\end{array}\end{array}$ & $\begin{array}{l}\text { 'But will he come at all?' } \\
\text { (I was sure he wouldn't come.) }\end{array}$ \\
$\begin{array}{l}\text { Latin } \\
\text { (expecting a } \\
\text { negative response) }\end{array}$ & Neuželi on pridët? & $\begin{array}{l}\text { 'He is surely not going to come?' } \\
\text { (I hope not.) }\end{array}$ \\
$\begin{array}{l}\text { Latin } \\
\text { (hoping for a } \\
\text { positive response) }\end{array}$ & $\begin{array}{l}\text { Num veniet? } \\
\text { 'So he's coming then?' } \\
\text { (I was sure he wouldn't come.) }\end{array}$ \\
\hline
\end{tabular}

$\$ 12$ Centripetal type:

\begin{tabular}{lll}
\hline Chinese & Lái ma? & 'Is he coming?' \\
Latin & Venietne? & 'Will he come?' \\
Russian & Pridët li? & 'Will he come?' \\
Finnish & $\begin{array}{l}\text { Puhutte-ko te } \\
\text { suomea? }\end{array}$ & $\begin{array}{l}\text { 'Do you speak } \\
\text { Finnish?' }\end{array}$ \\
\hline
\end{tabular}

\$13 The use of interrogative words is particularly convenient, since they bear precisely on the word that, according to the language, precedes or follows them. For example:

\begin{tabular}{llll}
\hline Latin & \multicolumn{2}{l}{ Illene veniet? } \\
\multirow{2}{*}{ Russian } & On $\quad l i \quad$ pridët? 'Is it him who will come?' \\
& he & INT & will come \\
\hline
\end{tabular}

In these sentences, the interrogative particle (Chinese $m a$, Lat. -ne, Rus. li) immediately follows the word signifying 'him' and places the interrogative focus on this word.

$\$ 14$ Despite appearances and even though the question concerns the nucleus, they are not strictly speaking nuclear interrogatives, since the nucleus is full, and the question therefore does not reside in the interior of a nucleus, but rather on the connection, or to be more exact, on the extremity of the connection that touches the nucleus. The question is not directed at discovering whether there is a connection in a given sentence (Venientne Aulus? 'Is Aulus coming?', Stemma 202), but at discovering whether it is a particular given nucleus 
rather than any other given nucleus that is attached to the group of sentence connections (Aulusne veniet? 'Is it Aulus that is coming?', Stemma 203).

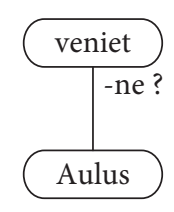

Stemma 202

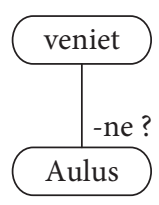

Stemma 203

$\$ 15$ In the graphical representation, these two types of stemma can be distinguished in terms of the point at which the interrogative word is placed on the connection line.

$\$ 16$ French has developed, from questions with inversion of the verb être, a process similar to the reinforcing process for nuclear interrogatives that was discussed above (Chapter 81, $\$ 1 \mathrm{ff}$. and Chapter 267, §2ff), for example Est-ce qu'Alfred est venu? lit. 'Is it that Alfred has arrived?'

$\$ 17$ The phrase est-ce que is more or less frozen and in this case, it is equivalent to the interrogative particle in centrifugal languages $(\$ 11)$, for example:

\begin{tabular}{lll}
\hline Latvian & Vai vińš saka? & 'Did he say...?' \\
Low Breton & Hag eñ a lavar? & 'Did he say...?' \\
\hline
\end{tabular}

\$18 One has often remarked that if French were an exotic language and examined for the first time by missionaries ignorant of its history, one would assign it a preposed interrogative word esk'(a), for example: Esk Alfred viendra? 'Will Alfred come?', Esk' il fait beau? 'Is it nice (weather)?'. The use of this new interrogative word esk'(a) is strictly limited to a question pertaining to a verb.

$\$ 19$ French also provides a typical example of the manner in which an interrogative word can develop from inversion. Take the following sentence with the anontive form, where the question is expressed by inversion: Vient-il? 'Is he coming?'. Colloquially it is pronounced [vjẽti?]. Yet in everyday speech, a false break is frequently added [vjẽ-ti?] in which the element [-ti] is perceived as a postposed interrogative word, with exactly the same function as the preposed interrogative word esk'(a) in [Esk'i vjẽ ]. What clearly proves that the element - $t i$ has really taken on the function of an interrogative word is the fact that, even though it remains limited to the function of a verbal interrogative word like esk'(a), it has nevertheless spread outside of its original person (anontive) to the two ontive persons. Therefore in colloquial French it is possible to hear the very inelegant and even very incorrect: Tu viens-ti? 'Are you coming?' Je viens-ti? 'Shall I come?' J'sais t'i c'que vous avez à m'agoniser comme ça 'Do I know why you torment me like that?' (Maupassant, Contes, La mère aux monstres). 
\$20 Finally, a fourth and final process for marking the interrogative connection is that of languages that possess a true interrogative verb. Such is the case for example in Greenlandic, where the interrogative verb appears as a suffixed form:

\begin{tabular}{lll}
\hline Declarative & $\begin{array}{l}\text { Kimek } \\
\operatorname{dog}\end{array}$ & $\begin{array}{l}\text { sinigp-ok. } \\
\text { sleep-DECL } \\
\text { Interrogative }\end{array}$ \\
& $\begin{array}{l}\text { Kimek } \\
\operatorname{dog}\end{array}$ & $\begin{array}{l}\text { sinig- } a ? \\
\text { sleep-INT? }\end{array} \quad$ 'The dog is sleeping.' \\
\hline
\end{tabular}

\$21 This is the same process that can be found in Finnish, which has a negative auxiliary:

\begin{tabular}{lll}
\hline & Singular & Plural \\
\hline 3rd & ei & eivät \\
2nd & et & ette \\
1 st & en & emme \\
\hline
\end{tabular}

This negative verb is constructed in the present indicative with the stem of the verb to be negated, which therefore becomes the auxiliated of the negative verb (cf. Chapter 23, \$11), e.g. Finn. anna is the stem of the verb 'give', so en anna = 'I do not give'.

$\$ 22$ This can be compared to the case in English, which can only express a connective interrogative using an interrogative auxiliary verb. The most frequent example is the verb do.

\$23 Breton employs the auxiliary ober 'do' for the affirmative, the interrogative, and the negative. This process is used frequently with questions, where it is combined with rising intonation, e.g. Kaozeal a ret brezoneg? 'Do you speak Breton?', lit. '(The action of) speak you do Breton?'

\$24 In English, the interrogative auxiliary is most often the verb to do, but this process is often combined with inversion: Do you speak English?

\$25 The English expression appears similar to the general use of the periphrastic expression formed with the auxiliary 'do' in the three Brythonic languages: Breton, Welsh, and Cornish. This fact is perhaps no accident. The Brythonic mother language of Great Britain is one of the substrata known to have influenced English from a distance.

\section{Chapter 85. Responses to connective interrogatives}

$\$ 1$ Unlike the nuclear interrogative which has an empty nucleus (Chapter $79, \$ 9$ ) and which has a response with a full nucleus (Chapter $80, \$ 17$ ), the connective interrogative uses a full nucleus and the corresponding response uses an empty nucleus. 
\$2 This parallelism is easily explained by the fact that, in a connective interrogative, the content of the nucleus is given and since the connection alone is being questioned, the response can be one of two types. The one confirms the existence of the connection and the other denies this connection. Two conventionalized words suffice, namely yes for confirmation and no for refutation. Yes means 'There is a connection.' No means 'There is no connection'.

$\$ 3$ The conventional affirmative word is so convenient and so frequently used that, in order to avoid repetition, one of its numerous substitutes (Fr. succédanés), which are available in all languages in which it exists, is often used instead:

\begin{tabular}{ll}
\hline & Substitute words \\
\hline $\begin{array}{l}\text { Sustitutes for oui } \\
\text { in French }\end{array}$ & $\begin{array}{l}\text { bien sûr, entendu, en effet, } \\
\text { assurément, sûrement, } \\
\text { évidemment, ça va de soi, } \\
\text { certes, certainement, d'accord }\end{array}$ \\
$\begin{array}{l}\text { Sustitutes for ja } \\
\text { in German }\end{array}$ & freilich, gewiss \\
$\begin{array}{l}\text { Sustitutes for da } \\
\text { in Russian }\end{array}$ & $\begin{array}{l}\text { konečno, izvestno, ladno, } \\
\text { bezuslovno, razumeetsja, } \\
\text { kak by nak }\end{array}$ \\
$\begin{array}{l}\text { Sustitutes for da } \\
\text { in Slovene }\end{array}$ & seveda \\
\hline
\end{tabular}

$\$ 4$ Perfect knowledge of the substitutes for the conventional affirmative word is one of the processes that give the impression of great ease of conversation in a foreign language. The current author has the memory of having succeeded, thanks to this "trick", in holding a two-hour conversation in a language that he did not know at all, understanding absolutely nothing, but coming across as very interested. His interlocutor declared to mutual friends the next day that he had met with a remarkably intelligent man, certainly because he was always in agreement with him.

$\$ 5$ Sometimes it is necessary to specify, potentially via a yes or a no, the exact meaning to be attributed to the sentence word of politeness thanks:

Mme Jourdain: Un peu de sauce?

Christian: Merci.

Mme Jourdain: Merci oui ou merci non?

Christian: Merci tout court... J'en ai déjà.
'Mrs. Jourdain: A little sauce?

Christian: Thanks.

Mrs. Jourdain: Thanks yes or thanks no?

Christian: Thanks period... I already have some.'

(Yvon Noé, Christian, II)

$\$ 6$ The words yes and no are anaphors (Chapter 43, \$1ff.); they are empty words which are immediately filled with the content of the question they answer, either positively or negatively. 
\$7 Consider the sentence: Was it you that I saw yesterday morning at nine o'clock as I was getting out of a taxi and as my father ran out of the post office into the street leading to the Place de la Préfecture and from there on to the train station? A response Yes! means: It was indeed me that you saw yesterday morning at nine o'clock as you were getting out of a taxi and as your father ran out of the post office into the street leading to the Place de la Préfecture and from there on to the train station. And a response No! means: It was not me that you saw yesterday morning at nine o'clock as you were getting out of a taxi and as your father ran out of the post office into the street leading to the Place de la Préfecture and from there on to the train station. Yes and no are thus two empty words that are each equivalent to an entire sentence, and this sentence can potentially be very long (Chapter $46, \S 8$ ).

$\$ 8$ These two words are incidentally a modern creation. They hardly exist in ancient languages. In Latin for example the response to a connective interrogative typically repeated the verb from the interrogative sentence, with preceding negation in the case of a negative answer.

$\$ 9$ For example, a normal positive response to the question Venitne Caesar? 'Is Caesar coming?' was typically Venit, and the negative response was Non venit. The response in this case does not use an empty nucleus, but a full nucleus. Since the nucleus is already full, there is no way to fill it further; it is therefore simply repeated.

$\$ 10$ The creation of empty words of the type yes and no, does not, despite their convenience, necessarily imply that responses of the type just examined will be eliminated. In Russian for instance, the positive reply to the question Prišel li Ivan? 'Has Ivan come?'can either be Prišël, lit. 'Come', or Da 'Yes', both of which must be translated as oui in French, or even $D a$, prišel ' 'Yes, he has come. ${ }^{122}$ The first response, which is characteristically Russian, is even the most common of the two forms, especially among the people and in the countryside.

\$11 In addition to the anaphor oui, which represents an affirmative response to a positive connective interrogative in French, it is necessary to mention a variant, the anaphor $s i$, which also represents an affirmative reponse, but to a negative connective interrogative, e.g. N'êtes-vous pas venu? - Si 'Have you not arrived? - Yes'. The anaphor si actually signifies 'Yes, I have arrived' and thus indicates that there is affirmation of the content that was negated in the preceding question. In such a case, the answer oui is not clear, since it can also indicate affirmation of the negation which is therefore a confirmation of the negation (Chapter 85, \$16).

122. Translators' note: English seems to be closer to Russian than to French from this point of view, since it allows both Yes and He has (and also the combination Yes, he has) as a response to the question Has Ivan come? 
$\$ 12$ The anaphor $s i$, which is an affirmative response to a negative question, is not equally prevalent in all languages.

\$13 In English for example, there is no such response. The affirmative response to the negative question Is the book not red? is Yes, just as if the question had been the positive Is the book red?.

$\$ 14$ In Russian, an anaphor of the same type as si does not exist either, but instead of replacing it with an anaphor of the type yes, it is replaced by an anaphor of the type no. The negation in this case bears not on the negative semantic content of the question, but rather on the negation itself contained in the question. Since two negatives make an affirmative, more precisely a reinforced affirmative (cf. Chapter 95, \$6), the anaphor, despite its negative value, turns out to be affirmative. However, the anaphor alone is not sufficient in such cases; the question must also be repeated in its declarative form: ${ }^{123}$

\begin{tabular}{lll}
\hline Question: & On ne tam? & 'Is he not there?' \\
Response: & Net, on tam. & 'No, he is there.' \\
\hline
\end{tabular}

\$15 This particularity of Russian is found in an almost identical form in Japanese. The convention for reply to questions in Japanese is very awkward. If a Japanese person is asked Are you not coming to work today?, he will reply No if he is coming and Yes if he is not coming. According to oriental logic, if he is coming, he replies No because he means to say The implication suggested by your negative question is erroneous. I am in fact coming to work. In the opposite case, he answers with You have suggested that I am not coming to work; you are correct, thus Yes is the response (Honorables fantaisies de la langue japonaise, by Francis Sill Wickware, Digest of Life, in Selection of Reader's Digest, September 1949, p. 67).

$\$ 16$ Ignorance of this particularity, which means that in the same situation, Rus. net 'no' should be translated into English as yes, rather than no, can sometimes lead to errors in translation:,

\begin{tabular}{|c|c|}
\hline Russian & English translation \\
\hline $\begin{array}{l}\text { - Čto ž ty xmuriš' cja, brat, sprocil ego } \\
\text { Kirila Petrovič, ili psarnja moja tebe ne } \\
\text { nravitsja? } \\
\text { - Net, - otvečal on curovo, - psarnja } \\
\text { čudnaja,... }\end{array}$ & $\begin{array}{l}\text { '- Why are you scowling, brother, } \\
\text { asked Kirila Petrovič? Do you not like } \\
\text { my kennel? } \\
\text { - Yes, answered harshly Dubrovsky, } \\
\text { the kennel is marvelous, ... }\end{array}$ \\
\hline \multicolumn{2}{|c|}{ (Pushkin, Debrovski) } \\
\hline
\end{tabular}

123. Nina Potapova, Le Russe 'The Russian', first part, p. 31 . 
In such a context, Rus. net should be translated as si in French, but in the first published translation of this text, which was otherwise good in general, it was translated as non!

$\$ 17$ It should not be forgotton that in French, the response to a connective interrogative cannot be expressed by anything other than oui (si) or non. The necessity to answer in this way has far-reaching consequences.

\$18 A game, called Ni oui ni non 'Neither yes nor no', consists of asking questions to which one can only reply with yes or no. It is clear that under these conditions, the questions posed are strictly limited to connective interrogatives. Any nuclear interrogative would remain unanswered. This game, although it may seem childish, constitutes nonetheless an excellent exercise for those who want, for whatever reason, to practice using connective interrogatives (Chapter 85, \$19).

$\$ 19$ In social situations, public services often collect information from the public via forms, in which certain questions are accompanied by the indication Reply only with yes or no. In such cases, it is evident that the questions should necessarily be formulated as connective interrogatives, otherwise the public would be unable to reply with just yes or no.

$\$ 20$ The need to conduct an urgent inquiry may require posing to a sick or severely injured person questions to which he can reply with minimum effort, that is, with just yes or no. These questions should of course be connective interrogatives.

\$21 This is the situation imagined by J. Verne in Captain Hatteras, II, chapter III, 2nd paragraph, Altamont's first words. The English members of a polar expedition find the survivor of an American polar expedition, a man by the name Altamont. They find him half dead and of course want to question him despite his extremely weak state.

"Altamont's account was still incomplete and, after a few minutes' rest, the doctor resumed this precious conversation with him; he posed questions in a form that required a simple nod of the head or a movement of the eyes for an answer".

Altamont's gestures were evidently signs that conventionally signify yes or no. On page 247 (II, 2), we learn that Altamont's responses are noted by J. Verne as yes. It is clear that the questions posed by the doctor to Altamont, in order to fulfil their purpose, can be nothing other than connective interrogatives.

$\$ 22$ Sometimes it is only possible, when overhearing a telephone conversation, to hear one of the two speakers, and it is sometimes the case that this person, be it due to shyness or a lack of eloquence, replies only with yes or no. The impression of the conversation is therefore that it is completely monotonous, since the only replies heard are those with an empty nucleus. For example: ... Yes. ... No. ... No. ... No. ...Yes. ... Yes. It is certain that the mysterious speaker on the other end of the line used connective interrogatives.

$\$ 23$ Sometimes the phone call can even deliberately take on this form, the two speakers having conspired to prevent one of them, in a café for example, from revealing a secret that it would be in his interest to keep. 
\$24 Finally, it is extremely important for the modern language teacher who wishes to obtain responses from his students to know how to obtain them by way of nuclear interrogatives, since connective interrogatives would result in nothing more from the students than laconic and monosyllabic anaphors. Nothing is more sadly amusing than to see a clumsy modern language teacher strive to enliven a conversation with a student using just connective interrogatives.

\$25 The experienced teacher must be capable of asking at will either nuclear interrogatives or connective interrogatives. He can even adjust the difficulty of the responses, that is, start with connective interrogatives when the student is being taught the empty anaphors yes and no at the very beginning. For example: Question: Is the book red? Response: Yes or no.

$\$ 26$ Then, remaining on the connective plane, the teacher progressively has his students add to the anaphor the words from the question in the form of a declarative sentence. For example: question Is the book red?, response Yes, the book is red, or No, the book is not red. $\$ 27$ After this stage, the teacher can proceed to nuclear interrogatives with some chance of success. Sufficiently used to replying with an empty nucleus, the students can then try to respond with a full nucleus. For example:

Question What is red?

Answer It is the book that is red.

\$28 This verbal mechanism constitutes the basic arsenal of every foreign language teacher who wants to teach with the direct method.

\section{Chapter 86. Exclamatives}

$\$ 1$ In the set formed by question and negation, it is also necessary to clear a special spot for exclamation.

$\$ 2$ In a number of languages, the expression of exclamation is more or less related to that of questions. Many words are simultaneously interrogative and exclamative. We follow the convention that calls these words exclamative-interrogatives.

$\$ 3$ One can easily conceive of the relationships of question and exclamation. A question is, as we have seen (Chapter $78, \S 2$ ), the natural reaction of a mind that is in doubt and wants to free itself of this doubt. But in reality this interrogative reaction is the second reaction to come about; it arises when the motive of doubt reaches the intellect. The motive first reaches the affective consciousness and shocks the intuitive being, triggering a more reflective and reasoned response. Exclamation is the translation into language of this first reaction, which then naturally develops into a question. 
$\$ 4$ These considerations suggest that, having looked at interrogatives, we must now proceed to exclamatives.

$\$ 5$ As with interrogatives, two types of exclamative can be distinguished: nuclear exclamatives and connective exclamatives.

$\$ 6$ Nuclear exclamatives bear on the content of a nucleus. In a number of languages, nuclear exclamation can be expressed by the same (or similar) marker as for interrogatives:

\begin{tabular}{ll}
\hline French & Quel gentil enfant! \\
English & What a nice child! \\
German & Welch' ein artiges Kind! \\
\hline
\end{tabular}

\$7 Exclamation can also be marked by the use of the genitive, when it exists in a language. This is the case in particular in German: $O$, des artigen Kindes! 'Oh, the good child!'.

$\$ 8$ Connective exclamatives, like connective interrogatives, bear on a connection, that is, on the structure of the entire sentence. They are expressed in diverse ways, but notably in the same ways as for questions. For instance in the following examples in French, the same postposed index appears

\begin{tabular}{ll} 
Madame Blandin: Mange-t-il! Non, mais & 'Is he eating! Look, is he \\
mange-t-il! Regardez-le. Ça en est inconvenant. & eating! Look at him. \\
(Henri Lavedan, Viveurs, Act II, p. 171). & It's unseemly' \\
- Cré nom! J'ai-t-il mal aux pieds! & 'Confound it! \\
(Edmond About, Le nez d'un notaire, I; words & Do my feet hurt!' \\
attributed to a ballerina, see also Chapter $84, \$ 19)$. & \\
\hline
\end{tabular}

$\$ 9$ The connective exclamation is readily expressed in French by the pronoun $c e$, which is used to intensify the meaning (Chapter $73, \$ 16$ ) of what it refers to. This pronoun is therefore equivalent to an adverb of quantity, whilst retaining the exclamative nuance of the sentence. For example:

\begin{tabular}{|c|c|}
\hline $\begin{array}{l}\text { Eve. - Ce qu'elle est gourmande! } \\
\text { Sous prétexte qu'elle est ici le } \\
\text { bras droit de M. Honoré, elle secroit } \\
\text { tout permis. } \\
\text { (Henri Lavedan, Viveurs, Act I, p. 3) }\end{array}$ & $\begin{array}{l}\text { 'How gourmande she is! Under } \\
\text { the pretext that she is Mr. } \\
\text { Honorés right-hand man here, she } \\
\text { thinks she can get away with anything.' }\end{array}$ \\
\hline $\begin{array}{l}\text { Suzanne. - Vous êtes rigolo, non } \\
\text { ce que vous êtes rigolo! } \\
\text { (Denys Amiel, Ma Liberté, Act II, p. 21). }\end{array}$ & $\begin{array}{l}\text { 'You are comical, no, } \\
\text { how comical you are!' }\end{array}$ \\
\hline
\end{tabular}


$\$ 10$ Often the emotion that the surprise causes has the effect of discarding the use of superior grammatical forms and therefore transforming for example a verbal expression into a simple nominal form. In other words, the verb will appear in its nominal form, which is the infinitive (Chapter 180, \$1). This happens in the following Greek sentence and in its French translation: Gr. Emè patheîn táde, Fr. Moi, souffrir de telles choses!, lit. 'Me, suffer from such things!'.

\section{Chapter 87. Nuclear negation}

$\$ 1$ Every negated form stems from an affirmation. The negated information is expressed in the same way as the affirmed information, the only difference being that a marker of negation is present. The study of negation thus revolves around the study of the negative marker.

\$2 The marker of negation varies according to the type of negation at hand. It is therefore necessary, as with interrogatives and exclamatives, to distinguish between nuclear negation and connective negation..

$\$ 3$ Nuclear negation is the type that bears on a nucleus. In the case of a nuclear interrogative, e.g. Who has come?, it is evident that emphasis is on a nucleus, on the nucleus of the first actant. If instead of responding with the answer Alfred has come, in which the empty nucleus is replaced with the name of the person who has come, the reply is Nobody has come, in which the empty nucleus is replaced with the general negation word nobody, it is clear that it is a nucleus (that of the first actant) that is concerned.

$\$ 4$ Just as there are general interrogative words (Chapter $80, \$ 1 \mathrm{ff}$.), it is necessary to acknowlgede general negative words, which express the semantic degree zero of the actant or circumstant that normally fills the nucleus.

$\$ 5$ General negative words correspond in principle to general interrogative words (Chapter 80). We distinguish in English for example:

\begin{tabular}{lll}
\hline $\begin{array}{l}\text { General negation words of } \\
\text { nominal actants }\end{array}$ & $\begin{array}{l}\text { Person } \\
\text { Thing }\end{array}$ & $\begin{array}{l}\text { nobody } \\
\text { nothing }\end{array}$ \\
& Place & nowhere \\
General negation words & Time & never \\
of circumstants & Manner & by no means, in no way \\
& $\begin{array}{l}\text { General negative } \\
\text { adjective }\end{array}$ & no, not any \\
\hline
\end{tabular}


$\$ 6$ All these general negation words exist in principle in all languages. The following comparative table lists these words for some of the most important languages:

\begin{tabular}{llllll}
\hline English & French & Latin & Greek & German & Russian \\
\hline nobody & personne & nemo & oudeís & niemand & nikto \\
nothing & rien & nihil & oudén & nichts & ničego \\
nowhere & nulle part & nusquam & oudamồ & nirgends & nigde \\
never & jamais & nunquam & oudépote & nie & nikogda \\
byno means & nullement & nequaquam & oudamōs & keineswegs & nikak \\
no & aucun & nullus & oudeís & kein & nikakoj \\
\hline
\end{tabular}

\section{Chapter 88. Connective negations}

\$1 In addition to nuclear negation, there is also connective negation, similar to what we see for questions.

\$2 Connective negation involves full nuclei that have a positive meaning, but the connection of which is negated by way of a marker that, bearing on the connection, applies to the entire sentence.

\$3 The marker of connective negation (e.g. not) is an empty word that must appear in the stemma inside the nucleus of a full word (e.g. sing) on the connective group of which it bears (Stemma 204):

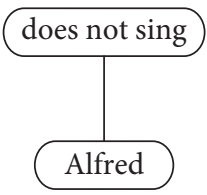

\section{Stemma 204}

$\$ 4$ The negative marker can either precede or follow the central node on the spoken chain depending on the language at hand.

$\$ 5$ Most of the time, the marker of negation precedes the central node of the sentence, at least in European languages:

\begin{tabular}{lll}
\hline Greek & Ou vomizei & 'He does not think.' \\
Latin & Non intelligit & 'He does not understand.' \\
Italian & Non capisce & \\
\hline
\end{tabular}




\begin{tabular}{|c|c|c|}
\hline Spanish & $\begin{array}{l}\text { Quien no ha visto Sevilla, } \\
\text { no ha visto maravilla. }\end{array}$ & $\begin{array}{l}\text { 'Whoever has not seen Seville, } \\
\text { has not seen a wonder.' }\end{array}$ \\
\hline Russian & Ne ponimaet. & \multirow{4}{*}{ 'He does not understand.' } \\
\hline Polish & Nie rozumie. & \\
\hline Czech & Ne rozumí & \\
\hline Serbo-Croatian & Ne razumije. & \\
\hline Romani & $\begin{array}{l}\text { Ma činger miro sano gadoro. } \\
\text { not tear my nice shirt }\end{array}$ & 'Do not tear my nice shirt.' \\
\hline Ancient Egyptian & $N m d w . n . f$ & 'He does not speak.' \\
\hline Georgian & $\begin{array}{ll}\text { Melani šavi ar aris. } \\
\text { ink } & \text { black not is }\end{array}$ & 'The ink is not black.' \\
\hline Chinese & $\begin{array}{l}\text { Tā bú pà wǒ. } \\
\text { he not fear me }\end{array}$ & 'He does not fear me.' \\
\hline Bantu & $\begin{array}{lll}\text { Kansi } & \text { u endi na sue. } \\
\text { not you come with us }\end{array}$ & 'Do not come with us.' \\
\hline
\end{tabular}

$\$ 6$ Worth noting is the fact that this structure was dominant in the pidgin established among French, German, and Russian prisoners in the war camps from 1914-1918, ${ }^{124}$ although only Russian has this order; it is not present in German or French:

French-German-Russian pidgin of 1914-1918

\begin{tabular}{ll}
\hline $\begin{array}{l}\text { Moi nix bouffer, } \\
\text { nix rabot. }\end{array}$ & 'If I have nothing to eat, I won't work', \\
& lit. 'I not eat, not work.
\end{tabular}

$\$ 7$ In certain languages where negation precedes the verb, agglutination occurs between the verb of the central node and the preceding negation. The negation becomes a sort of prefix

\begin{tabular}{|c|c|c|c|c|}
\hline Latin & \multicolumn{4}{|c|}{ nolo 'I don't want' (instead of non volo) } \\
\hline Latvian & \multicolumn{4}{|c|}{ vińš nav 'it isn't', instead of vińš ir 'it is' } \\
\hline Finnish & $\begin{array}{l}\text { Eitte } \\
\text { 'You don't }\end{array}$ & $\begin{array}{l}\text { puhu } \\
\text { speak }\end{array}$ & $\begin{array}{l}\text { suomea. } \\
\text { Finnish.' }\end{array}$ & (vs. Puhutte suomea 'You speak Finnish') \\
\hline Basque & $\begin{array}{l}\text { Gizona } \\
\text { 'The man }\end{array}$ & $\begin{array}{l}\text { ezta } \\
\text { isn't }\end{array}$ & $\begin{array}{l}\text { on. } \\
\text { good.' }\end{array}$ & (vs. Gizona ona da 'The man is good') \\
\hline
\end{tabular}

124. Translators' note. Tesnière does not use the modern term pidgin, but "petit nègre", lit. 'little negro', a term used initially to designate the simplified French used in French colonies at the beginning of the 20th century. 
$\$ 8$ An analogous contraction is sometimes observed in Russian with the verb 'be':

\begin{tabular}{llll}
\hline \multirow{2}{*}{ Russian } & Ego & zdes' & net. \\
& he.GEN & here & it isn't
\end{tabular} 'He isn't here'

$\$ 9$ The position of the negative marker after the verb of the central node in the spoken chain seems much less widespread:

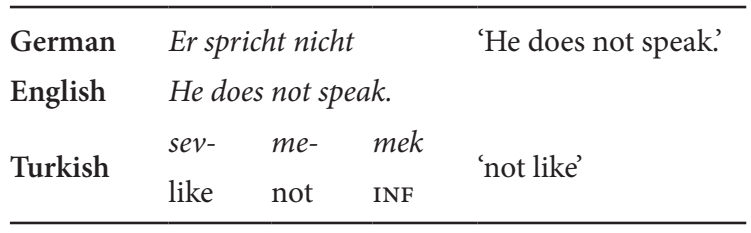

This is also the case in Dutch, Catalan, Occitan, and Chuvash.

$\$ 10$ In the case of agglutination, the marker of negation placed in the spoken chain after the verb of the central nucleus becomes a suffix rather than a prefix. This is the case in Tatar and in Mari.

\begin{tabular}{llllll}
\hline \multirow{3}{*}{ Tatar } & Til & joxše & tugel & & \\
& tongue & good & not & & \\
\multirow{4}{*}{ Mari } & Jolme & poro & og & ol & \\
& tongue & good & not & AUx & \\
\hline
\end{tabular}

\$11 Finally, although the matter concerns style more than grammar, sometimes the marker of negation is completely absent and it is by way of a somewhat ironic contradiction that the sentence, which is grammatically positive, must be understood as semantically negative. For example, the French expression Je vais me gêner 'Just watch me!', lit. 'I will hold back', or the following report from a colonial journey: ${ }^{125}$

The slightest stream was impassable: we had to make a bridge by cutting down a tree or, like monkeys, pass from tree to tree through the air, a convenient system for people loaded down! $\$ 12$ The irony is also evident in the language that adults frequently use to speak to children: No, it was the cat! It is likely that this expression has its origin in a situation where a child found it handy to blame a wrongdoing (having broken a dish or eaten some forbidden cake) on the cat:

Child: It wasn't me!

Adult (ironically): No, it was the cat!

125. Translators' note: Some irrelevant examples have been omitted here. 
$\$ 13$ In ancient Greek, there were two negations, an objective negation $o u(k)$ that served

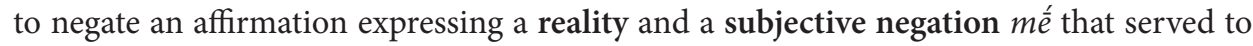
negate a speculation of the mind, be it intellectual (supposition) or volitive (desire, intention, willingness) or to express a feeling (fear), for example Ou dakrúomen 'We will not cry' in contrast to Mé dakrúōmen 'Let us not cry'. In general, ou corresponds roughly speaking to the meaning of the indicative and $m \bar{e}$ to the meaning of the other moods (imperative, subjunctive, optative, and even infinitive).

$\$ 14$ The effect of a negation is destroyed by a word like French mais 'but' or like sondern 'but rather' in German, which is specifically intended for this use:

\begin{tabular}{ll}
\hline French & Je ne suis pas grand, mais petit. \\
German & Ich bin nicht groß, sondern klein.
\end{tabular}

\section{Chapter 89. Anticipating negation}

$\$ 1$ It is sometimes the case that a negation bearing on a subordinate clause is expressed by anticipation using a negative marker in the main clause. This particularity occurs above all with verbs of volition (Chapter 60, 24 ).

$\$ 2$ Wanting

Noli me tangere.

Latin lit. 'Don't want to touch me.'

'Don't touch me.'

\section{$\$ 3$ Commanding}

\begin{tabular}{|c|c|c|}
\hline Russian & Literal & Idiomatic \\
\hline $\begin{array}{l}\text { Nam nikogo ne } \\
\text { veleno puskat'. } \\
\text { (Gogol, Taras Bulba, p. 154) }\end{array}$ & $\begin{array}{l}\text { 'It is not ordered } \\
\text { to.us to let anyone } \\
\text { enter.' }\end{array}$ & $\begin{array}{l}\text { 'He ordered us to not allow } \\
\text { anyone to enter.' }\end{array}$ \\
\hline $\begin{array}{l}\text { Zdes', govorit, etogo } \\
\text { ne veljat, } \\
\text { (Tolstoy, Life of a Peasant } \\
\text { Woman, Chapter XXI, at the end) }\end{array}$ & $\begin{array}{l}\text { 'Here, he says one does not } \\
\text { order that (to moan).' }\end{array}$ & $\begin{array}{l}\text { 'Here, he says, one } \\
\text { forbids that (to moan).' }\end{array}$ \\
\hline
\end{tabular}

\section{$\$ 4$ Necessitating}

Rus. Ne nado pystite! 'Stop it! Let me go!' (Tolstoy, Resurrection). This is the response from Katiousha, who has been forced to the limits of her virtue by the persistence of Prince Nekhlioudov; with these words, she is trying to repel him. 


\section{$\$ 6$ Hoping}

Ger. Ich hoffe nicht, dass Sie krank sind, lit. 'I do not hope that you are sick', that is 'I hope that you are not sick'. The same holds in the short expression Ich hoffe nicht, 'I hope not'.

\section{\$7 Pretending}

Henri IV étant à Fresne, chez le maréchal de Biron, demanda l'explication d'un vers grec; quelques maîtres des requêtes qui se trouvaient là ne firent pas semblant d'entendre.
'Henri IV, who was in Fresne at Marshal de Biron's, asked for the explanation of a Greek verse; several Masters of Requests who were there did not pretend to hear.'

(D’Avenel, La noblesse française, p. 285)

It is clear that this means 'pretended not to hear'.

$\$ 8$ In Latin and Greek, the anticipation of negation is obligatory with declarative verbs:

\begin{tabular}{|c|c|c|c|}
\hline & & Literal & Idiomatic \\
\hline Latin & Negavit se esse paratum. & $\begin{array}{l}\text { 'He denied } \\
\text { he was ready'. }\end{array}$ & $\begin{array}{l}\text { 'He said he was } \\
\text { not ready.' }\end{array}$ \\
\hline Greek & $\begin{array}{l}\text { Ohi stratiōtai ouk éphasan } \\
\text { iénai tô̂ prósō. }\end{array}$ & $\begin{array}{l}\text { 'The soldiers did } \\
\text { not say they } \\
\text { would go further.' }\end{array}$ & $\begin{array}{l}\text { 'The soldiers said } \\
\text { that they would } \\
\text { not go further.' }\end{array}$ \\
\hline
\end{tabular}

\section{Chapter 90. Agreement of junctives with negation}

$\$ 1$ Junctives (i.e. coordinating conjunctions, Chapter $39, \$ 4$ ) readily agree with negation. There are therefore two different junctives that express the same idea of coordination, one for the positive and another for the negative.

$\$ 2$ In French et 'and' (and ou 'or') are used in positive sentences, whereas in the corresponding negative sentences, $n i$ 'nor' is used:

\begin{tabular}{|c|c|}
\hline \multicolumn{2}{|c|}{ French $e t$ and $n i$} \\
\hline $\begin{array}{l}\text { Positive } \\
\text { et }\end{array}$ & $\begin{array}{l}\text { Aflred et Bernard sont venus. } \\
\text { 'Alfred and Bernard have come.' }\end{array}$ \\
\hline $\begin{array}{l}\text { Negative } \\
n i\end{array}$ & $\begin{array}{l}\text { Ni Alfred ni Bernard ne sont venus. } \\
\text { 'Neither Alfred nor Bernard has come.' }\end{array}$ \\
\hline $\begin{array}{l}\text { Positive } \\
\text { et }\end{array}$ & $\begin{array}{l}\text { Aflred rit et chante toujours. } \\
\text { 'Alfred always laughs and sings.' }\end{array}$ \\
\hline $\begin{array}{l}\text { Negative } \\
n i\end{array}$ & $\begin{array}{l}\text { Alfred ne rit ni ne chante jamais. } \\
\text { 'Alfred never laughs nor sings.' }\end{array}$ \\
\hline
\end{tabular}


$\$ 3$ Similarly, aussi 'also' is used in a positive sentence and non plus 'either' in a negative sentence:

\begin{tabular}{lc}
\hline \multicolumn{2}{c}{ French aussi and non plus } \\
\hline Je chante. Alfred chante aussi. & 'I sing. Alfred also sings.' \\
Je chante pas. Alfred ne chante & 'I don't sing. Alfred doesn't \\
pas non plus. & sing either.' \\
\hline
\end{tabular}

$\$ 4$ In the same way, in English nor and neither are set against or and either: Alfred and Bernard have come, Neither Alfred nor Bernard has come, I speak English and you speak English too, I do not speak English and you do not speak English either, He speaks English and so do I, He does not speak English, nor do I.

$\$ 5$ German has the opposing forms weder...noch 'neither...nor':

\begin{tabular}{|c|c|}
\hline \multicolumn{2}{|c|}{ German weder...noch } \\
\hline Alfred und Bernard sind gekommen. & 'Alfred and Bernard have come'. \\
\hline $\begin{array}{l}\text { Weder Alfred noch Bernard } \\
\text { ist gekommen. }\end{array}$ & $\begin{array}{l}\text { 'Neither Alfred nor Bernard } \\
\text { has come'. }\end{array}$ \\
\hline
\end{tabular}

$\$ 6$ But German auch 'also' adapts just as well to the positive as to the negative:

\begin{tabular}{lc}
\hline \multicolumn{2}{c}{ German auch } \\
\hline $\begin{array}{l}\text { Alfred singt. Ich auch } \\
\text { Alfred singt nicht. Ich auch nicht. }\end{array}$ 'Alfred sings. Me too.' \\
\hline
\end{tabular}

$\$ 7$ In Russian as in English, the junctive $i$ 'and' agrees with the negated form $n i$.

Ix razgovor blagorazymnyj, Konečno ne blistal nu čyvstvom, Ni poètučeskum ognëm, Ni ostrotoju, ni umom, Ni obščežitija iskusstvom,
'Their conversation full of common sense...

Was not brilliant in terms of sentiment,

Nor in terms of poetic fire,

Nor in terms of spiciness of spirit,

Nor in terms of social skills,

(Pushkin, Eugene Onegin, II-11)

$\$ 8$ Like the junctive auch in German, the Russian junctive tože does not have a negative form:

\begin{tabular}{|c|c|}
\hline \multicolumn{2}{|c|}{ Russian tože } \\
\hline Ja tože èto znaju. & 'I too know that.' \\
\hline Ja tože ètogo ne znaju. & 'I too don't know that'. \\
\hline
\end{tabular}




\section{Chapter 91. Double-trigger negation in French}

$\$ 1$ The question of negation in French is poorly explained in grammars. Instead of observing that negation is formed of the two words ne and pas, which are independent of each other and constitute a subtle and nuanced articulation, the first thing they do is to render the mechanism inflexible by the sacred formula that shackles them together: "French negation is ne...pas".

\$2 The result of such teaching is immediately apparent. The articulation, being set in stone, can no longer function correctly, and its nuanced flexibility, which is its principal characteristic and which gives French a great deal of facility, becomes a completely rigid mystery for foreigners.

$\$ 3$ A comparison aids understanding in this area: One can say that $n e$ and pas behave as elements of flexibility like an elbow or a knee, these normally contributing flexibility to the superior and inferior bones of the arm or leg. If for one reason or another, flexibility seizes up or amputation occurs and the bones are joined together in such a manner that normal flexibility is destroyed, then the arm or leg becomes stiff. Such is however the preferred explanation that the majority of grammarians do not hesitate to give to their students. This limited and rigid explanation replaces the healthy and subtle flexibility of the construction.

$\$ 4$ It seems clear that the double nature of French negation imposes the conclusion that, since it is morphologically necessary to employ two words, it must be the case that negation involves two syntactic functions, which together constitute a negation, each of the two words expressing a distinct function.

$\$ 5$ In spite of this evidence, the only French grammarians who acknowledge the double character of French negation and who have reached an appropriate conclusion are J. Damourette and E. Pichon, whose theory - the one theory that sufficiently takes these facts into account - should be adopted with reservation in the classroom. This theory is the direct inspiration for the exposition that follows. Our account is henceforth completely based on their work. ${ }^{126}$ According to Damourette and Pichon, French negation is split into two markers, the first of which is the discordantial ne, and the second the forclusive pas. It is the combination of the discordantial and the forclusive that constitutes French negation.

\section{Chapter 92. The French discordantial}

$\$ 1$ The discordantial ne alone does not constitute a negation. It merely prepares a coming negation. The forclusive is what actually realizes the negation. The mechanism can be

126. Jacques Damourette \& Edouard Pichon, Des mots à la pensée; Essai de grammaire française, volume I, Chapter 7, p. 129ff. and "Sur la signification psychologique de la negation en français", Journal de Psychologie, 1928, number 3, pp. 228-254. 
compared to a musical composition that consists of a dissonance (discordantial) and its resolution in a consonance (forclusive).

$\$ 2$ We have seen (Chapter 87 ) that every negation is derived from an affirmation. This means that before negating the content of a sentence, the mind must first affirm it in order to then negate it. There is thus a real decoupling. When I say Alfred ne chante pas 'Alfred is not singing', I detach my thought from the sentence Alfred chante 'Alfred is singing'.

$\$ 3$ Yet whereas most other languages express negation by means of a single marker that either precedes or follows the main verb (Chapter $88, \S 4 f f$.) according to the language at hand, French has two steps. It first dissociates thought from the affirmative and then reassociates it with the negative, which enables it to nuance the degree of negation. The discordantial serves to decouple the thought, and the forclusive to reestablish the thought in the negative.

$\$ 4$ The result is that the discordantial must appear in front the forclusive on the spoken chain, at least in front of the connective forclusive (Chapter $93, \$ 4$ ), for it is obviously not possible to reassociate something that has not first been dissociated.

\$5 The discordantial is generally placed before the verb of the central nucleus in the spoken chain, and the forclusive after the verb. The verb of the central nucleus is flanked on one side by the discordantial and on the other side by the forclusive (Schema 205).

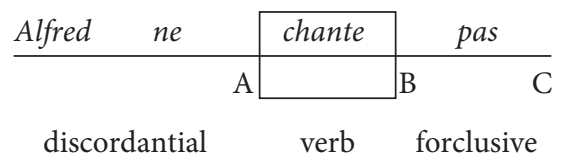

\section{Schema 205}

$\$ 6$ At the precise moment when we have already articulated the discordantial ne and as a consequence reached point $\mathrm{A}$ in the spoken chain, we have already performed the decoupling, but the reestablishment has not yet occurred.

\$7 After having just articulated the verb at point B, we already know that the notion 'Alfred sings' has been decoupled and that there is therefore a dissonance between the two; but the nature of the resolution is still unknown.

$\$ 8$ It is only at point $C$ at the end of the sentence after we have expressed the forclusive pas that we finally know the nature of the coupling, which is not realized here, and we know that not only is our thought not congruent with the sentence Alfred chante, but rather that it agrees with the complete and entire negation of this clause.

$\$ 9$ The discordantial marks nothing more than a mismatch of the mind concerning a given proposition. It leaves the thought in suspense concerning the clause to which the thought will adhere and for which resolution will erase the inadequacy. 
$\$ 10$ Be that as it may, the tandem formed by the discordantial and the forclusive is a circumstantial index (cf. Chapter 41, \$1ff.), subordinate to the verb it marks as negative (Chapter $129, \$ 21)$. In this sense, the negation functions like a softened translative (Chapter $168, \$ 5$ ).

\$11 The discordantial is not limited to the role of introducing the forclusive; it can also be employed in isolation where a discord is to be marked. We will now take inventory of these uses, or at least of the main ones. The merit of Demourette and Pichon's theory is the ability to show the independence of the discordantial; the liberty of appearance now allows us to understand its uses in isolation.

$\$ 12$ Among the meanings it carries in isolation, one characteristic use occurs with a comparative of inequality. Take for instance the French sentence Alfred est plus grand que je ne le suis 'Alfred is bigger than I am'. The discordantial ne does not express a negation, since the fact that Alfred is bigger than me does not imply in any way that I am not big. The discordantial here marks the fact that there is simply discord or a difference between Alfred's height and mine, since one is bigger than the other.

\$13 Similarly, the expressions plutôt que 'rather than' and à moins que 'unless' must be attached to the comparative of inequality, both of which lead to the use of the discordantial.

Je tombai plutôt que je ne m'assis sur le banc.

(Comtesse de Ségur, Le Général Dourakine, XX)

Un lièvre en son gîte songeait

Car que faire en un gîte à moins que l'on ne songe?

(La Fontaine, Le lièvre et les grenouilles

'The hare and the frogs', 1, 2, Fables, II-14)
'I fell rather than I (ne) sat down on the bench.'

'A hare in its shelter was dreaming, for what can be done in a shelter other than (ne) dream?'

\$14 Among the notions that lead to the use of the discordantial, Damourette and Pichon point to verbs that express fear, caution, and hindrance.

\$15 Fear: The use of the discordantial is easy to explain in the case of fear, since fear is by definition a type of discord. There is a discrepancy between what is hoped for and what is expected, e.g. Je crains qu'il ne vienne. 'I fear he (ne) will come'. Further:

Nous n'avons plus à craindre que
la main gauche ne reprenne ce que
le main droite a donné.
(Mme Julie Lavergne, La Diane
de Marly, p. 123).
Inquiets qu'on ne revînt sur cette
nouvelle décision, M. Ruffin et son
ami Colson pressèrent tant qu'ils
purent l'envoi des statues.
(Mme Julie Lavergne, La Diane
de Marly, p. 122).

'We no longer have to fear that the left hand (ne) take back what the right hand has given.'
'Worried that they (ne) would go back on this new decision, Mr. Ruffin and his friend Colson hurried the sending of the statues as much as they could.' 
\$16 Caution:

\begin{tabular}{|c|c|}
\hline Prenez garde qu'on ne vous voie. & $\begin{array}{l}\text { 'Be careful that no one sees you', } \\
\text { lit. 'Be careful that one (ne) sees you' }\end{array}$ \\
\hline
\end{tabular}

$\$ 17$ Hindrance:

\begin{tabular}{ll}
\hline $\begin{array}{l}\text { Rien n'empêche que vous } \\
\text { ne veniez me voir. }\end{array}$ & 'Nothing is preventing you \\
\hline
\end{tabular}

$\$ 18$ The use of the discordantial is also necessary with avant que 'before', given that the discord between the dates of the two processes separated by avant que being noticeable, e.g.: 127

\begin{tabular}{ll}
\hline $\begin{array}{l}\text { Espérons que vous serez arrivé } \\
\text { avant qu'il ne parte. }\end{array}$ & '(We) hope you will arrive \\
& before he (ne) departs. \\
\hline
\end{tabular}

\section{Chapter 93. French forclusives}

$\$ 1$ We have just seen that the discordantial appears in other diverse contexts in addition to its appearance with the forclusive, but it is also true that there are several variants of the forclusive as a response to the discordantial.

$\$ 2$ A forclusive can be nuclear or connective.

\$3 A nuclear forclusive can take on diverse forms according to the nature of the nucleus that it bears on. Nuclear forclusives are simply the general negative words that we have already seen (Chapter 87, \$5). Examples: Alfred ne frappe personne 'Alfred hits nobody', Alfred ne fait rien 'Alfred does nothing'.

$\$ 4$ A nuclear forclusive is formed just like any other particular word and consequently can appear before or after the discordantial ne, which invariably appears before the verb. For example, the nuclear forclusive of the first actant appears at the front of the sentence and therefore precedes the discordantial ne in the spoken chain, whereas the nuclear forclusive of the second actant appears later in the sentence and thus follows the discordantial ne in the spoken chain: Personne ne chante 'Nodody sings', but Alfred ne frappe personne 'Alfred hits nobody'.

127. Concerning the question of the expletive ne, see A. Moufflet, Encore le massacre de la langue française, II, 1935, pp. 135-136. 
\$5 The forclusive is plus when the negation bears on the continuation of the affirmed proposition: Alfred n'est plus jeune 'Alfred is no longer young', which is the negation of Alfred est encore jeune 'Alfred is still young.'

$\$ 6$ The connective forclusive is expressed by the word pas: Alfred ne chante pas 'Alfred does not sing. But there are a number of substitutes for the word pas, such as point, mie, goutte, etc. The meaning of these words is explained etymologically in sentences such as Je ne marche pas 'I do not walk', lit. 'I (ne) walk step', Je n'écris point 'I do not write at all', lit. 'I (ne) write point', Je ne mange mie 'I do not eat at all', lit. 'I (ne) eat bread', Je ne bois goutte 'I do not drink at all', lit. 'I (ne) drink drop'.

\$7 In contemporary French, the most frequent connective forclusive is pas. The forclusive point is a little less frequent and has a rural flavor. The forclusive mie is archaic, and the forclusive goutte is used almost exclusively in the expression n'y voir goutte 'not see a thing'. $\$ 8$ A connective forclusive cannot appear in place of a nuclear forclusive. Therefore Balzac, whose style is somewhat controversial, expresses himself carelessly when he writes Dans cette épouvantable guerre, les deux partis ne faisaient pas de prisonniers 'In that horrible war, both parties did not take prisoners' (Balzac, Les Chouans, III), which can mean that only one of the two parties took prisoners. If Balzac had wanted to avoid this ambiguity, he could have done so by writing Dans cette épouvantable guerre, aucun des deux partis ne faisait de prisonniers 'In this horrible war, neither of the two parties took prisoners.'

$\$ 9$ We have seen (Chapter $92, \$ 4$ ) that the connective forclusive must appear in the spoken chain after the discordantial. But we have also seen (above, \$4) that this obligation is not always applicable to the nuclear forclusive. For this reason, the forclusive pas has connective value at the end of a sentence, e.g. Un honnête homme ne ment pas 'An honest man does not lie, but it has nuclear value at the front of a sentence, e.g. Pas un honnête homme ne ment 'No honest man lies'. Similarly, the nucleus affected by forclusion is a function of the position of plus: Un homme ne ment plus 'A man no longer lies' / Plus un homme ne ment 'There are no longer any men who lie'.

\$10 In addition to the forclusive, which, after the discordantial has decoupled the thought from a positive interpretation, takes up the thought with the opposite meaning, it is necessary to acknowledge that other words furnish a variety of different resolutions of the discord. The main examples of such words are restrictive or limitative.

$\$ 11$ The restrictive word expresses that the reestablishment, rather than being zero, has a positive, but very limited quantity. Restrictiveness is expressed by the word guère: Je ne suis guère riche 'I (ne) am hardly rich'. Instead of being resolved to zero as in Je ne suis pas riche 'I am not rich', the mismatch in richness is resolved to an infinitely small quantity, but which is nevertheless positive.

\$12 The limitative word also expresses a reestablishment with an inifinitely small quantity, but it also expresses the extent of the limitation. Limitativeness is expressed by the word que followed by the expression of quantity that limits the positive expression: Je n'ai que 
deux francs dans ma poche 'I (ne) have only two francs in my pocket'. The dissociation is resolved here in the limited but nevertheless positive quantity of two francs.

$\$ 13$ The group composed of the discordantial and the limitative is therefore equivalent to the adverb seulement 'only': J'ai seulement deux francs dans ma poche 'I have only two francs in my pocket.' This is why the majority of foreigners find it more convenient in such a case to employ the adverb seulement, which exactly translates a word from their language (Eng. only, Ger. nur, Rus. tolko) rather than the subtler and more nuanced expression that French speakers instinctively prefer.

$\$ 14$ The limitative word also has the advantage of being more precise than the adverb seulement, which can bear indifferently on the word that precedes or follows it: Il est resté cinq minutes seulement 'He stayed five minutes only' or Il est resté seulement cinq minutes 'He stayed only five minutes'. Indeed, since, as we have seen (Chapter $92, \$ 4$ ), the coupling can only occur after the decoupling and since the limitation is introduced by que, it is evident that the limitation can only be placed after the limitative word on the spoken chain: $I l$ n'est resté que cinq minutes 'He rested only five minutes'.

\$15 Due to this particularity, it is possible to distinguish between sentences such as the following: On a le droit de ne faire que les trois premiers exercices 'We have the right to do only the first three exercises' and On n'a le droit de faire que les trois premiers exercices 'We only have the right to do the first three exercises'. In the first case, The right is positive; for example that of the test taker to do only the first three exercises instead of them all, which is nonetheless not prohibited. In the second case, the right spoken after que is subject to a limitation: the test taker is not permitted to do more than three exercises.

$\$ 16^{128}$

\section{Chapter 94. Extension and evolution of double-trigger negation}

$\$ 1$ The system of double-trigger negation using the discordantial and a forclusive is specifically French. But it also extends in certain cases to several related languages. In Italian it is possible to say Non è mica vero 'That is not true', where non plays the role of a discordantial and mica that of a forclusive. But this expression, far from being the norm, is only a local phenomenon, in particular around Florence.

\$2 However, double-trigger negation is the only possibility in Breton as in French: Breton Breiz-Izel n'eo ket braz 'Lower Brittany is not big. In this Breton expression, the discordantial $n$ ' and the forclusive ket correspond exactly to their French counterparts ne and pas: $\mathrm{La}$ Basse-Bretagne n'est pas grande.

128. Translators' note: We have omitted an irrelevant example from the end of this chapter. 
$\$ 3$ Similarly, it is possible to reinforce French general interrogative words by placing them in a main clause with the verb être 'be' and by relegating the main body of the question to a subordinate clause (Chapter $81, \$ 1 \mathrm{ff}$.). Similarly, it is possible using the same means to reinforce a negation that bears on a nucleus in particular. Therefore it is possible to say Ce n'est pas Alfred qui frappe Bernard 'It is not Alfred that hits Bernard', or Ce n'est pas Bernard qui frappe Alfred 'It is not Bernard that hits Alfred', where the negation bears on Alfred or Bernard, respectively.

$\$ 4$ In certain rare archaic French expressions, the discordantial alone can express negation: Je ne sais 'I don't know', Je ne puis 'I can't'. But this use is extremely limited, and is losing ground.

$\$ 5$ In contrast, the use of the forclusive alone with the value of negation is increasing in everyday speech and is therefore starting to replace double-trigger negation, which is nevertheless still the only correct form in modern French. An expression like Je sais pas 'I don't know' instead of Je ne sais pas is frankly a careless use of French and is even particularly common. The following two examples by Céline, a writer who made it his speciality to write in popular French and with slang, illustrate this familiar use of French:

Mais Madame Gorloge, elle se frappait pas comme maman...Ça l'arrêtait pas de tricoter, les esclandres et les rugissements.

(Céline, Mort à crédit, p. 198).

C'est en somme que beaucoup plus tard qu'on a commencé à se rendre compte que c'était chiant d'être travailleur. (Céline, Mort à crédit, p. 198)

\begin{abstract}
'But Mrs. Gorloge, she didn't get herself worked up like Mum... Scandals and uproar did not interfere with her knitting.'
\end{abstract}

'In short, it was only much later that people came to realize how lousy it is to be a worker.'

$\$ 6$ Not only the connective forclusive tends to be employed alone with the value of negation, but rather the nuclear forclusive is also employed alone, and this occurs even in elevated French: Qui avez-vous vu? - Personne 'Who did you see? - No one', Quand l'avezvous vu? - Jamais 'When did you see him? - Never'.

\$7 Note that the forclusive, when it is appears in addition to an expression that is normally constituted with the discordantial alone, provides these expressions with a negative form. Thus à moins que l'on ne songe pas 'unless one does not think of it' is the opposite of à moins que l'on ne songe 'unless one (ne) thinks of it', and Je crains qu'il ne vienne pas 'I fear that he is not coming' is the opposite of Je crains qu'il ne vienne 'I fear he (ne) is coming. In the first case, what one fears is the 'not-coming', whereas in the second case, it is the 'coming' that one fears. The explanation given for this by A. Moufflet (Encore le massacre de la langue française, II, 1935, p. 136), who settles for a simple distinction between expletive $n e$ and negative ne, does not get to the bottom of the matter and is therefore not very insightful. 
$\$ 8$ In these negative expressions, since ne keeps its role as a discordantial, pas alone assures that negation obtains, since its appearance reverses the positive meaning of the sentence and in so doing, makes the sentence negative. In this case, the use of pas as the sole marker of negation is perfectly correct. These expressions have certainly contributed to the preference for pas alone as the marker of negation, even in other cases, that is, even in the cases that were mentioned above in $\$ 5$, which are nevertheless still incorrect in contemporary French.

\$9 Thus while the use of the discordantial alone as a complete negation is archaic and belongs to the French of the past, the use of the forclusive with this same value is is still just slang and belongs to the French of tomorrow. It seems that double-trigger negation of modern French is in an intermediary state of equilibrium between the two stages. The gradual substitution of the forclusive for the discordantial to express complete negation has the effect of gradually transforming a negative marker that is preposed to the verb into a negative marker postposed to the verb.

\begin{tabular}{ll}
\hline Preposed negation & Je ne sais. \\
Double-trigger negation & Je ne sais pas. 'I don't know.' \\
Postposed negation & Je sais pas. \\
\hline
\end{tabular}

\$10 German provides a striking parallel to the evolution of French. In Germanic, the negation was $n i$ and it preceded the verb, ${ }^{129}$ e.g. Gothic Ni skuld ist 'It is not permitted.' ${ }^{130}$ In addition to ni, Old High German started to develop compound negations, e.g. nieman, niwicht, etc. In the 12th century nicht < niwicht, at first a particle reinforcing Middle High German ne, en (< Old High German ni) spread more and more, and the classic state of Middle High German is strangely similar to that of French: Ich enkan sinn anders niht verstān 'I cannot otherwise understand it' (Walther von der Vogelweide, Eloge de l'Allemagne ${ }^{131}$ ). From 1200 on, the proposed negation en- was employed alone in progressively rarer cases, and in modern German, postposed negation has become entirely dominant. Since the presence of double-trigger negation corresponds to the time when French influence was at its greatest, it would not be unreasonable to suppose that double-trigger negation in German was an imitation of French. The parallelism is striking.

$\$ 11$ A forclusive with the value of a complete negation readily appears with the preposition de 'of' followed by the noun of the negated person or thing. This common expression appears in elevated French:

129. Cf. Hermann Paul, Deutsche Grammatik, IV, $\$ 506$.

130. Cf. Mossé, Grammaire de la langue gotique, $\$ 252$.

131. Cf. Mossé, Manuel de l’allemand du Moyen Age, p. 417. 
Point d'argent, point de Suisse, et ma porte était close.

(Racine, Les Plaideurs, I-1)

Salomon: Il n'y aurait pas de déshonneur. On ne se quitte pas, malgré tout, après quatre ans, sans un petit machin.

Madame Blandin: Non, mon cher. Pas de petit machin... pas le moindre. Un grand accablement et un bon débarras... (Henri Lavedan, Viveurs, Acte IV, p. 281)
'No money, no Swizterland, and my door was closed'

'Solomon: There would be no dishonor. We are not separating, despite everything, after four years, without some difficulty.

Mrs. Blandin: No, my dear.

No difficulty...not in the least. Much despondency and good riddance.

\$12 The development of this use of de 'of' can even be seen in certain positive expressions that stand in opposition to negative expressions, in particular with verbs of volition like vouloir 'want', which is normally transitive: Même le vieux Rabbe, qui est prêt à s'engager, si on veut de lui! Even old Rabbe, who is ready to get involved, if he is wanted!' (Martin du Gard, Les Thibaud, Eté 1914, III, 71, p. 22).

\section{Chapter 95. Double negation}

\$1 In Latin, German, and English, the negation, which is generally marked morphologically by $n$, has a simple form in cases of connective negation: Lat. non, Ger. nicht, Eng. not. \$2 With nuclear negation, however, the negation can appear in simple or compound form. The compound form is obtained by agglutination of the negation with a general word, the latter being called a semi-negative (cf. Chapter 96, \$2), because even though the word alone has no negative value, it is destined to combine with negation:

$$
\begin{array}{ll}
\text { Lat. } & \text { non }+ \text { ullus }=\text { nullus, } \\
\text { Ger. } & \text { nicht }+ \text { jemand }=\text { niemand, } \\
\text { Eng. } & \text { not }+ \text { anybody }=\text { nobody } .
\end{array}
$$

\$3 Regardless of whether they are composed of a simple connective negation or of a nuclear negation containing a simple negation, all negative words - that is, all words containing negative meaning - have in common that they are impermeable. One negative word cannot be penetrated by the negative value of another. Given two negative words, the negative values cannot interpenetrate, rather, they exclude each other.

$\$ 4$ This is what classic Latin grammars teach with the rule: Two negatives make a positive. This expression means that when two negations occur in the same sentence, rather than reinforcing each other, they bear on each other and thus cancel each other out. This occurs in the sentence Nemo hoc nunquam dixit 'Nobody never said that'. The two negations 
nemo 'nobody' and nunquam 'never' cancel each other out, and instead of conveying the meaning 'Nobody ever said that', they mean 'There is no person who has never said that', which means that everyone has said that at one time or another. The same mechanism occurs in non nullus, in which the negation non cancels the negation nullus, the result being that the expression means 'not no one', which is equivalent to 'someone', and the plural nonnulli means 'some people'.

$\$ 6$ But on closer inspection, it quickly becomes apparent that traditional teaching of classic grammars - according to which two negations have the value of a positive - is somewhat inexact. Two negatives do not equal a positive, but rather more than a positive. Why use a more complicated process than an ordinary positive to express nothing more than a simple positive? But it is clear that the result of a double negation is more categorical than the simple positive. This observation can be expressed succinctly with the following rule: Two negatives equal a strengthened positive.

$\$ 7$ For example the Latin nuclear negation in Nemo hoc nunquam dixit signifies more than just 'That is said'. It signifies 'There is no one who has never said that', which means 'That is said, there is no doubt about it'.

$\$ 8$ The same is true of connective negation in Lat. Nec non dixit, where nec = et non, which means in reality et non non dixit, the first non canceling out the second, and therefore the clause as a whole means 'and he says', or more accurately 'he does not refrain from saying', i.e. 'and he says, there is no doubt about it'.

$\$ 9 \mathrm{Nec}$ non instead of et is an example of artificial elegance, which occurs above all in modern Latin, in particular in university theses and writings. Candidates make every effort to mimic, somewhat incorrectly, classical authors, for whom this expression had become a cliché.

$\$ 10$ In Greek, the two negations ou or mé appear together and provide extremely abbreviated expressions in which they behave as if the first is part of the main clause, and the second part of a subordinate clause dependent on the first. In this case, the two negations do not negate each other, since they are perceived as taking part semantically in separate clauses, and so they conserve their full value in their respective clauses.

$\$ 11$ This is what happens with the combination ou $m \bar{e}$, where the first negation applies to the reality of the thought of the speaker, whereas the second applies to the content of the fear that the speaker perceives. For example, Ou mế dusmenếs ésēi phílois 'You are not, I suppose, going to be unpleasant to my people' (Euripides, Médée, 1151).

$\$ 12$ However in the expression $m e^{\prime} o u$, in contrast, the first negation $m \bar{e}$ applies to the object of a feeling such as fear, whereas the second negation ou applies to the content of the thing feared. For example Dédoika mē ou therapeúe 'I fear that he will not take care of himself', in contrast to Dédoika mē therapeúē 'I fear that he would take care of himself'.

$\$ 13$ Similarly in Latin, ne non stands in opposition to ne: Timeo ne non veniat 'I fear he is not coming', in contrast to Timeo ne veniat 'I fear he is coming'. 
$\$ 14$ In French the mechanism of double-trigger negation complicates the situation. It is quite evident that the discordantial cannot cancel out the forclusive, nor vice versa, since they are both necessary for the negation to be complete.

\$15 Likewise, two forclusives - at least two nuclear forclusives - do not cancel each other. Instead they have the ability to appear with the same discordantial, sharing it in a sense. For example: Personne n'a jamais rien vu d'aussi beau 'Nobody has ever seen anything so beautiful', lit. 'Nobody (ne) has never seen nothing so beautiful', where the common discordantial is ne and the forclusives of different categories are personne, jamais, and rien. The same phenomenon occurs in Italian: Non lo ha mai detto nessuno 'Nobody ever said it', lit. 'Nobody never said it'.

\$16 However, a connective forclusive, since it applies to the entire sentence, cancels out nuclear forclusives, which apply only to a single nucleus. Sentences of this sort are actually incorrect in French: Je ne dis pas rien, lit. 'I (ne) am not saying nothing', is quite incorrect and contrary to the genius of the French language; it can only ever mean 'I am saying something, the connective forclusive pas cancelling the negation expressed by the discordantial ne and the forclusive rien.

$\$ 17$ The error just described is common in colloquial language. It is the type of language attributed to Martine by Molière as early as the 17th century in Les Femmes savantes:

\begin{tabular}{|c|c|}
\hline $\begin{array}{l}\text { Martine: Quand on se fait entendre, } \\
\text { on parle toujours bien. Et tous vos } \\
\text { beaux dictons ne servent pas de rien. } \\
\text { Philaminte: Eh bien! Ne voilà pas } \\
\text { encore de son style? Ne servent } \\
\text { pas de rien. }\end{array}$ & $\begin{array}{l}\text { Martine: Provided one is understood, } \\
\text { one speaks well enough, and all } \\
\text { four fine speeches don't do me no good. } \\
\text { Philaminte: You see! Is not that } \\
\text { her way of speaking? Don't do me no good! }\end{array}$ \\
\hline $\begin{array}{l}\text { Bélise: O cervelle indocile! } \\
\text { Faut-il qu'avec les soins qu'on } \\
\text { prend incessamment. On ne te } \\
\text { puisse apprendre à parler } \\
\text { congrument? De pas mis avec } \\
\text { rien tu fais la récidive; Et c'est, } \\
\text { comme on t'a dit, trop d'une négative. }\end{array}$ & $\begin{array}{l}\text { Bélise: O intractable brains! How } \\
\text { is it that, in spite of the trouble we daily tal } \\
\text { we cannot teach you to speak } \\
\text { with congruity? In putting not with } \\
\text { no, you have spoken redundantly, and } \\
\text { it is, as you have been told, a } \\
\text { negative too many. }\end{array}$ \\
\hline
\end{tabular}

(Molière, Les Femmes savantes, II, 6)

It must be said in Martine's defense that even if the expression she uses is incontestably incorrect, the "incessant concerns" of Bélise are extenuating circumstances for her. Bélise's insightful explanations are not exempt from criticism either, because even if it is right to say that the use of pas with rien in French is false, it is also false to see these words as negatives, whereas, as we have seen, they are in reality forclusives, one connective and the other nuclear.

\$18 Independent of the exclusion of the connective forclusive and the nuclear forclusive, and just like in the languages examined at the start of this chapter, two complete 
negations or even simply two negative ideas expressed by a given process cancel each other in French so that the sentence receives a positive meaning. This is what occurs for example in French Il ne laissait pas d'être inquiet 'He did not fail to be concerned'. In this sentence, the negation expressed by the combination of the discordantial ne and the forclusive pas cancels out the negation contained semantically in the verb laisser, so much so that the sentence ends up meaning 'He was in fact very concerned'. Similarly:

Il n'y avait pas jusqu'à la cloche de la chapelle qui ne vibrât de terreur, et qui ne mêlât sa plainte longue et sonore au fracas des éléments.
'Even the chapel's bell vibrated with terror and added its long and ringing moan to the roar of the elements.'

(Charles Nodier, Le Génie Bonhomme)

In this sentence, the first negation expressed by $n e$ and pas cancels the following negation, which is indicated by ne. The meaning is reinforced: 'The very landscape has changed'.

$\$ 19$ Note that the calculation of two negations equivalent to an affirmation is in itself already complicated enough and sometimes leads to a slip created by the context and which causes the speaker or writer to say exactly the opposite of what was intended. For example a newspaper, which is in general correctly written, put the following declaration, which was evidently intended to reassure public opinion, in the mouth of M. Robert Schumann:

\begin{tabular}{ll}
\hline Eloignez de votre pensée qu'en & 'Banish from your mind that \\
aucun cas nous ne devons & on no account must we \\
envisager l'hypothèse d'une & envisage the possibility of a \\
dévaluation. & devaluation.'
\end{tabular}

(Midi Libre, October 17, 1946)

\$20 Finally, note that double negation is also at the origin of the Russian anaphor net 'no' with the value of 'yes' (cf. Chapter $85, \$ 14-16$ ), since, as we have indicated (Chapter 85, $\$ 14)$, the anaphoric negation net bears on the negation contained in the negative question.

\section{Chapter 96. Permeable negation}

\$1 Expressing negation like Fr. Personne n'a jamais rien dit nulle part à ce sujet 'Nobody ever said anything anywhere about that', lit. 'Nobody never said nothing nowhere about this subject', is a very delicate matter in certain languages due to the impermeability of negation, since all the negative words accumulated conflict with each other and cancel each other out. This is why in addition to impermeable negative words, these languages possess a parallel series of permeable negative words, which cannot in principle express negation alone, but which can combine with an impermeable negative word. 
\$2 The permeable negative words, which are known as semi-negative words, are the following:

\begin{tabular}{lll}
\hline English & Latin & German \\
\hline anybody & ullus & jemand \\
anything & quidquam & etwas \\
anywhere & usquam & irgendwo \\
ever & unquam & je \\
byany means & & irgendwie \\
any & ullus & ein \\
\hline
\end{tabular}

$\$ 3$ In order to establish a sentence with a nuclear negation bearing on more than one nucleus, it is necessary to avoid filling more than one nucleus with impermeable negative words. A single chosen nucleus is filled with an impermeable negative word, and all the others are filled with permeable negative words such that the negations cannot cancel each other. For example Lat. Nemo hoc unquam dixit 'No one has ever said that' or Nunquam hoc ullus dixit 'Never has anyone said that', unlike Fr. Personne n'a jamais dit ça, lit. 'No one never said that', avoids placing nunquam and nemo in the same sentence. At the same time, at least one of these words must appear, whereas the other takes on the nonimpermeable form unquam or ullus.

$\$ 4$ The same thing occurs in German:

\begin{tabular}{ll} 
Das hat keiner je gesagt. & 'Nobody ever said that.' \\
Das hat niemals einer gesagt & 'Never did anybody say that.' \\
\hline
\end{tabular}

$\$ 5$ As can be seen in the preceding examples, the general negative impermeable word is always the one that appears first in the spoken chain.

$\$ 6$ In contrast to Latin and English, Russian and other Slavic languages in general are not familiar with impermeable negative words. All the negative words in these languages are permeable. The negations that they contain therefore do not cancel each other, and the rule that two negations constitute a (reinforced) affirmation is inapplicable. Quite to the contrary, when one of these words is negative, all of the others have to be negative too, as though they are compelled to agree with the negative value of the first.

$\$ 7$ For example in Russian: Nikto nigde nikogda ètogo ne skazal 'Nobody nowhere did not say that anywhere', lit. 'Nobody nowhere never did not say that'

$\$ 8$ The same system is found in Greek: Oudeis oudèn hupopteúei 'Nobody suspects anything', lit. 'Nobody suspects nothing'.

$\$ 9$ In Latin and Greek, connective negation (non vs. ou $(k)$ and $m \bar{e}$ ) is, remarkably, impermeable to its left only; that is, its negative value cancels the negative value of another 
negative word that appears before it in the spoken chain and ends up as a reinforced affirmation. On the other hand, far from excluding another negative word appearing after it in the spoken chain, it agrees with its negative value.

$\$ 10$ Therefore in the Lat. Nemo non putat or in the Gr. Oudeis ou nomizei, lit. 'Nobody not thinks', the negations non and ou 'not', which are impermeable to their left, do not merge with the negative words nemo and oudeis 'nobody', and, as a consequence, the two negations cancel each other out. The meaning is therefore 'There is nobody who does not think', in other words, 'Everybody thinks'.

$\$ 11$ In contrast, nothing prevents ouk from penetrating oudeis in Gr. Ouk oudeis nomízei and non from penetrating nemo in Lat. Non nemo putat, lit. 'Not nobody thinks', since oudeis and nemo appear to the right of ouk and non, rather than to the left. The result is that the two negations do not cancel each other, which means that the expression is decidedly negative; with the meaning 'Nobody thinks'.

$\$ 12$ In the interest of clarity, we will represent the one-sided impermeability of the negation $o u(k)$ with a left bracket to its left: $[o u(k)$. Hence we write Oudeis [ou nomízei, where the bracket to the left of $o u(k)$ represents its impermeability and therefore separates it from oudeis. As the two negations cancel each other, the meaning is 'Everybody thinks'. However, in [Ouk oudeis nomizei, the bracket representing impermeability does not separate ouk from oudeis and hence the negative meaning of the sentence obtains: 'Nobody thinks'.

$\$ 13$ Further, it should be noted that impermeability is only valid when both of the negations bear on the whole sentence. If one of the two negations bears on only one of the nuclei, only the nucleus in question becomes positive, whereas the sentence as a whole remains negative. The cancelation of the two negations is only valid for the nucleus that, other than the general negation of the sentence, is under the influence of the particular negation pertaining to that nucleus. Asklēpiòs [ouk agnoíai... toîs ekgónois [ou katédeixen autó 'It is not due to ignorance that Asclepios did not reveal that to his sons' (Plato, Republic, 406 C). ${ }^{132}$

132. Cf. Jean Humbert, Syntaxe grecque, 1945, p. 368. For all questions concerning negation in Greek, the good explanations contained in this book are particularly insightful, p. 345ff. [2nd revised edition, 1954]. 



\section{BOOK D}

\section{Valency}

\section{Chapter 97. Valency and voice}

$\$ 1$ We have seen (Chapter 50, \$5ff.) that there are verbs with no actant, verbs with one actant, verbs with two actants, and verbs with three actants.

\$2 Similarly, we have seen that there are also different types of actants: first actants, second actants, and third actants (Chapter 51). The nature of the verb that governs these actants varies according to whether it governs zero, one, two, or three actants. It is evident that a speaker does not perceive a verb that is susceptible to governing only one actant in the same manner as one that is susceptible to governing two or three actants, or one that is susceptible to governing no actant at all.

$\$ 3$ The verb may therefore be compared to a sort of atom, susceptible to attracting a greater or lesser number of actants, according to the number of bonds the verb has available to keep them as dependents. The number of bonds a verb has constitutes what we call the verb's valency.

$\$ 4$ The psychological conception of the verb according to its valency in relation to its possible actants is what we call voice in grammar. ${ }^{133}$ A verb's voice therefore depends for the most part on the number of actants that it is can take.

$\$ 5$ Note also that it is not necessary for the verb’s valency to be completely filled by its actants and for the verb to be saturated. Certain valency slots can remain unrealized or open. For instance the divalent verb sing can appear without its second actant. Such is the case in Alfred is singing as opposed to Alfred is singing a song. The same is true of the trivalent verb give; it can appear without its second or third actant: Alfred gives to the poor (Stemma 206), Alfred gives a hand (cf. Stemma 207).

133. The French reform of 1910 was misguided when it prescribed the term forme 'form' in place of voix 'voice'. It had the effect of replacing an indispensable notion of syntax with a totally different morphological concept, which presents the grammar user with confusion that s/he should rather be warned against (cf. G. Galichet, Essai de Grammaire Psychologique, p. 92). It is an example of one of the many terminological thefts committed by morphologists at the syntacians expense (cf. Chapter 15, \$10-11, and Chapter $51, \$ 10$, note 75 ). 


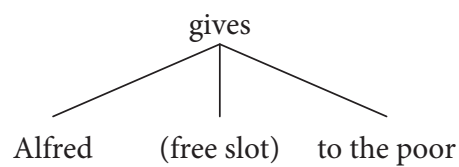

Stemma 206

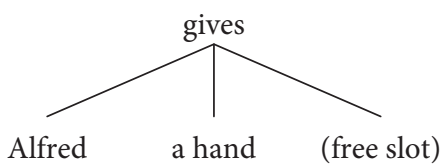

Stemma 207

\section{Chapter 98. Avalent verbs}

$\$ 1$ Verbs without actants, avalent verbs, - that is, those that have no valency - are known in traditional grammar as impersonal. But it has been recognized that this term is poorly suited, since verbs that are said to be impersonal exist in personal moods (indicative, subjunctive, for example: It is raining) as well as in impersonal moods (infinitive, participle, for example: to rain). It has therefore been proposed that the term impersonal be replaced with the term unipersonal, since verbs without an actant exist only in the anontive singular (Lat. Pluit, Eng. It is raining, Fr. Il pleut, Ger. Es regnet).

$\$ 2$ But the term unipersonal is no better suited to verbs for which the notion of person is essentially unknown than the term impersonal in view of the fact that these verbs take no actants. For this reason, we prefer the term avalent, since it says what it means.

$\$ 3$ The absence of an actant in avalent verbs is easily understood if it is compared to a play without actors. It is snowing simply expresses a process that takes place in nature without there being an actor at its origin (cf. Chapter 50, $\$ 6$ and 8).

$\$ 4$ Concerning the apparent subject that appears in certain languages (Fr. Il pleut 'It is raining, Il neige 'It is snowing', Il vente 'it is windy', lit. 'It is winding'; Ger. Es regnet 'It is raining'), it is in reality nothing more than an anontive singular marker of the verb (cf. Chapter 50, \$7).

$\$ 5$ Sometimes the explanation put forward is that impersonal verbs are derived from former monovalent verbs, the actant of which is simply implied today. This explanation is based on the Greek expression: Zeùs húei 'Jupiter is raining', Ho theòs húei 'The god is raining. It is indeed possible that at a time when primitive animacy populated nature with spirits, which were taken to be the agents of all of nature's phenomena and which were in reality merely the personification of the forces of nature, especially by the Greeks, whose imagination was fertile and aesthetic, personnified agents were attributed meteorological phenomena. But that is no more than a historical and mythological motivation, which has nothing to do with the current perception of modern speakers, who perceive a process without an actant. ${ }^{134}$

134. These are examples of idioms that are "rationalized backwards", as E. Benvéniste rightly states in his Structure des relations de personne dans le verbe, Bulletin de la Société Linguistique de Paris, 43, 1947, page 6. 
$\$ 6$ In the case of meteorological phenomena, the process is conceived of as a state in English, for example It is cold, It is warm, and in German, for example Es ist kalt, Es ist warm, in which the verb be is used. In French however, the verb be is associated with an action and the verb faire 'to make/do' is used for states (cf. Chapter 36, \$12): Il fait froid 'It is cold', lit. 'It makes cold', Il fait chaud 'It is hot', lit. 'It makes warm', Il fait jour, 'It is daytime', lit. 'It makes day', Il fait bon 'The weather is good', lit. 'It makes good', Il fait beau 'The weather is nice', lit. 'It makes beautiful'.

\section{Chapter 99. Monovalent verbs}

$\$ 1$ Verbs with one actant, i.e. monovalent verbs, are known in traditional grammar either as neutral or, to use a more recent and precise term, as intransitive. The verbs doze, travel, flow are intransitive.

\$2 It is possible to say Alfred is sleeping or Alfred is falling (Stemma 208), but it is impossible to say, and moreover it is impossible to imagine, these actions involving another actant in addition to Alfred. One cannot doze, travel, or flow someone or something.

$\$ 3$ Verbs with one actant are often verbs of state (cf. Chapter $36, \$ 15$ ) and this explains why they are expressed in English and French by the verb be/être followed by a predicative adjective, e.g. The tree is green. ${ }^{135}$ But they can also be verbs of action, in which case the nuance, which is quite subtle, at least in French, can be expressed by the use of a different marker: Unlike L'arbre est vert 'The tree is green', which expresses the state of the tree in all its passivity, L'arbre verdoie 'The tree becomes verdant' suggests the notion of an active internal force responsable for the tree's greenery. We all remember the tale Bluebeard, in which Perrault has Sister Anne say: Je ne vois rien que le soleil qui poudroie et l'herbe qui verdoie 'I see nothing but the sun making dust and the green grass'.

$\$ 4$ The nuance of action is clearly expressed in Occitan by the suffix -ejà in verbs such as amarejà 'become bitter', blanquejà 'appear/become white', negrejà 'appear/become black. ${ }^{136}$ $\$ 5$ With verbs with one actant, it is sometimes difficult to determine if the single actant is a first actant or a second actant. For example the Fr. Il faut une loi 'A law is needed' is sometimes logically analyzed as Une loi faut, as if Fr. falloir were equivalent to Eng. need. It is no less true that the linguistic intuition of most French speakers today sees une loi as the complement of il faut.

$\$ 6$ Likewise, meteorological verbs employed as verbs with one actant can also be a nuisance. The expression Il pleut des hallebardes 'It is raining cats and dogs', lit. 'It is raining halberds', can sometimes be understood as Des hallebardes pleuvent 'Halberds are raining. But the halberds (or cats and dogs in English) should really be analyzed more as the object of the raining than

135. Cf. Chapter 23, \$14f. and Chapter 67, \$3.

136. Lamouche, Grammaire languedocienne, p. 139. 
as the subject, which would be more like the raining gods of the Greeks (cf. Chapter $98, \$ 5$ ). Moreover, hallebardes, which is plural, cannot be interpreted grammatically as the subject of the verb pleut, which is singular (cf. Chapter $61, \$ 9$ ). The conclusion reached is therefore that the only actant des hallebardes is a second actant rather than a first actant. In this case, as in many other cases, linguistic observation, which is just as introspective as it is objective, leads to very different conclusions from those that seem to be imposed by logic a priori.

$\$ 7$ This is also the case with the expression Vive la France 'Long live France', which Ferdinand Brunot examines as follows: ${ }^{137}$

"It is possible... that in Vive la France, la France was the subject of Vive, but it no longer appears as such to the speaker. But that is what the observer wants to believe. Following language variation is a field of study... It is another, and quite different field to examine languages as they are. After the logical error from times gone by, let us not fall into the etymological trap."

$\$ 8$ We can therefore conclude that in expressions like Il faut une loi (\$5), Il pleut des hallebardes (\$6), Vive la France (\$7), the single actant is not a first actant, but rather a second actant. $\$ 9$ It is even possible to find monovalent verbs where the single actant is a third actant. This is the case in particular in German expressions such as Es ist mir warm, lit. 'To me it is warm' (cf. Chapter 98, \$6), that is 'I'm hot', where the actant, which is in the dative case, is the person to whom the sensation of warmth expressed by the verb is attributed.

$\$ 10$ Finally, the verb changer 'change' in French has a particular value when it is conceived of as a verb with one actant. In such a case, it is constructed with a circumstant preceded by $d e$, and whereas with two actants, the verb is as follows: L'horloger change le ressort de ma montre 'The watchmaker is changing the spring in my watch', its form is as follows with just a single actant: Alfred change de veste 'Alfred is changing his jacket' (cf. Chapter 57, \$6). The notion of changer as a monovalent verb is one of the particularities of French that is most puzzling for foreign speakers, who often make the mistake of saying J'ai changé la chemise instead of J'ai changé de chemise 'I changed my shirt'.

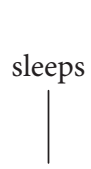

Alfred

Stemma 208

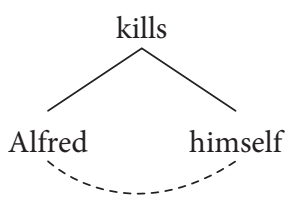

Stemma 209

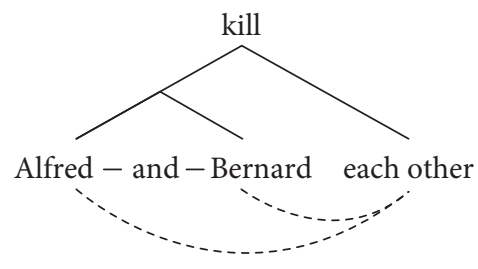

Stemma 210

137. Brunot, La pensée et la langue 'Thought and language', 1922, p. XIII. 


\section{Chapter 100. Transitive verbs}

$\$ 1$ Verbs with two actants are known in traditional grammar as transitive, because in a sentence such as Alfred hits Bernard (cf. Stemma 6), the action passes or transits from Alfred to Bernard.

\$2 But traditional grammar does not have a special term for verbs with three actants. It groups them together with verbs with two actants under the name transitive. This is clearly a considerable oversight, since, other than the fact that verbs with three actants correspond to two well-defined types (verbs of saying and verbs of giving, Chapter $106, \S 3$ ), they are structurally the most complex and the most difficult to handle.

$\$ 3$ On the other hand, traditional grammar correctly distinguishes between four types of transitive voice, which are consequently types of sub-voice which we will call diathesis, after the term used by the Greek grammarians.

$\$ 4$ If an action has two actants, it is wise to interpret them differently according to the meaning that each expresses, or to use more traditional terminology, to interpret them according to the action that transits from the one actant to the other.

\$5 Take for example the transitive verb hit and two actants A (Alfred), who does the hitting, and B (Bernard), who receives the hits. In the sentence Alfred hits Bernard (Stemma 6), we say that the verb hits is in the active diathesis because the first actant performs the action of hitting, and its participation in the action is fully active.

$\$ 6$ But we can also express the same idea by means of the sentence Bernard is hit by Alfred (Stemma 95). We say that the verb hit is in the passive diathesis, since the first actant is the recipient, and its participation in the action is completely passive.

$\$ 7$ The active and the passive are the fundamental diatheses of the transitive voice, but they are not the only ones, since they can also be combined.

$\$ 8$ For example, it can occur that the same person (or thing) performs the hitting and receives the hits. This person or thing is therefore both the active and passive actant, or the first and second actant. This is the case in sentences such as Fr. Alfred se tue or Eng. Alfred killed himself (Stemma 209). We say in this case that the verb is in the reflexive diathesis, because the action that comes from Alfred ends equally with Alfred, as if it were reflected by a mirror. Moreover, in the same way we can also say Alfred looks at himself in the mirror.

$\$ 9$ Finally, there can be two parallel or inverse actions, each of the two actants playing an active role in one action and a passive role in the other. This is the case in sentences such as Fr. Alfred et Bernard se tuent or Eng. Alfred and Bernard kill each other (Stemma 210). We say that the verb is in the reciprocal diathesis because the action is reciprocal. 
\$10 The four diatheses of transitive voice can be summarized in the following schema:

\begin{tabular}{ll}
\hline Active & $\mathrm{A} \longrightarrow \mathrm{B}$ \\
Passive & $\mathrm{A} \rightleftarrows \mathrm{B}$ \\
Reflexive & $\mathrm{A}$ \\
Reciprocal & $\mathrm{A}$
\end{tabular}

\section{Chapter 101. The active diathesis}

$\$ 1$ We have seen (Chapter $100, \$ 5)$ that the active diathesis is where the action transits from the first actant to the second actant.

\$2 The presence of a second actant is therefore enough to expose the active nature of a verb. For this reason, in languages that have a sufficiently clear process for identifying the first actant, such as those with case, the verb does even not need to be expressed for the active diathesis to stand out. The active diathesis is a direct result of the presence of a second actant. In such cases, the diathesis could be said to be virtual.

$\$ 3$ Take for example the colloquial Russian expression Čto vy?, lit. 'What you?' in which the first word is the interrogative neuter pronoun Cto 'what' (Lat. quid?) and the second word vy 'you' is the personal antiontive of the polite plural in the nominative (Fr. vous). The expression can, depending on the circumstance, mean 'What are you doing?' or 'What are you saying?' The exact nature of the activity of the first actant $v y$ cannot be identified, since the verb is not expressed, but it is clear that the verb can be nothing other than an active verb, since there are two actants, of which one is necessarily the second actant.

$\$ 4$ The same absence of the verb can be found in Latin in Vergil's famous passage (Aeneid, IX, 427) Me, me, adsum qui feci 'Me, me, here I am the one who did it', where the accusative $m e$ 'me' is clearly not in opposition to the subject of adsum 'here I am'; for even though it is not expressed, the subject could only ever be in the nominative. The accusative me must therefore be the second actant of a verb other than adsum, a verb that is not expressed but is evidently imagined in the active voice, since it takes a second actant.

\$5 What is more, this is exactly what is understood from the situation in its context. Vergil describes an ambush in which two Trojan heroes, Nisus and his friend Euryalus, are surprised by a group of Rutuli commanded by Volsus. Nisus, who at first remains hidden, wishes to free Euryalus and throws a deadly spear that pierces the body of Sulmon. Seeking vengeance and seeing only Euryalus, it is against Euryalus that Volsus turns his fury and he strides towards him with sword in hand. At that moment, Nisus, jumping out from his hiding spot, pronounces the sentence in question, thus seeking heroically to draw attention to himself and deflect the blow menacing Euryalus. 
$\$ 6$ It is evidently this blow that constitutes the action for which me is the second actant. The meaning is therefore something like 'It is me that you must strike, It is to me that you must give your blow. The absence of a first actant is due to the fact that it is an imperative. \$7 It is easy to see that such an expression is difficult to translate. The section dedicated to foreign and Latin expressions in the petit Larousse falls into the trap of interpreting the expression as the opposite of what it should have been when it translates the expression as It is me, me, who did it. The Budé collection's translation is more cautious: Me! Me! It is me who did everything. But while the translator avoids misinterpretation, he leaves an ambiguity in the meaning of the first two me's, which run the danger of being assimilated to the third me, which is clearly a first actant. This difficulty is not easily avoided in languages like English or French that do not have a morphological means to mark the distinction between the second and first actant.

$\$ 8$ However, stemmatic representations can be used to capture the delicate meaning of this passage (Stemma 211).

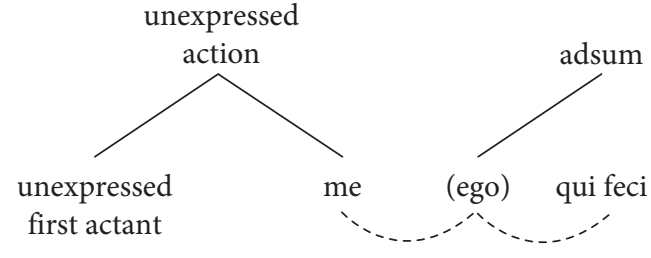

Stemma 211

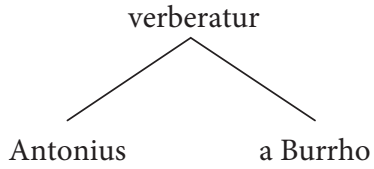

Stemma 212

\section{Chapter 102. The passive diathesis}

$\$ 1$ We have seen (Chapter 100, \$6) that the passive diathesis is where the first actant receives the action performed by the other actant.

$\$ 2$ The passive diathesis is therefore the inverse of the active diathesis. In other words, the transition occurs in the opposite direction, since the first actant, which is at the origin of the transition in the active diathesis, is the goal in the passive diathesis.

$\$ 3$ The inversion of the transit's direction necessitates a marker for the passive diathesis to provide a clear contrast with the active diathesis.

$\$ 4$ This marker can be, as is consistently the case in morphology, expressed by two processes: one analytical or periphrastic, and the other synthetic.

$\$ 5$ The analytical marker of the passive or the auxiliary of the passive is the verb be in English, in German the verb werden and in Danish the verb blive. The auxiliated is the anterior participle (i.e. past participle, cf. \$9) in both cases: Eng. I am loved, Ger. Ich werde geliebt, Dan. Jeg bliver elsket. 
$\$ 6$ The synthetic process for expressing the passive consists of a system of morphological forms, each of which is made of a single word that contains a passive meaning: Lat. fertur, Gr. phéretai, Sanskrit bhàrate, 'it is carried. This consistency seems to indicate that the synthetic form was already in usage in Indo-European: ${ }^{*}$ bhéretai.

$\$ 7$ Note that in Latin the passive forms can be used, by way of their semantic evolution, to express verbal notions that are now indistinguishable from notions that are strictly active. Latin grammars call verbs that have a passive form combined with an active meaning deponents: loquitur '(he) speaks'.

$\$ 8$ The passive diathesis is foreign to the nature of French, which only ever uses it to translate Latin texts, and which very rarely uses it spontaneously. However, the passive is deeply rooted in the grammatical system of Latin, where its usage is quite normal: Amor a patre 'I am loved by father' (Chapter 49, \$14,15, and 16), Antonius a Burrho verberatur 'Antonius is hit by Burrho' (cf. Stemma 212).

$\$ 9$ While it is true that the anterior participle of French, the so-called past participle, is a form of the passive diathesis, this is an isolated usage of the passive, which is not part of any system and which is not in opposition to an active past participle. The French participle mangé 'eaten' is anterior and passive and does not stand in opposition to an active anterior participle, since, while it is true that the participle mangeant 'eating' is an active participle, it is not, in contrast, an anterior participle, but a concomitant participle, which means that it does not express anteriority, but simultaneity.

\$10 The fact that the passive is not deeply rooted in the French verb is reflected not only in the fact that the concept of the passive is easily confused with the notion of state expressed due to the use of the auxiliary être, but also in the fact that it becomes a hazy notion when dealing with nominal forms rather than strictly verbal forms, i.e. when dealing with impersonal moods rather than personal moods, for example, the infinitive or participle, which are not really true verbal forms.

$\$ 11$ Therefore in the French sentence J'ai vu manger des chiens, lit. 'I saw eat dogs', the diathesis of the infinitive manger is ambiguous. The sentence can either be understood with an active meaning, namely that the object of the scene was the dogs who were eating, or with a passive meaning, namely that the dogs were being eaten (Chapter $109, \$ 4)$. That is why the infinitive can, when it has passive meaning, be constructed with a passive complement:

En 1824, leurs hôtes firent tracer la promenade des Anglais sur la grève où l'on voyait encore tirer les filets par les pêcheurs
'In 1824, their occupants drew up the promenade des Anglais on the shore where you could still see the fishermen pull up the nets', lit.'...you could still see pull up the nets by the fishermen' 
\$12 It is also common to find uses of the infinitive in French where the diathesis is grammatically ambiguous, and where an active form expresses a passive idea, although its grammatical correctness is somewhat dubious. For example the following advertisment: Si votre fer à repasser a besoin de nettoyer, frottez-le avec... 'If your iron needs to be cleaned, rub it with..., lit. '...needs to clean...' (Some advice, Midi libre, May 16, 1949).

$\$ 13$ The same ambiguity exists for the present participle, and it is common to say that a piece of glass or porcelain is breakable, not when it actively breaks another object, but in contrast when it is prone to being broken. Likewise, une couleur voyante, lit. 'a seeing color', is not a color "that sees", but a color that grabs the eye and that consequently must "be seen", i.e. 'a loud color', and the expression séance tenante, lit. 'holding session', alludes not to a session "that holds", but to a session "that is being held" and means 'immediately'.

$\$ 14$ The French present participle is so disengaged from the system of diathesis that it can be applied not only to a first actant of the passive, but even to a circumstant. Une rue passante, lit. 'a passing street', is neither a street "that passes", nor is it a street "being passed", but rather it is "a street that is often passed" i.e. 'a busy street'. Likewise, une soirée dansante, lit. 'a dancing party', is a party "where people dance” (cf Chapter 198, \$10). ${ }^{138}$

$\$ 15$ In contrast to French, Latin systematically distinguishes between the passive diatheses and the active diathesis, as much in the infinitive as in the different types of participles: Lapides conjici coepti sunt, lit. 'Rocks were started to be thrown', that is, 'They started to throw rocks'.

\$16 Neutral or intransitive verbs cannot have a passive diathesis and it is easy to see why: they are monovalent verbs, and as such they have a single actant. As a consequence, the action can only occur in one direction.

$\$ 17$ Just as the unique actant of monovalent verbs can be a second actant, which means that there is no first actant (Chapter $99, \$ 5-8$ ), the two actants of a divalent verb can be a first actant and a third actant, meaning that there is no second actant.

$\$ 18$ This is the case with the verb plaire 'please' in French, just as in many other languages (Ger. gefallen, Rus. nravitsja). It is impossible to être plu 'be pleased' by the person you please: Le livre me plait 'The book pleases me / I like the book', Ger. Dieses Buch gefällt mir, Rus. Ėta kniga mne nravitcja.

$\$ 19$ It is clear that due to the lack of a second actant, which would render the inversion of the direction of the transition possible, verbs of this type are no more inclined to having a passive than monovalent verbs.

138. Translator's note: The same is true in English: a smoking area is an area "where one smokes", not an area "that smokes"; a living room is not a room "that lives", but a room "where one lives". 


\section{Chapter 103. The reflexive diathesis}

$\$ 1$ We have seen (Chapter $100, \$ 8$ ) that the reflexive diathesis is where the first actant is the same person as the second actant.

\$2 The reflexive diathesis is present in the personal noun, in the reflexive verb (which contains it), and in the reflexive possessive adjective (which derives from it). It is with these three types of words that it is necessary to acknowledge the notion of the reflexive.

$\$ 3$ By definition, we can draw the following conclusions: 1) that the personal noun or reflexive index always refers anaphorically to the first actant and 2) that as a consequence, it is itself never the first actant, but always the second or third actant: ${ }^{139}$ Alfred looks at himself, Alfred talks to himself, The good and the bad follow each other, Alfred and Bernard talk to each other. This is why in languages with case (Greek, Latin, German, Russian, etc.), personal reflexive nouns or indices never appear in the nominative.

$\$ 4$ In certain languages, the reflexive notion is merged with that of person and is therefore inseparable from it. English, for instance, has a series of ordinary personal nouns and a complete and contrasting series of parallel personal reflexive nouns:

\begin{tabular}{|c|c|c|c|}
\hline & & Ordinary series & Reflexive series \\
\hline \multirow{6}{*}{ Singular } & \multirow{3}{*}{ Anontive } & she (fem.) & herself \\
\hline & & he (masc.) & himself \\
\hline & & it (neut.) & itself \\
\hline & \multirow[t]{2}{*}{ Antiontive } & thou (archaic) & thyself \\
\hline & & you (current) & yourself \\
\hline & Autoontive & $I$ & myself \\
\hline \multirow{3}{*}{ Plural } & Anontive & they & themselves \\
\hline & Antiontive & you & yourselves \\
\hline & Autoontive & we & ourselves \\
\hline
\end{tabular}

$\$ 5$ In many languages (French, German, Eskimo, etc.), the difference between the reflexive and the non-reflexive does not appear in any of the ontive forms, and reflexive forms are the exclusive prerogative of the anontive. ${ }^{140}$

139. Translators' note: In French the reflexive se can be used only for the second and third actants: Alfred observe Bernard 'Alfred looks at Bernard' vs. Alfred s'observe 'Alfred looks at himself'; Alfred parle à Bernard 'Alfred talks to Bernard' vs. Alfred se parle 'Alfred talks to himself'. No reflexive form is used for other dependents: Alfred parle de lui 'Alfred talks about him/himself'.

140. Translators'note: Compare this with Il me lave 'He washes me', Il te lave 'He washes you', Il le lave 'He washes him'. 


\begin{tabular}{|c|c|c|c|c|}
\hline & & Autoontive & Antiontive & Anontive \\
\hline & & (without a special fo & for the reflexive) & Reflexive \\
\hline \multirow{2}{*}{ French } & Sing. & $\begin{array}{l}\text { Je me lave. } \\
\text { 'I wash myself.' }\end{array}$ & $\begin{array}{l}\text { Tu te laves. } \\
\text { 'You wash } \\
\text { yourself.' }\end{array}$ & $\begin{array}{l}\text { Il se lave. } \\
\text { 'He washes } \\
\text { himself.' }\end{array}$ \\
\hline & Plural & $\begin{array}{c}\text { Nous nous lavons. } \\
\text { 'We wash } \\
\text { ourselves.' }\end{array}$ & $\begin{array}{l}\text { Vous vous lavez. } \\
\text { 'You wash } \\
\text { yourselves.' }\end{array}$ & $\begin{array}{l}\text { Ils se lavent. } \\
\text { 'They wash } \\
\text { themselves.' }\end{array}$ \\
\hline \multirow{2}{*}{ German } & Sing. & $\begin{array}{l}\text { Ich wasche mich. } \\
\text { 'I wash myself.' }\end{array}$ & $\begin{array}{c}\text { Du wäschst dich. } \\
\text { 'You wash } \\
\text { yourself.' }\end{array}$ & $\begin{array}{l}\text { Er wäscht sich. } \\
\text { 'He washes } \\
\text { himself.' }\end{array}$ \\
\hline & Plural & $\begin{array}{l}\text { Wir waschen uns. } \\
\text { 'We wash } \\
\text { ourselves.' }\end{array}$ & $\begin{array}{c}\text { Ihr wäscht euch. } \\
\text { 'You wash } \\
\text { yourselves.' }\end{array}$ & $\begin{array}{c}\text { Sie waschen sich. } \\
\text { 'They wash } \\
\text { themselves.' }\end{array}$ \\
\hline
\end{tabular}

$\$ 6$ But while the form of the reflexive is often linked to that of the personal noun, the notion of the reflexive per se is independent from the notion of person. It is possible for the reflexive to be formed on a completely different plane from the non-reflexive and for the reflexive personal noun, in contrast to the ordinary personal noun, which carries the third person, to not distinguish grammatical person. In such a case, it is impossible to say that there is an autoontive reflexive, an antiontive reflexive, and an anontive reflexive, since the form of the reflexive is the same in all three cases and it is only by virtue of being translated into a language like English or German that the notion of person must be brought into play.

$\$ 7$ Such is the case in Russian and in the other Slavic languages, in Baltic languages, in Scandinavian languages, in Low Breton, and in a certain number of other languages, for example Udmurt, Turkish, and Tatar.

$\$ 8$ Take for example the Russian sentence Ja ego prinjal u sebja 'I received him at my place'. The reflexive personal noun remains unchanged, regardless of the person or number of the first actant, whereas the English translation changes accordingly:

\begin{tabular}{|c|c|c|}
\hline On & & 'He received him at his place' \\
\hline Ty & ego prinjal u sebja & 'You received him at your place' \\
\hline$J a$ & & 'I received him at my place' \\
\hline
\end{tabular}

In other words, the Russian-speaker thinks and expresses something as He received him at oneself's, You received him at oneself's, I received him at oneself's, etc. sebja where the reflexive always has the same value, regardless of the person to which it refers.

$\$ 9$ The same is true of the possessive adjective; it is always the same in Russian, regardless of the person that it refers to: 


\begin{tabular}{|c|c|c|c|}
\hline & Russian & Translation & Literally \\
\hline Anontive & On ljubit & 'He likes his house' & \multirow{6}{*}{ 'one's house' } \\
\hline Antiontive & Ty ljubish & 'You like your house' & \\
\hline Autoontive & Ja ljublju & 'I like my house' & \\
\hline Anontive & Oni ljubjat & 'They like their house' & \\
\hline Antiontive & Vy ljubite & 'You like your house' & \\
\hline Autoontive & My ljubim & 'We like our house' & \\
\hline
\end{tabular}

\$10 Under these conditions, it is inappropriate to speak of the anontive, antiontive, or autoontive reflexive in Russian: there is a common reflexive and that is all. This reflexive is independent of the notion of person, or to be more exact, it is above the notion of person, which appears only in translation.

$\$ 11$ This is why foreign speakers sometimes have such difficulty grasping the pure value of the Russian reflexive and why it is so difficult to translate into our western languages, where it is not familiar and where we have difficulty disassociating it from the notion of person. This can be clearly demonstrated by the following Russian expressions:

\begin{tabular}{lll}
\hline Russian & Literal & Idiomatic \\
\hline On svoj brat. & 'He is his own brother.' & 'He is a friend. / He is one of us.' \\
On svoj čelovek. & 'He is his own man.' & 'He is an old acquaintance.' \\
My zdec' svoi. & 'We are our own here.' & 'We are among ourselves.' \\
Svoj svoevo iščet. & 'Its own seeks its own.' & 'Birds of a feather flock together.' \\
Svoja ruka vladyka. & 'One’s own hand is master.' & 'One is never served better than at home.' \\
Svoi suxari lučše & 'One’s own biscuits are & 'A bird in the hand is worth two in the \\
čužix pirogov. & better than foreign tarts' & bush' \\
Svoi karety & 'own cars' & 'masters' carriages' \\
Svoi lošadu & 'own horses' & 'masters' horses' \\
& $\begin{array}{l}\text { Husband of own wife's sister, } \\
\text { that is, of the one coming }\end{array}$ & 'brother-in-law' \\
frojak & or family (cf. $\$ 22)$ & \\
\end{tabular}

$\$ 12$ The reflexive is particularly present in the Czech expression Jdi s sebou 'Come with me', where the reflexive sebou does not refer to the antiontive contained in the imperative $j d i$, but, by way of a drastic semantic shortcut, to the autoontive implied by whomever employs this imperative. ${ }^{141}$

141. Translator's note: Tesnière's interpretation of Jdi S Sebou was incorrect. That does not exist in modern Czech. 
\$13 In western Slavic (Czech, Slovak, and Polish), the personal reflexive noun, which is subordinate to the verb, survives in the verbal noun derived from this verb: Czech Učeni se cizím jazykum je někdy nesnadné, Slovak Učenie sa cudzim jazykom je niekedy t ažké, lit. 'The teaching oneself foreign languages is sometimes difficult', i.e. 'Foreign language learning is sometimes difficult', Polish Zbogacenie sie, lit. 'The enriching oneself', i.e. 'the enrichment', cf. from the 15th century o zachowaniu się przy stole, lit. 'On the conducting oneself (properly) at table, i.e. 'on table manners'.

$\$ 14$ The reflexive is equally valid for all persons of the singular and plural in the Baltic languages, which are the Germanic cousins of the Slavic languages. The reflexive verb is composed of the simple verb suffixed with the reflexive personal noun: Lithuanien rašau-si, lit. 'I write myself', i.e. 'I sign', slepiu 'I hide (something)', slepiuo-si 'I hide myself'. It is curious that while the personal noun -si in Lithuanien is suffixed to simple verbs, it appears, on the other hand, between the preverb and the verb in compound verbs: pa-rašau 'I subscribe', $p a-s i$-rašau, lit. 'I subscribe myself', i.e. 'I sign', pa-slepiu 'I hide (something)', pa-si-slepiu 'I hide myself'.

$\$ 15$ The reflexive noun infixed between the preverb and the verb survives in the verbal noun derived from the verb: pa-si-slepimas 'the hiding oneself', pa-si-elgimas, lit. 'the conducting oneself', that is, 'the behavior'.

$\$ 16$ In Latvian as in western Slavic, the reflexive personal noun survives (in its suffixed form) in the verbal noun. The verbal noun of the verb redzet 'see', which is redzešana 'the seeing', has a reflexive form redzešanas 'the seeing oneself', which is common and is employed in particular in the genitive in the common expression uz redzešanuos, lit. 'until the seeing oneself', i.e. 'See you!' (Fr. Au revoir!).

$\$ 17$ The value of the Slavic and Baltic reflexive is also found in the Scandinavian languages. But it seems to be present only with secondary status, a fact that suggests that it is not inherited from an earlier linguistic state, but is rather a form borrowed from a neighboring group, perhaps Baltic or Slavic.

$\$ 18$ In Old Norwegian, the generalization of the reflexive with all persons is not complete. In contrast to the other persons - which have the suffix -sk as the reflexive marker, the trace of a former autonomous postposed reflexive personal noun - only the singular autoontive form conserves the suffix $-m k$, a trace of the former autonomous personal autoontive noun mik:

\begin{tabular}{|c|c|c|c|c|c|}
\hline & Infinitive & & 'find' & & 'find oneself' \\
\hline \multirow[t]{3}{*}{ Singular } & $\begin{array}{l}\text { Anontive } \\
\text { Antiontive }\end{array}$ & finn-r & $\begin{array}{l}\text { 'he finds' } \\
\text { 'you find' }\end{array}$ & ${ }^{*}$ finn-sk $>$ finn-zk & $\begin{array}{l}\text { 'he finds himself' } \\
\text { 'you find yourself' }\end{array}$ \\
\hline & Autoontive & finn-a & 'I find' & finno-mk & 'I find myself' \\
\hline & Anontive & finna-a & 'they find' & finna-sk & 'they find themselves' \\
\hline \multirow[t]{2}{*}{ Plural } & Antiontive & finn-ep & 'you find' & finnep-sk $>$ finne-zk & 'you find yourselves' \\
\hline & Autoontive & finn-om & 'we find' & finnom-sk & 'we find ourselves' \\
\hline
\end{tabular}


$\$ 19$ From the 13th century, the singular autoontive came under the analogical influence of the plural autooontive, and the original difference has since disappeared now that the reflexive has the same suffix for all the persons:

\begin{tabular}{lll}
\hline \multirow{4}{*}{ Singular } & Anontive & \\
& Antiontive & finn- $z$ \\
& Autoontive & finnum- $z$ \\
& Anontive & finna- $z$ \\
Plural & (infinitive) & \\
& Antiontive & finni- $z$ \\
& Autoontive & finnum- $z$ \\
\hline
\end{tabular}

\$20 This morphological state survives in the modern Scandinavian languages, with the one difference that the reflexive suffix $-z$ has softened to $-s$ : Swedish finna-s 'to find oneself', Norwegian anda-s 'breathe', Danish mede-s 'meet (each other)'.

\$21 Moreover, it should be noted that this form is only conserved with the value of the recessive (cf. Chapter $115, \$ 2$ ), the true reflexive value now being expressed by a different form in which the reflexive noun is not agglutinated (cf. above, \$5), such as in French and German, e.g. Swed. Han tvålar sig 'He washes himself'.

$\$ 22$ The same value of the reflexive is found in Low Breton, where the modern group en $\mathrm{em}$ is valid for all the persons of both numbers:

\begin{tabular}{|c|c|c|}
\hline \multicolumn{3}{|c|}{ Low Breton reflexive en em } \\
\hline Heñ & \multirow{6}{*}{ en em walc'h } & 'He washes himself.' \\
\hline $\mathrm{Te}$ & & 'You wash yourself.' \\
\hline$M e$ & & 'I wash myself.' \\
\hline$I$ & & 'They wash themselves.' \\
\hline C’hwi & & 'You wash yourselves', \\
\hline Nimp & & 'We wash ourselves.' \\
\hline
\end{tabular}

In Breton as in Latvian, the reflexive of the verb is also valid for the corresponding verbal noun; in Middle Breton where the reflexive participle was simply em, the verbal form was em gannaff 'fight oneself' and the verbal noun form emgann 'battle', lit. 'the battling oneself'. \$23 This meaning of the concentrated reflexive must have already been present in IndoEuropean, if we go by the agreement of all the languages that have just been examined and by the etymology of the Indo-European word for 'sister', which was originally a compound form ${ }^{*}$ swe-sor: Lat. soror, Ger. Schwester, Rus. sestra, 'the own feminine person', i.e. 'the one from the group', probably in opposition to the word for 'woman' * $u g^{w} h$-sor 'the feminine 
person who has been transported (i.e. we-ogwh, Lat. veh-o 'I transport') from another group', a word that perhaps conserves distant memory of an ancient rite of abduction.

$\$ 24$ An analogous situation is encountered locally in certain dialects of French. In Sète, S'en anan 'We are leaving' (and S'en anas 'You are leaving') are formed with the reflexive se (compare with forms of s'en aller 'leave' in standard French: Nous nous en allons 'We are leaving', Vous vous en allez 'You are leaving'). ${ }^{142}$ But it should be noted that this expression is only valid for the plural autoontive and antiontive, which creates doubt concerning its origin, all the more so because it appears to be recent. What is more, the spread of the phenomenon is extremely limited; it does not reach Montpellier (17 miles to the North-East). But it seems to include Marseillan and Agde (10 miles to the South-West). According to the same author who unfortunately does not provide more details, this use of se exists "not only in other dialects of Occitan, but also in certain parts of northern France." 143

\section{Chapter 104. The reflexive possessive adjective}

$\$ 1$ The reflexive possessive adjective is reflexive in the sense that it refers to the first actant. In other words, the possessor of the second actant to which the adjective is subordinate is the first actant. In the Latin sentence Magister discipulum suum amat 'The teacher loves his student', suum 'his/her/its/their' indicates that discipulum, to which it is subordinate, refers to the student of the first actant magister 'teacher'.

\$2 The Latin reflexive possessive adjective suus refers obligatorily to the first actant (in a complement clause subordinate to the first actant of the main clause).

\$3 The result is that if the reference is to another word besides the first actant, it is necessary to employ not the reflexive possessive adjective, but the non-reflexive genitive of the anontive personal noun, eius 'of him/her/its/their'. Therefore Magister discipulum eius amat 'The teacher loves his student' is used if the student is the student of somebody other than the teacher who is the first actant.

$\$ 4$ When there is a sentence with two possessors of which the first is the first actant, and the other is another word of the sentence, the possessive adjective must be used in the first but not in the second case. Hence the possessive adjective his is expressed differently in Latin depending on whether or not it is reflexive and whether or not it refers anaphorically

142. Léon Lamouche, Grammaire languedocienne, Montpellier, 1942, p. 55.

143. One of the dialects in which this expression occurs is that of Gondecourt (North), where it is possible to hear the plural ontive nous se lavons 'we wash oneselves', vous se lavez 'you wash oneselves'; cf. Gougenheim, Review of E. Cochet: "Le patois de Gondecourt (Nord)", Romanica, I (1936), p. 30. 
to the first actant: Magister discipulum suum amat at eius vitia odit 'The teacher loves his student (i.e. the student of the teacher) and detests his faults (i.e. the faults of the student)'. $\$ 5$ The same difference exists in German in sentences such as Der Lehrer liebt seinen Schüler und hasst dessen Laster 'The teacher loves his student and hates his faults' and where there is an opposition between

\begin{tabular}{ll}
\hline Reflexive & Non-reflexive \\
\hline $\begin{array}{l}\text { Die Frau sah ihren Hund., } \\
\text { 'The woman saw her dog.' }\end{array}$ & $\begin{array}{l}\text { Die Frau sah deren Hund. } \\
\text { ('her own dog') }\end{array}$ \\
\hline
\end{tabular}

$\$ 6$ The same opposition exists in Danish, Russian, Eskimo, and Georgian:

\begin{tabular}{|c|c|c|}
\hline & Reflexive & Non-reflexive \\
\hline Danish & Kvinden saa sin Hund. & Kvinden saa dens Hund. \\
\hline Russian & Ženščina videla svoju sobaku. & Ženščina videla eё sobaku. \\
\hline Eskimo & aRnap Kimi-ne takuwā. & aRnap Kimi-a takuwā. ${ }^{163}$ \\
\hline \multirow[t]{2}{*}{ Georgian } & K'ali xedavda t'avis zayls. & K'ali xedavda imid zayls. \\
\hline & $\begin{array}{l}\text { 'The woman saw her dog'. } \\
\text { ('her own dog') }\end{array}$ & $\begin{array}{l}\text { 'The woman saw her dog.' } \\
\text { ('some other woman's dog') }\end{array}$ \\
\hline
\end{tabular}

$\$ 7$ In languages such as English and Basque where the anontive possessive adjective is not uniquely reflexive but can also refer anaphorically to a word other than the first actant, the possessive adjective can lead to confusion, for the anaphor that it licenses has an ambiguity that is difficult to avoid.

$\$ 8$ In the English sentence The teacher loves his student but detests his faults, his can just as well refer to the teacher's faults as to the student's.

\$9 The same is true in Basque Haurra bere aitarengana igorri du 'He sent the child to his father's', bere 'his' can just as well signify that the father is the father of the child or the father of the person sending the child. ${ }^{145}$

$\$ 10$ This ambiguity can be troublesome when translating a text into a language that does not allow the ambiguity. In such a case, the initial stemmatization of the sentence would be useful to the translator, since it enables him/her to pinpoint the exact meaning and choose between Stemma 213 (Lat. eius vitia) and Stemma 214 (Lat. sua vitia).

144. Finck, Die Haupttypen des Sprachbaus, Leipzig, Teubner, 1910, p. 41.

145. Lafitte, Grammaire basque (navarro-labourdin littéraire), Bayonne, 1944, p. 92. 


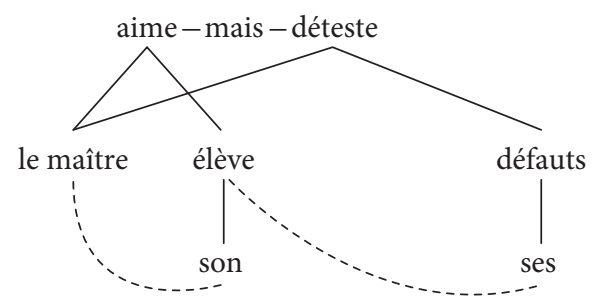

Stemma 213



Stemma 214

\section{Chapter 105. The reciprocal diathesis}

$\$ 1$ The reflexive diathesis and the reciprocal diathesis share the fact that they combine an active and a passive process. But with the reflexive, the active process is, at least psychologically, prior to the passive process, since it is evidently not possible to receive a blow before the blow is given, whereas with the reciprocal, the active and the passive process are simultaneous. These relationships can be expressed with the following formulas:

\begin{tabular}{lll}
\hline Reflexive & $=$ active + passive & successively \\
Reciprocal & $=$ active + passive & simultaneously
\end{tabular}

\$2 The reciprocal is therefore always in the plural, which is natural, since there are two parallel processes, whereas the reflexive can be in the singular or plural, depending on whether one or two actants are transmitting the action to themselves.

$\$ 3$ It is therefore always necessary to distinguish - especially when analyzing the exact meaning of a French sentence in view of its translation into a foreign language - between the reflexive plural and the reciprocal. The reflexive singular does not risk being confused with the reciprocal, since the reciprocal is always plural, which means that the reflexive singular is always a true reflexive. But sentences with the reflexive plural, for example Alfred et Bernard se frappent 'Alfred and Bernard hit themselves/each other' can sometimes be ambiguous, either with two reflexive processes whereby each actant performs the action on himself, or as two parallel and inverse processes, which is the defining aspect of the reciprocal.The transition of the process is represented schematically with arrows as follows:

$\begin{aligned} & \text { In the first case } \\ & \text { (reflexive plural) }\end{aligned}$
$\begin{aligned} & \text { In the second case } \\ & \text { (reciprocal) }\end{aligned}$


$\$ 4$ The confusion between the plural reflexive and the reciprocal is easily avoided in French, with the addition of l'un l'autre 'each other' (Stemma 215) or with the addition of the preverb entre before the verb in order to indicate that there is a reciprocity: Alfred et Bernard se frappent l'un l'autre 'Alfred and Bernard hit each other', Les loups se dévorent entre eux or s'entredévorent 'The wolves devour each other'. Likewise, the French say s'entr'aider 'help each other' or even s'entre-rendre service 'help each other out.' ${ }^{146}$

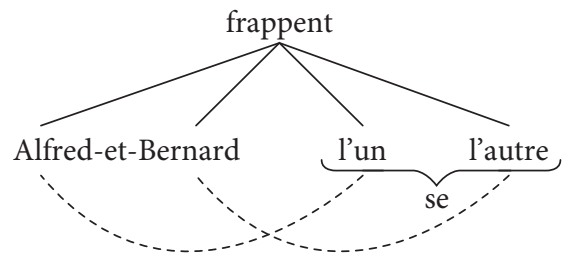

Stemma 215

$\$ 5$ Most foreign languages have special markers for the reciprocal: Lat. inter se, the reciprocal Inter se amant 'They adore each other', which is different from the reflexive plural Se amant 'They adore themselves'; Breton an eil egile 'each other': I en em gar an eil egile 'They adore each other'; Rus. drug druga: Oni ljubjat drug druga 'They adore each other'; etc.

\section{Chapter 106. Trivalent verbs}

\$1 Even though traditional grammar does not distinguish between verbs with two actants and verbs with three actants, merging them under the global title of transitive verbs (Chapter 100, $\$ 2$ ), verbs with three actants present a certain number of particularities due to their trivalency and which suffice to justify special examination.

\$2 Firstly, the central importance of trivalent verbs for those who study a foreign language cannot be emphasized enough. Monovalent verbs, since they have only one actant, cannot be formed differently in foreign languages from the French and in treating them like in French, the chance of getting them right is close to $100 \%$. Divalent verbs, due to the fact that they have two actants which can switch places, can therefore be thought of in a different way to the French and therefore if they are treated as in French, the chance of being right is more like $50 \%$. This percentage becomes disastrous with trivalent verbs, which take three actants and can therefore be constructed in $3 \times 2=6$ ways. The chance of finding the same arrangement of actants as in French in another language is now only one in six, that is around $17 \%$, and in return the chance of getting them wrong climbs to five in six, that

146. P.-J. Stahl (pseudonym for Jules Hetzel), Les histoires de mon Parrain, Paris, Hetzel, p. 187). 
is around $83 \%$. Under these conditions, it is easy to see why particular special attention should be paid to such dangerous verbs when studying foreign languages.

$\$_{3}$ Verbs with three actants are in principle verbs of speaking and giving. So in the sentence Alfred gives the book to Charles, the first actant is Alfred, the second the book, and the third Charles (cf. Stemma 77). Likewise in the sentence Alfred says hello to Charles; the first actant is Alfred, the second hello and the third Charles.

$\$ 4$ The French verb demander 'ask' belongs to both series. In Alfred demande le livre à Charles 'Alfred asks Charles for the book', Alfred asks for the book in order to have it. In Alfred demande l'heure à Charles 'Alfred asks Charles for the time', Alfred asks for the time in order to know it. A number of foreign languages draw a distinction between 'ask to have' (give series) and 'ask to know' (say series), cf. Ger. Alfred bittet Karl um das Buch 'Alfred asks Karl for the book', but Alfred fragt Karl nach der Zeit 'Alfred asks Karl for the time'.

$\$ 5$ The verbs of saying and giving do not only cover verbs expressing these notions, but also verbs expressing the opposite notion. The argument structure of Alfred demande un renseignement à Charles 'Alfred asks for information from Charles' is, contrary to English, identical to that of Alfred donne un renseignement à Charles 'Alfred gives information to Charles'. Other words the meanings of which are a nuanced versions of these basic verbs can also occur in these structures. Therefore in place of say, it is possible to find the iterative repeat, the intensives confirm or demonstrate, and the diminutives insinuate and whisper.

$\$ 6$ With French reflexive verbs, the second actant is of course the reflexive personal noun itself. Such is the case with the verbs s'adresser à 'to address' (verb of saying), se fier à 'to trust', se presenter à 'to introduce oneself to', s'adonner à 'devote oneself to' (verb of giving).

$\$ 7$ Given the above, the principle verbs of saying are: say, tell, express, state, report, relate, present, explain, teach, demonstrate, prove, specify, mark, declare, proclaim, confirm, affirm, deny, assure, certify, guarantee, swear, mean, order, command, assign, recommend, indicate, mention, insinuate, suggest, whisper, claim, concede, confide, allow, ask (to know, cf. $\$ 4)$, answer, hide, admit, confess, reveal, denounce, divulge, announce, communicate, learn, repeat, recite, utter, cite. These verbs are sometimes called declarative verbs.

$\$ 8$ The principle verbs of giving are: give, provide, procure, attribute, distribute, relegate, confer, grant, delegate, award, administer, promise, accord, refuse, give up, sacrifice, leave, abandon, lend, entrust, give back, pay, pay back, bring, transmit, replace, deliver, send, dispatch, ask (to have, cf. \$4), remove, take away, subtract, steal.

$\$ 9$ These lists of unorganized examples show the extent to which it would be interesting for the classification of the items of vocabulary to impose some order on the different variants of a single basic idea by analyzing the basic meaning and all possible nuances. Charles Bally rightly advocated such a classification in his Traité de Stylistique française (cf. Chapter 127, §4). ${ }^{147}$

147. Heidelberg, Winter \& Paris, Klincksieck, 1909, see especially Vol. I, pp. $104 \mathrm{ff}$. 
\$10 While it is true that monovalent verbs cannot appear in the passive because they only have one actant (Chapter 102, \$16), it is also true that trivalent verbs can have two types of passive according to whether the first actant of the passive is the second or third actant of the active.

\$11 In the first case, the passage of the active to the passive takes place between the second actant, which becomes the first actant, and the first actant, which becomes the complement of the passive, whereas the third actant is not at all affected by the inversion. The passive of Alfred donne le livre à Charles 'Alfred gives the book to Charles' is therefore Le livre est donné par Alfred à Charles 'The book is given by Alfred to Charles', the third actant $\grave{a}$ Charles conserving the same value in both cases, and as a consequence, the same marker. This type of passive is in principle the only passive that French has at its disposal for verbs with three actants.

$\$ 12$ But in other languages, it is possible for the passage from the active to the passive, instead of involving the first actant and the second actant, to involve the third actant and the first actant to the exclusion of the second actant, which remains a complement even though the verb is passivized as far as the third actant is concerned. The English sentence Alfred gives the book to Charles, which in addition to a passive concerning the second actant: The book is given by Alfred to Charles, also has a passive concerning the third actant: Charles is given the book by Alfred, which is in theory impossible to translate into French. In such cases, it is the second actant the book that remains unchanged and conserves the same value and the same marker in both cases. This turn of phrase, which is characteristically English, risks being mistranslated into French by those who are not familiar with it. The title of the article in an English newspaper Motorist refused a license does not mean that a driver has refused a driver's license, but that a driver's license has been refused to a driver. ${ }^{148}$

$\$ 13$ Just as the single actant of monovalent verbs can be a second actant (Chapter $99, \$ 5-8$ ) and the two actants of a divalent verb can be a first actant and a third actant (Chapter $102, \$ 17)$, it can also occur that the three actants of a trivalent verb are not a first actant, a second actant, and a third actant. The third actant can be absent. There exist, at least in certain languages, trivalent verbs without a third actant, but which, on the other hand, have two second actants. This is the case for verbs, which, in languages that have case, are constructed with two accusatives, for example Lat. Antonius docet pueros grammaticam 'Antoine teaches the children grammar'; the same in Greek: didáskein tinà grammatikến 'teach someone grammar'.

148. Heinrich Straumann, Newspaper Headlines. A Study in Linguistic Method, London, G. Allen and Unwin Ltd, 1935, cited in the Bulletin de la Société linguistique Paris, volume 36, 1935, p. 97. 
\$14 The construction of certain verbs with two accusatives is also present in German: Wer hat dich solche Streiche gelehrt? 'Who taught you such tricks?', Das Buch kostete mich einen Taler 'The book cost me a dollar', Das habe ich dich nicht geheissen 'I did not order you to do that' (cf. Chapter 108, \$9).

\$15 It is clear that in such cases, the two second actants are not to be conceived of in the same fashion. It is tempting to maintain that one of the two accusatives alone is the second actant, namely pueros in the Latin example, and that the other one (grammaticam) is a circumstant, an accusative of relation, such that the sentence in Latin would have the exact signification: Antoine teaches the children in aspects of grammar. We will see further below (Chapter 108, \$9) that this justification is not essential.

\$16 Parallel to divalent verbs constructed with two accusatives, there exist in Latin verbs constructed with two datives: Id est mihi gaudio, lit. 'That is to me to joy', that is 'That is a joy to me', Id est mihi cordi, lit. 'That is to me to heart', that is 'I have my heart set on it'. Just as with the two accusative actants, the two dative actants are conceived of differently. It is equally possible to argue that one of the two (mihi) is, due to its predicative character, the true third actant, whereas the other dative (gaudio, cordi), which functions rather like a predicative complement, is in reality a circumstant.

$\$ 17$ With their three actants, trivalent verbs have a more complex structure than divalent verbs. From a historical and genetic point of view, the trivalent type seems to appear only after the divalent type. Many Latin verbs formed with a preverb are therefore either constructed as verbs that have two actants but with a preposition that serves as the preverb, and the object of the preposition, i.e. with a group that constitutes a circumstant, or they are constructed with a simple third actant. The only semantic difference is that in the first case, the verb is taken in its true meaning, whereas in the second case, it is taken in a figurative sense: iniicere se in medios hostes 'throw oneself into the middle of the enemy', iniicere terrorem alicui 'inspire terror in someone.' This all occurs as if the expression with three actants were merely a development of the expression with two actants extended by a prepositional circumstant. In addition, it conforms to semantic evolution that the true meaning of an expression with two actants and a prepositional circumstant predates the figurative meaning of the expression with three actants (cf. also Chapter 113, \$11).

\$18 The growing complexity of the verbal actant system has every chance of being a function of the progress of the human mind, which gives rise to more and more complex agentive systems. This leads us to ask if there might also exist, beyond trivalent verbs, tetravalent verbs. If we set aside periphrastic phrases with tetravalent value, which are explored in the following chapter (Chapter 108,\$10), it appears that there is no language in which simple verb forms exist with more than three actants.

$\$ 19$ But just as divalent and trivalent verbs must have successively arisen over thousands of years, with the intellectual development of humanity, it is not out of the question that in a more or less distant future, simple tetravalent verbs could develop. These verbs would be 
even more difficult to use than trivalent verbs, and the risk of error when translating from one language to another would be even greater. Tetravalent verbs could be conceived of in $4 \times 3 \times 2=12$ different ways, such that the possibility of equivalency across two languages would only be $1 / 12$ and conversely, the possibility of getting them wrong would be 11/12, that is about $92 \%$ (cf. Chapter 106, \$2).

\$20 The question of the genesis of polyvalent verbs leads to the question of the genesis of actants, for which there is an analogous solution. It is clear that if the glottogenesis hypothesis suggests that the appearance of varying degrees of verb valency in language took place in the order of increasing valency and if languages therefore developed their verbs in the following order: avalent, monovalent, divalent, and trivalent, it can be inferred that actants developed in the following order: first actant, second actant, and third actant, conforming to the development of an increasingly complex actant structure. If monovalent verbs are derived from avalent verbs, which by definition could only have circumstants as their subordinates, we are led by extrapolation to stipulate that actants are perhaps no more than former circumstants, which would explain why, as we have observed above (Chapter $57, \$ 1$ ), the boundary between the two is so vague and so difficult to nail down.

\section{Chapter 107. Variation in the number of actants}

$\$ 1$ The meaning of two verbs frequently differs only in the number of actants that the verbs have. Hence the verb topple differs from the verb fall only by the presence of an additional actant. If Alfred falls, the fall that he undergoes is just as present in Bernard topples Alfred. It is merely the number of actants that is different, since fall has only one actant, Alfred, whereas topple has two, Bernard and Alfred.

\$2 The same is true of the verb show, which differs from see only by the presence of an additional actant. Indeed, if Alfred sees a picture, the action that he accomplishes does not differ from the action in Charles shows a picture to Alfred. But see has only two actants, Alfred and the picture, whereas show has three, Charles, the picture, and Alfred.

$\$ 3$ A certain number of verbs are related in the same way as the preceding ones:

\begin{tabular}{ccc}
\hline One actant & Two actants & Three actants \\
\hline fall & topple & \\
die & kill & \\
go & get & send \\
& see & show \\
& know & say \\
& have & give \\
\hline
\end{tabular}


$\$ 4$ The preceding table helps us to understand the crucial presence of verbs of saying and giving (Chapter 106, \$3-7) among the verbs with three actants, since the notions they express correspond to the elementary notions of knowing and having, but with an additional actant.

$\$ 5$ It is easy to see that in all the preceding cases, the presence of a supplementary actant can be licensed by the verb make, which as a consequence behaves as if it brings with it a supplementary valency. We have the following relationships:

\begin{tabular}{|c|c|c|}
\hline topple & & make fall \\
\hline kill & & make die \\
\hline send & $\leftrightarrow$ & make get \\
\hline show & & make see \\
\hline say & & make know \\
\hline give & & make have \\
\hline
\end{tabular}

$\$ 6$ The semantic correspondence here, which is frequent among verbs that differ only with respect to the number of actants, enables many languages to implement a mechanism that assures variation in the number of actants by means of a morphological marker. This marker, which always remains the same, is valid for a large number of verbs and hence assures a coherent grammaticalized system of relations between verbs of the same meaning but with different valencies.

$\$ 7$ Such a marker is very useful in a language, since it means that, by virtue of a sort of corrective operation, it is possible to use verbs of a given valency with one more or one fewer actants. Therefore a verb with two actants can be extended to take three actants or reduced to taking a single actant.

$\$ 8$ The operation that increases the number of actants by one constitutes what is known as the causative diathesis, known to German grammarians as factitive diathesis.

$\$ 9$ The inverse operation, which reduces the number of actants by one, constitutes what we call the recessive diathesis.

\section{Chapter 108. The causative diathesis, the new actant}

\$1 If the number of actants is increased by one, the new verb is said to be causative in relation to the non-augmented verb. We can therefore say that with respect to meaning, topple is the causative of fall (cf. Chapter 107, \$1) and show is the causative of see (cf. Chapter 107, \$2). $\$ 2$ In this case, the new actant is always, if not the agent of the process, at least, in an intermediate but often more efficient and therefore more real fashion, its instigator. Therefore if Alfred (A) sees a picture (B), it is evidently Alfred who is the agent of the seeing, but if 
Charles $(C)$ shows the picture (B) to Alfred (A), it is, from behind Alfred, Charles who is the promoter responsible for the action carried out by Alfred.

$\$ 3$ Once the causative operation introduces the new actant, it is necessary to examine the way in which the new actant is integrated into the preexisting system of actants.

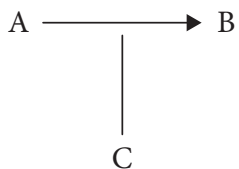

Schema for $\$ 2$

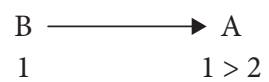

Schema for $₫ 4$

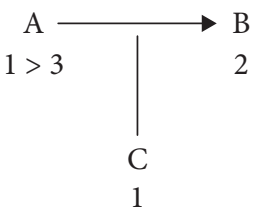

Schema for $\$ 5$

\$4 If it is a verb with one actant (A), this actant, which is most often the first actant, becomes the second actant, whereas the new actant (B) overtakes it as first actant. This can be seen in the comparison between the monovalent verb mourir 'die' and its periphrastic divalent causative faire mourir 'make die' in the sentences Alfred (first actant) meurt 'Alfred dies' and Bernard (first actant) fait mourir Alfred (second actant) 'Bernard makes Alfred die / Bernard kills Alfred'.

\$5 If, in contrast, it is a verb with two actants, the first actant (A) becomes the third actant, and the new actant takes its place as the first actant, while the second actant remains unchanged. This can be seen in the comparison of the divalent verb apprendre 'learn' with its periphrastic causative trivalent counterpart faire apprendre 'make learn', e.g. Alfred (first actant) apprend la grammaire (second actant) 'Alfred learns grammar', and Charles (first actant) fait apprendre la grammaire (second actant) à Alfred (third actant) 'Charles makes Alfred learn grammar / Charles teaches grammar to Alfred'.

$\$ 6$ This explains the rule of French grammar, which asserts that if the infinitive itself has a direct object, its subject becomes a prepositional complement: Je (C, first actant) fais réciter l'enfant (B, second actant) 'I make the child recite', but $J e$ (C, first actant) fais réciter sa leçon (B, second actant) à l'enfant (A, third actant) 'I make the child recite the lesson.' ${ }^{149}$

\$7 The causative complement of faire apprendre 'make learn' is exactly the same, at least in French, as its equivalent enseigner 'teach': Charles (first actant) enseigne la grammaire (second actant) à Alfred (third actant) 'Charles teaches the grammar to Alfred'.

$\$ 8$ The preposition that introduces the former first actant, which has become a third actant, is generally $a$ ' 'to', but can sometimes be par 'by', which expresses the role of the instrument, to which the agent, which has become a simple agent of execution, has been reduced by the passage of the instigator in the foreground. This is why it is possible to say Charles fait tuer Bernard par Alfred 'Charles has Alfred kill Bernard'.

149. Grammaire Larousse du $X X^{e}$ siècle, p. 95. 
$\$ 9$ But things are not necessarily the same in all languages. Therefore in Latin, on the one hand we have Doceo pueros 'I (first actant) teach the children (second actant)', and on the other hand we have Doceo grammaticam 'I (first actant) teach grammar (second actant)', and the two second actants remain in the accusative in the complex trivalent Doceo pueros (second actant) grammaticam (second actant) 'I teach grammar to the children'. While there are three actants in this sentence, there is no third actant, but rather two second actants (cf. Chapter 106, \$13).

$\$ 10$ Finally, in the case of trivalent verbs, the intervention of the causative auxiliary creates a tetravalent actant structure (cf. Chapter $106, \$ 18$ ), in which the first actant is relegated to the role of the fourth actant by the new actant, which takes its place as the first actant, whereas the second actant and the third actant remain unchanged. This can be seen in the comparison of the trivalent verb donner 'give' with its periphrastic tetravalent causative faire donner 'have give' in the following two sentences: Charles (first actant) donne le livre (second actant) à Alfred (third actant) 'Charles gives the book to Alfred' and Daniel (first actant) fait donner le livre (second acant) à Alfred (third actant) par Charles (fourth actant) 'Alfred has Charles give the book to Alfred'. We note that in French the preposition that precedes the first actant, which has become the fourth actant, is par 'by'.

$\$ 11$ We also observe that in certain cases of this sort, the second actant can remain unstated, which reduces the actant structure to three actants. In such a case, the identity of the person who provides the book (Charles) is of course not pronounced. Consider the trivalent structure of the French verb procurer 'procure' (Ger. verschaffen): Daniel (first actant) procure le livre (second actant) à Alfred (third actant) 'Daniel procures the book for Alfred'.

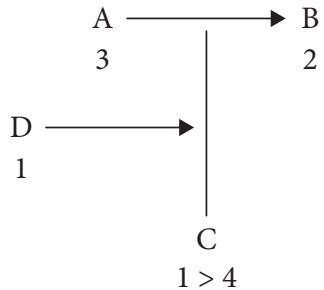

Schema for $\$ 10$

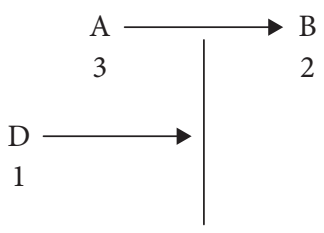

(C)

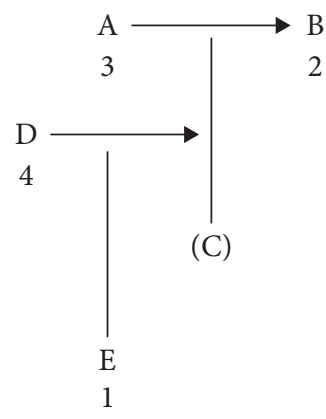

Schema for $\$ 12$

$\$ 12$ But this verb can in turn be made tetravalent by the adjunction of the causative auxiliary: Ernest (first actant) fait procurer le livre (second actant) à Alfred (third actant) par Daniel (fourth actant) 'Ernest had Daniel get the book for Alfred'. In this case, the identity of the person who provides the book (Charles) is still unknown. 
$\$ 13$ In all of the preceding cases, it is as though the causative auxiliary faire has a valency that takes the place of the valency of the preexisting non-causative verb, which finds itself shifted after all the pre-existing valencies of the verb such that the former first actant becomes the second actant in divalent causatives, the third actant in trivalent causatives, and the fourth actant in tetravalent causatives.

\section{Chapter 109. Causative and passive}

\$1 A divalent verb the first actant of which is replaced by the new actant can itself be in the active or passive diathesis. There can therefore be an active transitive causative and a passive transitive causative.

\$2 The relationship between the new actant and the former one can in turn be in the active or passive diathesis. It is therefore possible to have active causatives and passive causatives.

$\$ 3$ Theoretically, there are four possible combinations:

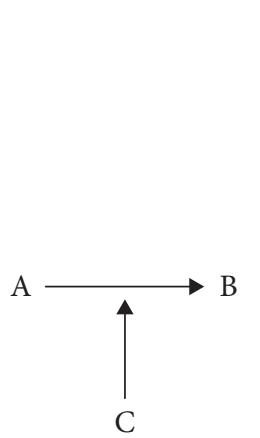

Case 1

\section{Case 1 Active causative of active transitive \\ Case 2 Active causative of passive transitive \\ Case 3 Passive causative of active transitive \\ Case 4 Passive causative of passive transitive}

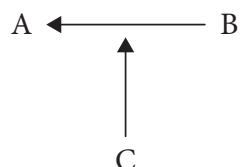

Case 2

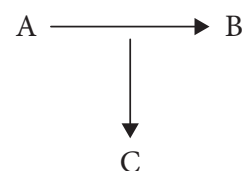

Case 3

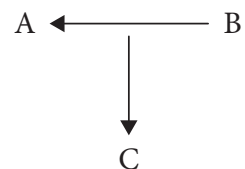

Case 4

$\$ 4$ The majority of our European languages know only the active causative, which applies indifferently to active transitives and passive transitives. Therefore in French, the same structure is used for Charles (C) fait boire Alfred (A) (Schema 1) 'Charles makes Alfred drink' and Charles (C) fait boire le café (B) (Schema 2) 'Charles has (someone) drink the coffee', even though Alfred here plays the role of the consumer (first actant, active causative of the active transitive, Schema 1), in contrast with le café (B), which appears here only as what is being consumed (second actant, active causative of the passive transitive, Schema 2), that is, with the same ambiguity that has already been mentioned above (Chapter 102, \$11).

$\$ 5$ However, it would be impossible to say ${ }^{*}$ Alfred est fait boire par Charles 'Alfred is made drink by Charles' (passive causative of the active transitive, Schema 3), or ${ }^{\star}$ Le café est fait 
boire par Charles 'The coffee is made drink by Charles' (passive causative of the passive transitive, Schema 4.).

$\$ 6$ But Semitic languages, Hebrew for example, clearly distinguish between the active causative and the passive causative, but at the same time allowing the active or passive nature of the transitive diathesis to which the causative applies to remain ambiguous.

\$7 Therefore, next to the Hebrew verb akal 'he ate', we have:

\begin{tabular}{|c|c|c|}
\hline \multirow{2}{*}{$\begin{array}{l}h \grave{i} \bar{p}^{`} i l \\
\text { (active causative) }\end{array}$} & $\begin{array}{l}\text { he'éǩil } \\
\text { (active causative of } \\
\text { active transitive) }\end{array}$ & 'he fed' \\
\hline & $\begin{array}{l}\text { he'éǩil } \\
\text { (active causative of } \\
\text { passive transitive) }\end{array}$ & 'he fed (someone)' \\
\hline \multirow{2}{*}{$\begin{array}{l}\text { hop'al } \\
\text { (passive causative) }\end{array}$} & $\begin{array}{c}\text { ho'ǒkal } \\
\text { (passive causative of } \\
\text { active transitive) }\end{array}$ & 'he was fed' \\
\hline & $\begin{array}{c}\text { ho'ókal } \\
\text { (passive causative of }^{\text {passive transitive) }} \text { (169 }^{1}\end{array}$ & 'it was fed' \\
\hline
\end{tabular}

$\$ 8$ The same distinction exists in Turkish, but occurs less often in modern Turkish where the fourth form has become obsolete: ${ }^{151}$

\begin{tabular}{ll}
\hline Turkish & \\
\hline sev-dir-ir & 'he makes (someone) love' \\
sev-il-dir-ir & 'he makes (someone) be loved' \\
sev-dir-il-ir & 'he is made love' \\
${ }^{*}$ sev-il-dir-il-ir & 'he is made be loved' \\
\hline
\end{tabular}

\section{Chapter 110. Causative and reflexive in French}

$\$ 1$ Among the principles that we have identified as conditioning the structural function of the reflexive and the causative in French, there are two that must necessarily conflict every time the reflexive diathesis must be used with the causative voice.

150. J. Touzard, Grammaire hébraïque abrégée 4, 1911, p. 42.

151. Translators' note: Tesnière's assessment of these forms was inaccurate. The third form, sev-dir-il-ir, is also not used in modern Turkish. 
$\$ 2$ On the one hand, we have seen (Chapter $103, \$ 3$ ) that in reflexive verbs, the index se 'oneself' always refers anaphorically to the first actant.

$\$ 3$ On the other hand, we have just seen (Chapter 103, \$3) that the intervention of a new causative actant, which assumes the role of the first actant and takes the value of an instigator, has the effect of relegating the former first actant to the function of the third actant, with the much different value of simple agent of execution. In this respect, the index se, since it always refers to the same person, no longer refers to the first actant, since the first actant has become the third actant.

$\$ 4$ The result of this is an unsolvable antinomy, which means that it is difficult to reconcile the causative and the reflexive. Sentences such as Bernard fit se raser Albert 'Bernard made Albert shave himself' are therefore far from being considered elegant, and they somewhat shock the linguistic intuition of French speakers, who prefer to avoid such constructions when they are concerned with the purity of language.

$\$ 5$ The same thing is true of course of the reciprocal: La terreur faisait s'entrechoquer ses mâchoires, lit. 'The terror made his jaws knock each other', that is 'The terror made his jaws chatter' (Marianne, April 14, 1937).

$\$ 6$ This consideration does not come into play when the auxiliary is a verb of volition (modal auxiliary), because the first actant of the auxiliary is always the same as that of the auxiliated. When I say Alfred veut voir Bernard 'Alfred wants to see Bernard', it is clear that it is the same Alfred who is the first actant of veut and of voir. Therefore, when I say Alfred veut se voir dans la glace 'Alfred wants to see himself in the mirror', since the index $s e$ of the auxiliated refers to the first actant of the auxiliated, it refers ipso facto to that of the auxiliary such that the principle that the reflexive index must refer to the first actant is perfectly respected.

\$7 The contradiction between the causative and the reflexive does not come into play either when the index, instead of pertaining to the auxiliated alone, pertains to the entire group consisting of the auxiliary and the auxiliated. Given that the auxiliary expresses the grammatical characteristics of the group and that the auxiliated expresses only the semantic value of the verbal root, the reflexive index se refers anaphorically to the first actant of the auxiliary, and the principle that the index se must refer to the first actant is respected. ${ }^{152}$

\$8 This can explain sentences such as Alfred se fait raser, lit. 'Alfred makes (someone) shave himself', that is 'Afred gets himself shaved', in which the index se, which precedes (rather than follows) the causative auxiliary fait, refers anaphorically to Alfred.

152. Lucien Tesnière, Théorie structurale des temps surcomposés, Mélanges Bally, 1939, p. 160. 
$\$ 9$ Reflexive factitives of this type have a particular stylistic value, since the anaphoric reference refers to the instigator and not to the agent of the action. Therefore sentences of the type Alfred s'est fait tuer 'Alfred got himself killed', while considering Alfred as the primary cause of his own death, in no way imply that his role as instigator is intentional or conscious, and that he is therefore ultimately responsible for having caused his death. Quite to the contrary, they indicate that Alfred did not have the intention of causing his death and that it was in fact unexpected, although it is true that it was his own fault, but an unconscious fault for which he is not responsible. The same remark is valid for all analogous expressions: Alfred s'est fait battre 'Alfred was beaten (up)', Alfred s'est fait voler 'Alfred got himself robbed', Alfred s'est fait pincer 'Alfred got himself caught', etc.

\section{Chapter 111. New valency}

\$1 While the addition of a new valency in the causative has led us to study the tribulations of the new actant in the preceding chapters, it is evident that the intervention of this new actant in the actant structure of the verb also invites us to examine more closely the perturbation that the new actant creates in the structure itself, and as a consequence to analyze the notion of the causative itself.

$\$ 2$ As stated above (Chapter 107, \$8), the new actant, which has the value of an instigator and the existence of which was revealed in the preceding chapter (cf. Chapter 108, \$2), provides all causative verbs with an additional valency slot compared with that of the corresponding non-causative verbs.

$\$ 3$ Therefore the verbs that we have studied above (cf. Chapter 98) under the name avalent verbs, because they express an action without an actant, result in constructions with a single actant when they are combined with a causative. For example, in comparison to the French sentence Il pleut 'It rains', which lacks an actant, we have the sentence with one actant La condensation de la vapeur d'eau fait pleuvoir 'The condensation of water vapor causes (it to) rain'.

$\$ 4$ In the same way monovalent verbs produce divalent verbs when they become causative. For example, Fr. Bernard tombe 'Bernard is falling' $\rightarrow$ Alfred fait tomber Bernard 'Alfred makes Bernard fall'.

$\$ 5$ Still in the same way, verbs with two actants become, when they are combined with a causative, verbs with three actants, e.g. Bernard frappe Alfred 'Bernard hits Alfred' $\rightarrow$ Charles fait frapper Alfred par Bernard 'Charles has Alfred hit by Bernard'.

$\$ 6$ Finally, verbs that take three actants become, when they are causative, verbs that take four actants, e.g. Charles donne le livre à Alfred 'Charles gives the book to Alfred' $\rightarrow$ Daniel fait donner le livre à Alfred par Charles 'Daniel has Charles give the book to Alfred'. 


\section{Chapter 112. Analytical markers of new valency}

\$1 The intervention of new valency can be marked by an analytical process (via the use of a causative or factitive auxiliary) or by a synthetic process (via the use of a special form of the verb), or it can lack morphological marking altogether.

$\$ 2$ The normal causative marker in French is the verb faire, which is found with this value in a large number of environments: La condensation de la vapeur d'eau fait pleuvoir 'The condensation of water vapor causes it to rain', Bernard fait tomber Alfred 'Bernard makes Alfred fall', Charles fait frapper Alfred par Bernard 'Charles has Alfred hit by Bernard', Daniel fait donner le livre à Alfred par Charles 'Daniel has Charles give the book to Alfred', etc.

$\$ 3$ In these uses, the causative auxiliary faire conserves its ability to take an oblique personal index, which it can be difficult to identify as either the second or third actant, e.g. Cécile: On voulait me faire vous écrire 'They wanted to make me write to you' (Berthe Vadier, La petite Nièce, Scène VII, Magasin d'éducation, 1881, II, p. 2772), but On voulait me faire écrire can be interpreted as 'They wanted to make me write' or 'They wanted to make (someone) write to me'.

$\$_{4}$ The block made up of the auxiliary faire and its auxiliated is perceived so much as a single unit by French speakers that they sometimes prefix it with the iterative preverb re-, which should actually precede only the auxilliated: Ils ont été obligés de refaire faire le plafond 'They were obliged to have the ceiling redone' (heard on April 30, 1935). The correct sentence would have been Ils ont été obligés de faire refaire le plafond.

$\$ 5$ The causative auxiliary in German is normally lassen: Der General ließ eine Brücke schlagen 'The general had a bridge built'. But this auxiliary is much less common than in French, German preferring instead to employ other means most of the time when it expresses the factitive (Chapter 126 and 127).

$\$ 6$ In contrast, the verb laisser in French never has the value of a causative. That is why the rare times it can be seen to be used in this way are most likely due to the influence of a Germanic substratum, whether Alsatians or native German speakers: Il laissa atteler le cheval noir 'He had the black horse harnessed'. ${ }^{153}$

$\$ 7$ Latin does not possess a causative auxiliary that is frequently used. It could, however, employ the verb cogo with a similar meaning, but the true meaning of this verb, which means 'force' conserves its full value: Eum fugere coegit '(He/she/it) forced him to flee'. And this is more a matter of vocabulary than a systematic trait of the grammar proper.

153. Mme de Stolz, La maison roulante, p. 197. 
\$8 The common causative auxiliary of verbs of state in French is rendre 'render'. It is easy, in fact, to verify that rendre is equivalent to faire être 'make be' in meaning. Rendre heureux 'make happy' can be analyzed as faire être heureux 'make be happy', which is less correct, it is true, but perfectly clear from a semantic point of view. Furthermore, the auxiliary rendre is at least as common in French in combination with predicative adjectives as the auxiliary faire is with infinitival verbs. It is common to hear rendre heureux 'make happy', rendre malheureux 'make unhappy', rendre furieux 'make furious', rendre malade 'make sick', rendre inutile 'make useless', rendre practicable 'make viable', rendre gourmand 'make greedy', etc...

$\$ 9$ It is worth taking a closer look at the union rendre attentif 'make aware.' This expression comes from Alsatian French, in which it is common to hear and to read Je vous rends attentif à ce fait, que... 'I make you aware of the fact that..., whereas the Parisian is more likely to employ the fixed expression J'attire votre attention sur ce fait, que...'I draw your attention to the fact that.... The Alsatian usage could be attributed to regionalism if it were not for the fact that it is legitimised by its presence in celebrated literature. George Sand herself writes ...La Reine des prés, ...voulait le rendre attentif à ses discours 'The Queen of the meadows, ... wanted to make him attentive to her speeches.' ${ }^{154}$

\$10 The use of the verb rendre as a causative auxiliary is inherited from Latin, which has the following structure: reddere aliquem beatum 'make someone happy'.

$\$ 11$ Instead of the auxiliary rendre, French sometimes uses the auxiliary faire as a causative for a verb of state, e.g. faire quelqu'un général 'make someone general'.

\$12 The causative auxiliary faire of the verbs of state was already common in Latin, e.g. Romani Ciceronem consulem creaverunt 'The Romans made Cicero consul' (Chapter 68, $\$ 8$ ), and in Greek this verb was even the ordinary causative auxiliary of verbs of state: poieîn tina beltío 'make someone better', poieîn tina otratēgón 'make someone general'.

\section{Chapter 113. Synthetic markers of new valency}

$\$ 1$ The synthetic marker that indicates the causative value of a verb can be a derivative form, a composite form, or the utilization of a preexisting opposition between a causative and a non-causative verb.

\$2 Derived causative forms can be marked in principle by an internal or external inflection.

$\$ 3$ At first sight, doubling seems to be a process of external inflection, since it appears as a prefix. But this is not the case, since, being taken from the root form, it affects a form that is not independent of this root, but which reproduces it in part, and which is therefore different for each root. This process, which is encountered in Indo-European, is quite rarely

154. George Sand, Gribouille, p. 82. 
employed. It is found practically only in the Lat. si-sto 'I make (something) stand up' in comparison to sto 'I stand up'.

$\$ 4$ Most often, a purely internal inflection does not exist, so it is accompanied by an external marker.

$\$ 5$ In Hebrew this marker is a prefix, the prefix $h i-$, which is added to the internal vocalic variation of the stems. Therefore the causative of the verb päqad 'ordered/he counted' is $h i$-pqìd '(he) appointed (someone)'. This prefix survives with just one other vowel in the corresponding passive form $h u-\overline{p q a d}$ 'he was appointed' (cf. Chapter 109, \$7).

$\$ 6$ The external marker of the causative, in contrast, is a suffix in Indo-European, where in addition to the simple verb, which was formed with in the e-grade, the corresponding causative verb was in the o-grade, with adjunction of the suffix ${ }^{*}-e y$-. In this way from the root ${ }^{*} m e n$ - 'think', the causative ${ }^{*} m o n-e y-\bar{o}$ 'I make think' can be formed.

$\$ 7$ This type survives in the causative diathesis of Sanskrit, and in Slavic in a certain number of verbs with the suffix - $i-$, for example Old Slavic lož- $i-t i$ 'lay flat' or, in opposition to the Slavic e-grade, Rus. teč' 'flow', the factitive in o-grade of Old Slavic *točiti 'sharpen', initially 'make (water) flow (on the grindstone)', Rus. točit' 'sharpen', Slovenian točiti 'pour'. It also survives in a few Greek and Latin verb structures, such as Lat. moneō 'I warn/advise', and in Germanic synthetic factitives.

$\$ 8$ In contrast to the strong (i.e. Indo-European) monovalent verb, liegen 'lie' (preterit -lag, past participle gelegen), there exists in German a causative legen 'lay down', which otherwise should be written etymologically as *legen, since it represents the o-grade $\log$ - > Ger. *lag- of the Indo-European root ${ }^{*}$ leg-.

$\$ 9$ In the course of the evolution of Indo-European to Germanic, the Indo-European suffix - ey-progressively reduced to Germanic * $j$ - (at the origin of the Germanic causatives in *-i-an, cf. *fall-i-an 'make fall, fell' - Ger. fällen) and then completely disappeared, notably in modern German, but not without leaving a trace that is present in the umlaut or mutation associatd with the vowel of the verb's stem. The result of this is that the external marker of the causative has completely disappeared, but in the process has reinforced the internal marker, which alone has survived in German.

$\$ 10$ In addition to its simple verbs, German possesses a series of causative doublets, the meaning of which has at times evolved somewhat, but which have also often retained a semantic causative connection to the simple verbs from which they are derived.

\begin{tabular}{ll}
\hline Simple verbs & Causative doublet \\
\hline beissen 'bite' & beizen 'corrode' \\
reissen 'rip' & reizen 'excite' \\
biegen 'bend' & beugen 'bend'
\end{tabular}




\begin{tabular}{ll} 
fliessen 'flow' & flossen 'pour' \\
sinken 'sink' & senken 'sink' \\
springen 'jump' & sprengen 'blow up' \\
zwingen 'force' & zwängen 'force' \\
verschwinden 'disappear' & verschwenden 'waste' \\
essen 'eat' & ätzen 'etch' \\
fahren 'drive (a car)' & führen 'lead' \\
fallen 'fall' & fällen 'cut down' \\
walzen 'roll' & wälzen 'roll' \\
\hline
\end{tabular}

$\$ 11$ It should be noted that the forms of all these causatives agree chronologically with their meaning, in that both the form and the meaning of the causatives arose after their simple counterparts. Concerning meaning, the actant structure of the causatives, which take two actants, is a more recent development than the structure of the simple forms, which take just one actant (because they are all intransitive). Concerning form, the simple non-causative verbs belong to the strong conjugation paradigm, which means that morphologically they date back to Indo-European, whereas the causatives derived from them belong to the weak conjugation paradigm, which is a Germanic structure and therefore more recent.

$\$ 12$ Very often, the marker of the causative is purely external, and it therefore consists merely of an affix (suffix or prefix).

$\$ 13$ For instance, French derivatives are formed with the suffixes -iser and -fier, both coming from more or less learned words.

$\$ 14$ The suffix -iser is of Greek origin (dramat-iser 'dramat-ize'). But it can now be found in words of Latin origin (canal-iser 'canalize, channel', neutral-iser 'neutralize'), French (brutal-iser 'treat roughly', égal-iser 'equalize'), and in borrowed words (macadam-iser from Eng. tarmac).

\$15 The suffix -fier is of learned origin and can be used to derive words such as ampli-fier 'amplify', boni-fier 'improve', lubri-fier 'lubricate', codi-fier 'codify'. By analogy with this type of structure, the familiar term cocu-fier 'be unfaithful' was derived, the cheeky irony of which persists in the analogous formations statu-fier 'raise a statue in honor of' and even amusingly, compte rendu-fier 'produce the report of someone's publication'.

$\$ 16$ The marker of the causative can, in contrast, be a preverb. German has, next to the monovalent verbs warten 'wait' (constructed with the preposition auf 'for', which introduces a circumstant) and wohnen 'live' (constructed with a locative preposition, which can also introduce a circumstant), composite forms of these verbs er-warten 'await' and be-wohnen 'occupy', which retain the original meaning even though they are now divalent. 
The two structures Ich warte auf ihn 'I wait for him' and Ich erwarte ihn 'I await him' are just as correct as each other and the same goes for Alfred wohnt in diesem Haus 'Alfred lives in this house' and Alfred bewohnt dieses Haus 'Alfred occupies this house'. German grammar even states that one of the essential functions of the preverb be-is to change intransitive (monovalent) verbs into transitive (divalent) verbs.

$\$ 17$ Finally, many languages make use of forms that have a double external marker to indicate causative meaning, i.e. they are derived with a suffix and are constructed with a prefix. In French, dé-ferr-er un cheval is a causative that expresses the idea of removing the horseshoe from the hoof of a horse. The same notion is expressed in Slovenian by the verb iz-bos-iti: izbositi konja 'remove the horseshoes from a horse'. The Slovenian verb is a denominative, as is the corresponding French verb. But the value of the preverb and the resulting semantic process are not the same in the two languages. In French, the word fer ( $\dot{a}$ cheval) 'horseshoe' is a noun referring to the object that was on the hoof before the action. However, the Slovenian word bos 'bare hoof' is an adjective that describes the state of the horse after the action (resultative).

$\$ 18$ In Georgian, the causative marker is external and double, since it contains both the preverb $a$ - and the suffix -in-eb:

\begin{tabular}{lc}
\hline \multicolumn{2}{c}{ Georgian } \\
\hline v-a-cer & 'I write' \\
v-a-cer-in-eb & 'I make write' \\
\hline
\end{tabular}

$\$ 19$ Georgian has the ability to create causatives of causatives by repeating the suffix -in$e b$ : $\boldsymbol{v}$-a-cer-in-eb-in-eb, lit. 'I make make write', that is, 'I (D) make somebody (A) write by means of an intermediary (C)’ (cf. Chapter 108, \$10). It is hardly necessary to say that each appearance of the suffix -in-eb adds a valent; verbs of this type therefore have two valents more than the corresponding simple forms.

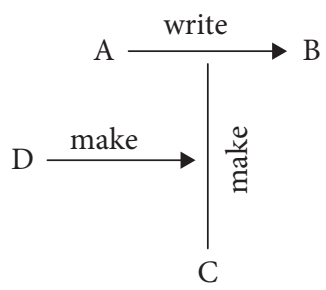

Schema

$\$ 20$ Finally, German, and to a lesser degree Latin, use as a causative marker a process that consists of a preexisting non-grammaticalized semantic opposition between causative and non-causative verbs. 
\$21 In German, machen 'to make', which has a causative value in relation to werden 'to become', enables causative locutions to be developed alongside the numerous non-causative locutions in which werden is formed with the preposition $z u$ and a noun: zum Mörder werden 'to become a murderer' $\rightarrow$ zum Mörder machen 'to make someone a murderer'.

\$22 But the most widespread process is the one in Latin that consists of opposing the verb eo 'I go' with the verb do 'I give', per-eo 'I perish' $\rightarrow$ perdo 'I lose', ven-eo 'I am sold', lit. 'I go to the sale' $\rightarrow$ ven-do 'I sell', lit. 'I give to the sale. The structure of these last verbs ressembles that of Ger. feil-bieten 'put up for sale'.

$\$ 23$ Among the verbs of which German commonly uses the semantic value to express the opposition between the causative and the non-causative, kommen 'come' and bringen 'bring' = 'make come' play a particularly important role: unter-kommen 'to find a place to stay' $\rightarrow$ unter-bringen 'to lodge', zustande-kommen 'to be realized' $\rightarrow$ zustande-bringen 'to realize.

\section{Chapter 114. New valency with a zero marker}

$\$ 1$ Instead of being marked by an analytic or synthetic process, new valency can also be non-marked, which means, to use correct grammatical terminology, that the marker of new valency is zero (cf. Chapter $17, \$ 1$ ).

$\$ 2$ When the marker is zero, we see that normal monovalent verbs are misused with the value of divalent verbs, or that verbs that are normally divalent are employed with the value of trivalent verbs.

$\$ 3$ Among the monovalent verbs, it is necessary to signal in particular certain transitive uses of French intransitive verbs, which have become established in the bureaucratic offices of the League of Nations in Geneva: répondre une lettre 'to reply a letter', circuler un dossier 'to circulate a document'. It is most likely that this is the result of an English influence, since in English it is common for the number of actants to vary without this variation being indicated by a marker.

$\$ 4$ Note also a divalent use of the verb sauter in the sense of 'blow up (a building)'. This use seems to have been established during the war: Nous avons sauté la douane 'We skipped customs.'155

$\$ 5$ Similarly, the verb tomber 'fall' (which is normally monovalent in French) can sometimes be used divalently, above all in the language of sport, where it is common to say that a boxer or a soccer player $a$ tombe 'toppled' his adversary. This usage is possibly of southern origin, since in Occitan, spectators of a brawl commonly call out Toumba lou! 'Take him

155. Paris Soir, August 5, 1939. 
down!'. Southern French speakers often make the error of using expressions such as J'ai tombé mon livre 'I dropped my book', lit 'I fell my book', in which the divalent character of the verb tomber in their local dialect shows through: Ai toumbat moun capel 'I dropped my hat.' ${ }^{156}$ Everyone in this sunny place knows that when it gets hot, On tombe la veste 'One takes off one's jacket', lit 'One falls one's jacket'.

$\$ 6$ We have seen that a certain number of verbs of movement that are normally monovalent can become divalent and that monter 'climb', descendre 'descend', avancer 'advance', reculer 'move back', sortir ${ }^{157}$ 'go out' are often used instead of faire monter, faire descendre, faire avancer, faire reculer, faire sortir. It is true that sortir in its divalent use is vulgar when the second actant is a person. It is more vulgar to say sortir quelqu'un 'throw someone out' than to say sortir un pot de fleur 'take out a flower pot'.

\$7 Finally, it can occur that verbs with one actant are constructed with two actants when the second actant, instead of referring to a notion outside of the process, refers simply to the content of the process: Fr. vivre sa vie 'live one's own life', Dormez votre sommeil, grands de la terre! 'Sleep your sleep, you in high places!' (Bossuet), Gr. hodòn iénai makrán 'travel a long route, Lat. tutiorem vivere vitam 'live a life more secure', Ger. seinen Weg gehen 'go one's way'. In such cases, the accusative used in languages with case is called the accusative of the internal object. It is necessary to acknowledge that monovalent verbs treated in this manner do not cease to be semantically monovalent, despite their apparent divalency. $\$ 8$ The new zero-marked valency can also be encountered in divalent verbs, which adopt a causative trivalent value that they do not normally have. This is the case in the following Latin sentence: Caesar pontem fecit (Caesar, De bello Gallico, III, 44, I), 'Ceasar had a bridge built', not 'Ceasar built a bridge', for it is evident that Ceasar himself did not construct the bridge, but rather he had the bridge built by his men, cf. also Gr. apóduson kai toûton (Lucien, Dialogues des Morts, XIX) 'have him undress' (not 'undress him'), since it is evidently not Hermes who is going to undress the philosopher; Rus. On sšil sebe kostjum 'He had a costume made for himself'.

\section{Chapter 115. The recessive diathesis with a reflexive marker}

\$1 Unlike the factitive diathesis, the recessive diathesis reduces the number of actants by one.

\$2 It is rare for grammarians to have recognized the existence of the diathesis that plays the inverse role of the factitive diathesis, and it is even rarer for them to have recognized

156. Cf. Lamouche, Grammaire languedocienne, p. 110.

157. Cf. A. Malblanc, Pour une stylistique comparée du français et de l'allemand, Paris, 1963, \$57 bis. 
its exact value. This situation is clearly evident in the diversity of terms that have been used for it: reversive (by Damourette in his communication of June 15, 1935 at the Sociéte Linguistique de Paris), regressive, retroactive. Some of the words are excellent, but since they all have a pre-established meaning, which risk leading to error, we prefer to adopt the synonymous, but nevertheless unexploited, term recessive (cf. Chapter 107, \$9).

$\$ 3$ In French and many other languages, the marker of the recessive diathesis is the same as that of the reflexive diathesis.

$\$ 4$ The use of the reflexive with recessive value is easy to justify. Due to the lack of a synthetic recessive form or even simply a specialized form, the language quite naturally exploited the form by which verbs with two actants most resemble verbs with one actant. Yet it is evident that this form is that of the reflexive diathesis, since, even though it involves two actants, these two actants denote a single person, or to be more precise, it is the same person that appears in the role of the first actant and the role of the second actant. We can see that it is easy to pass from the notion that two actants can denote the same person to the notion of a single actant.

$\$ 5$ Verbs constructed with the so-called reflexive personal noun can thus have the value of a true reflexive or of a recessive, which is a very different value. It is therefore important in good syntax to establish the difference between the two with as much precision as possible.

$\$ 6$ A classic joke known to clowns in French circuses can be used to illustrate the difference. A clown who is sitting down and who wants to give the impression that he is seizing himself by the collar and pulling himself upward, which creates a comical effect of buffoonery, since everyone knows that it is a stunt and that the clown cannot really pull himself up, due to the fact that he has no hold outside of his own body. But skillful clowns succeed in giving the impression that they are truly generating an upwards force on themselves. In this case, it is possible to say of the clown that he se leve 'lifts himself', which is reflexive. When, on the contrary, somebody is sitting and s/he se lève 'stands up', which is the usual meaning of this expression, there is no notion of reflexivity and the verb is simply in the recessive voice.

$\$ 7$ This assertion is easy to verify using a comparison with foreign languages. Eng. Alfred stands up and Ger. Alfred steht auf, which are the exact equivalents of Alfred se lève, are monovalent verbs that cannot take more than one actant. They consequently prove that the corresponding French expression, despite the presence of the reflexive personal noun $s e$, has no reflexive value, but that the se here is the marker of the recessive voice and that its role is merely to permit the use of the divalent verb lever 'lift' with the value of a monovalent verb. However, it would be futile to seek to capture the nuance described above in $\$ 6$ with the corresponding monovalent English or German verb.

$\$ 8$ This nuance is subtle and it is sometimes difficult to effectively determine whether or not the reflexive personal noun has completely lost its reflexive value and consequently 
whether or not the verb is recessive. Since the recessive was originally just a particular use of the reflexive, a number of verbs are still evolving, which means that although the difference between the reflexive and the recessive meaning is theoretically very clear, there is nevertheless no dividing line drawn up between the two voices.

$\$ 9$ But in a number of cases, a little elementary reflection on the meaning of the sentence can enable us to recognize that since the reflexive value does not deliver a plausible meaning, the value in question is necessarily that of the recessive. This is the case with sentences in French such as Les maisons se construisent lentement 'The houses are being built slowly', Le blé se sème en automne 'The seed is sown in autumn', Cette montagne se voit de loin 'This mountain can be seen from afar', La porte s'ouvre 'The door opens', Cet objet se vend bien 'This object is selling well', Ce livre se lit facilement 'This book is easy to read', lit. 'This book SE reads easily', since it is quite evident that the houses do not build themselves, that the wheat does not sow itself, that the mountain does not see itself from afar, that the door does not lift its own latch, that the object does not proceed to sell itself and that the book does not read itself.

$\$ 10$ These considerations lead us to formally condemn the term pronominal verb, since it is a morphological term, not a syntactic one, and because it ignores the syntactic reflection that is necessary to distinguish between two voices that are so easily confused. To advocate the use of the term pronominal is to suggest that we should settle for taking note of the morphological marker and to therefore relieve ourselves of any real syntactic comprehension. Pronominal is a morphological term. The term reflexive, in contrast, expresses a syntactic notion. So we are in full agreement here with what Galichet says on this subject in his Essai de Grammaire psychologique, p. 94.

$\$ 11$ The terms inherently and accidentally should also be rejected since they generate the same confusion.

$\$ 12$ Grammarians have distinguished between inherently reflexive verbs and accidentally reflexive verbs. They meant by this that, since inherently reflexive verbs are reflexive by nature, they must obligatorily have a reflexive form and cannot take on a non-reflexive form. For example: s'évanouir 'faint'. On the other hand, accidentally reflexive verbs are defined as verbs that are normally non-reflexive but which can accidentally become reflexive, and which can therefore sometimes appear in their reflexive form and sometimes in their non-reflexive form. For example: cacher 'hide' in cacher quelque chose 'hide something' and se cacher 'hide' (monovalent).

$\$ 13$ The appalling habit of substituting purely external, formal and morphological terms for syntactic concepts became established in official grammatical classification, due to the support of an influential but nefarious patronage and the reflexive verbs were debaptized and rebaptized pronominal verbs. However, the terminological distinction between verbs that are inherently and accidentally pronominal was kept. In one sense, the new terminology was more straightforward, since it encouraged us to focus only on the presence or absence of the reflexive form, and it therefore corresponded more precisely to the purely 
formal definition of verbs referred to as inherently or accidentally reflexive according to whether or not they could be constructed with the reflexive form. However, this practice did away with the term reflexive as well as with the impetus to take note of the semantic value of these categories.

$\$ 14$ Yet it is precisely this value that it is essential to understanding in syntax. And it is paradoxical to note that the so-called accidentally reflexive or pronominal verbs are precisely the ones for which the reflexive diathesis has its full value, according to our definition above (Chapter 100, \$8), since the source and the target of the action is the same actant, which means that there is "reflection" of transfer and that, in contrast, the so-called inherently reflexive verbs, which are always used with the reflexive pronoun, have no corresponding non-reflexive form to which they could stand in contrast in order to affirm their reflexive value in the strict sense of the word.

$\$ 15$ In other words, it is the verbs known as accidentally reflexive that in fact serve essentially to express reflexive value, whereas the inherently reflexive verbs are reflexive only accidentally, since they denote actions that do not contain, or that no longer contain, any degree of reflexivity; such as the recessive verbs se tromper 'be mistaken', se lever 'get up', etc. $\$ 16$ This amounts to saying that it is the true reflexives that are known as accidentally reflexive and that it is the pseudo-reflexive verbs such as the recessive verbs that are known as inherently reflexive. This suffices to show how fundamentally terrible terminology can be when it, although originally designed to express syntactic notions, has been inopportunely shifted from its true purpose in order to express morphological notions of a much different nature.

$\$ 17$ The recessive marked by the use of the reflexive is particularly developed in the mediteranean languages with sentences such as Si parla italiano '(One) speaks Italian', Se habla español '(One) speaks Spanish'. It is quite evident that it is not the Italian and Spanish languages that themselves perform the action of speaking and that the use of the reflexive only serves to mark the presence of the monovalent verb 'speak', which is normally divalent.

\$18 In Russian, the marker of the recessive is a form of the personal reflexive noun: sebja, which is abridged and suffixed with - sja or $-s^{\prime}$ (Chapter $103, \$ 8$ ). This is why the form is the same for the three persons and both numbers:

\begin{tabular}{llll}
\hline & Russian & Idiomatic & Literal \\
\hline Anontive & ošibaetsja & 'He is wrong' & 'He fools oneself' \\
Antiontive & ošibaeš'sja & 'You are wrong' & 'You fool oneself' \\
Autoontive & ošibajus' & 'I am wrong' & 'I fool oneself' \\
Anontive & ošibajutsja & 'They are wrong' & 'They fool oneselves' \\
Antiontive & ošibaetes' & 'You are wrong' & 'You fool oneself'
\end{tabular}




\section{Autoontive ošibaemsja 'We are wrong' 'We fool oneselves'}

But it is only by way of etymology, i.e. by way of its ancient history that this suffix is reflexive. It is no longer reflexive today and has only recessive value, and the non-abridged personal noun sebja must instead be used to express the notion of the reflexive. ${ }^{158}$

\section{Chapter 116 . The recessive diathesis with a passive marker}

$\$ 1$ In addition to the use of the reflexive form as a marker of the recessive, its use as marker of the passive should also be acknowlegded. This use is justified in a very similar way to that of the reflexive usage. It is true that the change in the direction of the transfer between the two actants and the transformation of the second actant to the first actant and the first actant to the complement of the passive do not influence the total number of actants present. But all it needs is for the complement of the passive to be overlooked for there to be a single overt actant expressed and for the verb in this respect to come closer to monovalent verbs.

\$2 By the modification of the actant structure to which it is exposed, the recessive marking the passive is related to the recessive marking the reflexive. It is in this sense that recessive verbs could have been said to have passive value, which is a bit inaccurate, since it would be more correct to say the passive diathesis takes on a recessive value.

$\$ 3$ Such is the case in Latin, with for example Domus in hac regione cito aedificantur 'Homes are built quickly in this country'.

$\$ 4$ The Latin passive is therefore frequently translated by the French recessive: Lat. exerceri $\rightarrow$ Fr. s'exercer 'train' (monovalent).

$\$ 5$ The use of the passive with recessive value is quite frequent in German where structures such as Die Tür wurde aufgemacht 'The door opened' are quite common, as with Fr. La porte s'ouvrit. ${ }^{159}$

$\$ 6$ Finally, the Latin recessive use of the impersonal passive should also be acknowledged: Dormitur 'One is sleeping', lit. '(It) is slept', Amatur 'One loves', lit. 'It is loved', Itum est 'One went', lit. 'It is gone', Ut valetur? 'How is it going?', lit. 'How is worked?'. The passive presents

158. See Roman Jakobson, Introduction to Russian (Review of L. Trager The Slavonic and East European Review, XXII, October 1944, p. 130).

159. Moreover this is a question of diathesis, not a question of aspect as A. Malblanc seems to assume in his book, which is otherwise excellent, Pour une Stylistique comparée du français et de l'allemand, Didier, (1944), p. 32-33. 
the advantage that a first actant complement can be left in the passive, which would be much more difficult in the active because this actant would be the first actant.

\$7 The impersonal passive is very widespread in Latin and German, and it is highly convenient even in French when the speaker wishes to avoid stating the agent of a process.

$\$ 8$ The impersonal passive, which is content to express the process without consideration of the person who accomplished it, is restricted to avalent verbs. This is why it can be employed even with monovalent verbs, such as for example in the expression Dormitur lit. 'Is slept', Itum est lit.'Is gone', Es wurde getanzt 'there was dancing', lit. 'It was danced', Es wurde gearbeitet, lit. 'It was worked'. In such cases, the subject is left in shadow, as Bally points out. ${ }^{160}$

$\$ 9$ We have already seen (Chapter 37, \$45) that in German the impersonal passive with imperative mood can be expressed by the past passive participle alone: Aufgepasst! 'watch out!', lit. 'Watched up!', Stillgestanden! 'attention!', lit. 'Stood still!'.

$\$ 10$ Certain languages have only the form of the reflexive diathesis to express the passive, which is then the recessive form. This is the case in the Scandinavian languages, where the passive diathesis is expressed by the deponent, which is essentially nothing other than a reflexive verb with recessive value: Dan. lykkes 'succeed' (monovalent). ${ }^{161}$

$\$ 11$ We should also mention a frequent confusion in Turkish between the passive and the reflexive (i.e. the recessive). ${ }^{162}$

$\$ 12$ The affinity between the recessive with a reflexive marker and the recessive with a passive marker explains why it is often necessary to pass from one to the other when translating from one language to another. Therefore the recessive with a reflexive marker in the Fr. La porte s'ouvrit 'The door opened' corresponds to the recessive with a passive marker in the Ger. Die Tür wurde aufgemacht, and the recessive with the passive marker in the Italien Si parla inglese corresponds to the passive participle of Eng. English spoken.

\section{Chapter 117. The recessive diathesis with a zero marker}

$\$ 1$ The recessive diathesis is not obligatorily tied to the presence of a marker like the reflexive or the passive. Verbs with recessive value that are not morphologically marked in any way can also exist. It is simply the case that a verb with a given valency can also be used

160. Linguistique générale et Linguistique française, p. 370 [3rd edition, 1950, §578].

161. The Scandinavian deponent is of course of a purely syntactic nature and is therefore different from the Latin deponent, which is more morphological (cf. Chapter 102, \$7).

162. J. Deny, Grammaire turque, $\$ 573$. 
with one valency slot less, for example normally divalent verbs have monovalent uses. In such cases the marker of the recessive diathesis is said to be zero (cf. Chapter 17, §1).

\$2 This is the normal case in Indo-European, where the verbal root expresses processes which were not associated with a particular diathesis. This is a little like in English, where the verb get can be monovalent with the meaning 'become' or it can be divalent with the meaning 'obtain'.

$\$ 3$ In Greek the verb ékhō can be divalent, in which case it has the meaning 'have', or it can monovalent, in which case it has the meaning 'feel, be': êu ékhō 'I feel good'. Likewise: Êu práttei he polis, lit. 'The city does well', that is, 'The city is happy'.

$\$ 4$ It is also possible to find monovalent uses of French verbs that are normally divalent. We point in particular to the verb coller 'stick' because it is a neologism. This verb is normally divalent, but the new generation of students in Montpellier and in the South of France grant the verb coller monovalency when they speak of failing an exam. They say Alfred a collé 'Alfred has failed' instead of Alfred a été collé 'Alfred has been failed.' ${ }^{163}$

\$5 French often presents an analogous situation when the second actant is not expressed, but is instead incorporated semantically into the verb. This occurs for example with the verb cuire 'cook, bake' when the thing that is to be baked is implied. In such a case, the second actant, although not expressed, does not block the corresponding valency any less, such that the verb, which is normally divalent, becomes monovalent. Therefore in certain regions of France, cuire alone means 'bake the bread'.

$\$ 6$ Furthermore, the second actant, which is absent and which designates the thing that is cooked, can vary from one region to another. In Provençal, mettre à cuire 'put on to cook' means to prepare the dish par excellence, the only one available for a long time in Provence, le pot-au-feu 'beef stew'. For the same speakers, mettre à bouillir 'put on to boil' means 'to do the washing'.

$\$ 7$ The generalization of recessive verbs to the detriment of the non-recessive verbs from which they derive constitutes, by way of the semantic integration of the nucleus that corresponded to the nullified valent, an undeniable enrichment of the language.

\section{Chapter 118. Different degrees of the recessive}

\$1 The recessive diathesis, since it has the effect of diminishing the number of actants by one, reduces trivalent verbs to divalent verbs, divalent verbs to monovalent verbs, and monovalent verbs to avalent verbs.

163. A fact that has been observed by the author since 1946, and probably earlier. 
\$2 Taking the French trivalent verb dire as an example, we can see its normal trivalent structure in the sentence Alfred dit tant pis à Charles... 'Alfred said too bad to Charles'. But it is commonly employed in the recessive diathesis se dire: Dommage, se dit Alfred 'Too bad, Alfred said to himself', i.e. 'Too bad, thought Alfred'. The recessive value is perfectly clear in this case, since it is evident that Alfred did not have a conversation with himself. The verb se dire often corresponds to the German verb meinen 'think', which is effectively divalent.

$\$ 3$ The recessive diathesis transforms divalent verbs into monovalent verbs. Such is the value of the French verbs se tromper 'be mistaken', se réveiller 'wake up' (monovalent), s'effrayer 'be frightened', which are equivalent to the German monovalent verbs irren, erwachen, and erschrecken. The verb s'amoindrir 'become less' has the German monovalent equivalent formed from a monovalent verb werden 'become' and the comparative adjective geringer 'less': Notre fortune s'amoindrit, Unser Vermögen wird geringer 'Our fortune is diminishing.

$\$ 4$ It is now possible to understand that people from the Midi, who take the verb tomber to be divalent (Chapter 114, \$5), can only employ it as a monovalent verb if it in the recessive diathesis. This is why they say Je me suis tombé 'I fell' instead of Je suis tombé. The sentences J'ai tombé un livre 'I dropped a book' and Je me suis tombé 'I fell', which are incorrect for Parisians, are only two manifestations of one and the same phenomenon of structural syntax: the divalent conception of the verb tomber.

\$5 Finally, monovalent verbs employed in the recessive diathesis become avalent. These verbs are easily recognizable by the presence of an apparent subject and the absence of real actants: Fr. Il s'agit d'un livre 'One is dealing with a book', Ger. Es handelt sich um ein Buch, where the prepositions d' and um reveal that d'un livre and um ein Buch are not actants but circumstants.

$\$ 6$ The preceding examples demonstrate that the value of the personal index se is not recessive in the literary expression Madame se meurt 'Madame is dying', lit. 'Madame dies herself', since the first actant Madame is still present, and it is consequently a monovalent verb. The index se therefore has a completely different value here, which is confined to that of the reflexive, since it seems to signal the battle Madame is engaged in during her final agony.

$\$ 7$ It is necessary to point to the use of the integral recessive here, which reduces the actants to zero whatever the number of original actants. Such is the case with the Latin impersonal passive, which renders all verbs avalent, whatever their original valency. This explains how the verb amo '(I) love', which is originally divalent, has no more valency when used in its impersonal passive form amatur, lit. 'is loved' than the verb eo 'I go', which is monovalent in its corresponding form itur, lit. 'is gone.' The Latin expressions amatur lit. 'is loved', itur lit. 'is gone', itum est lit. 'has gone', dormitur lit 'is slept', Ut valetur? lit. 'How is worked?' are, with respect to the absence of an actant, similar to the meteorological verbs like pluit '(it) is raining'. In each of these cases, the verb simply expresses a process that occurs independent of any actant. 
\$8 The impersonal passive seems to have been a common trait of the Italo-Celtic group of languages: Umbrian ferar lit. 'will be carried', Irish berir lit. 'is carried'. The same expression exists in Low Breton, where it is known to grammarians as the indefinite form, and where, as in Latin, it expresses an integral recessive and is simultaneously valid for divalent and monovalent verbs: gweler lit. 'is seen', êr lit. 'is gone', efer lit. 'will be gone’.

$\$ 9$ Outside of the Italo-Celtic group, the characteristic $-r$ is found only in Tocharian, where it has exactly the same value as in Italo-Celtic. ${ }^{164}$

$\$ 10$ The similarities of these distinct languages suggest the hypothesis that the ending ${ }^{*}-r$ would have characterized an impersonal in Indo-European.

$\$ 11$ In bringing this hypothesis to attention, ${ }^{165}$ Meillet emphasizes that the characteristic ${ }^{*}-r$ survives only in the peripheral languages (Italo-celtic, Tocharian), where the remains of the oldest forms of Indo-European survive. This observation, according to which the forms in ${ }^{*} r$ would be extremely old, is consistent with the hypothesis put forward above (Chapter $106, \$ 18)$, and according to which the less complex the actant structure, the greater the chance that it is old. It would have been the development of monovalent and divalent verbs that would have caused this impersonal to take, secondarily and by ricochet, a recessive value, i.e. a relative value, whereas it would have originally expressed an absolute avalent value.

$\$ 12$ The impersonal passive is very convenient even in French when the speaker wants to avoid designating the subject of a process. The passive presents the advantage of allowing an actant to be left in shadow, which would be more difficult in the active, since this actant would be the first actant.

$\$ 1314.15{ }^{166}$

$\$ 16$ In French expressions of this sort, the indeterminate index on 'one' is often used as the first actant: On parle français, lit. 'One speaks French', i.e. 'French is spoken'.

$\$ 17$ The index on is vague and marks only the fact that a first actant is present, but without precisely naming it: on is everybody and nobody; the listener remains in complete ignorance of the agent of the process.

\$18 That is why it is bad French to replace the personal noun nous 'we' with the impersonal noun on 'one', which has only a structural value and no semantic value, and to say, as young

164. See Revue Celtique, 34, p. 139, cited according to Meillet and Vendryes. Traité de Grammaire comparée des langues classiques, 1924, \$524. [2éd. 1948, \$529].

165. Meillet, Introduction à l'étude comparative des langues indo-européennes, 1934, p. 235.

166. Translators' note: We omit $\$ 13-15$ here because Tesnière closely repeats the content of $\$ 8 f f$. in Chapter 116. 
people unfortunately do more and more: On a été se promener, lit. 'One went for a walk', On a bien rigolé, lit. 'One had a good laugh' instead of saying Nous avons été nous promener, Nous avons bien rigolé. Purists therefore condemn these expressions with good reason; they bear witness to loose and imprecise thought, and far from enriching the language, they lamentably impoverish it.

$\$ 19$ The use of on is therefore equivalent to the absence of an actant. It plays the role of an integral recessive marker and results in an avalent verb.

\section{Chapter 119. Causative and recessive in French}

\$1 Given that the causative and the recessive constitute opposing mechanisms, since the goal of one is to increase the number of actants and the goal of the other is to reduce it, it would be contradictory to employ both in the same sentence. In French, the index se, when it is recessive, far from marking the presence of an actant, indicates rather that the number of actants has been reduced by one. So, for a divalent verb which has two actants, if the causative marker increases its number to three, the recessive marker would bring it back down to two.

$\$ 2$ Under these conditions, it may seem paradoxical to employ the index se of the value of which is to express an actant, given that the goal of the recessive is not to express an actant, but on the contrary to reduce by one the number of actants. And it is therefore conceivable that there may be reluctance to use it in such cases.

$\$ 3$ French therefore avoids the simultaneous use of the recessive index se with the causative marker. This is why it is not possible to say ${ }^{*}$ Bernard fait se lever Alfred 'Bernard makes Alfred get up', but rather Bernard fait lever Alfred, lit. 'Bernard makes lift Alfred'.

$\$ 4$ The sentence ${ }^{*}$ Bernard fait se lever Alfred would in fact generate too much of an impression of three actants: Bernard, Alfred and se. There are, however, only two true actants, Bernard and Alfred, a number that becomes much clearer if the index se is simply removed: Bernard fait lever Alfred. Furthermore, the index se can designate no other actant than Alfred.

\$5 The result is that the absence of se necessitates all the more that the recessive value of the verb be clearer. This is why it is found above all with the verbs se lever 'get up', s'asseoir 'sit down', se coucher 'lie down/go to bed', se dresser 'rise up', se taire 'be silent', se tromper 'be mistaken', and why it is possible to say Bernard fait lever Alfred 'Bernard makes Alfred get up', Bernard fait asseoir Alfred 'Alfred makes Alfred sit down', Bernarnd fait coucher Alfred 'Bernard makes Alfred lie down/go to bed', Bernard fait taire Alfred 'Bernard makes Alfred be silent', Bernard fait tromper Alfred 'Bernard makes Alfred be mistaken', Cela fait dresser les cheveux sur la tête 'That makes one's hair stand on end'. 
$\$ 6$ The same is true of the verb envoyer 'send', which is semantically the causative of the verb aller 'go'. This is why it is possible to say colloquially without se: se promener 'walk' $\rightarrow$ envoyer promener quelqu'un 'send someone for a walk', se coucher 'go to bed' $\rightarrow$ envoyer coucher quelqu'un 'send someone to bed'.

$\$ 7$ The use of $s e$ with verbs that are clearly recessive is thus disputable and open to criticism. On les fit se coucher dans la rizière 'They were made to sleep in the rice field' (Paul Adam) has even been judged as a "French mistake", a judgment that seems quite severe to G. Gougenheim. ${ }^{167}$

$\$ 8$ The tendency to maintain the reflexive index with the factitive of verbs that are clearly recessive is gaining, especially in modern times, when it can even be found to be used by good writers:

\begin{tabular}{ll}
\hline ...l'obstination de la bête à & '...the creature's obstinacy to \\
marcher sur ses talons le fit & follow his footsteps soon \\
bientôt se retourner & made him turn round' \\
(Maupassant, Contes: Mademoiselle Cocotte)
\end{tabular}

This tendency occurs in particular with remarkable frequency in the works of Roger Martin du Gard and above all in the works of Emile Zola.

$\$ 9$ When the value of the index se is not recessive, but clearly reflexive, the contradiction between the causative and the recessive no longer arises. But yet again we are met with the difficulty that stems from the antinomy between the causative and the reflexive that we have already pointed to above (Chapter 110).

$\$ 10$ The simultaneous use of the causative and the pronominal form (recessive or reflexive) is always rather delicate.

167. Bulletin de la Société Linguistique de Paris, tome 40, proceedings of Thelma Fogelberg, La langue et le style de Paul Adam, p. 97. 


\section{BOOK E}

\section{Metataxis}

\section{Chapter 120. Metataxis}

$\$ 1$ Although the structural analysis of simple sentences is always founded on the same general principles regardless of the structure that the language uses to express a given semantic exprimende (Chapter $16, \$ 1$ ), this does not mean that different languages always make use of identical structures to express ideas that are nevertheless equivalent on the semantic plane.

$\$ 2$ In such cases, the translation of one language into another necessitates the use of a different structure. We call this structural change metataxis.

$\$ 3$ It goes without saying that metataxis can only occur during the passage from one language to another, i.e. during translation.

$\$ 4$ By definition, metataxis involves a difference between the stemma of the sentence to be translated and that of the resulting sentence in the target language.

$\$ 5$ These types of translation are particularly delicate, since it is necessary not just to proceed with the somewhat mechanical operation of replacing one word with another, but to substitute a different structure for the structure of the sentence being translated and consequently to rethink the sentence in the target language.

$\$ 6$ For this reason translations involving metataxis are in a sense deep translations. Experience has shown that in such cases, superficial translations are not only clumsy, but often even inaccurate.

$\$ 7$ The result is that when metataxis is involved, it must occur before the translation itself occurs, since the adopted structure dominates the entire process and influences the choice of translation to such an extent that the translation risks not only being inaccurate but even completely non-realizable if the question of the correct structure is not resolved from the start and if the translator recklessly sets out on a path that he cannot depart from (cf. Chapter $123, \S 3)$.

$\$ 8$ Metataxis is merely an application of the principle that structure is independent of semantics, which was discussed above (Chapter $20, \$ 17$ ), since it comes down to expressing a semantically identical idea using a structurally different sentence.

$\$ 9$ Of course the semantics is what needs to be translated, not the structure, since the user of the translation needs to know only the semantic content of the sentence and is in theory not interested in its structure, which is the translator's domain. 
\$10 The translator even has the duty to be discrete and to hide all structural intricacies that constitute the technique of translation. This technique can be of great professional interest to the translator whose profession it is, but it presents absolutely nothing of interest to the user of the translation, who asks, on the contrary, to be free from all constraint that could limit his direct access to the idea expressed. What is important for a guest is that he is served a good dinner; how the dinner was prepared is not important. The latter is the exclusive domain of the cook and the result is a confusion of genres if the techniques of culinary art, which have their place in the pantry, are confused with the ineffable joy of gastronomic pleasures, which is experienced in the dining hall.

\$11 There are all sorts of degrees of metataxis, according to the extent of the structural change required for the translation. This change can go from a simple appeal to a new grammatical category, and so to a different type of word, to the complete transformation of the structural organization including changes to the central node.

\section{Chapter 121. Simple metataxis}

$\$ 1$ Every language establishes its own associations between the categories of thought and the categories of grammar that express them. These associations are such that in order to express a certain type of notion, the language is more likely to call upon a certain grammatical category than another.

\$2 But since not all languages necessarily appeal to the same grammatical category to express the same category of thought, the translation from one language to another sometimes requires the use of a different grammatical category. This is the simplest form of metataxis.

$\$ 3$ Take for example the idea of displacement, i.e. of change of location. To express the idea of displacement, German, like English, has a special and frequently used category: resultative adverbs, improperly referred to as separable particles. Yet the only category that is in principle likely to express a change of location in French is the verb. This means that in general an adverb of displacement in German can only be translated into French by a verb. Take for example the imperative sentence in Ger. Fort!, lit. 'Away!' (cf. Chapter 77, \$11). The only practical way to express this command in French is to use a verb in the imperative: Va-t-en! or Allez-vous en! 'Go away!' (cf. Chapter 37, \$44).

$\$ 4$ The same is true of resultative adverbial locutions in German that are formed by the preposition um followed by a noun. One of the values of this expression can only be translated into French by the verbal expression faire le tour, lit. 'do the circuit': Ger. Gehen Sie um das Haus! 'Go round the house!', Fr. Faites le tour de la maison!, lit. 'Do a turn around the house!' 
\$5 In the union of the words faire le tour, the verb faire 'do, make' contaminates the noun tour 'turn' and confers to it the possibility of expressing a secondary idea of change of place. In these conditions, the French word tour - even though it is not a verb, but a noun becomes the semantic equivalent of the German preposition um: Ger. eine Reise um die Welt 'a trip around the world', Fr. le tour du monde, lit. 'the turn of the world'. Therefore, with respect to metataxis, in this particular expression and quite exceptionnally, a French noun corresponds to a German preposition.

$\$ 6$ The same type of change of category occurs across the German expression jemandem das Versprechen abnehmen 'take a promise from someone' and its French equivalent faire promettre à quelqu'un 'make someone promise', since it is in the analytical factitive of the verb promettre 'promise' that French finds an equivalent to the German verbal noun das Versprechen 'the promise'.

\$7 When the category of a word is linked to that of another word, the metataxis from this word to a word of a different category automatically provokes a parallel transformation of the word that is linked to it.

$\$ 8$ Therefore, given that the adverb is to the verb as the adjective is to the noun, it is necessary, as we have explained above (Chapter $32, \$ 19$ ), if a noun is to be changed into a verb or vice versa, to also change the adjective to an adverb or vice versa: Fr. un diner léger 'a light dinner' $\rightarrow$ il dîne légèrement 'he dines lightly'.

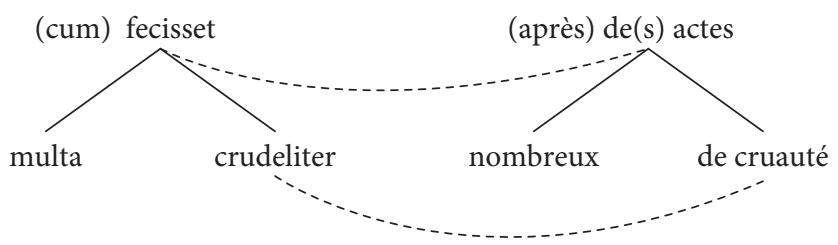

Stemma 216

Stemma 217

$\$ 9$ This is why when the Lat. cum...multa crudeliter...fecisset 'having performed many cruel acts' (Cornelius Nepos, Lysandre, 4,1) is translated with the Fr. après de nombreux actes de cruauté - assuming that the Latin verb fecisset 'do' is to be translated with the French noun actes 'acts' - the Latin adverb crudeliter 'cruelly' must also be changed to a French adjective, which is represented here by the adjectival expression composed of the noun cruauté 'cruelty' preceded by the preposition de 'of' (Stemma 216, Chapter 192).

$\$ 10$ Likewise, if the Rus. kogda pogoda ustanovilas' nadolgo, lit. 'when the weather is established for a long time' (Ivan Turgenev), is translated into idiomatic French as pendant les longues périodes de beau temps 'during the long periods of nice weather' and if the Russian verb ustanovilas' 'is established' is translated with the French noun périodes 'periods', the Russian adverbial expression nadolgo 'for a long time' must therefore also be changed to the adjective longues 'long.' 


\section{Chapter 122. Inversion of actants}

\$1 Metataxis takes place each time the actant structure of a verb differs from one language to another. In such cases, the actant of one language corresponds to another acant in the other language, and the translation across languages is only possible if the nature of the actants is changed. This is one of the most frequent forms of metataxis.

\$2 We refer to this change in the nature of the actants with the term inversion of actants. But it should be noted that the term inversion should not be associated with the linear plane of the spoken chain, as is the case for metathesis, but rather with the internal plane of structural order. This means that a change in the linear order of words on the spoken chain does not necessarily take place, since linear order is completely independent of the inversion of actants.

\$3 Take for example the Latin sentence Tela milites deficiunt 'The soldiers lack arrows'. This sentence corresponds to the French sentence Les traits font défaut aux soldats, lit. 'The arrows are lacking to the soldiers'. Yet we observe that in order to express the second Latin actant milites, French is obliged to use the third actant aux soldats. We call the translation of the secondary Latin actant with a third French actant an inversion of actants, since the actant conceived of as the second actant in Latin is conceived of as the third actant in French (see Stemma 218, 219).

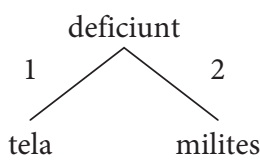

Stemma 218

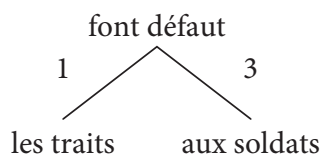

Stemma 219

$\$ 4$ Moreover, in French even the inversion of actants can lead to a parallel modification of the circumstants. Therefore it is Le blé manquait à l'armée 'The army was lacking wheat', lit. 'wheat was lacking for the army', but L'armée manquait de blé 'The army was lacking wheat'. $\$ 5$ With completely different exteriors, due to their different vocabulary, we have exactly the same phenomenon of structural syntax in the Latin sentence Aegre necem effugit ' $\mathrm{He}$ escaped death with great difficulty' and the French sentence Il échappa à grand'peine à la mort.

$\$ 6$ It is by an analogous phenomenon in German that the verb helfen is constructed with a third actant, whereas French and English employ a second actant: Ger. Sein Knecht half $i h m \rightarrow$ Eng. His servant helped him, Fr. Son valet l'aida; Ger. Ihm wurde von seinem Knechte geholfen $\rightarrow$ Eng. He was helped by his servant, Fr. Il fut aidé par son valet. Nevertheless, we note that the construction of the French verb aider 'help' with a third actant, which is incorrect, is however quite widespread in colloquial speech: Son valet lui aida 'His servant helped him'. 
\$7 It can be seen that the number of inversions of actants necessary between two languages is large and that if a complete list were to be drawn up, then all the vocabulary in that language could be exhausted without the list ever being accomplished. If it is added that the same is true each time we consider a new different language, it is easy to understand that we do not in any way claim to be exhaustive and that we will restrict ourselves from now on to illustrating the theory by using a few particularly characteristic examples.

$\$ 8$ But it should not be forgotten that if one wishes to master a foreign language and be capable of forseeing the inversions of actants that must take place prior to the translation of one language into another, it is necessary to have in-depth knowledge of the actant structure of verbs, as much in the source language as in the target language.

$\$ 9$ This insight is essential for lexicographers who should never speak of a verb without indicating its actant structure. Despite knowledge of its meaning, a given verb is unusable if its actant structure is not known.

$\$ 10$ Yet unfortunately, the majority of dictionaries do not provide any firm doctrine about actant structure, and as a consequence, they also provide no typographic procedure for signaling actant structure lexicographically. This is why they limit themselves - and this is true of only the best of them - to giving guidance in terms of phraseology, which is only as useful as it is abundant. In other words, they only provide a greater or lesser number of examples, among which the user of the dictionary might be able to find one that would enable him, if he reasons by analogy, to compensate for the absence of a theoretical doctrine, which the dictionary is incapable of providing.

$\$ 11$ The examples in $\$ 3$ and $\$ 4$ show the correspondence between a second actant in Latin and a third actant in French. The following example shows a different correspondence, that of a first actant in Latin, a second actant in English, and a third actant in French: Lat. Legatorum tarditas repudianda est, Eng. We must abandon the slow pace of diplomacy, Fr. Il faut renoncer aux lenteurs de la diplomatie.

$\$ 12$ On the other hand, it is, for example, possible to find a correspondence between a German third actant and a French first actant in the sentence: Ger. Es ist mir kalt, lit. 'It is cold to me', Fr. J'ai froid 'I am cold'.

\section{Chapter 123. Double inversion of actants}

$\$ 1$ Inversion need not be limited to single actants, but can involve two or more different actants. We say in such cases that there is double or multiple inversion.

\$2 This is why the English sentence I miss you and the German sentence Ich vermisse Sie have to be expressed in French by the sentence Vous me manquez. This translation requires that the first actant in English and German become the third actant in French, while the second actant in English and German becomes the first actant in French (see Stemma 220 and 221). 


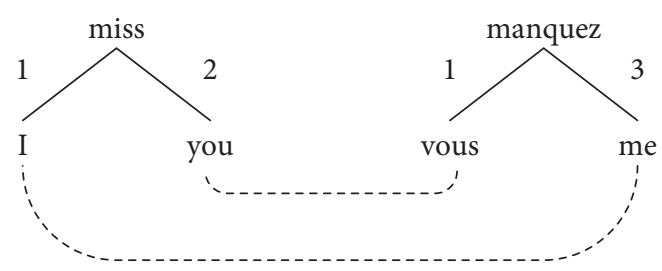

Stemma 220

Stemma 221

$\$ 3$ This example is typical, since it emphasizes how the reversal of actants is indispensable before translation. It is an amusing experience to give the English or German sentence to people who know these languages but have no experience with translating. They never fail to rush headlong into the French sentence beginning with $J e . .$. , but they immediately stop, incapable of finding the verb that corresponds to the English or German verb. The truth is that the corresponding French verb has a very different actant structure and they have gone down a dead-end street by beginning to translate the first actant without having first made sure that the actant structure of the French sentence is the same as for the English or German source sentence. Once they are set out on a false path, naturally drawn to basing the actant of French on the English and German model that they have in mind, and impelled by the beginning of their translation to continue to imagine the sentence in this way, the inexperienced translators can of course go no further and the translation goes nowhere. In order to get them to understand the impasse they have found themselves in, it is necessary to explain to them the theory of the inversion of actants. By applying this theory, they can then be invited to backtrack and to rethink the sentence with the French actant structure, before reattempting the translation, this time taking the correct path. In other words, they should postpone the first actant of the English or German sentence, which falsely offers itself as the starting point, transforming it into the third actant of the French sentence, and on the other hand taking the second actant of the English or German sentence as the French first actant. It is hardly necessary to state that the majority of translators, lacking an understanding of the principles of inversion, can only improve their skills of translation by accumulated experience, slowly and haphazardly, depending on the sentences that they encounter and the translations that could be proposed thanks to favorable intuitions. They are therefore helplessly abandoned to a long and unmethodical task, amidst a jumble of innumerable facts, which only a solid doctrine can lead them to correctly classify, predict, and master.

$\$ 4$ The eventuality of inversion of course increases as the number of actants increases. This is why the handling of verbs with three actants is so riddled with pitfalls, as we have seen above (Chapter 106, \$2).

$\$ 5$ It should be noted that the traps that accompany the inversion of actants vary according to the different actant structures encountered in different foreign languages. We have already seen (Chapter $106, \$ 13$, and $108, \S 9$ ) that the verb corresponding to the English verb teach has two second actants in Latin. Yet the French equivalent enseigner is formed with the 
subject taught as the second actant and the person to whom it is taught as the third actant. The result of this is that the Latin second actant representing the person to whom the subject is taught must become the third actant in French: Lat. Doceo pueros grammaticam '(I) teach the boys grammar', Fr. J'enseigne la grammaire aux enfants 'I teach grammar to the boys'.

$\$ 6$ As for Russian, it uses an actant structure that is different from that of both Latin and French. It is the person to whom the subject is taught that is interpreted as the second actant. The Russian sentence Uču detej grammatike, if translated literally, keeping the Russian actant structure, corresponds to the French ${ }^{\star} J$ 'enseigne les enfants à la grammaire 'I teach the kids to grammar'. From this it follows that:

First: In order to translate the Latin sentence into Russian, the second actant must be changed to the third actant, not as in French to the person to whom the subject is taught (Lat. pueros $>$ Fr. aux enfants), but rather the subject taught (Lat. grammaticam, Rus. grammatike).

Second: In order to translate the Russian sentence into French, the Russian second actant detej must be changed to the French third actant aux enfants, and the Russian third actant grammatike to the French second actant la grammaire, and of course vice versa if the translation is from French to Russian.

$\$ 7$ Concerning the verb 'teach', the comparative actant structure of Latin, French, and Russian is summarized in the following table:

\begin{tabular}{lll}
\hline & Person who is taught & Subject taught \\
\hline Latin & second actant & second actant \\
French & third actant & second actant \\
Russian & second actant & third actant \\
\hline
\end{tabular}

$\$ 8$ This table brings out the extreme complexity that results from such a collection of correspondences, and it gives an idea of the complications which must be faced when a verb taking three actants has a different actant structure across languages. It is clear that it is easy to get confused and that the lost polyglot cannot find his way without some guidance in the form of a solid theory of the inversion of actants.

\$9 Knowledge of true actant structure is the only means of guiding the user of a foreign language through such a maze, provided of course that the user does not consider it an abstract and rigid schema, but rather a source of inspiration to understand the spirit in which the language must be felt and thought. Therefore, in Russian, even practical knowledge of the inversion of the second and third actants for 'teach' in relation to French enseigner is a fragile and limited acquirement, if in reality everything independently lies on knowledge of the verb apprendre 'learn', since the two issues are connected and it is worth relating them to the structural conception they depend on, namely to their actant structure. 
\$10 This brings out the following facts: the verb enseigner, which is trivalent, behaves like the semantic causative of the verb apprendre, which is divalent: enseigner quelque chose $\dot{a}$ quelqu'un 'teach something to someone' is in fact the semantic equivalent of faire apprendre quelque chose à quelqu'un 'make someone learn something'. Yet the Russian is so aware of this equivalency that, if he translates the idea of enseigner with the verb učit', which is etymologically causative (cf. Chapter $113, \$ 7$ ), he resorts to expressing the idea of apprendre 'learn' with the recessive voice of the same verb expressed using the marker -sja: učit'sja, which is etymologically reflexive (Chapter $115, \S 3,4$, and 18). From this point on, it is normal that if the second actant, which denotes the person to whom the subject is taught, is identified with the first actant in order to reduce the number of actants by one, the actant denoting the subject taught remains a third actant (cf. Chapter 108, \$5) in the recessive verb as well as in the causative verb from which it arises. This is why the Russian verb učit'sja is constructed with the dative of the subject taught; the Russian speaker, thinking Anton učit Borisa grammatike, lit. 'Antoine teaches Boris to the grammar', is automatically led to think Anton učitsja grammatike, lit. 'Antoine teaches himself to the grammar' with the same actant structure, in other words limiting himself to replacing the second actant Borisa with the reflexive index -sja. It is easy to see that the foreigner wishing to learn Russian in detail and wishing to think in Russian can only accomplish this goal by relating the two verbs $u c ̌ i t^{\prime}$ and $u c ̌ i t^{\prime}$ sja to the same concept of actant structure.

\section{Chapter 124. Inversion of actants and circumstants}

\$1 It is frequent for circumstants to be involved in the phenomena of actant inversion. Actants can be replaced by circumstants, or vice versa, during translation to another language.

\$2 The complement of price in English is considered a second actant: The book costs what? It costs ten pounds. In Latin on the other hand, the complement of price is a circumstant for which the marker is the ablative, which means that the verb constare/stare with the meaning 'cost' is constructed with the ablative: Liber pretio magno stat, lit. 'The book costs a large price', i.e. 'The book is expensive'. The translation from Latin to English therefore entails the transformation of the circumstant into a second actant.

$\$ 3$ The same holds of the Latin verb interdicere 'forbid', which is constructed in Latin with the third actant of the person who is banned from doing something and the circumstant of the thing that is forbidden, which is in the ablative: interdicere alicui aliqua re, lit. 'forbid to someone about something. In French however, while the person who is banned from doing something is also construed as a third actant, the thing that is forbidden is interpreted as a second actant, and the French equivalent is therefore interdire quelque chose à quelqu'un, lit. 'forbid something to someone'. The ablative circumstant alique re hence becomes the second actant quelque chose in the French translation. 
$\$ 4$ An analogous phenomenon can be seen for the verb emprunter 'borrow', which is interpreted in French as a verb with three actants and follows the actant structure of the verb donner 'give'. This association occurs by virtue of the principle discussed above (Chapter $106, \$ 5)$, according to which trivalency is not only the trait of verbs of giving, but also of their opposites, and because emprunter is the opposite of prêter 'loan,' ${ }^{68}$ which is no more than a variant of donner, since a loan is a provisional giving, subject to the obligation of returning the item. This is the reason why the French say emprunter quelque chose $\dot{a}$ quelqu'un, lit.'borrow something to someone', i.e. 'borrow something from someone'.

$\$ 5$ In German and English, the person who loans something is not interpreted as a third actant (having a more concrete attributive value and consequently being unable to apply to the exact opposite of an attribution), but rather as a circumstant that indicates the origin. The German equivalent is etwas von jemandem leihen or borgen 'borrow something from someone, which German speakers often wrongly translate into French according to their substrate with the incorrect French ${ }^{*}$ emprunter quelque chose de quelqu'un.

$\$ 6$ The correct translation from German to French requires the circumstant to be transformed into a third actant and the translation from French to German requires on the other hand that the third actant be changed to a circumstant.

\$7 The same is true of the verb acheter 'buy': Ger. etwas von jemandem kaufen 'buy something from someone', Fr. acheter quelque chose à quelqu'un, lit. 'buy something to someone'.

$\$ 8$ Latin takes on the same structure as German: emere aliquid ab aliquo 'buy something from someone', and for this reason the sentence Ranae... regem petiere ab Joue 'The frogs demanded a king from Jupiter' (Phaedrus, 1, 2, II) must be translated into French with Les grenouilles demandèrent un roi à Jupiter.

$\$ 9$ However, it is possible for a French circumstant to correspond to a Latin first actant. This is the case in the following Latin sentence: Potest mihi denegare occupatio tua (Cicero, Ad familiares, V, 12), lit. 'Your occupation can refuse it to me.' In order to translate in the spirit of French, the Latin first actant occupatio tua 'your occupation/engagement' must be transformed into the French circumstant à cause de tes occupations 'due to your

168. Foreign speakers, at least those from central Europe, are often not aware of the existence of the verb emprunter 'borrow' and they substitute the verb prêter 'loan'. They may therefore say Je n'ai pas reçu mon mandat, alors je vais prêter de l'argent à mon ami 'I did not receive my money order, so I lent money to my friend', when they meant to say 'borrowed money from my friend'. Their use of the verb prêter in French should therefore not be trusted, since they often say the opposite of what they intended to say, and it is not always easy and sometimes not even possible to know exactly what they meant to say. Therefore with the sentence J'ai prêté de l'argent à mon ami, et il ne me l'a pas refusé 'I loaned money to my friend and he accepted it', the foreign speaker often intends to say that his friend agreed to loan him money, whereas his French interlocutor understands that he is the one who loaned money to his friend, who accepted it. 
engagements': Tu peux me le refuser à cause de tes occupations 'Due to your engagements, you can deny me it'.

\$10 As with the inversion of actants, there can be double inversion of actants and circumstants. We will first examine the inversion of an actant and a circumstant in addition to that of two actants.

$\$ 11$ This occurs in the Latin sentence Frumentum exercitui deerat 'The army lacks wheat', which corresponds to the French sentence L'armée manquait de blé. ${ }^{169}$ The Latin third actant exercitui 'army' becomes the first actant l'armée in French, whereas the Latin first actant frumentum 'grain' becomes the French circumstant de blé. The situation is the same in the Latin sentence Tibi tot civium neces impunitae fuerunt, Eng. You were not punished for the death of so many citizens.

$\$ 12$ In the following sentence, an English second actant becomes a Latin third actant and a Latin second actant becomes an English circumstant: Lat. Gratulor tibi victoriam, Eng. I congratulate you on your victory.

\$13 On the other hand, a German circumstant is translated as an English first actant, whereas the German first actant corresponds to the English second actant in the following sentence: Ger. Zum Ausschuss gehören fünf Deutsche, Eng. The committee contains five Germans.

$\$ 14$ Finally, double inversion can simultaneously concern a circumstant that becomes an actant and an actant that becomes a circumstant. This is the case with the Latin sentence Tua scelera dii in nostros milites expiaverunt. The English translation The gods have punished our soldiers for your sacrileges is obtained by translating the Latin circumstant in nostros milites with the English second actant our soldiers, and the Latin second actant tua scelera with the English circumstant for your sacrileges.

\section{Chapter 125. Metataxis and the passive}

\$1 The translation from one language to another, or even a different formulation of the same idea in the same language, quite often leads to a change in the diathesis of the verb, which results in a change in the actant structure. In such cases, the inversion of actants and circumsants is made more complicated by a change in diathesis.

\$2 The simplest example is the change of the active to the passive. It is clear that the actant structure will be automatically reversed in the changeover, since one is the opposite of the other.

169. Translators' note: We have added the underlines here to help show the correspondences. 
$\$ 3$ The second actant of the active verb becomes the first actant of the passive verb, and the first actant of the active becomes the counter-subject of the passive (Chapter 51, $\$ 16-18)$. And of course the opposite transformation occurs in the passage of the passive to the active.

$\$ 4$ Since French has a preference for the active diathesis, and given that the passive was developed almost uniquely for translating foreign languages such as Latin and German (cf. Chapter 102, \$8), it is the passage of the passive to the active that occurs most often when translating to French. But in certain cases, which have mostly to do with stylistic considerations, both active and passive diatheses can be used, and such cases are beneficial for studying the exactness of the actant relations discussed in the preceding paragraph: Alfred will sing God Save the Queen $\rightarrow$ God save the Queen will be sung by Alfred.

$\$ 5$ Metataxis of the active and passive is especially frequent when the translation is from Latin to French, or vice versa. The passive Latin sentence Lex data est a sapiente 'The law was created by a wise man', can be translated into French by changing the passive diathesis to an active one, causing an inversion of actants: C'est un sage qui a fait cette loi 'It was a wise man who created this law'

$\$ 6$ Metataxis of the active and passive does not exclude the possibility of a concurrent semantic reversal of the verb. Take for example the verb delight; it has a opposite meaning to that of like insofar as the actants must be reversed in order to pass from one to the other: Anthony likes reading $\rightarrow$ Reading delights Anthony. If Latin employs the verb delight and English the verb like, and if Latin employs the passive diathesis and English the active diathesis, the following correspondence is obtained: Lat. Antonius lectione delectatur $\rightarrow$ Eng. Anthony likes to read. The two simultaneous reversals of actants necessary for the translation from Latin to English - even though they nullify the reversal of the first actant which remains the same in both languages - complicate, on the other hand, the question of the other actant, which is represented in Latin by the ablative lectione (cf. chaper 51, $\$ 18$ and Chapter 52, \$18) and by the infinitive second actant to read in English.

\section{Chapter 126. Metataxis and causatives}

$\$ 1$ While the metataxes provoked by the transposition from the active diathesis to the passive and vice versa are relatively simple, the operation becomes more complicated if the causative voice features in either the source or target language, as its use raises some delicate questions, which can easily create confusion. First of all, it is possible for the causative verb to be synthetic in one language but analytic in the other. Such is the case for a quite large number of verbs, notably in Greek, German, and Russian in relation to French. But for there to be true metataxis and not simply the use of a different morphological marker, the auxiliated that is constructed with the factitive auxiliary in one language must be at 
least partially contained in the synthetic factitive verb of the other language. This case is quite rare because it supposes that the two languages possess the means to express the same semantic combination while distributing it differently such that the verb that is constructed with the causative is synthetic in one language but analytic in the other. In other words, the verb is analytic in the language with the synthetic causative and synthetic in the language with an analytic causative. The result is that since the importance of the semantic content of one of the verbs compensates for that of the other, the difference between the two is lifted as soon as they appear together forming a single semantic unit. This is the case in the German expression holen lassen 'have get', which expresses the same semantic complex as French aller chercher, lit. 'go seek', 'fetch', although its semantic apportionment is different in the two languages. In German the marker of the causative diathesis is analytic and is represented by the causative auxiliary lassen 'have', whereas in French it is included in the meaning of the synthetic causative envoyer, which is analyzed semantically as faire aller 'make go'. In German however it is the idea of aller 'go' that is included semantically in the synthetic verb holen 'get', which also contains the idea of 'find', whereas this idea is expressed analytically in French chercher. While the similarity of the semantic complex is expressed by different means in the two languages, the meaning that results from the addition of the varying parts is the same. This situation can be summarized with the following schema:

\begin{tabular}{|c|c|c|c|}
\hline \multirow{2}{*}{ German } & $\begin{array}{c}\text { Analytic verb } \\
\text { (factitive auxiliary) }\end{array}$ & \multicolumn{2}{|c|}{ Synthetic verb } \\
\hline & lassen & \multicolumn{2}{|r|}{ holen } \\
\hline $\begin{array}{l}\text { Idea } \\
\text { expressed }\end{array}$ & 'have' & 'go' & 'get' \\
\hline \multirow{2}{*}{ French } & \multicolumn{2}{|l|}{ envoyer } & chercher \\
\hline & \multicolumn{2}{|c|}{ Synthetic verb (causative) } & Analytic verb \\
\hline
\end{tabular}

$\$ 3$ But the majority of the metataxes resulting from the use of the causative voice are due to a difference in the number of actants. By definition this difference involves one more actant than the other, such that the two languages present different actant structures, which necessitates a fundamental transformation during translation, the only option being to represent the additional actant in one language using a circumstant in the other.

$\$ 4$ We have seen (Chapter 108, \$5) that in French when verbs with two actants become causatives with three actants, the intervention of a new actant has the effect of relegating the first actant to the role of a third actant, and the new actant itself becomes the first actant of the causative verb.

\$5 The specifically French process that consists of substituting a new actant for an old one in the place of the first actant is far from being as well developed in Russian and German. These types of languages prefer not to use the causative, and they simply present 
the instigator in the form of a causal circumstant instead, which has the effect of leaving the actants in their position.

$\$ 6$ When translating these types of expression from German or Russian into French, this particularity requires the transformation of the verb into a causative verb and the causal circumstant into a first actant. This enables the construction of much more idiomatic sentences in French. This is one of the reasons why it is much more difficult to translate the French causative into German or Russian, languages where its use is much scarcer than in French and which often resort to using a different actant structure.

$\$ 7$ All metataxes of this sort involve double inversion, since the circumstant of the foreign language becomes the first actant in French, and the original first actant is relegated to the role of a second actant.

$\$ 8$ It is worth reflecting on the mechanism of this metataxis and the resulting equivalencies, which are the key to many translations, not only from Latin, but from German, Russian, and in general from all such foreign languages.

$\$ 9$ Take for example the Latin sentence Ipsa liberatione et vacuitate omnis molestiae gaudemus 'Liberty and absence of pain alone are responsible for our joy' (Cicero, De finibus... I-11-37), which must be translated into French with C'est uniquement l'exemption et l'absence de toute douleur qui nous met en joie. The Latin circumstant ipsa liberatione... becomes the first actant exemption... in French, and the Latin first actant, which is part of the verb gaudemus, appears in French as the second actant nous.

$\$ 10$ Metataxis of this sort is extremely frequent when translating from German to French, and translations from this language would be hopeless without recourse to the indicated procedure, a fact that has already been recognized by the good theoreticians of the comparative typology of German and French.

$\$ 11$ A. Malblanc gives excellent examples of this in the chapter entitled Encore "faire" in his insightful study Stylistique comparée du français et de l’allemand (\$138): Ger. Davon zitterten die Fensterscheiben 'The window panes shook from that' $\rightarrow$ Fr. Cela fit trembler les vitres 'It made the window panes rattle'; Ger. Bei diesen Worten erbleichte Hans 'At these words, Hans went pale' $\rightarrow$ Fr. Ces paroles firent pâlir Jean 'These words made John go pale'; Ger. Vor dem nahenden Feind entflohen die Einwohner in die Wälder 'Before the approaching enemy, the inhabitants fled into the forests' $\rightarrow$ Fr. L'approche de l'ennemi fit fuir les habitant dans les forêts 'The enemy's approach made the inhabitants flee into the forests'.

$\$ 12$ Commenting on these instances of metaxis, A. Malblanc quite rightly writes:

"In German the idea of causality underlying French factitive verbs disappears; German translates the idea by choosing verbs with the appropriate image, ... only acknowledging the causal liaison as the implicit and objective judgment in terms of a demonstrative adverb (davon). Moreover German will often objectify the causal judgment expressed directly by faire, by making it implicit in a preposition." 
This is another way of acknowledging that the German circumstant davon, bei diesen Worten corresponds to a first actant in French, e.g. cela, ces paroles, whereas the German first actant die Fensterscheiben, Hans corresponds to a French second actant les vitres, Jean.

$\$ 13$ Such issues are often complicated by other processes of translation that prevent them from appearing in their simplest form and which make them seem less clear at first sight: Ger. Sie schienen die Grösse seiner Handlung ganz über dem Verbotenen, das sie so nebenher an sich hatte, zu übersehen 'They seemed to overlook the greatness of his act due to its incidental forbiddenness' $\rightarrow$ Fr. Ce que son action comportait subsidiairement de défendu semblait les empêcher d'en voir la grandeur 'What was incidentally forbidden in his action seemed to prevent them from seeing its greatness'. When the phenomenon is disengaged from the grammatical envelope surrounding it and reduced to its essential features, we see that the German circumstant über dem Verbotenen, lit. 'beyond the forbidden', corresponds to the French first actant ce que son action comportait subsidiairement de défendu, and the German first actant Sie 'they' corresponds to the French second actant les 'them'.

$\$ 14$ The Scandinavian languages conceive of this type of sentence in the same way as German. For example, Dan. Det er en almindig Opfattelse, at Jorden er blevet lille, efter at Afstandene formindeker Aar for Aar of Fly, Biler og Motorbaade $\rightarrow$ 'It is a very widespread idea that the earth has shrunk since distances have become shorter through the years due to planes, cars, and motor vessels'.

\$15 Metataxis between Russian and French is of the same nature as metataxis from Latin and German: Rus. Iz-za šuma ničego ne slyšno, lit. 'Because of the noise nothing is heard' $\rightarrow$ Fr. Le bruit empêche de rien entendre 'The noise prevents (one) from hearing anything'. As before for German and Latin, the Russian circumstant iz-za šuma 'because of the noise' becomes the French first actant le bruit 'the noise', and the Russian first actant ničego 'nothing' becomes the French second actant rien 'nothing'.

$\$ 16$ It is necessary to refer to metataxis in the translation of the title of the famous comedy by Griboyedov Gore ot uma, which is generally translated somewhat approximately as $L e$ Malheur d'avoir trop d'esprit 'The misfortune of being too intelligent'. Yet if we take note of the nature of metataxis, as has just been shown, it is evident that a translation should take on the following structure: L'esprit fait souffrir 'Intelligence causes suffering' or L'esprit rend malheureux 'Intelligence makes one unhappy'.

$\$ 17 \$ 18 .^{170}$

$\$ 19$ A variant of this is where the first actant in the foreign language corresponds to a third actant in French. This is the case in the German sentence Dadurch kann ich Zeit gewinnen,

170. Translators' note: Two irrelevant paragraphs have been omitted. 
lit. 'Through that I can gain time'. The corresponding French is Cela me fait gagner du temps 'That makes me gain time'. The German actant dadurch 'through that' is represented by the first actant cela in French, and the German first actant ich is no longer represented by a French second actant, but by the third actant $m e$.

$\$ 20171$

\$21 Examples of this sort are frequent, especially when the idea to be expressed is not that of teaching, namely faire apprendre 'make learn', but of faire oublier 'make forget', which is practically impossible to express in a number of languages unless a radically different actant structure from that of French is used. The causer of the forgetting, instead of assuming the role of the first actant as in French, is presented here as a causal circumstant expressing the cause of the forgetting; Ger. Die Malerin hatte ich über der Schriftstellerei ganz vergessen 'I had completely forgotten the painter due to my writing' (Hermann Hesse, Peter Kamenzind, p. 53) $\rightarrow$ Fr. Mon activité d'écrivain m'avait fait complètement oublier la femme peintre 'My writing had made me completely forget the woman painter'.

$\$ 22$ The same correspondence occurs between Latin and English. Take the Latin sentence Dum obsequor adulescentibus, me senem esse sum oblitus. ${ }^{172}$ The most elegant way to translate this meaning into English is to transform the circumstantial clause dum obsequor adulescentibus into a nominal node and to make it the first actant of the causative verb: $M y$ complaisance toward young people made me forget my old age. ${ }^{173}$

$\$ 23$ Finally, the same mode of expression is encountered in Russian: Čerez nix ona zabyla cvoju černuju bedu (Dostoyevski, The Idiot, VI), lit. 'By them she forgot her dark trouble', Fr. Ils lui firent oublier sa misère noire 'They made her forget her dark trouble'. As in German and Latin, the Russian circumstant čerez nix becomes the French first actant $i l s$, and the Russian first actant ona becomes the French third actant lui.

$\$ 24$ The notion of the causative verb is so developed in French that it is common, when translating foreign sentences, to use sentences that are not directly causative, but that are constructed in the same manner. The existence of the causative auxiliary faire often gives rise, during translation, to the use of the verb voir, as an auxiliary which increases by one the number of actants: Ger. Zu dieser Zeit wurde ein großer Dichter geboren 'At this time a great poet was born', Fr. Cette époque vit naître un grand poète 'This time saw a great poet born.' ${ }^{174}$

171. Translator' note: An irrelevant paragraph has been omitted.

172. Cicero, De Oratore, II, 4, 15 .

173. Riemann \& Goelzer: Grammaire latine complète, according to $\$ 110$.

174. A. Malblanc, Pour une stylistique comparée du français et de l’allemand, 2nd edition 1963, \$197f. 


\section{Chapter 127. Metataxis and anti-causative}

\$1 The French causative can also be represented, under the same conditions, by its opposite, which can therefore be called the anti-causative. Of course the analytical marker of the anti-causative is no longer the positive auxiliary faire, but one of the verbs expressing the opposite idea, such as the semantically negative auxiliary verb empêcher 'prevent, hinder, stop': empêcher quelqu'un de boire 'stop someone from drinking', which is in fact the opposite of faire boire quelqu'un 'make someone drink'.

$\$ 2$ Take for example the Latin sentence Solem prae iaculorum multitudine et sagittarum non videbitis 'You will not see the sun from the multitude of bolts and arrows', where the negative idea is expressed in Latin by non 'not'. This sentence is elegantly translated into French with La multitude des traits et des flèches vous empêchera de voir le soleil 'The multitude of spears and arrows will prevent you from seeing the sun. The Latin circumstant prae iaculorum multitudine becomes the first actant la multitude des traits in French, and the Latin first actant included in the verb videbitis becomes the French second actant vous 'you', which does not prevent the Latin second actant solem from remaining a second actant as the French le soleil.

$\$ 3$ The same thing occurs in the metataxis of At prae lacrimis non queo plura dicere 'Due to tears I cannot say more' (Cicero, à Tullia, 29, IV, 58) $\rightarrow$ Fr. Mais les larmes m'empêchent d'en dire advantage 'But the tears prevent me from saying more'.

$\$ 4$ The anti-causatve empêcher is in a direct semantic relationship with a certain number of other French verbs that proceed semantically from each other and only involve simple ideas such as those of causation and negation. If the opposite of faire is empêcher, then ne pas empecher 'not hinder' is permettre 'permit, allow', and ne pas permettre 'not permit' is défendre 'forbid, prohibit'. We can see how a large number of words pertain to several simple notions. These are elementary ideas that constitute a semantic system comparable to the elementary system that organic chemistry represents in its organization of matter. But organic chemistry, a material science, is incomparably more advanced than the corresponding semantic system, which is barely out of its preliminary stages and the utility of which is far from being acknowledged. However, who could not recognize the potential advantages for translation techniques of detailed knowledge of the economy of the semantic system such as the system represented by the verbs faire, empêcher, permettre, défendre and those represented by other semantically connected verbs, which it is necessary to manage when solving the problems that metataxis poses (cf. Chapter 106, \$9)?

$\$ 5$ Hence the verb empêcher is very useful for reflecting the idea expressed by the Russian verb davat' in the sense of 'allow', when it is used in the negative: Groza ne daët mne spat', lit. 'The storm does not allow me sleeping' $\rightarrow$ Fr. L'orage m'empêche de dormir 'The storm is preventing me from sleeping. 
$\$ 6$ The French anti-causative can itself be used negatively. In this case, it should be noted that although the anti-causative is the opposite of the causative, the negative anti-causative does not have exactly the same semantic nuance as the causative. Ne pas empêcher quelqu'un de boire 'not prevent someone from drinking' is not the same thing as faire boire quelqu'un 'make someone drink. The second formulation expresses an activity that is not implied by the negation of the opposite activity in the first.

$\$ 7$ This quite subtle nuance, which the use of the negative anti-causative provides, corresponds almost exactly to what German expresses with the circumstant meinetwegen 'as far as I am concerned': Meinetwegen dürfen Sie rauchen 'You can smoke as far as I'm concerned' $\rightarrow$ Fr. Je ne vous empêche pas de fumer 'I am not stopping you from smoking.'

$\$ 8$ When translating from Russian, as in German, the French equivalent often makes use of the negative anti-causative: Rus. Ja vsë ravno eё ljublju, lit. 'I like it just the same' or 'I like it regardless' $\rightarrow$ Fr. Ça ne m'empêche pas de l'aimer 'That doesn't prevent me from liking it'.

$\$ 9$ Like German, Russian possesses a special adverb for expressing the same nuance as the French anti-causative, the word požaluj, which is always difficult to translate into French or English. It can be translated into English with if you want, I'm good with that, OK, right, etc..., Russian: Kolpaki, požaluj, možno nadet' i čistye (Gogol, The Inspector General, I, 1), lit. 'It is possible, conceded, to give them clean hats' $\rightarrow$ Eng. OK! Let them have clean hats!

$\$ 10$ But the best translation most often involves using the negative anti-causative: Rus. Tam... požaluj opjat' možete ego povesit', lit. 'You can požaluj hang it up there' $\rightarrow$ I'm not preventing you from hanging it up there.

\section{Chapter 128. Semantic reversal of nodes connected vertically}

$\$ 1$ Another type of metataxis is as follows: When a governing node is in connection with a subordinate node, it can occur that the repartitioning of exprimendes (cf. Chapter 16, \$1) between the two nodes is reversed, so that the idea expressed in one language by the governing node is expressed by the subordinate node in the other language and vice versa.

$\$ 2$ There is therefore a sort of criss-crossing between the two languages, and while the connection remains structurally the same in the two languages, there is nevertheless a semantic reversal during the changeover from one language to the other, which results in the hierarchical swapping of the exprimendes' positions from one language to the other.

$\$ 3$ The situation appears clearly in the stemma; while the symbol (cf. Chapter 33) expressing the structural value of each node remains the same, the exprimendes are head-to-tail in relation to each other.

$\$ 4$ Take for example the German sentence Die grosse Gefahr entmutigte ihn nicht 'The great danger did not intimidate him. A Malblanc proposes the French equivalent $\mathbf{L a}$ 
grandeur du danger ne le décourageait pas 'The greatness of danger did not deter him'. We can see that while both languages represent this with an identical structure containing a governing noun (Ger. die Gefahr, Fr. la grandeur) and a subordinate adjective (Ger. gross, Fr. $d u$ danger, which is the equivalent of an adjective as will be demonstrated below (Chapter 192, \$1-3)), on the other hand the disposition of the exprimendes is reversed, since the idea of danger is expressed by the governing node in German and by the subordinate node in French, whereas the idea of greatness is expressed by the subordinate node in German and by the governing node in French.

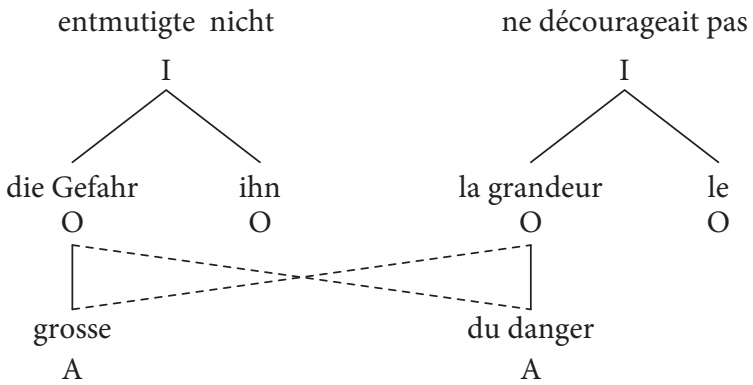

Stemma 222

Stemma 223

\$5 The stemmatization of these two sentences enables us to verify that even though the symbolic stemma (cf. Chapter 33, \$8) is the same, the exprimendes on the other hand appear here head-to-tail, emphasized by a set of lines showing the semantic correspondence of one stemma to the other (cf. Stemma 222 and 223).

$\$ 6$ The mode of expression in French is more abstract here than in German, since the idea of greatness, the abstract nature of which corresponds in principle to the adjectival structure (cf. Chapter $84, \$ 8$ ), is represented by the noun grandeur, which means that the noun danger must be represented by the adjectival expression $d u$ danger.

$\$ 7$ This is even more clear in the Latin expressions alta arbore, in media arbore, Eng. at the top of the tree, in the middle of the tree, where the Latin, which is closer to reality, expresses the concrete object of the 'tree' with the noun arbore, and it expresses the more abstract notion of 'height' with the adjective alta, whereas English is more inclined to mirror the conception of the phrase, representing the notion of 'tree' with the adjectival expression of the tree and conversely, expressing the notion of its 'height' with the noun (the) top.

$\$ 8$ The Latin adjectival subordinate can be represented by a noun in apposition: post Ciceronem consulem, Eng. after Cicero's consulate. Here again the Latin is closer to reality, since it is a concrete being that is expressed by the noun Cicero, while the more abstract notion of his function as consul is expressed by the noun consulem, which as an apposition functions like an adjective, whereas English uses consulate as the abstract noun and Cicero's as the equivalent of an adjective. 
$\$ 9$ In such cases, Latin makes heavy use of nominal forms of the verb, in particular of present participles and especially anterior participles, and of the gerundive, which provides it with its preferred forms of expression.

\$10 If the word that Latin uses to fill the role of the subordinate adjective is a participle, it is generally represented in French or English by an abstract noun.

$\$ 11$ For example the present participle in the sentence Mortem venientem nemo hilaris excipit (Seneca, Letters, 30, 12) ${ }^{175} \rightarrow$ Eng. No one receives the approach of death with gaiety. Here the exprimende represented in Latin by the subordinate present participle venientem 'coming' is represented in English by the governing noun the approach and in contrast, the exprimende represented by the governing noun mortem in Latin is represented by the adjectival subordinate group of death.

$\$ 12$ In the following sentences however, there is an anterior participle:

\begin{tabular}{|c|c|}
\hline Latin & English \\
\hline $\begin{array}{l}\text { Lacedaemoniis nulla res tanto erat } \\
\text { damno quam disciplina Lycurgi } \\
\text { sublata. (Livy, XXXVIII, 34, 9) }\end{array}$ & $\begin{array}{l}\text { Nothing caused Lacedaemon as } \\
\text { much pain as the loss of the } \\
\text { constitution of Lycurgus. }\end{array}$ \\
\hline $\begin{array}{c}\text { Ab urbe oppugnanda Poenum } \\
\text { absterruere conspecta moenia. } \\
\quad(\text { Livy, XXIII, I, 10) }\end{array}$ & $\begin{array}{c}\text { The sight of the walls } \\
\text { deterred the Carthaginian from } \\
\text { attacking the city. }\end{array}$ \\
\hline $\begin{array}{l}\text { Angebant virum Sicilia } \\
\text { Sardiniaque amissae. } \\
\quad \text { (Livy, XXI, I, 5) }\end{array}$ & $\begin{array}{c}\text { The loss of Sicily and Sardinia } \\
\text { tormented this man. }\end{array}$ \\
\hline Urbem captam hostis diripuit. & $\begin{array}{l}\text { After the capture of the city, } \\
\text { the enemy pillaged it. }{ }^{195}\end{array}$ \\
\hline$a b$ Urbe condita & $\begin{array}{c}\text { since the foundation } \\
\text { of the City. }\end{array}$ \\
\hline
\end{tabular}

It is easy to observe that the Latin subordinate anterior participles sublata 'lost', conspecta 'viewed', amissae 'lost', captam 'captured', and condita 'founded' correspond semantically to the English governing nouns the loss, the sight, the loss, the capture, the foundation, and that on the other hand, the Latin governing nouns disciplina 'constitution', moenia 'walls', Sicilia... 'Sicily', urbem 'city', Urbe 'City' correspond to the English adjectival subordinate groups of the constitution, of the walls, of Sicily, of the city, of the City.

175. Cf. Riemann \& Goelzer, Grammaire latine complète, 1902, p. 73.

176. Cf. Riemann \& Goelzer, ibid., 1902, p. 57, 354, 308. 
$\$ 13$ Finally, Latin subordinate verbal adjectives frequently correspond semantically to English governing infinitives and on the other hand Latin nouns governing verbal adjectives frequently correspond semantically to English second actants of the verb:

\begin{tabular}{cc}
\hline Latin & English \\
\hline $\begin{array}{c}\text { cupidus videndae urbis } \\
\text { Tanto oneri sustinendo } \\
\text { impar est. }{ }^{196}\end{array}$ & $\begin{array}{c}\text { eager to see the city } \\
\text { He does not have the strength to } \\
\text { bear such a great burden. }\end{array}$ \\
\hline
\end{tabular}

The Latin verbal adjectives videndae 'seeing' and sustinendo 'bearing' correspond semantically to the English verbs see and bear, whereas the Latin governing nouns correspond to the English second actants the city and a great burden.

$\$ 14$ By contrast, it is possible for a Latin abstract noun to correspond to an English verbal adjective, especially when the two notions in connection present a certain degree of abstraction, such that neither of them has a character that is clearly more concrete than the other:

\begin{tabular}{|c|c|}
\hline Latin & English \\
\hline $\begin{array}{c}\text { Non sine varietate doctrinae } \\
\text { satis politus et sapiens esse } \\
\text { orator potest. } \\
\text { (Cicero, de Oratore, III, } 21,80 \text { ) }\end{array}$ & $\begin{array}{c}\text { Without varied knowledge an } \\
\text { orator can neither have enough tact } \\
\text { nor enough taste. }\end{array}$ \\
\hline $\begin{array}{c}\text { contumelia maledicti } \\
\text { (Cicero, pro Sulla, } 8,25)\end{array}$ & a biting insult \\
\hline $\begin{array}{c}\text { gravitas dicendi } \\
\left(\text { Cicero, pro Sextio, 62, 130) }{ }^{197}\right.\end{array}$ & rousing eloquence \\
\hline
\end{tabular}

The equivalent of the adjective in Latin is a genitive (doctrinae, maledicti, dicendi), whereas it is a verbal adjective in English (varied, biting, rousing).

\$15 All the facts cited in this chapter illustrate the complete independence of structure from semantics (Chapter 20, \$17 and Chapter 120,\$8), since structural correspondences do not match with semantic correspondences. A comparison of stemmas 222 and 223 may help to make this situation more clear.

\section{Chapter 129. Change of the structural center}

\$1 When the semantic reversal of connected nodes involves a verbal node, the structural center changes.

177. Cf. Riemann \& Goelzer, ibid., p. 58.

178. Cf. Riemann \& Goelzer, ibid., pp. 308 and 373. 
$\$ 2$ Not all languages choose the same semantic exprimende for the verb at the structural center of the sentence. It is difficult to imagine that there can ever be hesitation between the verb itself and one of the actants, the two being of different natures, but there is often an opposition between the verb and one of its circumstants, as if the verb itself were ultimately just a circumstant promoted to the dignity of the structural center (adverb of quiddity, Chapter 37, \$36f.).

$\$ 3$ French therefore does not always choose the same circumstant as Latin, German, or Russian for the structural center. French has a preference for circumstants with a more abstract character than is the case in these other languages. And this is why M. Malblanc could quite rightly state that in the eyes of a French speaker,

"it seems that German is trying to exhaust the multiplicity of concreteness with the multiplicity of the verbs it uses" and "that the German verb...is more perceptually meaningful and expresses more relations than the French verb"."179

This is why the current author rightly establishes the opposition between the "image" verb of German, which refers semantically to what is real, and the "sign" verb of French, which is on the plane of understanding.

$\$ 4$ The situation is clear when the circumstant is expressed in Latin, German, or Russian by the type of word that expresses it most naturally, namely an adverb. In such cases it is easy to classify the numerous examples that illustrate this structure according to the nature of the adverb, depending on whether it is a temporal or locative adverb, an adverb of manner, etc.

$\$ 5$ In contrast, the abstract circumstant, which remains an adverb in Latin, German, and Russian, takes on the role of the structural center in French and the sentence is organized around this center, which therefore becomes the verb.

$\$ 6$ Whereas the most concrete circumstant assumes the function of the structural center in Latin, German, and Russian, and consequently figures as the verb, the same circumstant cannot assume any other role in French than that of a circumstant, and for this reason, if it is expressed by a verb, as is often the case, its verbal form must be changed to that of a circumstant. This is easy thanks to the use of one of the forms of the verb which, like the impersonal forms (infinitive, participle, and especially gerundive), are not strictly speaking verbal forms, but nominal and adverbial forms.

\$7 Take for example the Latin sentence Antonius modo profectus est 'Anthony has just left', in which the adverb modo 'just' is a temporal adverb used to express the recent past. French gives this adverb the verbal value of an auxiliary of the recent past using the verb venir 'come', whereas the idea of a departure expressed by the Latin verb profectus est 'has left' is

179. A. Malblanc, Pour un stylistique comparée du français et de l'allemand, $2^{\mathrm{e}}$ éd., 1963, \$37-39. 
rendered in French by the nominal form of the infinitive partir 'leave', itself preceded by the preposition de 'of', which makes it a circumstant. The result is the corresponding French sentence Antoine vient de partir (see Stemma 224 and 225).

$\$ 8$ German and Russian behave here exactly like Latin: Ger. Anton ist eben fortgegangen, Rus. Anton tol'ko čto ušël 'Anthony has just left'.

$\$ 9$ The same opposition appears if the German adverb expresses duration; Der Fluss steigt unaufhörlich 'The river is rising steadily' $\rightarrow$ Fr. Le fleuve ne cesse de monter 'The river is not ceasing to rise'. The same holds of Ger. vollends tun 'completely do', which corresponds to Fr. achever de faire 'finish doing'.

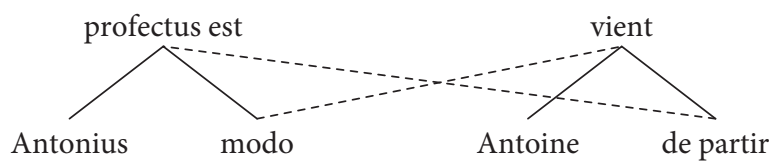

Stemma 224

Stemma 225

\$10 It is worth pointing to an adverb of location that can be employed with the value of a temporal adverb: the German comparative adverb weiter 'further', is often translated with the French verb continuer 'continue':

\begin{tabular}{cc}
\hline German & French \\
\hline $\begin{array}{c}\text { Lesen Sie weiter. } \\
\text { 'Read further. } \\
\text { Schreiben Sie weiter. } \\
\text { 'Write further.' }\end{array}$ & $\begin{array}{c}\text { Continuez à lire. } \\
\text { 'Continue to read.' } \\
\text { Continuez à écrire. } \\
\text { 'Cir glauben weiter, dass... } \\
\text { 'We think further that... }\end{array}$ \\
$\begin{array}{c}\text { Nous persistons à croire que... } \\
\text { 'We continue to think that...' }\end{array}$ \\
\hline
\end{tabular}

Weiter used with imperative value (cf. Chapter 37, \$39) alone corresponds to the French imperative continuez (cf. Chapter $77, \$ 11$ ) and it is often sufficient to translate the German adverb with the French verb in the imperative without having to be concerned about translating the German verb with a French adverb. This is the case in the expression Geben Sie den Salat weiter, lit. 'Give the salad further', which is translated as Passez la salade 'Pass the salad', or in the expression familiar to certain young middle school students, who, when seated at the end of a row, punch their neighbor saying: Ger. Gib das weiter!, lit. 'Give that

180. This example, as well as many of the examples that follow, is taken from Malblanc's Stylistique comparée du français et de l'allemand, Paris, $1963, \$ 124$, which contains an abundant collection of such cases, which we encourage the reader to discover. 
further' $\rightarrow$ Fr. Passe ça à ton voisin! 'Pass that to your neighbor', or simply Fais passer!, lit. 'Make pass!'.

$\$ 11$ Among the German temporal adverbs that correspond to French verbs, anfangs 'at first' and endlich 'finally' are worth mentioning; they express the order in which processes occur:

\begin{tabular}{cc}
\hline German & French \\
\hline anfangs tun \\
'do first' & $\begin{array}{c}\text { commencer par faire } \\
\text { 'begin by doing' } \\
\text { endlich tun } \\
\text { 'finally do' }\end{array}$ \\
Er zieht sich schnell an. & finir par faire \\
'He gets dressed quickly.' & 'll se dépêche de s'habiller. \\
\hline
\end{tabular}

$\$ 12$ What has just been said about temporal adverbs is also valid for adverbs of manner and similarity: Lat. Hac re careo aegre, lit. 'I reluctantly lack this thing' $\rightarrow$ Fr. J'ai de la peine à m'en passer 'I find it difficult to do without it'.

$\$ 13$ German makes heavy use of this type of adverb:

\begin{tabular}{|c|c|}
\hline German & French \\
\hline $\begin{array}{l}\text { Er leugnet hartnäckig. } \\
\text { 'He denies stubbornly.' }\end{array}$ & $\begin{array}{l}\text { Il s'obstine à nier. } \\
\text { 'He persists in denying.' }\end{array}$ \\
\hline $\begin{array}{l}\text { Sie hätten die Flotte beinahe } \\
\text { überrumpelt. } \\
\text { 'They would have almost } \\
\text { surprised the fleet.' }\end{array}$ & $\begin{array}{l}\text { Ils faillirent surprendre } \\
\text { la flotte. } \\
\text { 'They fell just short of } \\
\text { surprising the fleet.' }\end{array}$ \\
\hline $\begin{array}{l}\text { Man hat sogar gesagt... } \\
\text { 'One even said...' }\end{array}$ & $\begin{array}{c}\text { On a été jusqu’à dire... } \\
\text { lit. 'One has been until saying...' }\end{array}$ \\
\hline
\end{tabular}

By virtue of this same principle, the German adverb gern 'with pleasure' is translated with the French verb aimer 'like': Ger. Ich lese gern, lit. 'I read with pleasure' $\rightarrow$ Fr. J'aime lire 'I like to read'. The result of this is that the German comparative adverb lieber 'preferably' corresponds to the French verb préférer 'prefer', which has the comparative semantic value: Ger. Ich lese lieber, lit. 'I read preferably' $\rightarrow$ Fr. Je préfère lire 'I prefer to read'. This is the best way to translate the word aimer into German, the use of the German verb lieben 'love' being restricted to the expression of the idea of 'love. This is why J'aime le vin 'I like the wine' should not be translated, as is too often the case with beginners of German, with Ich liebe den Wein 'I love the wine', but with Ich trinke gern Wein, lit. 'I drink wine with pleasure'.

$\$ 14$ The following sentences appear to be of this type: Ger. Wir fahren bequemer 'We travel more comfortably by car', Fr. Il sera plus commode d'aller en voiture 'It will be more 
comfortable to go by car' (rather than by foot); Ger. Wir fahren besser $\rightarrow$ Eng. It is better for us to drive.

\$15 The semantic content of the German adverb very often corresponds to that of a French declarative verb. Sentences of this type can only be appropriately translated by using a declarative verb in French: Ger. Er ist bekanntlich schon tot, lit. 'He is already dead as is known' $\rightarrow$ Fr. On sait qu'il est déjà mort 'One knows that he is already dead' (cf. 226 et 227).

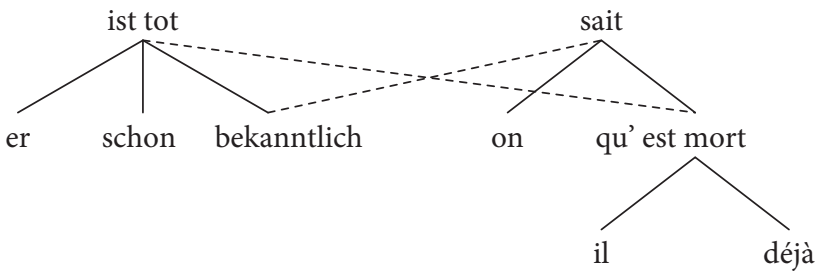

Stemma 226

Stemma 227

\$16 An analogous expression can be found in the German sentence Er ist angeblich angekommen 'He has supposedly arrived' $\rightarrow$ Fr. On prétend qu'il est arrivé 'One maintains that he has arrived', On le dit arrivé, lit. 'One says (of) him (that he has) arrived'.

$\$ 17$ Sometimes French expresses what would normally be declarative verb using an adverb. This is the case in the sentence Décidément, cet homme est fou 'Obviously, this man is crazy', which of course does not mean that he is crazy in an obvious manner, but rather that upon examination, the opinion is reached that he is crazy. The comparison of the stemma of this sentence and the explanation that we have given above brings out the fact that the sentence is perceived as having the same structural type as the German sentences cited above. Compare this with Fr. Après mûr examen, il est certain que cet homme est fou 'After examination, it is certain that this man is crazy' (cf. Stemmas 228 and 229). Undoubtedly this is why Fr. décidément 'obviously' expresses a nuance that is so difficult to represent in foreign languages, cf. also: Cet homme, assurément, n'aime pas la musique 'Quite clearly this man does not like the music' (Molière, Amphitryon, II, 1).

$\$ 18$ Latin here is like German:

\begin{tabular}{cc}
\hline Latin & French \\
\hline Melius peribimus & Il vaut mieux que nous périssions. \\
'We will die better.' & 'It is better that we die.' \\
(Livy, I, 13, 3) & \\
Insipienter sperat & Il a tort d'espérer. \\
'He hopes in vain.' & 'He is wrong to hope.' \\
\hline
\end{tabular}




\begin{tabular}{cc}
\hline Latin & French \\
\hline Haec dicuntur et creduntur & C'est la plus grande folie de dire \\
stultissime & et de croire de pareilles choses. \\
'Saying and believing this is & 'It is the greatest madness to say \\
most foolish' & and believe such things.' \\
(Cicero, de Natura deorum, II, 28, 70) & \\
\hline
\end{tabular}

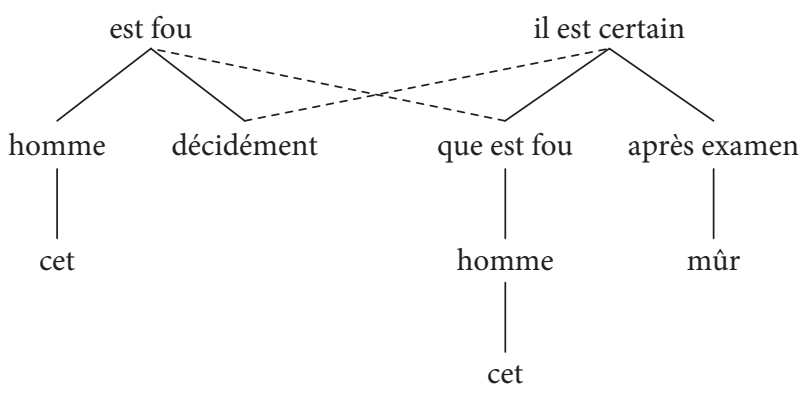

Stemma 228

Stemma 229

$\$ 19$ Knowledge of these types of correspondence often leads to good translations which would not occur by other means. An attempt to translate the Russian sentence Udivitel'no umirajut russkie ljudi, lit. 'Russians die in a surprising manner' (Turgenev, A Sportsman's Sketches, XVI, Death) into French with the same structure Les Russes meurent d'une façon étonnante would be futile. The Russian verb remains a verb in French, even though a much more adequate expression for the same idea can be obtained by changing the Russian adverb udiviltel' $n o$ 'in a surprising manner' into a French verb: Les Russes ont une façon étonnante de mourir 'Russians have a surprising manner of dying'.

$\$ 20$ In the same conditions, the German adverb of quantity commonly becomes a verb in French: Ger. Er trinkt $z$ u viel Wein 'He drinks too much wine' $\rightarrow$ Fr. Il abuse du vin 'He overdoes the wine'.

\$21 Finally, there is often good reason to treat the German negation nicht as a true adverb (cf. Chapter 92, \$10) and to translate it into French using a verb, the German verb being in turn translated into French with an infinitive preceded by a preposition. Thus in the German subordinate causal expression um dem Feind nicht zu begegnen 'to not encounter the enemy', the negation nicht is best rendered by the French verb éviter 'avoid', which results in the translation pour éviter de rencontrer l'ennemi 'to avoid encountering the enemy'.

\$22 Conversely, it is sometimes the German negation that assumes the role of the verb: Ger. Mit der Liebe ist nicht zu spassen $\rightarrow$ Fr. On ne badine pas avec l'amour 'One does not dally with love. The negation essentially becomes the governing node, along with the auxiliary ist, of $z u$ spassen 'joke, dally', from which it is therefore dissociated, whereas in French it remains subordinate to the governing node badine 'dally'. 


\section{Chapter 130. Resultative adverbs}

\$1 Among the adverbs that typically correspond to French verbs, note should be taken in particular of the German particles said to be separable, which are simply resultative adverbs indicating the result of the process rather than the way in which it takes place (cf. Chapter 37, \$40): Ger. Ich mache die Tür auf, lit. 'I make the door up' $\rightarrow$ Fr. J'ouvre la porte 'I open the door'; Ger. Ich mache die Tür $z u$, lit. 'I make the door to' $\rightarrow$ Fr. Je ferme la porte 'I close the door.' The separable particles auf 'up (open)' and $z u$ 'to (closed)' indicate the diametrically opposite result of the identical process expressed by the verb machen.

$\$ 2$ The German resultative $a b$ 'from' provides a series of good examples of the same phenomenon: abbetteln 'obtain by begging', abschmeicheln 'obtain by flattering', ablügen 'obtain by lying', abschwindeln 'obtain by deceiving'.

$\$ 3$ German $a b$ here expresses the result of separating something from someone and there is therefore little choice but to translate it using the French verb obtenir, whereas the German verb expresses the process by which the separation was obtained and can only be expressed in French using the gerundive.

$\$ 4$ Although it has a different meaning, since it expresses a notion of change, the resultative um 'over, around' is dealt with in the same way: umstimmen 'change over', umschalten 'switch over'.

\$5 Finally, we bring to the reader's attention, among other such particles, the particle aus 'out', which expresses the locative idea of exiting, but which often takes the figurative value of exiting a process that is currently taking place, i.e. to finish the process: Ger. Er ist ausgewachsen, lit. 'He has grown out', Fr. lit. Il est sorti du processus de croissance, lit. 'He has left the process of growing' $\rightarrow$ Fr. Il a fini de croitre 'He has finished growing', Il a achevé sa croissance 'He has finished his growth'.

$\$ 6$ When the tendency for agglutination (Chapter 11) has the effect of transforming the German separable particle into an inseparable one - that is, to a true preverb - it is in the German preverb that the semantic characteristics (studied above in the context of particles) are found.

$\$ 7$ The preverb ver- in German expresses the fact that a process has reached its final stages and that it should be interpreted negatively: Ger. verspielen 'gamble away', die Zeit verschlafen 'oversleep', sein Vermögen vertrinken 'drink away one's fortune', verscherzen 'lose by one's own fault, forfeit', verspeisen 'lose by eating, consume', seinen Verstand versaufen 'drink oneself silly'.

$\$ 8$ However, the German preverb er- can be translated in a variety of ways, since it is the resultative particle par excellence (cf. Chapter $113, \$ 16$ ). It can be applied to a large number of different results, which it may be useful to distinguish in French: Ger. Er erbrach den Brief, 'He broke open the letter', Fr. Il ouvrit la lettre en brisant le cachet 'He opened the letter by breaking the seal'. 


\section{Chapter 131. Movement and displacement}

$\$ 1$ When in the presence of a resultative particle with spatial value, which is a frequent occurence in German, and in order to understand the translation mechanism it is necessary to understand the fundamental difference between movement and displacement.

$\$ 2$ A priori, this difference may seem pointless and contrived, but it does in fact play a considerable role in a large number of languages, and this is why it should be carefully analyzed. $\$ 3$ It is true that the distinction is delicate and that the confusion is not reduced by the simple fact and the common observation that in practice the simplest means of obtaining a displacement from one place to another is to perform movement in the form of walking. $\$ 4$ But displacement is the goal pursued and movement is merely the means. And it is possible to imagine their dissociation, that is to imagine displacement without movement or movement without displacement.

$\$ 5$ When I have someone drive me somewhere or I settle down comfortably in the corner of my train compartment, I can remain completely immobile throughout the entire journey. Arriving at my destination, I have obtained the displacement I wanted without having made any movement.

$\$ 6$ In contrast, the squirrel walking in its wheel is performing a movement that can be very fast, but the wheel is not fastened to its axle and so moves under the squirrel's feet such that the squirrel does not obtain any displacement and always ends up in the same spot. His fate is comparable to that of a cycling mannequin who pedals incessantly on a suspended bicycle in a sports shop window. The wheels spin in midair because they have no contact with the ground. The cyclist makes a movement, but he undertakes no displacement.

$\$ 7$ If the problem is reduced to its essential elements, movement is intrinsic, whereas displacement is extrinsic.

$\$ 8$ Movement is intrinsic, which means that the nature of movement necessary for displacement is tied to the physical conditions of its subject. To move from a point on the bank of a river to another point a kilometer away on the same bank, a man walks (or runs), a bird flies, a fish swims, a serpent slithers. Their destination is the same, but the means of reaching it are different, because each creature moves in the most convenient way for it and this movement depends on the structure of its body, and this structure differs according to the species it belongs to. The movement of each creature depends not on the destination, but on its physical possibilities and realities. This is why there are as many different movements as there are different bodies and why they are as complex as the structure of these bodies. These movements are expressed in vocabulary by an indefinite number of highly specialized verbs, such as marcher 'walk', courir 'run', trotter 'trot', galoper 'gallop', sauter 'jump', sautiller 'hop', ramper 'crawl, slither', voler 'fly', nager 'swim', etc...

$\$ 9$ Displacement on the other hand is extrinsic. It is a change of location, and as such it is not centered on the subject of the displacement, but on the space in which it occurs. It therefore 
does not participate in the living grace of the moving subject. A movement can be pretty and graceful, for example the leap of a cat or a tiger, or the movements of a dancer. However it is not possible to speak of the beauty or the grace of displacement independent of the movement that causes the displacement. Displacement depends on space, and thus on solid geometry. The concepts of displacement do not have any aesthetic value, only mathematical value. Notions are opposed pairwise according to the axes of three-dimensional space: high and low, in front and behind, right and left. The number of possible displacements in space is therefore relatively small and the number of words that express displacement relatively limited and easily recognizable since they form opposing pairs: Fr. monter and descendre 'go up' and 'go down', aller and venir 'go' and 'come', entrer and sortir 'enter' and 'exit'; Ger. auf and $a b$ 'onto' and 'from', hin and her 'away' and 'hither', ein and aus 'in' and 'out', etc...

$\$ 10$ Confusion between movement and displacement has drawbacks from a pedagogical point of view. Traditional terminology has the major flaw of reinforcing the confusion by denoting displacement with the term movement, which results in explanations that are difficult to understand for students (cf. Chapter 37, \$12). The truth of the matter is that it is the students who are right and the knowledge that they are being asked to acquire is the professional misrepresentation and the inexact terminology of their teachers, who really mean displacement when they speak of movement.

$\$ 11$ In the example given above (Chapter 37), what is important is not whether or not the subject in the garden is moving or still, but rather whether or not there is a change of location with respect to the garden. If the walking occurs within the confines of the garden, there is no change of location. But there is a change of location if the walk takes the subject outside the limits of the garden, from inside to outside the garden, even if the subject is completely paralyzed and is obliged to effect this change of position in a wheelchair pushed by another person, such that he himself remains completely immobile.

$\$ 12$ The same problem as for Latin also applies to German, Russian, and a host of other modern languages. This is why it is advisable to adopt the new terminology translocal and intralocal mentioned above (Chapter 37, \$13).

$\$ 13$ Thanks to this terminology, it is now easy to see that the German verb expresses movement whereas the French verb expresses displacement, or to use Malblanc's terminology, the German verb indicates the "nature" and "character" of the action, whereas the German particle, which corresponds to the French verb, expresses the meaning.

$\$ 14$ Take for example the German sentence Anton schwimmt über den Fluß 'Anthony is swimming across the river', in which the verb schwimmt expresses movement and the circumstant über den Fluß 'across the river' expresses displacement. The corresponding French sentence cannot be Antoine nage à travers le fleuve because French prepositions such as à travers 'across' cannot take on the resultative value of the corresponding German words, which allows German to quite naturally express change of location. Since the only type of word in French that can express displacement is the verb, there is no choice but to say in French Antoine traverse le fleuve à la nage or en nageant, lit. 'Anthony crosses the river by swimming', 
in which the displacement is expressed by the verb traverser and the movement is expressed by the circumstant, which can either be derived from the abstract noun la nage 'the swimming' made into the adverbial expression à la nage, lit. 'by the swimming', or obtained by using the verb nager 'swim' in the gerundive form en nageant 'swimming' (Stemmas 230 and 231).

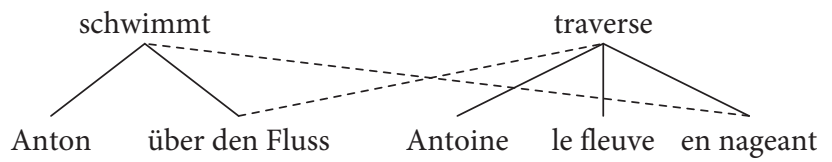

Stemma 230

Stemma 231

$\$ 15$ The idea is so robust and the movement is so secondary (in the expression of displacement) that it can be replaced with the indication of a connected but completely different activity. It is therefore possible to say in German: Er bimmelte die Straße hinauf 'He went up the street jangling', lit. 'He jangled the street up'.

$\$ 16$ This is also why, when the German particle is used alone with imperative value, it is simplest to translate into French using an imperative verb. The German command Heraus! 'Out!' (cf. Chapter 77, \$11) can be expressed in French by Sortez! 'Leave!'. Note that this unkindly expression, especially in its colloquial form Raus! 'Out!', was common in the vocabulary of the German officers in German war camps during the First World War, where they commanded French prisoners to exit the barracks for the roll call, for example. The French prisoners, who had quickly understood the notion of displacement expressed by this particle, inevitably had to resort to using a verb to express it in French. This is the origin of the verb raousser 'come out', which was short-lived, since it only lasted as long as the jargon from the camps, but which the French prisoners of war who were in Germany during the First World War might remember.

$\$ 17$ It is worth noting that the verb raousser, which must have completely disappeared by 1919 , was recreated in the same conditions during the Second World War, where it was reported in the slang of the deportortation camps in Germany, ${ }^{181}$ so it is true that the same causes always produce the same effects.

\section{Chapter 132. Change of the structural center via subordination}

$\$ 1$ When one of the two languages across which there is metataxis, generally French, has an analytical structural center - i.e. the exprimende of the verbal node is analyzed into two elements, one of which is the verb but the other of which is one of the verb's direct subordinates - this subordinate appears in the stemma on the same level as its semantic

181. According to the communication of F. Max at the Société de Linguistique in his talk on December 15, 1945, cf. Bulletin de la Société de Linguistique de Paris, 43, p. X. 
correspondent from the other language while the node that is in turn subordinate corresponds semantically to the verb in the other language.

\$2 The criss-crossing that results from this is therefore lopsided. In other words, one of the anaphoric lines in the comparative stemma that we use to bring out the semantic correspondence is horizontal, whereas the other, instead of joining two nodes that are separated in height by one level, connects two nodes where the difference in height is two levels. The following stemma illustrates the theoretical form,

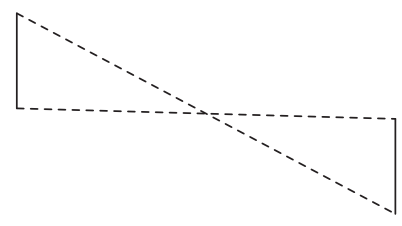

which in practice is often somewhat deformed by the constraints of graphic representation.

$\$ 3$ These considerations are illustrated by the German sentence Mit knapper Not entging er seinen Feinden 'He barely eluded his enemies'. The only suitable way of translating this sentence into French is with a sentence such as Il eut bien de la peine à échapper à ses ennemis 'He had difficulty escaping his enemies'. The phrase mit knapper Not 'with great difficulty = barely', which has adverbial value, is made into a verb Il eut bien de la peine 'He hardly' and making the German verb entging 'eluded' an infinitive preceded by $a$, namely the French circumstant à échapper 'to escape/to elude'.

$\$ 4$ The stemma of these sentences is established in the following manner (cf. Stemmas 232 and 233):

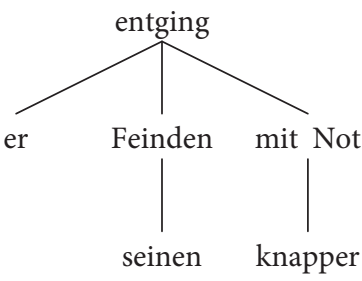

Stemma 232

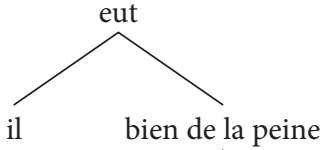

à échapper

à ennemis

ses

Stemma 233

\$5 The same particularity is valid for Russian. Under Turgenev's feather in A Sportsman's Sketches at the beginning of the sketch entitled The Prairie of Biega can be found the following sentence: Uže ja s trudom različal otdalennye predmety, which translates literally into 
French as Je distinguais avec peine les objets éloignés 'I discerned the distant objects with difficulty'. But the French translation, which keeps the prepositional phrase $s$ trudom and the Russian verb, is clumsy and does not at all give the same impression as the Russian sentence. The prepositional group s trudom should be made into a verb and the verb različal into an infinitive preceded by a preposition, which results in the more idiomatic French translation J'avais déjà de la peine à distinguer les objects éloignés 'I already had difficulty discerning the distant objects'.

$\$ 6$ The stemmas of these sentences are as follows:

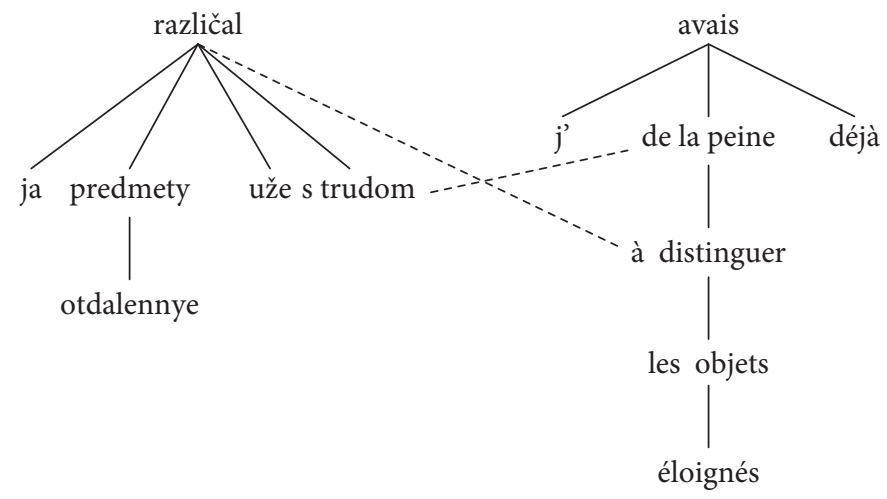

Stemma 234

Stemma 235

\$7 All the French sentences beginning with c'est... qui, c'est... que, c'est... dont, etc. are of this sort. It is the favorite method for French to emphasize an exprimende, which other languages emphasize by placing at the beginning of the sentence and pronouncing with particular vigor. French on the other hand is content with extracting the exprimende from its clause to make it into a governing clause as the attribute of the verb être (cf. Chapter 67), whereas the rest of the sentence is subordinated and introduced by the relative pronoun $q u i, q u e, d o n t$, etc..., the antecedent of this relative pronoun being the exprimende: Ger. Anton schlägt Bernhard, lit. 'Anthony hits Bernard' $\rightarrow$ Fr. C'est Antoine qui frappe Bernard 'It is Anthony who hits Bernard' (see Stemma 236 and 237).

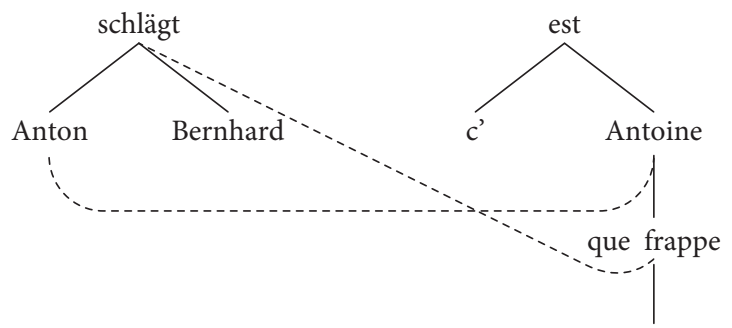

Bernard 
$\$ 8$ This type of metataxis explains the expression pronounced so often by central Europeans Je suis pour la première fois ici 'I am for the first time here'. This expression is nothing other than the translation from a substratum of Germanic origin: Ich bin zum ersten Male hier 'I am here for the first time'. The true way to express this idea in French consists of expressing the idea of time in verbal form by saying C'est la première fois 'It is the first time' and transforming the principle verb into a subordinate verb by saying que je suis ici 'that I am here': C'est la première fois que je suis ici.

\section{Chapter 133. Parataxis and hypotaxis}

$\$ 1$ A last type of metataxis is one where a coordinate structure in one language corresponds to a subordinate structure in another language.

\$2 Coordination consists of establishing two exprimendes on the same structural level. The resulting arrangement is what is called parataxis, Gr. para meaning that two nodes are placed adjacent to each other. The term parataxis is therefore the Greek term that corresponds to the Latin term coordination. The objects of parataxis, or coordination, appear in the stemma on the same horizontal line.

$\$ 3$ In contrast, subordinate structures are those in which one exprimende is placed below the other. The resulting arrangement is called hypotaxis, Gr. hypo meaning that one node is placed under the other. The term hypotaxis is therefore the Greek term corresponding to the Latin term subordination. The objects of hypotaxis, or subordination, are presented in the stemma on the same vertical line.

$\$ 4$ A given exprimende can be paratactic or hypotactic, and the passage from one form to the other results in a perceptible difference in meaning. But since hypotaxis is more abstract than parataxis, it is in fact not always perceived by the speaker, such that even if there is true hypotaxis between the ideas, the hypotactic relation is not necessarily identified, in which case the idea is expressed somewhat inexactly using a paratactic structure.

$\$ 5$ Take for example the sentence Alfred est heureux, parce que son père est mort, mais il n'a pas souffert 'Alfred is happy because his father died, but he did not suffer', which seems strange in French, because it appears to be saying that Alfred is happy about the death of his father. But what was meant is that Alfred is not happy about the death of his father, but rather about the fact that his father died without suffering. What appears in the form of a causal clause should really appear as a concessive or restrictive clause: Alfred est heureux, car, si son père est mort, il n'a pas souffert 'Alfred is happy because, while his father died, he did not suffer'. The shocking aspect of the former sentence has disappeared from this sentence. $\$ 6$ The following schema shows the hypotactic relation between the ideas and the limitations of paratactic expression: 
A

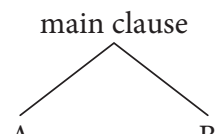

A
A

main clause

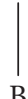

B

causal clause

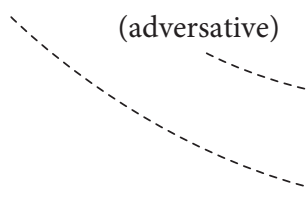

Parataxis

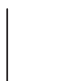

C

concessive clause

Hypotaxis

We can see that the first causal link of the parataxis is in reality a concessive of the second causal link, which appears only to be coordinated to the first by an adversative coordinator mais 'but', but which is in reality the true cause.

$\$ 7$ Such examples of parataxis are not rare in French:

\begin{tabular}{ll}
\hline $\begin{array}{l}\text { Madame Fernel se livre à des } \\
\text { calculs économiques qui ont }\end{array}$ & 'Mrs. Fernel does economical \\
pour but, sans doute, de trouver & calculations that aim, \\
le moyen d'élargir la manche & undoubtedly, to find \\
sans ajouter du drap. Ce problème & the means to enlarge the sleeve \\
est la quadrature du cercle de & without adding cloth. This problem \\
toutes les mères de familles, & is every mother's version \\
j'entends de celles qui & of squaring the circle, \\
ne sont pas avares, mais & I mean, for those who \\
qui répugnent à la nécessité & are not miserly, but \\
de rapiécer les habits de leurs enfants. & who are loathe to patching up \\
\end{tabular}

(Ulbach, M. et Mme Fernel, III)

It should be apparent that the hypotaxis sans être avares 'without being miserly' would be clearer here. Likewise with the following example:

$\begin{array}{ll}\text { Mon agent devait être un agent } & \text { 'My policeman must be an officer } \\ \text { de l'ancienne police, car il bousculait } & \text { of the old police, because he } \\ \text { mon bagage mais il me parlait } & \text { jostled my baggage but spoke to } \\ \text { tendrement } & \text { me tenderly' }\end{array}$

(Jean Giraudoux, Siegfried et le Limousin, p. 246)

Evidently the hypotaxis s'il est vrai qu'il bousculait mon bagage 'although it is true that he jostled my baggage' would be more explicit here.

$\$ 8$ Languages generally start out by expressing slightly complex ideas in paratactic form. It is only as they develop that they become capable of perceiving and expressing hypotactic links. They therefore reflect human development in this regard. A child begins by 
organizing ideas in paratactic form, and only after the child's mind has acquired some maturity can it express ideas in hypotactic form.

$\$ 9$ In any given language, hypotaxis can therefore only appear after parataxis. Hence Latin, even though it reached a high degree of abstraction, tends nevertheless to represent semantic groups in terms of parataxis, where in the same situation French uses hypotactic links. In such cases, the Latin paratactic structure should be translated with a French hypotactic structure.

\$10 For unrelated languages however, abstract development can be more or less advanced. For this reason, sometimes certain languages - for instance Germanic languages such as English and German or Slavic languages such as Russian, which went through their development of civilization after Latin - still formulate ideas paratactically, whereas French expresses them hypotactically. In such cases, English, German, and Russian paratactic structures should be translated with French hypotactic structures.

$\$ 11$ In Latin, two coordinated verbs are often used to express sentences that should be translated into French or even into English by a verb accompanied by an adverb:

\begin{tabular}{|c|c|c|}
\hline $\begin{array}{l}\text { Latin } \\
\text { parataxis }\end{array}$ & $\begin{array}{l}\text { Literal } \\
\text { translation }\end{array}$ & $\begin{array}{l}\text { English } \\
\text { hypotaxis }\end{array}$ \\
\hline orare atque obsecrare & 'plead and entreat' & $\begin{array}{l}\text { request insistently } \\
\text { (cf. Stemma } 238 \text { and 239) }\end{array}$ \\
\hline $\begin{array}{l}\text { auxilium implorare } \\
\text { et flagitare (Cicero, } \\
\text { pro Rabirio, } 3,9)\end{array}$ & 'demand and implore help' & ask for help urgently \\
\hline $\begin{array}{l}\text { appetere atque deposcere } \\
\text { (Cicero, Philippicae } 3 \text {, } \\
13,33 \text { ) }\end{array}$ & 'strive and require' & to seek with ardor \\
\hline $\begin{array}{l}\text { interdicit atque imperat } \\
\text { (Caesar, de bello } \\
\text { Gallico, V, 2, 55) }\end{array}$ & 'he forbids and commands' & he forbids expressly \\
\hline $\begin{array}{l}\text { Tiberim transnatat } \\
\text { nec arma dimittit. }\end{array}$ & $\begin{array}{l}\text { 'He swims across the Tiber and } \\
\text { does not let go of his weapons.' }\end{array}$ & $\begin{array}{l}\text { He swims across the Tiber } \\
\text { without letting go of his } \\
\text { weapons. }\end{array}$ \\
\hline
\end{tabular}

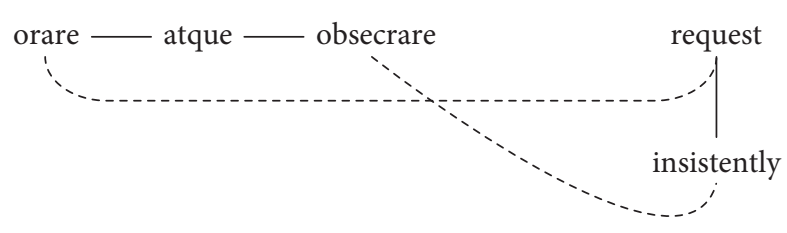

Stemma 238

Stemma 239

182. Riemann et and Goelzer, Grammaire latine complète, pp. 210, 211, and 378. 
Note that in the preceding examples, it is the semantic exprimende that appears second in the spoken chain in the case of parataxis, whereas it is the subordinate in the case of hypotaxis.

$\$ 12$ In the following examples, it is the first exprimende that corresponds to the subordinate in the hypotactic structure:

\begin{tabular}{lll}
\hline $\begin{array}{l}\text { Latin } \\
\text { parataxis }\end{array}$ & $\begin{array}{l}\text { Literal } \\
\text { translation }\end{array}$ & $\begin{array}{l}\text { English } \\
\text { hypotaxis }\end{array}$ \\
\hline $\begin{array}{l}\text { divellere ac distrahere } \\
\text { (cf. Stemma 240 and 241) }\end{array}$ & 'uproot and divide' & violently separate \\
$\begin{array}{l}\text { se applicare et adiungere } \\
\text { (Cicero, De amicitia, 14, 48) }\end{array}$ & 'apply and attach' & intimately unite ${ }^{202}$ \\
\hline
\end{tabular}

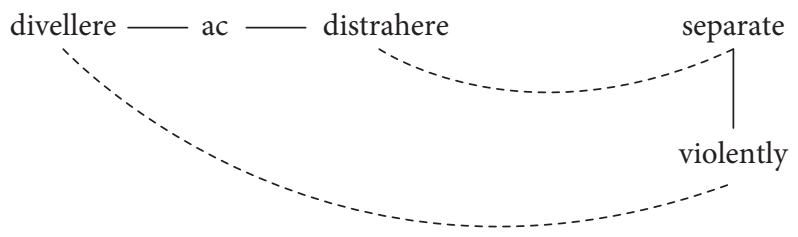

Stemma 240

Stemma 241

$\$ 13$ Similarly, expressions composed of two coordinate nouns in Latin are to be translated into English using a noun and a subordinate adjective:

\begin{tabular}{lll}
\hline $\begin{array}{l}\text { Latin } \\
\text { parataxis }\end{array}$ & $\begin{array}{l}\text { Literal } \\
\text { translation }\end{array}$ & $\begin{array}{l}\text { English } \\
\text { hypotaxis }\end{array}$ \\
\hline $\begin{array}{l}\text { ratio et doctrina } \\
\text { (Cicero, Tusculanes, } \\
\text { III, 1, 2) }\end{array}$ & 'method and instruction' & systematic instruction \\
$\begin{array}{l}\text { oratio et facultas } \\
\text { (Cicero, pro Archia, 3, 4) }\end{array}$ & 'discourse and talent' & an oratory talent \\
$\begin{array}{l}\text { vis et potentia } \\
\begin{array}{l}\text { aestus febrisque } \\
\text { (Cicero, Catiline Orations, }\end{array}\end{array}$ & 'violence and power' & violent power \\
$\begin{array}{l}\text { I, 13, 31) } \\
\text { temeritas et casus } \\
\text { (Cicero, de Divinatione, }\end{array}$ & 'courage and chance' & blind chance \\
$\begin{array}{l}\text { III, } 41,85) \\
\text { studium et aures } \\
\text { (Cicero, pro Archia, 3, 5) }\end{array}$ & $\begin{array}{l}\text { 'eagerness and ears } \\
\text { (i.e. attention)' }\end{array}$ & \\
\hline
\end{tabular}




\begin{tabular}{lll}
\hline $\begin{array}{l}\text { Latin } \\
\text { parataxis }\end{array}$ & $\begin{array}{l}\text { Literal } \\
\text { translation }\end{array}$ & $\begin{array}{l}\text { English } \\
\text { hypotaxis }\end{array}$ \\
\hline $\begin{array}{l}\text { furor ac tela } \\
\text { (Cicero, Catiline Orations, } \\
\mathrm{I}, 1,2)\end{array}$ & 'furor and weapons' & furious weapons \\
$\begin{array}{l}\text { spectator et testis }{ }^{203} \\
\text { (cf. Stemma 242 and 243) }\end{array}$ & 'viewer and witness' & $\begin{array}{l}\text { Fr. un témoin oculaire } \\
\text { lit. 'an ocular witness', } \\
\text { i.e. 'an eyewitness' }\end{array}$ \\
\hline
\end{tabular}

Here the semantic exprimende, which appears first in the spoken chain in the parataxis, is the subordinate in the hypotactic translation:

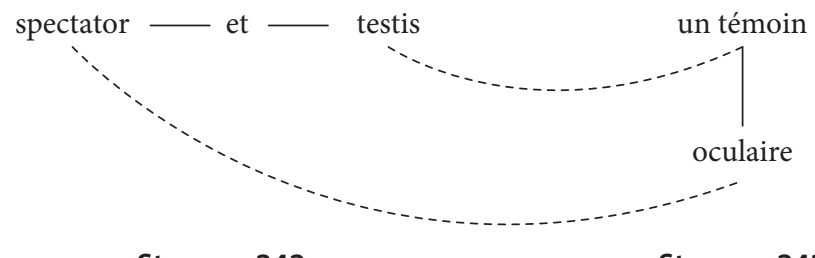

Stemma 242

Stemma 243

\$14 In the following example, it is, on the contrary, the second exprimende in the paratactic structure that appears as the subordinate in the hypotactic translation.

\begin{tabular}{lll}
\hline Latin & $\begin{array}{l}\text { Literal } \\
\text { translation }\end{array}$ & $\begin{array}{l}\text { English } \\
\text { hypotaxis }\end{array}$ \\
\hline $\begin{array}{l}\text { moderatio et sapientia } \\
\text { (cf. Stemma 244 and 245) }\end{array}$ & 'moderation and wisdom' & sensible moderation \\
\hline
\end{tabular}

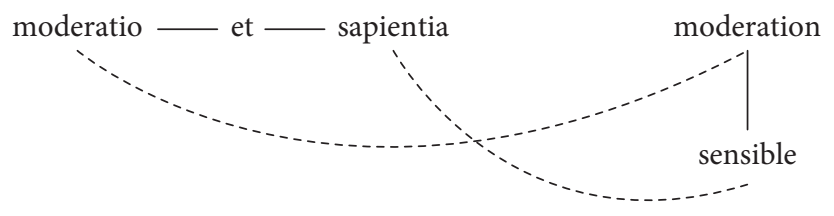

Stemma 244

Stemma 245

184. Ibid., p. 75.

185. Ibid., p. 75. 
\$15 The most complex cases of metataxis are of course those in which the subordinate nodes are clauses. In such cases, Latin often uses coordinate clauses, whereas English and French use clauses linked by subordination. Such is the case in the following sentence $(\$ 6)$ :

\begin{tabular}{ll}
\hline \multicolumn{1}{c}{ Latin } & \multicolumn{1}{c}{ English } \\
\hline $\begin{array}{l}\text { Cum plerique arbitrentur, res } \\
\text { bellicas majores esse quam }\end{array}$ & $\begin{array}{l}\text { With most people thinking that the } \\
\text { things of war are more important than } \\
\text { urbanas, minuenda est haec }\end{array}$ \\
those of civilian life, it is \\
opinio (A). Multi enim bella & advisable to correct this opinion (A). \\
saepe quaesiverunt propter & Because, if many men have \\
gloriae cupiditatem... (C); & sought war because they wanted glory (C), \\
vere autem... multae res & there have been many instances of \\
extiterunt urbanae majores & achievement in peace more important \\
clarioresque quam bellicae (B) & and no less renowned than in war (B). \\
\hline
\end{tabular}

\$16 In German and English, parataxis can be found especially in sentences of the following type: Ger. Der ist imstande und erwürgt mich (Grünau), lit. 'He is capable and strangles me' $\rightarrow$ Eng. He is capable of strangling me; Ger. Seien Sie so gut und geben Sie mir das Buch, Eng. Be so kind and give me the book $\rightarrow$ Fr. Ayez la bonté de me donner le livre, Eng. Be so kind as to give me the book. This colloquial expression is very frequent in German, and less so in English, where hypotaxis is usually preferred in formal language. Note also the parataxis in English in the following familiar expression: Give me the book, you are a good boy.

$\$ 17$ Note also the parataxis in colloquial English of one verb subordinated to another verb of movement: Go and fetch me the book; you, come and put some paper down (D. H. Lawrence, Aaron's Rod).

$\$ 18$ This expression also occurs in Russian in conversational style: Byd'te dobry i dajte mne ètu knigu 'Have the courtesy to give me that book', lit. 'Be good and give me that book'; Pojdu skažu 'I will go say that', lit. 'I will go I will say that'; Pojdu osvedomljus', lit. 'I will go I will find out'.

$\$ 19$ Also worth noting is the opposition of German parataxis and French hypotaxis in the German Vercingetorix hoffte seinen Sieger zu besänftigen und lieferte sich selbst aus 'Vercingétorix was hoping to placate his victor and delivered himself to them' $\rightarrow$ Fr. Vercingétorix, espérant adoucir le vainqueur, vint se livrer lui-même 'Vercingétorix, hoping to placate his victor, delivered himself to them.' ${ }^{186}$

186. A. Malblanc, Pour une stylistique comparée du français et de l'allemand, $\$ 151$. 
\$20 Finally, a paratactic third actant in German corresponds to a determinative complement in French:

\begin{tabular}{|c|c|c|}
\hline German & French & English translation \\
\hline $\begin{array}{l}\text { jemandem etwas zur } \\
\text { Unterschrift vorlegen, } \\
\text { lit. 'lay something down } \\
\text { to someone for signing' } \\
\text { (cf. Stemma 246) }\end{array}$ & $\begin{array}{l}\text { soumettre quelque chose à } \\
\text { la signature de quelqu'un, } \\
\text { lit. 'submit something to the } \\
\text { signing of someone' } \\
\text { (cf. Stemma 247) }\end{array}$ & $\begin{array}{l}\text { 'lay something } \\
\text { down for someone } \\
\text { to sign' }\end{array}$ \\
\hline $\begin{array}{l}\text { jemandem die Hand drücken, } \\
\text { lit. 'shake the hand } \\
\text { to someone' }\end{array}$ & $\begin{array}{l}\text { serrer la main de quelqu'un, } \\
\text { lit. 'shake the hand of } \\
\text { someone' }\end{array}$ & $\begin{array}{l}\text { 'shake someone's } \\
\text { hand' }\end{array}$ \\
\hline $\begin{array}{l}\text { jemandem zu Hilfe } \\
\text { eilen, lit. 'hurry to } \\
\text { someone to help' }\end{array}$ & $\begin{array}{l}\text { courir au secours de } \\
\text { quelqu'un, lit. 'run to the } \\
\text { aid of someone' }\end{array}$ & $\begin{array}{l}\text { 'run to someone's } \\
\text { aid' }\end{array}$ \\
\hline
\end{tabular}

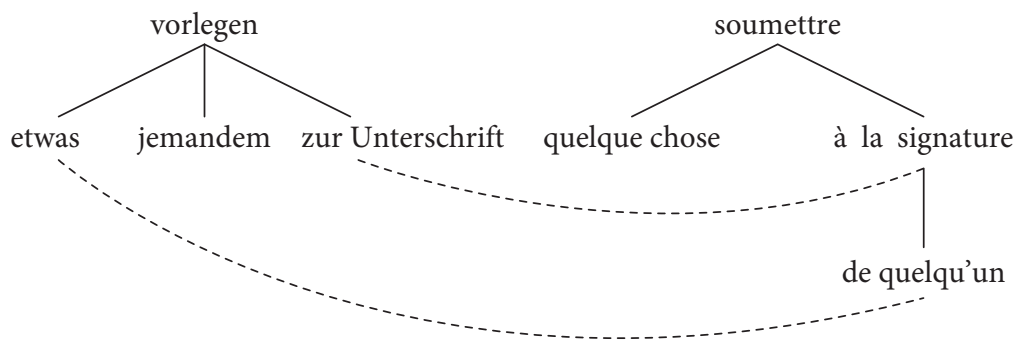

Stemma 246

Stemma 247

\$21 It also occurs, though less often, that French uses parataxis where German uses hypotaxis:

\section{German}

Moreau, der schon vor Tagesanbruch

zu Pferde gestiegen war, ritt an der Spitze seines Stabes, während in einiger Entfernung Richepanse und Decaen die vorgeschriebene Bewegung ausführten.

'Moreau, who had gotten on his horse before dawn, rode at the front of his company, while Richepanse and Decaen performed the required maneuver.'
French

Moreau, à cheval avant le jour, était à la tête de son état-major, et, un peu plus loin, Richepanse et Decaen exécutaient le mouvement qui leur était prescrit.

'Moreau, on his horse before the dawn, was at the front of his company, and, a little farther along, Richepanse and Decaen performed the required maneuver. ${ }^{207}$

187. A. Malblanc, Pour une stylistique comparée du français et de l'allemand, p. 69, 2nd edition 1963, $\$ 132$.

188. Ibid., p. 106-107. 
\$22 It is important not to confuse parataxis, where the two nodes are semantically coordinate, with the type of hypotaxis that lacks a morphological marker i.e. where they are semantically subordinate but there is no marker of subordination, such that they are morphologically coordinate. It is clear that there is no metataxis when the same sentence is semantically subordinate in both languages, even if one language uses a morphological marker of subordination but the other does not, since in such cases, this is a morphological difference, not a semantic one. In order to have metataxis, there has to be semantic subordination in one language and semantic coordination in the other, one language marking semantic hypotaxis that the other does not sense.

\$23 Rus. zaxočeš', pojdu, lit. 'You will want, I will go', meaning 'If you want, I will go', does not constitute metataxis in relation to English, since even though it is not marked morphologically, hypotaxis is semantically perfectly perceptible, and there is therefore hypotaxis in Russian just as there is in English, even though the marker of this hypotaxis is zero in Russian and if in English.

\$24 Most accounts of parataxis are fundamentally inaccurate, since they fail to recognize the distinction between parataxis, which is a syntactic phenomenon, and its marker, which is a morphological phenomenon and they therefore constantly confuse parataxis with hypotaxis without a marker. 



\section{PART II}

\section{Junction}

\section{Chapter 134. Complications of the simple sentence}

$\$ 1$ After having established in Part I what the schema of the simple sentence is what one arrives at after having eliminated complicating elements, it is now appropriate to study what these complicating elements are.

$\$ 2$ They boil down to two phenomena of quite different natures, junction (Fr. jonction) and transfer (Fr. translation). Connection, junction, and transfer are thus the three big bosses that preside over all facts of structural syntax.

$\$ 3$ Junction combines nodes of the same nature in such a way that the sentence, which has taken on these new elements, becomes larger and longer.

$\$ 4$ Transfer, in contrast, involves changing the constitutive elements of the sentence from one type to another, so that the sentence gains in variety, not in size. As in the case of junction, the sentence becomes longer, but by way of a different mechanism.

$\$ 5$ As we have already seen above (Chapter 38 ), we call the words junctives that serve to mark junction and the words translatives (Chapter 40) that serve to mark transfer.

$\$ 6$ Being outside of the simple sentence, junctives and translatives do not belong to any of the four categories of fundamental words. They are empty words (Chapter 38), that is, they are simple grammatical tools. Junctives and translatives are thus the two great classes into which the grammatical tools are split.

$\$ 7$ Since they are not fundamental words, junctives and translatives cannot be represented by one of the symbols A, E, I, O (Chapter 33, \$2). We have seen (Chapter $38, \$ 11$ ) that we abbreviate them with lower case letters, which stand in contrast to the upper case latters that serve to abbreviate the full words:

$\mathrm{j}=$ junctive $\quad \mathrm{t}=$ translative

$\$ 8$ Junctives and translatives cannot be integrated into the stemmas in the same manner as constitutive words. They require a representation in the stemma that is consistent with their function in the sentence. This representation will be studied when junction (Chapter 136) and transfer (Chapter 155) are examined.

$\$ 9$ Traditional grammar often confuses junctives and translatives with a single common designation, which is also quite vague, i.e. conjunction (coordinate conjunction and subordinate conjunction, Chapter 164, \$20-22). Traditional grammar has neither 
recognized the true nature of these words nor the proper character of each, and it therefore has not cast light on the fact that they are irreducibly opposites.

$\$ 10$ Junction is a quantitative phenomenon, comparable to addition and multiplication in arithmetic. Its effects on the simple sentence are relatively limited in number and scope. It permits a considerable augmentation of sentence dimensions, but it does not provide a means to amplify the sentence infinitely.

$\$ 11$ In contrast, transfer is a qualitative phenomenon. The effects of transfer are infinitely more varied, and it permits one to augment the dimensions of the simple sentence in infinite proportions and to give it unlimited possibilities theoretically.

$\$ 12$ What one encounters in the varying structures of the world's languages leads to the glottogonic hypothesis concerning the order of appearance, during prehistory, of the three phenomena (connection, junction, and transfer).

$\$ 13$ The former of these three phenomena apparently precedes the other two, since they presuppose it. One actually cannot even imagine how a language would have been able to acknowledge junction or translation without first having connection as a precondition. This fact is imprinted in all languages up to this day, for they can construct simple connections without junction and transfer, whereas the inverse is impossible. One cannot acknowledge a sentence the structure of which is based on junction or transfer without the junction or transfer being based logically on a base of connections.

$\$ 14$ Junction and transfer are two phenomena that impose themselves on connections, and they develop in diverging directions. The one does not presuppose the other. Indeed, there can be sentences in our languages that have, in addition to a necessary common base of connections, phenomena of junction without transfer, or conversely, phenomena of transfer without junction.

$\$ 15$ However, in sentence structure transfer corresponds to an intellectual development that is more elaborate and as a consequence, it stems from a more advanced civilization than junction. One tends then to think that the primary facts of junction had to develop prior to the primary facts of transfer.

$\$ 16$ But this insight does not mean that all the facts of junction are prior to the development of transfer. The two phenomena grew in different directions and neither relies on the other, even if the one is roughly prior to the other. This does not at all mean that the two stand in a constant and absolute chronological relation to each other. Indeed, phenomena of junction have continued to develop after the facts of transfer had already appeared. Furthermore, they are continuing to develop in our times and they are doing so even before our eyes in the most evolved languages.

\section{Chapter 135. Duplication and junction}

$\$ 1$ When two nuclei of the same nature have the same function in a sentence, we say that there is duplication (Fr. dédoublement). 
\$2 Therefore in the sentence Alfred and Bernard fall, Alfred and Bernard both take on the function of the first actant. In such cases, we say that the first actant is duplicated, since it is represented by two persons.

\$3 One must guard against saying that this sentence has two actants, for the verb sing is monovalent, so the sentence cannot have more than a single actant. But that actant is duplicated. Or, if one prefers, one can say that the sentence has two first actants.

$\$ 4$ Duplication is the result of the addition of two sentences, the one being Alfred falls and the other Bernard falls. One can say that Alfred falls + Bernard falls $=$ Alfred and Bernard fall. One can even employ the operation in the form of addition of traditional arithmetic:

\begin{tabular}{rr}
\hline $\begin{array}{l}\text { Alfred } \\
\text { Bernard falls. }\end{array}$ \\
Alfred and Bernard fall.
\end{tabular}

\$5 The two actants Alfred and Bernard cannot be put in the plural, for they are two different persons, each of which exists only as a single entity and as a consequence, they cannot be conceived of in the plural. But the action that the two perform is common and that is why the verb appears in the plural. This obvious truth is acknowledged in elementary grammars when they state that the plural verb agrees with two singular subjects, that is, the two singular first actants want their verb to be plural.

$\$ 6$ The number of terms of this sort of addition is unlimited. We can have Alfred falls + Bernard falls + Charles falls $=$ Alfred, Bernard, and Charles fall, and so on, without limitation in the number of terms. In such a case, one can say that there is no duplication, but rather triplication, etc. or more generally, multiplication.

$\$ 7$ When there is duplication, the two duplicated terms fulfill the same structural function. The two are alike, and this functional identity creates a link between them. This link is the basis of junction. In this sense, one can say that junction is the necessary consequence of duplication.

$\$ 8$ Two nodes affected by junction are called joined. Such is the case in the sentence Alfred and Bernard fall. One says that Alfred and Bernard are joined, or, leading to the same result, that and joins Alfred and Bernard.

$\$ 9$ Junction operates between two nodes of the same type, regardless of the nature of this type. Thus there can be junction between two actants (e.g. Men fear poverty and death) or between two circumstants (e.g. Alfred works quickly and competently); between two verbal nodes (e.g. Pass me the rhubarb and I'll pass you the senna) or between two adjectival nodes (Fr. ...un saint homme de chat, bien fourré, gros et gras '... a holy (man of) cat, well furlined, big, and fat' La Fontaine, Fables, VII, 16) (cf. also Chapter 272, §8).

$\$ 10$ It is however absolutely necessary that the two nodes be of the same nature. Just as it is impossible to add a pear and an apple, one cannot join an actant and a circumstant, nor a verbal node and a nominal node. 
$\$ 11$ Likewise, one avoids in general joining two disparate nodes, that is, two words that are constituted by procedures that are too different. One can say Le regal fut petit et sans beaucoup d'apprêts 'The meal was small and without any preparations' (La Fontaine, Fables, I, 18), although sans beaucoup d'apprêts gets its adjectival value only from a semantic operation of sequence to which petits is not subjugated. But the purists condemn the junction of an actant and a subordinate clause: ...c'est elle qu'avait mille fois mérité la danse et même que je l'étende '... it is her who had well deserved the dance and even that I lay her' (Céline, Mort à credit, p. 22) taken from an intentionally vulgar style; however Colette, whose French is generally very pure, risks Il apprit son nom et qu'on l'appelait «Sido» 'He learned his name and that he was called Sido'(La Maison de Claudine, II, 16).

\section{Chapter 136. Graphic representations}

$\$ 1$ The principle of graphic representation of junction consists of linking the joined elements with a line that we will call a junction line.

$\$ 2$ Two nodes cannot be joined unless they are of the same nature and as a consequence, they appear on the same structural level. The junction line has to be horizontal.

$\$ 3$ If junction is marked by a junctive, the junction line will be constituted by two parts. The junctive appears between these segments.

\section{Alfred — and — Bernard}

$\$ 4$ Two joined nodes conserve their similar vertical connections. As a result, the graphic cluster formed by the two vertical connections and the junction line constitute a triangle (Stemma 248).

$\$ 5$ The junction line is identical to the apposition line (Chapter $69, \$ 7$ ), since both are horizontal. However, it is impossible to view them as the same thing. Indeed, the vertical connections that accompany the junction line by definition necessarily constitute a triangle for which they are the base. In contrast, the apposition line is never the base of a triangle, since the nature of apposition demands that the connection between the word in apposition and the governor of the word to which it is in apposition not be directly connected, but rather they are mediated.

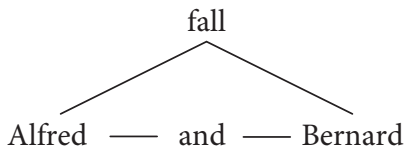

Stemma 248

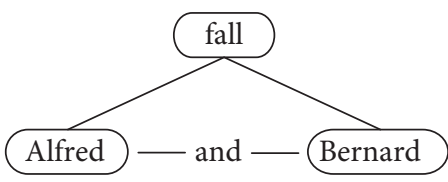

Stemma 249 
$\$ 6$ The junctive is not part of either of the two nuclei that it joins together. Just as the mortar that binds two bricks is not part of either, or as the coupling that unites two rail cars appears external to both, a junctive remains outside of the two nuclei it unites. Thus the junctive is not intra-nuclear, but rather extra-nuclear.

$\$ 7$ Since the function of the junctive is by definition to appear between two nuclei, it is always present as an inter-nuclear element (Chapter 39, \$3). The inter-nuclear character of the junctive is apparent in the stemma, that is, it is apparent in the case that one chooses to include the nucleus circles in the stemma (Chapter 22, \$16, and cf. Stemma 249).

$\$ 8$ We will see further below (Chapter 157, \$7) that in comparison to the junctive, the translative is inter-nuclear. As a result, junctives that combine translatives are exceptionally intra-nuclear. However, one should note that when a junctive appears inside a nucleus, this occurs not because it functions as a junctive, but because it joins elements that are in their own right already inside the nucleus.

\section{Chapter 137. Junction without a junctive}

$\$ 1$ The easiest way to join two nodes is to juxtapose them. There is then no junctive present. This situation can be expressed using the grammatical terminology that views the junctive as zero.

\$2 The zero junctive exists in a certain number of languages: Fr. Je vois, je sais, je crois, je suis désabusée 'I see, I know, I believe, I am disenchanted' (Corneille, Polyeucte, V, 5), Lat. Veni, vidi, vici 'I came, I saw, I was victorious' (Ceasar);

\begin{tabular}{llllllll}
\hline \multirow{3}{*}{ Chinese } & Huí & jiā & gào & sù & $t \bar{a}$ & $f \bar{u}$ & qìn \\
& return & home & say & inform & his & father & parent \\
& \multicolumn{7}{c}{ 'He returned home and said to his father'208 } \\
\hline
\end{tabular}

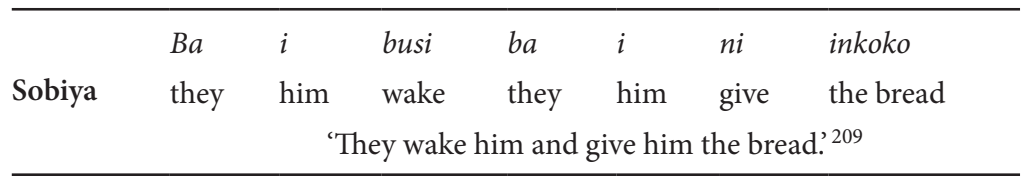

$\$ 3$ After an enumeration of joined elements, the group that it represents can be evoked together by a word that stands for all of them. We will call this word resumptive, since it stands for all the preceding elements that are joined. We can see this occurring in the

189. Finck, Die Haupttypen des Sprachbaus, 1910, p. 30.

190. Ibid., p. 70. 
sentence Femmes, moine, vieillards, tout était descendu 'Women, (a) monk, and old people, all had descended' (La Fontaine, Fables, VII, 9); tout 'all' is the resumptive element that stands for the joined elements femmes, moine et vieillards 'women, (a) monk, and old people'.

$\$ 4$ The resumptive element provides the synthesis for the content that has already been supplied by the enumeration of joined elements. Conversely, one can analyze the joined elements that were expressed as a block afterwards:

Assis, qui sur le lit, qui sur les tabourets de bois ou sur des sièges de hasard, nous étions là tous les sept.
'Seated, the ones on the bed, the others on the wooden stools or on random seats, we were all seven there.'

(G. Duhamel, Le desert de Bièvres, p. 54)

$\$ 5$ The analysis after the fact of the joined elements is encountered in Latin in familiar style: qua cibi, qua quietis immemor nox 'a forgetful night as much for nourishment as for relaxation' (Tive-Live, 9, 3, 4). Riemann, who cites this example (Syntaxe latine, \$272, R. II), posits that the qua is perhaps the ablative of the indefinite pronoun (ali) qua (parte) (cf. Chapter 177, \$16) and he accordingly correctly approaches the French expressions mentioned above.

$\$ 6$ One should not confuse junction without a junctive with composition by juxtaposition. In junction without a junctive, one is dealing with the juxtaposition of two nodes, two actants for example, whereas in composition, one is dealing with the same actant that is designated by two different appellations. The distinction is relatively easy to make if one thinks of the two nodes continuing to designate two distinct notions, whereas the compound nodes constitute but one and the same node and as a consequence, they can only designate a single notion.

$\$ 7$ Therefore there is junction without a junctive when, for example, two nodes are preceded or followed by an element that concerns them and that is placed as a common factor: Fr. notre joli petit chat 'our cheerful small cat.' 191

$\$ 8$ One finds a curious use of the communal factor of a pre-posed element in the French expression ces Messieurs Dames, lit. 'these Gentlemen Ladies', that is 'all these people', which is rarely written, since it resides in spoken language and is therefore quite colloquial. Those who decide to write it sometimes include an et 'and' that is purely imaginary because one does not hear it: ces Messieurs et Dames (Paul Darcy, La perle noire, p. 60). But one also finds the most accurate spelling ces Messieurs-dames (Midi Libre, De ma lucarne, March

191. Translators' note: The distinction here can also be illustrated with coordination where an element is a common factor to the conjuncts, e.g. old men and women. 
3rd, 1948). ${ }^{192}$ In this example, the prefixed element mes- 'my' pertains to both -sieurs 'sirs' and dames 'ladies', for one is dealing with a semantic amalgam between Messieurs and Mesdames. Since it is evident that these two appellations designate two different actants, one is of course dealing with junction.

$\$ 9$ Conversely, one can find simple juxtaposition of two verbs with a single shared suffix. This is the case in Turkish:

\begin{tabular}{lccl}
\hline \multicolumn{4}{c}{ Turkish } \\
\hline Yarın & gel-ir & bak-ar- & im \\
Tomorrow & com-ing & see-ing & I \\
'Tomorrow I will come and see.' \\
\hline
\end{tabular}

S10 Similarly, junction can sometimes concern two endings that are added in such a manner that they form a complex ending where the meaning of the one is added to that of the other. This is the case in the Russian expression pojdëmte 'let's go', which has long fascinated etymologists. Some want to see an abbreviated form of the ethical dative tebe 'to you' in the element -te, which would correspond to the personal antiontive substantive ty 'you'. But the fact that pojdëmte is a plural antiontive that expresses plurality or politeness - in contrast to pojdëm, which, although it is also inclusive, includes the antiontive singular - forces one to admit that one is dealing with a contamination between the autoontive pojdëm and the antiontive pojdëte, in which the ending -te of the antiontive has attached to the ending - $m$ of the autoontive (cf. Jakobson, attributed to Georges Trager, Introduction to Russian: The Slavonic and East European Review, October 1944, p. 132).

$\$ 11$ In contrast, composition, which is generally marked by a hyphen, occurs when one is dealing with two denominations that designate the same actant or the same action and are of a complex nature and thus contain two components. This is the case with the French substantive reine-marguerite 'China aster', where one is not dealing with the junction of a reine 'queen' and a marguerite 'daisy', but rather with a designation consisting of two terms but denoting a single type of flower, which has the character of both a queen and a daisy.

$\$ 12$ This type of composition, which one should understand in terms of junction (cf. Chapter $133, \$ 18$ ), is particularly frequent in Russian, where it is common to designate a single complex process using two verbs that are unified orthographically using a hyphen: On prišël-smotrel, lit. 'he came-saw', that is 'He came and saw', žil-byl 'there was one time', lit. 'lived-was' (with the verbal substantive žit'ë-byt'ë, lit. 'the life-essence'; Žil-byl mužik da $b a b a$, lit. 'Lived-was a mujik and a peasant', that is 'There was once a peasant and his wife'.

192. Cf. A. Moufflet, Contre le massacre de la langue française, I, 1930, p. 176. 
\$13 The proof that one is dealing with a true composite verb is found in the following sentence, which the author himself heard in Russian: Ja jab(lo)ki sidela-ela, lit. 'I was sit-eating apples', that is 'I was sitting and eating apples'. In this sentence, the second actant jab(lo)ki evidently cannot depend on the governor sidela, even though the two are contiguous, since one cannot be sitting the apples, nor can it depend on ela alone, since it is separated from it in the spoken chain by the other governor sidela. One is hence forced to admit that the governor of $j a b(l o) k i$ is the compound group sidela-ela.

\section{Chapter 138. Linear varieties of junctives}

\$1 This chapter examines the manner in which the junctive must appear on the spoken chain in relation to the joined elements.

\$2 The process that is most common consists of inserting the junctive between the two joined elements: Eng. Alfred and Bernard. This process occurs in a large number of languages:

\begin{tabular}{llll}
\hline French & et & Russian & $i$ \\
Latin & et & Serbo-Croatian & $i$ \\
Italian & $e$ & Low Breton & ha \\
Spanish & $y$ & Greek & kai \\
German & und & Arabic & wa \\
English & and & Basque & eta \\
Dutch & en & Georgian & da \\
Latvian & un & & \\
\hline
\end{tabular}

The same process is present in Rumanian, Armenian, Mari, and Komi, etc.

$\$ 3$ If the nodes to be joined are many, the junctive can be repeated between each two joined elements:

J'ai perdu ma force et ma vie, Et mes amis et ma gaîté.

(Alfred de Musset, Tristesse)

On instruit les enfants à craindre et à obéir: l'avarice ou l'orgueil ou la timidité des pères leur enseigne l'économie ou la soumission.

(Vauvenargues)
'I lost my strength and my life, And my friends and my lightness.'

'One instructs the children to believe and to obey: the avarice or the pride or the timidity of the fathers teaches them economy or submission.' 
$\$ 4$ But most often when there are more than two nodes to be joined, the junctive appears only between the last two: Eng. Alfred, Bernard, and Charles; Fr. Il est grand, gros et gras ' $\mathrm{He}$ is big, fat, and greasy'; naitre, vivre et mourir 'Be born, live, and die'.

$\$ 5$ The junctive can appear in front of each of the joined elements. In such a case, it takes the value of particular insistence: Lat. Et perdunt operam et deridentur turpiter 'And they lost their time and they were laughed at shamefully' (Phaedrus, Fables, I, 25, 2).

$\$ 6$ The repetition of the junctive is particularly frequent when it is negative: Fr. Ni l'or ni la grandeur ne nous rendent heureux 'Neither gold nor grandeur makes us happy'.

$\$ 7$ If the negation bears on only one of the two joined elements, one cannot set the positive element in contact with the negative element, at least not in French. But this situation is perfectly possible in Latin with nec 'and not' and et 'and', and in such cases, one can generally translate to English using on the one hand ..., on the other hand.... Thus one encounters the following in Latin, the first conjunct being positive and the second negative:

Et, quem tenebat ore dimisit cibum $\mathrm{Nec}$, quem petebat, adeo potuit Attingere.
'On the one hand, he let the food he held escape from his mouth, and on the other hand he cannot catch the one he desired.'

(Phaedrus, Fables, I, 4, 6-7)

The inverse order is also possible: Illum a te tanti fieri nec mirror et gaudeo 'That you attach great importance to him, on the one hand I am not surprised and on the other hand, I am delighted'.

$\$ 8$ Finding the junctive after the second conjunct is quite rare. The process does exist in Latin, however, where it appears to be inherited from Indo-European: Senatus populusque Romanus 'the Senate and people of Rome', terra marique 'on land and on sea', domi bellique 'in peace as well as in war.' This process unifies the two conjuncts in a more intimate manner than the other process and creates a group that is more strongly unified.

$\$ 9$ The junctive after the second conjunct also appears in Greenlandic:

\begin{tabular}{ccc}
\hline Tiki-mat & kia-zu-ñeR-mi-lo & masa-Ki-mat \\
when he arrived & of sweat and & was drenched \\
'When he arrived, he was wet with sweat.'212
\end{tabular}

$\$ 10$ A postposed junctive can also be repeated: Gr. patếr andrôn te theôn te 'the father of men and gods' (Homer, Iliad, I, 544).

193. Finck, Die Haupttypen des Sprachbaus, 1910, Leipzig, Teubner, p. 44. 
$\$ 11$ But the expression that is by far the most frequent in Greek consists of combining the postposed junctive with an interposed junctive in such a way that it appears as though two junctives are present: Atreídai te kai álloi euknếmides Akhaioí 'Atrides and other Greeks with nice greaves'.

$\$ 12$ As one can see, the position of the junctive on the spoken chain can affect the linear structure in diverse ways.

\section{Chapter 139. Semantic varieties of junctives}

$\$ 1$ Concerning the semantic variety of junctives, the first distinction one should make concerns their structural position. Some junctives serve to join subordinate nodes as often as they do to join structural centers. In other words, they are just as often junctives of words as they are junctives of sentences. Others, in contrast, are more narrowly specialized at joining two structural centers; in other words, they are generally only junctives of sentences.

\$2 The first type, having adapted to more diverse circumstances, expresses a notion that is more flexible and more general. One distinguishes between two principle nuances: the adjunctive junctive and the disjunctive junctive.

$\$ 3$ The adjunctive junctive in French is et 'and'. As in many languages, it has the particularity of agreeing with the negation. It is thus expressed by its negative variant $n i$ 'nor' (Chapter 90).

$\$ 4$ Note the particular value of encore 'still, yet' (cf. Chapter 37, \$33) as a junctive: Mais ce qui les intéressait le plus c'étaient encore les copistes 'But what interested them the most was still the copyists' (Zola, L'Assommoir, Chapter 3, p. 83).

$\$ 5$ The disjunctive junctive in contrast is ou 'or', which serves to mark the alternative between two terms. The reinforced variant ou bien 'or even' has the effect of emphasizing the alternative in a manner that is particularly energetic.

$\$ 6$ Note that these junctives, which can be junctives of words as well as of sentences, show identical linear variety. Thus they are particularly subject to being duplicated: Fr. (et) l'un, et l'autre '(and) the one and the other'; ni l'un, ni l'autre 'neither the one nor the other'; (ou) l'un, ou l'autre '(either) the one or the other'. In an enumeration, they prefer to be placed only between the two last joined elements: le roi, l'âne, et moi 'the king, the donkey, and me'; le roi, l'âne, ni moi 'the king, the donkey, and not me'; Avant l'affaire, le roi, l'âne, ou moi, nous mourrons 'Before the matter, the king, the donkey, or me, we will die' (La Fontaine, Fables, VI, 19).

\section{Chapter 140. Antinomic junctives}

$\$ 1$ In contrast to the previous ones, junctives that are uniquely for sentences do not have to have the same flexibility to adapt. They often take on a semantic nuance conforming to 
the relation between the meanings of the two sentences. Since the junctive introduces the second sentence, it underlines the semantic orientation in relation to the first sentence and thus most often permits one to see the direction in which the thought is evolving and what the result of the idea is going to be.

\$2 From this point of view, one can compare the role of junctives of sentences to that of arrows at a forking of paths. The arrows point to the paths that are offered to the traveler. Hence one can say that they are the sign posts of the sentence.

$\$_{3}$ Junctives are therefore very useful, since they can serve to mark the articulations of the sentence. A sentence for which all the articulations are emphasized by a junctive is easily comprehensible. One is, though, dealing with a style that is a bit wordy.

$\$ 4$ But the richness of junctives presents a danger: one could take their logical value as primary in order to hide an absence of a firm thought behind apparent clarity. Stated otherwise, one is dealing with a thought process without actual thought, like a sign post for indicating paths in the absence of the paths.

\$5 Furthermore, a really strong thought can easily arise from a junctive; it has its own internal vigor. One is dealing with minimalist style.

$\$ 6$ One can therefore easily perceive that it is possible to imagine an empty thought, a thought process without actual content. Such is the case in the following composed phrase, which consist only of empty frames: Eng. You know well that... and that... But... Yet... So...' One could abbreviate this with QED (quod erat demonstrandum). The proof has perfect logic, and is even luminous, but it ignores what has been demonstrated.

\$7 The possibility to think vacuous thoughts helps one understand the primordial utility of junctives. This is why to understand a foreign language and disentangle texts in that language, it is essential to master as soon as possible the semantic mechanisms of the junctives that show the direction of the sentence. Before having understood the precise semantic value of the sentence, one knows in which direction to seek it.

$\$ 8$ Subject to semantic nuances, the junctives of sentences border on adverbs, so that distinguishing between the two can be difficult. An adverb such as cependent 'however', for example, often presents a meaning that is closely related to that of the junctive mais 'but'.

$\$ 9$ Sentence junctives are of two different types: antinomic junctives, which emphasize an opposition, and dialectic junctives, which conform to the contours of logical reasoning.

$\$ 10$ The most common of the antinomic junctives in English is the adversative junctive but, which expresses the most general contrast: good but expensive.

$\$ 11$ A certain number of adverbs can serve to follow the adversative but; they add quite delicate semantic nuances. The French adverbs cependant and pourtant add a concessive nuance, which is weaker in cependant and more energetic in pourtant: Le temps menace, cependant il fait beau 'The weather is threatening, however it is nice'; Le sol est mouillé, pourtant il n'a pas plu 'The earth is wet, although it did not rain'. The adverb néanmoins 'nevertheless' indicates a restriction: Je suis très pressé, néanmoins je tâcherai de trouver 
quelques minutes pour vous recevoir 'I am in a big hurry, nevertheless I will try to find a few minutes to see you'. The adverb toutefois 'notwithstanding' indicates an exception: L'appartement est confortable, toutefois, il ne comporte pas d'ascenseur 'The apartment is comfortable, notwithstanding it does not have an elevator'.

$\$ 12$ In French the most frequent adversative is mais 'but', and in German aber 'but': bon mais cher; gut aber teuer 'good but expensive'. In Russian the same junctive is no: xorošo no dorogo 'good but expensive'.

$\$ 13$ Worth noting is that the terms that are linked by these junctives can swap positions on the spoken chain, which produces the opposite meaning of course and does not necessitate that the junctive be changed: Eng. expensive but good, Fr. cher mais bon, Ger. teuer aber gut, Rus. dorogo, no xorošo.

$\$ 14$ One can discern two quite subtle nuances of opposition according to whether one passes from a negative notion to a positive one, or from a positive notion to a negative one, as if the one compensated for the other.

$\$ 15$ If one intends to change from a negative to a positive, English will commonly employ on the other hand, Fr. en revanche, Ger. dafür, and Rus. zato: Eng. I had a dreadful lunch, on the other hand, I had an excellent dinner.

$\$ 16$ When a negative notion motivating the adversative junctive mais 'but' is not expressed, the mais can take from this omission the value of emphasis often expressed by the tone of the element that introduces the sentence: Nous vous croyons capables de tout, mais de tout 'We believe you to be capable of anything, really of anything at all' (Las Cases, Mémorial de Sainte-Hélène, 16, VII, 1816).

$\$ 17$ If, in contrast, one is interested in changing from positive to negative in French, one increasingly tries to employ the locution par contre 'in contrast', which was condemned by the purists not long ago: J'ai fait un excellent déjeuner, par contre j'ai fait un dîner exécrable 'I had an excellent breakfast, in contrast, I had a dreadful dinner'.

$\$ 18$ In order to emphasize the opposition between the first positive term and the second negative term - in cases where one is not inclined to place the adversative junctive in front of the latter term - one can readily choose to place an adverb in front of the first term. This adverb is then called a pre-adversative. The pre-adversative marks the concession that the negation serves to turn into a reinforced affirmation. The meaning of the pre-adversative is thus a little bit like it is true that.

$\$ 19$ The pre-adversative is so well specialized in this role - a role consisting of sweetening the pill before criticism - that one expects above all a forewarning heralding a second term that is opposed to the first one. A shower of praise introduced by the pre-adversative is then worrying, because we are still anxious to know the criticism that will follow, the feared but. 
\$20 In French the pre-adversative is certes 'certainly', if it is strongly accented, but bien 'it is true, indeed' if it is softer.

...Je vois bien quelque chose, Mais je ne sais pour quelle cause Je ne distingue pas très bien.
'I have indeed seen something,

But I do not know why

I cannot discern what it is.'

(Florian, Fables, II, 7)

$\$ 21$ Note as well the use of encore (cf. Chapter $37, \$ 33$ and $139, \$ 4$ ) as a pre-adversative: Passe encor de bâtir: mais planter à cet âge! 'It's one thing to build, but to plant at this age!' (La Fontaine, Fables, XI, 8, Le vieillard et les trois jeunes hommes 'The old man and the three young men').

$\$ 22$ In German the pre-adversative is zwar 'admittedly', which is very strong: Zwar brechen die Tapfersten durch, aber die Verwirrung wächst 'Admittedly the bravest are breaking through, but the confusion is growing' (Goethe, Fr. Campaign, September 27).

$\$ 23$ In addition to the antinomy between opposing terms, one can distinguish between a attenuated variant that establishes a contrast between distinct terms and a stronger variant that establishes an opposition between contradictory terms.

$\$ 24$ The attenuated variant is characteristic of the Russian junctive $a$, which simply marks a lack of similarity between two terms. One senses the difference between Rus. $a$ and no in the two examples that follow: Ja xotel govorit', a on xotel pisat' 'I wanted to talk, he wanted to write' and Ja xotel govorit', no ne mog 'I wanted to write, but could not'. Since they are distinct, the various terms joined by $a$ can be reversed without it being necessary to change the junctive: On xotel pisat', a ja xotel govorit', 'He wanted to write, I wanted to talk'.

$\$ 25$ As one can see from the preceding examples, the simplest way to render the Rus. $a$ to English is to juxtapose the two joined terms. In emphasizing somewhat the resulting opposition by using a junctive, one risks weakening it.

$\$ 26$ The accented variant establishes an opposition between contradictory terms, that is, between terms that exclude each other: Fr. Alfred réussira, au contraire Bernard échouera 'Alfred will succeed, in contrast Bernard will fail'. It should be evident that someone cannot both succeed and fail simultaneously. Like other contrasts, the contradictory terms can be swapped: Bernard échouera, au contraire Alfred réussira. The locution au contraire in contrast, to the contrary' can be reinforced by bien or tout: bien au contraire, tout au contraire 'quite to the contrary'.

$\$ 27$ In view of the strict opposition that it implies between the terms that it joins, au contraire can only be employed between two terms that are sufficiently contradictory. Hence au contraire is inappropriate when one simply has to express a distinct or different matter. A 
gentleman who steps on the toes of a lady excuses himself by saying J'espère que je ne vous ai pas fait mal 'I hope I did not cause you pain'. If the lady responds Au contraire, it indicates forcibly that the matter did not cause pain, but the response contains ridicule and has the effect of masking discontent at the clumsiness of the gentleman behind a polite response.

$\$ 28$ Ger. sondern 'but rather' (cf. Chapter $88, \$ 14$ ) precedes a contradictory affirmation of a preceding negation; Dieses Buch ist nicht rot, sondern blau 'This book is not red, but rather blue.' In this case, Fr. mais 'but' can be expressed as mais bien. One can also use mais au contraire or simply au contraire.

\$29 Worth noting is that the terms joined by Ger. sondern cannot be exchanged. One cannot say ${ }^{\star}$ Dieses Buch ist blau, sondern nicht rot 'This book is blue, but rather not red'. The negative character of the first term is in fact obligatory.

\$30 A paradoxical matter concerns the Russian junctive $a$. It acts as an attenuated variant that establishes an opposition between different terms. It also acts as an accentuated variant that establishes a contrast between contradictory terms. The first of these contradictory terms is negative: Ėta kniga ne krasnaja, a sinjaja 'This book is not red, but blue'.

\section{Chapter 141. Dialectic junctives}

$\$ 1$ Having the function to show the direction of thought and to emphasize detours, junctives excel at specifying the relations of cause and effect between the joined terms. We reserve the name dialectic junctives for those that assume this role.

\$2 The simplest dialectic junctive is the causal junctive; it introduces the cause that explains the effect expressed by the preceding term. In French, the most common causal junctive is car 'because'. One also sometimes encounters en effet 'indeed' or even c'est qu'en effet 'and indeed', the latter expressing a minor pleonasm: Rothschild peut payer, car il est riche 'Rothschild can pay, because he is rich'; Rothschild peut payer, en effet, il est riche 'Rothschild can pay; indeed, he is rich'; Rothschild peut payer, c'est qu'en effet il est riche 'Rothschild can pay, and indeed, he is rich'.

$\$ 3$ The inverse junctive, which plays the opposite role of the causative, is consecutive. It announces the effect that is the consequence of the preceding term. In French, the most common consecutive junctive is donc 'so' or one of its variants, c'est pourquoi 'that is why' or par conséquent 'as a consequence', the latter establishing a narrow connection to the reasoning of logic. One can also employ aussi and so', which commonly evokes inversion: Rothschild est riche, donc il peut payer 'Rothschild is rich, so he can pay'; Rothschild est riche, c'est pourquoi il peut payer 'Rothschild is rich; that is why he can pay'; Rothschild est riche, par conséquent il peut payer 'Rothschild is rich, and as a consequence, he can pay'; Rotschild est riche, aussi il peut payer 'Rothschild is rich, and so he can pay', or better Rothschild est riche, aussi peut-il payer. 
$\$ 4$ Since one of the joined terms expresses the cause and the other the effect, their respective order on the spoken chain can be switched according to whether they are joined by the causal junctive car or by the consecutive junctive donc; Rothschild peut payer, car il est riche 'Rothschild can pay, because he is rich'; Rothschild est riche, donc il peut payer 'Rothschild is rich, so he can pay'.

$\$ 5$ A frequent occurrence is the appearance of a consecutive junctive that is preceded by a clause, this clause being introduced by a special junctive, which functions to introduce a new fact. This junctive is or 'now, but'. It has a marked position in the reasoning of syllogisms. After the expression of the first term, one is interested in drawing a conclusion from reason. Thus classical syllogisms appear in the following form: Tous les hommes sont mortels; or Socrate est un homme; donc Socrate est mortel 'All men are mortal; now Socrates is a man, so he is mortal.

\section{Chapter 142. Justificational junctives}

$\$ 1$ Special attention must be granted to justificational junctives. These junctives occupy a position in the set of logical expressions that is clearly defined but often poorly described.

\$2 Justificational junctives are causal, since when they appear, the two joined terms appear in the spoken chain in the same order as when the causal junctive is used and in the inverse order to when the consecutive junctive is used.

$\$ 3$ There is, however, a clear nuance that separates justificational junctives from causal junctives. The latter merely identify the preceding clause as the effect, whereas the former present the explication of this effect in the form of a justification, as if the mind sees itself as venturing out and thus feels the need to justify its conclusion.

$\$ 4$ A certain number of junctives in French and German can assume the justificational role, but in neither of these languages is the junctive limited to only the justificational role. Stated otherwise, there is no justificational junctive that is specialized in this role. It is therefore necessary to first seek a prototype of the mechanism and to study its function.

$\$ 5$ In contrast to French and German, the existence of a specialized justificational junctive is typical of most Slavic languages, as if the junctive were part of a special dialectic process that is particularly dear to the Slavic mentality. One first produces an idea and then establishes its legitimacy after the fact.

$\$ 6$ Strikingly, the majority of Slavic languages have a justificational junctive that performs the same role in every language of the family. The form of the junctive varies, in contrast, from the one language to the next, and further, the form of the junctive in each does not derive from the same root. Thus the function is characteristic of the Slavic languages, but not of a particular word. 
\$7 In order to express this idea, one could, considering the original form common to the Slavic languages and that this form survives in them today, speak here not of a word that has changed according to meaning, but rather of the means of expressing the meaning changes.

$\$ 8$ In Russian the supporting word is ved': Rotšild možet zaplatit', ved' on bogat 'Rothschild can pay, for he is rich'. The Russian speaker begins with the statement that Rothschild is capable of paying. He does not then add the cause of his assertion in the form of an explication, but rather he adds the cause in the form of a justification.

$\$ 9$ The translation of the jusficational junctive into French is delicate. In any case, one should avoid the consecutive junctive donc 'so', which constitutes a false rendering of the characterized meaning. To convince oneself of this, it suffices to consider that it would be illogical to say in Fr. Rothschild peut payer, donc il est riche 'Rothschild can pay, so he is rich'. Indeed, it is not the case that Rothschild is rich because he can pay, but rather he can pay because he is rich. The cause should not be taken as the consequence.

$\$ 10$ The most common justificational junctive is expressed quite simply in French with the adversative junctive mais 'but, for', which, however, is not specialized at all in the role of a justificational junctive: Rothschild peut payer: mais il est riche! 'Rothschild can pay, for he is rich!' The French expression c'est que 'it is that' can also be employed; this expression is commonly preceded by a mais of protest: Rothschild peut payer: c'est qu'il est riche! Or better yet: Rothschild peut payer: mais c'est qu'il est riche!.

$\$ 11$ Another means of expressing the meaning involves an intervening savoir 'know', which justifies the consequence after the fact via the knowledge that one had of the cause: Rothschild peut payer: vous savez bien qu'il est riche, lit. 'Rothschild can pay: you know well that he is rich.

\$12 Moreover, one should acknowledge that the justificational word in Russian and Slovak $v e d$ ' is derived from a stem that has the meaning of knowing: Rus. vedat' 'know'.

$\$ 13$ But the process that is most elegant for rendering justificational meaning in French is to make a question out of the following term. This term is negative if the preceding term is positive, and positive if the preceding term is negative: Rothschild peut payer: n'est-il pas riche? 'Rothschild can pay; is he not rich?'. Conversely, one would say of a poor man: Job ne peut pas payer: est-il riche? 'Job cannot pay: is he rich?'.

$\$ 14$ The justificational junctive is employed frequently in Russian in written language, where it promotes the progression of reasoning, as well as in spoken language, where it evokes much vivacity:

Skaži-ka djadja, ved' ne darom Moskva, spalënnaja požarom

Frantsuzu otdana?

Ved' byli-ž dxvatki boevye?
'Say, Uncle, it is not for nothing that Moscow, leveled by a blaze, has been handed over to the French? For here really were skirmishes where people fought?

(Lermontov, Borodino) 
\$15 The justificational junctive is found with exactly the same use in Slovenian (saj), in Polish (więc), ${ }^{194}$ in Czech $\left(v z ̌ d y t^{\prime}\right)$, and in Slovac (ved'): Czech Vždyt' ty jsi byl pravý umělec 'But you were a true artist' (Fr. Langer, Periferie, p. 20).

$\$ 16$ The justificational junctive even extends beyond the Slavic languages, since it is present in the form doara in Romanian, where the influence of Slavic has been considerable. This influence resides not so much on the words of the languages, which are for the most part of Latin origin, but rather on the meaning that they express.

$\$ 17$ In French, the word that is employed most often with the value of a justificational junctive is, as we have seen above ( $\$ 10$ and 15 ), the adversative junctive mais.

$\$ 18$ And as we have seen above ( $\$ 9$ ), the justificational junctive is never expressed in good French with the junctive donc, which has consecutive value, so it expresses the opposite meaning in a sense. However, it should be noted that Slavic speakers who speak French have a tendency to employ Fr. donc 'so' with the value of the Russian justificational junctive. This unusual practice, which can be revealed only by way of abstract and nuanced analysis, gives their French a strange syntactic resonance, which is part of what one calls "Slavic charm". This expression, which, again, is strange in French, was noted by Roger Martin du Gard, who did not hesitate to place the following sentence in the mouth of a Russian:

Il demanda au Russe: - Praznovski est ici? - Il est donc arrivé ce matin.
'He asked the Russian: - Is P. here?

- So he arrived this morning.'

(Les Thibaut, VII, 19, p. 241)

$\$ 19$ In German the supporting junctive is $j a$ 'you know' placed after the verb: Er kann

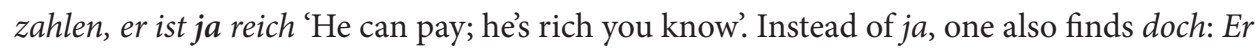
kann zahlen, er ist doch reich. As we have stated, neither of these two words is specialized with justificational value. The more frequent $j a$ has the meaning of 'yes' and doch of 'but'.

\section{Chapter 143. Structural variety of junction}

$\$ 1$ The varying positions of appearance for the junctives on the spoken chain must not be confused with the structural variety that results from joining the conjuncts and that appears in the stemma.

194. Cf. Zur Bedeutungsentwicklung der polnischen Partikel więc, Lund Universitets Arsskrift, N. F. Avd. 1, Bd. 33: 5, Lund 1937. 
$\$ 2$ As we have seen (Chapter $136, \$ 4$ ), as soon as two words are joined with a vertical connection, the stemma takes on the form of a triangle. The resulting study of these triangles permits one to acknowledge the varieties of form that can appear in the stemma.

$\$ 3$ In order to facilitate this study by employing an adequate terminology, the best thing to do is to adopt the common terminology of heraldry: coped, shod, and dressed. These terms provide the precise ability to designate different geometric types that are susceptible to appearing in the stemma.

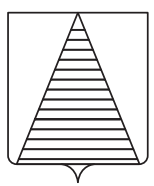

Coped

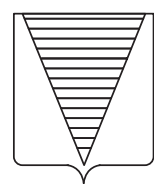

Shod

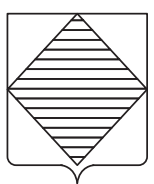

Dressed

$\$ 4$ The coped stemma is the most common type. It occurs every time a subordinate node is duplicated; the duplicate is a first actant in Alfred and Bernard love their parents (Stemma 250); the duplicate is a second actant in Alfred loves his father and his mother (Stemma 251), and it is an attributive adjective in a fat and stout cat (Stemma 252).

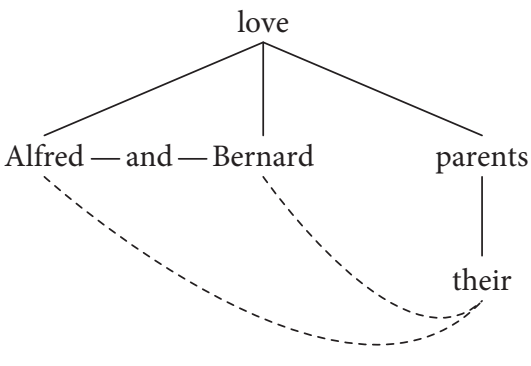

Stemma 250

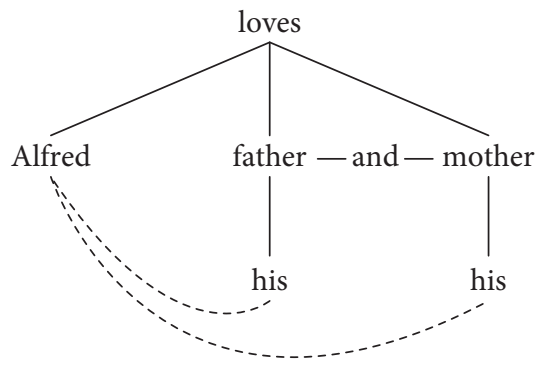

Stemma 251

\$5 There can be junction between a term without a subordinate and the same term with a subordinate. Indeed the meaning of the two is not identical, since that of the second is restricted by a subordinate that is adjoined to it (Stemma 253).

Toute sa personne velue Représentait un ours, mais un ours mal léche.
'His entire hairy person

Represented a bear, but an unkept bear'

(La Fontaine, Fables, XI 7) 


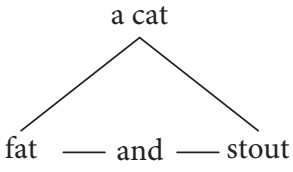

Stemma 252

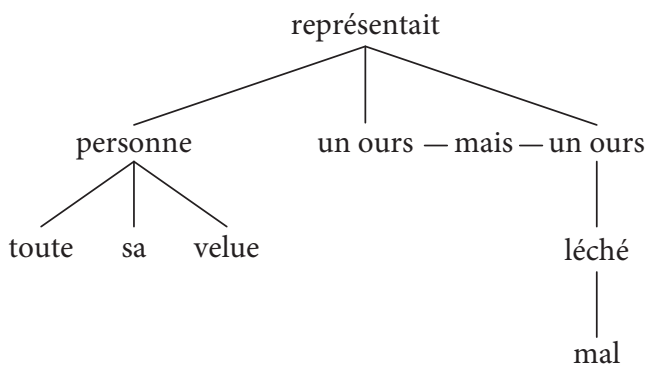

Stemma 253

$\$ 6$ The inverse of this situation occurs when a shod stemma presents itself, where there is a duplication of the governing node, for example in the sentence The children laugh and sing (Stemma 254).

\$7 Lastly, a dressed stemma is one that results from the superimposition of the coped and shod types. The two triangles join base to base creating a diamond shape. The dressed stemma is present when the duplicated node is both the subordinate of a unique governing node and the governor of a unique subordinate node. This is the case, for instance, when the duplicated actant governs a shared attributive adjective: Alfred buys new books and folders (Stemma 255).

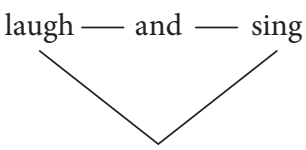

the children

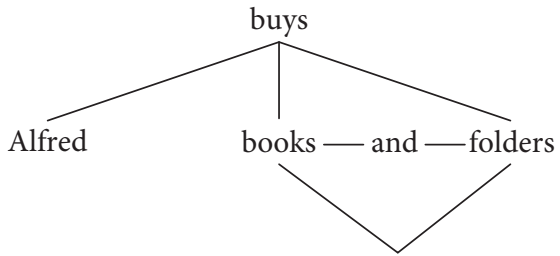

new

\section{Stemma 254}

Stemma 255

$\$ 8$ The preceding types are susceptible to being joined to each other by a superior node, which provides infinite variety. For example, one can have double-coped, double-shod, or double-dressed junction.

$\$ 9$ The sentence The boys and the girls collect buttercups and daisies provides a doublecoped stemma (Stemma 256).

S10 Similarly, the following sentence provides a double-dressed stemma: These children give new books and folders to their friends and poor schoolmates.

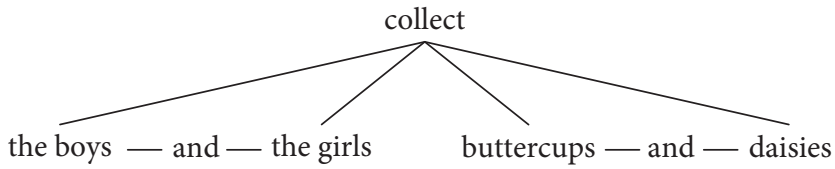




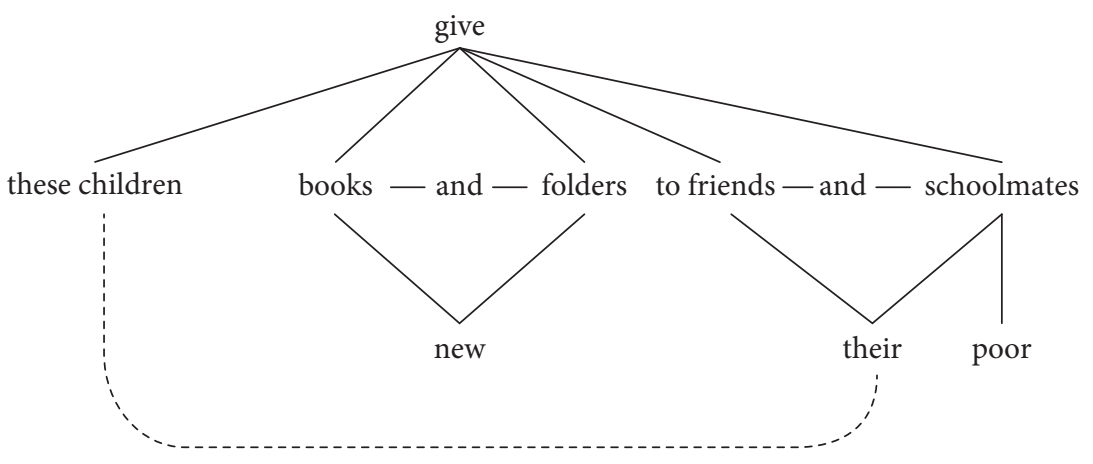

Stemma 257

$\$ 11$ One can also have combinations that are simultaneously coped and shod and dressed among each other. Thus one will have coped-shod junction in the sentence Alfred and Bernard work and Charles sings and laughs (Stemma 258).

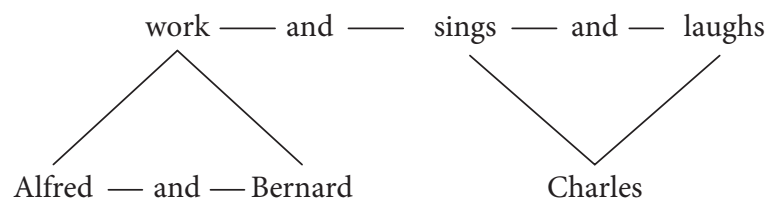

\section{Stemma 258}

$\$ 12$ In a word, all combinations of coped, shod, and dressed are possible, under the condition that the figures do not come to interfere with each other. Such interference would result in crossing or plexus, which are complications of a special type that are examined in the next chapter.

\section{Chapter 144. Plexus}

$\$ 1$ If when reaching from each of the two extremities, a junction line cuts across at least two vertical connection lines, two of the lines necessarily cross in the tree. This is what happens, for instance, when the two terms of a duplicated node each govern two subordinates, for instance in a sentence like The children love and honor their parents (Stemma 259).

\$2 The crossing that appears in Stemma 259 is heterogeneous, since it occurs with two lines that express connections of different types. Essentially, one is dealing on the one hand with a connection line between a verbal node and the second actant, and on the other hand with a connection line between the other verbal node and the first actant. 


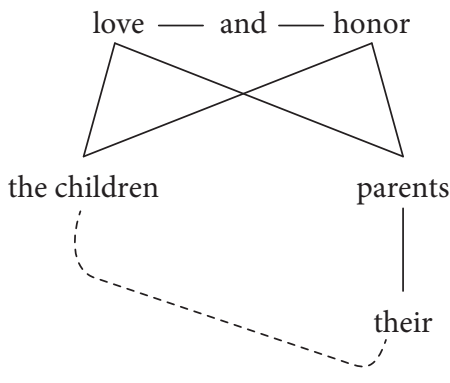

Stemma 259

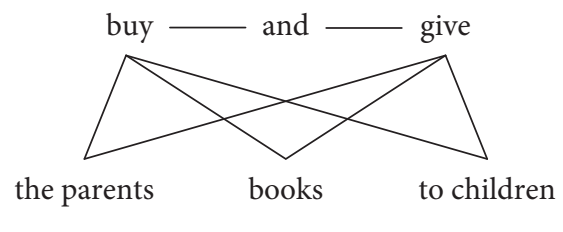

Stemma 260

$\$ 3$ The sentence for Stemma 259 is, like the preceding one (Chapter 135, \$4), the result of an addition: The children love their parents + The children honor their parents $=$ The children love and honor their parents, which one can represent using a schema of arithmetic in the following manner:

\begin{tabular}{ll}
\hline The children love & their parents. \\
The children honor & their parents. \\
\hline The children love and honor & their parents.
\end{tabular}

$\$ 4$ As soon as the number of subordinates that are connected to the governor reaches three, the number of crossings cannot be less than three. Such is the case for the sentence The parents buy and give books to the children (Stemma 260), where the stemma contains three heterogeneous crossings.

$\$ 5$ The more the duplicates are numbered and varied, the more the number of crossings increases. They very quickly generate a crisscrossing of lines in the stemma to which we give the name plexus.

$\$ 6$ The facts become more complicated as soon as duplication occurs amongst multiple connected nodes, the one being a governor and the other being a subordinate. Indeed, each of the terms of one of the nodes is potentially in connection with the terms of the other. The number of junction lines, that is the number of possible combinations between the different terms of each node, is expressed not by the sum of these nodes, but by their product.

\$7 Take for example the sentence Alfred and Bernard play and laugh, the governors being two in number (play and laugh) and the subordinates also being two in number (Alfred and Bernard). The number of coordination lines equals the number of possible combinations: $2^{2}=4$ (Stemma 261).

$\$ 8$ The crossing that one obtains in the preceding example is different from what we have seen above in $\$ 2$. The crossing is no longer heterogeneous, but rather homogeneous, since it concerns two connection lines that both connect one of the nodes of the duplicated verbs to one of the terms of the duplicated first actant. 


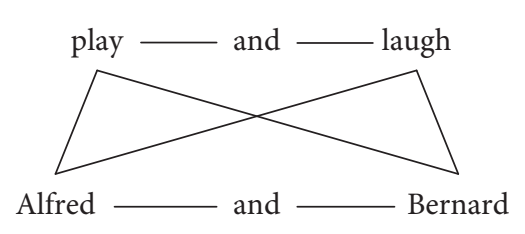

Stemma 261
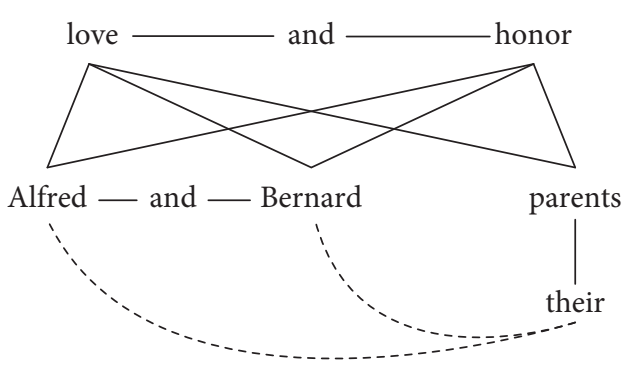

Stemma 262

$\$ 9$ Moreover, a homogeneous crossing can be complicated by a heterogeneous crossing. Hence in the sentence Alfred and Bernard love and honor their parents, we have, in addition to the homogeneous crossing that occurs with the connection lines that link the duplicated verbal node and the duplicated first actant, a heterogeneous crossing that occurs with these same connection lines and one of those that links the same duplicated verbal node to the shared second actant (Stemma 262).

\$10 We also have a heterogeneous crossing in the inverse case, that is, in a sentence like The children love and honor their father and their mother, where the crossing occurs between one of the connection lines that links the duplicated verbal node to the shared first actant and those lines that link one of the same duplicated verbs to a second actant that itself is also duplicated (Stemma 263).

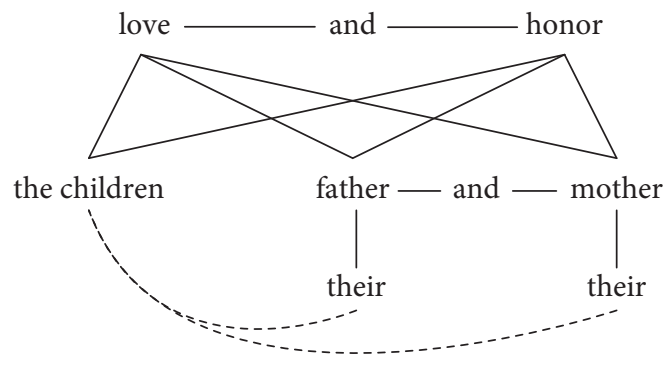

\section{Stemma 263}

$\$ 11$ Of course the crossing is also heterogeneous when it occurs between connection lines that link the duplicated verbal node to a first actant which is also duplicated and the lines that link the same duplicated verbal node to a second actant that is also duplicated (Stemma 264). 


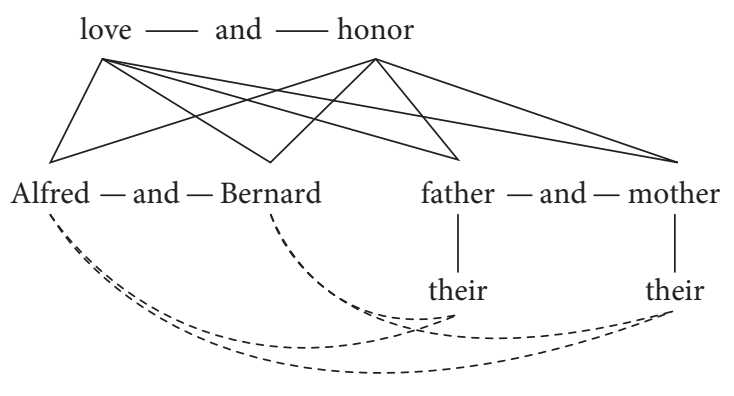

Stemma 264

\$12 As one can see, as soon as several terms in connection are duplicated, plexus obtains. If the number of duplications of each term in connection is equal, the mathematical formula that permits one to calculate the number of connection lines that form the plexus is easy to give. It consists of taking the square of the number of joined terms with each node and multiplying it by the number of connections. Thus in the example above, the joined terms are two for each node, two for the verbal node as well as for the subordinate nodes of the first and second actants, so the base number is 2 and its square is $2^{2}$; on the other hand, the number of connections is two: the connection between the governing verbal node and the first actant and the connection between the governing verbal node and the second actant; in conclusion, we multiply the square $2^{2}$ by 2 , that is $2^{2} \times 2=4 \times 2=8$.

$\$ 13$ But if one no longer wants to calculate the number of connections that the plexus has, but rather the number of possible combinations, i.e. the number of additional sentences, the formula is calculated differently. Indeed, one no longer has to multiply the number of terms joined to each node by the number of connections, but rather one has to provide the number of connected nodes as explained. Thus in the example above, the number of terms coordinated to each node is two and the number of nodes in connection is three. The number of possible combinations will therefore be $2^{3}=8$.

$\$ 14$ In this particular case, the number of connection lines and possible combinations is the same, namely 8 . But as soon as the number of nodes in connection and, more importantly, the number of duplicated terms of each node increases, the total number of possible combinations - that is, the number of additional sentences - increases more rapidly than that of the connection lines.

$\$ 15$ If we take, for example, a duplicated verb with three actants each of which is in turn duplicated, whereby the number of duplicated terms is two each time, the number of junction lines will be $2^{2} \times 3=12$, whereas the number of additional sentences will be $2^{4}=16$. This is the case in the sentence The father and the mother buy and give the books and folders to Alfred and to Bernard (Stemma 265). 


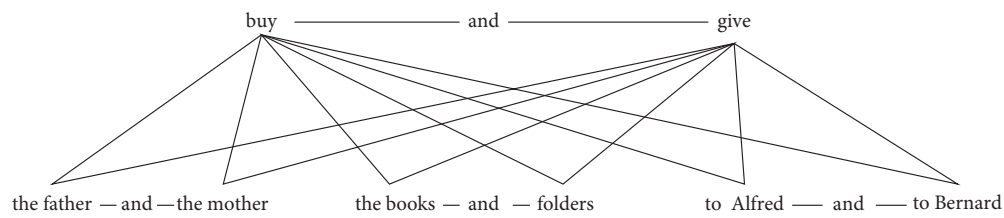

Stemma 265

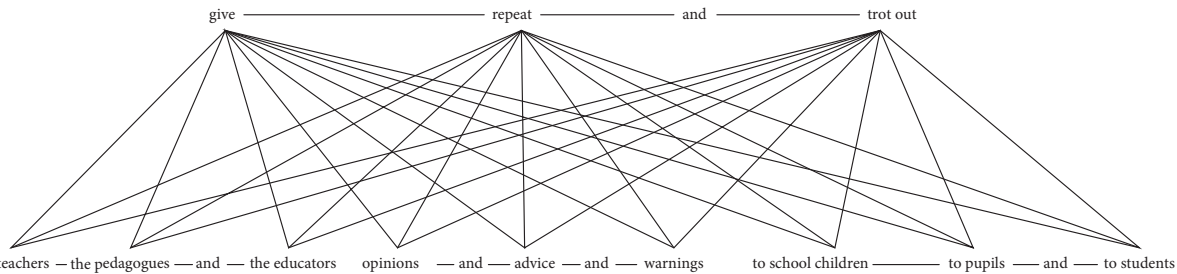

Stemma 266 
$\$ 16$ The progression is very rapid. If we now take, for example, a duplicated verb with three actants each of which is also duplicated, the number of duplicated terms being 3 each time, the number of junction lines will be $3^{2} \times 3=27$, whereas the number of additional sentences will be no less than $3^{4}=81$. This is the case in the sentence The teachers, the pedagogues, and the educators give, repeat, and trot out opinions, advice, and warnings to schoolchildren, to pupils, and to students (Stemma 266).

$\$ 17$ This sentence, even though it contains only 27 connection lines, is the result of no less than 81 different sentences:

\begin{tabular}{|c|c|c|c|}
\hline The teachers & giveo & pinions & to the pupils. \\
\hline The pedagogues & give & opinions & to the pupils. \\
\hline The educators & give & opinions & to the pupils. \\
\hline The teachers & repeat & opinions & to the pupils. \\
\hline$\ldots$ & & & \\
\hline
\end{tabular}

$\$ 18$ The stemma here is merely the image of connections that are established in our mind. Hence the speaker who produces the sentence above expresses the content of 81 different sentences with a single sentence. One is mystified by the complexity, granularity, and power of the instrument that the gift of language has placed at our disposal.

\section{Chapter 145. Bifid sentences}

\$1 When there is a duplication of two connected nodes and as a consequence, a duplication of the connection itself, two cases can present themselves according to whether the junction is total or partial.

$\$ 2$ So far we have examined only total junction, that is, those junctions that cross each other at the extremities in such a manner that each of the two duplicated terms of the nodes remains connected to the two duplicated terms of the other.

$\$ 3$ We are now going to examine partial junction, that is, those cases that have crossing lines at one extremity of the connection but not at the other. The latter two terms are not connected to each other, but they remain independent, each being connected to only one of the terms at the other extremity.

$\$ 4$ The extremity at which the junction is established is always that of the governor. The two subordinate terms remain independent.

$\$ 5$ We will give to sentences of this type the name bifid sentence by virtue of the structure of their lower extremity. Such structures resemble the bifid leaves in botany, as though they are split into two separate parts by a quite deep acute angle (see figure). 


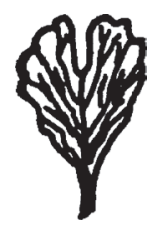

Bifid leaf

$\$ 6$ The stemmas of bifid sentences are completely different from those of total junction, the absence of the lower junction producing a much different shape.

$\$ 7$ Indeed, instead of obtaining triangles as in the coped stemmas (Chapter $143, \$ 4$ ) or dressed stemmas (Chapter 143, \$7), we merely have corners that are formed by the superior sides of the triangles.

$\$ 8$ Moreover, the meaning is not at all similar in these cases. As an example, take the situation presented by La Fontaine in his fable Le singe et le chat 'The monkey and the cat' (XVI, 9). One can sum up their cooperation in the sentence Raton (the cat) extracts and Bertrand (the monkey) eats the chestnuts. This sentence is bifid, since there is a division of labor and because the one extracts and the other eats the nuts (Stemma 267).

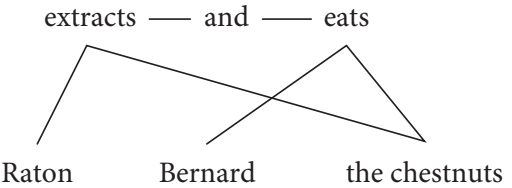

Stemma 267

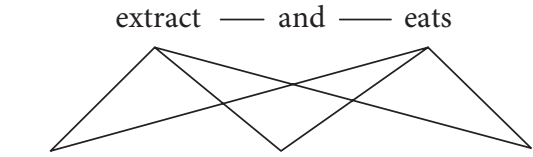

Raton - and - Bernard the chestnuts

$\$ 9$ If, in contrast, we examine the sentence Raton and Bertrand extract and eat the chestnuts, the meaning is completely different. One is no longer dealing with the exploitation of the one by the other, but rather they are working and consuming together (Stemma 268).

\$10 In the first case, each of the verbs, since it governs only a single first actant, remains in the singular, whereas in the second case, the verbs each govern both of the joined first actants and they therefore appear in the plural.

$\$ 11$ Similarly, the first case brings just two sentences into play: Raton extracts the chestnuts and Bertrand eats the chestnuts. These two sentences allow for addition no more than a pear and an apple allow for addition.

$\$ 12$ The second case, in contrast, brings four sentences into play that one can easily add up: 


\begin{tabular}{|c|c|c|c|c|}
\hline \multirow{2}{*}{$\begin{array}{l}\text { Raton } \\
\text { Raton }\end{array}$} & & extracts & & the chestnuts. \\
\hline & $\begin{array}{l}\text { Bertrand } \\
\text { Bertrand }\end{array}$ & extracts & $\begin{array}{l}\text { eats } \\
\text { eats }\end{array}$ & $\begin{array}{l}\text { the chestnuts. } \\
\text { the chestnuts. } \\
\text { the chestnuts. }\end{array}$ \\
\hline
\end{tabular}

\$13 The bifid sentences are comparable to monsters that have two heads or two bodies. Also, we can authorize ourselves to use the same terminology as biologists: assimilating the head to the beginning of the sentence and the lower extremity of the body to the end of the sentence, we discern catadidymic sentences, which have the bifidity reaching downward, and anadidymic sentences, which have the bifidity reaching upward.

$\$ 14$ Ignoring the number of duplicated terms, catadidymic sentences are comparable to the dragon with multiple heads and anadidymic sentences to the dragon with multiple tails in the fable (cf. La Fontaine, Fables, I, 12).

$\$ 15$ As an example of a catadidymic sentence, we can take the example above (\$8): Raton extracts and Bertrand eats the chestnuts.

\$16 The duplicated governing node can be that of a verb and that of the same verb in the negative. Such is the case in the verse Le crime fait la honte et non pas l'échafaud 'The crime creates shame, not the execution scaffold' (Thomas Corneille, Le comte d'Essex, IV-3). The stemma for this sentence is as follows:

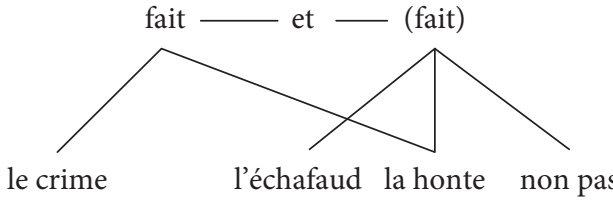

Stemma 269

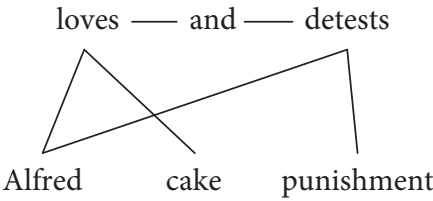

Stemma 270

$\$ 17$ The benefit of producing stemmas like these here becomes apparent in practice. For at first blush, most people are tempted to perceive them as anadidymic instead of as catadidymic, and in so doing to construe the term l'échafaud as a second actant like la honte, which renders the sentence completely unintelligible.

$\$ 18$ We have an example of an anadidymic structure in the sentence Alfred loves cake and detests punishment (Stemma 270). The structure of this sentence is the exact opposite of that for the sentence in $\$ 8$.

$\$ 19$ Similarly, the anadidymic sentence corresponding to the catadidymic sentence in $\$ 16$ is furnished by a sentence such as Alfred loves roses, not thorns (Stemma 271).

$\$ 20$ Sentences of this type admit structural variants of every sort, particularly in conversational style where they are rendered with particular liveliness: 
Anna: ... Un homme de trente-six ans, qui a fait la guerre, qui a vécu... C'est une femme expérimentée qui lui convient. Pas une jeune fille.
'Anna: ... A man of 36 years, who has been in war, who has lived... An experienced woman is suited for him. Not a young girl.'

(Louis Verneuil, Vive le Roi, p. 28)

\$21 Of course in a sentence where the verb has but a single actant, and where it is sometimes difficult to determine if this actant is a first or a second actant (Chapter $99, \S 5$ ), it is also difficult to discern whether one is dealing with a catadidymic or an anadidymic sentence. Such is the case in the verse: Il est bon de parler et meilleur de se taire 'It is good to speak and better to be silent' (La Fontaine, Fables, VIII, 10). The stemma (272) for this sentence is shown as follows:

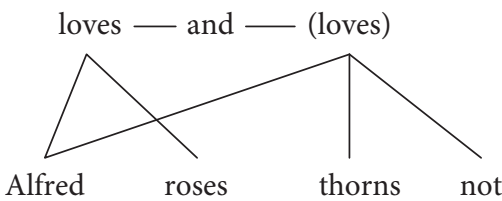

Stemma 271

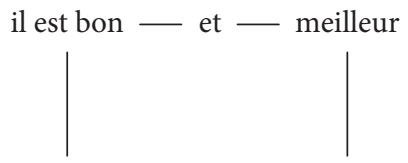

de parler de se taire

\section{Stemma 272}

\section{Chapter 146: Double bifidity}

\$1 It can occur that bifidity is duplicated, that is, that the sentence is split at the two ends, whereby the center is shared.

$\$ 2$ Sentences of this sort are simultaneously catadidymic and anadidymic. Continuing to be inspired by the terminology of biologists, we will call these sentences anacatadymic.

$\$ 3$ Take the following verse as an example: L'un portait sa cuirasse, l'autre son bouclier 'The one carried his armor, the other his shield' (Chanson de Malborough). There is no junction between the two primary actants l'un 'the one' and l'autre 'the other', nor between the two secondary actants cuirasse 'armor' and bouclier 'shield', but rather the central verb portait 'carried' is common to both of the two added sentences l'un portait sa cuirasse + l'autre portait son bouclier 'the one carried his armor + the other carried his shield'.

$\$ 4$ This sentence behaves like a dragon that has both multiple heads and multiple tails, but just one trunk. Or even like Siamese twins who are joined together back to back.

$\$ 5$ The stemma of doubly bifid sentences is delicate. Indeed, if one constructs it like Stemma 256, each of the two first actants, l'un and l'autre, corresponds to one of the second actants, cuirasse and bouclier. 
$\$ 6$ Yet each of the two actants is restricted in its bearing: the primary actant l'un 'the one' relates only to the second actant cuirasse 'the armor', and the first actant of the other relates only to the second actant bouclier 'the shield'. Each does not bear on the other second actant, i.e. l'un 'the one' does not bear on son bouclier 'his armor', and l'autre 'the other' does not bear on sa cuirasse 'his armor'.

$\$ 7$ In order to find a way of representing these facts in a stemma, one has to consider that the verbal node is not semantically duplicated, but rather structural duplication occurs, since its valents are twins, the one serving as the first first actant and the first second actant and the other as the second first actant and the second second actant.

$\$ 8$ The difficulty signaled above is resolved by rendering the twin valency of the verb using a short horizontal line that one places under the nucleus circle. Each end of this line represents one of the groups of twin valents. Using this line, the two midsections of the sentence can each build on a valency set. (Stemma 273).

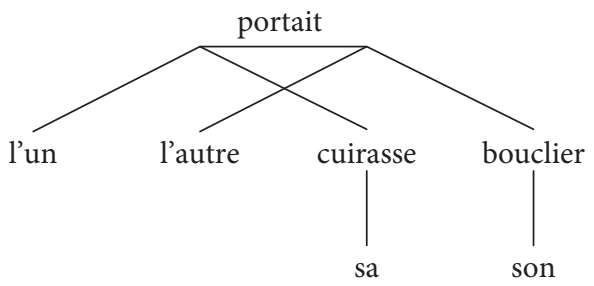

\section{Stemma 273}

\$9 Whenever such double bifidity occurs, one must resort to this type of stemmatic representation, for this is the only means to represent graphically the status that is reserved for the subordinate actants in relation to the communal verbal node.

\$10 Sentences with double bifidity are encountered frequently:

\begin{tabular}{|c|c|}
\hline $\begin{array}{l}\text {... L'huître est pour le juge, } \\
\text { Les écailles pour les plaideurs. } \\
\text { (La Fontaine, Fables, IX, 9) }\end{array}$ & $\begin{array}{l}\text { 'The oyster is for the judge, } \\
\text { the shells for the litigants.' }\end{array}$ \\
\hline $\begin{array}{l}\text { L'Angleterre prit l'aigle, } \\
\text { et l'Autriche l'aiglon. } \\
\text { (Victor Hugo, Les Chants du } \\
\text { Crépuscule, Napoléon II, IV, 6) }\end{array}$ & $\begin{array}{l}\text { 'England took the eagle, } \\
\text { and Austria the eaglet.' }\end{array}$ \\
\hline
\end{tabular}

$\$ 11$ The presence of anacatadidymic sentences is indicated in a special way when the one group of actants is l'un...l'autre 'the one...the other'. In addition to the examples in $\$ 3-8$, one has: 
L'un portait la sardine blanche,

L'autre le jaune baudrier.

(Nadaud, Les Deux Gendarmes)

Quant à son temps, bien le sut dispenser: Deux parts en fit, dont il soulait passer L'une à dormir, et l'autre à ne rien faire. (La Fontaine, Poésies diverses, 1 , Epitaphe d'un paresseux)
'The one carried the white peg,

The other the yellow strap.'

'Concerning his time, he knew to dispense it:

He made two parts of it, one of which he spent sleeping, and the other doing nothing.' (Epitaph of a lazy man)

\$12 Anacatadidymic sentences can involve an actant and a circumstant: The cat (introduced by a peasant in his pantry in order to catch the rat that is eating his cheese) ate the rat first and the cheese second.

$\$ 13$ In addition to simple bifid sentences, anacatadidymic sentences give rise to extreme and diverse complications:

\begin{tabular}{ll} 
L'Italienne ne croit être aimée & 'An Italian believes herself to be loved \\
de son amant que quand il est & by her lover only when he is capable of \\
capable de commettre un crime & committing a crime for her; an English \\
pour elle; l'Anglaise une folie, & woman an extravagance, and a French \\
et la Française une sottise. & woman a silly thing.' \\
(Chamfort) & \\
\hline
\end{tabular}

A person asked about his self-esteem responded: Very little when I reflect on myself, a lot when I compare myself to others.

\section{Chapter 147. Sentences with comparison}

\$1 Concerning bifidity, one has to grant special status to sentences that express a comparison, for the two compared terms are such that the one is interpreted with respect to the other, as if they are joined and can depend on the same governor.

\$2 From this point of view, the adverbs as and like that connect the compared terms assume the function of a junctive.

$\$ 3$ Of course in order for sentences that contain a comparison to be bifid, it is necessary for them to have at least one element of comparison that serves as the point of junction (cf. \$110). In other words, there has to be a certain parallelism between the two joined terms. Thus if the comparison bears on totally different sentences, the absence of a shared element blocks bifidity (cf. Chapter 135, \$10).

$\$ 4$ In the most common type of comparison, the joined element is the first actant: Alfred sleeps like a baby, that is, like a baby sleeps. The governor sleeps is shared by the two first actants, which are joined by the adverb like (Stemma 274). 


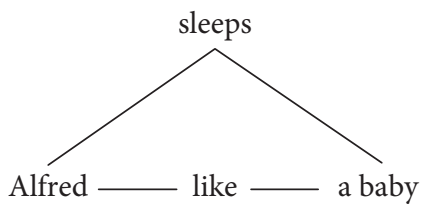

Stemma 274

$\$ 5$ A large number of sentences conveying a comparison are constructed in this manner: Planchet, mon ami, dit d'Artagnan, tu raisonnes comme un fromage 'Planchet, my friend, you reason like cheese' (A. Dumas, Le vicomte de Bragelonne, De la Société qui se forme rue des Lombards...).

\begin{tabular}{ll}
\hline Alfred est sourd comme un pot. & Alfred is (as) deaf as a post. \\
Alfred est blanc comme neige. & Alfred is white as snow. \\
Alfred est fort comme un Turc. & Alfred is (as) strong as an ox. \\
\hline
\end{tabular}

$\begin{array}{ll}\text {...Quand dans ma chambre vint s'asseoir } & \text { '...When into my room came to sit down } \\ \text { Un pauvre enfant vêtu de noir, } & \text { A poor child dressed in black } \\ \text { Qui me ressemblait comme un frère } & \text { Who resembled me like a brother' }\end{array}$

(A. de Musset, La Nuit de Décembre)

$\$ 6$ In the following comparison, the joined element is the second actant: I treat you like a friend, that is, like I treat a friend.

$\$ 7$ The analysis of comparisons of this type is especially necessary in English because nothing distinguishes a first actant from a second actant. A sentence like Alfred loves Bernard like a brother can mean that 'Alfred loves Bernard like a brother does' (Stemma 275) or, in contrast, that 'Alfred loves Bernard like he loves a brother' (Stemma 276).

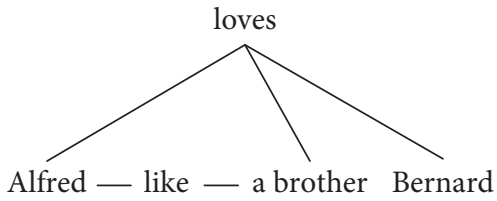

Stemma 275

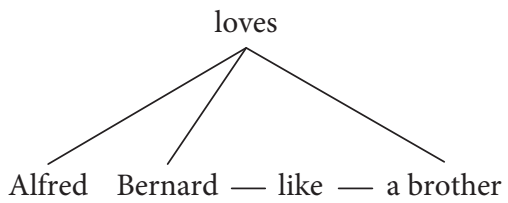

Stemma 276

$\$ 8$ The establishment of a stemma can be useful for determining which of these two interpretations is better, especially when one has to translate an English text into a language with case such as Latin, where 'brother' must be put in the nominative in the first case (sicut frater) and in the accusative in the second case (sicut fratrem). 
$\$ 9$ The joined element in the following sentence is the third actant: Vous me dites la vérité, Jeanne? La vérité comme à un ami, comme à un frère, comme à un confesseur 'Are you telling me the truth, John? The truth like to a friend, like to a brother, like to a confessor' (George Sand).

$\$ 10$ The element of comparison can be a determinative complement: Lat. Non debent esse amicitiarum, sicut aliarum rerum, satietates 'One should not grow tired with friendships as with other things' (Cicero, De amicitia, 67).

\$11 In the sentence Il fait noir comme dans un four, lit. 'It turned black like in an oven', that is 'It was pitch dark', the element of comparison dans un four 'in an oven' is joined with nothing. It is a circumstant that is isolated from its governor il fait noir, which is an avalent verb. All the more, one can say that the governor is duplicated and that the circumstant dans un four is subordinate only to the two terms of this duplication: Il fait noir comme (il fait noir) dans un four 'It turns black like (it turns black) in an oven. There is actually no parallelism between the element of comparison and the other element. In these conditions, there is indeed junction (Chapter $143, \S 5$ ), but, as we have seen above in $₫ 3$, there can be no bifidity. \$12 The adjective same, which introduces a comparison between two terms of identity, furnishes a variant of comparison and leads to a bifid sentence. In the Latin sentence Incidit in eandem invidiam quam pater (Cornelius Nepos, Cimon, III, 1) and its English counterpart He was exposed to the same hatred as his father, the two terms of identity he and his father are the first actant of the governor was exposed.

$\$ 13$ In the Latin sentence Iisdem libris utor quibus tu 'I used the same books as you', duplication occurs with the two terms libris 'books' and quibus 'which' in such a manner that the two appear in the same case, the ablative.

$\$ 14$ Duplication can take place between the same term envisaged in two separate time frames: Il est le même qu'il était 'He is the same as he was'. The duplication takes place in the verbal node, which is expressed once in the present and once in the past: est 'is' and était 'was'.

\$15 From the point of view of comparison, the adjective autre 'other' presents the same characteristics as the adjective même 'same', which is its opposite: Lat. Longe alius est atque erat, Fr. Il est tout autre qu'il n'était, lit. 'He is all other as he was', that is 'He is much different than he was'.

\section{Chapter 148. Sentences with a comparative}

\$1 The comparative differs from comparison insofar as it introduces a quantitative element. \$2 While comparisons express merely an analogy between two terms, e.g. Alfred is as strong as an ox, comparatives also measure the degree of the analogy, e.g. Alfred is stronger than an ox. Comparatives acknowledge the quality as well as the quantity of the two terms. 
$\$ 3$ In a sentence of comparison that expresses merely an analogy between Alfred and an ox in the area of strength, since both have this quality, the quality is attributed to both of them, and it is the element of comparison. In contrast, it is the measure of this quality in each of them that is the element of comparison in the comparative sentence.

$\$ 4$ The introduction of a quantitative notion, which can be compared to an equal, a plus, or a minus, gives rise to three types of comparatives: comparatives of equality, superiority, and inferiority.

$\$ 5$ But this notion of quantity, although it expresses the comparison by means of a measure, does not change the fundamental nature of the sentence. Therefore comparatives are, as soon as an element of comparison permits duplication, bifid like sentences of simple comparison.

$\$ 6$ Thus in the sentence Alfred is stronger than an ox, the two elements of comparison Alfred and an ox represent the two terms of a duplicated first actant, the governor of which, is strong, is common to both: Alfred is stronger than an ox (is strong).

$\$ 7$ The most frequent comparative sentences are those where the duplicated element is the first actant:

\begin{tabular}{|c|c|}
\hline $\begin{array}{l}\text { Il ne faut pas être plus } \\
\text { royaliste que le roi. } \\
\text { (Chateaubriand, La Monarchie } \\
\text { selon la Charte, p. 94) }\end{array}$ & $\begin{array}{l}\text { lit. 'One must not be a greater royalist } \\
\text { than the king', that is } \\
\text { 'One must not be more Catholic } \\
\text { than the Pope.' }\end{array}$ \\
\hline $\begin{array}{l}\text { Rien ne nous rend si grand } \\
\text { qu'une grande douleur. } \\
\text { (A. de Musset, La Nuit de Mai) }\end{array}$ & $\begin{array}{l}\text { 'Nothing renders us as great } \\
\text { as great pain.' }\end{array}$ \\
\hline
\end{tabular}

$\$ 8$ An ambiguity that is analogous to the one presented above (Chapter $147, \$ 7$ ) in sentences of comparison can also exist in comparative sentences. When Marius pretends that he jumps higher than the Eiffel Tower, he is not exaggerating in the least, but rather he is taking care to specify that between the two compared first actants, the Eiffel Tower and himself, the quantitative comparison must be established with respect to the same quality, which is the height of the jump that they both perform; it is not - contrary to what one might understand - a function of two distinct qualities: the height of the jump and the height of the Eiffel tower. He is referring to the first reading when, after performing a jump of several centimeters, he triumphantly declares: "Request of the Eiffel tower that it do the same!".

$\$ 9$ The element of comparison need not be a quality across two different subjects, but rather it can occur across two qualities associated with a single subject: Alfred is more stupid than mean.

\$10 Finally, the comparative can bear on a circumstant: There is more happiness to give than to receive (Acts of the Apostles, XX, 35). 
\$11 Comparatives are extremely diverse across different languages. In our languages, where the compared intensity of a quality is expressed by a marker incorporated into an adjective that expresses this quality, this marker can be analytical as in the Fr. plus grand, or synthetic as in the Eng. bigger. The synthetic process inherited from Latin survives in some French adjectives: Lat. maior > Fr. meilleur 'better'.

$\$ 12$ Unlike English, Latin employs the comparative with the same intent, to compare the same quality across two subjects or two qualities in a single subject: Lat. Fortior est quam prudentior 'He is more brave than smart', lit. 'He braver than smarter'.

$\$ 13$ Like the sentences above (Chapter 147, $\$ 3$ and $\$ 10$ ), comparative sentences are bifid only when at least one clear element of comparison is present. Thus, since the elements of comparison are completely dissimilar, one cannot speak of bifidity in the following sentence: I would like to have as many pieces of gold as there are stars in the sky.

\section{Chapter 149. Anaphoric junction}

$\$ 1$ Junction can be the consequence of anaphora. When an anaphor relates two independent sentences to each other (Chapter $42, \$ 10$ ), the two sentences are nevertheless joined in a sense, no matter how loose this conjunction is, and this is so even though the bond between them is entirely semantic and in no way structural.

\$2 But this junction differs from junction proper insofar as one is not dealing with duplication. The words of each of the two sentences take part in completely different sentences and can play, each in its own sentence, completely different roles.

$\$_{3}$ On the spoken chain, sentences joined semantically remain structurally entirely independent. It can occur, however, that one of them is embedded in the other; the former has been inserted as if it were in parentheses, so that it splits its host into two parts. Sentences that are inserted into others in this manner are called parenthetical (Fr. incise).

$\$ 4$ Due to their structural independence, one lacks a structural means to classify inserted sentences. One is therefore forced to classify them according to the semantic connection between the parenthetical clause and its host. This connection can be one of coordination or subordination.

$\$ 5$ One has a good example of the semantic connection in a case of coordination in the following verse:

A ces mots, l'animal pervers

(C'est le serpent que je veux dire,

Et non l'homme: on pourrait aisément s'y tromper...)
'With these words, the wicked animal

(It's the snake I am focusing on,

And not the man: one could

easily be confused...)'

(La Fontaine, Fables, X-1) 
In this example, the inserted anaphoric c ' it' refers directly to the animal mentioned in the preceding sentence, where it plays the role of an actant.

$\$ 6$ The semantic connection can also be looser:

\begin{tabular}{cc}
\hline Mais un fripon d'enfant & 'But a rascal child \\
(cet âge est sans pitié) & (this age is pitiless) \\
Prit sa fronde et, du coup, & Took his slingshot and, with a shot, \\
tua plus qu'a moitié & killed by more than half. \\
La volatile malheureuse. & The poor winged creature.
\end{tabular}

(La Fontaine, Fables, IX, 2)

Here the anaphor cet 'this' in the parenthetical sentence evidently does not refer to the fripon d'enfant 'rascal child' of the host sentence, but to the âge 'age' of the mischievous child, even though the word âge is expressed only in the inserted sentence.

\$7 The connection is also quite vague when the anaphor in the parenthetical sentence refers to the entirety of this sentence instead of to an actant contained within it. Take the following verse as an example:

\begin{tabular}{cc}
\hline Je suis jeune, il est vrai, & 'I am young, that is true, \\
mais aux âmes bien nées & but to souls of good birth \\
La valeur n'attend point & Worth is not measured in \\
le nombre des années. & the number of years.'
\end{tabular}

(Corneille, Le Cid, II, 2)

The first actant in the parenthetical sentence (il 'that' is merely an apparent subject, cf. Chapter 50, \$7) does not refer to a particular actant of the host sentence, but rather it is an idea expressed in the host sentence that is much more vague. The first actant of est vrai is true' is the group Je suis jeune 'I am young.

$\$ 8$ What is true in this case - i.e. Je suis jeune - is already indicated by the expression immediately preceding adversative conjunction mais 'but'. The propositional group il est vrai 'it is true' is increasingly taking on the value of a simple non-analyzable pre-adversative conjunction (Chapter 140, \$18).

$\$ 9$ This unanalyzed pre-adversative conjunction has not yet ceased to be analyzable, however, for its formation is still transparent. It is therefore not the same as the pre-adversative word zwar in German (Chapter 140, 22 ), for which the analysis es ist wahr 'it is true' is no longer directly sensed, although it is visible in the etymology.

$\$ 10$ Similarly, one has to account for the behavior of the anaphor c' in c'est-à-dire 'that is', lit. 'that is to say', in French by the acknowledgment of a semantic link of coordination. This link is increasingly non-analyzable, although one senses in general that it is a junctive that furnishes the explication of the term or sentence that precedes it. 
$\$ 11$ Such is also the value of the id in the common Latin expression id est 'that is', which has exactly the same value as the French c'est-à-dire.

\$12 As we have seen ( $\$ 14$ above), the semantic link that connects the parenthetical sentence to the host sentence can also be of the subordinate type. But it is the host sentence that is semantically subordinate to the inserted sentence, the latter playing the role of the governor. Such is the case in expressions of the type dit-il 'he said', dit-on 'rumor has it', where the things said are in fact the second actant. Take the sentence Merci, dit-il 'Thank you, he said' as an example; it is evident that that the thing said, i.e. merci, is the second actant of the verb dit 'said'. It should be noted here that in the archaic expression ce dit-on, lit.'that said one', despite inversion, $c e$ assumes the function of the second actant, whereas on assumes that of the first actant.

$\$ 13$ The examination of such sentences demonstrates that the semantic connection between the parenthetical and host sentence can be extremely diverse. Such is the case, as we have seen, when the link is very loose, so that the clauses brought together are not related to each other in rigorous and limited logical ways. Indeed, great liberty of interpretation reigns between the inserted and host clauses.

\section{Chapter 150. Connective junction}

$\$ 1$ Just as it can be the result of anaphora, junction can also be the consequence of a connection that is, as we have seen, structural as well as semantic.

$\$ 2$ Such is the case when there is a double connection, that is, when the same nucleus simultaneously depends on two separate and independent governors without any structural connection between these governors.

$\$ 3$ It is quite evident that the fact of having the same subordinate, although with different titles, creates a connection of a sort between these governors.

$\$ 4$ But this junction, which we will call connective, contains duplication no more than anaphoric junction does (Chapter 149, \$2).

$\$ 5$ To analyze the phenomenon of a double connection, one must distinguish between the two connections and consider with care what the nature of the first might be, as well as what that of the second might be.

$\$ 6$ Take the German sentence Wenn meine Mutter zu mir "Lieber Junge" sagt, so ist das so viel als wenn eine andere wer weiss was anstell 'When my mother says to me "Dear boy", it's like when someone else does God knows what'. The pronoun was 'what' is, on the one hand, the second actant of wer weiss 'who knows', but on the other hand, it is the second actant of anstellt 'does', or to be more exact, the group wer wei $\beta$ was 'who knows what' is the second actant of anstellt 'does'. 
$\$ 7$ The first connection is established between anstell 'does' and the shared subordinate that plays the role of the second actant. The second connection is the one that exists between weiß 'know' and the shared subordinate that also plays the role of a second actant, but on a different plane.

$\$ 8$ While the shared nucleus readily plays the role of the second actant in the second connection, it also easily plays whatever other role is necessary in the first connection.

$\$ 9$ Examine the following sentence:

$\begin{array}{ll}\text { Vous ne me ferez pas l'injure de } & \text { 'You won't insult me by } \\ \text { croire que j'ajouterai foi à cette } & \text { believing that I'll trust } \\ \text { fable absurde répandue dans } & \text { this absurd fable spread to } \\ \text { je ne sais quel but. } & \text { I don't know what end.' }\end{array}$

(A Dumas, Le Vicomte de Bragelonne, Comment il est bon d'avoir deux cordes a son arc)

The shared nucleus quel but 'what end' plays the role in the first connection of an actant transferred to a circumstant of destination by the preposition dans 'in'.

$\$ 10$ In the following Latin verses

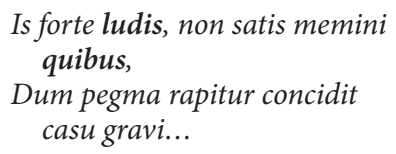

Is forte ludis, non satis memini quibus,

Dum pegma rapitur concidit casu gravi...
'This one, during I don't remember which games,
Fell badly while the scenery was carried off...'

(Seneca, Phaedra, V, 7)

the shared nucleus ludis also plays the role of an actant in the first connection, but it is transferred to a temporal circumstant by the use of the ablative.

$\$ 11$ In the Latin sentence Boni nescio quomodo tardiores sunt 'Respectable people are, I do not know in what way, too slow to act' (Cicero, pro Sestio, 47, 100), the shared nucleus modo 'manner, way' plays the role of a manner circumstant.

$\$ 12$ In the English sentence I... read them over and over, I don't know how many times more (Dickens, David Copperfield, I, 10, p. 196), the shared nucleus many times also plays the role of a quantity circumstant.

$\$ 13$ In all these examples, it is easy to verify that the shared nucleus, despite the varied roles that it plays in the first connection, always plays the role of the second actant in the second connection, regardless of whether one has Fr. je ne sais dans quel but 'I don't know to what end', Lat. non satis memini quibus 'I don't remember which', Lat. nescio quomodo 'I don't know in what way', or Eng. I don't know how many times.

$\$ 14$ In contrast, the shared nucleus plays the role of a predicate in the second connection of the sentences that contain expressions of the French type ne fût-ce que, lit. 'it was only'. 
Thus in the French sentence Si j'avais ne fût-ce que dix francs, je prendrais le tramway 'If I had (it was) only ten francs, I would take the tram', where dix francs 'ten francs' plays the role of the second actant in the first connection.

$\$ 15$ Similarly, the common nucleus plays a predicative role in the second connection of sentences containing the French expression qui de droit, lit. 'who of eligibility'. Thus in the French sentence Je me plaindrai à qui de droit 'I will complain to whom it may concern', where it has the role of the third actant in the first connection. 
PART III

Transfer 



\section{Introduction}

\section{Chapter 151. The theory of transfer}

$\$ 1$ Like junction, transfer is a phenomenon that complicates the simple sentence. But the impact of transfer in this regard is much greater than that of junction.

\$2 Take a phrase such as Fr. le livre de Pierre 'the book of Peter, Peter's book'. Traditional grammar examines the structure in terms of a preposition, since a relation of possession is expressed by the preposition de. Now take the corresponding Latin expression liber Petri, lit. 'book Peter's'; Latin grammar acknowledges the syntax of case, since Petri is in the genitive. Lastly, take the English phrase Peter's book. The structure this time is attributed to the Saxon genitive 's. The study of this expression is approached from three different perspectives, according to whether one is dealing with Latin, French, or English.

$\$ 3$ Yet in all three cases, one has the same exprimende, and in good syntax, one should be interested in discovering the exact nature of the construction in the same area, instead of dispersed across three different chapters of morphology.

$\$ 4$ Indeed, those who learn foreign languages would - instead of being forced to seek explanations of syntactically similar facts in different locations and even under different names - see their studies facilitated if they could find the same facts together in the same spot (as in the grammar of their mother tongue), regardless of the language they are studying.

$\$ 5$ On the other hand, examining the facts that are, despite the diversity of morphology, of the same syntactic nature facilitates the edification of a general syntax, since it permits one to establish the facts on a truly syntactic basis, instead of always being erroneously located on the morphological plane, a practice that has the deleterious effect of distorting understanding and classification.

$\$ 6$ Freed from this irritating servitude, the syntactician, who now always finds his interest in the same spot, would not be obliged to seek it at the four corners of the horizon. Classification would be easier, the comparisons more fruitful, and the interpretation more penetrating. The creation of a solid doctrine would in turn react positively to the resulting classification of facts.

$\$ 7$ In order for us to conform to this plan, we commence by analyzing first the expression that interests us in French. Take the expression le livre de Pierre 'the book of Peter, Peter's book. Grammarians generally account for this structure - or they believe to account for 
it - by explaining that the preposition de expresses a relation of possession between le livre and Pierre, that is, a relation of belonging between the possessed (le livre) and a possessor (Pierre). But his account is not inexact, since it is a fact that one says le chien du maitre 'the dog of the master' when one wants to state that it is the dog that belongs to its master.

$\$ 8$ But one quickly sees that this explanation is superficial when one considers that the expression can be turned around and one can also say le maitre du chien 'the master of the dog', which in no way signals that the maître 'master' belongs to the chien 'dog'. It is therefore evident that one has taken up the matter from too narrow of a perspective, this perspective overlooking syntactic reality.

$\$ 9$ Now take the expression le train de Paris 'the train to/from Paris'. One is inclined, especially if one is a foreigner, to interpret the preposition de as expressing the origin of the train. For the foreigner, one says le train de Paris because one is dealing with the train that has come from Paris.

$\$ 10$ But it is simple, especially for a Francophone, to see that, upon reflection, this explication is also just as superficial as the previous one, because le train de Paris can denote the train that is going to Paris as well as the one that is coming from Paris. Certainly the context avoids the ambiguity in most cases, but being duped is not necessary. When the traveler asks of the station manager $A$ quelle heure arrive le train de Paris? 'At what time does the Paris train arrive?' or even A quelle heure part le train de Paris? 'At what time does the Paris train depart?', the preposition de is not expressing the direction of the train, since it is departing in the same manner in both cases, but rather the verb is expressing the direction, the verb arrive in the one case and the verb part in the other.

$\$ 11$ But in the absence of a context that indicates which train one is dealing with, the expression is indeed definitely ambiguous. And if at the same time that a train is coming into Paris another train is departing from Paris, a traveler who asks the station manager Ou est le train de Paris? 'Where is the Paris train?', the station manager will not hesitate to ask the traveler to specify his question: "Is it the train to Paris that you are asking about or the one that is coming from there?"

$\$ 12$ Take further the union of the words la gare de Sceaux 'the Sceaux station'. This expression also contains an ambiguity, since in Paris one commonly uses this name to denote the station in Sceaux as well as the station in the Luxembourg quarter from where one takes the train to Sceaux. The author conserves the memory of a grammatically enlightening experience that he had the day when he - having given some friends from out of country a meeting place in the Sceaux station in order to take them to dinner in the Latin quarter - could not find them at the meeting point. He had to access the courtesy of the station manager in the Sceaux station in Luxembourg to page his guests, who were placidly waiting at Sceaux, and have them sent to Paris. 
$\$ 13$ Lastly, one could see in a campaign pamphlet from 1946 that the same political party was sponsoring two candidates for the election, the one being the interné de la Résistance 'the interned of the resistance' and the other being the interné de la Gestapo 'the interned of the Gestapo', la Résistance standing in opposition to la Gestapo. It is evident that the preposition de functions quite differently in the two formulations. In the first case, one is dealing with someone who was interned because he took part in the resistance, and in the second case, one is dealing with someone who was interned by the Gestapo.

$\$ 14$ If, in different examples, the preposition de can simultaneously express a relation and its inverse, the value of this preposition must be larger than what one normally attributes to it.

$\$ 15$ One persists in the attempt to grant it a definitive semantic value when it has merely structural value that is much more general. One observes, in fact, that as in le livre de Pierre, le train de Paris, la gare de Sceaux, interné de la Résistance, and interné de la Gestapo, the element introduced by de is always the subordinate of the governing noun (or of the nominal adjective) (cf. Stemma 32, 277, 278, 279, and 280).

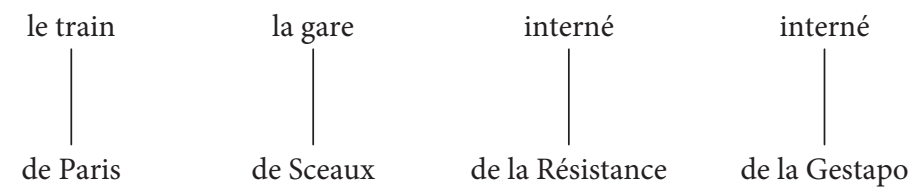

\section{Stemma 277 Stemma $278 \quad$ Stemma $279 \quad$ Stemma 280}

$\$ 16$ Yet we have seen (Chapter $63, \$ 5$ ) that the most common subordinate of the governing noun is an attribute and (Chapter $63, \$ 6$ ) the role of the attribute is commonly played by an adjective.

$\$ 17$ There is therefore reason to admit that the phrase de Pierre, de Paris, etc. since it is subordinate to the governing noun, has the value of an adjective, that is, even though they do not look like adjectives, they are in fact syntactically the same as adjectives.

$\$ 18$ But the words that immediately follow the preposition de are nouns. Far from presenting a difficulty, this observation provides us, in contrast, with an explanation of the preposition $d e$. If, since Pierre is a noun, the phrase de Pierre takes on the syntactic value of an adjective, this occurs because the preposition de has changed the syntactic character of Pierre. Out of a noun, it has made an adjective syntatically.

$\$ 19$ We call this change in syntax transfer (Fr. translation). ${ }^{195}$

195. Translators' note: In French, the term translation has only a physical sense, meaning the process of moving something from one place to another. 


\section{Chapter 152. The mechanism of transfer}

\$1 Essentially, transfer involves the changing of the grammatical category of a content word to another grammatical category, that is, one type of word is changed to another type of word.

$\$ 2$ In the phrase le livre de Pierre 'the book of Peter, Peter's book', the noun Pierre becomes an attributive adjective syntactically as in le livre rouge 'the red book'. Even though it is not morphologically an adjective, it acquires the syntactic characteristics of an adjective, that is, it acquires adjectival value. The subordinate de Pierre plays a role in the union of words that is similar in every way to the subordinate rouge.

$\$ 3$ Indeed, nothing distinguishes the phrase le livre de Pierre syntactically from the phrase le livre rouge. In both cases, the subordinate plays the same role as an attribute of the word livre. Whether it is about a livre de Pierre or a livre rouge, one is dealing with the expression of a quality of the book that distinguishes it from other books (cf. Chapter $65, \$ 4$ and Stemma 32).

$\$ 4$ In turn, the change of category has the effect of leading to, or more or less permitting, a change of function, the function of different words being linked to their category.

$\$ 5$ Therefore transferring de Pierre to an adjective, a unit that one traditionally calls a determinative complement, permits the noun Pierre to play the role of an attribute to another noun, just as if it were really an adjective. ${ }^{196}$ It no longer behaves like an actant, but rather it has become an attribute.

$\$ 6$ But this structural effect is not what characterizes transfer; it is, rather, a consequence of transfer. It is of a different nature, since it is structural and not categorical.

$\$ 7$ There is hence reason to distinguish carefully between the two operations. The first changes category and thus constitutes transfer. It commands the second. The second changes function and in turn commands the structural possibilities.

\$8 Transfer is thus the prerequisite for certain connections, but it is not the direct cause of these connections. Connections are based on the structure of the simple sentence. They are established automatically between certain categories of words and are marked by nothing. Connections are so natural that the possibility that they exist is enough for them to exist.

$\$ 9$ Hence a translative does not establish a connection. It is, rather, content to perform transfer, that is, to change the category of the transferred expression. As soon as the expression has changed category due to transfer, the connection from it is established.

196. Translators' note: Tesnière used the term complément déterminatif to denote a prepositional phrase (introduced by $d e$ ) that is dependent on a noun. The term in modern French grammars is complément de nom. English grammars have no special term for such expressions, but one sometimes encounters the term genitive construction. 
\$10 In order to comprehend the nature of transfer, it is important not to lose sight of the fact that it is a syntactic phenomenon and that as a consequence, it goes beyond the morphological facts upon which we are erroneously accustomed to basing our reasoning about syntax. Therefore those who persist in seeing only morphological entities in words are condemned to understand nothing.

$\$ 11$ Indeed, the transferred word conserves the characteristics of category morphologically that it had before undergoing transfer. Certain people are incapable of escaping the morphological plane and as a consequence, rebel against syntax. These people cannot resolve to consider that a noun becomes an adjective by way of transfer. For them, Pierre is a noun not only morphologically, but also syntactically. Pierre is, despite everything, irrevocably condemned to remain immutable, regardless of the function it takes on, for in their eyes, only form counts.

\section{Chapter 153. The role and importance of transfer}

\$1 Transfer has the effect (but not the goal) of resolving the difficulty that arises for the speaker who has begun a sentence of a given structure but is then, in the course of speaking, obliged to improvise in order to work in a word belonging to a category that is not directly connectable to one of the words in the part of the sentence that has already been spoken.

$\$ 2$ From the point of view of its role and of its utility in the sentence, transfer is the phenomenon that makes up for differences in category and it hence permits one to organize whatever sentence one desires by transforming whatever type of word to whatever other type of word.

$\$ 3$ It is a fact that one never encounters any normal speaker of a language coming up short with a sentence that has already been initiated due to the lack of ability to introduce a given word, this word having combinatory potential that does not agree with that of the words that have already been spoken.

$\$ 4$ Thus whatever the sentence is that has been initiated, the speaker will always find a means of overcoming the difficulty by appealing to transfer at an opportune moment. Transfer permits the speaker to transform the category of the problematic word that rises to his lips to a category that is connectable to preceding material.

$\$ 5$ Transfer is thus the phenomenon that permits one to realize any sentence structure by manipulating the base categories, that is, by manipulating the fundamental types of words. In this manner, the speaker never ends up mouth gaping without the ability to complete the sentence. Transfer is not only useful, but also necessary and even indispensable.

$\$ 6$ Transfer can be compared to the subterfuge of the rascals who Propser Mérimée places in the scene in the Chronique du règne de Charles IX (Chapter 23) and who have invaded 
the cabaret of Beaugency because they are hungry and want to eat meat, which is prohibited on Friday. They force a monk to transform chicken into fish by baptizing it: "I baptize you a carp." It is indeed by a similar subterfuge that a speaker subconsciously gives a noun the quality of an adjective with tacit complicity of the interlocutors.

\$7 Transfer is thus one of the principle mechanisms by which the independence of the structural and semantic levels is established, as mentioned above (Chapter 20, \$17).

$\$ 8$ The process is so simple and so natural that it constitutes one of the most common phenomena of human language.

$\$ 9$ An experience the author had during a talk permitted him to observe that of the 200 words that the orator employed, he did not employ less than 47 transfers, thus approximately one transfer per four words.

\$10 Yet if one considers that a somewhat less rapid production of words can easily reach 400 words per minute, it is easy to calculate that this represents approximately 100 transfers per minute, thus approximately two transfers per second.

$\$ 11$ One is amazed when one considers the rapidity with which transfer occurs and the flexibility that it requires in our speech faculty, this faculty accessing the subtle mechanism with such allure, subconsciously and without taking it into account.

\$12 This impression confirms the judgment that we have already produced (Chapter 144, $\$ 18$ ), our judgment concerning junction, about the considerable ability that confers this marvelous tool to our intellect with which it is endowed in the form of language.

$\$ 13$ One sees the importance of recognizing the phenomenon of transfer, which peppers discourse and hence qualifies as an essential characteristic of human language.

\section{Chapter 154. The terminology of transfer}

$\$ 1$ The importance of transfer in the mechanism of structural syntax motivates us to establish a precise terminology.

\$2 We reserve the term transfer for the set of operations that will be described. This term has the advantage that it does not designate a grammatical phenomenon. This advantage is not negligible. The term translation can be introduced in the majority of languages, the one exception being English however, for which it is necessary to seek another equivalent, perhaps transfer, since the word translation already has the meaning of 'translation' there. ${ }^{197}$

197. Translator's note: It should be obvious that we have followed Tesnière's suggestion here to use the term transfer in English as the translation of Tesnière's French term translation. 
$\$ 3$ The word as it presents itself before undergoing transfer receives the name source (Fr. transférende). The source is thus the nucleus that is called upon to undergo transfer.

$\$ 4$ In contrast, the word that has already undergone transfer will receive the name target (Fr. transferé). The target is thus the same nucleus after transfer has changed it to a new category. It is the word or phrase resulting from transfer.

$\$ 5$ Lastly, when there is a morphological marker to indicate transfer, this grammatical tool receives the name translative (Chapter $38, \$ 7,10$ and $134, \$ 5$ ).

$\$ 6$ Source, target, and translative are thus the three essential players in transfer.

\$7 Moreover, it is important to be able to indicate from what category to what other category transfer occurs. We have seen (Chapter $32, \$ 21$ ) that there are four types of fundamental words, which form the quadrilateral of the base on which all structural syntax is built: noun, adjective, adverb, and verb. As a consequence, transfer can change a given source to any of these categories.

$\$ 8$ We will call transfer nominal, adjectival, adverbial, or verbal when it has the effect of changing the source into a noun, adjective, adverb, or verb.

$\$ 9$ Conversely, we will use the terms denominal, deadjectival, deadverbial, and deverbal to denote transfer that produces a target from one of these starting categories.

\section{Chapter 155. The graphic representation of transfer}

$\$ 1$ To express transfer, we will adopt the symbol $>$, which is preceded by the symbol for the source and followed by the symbol for the target. Hence the transfer contained in de Pierre will be represented as $\mathrm{O}>\mathrm{A}$, since it has the effect of changing the nucleus Pierre from the nominal category, for which the symbol is $\mathrm{O}$, to that of the adjectival category, for which the symbol is A.

$\$ 2$ The symbol > (in $\mathrm{O}>\mathrm{A}$ ) marks the direction of transfer, because in this case it indicates an instance of transfer that is denominal and adjectival. It thus shows the same direction as the arrow for which it would be the point.

$\$ 3$ This particularity allows one to reverse the direction of the symbol as need be. Thus A $<\mathrm{O}$ indicates that one is dealing with an adjective stemming from the transfer of a noun.

$\$ 4$ One can thus establish a formula for each variety of transfer. This formula indicates the category of the source, the category of the target, and hence the meaning of the transfer, which is given with the characteristics of the abbreviated form. This practice allows one to show transfer efficiently.

$\$ 5$ The formula for transfer and the symbols $>$ and $<$ have value only on the linear plane. They can only be used in the spoken chain, that is, in text form where the concern is one of transfer, or in their titles. Therefore one will indicate transfer with $\mathrm{O}>\mathrm{A}$ or $\mathrm{A}<\mathrm{O}$. 
$\$ 6$ Since they are strictly linear, the symbols $>$ and $<$ are resistant to structural use. They are not suited to appearing in stemmas.

\$7 In order to show transfer in the graphic stemma, we have to adopt a symbol other than $>$ or $<$. We will therefore appeal to the symbol $\mathcal{T}$, which approximates the letter $\mathrm{T}$, the first letter of the word transfer.

$\$ 8$ The advantage of this symbol is that it readily lends itself to the schematic representation of transfer and permits a graphic schema that is appropriate to show the three players involved in transfer: the source, the target, and the translative.

$\$ 9$ The target and the translative are placed under the horizontal bar of $\mathcal{T}$ and the target is placed above it.

\$10 Concerning the order of the target and the translative under the horizontal bar, we will simply adopt the same order as in the spoken chain, which has the advantage of reflecting actual linear order.

\$11 But in order to avoid all confusion between the source and the translative, we have to switch the direction of the lower hook on the vertical bar toward the translative.

\$12 The symbol of transfer will therefore be $\tau$ or $\tau$ according to whether the translative precedes or follows the source.

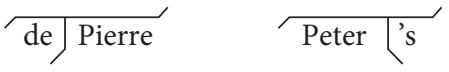

$\$ 13$ The principle of graphic representation is summarized with the following schemas.

\begin{tabular}{|c|c|}
\hline Tars & \\
\hline $\begin{array}{l}\text { Preposed } \\
\text { translative }\end{array}$ & Source \\
\hline
\end{tabular}

\begin{tabular}{|c|c|}
\hline & \\
\hline Source & $\begin{array}{l}\text { Postposed } \\
\text { translative }\end{array}$ \\
\hline
\end{tabular}

\$14 The role of transfer appears in its full scope if one represents the elements of transfer using their symbols (Chapter $33, \S 1$. and Chapter $134, \$ 7$ ). And so the transfer contained in de Pierre is expressed by the following symbolic schemas:

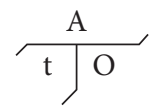

\$15 If the goal is to represent this same transfer with a concrete schema as opposed to an abstract one, one starts by considering that the words of the spoken chain must appear only once in the stemma. Yet the graphics that we recommend necessarily lead to representing these words twice, once in the form of the source and the translative, and once in the form of the target. To avoid this difficulty, it is expedient to represent one of the two terms of transfer, generally the target, with its symbol, or to put it in parentheses.

\$16 Take the instance of transfer in the phrase de Pierre. We represent this phrase with the real stemma in the following form:

$$
\frac{\mathrm{A}}{\text { de } \int \text { Pierre }}
$$


The translative $d e$ is placed under the horizontal bar of $\mathcal{T}$, with the lower hook on the vertical bar turned toward it, the target Pierre appearing on the other side of the vertical bar. The respective order of the source and the translative reproduces the actual order of words in the spoken chain. And finally, the result of transfer is indicated by the symbol A placed above the horizontal bar.

\section{Chapter 156. Transfer in stemmas}

\$1 The advantage of the graphic representation that we have adopted for transfer appears as soon as one seeks to integrate transfer into the stemma.

\$2 Indeed, one observes that the nucleus where transfer is produced behaves as the source with respect to lower connections and like the target with respect to the upper connection. Below the horizontal bar appears the source and the translative, and the target appears on top of it. Therefore a connection with the governor occurs with the target and the connections with subordinates occur with the source.

$\$ 3$ Take for example the title of the work by Anatole France Le livre de mon ami ‘The book of my friend, My friend's book. Transfer is represented as follows:

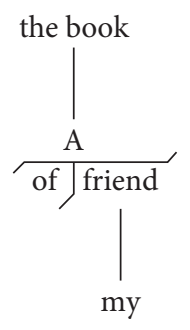

\section{Stemma 281}

\$4 This representation has the advantage of simultaneously showing that the source friend is a noun governing the adjectival subordinate $m y$, as the lower connection shows, whereas the result of the transfer of friend, which has the value of an attributive adjective, is subordinated by the upper connection to the governor book.

$\$ 5$ This arrangement allows one to superimpose two instances of transfer when the target of the one is subordinate to the source of the other, as for example in the sentence Write in the book of your friend (Stemma 282). Indeed, the source of the upper instance of transfer always finds itself occupying the favorable position in the stemma with respect to the connection that links it to the target of the lower instance of transfer, and vice versa. 


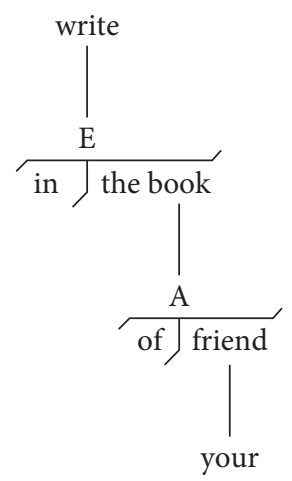

\section{Stemma 282}

$\$ 6$ One can now see how transfer overcomes the lack of connective compatibility between the different nuclei and how it renders categories connectable that are otherwise non-connectable. In the sentence Write in the book of your friend, there are, in addition to the verb write, two nouns, book and friend, which cannot be connected to each other, a noun being incapable of entering into a direct vertical connection with another noun.

\$7 But the lower instance of transfer has the effect of repairing the difference in category between the noun friend and the adjective (A) that then enters into a vertical connection with the governing noun book, since it transforms the noun friend to an adjective.

$\$ 8$ Likewise, the upper instance of transfer has the effect of repairing the difference in category between the noun book and the adverb $(\varepsilon)$ that must enter into the connection of a circumstant with the verb write, since it transforms the noun book to an adverb of location that indicates the place where one writes, that is, to a circumstant.

$\$ 9$ It appears therefore that what we have said above (Chapter $65, \$ 4$ ) about the structure of this type of stemma could only be provisional. Now that we have examined the nature and the graphic representation of transfer, we are in a position to return to our first examples and to be more precise about the stemmas of these examples (Stemmas 32, 139, and 140). Each of these three stemmas contains an instance of transfer; the symbol is therefore added (Stemmas 283, 284, and 285).

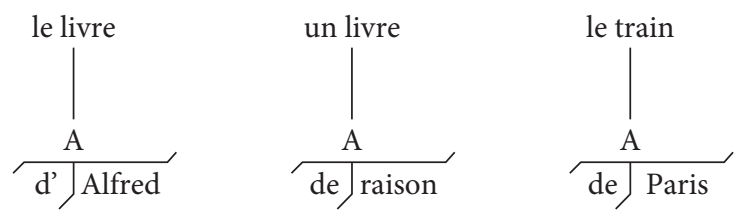




\section{Chapter 157. Translative and nucleus}

$\$ 1$ The received wisdom is that the words that we call translatives are small invariable words destined to mark relations between content words.

$\$ 2$ One states, for example, that in le livre de Pierre, the preposition de has the function of indicating the relation between livre and Pierre.

$\$ 3$ One hence presents translatives as tools that serve to relate content words to each other. By doing so, translatives are viewed as conjunctive tools, that is, sometimes as inter-nuclear and sometimes as extra-nuclear elements.

$\$ 4$ We have seen above (Chapter 151, \$7, 9, 11, and 12) how this conception is deceptive. In analyzing the relation that the preposition is supposed to establish between the nuclei, we have observed that one could arrive at superficial conclusions.

$\$ 5$ Viewing translatives to be conjunctions would relegate them to the related role of junctives, and in so doing, they would be instruments of a much too narrow operation (Chapter 151, \$14).

$\$ 6$ In reality translatives mark transfer, that is, they mark an operation that reaches much further down than junction.

$\$ 7$ The common conception is erroneous. Translatives are not inter-nuclear, that is, external to nuclei, but as we have already stated above (Chapter $40, \$ 2$ ), they are internal to nuclei. In de Pierre, the translative de is part of the same nucleus as Pierre.

$\$ 8$ The matter springs from evidence produced by the examination of the Latin phrase liber Petri 'Peter's book'. In the linear order of the spoken chain, the ending - $i$, which expresses the would-be relation between liber and Petrus, in no way occupies an intermediate position between these two words, since it appears at the end of the second word.

\$9 We are therefore forced to construct the stemma of this phrase by incorporating the ending in the same nucleus as the stem Petr- (Stemma 286).

$\$ 10$ Yet one is dealing with the same sort of transfer in both the French and Latin stemma, for it is of the same nature $(\mathrm{O}>\mathrm{A})$ and it produces the same syntactic and structural effect. We can therefore do no different than represent it in the same manner and we are thus led to include the translative inside the nucleus of Pierre (Stemma 287) (compare to Stemma 32).

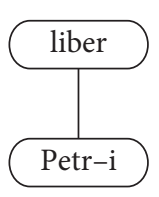

Stemma 286

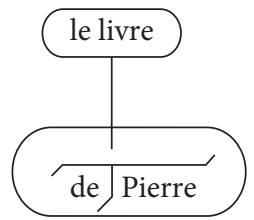

Stemma 287 
\$11 This representation points to the fact that, as we have already shown above (Chapter $152, \$ 8$ and $\$ 9$ ), the translative does not establish the connection, but rather it only renders it possible and the connection is hence established of its own accord.

$\$ 12$ It is therefore not more appropriate to view de as linking Pierre and livre in le livre de Pierre than it is to consider -ing as linking interest and book in an interesting book.

$\$ 13$ If the translative is intra-nuclear, that is strong evidence that the transfer it represents is also intra-nuclear. The transferred nuclei must also include the symbol $\mathcal{T}$ as well as the translative. That is effectively what has occurred in the preceding stemma (Stemma 287).

$\$ 14$ These nuclei are hence divided by the horizontal bar of the symbol $\mathcal{T}$ into two parts, one of which, the lower one, contains the source and the other, the upper one, the target or its symbol. This is presented schematically in the following manner: $\rightleftharpoons$. This bipartite division shows that those nuclei are mixed that are the seat of transfer.

\$15 The intra-nuclear character of a phenomenon as important as transfer has the effect of organizing the study of the nucleus toward the intra-nuclear analysis. This study is to structural syntax what chemical analysis is to the study of the body.

$\$ 16$ It therefore appears that the future of syntactic research is in the area of intra-nuclear investigation. This investigation alone will lead to insights about the interior of the nucleus. It will shed light on the phenomena that are located in the nucleus. The investigation will follow an intellectual pattern, beginning with the least complicated structures and progressing to more complicated ones, in a manner similar to how one proceeds from the cell, from the molecule, and from the atom in the order of materials.

\section{Chapter 158. The life and evolution of transfer}

$\$ 1$ The nucleus is thus revealed as an organism that at its core involves subtle and complex operations. Like all organisms, it is alive, that is, it evolves and with time it experiences developments and transformations that have their own history.

\$2 Hence one should discern among two types of transfer where the nucleus is the seat, those instances of transfer that are still alive and those that are already frozen in the rigidity of death. As transfer ages, it weakens and has the tendency to no longer be alive. It becomes frozen when the source is no longer alive and has nothing more than etymological value.

$\$ 3$ A very good example of this distinction is furnished for us by the opposition between the present participle and the verbal adjective. In the case of the present participle, transfer is still quite alive and fully active because as the name indicates, the participle simultaneously behaves like a verb (in terms of its lower connections) and like an adjective (in terms of its upper connection). In the case of the verbal adjective, the transfer is no longer alive, 
but rather it is frozen with the value of an adjective and without having conserved its original verbal value.

$\$ 4$ Thus in the part of the sentence des étapes fatiguant les plus resistant 'stages tiring the most resistant ones', the present participle fatiguant 'tiring' conserves the faculty of governing the second actant les plus résistants 'the most resistant ones' just as the corresponding verb fatiguer 'tire' does. In contrast, in the expression des étapes très fatigantes 'very tiring stages' the verbal adjective fatigantes has lost this faculty, since it has given up its ability to act as a verb in order to become a true adjective syntactically. The result is that its earlier status as a verb is now nothing more than an etymological souvenir (Chapter 200, $\$ 11$ and 12).

$\$ 5$ Likewise, the present participle fatiguant 'tiring' remains as invariable as the verb from which it arises and to which it still owes its status, whereas the verbal adjective fatigant-e-s 'tiring-FEM-PL' agrees in gender and number because it has become a full adjective that no longer retains any of its original verbal value (cf. Chapter 200, \$9).

$\$ 6$ Finally, the matter is visible in the orthography of the word fatiguant, which, when it is a present participle, preserves the orthography that it takes from the verb from which it stems. It maintains the diacritic $u$, a fact that is motivated only by way of the verbal endings beginning with $e$, as in the future il fatigu-era, whereas it is of no use before the $a$ of il fatiguait 'he tired.' ${ }^{198}$ In contrast, the verbal adjective fatigantes 'tired' no longer has any link to the verb in its quality as an adjective. It has completely and quite simply eliminated the $u$, which serves no purpose and is merely dead weight (cf. Chapter 200, \$11).

$\$ 7$ As one can see, transfer frozen in death is indistinguishable from derivation. Indeed, a number of derivatives are, when one examines them closely, nothing more than former transferred nuclei (cf. Chapter 200, \$17).

$\$ 8$ Regarding its dual nature, the node that is the seat of a transfer corresponds less and less to a punctual character, this punctual character suggesting the term node at first blush.

$\$ 9$ Worth remembering is that we first conceive of the node as a geometric vertex of connections that come together (Chapter 3, \$2f.), that is, as a point.

$\$ 10$ Accordingly, we were led (Chapter $22, \$ 4$ ) to expand the node notion and replace it with that of the nucleus.

$\$ 11$ As the exploration proceeded, we learned what all must be placed in the interior of the nucleus. The nucleus continued to take on more weight and we were led to grant it an ever greater size, which culminated in the use of the nucleus circle.

198. Translators' note: In French orthography, as in English orthography, the letter $g$ is pronounced /g/ before $a$ but /3/ before $e$ (cf. English gas vs. genius). To have the pronunciation /g/ before $e$, an $u$ must be added, as in fatiguer /fatige/. 
$\$ 12$ The nucleus is therefore, so to speak, like a star that appears as a point to the naked eye, but that has an apparent diameter, as soon as one examines it under a certain magnification (Chapter 22, \$13).

$\$ 13$ The node is hence split, since the superior and inferior connections have a point of attachment on the perimeter of the nucleus circle. Therefore in the phrase a prince loved by the gods, the connection from loved to prince has its point of attachment at the top of the nucleus circle, whereas the connection from loved to by the gods has its point of attachment at the bottom of the same nucleus circle (Stemma 288 and 291).



by the gods

\section{Stemma 288}

$\$ 14$ When transfer is frozen, as for example in the verbal adjective, the attachment of the superior connection line is no longer different from that of the inferior connection, for the nucleus is no longer double and as a consequence, the node is no longer dissociated.

\$15 Since the transfer ceases to be alive, the nature of the target now occupies the entire nucleus. While the target occupied at first only the superior part of the nucleus, it now takes over the entire nucleus; it now substitutes entirely for the source from which it stems, and it therefore attaches directly to the upper connection line and descends into the lower part of the nucleus.

$\$ 16$ The result is that one can measure the aging and death of the transfer in a nucleus that has collapsed in its weakening at the point of attachment of the superior connection.

$\$ 17$ This weakening can sometimes be somewhat delayed. In certain languages, the target preserves the inferior connections of the source even after transfer has occurred.

\$18 Such is the case in Sanskrit, where the inferior connections of the second actant of dhvárati 'he dammages' are preserved in the action noun dhürtih, which can still be constructed with the accusative: Ná tam dhūrtih 'We cannot damage it' (Rigveda, VIII, 27, 15), although this is an exceptional construction. The verbal rection here is also encountered in Avestan (cf. Benvéniste, Noms d'agent et noms d'action en indoeuropéen, pp. 10 and 19): Astā išum 'who launches the bolt'.

$\$ 19$ The delayed weakening of the attachment point of the inferior connection constitutes an incorrect construction that is clearly perceived by the linguistic sensitivity of French speakers. For instance, a construction is perceived as incorrect that preserves a locution 
adverbial as the subordinate of an action noun, this locution adverbial having depended on the verb from which the action noun is derived:

\begin{tabular}{ll}
\hline Il (Henri I, Duc de Montmorency) & 'He (Henry I, Duke of Montmorency) \\
prit d'abord le titre de seigneur & first took the title of Lord of Damville \\
de Damville et prit celui de duc & and (thus) took the title of Duke of \\
de Montmorency à la mort, sans & Montmorency after the death, without \\
enfants, de son aîné. & children, of his eldest' \\
\multicolumn{2}{c}{ (Larousse du XX }
\end{tabular}

It is evident that sans enfants is a locution adverbial subordinate to the verb mourut in the sentence Il mourut sans enfants 'He died without children'. The action noun la mort 'the death' is derived from this verb.

\section{Chapter 159. The survival of transfer}

\$1 When transfer has ceased to be alive, one can sometimes find a trace of it inside the nucleus that was its seat. However, this is merely an etymological remnant that is at times of considerable historical interest, but that actually no longer has bearing on modern usage. From this point of view, one can say that nuclei are sometimes the cemeteries of transfer. An example will illustrate how this expression is to be understood.

\$2 Latin possesses the adjective (A) mediterraneus 'what is at the middle of the earth'. Thus when describing Britannia (modern Great Britain), Caesar wrote: Nascitur ibi plumbum album in mediterraneis regionibus, in maritimis ferrum 'There are tin mines in interior regions of the earth and iron mines in the maritime regions' (De bello Gallico, V, XII, 5).

$\$ 3$ The Latin adjective mediterraneus $(\mathrm{A})$ is derived from the noun $(\mathrm{O})$ terra 'the earth', which can be expressed by the formula $\mathrm{O}>\mathrm{A}$ (Chapter 155, \$4).

$\$ 4$ Lat. terra comes from Indo-European ${ }^{\star}$ ters- $a$. Some etymologists have hypothesized that this form might be a nominal adjective; it was transferred to a noun $(\mathrm{A}>\mathrm{O})$, having the meaning of 'the dried', from the same root as Lat. torreo 'I dry', Fr. torr-éfier 'roast', Eng. torr-id. If this hypothesis is correct, the formula of successive transfer, by which one arrives at Lat. mediterraneus, would be $\mathrm{A}>\mathrm{O}>\mathrm{A}$.

\$5 The Latin adjective mediterraneus has become the French adjective méditerrané, which preserves the same meaning as in Latin. Thus Buffon still says golfes méditerranés, that is, the gulfs that are situated in the middle of the earth. But in this sense, the adjective méditerrané is anachronistic in modern French.

$\$ 6$ Above all, the adjective is conserved in the feminine as an attribute subordinate to the feminine noun mer. It appears in une mer méditerranée, that is, 'a sea situated 
in the middle of the earth'. The union of words is shown in the following stemma (Stemma 289):

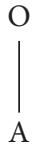

\section{Stemma 289}

\$7 However, most often one does not express the noun mer; one is rather content to transfer the adjective méditerranée to a noun. This noun of course preserves the feminine gender of the noun mer from which it stems (cf. Chapter 177, \$6). Therefore one will say la mer Caspienne est une méditerranée 'the Caspian is a mediteranean', which signifies that it is a sea situated in the middle of land, an interior sea. This new noun is in origin merely a transferred adjective $(\mathrm{A}>\mathrm{O})$, which, when added to the preceding formula, produces the new formula $\mathrm{A}>\mathrm{O}>\mathrm{A}>\mathrm{O}$.

$\$ 8$ The adjective méditerrané, like the noun méditerranée that is derived from its transfer, tends moreover to be employed in modern French more and more exclusively to designate the méditerranée par excellence, that is, the large interior sea situated between Europe, Africa, and Asia, la mer Méditerranée, or as a noun, la Méditerranée 'the Mediterranean'.

$\$ 9$ In turn this noun gives rise to the adjective méditerranéen via a derivational suffix ( $\mathrm{O}$ $>\mathrm{A}$ ); the formula now stretches out to $\mathrm{A}>\mathrm{O}>\mathrm{A}>\mathrm{O}>\mathrm{A}$. This adjective is a purely French formulation, which never developed in Latin. However, one should note that if it had already existed, it would have been able to be of the type ${ }^{*}$ mediterr-an-e-an-us, with repetition of the suffix -an-corresponding the double transfer $\mathrm{O}>\mathrm{A}$.

$\$ 10$ But not all the transfers contained in the formula $\mathrm{A}>\mathrm{O}>\mathrm{A}>\mathrm{O}>\mathrm{A}$ are alive. The first belongs to the etymology of Indo-European, the second comes from Latin derivation and is moribund in French, where it survives only in erudite language. Only the third and fourth instances of transfer in the formula are still quite alive in modern French. If we want to be content with emphasizing these latter two, we can place the two frozen transfers in parentheses, the ones that have merely etymological value. The structure of the nucleus méditerranéen - that is, the structure that French speakers sense in our modern times - is hence expressed by the formula: $(\mathrm{A}>\mathrm{O}>) \mathrm{A}>\mathrm{O}>\mathrm{A}$.

$\$ 11$ One takes from this formula that the perception of modern Francophones is no longer directly influenced by the frozen transfers $(\mathrm{A}>\mathrm{O}>\mathrm{A})$. These can only be uncovered by etymological exhumation. They are now integrated into the semantic value of the word, and it is only by subtle and insightful intellectual effort that the mind can abstract over them. 
$\$ 12$ To convince oneself of this fact, it suffices to consider the manner in which the candidates for the baccalauréat reacted to the sentence cited above in $\$ 2$ when it was presented to their sagacity in 1928 in Strasbourg.

$\$ 13$ The problem for them consisted in retrospectively perceiving the denotation of the word mediterraneus with a translation that is less than the Fr. méditerranéen (Lat. * mediterraneanus), which was more familiar to them.

$\$ 14$ The majority of them were confused and they translated mediterraneus 'what is in the middle of earth' to méditerranéen, without seeing the semantic nuance and without stopping to consider the geographic contradiction that can arise when these mediterranean regions are situated in England.

\$15 The lesson that one can take from this is that every nucleus, since it is susceptible to being a transfer cemetery, is and should be suspect.

$\$ 16$ Furthermore, every nucleus, and as a consequence every content word, can hide transfers so old that the trace of transfer has completely disappeared, which renders etymological investigation incapable of uncovering them.

$\$ 17$ While the ancient history of nuclei can be uncovered by way of etymological investigation, their prehistory is completely inaccessible to us, and attempting to reconstruct it is a fruitless endeavor. However, it would be a mistake of reasoning to conclude that nuclei lack a prehistory. The destruction of archives erases our knowledge of history, but it does not erase history itself.

\section{Chapter 160. Markers of transfer}

\$1 When transfer is marked, we give its marker the name translative (Chapter 154, \$5); the translative is therefore the marker of transfer. As stated above (Chapter 134, §7), we adopt lower case $t$ as the symbol of the translative.

$\$ 2$ The translative most frequent in French is the preposition de, the uses of which are numerous and varied. It is interesting to note that, via its meaning as well as via its etymology, this word evokes in the speaker the subconscious association of the category of the source 'from', from which the target stems.

$\$ 3$ On the spoken chain, the translative can precede or follow the source. One calls the translative a preposition if it precedes the source and a postposition if it follows it.

$\$ 4$ Certain languages prefer prepositions, and others postpositions. French, English, German, Latin, Greek and in general our European languages prefer prepositions. In contrast, the Finno-Ugric languages (Hungarian), Turco-Tatar (Turkish), Caucasian (Georgien), and Basque prefer postpositions: Hungarian az asztal elött 'in front of the table'. 
\$5 Moreover it is not rare to encounter postpositions in languages that normally employ prepositions. Such is the case in German with the postpositional translative gegenüber 'across from', mir gegenüber 'across from me'.

$\$ 6$ The usual terminology, since it does not acknowledge the nature of translatives, persists in calling this type of word a preposition, according to the criterion of position. This practice leads to rules that challenge good sense. One is accustomed to saying that "the German preposition gegenüber must be placed after its complement". One sees the irony in the paradox of the statement, saying that a preposition is placed after something. It is attempting the impossible to pretend to teach grammar and form grammatical intelligence by way of such an extreme doctrine (cf. Chapter 27, \$8).

$\$ 7$ A translative can require its complement to have variable case depending on whether it is preposed or postposed. The German translative zufolge is constructed with the genitive when it is a preposition and with the dative when it is a postposition: zufolge deiner Befehle, deinen Befehlen zufolge 'according to your orders'.

$\$ 8$ The two Latin words causa 'in view of' and gratia 'for the love of', which are ablatives employed as translatives, are postpositions: Lat. filii gratia 'for the love of his son'.

$\$ 9$ A translative can be doubled. This is generally the case when the semantic nuance that it expresses is complex: Fr. une bouteille de vin de derrière les fagots, lit. 'a bottle of wine from behind the firewood', that is 'a bottle of the best wine', Rus. iz-za ostrova 'from behind the island'.

$\$ 10$ Doubled translatives allow one in particular to precisely capture the relations of two nuances that are semantically contradictory. The Fr. d'avec, lit. 'from with', is suitable for indicating that the commutative link expressed by avec 'with' is subsequently delinked by a separation: distinguer une chose d'avec une autre 'distinguish one thing from another'.

\$11 Transfer can even be multiplied and thus necessitate the use of multiple translatives. Such is the case in the French expression voir les choses par en dedans 'see the matter from the inside', lit. 'see the matter by in inside', where the analysis allows one to acknowledge multiple successive transfers. The translative dans 'in' becomes an adverb by the adjunction of the translative de-: dedans 'inside. The adverb dedans is clarified by the translative en 'in': en dedans, which in turn is clarified by the translative par 'by': par en dedans.

\section{Chapter 161. The agglutination of translatives}

$\$ 1$ Since they can be employed in sequence on the spoken chain, translatives end up agglutinating little by little to the sources that they transfer (Chapter 11, $2-4$ ).

$\$ 2$ Agglutination has the effect of transforming prepositions into prefixes and postpositions into suffixes or endings. 
$\$ 3$ One can see that under such conditions, prefixes and suffixes often have the value of translatives. But by reason of the early point at which they lost their autonomy (Chapter 11, $\$ 6$ ), the transfers that they effected when they were autonomous are most often transfers that are actually frozen today. Thus suffixes usually serve as markers of derivation. In this case, one calls them derivational suffixes (cf. Chapter 158, $\$ 7$ and 174).

$\$ 4$ Agglutination changes nothing in the graphic representation that we have presented in Chapter 156. It suffices to put the prefix or the suffix in the position of the translative. Hence the English phrase a striking example will be represented in the following manner (Stemma 290).

$\$ 5$ The economy of the stemma is not changed at all by agglutination, and the advantage remains of being able to easily integrate the target phrase. The matter is evident in the French verse Illustre rejeton d'un prince aimé des dieux 'Illustrious scion of a prince loved by the heavens' (La Fontaine, Fables, Dédicace au Dauphin, v. 7).

$\$ 6$ The inflectional endings will receive the same treatment in the stemma as the suffixes. Thus the Latin phrase liber Petri 'book of Peter, Peter's book' is represented in the following manner (Stemma 292).

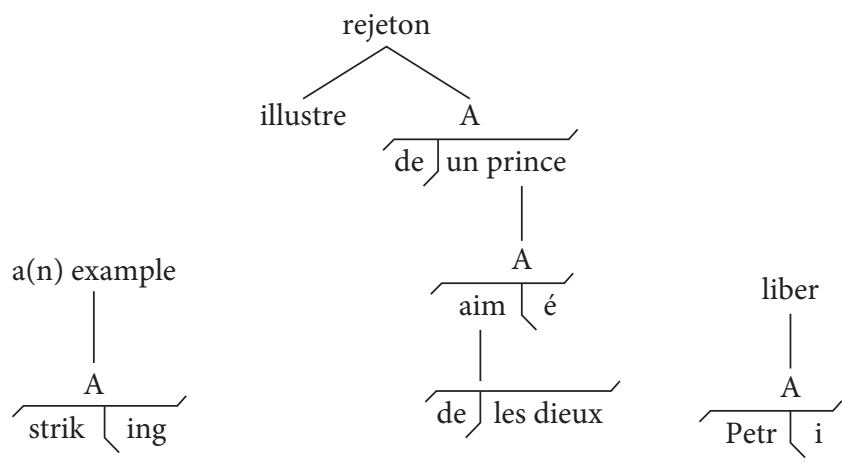

Stemma 290

Stemma 291

Stemma 292

$\$ 7$ When agglutination occurs between the personal nominal source and its translative, it is normally the translative that agglutinates to the source. In Latin for instance, the translative cum 'with', which is normally a preposition, becomes a postposition (cf. chapter 160, \$3) suffixed to the two ontive personal nouns: cum amico 'with a friend', but mecum 'with me', vobiscum 'with you'.

$\$ 8$ In some languages, the personal source agglutinates to the translative as a personal indexical suffix. The translative seems to conjugate like a verb in such cases.

$\$ 9$ This is the situation in Breton, where prepositions take a personal index as a suffix. Breton grammar calls this sort of suffix a pronominal suffix. 
\$10 Thus the preposition evit 'for' is inflected in the following manner:

\begin{tabular}{lc}
\hline \multicolumn{2}{c}{ Breton } \\
\hline evid-on & 'for me' \\
evid-out & 'for you' \\
evit-añ & 'for him' \\
evit- $i$ & 'for her' \\
evid-omp & 'for us' \\
evid-oc'h & 'for you' \\
evit-o & 'for them' \\
\hline
\end{tabular}

\$11 Suffixed pronouns in Breton sometimes evoke the personal endings. For instance, with the plural autoontive the pronoun suffixed in evid-omp 'for us' is a form closely related to the ending of gre-omp 'we do', present form of the auxiliary ober 'do'.

$\$ 12$ The same phenomenon is observed in Hungarian, even though one is dealing with postpositions and no longer with prepositions of the sort that one has in Breton. The personal indices are nevertheless suffixes: Hungarian elött-em 'before me'.

\section{Chapter 162. Transfer without a marker}

\$1 Sometimes transfer is not marked. In such cases, we say that the marker of transfer is zero (Chapter 17), that is, transfer occurs without a translative. But transfer has occurred nonetheless. Regardless of whether or not transfer is signaled by a morphological marker, the syntactic phenomenon remains the same.

$\$ 2$ Take for example the union of words in Fr. un ruban orange 'an orange ribbon' and une étoffe citron 'a yellow fabric', lit. 'a lemon fabric'. The words orange 'orange' and citron 'lemon', which are real nouns, are employed with the value of adjectives to designate the color of the two objects, not their substance. Therefore transfer has changed the nouns to adjectives. The color quality of the source noun motivates the transfer to an adjective target.

$\$ 3$ Transfer of a noun to an adjective without the use of a marker is so normal that it does not cause difficulty. It occurs particularly frequently with proper nouns of person, probably because the majority of these nouns cannot be rendered (morphologically) as adjectives: la tour Eiffel 'the Eiffel tower', le dîner Durand 'Durand dinner', that is, the dinner that is prepared by Durand or that is given in honor of Durand (cf. Stemmas 141 and 143).

$\$ 4$ The noun that has been transferred to an adjective is of course an adjective together with all its subordinates. Thus one correctly says in Fr. Cet homme est vieux jeu 'This man is old fashioned', lit. 'This man is old game'. 
\$5 Transfer without a marker can occur for any type of word. Hence adjectives are often transferred to adverbs without the appearance of a marker, that is, without an autonomous translative or a derivational suffix: Fr. boire frais 'drink fresh', boire sec 'drink parched', taper dur 'hit hard' (cf. Chapter 205, \$16).

$\$ 6$ The existence of transfer without a translative puts an end to all theories that strive to base syntax on morphology and thus acknowledge only those syntactic facts that are expressed clearly by a morphological marker (Chapter $17, \$ 4$ ).

$\$ 7$ Indeed, it is evident that when one says la tour Eiffel or le dîner Durand, the nouns Eiffel and Durand are not playing the role of nouns, but rather of adjectives, even though nothing marks these adjectives morphologically. Nothing indicates whether the expression is designating Mr. Eiffel or Mr. Durand himself and in so doing, it is not qualifying an object by the character trait that is associated with Mr. Eiffel or Mr. Durand.

$\$ 8$ If one ignores an instance of transfer under the pretext that it is not marked morphologically, one is condemned to acknowledge only a portion of the overall cases of transfer (Chapter 17, \$5). The attempt to construct a complete system from this incomplete inventory is doomed to failure, since one seeks in vain to discern the structure of an edifice that one can see only in part (Chapter 17, \$6).

$\$ 9$ One should note that in languages with case, the nominative provides a nucleus that is not transferred. Every transfer must hence be marked by an oblique case, at least the accusative. Therefore transfer of nouns without a marker does not exist in languages with case, and a transferred noun is never in the nominative: Lat. Tres annos regnavit 'He ruled for three years', lit. 'He ruled three.ACC years.ACC', Fr. Il régna trois ans, lit. 'He ruled three years.

\$10 In this area there is an essential fact for French [and English] speakers, for, since French [and English] does not have case, the marker is not present, i.e. it is zero. Of course this zero marker distinguishes between two categories, the translation of which varies in many foreign languages.

\section{Chapter 163. Transfer and linguists}

$\$ 1$ While the notion of transfer has Noт been clearly recognized, expressed formally, studied methodologically, and explicitly integrated into a system of syntax, it has nonetheless been sensed by most linguists, perceived by their linguistic sensitivities, sought after, at least subconsciously acknowledged by intuition, and foreseen as a future program of research. Some linguists have even sometimes moved closer to it by allusion, whereby they are more or less bothered by the need to conceive and expose a syntactic notion with the framework and terminology of morphological syntax. 
\$2 To my knowledge, Charles Bally may have been the first who, after he had discerned the complete richness of syntactic developments, sensed the need to acknowledge the notion of transfer. He understood its power so well that he was obsessed by the idea.

$\$ 3$ In August 1922, he devoted an article to critical examination of Ferdinand Brunot's La pensée et la langue 'Thought and language,, ${ }^{199}$ where he wrote, among other things, the following:

"The categories are a reality, and if language can pass so easily from signs of one category to signs of another, it does so by way of a set of transference procedures that it places at the service of speech and that as a result prove the reality of the categories between which it passes" (p. 119)

and

"...a linguistic sign is transposed when it, without losing the value that its category attributes to it, plays the role of a sign belonging to another category" (p. 119, note 1),

and further

"It is transposition that proves the category" (p. 120).

$\$ 4$ During this time, Bally was conscious of the deep roots that transfer has in the linguistic system and he seized upon the essential importance that it presents: “...it delves deep into the mechanism of language, and often the manner in which an idiom effects functional changes suffices to characterize it" (p. 119).

$\$ 5$ Taking into account the complete extent to which syntax is called upon to take from this notion in the future, Bally deplored the fact that in his times, transposition was not the object of the study that it merited:

"But transposition has never been the object of study, but rather it is statically seen as a result, as accomplished fact. In the first case, the sign bears a mask that it can lift at will, and in the second case, the mask molds to the face and replaces it" (p. 120, note 1).

$\$ 6$ With these statements, Bally was capturing the distinction we drew above (Chapter $158, \$ 2$ ff.) between living and frozen transfer: Bally's true and functional transposition, a static process, is living transfer, whereas when the transposition became habitual, a historic process, it is frozen transfer.

\$7 In the years that followed, this idea crystalized in Bally's thoughts and in 1932, he did not hesitate to admit that in one particular given case, "the noun has changed its category and is no longer a true noun". ${ }^{200}$

199. L L Lensée et la langue, Bulletin de la Société de linguistique de Paris, 1922, p. 177.

200. Linguistique générale et lingustique française, Paris, 1932, p. 295. [3rd edition, Bern, 1950, p. $292, \$ 473]$. 
$\$ 8$ The idea was in the air. At the time, between 1926 and 1933, one could find the following in Juret's writings:

"The analogy of function sometimes requires one word or a phrase of words to pass ('transposition') from one category into another. In Greek an adjective can become an abstract or proper noun by shifting the word accent: glaukós > Glaûkos, phaidrá > Phaídra, purrós > Púrros, diogenếs > Diogénēs, kaké > kákē, leukē > leúkē 'white poplar'. The article in Greek forces an adjective, an adverb, an infinitive, or even an entire clause to change to a noun: ohí pálai 'the ancients'. Latin, since it does not have varying accents or articles, employs adverbs, adjectives (asinarius), and infinitives as nouns less freely (see Latin syntax)."

$\$ 9$ In his presentation to the Société de Linguistique on January 28th, 1933, G. Guillaume said the following about the numerals of the languages in the Far East:201

“The numerals as grammatical number (also like the French article) are essentially tools that enable one to employ nouns (explicit transposition from a continuous noun to a discontinuous noun); the facts of classification must be seen as secondary."

\$10 In an article from 1933, Gougenheim observed:202

“...the use of a well-defined grammatical category turned away from its proper value. We observe the encroachment of stylistics on syntax. Encroachments of this sort enrich the means of expression that a language has and permits it to adapt to complex forms of thought."

$\$ 11$ In 1933 E. Benvéniste, basing his claims on Porzig’s study (IF., XLII, pp. 221-274) of Indo-European neuters in ${ }^{*}$-men, declared that the abstract derivatives in ${ }^{*}$-ti- indicate "transfer" from the act to the object. This is indeed an instance of transfer and, more precisely, what we have called frozen transfer (cf. \$158, Chapter 2, 7).

$\$ 12$ Two years later in 1935, the same E. Benvéniste recognized the existence of ancient suffixed elements in the genesis of Indo-European nominal inflection. ${ }^{203}$ Although these elements had been frozen for a long time, he was led to posit all the characteristics of translatives. Thus the suffix ${ }^{*}$-men- appeared to him to be a specialized nominal derivation tool serving in particular to constitute causative derivatives in ${ }^{*}-e n-t-,{ }^{*}-e n-g-{ }^{*}$ - en - do -, etc. (p. 177), and constituting a germ of an oblique case and other derivatives (p. 184). This find was precise confirmation of the existence of transfer at a prehistoric time and the proof of its permanence throughout the ages.

201. Bulletin de la Société de Linguistique de Paris, 1933 p. XIV.

202. Le 'nous' de solidarité et de substitution, Revue de Philologie française, 1933, p. 117.

203. Origine de la formation des noms en indo-européen 'Origin of the formation of nouns in Indo-European', I. 
$\$ 13$ When I decided in 1934 to publish my article Comment construire une syntaxe 'How to construct a syntax ${ }^{204}$ simultaneously with my Petite Grammaire russe, ${ }^{205}$ the article was intended to explain to the reader what could be somewhat enigmatic and confusing, a syntax conceived in a resolutely novel spirit and according to an entirely new plan. I found myself having to choose between the French name translation [translated here by transfer], which I had already given to the phenomenon, and that of transposition, which I had then just recently found in Bally's, Juret's, and Guillaume's works. While I have, after much contemplation, chosen the former, I have done so not out of vanity (for I was actually excited to have learned that these authors, like me, recognized the essential notion in their own way; this knowledge was in fact great encouragement for me). I have done so because the term translation (Eng. transfer) is shorter by one syllable and more manageable, and above all because it is the key to an entire system of efficient terminology (exposited above in Chapter 154, \$1-5).

$\$ 14$ In an article from 1936, ${ }^{206}$ Kuryłowicz cites some examples of the double nature of parts of speech emphasized by Slotty:

“...There are the 'anaphorical' adjectives, which are true adjectives with respect to their lexical value, but which function as nouns from a syntactical point of view. There are participles the lexical value of which is that of the corresponding personal verb but that could also be qualified as adjectives by virtue of their syntactic function, etc."

$\$ 15$ Finally, in one of his articles on the defense of the French language, Dauzat writes: ${ }^{207}$

"In the expression of the sort billet de banque 'bank bill' (even when the elements maintain their autonomy), the preposition de, without an article, corresponds to a complement that is not individualized: 'bills circulated by some bank' (in plural: des billets de banque 'bank bills'- banque is singular). The complement could have been replaced by an adjective without having changed the meaning: un billet bancaire, if bancaire were used this way."

$\$ 16$ All these citations show that even though it still cannot rightfully directly cite other grammars, transfer has nonetheless been present for and even partially recognized by the most insightful minds for thirty years.

204. Bulletin de la Faculté des Lettres de Strasbourg, 12th year, number 7, May-June 1934, pp. 219-229.

205. Paris, Didier, 1934.

206. Dérivation lexicale et derivation syntaxique, Bulletin de la Socété de Linguistique de Paris, 1936, p. 79.

207. Préposition et particule, Le Monde, July 2, 1947. 
But in each of these cases, transfer is only perceived from a distance; it remains vague and imprecise, nobody having recognized its essential nature. As a consequence, no one has sought to expound on it in a systematic way and grant to it the position that it deserves in the system of syntax as a whole.

\section{Chapter 164. Varieties of transfer in stemmas}

$\$ 1$ Once the principle of transfer is acknowledged, one quickly sees that the facts of transfer actually affect a multitude of different forms. It is important to take inventory of the diverse possible types of transfer and to recognize their exact nature, so that one establishes a bit of order and can set up a method of classification.

$\$ 2$ One should first examine the different types of structure by which transfer presents itself from the point of view of the stemma.

$\$ 3$ Among the types that are straightaway discernible, we distinguish between cascading transfer and inverse transfer.

$\$ 4$ Cascading transfer is present when the stemma presents multiple transfers according to the same formula, the target of each additional instance of transfer being subordinate to the source of the previous instance of transfer, whereby the latter governs the former. Instances of transfer that depend on each other constitute distinct stages and form superimposed levels. One can compare the structure to the successive downward steps of a waterfall.

$\$ 5$ The type of adjectival clause that occurs most often is given with the formula $\mathrm{O}>\mathrm{A}$, the $\mathrm{A}$ of each stage always depending on the $\mathrm{O}$ of the superior stage (see the symbolic Stemma 293).

$\$ 6$ One has a good example of cascading transfer in the periphrastic expression the cousin of the son of the wife of my uncle (Stemma 294), a circumlocution that is voluntarily convoluted and hence ridiculous, used by certain hoaxers who want to confuse the listener because with its expression, they are merely denoting themselves.

$\$ 7$ Adjectival clauses generally have an awkward effect: La guerre de cent ans est l'objet du plus triste des chapitres de l'histoire de la France du Moyen Age 'The Hundred Years War is the object of the saddest chapter of the history of France in the Middle Ages'. Writers avoid such structures. One assumes that Flaubert was never consoled at having written une pipe d'écume de mer 'a pipe of sea froth'.

$\$ 8$ Inverse transfer occurs when the stemma presents two transfers, in vertical connection, that are opposites of each other.

$\$ 9$ The most representative type of inverse transfer is the one where the target nucleus of the formula $\mathrm{A}>\mathrm{O}$ governs the target nucleus of the formula $\mathrm{O}>\mathrm{A}$, a situation that results in the symbolic Stemma 295. 


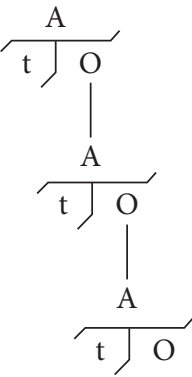

Stemma 293
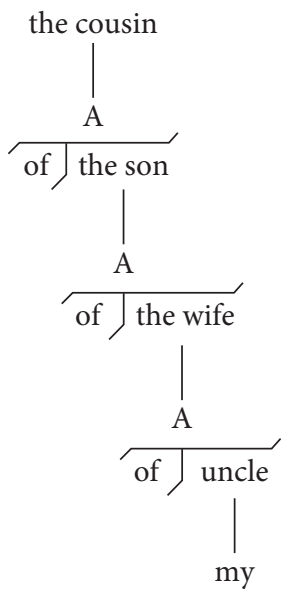

Stemma 294

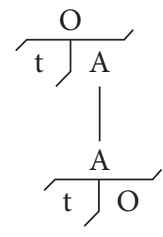

Stemma 295

$\$ 10$ The French expression un imbécile de marmiton, lit. 'a fool of kitchen boy', provides an example of this syntactic structure: the governor is the target adjective imbécile 'stupid, fool', which is changed to a noun by the indefinite article un, and the subordinate is the noun marmiton 'kitchen boy', which has been transferred to an adjective by the translative de (cf. Stemma 314).

$\$ 11$ Finally, one should distinguish between first and second-degree transfer. This distinction is of great importance.

$\$ 12$ We have seen (Chapter 152, \$1 and Chapter 154, \$7) that transfer always has a given category as a point of departure (the source) and a point of arrival (the target), whereby the category of the word at hand is what counts.

$\$ 13$ If the source is a type of word - that is, an element of a simple sentence and no more, and does not govern an entire sentence - we say that the transfer is of first degree.

$\$ 14$ If, in contrast, the source is a verbal node with all its eventual subordinates - that is, an entire sentence - we say that the transfer is of second degree.

\$15 First-degree transfer occurs among elements of the same order and often even of the same syntactic stage. Second-degree transfer, in contrast, obligatorily contains a change of the syntactic level, because a governing node is transferred to a type of word that plays the role of a subordinate in another governing node that is hierarchically superior.

\$16 The change in syntactic level that occurs in cases of second-degree transfer is thus a descent down the structural hierarchy, since it degrades the verbal node in order to subordinate it by one degree. The verbal node is assigned the same subordinate role that is assigned to any other element of the simple sentence. This is what traditional grammar implicity recognizes when it designates second-degree transfer using the term subordination. 
$\$ 17$ As a consequence, every instance of transfer that has a subordinate verb in turn governing a sentence is by definition an instance of second-degree transfer, and in every instance of second-degree transfer, the governing subordinate verb is in turn always the target.

$\$ 18$ We have seen above (Chapter 154, \$5) that the marker of transfer is the translative. Since the translative of first-degree transfer is not the same as the translative of second degree, we will distinguish between the two by using the abbreviated designations firstdegree translative and second-degree translative.

$\$ 19$ Traditional grammar recognizes first-degree translatives as prepositions or postpositions (Chapter 160, \$3) and second-degree translatives as subordinate conjunctions.

$\$ 20$ Although traditional grammar does not recognize transfer and therefore all the more does not acknowledge the distinction between first and second-degree transfer, it has nonetheless implicitly sensed that translatives, which are the tools for the one or the other type of transfer, constitute two distinct types of words, for it has given them distinct names. \$21 But the difference rests on a shaky theory and has the drawback of distorting the economy of the linguistic system. It positions second-degree translatives closer to the junctives by way of the generic designation conjunction (coordinate conjunction $=$ junctive, subordinate conjunction $=$ second-degree translative) and in so doing, it distances the firstdegree translatives from the second-degree translatives by way of the completely different designation preposition (cf. Chapter 134, \$9).

$\$ 22$ This incoherence can generate confusion in the mind of the reader. We therefore believe it to be good practice to show the relationships between the traditional terminology and the terminology that we are currently adopting using the following table:

\begin{tabular}{ll}
\hline Traditional terminology & Terminology adopted here \\
\hline coordinate conjunction & junctive \\
preposition & first-degree translative \\
subordinate conjunction & second-degree translative \\
\hline
\end{tabular}

\section{Chapter 165. Nuclear varieties of transfer}

\$1 Other varieties of structural transfer are based on their appearance inside the nucleus.

\$2 From this point of view, we say that transfer is simple when the nucleus contains only one instance of transfer.

$\$ 3$ But the same nucleus can contain two successive instances of transfer. In such cases, we say that double transfer is present. 
$\$ 4$ Take for example the French noun le commerçant 'storekeeper'. It is transferred from the verb commercer 'trade'; the transfer occurs by way of the adjectival suffix -ant and results in the present participle commerçant. But the adjective that is the present participle commerçant is itself transferred to a noun by the article le. There is therefore double transfer, which is given by the formula I $>$ A $>\mathrm{O}$ (cf. Chapter $217, \S 5$ ).

$\$ 5$ Just as there is double transfer, there is also multiple transfer to a high degree: triple, quadruple, etc. according to whether the number of transfers contained in the interior of the nucleus is three, four, or even more.

$\$ 6$ The number of transfers that are susceptible to appearing in the interior of a nucleus is theoretically unlimited. Multiple transfer, however, becomes less frequent as the number of terms that it constitutes increases. In practice, quadruple transfer constitutes a limit that is rarely exceeded.

\$7 Moreover, in the case of multiple transfer, certain transfers - in general the oldest ones, that is, the first ones - are frozen and can only be identified via etymological investigation (cf. Chapter 159, \$10).

$\$ 8$ Among the instances of double transfer, one particular case is reversive transfer.

\$9 Reversive transfer obtains when in the same nucleus, the second transfer is the inverse of the first. The ending category of reversive transfer is the same as the starting category.

\$10 Take for example the English noun the afternoon. In order to explain the genesis of this expression, one departs first from the noun noon, which is transferred to a temporal adverb by the translative after. The adverbial expression after noon is in turn retransferred back to a noun by the article the. The formula of this instance of reversive transfer is thus $\mathrm{O}>\mathrm{E}>\mathrm{O}$. Note that the orthography shows signs of the second instance of transfer, since the adverb is after noon in two words, whereas the noun is afternoon in one word.

$\$ 11$ If from a structural point of view, reversive transfer returns to its point of departure, the result is not the same from a semantic point of view. The two instances of transfer and the passage through an intermediate category leave an indelible trace on the transfer (cf. Chapter 159, \$8).

$\$ 12$ Indeed, while noon and afternoon are both nouns, they are nouns having different denotations. The meaning of afternoon is essentially charged with all the meaning of noon as well as with additional semantic meaning that it owes to the successive transfer that it undergoes, passing through the category of temporal adverb.

$\$ 13$ The distinction becomes even clearer when one has transfer without a marker. Take the nominal node formed in French by the noun pied 'foot' and the adjectival subordinate $b o t,{ }^{208}$ the two constituting the expression pied-bot 'club-foot', which designates a foot

208. Translators' note: The origin and the meaning of this adjective are uncertain. It appears only with pied in pied-bot. Cf. Fr. botte 'boot' and Eng. butt. 
bearing a deformity. This noun can be transferred to an adjective by transfer without a marker: Byron était pied-bot 'Byron had a club-foot'. In turn, this adjective can be transferred anew to a noun by reversive transfer without a marker and accordingly, one says un pied-bot to designate the person who has a club-foot, not the foot itself. If the form of the transferred noun is the same as that of the source noun, the trace of the changes that the nucleus undergoes is clearly discerned in the difference in meaning that each expresses.

\section{Chapter 166. Formal transfer}

$\$ 1$ There is reason to reserve a spot for formal transfer, which denotes a special relationship to the nucleus and which, as we will see, can be classified neither as extra-nuclear nor intra-nuclear.

$\$ 2$ The source here is not in a syntactic state, or, to be more exact, it is not by virtue of its ability to bear a given syntactic category and to depart from this category that it undergoes transfer.

$\$ 3$ It is not the syntactic content of the word that is transferred, but rather its exterior form, with no account taken of its eventual syntactic state. For this reason, we call the phenomenon formal transfer.

$\$ 4$ The target can thus have an acknowledged syntactic status, or it can lack this status, since the source category is not important. For the same reason, one cannot classify formal transfer as being of first or second degree. Since formal transfer departs from whatever word category and arrives somewhere else, the question of category status simply does not arise.

$\$ 5$ It is the transfer itself that gives its syntactic status to the source, because it changes the source into a different category and makes it enter into a nucleus automatically. From this point of view, we can say that formal transfer is novonuclear.

$\$ 6$ The target category of formal transfer is always that of a noun. Since there is no clear starting category, formal transfer can perhaps be represented by zero $>\mathrm{O}$.

$\$ 7$ Formal transfer never has a marker. It is therefore sometimes difficult to recognize, and when the source belongs to a transferrable category, it is susceptible to being confused with true syntactic transfer.

$\$ 8$ Take for example the French couplet

\begin{tabular}{ll}
\hline Philaminte: J'aime SUPERBEMENT et & 'Philaminte: I love SUPERBLY and \\
MAGNIFIQUEMENT: & MAGNIFICANTLY: \\
Ces deux adverbe joints font & These two adverbs combine \\
admirablement. & admirably'.
\end{tabular}

(Molière, Les Femmes savantes, III, 2)

The two words superbement 'superbly' and magnifiquement 'magnificantly' undergo formal transfer. Philaminte does not intend to say that she loves a superb manner and a 
magnificent manner, but rather that she loves the two words superbement and magnifiquement, which she designates specifically as adverbs.

$\$ 9$ As adverbs, these two words are employed in the sonnet to Princess Uranie during her fever; Trissotin has come to read to her. The two words function essentially as circumstants since one refers to treating an enemy superbly and the other to putting him up magnificently.

$\$ 10$ But when Philaminte says these two words, she no longer employs them in the function of circumstants; she cites them rather as forms that, as such, are transferred to nouns, and in this regard, they play the role of second actants in the sentence.

$\$ 11$ And this is why the words are written in small caps in the text, for one knows that one can spare oneself the trouble of informing the reader via an artificial structure that something unusual is going on in the sentence. This something is quite simply formal transfer.

$\$ 12$ The scene from Molière that we come to cite contains numerous formal transfers of the same sort:

Armande: A PRUDENCE ENDORMIE

il faut rendre les armes.

Bélise: LOGER SON ENNEMIE est

pour moi plein de charmes.

Armande: Que RICHE APPARTEMENT est lá joliment dit.
'Armande: We must surrender to DORMANT WISDOM.

Bélise: Putting up one's enemy

has great charm for me.'

'Armande: WHAT A RICH APARTMENT sounds so good.'

(Molière, Les Femmes savants)

\$13 As a general rule, there is formal transfer each time one reports the exact words employed by another. Such is the case in the joyous boasts of soldiers to their leader of a campaign:

- Peut-être seras-tu general. '- Maybe you will be a general.
- Ce "peut-être" est un insulte. - That "maybe" is an insult.'
(Roger Boschet, Le Général Daumesnil,
Hachette, 1938, p. 63)

Toutes les nuits... le roulement de la voiture, le "porte, s'il vous plait!» du cocher, le faisaient tressaillir.
'Every night... the rattle of the car, the "door, please!" of the coachman, startled him.'

(A. Daudet, Le petit Chose 'The little Thing', first part, X)

$\$ 14$ Ausonius' words Arma virumque peritus (Epigrammata, 237), lit. 'skillful at arms and heros', are of this type and mean '(he) who knows his Aeneid'. Indeed, the accusative form Arma virumque 'arms and heros' can only be explained by the reference to the first verse of the Aeneid of Vergil Arma virumque cano 'I sing arms and heros', where it is the 
accusative second actant of cano 'I sing', while the subordinate of peritus should otherwise have been in the genitive, cf. antiquitatis nostrae peritus 'skillful at the past of our history' (Cicero, Brutus, 205).

$\$ 15$ In Russian, a word that is the object of a citation bearing formal transfer has the status of a neuter noun, a fact that is visible when an adjective showing gender accompanies it. Služil on čto li v opolčenii? - Kakoe v opolčenii, lit. 'He served in the militia, right? - What "in the militia"?', that is 'He served in the militia - In the militia, come on!' (Turgenev, Nesčastnaja, V).

$\$ 16$ The citation to which one is referring can consist of one empty function word:

\begin{tabular}{|c|c|}
\hline $\begin{array}{l}\text { Avec des SI et des MAIS, on construirait } \\
\text { Paris en un jour. (Proverb) }\end{array}$ & $\begin{array}{l}\text { 'With IFs and BUTs, one } \\
\text { could build Paris in one day.' }\end{array}$ \\
\hline $\begin{array}{l}\text { Avec un si on mettrait Paris } \\
\text { dans une bouteille. (Proverb) }\end{array}$ & $\begin{array}{l}\text { 'With an IF one could put Paris } \\
\text { in a bottle.' }\end{array}$ \\
\hline $\begin{array}{l}\text { Se quereller pour un ouI } \\
\text { et pour un NON. }\end{array}$ & $\begin{array}{l}\text { 'To quarrel about the slightest } \\
\text { thing', lit. 'To quarrel for a } \\
\text { YES and for a No.' }\end{array}$ \\
\hline $\begin{array}{l}\text { Un prêtre, un ouI, trois mots latins } \\
\text { A jamais fixent vos destins. (Voltaire) }\end{array}$ & $\begin{array}{l}\text { 'A priest, a YEs, three words in Latin } \\
\text { Forever fix your destiny.' }\end{array}$ \\
\hline
\end{tabular}

$\$ 17$ The citation to which it alludes is often represented only by one of the words in the sentence that has actually been uttered:

\begin{tabular}{ll}
\hline ..De faux tiroirs dissimulaient & '...False drawers hid the heavy \\
le lourd battant de métal. Léonie & metal shutter. Léonie formed the \\
forma le mot qui était le Sésame & word that was the Sesame of the \\
du coffre & chest'
\end{tabular}

(François Mauriac, Les chemins de la mer, p. 18)

This is an allusion to the famous sentence of Ali Baba in the One Thousand and One Nights: "Open Sesame!" In the same way, Fr. des adieux 'farewells' are salutations by which one takes one's leave from someone by embellishing: Je vous recommande à Dieu 'I recommend you to God'. And Fr. se faire des mamours 'to caress' is to express love by pronouncing the words m'amour = mon amour 'my love'.

$\$ 18$ One can name a literary work by using formal transfer of the first words that compose it, like in the example of Arma virumque given in $\$ 14$. The process was common among the Jews where the acrophonic denomination of a work was usually used for the title. Thus in Hebrew Barês šit generally meant 'the Genesis', because the first book of the Bible started with the word Barêsi $i \underline{t}$ 'In the beginning (God created the heaven and the earth)'.

$\$ 19$ The use of acrophonic denominations as titles remained traditional in the Church where it is still usual for bulls, encyclical letters, and prayers: the Unigenitus bull, the Rerum 
encyclic letter, a Kyrie eleison, an angelus, an Our Father, Fr. un Je vous salue Marie, lit. 'an I-hail-you-Mary'.

\$20 One can note that formal transfer easily affects foreign words. Their external form stands out especially since their meaning is less evident: Je pratique énergiquement le NIHIL ADMIRARI 'I practice the NIHIL ADMIRARI energitically' (E. About, Le roi des montagnes, IV) (cf. Chapter 191, \$8).

\section{Chapter 167. Categorical varieties of transfer}

\$1 Transfer often indicates the semantic value of the target category, that is, the category to which the source is transferred. Hence it is marked by a different translative in Fr. Alfred arrive de Paris 'Alfred is arriving from Paris' and Alfred arrive par Paris 'Alfred is arriving by way of Paris'. In the two cases, the category of the target is an adverb and more specifically, an adverb of location. But the phrase de Paris 'from Paris' is an adverb that indicates the starting point, whereas the phrase par Paris 'by way of Paris' is an adverb that indicates the place of passage.

\$2 On the other hand, we have seen (Chapters 34-37) that in the interior of each of the different types of content words that correspond to a basic grammatical category, one has to establish subdivisions or subclasses.

$\$ 3$ Concerning the adjective category, we have been led (cf. Chapter $35, \S 7$ ) to distinguish attributive adjectives of quality and quantity from adjectives of personal and circumstantial relations, all of which belong to the general category of adjective, but each differing from the others in its proper nature inside the adjective category.

$\$ 4$ Yet one can observe that if transfer specifies the semantic value of the target category, it is in contrast much less specific regarding the subclass of the source.

$\$ 5$ Hence the same translative de can transfer a noun to a qualitative adjective (un homme de génie 'a man of genius', une femme de tête 'a strong-minded intellectual woman', lit. 'a woman of head') as well as to an adjective of personal relation or a possessive adjective (le livre de Pierre 'the book of Peter', which is on the same structural plane as mon livre 'my book') or to a relational adjective of circumstance (le train de Paris 'the Paris train').

$\$ 6$ Furthermore, the general category itself is not always specified without ambiguity, and the same translative can serve to specify two distinct target categories. Such is the case with the translative de; it can transfer a noun to an adjective (le livre de Pierre 'the book of Peter') as well as to an adverb (regarder de côté 'look askance', lit. 'look of side'). It corresponds to the formula $\mathrm{O}>\mathrm{A}$ as well as to the formula $\mathrm{O}>\mathrm{E}$.

$\$ 7$ But if transfer does not specify the subclass of the category to which it changes the source, it nevertheless no less assigns it to another category, but also to one of the subclasses within this category. 
$\$ 8$ The same holds for the examples given above in $\$ 5$, where the translative indicates merely that the noun has been assigned to the category of adjective $(\mathrm{O}>\mathrm{A})$. It nevertheless indicates that it has at times been changed into the subclass of qualitative adjective (un homme de génie 'a man of genius'), at other times into the subclass of adjective of personal relation (le livre de Pierre 'the book of Peter'), and yet at other times into the subclass of the circumstantial adjective (le train de Paris 'the Paris train') (cf. Chapter 35, \$22).

$\$ 9$ The imprecision, if not of the target category, at least of its subclass, furnishes us with an explanation for the paradoxical fact we encountered above (Chapter 151, \$3-14), namely that the same translative can express a relation and its inverse simultaneously.

$\$ 10$ Hence, one is dealing with the same relation, from whatever perspective one views it. The road from Etampes to Arpajon is always the same road regardless of whether one is going to Etampes or to Arpajon.

$\$ 11$ Even though in le livre de Pierre 'Peter's book' and le chien du maitre 'the master's dog' (Chapter 151, \$7-8), the source is transferred to an adjective, it is nonetheless transferred to an adjective of personal relation (a so-called possessive adjective), without this relation actually being specified in the least. The expression le livre de Pierre denotes a book that is characterized by the fact that it stands in a relation to Pierre. Le chien du maitre denotes a dog that is characterized by the fact that it stands in a relation to the master. But the transfer remains silent, not only in its nature but also in the direction of this relation. The result of this is that the same relation exists with the opposite direction. The relation between Pierre and the book, and that between the master and the dog is constant, regardless of the meaning that one envisages. This is why one can say le possesseur du livre 'the owner of the book' and le maitre du chien 'the master of the dog' just as well as the opposite: le possesseur $d u$ livre is a possessor who is characeterized by the fact that he stands in a certain relation to the book; le maitre du chien is a master who is characterized by the fact that he stands in a certain relation to the dog.

$\$ 12$ This argumentation shows the extent to which the received term possessive adjective can be inexact and misleading. This term seems to indicate possession or belonging of one subject to another, whereas one is actually dealing with a general relation of possession or belonging between the two, which in no way implies a direction in which this relation must be understood.

$\$ 13$ For the same reason, le train de Paris (above Chapter 151, \$9-10) can designate the train that is coming from Paris as well as the train that is traveling to Paris. Transfer does no more than change the noun Paris to an adjective of circumstantial relation, that is, to an adjective that indicates that there is a circumstantial relation regarding location between $l e$ train and Paris. It is a train that establishes the connection between a certain location and Paris. It establishes this connection in both directions, and the transfer itself never specifies whether it should be understood in the one direction or in the other. 
$\$ 14$ In this manner, it is possible to explain why the same translative can serve in the expressions interné de la Résistance 'prisoner of the resistance' and interné de la Gestapo 'prisoner of the Gestapo' (above Chapter 151, \$13). One can be dealing in both cases with the same prisonner, since he was in a certain relation with la Résistance and in a certain relation with la Gestapo. There is nothing surprising about this considering that la Résistance and la Gestapo were battling each other and so there was necessarily a certain relation between the two.

\section{Chapter 168. Attenuated transfer}

$\$ 1$ In the case of indefinites such as Fr. déjeuner 'have breakfast', dîner 'have dinner' souper 'have supper', we are dealing with transfers according to the formula $\mathrm{I}>\mathrm{O}$, in which the infinitive is a verb transferred to a noun.

\$2 Yet the infinitive, which is already a noun by way of transfer, can also receive a nominal index in the form of the article: le déjeuner 'the breakfast', le diner 'the dinner', le souper 'the supper'.

$\$ 3$ The passage of a verbal category to that of a noun is marked in two ways, first by the use of the infinitive and second by the use of the article.

$\$ 4$ Neither of the two translatives suffices alone to establish transfer. Each of them contributes only one part, and only by virtue of combining and unifying their forces can they fully establish the syntactic function of transfer.

$\$ 5$ Each of the two translatives has reduced value as a translative and can effect only attenuated transfer, which means each is an attenuated translative.

$\$ 6$ One observes an analogous phenomenon in languages with case morphology. These languages possess prepositions and postpositions that demand a certain case for their nouns.

$\$ 7$ Such is the case, for example, in Latin, where with a friend is expressed as cum amico. While the translative with in English suffices alone to effect transfer, the Latin translative cum requires the use of ablative case in amico.

\$8 While the English preposition with alone effects transfer, Lat. cum and the use of the ablative case each only accomplish a part of the transfer, since both must be present to complete transfer. The value of each as a translative is hence attenuated.

\$9 This hybrid mechanism appears generally as an intermediate stage in our languages, intermediate between the period when transfer is effected entirely by flection and when it is effected entirely by an autonomous translative.

$\$ 10$ A good example of the first case, which seems to be from the oldest stage to which one can reach back in the history of Indo-European languages, is provided for us by the Latvian 
Es esmu istab $\bar{a}$ 'I am in the room', where the use of case, the locative in istab $\bar{a}$, suffices alone to effect the same transfer as the translative which is the English preposition in.

$\$ 11$ The intermediate stage, where one has to combine the effect of case as a translative with a translative word, is represented by Greek, Latin, German, the Scandinavian languages, and the Slavic languages, excepting Bulgarian.

$\$ 12$ The later stage is that of French, the neo-Latin languages, and English, where the preposition alone assures the integrity of transfer, without the necessity of case.

$\$ 13$ As one traces this evolution, it is necessary to admit that the value of transfer passes progressively from case endings to autonomous translatives.

$\$ 14$ Transfer expressed by case endings becomes increasingly attenuated as soon as the automous translative appears to reinforce transfer.

$\$ 15$ Conversely, the autonomous translative, which stems from a simple additive appearing as reinforcement, increasingly takes on the value of a translative as the case endings become weaker.

$\$ 16$ The final result is that the case endings - completely devoid of their value as translatives, which was their raison d'être - become dead weight to be more or less eliminated and are hence completely replaced by the autonomous translatives.

$\$ 17$ This evolution can be observed in the majority of Indo-European languages, where it is a sign of the passage from a proper Indo-European language to one that is of a completely different sort. From this point of view, one can say that the Indo-European languages are becoming "de-Indo-Europeanized".

\$18 There can also be attenuated transfer when the translative is not replaced by another translative, but rather loses its value because it is in the process of falling into obsolescence.

$\$ 19$ In such a case, it is sometimes particularly difficult to detect transfer that is marked at the origin and moribund, since it no longer responds to a productive operation of transfer. Such instances of transfer have etymological value only, whereby the origin must be sought in the history of the language and in certain substrata that are difficult to discern.

\$20 Such is the case with the translative de in Fr. De quoi ? 'What?'. This form is not the result of productive transfer, although it did arise from transfer at some point in its etymological development, but rather it conserves only a type of semantic and stylistic value that is, incidentally, quite clear.

\$21 The French expression de quoi? remains alive only in its rogue and provocative tone, which is perfectly clear for Francophone speakers. It is a rude way to close the mouth of someone who is balking.

$\$ 22$ Even though it is very difficult to examine the history of expressions that reside on a substratum - because in this case, there is no historical continuity between the original expression and the modern French expression - one does seem to be dealing with a 
substratum that is analogous to the one that is encountered in spoken southern colloquial French, in particular in the southwest.

\$23 A person from Montpellier therefore expresses the interrogatives quoi and que 'what' using dequé: dequé voulés? 'What do you want?'209 It seems that there was a nuance in Occitan between per qué 'why, for which reason' and per dequé 'why, with which purpose. ${ }^{210}$

\section{Chapter 169. Indices}

$\$ 1$ It is necessary to establish a parallel between attenuated translatives and certain translatives that can sometimes also appear when there is no transfer to be carried out.

\$2 Transfer consists of two category operations, the first consisting of extraction of the source from its original category, and the second of assigning it to its new category. The translatives that we are now concerned with here perform only this second operation.

$\$ 3$ This boils down to the statement that translatives mark the category of word that one is dealing with clearly, but that they are unhelpful at indicating the fact that the word comes from another category because that word already belongs to the category indicated by the translative.

$\$ 4$ Such translatives do not therefore have a clear value as translatives, since they do not really effect transfer. They merely indicate the category of the word that they accompany, without changing it.

$\$ 5$ They do not have transferring value, but rather just indicative value. They are therefore called indices (cf. Chapter 41).

$\$ 6$ Indices can be former autonomous words or former translatives that have lost their value as translatives. But this concerns only the historical point of view of their etymology. From a static point of view, one observes simply that their role is to indicate the category of the content word that they bear on.

$\$ 7$ The most frequent indices in our European languages are the article and the personal index.

$\$ 8$ The article, such as it exists in French and in many other languages (Italian, Spanish, English, German, etc.), is a nominal index that can also serve as a translative.

$\$ 9$ Thus it can serve to mark transfer from the adjective category to the noun category $($ A > O) (Chapter 177, \$2). The article distinguishes between the noun the general and the adjective general.

209. Lamouche, Grammaire languedocienne, p. 60.

210. Ibid., p. 121. 
\$10 But most frequently the article has the value of a nominal index only and is content to mark the nominal character of a word that is by its very nature already a noun.

$\$ 11$ In English one will employ the article the in front of the noun horse: the horse. It is evident that the article here is not a translative and that it does not serve to transfer the word horse to a noun, since horse already is a noun.

$\$ 12$ The article is content in this case to indicate that a word is present that originated from a different category.

$\$ 13$ Similarly, the personal index does not effect transfer, at least not in English, since it in no way functions to transfer a word (to a verb) that would belong to another category.

$\$ 14$ The personal index functions only to indicate the person of the verb (Chapter 59, \$8), that is, to specify if the verb has to be expressed with the anontive, the autoontive, or the antiontive. It is content to mark the category of person, which is a subdivision of the verb.

$\$ 15$ Hence the personal index suffices to assure the personal conjugation of the verb, and it serves in this role in a number of languages (cf. Chapter $61, \$ 1 \mathrm{ff}$.).

$\$ 16$ Given that the same tools can serve simultaneously as translatives and indices, it is sometimes extremely difficult to distinguish translatives from indices.

$\$ 17$ The historical definition that is all too frequent in grammars takes the article to be a former demonstrative. This practice is rubbish, and it masks reality by examining the issue through the lens of a historian, that is, by anachronistically substituting an ancient fact for the one that one pretends to observe. No doubt an observation thus deliberately deformed by so clear an error of method is fundamentally unsuitable to shed light on the actual syntactic value of present-day articles.

$\$ 18$ The difference between the two realities that hide the uniformity of the term personal pronoun is consistent. One mistakenly designates both the personal noun and the personal index as a personal pronoun. It is also a mistake to assume the personal index was once a personal noun.

$\$ 19$ In order to represent connections of this sort graphically, one is tempted to draw a distinction in length between connection lines: the line can be shorter for immediate subordinates, since one is dealing with fallen satellites (cf. Chapter 29, \$18), and longer for intermediate subordinates where the connection is looser (cf. Stemma 296, the three small boys, and 297, Moi, je danserai 'Me, I will dance', cf. Chapter 61, \$11f.).
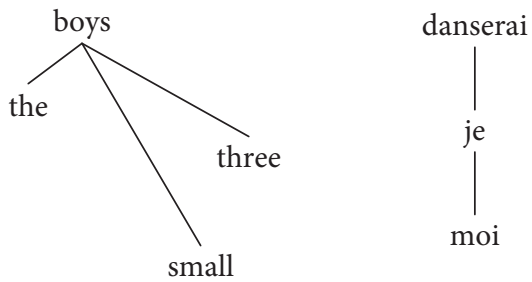
\$20 But it is simpler and more in line with the present facts to integrate the indices into the nucleus of the governing term, since one is in fact dealing at present with fallen satellites of a governor (cf. Chapter 29, \$18, 19, 20 et cf. Stemma 34).

\section{Chapter 170 . The auxiliary verb}

\$1 Certain translatives can have the effect of transferring the source of a subcagetory (cf. Chapter 37, \$5) to another subcategory while leaving it in the same category.

$\$ 2$ In Sanskrit, the translative sma postposed to a verb suffices to change the verb from its subcategory in the present to that of the past, without having passed through another nonverb category: Sanskrit prativasati 'he lives', prativasati sma 'he lived'.

$\$ 3$ The languages of Europe often employ a translative process of the same nature in their verb conjugations. This process differs from the one just mentioned in two essential areas: firstly, the translative is preposed, and secondly, the translative, instead of being invariable, is variable (below Chapter $30, \$ 11$ ).

$\$ 4$ Thus French contrasts the past Alfred a parlé 'Alfred talked' with the present Alfred parle 'Alfred talks'. It is the verb $a$ 'has' that indicates, even though it is in the present, that the verb parler 'talk' must be understood in the past.

$\$ 5$ The verbs that aid other verbs by transferring them to a different subcategory receive the name auxiliary verbs. Auxiliary verbs have been emptied of their semantic content (Chapter 28, \$13) to become simple translatives for their category.

$\$ 6$ In the French sentence Alfred a frappé Bernard 'Alfred hit Bernard', the auxiliary a 'has' is devoid of its proper meaning of 'possession'; it has become a simple grammatical index of the past.

$\$ 7$ Although they are not invariable, the auxiliary verbs are no less translatives. Due to their variability and complexity of use, employing them correctly can be most delicate and a complete mastery of their use is very difficult to acquire.

$\$ 8$ Thanks to auxiliary verbs, a large number of languages have the ability to augment their tense system. They can extend this system and enrich it by way of increasing the number of verb constructions at their disposal.

$\$ 9$ Verb forms that have not been transferred constitute what one calls simple tenses (Chapter 11, \$6). The transferred verb forms that contain one or more auxiliary verbs are called periphrastic tenses, because the simple verbs have been replaced by periphrasis, or compound tenses. The verb form, instead of being simple, is composed of two forms, the auxiliary verb and the auxiliated verb (Chapter $23, \$ 11$ and $67, \$ 6) .^{211}$

211. See Lucien Tesnière, Théorie structurale des temps composés, Mélanges Bally, Geneva, 1939. 
\$10 Auxiliary verbs are empty words, but they constitute the primary verbal node of the sentence. They are empty constitutive words (Chapter 29, \$16).

$\$ 11$ The compound tenses are hence dissociated nuclei containing a morpheme, the auxiliary, which is constitutive but empty; this verb assures the structural function. The nucleus also contains a semanteme, which is the content word that is subsidiary; this verb assures the semantic function (Chapter 23, $\$ 10$ and 11).

$\$ 12$ One ordinarily classifies the compound tenses according to the subcategory into which they transfer the source. One distinguishes between auxiliaries of tense (past, future), auxiliaries of voice (passive), etc. One says, for example, that in the compound tense Alfred a parlé 'Alfred spoke', the verb $a$ is an auxiliary of the past, whereas in the compound tense Alfred will speak, the verb will is an auxiliary of the future.

$\$ 13$ The verbs that are most commonly employed as auxiliaries are be (and Ger. werden 'become'), have, do, go (Fr. Alfred va parler 'Alfred is going to speak'), and come (Fr. Alfred vient de parler 'Alfred has just spoken', lit. 'Alfred comes to speak').

$\$ 14$ The same auxiliary can exercise, according to the conditions in which it is employed, different types of transfer. In French the verb être serves both as the past auxiliary in Alfred est venu 'Alfred came' and as the passive auxiliary in Alfred est frappé 'Alfred is hit'.

\$15 Therefore it is essential for the French speaker who wants to express meaning that would require the auxiliary être in French in a foreign language to distinguish between the auxiliary of the past and the auxiliary of the passive. Experience in teaching foreign languages to French speakers demonstrates how difficult it is to obtain the correct analysis of these auxiliaries. The weakness of inexperienced learners is to consistently confuse the past and the passive when translating into a foreign language.

$\$ 16$ What complicates the mechanism all the more is the fact that auxiliaries can be combined. This occurs in Ger. Alfred wird geschlagen werden 'Alfred will be hit', where the same auxiliary werden is employed once as an auxiliary of the future (wird) taking an infinitive and once as an auxiliary of the passive (werden) taking a past participle.

\section{Chapter 171. Empty preverbs}

$\$ 1$ By way of a delicate and specific mechanism of the Slavic languages, preverbs can serve as translatives of subcategory (Chapter $170, \$ 1$ ).

$\$ 2$ Take the Russian verb pišu 'I write'; it allows composition with the preverb pere- 'trans-' and thus gives rise to perepišu.

$\$ 3$ The preverb pere- is resultative (cf. Chapter 129), that is, it is a circumstant expressing the result of an action, so that perepišu signifies the result obtained by the action expressed with pišu. 
$\$ 4$ Resultatives - which indicate that a result is obtained, that is, that the action has reached its conclusion - evoke perfective aspect by definition (cf. Chapter $37, \$ 22$ ), which indicates that the action is complete. Hence preverbs have perfective value.

$\$ 5$ Since the result necessarily follows the action, if the simple imperfective pišu has present value, the perfective composite form perepišu will take future meaning from this fact, even though its exterior morphology is that of the present.

$\$ 6$ Thus the compound form perepišu differs from the simple pišu by a double relation, on the one hand in its semantic value and on the other hand in its grammatical subcategory value.

$\$ 7$ From a semantic point of view, the preverb pere- 'trans-' adds to the meaning of the verb 'write' the meaning '(once) again', which results in the meaning 'rewrite'/'copy' for the compound verb. The preverb pere- is hence a full word.

$\$ 8$ From the grammatical point of view, the preverb pere- changes the verb pišu from the subcategory of present to the subcategory of future. It is hence an empty word.

$\$ 9$ Since it unites in itself the characteristics of a full word and that of an empty word, the preverb pere- is hence a composite word (cf. Chapter $28, \$ 8$ ).

$\$ 10$ Finally, while pišu means 'I write', perepišu does not mean 'I rewrite' but rather 'I will rewrite'.

\$11 If the Russian system were to stop there, it would be impossible to form on a simple verb different composites with different semantic nuances without changing them to a subcategory of the perfective or future.

$\$ 12$ But Russian has another mechanism at its disposal, which, arising this time from derivation, has imperfectivizing value. It suffices to employ the imperfectivizing derivational suffix, which is $-y v a$ - here, to avoid expressing the perfective and as a consequence, the verb does not pass from the present to the future.

$\$ 13$ Thus one can still express the idea 'I rewrite' in Russian in the present. One employs the form perepisyvaju (Chapter $37, \$ 51$ ), where the perfective value of the preverb pere- is suppressed by the imperfective value of the suffix $-y v a-$.

$\$ 14$ In this form, the perfective value of pere- and the imperfective value - yva-cancel each other, the semantic value of pere-remaining alone.

$\$ 15$ All in all, the preverb in Russian adds both perfective and semantic value to the simple verb, but the imperfective suffix removes the perfective value alone, the semantic value remaining intact.

$\$ 16$ As loaded as it is, the preverb pere- remains structurally subordinate to pišu, to which it is narrowly agglutinated (cf. 37, \$51). It is a subsidiary full word (Chapter 29, \$16).

$\$ 17$ If the Russian mechanism remained intact, it would be possible to form a present form for compound preverbs, but impossible to render a future to simple preverbs. 
\$18 But in addition to these full preverbs such as pere-, Russian has developed a certain number of preverbs - generally a distinct one for each verb - that have been emptied of their semantic content and that one hence calls empty preverbs. ${ }^{212}$

$\$ 19$ An empty preverb in Russian is na-, which has the effect of adding simple future to the verb, without including any semantic nuance: napišy 'I will write.'

\$20 Empty preverbs can easily be recognized by the fact that they are incompatible with imperfective suffixation. Indeed, it would serve no purpose to perfectivize a verb with an empty preverb, which would add no semantic content to it at all. That is why ${ }^{*} n a-p i c-y v a-j u$ does not exist in Russian; it would say no more than pišy.

$\$ 21$ Having no semantic value, empty preverbs are content to transfer the verb from the subcategory of present to the subcategory of future.

$\$ 22$ As a result, empty preverbs retain exactly the value of a translative for subcategory and do not do more.

\section{Chapter 172. Functional varieties of transfer}

$\$ 1$ Certain translatives of subcategory serve only to transfer the source from one subcategory that permits it to take on a certain function to another subcategory that permits it to take on a different function.

\$2 This is a prerequisite for the condition, but not the cause of the connection (Chapter $152, \$ 8)$. Translatives of this sort seem to have the effect of evoking a change in function, not a change in category.

$\$ 3$ We will call these instances of transfer functional transfers.

$\$ 4$ We have examples of functional transfer in the processes used to distinguish between the actants. Nevertheless, these actants remain nouns, regardless of the specific marker that affects them, according to the function that they eventually assume in the sentence (Chapter 52).

\$5 The English translative to is a functional translative when it transfers the first actant to the category of a third actant, leaving the category noun intact; Alfred gives the book to Bernard. $\$ 6$ In languages with case morphology, the same sort of transfer is produced by the use of the dative: Lat. Antonius dat librum Paulo 'Antonius gives the book to Paulus' and Ger. Alfred gibt seinem Bruder das Buch 'Alfred gives his brother the book. The same holds in Greek and the Slavic languages, Bulgarian being the one exception.

212. Cf. Boyer \& Speranski, Manuel pour l'étude de la langue russe 'Handbook for the study of the Russian language', Paris, Colin, 1905, p. 245. 
$\$ 7$ The syntactic presentation of the phenomenon has the advantage of grouping an analogous mechanism under the same banner, despite the morphological difference of the marker. Morphologically, synthetic languages like Latin use case, whereas analytic languages such as French use a preposition. The syntactic phenomenon is no less exact than in morphology.

\section{Chapter 173. Semantic varieties of transfer}

$\$ 1$ We have seen (Chapter $152, \$ 1$ ) that transfer has the effect of transferring a word of one grammatical category to a word of another category. In the phrase de Pierre 'of Peter', the noun Pierre has in fact been transferred to an adjective.

\$2 The proponents of morphological syntax might object here that the noun remains a noun and that semantically, there will always be a difference between a noun transferred to an adjective and an actual adjective.

$\$ 3$ There is a nuance in meaning that can be sensed clearly according to the relative autonomy of the translative, i.e. according to whether the translative is still autonomous or whether it is frozen in the form of a suffix. In the second case, the quality expressed by the new adjective is more permanent than that expressed by the translative. Le train parisien 'the Parisian train' or un journal parisien 'a Parisian journal' differs from the train de Paris or un journal de Paris.

$\$ 4$ The train parisien is more impregnated with a proper Parisian quality than the train de Paris. If one utilizes the same chain of wagons tomorrow to travel to Berlin or Madrid, the train will nevertheless remain Parisian by virtue of the good style of its interior furnishings, by the elegance of its decoration, etc. but it will not remain the train de Paris, rather it becomes the train de Berlin or the train de Madrid.

\$5 Likewise, the journal de Paris is a journal that has its place of publication in Paris, whereas the journal parisien is one that focuses on the traditional good style of Paris. The distinctive features of this journal are its conformity to the habits of life in Paris and the importance it reserves for information that is likely to be of interest to those living in Paris.

$\$ 6$ The matter is quite evident. But when we say that a noun transferred to an adjective has become an adjective, we are examining the matter from a purely structural point of view, and we in no way intend to make a clean sweep of all the semantic resources that the difference between an adjective that is a proper adjective and one that has become an adjective via transfer offers to the French language.

$\$ 7$ There is an analogous difference between two Frenchmen, the one being born a Frenchman and the other being a naturalized Frenchman. The latter can try very hard, but only after long acclimation will he succeed at acquiring, if he acquires it at all, the manner of being and behaving like a Frenchman. He will retain for a long time, sometimes for his entire life, the indelible mark of his origin. But this situation does not mean that once naturalized, he 
will not enjoy all the civil rights of a French citizen and all the legal privileges granted to the French. By considering this point of view, one can say that a true adjective is an adjective by birth, whereas a noun that has been transferred to an adjective is a naturalized adjective.

$\$ 8$ The distinction is acknowledged and expressed by traditional grammar when it designates an adjective transferred into a noun using the term nominal adjective.

$\$ 9$ In any case, the adjectival character of a noun that has been transferred to an adjective is not only undeniable, but it is also very useful to recognize when one is translating a text from one language into another. This insight holds under the condition that one is of course concerned about the character of the target and not about that of the source.

$\$ 10$ When translating, one is actually often led to render an adjective of one language using a transferred noun in the other language, or vice versa.

$\$ 11$ Such is the case with adjectives of location ending in -er in German. These adjectives correspond quite often to place names in French that have been transferred to adjectives by de: Ger. die Frankfurter Zeitung, Fr. la Gazette de Francfort 'the Frankfurt newspaper' (Chapter 194, §20).

$\$ 12$ This equivalency shines full light on the false meaning that foreigners produce in French when they understand that the train de Paris is 'the train that is coming from Paris'. Indeed, in German the equivalent of this expression is quite simply der Pariser Zug 'the Paris train, an expression that designates the train that is coming from Paris as well as the train that is going to Paris (Chapter 151, §9-10).

\section{Chapter 174. Derivation}

$\$ 1$ We have seen (Chapter $158, \$ 7$ ) that derivation is frozen transfer.

\$2 It should not surprise us that when classifying types of derivation, we find structural relations analogous in every way to those relations that exist between the different nuclei of a verbal node.

$\$ 3$ Nouns thus give rise to derivatives which have been formed in accordance with a system that is an exact copy of the structural system to which they correspond. From a semantic point of view, all types of derived nouns are structured according to the relation to the verb of the verbal node on which they are centered.

$\$ 4$ If one refers to the verb of action, for instance, one can distinguish action nouns, actant nouns, and circumstant nouns among the derived nouns that semantically arise from them.

$\$ 5$ Action nouns are denoted in traditional grammar with the Latin designation nomina actionis. In French, they most frequently appear with the suffix -tion (-sion): acclamation, affirmation, direction, pression 'pressure', discussion, éclosion 'hatching', intrusion. There are also action nouns formed with the suffix -ment, e.g. balbutiement 'stammering', remerciement 'thanks'. 
$\$ 6$ In German, action nouns are generally formed with the suffix -ung: die Handlung 'the action', die Zeichnung 'the drawing'. In English, one often encounters the suffix -ing in this use in the words that have not adopted the -tion (-sion) of French, e.g. cheering. In Russian, the most frequent action nouns are the verbal nouns with the suffix -nie of the form of the past participle and that as such are morphologically related to the paradigm of verb conjugation: stradanie '(the) suffering', učenie 'instruction'.

$\$ 7$ In addition, action nouns are formed, especially in German, without a suffix; the verb stem alone appears, whereby the phonetics alone are modified: Ger. der Schnitt 'the cut'.

$\$ 8$ Just as we have been led to distinguish between three types of actants - the first actant, the second actant, and the third actant (Chapter 51) - we are led to distinguish between three types of corresponding derived nouns.

$\$ 9$ The noun that is understood as the locus of the action corresponds to the first actant. It is the agentive noun, denoted in traditional Latin grammar with the term nomen agentis.

\$10 Agentive nouns are generally formed in French with the suffix -eur (-teur, -seur): acteur 'actor', donneur 'donor', chanteur 'singer', chasseur 'hunter', and with the feminine suffix -euse (chanteuse 'singer'), -eresse (chasseresse 'huntress'), or -trice (actrice 'actor', donatrice 'donor').

$\$ 11$ Grammarians have also remarked that in French action nouns in - $(t)$ ure and - $(t)$ ion often correspond to agentive nouns in -(t)eur: directeur vs. direction, percepteur 'tax collector' vs. perception 'perception, tax collection', éditeur vs. edition. But these three possibilities merely exist in facteur 'mailman, factor' vs. facture 'bill, workmanship' vs. faction 'faction, guard duty' (with notable semantic shift), législateur vs. legislature vs. legislation.

$\$ 12$ The suffix of the agentive noun in French is the historical continuation of the Latin suffix -or/-tor (Lat. imperator 'commander'), which also appears in Italian as -tore (il trovatore 'the minstrel') and in Sp. -dor (el conquistador 'the conqueror').

$\$ 13$ The suffix of the agentive noun is generally -er in the Germanic languages (English the singer, Ger. der Sänger), and -tel' in the Slavic languages (Rus. učitel' 'teacher').

$\$ 14$ The noun that undergoes the action and that is designated by the action corresponds to the second actant. In opposition to the term agentive noun, one can call this noun the patient noun. Very often the patient noun takes the form of a nominal past passive participle: l'accusé 'the accused', l'employé 'the employed', le vaincu 'the defeated', le commis 'the clerk' (from commettre 'commit').

\$15 Finally, the noun that expresses the result of the action corresponds to the third actant; it is always understood as a reference to this action. One can call it the attributer noun: donataire 'beneficiary', légataire 'legatee', destinataire 'addressee', mandataire 'representative' (the one to whom something is given (donné), passed on (légué), addressed (destiné), etc.).

$\$ 16$ Just as there are names for the actants, there also names for the circumstants, which are freely formed in French with the suffix -oir(e), -toir(e),-soir(e). We are content to cite 
the place nouns: dortoir 'dormitory', abattoir 'slaughterhouse', réfectoire 'refectory', laboratoire 'laboratory' and the instrument nouns: grattoir 'scraper', arrosoir 'watering can', baignoire 'tub'.

$\$ 17$ If the derived noun, instead of referring to a verb of action, refers to a verb of state, one is dealing with an abstract noun. Abstract nouns are often derived from qualitative adjectives. In most languages that have gender, abstract nouns are feminine. In French they present the suffix -té, or sometimes -eur, -esse, or -ance: beauté 'beauty', bonté 'goodness', grandeur, douceur 'mildness', fraîcheur 'freshness', tendresse 'tenderness', politesse 'politeness', puissance 'power', élégance 'elegance'.

\$18 The suffix that is used most often to form derived abstract nouns in German is -heit: die Freiheit 'the liberty', and in Eng. -ness: greatness.

$\$ 19$ We have seen (Chapter $161, \$ 3$ ) that frozen transfer constituting derived nouns has a derivational suffix for a translative.

$\$ 20$ Etymology shows that this suffix is often a former autonomous word that appears under an agglutinated form and is frozen in the derived noun (Chapter 161, \$2).

$\$ 21$ The suffix of the abstract Germanic noun -tum (Ger. Eigentum 'property'), Eng. -dom (Kingdom) was still an autonomous noun in Gothic dōms and in Old English dōm 'judgement’ (cf. Chapter 65, \$20).

$\$ 22$ The same is true of the abstract Germanic suffix: Eng. -hood (childhood), Ger. -heit (Kindheit 'childhood'); it is a former autonomous noun attested by the Gothic haidus 'essence, nature'; it was still alive in the Old English hād and in Middle High German heit. \$23 The same holds for the French suffix -ard (renard 'fox'), which produces a pejorative value (pendard 'rascal', soudard 'boor', dreyfusard, the latter word being created with pejorative value during the Dreyfus affair) and which appears as the autonomous word hard in Germanic. Further, the suffix -aud (finaud 'wily', rustaud 'tacky') comes from the root of the autonomous Germanic word hald-an 'hold'.

$\$ 24$ The adverbial suffix - ment is also a former autonomous word, since bonnement arises from Lat. bona mente 'of good spirit' (Chapter 205, \$4).

$\$ 25$ Finally, the French suffix -fier (stemming from medieval Lat. -ficare) is linked to the autonomous verb of classical Lat. facere 'do': Fr. pétrifier 'petrify', falsifier 'falsify', hence by analogy statufier 'make into a statue' (Chapter 113, \$150).

\section{Chapter 175. Composition}

$\$ 1$ In a two-root composition, the modifier (cf. Chapter $21, \$ 9$ ) is the source of transfer; it is transferred to a category that is susceptible to being subordinated to the modified word (cf. Chapter 65, \$9). 
\$2 The compound word contains a frozen transfer in its modifier.

$\$ 3$ Such cases of transfer can be marked by a case ending or by a translative incorporated into the compound form. Transfer can also occur without a marker (cf. Chapter 192, \$17 and Chapter 193, \$15).

$\$ 4$ The Germanic genitive ending $-s$ that marks $\mathrm{O}>\mathrm{A}$ transfer is present in the first element of the compound word: Landsknecht 'mercenary', lit. 'land servant'. The translative value of the etymological ending has of course completely faded in the French loanword lansquenet.

$\$ 5$ In contrast, the second element of the compound word mappemonde 'map of the world' contains the transfer. This word stems from the Medieval Lat. mappa mundi, which quite lit. designates the 'sheet of the world'.

$\$ 6$ Finally, the French translative $d e\left(d^{\prime}\right)$ is wedged in the word bédane (an old word for 'mortise chisel'), which can still be written as bec-d'âne, a form that shows its etymological origin. In contrast the orthography of gendarme 'policeman' is today frozen even though the etymology (gens d'armes 'people of arms') is still quite visible. The more complex the derivation, the more difficult it is to identify the translative in the compound form and the less visible the etymology, e.g. Fr. se gendarmer 'self-discipline (verb)', fleurdelisé (marked with fleur de lis 'fleur-de-lis', lit. 'flower of lily').

$\$ 7$ We have an example of transfer without a marker in English postman and in English or French in numerous stereotypical loanwords: Eng. philosopher < Gr. Philó-sophos 'friend of wisdom' (cf. Chapter 65, \$11), marshal < Old High German marahscale 'horse servant', orang-outang < Malay orang-outan 'wood man'; Fr. clavecin 'hapsichord' < Medieval Latin clavicymbalum 'key cymbal', Fr. marsouin 'porpoise' < Scandinavian (Danish and Swedish) marsvin 'sea pig', Fr. édredon 'eiderdown' < Icelandic aederdun 'eider down', Fr. loup-garou 'werewolf' < Old Frankish *wariwulf 'man wolf', Fr. Brahmapoutre 'Brahmaputra River' $<$ Sanskrit brahma-putrah 'son of Brahma'.

$\$ 8$ The Greek adjective rhododáktulos, which belongs to the same class, deserves special mention. Consider Homerian epithets about the nature of Aurora: rhododáktulos Ēōs 'rose-fingered Aurora' (Odyssey II, 1). The first element of the compound form contains an instance of transfer $\mathrm{O}>\mathrm{A}$ without a marker by way of which the noun composing 'rose' is transferred to an adjective. This instance of transfer corresponds to the graphic representation in Stemma 298.

$\$ 9$ Yet to the dissatisfaction of French speakers, the French noun rose is also the object of the same type of marker-less transfer (Chapter 193, \$2). In contrast to Greek, such transfer in French changes rose to a color adjective: une étoffe rose 'rose-colored fabric'. Given the necessity to render Greek marker-less transfer in French, a marker of transfer is needed. For this reason, the first translators of Homer traditionally translated rhododáktulos with aux doigts de rose 'with rose-like fingers', using the translative de. 
That is also what Germans understand, who - since they are more sensitive than us to the semantics of Greek compounds and since they have a mechanism at their disposal that is analogous to the Greek - have adopted the translation Rosenfinger. ${ }^{213}$

\$10 But a frequent experience of the author, and one that is easy to repeat, demonstrates that for most French speakers, the noun rose is also the object of the same type of markerless transfer (Chapter 193, 2 ), which, in contrast to Greek, changes rose to a color adjective: une étoffe rose 'pink fabric'. Given the necessity to render Greek marker-less transfer in French, a marker of transfer is needed. For this reason, the first translators of Homer traditionally translated rhododáktulos with aux doigts de rose 'with rose-like fingers', using the translative de. Those who study Greek today and who no longer sense the meaning in the way of earlier Hellenists - understand the Homerian epithets as if the expression is truly 'Aurora with pink fingers. ${ }^{214}$ This interpretation of the Homerian epithet is possible only by way of complex multiple transfer according to the formula $\mathrm{O}>\mathrm{A}>\mathrm{O}>\mathrm{A}$ : $\mathrm{O}$ (rose 'rose') $>$ A (rose 'pink', cf. Chapter 193) > O (le rose, that is the color pink) > A (de rose, qualitative adjective, cf. Chapter 192). This transfer is illustrated with Stemma 299. But by doing this, one is substituting in an instance of transfer in French that applies only to the color of the rose, whereas the Greek expression applies to all the qualities of the rose.

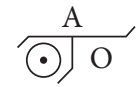

Stemma 298

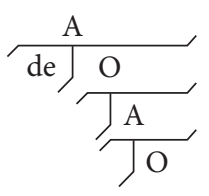

Stemma 299

$\$ 11$ Moreover, most French speakers who are devoted to the study of Greek in our times merely obey a forced admiration that conforms to the traditional teachings that their masters transmit to them. One hears that the image is sublime and as a consequence, one should be in ecstasy before it, or otherwise be judged uncultured. But few French speakers sense the real beauty in it.

$\$ 12$ And it is a revelation for most of them when one reveals the true meaning of the transfer of the Greek word, in which the fingers of Aurora do not just have a rose color, but rather all the qualities of roses. To seize upon the richness of these qualities and the beauty of the resulting image, one need merely look at the corner of one's fingers held up to sunlight. The flesh of the fingers appears with translucent and diaphanous matter like

213. Cf H. Paul, Deutsche Grammatik, 1920, volume 5, p. 29.

214. Cf. Mario Meunier, La légende dorée ‘The golden legend', 1924, p. 10, 1-21. 
a rose petal. In this manner, one can understand why this image of rose-fingered Aurora generated such enthusiasm in those who truly understood it.

$\$ 13$ The transfer included in the modifying element of the compound word can be merely an instance of functional transfer (cf. Chapter 172, $\$ 1-3$ ). Such is the case when the modifying noun is the second actant of the modified part. Transfer in such cases occurs without a marker: Fr. abat-jour 'lampshade', lit. 'pull down-day', cure-dent 'toothpick', lit. 'clean out-tooth', cache-nez 'muffler', lit. 'hide-nose'; Lat. armiger 'one who carries arms', agricola 'farmer, one who cultivates the fields', animadverto 'I believe', that is, 'I turn my mind to'; Lat. credo 'I believe', that is 'I give credence', as well as the corresponding Sanskrit form çráddadhāmi, cf. for parallel semantics see Old Slavic věro jęti 'believe', lit. 'take faith'; Ger. Briefträger 'postman', lit. 'letter carrier', Herzog 'duke', etymologically 'conductor of the army, from which we have the Slavic calque voevoda 'head of the army, voivode', SerboCroatian vojvoda 'duke, voivode'.

\section{Chapter 176. Classification of the facts of transfer}

$\$ 1$ The facts of transfer are so numerous and so variable that it is necessary to first preview the order in which it is most advantageous to present them.

\$2 The fundamental distinction is between first-degree transfer and second-degree transfer (Chapter 164, \$12-17).

$\$ 3$ Inside each of these two great divisions, we will order the types of transfer according to their nuclear content: simple transfer, double transfer, triple transfer, etc. (Chapter 165).

$\$ 4$ Inside each of these subdivisions, we will classify the nucleus according to the category to which it belongs: noun (O), adjective (A), adverb (E), verb (I).

$\$ 5$ But we have seen (Chapter 154, \$7-9) that it is necessary, on the one hand, to consider the source category and, on the other hand, the target category. Thus one should choose between these two categories in order to determine the hierarchy of criteria for the classification.

$\$ 6$ The target categories present shared characteristics more often than the source categories. In addition, they are generally clearer because they are less likely to conceal frozen transfers which, since they are no longer productive, can be difficult to establish (Chapter 165, \$7). Therefore we will give advantage to the target categories in our classification.

$\$ 7$ Hence we will study transfer successively in the following order: nominal transfer, adjectival transfer, adverbial transfer, and verbal transfer. And only in each of these categories will we examine denominal transfer, deadjectival transfer, deadverbial transfer, and deverbal transfer, respectively. 
$\$ 8$ The entirety of transfer facts to be examined is summarized succinctly with the following table:

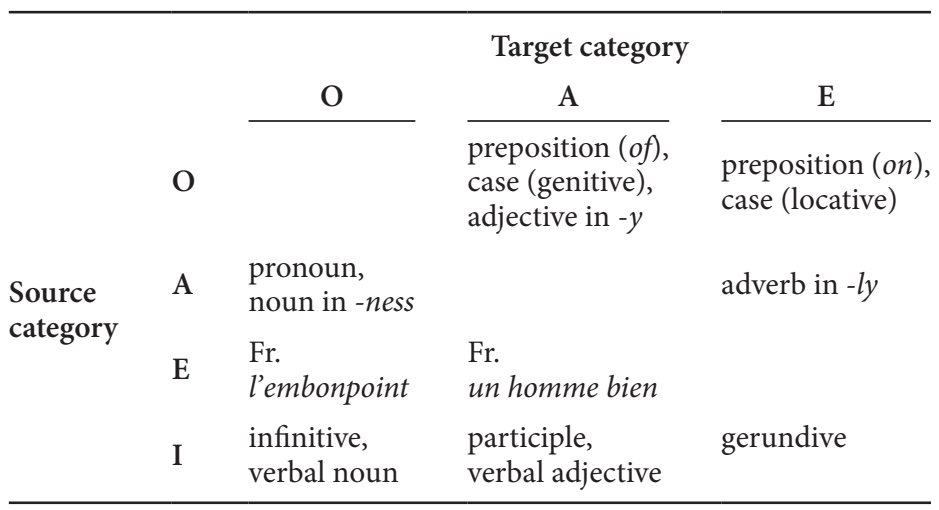

$\$ 9$ Concerning translatives, it is also necessary to preview a classification for them as well. But since this classification rests at least partially on morphological criteria, it will be considered only when absolutely necessary, that is, when the classification presented above does not distinguish between the varieties of transfer at hand.

\$10 The principle characteristics capable of distinguishing between these translatives are as follows: 1) constitutive or subsidiary (Chapter 29), 2) autonomous or agglutinated (Chapter 29, \$6-7), and 3) variable or invariable (Chapter 30).

$\$ 11$ The classification of translatives can be summarized with the following table:

\begin{tabular}{|c|c|c|c|c|}
\hline \multicolumn{5}{|c|}{ Translatives } \\
\hline & \multicolumn{2}{|c|}{ Constitutive } & \multicolumn{2}{|c|}{ Subsidiary } \\
\hline & \multicolumn{3}{|c|}{ Autonomous } & \multirow[t]{2}{*}{ Agglutinated } \\
\hline Variable & $\begin{array}{l}\text { auxiliary } \\
\text { verbs }\end{array}$ & & $\begin{array}{l}\text { article, } \\
\text { relative pronoun }\end{array}$ & \\
\hline Invariable & & & $\begin{array}{l}\text { preposition, } \\
\text { subordinate } \\
\text { conjunction }\end{array}$ & $\begin{array}{l}\text { ending, } \\
\text { empty preverb }\end{array}$ \\
\hline
\end{tabular}





\section{BOOK B}

\section{First-degree transfer, simple transfer}

\section{Chapter 177. Transfer of a specific adjective to a noun $(A>0)$}

$\$ 1$ Typical nominal transfer occurs when a descriptive adjective is changed to a noun. $\$ 2$ This transfer is generally marked by the use of the article (definite or indefinite): Fr. le livre noir et le rouge 'the black book and the red (one)', un livre noir et un rouge 'a black book and a red (one)', La mauvaise monnaie chasse la bonne 'Bad money chases good (money)' (Stemma 300), Dieu est d'ordinaire pour les gros escadrons contre les petits 'God is the staple for the large squadrons against the small (ones)' (Bussy-Rabutin).

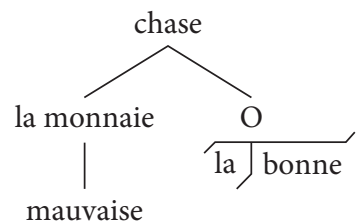

Stemma 300

$\$ 3$ The article provides an extension to the adjective, which is necessary for the adjective to become a noun (Chapter $34, \$ 12$ and 18).

$\$ 4$ The transfer in question is widely acknowledged in traditional grammar, where the transferred adjective is called a nominal adjective (Chapter 173, §8).

$\$ 5$ In the preceding examples, the noun that must be created in order to comprehend the value of the transferred adjective is expressed as well. But often ellipsis of the noun occurs and nothing remains to indicate the origin of the noun: l'oral 'the oral (exam)', les hauts-de-chausses 'breeches', lit. 'high-of-hose', les hauts de Hurle-Vent 'Wuthering Heights', l'inter(-urbain) 'inter urban (telephone)', un bleu, lit. 'a blue', that is, 'a bruise' (a blue mark), 'overalls' (a blue piece of work clothing), or 'a rookie, a new recruit' (like un steack bleu 'an underdone steak').

$\$ 6$ The nouns, which are frequently subject to ellipsis, thus give rise to new nouns by way of frozen deadjectival transfer, which form semantic series ordered around the newly disappeared noun. Of course these new nouns are of the same gender as those from which they stem semantically (cf. Chapter 159, \$7). 
\$7 Examples with the masculine:

Nouns of animals: Fr. un quadrupède 'a quadruped', un mammifère 'a mammal', un carnivore 'a carnivore'; the nouns of men: un jeune 'a young (man)', un vieux 'an old (man)', un poitrinaire 'a consumer', un noble 'a noble', le souverain 'the sovereign', le général 'the general', un bleu 'a rookie', un noir 'a black (man)', un jaune 'a yellow (man)'; Rus. gorodovoj 'town sergeant', lit. 'town's'; the nouns of periodicals: le journal 'the journal' (from journalier 'daily'), un périodique 'a periodical', un quotidien 'a daily'; nouns of words: le substantif 'the substantive', and in particular, the grammatical moods: l'adjectif 'the adjective', l'infinitif 'the infinitive'; l'indicatif 'the indicative', le subjonctif 'the subjunctive'; names of drugs: un vomitif'an emetic', un sudorifique 'a sudorific', l'apéritif 'the aperitif'; names of instruments: un moteur 'a motor', un carburateur 'a carburator', un ventilateur 'a ventilator'; names of abstract ideas: le haut 'the top', le bas 'the bottom', le beau 'the beautiful', le bon 'the good', le vrai 'the true', le faux 'the false', le sublime 'the sublime', le droit 'the right', le propre de l'homme 'the peculiarity of the man', lit. 'the own of the man'.

$\$ 8$ Examples with the feminine:

Names of women: une danseuse 'a (female) dancer', une pêcheuse 'a (female) fisherman', une serveuse 'a waitress', une ouvreuse 'an usherette'; in particular names of female workers: une brodeuse 'an embroiderer', une blanchisseuse 'a laundress', une glaneuse 'a (female) gleaner', une repasseuse 'a (female) presser', une fileuse 'a spinster', une vendangeuse 'a (female) harvester'; names of machines: une fraiseuse 'a grinder', une bobineuse 'a winder', une lessiveuse 'a boiler', une couveuse 'an incubator', une moissonneuse-lieuse 'a combine harvester', une mitrailleuse 'a machine gun'; nouns of liquor: la chartreuse 'the chartreuse', la bénédictine 'the benedictine'; names of notes of music: une ronde 'whole note', lit. 'a round', une blanche 'a half note', lit. 'a white', une noire 'a quarter note', lit. 'a black'; names of songs: une berceuse 'a lullaby', la marseillaise 'the Marseillaise', la brabançonne 'the Brabant'; names of dances: une allemande 'a German'; the names of celebrations: la Saint-Jean 'St John's Eve'; names of lines: une droite 'a straight (line)', une verticale 'a vertical (line)', une horizontale 'a horizontal (line)', une perpendiculaire 'a perpendicular (line)'; in Russian, names of rooms (komnata) of accommodation: ubornaja 'bathroom,' '(room) of toilette, priëmnaja 'anteroom', lit. '(room) of reception'; names of cars: une motrice 'convoy car', une automobile 'a car.'215

$\$ 9$ The genre of this last word caused a lot of ink to be spilled a half century ago, and for no good reason. Certain grammarians assumed that the word had been masculine and that it was correct to say un automobile. Everyone meddled in the matter, even the Conseil d'Etat: Les autos trépidants (le Conseil d'Etat venait de decider qu'on disait un et non une auto), à

215. Translators' note: To this list of feminine nouns/adjectives, one can add the designations for clause types: une principle 'a main (clause)', une subordonée 'a subordinate (clause)', une relative 'a relative (clause)'. We faced those forms many times during the translation. 
la hauteur de la rue de Berri, commençaient à échelonner 'The fearful.masc cars (the Conseil d'Etat decided that one should say un, not une, auto) at the top of Berri street started to stagger themselves' (Morand, 1900, p 132). And it is a fact that at the beginning of the century, certain more or less inspired purists advocated for masculine gender and preached for it using the fallacious pretext that the noun from which it stems was the word véhicule 'vehicle', which is masculine. But this was a very artificial attempt and the explanation was not adopted. The Nouveau Larousse illustré gives masculine, but a quarter of a century later the Larousse du XXe siècle gives the feminine and is content to add "Some make the word masculine". Indeed, nobody hesitates nowadays to acknowledge that the word is feminine.

$\$ 10$ It was easy to see what was correct, since at the time that the controversy was raging, the strongest advocates for the masculine did not hesitate to say: une quarante chevaux 'a forty-horsepower (machine)', une Renault 'a Renault'. One always said une sans soupapes 'a (car) without valves', une Peugeot 'a Peugeot', just like one says une Citroën 'a Citroën'. Of course no one actually still has an automobile, but rather one has a voiture 'car', which proves that the semantic foundation for the word automobile was the noun voiture, which is of course feminine.

\$11 The same adjective is sometimes employed simultaneously as an adjective transferred to a noun, and as an adjective subordinated to a noun. One says un plat plat 'a flat dish' as opposed to un plat creux 'a shallow dish' (Stemma 301). ${ }^{216}$

$\$ 12$ It can also occur that between two adjectives, one hesitates concerning which of the two is transferred to a noun. Such is the case with the well-known pleasantry:

\begin{tabular}{ll}
\hline $\begin{array}{l}\text { Madame: Chéri, je t'annonce une } \\
\text { bonne nouvelle (Stemma 302). }\end{array}$ & 'Mrs.: Dear, I have good news. \\
$\begin{array}{l}\text { Monsieur: Laquelle? } \\
\begin{array}{l}\text { Madame: Eh bien! Oui, une } \\
\text { nouvelle bonne. (Stemma 303) }\end{array}\end{array}$ & Mr.: What? \\
\hline
\end{tabular}

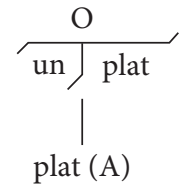

Stemma 301

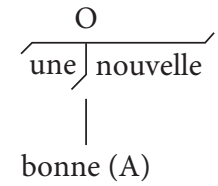

Stemma 302

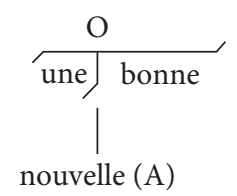

Stemma 303

\$13 Numeral adjectives can be changed to nouns in the same manner as qualifying adjectives: trois-six (brandy consisting of a drinkable mix of three parts alcohol by weight of a certain degree and three parts water).

216. Cf. A. Moufflet, Contre le massacre de la langue française, II, 1935, pp. 15-17 and 75. 
$\$ 14$ Numeral adjectives can hence be represented by letters with algebraic value. The unknown number is represented by $x$ : Mister X. By an analogous mechanism, one speaks of $J 3$.

\$15 In Greek, it is also the article that transfers descriptive adjectives to nouns: ho sophós 'the wise (man)', oi díkaioi 'the just (men)', tò kalón 'the beautiful', tà hagathá 'the goods', tò hupsēlótaton tōn déndrōn 'the tallest of the trees'.

$\$ 16$ And as in French, the noun can be elided: Gr. ho ákratos (oînos) 'the pure (wine)', hē oikouménē (gē) 'the inhabited (earth)', hē nikôsa (gnốmē) 'the dominant (view)', hè husteraía (èméra) 'the next (day)'. The same is true in Latin (cf. Chapter 137, §5).

$\$ 17$ In German, just as in Greek and French, an adjective introduced by an article is transferred to a noun, which is indicated in orthography by the use of upper case script: Der Arme und der Reiche 'the poor (man) and the rich (man)' (title of a Grimm fairy tale), die Eltern 'the parents', lit. 'the elders', which has been replicated in the Slovene starši, same meaning.

\$18 The mechanism just described is very expressive and lively in slang: une babillarde, lit. 'a chattering', that is 'a letter', ma profonde, lit. 'my deep', that is 'my pocket'.

$\$ 19$ In English, the marker of an adjective transferred to a noun is the numeral noun one employed as a pronoun: the black book and the red one.

$\$ 20$ In Breton the marker of the nominal adjective is the special translative with nominal value hini, plural re: al levr du hag an hini ru 'the black book and the red one', al levriou du hag ar re ru 'the black books and the red ones'.

$\$ 21$ It is striking to see the English numeral adjective one take the same pronominal value as hini of Breton, whereas the associated development of meaning is completely unfamiliar for Ger. ein, which is nevertheless etymologically related. The tempting hypothesis in this area is that the development of the translative value $\mathrm{A}>\mathrm{O}$ of Eng. one is due to a Celtic substratum. This hypothesis seems to be confirmed by its usage in Welsh which, in the same environments and with the same construction as Breton hini, employs the name of the number 'one': yr un coch 'the red one'.

$\$ 22$ In Basque, the descriptive adjective followed by the postposed article is transferred to a noun: on-a 'the good' (cf. Lafitte, Grammaire basque, \$325).

\section{Chapter 178. Transfer of a general adjective to a noun $(A>0)$}

$\$ 1$ General adjectives (cf. Chapter $35, \S 2$ ) can be transferred to the same sort of nouns as specific adjectives.

\$2 In general, traditional grammar reserves the name pronoun for the nouns corresponding to determinative adjectives, from which they arise by transfer. Hence in French, lequel 
'which one' (Stemma 304) is the interrogative pronoun corresponding to the interrogative adjective quel 'which' (Chapter $34, \$ 4$ and Chapter 53, \$3).

$$
\overbrace{\text { le } \mathrm{O} \text { quel }}^{\text {O }}
$$

\section{Stemma 304}

$\$ 3$ One is motivated to generalize this terminology and to stringently reserve the name of the pronoun for all those adjectives transferred to nouns and only for them (cf. Chapter 53, $\$ 3$ and 4 and Chapter 59, $\$ 9)$.

$\$ 4$ From this point of view, it appears that the qualifying adjective that has been transferred to a noun - traditionally known as a nominal adjective - could also be justly named descriptive pronoun.

$\$ 5$ The identity of this transfer has been perceived by the linguistic sensitivities of French speakers. Indeed, one finds the same translative as a marker of the transfer of a determinative adjective to a noun as one finds for qualifying adjectives: most often, the translative is the definite article le 'the' or the indefinite article un 'a', and on occasion it is the personal noun lui 'it'. Worth noting is that if aucun 'no/none' functions as an adjective or as a pronoun, it nevertheless stems etymologically from the adjective ${ }^{*}$ auc- $(<$ Lat. aliquis $)$ and has become a pronoun by the addition of the translative $u n$. The original meaning, which is conserved in d'aucuns 'some people', is positive as is that of personne 'nobody' and that of rien 'nothing' ( $<$ Lat. rem 'thing'). These forms only take on negative meaning by way of the frequency of use with the discordantial ne (cf. Chapter 92).

\begin{tabular}{lllll}
\hline & French & English & French & \multicolumn{1}{c}{ English } \\
\hline Interrogatives & quel? & 'which?' & lequel? & 'which one?' \\
\cline { 2 - 5 } Possessives & mon & 'my' & le mien & 'mine' \\
\cline { 2 - 5 } Iel & 'such' & un tel & 'such (a) one(s)' \\
\multirow{2}{*}{ Indefinites } & quelque & 'some' & quelqu'un & 'someone' \\
& chaque & 'each' & chacun & 'each one' \\
\cline { 2 - 5 } Demonstratives & ce...(-ci) & 'this' & celui(-ci) & 'this one' \\
\hline
\end{tabular}

Regardless of the translative le, the difference in form between the possessive adjective and the possessive pronoun comes only from the fact that the original adjective mon was not accented, whereas the pronoun (le) mien was.

$\$ 6$ French has also developed further differences in phonetics between the pronoun and the adjective: tous is pronounced [tu] when it is an adjective (tous les hommes sont mortels 'all men are mortal') and [tus] when it is a pronoun (tous sont mortels 'everyone is mortal'). 
\$7 In Breton we find a correspondence that is analogous to what we find in French. The translative for the pronoun is generally hini, plural $r e$, as it is for the specific adjective (cf. Chapter 177, \$20).

\begin{tabular}{|c|c|c|c|}
\hline \multicolumn{4}{|c|}{ Breton } \\
\hline & \multirow[t]{2}{*}{ Adjectives } & \multicolumn{2}{|c|}{ Pronouns } \\
\hline & & Singular & Plural \\
\hline Interrogatives & $\begin{array}{l}\text { pe? } \\
\text { 'which' }\end{array}$ & $\begin{array}{l}\text { pehini? } \\
\text { 'which one?' }\end{array}$ & $\begin{array}{l}\text { pere? } \\
\text { 'which ones?' }\end{array}$ \\
\hline Exclamatives & $\begin{array}{l}\text { pebez! } \\
\text { 'what!' }\end{array}$ & $\begin{array}{l}\text { pebez hini! } \\
\text { 'what man!' }\end{array}$ & $\begin{array}{l}\text { pebez re! } \\
\text { 'what men!' }\end{array}$ \\
\hline Demonstratives & $\begin{array}{l}\text {-mañ } \\
\text { 'this' }\end{array}$ & $\begin{array}{l}\text { hemañ } \\
\text { 'this one' }\end{array}$ & $\begin{array}{l}\text { ar re-mañ } \\
\text { 'these ones' }\end{array}$ \\
\hline Possessives & $\begin{array}{l}m a \\
\text { 'my' }\end{array}$ & $\begin{array}{l}\text { ma hini } \\
\text { 'mine' }\end{array}$ & $\begin{array}{l}\text { mar re } \\
\text { 'mine' }\end{array}$ \\
\hline Negatives & $\begin{array}{l}\text { ebet } \\
\text { 'no' }\end{array}$ & $\begin{array}{l}\text { hini ebet } \\
\text { 'none' }\end{array}$ & \\
\hline \multirow{3}{*}{ Indefinites } & $\begin{array}{l}\text { pep } \\
\text { 'each' }\end{array}$ & $\begin{array}{l}\text { pep-hini } \\
\text { 'each one' }\end{array}$ & \\
\hline & $\begin{array}{l}\text { hevelep } \\
\text { 'same' }\end{array}$ & $\begin{array}{l}\text { an hevelep hini } \\
\text { 'the same' }\end{array}$ & $\begin{array}{l}\text { an hevelep re } \\
\text { 'the same' }\end{array}$ \\
\hline & $\begin{array}{l}\text { all } \\
\text { 'other' }\end{array}$ & $\begin{array}{l}\text { an hini all } \\
\text { 'the other' }\end{array}$ & $\begin{array}{l}\text { ar re-all } \\
\text { 'the others' }\end{array}$ \\
\hline \multirow{2}{*}{ Qualificatives } & \multirow{2}{*}{$\begin{array}{l}r u \\
\text { 'red' }\end{array}$} & $\begin{array}{l}\text { an hini ru } \\
\text { 'the red one' }\end{array}$ & $\begin{array}{l}\text { ar re ru } \\
\text { 'the red ones' }\end{array}$ \\
\hline & & $\begin{array}{l}\text { unan ru } \\
\text { a red one' }\end{array}$ & $\begin{array}{l}\text { re ru } \\
\text { 'red ones' }\end{array}$ \\
\hline
\end{tabular}

\section{Chapter 179. Transfer of an adverb to a noun $(E>0)$}

\$1 The transfer of an adverb that passes directly to the category of a noun is rare. We will see (Chapter $216, \$ 6)$ that more often the adverb becomes an adjective and the adjective then becomes a noun, in which case one is dealing with double transfer.

\$2 In a number of cases, one can hesitate. One is lead to ask whether the adverb transferred to a noun is not actually considered to be an adjective. Indeed, as we have said (Chapter 165, $\$ 7$ and Chapter 176, \$6), while the result of transfer is always clear, it is sometimes necessary to hesitate at its beginning.

$\$ 3$ The direct transfer $\mathrm{E}>\mathrm{O}$ of an adverb to a noun seems evident in le bien 'the good', le mal 'evil', where the adverb bien 'well' or mal 'badly' is transferred to a noun by the translative le. 
\$4 There is seemingly also direct transfer of an adverb to a noun in French with cases like the following: peu d'eau 'little water', lit. 'few of water', beaucoup d'or 'much gold'. Indeed, peu 'few' and beaucoup 'a lot' are adverbs of quantity. The noun transferred to an adjective of quiddity (Chapter 195, \$6) that they govern, however, shows that they function as nouns, since an adjective cannot be subordinate to an adverb (Stemma 305).

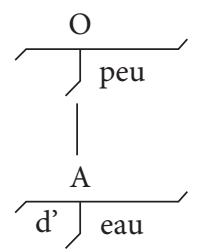

\section{Stemma 305}

$\$ 5$ One has to therefore acknowledge that if one traces the etymology, the transfer of beaucoup to a noun is double, since one has to begin with coup 'knock', which is a noun. The noun coup is then transferred to an adverb in the expression beau coup 'nice knock', frozen and written as one word in the adverb beaucoup 'a lot', which is in turn transferred to a noun so that the transfer is an instance of reversive double transfer $(\mathrm{O}>\mathrm{E}>\mathrm{O})$.

$\$ 6$ The direct transfer $\mathrm{E}>\mathrm{O}$ seems certain in the nominal use of the Latin locative adverb hic in French: C'est là le hic 'It's there the glitch'.

$\$ 7$ One finds the same procedure in Greek in the transfer of the time adverb nûn 'now' to a noun by way of the article: tò nûn (cf. Chapter $222, \$ 13$ ).

\section{Chapter 180. The infinitive}

$\$ 1$ One can say in general that a verb transferred to a noun is, when the transfer is marked, an infinitive. ${ }^{217}$

$\$ 2$ An infinitive is a verb by its source and a noun as a target of transfer. Hence the infinitive has characteristics of both a verb and a noun.

$\$ 3$ For this reason, the infinitive, as Benvéniste has rightly shown, ${ }^{218}$ is not a unary notion: every type of infinitive retains the value of its verbal source.

$\$ 4$ From the verb from which it stems, an infinitve retains the ability to govern two types of subordinates, actants and circumstants.

217. Cf. Bally, Linguistique générale et linguistique française, 1937, \$70, [3rd edition, 1950, \$184].

218. Noms d'agent et noms d'action en indo-européen, p. 92. 
\$5 Conversely, from the noun that it becomes, the infinitive acquires the faculty to assume the role of an actant (first actant, second actant, etc.) (cf. Chapter 50, \$2).

$\$ 6$ All told, the inferior connections of the infinitive are those of a verb (cf. Chapter 184, \$1), whereas the superior connections are those of a noun (cf. Chapter 183, \$1-2).

$\$ 7$ The infinitive appears as an intermediate type between a verb and a noun. It is a mixed category, straddling two other categories.

$\$ 8$ The infinitive is hence no more a verb than it is a noun.

$\$ 9$ For this reason, it is the object of special treatment in the German sentence. The verb appears in general in second position in German (it appears in first position in an interrogative sentence and in last position in a sentence introduced by a subordinator). ${ }^{219}$ Yet the infinitive occupies a special position (cf. Chapter $58, \$ 4$ and $\$ 9$ ) that is completely different from the position of the verb, precisely because the German speaker does not perceive it to be a verb.

$\$ 10$ But when one speaks of a verb and of the need to call it something, the necessity to objectify it and consider it as a notion rather than as a function leads one to cite it in a form that is closest to the noun, that is, according to the verbal form that has been transferred to a noun, i.e. as an infinitive, e.g. the verb love.

\$11 Thus the German grammarians who decided to germanize the grammatical terminology proposed to replace the Latin loanword der Infinitiv with the word die Nennform, which is composed of purely German elements. Literally it means 'the form serving to name', just as they replaced the Latin loanword das Nomen with the compound word das Nennwort 'the naming word'.

\$12 However, the practice of designating a verb by way of the infinitive is far from universal.

$\$ 13$ The tradition for the classic languages is to designate Latin and Greek verbs by way of the first person singular present indicative, e.g. the verb amo 'I love' in Latin and the verb lúo 'I untie' in Greek.

$\$ 14$ In Sanskrit, the practice is to designate the verb by way of the ontive singular present indicative, e.g. the verb bhárati 'he carries' (Chapter 53, \$10 and \$17).

$\$ 15$ In the Semitic languages, verbs are designated by the third person of the masculine singular of the simple past, e.g. qātal '(he) killed' in Hebrew and qatala 'he killed' in Arabic (Chapter 53, \$10).

$\$ 16$ In Basque, one designates the verb with its participle: the verb bilhatu 'sought.'20

219. Lucien Tesnière Une survivance pédagogique: l'inversion et le rejet dans la construction de la phrase allemande 'A pedagogical relic: inversion and rejection in the construction of the German sentence', Les langues modernes, March-April 1947, pp. A-21ff.

220. P. Lafitte, Grammaire basque, 1944, p. 200. 
$\$ 17$ The practice of designating the verb with the infinitive is not always possible. In certain languages, there is no infinitive form, or its use is highly restricted. Such is the case in Bulgarian. For this reason, grammarians have adopted the Greco-Latin tradition of designating the verb with the autoontive present indicative, e.g. običam 'I like.221 The same is true for Albanian, e.g. lâ 'I let'.

$\$ 18$ The practice employed for our modern western languages of designating a verb by way of the infinitive is very unfortunate, because it is paradoxical and harmful.

$\$ 19$ It is paradoxical because it makes no sense to begin the search for a verb by pursuing the only form that is not really verbal.

\$20 It is harmful because it suggests and spreads the false notion that the infinitive is a verb, and it hence renders the correct comprehension of verb transfer difficult to understand. One cannot emphasize enough that an infinitive is not a verb.

\section{Chapter 181. The evolution of the infinitive}

$\$ 1$ As a nucleus in full evolution, the infinitive is evolving in a manner that matches the syntactic structure of the transfer from which it results.

$\$ 2$ As an intermediate form caught in the process of transfer, the infinitive is essentially something fluid; it is therefore difficult to grasp.

$\$ 3$ Indeed, according to the stage of advancement of the transfer from which it results, the infinitive can maintain a number of traits that are more or less verbal at the same time that it acquires a number of nominal characteristics.

$\$ 4$ Due to the nature of the clash of the verbal characteristics that are preserved and the nominal characteristics that are developed, the infinitive is susceptible to considerable variation across languages. There is hence no single characteristic, verbal or nominal, that can be used to define the infinitive.

$\$ 5$ All that is possible - and it will be necessary to do this - is to examine successively the different verbal and nominal characteristics that various types of infinitives have.

$\$ 6$ These characteristics include the following: 1) the inferior and superior structural connections that the infinitive is likely to have with the other nodes in the stemma it belongs to (Chapter 183 and 184), and 2) the verbal or nominal nature of the infinitive, which can be recognized mainly in the categories that it allows (Chapter 185 to 189).

$\$ 7$ When the transfer of a verb to a noun is very advanced and the verbal characteristics of the nucleus have been completely replaced by the characteristics of a noun, one is dealing

221. Léon Beaulieux, Grammaire de la langue bulgare, 1933, p. 170. 
with a noun pure and simple. This noun is distinguishable from an ordinary noun only in terms of the morphological traits that it maintains from the verb and by the awareness of its verbal origin that the speaker retains. That is why one calls the noun verbal.

$\$ 8$ At a further stage of development, its verbal origin fades and disappears completely, the transfer ceasing to be productive (Chapter 158). One is dealing with a derived form that is completely fixed; it has become an action noun (Chapter 174, \$5-7).

$\$ 9$ The Slavic and Baltic languages are particularly known for verbal nouns since they appear in a clear form: Rus. videnie 'the sight' from the verb videt' 'see', Latvian redzešana 'the review' from the verb redzet 'see'.

$\$ 10$ The verbal noun is easily distinguishable from the action noun insofar as it still takes part in verbal conjugations: Rus. vide-nie 'the sight' is a form of the infinitive verb vide- $t$ ' 'see', whereas the English action noun sight is not any conjugated form of the verb see.

$\$ 11$ Similarly, a verbal noun exists in principle for all verbs, since it is a form that one can always take from the verb, whereas it is not always possible to derive an action noun from a verb. In French, one cannot form a derived action noun ${ }^{*}$ fumation from the verb fumer 'smoke' like one can agitation from agiter 'flap, shake' and humiliation from humilier 'humiliate'.

\$12 The original parent of an infinitive and an action noun sometimes appears to be closely related in etymology to these words. Such is the case with the Slavic infinitive in - $t i$ (Serbian pisa-ti 'write', Rus. pisat' 'write'), which has the same original translative suffix as the action noun of Latin in -ti-o, e.g. admiratio 'admiration'.

$\$ 13$ One is also often motivated to translate an action noun across languages using an infinitive or vice versa: Lat. Cuius rei nulla est occultatio 'There is no way to hide this matter' (Caesar, De bello Gallico, VI, 21, 5), Ger. zum Friendeschluss geneigt 'disposed to conclude a peace agreement.222

\section{Chapter 182. The infinitive clause}

\$1 When a verb is transferred to a noun by the use of an infinitive, the node that it constitutes receives the name infinitive clause.

$\$ 2$ An infinitive clause is the result of first-degree transfer, since the transfer of a verb to a noun by way of the infinitive involves an instance of first-degree transfer.

222. Cf. A. Malblanc, Stylistique comparé du français et de l’allemand, Paris, 1963, \$142-171. 
$\$ 3$ The infinitive clause is far from being unknown in French; Alfred veut partir 'Alfred wants to leave', Bernard sait chanter 'Bernard knows (how) to sing', Alfred regardait valser les danseurs 'Alfred watched the dancers do the Walz', Saint Pierre entendit le coq chanter 'Saint Pierre hears the rooster crow', Bernarnd sentit la terre trembler 'Bernard feels the earth shake', Je désirerais vous voir 'I would want to see you'.

$\$ 4$ However, for reasons that are explained further below (cf. Chapter 188, $\$ 9,10 \mathrm{ff}$., and 26), the use of the infinitive clause in French is quite limited. In particular, its appearance is not permitted if the governing verb is declarative (dire 'say', croire 'believe', penser 'think', cf. Chapter 106, \$7). In such cases, French is obliged to employ second-degree transfer (cf. Chapter 241): Alfred croit que Bernard chantera 'Alfred believes that Bernard will sing', Je crois que Dieu est saint 'I believe that God is holy'.

$\$ 5$ French stands in contrast to Latin here, which does not know second-degree transfer with declarative governors and must employ first-degree transfer using infinitive clauses instead.

$\$ 6$ Latin is therefore the language that lends itself most to the study of infinitive clauses, and we will therefore use Latin examples to examine the mechanism.

$\$ 7$ Take the independent clause Deus est sanctus 'God is holy' (cf. Stemma 306). When we want to make this clause into the second actant of the verb credo 'I believe', it is necessary to transfer the entirety to a noun.

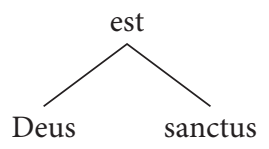

Stemma 306

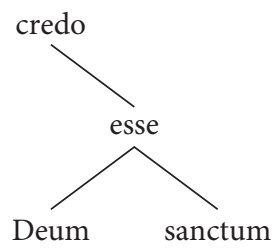

Stemma 307

$\$ 8$ To this effect, one has to transfer the verb est 'is' to a noun by way of the infinitve esse 'be'.

$\$ 9$ Otherwise, it is necessary to put the clause into the accusative, which is the mark of a second actant. The Latin infinitive cannot take on an accusative form, but the noun Deus 'God' and its attribute sanctus 'holy' are susceptible to accusative marking: Deum and sanctum.

$\$ 10$ The sentence is moreover neuter: Lat. Turpe est mentiri 'It is disgraceful to lie'; Gr. Toùs politas homonoein anagkaîon 'It is necessary for the citizens to be in agreement'.

$\$ 11$ And that is why one arrives at the Latin sentence Credo Deum esse sanctum 'I beleive God to be holy? 
$\$ 12$ The proof that the infinitive clause is an actant can be seen in the fact that it can be replaced by a pronoun, that is, it can be replaced by an actant that plays a role analogous to the resumptive form that we examined above in the area of junction (Chapter $137, \$ 3$ ). This resumptive form is the demonstrative pronoun, be it employed in the singular as hic 'this (one)' or in the plural as haec 'these (ones)':

Atque hoc quidem videre licet, eos qui antea commodis fuerint moribus, imperio, potestate, prosperis rebus immutari. (Cicero, De amicitia, 15, 54)

Non assentior iis qui haec nuper disserere coeperunt, cum corporibus simul animos interire.
'And one can observe that people of an otherwise simple nature are changed by the exercise of power and prosperity'.

'I do not agree with those who have recently supported this doctrine that the soul dies with the body'.

\$13 In order to transfer a clause to a nominal actant, Greek allows both first-degree transfer (in terms of the infinitive clause like in Latin) and second-degree transfer (in terms of a subordinate clause by way of an autonomous translative like in English and French): Légō se hamartánein or Légō hóti hamartáneis 'I say you are mistaken'.

\$14 The infinitive clause exists in English as it does in Latin and Greek: I suppose my friend to be very rich as well as I suppose that my friend is very rich.

$\$ 15$ As we have seen above $(\$ 9)$, the structure of the infinitive clause demands that its first actant appear in the accusative: Lat. Plerique deos esse dixerunt; nullos esse omnino Diagoras putavit 'Most people believe that the Gods exist, but Diagoras denies their existence entirely' (Cicero, De natura deorum, I, 1, 2), Iubeo eum venire 'I ordered him to come'.

\$16 Latin has also spread this particularity, undoubtedly by way of analogy, to infinitive clauses playing the role of a first actant:

Is est reipublicae status, ut eam unius consilio atque cura gubernari necesse sit. (Cicero, De natura deorum)

Utile erit fratrem tuum adesse. Aequos exisse adfertur.
'The state is in such a situation that monarchy has become a necessity'.

'The presence of your brother will be useful.'

'One bears the news that the equestrians have departed from their territory.' 
\$17 In Greek as in Latin, the first actant of the infinitive clause must be put in the accusative: Psếphisma epoíoun mèdéna eziénai ek tēs póleōs 'They issued a decree forbidding anyone to leave the city'.

\$18 The same holds in English when the first actant of an infinitive clause takes accusative form: I believe him to be sincere.

$\$ 19$ The infinitive clause also demands that the attribute of the first actant appear in the accusative: Lat. Credo Deum esse sanctum 'I believe God to be holy', Hēgoûmai Alézandron haxiothaúmaston eînai 'I believe Alexander to be worthy of admiration'.

$\$ 20$ When the infinitive clause is the transfer of a nominal sentence (cf. Chapter $66, \$ 8$ ), it is no more necessary to express the nominal verb of the infinitive clause than it is to express it in the independent clause from which it stems (cf. Chapter 66 , \$2). It suffices to express both the first actant and its attribute in the accusative: Lat. Salvum te cupimus 'We want you (to be) unharmed' (Phaedrus, II, 8, 17). It is hence incorrect to take the clause obtained in this manner as an infinitive, since it no more contains an infinitive than its source contains a verb.

\$21 Most characteristics of the infinitive clause result, as we will see (see especially Chapter 188), from the nature of the infinitive and in particular, from the loss of verbal characteristics.

\$22 Just like the node constituted by the infinitive is an infinitive clause (\$1), we will call the verbal nominal clause the node constituted by the verbal noun, which, as we have seen (cf. Chapter 181, \$7), is the result of the transfer of a verb to a noun in a more advanced state than that of an infinitive: Turkish Bizim gelmiş olduğumuzu bilmiyor 'He does not know that we have arrived' (cf. Chapter 188, \$23).

\$23 The verbal nominal clause in Turkish and Basque permits the expression of nominal subordinate clauses by way of first-degree transfer just like in Latin, whereas a large number of other languages, in particular French, must employ second-degree transfer to accomplish the same thing (cf. Chapter 188, \$26).

\section{Chapter 183. Inferior connections to the infinitive}

$\$ 1$ We have seen (Chapter $180, \$ 4$ ) that the infinitive retains the faculty of a verb to be the governor of two types of subordinates, actants and circumstants (Chapter 48, \$10).

$\$ 2$ The infinitive has Caruso as its first actant in Avez-vous entendu chanter Caruso ? 'Did you hear Caruso sing?'.

$\$ 3$ The infinitive governs the second actant mayonnaise in Fr. Réussir une mayonnaise est chose delicate 'To successfully make mayonnaise is a delicate matter'. Likewise, it governs the second actant vivre in savoir-vivre 'manners', lit. 'know-live'. 
$\$ 4$ The same situation is present in a majority of languages. In Greek the infinitive can govern a second actant:

\begin{tabular}{|c|c|}
\hline \multicolumn{2}{|c|}{ Greek } \\
\hline Nomós hēn autoîs toûto poieîn. & 'There was hence a law for them to enact.' \\
\hline Kalón esti timân toùs gonéas. & 'It is good to honor one's parents.' \\
\hline Pollến eîkhon epithumían tến pólin eisorân. & 'They had a great desire to see the town.' \\
\hline Pareskenázonto tến nēson poliorkēsai. & 'They prepared to besiege the island.' \\
\hline
\end{tabular}

$\$ 5$ We have seen (Chapter $158, \$ 18$ ) that Sanskrit sometimes retains the verbal faculty to govern a second actant even with an action noun, which is a verbal noun. ${ }^{223}$

$\$ 6$ The infinitive can have the attribute of a second actant as a subordinate. Thus the attribute un personnage is an attribute to the second actant se in Se croire un personnage est fort commun en France 'To see oneself (as) an important person is very common in France' (La Fontaine, Fables, VIII, 15, Le Rat et l'Eléphant).

$\$ 7$ Similarly, the infinitive retains the verbal faculty to govern a circumstant.

$\$ 8$ The subordinate circumstant that it governs is a manner adverb in Eng. Alfred hopes to succeed easily.

$\$ 9$ The subordinate circumstant is an adverb of quantity in Partir, c'est mourir un peu 'To depart is to die a bit' (Edmond Haraucourt, Seul, Rondel de l'Adieu). The same is true in the proverb Trop parler nuit 'Too much speaking is harmful'.

\$10 When a verb becomes a noun due to transfer, the adverb subordinated to it tends to be replaced by an adjective (Chapter $32, \$ 19 ; 76, \$ 1$, and Chapter $121, \$ 8$ ).

$\$ 11$ This substitution is a sign that the transfer is far advanced and that the infinitive has completely lost its verbal nature in order to entirely acquire the status of a noun: Fr. un grand dîner 'a large dinner', un souper fin 'a fine supper', Ger. ein glückliches Leben 'a happy life'.

$\$ 12$ But here also one sometimes observes facts of backwardation analogous to those mentioned above in $\$ 5$.

$\$ 13$ Hence the subordinate sometimes remains an adverb despite the appearance of an article: un pis aller 'a stopgap', lit. 'a badly go'.

223. Cf. the very insightful considerations of E. Benvéniste on the verbal rection of "doer nouns" (Noms d'agent et noms d'action en indoeuropéen 'Agent nouns and action nouns in Indo-European', Paris, 1948, pp. 11, 18-19 et passim). 
$\$ 14$ Despite its morphological appearance, the subordinate franc in the following expression is an adjective transferred to an adverb by way of transfer without a marker: avoir son franc parler 'to have a frank way of speaking. One actually employs franc as an adverb subordinate to the verb parler (cf. Chapter $205, \$ 16$ ), and this was so even before parler began to be transferred to a noun by the use of the infinitive: Je vous parle franc 'I am speaking to you frank(ly)'.

$\$ 15$ The circumstant that is subordinate to the infinitive can also be a noun transferred to an adverb, for example the noun patrie 'fatherland' is transferred to an adverb by way of the preposition pour 'for' in:

\begin{tabular}{lc}
\hline Mourir pour la patrie, & 'To die for one's fatherland \\
C'est le sort le plus beau, le plus & That is the best, the most \\
digne d'envie. & enviable fate.'
\end{tabular}

(Rouget de l'Isle)

\section{Chapter 184. Superior connections of the infinitive}

$\$ 1$ Whereas the inferior connections of the infinitive are those of a verb, the superior connections are those of a noun (Chapter 180,\$6), and the infinitive has the ability to assume the role of an actant in a sentence just like a noun does (Chapter 180, §5).

$\$ 2$ The infinitive assumes the role of a first actant in the sentence Réussir encourage à persévérer, lit. 'To succeed encourages perseverance.' The proof of this is that if one replaces the infinitive réussir 'to succeed' with a true noun with the same meaning, such as la réussite or le succès 'the success', the latter is also the first actant of the verb: La réussite encourage à persévérer, Le succès encourage à persévérer 'Success encourages perserverance'.

$\$ 3$ The infinitive can also be identified with a true noun. Such is the case in the nominal sentence where the copula est 'is' establishes a sort of syntactic equivalency between them. Thus in the following sentence, the infinitives mourir 'die' and chanter 'sing' are on the same syntactic plane as sort 'fate' and façon 'way', which are authentic nouns:

Mourir pour le pays est un si digne sort

Qu'on briguerait en foule une si belle mort.

(Corneille, Horace, II, 3)

Chanter, c'est ma façon de me battre et de croire.

(Rostand, Chantecler, II, 3)
'To die for one's country is a so dignified fate

That many desire such

a pleasant death.'

'To sing, that is my way to struggle and believe.' 
$\$ 4$ The use of an infinitive subject is frequent in French. In addition to the examples that have already been produced, one can add the following:

\begin{tabular}{l}
\hline $\begin{array}{l}\text { Et conter pour conter me } \\
\text { semble peu d'affaire. } \\
\text { (La Fontaine, Le pâtre et le lion }\end{array}$ \\
'The shepherd and the lion', \\
$\begin{array}{l}\text { Fables, VI, 1, v. 6) } \\
\text { Partir, c'est mourir un peu. } \\
\text { (Edmond Haraucourt, Seul, }\end{array}$ \\
\begin{tabular}{l} 
Rondel de l'Adieu) \\
\hline
\end{tabular}
\end{tabular}

\$5 In Greek, Latin, and German, as in French, the infinitive has the faculty to assume the role of a first actant:

\begin{tabular}{|c|c|c|}
\hline \multirow[t]{3}{*}{ Greek } & Prépei légein. & 'It is convenient to talk.' \\
\hline & $\begin{array}{l}\text { Kalòn esti timân } \\
\text { toùs gonéeas. }\end{array}$ & $\begin{array}{l}\text { 'It is good to honor one's } \\
\text { parents.' }\end{array}$ \\
\hline & $\begin{array}{l}\text { Éxésti soi agathôi } \\
\text { genésthai. }\end{array}$ & $\begin{array}{l}\text { 'It is possible for you to } \\
\text { become an honest man.' }\end{array}$ \\
\hline \multirow[t]{2}{*}{ Latin } & $\begin{array}{l}\text { Tempori cedere, id } \\
\text { est necessitati parere, } \\
\text { semper sapientis est } \\
\text { habitum. } \\
\text { (Cicero, Ad familiares, } \\
\text { IV, } 9,2 \text { ) }\end{array}$ & $\begin{array}{l}\text { 'To give in to circumstances, } \\
\text { that is, to acknowledge } \\
\text { necessity, has always } \\
\text { qualified as the mark } \\
\text { of a sage.' }\end{array}$ \\
\hline & Hoc me piget attingere. & $\begin{array}{l}\text { 'I can hardly speak of } \\
\text { this subject.' }\end{array}$ \\
\hline German & $\begin{array}{l}\text { Mit der Liebe ist nicht } \\
\text { zu spassen. }\end{array}$ & $\begin{array}{l}\text { 'One should not play } \\
\text { with love.' }\end{array}$ \\
\hline
\end{tabular}

$\$ 6$ An infinitive can also play the role of a second actant just like a noun.

$\$ 7$ Thus in French, the infinitive plays the role of a second actant in the sentence Alfred espère réussir 'Alfred hopes to succeed'. The proof of this is that one can replace the infinitive réussir 'succeed' with a true noun that has the same meaning such as réussite or succès 'success' ( $\$ 3$ above); these nouns are the second actant of the verb: Alfred espère la réussite, Alfred espère le succès 'Alfred desires success'. Sentences of this sort occur frequently in French: Alfred compte partir demain 'Alfred intends to depart tomorrow', Je ne sais de quel côte me tourner 'I do not know which way to turn'.

$\$ 8$ In Greek, things are the same as in French: Humâs elpízō periésesthai 'I hope that you will receive benefit'.

\$9 The situation is the same in languages that are typologically quite different from French and Greek, such as Turkish: Girmek istedi 'He wanted to enter'. 
$\$ 10$ We have seen (cf. Chapter $99, \$ 5$ ) that with verbs that take just one actant, such as il faut 'it is necessary', it is sometimes difficult to precisely determine whether this actant is a first actant or a second actant. The same difficulty obtains for the infinitive. It is no less difficult to determine the status of the infinitive in il faut travailler, lit. 'it is necessary to work', than it is to determine the status of une loi 'a law' in Il faut une loi 'A law is needed'.

\$11 Finally, the infinitive can, just like a noun, be in apposition to a noun (Chapter 69). This occurs constantly in Greek.

$\$ 12$ The infinitive is in apposition to a nominal first actant Hốra estí apiénai 'It is time to go', Kindunos ến autôi apothaneîn, lit. 'He is in danger to die', Nómos ēn autoîs toûto poieîn 'It was the law to do that'. The infinitives apiénai, apothanein, poiein are in apposition to the first actants hốra, kíndunos, nómos.

$\$ 13$ The infinitive is in apposition to a nominal second actant in Psếphisma epoíoun mèdéna exiénai ek tēs póleōs 'They issued a directive banning everyone from leaving the town', Pollến eîkhon epithumían tến pólin eisorân 'They had a great desire to see the town'. The infinitives exiénai and eisorân are in apposition to the second actants psếphisma and epithumian.

\section{Chapter 185. Infinitives and diathesis}

$\$ 1$ We have seen (Chapter $50, \$ 4$ and Chapter $97, \$ 1-4$ ) that diathesis is one of the essential characteristics of the verb. Diathesis is essentially a category that is maintained as an infinitive the longest.

$\$ 2$ Most languages that have infinitives draw a distinction between active and passive infinitives.

\begin{tabular}{|c|c|c|}
\hline & Active & Passive \\
\hline Greek & lúein 'release' & lúesthai 'be released' \\
\hline Latin & amare 'love' & amari 'be loved' \\
\hline French & aimer 'love' & être aimé 'be loved' \\
\hline English & to love & to be loved \\
\hline German & lieben 'love' & geliebt werden 'be loved' \\
\hline Hebrew & $p \bar{a} k \bar{d} \underline{d}$ 'count' & hippākēd 'be counted' \\
\hline Turkish & sev-mek 'love' & sev-il-mek 'be loved' \\
\hline
\end{tabular}

$\$ 3$ There is also a reflexive infinitive and a reciprocal infinitive. Examples of reflexive infinitives: Fr. se regarder dans un miroir 'observe oneself in a mirror', Ger. sich spiegeln 'to 
mirror oneself', Rus. umyvat'sja 'wash one's face', Turk. sevinmek 'like oneself'. Examples of reciprocal infinitives: Fr. Il se faut entr'aider: c'est la loi de nature 'One has to help each other: it is the law of nature' (La Fontaine, Fables, VIII, 17, L'ane et le chien 'The ass and the dog'), Turk. Anlamak için sevişmek lâzimdir 'To understand each other one has to like each other'.

$\$ 4224$

$\$ 5$ Since it is not incompatible with the infinitive, the notion of diathesis can appear in the infinitive clause.

$\$ 6$ Hence Latin easily renders a declarative verb that governs a subordinate infinitive clause in the passive. To accomplish this, it suffices for the declarative verb to take the first actant of the infinitive clause as its first actant and to thus put it in the nominative:

\begin{tabular}{ll}
\hline First actant in nominative & \multicolumn{1}{c}{$\begin{array}{c}\text { First actant in accusative } \\
\text { (infinitive clause) }\end{array}$} \\
$\begin{array}{l}\text { Galli dicuntur in Italiam transisse } \\
\text { 'The Gauls are said to have } \\
\text { entered Italy. }\end{array}$ & $\begin{array}{l}\text { Dicitur Gallos in Italiam transisse. } \\
\text { 'It is said the Gauls entered Italy.' }\end{array}$ \\
$\begin{array}{l}\text { Vulpes ad cenam dicitur ciconiam } \\
\text { invitasse. (Phaedrus I, 26, 3) } \\
\text { 'The fox is said to have invited the } \\
\text { stork to dinner.' }\end{array}$ & $\begin{array}{l}\text { Dicitur vulpem ad cenam ciconiam } \\
\text { invitasse } \\
\text { 'It is said the fox invited the stork } \\
\text { to dinner. }\end{array}$ \\
\hline
\end{tabular}

\$7 But if the infinitive is accompanied by an attribute, Latin considers this attribute to be a modifier of the first actant and puts it in the nominative: Prudens esse dicitur 'One says that he is wise', lit. 'He is said to be wise', Eques... sic lucutus traditur 'One reports that the knight spoke like that', lit. 'The knight is reported to have spoken like that'.

\$8 However, the notion of diathesis is far from being as clear with the infinitive as it is with the verb. And we have seen (Chapter 102, \$10-12) that the diathesis of the infinitive is sometimes ambiguous in French: Fr. J'ai vu manger des chiens 'I saw dogs eat / I saw (someone) eat dogs'.

\section{Chapter 186. Infinitives and mood}

224. Translators' note: We have omitted this paragraph entirely because Tenière produced inaccurate readings of the Hebrew verb haqtěl, 'kill'. See Chapter 109, $\$ 7$ for discussion of the diathesis associated with a similar Hebrew verb. 
\$1 The category of mood is a reflex of psychological attitude of the speaker in relation to the process that he expresses with the verb. Since these attitudes are susceptible to great variation and many nuances, the classification of moods is a delicate matter, and it is natural that grammarians have not developed a rigorous theory in the area.

$\$ 2$ Parallel to the psychological content in the speaker, who is sometimes more or less logical and sometimes more or less affected, one can distinguish in general between logical moods and affective moods.

$\$ 3$ The logical moods are above all those of thought. It is rare that they have a proper grammatical expression. However, they allow the expression of conjecture (cf. Chapter 259, \$4).

$\$ 4$ The affective moods are generally of the imperative type, since they express an action exercised by the speaker on the exterior world. ${ }^{225}$

$\$ 5$ The moods of the imperative type, the principle ones being the imperative, the subjunctive, and the optative, have their own grammatical expression in many languages. The indicative is the lack of a mood of the imperative type.

$\$ 6$ Since it is no longer a verb due to transfer, the infinitive quite naturally loses the strict faculty to distinguish between moods. The notion of mood is hence in principle a stranger to the infinitive.

\$7 Not in Greek, nor in Latin, French, or German can the infinitive be rendered to express mood. Instead, the grammars of these languages do not hesitate to view the infinitive itself as a type of mood. This practice is erroneous, however, in view of transfer. The infinitive arises from transfer and it is therefore futile to attempt to place it in the canon of moods that traditional grammar acknowledges, since traditional grammar ignores transfer.

$\$ 8$ However, the infinitive is still too close to its verbal origin to be entirely incompatible with the notion of mood. And by way of a phenomenon analogous to what has already been examined above (Chapter $158, \$ 18$, and Chapter $183, \$ 5,12$, and 13 ), the infinitive retains the ability to express certain modal nuances, if not in a manner that is active and explicitly marked, at least in a manner that is passive and not marked.

$\$ 9$ The extent to which this ability is preserved varies greatly according to the mood at hand.

\$10 The ability depends to a large extent on what the phonologists of the Prague school call the marker, that is, on the semantic characteristics that constitute the modal value.

225. This outline of the classification of moods agrees with the classification of interjections that I presented in the Mélanges, Haškovec, Imprimerie Globus, 8, rue Veveri, Brno, Czechoslovakia, 1936, pp. 343-352, see in particular p. 345, (cf. Chapter $46, \$ 20$ ). 
\$11 The modal characteristics are conserved in a general fashion all the more because their semantic marker is less prominent.

\$12 For this reason, the logical moods, which have no semantic marker, can be conserved for a long time in the infinitive.

$\$ 13$ In contrast the affective moods, which are often much more clearly marked, are much less compatible with the infinitive, which in general is incapable of expressing an accented marker of modality.

$\$ 14$ Among the moods that are not incompatible with the infinitive though, one has to mention the imperative.

\$15 Infinitives with imperative value are quite frequent in a majority of languages: $\mathrm{Fr}$. Agiter avant de s'en servir 'Stir before serving', Ger. Tür schließen 'Shut the door', Gr. Sù dé, ... tàs púlas anoíxas epektheîn 'You, ... you will open the door and rush outside' (Thuc. V, 9).

\$16 The infinitive with imperative value is well known in Indo-Iranien and Greek, and E. Benvéniste has shown (Origines de la formation des noms en indo-européen, p. 132-133) that these two moods can arise from the same ancient Indo-European form with the noninflected nominal suffix -en- (indefinite case).

$\$ 17$ In Italian the infinitive is used rigorously with the second person singular to express a negative command: Chiudi la porta 'Close the door', but Non chiudere la porta 'Don't close the door'.

\$18 Among the moods that are incompatible with the infinitive, one has to cite the optative and subjunctive first, since they are the affective moods. The conjectural must be mentioned as well ( $\$ 30$ in the present $\mathrm{ch}$.), which, although it is a logical mood, is very strongly marked semantically.

\$19 The optative seems to never be compatible with the infinitive. It is quite rare across languages and, among the Indo-European languages, only Sanskrit and ancient Greek retain it in a clear enough way that its function can be studied in a manner leading to insights.

\$20 For the subjunctive, one should not lose sight of the fact that it, as a marked mood, stands in opposition to the indicative, which is not marked (cf. $\$ 5$ and $\$ 10-13$ ).

\$21 Yet Latin can transfer independent clauses to infinitive clauses without the use of a marker: Deus est sanctus 'God is holy'. For this reason, infinitives can be subordinate to declarative verbs: Credo Deum esse sanctum 'I believe God to be holy'.

\$22 In contrast, Latin refuses to transfer independent clauses to infinitive clauses using a marker, and this is why infinitives cannot be subordinated to verbs expressing volition or fear.

\$23 For the subordinates of these verbs, it is necessary to employ second-degree transfer: Nobis imperat ut loquamur 'He ordered that we speak', Timeo ne veniat 'I fear that he is coming. 
\$24 The infinitive clause and the infinitive that is its central node are incapable in Latin of expressing modal meanings of volition and belief, which would demand the use of a marked mood in the independent clauses from which the subordinate clauses arise.

$\$ 25$ This fact explains why certain governing verbs in Latin do or do not allow a subordinate infinitive. According to the nuance of meaning that the subordinate infinitive expresses, a marked mood or unmarked mood is necessary.

$\$ 26$ One will say, for example, Non dubitabo proficisci 'I will not hesitate to depart' (unmarked mood), but Non dubito quin id verum sit 'I do not doubt that that is true' (marked mood due to doubt, even with negation).

$\$ 27$ Similarly, one will say Vereor loqui 'I do not dare speak' (unmarked mood), but Timeo ne veniat 'I fear that he is coming' (marked mood due to the idea of fear).

\$28 In contrast to Latin, Greek allows verbs expressing volition to govern an infinitive clause: Boúlomai se légein 'I want you to speak', Épeithe tòn demon strateúesthai 'He persuaded the people to undertake a campaign', Hēmâs deî tôn pragmátōn antékhesthai 'We have to occupy ourselves with our affairs'.

\$29 Thus it is probably due to the reluctant disappearance of all verbal characteristics (cf. above, \$8) that the infinitive in Greek does not entirely refuse to express modal nuance, this nuance being due to the marked mood of an independent idea of agentivity that is itself expressed by the governing verb.

\$30 Finally, the conjectural mood, which is inaccurately called the conditional (Chapter 259, $\$ 4$ ), seems in general to be a notion that is incompatible with the infinitive. Neither French nor Latin has a conjectural infinitive.

$\$ 31$ However, probably by way of a late development in the disappearance of verbal characteristics (cf. above $\$ 8$ and 29), Greek can construct the infinitive with the conjectural particle án: Hēgoûmai Aléxandron axiothaumastóteron án eînai ei sōpsronésteros egéneto 'I believe that Alexander would be more admirable if he had been more modest'.

\section{Chapter 187. Infinitives and temporal categories}

\$1 The infinitive stops reacting to the notions of tense proper. In our western languages, there is no infinitive that deserves the desigation of past or future, no more than there is one that deserves the designation of present. Since it is no longer a verb, the infinitive has departed from the categories of tense. One can say Alfred wants to come just as well as Alfred wanted to come or Alfred will want to come. The temporal notion is present in want, not in come.

$\$ 2$ But the infinitive remains susceptible to reacting to certain temporal categories that are related to those of tense, in particular to that of secution. 
$\$ 3$ Secution expresses the order in which the processes occur and whether they are anterior or posterior to each other, or concomitant with each other.

$\$ 4$ Concerning the categories of secution, it is necessary to arrange them in terms of what one inappropriately calls the past infinitive in many languages: Eng. to have seen, Fr. avoir $v u$, Ger. gesehen haben 'have seen'.

$\$ 5$ In particular, the category by which Latin contrasts the infectum with the perfectum pertains to secution. The infectum is concomitant, and the perfectum is anterior.

$\$ 6$ Latin has an infectum infinitive, e.g. capere 'take' (inappropriately called a present infinitive) and a perfectum infinitive cepisse 'have taken' (inappropriately called a past or perfect infinitive).

\$7 Latin also has a posterior infinitive capturum esse 'to become captured', which is not a form of the infectum nor of the perfectum: ferre 'carry', tulisse 'have carried', laturum esse 'become carried', esse 'be', fuisse 'have been', fore 'become been'. One very inappropriately gives the name future infinitive to this type of infinitive.

$\$ 8$ Since the infinitive has ceased to be sensitive to tense, the infinitive clause (cf. Chapter 182, $\$ 1$ ) cannot properly express tense.

$\$ 9$ But it does not need tense, for it is by definition always subordinate to a governor that does express tense. It therefore merely has to express the temporal concept of secution in relation to the tense of this governor. It accomplishes this task easily by using the anterior, concomitant, or posterior infinitive: Lat. Dicitur Gallos Italiam transisse 'One says that the Gauls crossed into Italy, Credo Deum esse sanctum 'I believe God to be holy', Pollicentur se obsides daturos esse 'They promised they would hand over the hostages'.

\$10 The same situation is valid for the posterior past that one very inappropriately calls the conditional (Chapter 257, \$11), even when it does not express any condition: Alfred m'a dit qu'il viendrait sûrement demain 'Alfred said to me that he would certainly come tomorrow'. The use of the term conditional has the effect of obscuring the facts that are clear in Latin: Credo eum, si tempus habuisset, omnia hodie fuisse confecturum' 'I believe that, if he had had the time, he would have finished everything today'.

$\$ 11$ From its verbal origin, the infinitive retains the ability to react to the notion of aspect like it does to the notion of secution. Latin discerns an imperfective infinitive (capere 'seize', concipere 'contain') and a perfective infinitive (cepisse 'have seized', concepisse 'have contained'). Russian also distinguishes between an imperfective infinitive pisat' 'write' and a perfective infinitive napisat' 'have finished writing'.

$\$ 12$ In Russian, the notion of perfective and imperfective aspect is retained in the verbal noun. It is almost impossible to clearly translate the difference into French between the imperfective otkryvanie and the perfective otkrytie. French only has the unique noun découverte 'discovery' at its disposal. But it is possible to shine light on this difference by way of example. 
\$13 In one of his novels, Tolstoy analyzes the psychology of Christopher Columbus and his sense of moral achievement by comparing the meaning of the imperfective otkryvanie with the perfective otkrytie.

$\$ 14$ According to Tolstoy, otkryvanie (imperfective) expresses that one is in the process of making a discovery. It delivers a greater sense of moral achievement because it is purer and because it results from a speculation of the spirit that is completely detached from personal goals that may be less lofty. It is analogous to the discovery of the solution to a math problem. The solution is beautiful in and of itself in a manner that is independent of the personal human circumstances that may have helped identify the solution.

$\$ 15$ In contrast, otkrytie (perfective) expresses that the discovery has been made. It delivers joy that is less pure, because the elation of the actual discovery is now absent. The original elation is replaced by the egocentric satisfaction associated with the individual who made the discovery. The sense of moral achievement is reduced significantly by the personal vanity that is now inseparable from it.

\section{Chapter 188. Infinitive and person}

\$1 The category of person is one of the verbal categories that disappears from the infinitive first and with the most consistency. Among the languages that distinguish between verbs and nouns (cf. \$25), one never finds an infinitive that is ontive or anontive. For this reason, the infinitive is judged to be impersonal (cf. Chapter $98, \$ 1$ ).

$\$ 2$ Languages like Turkish do not invalidate this generalization.

$\$ 3$ Certainly a common Turkish sentence such as Bizim gelmiş olduğumuzu bilmiyor ' $\mathrm{He}$ does not know that we have arrived' can, upon first examination, give rise to an objection. It appears as though olduğumuzu 'that we have arrived', which is a noun in terms of its superior connection because it is the second actant of bilmiyor 'He does not know', is verbal in terms of its inferior connections, i.e. because it has the first actant 'we' expressed by the suffix -umuz. Hence because it is nominal with respect to its superior connections and verbal with respect to its inferior connections, the word olduğumuzu would be an infinitive, and an infinitive that bears person morphology.

$\$ 4$ But upon closer examination, the objection cannot be maintained. Certainly the verb in Turkish has a trait in common with the noun, and it is therefore not always easy to distinguish the one from the other. In particular, the personal suffixes of the verb have a form that is closely related to the possessive suffixes of the noun.

$\$ 5$ But the distinction remains clear with certain persons, notably with the autoontive plural oldu-k 'we were', yol-umuz 'our path'.

$\$ 6$ It is therefore easy to observe that $-u m u z$ is not a personal suffix of the verb, but the possessive suffix of a noun. One can thus conclude that the word to which it attaches is 
not a verb, but a noun, which means that the inferior connections to olduğ-umuzu are not those of a verb, but those of a noun just like its superior connection, and therefore olduğ-umuzu is not an infinitive; it is rather a verbal noun that the Turkish speaker does not interpret to be a verb like we understand verbs in French or English, but rather it is interpreted as a type of noun like our having arrived.

\$7 One can make the same observation for the abbreviated infinitive that is formed in Turkish by way of the suffix - ma- and that is also a verbal noun, since it takes possessive suffixes: Bab-miz bizim çik-ma-mizi bekledi 'Our father is awaiting our departing'.

$\$ 8$ Moreover, the non-abbreviated infinitive, which is formed by way of the suffix -mak (çık-mak 'depart'), retains its inferior verbal connections and thus confirms our generalization (cf. above $\$ 1$ and $\$ 2$ ), since it refuses to accept any personal marker, be it a person marker or a possessive marker.

$\$ 9$ Since the infinitive is not capable of expressing the notion of person, one judges the first actant of an infinitive clause to be the first actant of the governing verb when this first actant is not expressly stated: Eng. Alfred can sing, Alfred wants to depart, Fr. Alfred croit rêver 'Alfred thinks he dreams'.

$\$ 10$ Hence when the first actant of the infinitive clause is distinct from that of the governor, one has to express it: Eng. Alfred asked Bernard to sing, Alfred watched the dancers do the walz, I like to see you dance, St Peter heard the rooster crow three times, Bernard feels the earth shake.

\$11 For this reason, the first actant of the infinitive clause must always be expressed in Latin: Alexander filium se Jovis esse contendebat 'Alexander pretended (himself) to be the sun of Jupiter'.

$\$ 12$ Such is the case in particular for the personal noun of the first actant: Lat. Te abire volo 'I want you to go', Fateor me esse Atheniensem 'I confess I am Athenian' (cf. Stemma 308). The same holds in Greek: Légō se hamartánein 'I say you are wrong'.

\$13 A few rare verbs in Latin can govern an infinitive clause that does not have an expressed first actant, which means that the infinitive takes the first actant of its governor as its first actant (\$9). Lat. Vereor loqui 'I hesitate to speak', Destitit loqui 'He stopped talking', Non possum currere 'I cannot run', Non dubitabo proficisci 'I will not hesitate to depart'.

$\$ 14$ This construction is possible in particular when the transferred verb is nominal (cf. Chapter 182, \$20), in which case the attribute of the first actant must appear in the accusative (cf. Chapter 182, \$9), like the first actant that is not expressed and with which it is connected: Lat. Sapientis est esse temperantem 'The wise man knows good measure' (Cicero, De officiis, 1, 80), Decet esse temperantem 'It is appropriate to know good measure', Contentum esse decet rebus suis 'One should be content with what one has', Non licet esse otiosum 'One is forbidden from being idle'.

$\$ 15$ The same holds in Greek: Kalòn thaneîn makhómenon (or makhómenous) hupèr tēs póleōs 'It is good to die while fighting for one's fatherland'. 
$\$ 16$ The ability to govern an infinitive clause with a first acant that is not expressed (cf. \$14) is more frequent in Greek than in Latin. In particular Greek, in contrast to Latin, permits the first actant of an infinitive to be absent when it is the same as that of the governor: Gr. Homologō eînai Athēnaîos 'I confess I am Athenian' (cf. Stemma 309), compared to Lat. Fateor me esse Atheniensem.

$\$ 17$ Of course a noun predicating on the absent first actant in Greek must appear in the nominative, just as is the case of the first actant of the governing verb. There is an immediate anaphoric connection between the two (see the example in the preceding paragraph and compare Stemma 308 with Stemma 309).

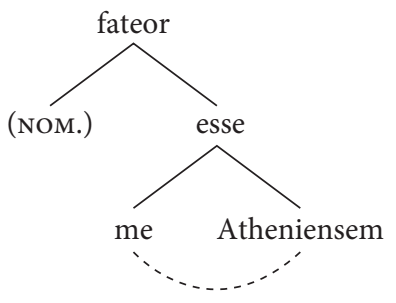

Stemma 308

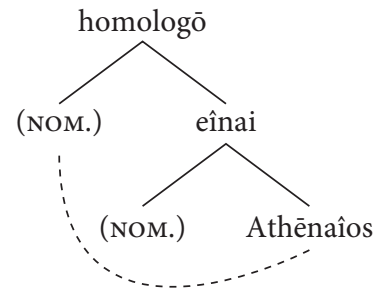

Stemma 309

\$18 Greek allows the same mix of the two constructions: a shared infinitive, but one that is doubled (cf. Chapter 135) with respect to its inferior connections and that governs a doubled first actant via these connections. The two terms of this first actant each arise from a different structure (despite what was said above in Chapter 135, §11) and are therefore in the nominative (the one), and in the accusative (the other): Kléon ouk éphè autos all'ekeînon stratēgein 'Kleon says that it was not himself but another (Demosthenes) who was general.'

$\$ 19$ Hence the aversion of the infinitive to the notion of person causes the infinitive clause to obey complicated constraints, which in turn renders its use difficult. This is certainly why the infinitive clause is quite rare in many languages.

\$20 The only means to escape the difficulty is to renounce the infinitive clause, be it by way of the verbal nominal clause or by way of the complete rejection of first-degree transfer in favor of second-degree transfer.

\$21 The verbal noun, since it is a noun and hence susceptible to governing a possessive adjective, is particularly suited to the transfer of an independent clause to a noun ( $>0$ ) when the first actant that it governs bears the category of person.

\$22 For while the infinitive, and as a consequence the infinitive clause, is hardly compatible with the notion of person, the verbal noun, and as a consequence the verbal nominal clause, permits the use of an oportune expedient in the form of the possessive suffix which is subordinate to the verbal noun as a substitute of the personal suffix for expressing the person of the first actant of the nominal clause. 
$\$ 23$ This is the procedure that Turkish employs. Turkish has the verbal noun - duk (-ecek for the future), which is intended just for this purpose (cf. \$6): Bizim gelmiş oldu $\breve{g}$-umuzu bilmiyor 'He does not know that we have arrived', Bizim geleceğimizi bilmiyor 'He does not know that we will arrive.'

$\$ 24$ French, like a large number of languages, avoids the infinitive clause by appealing to second-degree transfer (cf. Chapter 239, \$12): Alfred croit que Bernard chantera 'Alfred believes that Bernard will sing', Alfred desire que Bernard chante 'Alfred wants Bernard to sing', Je crois que Dieu est saint 'I believe that God is holy'.

$\$ 25$ The incompatibility of the notion of person with the category of the noun, and as a consequence with the infinitive, disappears of course in those languages that do not distinguish between verbs and nouns (cf. Chapter 32, §5; Chapter 54, $\$ 3$, note 83; Chapter 55, $\$ 3$; Chapter 61, \$12f.).

$\$ 26$ This explains the facts of Turkish ( $\$ 4$ and $\$ 23$ ), where there is a lack of markers that distinguish between verbs and nouns.

$\$ 27$ The incompatibility also probably explains the facts of Basque, where the personal form of the verb is susceptible to being transferred to a second actant by subcategory transfer at the same time that the personal characteristics are conserved.

$\$ 28$ This phenomenon is acknowledged by grammarians using different designations. Gèze speaks of a governed form, ${ }^{226}$ whereas Lafitte speaks of complementive mood. ${ }^{227}$

$\$ 29$ But one is dealing with the same phenomenon in both cases. The subcategory transfer of a verb-noun to a second actant occurs by way of the translative suffix -la: Ez daki ethorri garela 'He does not know that we have arrived', Ez daki ethorriko garela 'He does not know that we will arrive'.

\$30 Given the general incompatibility of the infinitive with the notion of person, one has to consider the personal infinitive of Portuguese to be an instance of quite retarded transfer (cf. Chapter 158, \$18): Es tempo de partirnos 'It is time for us to depart'.

\section{Chapter 189. Infinitives and number}

\$1 The category of number - or to be more exact, that which one is accustomed to calling "number" - is not a verbal category, but rather it is a nominal category.

$\$ 2$ It is not the case that the number bearing on the process itself cannot intervene in the verb. A process can occur numerous times and can be hence judged to be plural.

226. Gèze, Eléments de grammaire basque, Bayonne, 1873, p. 73.

227. P. Lafitte, Grammaire basque, Bayonne, 1944, p. 400. 
$\$ 3$ But in such cases one is accustomed to designating the category associated with plurality using a completely different term, that is, the notion of plurality itself is named using a different term from that for the plural. For this reason, a verb expressing a process that can occur multiple times is generally called frequentative or iterative.

$\$ 4$ Of course this verbal category is likely to survive in the infinitive, and iterative verbs normally possess an infinitive: Gr. rhiptázein 'throw often', Lat. iactare 'throw often', volitare 'flutter, factitare 'do often', Fr. tapoter 'tap repeatedly', Middle English flakeren 'flutter', Ger. flackern 'blaze', stottern 'stutter', klingeln 'ring', grübeln 'ruminate'.

$\$ 5$ In contrast, what one commonly understands the term grammatical number to mean in a verb is in reality the number of the first actant, not the number of the process: anontive or one of the singular or plural ontives.

$\$ 6$ Yet the actant is a noun. Number proper is hence essentially a nominal category, and as a consequence, that is what we will encounter in the infinitive.

$\$ 7$ The infinitive can take a plural marker as soon as it is no longer sensed to be a verb, but rather it is now a noun. This fact is visible when the article is used under the same synctactic conditions as for a noun: Fr. Alfred aime les bons diners 'Alfred likes the good meals', Ce linguiste étudie les parlers franco-provençaux 'This linguist studies Franco-Provincial dialects', Les diplomats ont entamé des pourparlers 'The diplomats have started the negotiations', les avoirs d'un industriel 'the possessions of an industrialist', les dires d'un expert 'the proclamations of an expert'.

\section{Chapter 190. Infinitives and extension}

$\$ 1$ While extension is peculiar to nouns (Chapter $34, \$ 18$ and Chapter $35, \$ 4 f$.), the article, which is the marker of extension (Chapter $41, \$ 21$ ), is the distinctive sign of a noun (Chapter 177, §3).

\$2 The infinitive also quickly acquires an article as soon as it develops nominal value.

$\$ 3$ In Greek, the infinitive can be considered as a noun and as taking a neuter article: Aiskhròn tò pseúdesthai 'The lying is disgraceful'.

$\$ 4$ The same situation holds in German, where every infinitive can be employed as a noun if one introduces it with a neuter article: das Entkommen 'the escape', das Entscheiden 'the deciding, ${ }^{228}$ etc. Das Überschreiten der Gleise ist verboten 'Crossing the tracks is forbidden', das Essen 'the food', das Trinken 'the drinking', das Leben 'the life', das Dasein 'the existence',

228. See A. Malblanc, Pour une stylistique comparé du français et de l'allemand, Paris, $1963, \$ 54$. 
das Wesen 'the essence', das Vergnügen 'the pleasure', das Vermögen 'the fortune.' The infinitive can even stem from Latin, das Interesse 'the interest'.

\$5 This use is also often possible in French with the masculine article: le boire et le manger 'the drinking and the eating', le savoir 'the knowing', le savoir-vivre 'the knowing how to live'. The infinitive can stem from Arabic: Eng. the traffic < Arabic tarig 'distribute', cf. Kluge Goetze, Etymologisches Wörterbuch der deutschen Sprache, 11, 1934, p. $624 .^{229}$

$\$ 6$ But in French the article most often makes the infinitive into a true noun: le déjeuner 'the breakfast', le dîner 'the dinner', le souper 'the supper' (Chapter $168, \S 1-5$ ), un parler 'a dialect'.

$\$ 7$ The entirely nominal nature of un aller, lit. 'a going', that is 'an outward journey', is seen in the possibility to conjoin this word with a true noun: un aller et retour 'a going and returning', that is 'a round trip'.

\section{Chapter 191. I > O transfer without an infinitive}

\$1 The transfer I > O can occur without the use of an infinitive.

\$2 A frequent occurrence in French is that a verb with imperative force is transferred to a noun: Un Tiens vaut mieux que deux Tu l'auras 'A bird in the hand is worth two in the bush', lit. 'One have is worth more than two you will haves' (La Fontaine, Fables, V, 3, Le petit poisson et le pêcheur 'The small fish and the fisherman'), un va-et-vient 'comings and goings', lit. 'a go-and-come', un rendez-vous 'a meeting', lit. 'a give-yourself-up', un laissez-passer 'a pass', lit. 'a let-pass', Cela vous a un petit gout de revenez-y 'That is addictive for you', lit. That has a little taste of come again', un décrochez-moi-ça, lit.'a getit-for-me', un suivez-moi, jeune-homme 'a follow me, young man', and with Latin words un vade mecum, 'a handbook', lit. 'a go with me'. [cf. also Eng. the do-it-yourself, I > O, a don't-mess-with-me face.]

$\$ 3$ The process has been borrowed by German: ein Stelldichein 'a rendez-vous', lit. 'a putyourself-there', das Vergissmeinnicht 'the forget-me-not', das Lebewohl 'the good-bye', lit. 'the live-well'.

$\$ 4$ This mechanism extends from the imperative to homophonous indicative forms, so that one cannot determine whether the forms were originally imperative or indicative: ${ }^{230}$

229. Translator's note: In modern Arabic, tarig translates as 'read', not as 'distribute'.

230. Hatzfeld, Darmesteter and Thomas, Dictionnaire general de la langue française, Traité de la formation de la langue, pp. $87 \mathrm{ff}$. 


\begin{tabular}{lll}
\hline French & Translation & Literal translation \\
\hline un monte-charge & 'a service elevator' & 'a carry-up-load' \\
un perce-neige & 'a snowdrop' & 'a pierce-snow' \\
un brise-glace(s) & 'an icebreaker' & 'a break-ice' \\
un prie-Dieu & 'a prie-dieu' & 'a pray-God' \\
un croquemitaine & 'a bogeyman' & 'a crunch-hand' \\
un croquembouche & 'a croquembouche' & 'a crunch-in-mouth' \\
un saute-ruisseau & 'errand boy' & 'a jump-stream' \\
un coupe-file & 'a pass' & 'a cut-line' \\
un grippe-sou & 'a penny-pincher' & 'a grab-penny' \\
un attrape-nigaud & 'a con game' & 'a catch-silly-boy' \\
un trompe-l'oil & 'a trompe-l'oeil' & 'a trick-the-eye' \\
un sauf-conduit & 'a safe-conduct' & 'a safe-conduct' \\
un perce-oreille & 'an earwig' & 'a pierce-ear' \\
un pince-nez & 'a binocle' & 'a hold-nose' \\
un accroche-cour & 'a kiss curl & 'a catch-heart' \\
un casse-tête & 'a puzzle' & 'a break-head' \\
un tire-au-flanc & 'a shirker' & 'a fire-on-side' \\
un pince-sans-rire & 'a deadpan man' & 'a pinch-without- \\
un va-nu-pieds & 'a tramp' & 'a go-bare-feet' \\
\hline & & \\
\hline
\end{tabular}

This is also the case of a lot of simple nouns: le troc 'the barter', la paye 'the pay', l'embauche 'the hiring', la foire d'empoigne 'the free-for-all', lit. 'the fair of grasp'; le maintien 'the support', le prix de revient 'the factory price', lit. 'the price of return'.

$\$ 5$ The conclusion of this development is found in words where the source is clearly an indicative form (as opposed to an imperative form):

\begin{tabular}{lll}
\hline French & Translation & Literal translation \\
\hline un vaurien & 'a rascal' & 'a is-worth-nothing' \\
un sot-l'y-laisse & 'an oyster (in chicken)' & 'a fool-leave-it-here' \\
un m'as-tu-vu & 'a show-off' & 'a have-you-seen-me' \\
le qu'en-dira-ton & 'the gossip' & 'the what-will-one-tell' \\
\hline
\end{tabular}

Elle faisait sa mademoiselle jordonne avec des filles deux fois plus grandes qu'elle 'She was doing her miss I-order-you-to with girls twice her height' (Zola, L'Assommoir, V). 
$\$ 6$ The transfer of an indicative verb to a noun can be marked in such cases. Instead of an article, a derivational suffix marks the noun. This is what we see with the verb in $J^{\prime}$ m'en fiche 'I don't give a shit'; French forms the noun by adding the derivational suffix -istel-isme: un j' m'en fichiste 'a not-giving-a-shit', le j'm'en fichisme 'the I-don't-give-a-shit'. $\$ 7$ French even transfers foreign words to French nouns: un lavabo 'a washbasin' (from Lat. lavabo... 'I will wash..., Psalms XXVI, 6), un credo 'a belief' (from Lat. credo... 'I believe...'), un confiteor 'a confessor' (from Lat. confiteor... 'I confess...'), un vasistas 'a fanlight' (from Ger. Was ist das? 'What is that?'), cf. Hebrew mān 'manna' (Exodus, XVI, 31), for which the Bible proposes a popular etymology: Hebrew Mān hü? 'What is this?' (Exodus XVI, 15). ${ }^{231}$

$\$ 8$ But since French speakers do not recognize that one is dealing here with a verbal form, it must have to do instead with formal transfer (Chapter 166).

$\$ 9$ But the source, because it is not a verb proper, can be a sentence word, for example a representative sentence word (Chapter $46, \$ 18$ ) is Fr. le tric-trac 'backgammon'.

\section{Chapter 192. Transfer of a noun to a descriptive adjective $(\mathrm{O}>\mathrm{A})$}

\$1 Typical adjectival transfer changes a noun to a descriptive adjective.

\$2 When such transfer is marked, the most commonly used translative in French is the preposition de: un homme de coeur 'a big-hearted fellow', lit. 'a man of heart', un homme de goût 'a man of taste', un poète de génie 'a poet of genius' (Stemma 310), un faim de loup 'a wolf's hunger', lit. 'a hunger of wolf', une Bretonne de race 'a purebread Breton cow', lit. 'a Breton of race', un paysage qui n'est pas d'imagination 'a landscape that is not only imagined', un homme de grand cœur 'a man with great heart', un homme de haute taille 'a man of high stature', des livres de toute espèce 'books of all sorts', un homme du métier 'a professional', lit. 'a man of the profession', un officier de génie 'an officer of genious', son intelligence et sa mémoire sont d'un genie 'her intelligence and memory are (those) of a genious', Je vous ai trouvé... d'une originalité de conceptions, d'une audace même 'I found you to have originality of conception, even daring', lit. 'I found you... of an originality of conception, of a daring even' (Denys Amiel, Ma Liberté, Acte I, p. 10).

$\$ 3$ All these expressions are true adjectives (cf. Chapter 151, $\$ 17$ ). The proof of this fact is that one can often replace them with an adjective without changing the syntactic structure of the sentence in the least, e.g. un poète de génie 'a poet of genius' is un poète génial 'a great poet'. Similarly, Old French de bon(ne) aire 'of good mood' (Chanson de Roland) has given modern French the adjective débonnaire 'debonair' (cf. Stemma 311). Likewise, with another translative, the preposition $a b$ 'of', common Lat. *ab oculis '(deprived) of eye' has given Fr. aveugle 'blind'.

231. Couroyer, L'Exode, in the Bible de Jérusalem, 1952, p. 84. 


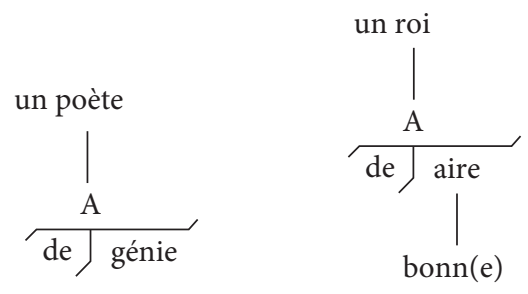

Stemma 310

Stemma 311

$\$ 4$ The translative value of the preposition $d e$ is so clear that it alone can sometimes initiate transfer and in so doing, it leaves one in suspense without needing to utter the target: $O n$ ne voit pas ce qu'on cause quand il fait nuit. C'est la raison de 'One does not see what one causes when it's dark. That is the reason of.' (Marcel Aymé, La Jument verte, p. 49).

$\$ 5$ Instead of the translative $d e$, one sometimes finds the translative $a$ 'to, of, with' in French: la femme à barbe 'the bearded lady', lit. 'the woman with beard', la Vierge à la chaise 'the Madonna with a chair', la Poule aux cufs d'or 'the goose that lays the golden eggs', lit. 'the hen of golden eggs', ces Dames aux chapeaux verts 'these Ladies with green hats', une voiture à bras 'a hand cart', lit. 'a car with arms', une lampe à arc 'an arc lamp'.

$\$ 6$ In languages with case, the marker of adjectival transfer is the genitive: Gr. mnôn tessárōn khốra 'a terrain of four mines', anếr pollôn etôn 'a man of many years', polloí tôn anthrốpōn 'many among the men', Lat. Res est magni laboris 'The matter is fraught with great difficulty', lit. 'The matter is of great work', puer novem annorum 'a child of nine years'.

$\$ 7$ It is also often necessary in English to translate these genitives using an adjective: corporis dolor 'physical pain', historiae fides 'historical truth'.

$\$ 8$ In Russian, as in Latin and Greek, the transfer of a noun to an adjective is marked by the genitive čelovek vysokogo rosta 'a man of high stature'.

$\$ 9$ The marker of transfer of a noun to an adjective is sometimes an adjectival suffix, for example Fr. -ien (un héros cornél-ien 'a Cornel-ian hero'), -eux (poussiér-eux 'dust-y'), Ger. -ig, (staub-ig 'dusty'), Eng. - $y$ (dust-y), Persian - $i$ (khâk-i 'dusty'), which is the source of Fr. kaki and Eng. khaki 'olive grab'. Concerning the nuance in meaning between the autonomous translative and the suffix, see Chapter $173, \$ 7$.

$\$ 10$ Adjectival transfer lifts the notion of the noun to the more general idea of the adjective. For this reason, the genitive, the essential characteristic of which is to express this transfer, has received the name genikế ptôsis in Greek, which means 'general case', or better 'generic, that which expresses genre', the adjective genikós being derived in Greek from the noun génos 'genre, kind'.

$\$ 11$ Latin speakers, who had obtuse minds that were incapable of seizing upon abstract concepts, did not comprehend the philosophical reach of Greek appellations. Retaining their narrow conception and envisioning only the particular case where the genitive serves 
to express the origine, the birth, and the paternity (Lat. Diodurus Timarchidi 'Diodorus, son of Timarchides', in Cicero, In Verrem, 2, IV, 138), they perceived only the genetic notion and translated the Greek adjective genikós with genitivus, as if they were gennētikós 'specific to the generation' in Greek, an adjective derived from the noun gennessis 'action of begetting, generation.'232 Therefore the true nature of the genitive, which was perfectly clear for the Greeks, has unfortunately been obscured by the tradition passed down by the Latins.

$\$ 12$ The transfer of a noun to a descriptive adjective can occur without a marker. It suffices quite simply to employ the noun with the value of an adjective without any translative: Fr. Il est vache 'He is mean', lit. 'He is cow', un sifflement canaille 'a mischievous whistle', lit. 'a crook whistle', un livre cochon 'a dirty book', lit. 'a pig book', une ferme-modèle 'a model farm', un navire-école 'a training ship', lit. 'a school ship', un exemplaire type 'a typical copy', lit. 'a type copy', une industrie-clé 'a key industry'; Lat. uber (O) 'teat' > (A) 'fertile.233

$\$ 13$ Many indications prove that despite the absence of a marker, transfer has clearly transformed the noun to an adjective: 1) the target can be modified by an adverb: Fr. Il est très vache, lit. 'He is very cow'; 2) the target can agree in number and take a plural marker: Fr. des propos cochons, lit. 'pig words'; and 3) the target can in turn be transferred to an adverb, just as it can to a simple adjective: Fr. se cocarder cochonnement, lit. 'to get drunk pigly' (Zola, L'Assommoir, III).

\$14 The transferred noun can retain an adjectival modifier: Fr. Il est vieux jeu 'He is oldfashioned', lit. 'He is old game', cf. Eng. It is old hat, Fr. Il est tout à fait nouveau genre 'He is quite new-fashioned', lit. 'He is quite new sort'.

\$15 The adjectival transfer of nouns is particularly frequent for names of people: Fr. la tour Eiffel 'the Eiffel tower' (cf. Chapter 65, $\$ 7$ and stemma312), l'épicerie Dupont 'the Dupont grocery store', le dîner Durand 'the Durand diner', un bouillon Duval 'the Duval broth', l'Académie Goncourt 'the Goncourt Academy'.

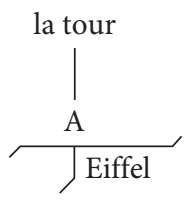

\section{Stemma 312}

232. Cf. K. E. Schmidt, Beiträge zur Geschichte der Grammatik, 1859, Ueber den Begriff der Grammatik, p. 320, reprinted by Max Müller, La Science du langage, translated to French by Harris Perrot, Paris 1867, p. 130.

233. Cf. Cousin, Evolution et structure de la langue latine, p. 56. 
\$16 The same is true of nouns that designate historical periods; they are easily transferred to adjectives when they qualify style: Fr. des ornements Renaissance 'Renaissance ornaments', le style Louis XIV 'the style (of) Louis XIV', un costume Régence 'a Regency costume', un boudoir Pompadour 'a Pompadour boudoir', Eng. a 16th century church.

$\$ 17$ The transfer of nouns to descriptive adjectives without a marker is common in the compound forms of Germanic, for example in German (cf. 175, \$3):

\begin{tabular}{ll}
\hline \multicolumn{2}{c}{ German compound nouns } \\
\hline $\begin{array}{l}\text { der Hausdiener } \\
\text { der Haarpinsel }\end{array}$ & 'the servant' \\
der Leidensgenosse & 'the companion in \\
suffering' & 'the copper engraving' \\
die Seereise & 'the sea voyage' \\
\hline
\end{tabular}

\$18 The proof that the noun is transferred to an adjective is that it often corresponds to a French [or English] adjective: die Vaterliebe 'paternal love', die Mutterliebe 'maternal love', die Kindesliebe 'childish love' (above \$7).

\section{Chapter 193. Transer of a noun to an adjective of color or material}

\$1 Among the adjectives that are the result of denominal transfer, those that designate a color or a material are particularly frequent.

\$2 For the adjectives of color, transfer often occurs without a marker in French. It suffices to employ a noun with the value of an adjective to designate an object that is particularly noted for its color. Most frequently, this object is a flower (rose, lilly, mallow) or a fruit (orange, chestnut): une étoffe rose 'a pink fabric', lit. 'a rose fabric' (Chapter 175, \$9), un chapeau marron 'a brown hat', lit. 'a chesnut hat'.

$\$ 3$ Of course the noun transferred in this manner retains its gender, and, since due to this fact it is not susceptible to agreeing with a noun of a different gender, it becomes invariable as an adjective: un chapeau rose 'a pink hat', une étoffe marron 'a brown fabric'.

$\$ 4$ It occurs only in an exceptional case that transfer leads to the creation of a variable form adapted to its new function as an adjective. Hence from the feminine nouns violette 'violet' and châtaigne '(sweet) chesnut', one derived the adjectives violet 'violet' and châtain 'brown (for hair)': un vêtement violet 'a violet piece of clothing', des cheveux châtains 'brown hair'. $\$ 5$ To end up with a material adjective, in contrast, one easily uses the preposition de in French: un bouton de nacre 'a mother-of-pearl button', 
C'était un jeune officier de trentecinq ans, brun, coquet, aimé des dames, beau valseur à la cour, et portant avec grâce les epaulettes de fer blanc.
'He was a young officer of 35 years, dark-haired, well turned-out, loved by women, a good walzer at court, and gracefully carrying shoulder pads of white iron.'

(E. About, Le Roi des montagnes, V)

\$6 In languages with case like Greek and Latin, the same transfer can be obtained by way of the genitive: Gr. khrusoû stéphános 'a crown of gold', Lat. flumen sanguinis 'river of blood'.

$\$ 7$ But most generally, the transfer of a material to an adjective occurs in Greek and Latin by way of a suffix: Lat. aur-eus, Gr. khrús-eos 'of gold'. This is also the case in the Germanic and Slavic languages: Eng. wood-en, Ger. holz-ern, Rus. derev-jannyj.

$\$ 8$ A noun transferred to a subordinate descriptive adjective can correspond to an actant of a verb that itself has been changed to a noun. When this actant is a first actant, one says that the transferred noun is subjective. When, in contrast, this actant is a second actant, one says that the transferred noun is objective. Take for example the English phrase the fear of the enemy; if this phrase corresponds to the idea that the enemy is doing the fearing, the noun is said to be subjective, but if it corresponds to the idea that one is fearing the enemy, the transferred noun is said to be objective.

\$9 The transfer of an objective noun to a qualitative adjective is normally marked in French with the translative de: l'amour de la gloire 'the love of glory' (because one loves glory).

$\$ 10$ In German, the preferred translative in such cases is a preposition that has a more concrete meaning than de has in French: Ger. die Liebe zum Ruhm 'the love of fame', der Wille zur Macht 'the desire for power' (cf. Chapter 220, \$13).

$\$ 11$ Whichever German preposition is chosen in such cases, French always employs the preposition de: eine Änderung in der Politik vs. un changement de politique 'a change in politics', die Herrschaft über den Wagen verlieren vs. perdre le contrôle de la voiture 'to lose control of the car' ${ }^{234}$

$\$ 12$ The same transfer can be marked by the genitive in languages with case, which is therefore called the subjective or objective genitive according to whether the actant that it represents is first or second. (cf. \$8). One has a subjective genitive in Lat. propter eorum ad quos venerate injurias 'due to the faults of those that he had come to find' (because those who he had come to find had faults). One has, in contrast, an objective genitive in Lat. rerum publicarum eversiones 'the reversals of the states' (Cicero, De senectute, 12, 40) (because one reverses the states).

234. Cf. Malblanc, Pour une stylistique comparée du français et de l'allemand, Paris, 1944, p. 101. 
$\$ 13$ Since nothing outside of context indicates whether the genitive is subjective or objective, sometimes a certain ambiguity can arise like in French or English (cf. \$8): Gr. ho polemíon phóbos 'the enemy's fear'.

$\$ 14$ The transferred noun, be it subjective or objective, can often be translated into English using an adjective. This fact confirms what we stated concerning the adjectival nature of the target (cf. Chapter 192, $\$ 7$ and 13): multarum rerum usus 'a long experience' (Cicero, De amicitia, 2, 6).

$\$ 15$ The transfer can occur without a marker (cf. Chapter $175, \$ 3$ ). This is the case in German compounds: Ger. der Bettwärmer 'the bed warmer'. In this case the transferred noun Bett 'bed' is objective because the warmer (first actant) warms the bed (second actant).

$\$ 16$ We observe that in German transfer without a marker (die Freiheitsliebe 'the love of liberty') expresses a quality that is more permanent than when transfer occurs with a marker (die Liebe zur Freiheit). ${ }^{235}$

$\$ 17$ The nouns evoking an idea of time or place are employed as circumstantial adjectives particularly often. In Russian, transfer is hence evoked by the suffix -nij: letnij 'summery'.

\section{Chapter 194. Transfer of a noun to an adjective (O $>A)$}

$\$ 1$ We have seen (Chapter $35, \$ 35$ and Chapter $167, \$ 8$ ) that the main relational adjectives are those of personal relations (belonging) and those of circumstantial relations.

$\$ 2$ In order to transfer a noun to an adjective of belonging, French generally uses the preposition de: le livre de Pierre 'the book of Peter'. But we have seen (Chapter 151, \$7f.) that the notion of belonging is conceived of in a very broad manner and it can apply to both the possessor and the possessed. One says both le chien du maitre 'the dog of the master' and le maitre du chien 'the master of the dog'.

$\$ 3$ The same procedure is found in most neo-Latin languages and in English: Eng. the book of Peter, It. il libro di Pietro, Sp. el libro de Pedro, Portuguese o livro de Pedro.

$\$ 4$ In languages with case, the genitive is generally used to transfer a noun to an adjective of belonging: Lat. liber Petri 'Peter's book' (cf. Chapter 151, \$1 and 157, \$8), Gr. ho tôे Pérsou akinákēs 'the Persian's scimtar', Ger. das Haus meines Vaters, Rus. dom moego otca 'my father's house'.

$\$ 5$ In Germanic the genitive of belonging can precede the noun to which it is subordinated, in which case it takes the place of the article: Ger. Peters Buch, Engl. Peter's book, my father's house. This is called the Saxon genitive.

235. Ibid., p. 102. 
$\$ 6$ Russian possesses an interrogative possessive adjective, čej 'of whom, whose' (cf. Chapter $35, \$ 19$ ), which contains the notion of belonging from the nominative. Of course when it is genitive - in which case it effects transfer of the noun (and the possessive interrogative that is subordinate to the noun) to an adjective of belonging - the notion of possession is expressed two times: it is therefore necessary to express possession two times in the French translation by employing the translative de two times: Čej ruki udar? vs. un coup de main de qui? 'a punch of the hand of whom'.

$\$ 7$ A noun transferred to an adjective of possession by way of the genitive can also be employed like a predicative or attributive adjective: Gr. Sōphrónōn estín kaì andròs kai gunaikòs ohútō poieîn 'It belongs to a sensitive man and to a sensitive woman to behave like that', Lat. Haec domus patris mei est 'This house belongs to my father', lit. 'This house is my father's', Est regis tueri subditos 'It is the king's duty to protect his subjects', Eng. $M y$ son is my son, and nobody else's.

$\$ 8$ A number of languages derive their possessive adjectives from nouns that have been transferred to adjectives of belonging (Chapter $35, \$ 18$ ). Such is the case in Greek with the

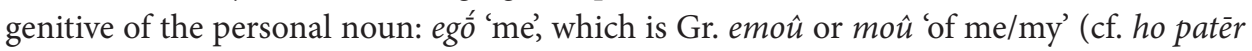
mo $\hat{u}$ 'the father of me', that is, 'my father') and this is the origin of the possessive adjective ho emós 'my'.

$\$ 9$ The same holds in Latin, where the genitive of the personal noun ego ' $\mathrm{I}$ ', which is mei 'of me', furnishes the possessive adjective meus, mea, meum 'my', that is, when it is declined like bonus, bona, bonum 'good'. Thus in archaic Latin the genitive of some personal nouns are declined like adjectives: hujus liber 'his book, huja toga 'his toga', hujum pectus 'his breast'; this usage is found up to Vergil: Cujum pecus? 'Who does this herd belong to?' (Bucolica, III, 1).

$\$ 10$ The same holds in the Germanic languages where the possessive adjective (e.g. Old Eng. min, Ger. mein 'my') is nothing other than the genitive form of the personal noun: Old English ic, Ger. ich 'I'.

$\$ 11$ In Basque, where the different cases of the noun are marked by the suffix endings, transfer of a noun to an adjective of belonging is indicated by the ending-aren: gizon-aren etxea 'the man's house'.

$\$ 12$ In Slavic, the agglutinated translative is a suffix: Ivanov dom 'John's house', Czech Husuv di̊m 'Hus' house'.

\$13 A language like Turkish appeals to an analogous procedure, but with the particularity that, in addition to the case ending of the subordinate noun, it requires the subordinate to be followed by a possessive suffix: baba-nın kitab-l 'the father's book', lit. 'father's his book'.

$\$ 14$ In a very familiar style, one also uses the preposition $a ̀$ 'to' in French to transfer a noun to an adjective of belonging: le père à Jean 'the father of John' (cf. Chapter 192, §5). 
$\$ 15$ Just as the transfer of a noun to an adjective of belonging is exceptionally marked in French at times with the translative $a$ instead of the translative $d e$ (above, $\$ 4$ ), it also occurs that in languages with case, the same transfer is marked by the dative, not by the genitive. Thus one will commonly say meinem Vater sein Haus, lit. 'to my father his house', in familiar and dialectal speech in certain regions of Germany instead of the classical das Haus meines Vaters 'the house of my father. This dative possessive replaced the genitive possessive in almost all of the German speaking lands in the 15th century. ${ }^{236}$

\$16 In Hungarian, one finds the possessive dative of a subordinate like in German, but with a possessive suffix on the subordinate as in Turkish: Péter-nek könyv-e, lit. 'to Peter his book', that is 'Peter's book'.

$\$ 17$ This same expression, which appears dialectally in German and which is the norm in Hungarian, is found in languages of a completely different type, for example in Greenlandic: Kim̃ip neKa 'to dog his flesh', that is, 'the flesh of the dog.237 This particularity suggests that one is perhaps dealing in German with an extremely old substratum of the language.

$\$ 18$ To transfer a noun to an adjective of belonging, it can suffice to employ the noun as an adjective. Such is the case in Hebrew: davār 'elōhim 'the word of God'. It would be somewhat inexact to say that in this case, the transfer is not marked; but the marker here is of a particular sort: instead of affecting the subordinate élōhim 'God', which is in its ordinary form, it affects the governor dēvār. The latter word takes on the special reduced form davār, which indicates that the following word is a subordinate, and it is thus a type of forward pointing marker. This form of the subordinate is called the constructed state (status constructus) by Hebrew grammars.

$\$ 19$ We have seen (cf. Chapter $35, \$ 22$ and Chapter $167, \$ 8$ ) that in addition to the adjectives of a belonging relationship, there are adjectives of a circumstantial relationship, or circumstantial adjectives. These are adjectives that evoke a circumstance of time or location. \$20 The circumstantial adjectives that result from the transfer of a noun often have a special marker.

\$21 Thus for those adjectives that evoke a circumstance of location, German possesses the indeclinable adjectival suffix -er: die Frankfurter Zeitung 'the Frankfurt newspaper', der Pariser Zug 'the Paris train'. This correspondence proves that the phrases de Francfort and de Paris in French (la gazette de Francfort, le train de Paris) are indeed real adjectives (Chapter 151, \$9-11 and Chapter 173, \$9).

$\$ 22$ The same is true of the transfer of a noun to a circumstantial adjective of location; such adjectives are marked in Basque by a suffixed ending of the locative genitive, which

236. Bach, Geschichte der deutschen Sprache, p. 124.

237. Finck, Die Haupttypen des Sprachbaus, Leipzig, Teubner, 1910, p. 40. 
is different from that of the genitive of belonging. For example, the noun etxe 'house' is transferred to a circumstantial adjective by the locative genitive ending -ko: etxeko anderea 'the mistress of the house'.

\section{Chapter 195. Transfer of a noun to an adjective of quiddity}

\$1 In order to reinforce the value of a given noun, one frequently subordinates an adjective to the noun, the adjective being derived from the same root as the noun. Thus in colloquial French, la vérité vraie 'the true truth' is distinguished from simple la vérité 'the truth', whereby one accords greater truth to the former.

$\$ 2$ In the same way it is possible to reinforce the meaning of a noun in terms of that noun itself transferred to an adjective without a marker: Madame Blandin: Mais les bouges? Les bouges-bouges? 'But the dives? The dive dives?.' It is evident that Madame Blandin desires to distinguish the dives that are true dives, $100 \%$ dives, from the dives that are less fully dives. By way of the same procedure, one calls an apple an apple apple in order to distinguish it from other uses of the word apple (e.g. horse apples). That is why Gougenheim quite happily proposed to call the mechanism distinctive repetition. ${ }^{238}$

$\$ 3$ By an analogous procedure, a noun can be reinforced by its plural form transferred to an adjective. This procedure is extremely old and comes at least from ancient Hebrew, where the transfer of the plural noun occured without a marker. This group served to express the notion par excellence, and as a consequence, an absolute superlative was understood: Heb. qodeš haqqơd we have the saint of saints. The same occurs in the Heb. šìr hašširìm 'the song of songs', that is, the song par excellence. The procedure is common in the Semitic languages: ${ }^{239}$ Ethiopian neguš negešti 'the king of kings', that is, the 'Negus'.

$\$ 4$ From Hebrew, the process has passed into the classic languages, and it is found in French: le roi des rois 'the king of kings', title in antiquity designating the king of Persia and in modern history, the king of France. We still say la reine des reines 'the queen of queens'. Le Solfège des solfèges will designate a book of solfège (music theory) considered by its author as the book of solfège par excellence.

$\$ 5$ A variant of this same procedure has made a fortune in advertising: la reine des montres et la montre des reines 'the queen of watches and the watch of queens', le roi des tabacs et le tabac des rois 'the king of tabaccos and the tabacco of kings'.

238. V. Gougenheim, La repetition distinctive, Le Français moderne, III, p. 345.

239. First editors' note: See C. Brockelmann, Grundriss der Vergleichenden Grammatik der semitischen Sprachen, Berlin, 1913, t. II, p. 256. 
$\$ 6$ The noun transferred to an adjective in this manner plays merely a reinforcing role, since it does not add anything semantically to the original noun. This is why one might baptize the category of this type of adjective with the term quiddity, which we have already adapted for the analogous adverb (cf. Chapter 37, \$35).

$\$ 7$ Adjectives of quiddity are hence often content to indicate what the content of the noun consists of to which they have been subordinated. They have no semantic value, but rather just structural value.

$\$ 8$ In a certain number of languages, and in particular in French, the nouns can be transferred to an adjective of quiddity by way of a preposition: Fr. la ville de Paris 'the city of Paris' (cf. Stemma 313), le pays de France 'the land of France', un amour d'enfant 'a dear kid', lit. 'a love of kid', un fripon d'enfant 'a mischevious kid', lit. 'a rascal of kid' (La Fontaine, Fables, IX, 2) (cf. Chapter 69, §16).

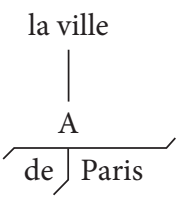

\section{Stemma 313}

$\$ 9$ Due to an error attributable to laziness of intellect, many grammarians teach that the preposition de is an expletive in an expression like la ville de Paris 'the city of Paris'. Indeed, we have already seen (Chapter 27, \$10f.) what should be thought of the expletive and for this reason, the term expletive should be banned from grammar terminology.

$\$ 10$ A noun that governs another noun, the latter having been transferred to an adjective of quiddity, can be most any noun: ville 'city', pays 'land, country', etc. But it often has a marked value and is diminutive-like (amour 'love', bijou 'jewelry', etc.), Fr. un amour de petit chapeau 'a dear little hat', ce magicien de Jaques 'this magician Jack'(A. Lichtenberger, Petite Madame, p. 278.

$\$ 11$ However, most often the affective value of these expressions is completely pejorative (fripon 'rascal', etc.): cet assassin de Wardes 'this assassin Wardes' (A. Dumas, Le Vicomte de Bragelonne, Comment il est bon d'avoir deux cordes à son arc), La Grèce est un traître de pays 'Greece is a treacherous country', lit. 'Greece is a traitor of country' (E. About, Le Roi de montagnes, IV, toward the end), coquin de sort! 'devil!', lit. 'rascal of fate', that is 'mischievous fate.

$\$ 12$ These allusions, which are hardly flattering to the ineptitude and bestiality of primitive mankind, are particularly frequent: cet âne de Durand 'this ass Durand', ce cochon de Morin 'this slob Morin' (title of a tale by Guy de Maupassant).

$\$ 13$ The expression can also easily take on a pejorative value even when the governing susbstantive alone has no pejorative meaning: sa pipelette de mère 'his talkative mother', 
lit. 'his chatterbox of mother' (A. Lichtenberger, Petite Madame, p. 175), leur concierge de maman 'their gossipy mother', lit. 'their caretaker of mother' (Robert de Beauplan, Petite Illustration, June 1,193), mon économiste de frère 'my economist of a brother' (heard in 1940), ton curé d'oncle 'your priest of an uncle' (heard in 1935), son pharmacien de père 'your pharmacist of a father' (Notre vieux lycée, Bulletin de l'Association des Anciens Elèves au Lycée Corneille de Rouen, 64, p. 299), ses deux vieilles filles de sœurs 'his two old-maidish sisters' (Duhamel, Le notaire du Havre, VII, p. 116).

$\$ 14$ The governing noun can be a personal noun:

Sagnarelle: Est-ce là la malade?

Géronte: Oui, je n'ai qu'elle de fille.

(Molière, Le Médecin malgré lui,II, 4)

Nous étions onze enfants dans

la famille, moi seule de fille,

(Sept frères tués au front,

Paris-Soir, 20-XII, 1936)

\author{
'Sagnarelle: Is that the sick person? \\ Géronte: Yes, I only have her \\ as a daughter.' \\ 'We were eleven children in \\ the family, me the only (one of) \\ daughter.' \\ ('Seven brothers killed in action')
}

\$15 The noun transferred to an adjective of quiddity by the translative de cannot be expressed when it is represented by the general adjective en 'of it', which refers anaphorically to the complete syntactic phrase introduced by the preposition $d e$ 'of' (cf. Chapter $60, \$ 10$ ).

\begin{tabular}{ll}
$\begin{array}{l}\text { Blandin: Ah! En voilà un vie. } \\
\text { (Henri Lavedan, Viveurs, Act II, p. 159) }\end{array}$ & 'Ah! There's one life' \\
$\begin{array}{l}\text { Claudine: En voilà un mufle! } \\
\text { (Henri Lavedan, Viveurs, Act II, p. 141) }\end{array}$ & 'Here is a lout!' \\
\hline
\end{tabular}

\$16 The adjective of quiddity exists in Italian and Spanish like it does in French: It. quel lazzarone di Giovanni 'this lout John', Sp. este picaro de Juan 'this lout John'.

$\$ 17$ The expression has passed from Italian to Serbo-Croatian, and one finds it in Ragusa of the 16th century ovaj vil od gospod, lit. 'this nymph of women' (cf. Vaillant, Zlatarić, \$485).

\$18 This expression stems from Latin where the transfer of a noun to an adjective of quiddity is marked - it is at least less familiar - by the use of the genitive that is called explicative: ${ }^{240}$ deliciae pueri 'jewel of a child', selus pueri 'a lout of a child', monstrum mulieris 'a monster of a woman', id lucre 'this profit', lit. 'this of profit', nihil novi, Fr. rien de neuf 'nothing (of) new.'. 41

240. Cf. Riemann and Ernout, Synaxe latine, $\$ 49$ and remark.

241. Riemann and Goelzer, Grammar latine complete, p. 290. 
$\$ 19$ The same expression is signaled in Irish by L. Sjoestedt Jonval: dochtúir mná 'a woman doctor', lit. 'a doctor of a woman. ${ }^{242}$

$\$ 20$ But in most languages, nouns cannot be transferred to adjectives of quiddity, and one has to be content with using an apposition instead. Such is the case in Latin: urbs Roma 'the city of Rome'. Similarly, one says die Stadt Paris 'the city Paris' in German.

\section{Chapter 196. Inverse sustantival and adjectival transfer}

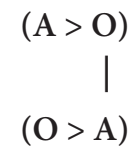

\$1 Transfer is inverse when an adjective transferred to a noun governs a noun transferred to an adjective of quiddity (cf. Chapter 195): Fr. un imbécile de marmiton, lit. 'an imbecile of kitchen hand' (Stemma 314) vs. un marmiton imbécile 'an imbecile kitchen hand', cf. Chapter 164, \$8-10.

\$2 Inverse transfer furnishes French with a means of foregrounding an adjective in a manner that other languages accomplish with word accent. In French, where word accent is final and moreover rather weak, one generally puts accent on the adjective because it is normally positioned after the noun in the spoken chain. In this area, one should take note of the fact it is contrary to the spirit of the French language to reinforce this accent. Instead, it is more convenient to overcome this inability by way of subterfuge in the form of inverse transfer. While inverse transfer does not change the position of the word accent, it does emphasize the importance of the adjective (that has been transferred to a noun), because it places the adjective in front of the noun that has been transferred to an adjective.

$\$ 3$ This process is strongly favored in French: Le bleu de Prusse 'the blue of Prussia, Prussian blue (also cyanide)' (cf. Chapter $38, \$ 8$ ), ce petit malin de Lulli 'this crafty Lulli' (Jules Chancel, Petit marmiton grand mucisien, Paris Delagrave, 1938, p 80), ce railleur de Jacques 'this mocker Jack' (A. Lichtenberger, Petite Madame, p. 233), cet imbécile de Durand 'this imbecile Durand', ces imbéciles heureux d'actionnaires, 'these happy imbecile shareholders' (Vendredi, January 1, 1937), cet idiot de Dupont 'this idiot Dupont', un cher stupide de petit mari 'a dear stupid little husband'(A. Lichtenberger, Petite Madame, p. 87), ce brutal de Jacques 'this brute Jack' (A. Lichtenberger, Petite Madame, p. 279).

$\$ 4$ A noun transferred to an adjective is often announced, reinforced, or replaced by the general adjective en, which refers anaphorically to an antecedent: Coupeau, très blagueur, en lança une bonne 'Coupeau, a real jokster, put forth a good (one)' (Zola, L'Assommoir,

242. J. Vendryes, Bulletin de la Société de Linguistique de Paris, volume 40, accounts rendered, p. 113. 
Chapter III, p. 91). The adjective en replaces a syntactic phrase introduced by the preposition de (Chapter $60, \$ 10)$ and one unconsciously completes it with something like une bonne, de blague 'a good joke'.

\$5 The noun transferred to an adjectival subordinate adjective can be a personal noun. Such is the case in the expression Pauvre de moi! 'Poor (of) me', which seems above all to be spread throughout middle French and in particular among speakers who have an affinity for Spanish (cf. Chapter $75, \$ 7$ ). A certain author puts it frequently in the mouth of a good grandmother whose origin is Spanish (cf. note 121).

$\$ 6$ The governor is frequently the indefinite article un transferred to a noun: Fr. un des jeunes 'one of the youths', un des vieux 'one of the old men', un de mes amis 'one of my friends'.

$\$ 7$ In this case, as was the case in $\$ 4$, the noun transferred to an adjective is often announced anaphorically by the general adjective en: Mais il y en avait un, alors, de coeur qui m'aimait pour tous 'But there was one, then, a heart that loved me for all' (Lamartine, Geneviève, CXXX), Moi, dit Attilio - j'en ai un, d’oncle, un frère à ma mère 'Me, said Atillio, I have one, an uncle, a brother of my mother' (Louis Bertrand, L'invasion, II, 1, p. 137), Tu n'en connais pas un, d'avocat ? 'You don't know one, a lawyer?' (ibid, III, 4, p. 307), J'en ai une, de cave, une vraie 'I have one, a cellar, a real one' (Martin du Gard, Les Thibault, VIII, 2, p. 37).

$\$ 8$ The adjective seul, which implicitly contains the meaning of un can figure in the same conditions in inverse transfer: Il est tout seul $(\mathrm{A}>\mathrm{O})$ de charpentier ' $\mathrm{He}$ is the sole carpenter' $(\mathrm{O}>\mathrm{A})$.

$\$ 9$ Number adjectives can be transferred under the same conditions as the indefinite article un: J'en ai eu deux, trois, peut-être bien quatre, de mères 'I had two, three, or maybe even four of them, mothers' (Lamartine, Geneviève, CXXXVII).

\$10 The un that has been transferred to a noun and that appears in inverse transfer can also govern the general adjective autre: En voilà un autre, pourtant, de triomphe 'Here is another one of them, yet, a triumph' (Lamartine, Geneviève, CXXX).

\$11 Inverse transfer can have a possessive pronoun as a governor, that is, an adjective of belonging that has been transferred to a noun (Chapter $178, \$ 5$ ). This expression no longer occurs in proper literature, but it occurs frequently in colloquial speech. Take for example the following situation: A spectator leaves his new hat in the cloakroom of a theater. After the performance, a thief profiting from the confusion seeks to steal the hat. The spectator sees what is happening in time. His normal reaction is to hurry to the thief and cry out: C'est le mien, de chapeau! 'That is mine, the hat!'. In a parallel case, the German speaker would employ an accent of insistence: Es ist MEIN Hut! 'That is MY hat!'

$\$ 12$ Although it is considered incorrect, this expression can be found with authors who are interested in producing colloquial speech: Demande donc à ton père s'il se gênera pour 
enlever le sien, de veston 'Ask your father if he will mind taking off his, (his) jacket' (Jean Sarment, Le voyage à Biarritz, Petite Illustration, 7-XI-1936, p. 4).

$\$ 13$ Inverse nominal and adjectival transfer is not unique to French. One finds it in Italian, Spanish, and English as well: It. quell'imbecille di Giovanni 'what imbecile of Giovanni', Sp. este imbececil de Juan 'this imbecile of John', Eng. his brute of a brother.

$\$ 14$ The process is nothing new. One finds it in Latin: multum auri 'a lot of gold', lit. much of gold'. The governing term of this expression is the adjective multus 'much' transferred to the neuter noun multum, whereas the subordinate term is the noun aurum 'gold' transferred to an adjective of quiddity by the use of the genitive auri.

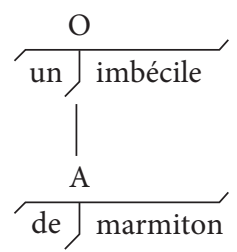

Stemma 314

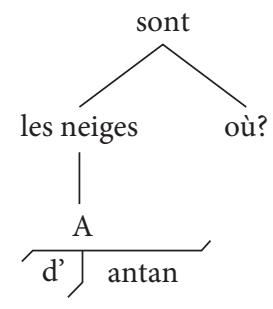

Stemma 315

\section{Chapter 197. Transfer of an adverb to an adjective (E $>A)$}

\$1 Even though it does not occur too frequently, transfer of an adverb to an adjective is far from unheard of. In French the marker of this type of transfer is principally the translative de: Mais où sont les neiges d'antan? 'But where are the snows of long ago?' (Villon, Le grand Testament, Stemma 315), la mode d'aujourd'hui 'the fashion of today', les modes d'hier et de demain 'the fashions of yesterday and tomorrow', un verre de trop 'one too many', lit. 'a glass of too'.

$\$ 2$ But this transfer can also occur without a marker. It is common to say C'est un homme bien 'It's a good man', lit. 'It's a well man', C'est un monsieur très bien 'It's a very good gentlemen' (Chapter 74, §9), Je me sens mal 'I feel bad', lit. 'I feel badly', and in a familiar and neglected style: C'est sur du papier comment ? 'It's on paper how?'.

$\$ 3$ An adverb that is transferred to an adjective without a marker is sometimes encountered preceding the noun of which it becomes a subordinate, and in so being, it builds a biradical compound form with the noun: l'avant-scène 'the foreground', l'arrière-saison 'the postseason', une arrière-boutique 'a back shop'.

$\$ 4$ The transfer of an adverb to an adjective without a marker is not unknown in Latin: omnis circa regio 'all the surrounding country', deorum saepe praesentiae 'from the frequent 
appearances of the Gods' (Cicero, De natura deorum), ${ }^{243}$ rusticanus vir, sed plane vir 'a man of the land, but a man who has mastered the word' (Cicero, Les Tusculanes, II, 22, 53).

\$5 With reference to this same sort of transfer, one can explain the origin of the indeclinable Latin adjective nequam 'worthless': homo nequam 'a hoodlum'.

$\$ 6$ The transfer of an adverb to an adjective with a marker is common in Greek: he ánō pólis 'the high city', ohi kátō theoi ' the gods of the underworld', ohi pálai ánthrōpoi 'the men of old, the ancients', apò tồ pánu arkhaiou 'since high antiquity'.

$\$ 7$ In German, one also finds transfer of an adverb to an adjective without a marker: Herr so und so 'Mr. so and so'.

$\$ 8$ Temporal and locative adverbs in German employ the derivational suffix -ig: morg-ig 'tomorrow's', gestrig 'yesterday's.

$\$ 9$ In Russian the derivational suffix -nij is used: $z d e s ̌-n i j$ 'from here', tamoš-nij 'from down their'.

\section{Chapter 198. The participle}

\$1 The transfer of a verb to an adjective can take place without a marker: Fr. la gent trottemenu 'mice', lit. 'the trot-slim gent' (La Fontaine, Fables, III, 18, Le chat et un vieux rat 'The cat and an old rat').

\$2 However, the most commonly used means to perform this transfer is to use the participle as the marker. Just like when the verb is transferred to a noun by using the infinitive (cf. Chapter 180, \$1), a verb transferred to an adjective is accomplished with the participle.

$\$ 3$ A participle has characteristics of both a verb and an adjective: a verb by the source it comes from and an adjective by the target it is.

$\$ 4$ It takes part both in the category of the verb and in the category of the adjective. For this reason, Greek grammarians gave the participle the name metokhikón, derived from the verb metékho 'I participate', which was translated by Latin grammarians to participium.

$\$ 5$ Greek grammarians, who were careful analysts of syntax, recognized the double nature of the participle early on, and from this point of view, one can only subscribe to the appellation that this observation suggested to them.

$\$ 6$ The term that they chose would have even been perfect if it had not the unfortunate property of being applicable to all other similar categories that undergo transfer, for example, to the infinitive (cf. Chapter 180), to the gerondive (cf. Chapter 224, \$10ff.), to the pronoun (cf. Chapter 18, $\$ 2$ and 3), etc.

243. Cf. Riemann \& Goelzer, Grammaire latine complète, pp. 76 and 231. 
\$7 The participle is not a verb. This fact is apparent in the particular manner that it reacts to diathesis.

$\$ 8$ Certainly it can occur that a participle exists in the active as well as the passive diathesis. Such is the case in Russian, where the passive stands in contrast to the active just as the concomitant participle stands opposed to the anterior participle.

\begin{tabular}{|c|c|c|c|}
\hline & & Active & Passive \\
\hline \multirow{2}{*}{ Participle } & Concomitant & nësuščij 'carrying' & nesom $(y j)$ 'being carried' \\
\hline & Anterior & nësšij ‘having carried' & nesën $(y j)$ 'having been carried' \\
\hline
\end{tabular}

$\$ 9$ Moreover, most languages tend to limit the active diathesis to the concomitant participle and the passive diathesis to the anterior participle. Such is the case in French in particular, where the concomitant participle (so-called present participle) is active (portant 'carrying'), whereas the anterior participle (so-called past participle) is passive (porté 'carried').

$\$ 10$ However, the notion of diathesis is much more hesitant in the participle than it is in the verb (cf. Chapter 102, $\$ 10,13$, and 14): Fr. une couleur voyante 'a loud color', lit. 'a seeing color', une rue passante 'a busy street', lit. 'a passing street'.

$\$ 11$ Similarly, the participle no longer receives the verb's ability to be compatible with the category of mood or with the category of tense. Confronted with the future past (conditional), e.g. Fr. Je serais, je ferais 'I would be, I would do', and the future Je serai, je ferai 'I will be, I will do', there is no conditional or future participle, even though these forms are morphologically possible: ${ }^{*}$ serant, ${ }^{\star}$ ferant.

$\$ 12$ However, Greek conserves the faculty to produce the participle with conjectural mood and to construct the participle with the conjectural particle án, just as it can with the infinitive, and probably for the same reason (cf. Chapter 186, \$31): Oîdá se toût’àn poiésanta ei edúnō 'I know that you would have done it, had you been able to'.

$\$ 13$ Greek also conserves the faculty to produce the participle in different tenses. Thus it has a future participle: Oud' ho kōlúsōn parên 'There was nobody to stop us' (Sophocles).

$\$ 14$ The participle no longer receives the faculty from the verb to react to the notion of person. That is why one attributes to it, like to the infinitive, the impersonal moods (cf. Chapter 188, \$1).

\$15 The first actant of the participle is also normally the noun to which it is subordinate:

N'est-ce point à vos yeux un spectacle assez doux

Que la veuve d'Hector pleurant à vos genoux?
'Is it not a sweet enough spectacle to your eyes

That Hector's widow mourns in your lap?'

(Racine, Andromaque, III, 4) 
It is evident that the first actant of pleurant 'mourning' is la veuve d'Hector 'Hector's widow'

\$16 Moreover, speakers often overlook this particularity, above all when they write, and in particular in journalistic style, which inevitably leads to ambiguities that are sometimes amusing: Seriously wounded, the doctor had the sixty-year old transported to the hospital. The result of this redaction is that the first actant of wounded is the doctor, and as a consequence, the doctor is the one who is wounded.

$\$ 17$ However, the participle retains the faculty, from the verb from which it stems, to be the governor of actant and circumstant subordinates (Chapter 180, §4).

$\$ 18$ Thus the participle governs the second actant mythology in a book recounting mythology to children.

$\$ 19$ The participle governs a circumstant, the adverb subitement 'suddenly', in Changeant subitement les drapeaux en haillons 'Suddenly changing the flags in tatters' (V. Hugo, Les Châtiments: L'expiation) (cf. also Moufflet, Contre le Massacre de la langue française, I (1930), p. 244.).

$\$ 20$ The governed circumstant is an adjective transferred to an adverb by transfer without a marker (cf. Chapter 205, \$16) in Légère et court vêtue... 'Light and short dressed..., that is 'Light and wearing a short dress...' (La Fontaine, Fables, VII, 10, La laitière et le pot au lait 'The milkwoman and the milk pot').

\$21 Conversely, the participle acquires the faculty to assume the role of an attribute from the adjective that it becomes (cf. Chapter $63, \$ 5$ ), and the role of a predicative expression (cf. Chapter 66 and 68), and the role of an apposition (cf. Chapter 70).

$\$ 22$ The participle assumes the role of an attribute in a book recounting mythology to children,

Mieux vaut goujat debout qu'empereur enterré.

(La Fontaine, Contes et Nouvelles:

La Matronne d'Ephèse)

Ventre affamé n'a point d'oreilles. (La Fontaine, Fables, IX, 17, Le milan et le rossignol)
'A standing boor is worth more than a buried emperor.'

'A hungry stomach has no ears.', lit. 'starved stomach ...'

$\$ 23$ The participle assumes the role of a predicate on the first actant in a number of valued idiomatic expressions from Greek: Adikeî Sōkrátēs kainá daimónia eisphérōn 'Socrates is guilty of introducing new divinities, lit. 'Socrates is guilty introducing new divinities'; Etúgkhane tuphlòs ốn 'He found himself to be blind', lit. 'He found himself being blind', Dēlos èn humîn epibouleúōn 'It was evident that he conspired against us', lit. 'He was evidently conspiring against us'; Élathen elthốn 'He arrived without one taking note of it', lit. 'He remained hidden coming'; Epuásato makhómenos 'He ceased to struggle', lit. 'He 
ceased struggling'; Oîda pénēs ón 'I know that I am poor', lit. 'I know being poor'; Phaneròs ê̂ prosión 'One sees that you are coming', lit. 'You are visible coming'.

$\$ 24$ The participle assumes the role of a predicate over the second actant in Latin: Vidi eum ingredientem 'I saw him enter', lit. 'I saw him entering'; Audivi eum canentem 'I heard him sing', lit. 'I heard him singing', and in Greek: Apophainō toûton pseudómenon 'I am showing what it means', lit. 'I show it meaning'; Horō se prosíonta 'I see you come', lit. 'I see you coming'; Aisthánomai autòn humîn epibouleoúnta 'I perceive that he is conspiring against you', lit. 'I perceive of him conspiring against you'.

$\$ 25$ The participle assumes the role of an apposition in:

\begin{tabular}{|c|c|}
\hline $\begin{array}{l}\text { Un moment elle est gaie, } \\
\text { un moment sérieuse, } \\
\text { Riant, pleurant, jasant, } \\
\text { se taisant tour à tour. }\end{array}$ & $\begin{array}{l}\text { 'One moment she is happy, } \\
\text { another serious, } \\
\text { Laughing, crying, chatting, } \\
\text { being quiet in turn.' }\end{array}$ \\
\hline \multicolumn{2}{|c|}{ (Destouches) } \\
\hline
\end{tabular}

\$26 In sum, the inferior connections of the participle are those of a verb, whereas the superior connections are those of an adjective.

$\$ 27$ First-degree transfer I > A occurs when a sentence word is transferred to an adjective, generally without a marker: J'étais une idiote à l'instant de vous prêcher le bonheur honnête et ran-plan-plan 'I was an idiot at the moment when I preached honest happiness to you and ratta-tap-tap' (H. Lavedan, Viveurs, IV).

\section{Chapter 199. The participle clause}

\$1 When a verb is transferred to an adjective by the use of a participle, the node that it constitutes receives the name participle clause: (a book) recounting mythology to children.

\$2 Like the infinitive clause to which it corresponds but on the adjectival plane, the participle clause arises from first-degree transfer (cf. 182, \$2).

$\$ 3$ For this reason, clauses such as This book recounts mythology to children nicely is susceptible to being transferred to the participle clause (a book) nicely recounting mythology to children.

$\$ 4$ The attributive participle clause is very frequent in German prose. The participle, while retaining all of its inferior connections, obeys the same rules of adjective agreement as an attributive adjective: ein heute Abend im Stadtheater in Gegenwart verschiedener berühmter Musiker stattfindender Konzert 'a concert that took place this evening in the municipal theater in the presence of different musicians', lit. '...taking place...; ein jeden Abend zu seinen Eltern nach Hause zurückkehrender Gymnasiast 'a high-school student (who is) returning home to his parents every evening. 
\$5 The usage of the participle to transfer an independent sentence to a participle clause is common in Turkish: beni gören adam 'the man who sees me', lit. 'the man seeing me'.

$\$ 6$ The use of the participle olan 'being', from the nominal verb olmak 'be', is commonly used in Turkish to transfer an independent nominal sentence to an adjective: evi olan bir adam 'a man who possesses a house', lit. 'a man his house being', evi büyük olan bir adam 'a man whose house is big', lit. 'a man his house being big', yüzü kara olan bir adam 'a man whose appearance is black', lit. 'a man his appearance being black', and in the negative saçı sart olmayan bir adam 'a man whose hair is not blond', lit. 'a man his hair not being blond', çocuğu güzel olmayan bir karı 'a woman whose child is not happy', lit. 'a woman her child not being pretty'.

\$7 More often than not, the positive participle olan from the nominal verb is not expressed in Turkish and instead of saying yüzü kara olan bir adam 'a man whose appearance is black', lit. 'a man his appearance being black', one commonly says yüzü kara bir adam, lit. 'a man his appearance black', likewise for saçı sarı (olan) bir adam 'a man whose hair is blond. These participle clauses that lack an overt participle remind one of infinitive clauses without an overt infinitive (cf. Chapter 182, \$20).

$\$ 8$ In particular, the participle olan with a verbal noun ending in -ecek (-acak) is generally not expressed with the anontive: yarm beni görecek (olan) adam 'the man who will see me tomorrow'.

$\$ 9$ The governing noun can no longer be expressed, in which case the attributive adjective is necessarily transferred to a noun (cf. Chapter 177, \$4 and 5): başı bozuk '(a man) whose head is spoiled', lit. '(a man) his head spoiled', that is 'a desperado, an irregular soldat, a bashibazouk".

\$10 While Turkish, in order to transfer a clause to an adjective, frequently makes use of the clausal participle, which is first-degree transfer, this does not mean that it is unknown to second-degree transfer. It is not impossible in Turkish to say bir adam ki evi var'a man who possesses a house', lit 'a man his house is present', etc. (cf. Chapter 250, \$16).

$\$ 11$ But this is an expression borrowed into Turkish. Turkish prefers first-degree transfer by way of a participle or a verbal noun when available.

$\$ 12$ In Basque, the transfer of a verb to an adjective is the same as that of a noun to an adjective, a fact that confirms what we have said above concerning the lack of distinction between verb and noun (cf. Chapter 188, \$25, 27 and 29).

$\$ 13$ This transfer is assured in the two cases by the translative suffix -en of the indefinite genitive, which, added to the noun verb as a personal mood, forms what Gèze calls a pronominal form, ${ }^{244}$ and Lafitte conjunctive mood. ${ }^{245}$

244. Eléments de grammaire basque, p. 129.

245. Grammaire basque, p. 394. 
\$14 Thus in Basque one also says Pierres-en lana 'the work of Peter', as well as egin du-en lana 'the work that he did', lit. 'the work of he did it'.

\section{Chapter 200. Evolution of the participle}

\$1 The double nature of the participle is inherent in the actual notion of this nucleus. It is also not surprising that one encounters this concept as far back as one can reconstruct the history of the participle.

\$2 E. Benvéniste has shown that the oldest forms of the participle with ${ }^{*}(e / o) n t$ - and verbal adjectives with ${ }^{*}-(e / o) n d$ - in Indo-European rest on the base of a nominal verb form by the adjunction of the nominal suffix *-en-.246

$\$ 3$ However, at the same time he recognized that the oldest conception of the participle in Indo-European was more indecisive, less clear, and "less strictly delimited" than it is in the majority of Indo-European languages. ${ }^{247}$

$\$ 4$ At a modern date, the comparison of the value of the different participle forms shows us that one is dealing, as with the infinitive (cf. Chapter 181, $\$ 1$ ), with a nucleus that is in full evolution. Hence in French the concomitant participle (so-called present participle) is in a stage of evolution less advanced than the anterior participle (so called past participle). $\$ 5$ Indeed, whereas the concomitant participle retains its indifference toward nominal categories of gender and number - it gets this indifference from the verb - and is thus invariable, the anterior participle has already acquired the adjectival faculty of agreeing in gender and number with the noun to which it is subordinated:

\begin{tabular}{ll}
\hline $\begin{array}{l}\text { Concomitant (present) } \\
\text { invariable participle }\end{array}$ & \multicolumn{1}{c}{$\begin{array}{c}\text { Anterior (past) } \\
\text { variable participle }\end{array}$} \\
\hline $\begin{array}{l}\text { une causeuse charmant } \\
\text { ses auditeurs } \\
\text { 'an orator charming } \\
\text { her auditors' }\end{array}$ & $\begin{array}{l}\text { une auditrice charmée } \\
\text { par l'orateur }\end{array}$ \\
$\begin{array}{l}\text { 'an auditor charmed-FEM-SG } \\
\text { by the orator' }\end{array}$ \\
$\begin{array}{l}\text { 'eurs champs moissonnant } \\
\text { farmers harvesting }\end{array}$ & $\begin{array}{l}\text { Heureux les épis mûrs et les blés } \\
\text { moissonnés. (Péguy, Eve) } \\
\text { 'Happy with the ripe corn and } \\
\text { des partisans convainquant } \\
\text { les néophytes } \\
\text { 'partisans defeating } \\
\text { the neophytes' }\end{array}$ \\
\hline
\end{tabular}

246. Origine de la formation des noms en indo-européen, pp. 128, 144, and 177.

247. Ibid., p. 126. 
$\$ 6$ Just as the evolved infinitive gives rise to the verbal noun (cf. Chapter $181, \$ 7$ ), the evolved participle gives rise to the verbal adjective.

\$7 The verbal characteristics of both the verbal adjective and the verbal noun are fading and are in the process of disappearing, whereas the adjectival-nominal characteristics are becoming increasingly pronounced.

$\$ 8$ In French, the verbal adjective is in a stage of transfer that is further evolved than that of the anterior participle.

$\$ 9$ Like the anterior participle, the verbal adjective stands in opposition to the concomitant participle insofar as it agrees in gender and number with the noun to which it is subordinated (cf. Chapter 158, \$5).

\begin{tabular}{|c|c|}
\hline Concomitant participle & Verbal adjective \\
\hline $\begin{array}{l}\text { une rue passant par le centre de la ville } \\
\text { 'a street passing by the town center' }\end{array}$ & $\begin{array}{l}\text { une rue passante } \\
\text { 'a busy street', lit. 'a passing-FEM-SG street' }\end{array}$ \\
\hline $\begin{array}{l}\text { un causeuse charmant ses auditeurs } \\
\text { 'a speaker charming her auditors' }\end{array}$ & $\begin{array}{l}\text { une femme (causeuse) charmante } \\
\text { 'a charming-FEM-SG woman' }\end{array}$ \\
\hline $\begin{array}{l}\text { J'ai rencontré la garde montant } \\
\text { prendre son poste. } \\
\text { 'I encountered the guard ascending } \\
\text { to take his post' }\end{array}$ & $\begin{array}{l}\text { La garde montante remplacera } \\
\text { la garde descendante. } \\
\text { 'The asending-FEM-SG guard will replace } \\
\text { the descending-FEM-SG guard.' } \\
\text { (Meihac \& Halévy, Libretto of Carmen, I) }\end{array}$ \\
\hline
\end{tabular}

\$10 However, the verbal adjective also stands in contrast to both the concomitant participle and the anterior participle regarding two traits that it takes from the verb and extends to the adjective.

$\$ 11$ The participles remain verbal forms in their orthography, whereas the verbal adjective frequently permits a different and generally simpler orthography (cf. Chapter 158, \$6).

\begin{tabular}{|c|c|}
\hline Concomitant participle & Verbal adjective \\
\hline $\begin{array}{l}\text { un raisonnement convainquant les auditeurs } \\
\text { 'an argument persuading the listeners' }\end{array}$ & $\begin{array}{l}\text { un raisonnement convaincant } \\
\text { 'a convincing argument' }\end{array}$ \\
\hline $\begin{array}{l}\text { une drogue provoquant de nausées } \\
\text { 'a drug provoking nausea' }\end{array}$ & $\begin{array}{l}\text { une toilette provocante } \\
\text { 'a provocative outfit' }\end{array}$ \\
\hline $\begin{array}{l}\text { une fume suffoquant les pompiers } \\
\text { 'smoke suffocating the firemen' }\end{array}$ & $\begin{array}{l}\text { une chaleur suffocante } \\
\text { 'stifling heat' }\end{array}$ \\
\hline $\begin{array}{l}\text { un homme vaquant à ses occupations } \\
\text { 'a man attending to his business' }\end{array}$ & $\begin{array}{l}\text { un employ vacant } \\
\text { 'a vacant job' }\end{array}$ \\
\hline $\begin{array}{l}\text { un courtisan intriguant pour obtenir une faveur } \\
\text { 'a courtisane scheming to obtain a favor' }\end{array}$ & $\begin{array}{l}\text { un courtisan très intrigant } \\
\text { 'a conniving courtesane' }\end{array}$ \\
\hline $\begin{array}{l}\text { deux arguments différant l'un de l'autre } \\
\text { 'two arguments differing from each other' }\end{array}$ & $\begin{array}{l}\text { deux arguments très différents } \\
\text { 'two very different arguments' }\end{array}$ \\
\hline $\begin{array}{l}\text { la semaine precedant l'examen } \\
\text { 'the week preceding the exam' }\end{array}$ & $\begin{array}{l}\text { la semaine immédiatement précédente } \\
\text { 'the immediately preceding week' }\end{array}$ \\
\hline
\end{tabular}


$\$ 12$ The inferior connections of the participle continue to be those of a verb, whereas the inferior connections of the verbal adjective are those of an adjective.

$\$ 13$ Hence the participle remains susceptible to governing an actant, whereas the verbal adjective loses this ability and can hence govern only an adverb (cf. Chapter 158, \$4).

\begin{tabular}{|c|c|}
\hline Concomitant participle & Verbal adjective \\
\hline $\begin{array}{l}\text { une femme attachant le collier } \\
\text { de son chien } \\
\text { 'a woman attaching the dog collar' }\end{array}$ & $\begin{array}{l}\text { une femme très attachante } \\
\text { 'a very appealing woman' }\end{array}$ \\
\hline $\begin{array}{l}\text { une rue passant par le centre de la ville } \\
\text { 'a street passing by the town center' }\end{array}$ & $\begin{array}{l}\text { une rue très passante } \\
\text { 'a very busy street' }\end{array}$ \\
\hline $\begin{array}{l}\text { une causeuse charmant ses auditeurs } \\
\text { 'a speaker charming her auditors' }\end{array}$ & $\begin{array}{l}\text { une causeuse charmante } \\
\text { 'a charming speaker' }\end{array}$ \\
\hline $\begin{array}{l}\text { J'ai recontré la garde montant } \\
\text { prendre son poste. } \\
\text { 'I encountered the ascending } \\
\text { guard taking his post.' }\end{array}$ & $\begin{array}{l}\text { La garde montante remplacera } \\
\text { la garde descendante. } \\
\text { 'The arriving guard will replace } \\
\text { the departing guard.' } \\
\text { (Meilhac \& Halévy, Libretto of Carmen, I) }\end{array}$ \\
\hline $\begin{array}{l}\text { une accusé convaincu de fraude } \\
\text { 'a defendant convicted of fraud' }\end{array}$ & $\begin{array}{l}\text { une spirite absolument convaincue } \\
\text { 'an absolutely convinced spiritualist' }\end{array}$ \\
\hline
\end{tabular}

$\$ 14$ The same distinction exists in Latin where the concomitant participle remains susceptible to governing a second accusative actant, whereas the participle that has become an adjective can only govern a noun that has been transferred to an adverb by way of a genitive translative.

\begin{tabular}{ll}
\hline Comcomitant participle & Verbal adjective \\
\hline $\begin{array}{l}\text { miles patiens frigus } \\
\text { a soldier who is suffering } \\
\text { from the cold' }\end{array}$ & $\begin{array}{l}\text { miles patiens frigoris } \\
\text { 'a soldier who knows how } \\
\text { to endure the cold' }\end{array}$ \\
\hline
\end{tabular}

$\$ 15$ The verbal adjective, however, maintains the superior connections of an adjective that the participle acquired (cf. Chapter 198, \$21-25).

$\$ 16$ At the end of their evolution and to the extent that speakers lose consciousness of the original ties with the verb, participles behave in every way in a manner that is comparable to that of an infinitive that has become an action noun (cf. Chapter 181, \$8), and participles end up being indistinguishable from ordinary adjectives.

$\$ 17$ The adjectives with - ant therefore stemming from a former concomitant active participle, and the adjectives in é, $-u$, etc. stemming from former passive anterior participles are therefore very numerous in French: savant 'learned', puissant 'powerful', charmant 'charming', attrayant 'attractive', prévoyant 'far-sighted', poignant 'harrowing', bienveillant 'benevolent', malvaillant 'malicious' (< veuillant, ancient form of voulant 'wanting'), méchant 
(< meschéant, concomintant participle of the old verb méchoir 'fall badly'); éveillé 'awake', résigné 'accepting', varié 'varied', étoffé 'stout', aîné 'elder' (< ains-né 'born before'), puîné 'younger' (< puis-né 'then born'); fourbu 'exhausted' (anterior participle of the old verb fourboire), absolu 'absolute', tortu 'twisted' (former anterior participle of the verb tordre); cf. also $d u$ pain rassis 'stale bread'.

\$18 The adjective commonly takes on a form that is different and generally more archaic than the form of the participle, which is more modern and less evolved in transfer:

\begin{tabular}{ll}
\hline Verbal adjectve & Comcomitant participle \\
\hline bienveillant 'benevolent' & voulant 'hoping for' \\
savant 'learned' & sachant 'knowing' \\
vaillant 'valiant' & valant 'being worth' \\
\hline
\end{tabular}

$\$ 19$ At times the historical perspective permits one to see two forms of the adjective that precede the modern participle, the older of which conserves the participle form of Latin (as with the word savant 'learned'):

\begin{tabular}{lll}
\hline $\begin{array}{l}\text { French adjective } \\
\text { (elevated register, }\end{array}$ & $\begin{array}{l}\text { French adjective } \\
\text { (colloquial register) }\end{array}$ & French participle \\
\hline $\begin{array}{l}\text { im-potent 'impotent' } \\
\text { dé-cadent 'decadent' }\end{array}$ & $\begin{array}{l}\text { puissant 'powerful' } \\
\text { mé-chant 'malicious' }\end{array}$ & $\begin{array}{l}\text { pouvant 'being able to' } \\
\text { éant 'coming due' }\end{array}$ \\
\hline
\end{tabular}

\$20 The historical perspective sometimes permits one to see that what had already become an adjective in Latin and French was still a sort of participle in Indo-European: Indo-European ^plē-no-s 'filled' Latin > Fr. plein 'full' (cf. Chapter 74, §16).

\$21 Thus the passage of a verb into a language often leaves the residue of a derived nominal in its wake.

\$22 When the transfer of a verb to an adjective ceases to be productive, traces of it remain fixed in the form of adjectival derivational suffixes. Hence the French suffix -able/-ible generally retains up to this day the verbal notions of ability and the passive diathesis: maniable 'what can be handled' from manier 'handle', prévisible 'what can be foreseen' from prévoir 'foresee'.

$\$ 23$ In this case, they can be glossed by the adjective susceptible 'susceptible' governing the infinitive of the passive diathesis: susceptible d'être manié 'susceptible to being handled', susceptible d'être prévu 'susceptible to being foreseen'. 


\section{Chapter 201. Transfer of a noun to an adverb $(\mathrm{O}>\mathrm{E})$}

$\$ 1$ The transfer of a noun to an adverb is an extremely frequent phenomenon in languages.

$\$ 2$ This type of transfer most often occurs by way of a preposition, as for the transfer of a noun to an adjective (Chapter 192, \$2). Moreover, the preposition can be the same in both transfers: J'arrive de Paris 'I am arriving from Paris' vs. le livre de Pierre 'Peter's book'. Locative adverbials of this type are hence actually composed of a preposition (de) and a noun (Paris).

\$3 The nouns transferred to adverbs in this way can play the role of adverbial sentences. Such is the case with the expression $D u$ diable si...! 'The devil take me if...!', lit. 'From the devil if...!' (cf. Chapter 77, \$9).

$\$ 4$ Prepositions can transfer nouns to locative adverbs: on the table, Alfred lives in Montpellier (Stemma 316), from Paris to the sea, You will pass by Tarascon, in my room, at the baker, behind the barracks.

$\$ 5$ Prepositions can also transfer nouns to temporal adverbs: Peter gets up at eight o'clock, in the morning, He works during the evening class, by a nice spring day, before the hour, after all, since his very tender childhood.

\begin{tabular}{|c|c|}
\hline $\begin{array}{l}\text { Avant l'affaire } \\
\text { La roi, l'âne, ou moi, } \\
\text { nous mourrons. } \\
\text { (La Fontaine, Fables, VI, XIX) }\end{array}$ & $\begin{array}{l}\text { 'Before the event } \\
\text { the king, the dunce, or me, } \\
\text { we will die.' }\end{array}$ \\
\hline $\begin{array}{l}\text { Joseph arriva dès les chats. } \\
\text { (G. Duhamel, Le jardin des } \\
\text { Bêtes sauvages, p. 194). }\end{array}$ & $\begin{array}{l}\text { lit. 'Joseph arrived } \\
\text { from the cats.' }\end{array}$ \\
\hline
\end{tabular}

$\$ 6$ The adverb that results from transfer with a marker can also be an adverb of manner; Fr. à cour ouvert 'with an open heart', au petit bonheur 'haphazardly', lit. 'with a little happiness', de bon cour 'heartily', lit. 'of good heart', un monsieur très bien de sa personne 'a very good-looking gentleman', lit. 'a gentleman very nice of his person' (cf. Chapter 197, $\$ 2)$, Deux pigeons s'aimaient d'amour tendre 'Two pigeons loved themselves tenderly', lit. '...of tender love' (La Fontaine, Fables, IX, II); En. by car, act as a good man, with pleasure, without joy, for fun.

$\$ 7$ For the nouns that are transferred to manner adverbs, it is necessary to examine those for which transfer serves to mark a cause or a goal: agir à dessein 'act on purpose', dans le dessein de 'in order to'.

$\$ 8$ One can also examine adverbial transfers, expressions that one uses to construct certain verbs with a preposition, in particular the verbs with one actant, and certain adjectives as well: penser à quelqu'un 'think of someone', songer à quelque chose 'think about something', 
se souvenir de quelque chose 'remember something. In a sense, these combinations indicate the manner in which one thinks, contemplates, or remembers. Further, the expression s'amuser de quelque chose avec quelqu'un 'to amuse oneself about something with someone' specifies the conditions in which one is amused. And the expressions être fidèle à son serment 'be true to one's oath', prêt au depart 'ready to depart', étranger à une conspiration 'foreign to a conspiracy' indicate the manner in which one is true, ready, foreign.

$\$ 9$ One can place the use of on dirait 'one would say'- appearing with a noun preceded by the translative de - under the same rubric: On dirait d'un fou 'It looks (like being) from a madman', such is the way that one expresses one's observation regarding a person with a bizarre allure. [To be compared with On dirait un fou 'He looks like a madman'.]

$\$ 10$ The target resulting from $\mathrm{O}>\mathrm{E}$ transfer, for which the translative is a preposition, can be a resultative adverb (cf. Chapter $37, \$ 40 \mathrm{ff}, 130$ and $171, \$ 3$ ) that indicates the circumstance or condition under which the action expressed by the verb is realized: Er hat sich um den Verstand getrunken 'He drank himself into a stupor', Wir haben ihn unter den Tisch getrunken 'We drank him under the table'; Ein schöneres Wiegelied, Mutter, hat mich noch nie in den Schlaf gesungen 'Never has a more pleasant lullaby put me to sleep, Mother', lit. '...has sung me in the sleep' ${ }^{248}$ (cf. Chapter 37, \$41), Er soll heute nach London 'He should leave for London today' (cf. Chapter 37, \$43).

$\$ 11$ In most languages of Europe, there are prepositions, the principle purpose of which is to transfer nouns to different types of adverbs: Ital. sotto la tavola 'under the table', Sp. sobre las olas 'on the waves', Eng. on the table, Breton war an dôl 'on the table'.

$\$ 12$ Transfer by way of a preposition is encountered in certain language families outside of Europe: Samoan $i$ lea mea 'in this place'.

$\$ 13$ The translative, instead of being preposed, can be postposed. Instead of saying that one is dealing with a preposition, one says that one is dealing with a postposition. Postpositions are generally rare in our European languages, which tend to employ prepositions instead. But postpositions are far from being unknown in European languages. One even encounters them in French: quelques jours après 'a few days later', vingt ans après 'twenty years later'.

$\$ 14$ Although unusual, postpositions are also not completely absent from Latin and Greek: Lat. filii gratia 'for the love of his son', honoris causa 'for the sake of honor', Gr. tês húbreōs héneka 'due to this insult'. One has them even in Russian: Xrista radi 'for the love of Christ'. $\$ 15$ To transfer nouns to adverbs, the use of postpositions is, in contrast, the norm in a large number of languages, in particular in the Ural-Altaic languages, in Greenlandic, in Georgian, in Basque, etc. Turkish el ile 'with the hand', el-im-de 'in my hand', oda-da in the room', Tatar soras-ble 'with appetite', Hungarian a szobá-ban 'in the room', nyár-on 'in

248. A. Malblanc, Pour une stylistique comparée du français et de l'allemand, \$55. 
summer', a gyermek-kel 'with the child', Finnish kirkon kohdalla 'on the side of the church', viikon perästä 'one week later', last kanssa 'with the kids', Komi pir-vile 'with a feast', Udmurt bazar-je 'at the market', Mari temle-dene 'with appetite', Chuvash tuta-pa 'with appetite', Greenlandic nuna-me 'in the country', nuna-kut 'on the land', Georgian klas-š i in the class', Basque hiri-an 'in town', negu-an 'in winter', atsegin-ekin 'with pleasure'.

\$16 In the languages with prepositions, it can occur that the adverb resulting from transfer of a noun is reinforeced by a true adverb that reinforces its meaning. This occurs frequently in German: zum Fenster hinaus 'out the window', lit. 'to the window outside', von Kind auf 'from childhood on' (cf. Lat. a puero, Chapter 202, \$9), German von nun an 'from now on'; one must guard against misconstruing these postposed adverbs as postpositions.

$\$ 17$ It can occur that in time adverbial locutions agglutinate. They end up orthographically as real adverbs, the etymology of which is transparent: Fr. partout 'everywhere' $(<$ par tout 'by all'), debout 'upright' ( $<$ de bout 'from tip'), autour de 'around' ( $<$ au tour de 'to the round of'), afin de 'in order to' ( $<$ à fin de 'to end of'), etc. Rus. naizust' 'by heart'.

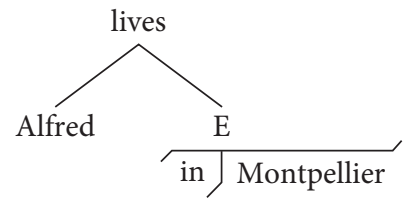

Stemma 316

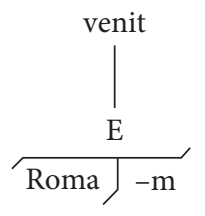

Stemma 317

\$18 The Slovenian adverbial locution po koncu 'upright' presents exactly the same transfer as the French agglutinated adverb debout. With this agglutination, the two languages have recourse to the same procedure in a manner that is entirely independent of each other, since the two nouns are etymologically unrelated: Fr. bout, Slovenian konec. This observation bears witness to the universality of transfer phenomenon and to the typological affinity of two idioms that are entirely distinct.

$\$ 19$ Concerning postpositions, they are most often agglutinated to the noun that they follow. In Latin, this is the case for the only frequently occurring postposition, which is cum employed as the translative of a personal noun: mecum 'with me', vobiscum 'with you' (cf. Chapter 161, §7).

\section{Chapter 202. Transfer of a noun to an adverb $(\mathrm{O}>\mathrm{E})$ by case}

\$1 The languages with case bring about transfer of a noun to an adverb by putting the noun in one of the oblique cases (never in the nominative, cf. Chapter 162, \$9).

$\$ 2$ Transfer of a noun to an adverb using the accusative: 
Place (translocal)

Place (distance)

Time (duration)

Manner

Relation

Quantity (cf. Chapter 37, $\$ 13$ and 131, \$12): Lat. Venit Romam 'He has come to Rome' (Stemma 317), Eo rus 'I am going to the countryside', Domum concessit 'He has gone home'

Gr. Hē pólis apékhei studious hebdomékonta 'The town is seventy stadia away', Lat. Castra hostium ab urbe nostra decum milia passum absunt 'The enemy camp is ten thousand paces away from our town';

Gr. Polùn khrónon apedémēsen 'He was absent for a time', Lat. Tres annos regnavit 'He ruled for three years', Ger. den ganzen Tag 'the entire day', Rus. celyj den' 'the entire day';

Gr. tà pánta krateîn 'to take away entirely'. Greek thus often transfers names to adverbs by simply putting them in the accusative plural;

Gr. pódas ōkùs Akhilleús, lit. 'Achilles light regarding his feet', that is in good English 'Achilles with light feet', Lat. vicem meam 'on my behalf';

Lat. Eos aliquid usus ac disciplina sublevabant 'Experience and discipline aided them somewhat', Ger. Es ist etwas zu groß 'It is a bit too big'

$\$ 3$ The genitive transfers a noun to an adverb:

Time Gr. nuktós 'of night', thérous 'in summer', Ger. Tags 'during the day', Winters 'in winter'

Manner Gr. Autòn eîkhe tēs kherós 'He took it by the hand', Tòv lúkon eîle tōn oốtōn 'He grabbed the wolf by the ears', Ger. guten Kaufs 'with a good purchase'

Gr. thaumázein tinà tês sophías 'admire someone for their wisdom', anếr thaumastòs

Cause tês sophías 'a man admirable for his wisdom', tồ skopoû stokházesthai, tugkhánein 'envision, strive for the goal'

Price Gr. misthoû ti práttein 'do something for the money'

$\$ 4$ The locative transfers a noun to a locative adverb (interlocal) (Chapter 37, \$13): Lat. Habitat Romae 'He lives in Rome', Carthagini 'in Carthage', domi militiaeque 'at home and in the army', that is 'in the interior as well as in the exterior', humi 'by earth', Latvian istabā 'in the room'.

$\$ 5$ The dative transfers a noun to an adverb:

\begin{tabular}{|c|c|}
\hline Time & Gr. tôi tetártoi étei 'in the fourth year' \\
\hline Comitative & $\begin{array}{l}\text { Gr. Apêlthe taîs oktố nausí } \\
\text { 'He moved away with eight ships' }\end{array}$ \\
\hline Instrument & $\begin{array}{l}\text { Gr. Autòn apékteine tôi xíphei } \\
\text { 'He killed him with his sword' }\end{array}$ \\
\hline Cause & $\begin{array}{l}\text { Gr. Orgêi tòn ekhthròn épaise } \\
\text { 'He struck his enemy out of anger' }\end{array}$ \\
\hline Manner & $\begin{array}{l}\text { Gr. biai 'in common', } \\
\text { koinêi 'in common', láthrai 'in secret' }\end{array}$ \\
\hline Quantity & $\begin{array}{l}\text { Gr. déka étesin metà taûta } \\
\text { 'tens years after that' }\end{array}$ \\
\hline
\end{tabular}


$\$ 6$ The ablative can transfer a noun to an adverb in Latin:

\begin{tabular}{|c|c|}
\hline $\begin{array}{l}\text { Place } \\
\text { (origin) }\end{array}$ & $\begin{array}{l}\text { Domo venit 'He is coming from the house', } \\
\text { Rure redeo 'I am returning from the countryside' }\end{array}$ \\
\hline $\begin{array}{l}\text { Place } \\
\text { (route) }\end{array}$ & $\begin{array}{l}\text { Porta Nomentana profectus est } \\
\text { 'He left by the Nomentana gate' }\end{array}$ \\
\hline $\begin{array}{l}\text { Time } \\
\text { (époque) }\end{array}$ & $\begin{array}{l}\text { aestate 'in summer', hieme 'in winter', } \\
\text { hora octava 'at eight o'clock', occasu solis 'at sunset' }\end{array}$ \\
\hline $\begin{array}{l}\text { Time } \\
\text { (duration) }\end{array}$ & $\begin{array}{l}\text { Oppidum decum diebus expugnavit 'He took } \\
\text { the town in ten days' }\end{array}$ \\
\hline Manner & $\begin{array}{l}\text { ordine 'in order', ratione 'with a method', } \\
\text { jure 'justified', agmine 'in marching order', } \\
\text { pedibus 'by foot', magna voce 'with a loud voice', } \\
\text { Teneo lupum auribus 'I am holding the wolf by the ears'; } \\
\text { the transfer of the noun entails the transfer of its attribute: } \\
\text { me auctore 'thanks to my initiate' }\end{array}$ \\
\hline Cause & Fame interiit 'He died of hunger' \\
\hline
\end{tabular}

In the two preceding cases, if the attribute subordinate to the noun is a participle, the phrase produces an expression that is appreciated in Latin and acknowledged in Latin grammars as an instance of an absolute ablative: Sic est locutus partibus factis leo 'The deeds being done, the lion spoke in this manner' (Phaedrus, Fables, I, 6), Urba capta hostis profectus est 'After having taken the town, the enemy departed':

\begin{tabular}{ll}
\hline Instrument & $\begin{array}{l}\text { Gr. khrêsthai toîs hóplois 'to make use one's arms', } \\
\text { Lat. Ferire alique gladio 'strike someone using a } \\
\text { sword', Haec domus saxo quadrato aedificata est 'This } \\
\text { house has been constructed with cut stones' }\end{array}$ \\
Quantity & Lat. viginti annis post 'twenty years later' \\
\hline
\end{tabular}

\$7 The instrumental transfers the Russian noun to an adverb

\begin{tabular}{ll}
\hline Place (route) & $\begin{array}{l}\text { morem 'by sea' } \\
\text { utrom 'in the morning', večerom 'in the } \\
\text { Time }\end{array}$ \\
'in suming', dnëm 'during the day', letom \\
Manner & $\begin{array}{l}\text { šagom 'walking' } \\
\text { Instrument in winter' }\end{array}$ \\
Quantity & $\begin{array}{l}\text { rukoju 'by hand' } \\
\text { dvumja godami molože 'two years younger' }\end{array}$ \\
\hline
\end{tabular}

$\$ 8$ In the languages with case, the use of case can be combined with a preposition or postposition. One is dealing then with attenuated transfer (cf. Chapter 168, \$8), whereby the translative function is divided between the two markers. 
$\$ 9$ Such is the case in Latin: Ambulat in horto 'He is strolling in the garden', ante portam 'in front of the gate', in urbe 'in the town', intra muros 'between the walls', trans Rhenum 'across the Rhine', post cenam 'after dinner', per totum diem 'the whole day long', post tres dies 'in three days', in tam multis annis 'within a few years' a puero, a pueris 'since childhood', per vim 'by violence', pro patria 'for the fatherland', Aderat cum gladio 'He was present with a sword' (so-called comitative meaning).

\$10 The same holds in Greek: amphì pûr 'around the fire', katà tôn petrôn 'from the hight of the rocks', en eirếnèi 'in times of peace', metà tòn thánaton 'after death'.

$\$ 11$ From this point of view, the typology of German is the same as that of Greek and Latin: auf dem Tisch 'on the table', in dem Garten 'in the yard', mit meinem Vater 'with my father'. $\$ 12$ The Slavic languages, which are very European in this area, also employ case with prepositions to transfer nouns to adverbs: na stole 'on the table', pered domom 'in front of the house', pod Moskvoju 'near Moscow', posle obeda 'after breakfast', c bratom 'with his brother'.

$\$ 13$ When the translative is a case, all the words in connection with the target word follow the same pattern and thus appear in the same case: Ger. auf einem steilen, schwierigen, sandigen Wege 'on a steep, difficult, sandy path' (cf. Chapter 8, \$11).

$\$ 14$ When, in contrast, the translative is just a preposition, it is a common factor and thus bears on the collection of subordinates: sur un chemin montant, sablonneux, malaisé 'on a climbing, sandy, difficult path' (La Fontaine, Fables, VII, 9, Le coche et la mouche) (cf. Chapter 8, \$11).

$\$ 15$ However, in Russian the preposition that accompanies the target word can be repeated in front of its subordinates: Rus. po Volge reke po shirokoj 'on the broad Volga river' (Pushkin), lit. 'on the Volga river, on the broad'.

\section{Chapter 203. Transfer of a noun to an adverb $(\mathrm{O}>\mathrm{E})$ without a marker}

\$1 Very often the transfer of a noun to an adverb occurs without a marker, at least in the languages without case. ${ }^{249}$

\$2 The process is encountered with whatever type of adverb is the result of transfer.

$\$ 3$ In French, transfer without a marker can result, for example, in a temporal adverb, e.g. Je partirai vendredi 'I will depart on Friday', or in an adverb of duration, e.g. La traversé dura trois heures 'The crossing lasted three hours'.

249. For in the languages with case, every transfer obligatorily entails the use of an oblique case, that is, of a case other than the nominative (cf. Chapter 162, p. 9). 
$\$ 4$ The same transfer without a marker can also result in a manner adverb: Il est malpoli de parler la bouche pleine 'It is rude to talk with one's mouth full'; avancer pas à pas 'advance step by step': boire goutte à goutte 'drink sip by sip'; vivre au jour le jour 'live from day to day'; le condamné s'avançait la corde au cou 'the condemned advanced the cord around his kneck'; Le cheval était en liberté, la bride sur le cou 'The horse was free, the bridle around its kneck'.

\$5 This is the case in particular when a noun transferred to a manner adverb indicates the thing that one is talking about: parler musique 'talk music', parler affaires 'talk business', parler argent 'talk money'.

$\$ 6$ One can also transfer a noun to a manner adjective without a marker; the noun in such cases is subordinate to an adjective of color, to which it is postposed: vert bouteille 'bottlegreen', bleu horizon 'sky-blue'.

$\$ 7$ In German, one finds the nominal complement of an agent of the verb transferred without a marker to a causal adverb (agent) subordinated to the past participle of this verb, which it precedes and with which it builds a compound form: mondbeglänzt lit. "by the moon'.

$\$ 8$ And in English, one finds the noun transferred to an adverb of quantity subordinated to the past participle of this verb, which it precedes and with which it builds a compound form: my eleven-year-old son.

\section{Chapter 204. Transvaluation}

\$1 Transfer can function incorrectly at times. Instead of transferring a full word of one category to a full word of another, it wrongly changes a full word to an empty word, or vice versa. The result of such transfer is that the translative, an empty word, permutes with the source or with the target full word, and is therefore no longer the instrument of transfer, but rather its object.

$\$ 2$ When a noun that is transferred to an adverb by transfer without a marker governs another transferred noun, it can occur that eventually it is no longer taken to be the source transferred by transfer with a marker, but rather it itself is interpreted as the translative of the other noun. Take for example the popular expression rapport à Bernard 'about Bernard', lit. 'relation to Bernard'. The linguistic sentiment ceases to interpret this example along the lines of Stemma 318, but rather Stemma 319 more accurately matches the reading. Thus the origin of prepositional locutions is explained nowadays correctly to an extent, such as with grâce à 'thanks to': grâce à Dieu 'thanks to God'. 


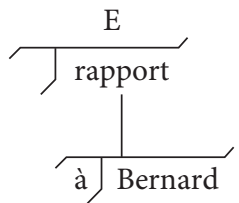

Stemma 318

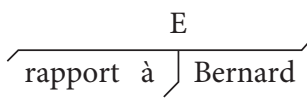

Stemma 319

$\$ 3$ The dated colloquial prepositional locution crainte de 'fear of' is explained in the same manner as rapport à:

Crainte pourtant de sinistre aventure, Allons chez nous achever l'entretien.
Lit. 'Nevertheless fear of sinister adventure, Let's go home to finish the discussion.'

(Molière, Amphitryon, 1-2)

$\$ 4$ When the noun transferred to an adverb by transfer without a marker governs an adjective (generally a participle), it can occur that in the long run, this adjective or participle is taken for a translative of the noun. Once a postposition, this new translative has the tendency in French to become a preposition, in accordance to the typology of French. Take for example Fr. excepté(s) les enfants 'except the children', lit. 'excepted the children' The linguistic sentiment that results from the evolution of the expression is to no longer interpret it according to Stemma 320, but rather Stemma 321 more accurately matches the reading.

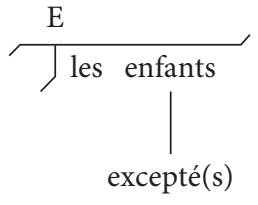

Stemma 320

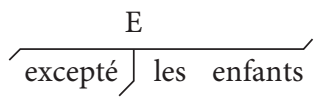

Stemma 321

\$5 Although rare, it can also occur that the transfer of a subordinate participle to a translative is accompanied by something that at its core is false morphology. The etymology of Ger. während 'during' is explained in this way; it dates only as far back as the 18th century: transfer using the genitive währendes Krieges 'during the war' became, by way of a false morphological shift, transfer with a preposition: während des Krieges.

\$6 Through time a participle calcifies to a translative, it passes from a full and variable category to an empty and invariable category, and it ceases to agree with the noun. This evolution is easy to follow through the history of the language: 


\begin{tabular}{|c|c|}
\hline $\begin{array}{l}\text { hormis (hors mis) } \\
\text { 'apart from', lit. 'out put' }\end{array}$ & $\begin{array}{l}\text { Attested since the } 13 \text { th century, } \\
\text { always invariable }\end{array}$ \\
\hline $\begin{array}{l}\text { excepté } \\
\text { 'except' }\end{array}$ & $\begin{array}{l}\text { Attested since the } 14 \text { th century, agreed with the noun } \\
\text { until the } 16 \text { th century, thereafter invariable }\end{array}$ \\
\hline $\begin{array}{l}\text { passé } \\
\text { 'after, gone' }\end{array}$ & $\begin{array}{l}\text { Modern, agrees with the noun if it follows it, but } \\
\text { invariable if it precedes it }\end{array}$ \\
\hline
\end{tabular}

\$7 The origin of expressions like the following ones is explained in this manner: avoir les larmes plein les yeux 'have eyes full of tears', de l'argent plein les poches 'pockets full of money', en avoir plein la bouche 'having a mouth full of it'. Further:

\begin{tabular}{|c|c|}
\hline $\begin{array}{l}\text { Salomon: ...je commence à en } \\
\text { avoir plein le dos de Germain } \\
\text { (Henri Lavedan, Viveurs, } \\
\text { II, p. 179) }\end{array}$ & $\begin{array}{l}\text { 'Salomon: ...I am beginning } \\
\text { to be fed up with Germain', } \\
\text { lit. '... to have the back full of...' }\end{array}$ \\
\hline $\begin{array}{l}\text { Retour d'un voyage en Corse, il } \\
\text { est venu nous faire visite. Garde } \\
\text { aussi les chemins battus, crainte } \\
\text { des loups. } \\
\text { (Charles Nodier, Trésor des fèves } \\
\text { et fleur des pois, p. 132) }\end{array}$ & $\begin{array}{l}\text { 'Returning from a trip to Corsica, he } \\
\text { came to visit us. Guard also } \\
\text { the beaten track, fear of } \\
\text { wolves.' }\end{array}$ \\
\hline
\end{tabular}

without forgetting the common expressions: Je viens vous voir, rapport à Bernard 'I am coming to see you about Bernard', and histoire de rire et de s'amuser 'just for a laugh and for fun', lit. 'history to laugh and to have fun'.

$\$ 8$ Charles Bally gave the name transvaluation to this passage, where the value of $\mathrm{O}$ (noun) is changed to that of $\mathrm{t}$ (preposition). ${ }^{250}$

$\$ 9$ By way of this sort of transvaluation - but with the inverse meaning because this time an empty word becomes a full word - a preposition $(\mathrm{t})$ can be transferred to an adverb (E). The most frequent translative for this sort of transfer in French is de, but there are other such translatives.

250. Linguistique générale et lingustique française, 1932, \$209 and 236. First editors’ note: In the completely redone second edition, Charles Bally preferred the term permutation of values over transvaluation; but he did not modify his analysis of the linguistic facts and the verb transvaluer as well as the noun transvaluation still appear many times during his exposition and in the index. Cf. 3rd edition, similar to 2nd edition, published by Francke, Bern, 1950: \$324, 2 and p. 220, 221, etc. 


\begin{tabular}{ll}
\hline Prepositions & Adverbs \\
\hline dans 'in' & dedans 'inside' \\
hors 'out of' & dehors 'outside' \\
sous 'under' & dessous 'underneath' \\
sur 'on' & dessus 'on top' \\
avant 'before' & auparavant 'previously' \\
sans 'without' & de sans 'without [it]' \\
\hline
\end{tabular}

The last example (sans vs. de sans) is encountered in certain regions of France, where people say de sans, lit. 'from without', thus disginuishing the adverb from the preposition: Je n'ai pas trouvé mon chapeau, alors je suis venu de sans 'I could not find my hat, so I came without it'.

\section{Chapter 205. Transfer of an adjective to an adverb $(A>E)$}

$\$ 1$ The transfer of an adjective to an adverb is a very frequent phenomenon in a majority of languages. Almost always the source is a qualitative adjective, and the target a manner adverb. Adverbs of manner could therefore be named qualitative adverbs (Fr. adverbes qualificatifs), a title that would be quite appropriate.

$\$ 2$ In French the translative is the suffix -ment: courageuse-ment 'courageous-ly', sage-ment 'wise-ly'. In the order of the process (Chapter 32, \$4), the verbal sentence Il lit distinctement et écrit lisiblement 'He reads distinctly and writes legibly' (Chapter 32, \$19 and Chapter $121, \$ 8)$ corresponds to the nominal phrase une lecture distincte et une écriture lisible 'a distinct reading and a legible writing.

$\$ 3$ Most neo-Latin languages assure the transfer of a qualitative adjective to a manner adverb by way of the suffix -ment, whereby the kinship to the Fr. -ment is apparent: It./Sp. viva-mente 'lively', It. dolce-mente 'gently', Sp. dulce-mente 'gently', Portuguese justamente 'precisely'.

$\$ 4$ This kindship is consistent with the communal origin of these formations and with their Latin etymology; adverbs such as Fr. bonnement 'simply' and Sp. buenamente stem from the Latin expression bona mente 'of good spirit'.

$\$ 5$ This etymology provides us with a precise indication about the genesis of the suffix -ment. One is dealing with the old inflected form mente 'from spirit', the ablative of the autonomous Latin noun mens. Thus a full word has become an empty word by agglutination. $\$ 6$ The same process is encountered in a certain number of languages, in particular in English, which specializes using the form - $l y$, the meaning of this suffix assuring the transfer of the qualitative adjective to an adverb, e.g. real-ly. The former autonomous noun of Germanic was *likas 'body', from which the German suffix -lich stems. 
\$7 By way of an analogous process, the Ural-Altaic languages employ a causal suffix to transfer a qualitative adjective to a manner adverb:

\begin{tabular}{|c|c|}
\hline \multirow[t]{4}{*}{ Hungarian } & nagy 'big' $\rightarrow$ nagy-on 'greatly' \\
\hline & $\operatorname{rossz}$ 'bad' $\rightarrow$ rossz-ul 'badly' \\
\hline & jó 'good' $\rightarrow$ jó-l 'well' \\
\hline & Beszél ön magyarul? 'Do you speak Hungarian?' \\
\hline Finnish & Puhutte suomea? 'You speak Finnish?' \\
\hline Turkish & Türk-çe söyler misiniz? 'Do you say in Turkish? \\
\hline
\end{tabular}

$\$ 8$ The same process is employed in Georgian, which produces adverbs with the causal suffix -ad (a): mdidari 'rich' $\rightarrow$ mdidar-ad 'richly'.

$\$ 9$ Japanese also transfers adjectives to adverbs using a suffix: yoroshii 'good $\rightarrow$ yoroshi-ku 'well', samui 'cold' samu-ku 'coldly'.

$\$ 10$ Finally one finds the same process in Basque: segur 'sure' $\rightarrow$ segur- $k i$ 'surely'.

$\$ 11$ When the suffix undergoes agglutination, it furnishes a case form. This holds in a large number of Indo-European languages, where adverbial case is an old case that has nevertheless not been completely integrated into the paradigm of declensions.

$\$ 12$ In Latin, the case suffix is most often $-e,-o$, or -ter: firmus 'firm' $\rightarrow$ firm-e 'firmly', subitus 'sudden' subit-o 'suddenly', fortis 'courageous' $\rightarrow$ forti-ter 'courageously'.

$\$ 13$ Greek normally appeals to the old adverbial case ending -ōs to form manner adverbs: díkaios 'just' $\rightarrow$ dikaí-ōs 'justly', sophós 'wise' $\rightarrow$ soph-ôs 'wisely'.

$\$ 14$ The same holds in Latvian, where the ending $-i$ is used: labs 'good' $\rightarrow$ lab-i 'well'.

$\$ 15$ In a large number of languages, the transfer of a qualitative adjective to a manner adverb occurs without a marker.

$\$ 16$ This process is widely called upon by the French, who use it to produce a large number of savory expressions:

\begin{tabular}{lll}
\hline French & Translation & Literally \\
\hline parler haut & 'speak loudly' & 'speak high' \\
parler bas & 'speak with a low voice' & 'speak low' \\
crier fort & 'scream loudly' & 'scream loud' \\
chanter faux & 'sing in falsetto' & 'sing false' \\
parler franc & 'speak frankly' & 'speak frank' \\
sonner creux & 'sound hollow' & 'sound hollow' \\
filer doux & 'toe the line' & 'go off soft' \\
taper dur & 'beat hard' & 'beat hard' \\
\hline
\end{tabular}




\begin{tabular}{lll}
\hline French & Translation & Literally \\
\hline battre froid & $\begin{array}{l}\text { 'give (someone) the } \\
\text { cold shoulder' }\end{array}$ & 'beat cold' \\
aller droit & 'go straight' & 'go right' \\
boire chaud & 'drink hot' & 'drink hot' \\
boire frais & 'drink fresh' & 'drink fresh' \\
boire sec & 'drink straight' & 'drink dry' \\
voir clair & 'see well' & 'see clear' \\
tourner rond & 'run smoothly' & 'turn round' \\
\hline
\end{tabular}

Notably, an adjective that has been transferred to an adverb without a marker is used to express the language that one uses to say something: parler français 'speak French'.

$\$ 17$ One also finds quite savory expressions in French where a qualitative adjective transferred to an adverb without a marker is subordinate to an adjective: un œeuffrais pondu 'a freshly laid egg', lit. 'a fresh laid egg', être fin prêt 'to be all set', lit. 'to be fine ready', arriver bon premier 'to nicely arrive first', lit. 'to arrive good first', without forgetting the Swiss expression that is so colorful: Il fait bon chaud 'It is pleasantly hot', lit. 'It is good hot'.

\$18 Transfer without a marker is normal in Romanian: El cântă ră 'He sings poorly'.

$\$ 19$ This is also the normal procedure in Breton where mad signifies both an adjective 'good' and an adverb 'well'.

\$20 German can transfer every adjective to an adverb without the aid of a marker: $E r$ schreibt gut 'He writes well'.

\$21 An adjective transferred to an adverb of manner like this by transfer without a marker can be subordinate to a qualitative adjective and thus form a composite form: weißgrau 'whitish gray', grüngelb 'greenish yellow', gelbrot 'yellowish red'.

\$22 Finally, an adverb obtained from a qualitative adjective by transfer without a marker can be a resultative adverb: sich satt essen 'eat until full', sich krank arbeiten 'work so hard that one becomes sick', sich tot lachen 'to laugh oneself to death', blank putzen 'scrub shiny', Er hat sich die Augen rot geweint 'He cried his eyes red', Die Achse ist warm gelaufen 'The axle ran itself warm' (cf. Chapter 37, \$47). ${ }^{251}$

\$23 Just as in German, Dutch can transfer an adjective to an adverb without a marker: Hij schrijft goed 'He writes well'.

\$24 To transfer an adjective to a manner adverb, Danish also needs no marker, but the transferred adjective takes on a shared gender: Han svarede regtigt 'He responds exactly'.

251. Cf. A. Malblanc, Pour une stylistique comparée du français et de l'allmand, \$55). 
\$25 Likewise, Russian uses no marker, but an adjective transferred to a manner adverb takes on a short neuter form: On govorit xorošo 'He speaks well'.

\section{Chapter 206. Transfer of a verb to an adverb, the gerundive}

\$1 The transfer of a verb to an adverb ( $>$ E) exists with the gerundive, which is a verb that has been transferred to a manner adverb.

\$2 A number of languages have a gerundive by way of simple transfer. Such is the case in Latin, Italian, and Russian.

$\$ 3$ Latin marks the gerundive with the ending -ndo: Legendo doctus evasit 'He has become learned by reading'.

$\$ 4$ Italian has conserved the ending of Latin: Alfredo parla mangiando 'Alfred speaks while eating'.

$\$ 5$ Russian marks the gerundive with the ending -ja (a), -uči (juči): Ja cidel čitaja 'I was seated while reading'.

$\$ 6$ The secution of all these gerundives is concomitant. Russian also posseses a synthetic anterior gerundive ending in - $v(-v s ̌ i)$ : Napisav pismo, ja pošël na počtu 'Having written the letter, I went to the post office.'

$\$ 7$ French does not possess a gerundive formed by simple transfer, rather it is obliged to employ double transfer (cf. Chapter 224, \$11ff.).

$\$ 8$ The transfer of a verb to an adverb can occur without the use of a gerundive, for example when a translative preposition appears with a source verb in personal mood:

\begin{tabular}{lll}
\hline French & Idiomatic & Literal \\
\hline $\begin{array}{ll}\text { manger à bouche que } \\
\text { veux-tu (dated) }\end{array}$ & $\begin{array}{l}\text { 'to eat as much as } \\
\text { crier à tue-tête }\end{array}$ & $\begin{array}{l}\text { 'eat to mouth that } \\
\text { you want' }\end{array}$ \\
$\begin{array}{l}\text { jouer à qui perd } \\
\text { gagne }\end{array}$ & $\begin{array}{l}\text { 'to shout one's head off' } \\
\text { of the game' }\end{array}$ & 'shout to kill-head' \\
\hline
\end{tabular}

\$9 The source verb can be a sentence word tirer à hue et à dia 'pull in opposite directions'.

\section{Chapter 207. Simple transfer to a verb}

\$1 Simple transfer to a verb occurs from a noun $(\mathrm{O}>\mathrm{I})$, very often from an adjective $(\mathrm{A}>\mathrm{I})$, and quite rarely from an adverb (E > I).

\$2 A noun is transferred to a verb when it takes the value of a sentence word: Votre serviteur! 'Your servant!' (sentence word of politeness), Fr. Bonne chance!, Ger. Viel 
Glück! 'Good luck!', Lat. Me infelicem! 'Unlucky me!' (emotive sentence word, see above Chapter 46, \$19, \#2).

$\$ 3$ The transfer of an adjective to a verb is such that one encounters it in a sentence with the verb be (cf. Chapter 67).

$\$ 4$ The flaw of traditional grammar has in general been to pay little attention to syntax. It has thoughtlessly classified these sentences as nominal sentences.

$\$ 5$ This can be true of predicative sentences that are found in a large number of languages and in particular in Latin: Domus nova 'The house is new' (cf. Chapter 66, \$2-8).

$\$ 6$ But one is speaking rubbish in such cases because one is confusing a sentence with the verb be with a pure predicative sentence (cf. Chapter $67, \$ 1$ ) and qualifying as a nominal a sentence the structural node of which is a verb: The house is new.

$\$ 7$ In reality, the nominal verb here assumes the role of a variable translative (cf. Chapter 30 , $\$ 11$ and $170, \$ 3, \# 2)$.

$\$ 8$ It serves to transfer the adjective new (A) to the verb is new. It is in fact an adjectiveverb (cf. Chapter 66, $\$ 7$ and 8).

$\$ 9$ The nucleus is new is hence a dissociated nucleus, since it contains two elements (cf. Chapter 23, \$14).

\$10 In this nucleus, the structural function is assured by the auxiliary is and the semantic function by the auxiliated new (cf. Chapter 67, $\$ 1,3$ and 6).

$\$ 11$ Adverbs transferred to a verb are extremely rare, but one comes across adverbs transferred to sentence words. Such is the case in German, where a transferred adverb can take the value of the imperative: Fort mit euch! (Storm, Der Schimmelreiter, p. 166) 'Get out of here!'.

\section{Chapter 208. Simple subcategory transfers $(A>A)$ and $(E>E)$}

\$1 Certain cases of transfer, instead of having source and target categories that are different, are content to transfer one element from one subcategory (cf. Chapter 37 and 167, \$2) to a different subcategory of the same mother category. We reserve the designation subcategory transfer (Fr. translation sous-catégorique) for this type of transfer.

$\$ 2$ The result of this type of transfer is that the source category is the same as the target category.

$\$ 3$ Conversely, when in transfer the source category is the same as that of the target category, one can only be dealing with subcategory transfer.

$\$ 4$ The cases of simple subcategory transfer that are most frequent involve adjectives $(\mathrm{A}>\mathrm{A})$ and adverbs $(\mathrm{E}>\mathrm{E})$. 
\$5 The subcategory transfer of an adjective that is most common is that of names of numbers, that is, the numeral adjectives. It consists of transferring a cardinal number to an ordinal number.

$\$ 6$ In most languages, this transfer is marked by the use of a suffix: Fr. -ième, Ger. -te, Eng. - th.

\$7 The suffix -ième is common in French for the transfer of a cardinal number to an ordinal adjective: deux-ième, trois-ième, quatr-ième. One commonly adds the suffix -ième to the symbol $n$, which designates a large number in mathematics: Je vous le dis pour la n-ième fois 'I'm telling you for the umpteenth time'.

$\$ 8$ One does the same in German with the suffix -te: Friedrich II (read: der Zwei-te 'the Second') 'Frederick II', Karl V (read: der Fünf-te 'the Fifth') 'Charles V'.

$\$ 9$ And in English one uses the suffix -th: George V (read: the Fifth).

$\$ 10$ Without a marker, the same transfer is quite rare in general, but in French it is the rule (starting from deux 'two') when it indicates the sequential number of souvereigns or the like, e.g. years, order of months, pages: Louis XIV (read: quatorze 'fourteen') 'Louis the fourteenth', Napoléon II (read: deux 'two') 'Napoleon the second', la pape Léon XIII (read: treize 'thirteen') 'the Pope Leon the thirteenth', l'an IX (read: neuf 'nine') 'the year nine', demain 6 (read six) juillet 'tomorrow the sixth of July', page 6 (read: six). [But François $1^{\text {er }}$ (read: premier 'First') 'Francis the first' or le $1^{\text {er }}$ juillet 'the first July' contrast with l'an I (read: un 'one') 'year one' or page 1 (read: un) 'page one'.]

$\$ 11$ Subcategory transfer of an adverb is not rare. It changes an adverb of one subcategory to another by way of a subcategory translative.

$\$ 12$ Hence one says in French Je vous attends depuis hier 'I've been waiting for you since yesterday', Envoyez-moi ce livre avant demain 'Send me this book before tomorrow'.

$\$ 13$ The adverbs hier 'yesterday' and demain 'tomorrow' can be transferred only by the prepositions depuis 'since', avant 'before', and pour 'for'.

$\$ 14$ The variety of subcategory transfers that are permitted within an adverb category reveals great subtlety.

$\$ 15$ The study of the indefinite possibilities that this type of transfer offers has not yet been attempted. One has to regret this state of affairs, since it would certainly be full of insights about the internal structure of the adverb category. 



\section{First-degree transfer, multiple transfer}

\section{Chapter 209. Double transfer}

$\$ 1$ We have seen (Chapter $165, \S 3$ ) that double transfer exists when the same nucleus contains two successive transfers.

$\$ 2$ One can thus define double transfer as an intra-nuclear set in which a first instance of transfer produces a target that is simultaneously the source for a second instance of transfer.

$\$ 3$ As a consequence, double transfer results from the side-by-side placement of two simple transfers belonging to one of the types examined above.

$\$ 4$ Hence an instance of double transfer of the sort $\mathrm{A}>\mathrm{O}>\mathrm{E}$ contains both a simple transfer of the sort $\mathrm{A}>\mathrm{O}$ and a simple transfer of the sort $\mathrm{O}>\mathrm{E}$.

$\$ 5$ Take for example the French expression (trancher) dans le vif 'take drastic action' (A > $\mathrm{O}>\mathrm{E})$; it contains first the transfer of an adjective to a noun $(\mathrm{A}>\mathrm{O})$ and then the transfer of a noun to an adverb $(\mathrm{O}>\mathrm{E})$.

$\$ 6$ Each of these transfers belongs of course to one of the types that we examined above.

$\$ 7$ The transfer $\mathrm{A}>\mathrm{O}$ of the adjective vif 'lively' to the noun le vif by the definite article is exactly of the sort that we examined above in Chapter 177 , \$5ff. Such transfer results in forms like l'oral 'the oral'.

$\$ 8$ Otherwise, transfer $\mathrm{O}>\mathrm{E}$ of a noun to an adverb by a preposition is exactly of the sort that we examined above in Chapter 201, \$4ff. Such transfer results in forms like dans ma chambre 'in my room'.

$\$ 9$ The graphic representation of double transfer can be conducted in two ways, according to whether one is producing a linear or structural image (Chapter $155, \$ 6$ ).

$\$ 10$ If the goal is to produce a linear image, we will be content to adopt the sign $>$ and to set the two transfers $\mathrm{A}>\mathrm{O}$ and $\mathrm{O}>\mathrm{E}$ end to end in the order they are produced and to write the shared element $\mathrm{O}$ just once. This shared element is simultaneously the target of the first instance of transfer $\mathrm{A}>\mathrm{O}$ and the source of the second transfer $\mathrm{O}>\mathrm{E}$. The resulting formula is $\mathrm{A}>\mathrm{O}>\mathrm{E}$.

$\$ 11$ If, in contrast, one desires to give double transfer an image that can be integrated into the stemma (Chapter 15 and following), one can employ the symbol $\mathcal{T}$ for each instance of transfer in such a manner that the shared element appears simultaneously in the position 
of the target of the first instance of transfer and in the position of the source of the second transfer.

\$12 One will thus often be led to produce a $\mathcal{T}$ that is as big as the case of transfer is recent and conversely, as small as the transfer is old (Stemma 322).

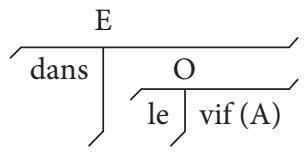

\section{Stemma 322}

\$13 There is no difficulty associated with this practice, however, since the older, the more fixed, and the closer to its death the first source of transfer is the smaller the $\tau$ indicating transfer.

\$14 One can observe that in the linear representation, the order in which the transfers are produced matches left-to-right order, whereas in the stemmatic representation, the order is the inverse, so that the right-most symbol (of the linear order) appears at the top of the structure. It is important to note this situation with care, so that one properly acknowledges the correspondence between linear and stemmatic order.

\$15 One can also acknowledge that in the stemmatic representation, we have positioned the two $\mathcal{T}$ in the same nucleus circle, since double transfer is by definition a set of two successive transfers that take place inside the same nucleus (above $\$ 1$ ).

\$16 Just as a nucleus containing an instance of transfer is divided by the horizontal bar of the $\mathcal{T}$ into two zones and constitutes a mixed nucleus that one can represent with a nucleus circle that contains a bipartite division (cf. Chapter 157, \$14), one can represent the nucleus containing double transfer using a nucleus circle containing a tripartite division (cf. Chapter 224, \$11 and Stemma 329).

\section{Chapter 210. Classification of double transfer}

\$1 The classification of the facts of double transfer is inspired naturally from the principles considered in chapter 176. These principles were intended to classify the facts of transfer in general. Hence we based this classification on the translatives that are the markers of transfer, and from there we observed successively 1) the presence or absence of transfer and 2) the nature of transfer.

$\$ 2$ Each of the two constituent transfers of a double transfer is susceptible to having a marker or not. This distinction provides a good point of departure for the classification of double transfer. One can distinguish: 


\begin{tabular}{ll}
\hline & Classification of Double transfer \\
\hline 1. & Double transfer with a double marker \\
2. & $\begin{array}{l}\text { Double transfer where the first instance } \\
\text { of transfer lacks a marker }\end{array}$ \\
3. $\quad \begin{array}{l}\text { Double transfer where the second } \\
\text { instance of transfer lacks a marker }\end{array}$ \\
4. $\quad \begin{array}{l}\text { Double transfer lacking } \\
\text { a marker entirely }\end{array}$ \\
\hline
\end{tabular}

$\$ 3$ But it is important to be able to distinguish between the second and third scenarios in the preceding paragraph. We have to be clear about what exactly is called the first and the second instance of transfer.

$\$ 4$ From this point of view, it is necessary to consider the following preliminary remark. If the instances of transfer at hand have a postposed translative as a marker (postposition, suffix), then the order in which they appear on the spoken chain matches the spoken chain. If, however, they have preposed translatives as markers (preposition, prefix), the order in which they appear in the spoken chain will be the inverse (Chapter 5 and Chapter $155, \$ 10 \mathrm{ff}$.).

\begin{tabular}{ll}
\hline \multicolumn{2}{c}{ Order of translatives } \\
\hline Second translative & First translative \\
who & is in the room \\
\hline
\end{tabular}

$\$ 5$ We will subdivide the division obtained according to the category of the elements that intervene in the transfer.

$\$ 6$ The three categories of interest - that of the source, the intermediate element, and the final target - can vary. In such a case, double transfer of the types $\mathrm{E}>\mathrm{A}>\mathrm{O}, \mathrm{A}>\mathrm{E}>\mathrm{O}$, $\mathrm{E}>\mathrm{O}>\mathrm{A}, \mathrm{O}>\mathrm{E}>\mathrm{A}, \mathrm{A}>\mathrm{O}>\mathrm{E}$, and $\mathrm{O}>\mathrm{A}>\mathrm{E}$ exhaust the possibilities.

$\$ 7$ But it can also occur that the source category is the same as the target category, in which case only the intermediate category is distinct.

$\$ 8$ In such a case, the second instance of transfer is necessarily the opposite of the first, and we are hence dealing with reversive transfer (cf. Chapter 165, §8-9).

$\$ 9$ On the other hand, two or even three of the sources can belong to the same category.

$\$ 10$ In such a case, we are dealing with one or two subcategory transfers.

$\$ 11$ Finally, it is necessary to grant a special status to those translatives that only ever occur with the second individual instance of transfer in cases of double transfer.

$\$ 12$ These translatives always have a target of a previous transfer as their source. The instance of transfer that they produce are hence always retransfers. For this reason, we call these translatives retranslatives. 


\section{Chapter 211. Double $\mathrm{O}>\mathrm{A}>\mathrm{O}$ transfer with a double marker}

\$1 One has transfer following the formula $\mathrm{O}>\mathrm{A}>\mathrm{O}$ when a noun transferred to an adjective is then transferred anew back to a noun. The source of the first instance of transfer being of the same category as the target of the second transfer, transfers corresponding to this formula are reversive transfers (cf. Chapter 165, $\$ 8$ and 9, Chapter 210, $\$ 8$ ).

\$2 Reversive transfer following the formula $\mathrm{O}>\mathrm{A}>\mathrm{O}$ is common in a large number of languages. Only the marker of each instance of transfer differs from one language to the next.

$\$ 3$ Take for example the word une dinde 'a turkey' in French (which is etymologically une poule d'Inde 'a hen from India'). This word is the result of double transfer, where the first instance of transfer is marked by the preposition $d$, which transfers the noun to an adjective, and the second by the indefinite article une, which transfers the adjective to a noun (Stemma 323).

$\$ 4$ Take now the German expression ein dreißiger Jahre 'a man in his thirties'; the two successive instances of transfer are both marked, as in the French example in $₫ 3$. But while the second instance of transfer, that of an adjective to a noun, is marked in the language by the article translative, the first, that of a noun to an adjective, is marked in German by the translative case, i.e. by the genitive, which stands in contrast to French where it is marked by an autonomous translative, i.e. by the preposition $d e$.

\$5 The same sort of transfer with a double marker is encountered in Greek: tà tôn phílōn 'the possessions of friends'. Transfer departs from the noun philos 'friend', for which transfer to a relative adjective is marked by the use of genitive case and transfer from this new adjective to a noun is marked by the article.

$\$ 6$ Reversive transfer of the sort $\mathrm{O}>\mathrm{A}>\mathrm{O}$ using a double marker also occurs in Turkish: babaninki 'that of the father', benimki 'mine'. In each of these words, the first instance of transfer - that of a noun to an adjective - is marked by the genitive suffix, which is -nin for the noun baba 'father' and -im- for the personal noun ben 'I, me', whereas the second instance of transfer - that of an adjective to a noun - is marked by the suffix - ki.

\$7 Basque has exactly the same typology as Turkish, which one can also see in reversive transfer with a double marker: aita-ren- $a$ 'that of the father', alhorre-etako- $a$ 'the one who is in the fields. In each of these words, the first instance of transfer - that of a noun to an adjective - is marked by the suffix of a possessive genitive -aren or by the genitive locative suffix -tako, whereas the second transfer - that of an adjective to a noun - is marked by the same suffix, which is none other than the postposed article $-a$.

$\$ 8$ The target of the second instance of transfer in double transfer can have anaphoric value and can refer to a preceding nucleus: Sp. el libro de Pedro y el de mi padre 'the book of Peter and that of my father', Eng. my father's book and Peter's one. 
\$9 In a number of languages, the second instance of transfer in double transfer can be marked in the same manner as if it were an instance of simple transfer. Such is the case in the Spanish examples which were given.

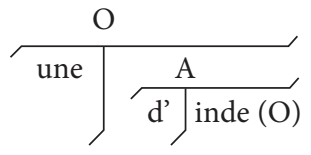

Stemma 323

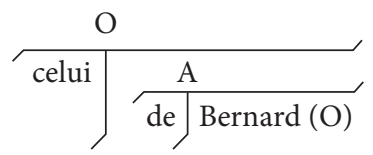

Stemma 324

\$10 However, certain languages - in particular French - have a special translative that serves the unique role of indicating that an element has already undergone an instance of transfer. One is dealing with a retranslative (cf. Chapter 210, \$12). This is why the retranslative celui must be followed by the translative $d e$ of first degree (preposition) or by a translative of second degree that is a relative pronoun (cf. \$16 and Chapter $246, \$ 4$ ).

$\$ 11$ In French the usual retranslative is celui 'the one', feminine celle, plural ceux 'those', femine plural celles: le livre d'Alfred et celui de Bernard 'the book of Alfred and the one of Bernard' (Stemma 324), la brochure d'Alfred et celle de Bernard 'the brochure of Alfred and the one of Bernard', les livres d'Alfred et ceux de Bernard 'the books of Alfred and the ones of Bernard', les brochures d'Alfred et celles de Bernard 'the brochures of Alfred and the ones of Bernard'.

$\$ 12$ One of the consequences of the nominal value of the translative celui and that of its equivalent in other languages is that these words tend to take an article, which is a nominal translative (cf. Chapter $34, \$ 18$, Chapter $41, \$ 21$, Chapter 177, 22 and 3, and Chapter 178, $\$ 5)$. This matter is visible in Breton, where hini always takes the article an hini ru 'the red' (Chapter 177, \$20). And it appears even in French in popular sayings and in dialects, in particular in Normandy: La ferme de Pierre Bénédicte? -... C’est la troisième après la celle à Porée 'The farm of Peter Benedict? - ... It is the third (one) after the one of Poree' (Maupassant, Contes, L'abandonné).

$\$ 13$ The use of the retranslative celui is limited to certain well-defined cases.

$\$ 14$ One should not confuse the retranslative celui with a simple translative. It is perfectly possible to say un livre d'Alfred et un de Bernard 'a book of Alfred and one of Bernard', employing the indefinite article as a translative, as one does for the transfer of a qualitative adjective: un livre noir et un rouge 'a black book and a red (one)'. But what distinguishes the retranslative celui from the translative $u n$ is that whereas the translative $u n$ can be employed as a marker of double transfer (un de Bernard), the retranslaitve celui, which is perfect as the marker of the second instance of transfer of double transfer (celui de Bernard), cannot serve as a marker of simple transfer: it is incorrect to use it to transfer an ordinary qualitative adjective and to say, for example, *le livre noir et celui rouge 'the black book and the red (one)'. 
\$15 In contrast to the translative $u n$, the retranslative celui is reserved for the transfer of nodes that have previously been transferred to adjectives, a fact that is clearly visible in Stemma 324.

\$16 Moreover, the translative celui is employed both as a retranslative of normal transfer (celui de Bernard 'the one of Bernard, Bernard's one') and also as we will see, as a retranslative of descending transfer (celui que vous m'avez donné 'the one that you gave me').

$\$ 17$ Furthermore, one must not confuse celui, which is merely a (re)translative, with celui$c i$ 'this (one)' or celui-là 'that (one)', which is a demonstrative adjective. Celui alone is vague and indeterminate. Only the particles $c i$ and la determine the precise meaning. The same role is played by a noun transferred to an adverb of belonging d'Alfred in the expression celui d'Alfred 'the one of Alfred'.

\$18 French makes abundant use of an anaphoric retranslative: La meilleure leçon est celle des exemples 'The best lesson is the one of examples' (La Harpe) cf. Stemma 325, toutes les petites tables groupées autour de celle d'honneur... 'all the small tables grouped around the one of honor...' (Henri Lavedan, Avant l'oubli, I, p. 24).

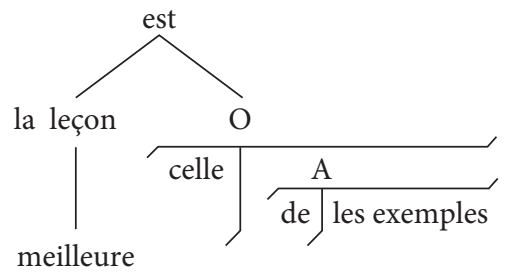

Stemma 325

$\$ 19$ The anaphoric retranslative of French is a special instrument that is characteristic of this language, so it constitutes one of the most unsolvable difficulties of the French language for most foreigners who do not have an equivalent in their language. This holds all the more because the true nature of this word has still not been analyzed methodologically and because the structural mechanism in sentences where it appears is in general explained quite incorrectly.

\$20 Nevertheless, not all foreign languages ignore the anaphoric retranslative, and one can find it in particular in Italian and German: It. quelle di mio padre 'the ones of my father', Ger. dasjenige Peters 'the one of Peter').

\section{Chapter 212. Double $\mathrm{O}>\mathrm{A}>\mathrm{O}$ transfer with the first instance of transfer lacking a marker}

$\$ 1$ Double transfer according to the formula $\mathrm{O}>\mathrm{A}>\mathrm{O}$ and where only the second instance of transfer is marked is what we encounter in the French group un pur sang 'a purebred', lit. 'a pure blood'. 
\$2 In order to penetrate the internal economy of this group, one has to submit it to an analysis of minutia.

$\$ 3$ The noun sang 'blood' designates first the red liquid in our veins and arteries. As such, it takes the qualitative adjective pur as a subordinate attribute.

$\$ 4$ This group can hence be transferred to a qualitative adjective by transfer without a marker and can apply to a horse that has not been mixed with another race, un cheval pur sang 'a pure bred horse', from where the governing noun sang is transferred to an adjective by transfer without a marker.

\$5 By way of the elision of cheval and with transfer of the new adjective pur sang to a noun without a marker, one obtains a new noun that designates a horse that has the quality of being a pure breed: un pur sang 'a purebred'.

$\$ 6$ Thus the noun that is transferred first to an adjective is then retransferred to a noun by reversive transfer. The expression starts as a noun and ends as noun after double transfer.

$\$ 7$ Phenomena of reversive double transfer of this sort are quite frequent in French: un sang-mêlé 'a mixed blood (person)', un menton bleu, lit. 'a blue chin', that is 'an actor', un pied-bot 'a club foot', that is 'someone with a club foot', un Peau-rouge 'a redskin', les gueules cassées, lit. 'the broken faces', that is 'veterans with severe facial injuries'. Il courait..., content de ramener ensuite sans perte ces vaillantes 'jambes de bois' 'He ran..., content then to take back these valiant wooden legs without loss', that is, 'the disabled' (Roger Baschet, Le general Daumesnil, p. 142), une conduite intérieure 'a sedan or saloon car', lit. 'an inside driving.

$\$ 8$ One can note that the two nouns, separated syntactically by double transfer and conversion, are also separated by their semantic evolution, which occurred parallel to their development in terms of transfer. In the case of pur sang 'pure blood', the first noun designates the liquid that flows through our veins and arteries, and the second noun designates, after reversive double transfer, a horse of a particular type.

$\$ 9$ The second noun can be of the same gender as the first: un pur sang 'a purebred', un sang-mêlé 'a mixed blood', un menton bleu 'a blue chin'.

$\$ 10$ However, reversive transfer can be accompanied by a change in gender, the gender of the new noun being in fact independent of the gender of the first; un Peau-rouge 'a redskin' designates in masculine a man of a certain race, whereas une peau rouge 'a read skin' designates a membrane covering our bodies.

$\$ 11$ That is why one encounters transfer that involves a change from feminine gender to masculine gender, le Languedoc, that is, the region where la langue d'oc 'the language of oc' is spoken, and un crème, that is, a café crème (vs. la crème 'the cream'), un vapeur 'a steamer' (vs. la vapeur 'the steam'), un trompette 'a trumpet', that is 'a soldier playing the trumpet' (vs. une trompette 'a trumpet'). There is also a tabacco bar that is called le Salambô 'the Salambo' in a large city in France. 
$\$ 12$ Conversely, reversive transfer results in passage from masculine gender to feminine in la batiste, the cloth that was first made by Baptiste Chambray, who lived in Cambrai in the 18th century, Elles sont une demi-douzaine de houdans... 'They are a half dozen houdan' (Paul Hervieu, Le petit Duc, Poules, p. 248), that is, 'chickens of the type from Houdan'.

\$13 After reversive transfer of the sort $\mathrm{O}>\mathrm{A}>\mathrm{O}$ - just as after simple transfer (Chapter $177, \$ 6)$ - the nouns that result from noun-adjectival transfer constitute a series of nouns with the same gender as that of the noun that has undergone ellipsis. Among the principle series formed in this manner, one can note in particular:

$\$ 14$ Masculine proper nouns:

\begin{tabular}{ll}
\hline Men & un Peau-rouge 'a redskin' \\
Countries & le Languedoc 'the Languedoc' \\
Wines & du champagne, du bourgogne, \\
& un côtes du Rhône (that is wine from la Champagne \\
& 'Champagne', la Bourgogne 'Burgundy', or \\
& les Côtes du Rhône 'the Rhone slopes') \\
& un brie, du gruyère, un Hollande (that is a cheese \\
from la Brie (region), Gruyère (city), or la Hollande & 'Holland'), un Petit-Suisse lit. 'a little Swiss' (a kind \\
Cheeses & that is 'a cream cheese', un chèvre lit. 'a goat' \\
& un Berliet 'a Berliet', un cinq-tonnes lit. 'a five-ton' \\
& le Normandie, le Jeanne d'Arc, un vapeur lit. 'a steam' \\
Trucks & un Pleyel, un Stradivarius. \\
Ships & Musical instruments
\end{tabular}

Concerning wines, witness the legend encountered in 1945 on a humoristic postcard representing a cheese merchant who says: $Y$ (Ils) sont aux pommes, mes chèvres, Madame 'They are with apples, my goats, Madam'. And concerning ships: Donnons à notre navire aérien un nom qui lui porte bonheur! Qu'il soit baptisé le Victoria! 'Let's give to our air boat a name that will bring it good luck! Let it be baptized the Victoria' (J. Verne, Cinq semaines en ballon, XI).

$\$ 15$ Feminine proper nouns:

\begin{tabular}{ll}
\hline Cars & $\begin{array}{l}\text { une limousine (from le Limousin, a French region), une Renault, une } \\
\text { Peugeot, une Citroën, une Ford, une quarante chevaux, lit. 'a forty horse' } \\
\text { (cf. Chapter 177, \$10) }\end{array}$ \\
$\begin{array}{l}\text { Small ships } \\
\text { (e.g. barges) }\end{array}$ & la Marie-Jeanne \\
Festivals & la Saint-Jean 'Easter', la Noël 'Christmas', la Toussaint 'Halloween' \\
\hline
\end{tabular}

$\$ 16$ In French double transfer with only the second instance of transfer marked often looks the same in practice as double transfer without a marker, since the marker of the 
second instance of transfer is the article, which can play the role of an index as well as of a translative. When the article is an index, its use is optional depending upon the syntactic rules for the article in general. That is why the double transferred noun un pur sang a purebred' can be employed without an article when it is in apposition: Pur sang authentique, ce cheval doit gagner la course '(Being an) authentique purebred, this horse must win the race'.

$\$ 17$ In Breton, one has examples of double transfer where only the second instance of transfer is marked: hini Per, hin Ber 'the one, the ones of Peter', re Vari 'the one(s) of Mary'.

\section{Chapter 213. Nouns denoting ships}

\$1 The gender of nouns denoting ships has been the topic of passionate discussion, whereby both grammarians and mariners have competed to produce their explanations. (cf. the ingenious arguments produced by A Dauzat, A propos des noms de navire 'About nouns denoting ships' in the journal Le Monde from November 29, 1950. These arguments do not appear to me to counter the point of view expounded below).

$\$ 2$ It is a fact that in French all nouns designating large ships - since there are no more galleys, galliots, caravels, and carracks (une galère, une galliote, une caravelle, une caraque)are masculine: un bateau 'a boat', un navire 'a ship', un vaisseau 'a vessel', un paquebot 'a cruise liner', un cargo 'a cargo ship', etc. For this reason, one says un cuirassé 'a battleship', un sous-marin 'a submarine', and not une cuirassée, une sous-marine.

$\$_{3}$ Among the members of merchant fleets, opinions are split, just as with military fleets. The crews, following popular sentiment, make large ships masculine and do not hesitate to say le Jeanne d'Arc.

$\$ 4$ In contrast, the officers commanding these ships, since they are more delicate and inclined to subtle refinements, gain acceptance for their sentiments via their philosophical opinons about the depth of language. They say la Jeanne d'Arc, because they are thinking of the soul of the ship, of its moral personality, of the symbol that it presents, and of the dear memories that it evokes. For them there is identification between the personality of the ship and the person Jeanne d'Arc. Saying la Jeanne d'Arc is a bit of a matter of professional faith for them; they emphasize a sort of real presence of Jeanne d'Arc on board the vessel. This sentiment is very noble, but the rougher and more down-to-earth sentiment of their crew has difficulty following them.

\$5 They are nevertheless the ones who carried the day, for the military always takes the higher ranks to be correct. A decision of the minister of the navy is responsible for declaring la Jeanne d'Arc and its consort feminine in gender. But this does not at all imply that this decision conforms to the spirit of the French language, to which the people are more faithful than the elite. 
$\$ 6$ Due to this confusion, a number of prudent journalists avoid taking a side; they instead designate ships without an article: Jeanne d'Arc, Normandie. This is a prudent, if not glorious strategy.

\$7 What is applicable to big ships is not applicable to small ones. Small ships receive feminine gender. One says la Marie-Jeanne because it is une barque 'a barque'. La BelleNivernaise of Alphonse Daudet was une péniche 'a barge'.

$\$ 8$ In Italian, where the often elided noun can be masculine or feminine, one finds both. One says il principessa Elena 'the Princess Helen', because the source noun is masculine (il vascello 'the vessel') - whoever comes to confuse the gender of vascelle with that of the princess risks unleashing a diplomatic incident. What is true for some is not true for others. However, one says la corazzata, since the source noun is feminine (la nave 'the ship'); and the result of this is that all battleships are feminine: la Dante Alighieri.

$\$ 9$ The gender of ships is much different in English, where mariners have a sort of conjugal love for them, like a mechanic has a love for his locomotive. Hence English, which does not have gender for objects, makes an exception for ships and machines, which are always feminine.

\$10 In German the names of large war vessels are masculine in principle like in French: der Lützow. But one finds the feminine for battleships, perhaps due to Italien influence: die Deutschland.

\section{Chapter 214. Inverse transfer $\mathrm{O}>\mathrm{A}>0$}

$$
\begin{aligned}
\mathrm{O}>\mathrm{A} & >\mathrm{O} \\
\mathrm{O} & >\mathrm{A}
\end{aligned}
$$

\$1 Double reversible transfer according to the formula $\mathrm{O}>\mathrm{A}>\mathrm{O}$ can figure in the governing of an inverse transfer of the sort: un imbécile de marmiton 'an imbecile of a kitchen boy' (above Chapter 196).

$\$ 2$ At first, it seems that even though the transfer of the governor of un drôle de corps lit. 'a strange of body', that is 'a strange body', is indentical in every way to that of the governor of un imbécille de marmiton, and that the word drôle here is an adjective transferred to a noun corresponding to the formula $\mathrm{A}>\mathrm{O}$ just like with the adjective imbécile.

$\$ 3$ However, when one examines the situation more closely, a major reason to reject this analysis comes to light. It has to do with the etymology of the word drôle.

$\$ 4$ Indeed, although dictionaries take drôle to be both an adjective and a noun and it is sensed more often than not to be an adjective by most French speakers, its origin is that of a noun, and it is sensed to be an adjective due to transfer, although this transfer is frozen and thus no longer productive. 
\$5 For a number of French speakers, the word retains its old meaning of 'pleasant mischief', and then 'child, ${ }^{252}$ and it is likely a loanword borrowed from Middle Dutch drolle 'chap, imp'.

$\$ 6$ Yet all these words are nouns. Etymologically, one therefore cannot consider drôle an adjective.

$\$ 7$ The same reasoning is valid any time it can be shown that the governing term was originally a noun, a fact that one can easily establish in general by consulting an etymological dictionary: un fou de chauffard 'a mad (man) of a driver', cette folle d'Adrienne 'this mad (woman) of Adrienne' (A. Lichtenberger, Petite Madame, p. 57), ce fourbe de Paul 'that deceitful (man) of Paul' (A. Lichtenberger, Petite Madame, p. 223); Eng. that fool of a waiter. $\$ 8$ However, this fact prohibits one from seeing an adjective in drôle and hence necessarily forces one to assume that it is a noun. Is it therefore nevertheless necessary to posit reversive transfer of the sort $\mathrm{O}>\mathrm{A}>\mathrm{O}$ to account for the nominal category of the governor? Is it no simpler to assume that one is dealing with a former noun without transfer as in la ville de Paris 'the city of Paris', cet âne de Durand, lit. 'that ass of Durand' (cf. Chapter 195, $\$ 8$ and $\$ 12$ ), that is 'that jerk Durand'? In such a case, the governing term is not transferred, so it is in no way an instance of reversive transfer.

$\$ 9$ This second hypothesis is no more satisfying than the one above in $\$ 3$, since three arguments support an analysis in terms of reversive transfer $\mathrm{O}>\mathrm{A}>\mathrm{O}$ of the governor.

$\$ 10$ The first is that the governor is subject to a change of gender, and it often takes the gender of the subordinate. One says un drôle de corps, lit. 'a strange of shape' = ' a strange shape', but une drôle d'idée 'a strange of idea', quel drôle de temps! 'what strange of times', but une drôle de situation 'a strange-of situation', without forgetting la drôle de guerre, lit. 'the strange of war', that is 'the Phoney War'.

$\$ 11$ The same is true of the noun bête, which is normally feminine. One can contrast the feminine cette grande bête de Russie 'this large beast of Russia' (A. Lichtenberger, Petite Madame, p. 177) to the masculine C'est seulement au déjeuner de midi qu'elle a osé raconteur à Jacques ce bête de rêve 'Only at lunch did she risk telling Jack about this stupid (of) dream' (A. Lichtenberger, Petite Madame, p. 55).

$\$ 12$ Yet we have seen (Chapter $210, \$ 10$ ) that reversive double transfer is susceptible to evoking a change in gender. The change in gender that arises here seems to be a distinctive sign by which one can recognize that one is dealing with reversive double transfer.

$\$ 13$ The second argument in favor of reversive double transfer $\mathrm{O}>\mathrm{A}>\mathrm{O}$ is that the source of transfer is subject to syntactic treatments that are only conceivable with an adjective and

252. First editors' note: Such is the case in Occitan also. See the article by the abbot De Sauvages, Dictionnaire Languedocien-français, new edition, Nismes, 1785, p. 249. The word was hardly used as an adjective in this language. 
that as a consequence can only be explained insofar as the source can be or has been seen as an adjective. This situation forces one to postulate the step A of reversive transfer.

$\$ 14$ These syntactic treatments are above all the superlative, an eminent adjectival category. It has been attributed to a noun only insofar as it was conceived of as adjectival, e.g. Le plus âne des trois n'est pas celui qu'on pense, lit. 'The most fool of the three is not the one that one thinks' (La Fontaine, Fables, III, 1, v. 37).

$\$ 15$ We repeat also that in the expressions of interest, the governor is often preceded by the adverbs si 'so' and très 'very', which can only be subordinate to an adjective: une si drôle d'idée 'such a strange idea', une très drôle d'idée 'a very strange idea'.

$\$ 16$ The third argument in favor of double transfer is that given the semantic appearance of a noun, the actual meaning that it bears is very often that of the adjective to which the noun has been transferred, e.g. Un saint homme de chat bien fourré, gros et gras 'A saintly male cat with a thick pelt, large and stout' (La Fontaine, Fables, VII, 16).

Ce brave homme de singe 'this brave male monkey' (Bathild Bouniol, Quand les pommiers sont en fleurs, 1861, Aventures d'un hanneton, p 95), ce brave garcon de chien 'this brave boy dog' (Barrès, L'ennemi des lois, p. 113). It is evident that the meanings of the nouns homme 'man' and garcon 'boy' have entirely disappeared behind the meanings of the adjectives saint 'saintly' and brave 'brave', since neither a chat 'cat' nor a singe 'monkey' can be called a man, nor can a chien 'dog' be called a garcon 'boy'.

$\$ 17$ In conclusion, the transfer of the governor of un imbécile de marmiton 'an imbecile of a kitchen boy' and of the governor of un drôle de corps 'an oddness of body' are clearly of different types, since the first is simple transfer according to the formula $\mathrm{A}>\mathrm{O}$, whereas the second is reversive transfer of the sort $\mathrm{O}>\mathrm{A}>\mathrm{O}$.

\section{Chapter 215. Double $\mathrm{O}>\mathrm{A}>\mathrm{O}$ transfer with the second transfer unmarked}

\$1 Double transfer where only the first instance of transfer is marked is very rare across languages.

$\$ 2$ The absence of a marker for the second instance of transfer is quite difficult to achieve. To accomplish this, one must allow for a certain amount of abstraction.

$\$ 3$ Such is the case in Greek: gráphesthai tina dōrodokías 'accuse someone of venality'. In this expression, the noun dorodokía is transferred by the use of the genitive to an adjective that is subordinate to the noun dikēn or gráphēn 'process', which can be expressed or not, in which case the genitive dōrodokías is transferred to a noun enriched anaphorically with the meaning of díkēn or gráphèn, but without a marker.

$\$ 4$ Likewise in Latin: Scipionis orationes meliores sunt quam Laelii 'Scipio's speeches are worth more than those of Laelius'. In this example, the noun Laelii is transferred by the 
use of the genitive to an adjective that is subordinate to a second instance of the noun orationes, which could be expressed but would constitute a breach of style since it would be a repetition. Actually what occurs is that the genitive Laelii is transferred to a noun enriched anaphorically with the meaning of orationes, but without a marker.

$\$ 5$ An expression that is even more difficult is what one encounters with H. L. Mencken in American English: That umbrella is the young lady I go with's. ${ }^{253}$ What makes this sentence difficult is the genitive marker 's; instead of being postposed to the noun lady, it behaves as though it is postposed to the entire group formed by lady and the relative clause I go with, which is subordinate to lady. The structure of this sentence is exactly the same as for the preceding Greek and Latin examples. The nominal node that has been transferred to an adjective by the use of the genitive is retransferred to a noun by an instance of transfer without a marker.

$\$ 6$ The difficulty of this type of transfer, which itself is due to the absence of a retranslative, demonstrates the utility of this word in the languages that possess it. These languages take a great ease of expression from it.

$\$ 7$ The partitive articles $d u(=d e$ le) vin 'some wine' and de la bière 'some beer' in French are also particular tools. The preposition de here plays the role of a translative and marks the first instance of transfer $\mathrm{O}>\mathrm{A}$, but the articles le and la play the role of simple indices and not of translatives. The second instance of transfer is not marked. That is why this expression seems so shocking at first to foreigners who are not used to it.

\section{Chapter 216. Nominal double transfer ending with the last transfer $A>0$}

\$1 Just as double transfer according to the formula $\mathrm{O}>\mathrm{A}>\mathrm{O}$, which was examined in the preceding chapters (Chapter 211-215), is based on simple transfer of the sort $\mathrm{O}>\mathrm{A}$ (Chapter 192-195), where the transferred element is itself transferred to a noun by adjoining the article, which results in a second instance of simple transfer of the sort $\mathrm{A}>\mathrm{O}$, one can theoretically produce double transfer from each of these simple transfers (Chapter 211, \$3).

$\$ 2$ In the present chapter, we examine double transfer where the instances of transfer are of the sort $\mathrm{A}>\mathrm{A}$ or $\mathrm{E}>\mathrm{A}$.

$\$_{3}$ Such is the case with double transfer of the sort $\mathrm{A}>\mathrm{A}>\mathrm{O}$, which starts with subcategory transfer of the sort A > A (Chapter 208, \$5) and continues with transfer of the sort A > $\mathrm{O}$ (Chapter 177, \$4). The instance of subcategory transfer can be marked: Fr. un douzième provisoire 'a twelfth provisional (one)', or it can occur without a marker: Fr. le six juillet 'the sixth of July', lit. 'the six July'.

253. Cf. Bulletin de la Société de Linguistique de Paris, 1922, p. XXII. 
$\$ 4$ It is by virtue of this same transfer that theater style produces le quatre 'the four' in order to designate the fourth act or act IV of a piece. For example, the director is able to say to the actors: En scène pour le quatre! 'On stage for the four(th act)'.

$\$ 5$ In the two preceding examples, only the second instance of transfer, that of the adjective to the noun $\mathrm{A}>\mathrm{O}$, is marked. The first, the subcategory transfer $\mathrm{A}>\mathrm{A}$ of a cardinal numeral to an ordinal numeral, is not marked.

$\$ 6$ Likewise, the addition of nominal transfer of the sort $\mathrm{A}>\mathrm{O}$ to simple transfer of the sort $\mathrm{E}>\mathrm{A}$ (Chapter 197) produces double transfer with the formula $\mathrm{E}>\mathrm{A}>\mathrm{O}$ (cf. Chapter $179, \$ 1)$.

$\$ 7$ One encounters this sort of double transfer with a double marking in Gr. ohi palaioi 'the ancients'. One has to distinguish the adverb pálai 'formerly'. An initial fixed transfer is included in the derivation and marked by the suffix -ios of the adjective palaió. Concerning the second instance of transfer, that of an adjective to a noun, it has the article as its translative.

$\$ 8$ The first instance of transfer lacks a marker in familiar French and is neglected: Nous sommes le combien aujourd'hui?, lit. 'We are the how many today?', that is 'What's the date today? ${ }^{254}$ The article le serves essentially to transfer combien from an adjective to a noun, but no marker is present to indicate that the adverb combien has been first transferred to an adjective (Chapter 197, \$2). One sees the same mechanism in Fr. un ci-devant 'a former (aristocrat)', and in the quite slipshod J'en ai du pour 'I've got (arguments) for'.

$\$ 9$ The same mechanism is encountered in Greek in transfer according to the formula E > A > O ohi pálai 'the ancients', where only the second instance of transfer is marked by the article, whereas the first lacks a marker (cf. Chapter 197, \$6).

\$10 It is, in contrast, the second transfer that is without a marker in the French expression C'est de trop; c'est déjà de trop 'It is (of) too much; it is already (of) too much' (Henri Lavedan, Viveurs, Act III, p. 197). Concerning the first instance of transfer, that of an adverb to an adjective, it has the preposition de 'of' as its translative (cf. Chapter $197, \$ 1)$.

\section{Chapter 217. Double I $>$ A $>0$ transfer}

\$1 The addition of nominal transfer of the sort $\mathrm{A}>\mathrm{O}$ to simple transfer of the sort $\mathrm{I}>\mathrm{A}$ (cf. Chapter 198, 199, and 200) delivers double transfer with the formula I > A $>$ O.

$\$ 2$ The targets that are relevant to this type of transfer are by definition participles (I > A) transferred to nouns.

254. Cf. A. Moufflet, Contre le massacre de la langue française, 1930, p. 47. 
$\$ 3$ These nouns stemming from participles can be agentive nouns (cf. Chapter 174, §9) with double marked transfer. The first instance of transfer is marked by the use of the participle, the second by the use of the article (definite or indefinite, cf. Chapter 177, \$2).

$\$ 4$ In a large number of languages, the participle constituting the first instance of transfer can be a concomitant participle.

$\$ 5$ Hence it is common in French to use a concomitant participle as a noun, this participle having been transformed to a noun by the article:

\begin{tabular}{lll}
\hline French & Literally & Translation \\
\hline le commandant & 'the commanding' & 'the commander' \\
un étudiant & 'a studying' & 'a student' \\
un commerçant & 'a trading' & 'a storekeeper' \\
les vivants & 'the livings' & 'the living' \\
les ressortissants étrangers & 'the foreign comings & 'the foreigners' \\
& (under the jurisdiction)' & \\
un brillant & 'a shining' & 'a brilliant' \\
un tournant & 'a turning' & 'a bend' \\
un délinquant & 'an offending' & 'a delinquent' \\
un pliant & 'a folding' & 'a folding chair' \\
un dépliant & 'a unfolding' & 'a leaflet' \\
\hline
\end{tabular}

$\$ 6$ The French noun restaurant 'restaurant', lit. 'feeding', is of this sort. However, a false assumption is that restaurant comes from local qui restaure 'place that feeds'; it comes, rather, from un bouillon qui restaure 'a broth that feeds'. It is only after the fact by way of metonymy (content for container) that one has designated the place where one serves food restaurant by the noun designating the broth that one serves. A metonymy of the same sort had already affected the word café 'coffee' at the end of the 17th century (from 'coffee' to 'cafe'), and the word bouillon 'broth' itself had to undergo an analogous fate in the 19th century: un bouillon Duval, a kind of popular restaurants founded by Duval serving traditional French cuisine.

$\$ 7$ The nouns ending in -ant stemming from participles rest in general on transfer (I > A) of a very evolved sort, and the instances of this sort of transfer readily appear as a consequence in various forms and with an orthography that is more or less archaic (cf Chapter 200): un fabricant 'a manufacturer', un intrigant 'a schemer', un enfant 'a child' ( $<$ Lat. infans 'one who does not speak'), le surveillant 'the guard', un agent 'an agent', un précédent 'a precedent', un différend 'a dispute'.

Celui qui met un frein à la fureur des flots Sait aussi des méchants arrêter les complots
'The one who impedes the flow Knows also the bad guys stop the plots.'

(Racine, Athalie, I, 1) 
$\$ 8$ This very expressive process remains very productive in slang (cf. Chapter 177): un grimpant 'a climber' (a pant leg), une toquante 'a ticker' (a watch).

\$9 This is also why the same derivatives are no longer sensitive to the notion of diathesis: cf. Fr. le plaignant 'the plaintiff', which stems from transfer of the recessive verb se plaindre 'to complain'.

\$10 Greek makes common use of a concomitant participle transferred to a noun by the article ho nûn légōn 'the orator who is speaking at this moment', eisin ohi légontes 'there are people who say', ohi tòn dêmon kolakeúontes 'the ones who flatter the people, the flatterers of people', ohi ep' emporían...paróntes 'the ones who are here to conduct commerce'.

$\$ 11$ Eng. ozone is of the same type as the Greek examples just considered, for it is a related to $o z \bar{o} n$, the Greek concomitant particle of the verb ózō 'I exhale an odor'.

$\$ 12$ Although less frequent - perhaps because the absence of the particle prevents the use of a marker for the second instance of transfer - the same phenomenon is not unknown in Latin: părentes 'parents' (concomitant particle of pario 'I give birth'), pärentes 'the subjects' (concomitant participle of pāreo 'I obey').

$\$ 13$ The process comes from Indo-European: ${ }^{\star} w \bar{e}-n t$-os (Lat. ventus, Fr. vent, Ger. Wind) 'the wind', lit. 'the blowing', concomitant participle of the root ${ }^{*} w e$ - 'blow' ${ }^{*} d-e /{ }_{o} n s$ (Lat. dens, Fr. dent, Gr. odous, Ger. zahn) 'tooth', lit. 'the (one) eating', concomitant participle of the root ${ }^{*} e d$ - 'to eat'.

$\$ 14$ The phenomenon is not common in German where it only appears in the fixed transfer of Germanic words or Latin loanwords.

\begin{tabular}{|c|c|}
\hline $\begin{array}{l}\text { Germanic } \\
\text { loanwords } \\
\text { in German }\end{array}$ & $\begin{array}{l}\text { der Hailand 'the Savior' (former concomitant participle } \\
\text { of heilen 'heal'), der Weigand 'the combatant' (former } \\
\text { concomitant participle of the retained archaic verb wigan } \\
\text { 'combat'), der Freund 'the friend' (former concomitant } \\
\text { participle of Germanic ‘frijōn 'to love'), der Feind } \\
\text { 'the enemy' (< Middle High Ger. fì (e)nt, concomitant } \\
\text { participle of Middle High German fien 'to hate') }\end{array}$ \\
\hline $\begin{array}{l}\text { Latin } \\
\text { loanwords } \\
\text { in German }\end{array}$ & $\begin{array}{l}\text { der Agent 'the agent', der Patient 'the patient', der Student } \\
\text { 'the student', der Assistant 'the assistant', der Konkurrent } \\
\text { 'the competitor, der Kontinent 'the continent' }\end{array}$ \\
\hline
\end{tabular}

$\$ 15$ The use of the anterior participle transferred to a noun by the article is no less frequent than that of the concomitant participle:

\begin{tabular}{lll}
\hline French & Literally & Translation \\
\hline un gradé & 'a graded' & 'an officer' \\
l'accusé & 'the accused' & 'the accused' \\
\hline
\end{tabular}




\begin{tabular}{|c|c|c|}
\hline l'inculpé & 'the charged' & 'the charged' \\
\hline un avoué & 'a confessed' & 'a solicitor' \\
\hline un agrégé & 'an aggregated' & 'a qualified teacher' \\
\hline un délégué & 'a delegated' & 'a delegate' \\
\hline un lettré & 'a lettered' & 'a man of letters' \\
\hline un déclassé & 'a demoted' & 'a demoted person' \\
\hline un nouveau-né & 'a new-born' & 'a newborn' \\
\hline un attaché & 'an attached' & 'an attaché' \\
\hline un blessé & 'a wounded' & 'a wounded person' \\
\hline un fondé de pouvoir & 'a founded of power' & 'a senior executive' \\
\hline un effronté & 'a fronted' & 'an impudent person' \\
\hline un décolleté & 'a cut (under the neck)' & 'a low-cut' \\
\hline un abrégé & 'a shortened' & 'a short guide' \\
\hline un résumé & 'a summarized' & 'a summary' \\
\hline un laissé pour compte & 'a left for count' & $\begin{array}{l}\text { 'an unsold article, } \\
\text { a rejected person' }\end{array}$ \\
\hline la fiancée & 'the engaged' & 'the fiancée' \\
\hline la mariée & 'the married' & 'the bride' \\
\hline une pensée & 'a thought' & 'a thought' \\
\hline l'assemblée & 'the assembled' & $\begin{array}{l}\text { 'a gathering, } \\
\text { a meeting' }\end{array}$ \\
\hline la fumée & 'the smoked' & 'the smoke' \\
\hline des frites & 'frieds' & 'French fries' \\
\hline une fusée & 'a flied out' & 'a rocket' \\
\hline un reçu & 'a recieved' & 'a receipt' \\
\hline un tissu & 'a weaved' & 'a fabric' \\
\hline une tortue & 'a crooked' & 'a turtle' \\
\hline un écrit & 'a written' & 'a piece of writing' \\
\hline un point & $\begin{array}{l}\text { 'anterior participle } \\
\text { of poindre 'dawn'” }\end{array}$ & 'a point' \\
\hline un benêt & $\begin{array}{l}<\text { Lat. benedictus, anterior } \\
\text { participle of benidicere } \\
\text { 'bless' }\end{array}$ & 'a simpleton' \\
\hline un commis & 'a commited' & 'an assistant' \\
\hline un sursis & 'a postponed' & 'a reprieve' \\
\hline l'envers & $\begin{array}{l}<\text { Lat. inversus, anterior } \\
\text { participle of invertere 'to } \\
\text { reverse' }\end{array}$ & 'the back, the wrong side' \\
\hline
\end{tabular}


\$16 The source of this double transfer can be the inferior term of a nominal and adjectival inverse transfer (Chapter 215, \$7): J'en ai (du fin et) du bien râpé 'I have (fine) and well grinded (one)' (J'ai du bon tabac 'I have good tobacco', popular song).

$\$ 17$ Finally, the source of this double transfer can be a sentence word (cf. above, Chapter 45) such as Sapristi! 'For God's sake!': Cette sapristi de grippe! 'This darn flu!'.

$\$ 18$ The anterior participle transferred to a noun by the article is also common in Greek: Peisístratos ho turanneúsas 'Psistrate, tyrant of Athens', lit. 'Pisistrate, the having been the tyrant of Athenians'.

$\$ 19$ The use of the translative celui (cf. Chapter $210, \$ 12$ and $211, \$ 11$ ) for the retransfer of the participle is quite fluid in French. It can only be justified insofar as the participle is actually sensed to be a participle, that is, sensed to be a verb transferred to an adjective. It is not justified when the participle is already sensed to be a veritable adjective, since the second instance of transfer cannot be interpreted as retransfer, for the first instance of transfer has not been perceived.

$\$ 20$ Concerning the legitimacy of the retransfer of the participle using the translative celui, the opinions of grammarians diverge.

$\$ 21$ The purists contest its existence categorically. According to Bescherelle, it is considered to be deviant by Maugard, Domergue, Girault, Duvivier, Noël, and Chapsal. This opinion is shared by Littré, and in present times by Moufflet ${ }^{255}$ and the French Academy. ${ }^{256}$ It is indisputable that this expression always has something more or less shocking about it, and writers concerned with good style have always avoided it.

$\$ 22$ Nevertheless, it existed earlier and has been used by such great authors as Racine, Montesquieu, and Voltaire. It is defended by avant-garde grammarians: Bescherelle, Ferdinand Brunot, and Damourette and Pichon. ${ }^{257}$

\$23 Due to the indulgent tolerance of these grammarians, actual use in the language is increasingly tending to employ the translative celui as a retranslative of the participle, not only in everyday French, which is overlooked, but also in journalistic and administrative style.

\$24 In 1936-1937, one could, after the changeover of their meters, therefore read the following notice inside taxis in Paris: Le compteur de cette voiture étant transformé, la somme

255. André Moufflet, Contre le massacre de la langue française, pp. 141 and 280, and Encore le massacre de la langue française, Paris 1935, p. 109.

256. Grammaire de l'Académie Française, p. 54.

257. Damourette \& Pichon, Des mots à la pensée. Essai de Grammaire de la Langue Française, II, p. 179ff. 
à payer est celle marquée au voyant 'The counter of this car being changed, the sum to be payed is the one shown with the indicator'.

\$25 The same is true of the constitution from the 19th of April 1946 approved by the referendum on the 5th of May. It contained the expression in question two times: Le conseil de l'Union française donne son avis dans le même délai que celui prévu pour les débats de l'Assemblée Nationale (Art. 73), il nomme à tous les emplois civils et militaires, sauf ceux prévus par les articles 77 et 96 (Art. 78) 'The committee of the French Union gives its opinion in the same timeslot as the one allotted to the debates of the National Assembly (Article 73), it nominates all the civil and military employees, except the ones foreseen by Articles 77 and 96 (Article 78)'.

\$26 In addition to the preceding cases where the transferred noun is agentive, one should not forget those cases where it is an abstract noun (cf. Chapter 174, \$6).

$\$ 27$ Such is the case for derivatives resulting from fixed transfer rendered by the derivational suffix -ance (-ence) in French. When this suffix appears in a form where one recognizes the formative of the comcomitant participle -ant (-ent), it is the marker of both the first instance of transfer $(\mathrm{I}>\mathrm{A})$ that results in an adjective and that of the second instance of transfer $(\mathrm{A}>\mathrm{O})$ : tolérance 'tolerance', souffrance 'suffering', croissance 'growth', naissance 'birth', convalescence 'convalescence', adolescence 'adolescence', patience 'patience.'

$\$ 28$ Like the precedents (cf. \$19), these derivatives are due in general to transfer (I > A) of a sort that is very evolved and as a consequence, they appear with an archaic orthography: bienveillance 'benevolence', vaillance 'courage', puissance 'power', une croyance 'a belief', une vacance d'emploi 'a job vacancy', omni-potence 'omnipotence', dé-cadence 'decadence'.

\$29 From their archaic origin as participles and the transfer I $>\mathrm{A}>\mathrm{O}$ from which they arise, these derivatives retain a mildness and a poetic aura that action nouns arising from the same source by way of a harsher and more direct transfer I $>\mathrm{O}$ do not have:

\begin{tabular}{|c|c|}
\hline $\mathrm{I}>\mathrm{A}>\mathrm{O}$ & $\mathrm{I}>\mathrm{O}$ \\
\hline $\begin{array}{l}\text { Combien j'ai douce souvenance } \\
\text { Du joli lieu de ma naissance } \\
\text { 'How often I have the sweet memory } \\
\text { of my birth place.' } \\
\text { (Châteaubriand, Les Aventures } \\
\text { du dernier Abencérage) }\end{array}$ & $\begin{array}{l}\text { Dante, pourquoi dis-tu qu'il n'est pire misère } \\
\text { Qu'un souvenir heureux dans les jours de } \\
\text { douleur? } \\
\text { 'Dante, why do you say that there is no } \\
\text { worse misery } \\
\text { Than a happy memory in days of suffering?' } \\
\text { (Alfred de Musset, Souvenir) }\end{array}$ \\
\hline $\begin{array}{l}\text { L'amour essentiel à notre penitence } \\
\text { Doit être l'heureux fruit de notre } \\
\text { repentance. } \\
\text { 'Love is essential to our penitence } \\
\text { It must be the joy of the result of } \\
\text { of our repentence.' (Boileau) }\end{array}$ & $\begin{array}{l}\text { Dieu fit du repentir la vertu des mortels. } \\
\text { 'God made repentence the virtue of } \\
\text { mortals.' } \\
\text { (Voltaire, Olympie, II, 2) }\end{array}$ \\
\hline
\end{tabular}


\$30 It must be added that the poetic aura of derivatives in -ance in the first column is also due to what arises from the two verbs of state that are commonly employed with impersonal voice. One said Il me souvient de mon enfance 'It reminds me of my childhood', Il me repent de cette faute 'I regret this mistake', before saying Je me souviens de mon enfance 'I remember my childhood', Je me repens de cette faute 'I regret this mistake'.

\$31 The transformation of a circumstant to a first actant that results from this allows one to say that the derived forms in -ance in the first column arise from the impersonal expressions and that la souvenance 'memory'and la repentance 'repentance' correspond to Il me souvient and Il me repent, respectively, whereas the infinitives in -ir in the second column arise from the personal expression that is more productive and that le souvenir the memory' and le repentir 'the remorse' correspond to Je me souviens 'I remember' and Je me repens 'I regret'.

\section{Chapter 218. Double transfer with the second transfer as E $>0$}

$\$ 1$ The addition of nominal transfer of the sort $\mathrm{E}>\mathrm{O}$ (Chapter 179) to simple transfer of the sort $\mathrm{O}>\mathrm{E}($ Chapter 201, \$5) results in reversive double transfer of the sort $\mathrm{O}>\mathrm{E}>\mathrm{O}$. $\$ 2$ This type of transfer is abundantly present in French with a double marker, the transfer of the noun to an adverb having a preposition as the translative and the instance of reversive transfer of the adverb to a noun having the article as its translative.

$\$ 3$ The preposition that serves as translative for the first instance of transfer is written without a hyphen: un in pace, lit. 'an in peace', that is, 'a rest-in-peace', le pour et le contre lit. 'the for and the against', that is, 'the pros and cons', l'entre deux guerres 'the (time) between two wars', un moins de trente ans, lit. 'a less than thirty years', that is, 'a man younger than thirty'. $\$ 4$ In contrast, agglutination is graphically marked by a hyphen in l'après-midi 'the afternoon', un avant-propos 'a foreword', un à-côté 'a perk', lit. 'a beside', un vis-à-vis 'a closed outlook', lit. 'a towards', l'entre-deux-mers, lit. 'the between-two-seas', that is, a kind of dry white wine coming form a French region between two rivers, un coq-à-l'âne, lit. 'a cock-toass', that is an abrupt change of subject in a conversation (passer du coq à l'âne 'jump from one subject to another').

\$5 Finally, agglutination is complete and acknowledged orthographically in the individual words l'aplomb 'the self-assurance' ( $<$ à plomb 'with lead'), un acompte 'a deposit' $(<\dot{a}$ compte 'with count'), un acoup 'a jolt' ( $<$ à coup 'with blow'), un aparté 'an aside' ( $<$ à part 'aside'), l'endroit 'the position' ( $<$ en droit 'in right'), l'entremets 'the dessert' ( $<$ entre mets 'between dishes').

$\$ 6$ One can also encounter double transfer of this type where only the first instance of transfer is marked. One says, for example - although the expression is not very refined De cinq à six me paraît être le meilleur moment 'From five to six seems to me to be the best time'. 
\$7 Finally, one encounters double transfer without any marker at all. Such is the case with French beaucoup (d'eau) 'much (water)', where neither etymological transfer of the noun (beau) coup '(nice) blow' to an adverb nor that of beaucoup to a noun is marked.

$\$ 8$ One has to acknowledge transfer of the sort $\mathrm{O}>\mathrm{E}>\mathrm{O}$ in de quoi 'of what' in the polite expression Il n'y a pas de quoi 'Think nothing of it, You're welcome', lit. 'There is no of what', which has become stereotyped as a response showing empathy. The first instance of transfer $(\mathrm{O}>\mathrm{E})$, which gives rise to the adverb subordinated to the verbal notion contained in the sentence word merci, is marked by the translative de, and the second instance of transfer $(\mathrm{E}>\mathrm{O})$, which renders the adverb as a noun subordinate to il $y a$, is not marked.

$\$ 9$ The same case is present in transfer of the sort A > E > O for peu 'little'. One is dealing etymologically with the colloquial Latin adverb pauci 'few in number', transferred to a quantity adverb by the use of the neuter form (Chapter 205, \$23). The French adverb peu that is derived from it is transferred to a noun in expressions of the sort peu d'eau 'little water'.

10. Finally, one of these instances of transfer in the double transfer can be a transvaluation (Chapter 204). Such is the case for the first instance of transfer in le dedans 'the inside', le dehors 'the outside', le dessus 'the above', le dessous 'the below', where the second instance of transfer has the article as its marker.

\section{Chapter 219. Double transfer with the second transfer as $\mathrm{O}>\mathrm{A}$}

$\$ 1$ The first type of transfer that is mentioned here is reversive transfer according to the formula $\mathrm{A}>\mathrm{O}>\mathrm{A}$.

$\$ 2$ This double transfer can be doubly marked, the first instance of transfer $(\mathrm{A}>\mathrm{O})$ by the article having translative value (cf. Chapter $177, \S 2$ and 3 ) and the second instance $(\mathrm{O}>\mathrm{A}$ ) by the preposition $d e$ (cf. Chapter 192, \$2), being agreed that, according to Chapter 210, $\$ 5$, the latter precedes the former in the spoken chain, the consequence being the forms d'un, de la, and $d u$ (de le).

Salomon: Et c'est moi qui ferai Actéon!... un

Actéon..., d'un moderne!

(Henri Lavedan, Viveurs, Act I, p. 38)

le jeu de la Belle

la quintessence du joli (Marivaux)
'And it's me who will play Actéon!... an Actéon..., a modern one!'

'the game of the beautiful (woman)'

'the quintessence of the pretty(ness)'

This expression often constitutes a neologism of the precious style during the beginning of the 18th century, as illustrated by the last example.

$\$ 3$ The syntactic structure here is also the explanation for the idiomatic expressions En voici d'une autre 'Here's another', En voilà d'une autre 'There's another', Mademoiselle Marie: En voici d'une autre 'Mademoiselle Marie: Here's another' (Genevray, l'Institutrice, scene 2, 
Magasin d'Education et de Récréation, 1881, II, p. 23). The feminine gender of the indefinite article une shows that ellipsis resulting in the adjective being transferred to a noun must involve a feminine noun such as, for example, nature 'nature' or espèce 'sort'.

$\$ 4$ The same double transfer of the sort $\mathrm{A}>\mathrm{O}>\mathrm{A}$ occurs in English in the expression $a$ friend of mine, to be compared with French un de mes amis, lit. 'one of my friends'. While the second instance of transfer here is marked with the preposition of as it is in French with the preposition $d e$ according to the same syntactic formula, the first instance of transfer is marked by the use of the possessive pronoun mine instead of by the possessive adjective $m y$ (cf. Chapter 178, \$5).

\$5 The second instance of transfer is marked, whereas the first is not, in a large number of French expressions such as: un bâton de rouge 'a lipstick', lit. 'a stick of red' (cf. Stemma 326), quelqu'un d'autre 'someone (of) else', Il n'y a que lui de riche et d'indépendant sur la terre 'There is only him, rich and independent on earth' (Charles Nodier, le Génie Bonhomme, p. 299), les fonds que j'avais de disponibles en ce moment 'the funds that I had (of) available at that time' (Jules Verne, Mathias Sandorf, first part, Chapter 3).

$\$ 6$ In Latin a reversive double transfer of the sort $\mathrm{A}>\mathrm{O}>\mathrm{A}$, where the second instance of transfer $\mathrm{O}>\mathrm{A}$ is marked by the genitive of the relative pronoun is generally nullified and replaced by the simple non-reflexive relative pronoun A: Quo in numero (instead of quorum in numero) tu certe fuisse 'You will certainly have been among them' (Cicero, Ad familiares, VII, 6, 2).

\$7 One also finds recursive transfer of the sort $\mathrm{A}>\mathrm{O}>\mathrm{A}$ where the first instance of transfer lacks a marker and where the subordinate term constitutes an instance of reversive transfer (Chapter 196): un imbécile d'individu 'an imbecile of an individual. The word individu derives by way of etymological transfer from the Latin adjective individuus 'indivisible', which is transferred to a noun in the form individuum 'what is indivisible' of scholastic Latin, which itself is retransferred to an adjective by the preposition $d e$ in French.

$\$ 8$ While the governing term of inverse transfer itself contains un instance of inverse transfer according to the formula $\mathrm{O}>\mathrm{A}>\mathrm{O}$ (Chapter 214), one can even have double inverse recursive transfer: un drôle d'individu 'a strange (of) person', un fou d'amoureux 'a person madly in love', lit. 'a mad(man) of lover' (see the abstract Stemma 327):

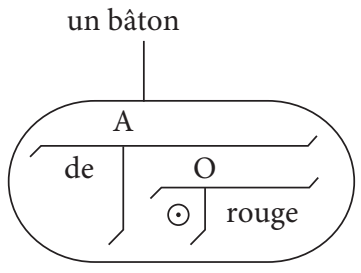

Stemma 326

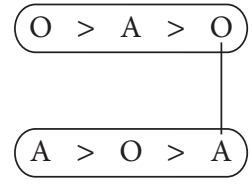

Stemma 327 un homme

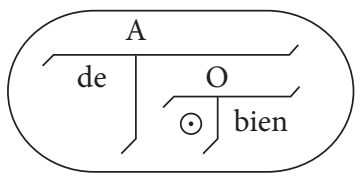


\$9 Finally, one has reversive transfer according to the formula $\mathrm{A}>\mathrm{O}>\mathrm{A}$, where the second instance of transfer lacks a marker, when the relative pronoun lequel is used as a "relative adjective" (cf. Chapter 249, \$14). The first instance of transfer from the relative adjective quel 'which' to the noun is marked by the article le (cf. Chapter 178, \$2-5), whereas the second lacks a marker. But this use of lequel with the value of an adjective, contradicting the translative le, is reserved for "comical or judicial style" (Bescherelle, Dictionnaire national, see lequel, p. 356). ${ }^{258}$

\begin{tabular}{lc}
\hline Lequel Hiérome, après & 'Which Hiérome, after \\
plusieurs rébellions, & a few rebellions, \\
Aurait atteint, frappé, moi & Would have hit me, \\
sergent, à la joue & the sergent, in the cheek \\
Et fait tomber d'un coup mon & And make my hat fall \\
chapeau dans la boue. & in the mud at once.'
\end{tabular}

(Racine, Les Plaideurs, II, 4) ${ }^{276}$

$\$ 10$ Among cases of double transfer where the second instance of transfer follows the formula $\mathrm{O}>\mathrm{A}$, one hardly finds double transfer of the sort $\mathrm{E}>\mathrm{O}>\mathrm{A}$, unlike reversive transfer according to the formula $\mathrm{A}>\mathrm{O}>\mathrm{A}$, which is relatively common.

$\$ 11$ The transfer $\mathrm{E}>\mathrm{O}>\mathrm{A}$ is encountered in the French expression un homme de bien 'a good man', lit. 'a man of good' (cf. Stemma 328). The first instance of transfer contained in this expression, that of the adverb bien 'well' being changed to the noun bien 'good', occurs without a marker, but that is nonetheless more than we have signaled with the marker in Chapter $179, \$ 3$. Concerning the second instance of transfer, transfer of a noun to a qualitative adjective is normally marked by the preposition $d e$ (cf. 192, \$2).

\section{Chapter 220. Double O > E $>$ A transfer}

\$1 Double transfer according to the formula $\mathrm{O}>\mathrm{E}>\mathrm{A}$ contains a simple instance of transfer of the sort $\mathrm{O}>\mathrm{E}$, which is the base for further transfer of the sort $\mathrm{E}>\mathrm{A}$.

$\$ 2$ Transfer according to the formula $\mathrm{O}>\mathrm{E}>\mathrm{A}$ is often marked by a double translative, as in French where each of the translatives is a preposition: Du côté de chez Swann 'Swann's Way', more lit. 'Over by Swann's place' (title of a novel by Marcel Proust). In this expression, the first instance of transfer is marked by the preposition chez (chez Alfred 'at Alfred's place') (cf. Chapter 201, \$5), and the second by the same preposition de 'of' as in a paragraph above (Chapter 192, \$2).

258. Translators' note: See Chapter $43, \$ 16$ concerning the use of lequel in this example. 
\$3 In Turkish, a language that has postpositions instead of prepositions, double transfer $\mathrm{O}>\mathrm{E}>\mathrm{A}$ is marked by two postposed translatives: $e l-i m-d e-k i$ 'that is in my hand'. The first postposed translative - $d e$ transfers the noun $e l$ - 'hand' contained in el-im 'my hand' to the locative adverb el-im-de 'in my hand' (Chapter 201, \$15). Then the second translative $-k i$ transfers the locative adverb to an adjective, which is expressed in English by a relative (that is, adjectival) clause. And the result is an expression like el-im-de-ki kitap 'the book that is in my hand?

$\$ 4$ We also have a parallel case in Russian where transfer is marked in the adjective: podmoskov-nyj 'from the neighborhood of Moscow'. The noun Moskva is first transferred to a locative adverb by way of the preposition pod 'near' and the instrumental case: pod Moskvoju 'in the neighborhood of Moscow' (Chapter 202, \$12). Then a second instance of transfer that has the adjectival suffix $-n y j$ as a marker transfers this adverbial locution to an adjective. This process of adjectival derivation, which includes the fixed preposition, is extremely frequent in Russian: na-stol-'nyj 'to be used on the table' for example, nastol'naja kniga 'bedside book' (cf. Chapter 192, \$8).

\$5 The same double transfer is frequent in French in second instances of transfer that lack a marker: la grève sur le tas 'the sit-down strike', un jour sans viande 'a day without meat'. Indeed if the first instance of transfer in such cases - that of a noun to an adverb - is marked by a preposition like sur 'on' or sans 'without' (cf. Chapter 201, \$4ff), no translative shows that the adverbial locution sur le tas 'on the heap' (meaning here 'on the job') or sans viande 'without meat' has been transferred to an adjective.

$\$ 6$ In a parallel case, the preposition suffices to evoke transfer and the target is not enunciated (cf. Chapter 192, \$4): Il y a un bon public pour 'There is good company for' (Paris-Soir, 2, III, 1937), without counting les jours avec 'the days with' and les jours sans 'the days without' as restricted periods of the last war. The noun that is not pronounced is l'alcool 'alcohol', which is only allowed in bars on certain days of the week.

$\$ 7$ The first instance of transfer can be marked by case: Lat. puer egregia indole 'a child of sunny nature. The ablative here transfers the noun indoles 'the nature, the disposition', which comprises the adjective egregius 'excellent', to a qualitative adjective.

$\$ 8$ Concerning double transfer of the sort $\mathrm{O}>\mathrm{E}>\mathrm{A}$, Latin prefers simple and direct transfer anyway, perhaps due to Greek influence. The translative is the genitive (Chapter 192, $\$ 6)$ : puer egregiae indolis 'a child of sunny nature'.

$\$ 9$ The first instance of transfer is marked by the dative in Lat. homo frugi 'a virtuous man'. But since the singular of this word had become rare and the second instance of transfer was not marked in any way, frugi ended up as an indeclinable adjective.

$\$ 10$ In Greek with the names of certain Attic demes (units of land around Athens), the first instance of transfer is sometimes marked by dative of place without a preposition: $h \bar{e}$ Marathôni mákhēe, in addition to the more common hē en Marathôni mákhē 'the battle of Marathon'. 
$\$ 11$ In German, Latin, Greek, and the majority of languages with case, the case that marks the first instance of transfer can be combined with a preposition (cf. Chapter 202, \$8ff.).

$\$ 12$ Hence one says in Ger. die Schalcht vor Reims 'the battle of Reims'.

$\$ 13$ In a similar case, French prefers the more abstract simple transfer $\mathrm{O}>\mathrm{A}$ over the double transfer $\mathrm{O}>\mathrm{E}>\mathrm{A}$, the latter being more consistent with the spirit of German: die Schlacht vor Reims, lit. 'the battle in front of Reims', that is 'the battle of Reims'; der Einfall in Marocco 'the invasion of Marocco'; der Schlüssel zu einem Schrank 'the key to a cupboard', die Liebe zum Ruhm 'the love of glory' (compare above \$8).

$\$ 14$ Greek, like German, can mark the first instance of transfer using case reinforced with a preposition: ho pròs hēmâs pólemos 'the war against us', oi amphí Astuágēn therapeutaí 'the servants around Astyge', ho perí tôs psukhês agốn 'the battle for life', hē par'emè eísodos 'the access beside me', hè epí Babulônos hodòs 'the road from Babylon', hè en Leúktrois mákhe 'the battle of Leucres'.

$\$ 15$ The same holds in Latin: vas ex auro 'a vase of gold', ietas adversus deos 'piety towards the gods', heres ex asse, lit. 'heir out of as (coin)' (left by the deceased), ${ }^{259}$ that is 'the universal legatee'. One should note in particular the nouns transferred to qualitative adjectives that indicate the functions of slaves, servus a pedibus 'slave for what concerns the feet', servus a bibliotheca 'slave for what is in the library', i.e. 'a librarian', servus a valetudinario 'slave for what has to do with sickness', i.e. '(male) nurse', libertus ab epistulis 'freed slave for what has to do with letters', i.e. 'secretary', libertus a rationibus 'freed slave for what concerns accounts', i.e. 'accountant'.

$\$ 16$ Finally, one can find double transfer with a marker in French of the sort $\mathrm{O}>\mathrm{E}>\mathrm{A}$ with ellipsis that is devoid of elegance: une moyenne de 68 franc par tonne départ mine 'a means of 68 franks per ton departure mine' (Le cri de Paris, XVII, IV, 1936), i.e. '...direct from the mine'; bouf mode, lit. 'beef style', i.e. 'beef dish'.

\section{Chapter 221. Double I $>0>A$ transfer}

\$1 Double transfer according to the formula $\mathrm{I}>\mathrm{O}>\mathrm{A}$ is simple transfer of the sort $\mathrm{I}>\mathrm{O}$ that is augmented by simple transfer of the sort $\mathrm{O}>\mathrm{A}$.

\$2 This sort of transfer is hence constituted by an infinitive or a verbal noun $(\mathrm{I}>\mathrm{O})$ transferred to an adjective $(\mathrm{O}>\mathrm{A})$ by a translative.

$\$ 3$ The adjectival infinitive is normally the subordinate of a noun: Fr. la manière d'être 'the manner of being', la façon de se comporter 'the way to behave', le plus sûr moyen de ne pas se tromper 'the surest way to not deceive oneself'.

259. [Syntax latine by O. Riemann and A. Ernout, Paris, new edition, 1940, p. 194, n. 1.] 
$\$ 4$ The governing noun can be the central node of a nominal sentence (cf. Chapter 73, in particular $\$ 17$, and Stemma 329). This turn is very appreciated in French, since it is so lively:

\begin{tabular}{lc}
\hline $\begin{array}{l}\text { Grenouilles aussitôt de sauter } \\
\text { dans les ondes; }\end{array}$ & $\begin{array}{c}\text { 'Frogs to jump straightway } \\
\text { into the waves; } \\
\text { Grenouilles de rentrer en leurs } \\
\text { grottes profondes. }\end{array}$ \\
$\begin{array}{l}\text { (La Fontaine, Fables, II, 14, } \\
\text { Le lièvre et les grenouilles) }\end{array}$ & $\begin{array}{l}\text { deep caves.' } \\
\text { Et les grenouilles de se plaindre } \\
\text { Et Jupin de leur dire } \\
\text { (La Fontaine, Fables, III, } 4, \text { Les } \\
\text { grenouilles qui demandent un roi) }\end{array}$ \\
\hline
\end{tabular}

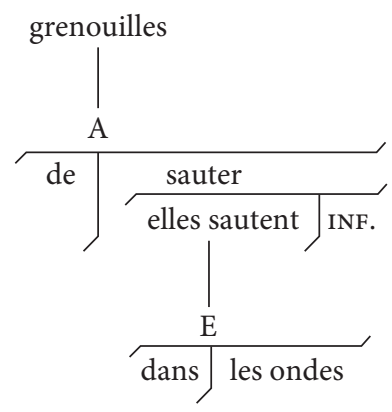

\section{Stemma 329}

\$5 The same transfer has been utilized in Occitan by Mistral: E mi dos furo de s'esquiha 'And my two mice to escape' (Mistral, Nouvelle prose d'almanach, p. 278)

$\$ 6$ In Turkish, the transfer of a verbal noun $(\mathrm{I}>\mathrm{O})$ to an adjective $(\mathrm{O}>\mathrm{A})$ occurs without a marker. Hence one has ol-duk, a verbal noun from ol-mak 'be', which can be employed as an adjective.

$\$ 7$ Turkish employs this mechanism principally for the second instance of transfer $(\mathrm{O}>$ A) in cases of double transfer according to the formula $\mathrm{I}>\mathrm{O}>\mathrm{A}$, which allows it to change an independent clause to an adjectival subordinate clause by way of first-degree transfer.

$\$ 8$ Turkish uses this process to such an extent that it can render the most varied types of subordinate clauses as adjectives: okumakta olduğumuz kitap 'the book that you are in the process of reading', gördüğ̈̈m adam 'the man that I saw', sevdiğimiz kiz 'the young girl that we have loved', yazmış olduğum mektup 'the letter that I have written'.

\$9 The same holds of the verbal noun of the future transferred to an adjective: Turkish satacă̆ım at 'the horse that I will sell', verecek olduğun para 'the money that you were about to give'. 
\$10 The same transfer permits Turkish to render subordinate clauses by transfer of first degree. For these cases, languages like French and English are forced to appeal to second-degree transfer with a relative pronoun (cf. Chapter 248, second degree): babast olduğum çocuk 'the baby of whom I am the father', gittiğim şehir 'the town to which I went'.

\section{Chapter 222. Double transfer according to the formula $\mathrm{A}>\mathrm{O}>\mathrm{E}$ or $\mathrm{E}>\mathrm{O}>\mathrm{E}$}

\$1 The second instance of transfer in cases of double transfer according to the formula $\mathrm{A}>$ $\mathrm{O}>\mathrm{E}$ or $\mathrm{E}>\mathrm{O}>\mathrm{E}$ is the simple transfer $\mathrm{O}>\mathrm{E}$ studied above (Chapter 201-203).

$\$ 2$ This second instance of transfer occurs on top of the first instance of simple transfer of the type $\mathrm{A}>\mathrm{O}$ or $\mathrm{E}>\mathrm{O}$.

$\$ 3$ In the first case, we are dealing with double transfer of the sort $\mathrm{A}>\mathrm{O}>\mathrm{E}$.

$\$ 4$ Most often this double transfer is doubly marked.

\$5 Such is the case in French when the first instance of transfer, that of the adjective to a noun, is effected by the article (cf. Chapter $177, \$ 2$ ), and the second transfer, that of the noun to an adverb, is effected by a preposition (Chapter 201, \$6). One thus obtains expres-

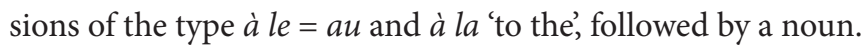

$\$ 6$ In French the noun in question is readily feminine designating a manner of behaving according to the series of feminine nouns discussed in chapter $177, \$ 8$. This noun always has the particularity that it is never employed alone after a first instance of transfer; it is rather the object of a second instance of adverbial transfer: $a ̀ 10 \mathrm{~km}$ à la ronde 'within a $10-\mathrm{km}$ radius', lit. 'to $10 \mathrm{~km}$ to the rounds', prendre quelque chose à la légère 'do not give something proper consideration', lit. 'take something to the light', filer à l'anglaise 'run off, take French leave', lit. 'go off to the English'.

\$7 The target can even be a cardinal adjective: à la six-quatre-deux 'without care, negligently', lit. 'to the six-four-two'.

$\$ 8$ In Greek, one can establish the second instance of transfer, the one of a noun to an adverb, by way of case. This occurs in the expression têi husteraíai 'the next day', where the first instance of transfer is marked as in English by the article, and the second by the use of the dative.

$\$ 9$ The first instance of transfer can have no marker: Fr. s'inscrire en faux 'to dispute', lit. 'to register in false', être habillé en noir 'to be dressed in black', laisser en blanc 'leave in white'. Indeed, if the second instance of transfer here is marked by the preposition en (cf. Chapter 201, \$6), the transfer of the adjective faux 'false' to a noun is, in contrast, indicated by nothing. 
\$10 With this in mind, one has to examine adjectives transferred by double transfer to quantity adverbs as they are employed in Greek in the comparative: polù meízōn, pollôi meizōn 'very much bigger'. In the first of these examples, the second instance of transfer is marked by the accusative, and in the second of these examples, by the dative.

$\$ 11$ In reversive double transfer of the sort $\mathrm{E}>\mathrm{O}>\mathrm{E}$, the first instance of transfer can be marked by the article, which transfers the adverb to a noun (cf. Chapter 179, $\$ 3$ ), and the second instance of transfer by a preposition that also transfers the noun obtained in this manner to an adverb (cf. Chapter 201, \$4): Fr. aller de l'avant 'to forge ahead', lit. 'to go from the front', Il va à l'encontre de tout ce qu'on fait 'He goes against everything one does'.

$\$ 12$ The first instance of transfer is sometimes unmarked. Thus in the French expression sans trop 'without too much', nothing indicates that the adverb trop is transferred to a noun (cf. Chapter 179, \$2) before this noun itself is transferred to an adverb by the preposition sans (cf. Chapter 201, \$4ff.).

$\$ 13$ The second instance of transfer can lack a marker. Such is the case for Gr. tò nûn 'at the moment', where the first instance of transfer, that of an adverb to a noun, is marked by the article tó (Chapter $179, \$ 7$ ), but the transfer of this noun to an adverb is marked by no translative at all (cf. Chapter 202, §5).

\section{Chapter 223. Double I $>0>$ E transfer}

\$1 Double transfer according to the formula $\mathrm{I}>\mathrm{O}>\mathrm{E}$ consists of simple transfer according to the formula $\mathrm{I}>\mathrm{O}$ augmented by simple transfer following the formula $\mathrm{O}>\mathrm{E}$.

$\$ 2$ In principle, this transfer contains an infinitive or a verbal noun ( $>\mathrm{O})$ transferred to an adverb.

$\$ 3$ When the first instance of transfer is marked by the use of the infinitive, the second is also generally marked by a translative.

$\$ 4$ The translative is often a preposition in French, which proves that the infinitive $\mathrm{I}>\mathrm{O}$ is treated exactly like a noun $\mathrm{O}(\mathrm{cf}$. Chapter 201, \$2):

Albert vient de partir

Grand roi, cesse de vaincre ou je cesse d'écrire

(Boileau, Epîtres, VIII)

Je vous défends de sortir

Je vous conseille d'attendre

Bernard cherche à comprendre
'Albert has just left',

lit. 'Albert comes to leave'

'Great king, cease conquering or I cease writing'

'I forbid you to leave'

'I advise you to wait'

'Bernard is trying to understand' 
Ah! bien! vous commencez à comprendre, je crois (A. Dumas, Le Vicomte de Bragelonne, La Société de M. Baisemeaux)

avoir quelque chose à faire

Deux augures ne pouvaient se regarder sans rire

Il faut manger pour vivre et non pas vivre pour manger (Molière, l'Avare, III, I)

Et conter pour conter me semble peu d'affaire (La Fontaine, Fables, VI-1,

Le pâtre et le lion)

Mon gentilhomme, donnez, s'il vous plait, aux garcons quelque chose pour boire (Molière, Le Bourgeois Gentilhomme, II, 5)
'Ah! Good! You are beginning to

understand, I believe'

'have something to do'

'Two augurs cannot look at each other without laughing'

'One should eat to live, not live to eat'

'And to recount for the sake of recounting seems to me to be of little support'

'Please give, my noble man, something to drink to the boys'

$\$ 5$ Such is the origin of the fixed structure c'est-à-dire 'i.e. that is (to say)', which is clearer in the corresponding question Qu'est-ce à dire ? 'What does that mean?'.

$\$ 6$ The proof that the second instance of transfer is indeed of the sort $\mathrm{O}>\mathrm{E}$ is that when the infinitive is translated into a foreign language by an action noun ( $\mathrm{I}>\mathrm{O}$ fixed), this second transfer alone is what remains: Er entschloss sich zur Unterhandlung 'He decided to negotiate. ${ }^{260}$

\$7 An infinitive transferred to an adverb remains impersonal (Chapter $188, \$ 1$ ). This is the reason the first actant is obligatorally that of the verb governing the adverb.

$\$ 8$ The logical necessity provides space - just like what was signaled above - for a number of inaccuracies: Le Gave était rejeté au loin, dans un lit nouveau, pour établir de larges approches... 'The Gave was rejected far off, in a new bed, for establishing broad approaches...' (Zola, Lourdes, p. 243); it was thus the Gave who had established broad approaches! La vie de chacun était trop précieuse pour la risquer imprudemment 'The life of each was too precious to risk it imprudently' (J. Verne, Le Capitaine Hattéras, II, 11, p. 322); it was thus life that risked life! En hiver, les kayaks sont retournés sur les échafauds pour les mettre à l'abri de l'appétit des chiens et des ours blancs 'In winter, the kayaks are turned over on the wood stands in order to protect them from the appetites of dogs and polar bears' (Musée de l'homme, 2nd floor, Eskimo of Angmagssalik, Paris, 1945).

260. A. Malblanc, Pour une stylistique comparée du français et de l'allemand, Paris 1963, \$140-171. Note the other examples that he considers in these places. 
$\$ 9$ The same structure is encountered in Russian in the expression ot nečego delat' 'by idleness', lit. 'from nothing to do', where the infinitive ( $\mathrm{I}>\mathrm{O})$ delat' is transferred to an adverb by the preposition $o t$ 'from'.

$\$ 10$ The same structure is encountered in Greek: hōs épos eipein 'for speaking thus'

$\$ 11$ In Greek, the translative preposed to the infinitive could be a conjunction of subordination: Humîn erô prìn apiénai 'I would say it to you before departure', Ohútōs eusebếs ên Zōkrátēs hốste mèdèn áneu theôn gnómes poieîn 'Socrates was so utterly pious that he would do nothing without the advice of the gods'.

$\$ 12$ In languages like Turkish, the translative of the infinitive is normally postposed.

$\$ 13$ This translative is a postposition in Anlaşmak için sevişmek lâzımdır 'To understand each other one has to love each other'.

$\$ 14$ The translative is a suffix in Kopek havlanmaktan vazgeçti 'The dog stopped barking', Selma hiç düşünmeden dedi 'Selma spoke without thinking.

$\$ 15$ The transfer of an infinitive to an adverb can be produced by translative case evident in declension: Turkish Çocuk ağlamağa basladı 'The child started to cry', Iskemlenin üzerine çıkmağa mecbur olur 'He is forced to climb on the chair', Bu bal yemeğe kıyamıyorum 'I am not daring to eat this honey'.

$\$ 16$ In a similar case, Greek readily preposes the article to the source infinitive (cf. Chapter $190, \$ 3$ ) eis tò nikêsai 'with a view to achieving victory’.

$\$ 17$ Moreover, only the use of the article permits Greek to mark the second instance of transfer using translative case.

$\$ 18$ This case can be the genitive Toû pántōn perigenésthai estokházeto 'He intends to surpass everyone', Pollákis tà alèthê lektéon, toû mế tina agnoeîn 'One has to tell the truth so that nobody ignores it', lit. '.. for the nobody ignoring.

$\$ 19$ This case can also be the dative Tōi poneîn sunekhôs ekrátēsan ohi Pōmaîoi... 'The Romans became masters by (the) working incessantly'.

\$20 One finds the same situation in German where the first instance of transfer is marked by the infinitive preceded by the article and the second by the dative of this article: Er ist über dem Lesen eingeschlafen 'He fell asleep while reading'.

\$21 When transfer of the sort I $>\mathrm{O}$ is very advanced and one is dealing with a true noun, the French infinitive is preceded by the article: avant le déjeuner 'before (the) lunch'. The first instance of transfer of this sentence is further evolved than with avant de déjeuner 'before having lunch', lit. 'before to lunch'.

\$22 The first instance of transfer is only marked by the use of an article in (déclaration) $\grave{a}$ l'emporte-pièce '(declaration) to the remove piece', that is 'cut-and-dried' (cf. also Chapter 206, §8), (habillé) à la va comme je te pousse, lit. '(dressed) to the go as I push you', that is 'in a slapdash manner'. 
\$23 In a certain number of very idiomatic French expressions, the first instance of transfer is not marked in any way, whereas the second is marked by the translative $a$ (or more rarely by de): (dire) à brûle-pourpoint '(say) point-blank', (boire) à tire-larigot '(drink) to one's heart's content', (chanter) à tue-tête '(sing) at the top of one's voice', (sauter) à cloche-pied 'hopping', (travailler) d'arrache-pied '(to work) relentlessly'.

$\$ 24$ The second transfer without a marker is exceptional in French: révérence parler, lit. 'reverence (to) speak', an ancient expression used for saying something that can be offensive. $\$ 25$ However, such transfer is present in a number of languages, in particular in Latin and Greek: Lat. Asinus iubetur vocem premere 'One commanded the ass to lower his voice', Gr. tò ep'emoí eînai 'as much as he depends on me', Épeithe tòn dêmon strateúesthai 'He persuaded the people to do a campaign', Pareskeuázonto tến nêson poliorkêsai 'They prepared to besiege the island', Toùs hippéas paréskhonto sustrateúein 'They furnished the knights to do a campaign with the army'.

\$26 The two transfers are fixed in German compounds where an infinitive transferred to a noun is transferred to a causal or manner adverb without a marker (cf. Chapter 203, \$7): lebensfroh, lit. 'glad to live', that is 'full of joy of life', lebenstreu 'true to life'.

\$27 The infinitive transferred to an adverb can be the subordinate of an adjective (cf. Chapter 77, \$1): Qui te rend si hardi de troubler mon breuvage? 'Who makes you so bold to disturb my drinking?' (La Fontaine, Fables, I, 10, Le loup et l'agneau 'The wolf and the lamb'), un travail facile à exécuter 'an easy job to do', Ils regardaient de belles dindes luisantes et dodues..., et grasses à faire craquer leur peau 'They looked at nice turkeys that were glowing, plumb, and fat to make their skin crack', Gr. kalòs horân 'nice to see', deinòs légein 'way of speaking', hetoîmos ên mákhesthai 'He was ready to fight'.

\$28 It can even occur that the infinitive transferred to an adverb has no governor and constitutes an adverbial phrase; Fr. Au revoir!, Ger. Auf Wiedersehen! 'See you!', lit. 'To the see again!', mikroû deîn 'little needed', emoí dokeîn 'methinks'.

$\$ 29$ The supine of Latin is a verbal noun with a theme $-u$ - (fourth declension), which is always transferred to an adverb:

1. Either to a locative adverb (translocal, cf. Chapter $37, \$ 13$ ), in which case it is accusative (cf. Chapter 202, \$2, a): Venio lusum 'I am coming to play', Venit narratum eam rem 'He came to speak of this matter';

2. Or to a manner or causal adverb, in which case it is in the ablative (cf. Chapter 202, $\$ 6$, e and f): facilis amatu 'easy to love', re iucunda auditu 'a pleasant thing to hear'.

\$30 The transfer of a verbal noun to an adverb by way of a preposition, which is firstdegree transfer, is the process that Turkish most often employs to transfer an independent clause to a subordinate circumstantial clause: dostum gel-diği-nde 'when my friend came', lit. 'in the my friend to come', ver-dik-ten sonra 'after he had given', lit. 'after the giving', bir 
şey bilmediğim cihet-le yazamadım 'I was not able to write because I knew nothing', lit. 'with side of my nothing to know'.

$\$ 31$ The same is true in Basque, where one employs the verbal noun (nominal infinitive in -te) transferred to an adverb by way of the inessive: erraite-an 'saying', lit. 'in the saying. ${ }^{261}$ $\$ 32$ In Basque, the lack of a distinction between verbs and nouns (cf. Chapter 188, \$25 and 27-29) even permits one to carry out the first instance of transfer ( $>$ O) by the use of a personal mood, the completive. The second transfer can be assured either (1) by a postposition, e.g. Gure aitak goaitatu zuen gu atera arte 'Our father waited (until we went out)', or (2) by a suffix: hor dela-rik 'when he is there', hor dela-kotz 'because he is there'.

\section{Chapter 224. Double transfer with the second transfer as $A>E$ or $E>E$}

$\$ 1$ Double transfer with the second instance of transfer according to the formula $\mathrm{A}>\mathrm{E}$ can have $\mathrm{O}>\mathrm{A}$ or I $>\mathrm{A}$ as its first instance of transfer.

$\$ 2$ The governor of the resulting subordinates of double transfer according to the formula $\mathrm{O}>\mathrm{A}>\mathrm{E}$ is often an adjective.

$\$ 3$ The second transfer, that of an adjective to an adverb (A > E, cf. Chapter 205), is not generally marked. In contrast, the first instance of transfer is usually marked.

$\$ 4$ In French, the translative marking this first instance of transfer is in principle a preposition that transfers the noun to an adjective: un seau plein d'eau 'a bucket full of water', un homme avide de gloire 'a man desirous of glory', un citoyen utile à l'Etat 'a citizen useful to the state', un homme semblable à un enfant 'a man similar to a child'.

$\$ 5$ In Latin, the translative is a case, the genitive for example, or the dative or ablative: plenus vini 'full of wine', cupidus gloriae 'desirous of glory', memor iniuriae 'who remembers an injustice'; utilis civitati 'useful to the state', nec pluribus impar '(sun) not unequal to many' (motto of Louis XIV); dives agris 'rich in lands', matre orbus 'deprived of her/his mother'.

$\$ 6$ The situation is the same in Greek, where translative case is generally the genitive or dative: plêrēs oínou 'full of wine', kenòs oínou 'empty of wine', áxios pollês timês 'worth a great amount', epistếmōn sophías 'versed in a science'; hómoios tôi patrí 'similar to his father', opphélimos têi pólei 'useful to the city'.

$\$ 7$ The governor can be a participle that has evolved to a greater or lesser extent: Fr. un enfant privé de dessert 'a child deprived of dessert', Lat. miles patiens frigoris 'a soldier who knows how to endure the cold' (cf. Chapter 199, \$14).

$\$ 8$ The governor can also be a verb: Le hasard décide de tout 'Chance decides anything and everything', lit. '... of everything', L'homme est un dieu tombé qui se souvient des cieux

261. Lafitte, Grammaire basque, p. 200 and 216. 
'A man is a fallen god who remembers (of) the heaven' (Lamartine, Premières Méditations poétiques, II, L'Homme), Lat. damnare aliquem proditionis 'condemn someone for betrayal', Gr. Metékho tês politeías 'I am part of the city', that is 'I am a citizen', Métesti moi tês ekeínou dunámeōs 'I share in his power', Árkhomai tês hodoû 'I am starting my route'.

$\$ 9$ Double transfer of the sort I $>$ A $>$ E contains a participle ( $>$ A) transferred to an adverb $(\mathrm{A}>\mathrm{E})$.

$\$ 10$ The second instance of transfer - that of a participle to an adverb - is normally marked in French when this adverb is an adverb of manner (cf. Chapter 210, \$1).

$\$ 11$ The marker is then the preposition en as for the adjective (cf. Chapter 222, \$9), which is natural, since the participle is a verb transferred to an adjective (cf. Chapter 198, $\$ 2$ ), (see Stemma 330): en chantant 'by singing'.

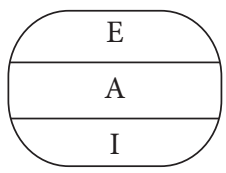

Stemma 330

$\$ 12$ One commonly gives the name gerundive to the phrase obtained in this manner by double transfer, as if it were obtained by simple transfer (cf. Chapter 206).

$\$ 13$ From a phonetic point of view, the form in -ant (aimant) can be an etymological continuation of the Latin gerundive in -(a)ando (amando) and of the concomitant participle in -ant(em) (amantem). From a historical point of view, the two possible etymologies can be supported. From a static point view, however, it is certainly the case that current French speakers sense the gerundive as a derived use of the concomitant participle.

$\$ 14$ The importance of the double transfer gerundive comes from the fact that languages that do not possess simple I > E transfer appeal to it to supplement the absence of simple I $>$ E transfer.

\$15 The gerundive is an expression that is abundantly represented in French: C'est en forgeant qu'on devient forgeron 'By forging one becomes a forger'.

...il nous faut en riant instruire la jeunesse.

(Moliére, L'Ecole des Maris, I, 2)

Nous l'avons, en dormant,

Madame, échappé belle.

(Molière, Les femmes savants, IV, 3)

La victoire en chantant nous ouvre la carrière.

(M. J. Chénier, Le Chant du Départ) '...we have to instruct the youth by laughing.'

'We have, by sleeping, Madam, a lucky escape.'

'The victory by singing opens a profession for us.' 
\$16 What proves that the gerundive does indeed involve deverbal adverbial transfer is that there is a semantically symmetrical type of negative transfer that is also adverbial and deverbal: the opposite of en riant 'by laughing' ( $\mathrm{I}>\mathrm{A}>\mathrm{E}$ ) is sans rire 'without laughing' (I $>\mathrm{O}>\mathrm{E})\left(\mathrm{cf}\right.$. Chapter 223, \$4). ${ }^{262}$

$\$ 17$ Since it is a verb transferred by double transfer to an adverb $(\mathrm{I}>\mathrm{A}>\mathrm{E})$, the gerundive can correspond to a noun transferred to an adverb by simple transfer $(\mathrm{O}>\mathrm{E})$ in other languages: Fr. En y entrant, ils virent toutes les horreurs de la guerre vs. Ger. Beim Eintritt in dasselbe sahen sie alle Schrecknisse des Krieges 'As they entered, they saw all the horrors of war.'263

\$18 The gerundive can also correspond to a verb transferred to a noun (infinitive) and retransferred to an adverb (I >> O $>$ E): Fr. Nous paierons en partant vs. Ger. Wir werden beim Fortgehen bezahlen 'We will pay when we depart' (cf. also I >> E, Chapter 254, \$14). ${ }^{264}$

$\$ 19$ The gerundive is essentially concomitant and is not susceptible to being formed from the anterior participle.

\$20 The gerundive is always invariable in French. Its duration as an adjective is so brief that the variability in gender and number of the adjective does not trump the invariability of the verb from which it arises and the adverb that it becomes.

\$21 Like the transferred infinitive, the transferred participle (and as a consequence the gerundive) remains impersonal. For this reason, its first actant is obligatorily that of a verb governing an adverb (cf. Chapter $223, \$ 7$ ). Hence in the last example of $\$ 15$, victoire 'victory' is the first actant of en chantant 'by singing.'

$\$ 22$ However, as for an infinitive transferred to an adverb (cf. Chapter 223, \$8), speakers nonetheless employ the gerundive very freely concerning this point:

$\begin{array}{cc}\text { C'est un vain qu'au Parnasse un } & \text { It is in vain that on Parnassus a } \\ \text { téméraire auteur } & \text { brave author } \\ \text { Pense de l'art des vers atteindre } & \text { Thinks of the art of verse reaching } \\ \text { la hauteur: } & \text { the heights: } \\ \text { S'il ne sent point du ciel } & \text { If he does not feel the secret } \\ \text { l'influence secrete, } & \text { influence of the sky, } \\ \text { Si son astre en naissant ne } & \text { If his star while rising didn't } \\ \text { l'a formé poète... } & \text { make him a poet... }\end{array}$

(Boileau, L'Art poétique, I)

262. Translators' note: French uses an infinitive form after sans 'without'. In contrast to the French verbal forms in -ant, which are exclusively adjectival, English verbal forms in -ing can occupy nominal positions, e.g. My laughing was inappropriate.

263. A. Malblanc, Stylistique comparée du français et de l'allemand, \$172.

264. A. Malblanc, Ibid. 
Of course the star is not rising, but rather the poet! Certains piliers... n'avaient été sauvés qu'en y passant, en temps utile, des fers 'Certain pillars... could have been saved only by adding iron supports when needed' (A. Maurois, Rouen dévasté, Revue de Paris, June 1948, p. 5). Of course the pillars do not add supports. These references lead us to be lenient concerning the following advice found in a café: Pour faciliter le service, notre amiable clientele est priée de payer en servant 'To facilitate service, patrons are asked to pay when served'.

\$23 The second instance of transfer lacks a marker if the adverb that it becomes is not a manner adverb. Such is the case in the following examples, where this adverb is a causal adverb:

\begin{tabular}{ll}
\hline $\begin{array}{l}\text { Le cigale, ayant chanté } \\
\text { Tout l'été, }\end{array}$ & $\begin{array}{c}\text { 'The cicada, having sung } \\
\text { Se trouva fort dépourvue } \\
\begin{array}{l}\text { Quand la bise fut venue. } \\
\text { (La Fontaine, Fables, I, 1, }\end{array}\end{array}$ \\
$\begin{array}{l}\text { La cigale et la fourmi) } \\
\text { Was completely exhausted } \\
\text { Un riche laboureur, sentant sa } \\
\text { fin prochaine, }\end{array}$ & When the cold wind arrived.' \\
$\begin{array}{l}\text { Fit venir ses enfants, leur } \\
\text { parla sans témoins. }\end{array}$ & 'A rich laborer, sensing his \\
(La Fontaine, Fables, V, 9, & coming end \\
Le laboureur et ses enfants) & and spoke to them without \\
Nourri dans le sérail, j'en & witness.' \\
connais les détours & \\
(Racine, Bajazet, IV, 7) & 'Nourished in established circles, \\
\hline
\end{tabular}

\$24 Doubly marked double transfer of the sort I $>\mathrm{A}>\mathrm{E}$ is common in Latin. It goes by the name ablative absolute: Urbe capta, hostis profectus est '(With) the city taken, the enemy departed. Transfer of the sort I > A is marked by the use of the anterior participle, and transfer of the sort $\mathrm{A}>\mathrm{E}$ by the use of the ablative.

$\$ 25$ The same expression occurs in Greek also, the only difference being that transfer of the sort $\mathrm{A}>\mathrm{E}$ is, instead of being marked by the ablative, marked by the genitive. This is a genitive absolute: thanóntos tôu Perikléous, lit. 'Pericles being dead', that is 'after the death of Pericles'.

\$26 Doubly marked double transfer of the sort I $>$ A $>$ E is encountered in the Greek adverb tukhón 'by chance,' where the first instance of transfer (I > A) is marked by the participle, and the second instance ( $>$ A) by the use of the accusative neuter.

$\$ 27$ In German, the second instance of transfer A > E is not more marked for the participle than for a simple adjective (cf. Chapter 205, \$20): Er kam singend 'He came singing', zerstreut schauen 'distracted glancing', versteckt reden 'speaking in code', lit. 'talk hidden', Es kommt ein Vogel geflogen 'A bird came flying', lit. 'A bird came flown', Das Kind kommt gelaufen 'The kid comes running', lit. 'The kid comes having run', Das kommt erwünscht 'That arrives with approval', lit. 'That comes wished'. 
\$28 Finally, the second instance of transfer is not marked in any of the elements in the French expression donnant donnant lit. 'giving giving', that is 'quid pro quo'. Both times transfer of the sort I > A of the verb to an adjective is marked by the participle, but no marker in either of the elements indicates that the obtained adjective has been transferred to a manner adverb that expresses the circumstances of reciprocity in which the two agree.

$\$ 29$ In Basque, the lack of a distinction between verb and noun allows the realization of the first instance of transfer I > A by the use of personal mood, the conjunctive, which is nothing other than an indefinite genitive of a personal form (cf. Chapter 198, $\$ 12$ and 14).

\$30 As far as the second instance of transfer goes $(\mathrm{A}>\mathrm{E})$, it is assured by superdeclension, ${ }^{265}$ by way of a suffix of the declension of the conjunctive. ${ }^{266}$ This suffix is, for example, that of the inessive in jin den-ean 'when he arrived' and that of the genitive-locative in jin den-eko 'a soon as he arrived'. 267

$\$ 31$ Double transfer where the second instance of transfer is subcategory transfer of the sort E > E can have O > E (cf. Chapter 201) or E > E (cf. Chapter 208) as its first instance of transfer.

\$32 In double transfer of the sort $\mathrm{O}>\mathrm{E}>\mathrm{E}$, the second transfer is subcategory transfer, since one is dealing with the transfer of an adverb to an adverb (cf. Chapter 208, \$11-13). The translative, however, is the same as for the first instance of transfer and one can hence have two prepositions as a consequence in French, which is not always irreproachable style: Ça remonte à pendant la guerre 'That goes back to war time', lit. '...to during the war' (Céline, Mort à credit, p. 18), boire jusqu'à plus soif 'to drink one's fill', lit. 'to drink till to no thirst'.

$\$ 33$ In double transfer according to the formula $\mathrm{E}>\mathrm{E}>\mathrm{E}$, the two instances of transfer are subcategory transfers: Fr. J'en ai besoin pour avant demain 'I need it for before tomorrow' (inelegant style).

$\$ 34$ The first instance of transfer can be frozen, the second alone being productive: Je suis arrivé depuis avant-hier 'I arrived the day before yesterday', Tâchez d'être prêt pour aprèsdemain, 'Endeavor to be ready by the day after tomorrow'.

265. Gèze, Grammaire basque, p. 60: Lafitte, Grammaire basque, p. 399.

266. Ibid., p. 391.

267. Ibid., p. 458. 


\section{Chapter 225. Double transfer where the second transfer is verbal}

$\$ 1$ Double transfer where the second instance of transfer is a verb is often reversive, that is, its first instance of transfer is deverbal. It corresponds to one of the following formulas: I $>\mathrm{O}>$ I or $\mathrm{I}>\mathrm{A}>\mathrm{I}$.

\$2 In these formulas, the first I represents the auxiliated verb that underwent nominal transfer and is hence transferred to a noun, an infinitive ( $\mathrm{I}>\mathrm{O}$ ), or to an adjective, a participle (I > A).

$\$ 3$ The second I, in contrast, represents a periphrastic verb form that results after the translative of the second instance of transfer has intervened; this translative is the auxiliary verb. $\$ 4$ Transfer of the sort I $>\mathrm{O}>$ I thus involves periphrastic verbal forms where the auxiliated verb appears as an infinitive, and transfer of the sort I > A > I involves periphrastic verbal forms where the auxiliated verb appears as a participle. ${ }^{268}$

$\$ 5$ Reversive transfer according to the formula $\mathrm{I}>\mathrm{O}>\mathrm{I}$ is constituted by an infinitve (I > O, cf. Chapter 180, \$1) transferred to a verb by an auxiliary verb (O > I, cf. Chapter 207).

$\$ 6$ Double transfer according to the formula $\mathrm{I}>\mathrm{O}>\mathrm{I}$ is frequent in a large number of languages, Fr. Albert va bientôt partir 'Albert is going to depart soon', Eng. I do not understand, Ger. Albrecht wird bald abfahren 'Albert is departing soon'.

$\$ 7$ When transfer has become frozen by agglutination of the auxiliary to the auxiliated, the periphrastic verbal form becomes a simple verbal form. Hence the French simple future partira 'will depart' is merely agglutination of the former future periphrastic partira 'depart-has', Rus. budu govorit' 'I will speak'.

$\$ 8$ Periphrastic forms are hence young forms, and they become simple forms by way of agglutination. And as these new agglutinated forms gradually age, they themselves are supplanted by younger forms that are more steady.

\$9 The first of these evolutions is a morphological process, and the second is a syntactic one. This is why the linguistic evolution that constitutes their union is complex and discontinuous.

\$10 Reversive transfer according to the formula $\mathrm{I}>\mathrm{A}>\mathrm{I}$ is constituted by a participle (I > A, cf. Chapter 198, \$2) transferred to a verb by an auxiliary (A > I, cf. Chapter 207).

$\$ 11$ The result of this is that a syntagma such as Fr. est parti, lit. 'is departed' (I > A $>$ I) is, due to the second instance of transfer, rigorously homologous to the French syntagma est grand: Albert est parti 'Albert has departed', Albert est grand 'Albert is tall'. ${ }^{269}$

268. See Lucien Tesnière, Théorie structural des temps composés 'Structural theory of compound tenses', Mélanges Bally, Geneva, 1939.

269. Translators' note: French (as well as German, see $\$ 19$ ) has a few verbs that construct their perfect with the auxiliary être 'be'. 
\$12 Transfer of the sort I $>$ A $>$ I is perhaps still more frequent in languages than transfer of the sort I > O > I: Fr. Albert est parti 'Albert has left', It. Sono andato 'I went', Ger. Albrecht ist abgefahren 'Albert has departed', Slovenian Kupoval bom 'I will buy'.

$\$ 13$ A substitute for the nominal verb can take the role of a translative. This occurs in German where one can sometimes utilize the verb heißen 'be called' in the same syntactic use as the verb sein 'be': Das heißt gelogen 'That is a lie', lit. 'That is-called lied'.

\$14 To the extent that the second instance of transfer - that of an adjective to a verb (A > I) - is realized, the participle tends to lose the ability to react to notions of gender and number that it would otherwise be susceptible to receiving from its transitory adjective character and it returns to the invariability that it had before its first instance of transfer (I > A).

$\$ 15$ Hence in French the participle transferred to a verb by the auxiliary être 'be' retains from its transitory adjectival nature the particularity of agreeing in gender and number with the first actant: Alberte est venue 'Alberta has come-FEM' like Alberte est grande 'Alberta is tall-FEM'.

\$16 The situation is the same in Latin and Greek and in the Slavic languages: Lat. Deleta est Carthago 'Carthage has been destroyed-FEM'; Gr. Leluménos eiên 'Could I have been untied-mASC', Leluménē eiên 'Could I have been untied-FEM'; Serbian Ivan je pisao pismo 'John has written-masC a letter', Marija je pisala pismo 'Mary has written-FEM a letter' (cf. Chapter 253, \$6 and 7).

$\$ 17$ The same is true in Russian, although the nominal verb is not expressed: Ivan pisal pis'mo 'John has written-MAsc a letter', Marija pisala pis'mo 'Mary has written-FEm a letter'; Polish Jan pisat list 'John was.writing-MAsC a letter', Maria pisała list 'Mary was. writing-FEM a letter'.

\$18 From this periphrastic form of the anontive with an unexpressed auxiliary, Polish produces by analogy simple agglutinated forms for the autoontive and antiontive: (cf. \$7), masc. pisałem vs. fem. pisałam 'I have written', masc. pisałeś vs. fem. pisałaś ' 'you ${ }_{\mathrm{sG}}$ have written', masc. pisaliśmy vs. fem. pisałyśmy 'we have written', masc. pisaliście vs. fem. pisatyście 'you ${ }_{\mathrm{PL}}$ have written'.

$\$ 19$ But in German, where predicative adjectives are invariable, the same holds of a participle transferred to a verb, since one is therefore dealing with a sentence that functions predicatively, that is, using the verb 'be' (cf. Chapter 207, \$5): Albrecht ist abgefahren 'Albert has departed'.

$\$ 20$ The transfer of the anterior participle, which is passive, by means of the auxiliary 'be' can only produce verbs of state. Therefore when one wants to express a verb of action, it is necessary to mark the active character of the transferred verb by one means or another.

\$21 A number of languages use the translative auxiliary 'have' to this end: Fr. Albert a écrit une lettre 'Albert has written a letter', Ger. Albrecht hat einen Brief geschrieben 'Albrecht has written a letter', Eng. Albert has written a letter. 
\$22 If when it is passive, the anterior participle agrees with the first actant (\$15-17), then conversely when it is active, it can only agree with the second actant, that is, if it retains its adjectival ability to agree (cf. \$27). In Old French this also occurred in independent clauses: Li Emperere out sa raisum fenie 'The emperor had finished-FEM his rant (Chanson de Roland, 193), Cruisiées ad ses blanches mains 'She (has) crossed-FEM-PL her white hands ${ }_{(\mathrm{FFM})}$. This agreement survived to the 17th century: Chaque goutte épargnée a ma gloire flétrie 'Each drop spared has sullied-FEM my fame ${ }_{(\mathrm{FЕM})}$ ' (Corneille).

$\$ 23$ Modern French does not retain agreement in the anterior participle with the auxiliary verb avoir 'have' unless the second actant precedes the participle, which basically only occurs if the second actant is a personal index or a relative pronoun (cf. relative clauses, Chapter 252): Je l'ai écrite, cette lettre 'I have written this letter', lit. 'I it have written-FEM, this letter ${ }_{(\mathrm{FEM})}$ '

\$24 Moreover it should be noted that agreement is only perceivable phonetically after a consonant. After a vowel, it has a value that is purely graphical, at least in Parisian French: Je l'ai lue, cette lettre 'I have read-FEM it, this letter ${ }_{(\mathrm{FEM})}$ ' This is the case of course not only when the participle is employed with the auxiliary avoir 'have', but also when it is employed with the auxiliary être 'be' (\$15): Alberte est venue 'Alberta has come-FEM' (pronounced as venu).

$\$ 25$ In certain regions, in particular in Normandy, the phenomenon is somewhat different. The characteristics $-e$ and $-s$ of the feminine and plural have disappeared, but a trace of them remains in the form of a compensatory elongation of the vowel. The result is that the final vowel is short with masculine, but long with the feminine and plural.

\$26 The author of this work, who acquired his French in the towns Rouen and Elbeuf (in Normandy), can attest to the fact that the invariability of participles ending in a vowel is the result of a conscious and very late acquisition for him (in 1926, 33 years old). He had clearly noted the brevity of the final vowel of the feminine and plural participles during his first contact with the French of Paris as a student (1912-1919), but he attributed this to some distant provincialism and took it to be a significant error. Still today, his sense of the language tends to motivate him to pronounce the final feminine or plural vowel long, and he reverts to the tendency as soon as he relaxes: Il est venu [ŭ] 'He has come', Elle est venue [ū] 'She has come-FEM', Ils sont venus [ū] 'They have come-PL'.

$\$ 27$ The complicated use of participles is addressed in terms of the infamous rules of participle agreement, which are unfortunately celebrated due to their diabolical reputation. The difficulties are due in part to the transitory nature of the participle ( $\$ 14)$.

\$28 Instead of marking the active character of the transferred verb in the second instance of transfer by the use of the auxiliary 'have' (cf. \$21), the Slavic languages mark it in the first instance of transfer by the preterit marker $-l$, which is an active anterior participle: Rus. Ivan pisal pis'mo 'John was.writing a letter.' The Slavic languages do not use a passive anterior participle in such cases. 
\$29 Although it is unusual, it sometimes occurs that cases of double transfer where the second instance of transfer is verbal are not reversive. Such is the case with transfer of the sort E > A > I, which is common in German: Der Wein ist aus 'The wine is gone', Alles ist aus 'Everything is gone', Der Teufel ist los 'The devil has been set loose', Sie ist noch nicht zurück 'She is not yet back', Meine Ruh' ist hin 'My peace has been disturbed' (Goethe, Faust, Margeret's room), Die Tür ist zu 'The door is closed', Sie ist fort 'She is gone. 270

\$30 In this type of structure, the first instance of transfer $(\mathrm{E}>\mathrm{A})$ of a resultative adverb lacks a marker (cf. Chapter $37, \$ 41$ ), and the second instance of transfer (A > I) is that of a predicative adjective obtained from the verb, marked by the translative auxiliary ist 'is' (cf. Chapter 170, \$7).

\section{Chapter 226. Nuclear elliptical transfer}

$\$ 1$ We have already seen many times (cf. Chapter 219, \$6 and Chapter $220, \$ 8$ and $\$ 13$ ) that double transfer is susceptible to the ellipsis of one of its interior terms.

\$2 This ellipsis has the effect of establishing a given instance of transfer as a new type of transfer that is shorter and is a summary of it.

$\$ 3$ The ellipsis is in fact comparable to what is widely known in phonetics as haplology: *amphi-phoreús 'a vase that one carries holding it on both sides', reduced to amphoreús 'amphora, vase with two handles'.

$\$ 4$ A similar phenomenon is observed in writing under the name haplography. Given two letters, two syllables, or two words that are phonologically identical or very similar, just one of them is written.

\$5 This is basically the same phenomenon as in syntax where the intermediate term in the tri-partite composition is subject to ellipsis, e.g. Ger. Öl-baum-zweig 'twig of an olive tree' reduced to Öl-zweig. ${ }^{271}$

270. Cf. A. Malblanc, Pour une stylistique comparée du français et de l'allemand, Paris, 1963, \$59.

271. Cf. Lucien Tesnière, Caribrod et la gare d'Orsay 'Caribrod and Orsay train station', Mélanges Miletič, Sofia, 1933, p. 91, with reference to previous publications: Le Ban de la Roche, Note de toponomastique 'The Ban de la Roche, Note of topomastics', La Vie en Alsace, August 1935, pp. 184186; Les tricomposés elliptiques et le nom de l'Alsace 'Elliptical tri-composed nouns and the name of Alsace', Mélanges 1945, V, Etudes linguistiques, Publications de la Faculté des Lettres de l'University de Strasbourg, 1947, pp. 47-88. 
$\$ 6$ These varying phenomena rest on the same psychological foundation. One is dealing with a significant tendency. As a consequence, one should not be surprised to also observe a manifestation of this phenomenon in transfer. Thus elliptical transfer is merely a sort of syntactic haplology.

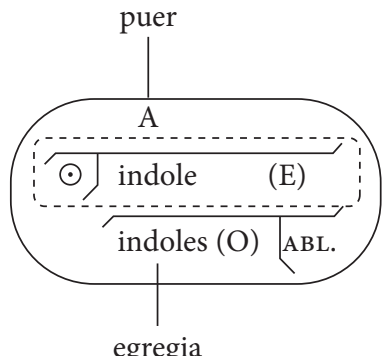

Stemma 331

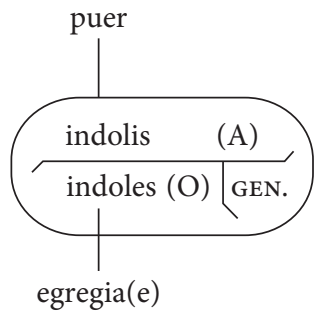

Stemma 332

$\$ 7$ Take the Latin expression puer egregia indole 'a child of an excellent nature'. We have seen above (cf. Chapter $220, \$ 7$ ) that this expression contains double transfer according to the formula $\mathrm{O}>\mathrm{E}>\mathrm{A}$ (cf. Stemma 331).

$\$ 8$ We have also seen (cf. Chapter $220, \$ 8$ ) that Latin prefers simple transfer of the sort O $>$ A over this sort of double transfer: puer egregiae indolis (cf. Stemma 332).

$\$ 9$ The substitution of $\mathrm{O}>\mathrm{A}$ for $\mathrm{O}>\mathrm{E}>\mathrm{A}$ furnishes a first example of elliptical transfer.

$\$ 10$ Ellipsis bears on the intermediate term E (shown in Stemma 331 using dashed encircling line). This intermediate term disappears completely from the nucleus.

$\$ 11$ At its core, this phenomenon has the same evolution that one observes in the change from Latin to French. As a consequence, concrete prepositions have the tendency to become abstract in French.

\$12 The Latin preposition $d e$ 'from' has the value of a translative in $\mathrm{O}>\mathrm{E}$ transfer, this type being the first instance of transfer in double transfer of the sort $\mathrm{O}>\mathrm{E}>\mathrm{A}$, where the second instance of transfer lacks a marker. This preposition takes, with the French preposition $d e$ 'of', the value of a translative in a direct transfer according to the formula $\mathrm{O}>\mathrm{A}$. The ellipsis of the E adverb step permits the French preposition to take a more abstract value.

$\$ 13$ Thus the preposition de, which can only be a translative for $\mathrm{O}>\mathrm{E}$ transfer in Latin (Deiecit se de muro 'He jumped from (the top of) the wall'), was able to become the translative for $\mathrm{O}>\mathrm{A}$ transfer in French (le pied du mur 'the foot of the wall').

$\$ 14$ Take the German expression die Liebe zum Ruhm 'the love of glory' as an example; we have seen (cf. Chapter 220, \$130) that it also contains double transfer of the sort O > E > A (cf. Stemma 333). 
\$15 However, French prefers simple O $>$ A transfer (cf. Chapter 220), which is more abstract (l'amour de la gloire 'the love of glory'), over double transfer where the intermediate adverb retains a certain concrete character.

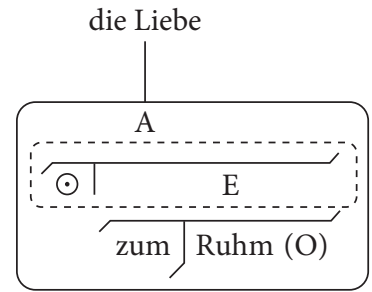

Stemma 333

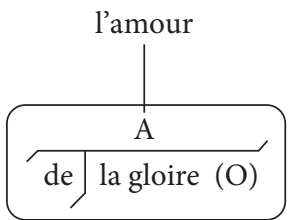

Stemma 334

\$16 The substitution of the abbreviated formula $\mathrm{O}>\mathrm{A}$ for the more complex formula $\mathrm{O}>$ $\mathrm{E}>\mathrm{A}$ is still an analogous manifestation of the ellipsis of transfer.

$\$ 17$ Ellipsis is even more clear when reversive transfer $\mathrm{A}>\mathrm{O}>\mathrm{A}$ is completely and quite simply nullified and replaced by the simple nucleus A. We have seen (cf. Chapter 219, \$6) that this is what happens in Latin when the second instance of such a transfer is marked by the genitive of the relative pronoun. A sentence such as Quorum in numero tu certe fuisses 'In their number you certainly will have been' (Cicero, Ad familiares, VII, 6, 2, cf. Stemma 335 ) is then simplified to Quo in numero tu certe fuisses (cf. Stemma 336).

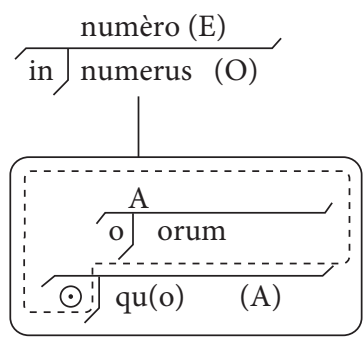

Stemma 335

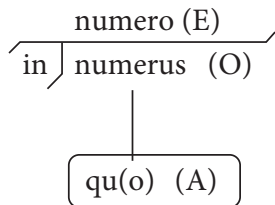

Stemma 336

\$18 The ellipses that we are examining have the effect of reducing double transfer to simple transfer (cf. \$7-16), or they eliminate transfer entirely.

$\$ 19$ By definition transfer takes place exclusively inside the nucleus (cf. Chapter 157, \$13 and 226, §10). Ellipsis that affects nuclei can be designated as nuclear. 
\$20 Ellipsis in transfer has the effect of creating new and shorter types of transfer (cf. §2), which tend to replace the original double transfer.

\$21 Elliptical transfer is hence one of the essential factors for the progression of language. This progression is realized little by little by the creation of a system of transfers, which becomes increasingly complex, rich, and nuanced over time.

\section{Chapter 227. Connective elliptical transfer}

\$1 In contrast to nuclear ellipsis, which is of interest only for transfer and as a consequence only for the interior of the nucleus where it appears, connective ellipsis is of interest to inter-nuclear relations, that is, to the connections that extend between nuclei.

\$2 Take the French sentence Ce commerçant a tout perdu à cause de la guerre 'This merchant has lost everything due to the war. The adverbial phrase à cause de la guerre 'due to the war' can be analyzed as two nuclear elements, the one (à cause 'due to') being the governor and the other (de la guerre 'of the war') being its subordinate (cf. Stemma 337).

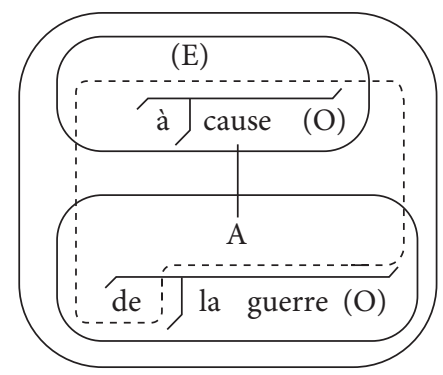

\section{Stemma 337}

$\$ 3$ But this analysis has merely etymological value and is no longer sensed by speakers. Instead, one interprets it as a single nucleus consisting of the source la guerre 'the war' and of the translative à cause de 'due to'.

$\$ 4$ On the one hand, this situation suggests that the two nuclei stem from one single nucleus, and as a consequence, the connection that extends between them must have disappeared.

$\$ 5$ On the other hand, it must be the case that the translatives of the two original nuclei have agglutinated to a single translative and this new translative hides the transferred noun of the governing nucleus also.

$\$ 6$ The ellipsis that occurs can hence be qualified as connective, since in addition to the two nuclei that it has reduced down to one, it represents a connection that its occurrence has caused to disappear. 
$\$ 7$ Connective ellipsis is not content to just reduce double transfer down to single transfer in the interior of a nucleus, but rather it causes two separate instances of simple transfer to merge into a single instance of simple transfer by fusing two nuclei.

$\$ 8$ This is what frequently occurs in languages when prepositions agglutinate to nouns and thus give rise to new prepositions or to new prepositional locutions. The latter are generally easily recognized insofar as they still contain the transfer $\mathrm{O}>\mathrm{A}$, which is necessitated in the original subordinate nucleus by the connection of the original governing nucleus with the noun.

\$9 This explains the many prepositional locutions in French that end with the translative de: faute de 'lack of', à cause de 'because of', à force de 'by force of', à bout de 'after', à condition de 'with the condition of', à l'aide de 'with the help of', au milieu de 'in the middle of', de peur de 'with fear of'; en face de 'across from', en dépit de 'despite', en raison de 'on account of', etc.

\$10 It also explains prepositions governing the genitive in languages with case: Lat. salutis suae causa 'in view of his greeting', filii gratia 'for the love of his son'; Gr. díkèn 'by way of', enantion 'in the face of', khárin 'for the love of', láthrai 'in hiding'; Ger. wegen 'because of', Rus. okolo 'near', vmesto 'instead of'.

$\$ 11$ Elliptical transfer can be simultaneously connective and nuclear, and in so being, it affects the transferred noun of the original source of the transfer.

$\$ 12$ This explains the Latin expression Habitat ad Castoris 'He lives near the Tempel of Castor.' The ellipsis bears here on the noun aedes 'tempel' and the expression is only intelligible if it is reconstructed: Habitat ad aedem Castoris (cf. Stemma 338 and Chapter 215, §3).

$\$ 13$ The Greek expressions that we saw above (Chapter $215, \$ 3$ ) are also explained in terms of ellipsis of this sort: gráphesthaí tina ( ${ }^{*}$ díkēn) dōrodokías 'accuse someone of venality'.

$\$ 14$ One encounters an analogous type of ellipsis in English expressions of the sort I am going to the grocer's. The noun here that has been removed by ellipsis is likely shop: ${ }^{\star}$ the grocer's shop.

$\$ 15$ Ellipsis of this sort also seems to explain Latin constructions like Interest regis 'It is of importance to the king', Interest mea 'It matters to me'.

$\$ 16$ It is evident that in order to comprehend these expressions, one has to place the noun that has been transferred to an adjective by the use of the genitive regis 'of the king' $(\mathrm{O}>$ A) on the same level as the possessive adjective mea 'my', which involves the same transfer, since it is derived from mei 'of me', which is the genitive of the personal noun ego 'I, me' (cf. Chapter 194, §9).

$\$ 17$ The genitive regis 'of the king' does not tell us a thing about the noun to which it is subordinated and which has disappeared due to ellipsis. However, agreement of the adjective mea, which takes the same translative case as the noun that follows it, shows us that we 
are dealing with the ablative and that as a consequence, we have the transfer $\mathrm{O}>\mathrm{E}$, which means mea is a circumstant of interest.

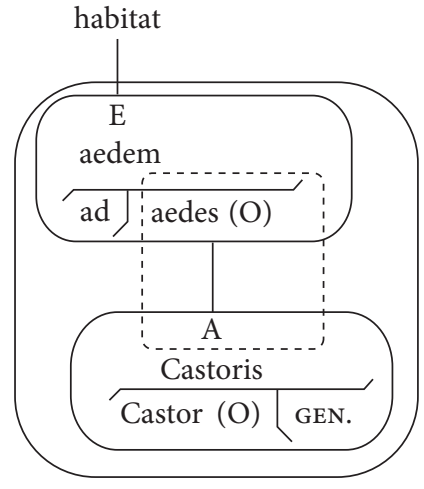

Stemma 338

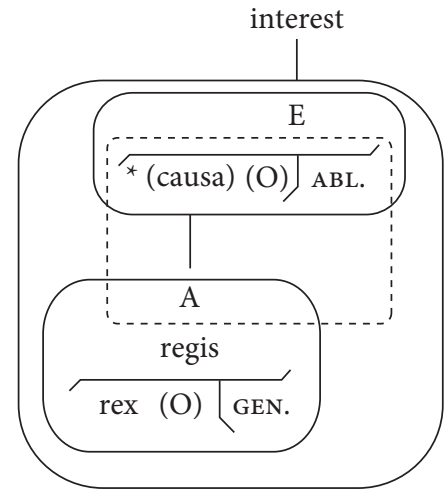

Stemma 339

\$18 On the other hand, gender agreement of mea indicates that this noun was feminine.

$\$ 19$ It is certainly difficult to reconstruct the elided noun based on these meager indicators. However, many prominent minds have come to the conclusion that it could well have been res or more probably, causa: ${ }^{\star}$ Interest (causa) mea, lit. 'It bears on my case', ${ }^{\star}$ Interest (causa) regis, lit. 'It bears on the king's case' (cf. Stemma 339).

$\$ 20$ This is what Gaffiot maintains and what André Desmouliez is inclined to believe, the latter being an assistant professor at the Faculté des Lettres in Montpellier.

$\$ 21$ What this may prove is that the noun that has undergone ellipsis is indeed causa. The two constructions that are possible with interest are the same ones as with causa: Interest regis 'That is of interest to the king' and Interest mea 'That is of interest to me', like regis causa 'in the interest of the king', and mea causa 'in my interest', vestra reique publicae causa 'in your interest and in the interest of the state' (Cicero, In Verrem, 5, 173).

$\$ 22$ However, one has to take note of the fact that the ellipsis of the noun has the effect of provoking transfer of the adjective that it governs to a noun (cf. Chapter 177, \$4-6).

$\$ 23$ The result of this is that the disappearance of the connection is compensated by the creation of a new type of transfer. Thus if the number of nuclei is diminished, the number of intra-nuclear transfers increases as a consequence.

$\$ 24$ Hence in the preceding example, the fusion of the subordinate nucleus $\mathrm{O}>\mathrm{A}$ with the governing nucleus $\mathrm{O}>\mathrm{E}$ - each of which is the locus of a simple transfer - has the effect of creating triple transfer of the sort $\mathrm{O}>\mathrm{A}>\mathrm{O}>\mathrm{E}$ in the single resulting nucleus. 


\section{Chapter 228. Triple transfer}

\$1 Just as one obtains double transfer by placing two simple transfers side by side, one obtains triple transfer by placing a double transfer and a simple transfer side by side, or vice versa.

\$2 The number of varieties of double transfer is greater than that of simple transfer. Indeed, by placing two simple transfers side by side, one multiplies the number represented by the one type of transfer by the number of the other type of transfer.

$\$ 3$ For the same reason, the number of possible varieties of triple transfer is greater than that of double transfer, and so on. Each new factor of transfer theoretically adds a multiplication to the number of possible varieties represented by the preceding transfer.

$\$ 4$ Thus the number of possible varieties of multiple transfer increases as the number of terms increases.

$\$ 5$ Multiple transfer becomes rarer, however, as the number of component transfers increases.

$\$ 6$ But it is no less true that the number of types of transfer increases considerably as the number of component transfers increases.

$\$ 7$ In order to gain an understanding of the economy of the system, there is no need to take a complete inventory of all the types of multiple transfer.

$\$ 8$ The impossibility of such a task increases anyway when one acknowledges that we envisage the facts of transfer without being limited in the number of languages that we consider and without being constrained by the linguistic information addressed. This holds despite the fact that linguistic information can be confined within narrow bounds for a given language, for the same facts of transfer are present in general across languages, although they are unfortunately presented throughout the grammars of the different languages in a disorganized manner and with greatly varying terminologies (Chapter 151, \$4).

$\$ 9$ Furthermore, taking inventory of the possible types of transfer in all accessible languages would be a project that is just as vain and unhelpful as it is ambitious.

\$10 It would be vain because one could never examine all languages and because those languages that have already disappeared from the surface of the globe without a trace would necessarily escape the investigation, which means the investigation could not be complete.

$\$ 11$ It would be unhelpful because the essential desideratum is not to take complete inventory of all possible types of transfer, but rather it is to show the economy of the general mechanism and its function by way of the analysis of diverse facts.

$\$ 12$ Even establishing a complete inventory of all varieties of possible transfer in a single language would necessitate years of investigation and classification, and the object of investigation would have to be the mother tongue of the investigator. 
\$13 Much more beneficial for such an author would be the study of the principles of transfer in his language and of the system of markers that the language employs. From this perspective, the limited number of types in turn conditions the number of varieties of transfer that are possible in the language.

$\$ 14$ One day these works will have been accomplished for as many distinct languages as possible, and it will therefore be possible to produce a synthesis of transfer by comparing these works.

$\$ 16$ From this point of view, one can say that the challenge of erecting a general syntax resides less with the diversity of languages and more with the varying grammatical doctrines adopted by those who pursue the task.

$\$ 17$ Thus if we are forced to attempt an inventory of the facts of transfer as complete as possible and we are also fully aware of the defects in this endeavor, then based on triple transfer, we can be content to always present the most diverse cases of transfer in the same order as above, but without aiming to be complete. We will only try to bring out the essential principles, which are still the same, and to analyze the details of the mechanism in order to enable full comprehension in the most advanced way possible.

\section{Chapter 229. Triple transfer ending with 0}

$\$ 1$ We will examine the different types of triple transfer successively in the following chapters.

$\$ 2$ For each type we will classify the facts according the marker of each type of transfer. To abbreviate the exposition, we will indicate the set of component transfers with the numbers 1,2 , and 3 and parenthesis will be used to indicate where a marker of transfer is absent. The resulting formula is what we will call the mark.

$\$ 3$ Type I > A > O $>$ O; Mark 1, 2, 3 .

This type is represented by Fr. à tout venant, lit. 'to all coming.'

Nuit et jour, à tout venant Je chantais, ne vous déplaise
'Night and day, to all comers

I sang, whether you like it or not.'

(La Fontaine, Fables, I, 1, La cigale et la fourmi)

1 ( $>$ A) Transfer marked by the use of the participle venant 'coming'.

$2(\mathrm{~A}>\mathrm{O})$ Transfer marked by the use of the determinative tout 'all'.

$3(\mathrm{O}>\mathrm{O})$ Subcategory transfer marked by the preposition $a$ ' to'.

$\$ 4$ In languages with case, case (the dative) marks the third instance of transfer: Gr. Éganáktei toîs pháskousin eînai Athēnaíois 'He got angry with the ones who said they were Athenians. 
1 (I > A) Transfer marked by the use of the participle pháskousin 'saying'.

$2(\mathrm{~A}>\mathrm{O})$ Transfer marked by the use of the article toîs 'the'.

$3(\mathrm{O}>\mathrm{O})$ Subcategory transfer marked by the use of the dative toîs pháskousin 'with the ones who said'.

Further: Ápésteilan tòn toùs hórkous dexómenon 'They are sending someone to receive the oaths', lit. 'They send the front to receive the oaths'.

$\$ 5$ Type $\mathrm{A}>\mathrm{O}>\mathrm{A}>\mathrm{O}$; Mark 1, 2, 3 .

This type is represented by Fr. La mort de Socrate est celle d'un sage 'The death of Socrates was the one of a sage' (J.-J. Rousseau).

$1(\mathrm{~A}>\mathrm{O})$ Transfer marked by the article un 'a'.

$2(\mathrm{O}>\mathrm{A})$ Reversive transfer marked by the preposition $d$ ' 'of'.

3 ( $\mathrm{A}>\mathrm{O}$ ) Reversive transfer marked by the retranslative celle 'the one' (lit. 'that', cf. Chapter 211).

Further: Fr. Il faut être plus sévère pour ses propres fautes que pour celles des autres... 'One should be more severe with one's own faults than with the ones of others', un des jeunes 'one of the young (people)', Il y a, dans sa chambre,... des livres de toute espèce. Il y en a de grands et de petits 'There are, in his bedroom,... books of all types. There are big and small (ones)' (J.-H. Fabre, La Science de l'oncle Paul, p. 5). ${ }^{272}$

$\$ 6$ Type $\mathrm{A}>\mathrm{O}>\mathrm{A}>\mathrm{O}$; $\operatorname{Mark}(1), 2,3$.

Fr. En voilà un de robuste, je l'espère 'Here is a strong one, I hope' (J.-H. Fabre, La Science de l'oncle Paul, p. 27).

$1(\mathrm{~A}>\mathrm{O})$ Unmarked transfer of an adjective to a noun.

$2(\mathrm{O}>\mathrm{A})$ Transfer of the noun thus obtained to an adjective by the preposition de 'of'.

$3(\mathrm{~A}>\mathrm{O})$ Reversive transfer of the adjective thus obtained to a noun by the indefinite article $u n$ 'a'.

Further: En voilà une de singulière 'Here is an odd one' (ibid., p. 214). Hein! On ne peut pas dire, en voilà une de phtisique! 'What! There is no doubt about it, there is one with tuberculosis' (Zola, Lourdes, p. 84). J'en ai un de joli 'I have a nice one'.

$\$ 7$ Type $\mathrm{A}>\mathrm{O}>\mathrm{A}>\mathrm{O}$; Mark 1, 2, (3).

This type is represented by Fr. J'en ai $d u$ fin et du bien rapé 'I have fine and nicely ground (tobacco)' (J'ai du bon tabac, popular song), (cf. Chapter 233, \$2).

272. Translators' note: Several French examples in this chapter use the pronoun en. The pronoun $e n$ is the genitive pronoun used for the pronominalization of de prepositional phrases: Je rêve de ballons 'I dream of balls' $\rightarrow$ J'en rêve 'I dream of them', J'ai beaucoup de ballons 'I have a lot of balls' $\rightarrow$ J'en ai beaucoup 'I have a lot'. 
$1(\mathrm{~A}>\mathrm{O})$ Transfer of the adjective fin 'fine' to a noun marked by the definite article le contained in the contracted form $d u$ (cf. Chapter 215, \$7).

$2(\mathrm{O}>\mathrm{A}) \quad$ Transfer of the noun thus obtained to an adjective marked by the preposition de contained in the contracted article $d u$.

3 (A > A) Transfer without a marker (partitive article) of the adjective thus obtained to a noun.

$\$ 8$ Type $\mathrm{A}>\mathrm{O}>\mathrm{A}>\mathrm{O}$; Mark (1), 2, (3).

This type is represented by Lat. Me tuae litterae nunquam in tantam spem adduxerunt quantam aliorum 'Your writings do not produce as much hope for me as the writings of others'.

$1(\mathrm{~A}>\mathrm{O})$ Unmarked transfer.

$2(\mathrm{O}>\mathrm{A})$ Transfer marked by the ending -orum of the genitive form aliorum 'of others'

$3(\mathrm{~A}>\mathrm{O})$ Unmarked transfer of the adjective thus obtained to a noun. Type A > O > A > O; Mark 1, 2, (3).

This type is represented by Fr. Il est bon de parler et meilleur de se taire 'It is good to speak and better to be silent'.

$1(\mathrm{I}>\mathrm{O}) \quad$ Transfer marked by the use of infinitive.

$2(\mathrm{O}>\mathrm{A})$ Transfer of the noun to an adjective marked by the preposition $d e$ :

$3(\mathrm{~A}>\mathrm{O})$ Unmarked transfer of the adjective thus obtained to a noun.

Further:

De parler, ça m'aide à travailler

(Jean-Jacques Bernard,

Nationale 6, p. 13)

Rien ne sert de courir; il

faut partir à point.

(La Fontaine, Fables, VI, 10,

Le lièvre et la tortue)

Passe encore de bâtir; mais

planter à cet âge!

(La Fontaine, Fables, XI, 8,

Le vieillard et les trois

jeunes hommes)
'Talking, it helps me work'

'Running does not help; one has to depart at the right time.'

'It is one thing to build, but to plant at this age!'

\$10 In transfer of this type, the translative of the second instance of transfer $(\mathrm{O}>\mathrm{A})$ can be reinforced by the translative que 'that': Fr. C'est un plaisir que de causer avec vous 'It's a pleasure (that) to converse with you'.

\$11 Type O > E > A > O; Mark 1, 2, 3 . 
Fr. Solitude pour solitude, j'aime mieux celle d'avant le mariage que celle d'après 'Solitude for solitude, I like the one before marriage more than the one after it' (H. Lavedan, Viveurs, Act III, p. 200).

$1(\mathrm{O}>\mathrm{E})$ Transfer of the noun mariage 'marriage' to an adverb marked by the preposition avant 'before'.

2 (E > A) Transfer marked by the preposition $d$ ' 'of'.

3 (A > O) Transfer marked by the retranslative celle 'the one'.

$\$ 12$ Type $\mathrm{O}>\mathrm{E}>\mathrm{A}>\mathrm{O}$; Mark 1, 2, (3).

Rus. naberežnaja 'embankment'.

$1(\mathrm{O}>\mathrm{E}) \quad$ Transfer of the noun bereg 'the bank' to an adverb of location by the preposition na: na beregu 'on the bank'.

2 (E > A) Transfer of the adverbial group preceding an adjective by the adjectival suffix -nyj, or feminine -naja (cf. Chapter 220, \$14).

$3(\mathrm{~A}>\mathrm{O})$ Transfer of the preceding adjective to an unmarked noun.

\$13 Type O > E > A > O; Mark 1, (2), 3 .

Fr. une sans soupapes 'one without valves', that is 'a car with a no-valve engine' (cf. Chapter $177, \$ 10)$.

$1(\mathrm{O}>\mathrm{E}) \quad$ Transfer of the noun soupapes 'valves' to an adverb marked by the preposition sans 'without'.

2 (E > A) Transfer of the adverbial group sans soupapes 'without valves' to an unmarked adjective.

$3(\mathrm{~A}>\mathrm{O}) \quad$ Transfer of the adjective thus obtained to a noun marked by the article une 'a' Further:

\begin{tabular}{|c|c|c|}
\hline French & Literal & Idiomatic \\
\hline un sans-cour & 'a without-heart' & 'a heartless person' \\
\hline un sans-culotte & 'a without-pants' & 'a partisan of 1789 French Revolution' \\
\hline un sans-le-sou & 'a without-a-cent' & 'a penniless person, a have-not' \\
\hline un en-cas & 'an in-case' & $\begin{array}{l}\text { 'a prepared meal that can be served as } \\
\text { need be' }\end{array}$ \\
\hline un enjeu & 'an in-play' & 'a stake, an issue' \\
\hline l'entrain & 'the in-train' & 'spirit, drive' \\
\hline l'embonpoint & 'the in-good-point' & 'stoutness' \\
\hline une averse & 'a in-torrents' & 'a shower (of rain)' \\
\hline $\begin{array}{l}\text { J'en ai un comme ça } \\
\text { (P. -J. Stahl, Les histoires } \\
\text { de mon parrain, p. } 169 \text { ) }\end{array}$ & & 'I have one like that' \\
\hline un à la manière de & 'an in the style of' & 'one in the style of someone' \\
\hline
\end{tabular}


With a marker for the third transfer with the plural: Je vous enverrai des cartes postales, des en noir et des en couleur 'I will send you postcards, some in black and some in color'. Les honnêtes femmes en ont des comme ça 'Fair ladies have some like that' (Midi Libre, 27 XI, 1948); with the retranslative: la loi de 1881, celle actuellement en vigueur 'the law of 1881, the one currently in force' (Le Journal, 12, V, 1937).

$\$ 14$ The first instance of transfer can be marked by a case that is reinforced by a preposition: Gr. tà pròs pólemon 'what is related to war', tà hupò gês hápanta 'all the things under earth', ohi perí Sōkrátēn 'the disciples of Socrates', ohi amphí tòn Kûron 'the people of Cyrus'. $\$ 15$ The first instance of transfer can be marked etymologically in French by a loanword with Latin case: un omnibus 'a local train (that stops everywhere)'.

$\$ 16$ The first instance of transfer can be replaced by transvaluation (cf. Chapter 204, \$8); un ultra 'an extremist'.

\section{Chapter 230. Triple transfer ending with A}

\$1 Type $\mathrm{O}>\mathrm{A}>\mathrm{O}>\mathrm{A}$; Mark 1, 2, 3 .

This type is represented by Basque gizon-aren-aren 'from the one of the man'.

$1(\mathrm{O}>\mathrm{A})$ Transfer of the noun gizon 'man' to an adjective by the suffix -aren for the possessive genitive: gizon-aren 'of the man'.

$2(\mathrm{~A}>\mathrm{O})$ Transfer of the adjective thus obtained to a noun by the article $-a$ : gizon-aren- $a$ 'the one of the man'.

$3(\mathrm{O}>\mathrm{A})$ Transfer of the new noun thus obtained to an adjective by the same suffix for the possessive genitive as above: gizon-aren-aren 'of the one of the man'.

$\$ 2$ Type $\mathrm{O}>\mathrm{A}>\mathrm{O}>\mathrm{A}$; Mark 1, (2), 3.

Fr. une lettre de d'Artagnan 'a letter of d'Artagnan' (A. Dumas, Le Vicomte de Bragelonne, Suite d'orage).

$1(\mathrm{O}>\mathrm{A})$ Transfer of the noun Artagnan (name of a place) to an adjective by the preposition d': d'Artagnan.

$2(\mathrm{~A}>\mathrm{O})$ Unmarked transfer of the adjective thus obtained to the noun d'Artagnan (name of a person).

$3(\mathrm{O}>\mathrm{A}) \quad$ Transfer of the new noun thus obtained to an adjective by the preposition de as above: de d'Artagnan.

Further: lieutenant de de Bracy 'de Bracy's lieutenant' (Ivanhoë, XXXII, translation from the Nelson Collection), la mère de de Maucroix 'de Maucroix's mother' (A. Dumas, Le Demi-Monde, I, 3).

$\$ 3$ In the two preceding examples, the transfer $\mathrm{O}>\mathrm{A}$ is marked by the same translative two times, the suffix -(r)en in Basque and the preposition de (d') in French. This repetition has the effect of favoring elliptical transfer by which the formula $\mathrm{O}>\mathrm{A}>\mathrm{O}>\mathrm{A}$ is 
abbreviated down to $\mathrm{O}>\mathrm{A}$ (cf. Chapter 227): Fr. prêt à obéir à un signe de Guiche ou de Bragelonne 'ready to obey a signal from Guiche or (from) Bragelonne'(A. Dumas, Le Vicomte de Bragelonne, the tents). Every Slavist knows the law that governs the displacements of accent in Slavic; it was discovered by de Saussure and is called the loi de Saussure 'Saussure's Law', and not loi de de Saussure 'de Saussure's Law'.

$\$ 4$ When the first instance of transfer has a different marker than the third instance and there is therefore no repetition, there can hardly be elliptical transfer: Fr. une attitude de Parisienne 'a posture of a Parisian'.

$1(\mathrm{O}>\mathrm{A})$ Transfer of the noun Paris, name of a place, to an adjective by the derivational suffix -ienne.

$2(\mathrm{~A}>\mathrm{O})$ Unmarked transfer, but indicated in orthography with upper case, of the adjective thus obtained to the noun Parisienne designating a person.

$3(\mathrm{O}>\mathrm{A})$ Transfer of the preceding noun to a relative adjective (Chapter 194) by the preposition de.

$\$ 5$ Type $\mathrm{O}>\mathrm{A}>\mathrm{O}>\mathrm{A}$; Mark (1), (2), 3 .

It is here that one locates the erroneous transfer according to which the French most often understand the Greek attribute rhododáktulos as 'with rose fingers' (cf. Chapter $175, \$ 10)$.

$1(\mathrm{O}>\mathrm{A})$ Unmarked transfer of the noun rose to a color adjective (Chapter 193).

$2(\mathrm{~A}>\mathrm{O})$ Unmarked transfer of the preceding relative adjective to a substantive.

$3(\mathrm{O}>\mathrm{A})$ Transfer of the preceding noun to a relative adjective (Chapter 194) by means of the preposition $d e$.

$\$ 6$ Type $\mathrm{I}>\mathrm{A}>\mathrm{O}>\mathrm{A}$; Mark 1, 2, 3 .

Fr. Les galons du commandant 'the stripes of the commander'

1 (I > A) Transfer marked by the use of the participle commandant.

$2(\mathrm{~A}>\mathrm{O})$ Transfer marked by the use of the definite article le contained in the contracted form $d u$.

$3(\mathrm{O}>\mathrm{A})$ Transfer marked by the use of the preposition de contained in the contracted form $d u$.

Further: Je vous ai trouvé d'un allant...! 'I found you with plenty of energy...!', lit. 'I found you of a going...!' (Denys Amiel, Ma liberté, Act I, p. 38).

$\$ 7$ Type I > A > O > A Mark 1, (2), 3 .

This type is encountered each time the article marking the second instance of transfer is lacking, since one is dealing with set expressions where there is no reason to use the article: Fr. les galons de commandant 'the stripes of commander', and the following productive construction: 
Voici douze jours d'accomplis.

(Paul Hervieu, Peints par

eux-mêmes, XVI)

Voilà encore un deputé socialiste d'élu.

Et une malheureuse concierge

de plus d'assassinée.

(A. Lichtenberger, Petite Madame, p. 175)
'Here are twelve days that have been accomplished', lit. 'Here are twelve days of accomplished'

'Here is a socialist deputy that has been elected. And one more poor caretaker that has been killed.' lit. '... of elected ... of killed.'

$\$ 8$ This is also the type that one encounters in Latin, because the article does not exist in this language: speciem pugnantis praebere 'look like fighting', lit. 'present the aspect of fighting'.

1 (I > A) Transfer marked by the use of the participle.

$2(\mathrm{~A}>\mathrm{O})$ Unmarked transfer.

$3(\mathrm{O}>\mathrm{A})$ Transfer marked by the genitive.

Further: Magna est admiratio copiose sapienterque dicentis 'One admires a very wise orator a lot' (Cicero, De officiis, II, 14, 48), Suis incommodes graviter angi non amicum sed se ipsum amantis est 'Being affected by our own concerns is not affection for our friends, but rather selfishness', lit. '...is the fact that someone loving not (his) friend, but himself' (Cicero, De amicitia, 3, 10).

$\$ 9$ In Latin, the first instance of transfer (I > A) can be marked by the use of the verbal adjective ending in -ndus, the form of which, which is nominalized by the second instance of transfer $(\mathrm{A}>\mathrm{O})$, is the base of the gerundive that one obtains by the third instance of transfer $(\mathrm{O}>\mathrm{A})$ : cupidus videndi 'desiring to see’ (cf. Chapter 231, \$9).

\$10 Type $\mathrm{O}>\mathrm{E}>\mathrm{O}>\mathrm{A}$; Mark 1, (2), 3.

Fr. la période d'après-guerre 'the post-war period', lit. 'the period of after-war'.

$1(\mathrm{O}>\mathrm{E})$ Transfer of the noun guerre 'war' to an adverb by the preposition après 'after'.

$2(\mathrm{E}>\mathrm{O})$ Unmarked transfer of the adverb thus obtained to the noun l'après-guerre 'the time after the war'.

$3(\mathrm{O}>\mathrm{A})$ Transfer of the new noun thus obtained to an adjective by the preposition d' 'of'.

$\$ 11$ Type $\mathrm{A}>\mathrm{O}>\mathrm{E}>\mathrm{A}$; Mark (1), 2, (3).

Fr. Etes-vous à même de faire cela? 'Are you able to do that?', lit. 'Are you at same to do that?'.

$1(\mathrm{~A}>\mathrm{O})$ Unmarked transfer of the adjective même 'same' to a noun.

$2(\mathrm{O}>\mathrm{E}) \quad$ Transfer of the noun thus obtained to an adverb by the preposition $\dot{a}$.

3 (E > A) Unmarked transfer of the adverb thus obtained to an adjective.

$\$ 12$ Type I > O $>$ E > A; Mark 1, 2, 3 . 
It is here that one has to locate the participle of obligation in German: Eine zu betrachtende Tatsache 'a fact that is to be observed'.

$1(\mathrm{I}>\mathrm{O}) \quad$ Transfer of the verb to a noun marked by the use of the infinitive betrachten 'observe'.

$2(\mathrm{O}>\mathrm{E}) \quad$ Transfer marked by the use of $z u$ 'to'.

3 (E > A) Transfer marked by the use of the participle betrachtend 'observing'.

$\$ 13$ Type I > O $>$ E > A; Mark 1, 2, (3).

Fr. un jour à venir 'a day to come'.

$1(\mathrm{I}>\mathrm{O}) \quad$ Transfer of the verb to a noun marked by the use of the infinitive.

$2(\mathrm{O}>\mathrm{E}) \quad$ Transfer of the noun thus obtained to an adverb by the preposition $\dot{a}$.

3 (E > A) Unmarked transfer of the adverb thus obtained to an adjective.

Further: un vent à décorner les bœufs 'a howling wind', lit. 'a wind to dehorn the beefs', un chasse à courre 'a fox hunt', lit. 'a hunt to run'.

$\$ 14$ In French, the first instance of transfer - instead of being marked by the use of the infinitive - can be marked by the article (cf. Chapter 223, \$22): Quelques interventions à la tribune, bien placées, courtes, mais là, à l'emporte-pièce 'Some interventions at the platform, well placed, short, but there, cut-and-dried', lit. '... with the carry-away-piece' (La femme de César, La Petite Illustration, January 8, 1938).

\section{Chapter 231. Triple transfer ending with E}

\$1 Type $\mathrm{O}>\mathrm{A}>\mathrm{O}>\mathrm{E}$; $\operatorname{Mark}(1), 2,3$.

This type is no different than à la légère, which has been examined above in terms of the formula $\mathrm{A}>\mathrm{O}>\mathrm{E}$ (Chapter 222, \$6). The initial adjective is replaced by a noun transferred to an adjective: Fr. apprêter un plat à la maître d'hôtel 'prepare a dish à la maître d'hôtel':

$1(\mathrm{O}>\mathrm{A})$ Unmarked transfer of the noun to an adjective.

$2(\mathrm{~A}>\mathrm{O})$ Transfer of the adjective thus obtained to a noun by the article la: la maître d'hôtel.

$3(\mathrm{O}>\mathrm{E}) \quad$ Transfer of the new noun thus obtained to an adverb by the preposition $\dot{a}$ : à la maître d'hôtel.

Since the article la 'the' used in this way is by definition feminine (cf. Chapter $222, \$ 6$ ), it sometimes influences the gender of the noun, e.g. à la hussarde 'brusquely' (hussard 'hussar' is masculine).

$\$ 2$ Type $\mathrm{A}>\mathrm{A}>\mathrm{O}>\mathrm{E}$; $\operatorname{Mark}(1), 2,(3)$.

This type is encountered in French when the result of the transfer A > A > O (cf. Chapter $216, \$ 3)$ is itself transferred to an adverb: Fr. Nous partirons le six 'We are departing on the sixth'. 

1 (A > A) Unmarked subcategory transfer (cf. Chapter 208, \$10).
$2(\mathrm{~A}>\mathrm{O})$ Transfer marked by the article (cf. Chapter $216, \$ 3)$.
3 (O > E) Unmarked transfer (cf. Chapter 203, \$3).

$\$ 3$ Type E > A > O > E; Mark (1), 2, 3 .

This type is no different than the type examined above in terms of the formula $\mathrm{E}>\mathrm{A}>\mathrm{O}$ (Chapter 216, §9). The final noun is itself transferred to an adverb: Gr. hupér tôn prósthen toxeúein 'shoot arrows over those in front'.

1 ( $\mathrm{E}>\mathrm{A}) \quad$ Unmarked transfer of the adverb prósthen 'those in front' to an adjective.

$2(\mathrm{~A}>\mathrm{O})$ Transfer of the adjective thus obtained to a noun by the article tôn.

$3(\mathrm{O}>\mathrm{E})$ Transfer of the noun thus obtained to an adverb by the preposition hupér 'over'.

$\$ 4$ Type E $>$ A $>$ O $>$ E; Mark 1, (2), 3.

Lat. a priori.

$1(\mathrm{E}>\mathrm{A}) \quad$ Fixed transfer of the Old Latin adverb * pri- 'before' to a comparative adjective by the derivational suffix ${ }^{*}$-us.

$2(\mathrm{~A}>\mathrm{O})$ Unmarked transfer of the comparative adjective thus obtained to a noun.

$3(\mathrm{O}>\mathrm{E})$ Transfer of the noun thus obtained to an adverb by the ablative reinforced with the preposition $a$.

Further: a posteriori, a fortiori.

$\$ 5$ Note that if the first instance of transfer is frozen in Latin, it is also frozen in all three cases in French and English. French orthography using the accent grave $a$ generates the false impression that the third instance of transfer is still productive. In the majority of cases, the French preposition $a$ is derived from the Latin preposition ad 'to', whereas in expressions of the sort $a$ priori, Lat. $a$ is a variant of the preposition $a b$ 'of, from'.

$\$ 6$ Type I > A > O P E Mark 1, 2, 3 .

Fr. jouer au plus vite arrivé, lit. 'to play to the most quickly arrived', that is 'to play Be-the-first-to-arrive.

1 (I $>$ A) Transfer marked by the participle.

$2(\mathrm{~A}>\mathrm{O})$ Transfer marked by the definite article le contained in the contracted form au.

$3(\mathrm{O}>\mathrm{E}) \quad$ Transfer marked by the preposition $\grave{a}$ contained in the contracted form $a u$. Further: Fr. au vu et au su de quelqu'un 'in full sight of someone', lit. 'in the seen and the known of someone', à l'insu de quelqu'un 'unbeknownst to anyone'; with a participle borrowed from Italian: à l'improviste 'without warning,' lit. 'at the improvized'; with a participle of frozen transfer borrowed from Latin: à l'envers 'upside-down', lit. 'to the reversed'. In Greek, the third instance of transfer is marked by the genitive reinforced by the preposition ek in: ek tôn paróntōn 'from the present situation'. 
\$7 Type I > A > O > E; Mark 1, (2), 3 .

Fr. (parler) à tort et à travers '(to talk) drivel'.

$1(\mathrm{I}>\mathrm{A}) \quad$ Frozen transfer marked by the participle.

$2(\mathrm{~A}>\mathrm{O})$ Unmarked transfer.

$3(\mathrm{O}>\mathrm{E}) \quad$ Transfer marked by the preposition $\dot{a}$.

$\$ 8$ The same double transfer is encountered in Latin, except that the third instance of transfer is marked by the use of an adverbial dative: in universum aestimanti 'on the whole (appraising)'.

$\$ 9$ The first instance of transfer (I > A) can be marked in Latin by the use of the verbal adjective with the ending -ndus. This form, when nominalized by the second instance of transfer $(\mathrm{A}>\mathrm{O})$, is the base of the gerundive, which one obtains via the third instance of transfer $(\mathrm{O}>\mathrm{E})$. In sum, the gerundive is the result of double transfer $\mathrm{I}>\mathrm{A}>\mathrm{O}$ retransferred to an adjective $(\mathrm{O}>\mathrm{A}$, cf. Chapter 230, \$9) or to an adverb $(\mathrm{O}>\mathrm{E})$ : Lat. Fabricando fit faber 'By forging one becomes a forger', lit. 'Working makes the worker'.

1 (I > A) Transfer marked by the verbal adjective in -ndus.

$2(\mathrm{~A}>\mathrm{O}) \quad$ Unmarked transfer.

$3(\mathrm{O}>\mathrm{E}) \quad$ Transfer marked by the use of the ablative.

Further: Legendo doctus evasit 'By reading, he has become knowledgeable', aptus agendo 'proper to act'.

\$10 The ablative marking the third instance of transfer can be reinforced by a preposition: Voluptatem poni in discendo 'He seeks his pleasure in study'.

$\$ 11$ The third instance of transfer $(\mathrm{O}>\mathrm{E})$ can be marked by the accusative reinforced by a preposition: Lat. Ad dicendum aggressus est 'He is getting ready to speak'.

$1(\mathrm{I}>\mathrm{A}) \quad$ Transfer marked by the verbal adjective ending in $-n d u s$.

$2(\mathrm{~A}>\mathrm{O})$ Unmarked transfer.

$3(\mathrm{O}>\mathrm{E})$ Transfer marked by the accusative reinforced by the preposition $a d$.

Further: natus ad agenum 'born to act'.

\$12 Type I > A > O > E; Mark 1, (2), (3).

This case is present in Latin, although it is rare: Opus est facto 'One needs to act', lit. '(The) need is (to have) done (something)' (cf. Ernout's note in the Syntaxe latine by Riemann \& Ernout, 1935, \$260, remark I, p. 525).

1 (I $>$ A) Transfer marked by the participle facto 'done'.

$2(\mathrm{~A}>\mathrm{O})$ Unmarked transfer.

$3(\mathrm{O}>\mathrm{E}) \quad$ Unmarked transfer.

$\$ 13$ Type $\mathrm{t}>\mathrm{E}>\mathrm{O}>\mathrm{E}$; Mark 1, 2, 3 .

Fr. au-dessous de la table 'below the table' (with elliptical connected transfer, cf. Chapter $227, \S 2-8)$. 
$1(\mathrm{t}>\mathrm{E}) \quad$ Transvaluation of the preposition sous 'under' to an adverb by the preposition de 'from'.

$2(\mathrm{E}>\mathrm{O})$ Transfer of the adverb thus obtained to a noun by the definite article le contained in the contracted form au.

$3(\mathrm{O}>\mathrm{E})$ Reversive transfer of the noun thus obtained to an adverb by the preposition $a$ contained in the contracted form $a u$.

Further: Au-dessus de la mêlée 'Above the battle' (title of a work by Romain Rolland).

$\$ 14$ Type A > O > A > E; Mark (1), 2, 3 .

Fr. Cette fois, Jacques est fâché pour de bon 'This time, Jack is angry for real' (A. Lichtenberger, Petite Madame, p. 280).

$1(\mathrm{~A}>\mathrm{O})$ Unmarked transfer of the adjective bon 'good' to a noun.

$2(\mathrm{O}>\mathrm{A})$ Transfer of the noun thus obtained to an adjective by the preposition $d e$ (cf. Chapter 215, \$7).

3 (A > E) Transfer of the adjective thus obtained to an adverb by the preposition pour.

Further: Fr. pour de vrai 'for real'.

$\$ 15$ Type A > O > E > E; Mark (1), 2, 3 .

Fr. On dirait un vieux labyrinthe inachevé, et d'où on pourrait sortir par partout 'It looks like an old incomplete labyrinth, from where we could exit to anywhere' (Vendredi, I, 1, 1937).

$1(\mathrm{~A}>\mathrm{O}) \quad$ Unmarked fixed transfer of the adjective tout 'every' to a noun.

$2(\mathrm{O}>\mathrm{E})$ Fixed transfer of the noun thus obtained to an adverb by the preposition par 'by'.

3 (E $>$ E) Subcategory transfer of the locative adverb partout 'everywhere' to the locative adverb indicating passage par partout 'by everywhere' by the preposition par.

\$16 Type O > A > I > E; Mark (1), (2), 3.

This type is encountered in Latin when a nominal phrase that is a clause governed by the nominal verb that is not expressed is transferred to an adverb: Caesare consule 'Ceasar being consul', that is, 'under the consulship of Ceasar'.

$1(\mathrm{O}>\mathrm{A})$ Unmarked transfer of the noun to an adjective.

2 (A > I) Transfer of the adjective to an unmarked verb, the nominal verb being unexpressed.

3 (I $>$ E) Transfer of the nucleus thus obtained to an adverb by the ablative.

\$17 Type I > A > I > E; Mark 1, (2), 3 .

This type is known in Latin as the ablative absolute. The source of transfer of the last instance of transfer $(\mathrm{I}>\mathrm{E})$ is a participle $(\mathrm{I}>\mathrm{A})$ that has already been transferred to a verb lacking a marker: Sic est locutus partibus factis leo 'The parts having been done, the lion spoke thus' (Phaedrus, I). 
1 ( $>$ A) Transfer of the verb to an adjective marked by the use of the participle.

2 (A > I) Unmarked reversive transfer of the ablative thus obtained to a verb.

3 (I $>$ E) Transfer of the unexpressed verb thus obtained by the ablative.

The ablative has the effect of transferring the verb to whatever adverb category: eo profecto temporal circumstant 'when he has departed', causal circumstant 'because he has departed', conditioned causal circumstant 'if he has departed', concessive circumstant 'although he has departed', etc. The same in the present: eo proficiscente 'when he departs, because he departs, if he departs, although he departs, etc'. The first instance of transfer is frozen in the Latin adjective invitus 'unwilling', which appears to derive from a former anterior participle of the verb 'want' (cf. vis 'you want'): Caesare invito 'Caesar here being opposed', that is, 'despite Caesar'.

\$18 The same expression, which probably has an Indo-European origin, also exists in Greek, but instead of being marked by the ablative, the third instance of transfer is marked by the genitive. This is what is called the genitive absolute: thanóntos tôu Perikléous 'after the death of Pericles'.

\section{Chapter 232. Triple transfer ending with I}

\$1 Triple transfer with the third instance ending with I generally has the last instance as A $>$ I.

$\$ 2$ Type $\mathrm{A}>\mathrm{O}>\mathrm{A}>\mathrm{I}$; Mark 1, 2, 3 .

One is dealing with double transfer of the sort A > O $>$ A (cf. Chapter 219, \$2) that continues with a verbal transfer: C'est du proper!, lit. 'That's (something) clean!', that is 'What a mess!'.

$1(\mathrm{~A}>\mathrm{O})$ Transfer of the adjective proper to a noun marked by the article le contained in the contracted form $d u$.

$2(\mathrm{O}>\mathrm{A})$ Transfer of the noun thus obtained to the contracted form $d u$.

$3(\mathrm{~A}>\mathrm{I}) \quad$ Transfer of the adjective thus obtained to a verb by the auxiliary être.

Further: Ah! C'est du joli!, lit. 'Ah! That's nice!', that is 'Shame on you!' (Henri Lavedan, Viveurs, Act II, p.159).

$\$ 3$ Type $\mathrm{A}>\mathrm{O}>\mathrm{A}>\mathrm{I}$; $\operatorname{Mark}(1),(2), 3$.

Fr. Il est très vieux beau 'It is a very ageing beau'.

$1(\mathrm{~A}>\mathrm{O})$ Unmarked transfer of the adjective beau 'beautiful' to a noun.

$2(\mathrm{O}>\mathrm{A})$ Unmarked reversive transfer of the noun thus obtained to an adjective.

$3(\mathrm{~A}>\mathrm{I}) \quad$ Transfer of the adjective thus obtained to a verb by the auxiliary etre (cf. Chapter 207, $\$ 3$ and 6). 
$\$ 4$ Type $\mathrm{A}>\mathrm{O}>\mathrm{A}>\mathrm{I}$; Mark (1), (2), (3).

Latin: Triste lupus stabulis 'A wolf is a sad thing for the stables'.

$1(\mathrm{~A}>\mathrm{O})$ Unmarked transfer of the adjective to a neuter noun.

$2(\mathrm{O}>\mathrm{A})$ Unmarked inverse transfer of the noun thus obtained to a predicative adjective.

3 (A > I) Unmarked transfer of the adjective thus obtained to a verb (cf. Chapter 207, $\$ 5)$.

Further: Gr. Tímion areté 'Virtue is precious', Ponēròn ho sukophántēs 'To be a sycophant is to be nasty'.

$\$ 5$ Type I > A > A > I; Mark 1, 2, 3 .

Fr. La difficulté fut d'attacher le grelot 'The difficulty was to attach the bell' (La Fontaine, Fables, II, 2, Conseil tenu par les rats 'Meeting held by the rats') (cf. Stemma 340).

$1(\mathrm{I}>\mathrm{O}) \quad$ Transfer of the verb to a noun marked by the infinitive: attacher 'attach'.

$2(\mathrm{O}>\mathrm{A})$ Transfer of the infinitive to an adjective by the preposition $d e$.

3 (A > I) Transfer of the adjective thus obtained to a verb by the auxiliary fut 'was' (cf. Chapter 207, \$6).

\begin{tabular}{|c|c|c|c|}
\hline \multirow[t]{3}{*}{ fut } & \multicolumn{3}{|c|}{ d'attacher (A) } \\
\hline & $\mathrm{d}^{\prime}$ & attacher $\quad(O$ & ) \\
\hline & & attacher (I) & -er (INF.) \\
\hline
\end{tabular}

Stemma 340

$\$ 6$ Type $\mathrm{O}>\mathrm{E}>\mathrm{A}>\mathrm{I}$; Mark 1, (2), 3 .

Fr. Ce n'est point de ma faute 'It's not (from) my fault'.

$1(\mathrm{O}>\mathrm{E})$ Transfer of the noun to an adverb by the preposition de (cf. Chapter 201, $\$ 7)$.

$2(\mathrm{E}>\mathrm{A}) \quad$ Unmarked transfer of the adverb thus obtained to an adjective.

3 (A > I) Transfer of the adjective thus obtained to a verb by the auxiliary est 'is' (cf. Chapter 207, \$6),

\$7 Type $\mathrm{O}>\mathrm{E}>\mathrm{A}>\mathrm{I}$; Mark (1), (2), 3 .

Fr. Aujourd'hui nous sommes vendredi ‘Today we are Friday, Today is Friday'.

$1(\mathrm{O}>\mathrm{E}) \quad$ Unmarked transfer of the noun vendredi 'Friday' to a temporal adverb (cf. Chapter 203, \$3).

2 (E $>$ A) Unmarked transfer of the adverb thus obtained to an adjective.

3 (A > I) Transfer of the adjective thus obtained to a verb by the auxiliary sommes 'are' (cf. Chapter 207, \$6). 


\section{Chapter 233. Quadruple transfer ending with 0}

\$1 Type $\mathrm{O}>\mathrm{A}>\mathrm{O}>\mathrm{A}>\mathrm{O}$; Mark 1, (2), 3, 4 .

This type of reversive double transfer is the same as what was examined above in terms of the formula $\mathrm{O}>\mathrm{A}>\mathrm{O}>\mathrm{A}$ (cf. Chapter 230, \$2), the soul difference being the adjective is then transferred to a noun: Fr. quatre ou six yeux tout aussi ardents que ceux de de Guiche 'four or six eyes just as ardent as those of de Guiche' (A. Dumas, Le vicomte de Bragelonne, The night).

$1(\mathrm{O}>\mathrm{A})$ Transfer of the noun Guiche, a place name, to an adjective by the preposition de: de Guiche.

$2(\mathrm{~A}>\mathrm{O})$ Unmarked transfer of the adjective thus obtained to the noun de Guiche (name of a person).

$3(\mathrm{O}>\mathrm{A})$ Transfer of the new noun thus obtained to an adjective by the preposition de as above: de de Guiche 'of de Guiche'.

$4(\mathrm{~A}>\mathrm{O})$ Transfer of the new adjective thus obtained to a noun by the retranslative ceux: ceux de de Guiche 'those of de Guiche’.

$\$ 2$ Type I > A > O > A > O; Mark 1, 2, 3, (4).

This is the same type as what was examined above (Chapter $229, \$ 7$ ), the only difference being that the source is a participle I (I > A) instead of an adjective A: Fr. J'en ai [du fin et] $d u$ bien rapé 'I have fine and nicely ground (tobacco)' (J'ai du bon tabac, popular song).

1 ( $>$ A) Transfer of the verb to an adjective by the participle.

$2(\mathrm{~A}>\mathrm{O})$ Transfer of the participle rape 'ground' to a noun marked by the definite article le contained in the contracted form $d u$.

$3(\mathrm{O}>\mathrm{A})$ Reversive transfer of the noun thus obtained to an adjective marked by the preposition de contained in the contracted form $d u$.

$4(\mathrm{~A}>\mathrm{O})$ Reversive unmarked transfer (partitive article) of the adjective thus obtained to a noun.

$\$ 3$ Type $\mathrm{A}>\mathrm{I}>\mathrm{O}>\mathrm{A}>\mathrm{O}$; Mark 1, 2, 3, (4).

Fr. Mais d'être borgne n'empêche pas d'être clairvoyant 'But to be one-eyed does not hinder one from being clairvoyant' (Gaston Picard, Revue Bleue, 1933, p. 21).

$1(\mathrm{~A}>\mathrm{I}) \quad$ Transfer of the adjective to a verb by the auxiliary être.

$2(\mathrm{I}>\mathrm{O}) \quad$ Transfer of the verb thus obtained to a substantantive by the infinitive.

$3(\mathrm{O}>\mathrm{A})$ Transfer of the noun thus obtained to an adjective by the preposition $\mathrm{de}$.

$4(\mathrm{~A}>\mathrm{O})$ Unmarked reversive transfer of the adjective thus obtained to a noun.

$\$ 4$ Type $\mathrm{A}>\mathrm{O}>\mathrm{E}>\mathrm{A}>\mathrm{O}$; Mark (1), 2, (3), 4 .

Fr. un atout 'an advantage'.

$1(\mathrm{~A}>\mathrm{O})$ Unmarked transfer of the adjective tout 'all' to a noun.

$2(\mathrm{O}>\mathrm{E})$ Transfer of the noun thus obtained to an adverb by the preposition $\dot{a}$ : $\grave{a}$ tout 'to all'. 
3 (E > A) Unmarked transfer of the adverb thus obtained to an adjective.

$4(\mathrm{~A}>\mathrm{O})$ Transfer of the adjective thus obtained to a noun, with agglutination of the preposition to the adjective transferred to a noun, by the indefinite article un.

Further: un entre-deux de dentelle, lit. 'a between-two of lace', that is 'a lace insert'.

$\$ 5$ Type I > O > E > A > O; Mark 1, 2, (3), 4.

Fr. un pourboire 'a tip' (The stage I $>\mathrm{O}>\mathrm{E}$ pour boire is attested in Molière, cf. Chapter $223, \S 4)$.

$1(\mathrm{I}>\mathrm{O}) \quad$ Transfer marked by the use of the infinitive.

$2(\mathrm{O}>\mathrm{E})$ Transfer marked by the preposition pour 'for'.

3 (E $>$ A) Unmarked transfer of the adverb thus obtained to an adjective.

$4(\mathrm{~A}>\mathrm{O})$ Transfer marked by the use of the article.

Further: une affaire 'a matter' < à faire 'to do', l'avenir 'the future' (stage I $>\mathrm{O}>\mathrm{E}>\mathrm{A})<\grave{a}$ venir 'to come' (cf. Chapter 230, \$13). The third instance of transvaluation is marked only insofar as French syntax demands the use of the article in front of the noun: Vous aurez affaire à moi 'You will be hearing from me'.

$\$ 6$ Type $\mathrm{t}>\mathrm{E}>\mathrm{E}>\mathrm{A}>\mathrm{O}$; Mark 1, 2, (3), 4.

Fr. un pardessus, lit. 'a by-over', that is 'an overcoat'.

$1(\mathrm{t}>\mathrm{E}) \quad$ Transfer of the preposition sur (sus) 'on' to an adverb by the preposition de: dessus 'over' (cf. above Chapter 204, \$8).

2 (E $>$ E) Subcategory transfer of the adverb dessus to the adverb of a different subcategory par dessus 'over, above' by the preoposition par 'by'.

3 (E > A) Unmarked transfer of the adverb thus obtained to an adjective.

$4(\mathrm{~A}>\mathrm{O})$ Transfer of the adjective thus obtained to a noun, involving agglutination of the preposition par to the adverb obtained by transvaluation dessus, by the indefinite article $u n$.

\section{Chapter 234. Quadruble transfer ending with A}

\$1 Type $\mathrm{A}>\mathrm{O}>\mathrm{A}>\mathrm{O}>\mathrm{A}$; Mark (1), 2, 3, 4 .

Fr. Mon soulier de droite... déferré... il ne manquait pas un clou à la semelle du de gauche 'My right shoe...removed...he was not missing a tack in the sole of the left (shoe)' (Marcel Aymé, La jument verte, p. 294)

$1(\mathrm{~A}>\mathrm{O})$ Unmarked transfer of the adjective gauche 'left' to a noun.

$2(\mathrm{O}>\mathrm{A}) \quad$ Transfer of the noun thus obtained to an adjective by the preposition $d e$.

$3(\mathrm{~A}>\mathrm{O})$ Transfer of the adjective thus obtained to a noun by the definite article le contained in the contracted form $d u$. 
$4(\mathrm{O}>\mathrm{A})$ Transfer of the new noun thus obtained to an adjective by the preposition de contained in the contracted form $d u$.

This reversive double transfer is evidently very risky and offensive to the good sensitivities of the purists. The author has obtained the same effect by using the translative celui in a correct manner: la semelle de celui de gauche 'the sole of the left (shoe)'. Note that this expression could be the base of quintuple transfer and it would be possible to oppose the sole of the right shoe to celle $d u$ de gauche 'that of the left shoe'. If we do not acknowledge such a grouping, it is because we have not encountered it.

$\$ 2$ Type $\mathrm{O}>\mathrm{E}>\mathrm{A}>\mathrm{O}>\mathrm{A}$; Mark 1, (2), (3), 4.

Fr. une âme de sans-culotte 'a spirit of a sans-culotte (revolutionary)' (cf. Stemma 341).

$1(\mathrm{O}>\mathrm{E})$ Transfer of the noun culotte 'pant' to an adverb by the preposition sans 'without'.

2 ( $\mathrm{E}>\mathrm{A}) \quad$ Unmarked transfer of the adverb thus obtained to an adjective.

$3(\mathrm{~A}>\mathrm{O})$ Unmarked transfer of the adjective thus obtained to a noun.

$4(\mathrm{O}>\mathrm{A})$ Transfer of the noun thus obtained to an adjective by the preposition $d e$.

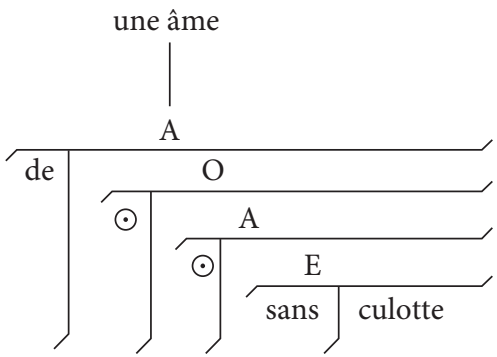

Stemma 341

$\$ 3$ Type I > A > I > O > A; Mark 1, 2, 3, 4.

Fr. (Quelle guigne)... d'être arrêtés 'What rotten luck...to be stopped' (J.-J. Bernard, Nationale 6, p. 8).

$1(\mathrm{I}>\mathrm{A}) \quad$ Transfer of the verb to an adjective by the participle.

2 (A > I) Reversive transfer of the participle to a verb by the auxiliary être (cf. Chapter $225, \$ 10)$.

$3(\mathrm{I}>\mathrm{O}) \quad$ Transfer of the verb thus obtained to a noun by the infinitive.

$4(\mathrm{O}>\mathrm{A})$ Transfer of the noun thus obtained to an adjective by the preposition $d e$.

Further: Ger. (das Bedauern der Karthager) nachgegeben zu haben 'the regret of the Carthaginians for have given up'.

$\$ 4$ Type $\mathrm{O}>\mathrm{A}>\mathrm{O}>\mathrm{E}>\mathrm{A}$; Mark 1, 2, 3, (4).

Fr. des aubergines à la parisienne 'eggplant à la parisienne (Paris style)'. 
$1(\mathrm{O}>\mathrm{A})$ Transfer of the noun Paris to an adjective by the feminine derivational suffix -ienne.

$2(\mathrm{~A}>\mathrm{O})$ Transfer of the adjective thus obtained to a noun designating the manner by which the eggplant is prepared by the definite article la.

$3(\mathrm{O}>\mathrm{E})$ Transfer of the noun thus obtained to a manner adverb by the preposition $\grave{a}$.

$4(\mathrm{E}>\mathrm{A}) \quad$ Unmarked transfer of the manner adverb thus obtained to an adjective.

Further: un jardin à la française 'a French-style garden' or à l'anglaise 'English-style', and a large number of expressions of the culinary arts: aubergines à la languedocienne 'eggplant Languedoc-style', artichauts à l'italienne 'artichokes Italian-style', anguilles à la tartare 'chopped raw eel', anguilles à la bourgeoise 'eel bourgeoise-style'.

$\$ 5$ Type $\mathrm{O}>\mathrm{A}>\mathrm{O}>\mathrm{E}>\mathrm{A}$; Mark (1), 2, 3, (4).

Fr. une bouchée à la reine, lit. 'a mouthful to the queen', that is 'vol-au-vent (puff pastry)'.

$1(\mathrm{O}>\mathrm{A})$ Unmarked transfer of the noun reine to an adjective.

$2(\mathrm{~A}>\mathrm{O})$ Transfer of the adjective thus obtained to a noun designating the manner in which dishes are prepared by the definite article la.

$3(\mathrm{O}>\mathrm{E})$ Transfer of the noun thus obtained to a manner adverb by the preposition $\grave{a}$.

$4(\mathrm{E}>\mathrm{A}) \quad$ Unmarked transfer of the manner adverb thus obtained to an adjective.

$\$ 6$ Type $\mathrm{O}>\mathrm{A}>\mathrm{O}>\mathrm{E}>\mathrm{A}$; Mark 1, 2, (3), (4).

Fr. un caneton rouennaise 'a duck Rouen-style'.

$1(\mathrm{O}>\mathrm{A})$ Transfer of the noun Rouen to an adjective by the derivational suffix -ais.

$2(\mathrm{~A}>\mathrm{O})$ Transfer of the adjecitive thus obtained to a feminine noun designating the manner in which duck is prepared by the feminine ending - $e$ of rouennaise.

$3(\mathrm{O}>\mathrm{E}) \quad$ Unmarked transfer of the noun thus obtained to a manner adverb.

4 (E $>$ A) Unmarked transfer of the manner adverb thus obtained to an adjective.

\$7 Type E > A > O > E > A; Mark 1, (2), 3, (4).

This type is the same as what we examined above (Chapter $231, \$ 4$ ) in terms of the formula $\mathrm{E}>\mathrm{A}>\mathrm{O}>\mathrm{E}$, the only difference being that the final adverb is transferred to an adjective, e.g. Fr. un raisonnement a priori 'an a priori argument'.

$1(\mathrm{E}>\mathrm{A})$ Fixed transfer of the adverb ${ }^{\star}$ pri- to a comparative adjective by the derivational suffix * -us.

$2(\mathrm{~A}>\mathrm{O})$ Unmarked transfer of the comparative adjective thus obtained to a noun.

$3(\mathrm{O}>\mathrm{E}) \quad$ Transfer of the noun thus obtained to an adverb by the Latin ablative reinforced by the preposition $a$.

4 (E > A) Unmarked transfer of the adverb thus obtained to an adjective. 
$\$ 8$ Type I > A > O > E > A; Mark 1, (2), 3, (4).

Lat. ex alticinctis unus atriensibus 'one of the slaves of the atrium with rolled up clothing' (Phaedrus, Fables, II, 5).

1 ( $>$ A) Transfer of the verb to an adjective by the participle cinctus 'surrounded'.

$2(\mathrm{~A}>\mathrm{O})$ Unmarked transfer of the adjective thus obtained to a noun.

$3(\mathrm{O}>\mathrm{E})$ Transfer of the noun thus obtained to an adverb by the ablative reinforced by the preposition $e x$.

4 (E > A) Unmarked transfer of the adverb thus obtained to an adjective.

\section{Chapter 235. Quadruple transfer ending with E or I}

\$1 Type t > E > O > E > E; Mark 1, (2), 3, 4 .

Fr. regarder quelqu'un par en-dessous 'to observe someone from below'.

$1(\mathrm{t}>\mathrm{E}) \quad$ Transvaluation of the preposition sous to a locative adverb by the translative $d e$.

$2(\mathrm{E}>\mathrm{O}) \quad$ Unmarked transfer of the adverb thus obtained to a noun.

$3(\mathrm{O}>\mathrm{E})$ Reversive transfer of the noun thus obtained to an adverb by the preposition en: en-dessous.

4 (E > E) Subcategory transfer of the adverb to an adverb of another sort by the preposition par.

\$2 Type I > A > O > A > I; Mark 1, 2, 3, 4 .

This is triple transfer of the sort I $>\mathrm{A}>\mathrm{O}>\mathrm{A}$ that we have already examined (cf. Chapter 230, \$6); it is extended by an instance of verbal transfer: (Et les tuyautés) sont d'un suivi '(And the fluted frills) are of a consistent (quality)' (Zola, L'Assommoir, Chapter VI).

1 (I > A) Transfer marked by the use of the participle suivi 'consistent'.

$2(\mathrm{~A}>\mathrm{O})$ Transfer marked by the use of the indefinite article $u n$.

$3(\mathrm{O}>\mathrm{A})$ Reversive transfer marked by the use of the preposition de.

4 (A > I) Marked transfer by the use of the auxiliary être 'be'.

Further: Gr. Oud’ho kōlúsōn parên 'There was no one to stop me' (Sophocles).

\section{Chapter 236. Quintuple transfer}

\$1 Type E > A > O > E > A > O; Mark 1, (2), 3, (4), 5.

This type is the same as what we examined above (Chapter 234, \$7) in terms of the formula $\mathrm{E}>\mathrm{A}>\mathrm{O}>\mathrm{E}>\mathrm{A}$, the only difference being that the final adjective is then transferred to 
a noun. The entire sequence contains the subformula $\mathrm{E}>\mathrm{A}>\mathrm{O}$ twice: Fr. L'a priori est un mode de raisonnement dangereux 'The a priori is dangerous mode of reasoning.'

$1(\mathrm{E}>\mathrm{A}) \quad$ As above, Chapter 234, $\$ 7$.

$2(\mathrm{~A}>\mathrm{O}) \quad$ Unmarked as above, Chapter 234, $\$ 7$.

$3(\mathrm{O}>\mathrm{E}) \quad$ As above, Chapter 234, $\$ 7$.

$4(\mathrm{E}>\mathrm{A}) \quad$ Unmarked as above, Chapter 234, $\$ 7$.

$5(\mathrm{~A}>\mathrm{O})$ Transfer from an adjective thus obtained to a noun by the article $l$ '.

\$2 Type I > A > O > E > A > O; Mark 1, (2), 3, (4), 5.

Fr. l'embonpoint 'stoutness, portliness'.

1 (I > A) Etymologically fixed transfer of the Latin verb pungo 'I stab' to an adjective by the participle punctus 'stabbed'.

$2(\mathrm{~A}>\mathrm{O})$ Unmarked transfer of the adjective thus obtained to the neuter Latin noun punctum 'blade, point'.

$3(\mathrm{O}>\mathrm{E})$ Transfer of the noun thus obtained, which becomes point in French, to an adverb by the preposition $e$.

$4(\mathrm{E}>\mathrm{A}) \quad$ Unmarked transfer of the adverbial locution thus obtained to the adjective en (bon) point.

$5(\mathrm{~A}>\mathrm{O}) \quad$ Transfer of the adjective thus obtained to a noun by the article $l e$.

$\$_{3}$ Type I $>$ A $>$ O $>$ E $>$ O $>$ E; Mark 1, (2), 3, 4, 5 .

This type is represented in French by à l'endroit 'the right way round', which, despite its appearance, is not of the same sort as à l'envers 'upside down' (cf. Chapter 231, \$6).

1 (I > A) Etymologically fixed transfer of the Latin verb dirigo '(I) direct' to an adjective by the participle directus 'directed'.

$2(\mathrm{~A}>\mathrm{O})$ Unmarked transfer of the French adjective droit 'right', from Lat. directus, to a noun.

$3(\mathrm{O}>\mathrm{E}) \quad$ Transfer of the noun thus obtained to an adverb by the preposition $e$.

$4(\mathrm{E}>\mathrm{O})$ Reversive transfer of the adverb thus obtained to a noun by the article $l$ '.

$5(\mathrm{O}>\mathrm{E})$ Reversive transfer of the noun thus obtained to an adverb by the preposition $\dot{a}$.

$\$ 4$ Type I > A > O > A > I > I; Mark 1, 2, 3, 4, 5 .

Fr. (Mademoiselle) va être (à la fois d'un comme il faut et) d'un troublant 'Ms. is going to be (both upstanding and) (sexually) disturbing' (Henri Lavedan, Viveurs, Act I, p. 29)

1 ( $>$ A) First-degree transfer of the verb il trouble 'it disturbs' to an adjective by the concomitant participle in -ant: troublant 'disturbing.'

$2(\mathrm{~A}>\mathrm{O})$ First-degree transfer of the adjective thus obtained to a noun marked by the indefinite article un: un troublant. 
$3(\mathrm{O}>\mathrm{A})$ First degree reversive transfer of the noun thus obtained to an adjective marked by the translative (preposition) de: d'un troublant 'disturbing', lit. 'of a disturbing'.

$4(\mathrm{~A}>\mathrm{I}) \quad$ First-degree transfer of the adjective thus obtained to a verb marked by the verb est 'is': est d'un troublant.

5 (I > I) First degree subcategory transfer of the verb thus obtained to its future form marked by the auxiliary va: va être d'un troublant 'is going to be disturbing'.

\section{Chapter 237. Sextuple transfer}

\$1 Type $\mathrm{E}>\mathrm{A}>\mathrm{O}>\mathrm{E}>\mathrm{A}>\mathrm{O}>\mathrm{E}$; Mark 1, (2), 3, (4), 5, 6 .

This type is the same as what we examined in the preceding chapter, the only difference being that the final noun is transferred to an adverb. The cycle $\mathrm{E}>\mathrm{A}>\mathrm{O}>\mathrm{E}$ appears twice in the formula. Fr. vivre dans l'a priori 'to prejudge everything', lit. 'to live in the a priori'.

$1(\mathrm{E}>\mathrm{A})$ Fixed transfer of the adverb ${ }^{*}$ pri- to a comparative adjective by the derivational suffix * ${ }^{*}$ s.

$2(\mathrm{~A}>\mathrm{O})$ Unmarked transfer of the comparative adjective thus obtained to a noun.

$3(\mathrm{O}>\mathrm{E})$ Transfer of the noun thus obtained to an adverb by the Latin ablative reinforced by the preposition $a$.

4 (E > A) Unmarked transfer of the adverb thus obtained to an adjective with the form a priori borrowed from Latin.

$5(\mathrm{~A}>\mathrm{O})$ Transfer of the adjective thus obtained to a noun by the definite article $l$ '.

$6(\mathrm{O}>\mathrm{E})$ Transfer of the noun thus obtained to an adverb by the preposition dans 'in'. $\$ 2$ Type $\mathrm{O}>\mathrm{A}>\mathrm{O}>\mathrm{A}>\mathrm{O}>\mathrm{E}>\mathrm{A}$; Mark (1), 2, (3), 4, 5, 6 .

The reversive transfer $\mathrm{O}>\mathrm{A}>\mathrm{O}$ appears twice in the formula; Fr. asperges à la Pompadour 'asparagus à la Pompadour (mistress of Louis XV)'.

$1(\mathrm{O}>\mathrm{A})$ Unmarked transfer of the noun Pompadour, a proper name, to an adjective.

$2(\mathrm{~A}>\mathrm{O})$ Reversive transfer marked by the adjective thus obtained to the noun Pompadour, name of a person.

$3(\mathrm{O}>\mathrm{A})$ Unmarked transfer of the noun thus obtained to an adjective.

$4(\mathrm{~A}>\mathrm{O})$ Transfer of the adjective thus obtained to a noun expressing the manner in which asparagus is prepared.

$5(\mathrm{O}>\mathrm{E})$ Transfer of the noun thus obtained to a manner adverb by the preposition à.

$6(\mathrm{E}>\mathrm{A}) \quad$ Unmarked transfer of the adverb thus obtained to an adjective. 


\section{Chapter 238. Septuple transfer}

\$1 Type $\mathrm{I}>\mathrm{O}>\mathrm{E}>\mathrm{A}>\mathrm{O}>\mathrm{I}>\mathrm{A}>\mathrm{O}$; Mark 1, 2, (3), (4), 5, 6, 7 .

Fr. (faire) l'affairé '(do) the busy (person)'.

$1(\mathrm{I}>\mathrm{O}) \quad$ Transfer of the verb to a noun by the infinitive faire.

$2(\mathrm{O}>\mathrm{E})$ Transfer of the noun thus obtained to an adverb by the preposition $\dot{a}$ (cf. Chapter 223, \$4).

3 (E > A) Unmarked transfer of the adverb thus obtained to an adjective (cf. Chapter $230, \$ 13)$.

$4(\mathrm{~A}>\mathrm{O})$ Unmarked transfer (except for in the orthography) of the adjective thus obtained to the noun affaire 'matter' (cf. Chapter 233, \$5).

$5(\mathrm{O}>\mathrm{I}) \quad$ Transfer of the noun thus obtained to a verb by derivation by the suffix -er: affairer 'to busy'.

6 (I > A) Transfer of the verb thus obtained to an adjective by the participle: affairé 'busy'.

7 (A > O) Transfer of the adjective thus obtained to a noun by the definite article le.

$\$ 2$ Type $\mathrm{E}>\mathrm{A}>\mathrm{O}>\mathrm{E}>\mathrm{O}>\mathrm{A}>\mathrm{O}>\mathrm{A}$; Mark 1, 2, 3, 4, 5, 6, 7 .

Fr. Les beautés du monde d'ici-bas me donnent par avance une idée des joies de celui de l'au-delà 'The beauties of this life give me an idea in advance of the joys of those beyond'.

$1(\mathrm{E}>\mathrm{A})$ Transfer of the adverb là 'there' to an adjective by the preposition de 'from'.

$2(\mathrm{~A}>\mathrm{O})$ Transfer of the adjective thus obtained to a noun by the definite article le contained in the contracted form $a u$.

$3(\mathrm{O}>\mathrm{E})$ Transfer of the noun thus obtained to an adverb by the preposition $a$ contained in the contracted article au.

$4(\mathrm{E}>\mathrm{O})$ Reversive transfer of the adverb thus obtained to a noun by the definite article $l$.

$5(\mathrm{O}>\mathrm{A})$ Transfer of the noun thus obtained to an adjective by the preposition $\mathrm{de}$.

$6(\mathrm{~A}>\mathrm{O})$ Reversive transfer of the adjective thus obtained to a noun by the retranslative celui 'this'.

$7(\mathrm{O}>\mathrm{A})$ Reversive transfer of the noun thus obtained to an adjective subordinate to the noun joies 'joys' by the preposition $d e$.

$\$ 3$ Although it does not contain less than seven instances of transfer, this multiple transfer occurs entirely in the interior of a single nucleus (Stemma 342).

$\$ 4$ The number of component transfers of a single occurrence of multiple transfer is theoretically unlimited, but in practice one never encounters more than seven, which is not to say that there could not be more. 


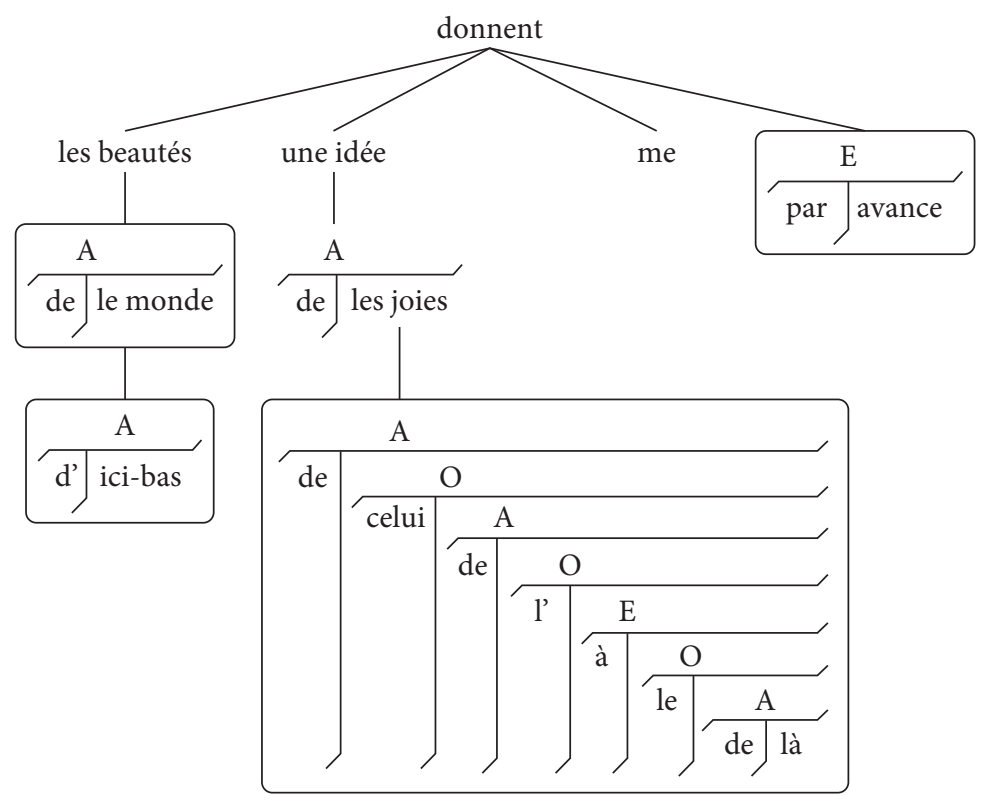

Stemma 342 


\section{BOOK D}

\section{Second-degree transfer, simple transfer}

\section{Chapter 239. Second-degree transfer}

$\$ 1$ We have already seen (Chapter $164, \$ 14$ and 15 ) that second-degree transfer is constituted by a verbal node moving to a different syntactic level. This node is reduced to the role of a simple element subordinate to a hierarchically superior node, but it retains all its inferior connections. Although the verb remains the center of the subordinate clause, it is thus merely an element of the main clause.

$\$ 2$ We have shown (cf. Chapter $164, \$ 16$ ) that traditional grammar has implicitly recognized this characteristic because it calls second-degree transfer subordination.

$\$ 3$ This is also the reason why 'subordinate mood' has been called subjunctive (Lat. subiunctivus, Gr. hupotaktiké égklisis) by traditional grammar. This mood is indeed frequent in subordinate clauses and its role is often, if not always, to mark subordination, at least in certain uses and in certain languages such as Latin and German.

$\$ 4$ Since it stands in for first-degree transfer, second-degree transfer becomes necessary when first-degree transfer (and nominalization of the infinitive, for instance, with the loss of verbal characteristics) becomes rigid and loses its full functional ability.

$\$ 5$ Secondary transfer is hence young in comparison to first-degree transfer, which is older.

$\$ 6$ One is of course not dealing here with absolute age, but rather relative age, and it is in this sense that traditional grammars draw the distinction in morphology between primary and secondary formations.

$\$ 7$ The relationship between secondary and first-degree transfer is hence entirely comparable to that between the compound and simple tenses. We endeavoured to show that the compound tenses are secondary morphological formations that are younger than the older formations of the simple tenses. ${ }^{273}$

$\$ 8$ Just as the compound tenses are analytical, second-degree transfer is also analytical, and for the same reason, that is, it is marked by a word independent of the verb that is not agglutinated to the verb.

$\$ 9$ Hence the verbal adjective fascinating (former participle, first-degree transfer), for example, is expressed synthetically in a single word, whereas the same transfer is expressed

273. Cf. Lucien Tesnière, Theorie structurale des temps composes 'Structural theory of compound tenses', Mélanges Bally, Geneva, 1939, pp. 153ff., notably pp. 180-181. 
analytically by two morphologically independent elements when it is of second degree: that fascinates; a fascinating object is an object that fascinates.

$\$ 10$ The advantage of this process is that transfer does not alter the properties of the source at all. These properties are conserved in the target, since the translative remains entirely independent.

$\$ 11$ This is why a verbal node that has been transferred to a noun by second-degree transfer retains all of its verbal characteristics, whereas these characteristics are likely to disappear when subjected to first-degree transfer by means of the infinitive, in particular concerning diathesis (cf. Chapter 185, \$7), mood (cf. Chapter 186, \$6), tense (cf Chapter 187, \$1), and above all, person (cf. Chapter 188, \$1).

$\$ 12$ Take for example an independent clause: Alfred hits Bernard. This clause stands as a whole, and its verb retains all its verbal characteristics when it is transferred to a noun by way of the translative that: I believe that Alfred hits Bernard.

$\$ 13$ Thanks to the independence of the translative, second-degree transfer permits the verb to eventually acquire the characteristics of other grammatical categories (noun, adjective, adverb) without causing the verb to lose its verbal characteristics as it would in the case of first-degree transfer.

$\$ 14$ The linear symbols for transfer (> or <, cf. Chapter 155, \$1 and 3) and the stemmatic symbols (Symbol or Symbol, cf. ibid., $\$ 7$ and 11-12) are valid for second-degree transfer just as they are for first-degree transfer.

$\$ 15$ However, it must be emphasized that when one is dealing with second-degree transfer and not with first-degree transfer, one should be precise. For this reason, the symbols used to separate source from target in cases of second-degree transfer will be "doubled" in a sense: $>>,<<$, and $\widetilde{\mathcal{T}}, \widetilde{\mathcal{T}}$.

$\$ 16$ Since the verb is susceptible to being changed by second-degree transfer to the same category as by first-degree transfer, we will distinguish between the following types of second-degree transfer: I > > O, I >> A and I > $>$ E. The type I > > I is by definition excluded, since the verb cannot be transferred to itself.

$\$ 17$ The value of the element (noun, adjective, or adverb) in the governing clause, which is that of the subordinate clause, is in general strongly perceived by the best instructors of primary education, whose main concern is to get their students to sense the analogy of function.

\section{Chapter 240. Correlation}

\$1 The connection that unites the governing clause with the subordinate clause is sometimes indicated morphologically by corresponding markers. One says that these markers are in correlation with each other.

$\$ 2$ In the governing clause, the subordinate is hence announced by a word that prefigures it by epitomizing its category. This word is called the antecedent. 
$\$ 3$ The subordinate clause is merely the expansion of the antecedent, and it has a translative as a marker. The form of the antecedent is often symmetrical to what we will call the subsequent. The latter translative is placed obligatorily at the head (or if it is a postposed element, at the tail) of the clause that it transfers.

$\$ 4$ The antecedent and the subsequent symmetrically correspond to each other. Some grammarians call this symmetry balancing, which indicates that the presence of the one presupposes the presence of the other. Hence the two form a couple. One calls them correlatives. $\$ 5$ Correlatives correspond two to two, the antecedent appearing in the governing clause and the subsequent in the subordinate clause.

$\$ 6$ Pairs of correlatives are particularly abundant in certain types of languages, in particular in the Indo-European languages:

\begin{tabular}{|c|c|c|}
\hline & \multicolumn{2}{|c|}{ Correlatives } \\
\hline & Antecedent & Subsequent \\
\hline French & tel 'such' & quel 'which' \\
\hline \multirow[t]{6}{*}{ Latin } & talis 'such' & qualis 'which' \\
\hline & tantus 'so great' & quantus 'as' \\
\hline & tam 'so' & quam 'that' \\
\hline & tot 'as many' & quot 'as' \\
\hline & tum 'then' & cum 'as' \\
\hline & totiens 'as many times' & quotiens 'as' \\
\hline \multirow[t]{3}{*}{ Greek } & oútōs 'so' & hōs 'as' \\
\hline & tóte 'then' & hote 'when' \\
\hline & tosoûton 'as many' & hoposon 'as' \\
\hline \multirow[t]{2}{*}{ English } & there & where \\
\hline & then & when \\
\hline \multirow[t]{2}{*}{ German } & der 'he' & wer 'who' \\
\hline & $d a$ 'there' & wo 'where' \\
\hline \multirow[t]{4}{*}{ Russian } & takoj 'such' & kakoj 'which' \\
\hline & tak 'thus' & kak 'as' \\
\hline & togda 'then' & kogda 'when' \\
\hline & stol'ko 'so' & skol'ko 'that' \\
\hline
\end{tabular}

\section{Chapter 241. I >> O transfer}

$\$ 1$ Of the types of secondary verbal transfer, I $>>\mathrm{O}$ is the easiest to recognize. One is dealing with a case where an independent clause, the center of which is a verb (I), is transferred to a noun that is subordinate to the verb of the governing clause, and thus becomes a simple element within the governing clause. 
\$2 Take the independent clause Alfred a raison 'Alfred is right' as an example. I can transfer it by way of the translative que to a noun: qu'Alfred a raison 'that Alfred is right'. This noun is susceptible to playing the role of the second actant of an independent clause. The two independent clauses are thus connected to each other, the one becoming the governing clause and the other the subordinate clause.

$\$ 3$ An affirmative sentence word (oui) or the negative sentence word (non) can be transferred to nouns by the translative of second degree que: Je crois que oui 'I think so', Je suis sûr que non 'I am sure no is the case', J'espère que si 'I hope yes'.

$\$ 4$ In a similar case, Italian employs the translative of first degree di: Dico di si 'I say yes', Dico di no 'I say no. The same holds in Occitan: Vous dise pas de non 'I didn't say you no' (Lamouche, Grammaire languedocienne, p. 117).

\$5 Second-degree transfer of the sort I $>>0$ occurs when a sentence has an incomplete sentence word (Chapter 46, \$5) (voici lit. 'see here', voilà lit. 'see there'), or an adverbial of locution transferred to a sentence word: Voici qu'on vient 'There is someone coming', Voilà qu'il pleut 'Look, it's raining'; Avec ça que l'ouvrier, échiné, sans le sou, méprisé par les bourgeois, avait tant de sujets de gaieté 'And so the worker, exhausted, without money, despised by the bourgeois, had so many reasons to be happy', lit. 'With that that...' (Zola, L' Assommoir, VII).

$\$ 6$ The subordinate clause plays the role of a second actant, that is, the role of what traditional terminology calls an object complement. The same terminology, which reserves the term complement for every subordinate clause that plays the role of a complement, should logically call the clause qu'Alfred a raison 'that Alfred is right' a subordinate complement clause (Fr. proposition subordonnée complétive).

$\$ 7$ However, it also occurs that the clause qu'Alfred a raison 'that Alfred is right' can play the role of the first actant, that is, the role of what traditional terminology calls the subject: Il est sûr qu' Alfred a raison 'It is certain that Alfred is right'. Traditional grammar cannot have been unaware of the fact that in both cases, the subordinate clause is of the same nature, the consequence being that both should be called complement clauses.

$\$ 8$ Traditional terminology is therefore motivated to say that in the sentence Il est sûr qu' Alfred a raison 'It is certain that Alfred is right', the clause qu' Alfred a raison 'that Alfred is right' is a subject complement clause, which is a contradiction, since the same terminology views the subject as the precise opposite of the complement.

$\$ 9$ This contradiction disappears if one considers what we have attempted to show above (cf. Chapter $51, \$ 13$ ), i.e. the subject is a complement like the others.

$\$ 10$ Identity formulated in this manner is purely structural. It resides on the observation that regardless of whether one is dealing with a first actant or a second actant, one is always dealing with an actant (cf. Chapter $48, \$ 6$ ), that is, with a noun $(\mathrm{O})$ directly subordinate to the verb (cf. Chapter $48, \$ 10$ ). 
\$11 In this study we will also avoid calling on the semantic opposition between the first actant and the second actant, and by not doing this, the accent is placed on the structural similarity of the types of subordinates. Thus the shared behavior of actants is emphasized. This is why we will call subordinate clauses that result from I $>>0$ transfer actantial subordinates.

$\$ 12$ This terminology is doubly advantageous. Firstly, it allows us to avoid the term subject complement clause and the detrimental contradiction that it establishes.

$\$ 13$ Secondly, it is nicely integrated into the system of terminology that we have already adopted when we have to establish the opposition between actantial clause (I >> O) and circumstantial clause ( $\mathrm{I}>>\mathrm{E}$, cf. below Chapter 254), these terms matching the distinction between actant and circumstant (cf. Chapter 48, \$2ff.).

$\$ 14$ An actantial clause is thus a verbal node transferred to an actant by second-degree transfer, and a circumstantial clause is a verbal node transferred to a clause by seconddegree transfer.

$\$ 15$ The possibilities for secondary nominal transfer are the same as for primary nominal transfer. For example, this type of transfer can render the verb capable of playing the role of an actant, just as is the case for the infinitive (cf. Chapter 184, \$7). It is the same as for réussir 'to succeed' in Alfred espère réussir 'Alfred wants to succeed' (first-degree transfer) as with qu'il réussira 'that he will succeed' (second-degree transfer): Alfred espère qu'il réussira 'Alfred hopes that he will succeed', which is semantically equivalent to the true noun la réussite in Alfred espère la réussite 'Alfred wants success'.

$\$ 16$ The nominal character of a verb that has been transferred to a noun by second-degree transfer is evident in the fact that it can eventually be conjoined with a true noun. Coordination of this sort is generally frowned upon from the perspective of style, in particular in French, but it occurs in German, which tends to be less prescriptive when it comes to questions of logic and style: Was soll ich mir sonst wünschen, als die ewige Seligkeit und dass wir zwei, solange wir leben, gesund dabei bleiben? 'What else should I hope for other than eternal spirituality and that we two remain healthy as long as we live?' (Grimm, Fairy Tales, The rich and the poor, p. 33).

$\$ 17$ The identity of the subordinate clause as a noun in German is quite evident in the form dass 'that', which is none other than the neuter article itself (das 'the'), the only difference being purely orthographic. This alternative orthography was established at the beginning of the 16 th century. ${ }^{274}$

$\$ 18$ No less suggestive is the process in Spanish that consists of placing the article in front of a clause that has been transferred to a noun ( $>$ O): No impide el que no se pueda vivir

274. Cf. H. Paul, Deutsches Wörterbuch, see dass 1, page 1041. 
sin comer 'That does not prevent one from being able to live without eating', lit. 'That does not prevent the that one is not able to live without eating.

$\$ 19$ The nominal character of the actantial subordinate clause has been recognized by Bally: "The conjunction que 'that' introduces a clause that has been transposed to a noun and que can thus pass for a type of article", ${ }^{275}$ and "In French $t u$ réussiras 'you will succeed' has an external marker of transposition in Je crois que tu réussiras 'I think you will succeed". 276

\section{Chapter 242. The marker of I >>0 transfer}

\$1 The simplest manner to connect a verbal node to another node is simple parataxis. Parataxis can establish a true semantic connection without a marker.

$\$ 2$ This process is commonly employed in a number of languages to connect independent clauses to declarative verbs, Il dit: «Ils sont trop verts et bons pour des goujats» 'He said: "They are too green and good for the boors".

Le sage dit selon les gens: $\quad$ 'The sage says according to people:

Vive le roi! Vive la ligue! $\quad$ Long live the king! Long live the league!'

(La Fontaine, Fables, II, 5, La chauve-souris et les deux belettes)

$\$ 3$ However, one is not dealing here with a connection that is purely semantic. Indeed, the second verbal node plays the role of the second actant of the first verbal node. But the two propositions remain independent of each other. There is no structural connection between the two. In orthography, one is content to place a colon after the first and to put the second in quotation marks. One then designates the result as direct speech (Fr. style direct).

$\$ 4$ It often occurs that the first clause is expressed in the middle of the second. One says that it has been inserted. In cases of insertion, the noun or index is produced after the verb: C'est vrai, dit Alfred 'It's true, Alfred said', Tu la troubles! Reprit cette bête cruelle 'You trouble her! This cruel beast went on' (La Fontaine, Fables, 10, Le renard et les raisins 'The wolf and the sheep').

275. Bally, Linguistique générale et linguistique française, 1st edition, \$70, p 65. [In his 3rd revised edition, Bern, 1950, (conforming to the 2nd edition, 1944), Bally abandoned this redaction, but one can find the same ideas expressed in $\$ 188$, p. 120.]

276. Ibid., $\$ 153$, p. 135, [Remark of the first editors: cf. 3rd edition, $\$ 297$, p. 184 and $\$ 183$, p. 117. Que appears in the category of transposers (Fr. transpositeurs), whereas the clause to be transferred takes the name transponend. It is interesting to compare this terminology with that of L. Tesnière, who seemed to have completely ignored Bally's 2nd edition.] 
\$5 In writing, one places the insertion between two commas, and it is not necessary to place the subordinate in quotation marks: Ils sont trop verts, dit-il, et bons pour des goujats 'They are too green, he said, and good for boors' (La Fontaine, Fables, III, 11, Le petit poisson et le pêcheur).

$\$ 6$ The insertions serve to report the words of someone else and are a common appearance. In addition to dit-il, lit. 'said he', in French, one finds a number of similar expressions:

\begin{tabular}{ll}
\hline fit-il & 'he made' \\
reprit-il & 'he went on' \\
continua-t-il & 'he continued' \\
observa-t $-i l$ & 'he observed' \\
protesta-t-il & 'he protested' \\
risqua-t $-i l$ & 'he dared to say' \\
insinua-t $-i l$ & 'he insinuated' \\
suggéra-t $-i l$ & 'he suggested' \\
répondit-il $i l$ & 'he responded' \\
rétorqua-t-il & 'he retorted' \\
\hline
\end{tabular}

We are overlooking a group of similar expressions: Alfred est, paraît-il, très intelligent 'Alfred is, it seems, very intelligent', Vous avez, ce me semble, attendu trop longtemps 'You have, it seems to me, been waiting too long. Further: Un tiens vaut, ce dit-on, mieux que deux tu l'auras 'One have, it is said, is worth more than to will-haves' (La Fontaine, Fables, V, 3, Le petit poisson et le pêcheur 'The small fish and the fisherman').

$\$ 7$ Writers and above all journalists constantly strive to renew and increase the inventory of expressions like dit-il 'he said'. In this use, one even finds rit-il 'he laughed', which is the style of serialized novels. One has extended this practice as far as expira-t-il 'he gasped' in a journal reporting on the hanging of Seyss-Inquart and his last words: Je crois à Allemagne, expira-t-il 'I believe in Germany, he gasped' (Midi-Libre, 17-X-1946).

$\$ 8$ But in order for there to be true transfer and subordination of the transferred clause, a semantic connection alone does not suffice. There must also be a structural connection, in which case one says that the subordinate clause is in indirect speech (Fr. style indirect).

$\$ 9$ In a number of languages, the transfer I $>>0$ occurs without a marker, and the subordinate is morphologically indistinguishable from a coordinate clause in direct speech, Bantu: Ba woni i lele 'They see (that) he is sleeping'.

$\$ 10$ The absence of a marker is not limited to exotic languages and can hence not be regarded as a primitive manifestation of language. It is also common in a number of European languages: Ger. Ich glaube er kommt 'I believe he is coming', Eng. I believe he is coming, No wonder Ruskin was fascinated by the place (professor B..., 1934, in Lafourcade, Recueil de textes de traduction, Grenoble, Arthaud, 1941?). 
\$11 But the process that is most widespread in languages involves marking $\mathrm{I}>>\mathrm{O}$ transfer using a translative:

\begin{tabular}{|c|c|c|}
\hline French & que & $\begin{array}{l}\text { Et moi je vous soutiens que mes vers sont } \\
\text { fort bons 'And me, I assure you that my verses } \\
\text { are very good' (Molière, Le Misanthrope, I, 2) }\end{array}$ \\
\hline Greek & hóti & $\begin{array}{l}\text { Légō hóti kalón estin arêtế. } \\
\text { 'I say that virtue is a good thing.' }\end{array}$ \\
\hline Greek & hos & $\begin{array}{l}\text { Légei hos hếxei. } \\
\text { 'He says that he will come.' }\end{array}$ \\
\hline German & dass & $\begin{array}{l}\text { Ich glaube, dass er spricht. } \\
\text { 'I think that he speaks.' } \\
\text { (cf. Chapter } 241, \S 17 \text { ) }\end{array}$ \\
\hline English & that & I believe that he speaks. \\
\hline Russian & čto & $\begin{array}{l}\text { Ja dumaju, čto on govorit. } \\
\text { 'I think that he speaks.' }\end{array}$ \\
\hline Serbian & $d a$ & $\begin{array}{l}\text { Já mislim da govori. } \\
\text { 'I think that he speaks.' }\end{array}$ \\
\hline Czech & $\check{z} e$ & $\begin{array}{l}\text { Jà myslím, že mluví. } \\
\text { 'I think that he speaks.' }\end{array}$ \\
\hline Lithuanian & $k a$ & $\begin{array}{l}\text { Vińi stāsta, ka nepazīstuot dārza augl'us. } \\
\text { 'They report that one does not know the } \\
\text { fruits of the orchard.' }\end{array}$ \\
\hline Romani & heu & $\begin{array}{l}\text { auke pende jo roma he godž, heu man hale } \\
\text { ando veš o rua? } \\
\text { 'and the peasants have said that the wolves } \\
\text { devoured me in the forest?' }\end{array}$ \\
\hline Hungarian & hogy & $\begin{array}{l}\text { Abban bizonyos vagyok, hogy el fog jönni. } \\
\text { 'I am certain he will come.' }\end{array}$ \\
\hline Turkish & $k i$ & $\begin{array}{l}\text { İyi bil ki gevezeler hiç bir zaman temiz } \\
\text { iş yapamazlar. } \\
\text { 'Be aware that a chatterbox never does } \\
\text { anything properly.' }\end{array}$ \\
\hline
\end{tabular}

It seems that the Turkish construction is borrowed into Turkish from the languages of Europe, and Turkish itself prefers first-degree transfer, which is typical of Turkish (cf. Chapter 188, \$23). One encounters an analogous translative in Italian, Spanish, Romanian, Sanskrit, Armenian, and Georgian.

$\$ 12$ The person corresponding to the first actant in the subordinate clause is of course rendered according to indirect speech. It is however necessary to note that Greek can leave the expression in direct speech even though it is part of a subordinate clause: Légei Basileùs hóti humîn oúk eimi polémios 'The Great King says that he is not your enemy', lit. 'The Great King says that I am not your enemy'. This occurs as if the translative hóti were replacing the colon of direct speech: 'The Great King says: I am not your enemy'. 
\$13 When the target $\mathrm{O}$ of I $>>\mathrm{O}$ transfer is the complement of the comparative (cf. below Chapter $265, \S 2-6$ ), the translative of first degree for the complement of the comparative appears immediately in front of the translative of second degree I $>\mathrm{O}$ transfer in the spoken chain.

$\$ 14$ This sequence does not lead to any problems in languages where the two translatives have different forms. Such is the case in German for example, where the first translative (second in the spoken chain) is dass 'that' and the second translative (first in the spoken chain) is als 'than, as'. The sequence als dass 'than that' is quite normal: Ich möchte lieber dass er stirbt, als dass er so leidet 'I would rather that he dies than that he suffers so'.

$\$ 15$ However, the situation is different in French, where the two translatives - although the one is for first-degree transfer and the other for second-degree transfer and the two thus mark essentially distinct instances of transfer - nonetheless both have the same form que, which results in the repetition (or dittology) que que, which is unsightly: J'aimerais mieux qu'il meure que qu'il souffre ainsi 'I would rather like that he dies than that he suffers so'.

$\$ 16$ French tries to manage the difficulty by replacing the second-degree transfer using the translative que 'that' with first-degree transfer (the infinitive) using de 'of', which leads to the sequence que de, which itself is not unusual: J'aime mieux qu'il meure que de le voir souffrir ainsi 'I would rather that he die than to see him suffer so'.

$\$ 17$ If the speaker does not have the verbal skill to succeed with this slight of hand, he can only reach to elliptical transfer to reduce the two ques down to just one: Rien ne paraît plus normal que les cadavres de malheureux condamnés viennent aujourd'hui échouer sur les côtes de Vendée 'Nothing seems more normal than that the corpses of the unlucky condemned wash up today on the banks of the Vendée' (L'Intransigeant, 10-11-1937), J'aime mieux...y en vouloir que ce soye lui qui m'en veuille 'I prefer... to be resentful (myself rather) than it be him who is resentful of me' (Henri Lavedan, Avant l'oubli, II, p. 47).

$\$ 18$ We have seen (cf. Chapter 182, \$5) that with declarative verbs, Latin ignores seconddegree transfer and uses a propositional infinitive of first-degree transfer instead.

$\$ 19$ However, this tendency is not absolute; secondary I >> O transfer is not entirely unknown in Latin. When one encounters it, the subordinate generally follows the governor (cf. \$26). The translative in such cases is ut 'that': Spero fore ut veniat 'I hope that he will come', Fac ut scia quando sis venturus 'Let me know when you will come', lit. 'Make that I know ...., Prope erat ut oppido potiretur 'He came to take the city', lit. 'He was near that he takes the city', Sie nihil haberet animus hominis nisi ut appeteret aut fugeret 'While the human spirit has no other perceptions than desire and aversion' (Cicero, Tusculan Disputations, I, 24, 56). 
$\$ 20$ This sort of expression requires the use of Lat. quod in the sense of 'the fact that': Lat. Praetereo quod eam sibi domum delegit 'I leave in silence the fact that he has chosen this residence' (Cicero, Pro Cluentio).

\$21 In Latin the translative can be the subjunctive, at least in familiar style: Sine abeam, lit. 'Allow that I depart', familiar for Sine me abire 'Let me depart'.

$\$ 22$ In contrast, languages that do not have primary I > O transfer (infinitive), like for example Bulgarian (cf. Chapter 180, \$17) or modern Greek, must employ second-degree transfer: Bulgarian Az moga da čakam 'I can wait', lit. 'I can that I wait', modern Greek Nomízō pôs eîmai 'I believe I exist', lit. 'I believe that I am'.

\$23 The situation where the infinitive is absent and second-degree transfer is hence dominant is also encountered in Romanian, Serbian, and Albanian: Romanian Vreau să cant pălăria mea 'I want to look for my hat', lit. 'I want that I seek my hat'. In eastern Serbian first degree I > O transfer also tends to dominate: Smem pitati 'I allow myself to demand' is literary, whereas colloquial style tends to employ second-degree transfer: Smem da pitam, lit. 'I permit myself that I demand'. ${ }^{277}$

$\$ 24$ There is hence a part of the Balkans where a defective infinitive is supplemented by second-degree transfer I >> O. It is remarkable that the languages influenced by this tendency belong to different branches of the Indo-European family: Slavic branch (Bulgarian and to a minor degree eastern Serbian), Greek branch, Albanian branch, and Latin branch (Romanian). The Slovenian linguist Miklosich of Slavic supposed that this expression was due to a substratum of ancient Dacian.

\$25 The same particularity is encountered at points of the globe far removed from the Balkans, in Bengali for example.

\$26 French uses the same translative que with governing verbs that contain - in addition to their declarative value - a modal affective value of fear, desire, order, defense, permission, obligation, etc.:

Je veux qu'on me distingue.

(Molière, Le Misanthrope, I, 1)

Je consens qu'une femme ait des clartés de tout. I I I agree that a woman has clarity of all.' (Molière, Les Femmes savantes, I, 3)
'I want one to recognize me.'

\$27 But a number of other languages use a different translative at times. Such is the case in Latin, which has a type of second-degree transfer (cf. above \$19). The Latin translatives are the conjunctions ut, ne, quin, quominus, etc.:

277. Meillet \& Vaillant, Grammaire de la langue serbo-croate, $\$ 205$. 


\section{Latin}

Nobis imperat ut loquamur.

Timeo ne veniat.

Interdictum erat Pythagoreis ne fabis vescerentur.

Impedit valetudo ne exeam.

Orat...ne patiatur civitatem...ab amicitia populi Romani deficere.

(Caesar, The Gallic Wars, VII, 39),

Nihil obstat qui exeamus or even

Nihil obstat quominus exeamus.
'He ordered that we speak.'

'I am afraid that he is coming.'

(Fr. J'ai peur qu'il ne vienne)

'The Pythagorians were prohibited that they eat beans.'

'The state of my health prevents that I go out',

'He (Eporedorix) asked him (Caesar) that he (Caesar) does not permit the state (of Aedui)...to renounce the friendship of the Roman people'

'Nothing prevents that we go out'.

\$28 Similarly, Greek employs the translative $m e^{\frac{1}{~}}$ with governing verbs expressing the notion of fear: Dédoika mế hēmartékamen 'I fear that we have made a mistake'.

$\$ 29$ Russian employs the translative čtoby with governing verbs expressing volition (desire): Ja želaju, čtoby on spal 'I desire that he sleeps'. This translative has been borrowed in the same form into Mari, Udmurt, and Tatar.

\$30 Finally, Latvian employs the translative ja (accented) when the governing verb expresses obligation: Mann ir já-dara tuo pat 'I must do the same', lit. 'To me is that it does the same thing'.

\$31 The first actant of the subordinate clause sometimes appears as an anticipatory second actant in the governing clause. This occurs notably in Greek and French: Gr. Légei Phílippon hóti téthnēke 'He says that Phillip died', lit. 'He says Phillip that he died', Fr. Nous allons voir le dénommé $X . .$. , ce qu'il sait faire 'We are going to see the one called X..., what he can do' (heard in 1936), Crois-tu, cette pauvre maman, qu'elle est dure à la détente 'Do you believe, this poor mother, that she is a miser' (Denys and Monique Amiel, Famille, Petite Illustration, 1, I, 1938, II, 4).

\section{Chapter 243. Connective indirect interrogatives}

$\$ 1$ The cases where the verbal node transferred to an actant by second-degree transfer (I $>\mathrm{O}$ ) is interrogative raise a certain number of questions and they therefore merit particular examination.

\$2 Just as one commonly calls indirect speech and discourse the mode by which the words of another are reported using second-degree transfer - that is, using a subordinate clause one commonly calls a question with second-degree transfer an indirect question, that is, a question that is expressed as a subordinate clause: 


\section{Direct interrogative \\ Indirect interrogative \\ Does Alfred hit Bernard? \\ I ask you whether Alfred hits Bernard.}

\$3 The question contained in the direct interrogative behaves in principle as a verbal center and constitutes an independent clause.

$\$ 4$ In indirect interrogatives, an independent verbal node becomes a second actant of the verb of another independent node: I ask you..., the latter hence becoming a governor.

$\$ 5$ Conversely, an independent interrogative clause that contains the question becomes subordinate. The indirect interrogative is hence in reality a subordinate interrogative.

$\$ 6$ While the subordinate that contains the question always implies interrogative force, it is not necessary for the governor to also explicitly express the idea of a question, but rather it is sufficient if it implicitly expresses this idea. Hence in addition to the sentence $I$ ask whether Alfred hits Bernard, where the interrogative is explicit, one uses the same syntactic structure in I don't know whether Alfred hits Bernard.

$\$ 7$ It is therefore important to determine, by the examination of structure in different languages, how subordination is marked in such cases, that is, in what way indirect interrogatives differ from direct interrogatives.

$\$ 8$ We have seen (cf. Chapters 83 and 84 ) that the marker of a direct interrogative was variable depending on whether the interrogative is nuclear or connective. Nuclear and connective interrogatives correspond to different types of syntactic structures (cf. Chapter 83, $\$ 7$ ). This distinction should not be neglected in the investigation of the markers of indirect interrogatives, nor should it be neglected in the investigation of the markers of direct interrogatives.

$\$ 9$ Indirect connective interrogatives do not differ in any way from direct connective interrogatives. Such is the case in particular in Russian: Pridët li Ivan? 'Is John coming?' $\rightarrow$ Ja ne znaju, pridët li Ivan 'I do not know whether John is coming'.

$\$ 10$ The same is true in the majority of Slavic languages: Serbian Da li ga vidiš, common for the more literary Vidiš li ga 'You see it?' $\rightarrow$ Ja pitam da li ga vidiš 'I ask you see it?'; Czech Zdali ho znáš, more common than the literary Znáš-li ho? 'You know him?' $\rightarrow$ Ptám se tě, $z$ dali ho znás 'I ask you, you know it'.

\$11 The same holds in Breton: Hag êt e'ch eo ma c'hoar da Baris? 'Has my sister gone to Paris?' $\rightarrow$ N'ouzon ket hag êt ec'h eo ma c'hoar da Baris 'I do not know my sister has gone to Paris'.

$\$ 12$ This situation is what is found in a large number of languages. Other languages, in contrast, have a marker for indirect interrogatives that is completely different from the marker for direct interrogatives.

$\$ 13$ Hence in English, where the direct interrogative marker is the use of the auxiliary (for example to do), the marker for indirect interrogatives is a translative (whether or if): Do you speak English? $\rightarrow$ I ask you if (whether) you speak English, Do you know if he is at home? 
\$14 In German the translative for indirect interrogatives is $o b$ 'whether/if', and in addition, $o b$ being a subordinator (Fr. subordonnant), the verb occupies the last position, whereas it occupies the first position in direct interrogatives: ${ }^{278}$ Sprechen Sie deutsch? 'Do you speak German?' $\rightarrow$ Ich frage Sie, ob Sie deutsch sprechen 'I ask you if you speak German'.

$\$ 15$ French (like the neo-Latin languages in general) also employs a marker for indirect interrogatives that is completely different from the direct marker. It is the same translative as for the I >> E transfer of an independent clause to a conditional causal subordinate clause (cf. Chapter 258, \$16): Parlez-vous français?, lit. 'Speak you French?' (interrogative marked by inversion of the personal noun and the verb), or Est-ce que vous parlez français? 'Do you speak French?' (preposed translative est-ce que, lit. 'is it that', using the same inversion as with est-ce, where the $c e$ 'it' is expanded in a subordinate clause introduced by que) $\rightarrow$ Je vous demande si vous parlez français 'I ask you if you speak French'.

$\$ 16$ This amphibology of the marker $s i$ 'if', which serves two quite disparate syntactic purposes, leads French speakers to incorrectly use the marker of the conditional for indirect interrogatives in foreign languages (Ger. wenn, Lat. si) instead of the correct marker for indirect interrogatives in these languages (Ger. ob, Lat. num): Ger. ${ }^{\star} I c h$ frage Sie, wenn Sie deutsch sprechen in place of the correct Ich frage Sie, ob Sie deutsch sprechen 'I ask you if you speak German'.

$\$ 17$ The same amphibology is encountered in Greek where the conjunction ei 'if' serves both as a marker of the conditional as well as as a marker of indirect interrogatives: Aporô ei pheúgei 'I ask myself if/whether he is fleeing. This phenomenon in Greek and French apparently rests on a deep structural tendency, the nature of which deserves acknowledgment and exploration.

$\$ 18$ Finally in Latin, the marker of indirect interrogatives is the use of the subjunctive: Aegrotatne pater tuus? 'Is your father sick?', or if the expected response is negative: Num aegrotat pater tuus? 'Your father isn't sick, is he?' $\rightarrow$ Quaero aegrotetne pater tuus 'I ask whether your father is sick', Quaero num aegrotet pater tuus 'I ask whether your father is by chance sick?

$\$ 19$ In the case of disjunctive interrogatives (cf. Chapter 139, \$5), the marker of the first term of disjunction is utrum and the marker of the second is an: Lat. Quaero utrum aeger sis an valeas 'I ask whether you are sick or whether you feel well'.

$\$ 20$ If the second term of the disjunction is the negative sentence word nec, the marker for the second term of a disjunctive interrogative is -ne, which is postposed: Quaero utrum aeger sis necne 'I ask whether you are sick or not'.

278. Lucien Tesnière, Une survivance pédagogique: l'inversion et le rejet dans la phrase allemande 'A pedagogical relic: inversion and its rejection in the German sentence', Les langues Modernes, March-April 1947, pp. A, $141 \mathrm{ff}$. 


\section{Chapter 244. Nuclear indirect interrogatives}

\$1 In sum, the differences between the markers of direct and indirect interrogatives are the same for nuclear interrogatives as for connective interrogatives.

\$2 But since these markers themselves are not the same, it is imperative to examine the structural difference between the markers for direct and indirect interrogatives in various languages.

$\$ 3$ In addition to the difference that they have with connective interrogatives, nuclear interrogatives obligatorily contain an interrogative word (cf. Chapter 79, \$10) that expresses the question located in the nucleus. This word does not exist to establish a connective interrogative.

$\$ 4$ The question word of nuclear interrogatives is present in both direct and indirect nuclear interrogatives.

$\$ 5$ Hence if there is no need to mark the opposition between direct and indirect interrogatives, an indirect nuclear interrogative does not differ in any way from a direct nuclear interrogative.

$\$ 6$ Such is the case in Russian and in the Slavic languages in the area of connective interrogatives (cf. Chapter 242, \$9ff.):

\begin{tabular}{|c|c|c|}
\hline & Direct question & Indirect question \\
\hline Russian & $\begin{array}{l}\text { Kto pridët? } \\
\text { 'Who will come?' }\end{array}$ & $\begin{array}{l}\text { Ja ne znaju kto pridët. } \\
\text { 'I don't know who will come' }\end{array}$ \\
\hline Serbian & $\begin{array}{l}\text { Ko ti je to kazao? } \\
\text { 'Who told you that?' }\end{array}$ & $\begin{array}{l}\text { Ne znam ko ti je to kazao. } \\
\text { 'I don't know who told you that' }\end{array}$ \\
\hline Czech & $\begin{array}{l}\text { Kdo přišel? } \\
\text { 'Who has come?' }\end{array}$ & $\begin{array}{l}\text { Nevím, kdo príšel. } \\
\text { 'I don't know who has come' }\end{array}$ \\
\hline
\end{tabular}

$\$ 7$ This is also the case in Breton: Piou a zo deut? 'Who has come?' $\rightarrow$ N'ouzon ket piou a zo deut 'I don't know who has come'.

$\$ 8$ The identical appearance of direct and indirect nuclear interrogatives is present in a large number of languages.

$\$ 9$ In other languages, however, the difference between direct and indirect interrogatives leads to a difference between the two types of nuclear interrogatives, despite the identical appearance of the relevant interrogative words.

$\$ 10$ This is the case in particular in French, where inversion of the person noun and the verb - which is rigorously observed in direct interrogatives as it is for connective interrogatives - is not maintained in indirect interrogatives: Qui êtes-vous? 'Who are you?' $\rightarrow$ Je vous 
demande qui vous êtes 'I ask you who you are', cf. also Dis-moi qui tu hantes et je te dirai qui tu es 'Tell me who you prey on and I will tell you who you are'.

$\$ 11$ In addition, the marker que of a direct nuclear interrogative (interrogative pronoun) appears in indirect nuclear interrogatives as ce que (relative pronoun). This difference actually indicates the presence of second-degree transfer of the sort I > A $>\mathrm{O}$ (cf. Chapter 269, \$2).

\$12 English has the same inversion as French (cf. \$10) for direct nuclear interrogatives: Who are you? $\rightarrow$ I ask you who you are.

$\$ 13$ German has the same difference as French (cf. \$10) for expressing direct nuclear interrogatives and connective interrogatives (cf. Chapter 243, \$14), and one encounters the same word order as in French and English, although for a different reason: ${ }^{279}$ Wer sind Sie? 'Who are you?' $\rightarrow$ Ich frage Sie, wer Sie sind 'I ask you who you are?.'

$\$ 14$ What distinguishes between indirect and direct nuclear interrogatives in Latin is the same as for connective interrogatives. Indirect interrogatives employ the subjunctive as a marker: Quis venit? 'Who has come?' $\rightarrow$ Quaero quis venerit 'I ask who has come'.

$\$ 15$ Unlike Latin, Greek does not have the optative (which is the equivalent of the subjunctive of subordination in Latin) as a marker for indirect interrogatives. The optative is only possible if the governing verbal node is in the past: Ouk édein tís eíe ohûtos ho anếr 'I didn't know which this man was'. More normally, however, Greek places indirect interrogatives in the indicative: Ouk édein tís estin ohûtos ho anếr or sometimes Ouk édein tís ên ohûtos ho anếr 'I didn't know who that man was'. However in the present, Greek does not distinguish between indirect and direct interrogatives: Tis estin ohûtos ho anếr 'Who is this man?' $\rightarrow$ Ouk oîda tís estin ohûtos ho anếr 'I don't know who this man is'.

\section{Chapter 245. I >> A transfer}

\$1 When second-degree transfer is of the sort I $>>A$, the subordinate clause is transferred to an adjective.

\$2 Take for example the sentence Les livres que vous avez sont précieux 'The books that you have are valuable'. It is evident that the subordinate clause que vous avez 'that you have' is an attribute that serves to characterize les livres 'the books' in the same way as the attributive adjective rares in Les livres rares sont précieux 'The rare books are valuable'.

279. Lucien Tesnière, Une survivance pédagogique: l'inversion et le rejet dans la phrase allemande, Les langues Modernes, March-April 1947, p. A, 25. 
\$3 The transferred subordinate expression can be an incomplete sentence word (cf. above Chapter 46, \$5), Fr. voici, voilà: le livre que voici 'the book that is here', l'homme que voilà 'the man who is there'.

$\$ 4$ For this reason, we will give an independent clause that has been transferred to an adjective the name adjectival subordinate clause.

$\$ 5$ Concerning meaning, one distinguishes between two types of adjectival subordinate clauses depending on whether the adjective is indispensable or not to the meaning of the governor. We will call the first type of adjectival subordinate clause essential, and the second accessory.

$\$ 6$ Essential adjectival subordinate clauses express a meaning that is indispensable to the meaning of the governing clause, and that as a consequence cannot be suppressed without changing meaning considerably. Take the sentence Les enfants qui travaillent mal doivent être punis 'The children who work poorly must be punished' as an example. It is evident that if one neglects the essential adjectival subordinate clause qui travaillent mal 'who work poorly', one obtains an independent clause, Les enfants doivent être punis 'The children must be punished' that has a much different meaning, since it signifies that all the kids must be punished, whether they work poorly or not.

\$7 The adjectival subordinate clauses that are essential are known in general as determinatives [in traditional French grammars], a term with the drawback that it is too broad, since by definition all subordinates determine their governor (cf. Chapter 21, \$9). ${ }^{280}$

$\$ 8$ An essential adjectival subordinate clause must not be separated from its governor by a comma (or by two commas). Doing so would have the effect of reducing the importance of the clause: L'hypocrisie est un homage que le vice rend à la vertu 'Hypocracy is an homage that vice renders a virtue' (La Rochefoucauld, Maximes).

Adieu donc. Fi du plaisir Que la crainte peut corrompre! (La Fontaine, Fables, I, 9, Le rat de ville et le rat de champs)

Honteux comme un renard qu'une poule aurait pris, (La Fontaine, Fables, I, 18, Le renard et la cigogne)
'Goodbye then. No more pleasure That fear can corrupt!'

'Ashamed like a fox that a hen has taken,'

280. Translators' note: The distinction Tesnière is drawing here is between restrictive and nonrestrictive relative clauses. We maintain Tesnière's terminology because he builds on it (e.g. essential vs. accessory). 
$\$ 9$ In particular, adjectival subordinate clauses with a noun that constitutes the title of a work (cf. Chapter $73, \$ 18$ ) are always essential adjectival clauses. In La terre qui meurt 'The earth that dies' by R. Bazin, one cannot omit the adjectival subordinate clause qui meurt 'that dies' without altering the meaning of the title significantly.

...Sugambrorum...

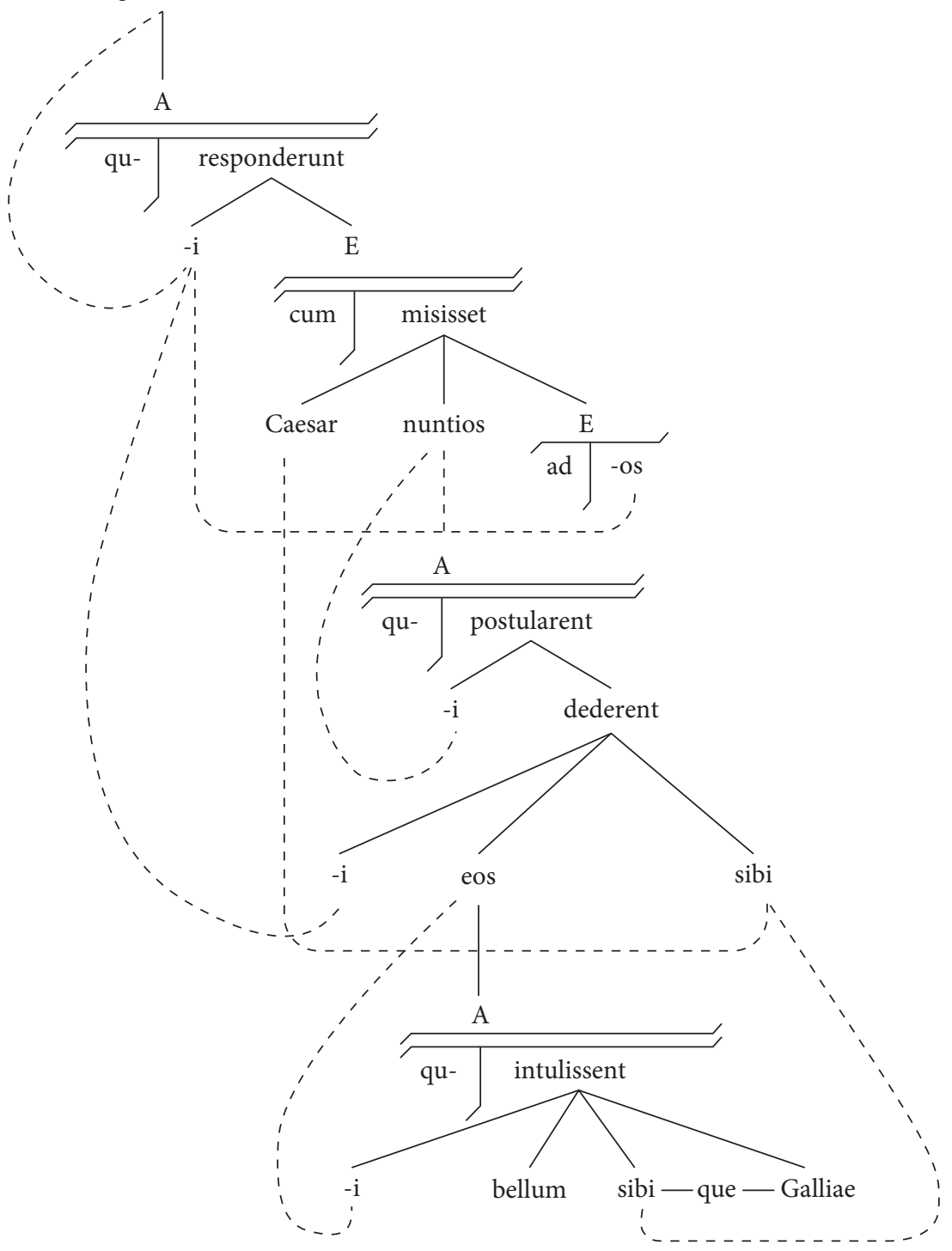

Stemma 343 


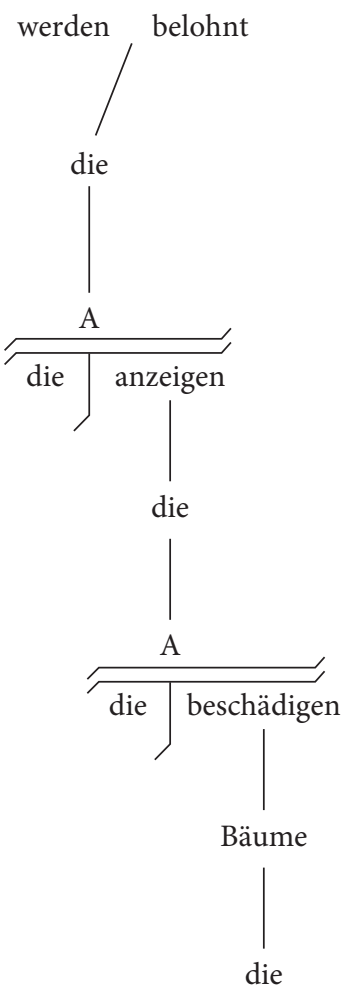

\section{Stemma 344}

$\$ 10$ Unlike essential adjectives, accessory adjectival subordinate clauses express a meaning that is not indispensable to the meaning of the governing clause. Take for example the sentence Les enfants, qui sont jeunes, doivent être protégés 'The children, who are young, must be protected'. The accessory adjectival subordinate clause can be suppressed without the meaning of the governor being significantly altered, for Les enfants doivent être protégés 'The children must be protected' in any case.

$\$ 11$ Accessory adjectival subordinate clauses are in general known as explicatives [in traditional French grammars], a term that is inexact, since the circumstantial notion that they incidentally contain (cf. Chapter $247, \$ 4$ ) need not be a causal circumstance (cf. Chapter $247, \$ 4$ ), but rather it can be most any circumstantial notion, for instance final (cf. Chapter $247, \$ 6$ ) or concessive (cf. Chapter 247, \$7).

$\$ 12$ The accessory adjectival subordinate clause takes advantage of being separated from its governor by a comma (or by two commas), which play the role of a sort of minor parenthesis and which emphasize that the subordinate is outside of the semantic nucleus of the 
governor: ${ }^{281}$ Cet enfant, qui est votre neveu, est blond 'This infant, who is your nephew, is blond'.

$\$ 13$ From a structural point of view, one has to take note that cascading transfer (cf. Chapter $6, \$ 4$ ) is encountered with first-degree transfer (type $\mathrm{O}>\mathrm{A}$, cf. Chapter $164, \$ 6$ and Stemma 294) as well as with second-degree transfer (I >> A): Lat. ...Sugambrorum... Ad quos cum Caesar nuntios misisset, qui postularent eos, qui sibi Galliaeque bellum intulissent, sibi dederent, responderunt... 'Caesar having sent messengers to them (the Sicambri), who were charged with demanding that they surrender to him those who had attacked him and Gaul, they responded...'(Caesar, De bello Gallico, IV, 16, 3) (cf. Stemma 343), Ger. Die, die die, die die Bäume beschädigen, anzeigen, werden belohnt 'Those who report those who damage the trees will be rewarded' (public notice, the pleasant wording of which is attributed to the management of a public garden) (cf. Stemma 344).

\section{Chapter 246. The marker of I >> A transfer}

$\$ 1$ The simplest type of deverbal transfer I >> A occurs without a marker. Simple parataxis indicates the nature of the subordinate's role.

\$2 Transfer without a marker of the sort $\mathrm{I}>>\mathrm{A}$ is encountered in a large number of languages.

\begin{tabular}{ll}
\hline Arabic & kānat wāhida lā tahbalu. \\
& lit. 'Was one, not she conceive.' \\
& 'There was a woman who did not conceive.' \\
Bantu & in-zoka i tu bona \\
& lit. 'the serpent we it see', \\
& 'the serpent that we see' \\
\hline
\end{tabular}

$\$ 3$ Parataxis is also encountered in certain European languages: Eng. the man I saw yesterday. The same expression exists in Breton: ar re ho kwel, lit. 'those you see', that is 'those who see you'.

$\$ 4$ But the majority of languages prefer to use a marker that is called a relative pronoun in our European languages.

281. Translators' note: The nucleus must be understood here as the projection of the node, that is, as a semantic constituent. 
$\$ 5$ For this reason, adjectival clauses are called relative clauses in traditional grammar, a term that ignores the syntax in order to focus on morphology.

$\$ 6$ Before proceeding further, it is necesssary to submit the relative pronoun to a detailed analysis.

$\$ 7$ The first striking point is that while other translatives that mark a subordinate clause que 'that' (cf. Chapter 242, \$11) for actantial subordinates and quand 'when' and si 'if' (cf. Chapter 254, \$5) for circumstantial subordinates - are invariable, the relative pronoun is variable: Eng. who, whom, whose; what, which; Fr. qui, que, quoi, dont; lequel, laquelle, lesquels; Lat. qui, quae, quod.

$\$ 8$ In contrast, when one forces oneself to render a relative clause in a stemma, one quickly sees that one is forced to position the relative pronoun in two positions: 1) as a translative under the symbol $\mathcal{T}$, and 2 ) as an actant subordinate to the verb of the transferred clause and as a consequence, in connection with this verb.

\$9 Take for example the pronoun in the French sentence: l'homme qui écrit 'the man who writes. The pronoun qui is a translative of the transferred clause the verb of which is écrit, because it transfers this clause to an adjective subordinate to l'homme. It is also the first actant of the same verb écrit, since as an anaphor it represents the word homme and is therefore the first actant of écrit (cf. Stemma 345).

$\$ 10$ Yet all evidence suggests that the stemma - if it is to be a trustworthy representation of the sentence - cannot position a word in two positions if that word appears only once in the sentence in question.

\$11 The relative pronoun is hence a word that has a double nature. It is composed of two syntactic elements that fall together, whereby the syntactic analysis reveals that these elements are in fact distinct. Each of these two syntactic elements occupies one of two positions in the stemma. The structural analysis is not clear due to the fused nature of the two elements.

$\$ 12$ The element that occupies the interior of the symbol $\mathcal{T}$ of the transferred verb is the proper translative, that is, it is the element that confers the value of an adjective to the subordinate. This element establishes transfer of the sort I $>$ A; it can be granted the same invariable characteristic as one grants to secondary translatives of the sort $\mathrm{I}>>\mathrm{O}$ and $\mathrm{I}>>$ E (cf. Chapter 43, \$12).

$\$ 13$ Concerning the element that is subordinate to the verb in the transferred clause, it does not differ at all from a personal noun when one reduces it down to its essence. Like a personal noun, this element is an anaphor, or rather it is its anaphoric quality that makes a noun out of it, since it is anaphorically linked to a noun (l'homme 'the man'). By virtue of its status as an anaphor, it must agree in gender and number with its antecedent, as is the case with all personal nouns. And it is this element that constitutes the variable aspect of the relative pronoun in general. 


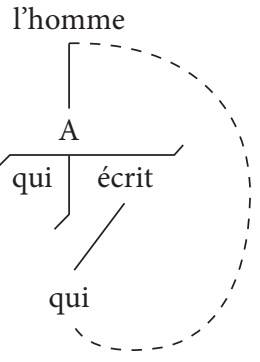

Stemma 345

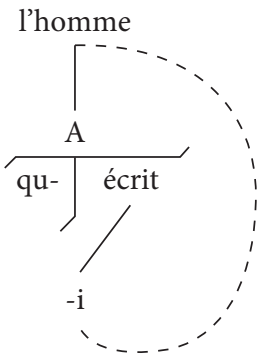

Stemma 346

$\$ 14$ Since we are inspired by received terminology to distinguish between morphemes and semantemes (cf. Chapter 23, \$10), we will reserve the name transfereme for the element of the relative pronoun that plays the role of a translative and the name anaphoreme for the element that plays the role of an anaphor. Transferemes are hence morphemes, and anaphoremes are anaphors, that is, they are morphemes when they are isolated in the dictionary, but they are semantemes as soon as they appear in the structure of a sentence and receive a position in a stemma (cf. Chapter $43, \$ 2$ ).

$\$ 15$ Evidently the isolation of each of the two elements is difficult. However if one nevertheless attempts to separate them in the stemma, one can say that although they are fused together solidly in a form such as Fr. qui 'that.NOM', the transfereme is $q u$ - whereas the anaphoreme is $-i$ (cf. Stemma 346).

$\$ 16$ One can thus attempt to render the preceding stemma in a new way, where the pronoun qui correctly appears just once, but is split into two parts: $q u+i=q u i$ (cf. Stemma 346).

$\$ 17$ This analysis leads to the insight that the personal relative pronoun of the European languages is probably the result of a prehistoric agglutination between the invariable translative element and a variable anaphoric element.

$\$ 18$ An examination of the oldest forms of the personal pronoun in Indo-European languages does not provide irrefutable historic proof of this agglutination.

$\$ 19$ But it is striking to observe that these forms are not contrary to the hypothesis suggested by the syntactic analysis, since they bear one or another trace of a former translative and/or a former anaphor: Lat. ${ }^{*} q u e+i s \rightarrow$ relative pronoun $q u i$, the interrogative pronoun of which, quis, can conserve an older variant: Gr. '(< Indo-European $y$-) + -os relative pronoun hōs; Sanskrit $y+a h$, neuter -ad (in composition) $\rightarrow$ cf. demonstrative pronoun sáh, neuter -tát, relative pronoun yah 'who', neuter theme yad.

$\$ 20$ Supposing that these forms retain the trace of distant agglutination, they have been subjected since that time - that is, since pre-Indo-European - to considerable alterations 
that render the goal of making them fit historical forms elusive. These difficulties are accentuated in modern Indo-European languages such as French.

The alterations have generated confusion. At its origin, this confusion is perhaps due to the fact that the nominative was in fact a former ergative (cf. Chapter 52, $\$ 8$ and Vaillant, Bulletin de la Société Linguistique de Paris, 37, 1936, p. 104).

\section{Chapter 247. The translative element of the personal pronoun}

\$1 The translative element of the personal pronoun, the invariable part, can appear in a prominent way in an adjectival clause.

\$2 Hence one sometimes encounters the conjunction as in English instead of the relative pronoun who: It was you as first made mention of her to me (Dickens, David Copperfield, III, p. 237). The translative element here has completely eliminated the anaphoric element, which has no marker.

$\$ 3$ It is also by way of the translative element in the personal pronoun and the subcategory of transfer that one can explain the circumstantial nuance that adjectival subordinate clauses often contain.

$\$ 4$ This circumstantial nuance can be causal: Fr. Les enfants, qui sont jeunes, doivent être protégés 'The children, who are young, must be protected', that is, 'The children must be protected because they are young. Lat.

Ingrata es...ore quae nostro caput

'You are ungrateful...you who has withdrawn your head Incolume abstuleris et mercedem postules. Safe and sound and who now demands reward.'

(Phaedrus, Fables, I, 9, The wolf and the crane)

Further: Spero, quae tua est prudentia, fore ut me non in discrimen adducas 'I hope that you, in your wisdom, do not put me in jeopardy'.

\$5 The causal nuance can be more conditional and in addition, even hypothetical (cf. Chapter $259, \$ 1 \mathrm{ff}$.). Such is the case with the loaded relative clause (Fr. relatif prégnant), to which J. Vendryes has recently drawn the attention of linguists. ${ }^{282}$

Ce vieux chêne a des marques saintes;

Sans doute qui le couperait

Le sang chaud en découlerait, Et l'arbre pousserait des plaintes
'This old oak has saintly marks

Without doubt, if someone hacks at it

The hot blood would flow

And the tree would moan.'

(Tristan l'Hermite, Promenoir de deux amants)

282. J. Vendryes, Sur un emploi du relatif: le relatif prégnant 'On a use of the relative: the loaded relative', Bulletin de la Société de Linguistique de Paris, 444-I, pp. $21 \mathrm{ff} ., 1948$. 
$\$ 6$ The circumstantial nuance is final in the sense of Latin grammars, e.g. Athenienses legatos miserunt, qui Apollinem consulerent 'The Athenians sent deputies who were charged with consulting Apollo', lit. '... who would consult Apollo'.

$\$ 7$ The circumstantial nuance is concessive in Fr. Les grands, qui les dédaignaient, les révèrent 'The important men, who despised them, revere them' (La Bruyère, Les Caractères, IX), that is 'The great ones revere them (the citizens who study the government), although they have despised them (before), Lat. Egomet, qui sero ac leviter Graecas litteras attigissem, tamen... complures Athenis ${ }^{283}$ dies sum commoratus 'I, who has only of late and in small measure been taken by Greek texts, nevertheless remained for a few days in Athens' (Cicero, De Oratore, I, 18, 82).

$\$ 8$ Finally, this circumstantial nuance is sometimes so attenuated that the translative is reduced to the role of a simple junctive so that the transfer is no different than simple junction. The relative pronoun in such cases is what one calls a link-word, or more precisely, a link relative pronoun.

$\$ 9$ The link relative pronoun is favored in the Latin sentence. It conveys a false syntactic bond to the sentence insofar as it generates the misleading appearance of an organized period that makes abundant use of hypotaxis. In reality, only parataxis is present: Lat. Quod ubi audivit..., lit. 'What when he hears..., that is, 'When he hears that....'

$\$ 10$ One is also dealing with a relative pronoun of liaison in French in expressions like Je l'ai vu qui courait, lit. 'I saw him who was running', which is indistinguishable in meaning from 'I saw him and he was running.'

$\$ 11$ Therefore one often says that in practice the relative pronoun at the beginning of a sentence is often the Latin equivalent of a junctive (atque) followed by a demonstrative pronoun (id): quod = atque id 'and that'.

$\$ 12$ Given these facts, we acknowledge the two elements in the relative pronoun the presence of which has been established above (cf. Chapter 246, \$11-13): the translative element, which is reduced to the role of a junctive in the previous case, and the anaphoric element, a demonstrative pronoun playing the role of a personal noun.

$\$ 13$ Finally, we sometimes find the same attenuated translative element as the first element of the sentence expressing a point of comparison after words expressing identity. Such is the case in the Lat. Iisdem libris utor quibus tu 'I use the same books as you'. The same expression is also possible with ac.

$\$ 14$ Similarly, after words expressing identity or difference, the translative element is sometimes reduced to the role of a simple junctive in Greek and Latin: Gr. Tến autến patrída ékhei kaì egó 'He has the same fatherland as I', lit. 'He has the same fatherland and I', Lat. Longe alius est atque erat 'He is entirely different than he was', lit. 'He is entirely other and he was'.

283. [The ending of the sentence has been slightly modified in the interest of brevity.] 


\section{Chapter 248. The anaphoric element in the personal pronoun}

$\$ 1$ In adjectival subordinate clauses, sometimes the anaphoric and variable part of the personal pronoun is predominant.

\$2 The anaphoric part ensures that the personal pronoun is an actant subordinate to the verb of the adjectival clause.

\$3 This actant can be the first actant, in which case it appears in the nominative in languages with case:

\begin{tabular}{|c|c|}
\hline \multicolumn{2}{|r|}{ Nominative relative pronouns } \\
\hline French & $\begin{array}{l}\text { le livre qui est sur la table } \\
\text { 'the book that is on the table' }\end{array}$ \\
\hline Latin & $\begin{array}{l}\text { Ad Hypanim fluvium, qui in Pontum influit, } \\
\text { Aristoteles ait bestiolas quasdam nasci quae unum } \\
\text { diem vivant 'On the banks of the Hypanis river, } \\
\text { which flows into the Pont, Aristotle pretended } \\
\text { there were insects that live only a day. }\end{array}$ \\
\hline Greek & $\begin{array}{l}\text { Ohûtos ho hegemon, hós tến patrída stérgei. } \\
\text { 'This general, who loves his fatherland.' }\end{array}$ \\
\hline English & Sancho Panza blessed the man who invented sleep \\
\hline German & $\begin{array}{l}\text { das Buch, welches auf dem Tisch liegt } \\
\text { 'the book, which is lying on the table' }\end{array}$ \\
\hline Russian & $\begin{array}{l}\text { čelovek kotoryj vas ljubit } \\
\text { 'a man who loves you' }\end{array}$ \\
\hline Slovenian & $\begin{array}{l}\text { človek kteri je prišel } \\
\text { 'the man who has come' }\end{array}$ \\
\hline Romani & $\begin{array}{l}\text { Mus mange te radov, so man tatiarla. } \\
\text { 'I have to find one of them, which warms me.' }\end{array}$ \\
\hline Hungarian & $\begin{array}{l}\text { Azt a munkást varoom, aki tegnap itt járt. } \\
\text { 'I am awaiting the worker who was here yesterday' }\end{array}$ \\
\hline Georgian & $\begin{array}{l}\text { Is šlida t'avis bolos, romelic' brcqinavda mzezed. } \\
\text { 'He (the peacock) spread its tail which shines from the sun'. }\end{array}$ \\
\hline
\end{tabular}

$\$ 4$ The actant subordinate to the verb in the adjectival clause can also be the second actant, in which case it appears in the accusative in languages with case:

Accusative relative pronouns

French le livre que vous voyez

'the book that you see'

Latin animal, quem vocamus hominem

(Cicero, De Legibus, I, 22)

'the animal that we call man' 


\begin{tabular}{ll} 
Greek & $\begin{array}{l}\text { ho adelphòs hòn stérgō } \\
\text { 'the brother that I love' } \\
\text { English }\end{array} \quad \begin{array}{l}\text { a mother I love (Byron) } \\
\text { der Brief, welchen ich lese } \\
\text { 'the letter that I read' } \\
\text { čelovek, kotorogo vy vidite } \\
\text { Russian }\end{array}$ \\
Turkish man that you see' \\
$\quad \begin{array}{l}\text { Hoca Nasreddin efendinin bir kuzusu var } \\
\text { imiş, ki gāyet ile besler imiş } \\
\text { 'Master Nasreddin had a lamb that he had } \\
\text { raised with care.' }\end{array}$ \\
\hline
\end{tabular}

$\$ 5$ In French the relative pronoun with double value, translative (I $>>A)$ and anaphoric, has the same form que as the translative for I $>>0$, which only has translative value (cf. Chapter 242, \$11): le livre que vous voyez 'the book that you see’ (I >> A) (cf. ci-dessus $\$ 4$ ) I Je sais que vous voyez ce livre 'I know that you see the book' ( $\mathrm{I}>>\mathrm{O})$. One must take care to avoid the confusion that this homonymy generates between these two translatives with essentially distinct functions.

$\$ 6$ Finally, an actant subordinated to the verb of the adjectival subordinate clause can be a third actant, in which case it appears in the dative in languages with case, or it is preceded (or followed) by a translative that marks the third actant in languages where the third actant is thus marked: Fr. l'homme à qui je parle 'the man to whom I speak', Lat. Neminem praetermisit cui non eadem dixerit, lit. 'He left out nobody, to whom he said the same thing', that is 'He did not fail to say the same thing to everyone', Gr. ohûtos ho hegemốn hôi peithontai ohi stratiotai 'this general who the soldiers obey'.

$\$ 7$ If two adjectival subordinate clauses are adjacent, Latin and Greek generally do not repeat the relative pronoun actant, the one serving for both clauses: Lat. hic miles, qui patriam amat et fortiter pugnat 'this soldier who loves his fatherland and fights bravely', Gr. ohûtos ho stratiôtees, hòs tến patrída stérgei kaì gennaíôs máketai (same meaning).

$\$ 8$ But if the relative pronoun represented in the two subordinate clauses is a different actant across the two clauses, only its translative element can serve for the two clauses; the anaphoric element must be repeated. One utilizes the demonstrative pronoun to this effect, which is the personal noun, Lat. hic dux, qui patriam amat, eique parent milites 'this general who loves his fatherland and whom the soldiers obey', lit. '... and him..., Gr. ohûtos ho hegemốn, hòs tến patrída stérgei, kai autôi peithontai ohi stratiôtai (same construction and same meaning).

$\$ 9$ The actant subordinate to the verb in the adjectival clause can be transferred to a circumstant (by way of a preposition or postposition, for example): 


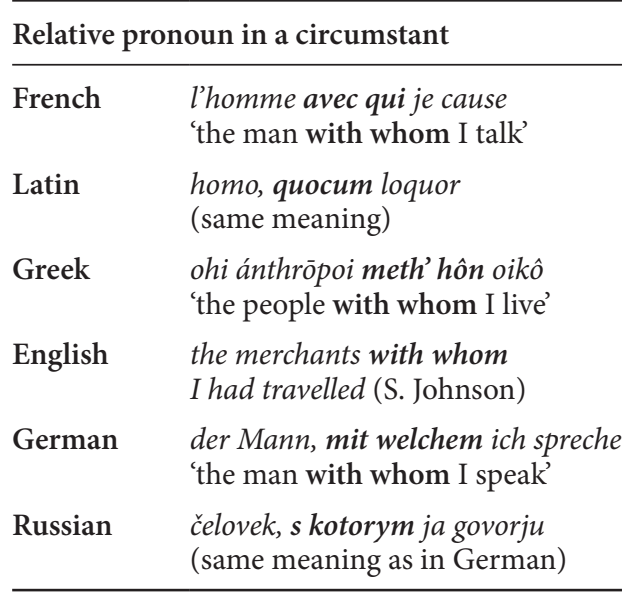

\$10 In Latin, where the translative is obligatorily a postposition with a personal locutive or allocutive noun (mecum 'with me', tecum 'with you'), the anaphoric element of the relative pronoun has the effect of generating a preference for the postposition (quocum) over the preposition (cum quo 'with whom').

\$11 In a similar case, English readily postposes the translative to the whole subordinate clause: The people whom I speak with.

$\$ 12$ Not only can the anaphoric element of the personal pronoun - that pronoun being an actant or a circumstant - be the direct and immediate subordinate of the verb in the adjectival subordinate clause, as is the case in the preceding example, but it can also be a mediated subordinate of the verb. Such is the case when the pronoun itself is transferred to an adjective by transfer $\mathrm{O}>\mathrm{A}$. In such a situation, the pronoun has as its governor a nominal actant or a circumstant that is itself subordinated to the verb of the adjectival subordinate clause.

$\$ 13$ The personal pronoun the anaphoric element of which is a noun transferred to an adjective exists in a number of languages where this marker is, according to the typology of the language at hand, sometimes a preposed or postposed translative and sometimes the genitive (in languages with case). The resulting adjective can be an adjective of personal relationship in the latter case (possessive adjective, cf. Chapter 35, \$18-21).

$\$ 14$ For this adjective, one finds the syntactic form dont in French and the competing analytic form de qui 'of whom':

Il faut plaindre le sort du prince infortuné

Dont le cour endurci n'a jamais pardonné (M.-J. Chénier)

Ceux de qui la conduite offre le plus à rire Sont toujours, sur autrui, les premiers à médire. (Molière, Le Tartuffe, I, 1)
'One should pity the fate of the unlucky prince

Whose hardened heart has never pardoned another.'

'Those whose behavior provides the most to laugh about

Are always the first ones to slander others.' 
\$15 If the relative pronoun is the adjective quel transferred to a noun by way of the article le (cf. Chapter 178, \$5), lequel, its form when it has been retransferred to an adjective is always analytic: duquel, de laquelle, desquelles. The nucleus of the anaphoric element of the relative pronoun contains recessive double transfer of the sort $\mathrm{A}>\mathrm{O}>\mathrm{A}$, where the first instance of transfer $(\mathrm{A}>\mathrm{O})$ is marked by the definite article le, and the second $(\mathrm{O}>\mathrm{A})$ by the preposition $d e$. These two markers can collapse forming a contracted article of the sort du: Les paysans attachés à la glebe étaient la propriété de leurs seigneurs, au pouvoir desquels rien ne pouvait les arracher 'The peasants tied up to the glebe were the property of their lords, from whose power nothing could free them' (J.-J. Rousseau).

$\$ 16$ The transferred pronoun dont in French must be placed at the front of the adjectival subordinate clause. This placement often prevents the pronoun from being subordinated to a noun that has been transferred to a third actant or to a circumstant by way of a preposition. This is why one cannot say: *l'homme au frère dont j'ai donnéce livre 'the man to the brother of whom I gave the book', or *l'homme en compagnie dont je suis sorti 'the man in whose company I departed. In this case, one has to appeal to the analytic pronoun de qui or to the retransferred pronoun of the sort duquel: l'homme au frère de qui (or duquel) j'ai donné ce livre 'the man to whose brother I gave this book', l'homme en compagnie de qui (or duquel) je suis sorti 'the man in whose company I departed. ${ }^{284}$

$\$ 17$ In Latin the form of the relative pronoun qui transferred to an adjective by the genitive is cuius: Athenienses ducem elegerunt, cuius ductu bellum gesserunt 'The Athenians chose a general, under whose leadership they waged war'.

\$18 An equivalent form exists in a number of Languages: Gr. ánthrōpos, ohû dómon horâis 'the man whose house you see', Eng. the man whose house you see, Ger. der Mann, dessen Haus du siehst (same meaning).

$\$ 19$ Russian possesses a synthetic form of the relative pronoun transferred to an adjective, čej 'whose', which is the relative pronoun corresponding to the possessive adjective of the sort moj 'my' (cf. Chapter $35, \$ 19$ ), čelovek, čej dom vy vidite 'the man whose house you see'. This form can also be transferred to an adjective by the use of the genitive and can be subordinated to a noun that has itself been transferred to an adjective by the use of the genitive, that adjective having been subordinated to another noun contained in the adjectival clause. The absence of such a synthetic relative pronoun in French forces one to express the transfer of the relative pronoun analytically using the preposition de to transfer both the noun and the relative pronoun; the result is two instances of the translative de: Rus. čelovek, čego doma kryšu vy vidite, Fr. l'homme de la maison de qui (or duquel) vous voyez le toit 'the man whose house you see the roof of'.

284. Concerning the difficulty using the oblique relative pronoun dont, cf. A. Moufflet, Encore le massacre de la langue française, II, 1935, pp. 111-112. 
\$20 A synthetic relative pronoun transferred to an adjective of the Russian type exists in most Slavic languages: Serbian priroda čijim se čudesima davimo 'the nature whose wonders we admire.

\$21 In general, the greater the subordination of the relative pronoun to the verb governing the adjectival clause is mediated, the less fluid the sentence is: un pays envahi trois fois en soixante-dix ans et dont un sixième de la population est sinistrée 'a country invaded three times in seventy years and a sixth of whose population was stricken' (France-Libre, 11, X, 1948).

\$22 The adjective to which the anaphoric element of the personal pronoun is transferred can be, as illustrated with examples above, an adjective of personal relationship, but it can also be a predicative adjective of a general quality (qualitative adjective) (cf. Chapter 35, $\$ 14-15)$.

\$23 Such an adjective is common in Latin, where it appears in the form of the relative adjective qualis, the correlative antecedent of which is talis: Amo te talem, qualis es 'I love you such as you are'.

$\$ 24$ In French, the relevant relative pronoun of this correlative is generally reduced to a translative element: Je t'aime tel que tu es 'I love you such as you are'.

\section{Chapter 249. Agreement of the anaphoric element}

\$1 Due to the anaphoric element that it contains, the relative pronoun is variable and it agrees with the noun to which it is linked by an anaphoric connection.

\$2 This agreement can be person agreement. Such is the case in German where in the case of the autoontive and antiontive, one has to specify the person by having the personal index follow the relative pronoun: ich, der ich spreche 'I who is speaking', lit. 'I who I am speaking', Vater unser der du bist im Himmel, lit. 'Our father, who you are in the sky'.

$\$ 3$ Due to this precision, the relative pronoun and the verb are considered autoontive singular: ich, der spricht 'I who is speaking',

Mich, die neben dir so klein sich fühlt. (Schiller, The maid of Orleans)

Sie, die im ganzen Rat der Weiber bestochene Richter sitzen hat. (Schiller, Don Carlos)
'Me, who feels (herself) so small next to you.'

'You, who has bribed judges in the entire committee of women.'

$\$ 4$ But most often only gender and number agreement is present: Lat. epistula, quam aceppi 'the letter that I received.' The relative pronoun quam 'that' is feminine singular because it has an anaphoric connection to its antecedent epistula 'letter', which itself is feminine singular. 
$\$ 5$ In principle, the relative pronoun does not agree in case with its antecedent, the case of the relative pronoun being determined by its proper function in its clause, and this function has nothing to do with the case of its antecedent in the governing clause.

$\$ 6$ However, it can occur that by way of a sort of improper hyperesthesia for agreement, certain languages will allow this agreement, which is in itself not justified by any grammatical consideration. This improper agreement is known as attraction.

$\$ 7$ Attraction is a common phenomenon in Greek. After a genitive or dative antecedent, the relative pronoun of a second actant can, instead of appearing in the accusative, appear in the same case as its antecedent: tôn agathôn áxios, hôn (instead of á) ékhei 'worthy of the possessions that he has'; taîs heortaîs parốn, aîs (instead of hàs) ágomen 'present at the festivities that we celebrate'.

$\$ 8$ The same phenomenon of attraction is encountered in Latin. But in contrast to Greek, it is extremely rare in Latin and hardly correct. G. Cuendet even remarks that it is so exceptional that the example cited is always the same: ${ }^{285}$ notante iudice quo (instead of quem) nosti populo 'the people, judge that you know, noting it (disgrace)' (Horace, Satires, I, 6, 14-15). ${ }^{286}$

$\$ 9$ In contrast, attraction in Latin can reach up to the antecedent noun provided that this noun follows the relative pronoun in the spoken chain and is taken up by a demonstrative in connection with it but that is not the subject of attraction. Hence instead of Lat. Litterae (without attraction) quas scripsisiti me delectaverunt 'The letters that you wrote to me delighted me', one can say Quas scripsisti litteras (with attraction), eae (without attraction) me delectaverunt.

$\$ 10$ Outside of Greek, attraction is hardly encountered in the old Germanic languages, Gothic bi waldufnja Pammei (instead of Patei) frauja fragaf mis 'according to the power that the Lord has given me' (Epistle to the Corinthians, II, 13), Old High German thaz iz liuhte allen then (instead of thie) in huse sint 'so that he is brilliant for all those who are in the house' (Tatian, 25, 2). ${ }^{287}$

$\$ 11$ The general tendency of stultification and loss of inflection impacts the anaphoric element as is the case for all manifestations of inflection.

$\$ 12$ This tendency has the effect of reverting the anaphoric element from a multiplicity of inflectional forms to a single unique non-inflected form, which ends up morphologically indistinguishable from the invariable translative.

285. G. Cuendet, Sur l'expression de la particule relative, Mélanges Bally, p. 94.

286. First editors' note: Note however the other examples in Riemann \& Ernout, Syntaxe latine, new edition, 1940, \$16 and Horace, Satires, published by Paul Lejay, Paris, Hachette, 1911, p. 178, note 15 and page 244, note 54. For the latter, this would not be a true instance of attraction, but rather it is an expression arising from ellipsis in colloquial language: notante iudice quo iudice notari nosti.

287. G. Cuendet, Ibid. 
$\$ 13$ One can follow this development in English starting with Old English: Fèt drigde mid pāère linvāède pe hē was mid begyrt 'He washed the feet (of his disciples) with the cloth that covered him' (John, 13, 5). ${ }^{288}$

$\$ 14$ This tendency causes Scandinavian to make use of invariable particles like er and sem (som), which are veritable conjunctions today: Old Norwegian Konungr graf Hokone swerp, Pat er hiqlten voro ór gulle 'The king gave to Haakon a sword which (= of which) the decoration was in gold' (Heimskringla), ${ }^{289}$ Swedish Vem var den flickan, som du slog? 'Who was the young girl that you hit?'

$\$ 15$ Finally, the same tendency produces expressions in French like imbécile que (and not *qui) je suis 'fool that I am', 290 l'homme que je suis 'the man that I am' (cf. Chapter $75, \$ 7$ ).

\section{Chapter 250. Disjunction of the translative and anaphoric element}

\$1 In a large number of languages, the translative element and the anaphoric element are completely disjoint, and each is represented by a separate word, the first (the translative) being invariable and the second (the anaphor) being variable.

$\$ 2$ This division is found in non-European languages, these languages not having realized the agglutination of the two elements prehistorically. In fact it is in light of the facts in non-Indo-European languages that we have been led to produce the hypothesis above (cf. Chapter 246, \$17).

$\$ 3$ However, one also encounters the division as a common form with a common origin in the Indo-European languages, where the old ossified form has tended or is tending to cede its position to a form that is more productive and expressive.

$\$ 4$ The historical relationship between the former agglutinated form and the disjoint form that replaces it is hence analogous in every way to what we have already had the occasion to consider above (cf. Chapter 239, $\$ 6$ and 7) with respect to certain primary and secondary forms.

$\$ 5$ Like for these morphological forms, the secondary syntactic construction does not build on the primary one. The secondary construction has, rather, been substituted for the primary construction and now replaces it outright. By way of fatal linguistic intuition, speakers find themselves appealing to the same structural process, which is the only process available because it is the only process that conforms to the structure of our mind and

288. G. Cuendet, Ibid. p. 96.

289. G. Cuedent, Ibid. p. 97.

290. H. Lavedan, Viveurs, IV, p. 287. 
to the interior form of the language that results from this mental structure and that governs structural syntax.

\$6 Therefore instead of the relative pronoun, which is the only correct form, colloquial French readily employs the invariable translative que 'that', whereas the anaphoric element will be expressed by an index.

$\$ 7$ If the relative pronoun is an actant, the personal index expressing its anaphoric element will be variable.

$\$ 8$ With the first actant, one has: C'est moi que je suis la providence 'It is me that I am providence' (Pierre Chaine, L'Heure H, p. 20) instead of the correct sentence C'est moi qui suis la providence 'It is me who is providence'.

\$9 With the second actant, one will have l'homme que je le vois 'the man that I saw him', instead of the correct form l'homme que je vois 'the man who I saw'.

$\$ 10$ With the third actant, one will have l'homme que je lui ai parlé 'the man that I spoke to him', instead of the correct form l'homme à qui j'ai parlé 'the man to whom I spoke'.

$\$ 11$ If the relative proform is a circumstant, the index expressing its anaphoric element will be a circumstantial index: le village que tu en viens 'the town that you came from it', instead of the correct form: le village dont tu viens 'the town from where you came'.

$\$ 12$ The circumstant can be obtained by transfer of a noun using a preposition: l'ami que tu vas chez lui 'the friend that you are going to him', instead of the correct form l'ami chez qui tu vas 'the friend to whom you are going'.

$\$ 13$ Finally if the relative proform is transferred to an adjective of personal relation by the use of the genitive, its personal element will be expressed by an adjective arising from a personal noun, that is, by the possessive adjective: l'homme que j'ai vu son chapeau 'the man that I saw his hat', instead of l'homme dont j'ai vu le chapeau 'the man whose hat I saw.' ${ }^{291}$

$\$ 14$ This phenomenon has been studied in general by G. Cuendet ${ }^{292}$ and, especially for Iranian languages, by E. Benvéniste. ${ }^{293}$ We will henceforth indicate the source of our information by enclosing their names in parentheses as a means of citing their articles.

291. C'est la jeune fille que sa mère nous a si bien reçus 'It is the young girl that her mother has received us so well' (Moufflet, Contre le massacre de la langue française, I, 1930, p. 237); la femme que je connais son mari 'the woman that I know her husband' (A. Moufflet, Encore le massacre de la langue française, II, 1935, p. 113); Il y a des dentistes que leurs doigts sentent le tabac 'There are dentists that their fingers smell tabacco' (ibid., p. 142).

292. Georges Cuendet, Sur l'expression de la particule relative, Mélanges Bally, Geneva, 1939, pp. 93-100.

293. E. Benvénise, Un emploi du relatif dans l'Avesta, Bulletin de la Société de Linguistique de Paris, 44, 1948, pp. 72-73. 
\$15 Among non-Indo-European languages, the expression in question is obligatory in Semitic languages (Benvéniste, p. 72).

$\$ 16$ It also exists in Turkish: adam ki saçı sarıdır, lit. 'a man that his hair is blond' (= 'of whom the hair is blond'), although Turkish prefers first-degree transfer in such cases using the participle (cf. Chapter 199, §5ff.).

$\$ 17$ The same expression is extremely widespread in the Indo-European languages.

$\$ 18$ Even though the expression is incorrect in French, it is the only surviving form with the third actant or the circumstant for speakers of Occitan (Provençal, Languedocian) (Cuendet, p. 95):

Sian tout d'ami galoi et libre Que la Prouvènço nous fait gau
'We are all happy and free friends

That the Provence makes (us) happy'

(Mistral, Cant di Felibre)

\begin{tabular}{ll}
\hline ... Dieu me counvido & '...God summons me \\
A comparèisse au tribunau & To appear at the tribunal \\
Que sis arrest soun eternau & That its rulings are eternal' \\
& (= 'the rulings of which are eternal') \\
(Mistral, Nerte, I, I Lou Laroun)
\end{tabular}

Occitan: l'ome que n'en parle, lit. 'the man that I speak of him', (Lamouche, Grammaire languedocienne, 1942, p. 62), un homes que los Angles lo tenian 'a man that the English hold him' (In Vida e Miracles de Santa Flor, p. 128, de Suzanne KravtchenkoDobelmann, Syntaxe du dialecte de Cahors au moyen-âge, Annales du Midi, Volume 64, $\mathrm{N}^{0} 18$, April 1952).

$\$ 19$ This expression, which is familiar to speakers of Occitan, shows up each time in the Occitan substratum of French. Heard in the region of Montpellier around 1945: L'autre jour, j'ai vu votre fils, qu'il était beau 'The other day I saw your son, that he was handsome' (= 'who was handsome').

\$20 It is no less frequent in colloquial Italian: la bambina che le hai dato il pane 'the baby girl that you gave her the bread' (= 'to whom you gave the bread') (Cuendet, p. 96).

$\$ 21$ But Spanish has reduced its role: la fuente que beben todos d'ella (Cuendet, p. 96), lit. 'the fountain that we all drink from it' (= 'from which we all drink').

$\$ 22$ Romanian has the mechanism as well, but it is avoided in the modern language (Cuendet, p. 96). This fact does not prevent one from commonly saying in this language: cartea pe care l'am vandut, lit. 'the book that I sold it' (= 'that I sold').

\$23 The same expression is encountered in most Celtic languages: Breton an den a gomzan anean a zo bras, lit. 'the man that I spoke of him (= 'of whom I spoke') is big', Welsh Teithi Hen a oresgynnwys mor y kyuoeth (Cuendet, p. 97), lit. 'Teithi Hen that the sea engulfed his 
realm' (= 'whose empire the sea has engulfed'), Middle Irish in fer is a scéal sin 'the man that his history is this' (= 'the man whose history is this') (Cuendet, p. 97).

$\$ 24$ In Middle High German, the expression also exists:

\begin{tabular}{l}
$\begin{array}{l}\text { Ich hän einen man, } \\
\begin{array}{c}\text { Das elliu disiu rīche zuo } \\
\text { sinen handen solden stān. }\end{array} \\
\text { 'I have a husband } \\
\text { in his hands.', lit. 'that all these kingdoms } \\
\text { should be between his hands' } \\
\text { (Nibelungenlied, line 815) }\end{array}$ \\
\hline
\end{tabular}

\$25 In modern German, this same expression is no more than a regionalism, which can be heard for example in Austrian Silesia: Der Mann, was ich ihm hab' Geld geliehen, lit. 'the man that I have loaned money to him', that is 'who I have loaned money to.' ${ }^{294}$

$\$ 26$ The anaphor sa-precedes the translative -ei in Gothic sa-ei: atta peins saei saihwip in fulhsnja, ${ }^{295}$ lit. 'your father that he sees (= who sees) into the secret'.

$\$ 27$ One finds a disjunction between the relative and anaphoric elements in Slavic: Czech ten prítel, co k nèmu chodíš (Cuendet, p. 98), lit. 'the friend that you are going to him' (= 'to whom you are going'), (everyday) Slovenian clovek, ki sem ga videl, lit. 'the man that I saw him' (= 'who I saw').

$\$ 28$ The same expression exists in modern Greek: to peidi pou eida tē mètera tou 'the child that I saw his mother' (= 'of whom I saw the mother') (Benvéniste, p. 72).

$\$ 29$ In Iranian languages, this expression is attested in Persian: mard ki ùrā pū man that I gave money to him' (= 'to whom I gave money’) (Benvéniste, p. 72). We believed that this expression was contemporary with Middle Persian: hān kas kēn yut hač avē... 'this man that without him (= without whom) ...' (Benvéniste, p. 72). But very recently (1948), E. Benvéniste has shown that it is necessary to locate the appearance of this expression further back in time, since one finds it in the recent part of Avesta [that is, before the

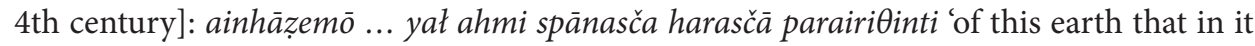
(= in which) dogs and men died'.

\$30 Finally, this expression exists in Albanian. Christoforidis writes in the translation of the Gospels in Tosk dialect: ky ësht ay qü unë thashë për atë se it is him that of him (= of whom) I said...' (Cuendet, p. 98).

294. Bach, Geschichte der deutschen Sprache, p. 108.

295. Mossé, Manuel de la langue gotique, p. 180. 
\$31 Benvéniste has correctly recognized (p. 73) that the innovation of which he wrote consisted of "dissociating the use of the relative and the case function".

$\$ 32$ Around 1939, Cuendet (p. 100), using slightly different terms, signaled "the universal tendency that existed to split the relative pronoun into two elements: a subordinate and an anaphor".

$\$ 33$ The one or the other linguist has been motivated to factually acknowledge the disassociation (cf. Chapter $246, \$ 15$ ), to which the structural analysis leads us, between a translative element (cf. Chapter 246, \$12) and an anaphoric element (cf. Chapter 246, \$13) in the relative pronoun.

\section{Chapter 251. Syntactic disjunction of the agglutinated relative pronoun}

$\$ 1$ If we acknowledge disjunction morphologically in terms of a transfereme and an anaphoreme in Indo-European languages (cf. above Chapter 250, $\$ 2$ and 15-16) and in the European languages that have evolved (ibid., $\$ 3$ and 17ff.), we observe that syntactically, the same disjunction is present in the agglutinated relative pronoun (cf. above, Chapter 246, \$17ff.).

$\$ 2$ That is, when one encounters such a pronoun in a sentence, it is impossible to rationally construct the stemma of this sentence and as a consequence, it is impossible to render the structure and to comprehend the structure without assigning a different position in the stemma to each of the two elements constituting the relative pronoun (transfereme and anaphoreme) (cf. above Chapter 246, $\$ 15$ and 16).

$\$ 3$ If in the example given above (Chapter $246, \$ 16$ ), these two positions are separate, they are nevertheless both present in the sentence. But this is not always the case.

$\$ 4$ In Latin in particular, it can occur that the anaphoreme is not in the same clause as the transfereme.

$\$ 5$ Such is the case when a subordinate relative clause is both the governor of another subordinate clause and when this subordinate precedes it in the spoken chain.

$\$ 6$ The three subordinates that constitute this structural set - the governing governing clause, the governing subordinate clause that depends on it, and the subordinate subordinate clause that depends on the latter - follow each other on the spoken chain in the following order (cf. above Chapter $5, \$ 8$ ): 1st governing governing clause, 2 nd subordinate subordinate clause, and 3rd governing subordinate clause.

$\$ 7$ Such is the case for example in the Latin sentence Est enim in manibus laudatio, quam cum legimus, quem philosophum non contemnimus? 'Indeed everyone has the eulogy in their hands: when reading it, is there a philosopher that escapes our scorn?' (Cicero, Cato Major, 4, 12) (Stemma 347), lit. 'Indeed everyone has in their hands the eulogy, which when we read, which philosopher do we not condemn?' 


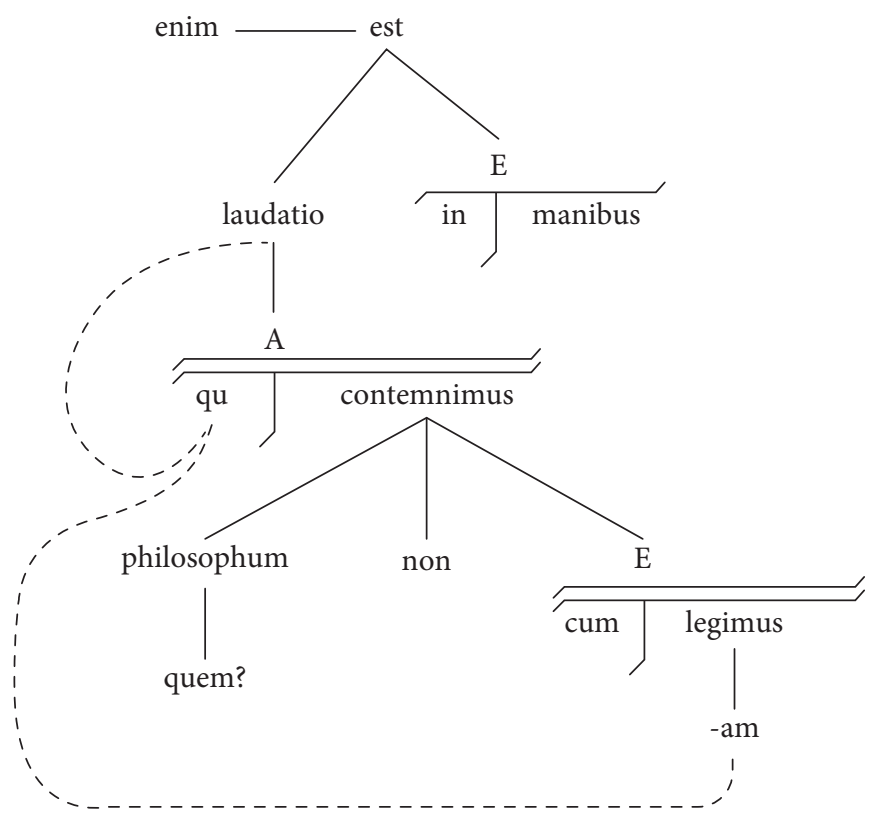

Stemma 347

$\$ 8$ Schema 348 shows the relationship of linear order to structural order (cf. above Chapter $4, \$ 1)$.

\begin{tabular}{|c|c|c|c|c|}
\hline $\begin{array}{l}\text { Governing } \\
\text { gov. clause }\end{array}$ & $\begin{array}{l}\text { Est enim in } \\
\text { manibus laudatio }\end{array}$ & & & \\
\hline $\begin{array}{l}\text { Governing } \\
\text { sub. clause }\end{array}$ & & $q u-$ & & $\begin{array}{l}\text { quem philosophum } \\
\text { non contemnimus? }\end{array}$ \\
\hline \multirow[t]{2}{*}{$\begin{array}{l}\text { Subordinate } \\
\text { sub. clause }\end{array}$} & & & $\begin{array}{l}\text {-am cum } \\
\text { legimus, }\end{array}$ & \\
\hline & $\begin{array}{l}\text { 'Indeed everyone has } \\
\text { in their hands the eulogy }\end{array}$ & wh- & $\begin{array}{l}\text {-ich when } \\
\text { we read }\end{array}$ & $\begin{array}{l}\text { which philosopher } \\
\text { do we not condemn?' }\end{array}$ \\
\hline
\end{tabular}

\section{Schema 348}

$\$ 9$ The transfereme $q u$ - of the relative pronoun quam that introduces the subordinate subordinate quam cum legimus is hence located in a favorable position for establishing an anaphoric connection to the antecedent laudatio, since the transfereme $q u$-constitutes the first part of the word that immediately follows this governing governing clause on the spoken chain.

$\$ 10$ The other part of the transfereme $q u$ - - even though it is placed on the spoken chain at the start of the subordinate subordinate clause quam cum legimus 'which when we read' - takes part in reality in the governing subordinate clause quem philosophum non contemnimus? 'which philosopher do we not condemn?', whereas its anaphoric element -am takes 
part in the subordinate subordinate clause in such a manner that the two elements of the relative pronoun $q u$-am 'wh-ich.Acc', which initiates the subordinate subordinate clause in the spoken chain, belong syntactically to two different clauses. The translative element $q u$-belongs to the governing subordinate clause, and the anaphoric element -am to the subordinate subordinate clause.

$\$ 11$ Given this position at the start of the subordinate subordinate clause, the translative element contained syntactically in the governing subordinate clause is no problem when one considers that every element contained in a subordinate clause is ipso facto part of the governing clause on which it depends (cf. Chapter $3, \$ 4$ to 6).

$\$ 12$ It is no less true that this structure, although it is perfectly correct in Latin, often makes the sentences difficult to translate into languages where the syntactic disassociation of the agglutinated relative pronoun does not exist or no longer exists, as in French for example, where the expression that results (cf. above $\$ 7$ ) in the literal translation "seems absolutely barbaric to us today". 296

$\$ 13$ In the syntactic sets just described, the governing subordinate clause is by definition always a relative clause because it is introduced by a relative pronoun ( $q u$ - $a m)$, the translative element of which $q u$ - belongs to it directly and the anaphoric element of which -am belongs to it as well, but indirectly, by way of the intermediate subordinate subordinate that contains it and that governs it.

$\$ 14$ This relative pronoun can be charged with circumstantial nuance (cf. above Chapter $247, \$ 3)$.

$\$ 15$ Hence the governing subordinate clause can be consecutive: Lat. Vestrane urbs electa est ad quam cum adirent ex Italia crucem civis Romani viderent? 'Was your town chosen (in order) that when one enters (it) coming from Italy, one sees the cross of a Roman citizen?' (Cicero, In Verrem, II, 4, 26).

$\$ 16$ This circumstantial nuance can also be final: Lat. Noli... adversum eos me velle ducere cum quibus ne contra te arma ferrem Italiam reliqui (Cornelius Nepos, Atticus, 4, 2), lit. 'Do not attempt to pull me into the war that you are waging against these men, who I left Italy in order to not carry arms with (them) against you', Nec Alpes aliae sunt, quas dum superant comparari nova possint praesidia 'There are no other Alps that for (them) to cross would give us the time to raise new forces' (Livy, 21, 41, 15).

$\$ 17$ Of course the verb of the relative governing subordinate clause with a consecutive or final nuance appears in the subjunctive (see the examples given above, $\$ 15$ and 16), like those of a consecutive clause (cf. below Chapter 261, \$5) and those of the final clause (cf. below Chapter 262, \$22).

296. Cf. Riemann \& Ernout, Syntaxe Latine, $\$ 18$. 
$\$ 18$ While the governing subordinate clause is always a relative subordinate clause regardless of the semantic circumstantial nuance with which it is charged - the subordinate subordinate clause can in contrast be of a different nature, and it is therefore in this respect that there is a diversity of manifestations of semantic disjunctions of the agglutinated relative pronoun. We will now consider the main varieties of these manifestations.

$\$ 19$ When the subordinate subordinate clause is a relative clause like the governing subordinate clause, one has two relative pronouns in sequence, the anaphoric elements of which both belong syntactically to the subordinate subordinate clause, but only the translative element of the second relative pronoun belongs syntactically to the subordinate subordinate clause, whereas the anaphoric element of the first relative pronoun belongs to the governing subordinate clause syntactically. The relative subordinate subordinate clause can itself be transferred to a noun ( $>>A>0$ ) as in the following example: Lat. Est enim... non satis politus in artibus, quas qui tenant eruditi appellantur 'He is thus insufficiently equipped with the insights that are necessary for one to be called a scholar' (Cicero, De finibus, 1, 26), lit. 'He is indeed insufficiently equipped with the insights that those who possess (them) are called scholars'.

\$20 However, very often the subordinate subordinate clause is circumstantial. It is a temporal expression in the example that we produced above (\$7) for our demonstration and to which we appealed above in Chapter 245, $\$ 13$ (top of Stemma 343).

\$21 The subordinate subordinate clause is suppositional (cf. below Chapter 259, \$4) in Lat. nolo... hunc... existimare ea me suasisse Pompeio quibus ille si parvisset... hic... tantas opes quantas nunc habet non haberet 'I do not want to see him (Caesar) think that I gave Pompey advice that, if he had followed (it), he would not have as many means as he has at its disposal today' (Cicero, Ad familiares, 6, 6, 5); Vos... vadenti Hasdrubali ad Alpes Italiamque (qui si se cum frater coniunxisset, nullum iam nomen esset populi Romani)... obstitistis (Livy, 26, 41, 13), lit. 'You, you have blocked the route for Hasdrubal marching to the Alps and to Italy (that, if he had connected with his brother, the name of the Roman people would no longer exist today)'.

$\$ 22$ The syntactic disjunction of the relative pronoun, which is impossible in modern French and for that reason difficult to translate, still existed in the French of the 17th century, probably due to the influence of the Latin of the writers of that time: Il y a partout la difficulté à laquelle si on succombe, on périt 'There is always the difficulty that if one succumbs (to it), one dies' (Bossuet, Deuxième avertissement, Volume XV, p. 254, ed. Lachat).

\section{Chapter 252. The antecedent of the relative clause}

\$1 Like every attributive adjective, the adjectival subordinate clause has a noun as its governor. The noun governing an adjectival subordinate clause is called its antecedent. 
\$2 Actually, it is not a structural antecedent in the sense that we have given to the word antecedent above (cf. Chapter 240, \$2), that is, an antecedent of the translative element of the personal pronoun, but rather it is the antecedent of the relative pronoun's anaphoric element.

$\$ 3$ However, due to the double nature of the personal pronoun, this term can be retained on condition that one makes it clear if need be that one is dealing with the anaphoric antecedent.

$\$ 4$ The designation is justified by the fact that, whether translative or anaphoric, the antecedent is the same word and that on the spoken chain, it usually precedes the subordinate clause:

\begin{tabular}{llr}
\hline Les livres & que vous avez & sont précieux. \\
(antecedent) & $\begin{array}{l}\text { (adjectival subordinate clause) } \\
\text { 'The books }\end{array}$ & that you have \\
\hline
\end{tabular}

$\$ 5$ When the antecedent is a personal noun $(\mathrm{O})$, it can occur that it is marked only by the possessive adjective that is derived from it by transfer of the sort $\mathrm{O}>\mathrm{A}$ : Lat. Vostra consilia accusantur, qui mihi summum honorem imposuistis 'They criticize the decision by which you conferred to me the greatest of dignities', lit. 'They criticize your decision, who conferred ...' (Sallust, Jugurtha, 85, 28). The antecedent of the adjectival clause introduced by the relative pronoun qui is the personal noun vos 'you' here, which is the source of the transferred possessive adjective vostra 'your'.

$\$ 6$ The anaphor that joins the relative pronoun to its antecedent tends to have the effect of moving the two closer to each other on the spoken chain, that is, to place them in linear sequence. In fact, the antecedent practically always precedes the relative pronoun on the spoken chain: l'homme qui vient, l'homme que je vois, l'homme à qui je parle, l'homme dont je parle 'the man who is coming, the man that I see, the man to whom I speak, the man of whom I speak'.

$\$ 7$ However, one can find examples where this sequence does not hold. When this happens, one is dealing with what is called a differed relative clause. Disjunction of this sequence is encountered either in elevated style or in colloquial style.

$\$ 8$ In elevated style and in particular in verse, it has been employed by the best authors: Phenix même en répond, qui l'a conduit exprès 'Phoenix himself answered for it, who had intentionally guided it' (Racine), George Sand ne s'y trompa point, qui avait du génie 'George Sand was not mistaken, who had genius' (Emile Faguet, Introduction to "Mariages de Paris" of Edmond About). The Abbott d'Olivet was probably a little severe when he criticized this turn, which the Abbott Desfontaines admitted in verse. ${ }^{297}$ One is less strict in our days: $M a$

297. Cf. Bulletin de la Société de Linguistique de Paris, 44, II, p. 121. 
femme cependant m'aidait, dont le mouvement le plus naturel est toujours le meilleur 'My wife however helped me, whose most natural movement is always the best' (André Gide, La Symphonie Pastorale, 1st folder, February 10). See however the disapproval of A. Dauzat in his article in Le Monde from 8-11-1950.

$\$ 9$ In colloquial style, the detached relative is generally awkward and it leads to amusing misunderstandings concerning the person of the antecedent: Fr. Elle a acheté un caleçon à son mari, qu'elle a payé très cher 'She bought trunks for her husband, that/which she paid a lot for' (heard by the author in 1944). Humorous almanacs abound with examples like J'ai offert un ravissant petit chat à ma femme, qui a les oreilles noires 'I offered a beautiful small cat to my wife, who/that has black ears'.

$\$ 10$ The tendency to place the relative form as close as possible to its antecedent impacts adjectival subordinate clauses in major ways. For example, colloquial English readily includes the group formed by the adjectival subordinate clause in the group constituted by the antecedent when the former is transferred to an adjective by the use of the Saxon genitive. F. Mossé has proposed giving the name global genitive to this expression, which is becoming more prominent in English: the man I saw yesterday's hat instead of the hat of the man I saw yesterday.

$\$ 11$ In all the preceding examples, the relative pronoun takes its proper value as a noun from its anaphoric connection to its antecedent, which is necessarily a noun.

$\$ 12$ But such a connection may not occur, and then the relative form remains an adjective. In such cases, it is no longer appropriate to speak of a relative pronoun, but rather one is dealing with a relative adjective.

$\$ 13$ In French the relative adjective is lequel, despite the transfer of the adjective quel to a noun by way of the article le (cf. Chapter $43, \$ 16$ ).

$\$ 14$ In Latin and in Greek, the form of the relative adjective is the same as that of the relative pronoun: Lat. adventum tuum cognovi, qui nuntius mihi gratissimus fuit 'I learned of his arrival, news that pleased me greatly', lit. '..., which news pleased me greatly', Caesari nuntiaverunt pulverem maiorem, quam consuetudo ferret, in ea parte videri, quam in partem legio iter fecisset 'They announced to Caesar that one had seen more dust than in the normal case in the direction in which (direction) the legion was marching' (Caesar, De bello Gallico, IV, 32, 10), Gr. Athēnaì, hế pólis estìn en têi Attikéti 'Athens, which (city) is located in Attica'.

\section{Chapter 253. Participle agreement}

$\$ 1$ We have seen (Chapter $225, \$ 14$ ) that an anterior participle that has been retransferred to a verb by way of the auxiliary (I > A $>$ I) was solicited by two tendencies. As a verb (I), the participle tends to be insensitive to the nominal categories of gender and 
number, but when it is changed to an adjective (A), it can take part in gender and number agreement.

\$2 In fact the question arises in French, where participle agreement poses various problems, concerning the location of participle agreement. The rules of participle agreement are complicated.

$\$ 3$ In order to see this agreement with the necessary clarity, one has to compare the mechanism in French with its equivalent in other languages that are susceptible to presenting the same phenomenon.

$\$ 4$ This leads us to pose the preliminary question concerning the knowledge of what the problems are that arise and what the conditions are that have to be fulfilled so that they arise.

$\$ 5$ First of all, the problems arise only in the compound tenses, since they are the only ones where the anterior participle is retransferred to a verb by way of an auxiliary (I > A > I).

$\$ 6$ If the auxiliary is the verb 'be', the condition is satisfied in a number of Indo-European languages, in particular in Latin and Greek, and in the Slavic languages (cf. 225, \$16-18).

$\$ 7$ But if the auxiliary is the verb 'have', the linguistic horizon is more restricted. The Slavic languages are excluded, because they do not utilize this auxiliary to form the compound tenses (cf. Chapter 225, \$16).

$\$ 8$ On the other hand, the anterior participle has to be variable, which a priori excludes English and Breton, where it is invariable like all other adjectives.

$\$ 9$ Finally, the anterior participle has to be variable not only when it is attributive, but also when it is predicative, since it plays the role of a predicative expression in the compound tenses. Yet in German, attributive adjectives are variable, whereas predicative adjectives are invariable. German is hence also excluded from the languages that are susceptible to developing agreement of the anterior participle in compound tenses formed with the auxiliary.

\$10 The Slavic and Germanic languages excluded, only the Romance languages can furnish a point of comparison with French. The base for comparison is therefore quite narrow.

$\$ 11$ The original tendency is that agreement obtains between an anterior participle that takes the auxiliary verb 'have' with the second actant subordinate to this verb. This is what occurs in Latin: Habeo cognitam amicitiam 'I have known friendship'.

$\$ 12$ In the case of an adjectival clause, agreement has a deep foundation in the syntax. Since such a clause is equivalent to an adjective (cf. Chapter $245, \$ 1-2$ ) and it determines or qualifies the antecedent, it is normal for it to agree in the same way as an adjective. It is thus necessary to consider that it is the clause as a whole that takes the mark of agreement. 


\begin{tabular}{|c|c|}
\hline Adjectival clause & Adjective \\
\hline $\begin{array}{l}\text { le livre que j'ai écrit } \\
\text { 'the book that I have written' }\end{array}$ & $\begin{array}{l}\text { un petit livre } \\
\text { 'a little book' }\end{array}$ \\
\hline $\begin{array}{l}\text { les lettre que j'ai écrite } \\
\text { 'the letters that I have written' }\end{array}$ & $\begin{array}{l}\text { une petite lettre } \\
\text { 'a short letter' }\end{array}$ \\
\hline $\begin{array}{l}\text { les livres que j'ai écrits } \\
\text { 'the books that I have written' }\end{array}$ & $\begin{array}{l}\text { de petits livres } \\
\text { 'short letters' }\end{array}$ \\
\hline $\begin{array}{l}\text { les lettres que j’ai écrites } \\
\text { 'the letters that I have written' }\end{array}$ & $\begin{array}{l}\text { de petites lettres } \\
\text { 'short letters' }\end{array}$ \\
\hline
\end{tabular}

\$13 But this tendency is not encountered in all cases, and the verbal preference for total invariability is realized in Occitan, Spanish, Portuguese and Romanian: Occ. Las flours que m'aviàs demandat 'the flowers that you demanded from me, ${ }^{298} \mathrm{Sp}$. los libros que he comprado 'the books that I bought' (cf. yo los he comprado 'I bought them'), Port. as mercadorias que tinha comprado 'the merchandise that I bought', Rom. cartea pe care l'am vandut 'the book that I sold?.

\$14 In Italian, the rule is to establish agreement when the participle follows the antecedent that is the second actant of the compound form: le lettere che ho scritte 'the letters that I write', le ho scritte 'I wrote them'.

\$15 This rule is sensible. Indeed, as much as it is logical to establish agreement between the participle and a second actant that precedes it, it is illogical to demand agreement with a second actant that has not yet appeared, since that actant is unknown at the moment when it is appropriate to establish agreement.

$\$ 16$ French has long hesitated and dithered in this area. The tendency toward invariability of the anterior participle with the auxiliary avoir 'have' is old. It was close to being established entirely at the end of the 12th century, when a reaction arose, probably due to the influence of grammarians. ${ }^{299}$

$\$ 17$ The evolution thus halted, one stopped midway between variability and invariability. In the 16th century, Marot borrowed the practice from Italian that establishes agreement between the anterior participle and second actant when the latter precedes the former: Je l'ai vue 'I saw her', lit. 'I her have seen.FEM'.

$\$ 18$ This practice took a long time to establish itself, and it only triumphed toward the end of the 18th century.

$\$ 19$ One will note that the practice is obligatorily in force in relative clauses, since the relative pronoun always appears in front of the relative clause (cf. Chapter 252, \$4).

298. Lamouche, Grammaire Languedocienne, p. 72.

299. Brunot, Grammaire historique de l'ancien français, 1899, p. 524. 
\$20 But the established usage since the end of the 18th century is full of difficulties and the rules that govern usage are most often due to convention and hence arbitrary. ${ }^{300}$

$\$ 21$ One therefore draws a distinction between la femme que j'ai vue peindre 'the woman that I saw painting' (cf. Stemma 349) and la femme que j'ai vu peindre 'the woman that I saw painted' (cf. Stemma 350), according to whether the woman is painting or being painted. Similarly: Les blés que nous avons vu semer sont déjá en grange, mais ceux que nous avons vus germer no sont pas encore coupés 'The wheat that we saw (people) sewing is already in the barn, yet the wheat that we saw sprouting is not yet cut'.

$\$ 22$ These distinctions are so subtle that even the best minds get confused. Rendering these distinctions as stemmas can be of service in this regard. Hence the difference between the examples from $\$ 21$ can be graphically registered by the stemmatic representation (cf. Stemmas 349, 350, 351, and 352).

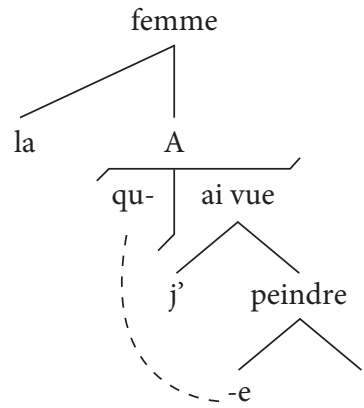

Stemma 349

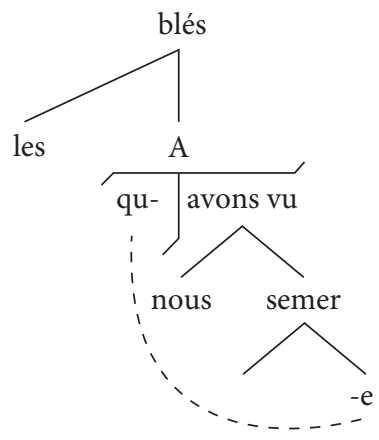

Stemma 351

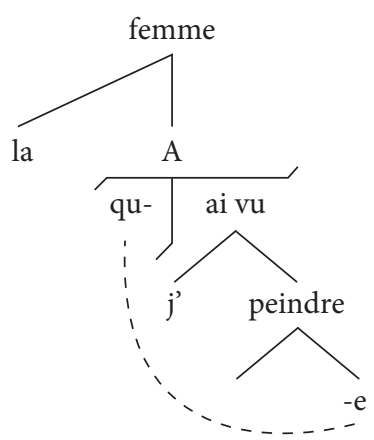

Stemma 350

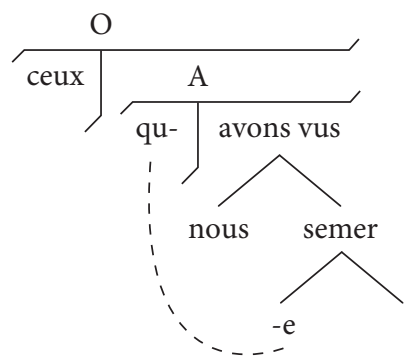

Stemma 352

300. Brunot, Ibid., p. 526. 
\$23 These subtleties, to which one formerly attached great importance, are no longer of interest to anyone, not even to grammarians, who have recognized the futility in the area and who are therefore the first to recommend a measure of tolerance concerning such matters.

\$24 The distinction exists only in writing and is even absent from the spoken language of educated people. They can say without turning a hair: la lettre que j'ai écrit 'the letter that I wrote' rather than la lettre que j'ai écrite. ${ }^{301}$ The rule has died due to the complexities. These complexities have effectively brought the anterior participle in French to the same status of invariability as in Provincial, Spanish, Portuguese, and Romanian.

\section{Chapter 254. I >> E transfer}

\$1 For this type of transfer, an independent clause is transferred to a circumstant on the verb of another clause that is independent and thus becomes its governor. Conversely, the transferred clause becomes a subordinate of this governing clause, and since it plays the role of a circumstant, we retain for it the traditional designation circumstantial clause.

\$2 Since a circumstant is normally an adverb, the subordinate circumstantial clause will be the equivalent of an adverb in the governing clause. Hence if it occurs that you arrived yesterday, the sentence I received you when you arrived is the equivalent of I received you yesterday.

$\$ 3$ This is why in one language or another, it can occur that the circumstantial clause (I >> E) is equivalent to a noun transferred to an adverb by first-degree transfer (I > E): Ger. Als sie am nächsten Morgen aufgestanden war, sah sie den Schreiber auf dem Platz, 'When she got up the next morning, she saw the clerk in the sqaure' (I >> E) $\leftrightarrow$ Fr. Le lendemain, $\grave{a}$ son réveil, elle aperçut le clerc sur la place, lit. 'The next morning, at her wakening, she saw the clerk in the square' $(\mathrm{I}>\mathrm{E}){ }^{302}$

$\$ 4$ The translative is hence the conjunction of subordination when, without which the subordinate clause would be independent. It is the translative when that transfers the independent clause you arrived to the circumstantial subordinate clause when you arrived.

$\$ 5$ In French, transfer of the sort I >> E can be realized by unique translatives of the sort quand (quand vous voudrez 'when you want'), où (où vous voudrez 'where you want'), comme (comme vous voudrez 'as you want'), si (si vous voulez 'if you want'). But these simple translatives are rare.

301. Gougenheim, Bulletin de la Société de Linguistique de Paris, 1944, II, p. 104.

302. Malblanc, Pour une stylistique comparée du français et de l'allemand, Paris, $1963, \$ 147$. 
$\$ 6$ This is however the case when the affirmative sentence word (Fr. oui 'yes') or the negative sentence word (Fr. non 'no') is transferred to a conditional clause by way of the translative si: Fr. Pouvez-vous venir me voir demain? Si oui, je vous attendrai à neuf heures. Sinon, je disposerai de ma journée 'Can you come see me tomorrow? If yes, I will expect you at nine. If not, I will change my day'.

\$7 This also occurs when a sentence word is the governor of a subordinate noun: Fr. J'évite cet homme, non que je le craigne, mais... 'I avoid this man, not because I fear him, but...', lit. '..., no that I fear him, but...' (cf. below Chapter 256, \$14).

$\$ 8$ But most often, French replaces the simple translative (I $>>$ E) with double transfer realized by way of the double translative composed of two translative parts: alors que 'while', depuis que 'since', tandis que 'whereas', pendant que 'while', cependant que 'whereas', avant que 'before', après que 'after', dès que 'as soon as', pour que 'in order that', bien que 'although'.

$\$ 9$ The first translative, which is the last to appear on the spoken chain (cf. Chapter 209, $\$ 14$ ) is invariably the same que 'that'. Yet this translative is that of the second-degree transfer I $>$ O.

\$10 Hence the independent source clause is first transferred to a noun.

$\$ 11$ Concerning the second translative (which is the first on the spoken chain), it is different for each transfer, and it is usually a translative of ordinary first degree, that is, a preposition: Fr. depuis 'since', avant 'before', après 'after', dès 'from', pour 'for'.

$\$ 12$ Thus the noun $\mathrm{O}$, which is the target of the first transfer of second degree (I >>O), is itself transferred to an adverb by first-degree transfer $(\mathrm{O}>\mathrm{E})$. There is hence a retransfer and the double transfer is of the sort $\mathrm{I}>>\mathrm{O}>\mathrm{E}$.

$\$ 13$ Indeed, take the independent clause Vous arriverez 'You will arrive': if it is transferred to a noun by second-degree transfer using the translative que (J'espère | que vous arriverez 'I hope | that you will arrive', like, J’espère la réussite 'I desire success', cf. Chapter 241, §15), it is entirely natural that the noun can in turn be transferred to an adverb by first-degree transfer using a translative of first degree: J'irai vous voir dès $\mid$ que vous arriverez 'I will come see you as soon as you arrive', as J'irai vous voir dès $\mid$ votre arrivée 'I will come see you upon your arrival'.

$\$ 14$ This process, which permits the replacement of simple second-degree transfer I >> E with double second-degree transfer I $>>\mathrm{O}>\mathrm{E}$, is quite widespread in French. It is also found in several foreign languages.

$\$ 15$ In the case of double transfer of the sort I $>>\mathrm{O}>\mathrm{E}$, the subordinate noun is frequently prefigured by an antecedent that takes it up and announces it (cf. Chapter 240, \$2). In French, this antecedent is often a demonstrative neuter pronoun ce 'that': Attends, jusqu'à ce que je revienne 'Wait until I return'.

$\$ 16$ It can occur that the antecedent is agglutinated to the second translative (the one that comes first on the spoken chain in French) and this agglutination is registered in 
orthography: Fr. Je l'aime, parce que c'est un honnête homme 'I love him because he is an honest man' [literally par ce que is 'by that that'].

$\$ 17$ The same situation is present in Russian: Ja ego ljublju, potomu čto on čestnyj čelovek (same meaning), cf. also Rus. c tem čtoby 'in order to'.

$\$ 18$ Often the antecedent can be a noun that stands in a relation with the meaning of the subordinate that it announces: de sorte que 'in such a way that', lit. 'of sort that', à condition que 'under the condition that', à moins que 'unless'; with agglutination: afin que 'in order that' [lit. à fin de 'to end that'].

$\$ 19$ In the case of junction between the transfers obtained by this process, it suffices to repeat the first translative que, and it is useless to repeat the second, that is, the preposition: J'irai vous voir dès que vous arriverez, que vous aurez une chambre à l'hôtel et que vous y serez bien installé 'I will come see you as soon as you arrive, as you get a room in the hotel and as you get comfortable there', like with J'espère que vous arriverez, que vous aurez un chambre à l'hôtel et que vous y serez bien installé 'I hope that you arrive, that you get a hotel room, and that you get comfortable there'.

\$20 This tendency for double transfer $(\mathrm{I}>>\mathrm{O}>\mathrm{E})$ is so essential to French that French speakers indirectly have the same sense with the simple translatives of the sort I > $>$ E.

\$21 Hence in the case of junction, these translatives, although they are simple, are treated as if they were double, and they are not completely repeated, but rather they appear only in the form of the translative for $\mathrm{I}>>\mathrm{O}$, which is que. Thus one will have, using the simple translative quand, the sentence: J'irai vous voir quand vous arriverez, que vous aurez une chambre à l'hôtel et que vous y serez bien installé 'I will come visit you when you arrive, (that) you get a room in the hotel, and (that) you get comfortable there'.

$\$ 22$ With the simple translative si, one even has a change in mood: J'irai vous voir si vous arrivez, que vous ayez une chambre à l'hôtel et que vous y soyez bien installé 'I will come see you if you arrive, (that) you get a room in the hotel, and (that) you get comfortable.

\section{Chapter 255. Circumstantials of time and place}

$\$ 1$ We have seen (cf. below Chapter 37, see in particular the table in \$52) that the adverb category contains a certain number of subcategories: locality (temporal adverbs, locative adverbs), relations (adverbs of goal, cause, and manner).

$\$ 2$ We will find the same subcategories in circumstantial clauses: temporal circumstantials, locative circumstantials, circumstantials of goal or finality, circumstantials of cause or causal clauses, circumstantials of manner).

$\$ 3$ In temporal circumstantial clauses, many languages distinguish between subcategories of aspect, secution, and time. 
$\$ 4$ Aspect is the category of the degree of achievement of a process, and therefore of the duration of its different stages.

\$5 Terminative aspect is the category of action that, after having lasted a certain time, stops in order to give way to another action or to the absence of action: Fr. Attends, jusqu'à ce que je revienne 'Wait, until I arrive'. The wait lasts a certain time and then ceases when the awaited person arrives.

$\$ 6$ While French uses double transfer here ( $>>0>E$ ), Latin employs simple transfer I $>$ E, the marker of which is the translative dum: Expecta, dum redeam 'Wait until I return'. One has, with a mild nuance in aspect, Lat. Donec eris felix, multos numerabis amicos 'As soon as you are happy, you will count many friends' (Ovid). Your friends will disappear from that day on when you are no longer happy.

$\$ 7$ Conversely, inchoative aspect is such that the action starts after another action or after the absence of an action and then lasts for an indefinite period of time: Depuis que vous êtes arrivé, il fait beau 'Since you arrived, the weather has been nice'. Nice weather is only envisioned from that moment forward starting with the arrival of the person at hand.

$\$ 8$ Finally, imperfective or durative aspect combines the two preceding types of aspect in the envisioned action: the action is viewed as having lasted a while when another action intervenes and as lasting for an indefinite period of time after this other action: Veuillez m'attendre deux minutes, dans la cuisine, pendant que je vais faire une course 'Would you wait two minutes for me, in the kitchen, while I am going to get something from the store'. The stay in the kitchen begins before the way to the store and it continues after it. Similarly, Alfred lisait tandis que j'écrivais 'Alfred read while I wrote'.

$\$ 9$ In contrast to aspect, secution is the category of relative time, that is, of time dated relative to another time. Secution can hence be concomitant, posterior, or anterior.

\$10 Concomitant secution is frequent in most languages, where it is marked by a translative. Often the translative is preposed:

\begin{tabular}{|c|c|c|}
\hline \multirow[t]{2}{*}{ French } & quand & $\begin{array}{l}\text { Quand le moment viendra d'aller trouver les morts, } \\
\text { J'aurai vécu sans soins, et mourrai sans remords. } \\
\text { 'When the moment comes to go and see the dead persons, } \\
\text { I will have lived without concern and will die without remorse.' } \\
\text { (La Fontaine, Fables, XI, } 4 \text {, Le songe }\end{array}$ \\
\hline & & $\begin{array}{l}\text { d'un habitant du Mogol) } \\
\text { Vous le verrez quand il viendra. } \\
\text { 'You will see him when he comes.' }\end{array}$ \\
\hline Italian & quando & $\begin{array}{l}\text { Lo vedrete quando verrà. } \\
\text { 'You will see him when he comes.' }\end{array}$ \\
\hline Latin & quando & $\begin{array}{l}\text { Eum videbis, quando venit. } \\
\text { 'You will see him when he comes.' } \\
\text { And the indicative: } \\
\text { Cum eum videbis, cum veniet. }\end{array}$ \\
\hline
\end{tabular}




\begin{tabular}{|c|c|c|}
\hline Greek & hote & $\begin{array}{l}\text { Autòn ópsei hóte hếxei. } \\
\text { 'You will see him when he comes.' }\end{array}$ \\
\hline \multirow[t]{2}{*}{ German } & $\begin{array}{l}\text { wenn, } \\
\text { als }\end{array}$ & $\begin{array}{l}\text { Sie werden ihn sehen, wenn er kommt. } \\
\text { 'You will see him when he comes.' }\end{array}$ \\
\hline & & $\begin{array}{l}\text { Past semelfactive: } \\
\text { Als er kam, war er schon krank. } \\
\text { 'When he came, he was already sick.' }\end{array}$ \\
\hline English & when & You will see him when he comes. \\
\hline Russian & $k o g d a$ & $\begin{array}{l}\text { Vy ego uvidite, kogda on pridët. } \\
\text { 'You will see him when he comes.' }\end{array}$ \\
\hline Romani & koma & $\begin{array}{l}\text { koma marel o manus } \\
\text { 'when the man dies' }\end{array}$ \\
\hline Arabic & lámmā & $\begin{array}{l}\text { lámmà balagiat min al-'umriašar }{ }^{a} \text { sinin } \\
\text { 'when she reached the age of } 10 \text { years' }\end{array}$ \\
\hline Hungarian & mikor & $\begin{array}{l}\text { Mindnyájan aludtunk, mikor a tüz kiütött } \\
\text { 'We were all sleeping when the fire went out.' }\end{array}$ \\
\hline Subiya & ha & $\begin{array}{l}\text { ha ba i bona } \\
\text { 'when they saw him' }\end{array}$ \\
\hline Samoan & 'a & $\begin{array}{l}\text { 'a se tasata 'ua fela 'ula'i } \\
\text { 'when a man makes proof of duplicity' }\end{array}$ \\
\hline
\end{tabular}

$\$ 11$ One can acknowledge the possibility of an equivalency across languages concerning second-degree transfer of a verb to a temporal adverb ( $>>$ E) with double transfer of first degree (I > A > E), with only the instance of I > A being marked: Ger. Als ich in Paris war, machte ich die Bekanntschaft... ${ }^{303}$ 'When I was in Paris, I got to know...' $\leftrightarrow$ Fr. Etant à Paris, je fis la connaissance de... 'Being in Paris, I got to know...'; Ger. Als er wieder zu ihnen kam, wurde er wie ein Prinz verhätschelt 'When he returned to them, he was spoiled like a Prince' $\leftrightarrow$ Fr. Rentré chez eux, il fut gaté comme un prince', lit 'Returned to them, he was spoiled like a Prince'.

$\$ 12$ In other languages, translatives are postposed:

\begin{tabular}{|c|c|c|}
\hline Eskimo & me & $\begin{array}{l}\text { kimek sinika-me } \\
\text { 'when the dog was sleeping' }\end{array}$ \\
\hline Turkish & zaman & $\begin{array}{l}\text { arkadaşııı gördünü zaman } \\
\text { 'when he saw his companions' }\end{array}$ \\
\hline Chuvash & te & $\begin{array}{l}\text { puneke kene te } \\
\text { 'when they went into the room' }\end{array}$ \\
\hline
\end{tabular}

$\$ 13$ Posterior secution expresses an action that occurs after another action: Fr. On cherche ce qu'il dit après qu'il a parlé 'One is looking for what he says after he has spoken' (Molière,

303. Malblanc, Pour une stylistique comparée du français et de l'allemand, Paris, 1963, \$147. 
Les Femmes savantes, II, 7). In other words, Trissotin is so over-subtle that people are still wondering what he wanted to say after he finished speaking. The sense that one is seeking in vain occurs after his speaking.

$\$ 14$ Posterior secution is marked in many languages by a translative:

\begin{tabular}{lll}
\hline English & after & $\begin{array}{l}\text { after he had died } \\
\text { German }\end{array}$ \\
nachdem & $\begin{array}{l}\text { nachdem er gestorben war } \\
\text { 'after he had died' }\end{array}$ \\
\hline
\end{tabular}

\$15 Conversely, anterior secution expresses an action that occurs before another: Fr. Avant que le coq chante, tu me renieras trois fois 'Before the rooster crows, you will have renounced me three times' (Matthew, XXVI, 34 and 75). The time of disavowel by Saint Peter is dated in relation to the crowing of a rooster, which it precedes.

$\$ 16$ Like posterior secution, anterior secution is marked in most languages by a translative.

\begin{tabular}{|c|c|c|}
\hline Greek & prín & $\begin{array}{l}\text { Ou próteron epaúsanto prín pántas apékteinan. } \\
\text { 'They will not cease before he has killed everyone.' }\end{array}$ \\
\hline Latin & $\begin{array}{l}\text { antequam } \\
\text { or } \\
\text { priusquam }\end{array}$ & $\begin{array}{l}\text { Tempestas minatur, antequam surgat. } \\
\text { 'The storm is threatening before she arises.' }\end{array}$ \\
\hline English & before & You must read this book before your father returns. \\
\hline German & bevor & $\begin{array}{l}\text { Sie müssen dieses Buch lesen, bevor ihr Vater zurückkommt. } \\
\text { 'They must read this book before their father returns.' }\end{array}$ \\
\hline
\end{tabular}

$\$ 17$ In Latin, the translative priusquam 'before' contains two elements that do not necessarily form a single word and can well be separated from each other on the spoken chain: Lat. Prius periere quam quod petierant contingerent 'They died before having obtained the object of their desire' (Phaedrus, I, 20, 5-6).

$\$ 18$ Posterior secution and anterior secution are expressed in French by double translatives $(\mathrm{I}>>\mathrm{O}>\mathrm{E})$. The translative of second degree $(\mathrm{I}>>\mathrm{O})$ is the input to transfer of first degree $(\mathrm{O}>\mathrm{E})$. The marker of second-degree transfer $(\mathrm{I}>>\mathrm{O})$ is the translative que, and that of first-degree transfer $(\mathrm{O}>\mathrm{E})$ is a clause, après 'after' or avant 'before' according to the context.

$\$ 19$ In French, first-degree transfer is not marked when one is dealing with anterior secution:

Il m'a dit qu'il ne faut jamais Vendre la peau de l'ours qu'on ne l'ait mis par terre. lit. 'He said to me that one should never Sell the pelt of a bear that one has not yet taken it down., that is '....count one's chickens before they are hatched.'

(La Fontaine, Fables, V, 20, L'ours et les deux compagnons) 
$\$ 20$ Circumstantial clauses in French are in general marked by a temporal adverb doubled from the translative que: Maintenant que l'hiver est terminé, nous allons avoir beau temps 'Now that winter is over, we are going to have nice weather', Aujourd'hui qu'il fait beau, nous allons pouvoir aller nous promener 'Today since it is nice, we are going to be able to take a walk'.

\$21 The temporal adverb can be the result of transfer from a noun $(\mathrm{O}>\mathrm{E})$ : Fr. Les choses commencèrent un après-midi de grand soleil qu'Honoré fauchait sur la plaine 'The matter began one sunny afternoon as Honoré was scything in the fields' (Marcel Aymé, La jument verte, p. 41).

\$22 Concerning expressions like the preceding ones, other languages place the translative on the spoken chain before the noun that has been transferred to an adverb: Ger. als er eines Abends uns besuchte 'when he visited us one evening' Fr. un soir qu'il nous rendait visite, lit. 'one evening that he visited us'.

$\$ 23$ Temporal adverbs of every subcategory are susceptible to being doubled in this way in French using the translative que: Je m'y perdrais là-dedans, même avec une boussole, s'écrie Lucienne. Déjà que je n'ai pas le sens de l'orientation 'I would get lost in there, even with a compass, exclaims Lucienne. What's more I don't already have a sense of orientation', lit. '... Already that I don't have a sense of orientation' (Achard, Vers un monde nouveau, p. 172); depuis ce matin que nous sommes ici 'since the morning that we have been here'.

$\$ 24$ Concerning locative circumstantials, they are less common than temporal clauses.

\begin{tabular}{lll}
\hline French & où & Restez où vous êtes. \\
Latin & $u b i$ & Mani ubi es. \\
Greek & ohû & Méne ou ề. \\
German & wo & Bleibe, wo du bist. \\
English & where & Stay where you are. \\
\hline
\end{tabular}

\$25 In many languages, locative translatives can serve to introduce a temporal clause: Lat. Haec ubi dixit, profectus est 'After he said that, he departed', lit. 'Where he said that, .... In Latin, the locative translative can also serve to introduce an actantial clause. Hence in the following verses of Propertius, the causal clause forming the protasis is picked up again by hinc 'from there' in the governing apodosis clause, hinc expressing the meaning 'that is why':

Seu, quia victa suis umeris haec arma ferebant, Hinc Feretri dicta est ara superba Iovis. (Propertius, Elegies, IV - 10 end)

Ego omnibus unde (= a quibus) petitur hoc consilii dederim (Cicero, Epistulae ad Familiares, VII, II, 1)
'Or as the victors carried these arms on their shoulders, that is why one has given the name of Feretrius to the Jupiter of this superb sanctuary'

'For me, I would permit myself to give consultation to all those from whom one demands justice.' (that is, those who are prosecuted)' 
\$26 In French, the use of the locative translative is obligatory for temporal circumstantials if the temporal idea is expressed by an antecedent that is an adverb or a word transferred to an adverb: Vous viendrez quand je vous le dirai 'You will come when I tell you to', but Vous viendrez le jour où je vous le dirai 'You will come on the day that I tell you', lit. 'You will come on the day where I tell you'.

$\$ 27$ This permutation of categories presupposes that they are sensed as having a certain degree of abstraction. It is therefore natural that the permutation is hardly present in the languages that tend to be concrete, as for example in German and Russian, which are as reluctant to employ it as French is willing to use it: Ger. der Tag als Sie gekommen sind 'the day when you came' Fr. le jour où vous êtes venu, lit. 'the day where you came').

\section{Chapter 256. Causal clauses}

$\$ 1$ Just as we have acknowledged relational adverbs (cf. Chapter $37, \$ 52$ and below Chapter $255, \$ 1$ ), we will be led to discern various types of relational circumstantial clauses among circumstantial clauses in general.

\$2 We will discern between causal clauses that are transferred to a causal adverb, final clauses that are transferred to a goal adverb, and modal clauses that are transferred to a manner adverb.

$\$ 3$ In French, the most common translative that transfers an independent clause to a causal subordinate clause is parce que 'because': Si l'on me presse de dire pourquoi je l'aimais, je sens que cela ne se peut exprimer qu'en répondant «Parce que cétait lui, parce que c’était moi» 'If one presses me to say why I loved him, I think that the answer can be given only with the response "Because it was him, because it was me" ' (Montaigne).

$\$ 4$ It often occurs in French that a speaker seeking brevity is content to express the translative parce que without expressing the transferred clause. One guesses the weakly conclusive value of the causal clause, which is basically merely a disguised affirmation: Mais comment se fait-il que tout le monde dise que c'est toi qui l'as guéri?... - Parce que. Pour une raison que je t'expliquerai plus tard et qui d'ailleurs n'a pas d'intéret 'But how did he arrange it that everyone says that it is you who cured him?... - Because. For a reason that I will explain to you later and that is moreover not of interest' (Jean Martet, La partie de boules, IV, p. 103).

$\$ 5$ One sees that French does not proceed directly to simple transfer (I >> E) (cf. Chapter $254, \S 5)$, but rather it reaches to triple transfer $(\mathrm{I}>>\mathrm{A}>\mathrm{O}>\mathrm{E})$, since it uses the translative parce que, lit. 'by that that' (cf. Chapter 270, \$10). The same obtains in Russian, where the translative is potomy čto (cf. Chapter 254, \$17).

$\$ 6$ In Greek the translative of second-degree transfer is not expressed, since the conjunction has the form dió(per). One observes the same thing in colloquial Russian: Ja ego ljublju potomu on čestnyj čelovek 'I love him because he is an honest man'. 
\$7 The same situation obtains in English, where the antecedent is even a different noun (cf. Chapter $254, \S 17$ ) to which the preposition that serves as the primary translative is agglutinated. The result is the translative because, a single word: He could not come, because he was ill.

$\$ 8$ In Italian, the secondary translative che 'that' is expressed, but the antecedent is not, so that it is directly preceded by the primary translative per 'for'. The two together are then written as the one word perché: Ti parlo così, perché ti voglio bene 'I speak with you like this because I care about you'.

$\$ 9$ It is probably due to Italian that one uses the translative pourquoi in regional French of the Midi, which in correct French gives the causal subordinate the appearance of the nuclear interrogative pourquoi 'why'. It is, however, intended to be the response to this interrogative: Je me repose, pourquoi je suis fatigue 'I am resting because I am tired'.

$\$ 10$ The same expression is heard in German from people who speak Yiddish; they employ the interrogative warum 'why' as a translative when they say Ich ruhe aus, warum ich bin müde 'I am resting because I am tired'.

\$11 Finally, it frequently occurs in Italian that the secondary translative che 'that' is expressed alone: Sbrigati, che ho fretta 'Hurry up because I'm in a hurry'.

$\$ 12$ The influence of Italian is probably responsible for this in regional French of the Midi. ${ }^{304}$ The proper causal translative is reduced down to its proper translative element, so that the transferred antecedent parce is not expressed. One commonly hears sentences in the Midi of France such as Ne vous penchez pas, qu'il y a des voitures 'Don't lean forward because there are cars', lit. '...that there are cars'.

$\$ 13$ In contrast, many languages use simple transfer with a unique translative to express causal clauses:

\begin{tabular}{|c|c|c|}
\hline Latin & quod or quia & $\begin{array}{l}\text { Laudaris, quod bonus es. } \\
\text { 'You are praised because you are good.' } \\
\text { Ego primam tollo, quia nominor leo. } \\
\text { 'I'm taking the first, because I call myself lion.' }\end{array}$ \\
\hline German & weil & $\begin{array}{l}\text { Ich kann dich nicht begleiten, weil ich hier bleiben muss. } \\
\text { 'I cannot accompany you because I must stay here.' }\end{array}$ \\
\hline Hungarian & mert & $\begin{array}{l}\text { Nem utazhatom el, mert beteg vagyok. } \\
\text { 'I cannot depart because I am sick. }\end{array}$ \\
\hline
\end{tabular}

\$14 In French - but this time in proper French - the causal translative parce que is reduced to a translative that is, properly stated, just que when it comes after a negative sentence

304. First editors' note: It is certainly the substratum of Occitan that leads speakers from the South of France to such syntactic expressions. The translative que 'that' commonly has causal value in Occitan: Es anat se passejâ que fasiè beu 'He has gone for a walk because the weather was nice'. The same is true of pourquoi in $\$ 9$, which translates perchè 'because'. 
word: J'évite cet homme, non que je le craigne, mais... 'I avoid that man, not that (because) I fear him, but....

\$15 The causal translative is also reduced to the conjunction que when there is disjuncive junction expressed by the junctive soit:

Un jour, soit que les tremblements de terre... eussent rompu la digue en un endroit, soit qu'une veine de rocher plus molle que les autres ê̂t donné passage au courant, toute la masse liquide s'était jetée hors de son lit
'One day either because the earthquakes... had broken the wall in one spot, or because a vein of rock softer than the others had given passage to the stream, the entire liquid mass had been ejected out of its bed'

(E. About, Le roi des Montagnes, IV)

$\$ 16$ In all the preceding examples, only the form of the translative for the causal clause varies, while the nature of the causal circumstant remains the same.

$\$ 17$ We are going to now see some types of causal subordinate clauses that present a variety of meanings in comparison to the typical causal clause that we have examined above and that therefore are semantic variants of it.

$\$ 18$ Whereas a purely causal circumstantial clause puts emphasis on the circumstance of the cause that explains the process expressed by the governing clause, a consecutive causal clause gives the impression at the same time that this causal circumstance entails this process as a consequence and that this circumstance is therefore expected. For this reason, the consecutive causal clause tends to precede its governing clause.

$\$ 19$ In French, the translative of a causal consecutive clause is comme 'as': Comme je m'ennuyais, je suis sorti 'As I was bored, I left'. French also appeals to fixed conjunctive expressions to express the causal consecutive clause, for instance vu que 'seeing that', lit. 'seen that', attendu que 'considering that', lit. 'expected that', étant donné que '(being) given that':

\section{J'eus un maître autrefois que je regrette fort 'I once had a teacher who I miss strongly Et que je ne sers plus, attendu qu'il est mort. And who I no longer serve, considering that he has died.'}

(Destouches)

\$20 In Latin the translative of a causal consecutive clause is the conjunction cum accompanied by the subjunctive: Cum id cupias, proficiscar 'As you desire it, I will depart'.

\$21 The translative of the causal consecutive clause is preposed in a number of languages:

\begin{tabular}{lll}
\hline Greek & hōs & $\begin{array}{l}\text { Hōs boúlei ápeimi. } \\
\text { 'As you desire it, I will leave.' }\end{array}$ \\
German & $d a$ & $\begin{array}{l}\text { Da du es wünschest, werde ich fortgehen. } \\
\text { 'As you desire it, I will leave.' }\end{array}$ \\
\hline
\end{tabular}




\begin{tabular}{lll}
\hline Hungarian & mivel & $\begin{array}{l}\text { Mivel engedetlen voltál, megbüntettelek. } \\
\text { 'As you were disobeying, I punished you' }\end{array}$ \\
Chinese & $y \bar{n}$ wei & $\begin{array}{l}\text { yìn wei jià lì dōng xī meí sòng } \\
\text { 'as the head of the family had not yet sent } \\
\text { his party gift' }\end{array}$ \\
\hline
\end{tabular}

\$22 Finally, in the coercive causal clause, the cause is not only given as leading to the result expressed by the governing clause, but the governing clause is understood as being the unavoidable consequence of the coercive causal clause:

\begin{tabular}{lll}
\hline French & puisque & $\begin{array}{l}\text { Puisque tu le desires, je partirai. } \\
\text { 'Since you want me to, I will leave.' } \\
\text { Latin }\end{array}$ quoniam \\
& & $\begin{array}{l}\text { Quoniam id cupis, proficiscar. } \\
\text { 'Since you want me to, I will leave.' }\end{array}$ \\
\hline
\end{tabular}

The Latin translative quoniam 'since' clearly expresses what one wants to say, since it arises etymologically from agglutination of the two words cum 'as' and iam 'already', the first word of which is the causal consecutive translative and the second word of which expresses the logical rigor that differentiates the coercive meaning from the causal consecutive meaning.

\section{Chapter 257. Conditional sentences}

\$1 If the cause expressed in a causal clause is given as a condition without which the process expressed by the governor will not be realized, the subordinate is said to be conditional.

$\$ 2$ In the sentence Alfred ira se promener parce qu'il fait beau 'Alfred is going for a walk because the weather is nice', the subordinate clause says only that the nice weather is the cause of the walk. The reality of this cause is not in question, which means the subordinate is simply causal.

$\$ 3$ In the sentence Albert ira se promener s'il fait beau 'Alfred will go for a walk if the weather is nice', in contrast, while it is true that the cause of the walk is also the nice weather, the reality of this cause is put in question. Alfred does not know whether it will come to pass, whether the weather will be nice or not. In the affirmative, he will go for a walk, but he will not in the negative. The cause that explains the walk is hence a condition and the subordinate is conditional.

$\$ 4$ Joseph Wilbois has unified these two notions, cause and condition, in the following analysis:

"The causal word bears two different ideas, a proper cause and a simple condition. The proper cause is the one that contains the totality of the effect: hence the collision is what breaks the glass, the cold is the cause that freezes water, etc. The condition is merely the impetus that unleashes the true cause: a piano is the precondition for 
listening to the pianist and war is the precondition for the emergence of a general, whereas neither the piano nor the war was the cause of the artist's talent or of the superior's attention. To produce the effect, the cause is sufficient, whereas the condition is merely necessary." 305

$\$ 5$ According to Wilbois, the cause is hence something more than the condition. He expreses the point as a logician. In grammar, matters are much different. The simplest grammatical concept is that of cause, and due to this concept, one can conceive of the concept of condition. In comparison to the mere cause, a condition is a restriction, that is, it is a complication because it contains an additional notion. The same is found in mathematics, where $12-6$ is a smaller but more complex numeral notion than 12 .

$\$ 6$ Therefore in most languages, the conditional sentence in general is a matter of greater complexity and uses more complex means of expression than the mere causal clause.

$\$ 7$ The notion of conditional clause is hence essentially a syntactic concept, since the conceived content determines the choice of the means of expression, that is, the morphological markers that express the content.

$\$ 8$ The conditional is hence not a morphological notion, and it is due to an unfortunate abuse - the fallacious notion that mood is involved - that one employs the term to designate a group of two temporal paradigms in French.

\$9 These temporal paradigms, which are grouped together incorrectly under the banner of conditional mood, are in reality a posterior past (past future) and an anterior posterior past (future anterior past) of the indicative mood: Alfred pensait qu'il ferait beau 'Alfred thought that it would be nice', Alfred pensait qu'il aurait fait beau 'Alfred thought that would have been nice'.

$\$ 10$ These paradigms of the indicative sometimes (but not always) serve to mark the governing clause of a hypothetical conditional clause (cf. Chapter 259). But in principle, they never serve to express a proper conditional clause.

$\$ 11$ One cannot emphasize enough that there is no conditional mood in French and how much difficulty the false notion of this alleged mood has caused for the sound grammatical conception of French. Moreover, the limits of use of this form do not agree with the expression of a condition, since it only exceptionally expresses a condition and is commonly used rather to express something quite different.

$\$ 12$ The notion of conditional mood is particularly pernicious for foreigners (cf. Chapter $259, \$ 13$ ) because it blocks them completely from recognizing the real structure of the temporal system in French and the fine architecture of this system. ${ }^{306}$

305. Wilbois, Devoir et durée 'Duty and duration', Paris, Alcan 1912.

306. Cf. Lucien Tesnière, L'emploi des temps en français, Bulletin de la Faculté des Lettres de Strasbourg, Strasbourg, 1927, special issue, pp. 39ff. 
\$13 The abusive use of the term conditional in morphology is merely one example among a hundred others of this pilfered and nefarious terminology by which morphology has slowly produced a nomenclature that deprives syntax of the terminology that legitimately belongs to syntax and that enriches morphology to the detriment of syntax (cf. Chapter 15, $\$ 11$; Chapter 51, \$10, note 75; Chapter 97, \$4, note 134).

$\$ 14$ But while French does not have the conditional mood (a morphological notion), this fact does not mean that it does not have conditional sentences (a syntactic notion)

\$15 We say "conditional sentence" and not "conditional clause" because one is not dealing with a clause, but rather with a sentence that is constituted of clauses that are at least two in number. One of these clauses alone expresses the condition, whereas the other is content to be subjected to the first.

$\$ 16$ Yet most grammarians are content to describe the particularities of the conditional sentence without taking the precaution to make it clear which of the two clauses they are designating.

$\$ 17$ The erroneous ambiguity makes it difficult to follow the majority of exposés on the grammar of conditional sentences. Hence foreigners generally do not find clarity in the French grammars they have in there hands, this clarity being so necessary for shedding light on such a delicate area.

$\$ 18$ Take for example the sentence S'il faisait beau, jirais me promener 'If the weather was nice, I would go for a walk. How can learners know that it is the first clause (in the indicative) that expresses the condition if the grammars do not produce a precise description of the clauses, while the second clause, which does not express a condition, contains the so-called conditional mood.

$\$ 19$ It is hence appropriate to carefully designate the two clauses that the conditional sentence contains. It is advantageous to reach to the two terms used by classical rhetoric for the study of periods in general: protasis and apodosis (cf. Chapter 274, \$6ff.).

$\$ 20$ In the example cited above, s'il faisait beau 'if the weather was nice' is the protasis and j'irais me promener 'I would go for a walk' is the apodosis.

$\$ 21$ The subordinate clause constitutes the protasis, whereas the governing clause constitutes the apodosis.

\$22 With this terminology established, it is easy to make it clear that the condition is expressed by the protasis (the subordinate clause), whereas the apodosis (the governing clause) contains the mood that is incorrectly called conditional, incorrect because it does not actually express any condition.

\$23 We will also call the first of the clauses (the protasis, the subordinate clause) the conditioning clause, because it presents the condition, and the second (the apodosis, the governing clause) the conditioned clause, because it supports the condition. Concering the generic term conditional, which has the defect of failing to make it precise whether the 
condition is super- or subordinate, we will reserve it for sentences or periods constituting the entirety of the conditioning and the conditioned clauses.

\$24 With this essential point of terminology now established, it becomes possible for us to examine the markers of each of the clauses. We now have some ability to express our observations in a comprehensible way.

\section{Chapter 258. The conditioning clause}

$\$ 1$ The conditioning clause is a circumstantial subordinate; the circumstance is a condition. In the sentence S'il fait beau, j'irai me promener 'If the weather is nice, I will go for a walk', the clause s'il fait beau is a conditioning clause.

$\$ 2$ The conditioning clause is usually a complete clause, but it can also be represented by a sentence word: si oui, sinon 'if yes, if no (if not)'. Hence the sentence word is transferred to an adverb of condition and the symbol of transfer is the following: $\mathcal{I}$ (cf. Chapter $45, \S 19$ ) >> E.

$\$ 3$ The subordinate conditioning clause is usually a protasis, the apodosis of which is a conditioned clause: S'il fait beau (protasis), j'irai me promener (apodosis) 'If the weather is nice, I will go or a walk'.

$\$ 4$ The verb of the conditioning clause clause is usually in the indicative mood.

$\$ 5$ Concerning the possible tense and secution of this verb, the two are only limited by the meaning, which demands that, due to the condition that they express, the protasis cannot be ordered in time after the apodosis, since the condition by definition cannot occur after the consequence that it entails.

$\$ 6$ Hence if the condition is in the future, nothing prevents the conditioning clause from being in the present: Si vous êtes d'accord (present), j'irai vous voir demain (future) 'If you agree, I will come see you tomorrow'

$\$ 7$ Nothing prevents the conditioning clause and the conditioned clause from being in the same grammatical tense, provided that this tense allows for a chronological subdivision that orders conditioning time before conditioned time. Fr. S'il fait beau cet après midi (future meaning), j'irai me promener (future, posterior to the precedent future) 'If the weather is nice this afternoon, I will go for a walk'; Si vous connaissez la question (present), vous devez comprendre combien elle est délicate (present, posterior to the precedent present) 'If you know the question, you have to understand how delicate it is'.

$\$ 8$ But it is evident that in a sentence such as S'il fait beau demain, je vais me promener aujourd'hui 'If the weather is nice tomorrow, I am going to go for a walk today', the tense of the conditioning clause clause (future meaning) is posterior to that of the conditioned clause (present tense) is impossible, because the idea that it expresses is illogical, absurd, and partially inconceivable. 
$\$ 9$ What is true of tense applies more strongly to secution, which means that the time of the conditioning clause must not be posterior to the time of the conditioned clause.

\$10 It is therefore possible to say Si vous avez lu cette lettre (anterior present), vous savez de quoi il est question (present) 'If you have read this letter, you know what it is about' or even Si vous avez visité Paris (anterior present), vous avez certainement vu la Tour Eiffel (also anterior present, but posterior to the precedent) 'If you have visited Paris, you certainly have seen the Eiffel Tower.

\$11 In contrast, it is impossible to say Si vous êtes d'accord (present), vous êtes venu me voir hier (anterior present) 'If you agree, you have come to see me yesterday', which would be absurd and contrary to common sense.

\$12 When the expressed process occurs in the future in French, it is expressed by the verbal form of the present: S'il fait beau cet après-midi, jirai me promener 'If the weather is nice this afternoon, I will go for a walk.

$\$ 13$ The same holds in English and German: Eng. If the weather is nice this afternoon, I shall have a walk, Ger. Wenn das Wetter heute nachmittag schön ist, werde ich spazieren gehen (same meaning).

$\$ 14$ The temporal form of the future does not generally appear in the conditioned clause. One sometimes has to allow for an exception to this rule, however, an exception that occurs very rarely. This exception appears when the marker $s i$ 'if' does not mark a condition which is by definition uncertain, but rather it signifies 'if it it is true that' or 'if it occurs that' and thus expresses a reality: Ne vous étonnez pas, dit-il, si pendant le souper Trüchen quittera souvent la table 'Do not be surprised, he said, if during dinner Trüchen will leave the table often' (A. Dumas, Le Vicomte de Bragelonne, p. 2762, La campagne de Planchet).

Le Reich est ainsi entré dans le jeu... Si la situation international n'en sera pas améliorée, on peut du moins espérer que la solidarité franco-britannique... s'en trouvera finalement raffermie

\author{
'The Reich has thus entered into \\ the equation...If the international \\ situation will not be ameliorated, one can \\ at least hope that Franco-British \\ solidarity...will finally be reaffirmed'
}

(Dernières Nouvelles de Strasbourg, 12-I-1936).

$\$ 15$ Outside of French and the Germanic languages, most languages allow the future to appear in the conditioning clause: Lat. Id persequar, si potero 'I will do it, if I can', lit. '... if I will be able' (Cicero, De re publica), It. Se farà bello, uscirò 'If it will be nice, I will go out', Rus. Esli u vas vremja budet, to pridite zavtra ko mne 'If you will have the time, come see me tomorrow'

$\$ 16$ In most European languages, the marker of the conditioning clause is a preposed translative: 


\begin{tabular}{|c|c|c|}
\hline French & $s i$ & $\begin{array}{l}\text { Si vous êtes d'accord, nous pouvons } \\
\text { aller nous promener. } \\
\text { 'If you agree, we can go for a walk.' }\end{array}$ \\
\hline Italian & se & $\begin{array}{l}\text { Se non è vero, è bene trovato. } \\
\text { 'If it is not true, it is well found.' }\end{array}$ \\
\hline Latin & $s i$ & $\begin{array}{l}\text { Si vis pacem, para bellum. } \\
\text { 'If you want peace, prepare for war.' }\end{array}$ \\
\hline Greek & $e i$ & $\begin{array}{l}\text { Ei tò déon práxeis díkaia akoúsei } \\
\text { 'If you do what you must, you will be called just.' }\end{array}$ \\
\hline English & if & If you don't care to go, we can stay. \\
\hline German & wenn & $\begin{array}{l}\text { Wenn Sie wollen, können wir spazieren gehen. } \\
\text { 'If you want, we can go for a walk.' }\end{array}$ \\
\hline Russian & esli & $\begin{array}{l}\text { Esli èta kniga vam nravitsja, to možete eë čitat'. } \\
\text { 'If you like this book, you can read it.' }\end{array}$ \\
\hline
\end{tabular}

$\$ 17$ But in languages with postpositions such as Turkish, the marker of the conditioning clause is a postposed translative, for example -sa in Turkish: On ikiden dört çıkarsa kaç kalir? 'If one takes away four of twelve, how many remain?'

$\$ 18$ In certain languages, the transfer of the independent clause to a subordinate conditioning clause can be marked by the position of the first actant; it appears after the verb: Ger. Soll ich mit dir das Zimmer teilen, Pudel, so lass das Heulen 'Am I to share the room with you, poodle, stop howling' (Goethe, Faust, I, 3rd part)

$\$ 19$ The same construction is not unknown in French:

Avait-il envie de dormir dans le jour, il se secouait pour se réveiller, afin de mieux dormir la nuit suivante. Avait-il peur, il chantait pour donner peur à ceux qui la lui avaient donnée. Avait-il envie de s'amuser, il retardait jusqu'à ce qu'il eût fini son travail...
Had he wanted to sleep in the day, he would have made an effort to get up, in order to sleep better the next night. Had he been afraid, he would have sung to frighten those who had caused him fear. Had he wanted to amuse himself, he would have waited until his work was finished...

(George Sand, Gribouille, p. 4)

\$20 One is evidently dealing with what was originally an interrogative marker. This marker has become a marker of transfer indicating a subordinate conditioning clause. A similar evolution certainly caused the verb est' 'be' in Russian followed by the interrogative marker $l i$ (cf. Chapter $84, \$ 12$ ) to become the translative for a subordinate conditioning clause: est' li > esli 'if' (cf. \$16).

\$21 When two conditioning clauses in French, the translative of which is $s i$, are conjoined, simple transfer I $>$ E, which si marks, is syntactically decomposed to a double transfer I $>>\mathrm{O}>\mathrm{E}$, for which only the second component (the first on the spoken chain) que (marking the transfer $\mathrm{I}>>\mathrm{O}$ ) has to be repeated in the joined clause, where it in addition evokes 
the subjunctive mood on the verb (cf Chapter 241, \$16): S'il fait beau et que vous ayez le temps, nous pouvons aller nous promener 'If the weather is nice and (that) you have the time, we can go for a walk'.

\$22 In the languages where transfer to a conditioning clause clause can be marked by the position of the first actant after the verb, this construction does not need to be repeated in the second of the two conjoined conditioning clauses: Old Swedish Farr annoer broper köpforpum ok annar hemo $i$ asku sitor, baper aghu per iammykit af arvi 'If one of the brothers goes on a voyage as a merchant and the other remains at home (lit. in the cinders), they will both receive equal parts of the inheritance. ${ }^{307}$

\$23 Finally, the conditioning clause can also lack a marker. Its syntactic relationship to the conditioned clause results then from simple parataxis: Lat. Negat quis, nego: ait, aic 'If someone says no, I say no, if someone says yes, I say yes' (Terence, Eunuchus, 251), Rus. Zaxočeš', pojdu 'If you want, I will come' (cf. Chapter 133, \$23).

$\$ 24$ One can get close to such expressions in French: Point d'argent, point de Suisse, et ma porte était close 'No money, no Switzerland, and my door was closed' (Racine, Plaideurs, I, 1).

$\$ 25$ In Russian, above all in colloquial Russian where transfer may or may not be marked, the verb of the conditioning clause and that of the conditioned clause can both appear as infintives: esli emu verit', to my vse duraki 'If we believe him, we are both idiots', lit. 'If to believe him,..., Volka bojat' cja, v les ne xodit' 'When one fears the wolf, one should not go into the forest', lit. 'Have fear of the wolf, not go into the forest'.

\$26 In a number of languages, the conditioning clause is usually summed up in front of the conditioned clause (cf. Chapter 240, \$2): Ger. so: Wenn Sie wollen, so können wir spazieren gehen 'If you want, (then) we can go for a walk', Rus. to: Esli èta kniga vam nravitsja, to mošete eë citat' 'If you like this book, then you can read it'.

\$27 These nuances of the condition are extremely diverse. The result of this diversity is that there are numerous types of conditioning clauses.

$\$ 28$ We will call those conditioning clauses restricted that limit the condition in some way. In a number of languages, this restriction is marked by the adjunction of a restrictive adverb to the translative of the conditioning clause, Fr. si seulement 'if only', Ger. wenn nur 'if only', Fr. J'irai vous voir, si seulement il fait beau 'I will come see you, if only it is nice' One sometimes employs a different translative, Eng. provided that, Fr. pourvu que: J'irai vous voir, pourvu qu'il fasse beau 'I will come see you provided that the weather is nice',

307. Cf. A. Sommerfelt, C. R. de Akerlund, Fornnordiska ordføljdstudier, Lund, 1935, in Le Bulletin de la Société de Linguistique de Paris, 36, 1935, fasc. 3, p. 86. 
Petit poisson deviendra grand

Pourvu que Dieu lui prête vie
'Small fish will become big

Provided that God grants it life'

(La Fontaine, Fables, V, 3, Le petit poisson et le pêcheur)

Lat. dum: Oderint dum metuant 'They will hate, provided that they fear' (cited by Cicero, De Officiis, 1, 28).

$\$ 29$ We will call those restricted conditioning clauses minimum clauses if they have been reduced down to a minimum. In French, the translative expression in this case is pour peu que: J'irai vous voir, pour peu qu'il fasse beau 'I will come see you, as long as the weather is nice.

\$30 We will call those clauses restrictive conditioning clauses that expressly limit the cases where the condition is called on to condition the conditioned clause. In many languages, this restriction is marked, like it is for the restricted conditioning clause (cf. \$28), by the adjunction of a restrictive adverb to the translative of the conditioning clause. But this adverb is commonly placed, in relation to the restrictive translative, in the reverse order of the restricted conditioning clause. Instead of Fr. si seulement 'if only' and Ger. wenn nur 'if only', the translative expression is hence Fr. seulement si 'only if' and Ger. nur wenn 'only if': Fr. J'irai vous voir seulement s'il fait beau 'I will come see you only if the weather is nice'.

$\$ 31$ We will call those clauses amplifying conditioning clauses that broaden the cases where the condition is applicable. These clauses hence constitute the opposite of restrictive conditioning clauses (cf. Chapter 30). Similarly, the translative expression that marks these clauses is constituted by the adjunction not of a non-restrictive adverb, but of a magnifying adverb to the translative of the conditioning clause: même si 'even if' instead of seulement si 'only if'. In French one can also call on the translative expression quitte $\grave{a}$, which is constructed with the infinitive: Tente la chance, quitte à échouer! 'Take a chance, even if it means failing!'.

\section{Chapter 259. Hypothetical sentences}

\$1 Just like the conditional sentence is a particular case of the causal clause, the hypothetical sentence is a particular case of the conditional sentence.

$\$ 2$ A sentence is hypothetical when the condition expressed in the protasis is itself the expression of a hypothesis.

$\$ 3$ In a hypothetical sentence, the conditioning clause (protasis) expresses a supposition and the conditioned clause (apodosis) expresses the conjecture that one bases on this supposition. 
$\$ 4$ Hence we will call the protasis the suppositional clause and the apodosis the conjectural clause.

$\$ 5$ It is clear that the hypothetical conditioning clause (the suppositional clause) expresses a supposition, so clear that colloquial French gladly uses the conjunctive idiom une supposition que 'supposing that' instead of the conjunction si 'if' as translative of the suppositional clause: Une supposition que je sois riche, je ferais de beaux voyage 'Supposing I were rich, I would take a nice trip?

$\$ 6$ Grammarians continued distinguishing between two types of suppositional clauses according to whether the expressed supposition is realizable or not. If it is realizable, the supposition receives the name potential. If the supposition is contrary to actual reality, it receives the name irreal.

$\$ 7$ In certain languages, hypothetical sentences are marked by subjunctive mood, which stands in opposition to the indicative mood, which is encountered in simple conditional sentences. Hence in contrast to the indicative that appears in conditional sentences, e.g. Felix ero si amicum habebo 'I will be happy, if I have a friend', Latin employs the subjunctive in hypothetical sentences. Future: Felix sim, si amicum habeam 'I would be happy, if (later) I had a friend', present: Felix essem, si amicum haberem 'I would be happy, if (now) I had a friend', past: Felix fuissem, si amicum habuissem 'I would have been happy, had I had a friend'.

$\$ 8$ Latin can also mark the suppositional clause with the translative $u t$ and the subjunctive mood. The meaning of the suppositional clause cannot be irreal in such cases, which means it is always potential: Ut desint vires, tame nest laudanda voluntas 'Even if the ability is absent, the intention is nonetheless to be praised' (Ovid, Ex Ponto Epistulae, 3, 4, 79).

$\$ 9$ German also employs the subjunctive in place of the indicative of the conditional sentence to mark the hypothetical sentence, while the possible markers of the subordinate protasis remains the same (Chapter 258, \$16-18): Wenn Sie wollten, könnten wir spazieren gehen 'If you wanted, we could go for a walk'.

\$10 In hypothetical sentences, Greek marks the potential with the optative mood and the irreal with the indicative mood, the suppositional clause being otherwise marked by a preposed translative and the conjectural clause by the translative án: Ei élthois, khairoimi án 'If you were to come, I would be happy', Ei ohi ánthropoi agathoi êsan, èudaimónoun án 'If the men were good, they would be happy'.

$\$ 11$ In a number of languages, one employs the past form of the verb as a marker, not for marking past meaning, but rather for marking the hypothetical meaning of the conditional sentence. The matter is particularly striking in French, where the verb has future meaning when it is in a present tense form in the conditioning clause and in an imperfect present past form in the supposition clause, whereas it is in the future in the conditioned clause and the past future (improperly called conditional, cf. Chapter 257, \$8ff.) in the conjectural clause: S'il fait beau, j'irai me promener (conditional sentence) 'If the weather 
is nice, I will go for a walk', S'il faisait beau, j'irais me promener (hypothetical sentence) 'If the weather was nice, I would go for a walk', cf. also

Si Peau d'âne m'était conté J'y prendrais un plaisir extrême.
'If Donkeyskin had been told to me

I would have been extremely pleased.'

(La Fontaine, Fables, VIII, 4, Le pouvoir des fables)

$\$ 12$ It often suffices in French to express the suppositional clause alone, the conjectural clause that it calls being foreseen: Si j'étais roi 'If I was king', Si jeunesse savait, si vieillesse pouvait 'If youth knew, if age could' (proverb).

$\$ 13$ This use of the past future (conditional) in the suppositional clause already marked by the translative $s i$ is a misspeak denoting a coarse way of speaking: Fr. ${ }^{\star}$ Si ce serait facile, ce serait déjà fait 'If it would be easy, it would have already been done', instead of the correct sentence Si c'était facile, ce serait déjà fait 'If it was easy, it would have already been done'.

This misspeak is one that very often betrays non-native speakers of French. It has been picked out by A. Daudet: Si j'aurais des actionnaires, si je réunirais des fonds 'If I would have the shareholders, if I would have the funds', attributed to M. de Sieboldt, Bavarian scholar (Contes du Lundi, The blind emperor, I), Si joserais demander à Mossié de vouloir bien signer son nom 'If I would ask Mister to be so kind to sign his name', said by the Swiss woman who is the maid in the hotel Rigi-Kulm (Tartarin sur les Alpes, I).

$\$ 14$ This is not to say that the past future cannot follow the tranlative si in French. But in such a case, the conjectural clause marked by the present past is independent of the conditioning clause marked by the translative si. This type of sentence is quite rare in French, where it lacks elegance: Si, faute de vent, le Repton aurait eu grand'peine à rejoinder le SaintEnoch, il pouvait envoyer ses embarcations 'If, for lack of wind, the Repton would have had difficulty reaching the Saint-Enoch, he could have sent skiffs' (J. Verne, Le Serpent de mer, XI, p. 185).

\$15 As a marker of hypothetical meaning in the sentence, English, like French, uses the past form of the verb. Instead of the auxiliary of the future (shall, will), it employs the past of this auxiliary (should, would), which results in a past future: We should be happy, if you came; Should I swing for it...

$\$ 16$ The same holds in German, where the hypothetical is marked by a past subjunctive form: Wenn er käme, wäre ich froh 'If he came, I would be content', Sollte uns der Feind angreifen... 'If the enemy were to attack us.... Instead of the auxiliary of the future (ich werde 'I will'), one employs the past subjunctive of this form (ich würde 'I would') in the suppositional clause: Wenn das Wetter schön wäre, würde ich spazieren gehen 'If the weather were nice, I would go for a walk'

$\$ 17$ The same is true in Russian. The verb of the hypothetical (supposition or conjecture) is always in the preterit and accompanied by the particle by: Esli by y menja bylo vremja, to ja by prišël $k$ vam 'If I had the time, then I would come see you'. 
\$18 In languages where the past form of the verb serves as the marker of hypothetical meaning (cf. above $\$ 11$ ), one obviously cannot use the past form of the verb as a marker of past time. Past time in such cases has been deprived of its natural marker. One uses a marker of secution in such cases instead of an unavailable tense form. One employs anterior secution in place of past tense, which expresses past time in conditional and hypothetical sentences: Fr. S'il avait fait beau, j'aurais été me promener 'If it had been nice, I would have gone for a walk' (cf. above $\$ 11$ ). The same is true of the very vulgar misspeak in the example above (cf. \$13), which is charged with familiar humor: ${ }^{\star}$ Si j aurais su que tu aurais venu, je m'aurais en allé 'If I would have known that you would have arrived, I would have left', instead of the correct sentence Si j'avais su que tu serais venu, je m'en serais allé 'If I had known that you had arrived, I would have left'.

$\$ 19$ In Latin, time in the hypothetical clause is marked both by secution and tense. If the hypothetical clause is in the future, one puts the verb in the future of the infectum: Felix sim, si amicum habeam 'I would be happy, if (later) I had a friend'. If it is in the present, one puts the verb in the past of the infectum (imperfect): Felix essem, si amicum haberem 'I would be happy (now), if I had a friend'. Finally if it is in the past, one puts the verb in the past of the perfectum (pluperfect): Felix fuissem, si amicum habuissem 'I would have been happy, if I had had a friend'.

\$20 In Russian, it is not possible to mark a difference in tense in the hypothetical clause, and the sentence Esli by u menja bylo vremja, to ja by prišel $k$ vam (cf. \$17) can mean 'If I had had the time, I would have come to see you' (past) as well as 'If I had the time, I would come see you' (present and future).

$\$ 21$ In certain languages, the conjectural clause is marked by a special translative that distinguishes it from the conditioned clause.

$\$ 22$ In Greek this marker is án: Ei élthois, khaíroimi án 'If you come, I would be happy' (potential), Ei êlthes, ekhárēn án 'If you had come, I would have been happy'.

$\$ 23$ In Russian, the marker is $b y$, which obligatorily appears not only in the conjectural clause, but also in the suppositional clause: Esli by u menja bylo vremja, to ja by prišël k vam 'If I had the time, I would come see you' (cf. \$17 and 20).

$\$ 24$ It can happen that the suppositional clause is not marked and its hypothetical meaning is a result of the context alone: Fr. Un degré de plus, il aurait été exorciste et investi du pouvoir de chasser les démons! 'One more degree, he would have been an exorcist and invested with the ability to chase away demons' (E. About, Le Roi des Montagnes, IV).

\$25 The hypothetical clause can combine with the comparative when the notion that serves as the point of comparison is itself the expression of a hypothesis. One is dealing with a hypothetical comparative clause.

\$26 The translative of the hypothetical comparative clause is comme si 'as if' in French: Alfred hurle comme si on l'égorgeait 'Alfred bellowed as if someone had cut his throat'. 
\$27 Latin has numerous translatives for the hypothetical comparative clause: quasi, tamquam, velut: Timent eum, quasi crudelis sit 'They fear him as if he were cruel'.

\$28 In Russian, the hypothetical comparative is marked by the translative expression kak budto by, which often experiences the reduction of one of its three elements (kak budto, budto by, kak by) or even of two (bydto): On smeëtsja, kak bydto ne ponimaet 'He laughs as though he does not understand'.

\section{Chapter 260. Concessive clauses}

$\$ 1$ While a causal clause expresses a cause that evokes the effect expressed by the governing clause, a concessive clause expresses a cause that might evoke a contrary effect.

\begin{tabular}{ll}
\hline $\begin{array}{l}\text { Causal } \\
\text { clause }\end{array}$ & $\begin{array}{l}\text { Aflred est généreux, parce qu'il est riche. } \\
\text { 'Alfred is generous because he is rich.' }\end{array}$ \\
$\begin{array}{l}\text { Concessive } \\
\text { clause }\end{array}$ & $\begin{array}{l}\text { Alfred est généreux, bien qu'il soit pauvre. } \\
\text { 'Alfred is generous, even though he is poor.' }\end{array}$ \\
\hline
\end{tabular}

\$2 From this point of view, a concessive clause can be considered the opposite of a causal clause.

$\$ 3$ This is why in the logical group formed by a causal clause and the governing clause which it evokes, it suffices to change the meaning of one of the clauses (and only of one of them) in order to transform causal meaning into concessive meaning. This change occurs in addition to the change of translative, of course.

$\$ 4$ Take the sentence Aflred est généreux, parce qu'il est riche 'Alfred is generous because he is rich' as an example. In addition to changing the translative, it suffices to put one of the two clauses in the negative in order to transform the second clause from causal meaning to concessive meaning.

\begin{tabular}{|c|c|}
\hline \multirow{2}{*}{$\begin{array}{l}\text { Concessive meaning } \\
\text { resulting from } \\
\text { semantic reversal } \\
\text { of the governing clause }\end{array}$} & $\begin{array}{l}\text { Alfred n'est pas généreux, bien qu'il soit riche } \\
\text { 'Alfred is not generous even though he is rich' }\end{array}$ \\
\hline & $\begin{array}{l}\text { Alfred est mesquin, bien qu'il soit riche } \\
\text { 'Alfred is stingy even though he is rich' }\end{array}$ \\
\hline $\begin{array}{l}\text { Concessive meaning } \\
\text { resulting from }\end{array}$ & $\begin{array}{l}\text { Aflred est généreux, bien qu'il ne soit pas riche } \\
\text { 'Alfred is generous, although he is not rich' }\end{array}$ \\
\hline $\begin{array}{l}\text { semantic reversal } \\
\text { of the causal subordinate clause }\end{array}$ & $\begin{array}{l}\text { Alfred est généreux, bien qu'il soit pauvre } \\
\text { 'Alfred is generous, although he is poor' }\end{array}$ \\
\hline
\end{tabular}

$\$ 5$ But of course if one adds negation to both of the clauses, the semantic relationship between the two remains causal: Il n'est pas généreux, parce qu'il n'est pas riche 'He is not 
generous because he is not rich' or Il est mesquin parce qu'il est pauvre 'He is stingy because he is poor'.

\$6 The usual translative of a concessive clause is quoique or bien que 'although' in French: Alfred est généreux, quoiqu'il soit pauvre or bien qu'il soit pauvre 'Alfred is generous, although he is poor'.

$\$ 7$ Whereas the causal clause appears in the indicative in French, the concessive clause appears in the subjunctive, probably because the two express opposite meanings.

$\$ 8$ One also frequently encounters the translative $s i$ 'if' in French as the translative of a subordinate concessive clause meaning 'if it is true that'. But in such a case, the concessive clause appears in the indicative: Je me résolus d'aller si lentement, et d'user de tant de circonspection en toutes choses, que, si je n'avançais que fort peu, je me garderais, au moins, de tomber 'I decided to go so slow and to use so much circumspection in all matters that, although I advanced only slowly, I would guard myself, at least, against falling' (Descartes, Discours de la Méthode, II).

\$9 The meaning of a concessive subordinate clause is also readily expressed in French by the idiom avoir beau, lit. 'have nice' (followed by the infinitive):

On avait beau heurter et m'ôter son chapeau,

On n'entrait pas chez nous sans graisser le marteau.
'Even if you knocked and took off your hat, You could not enter here without giving money (lit. greasing the hammer).'

(Racine, Les Plaideurs, I, 2)

$\$ 10$ In Latin, the translative is cum (and secondarily quamvis and licet) combined with the subjunctive, or quanquam, etsi, tametsi with the indicative: Cum sis callidus, amen deceptus es; quanquam es callidus, tamen deceptus es 'Although you are clever, you have been deceived'.

$\$ 11$ In the Germanic languages, concessive clauses are also marked by a preposed translative: Eng. Though Alfred is poor, he is very generous, Ger. Obschon Alfred arm ist, ist er donnoch sehr freigebig (same meaning).

$\$ 12$ In Russian, the translative of concessive clauses is xotja: Xotja on bednyj, on očen' $\check{s} c$ edryj 'Although he is poor, he is very generous. One should note that this translative, which is none other than the present participle of the Russian verb xotet' 'want', is related to Lat. quamvis. The genesis of this translative, which adds the notion of wanting in both Russian and Latin, probably arises from the same psychological process in both languages. $\$ 13$ One should also note the semantic similarity between the translative of concessive clauses and that of magnifying conditioning clauses même si 'even if' (cf. Chapter 258, \$31 and above \$8): Gr. kaíper, kaí ei, kaí ean, kán, Lat. etsi; Gr. ei kaí, eàn kaí, Ger. obschon, obgleich, Slovenian dasiravvno; all these translatives also have the meaning 'although'. 


\section{Chapter 261. Consecutive clauses}

$\$ 1$ While the causal clause expresses the cause that evokes the effect expressed by the governing clause, the consecutive clause expresses the consequence, that is, the effect produced by the cause expressed in the governing clause.

$\$ 2$ Like the concessive clause, but from a different point of view (cf. Chapter 260, \$2), the consecutive clause is hence the opposite of the causal clause, since the consequence is the opposite of the cause from a logical point of view.

$\$ 3$ The consecutive clause is hence a circumstantial clause expressing a consequence, that is, a clause that has been transferred to an adverb of consequence.

$\$ 4$ The translative of a consecutive clause is de sorte que 'so that' in French, with the almost synonymous variants de manière que, de façon que 'in such a way that', si bien que 'so much so that'. Clauses introduced by these translatives are all constructed with the indicative: $I l$ pleuvait à verse de telle sorte que nous fûmes obliges de nous mettre à l'abri 'It was pouring hard in such a way that we had to seek cover'.

\$5 In Latin, the translative of consecutive clauses is $u t$, which is introduced in the governing clause either by the manner adverb ita or, if one is dealing with a degree of quality, by the quantity adverb tam. In contrast to French, the consecutive clause in Latin always takes the subjunctive: Ita sunt territi, ut nemo resistere auderet 'They were so afraid, that nobody risked resistance, Tam sagax est hic homo, ut decipi non possit 'This man is so shrewd, that he cannot be fooled'.

$\$ 6$ The consecutive nuance is sometimes rendered by a mere relative pronoun (above Chapter $247, \S 3$ ). In addition to the junctive element (et, atque) that was revealed by the mechanism mentioned above (Chapter 247, $\$ 11$ and 12) and that permits one to decompose the relative pronoun qui into the elements $e t+i s$, it is necessary to substitute a true translative of attenuated value such as $u t$ (cf. above Chapter $247, \$ 8$ ) and to semantically decompose the relative pronoun qui into $u t+i s:$ Domus est, quae nulli mearum villarum cedat 'It is such a house that she does not cede it to any of my villas' (cf. also the example cited above in Chapter 251, \$19).

$\$ 7$ In Greek, the translative of the consecutive clause is hốste, which is often introduced in the governing clause by the manner adverb outōs. The consecutive clause sometimes appears with an infinitive and sometimes with the indicative: Oútōs eusebếs ên Sōkrátēs hốste oudèn áneu theôn gnốmes epoieí 'Socrates was so pious that he did nothing without the support of the Gods'.

$\$ 8$ In German, the translative of the consecutive clause is dass followed by the indicative and eventually preceded by the manner adverb so or a noun transferred to an adverb by the genitive der Art 'of the sort': Alfred war so müde, dass er nicht weiter gehen konnte 'Alfred war so tired that he could no longer walk' 
\$9 In Russian, the translative of a consecutive clause is čto followed by the indicative and sometimes preceded by the manner adverb tak: On mne ne pisal, tak čto ja ne znaju, kogda on pridët 'He did not write to me, so I do not know when he is coming.'

$\$ 10$ In sum, the expression of a consecutive clause is of the same sort in many languages of Europe. Only Latin is unusual because it uses the subjunctive mood when the other languages use the indicative.

\section{Chapter 262. Final clauses}

\$1 The final clause differs from the consecutive clause insofar as the consequence of the cause expressed in the governing clause is intentional and desired instead of accidental. ${ }^{308}$ $\$ 2$ The final clause, just like the consecutive clause, is hence the opposite of the causal clause. This is perhaps the reason why it appears in the subjunctive in French, whereas the causal clause appears in the indicative.

$\$ 3$ Since the intended and desired consequence is nothing other than a goal, a final clause is hence a clause transferred to a goal adverb. The circumstant that it expresses is the goal of the action expressed by the governing clause, that is, the intention of its first actant.

$\$ 4$ The most common translative of a final clause in French is afin que 'in order that': Vous réchauffez le serpent qui pique, afin qu'il pique plus sûrement 'You are warming the snake that bites, in order that he bites for sure' (Fléchier).

$\$ 5$ The transferred antecedent afin cannot be expressed if the governing clause contains volition marked by the use of the imperative. The translative is then reduced to its proper translative element que: Approchez, que je vous voie 'Approach (so) that I see you'; Ôte-toi de là, que je m'y mette 'Get out of there, (so) that I can sit down'.

$\$ 6$ The fixed antecedent in the translative of second degree afin is the noun fin. The term final stems from this noun.

$\$ 7$ One is of course dealing with the noun fin employed with the meaning 'aim, goal', as is still encountered in expressions like La fin justifie les moyens 'The end justifies the means', $\grave{a}$ ces fins 'to this end'.

$\$ 8$ But this meaning of the word fin is no longer its most common meaning in modern French, where the fin 'end' is sensed to be the opposite of 'commencement'. The word fin with the meaning 'aim, goal' is somewhat aged and is no longer employed except in elevated language.

308. Cf. F. Brunot, La pensée et le langage, p. 843. 
\$9 It is also not a surprise that fin has become aged in a fixed form in the agglutinated form afin, where it is strongly competitive with younger nouns, like for example intention 'intention' and especially but 'aim, goal'.

\$10 Thus we can explain the insistence of some to penetrate into the good language of the word but 'end, aim' in the translative expression of the final clause, dans le but de 'with the aim of'. This use of but is blocked by the desperate resistance of purists. The main argument of the purists is that one is aiming at a goal, whereby one is not inside the goal and therefore it is inappropriate to say dans un but 'in a goal'.

$\$ 11$ In spite of the theoretical validity of this argument, one can in fact observe a tendency of the word but 'aim, goal' to appear in final expressions.

$\$ 12$ Such is the case with the interrogative nuclear final word, the only really productive form of which is dans quel but?, lit. 'in which aim?' (or much less common dans quel dessein?, lit. 'in which design?'), whereas à quelle fin?, lit. 'to which end?', the only correct form, has quite obviously fallen out of favor.

$\$ 13$ This tendency is not recent, and one still finds the interrogative nuclear expression dans quel but?, which is frequently employed in Alexandre Dumas the father: Elle va en Angleterre, répondit Athos. - Et dans quel but? - Dans le but de faire assassiner Milor Buckingham 'She is going to England, responded Athos. - And to what end? - In order to have Milor Buckingham assassinated' (A. Dumas, Les trois Mousquetaires, II, Chapter 10, cf. ibid., II Chapter 13).

$\$ 14$ The vitality of this expression is measured by its frequency, which appears to be continually increasing in the works of Alexandre Dumas: Et dans quel but cette visite? 'And what is the purpose of this visit?' (Vingt ans après, I, Chapter 45, cf. also ibid., II, 12, Le Vicomte de Bragelonne).

$\$ 15$ The use of this nuclear interrogative expression has the increasingly common appearance of the conjunctive expression dans le but de as a consequence:

L'enquête ouverte sur ces mêmes faits en 1853 dans le but d'assurer l'exécution de legs stipulés par l'Empereur.
'The investigation opened on these same facts in 1853 in order to ensure the execution of the legacies stated by the Emperor.'

(Maupassant, Contes, A page of unedited history)

$\$ 16$ In spite of the desperate resistance of purists, the expression dans quel but? is encountered in our days under the feather of the most reputable authors: La lettre avait été communiquée d'urgence à la presse par Poincaré lui-même. Dans quel but? 'The letter had been passed on to the press by Poincaré himself. To what end?' (Roger Martin du Gard, Les Thibault, Summer 1914, III, 64, p. 143 and cf. ibid, p. 149).

$\$ 17$ Due to its structure and the fixed noun that it contains, the conjunctive expression afin que 'in order that' actually has the effect of being replaced by first-degree transfer using afin de 'in order to' followed by the infinitive. 
\$18 The translative of second degree afin que is thus trumped by the translative of first degree afin de.

$\$ 19$ Since the final clause is also semantically related to the modal clause, a frequent occurrence is for the final clause to entail a translative expression containing the noun manière 'manner' (or façon 'way') such as in de manière que in a manner that', de façon que 'in a way that': Soignez bien votre malade, de manière qu'il guérisse 'Take good care of your sick one, so that he gets better'.

\$20 The translative expressions de manière que and de façon que have a regrettable propensity to grow - under the influence of expressions such as de manière $\grave{a}$, de façon à - to de manière à ce que, de façon à ce que. The à ce in these expressions is superfluous and severely condemned, rightly so, by all grammarians, ${ }^{309}$ which has not prevented the practice from spreading more and more. But what is the means to effectively combat this abominable slovenliness when academics, whose duty it is to defend good style, are the first ones to render themselves guilty of employing the practice: ${ }^{310}$

\begin{tabular}{ll}
$\begin{array}{l}\text { Arrangez-vous de façon à ce que si, par } \\
\text { harsard, il (the king) vous adressait la } \\
\text { parole, il ne vous prenne point la } \\
\text { bouche pleine. }\end{array}$ & $\begin{array}{l}\text { 'Behave in a way that if } \\
\text { by chance he addresses you, } \\
\text { (A. Dumas, Le Vicomte de Bragelonne) } \\
\text { full mouth.' }\end{array}$ \\
$\begin{array}{l}\text { Elle les avait placés de manière à ce } \\
\text { qu'ils pussent voir le développement } \\
\text { superbe du couvert. }\end{array}$ & $\begin{array}{l}\text { 'She had placed them in a way } \\
\text { (Zola, L'Assommoir, VII) }\end{array}$ \\
\hline
\end{tabular}

\$21 In most languages, at least in the European languages, subordinate final clauses are marked by preposed translatives.

\begin{tabular}{lll}
\hline Latin $\quad$ ut & $\begin{array}{l}\text { Hanc vestem tibi do, } \\
\text { ut induas. }\end{array}$ \\
Greek hína & $\begin{array}{l}\text { Toûto tò himátion soì dídōmi, } \\
\text { hína endúéis. }\end{array}$ & $\begin{array}{l}\text { 'I'm giving you this dress, } \\
\text { so that you will put it on.' }\end{array}$ \\
German damit & $\begin{array}{l}\text { Iche dir dieses Kleid, } \\
\text { damit du es anziehst. }\end{array}$
\end{tabular}

$\$ 22$ Note that in Latin and Greek, the verb of a final clause appears in the subjunctive, as it does in French (cf. above $\$ 2$ ).

309. André Moufflet, Contre le massacre de la langue française, s. d. (1930), p. 133, Encore le massacre de la langue française, 1935, p. 228.

310. Translators' note: We have reduced the number of examples here to avoid unnecessary redundancy of illustration. 
\$23 In Latin, final meaning is sometimes rendered in the same way as consecutive meaning (cf. below Chapter $261, \$ 6$ ), by the simple relative pronoun and the subjunctive: Legatos Romam, qui auxilium ab senatu peterent, miserunt 'They sent ambassadors to Rome to request help from the Senate.

\section{Chapter 263. Modal clauses}

\$1 Modal clauses are those that are transferred to a manner adverb.

$\$ 2$ This is why they are commonly called manner circumstantials.

$\$ 3$ The term modal, which we adopt here, is only a stopgap solution, for in colloquial French the modal adjective does not normally signify what relates to manner, but rather what relates to mood, and the noun mood has a denotation in French grammar that is much different from that of manner. The adjective modal can denote what is related to manner only in scholarly French, building on Lat. modus 'manner'. But on the one hand it is difficult to find an adjective in French corresponding to the noun manner and on the other hand, it is also good to be able to designate the "circumstantial clause of manner" in some other way than by using this long periphrasis. We will therefore come to terms with this ambiguity, which is difficult to avoid, by being content to attract the reader's attention to it as our best apology.

$\$ 4$ A modal clause - a clause transferred to a manner adverb by second-degree transfer is rare, at least in our European languages.

\$5 However, one can find examples of such clauses in Latin, in particular for the negative modal: Nemo fit doctus, quin multum laboret 'Nobody has ever become knowledgeable without working a lot'.

$\$ 6$ In French, one finds the modal clause expressed by the subjunctive in expressions like advienne que pourra 'come what may', or with two subjunctives, the second by attraction, coûte que coûte 'whatever the cost', vaille que vaille 'somehow'. The ordinary gloss for the latter expression as tant bien que mal, lit. 'so well than badly' or à tout hasard 'by any chance', shows that one is dealing with transfer to an adverb.

$\$ 7$ In the avant-garde spoken French, the verbal notion is completely incorporated into the noun and the clause is reduced in the following way: Brouillard ou pas brouillard, je prendrai la mer à midi 'Fog or no fog, I am setting to sea at noon'.

$\$ 8$ This expression is very frequent in English, which readily reduces sentences down to their essential components: Fog or no fog (Shipbuilders, p. 68).

$\$ 9$ But second-degree transfer is not common in this case in French, where one normally reaches to double first-degree transfer $(\mathrm{I}>\mathrm{A}>\mathrm{E}$ ) in the form of the gerundive (cf. Chapter 224, \$14). 
$\$ 10$ Second-degree transfer of the sort I >> E is often only elliptical transfer (cf. above Chapter 226 and 227), which is composed of a more complex group of two simple transfers.

$\$ 11$ Take for example the French sentence Quand je partais en vacances, mon voisin me gardait ma maison, moyennant quoi je lui abandonnais toute la récolte de fruits de mon jardin 'When I went on vacation, my neighbor watched my house in return for which I sacrificed to him the entire harvest of fruit in my yard'. The second-degree transfer here (I $>$ E) is marked by the conjunctive expression moyennant quoi, lit. 'middleing what', which can be decomposed to:

1 (I >> A) second-degree transfer of the independent clause Je lui abandonnais toute la récolte de fruits de mon jardin 'I sacrificed to him the entire harvest of fruit in my yard' to an adjective marked by the translative element $q u$-contained in the relative pronoun quoi 'what'.

2 (A > E) first-degree transfer (more exactly, a transvaluation, cf. above Chapter 204) of the adjective thus obtained to an adverb by way of the translative moyennant 'middleing'.

$\$ 12$ Consider next the French sentence Décidez-vous à partir, auquel cas je me mettrai aussi en route 'Decide to leave, in which case I will set off, too'. The second-degree transfer (I >> E) marked by the translative (conjunctive expression) auquel cas can be decomposed to:

1 (I >> A) second-degree transfer marked by the translative element $q u$-contained in the relative pronoun auquel 'to which'. This A depends on the $\mathrm{O}$ (case) that follows.

$2(\mathrm{O}>\mathrm{E})$ first-degree transfer marked by the translative (preposition) à 'to' that is contained in the contracted form itself contained in the relative pronoun auquel [amalgam of $\dot{a}$ and lequel].

The target $\mathrm{A}$ of the first instance of transfer is hence connected to the source $\mathrm{O}$ of the second instance of transfer, and this connection is in the elliptical transfer I >> E.

$\$ 13$ The manner in which something is done can be expressed by comparison with another. The modal clause is thus a comparative clause.

$\$ 14$ In French, the translative of the comparative clause is comme 'as': J'aurais pu la tuer comme on assomme un chien qui désobéit 'I could have killed her as one knocks out a dog that desobeys' (Maupassant, Contes, Allouma, II); Il parlait comme coule une fontaine 'He spoke as a fountain flows' (Ibid., Duchoux); Ces gens-là mentent comme ils respirent, lit. 'These people lie as they breath', that is, 'These people are compulsive liars'.

$\$ 15$ In French, this type is also related to sentences subordinated by second-degree transfer with translative selon que 'depending on', lit. 'according as':

Selon que vous serez puissant ou misérable,

Les jugements de Cour vous feront blanc ou noir.
'Depending on whether you are powerful or miserable,

The Court's judgements will make you white or black.'

(La Fontaine, Fables, VII, 1, Les animaux malades de la peste) 
$\$ 16$ The same is true of subordinate sentences the translative of which is $a$ force de by dint of', a nuanced expression for which Italian sometimes employs a repeated imperative: Gira, gira, finalmente capitò in una viuzza 'By dint of wandering about (lit. Turn, turn), he arrived in an alley' (A. Pézard, Grammaire italienne, p. 214).

$\$ 17$ The comparative clause is very common across languages. One finds it for example in German, where it is introduced by the translative wie: Die dänischen Könige, die im elften Jahrhundert über England herrschten, fühlten sich keineswegs als Fremde, wie z. B. Knut seine Gesetze in altenglischer Sprache abfassen liess 'The Danisch kings, who ruled over England in the 11th century, saw themselves in no way as foreigners, as for example Knut had his laws drafted in the Old English langauge' (Karl Luick, Historische Grammatik der englischen Sprache, I, p. 19).

\section{Chapter 264. Quantity clauses}

\$1 A quantity clause is a clause that has been transferred to a quantity adverb (cf. Chapter 37, \$49).

\$2 Quantity clauses are generally introduced by a translative expression that often contains a quantity adverb and a common translative such as Fr. que 'that'.

$\$ 3$ The translative of a quantity clause is for example a translative expression such as autant que 'as much as' or tellement que 'so much that': Je travaillerai autant que vous voudrez 'I will work as much as you want'; Il se retournait tellement que sa femme s'en inquiéta 'He turned over so much that his wife became concerned' (Brillat-Savarin).

$\$ 4$ In Latin, the translative of a quantity clause is quantum: quantum in me erit'as much as I can'.

$\$ 5$ In Greek, the translative of a quantity clause is hóson or hōs: hóson gé m'eidénai 'as much as I know', hōs eikásai 'as much as one can surmise'.

$\$ 6$ In English, the expression that serves as the translative of a quantity clause is of the sort as much as: for as much as I know, as far as I can judge.

$\$ 7$ In German, one utilizes the expression so viel as the translative of a quantity clause: so viel als möglich 'as much as possible'.

$\$ 8$ In Russian, the translative of a quantity clause is the same as the nuclear interrogative of quantity skol'ko: Ty skaži naprjamik, skol'ko za nej dvižimogo i nedvižimogo 'Tell me squarely how much his fortune has climbed in possessions and real-estate.' (Gogol, The Wedding, I, 13), skol 'ko možno sudit', 'as soon as one can judge', skol'ko ja znaju 'as far as I know', without forgetting the common expression skol'ko ugodno 'as long as you want'.

\$9 The quantity clauses resulting from transfer can hardly be the result of second-degree transfer. One only ever encounters first-degree transfer with such clauses. 


\section{Chapter 265. Generalized indeterminate clauses}

\$1 A generalized indeterminate clause is a type of concessive clause that does not contain a functional concession of the sort associated with a concessive clause (cf. Chapter 260), but rather it contains a categorical concession that bears on only one constitutive element in the clause.

\$2 There are hence as many types of generalized indeterminative clauses as there are types of sentences and diverse ways to bring categories into play.

\$3 The translative of a generalized indeterminative clause generally varies across languages; it is constituted by two elements, the one indicating vagueness and the other indicating generalization.

$\$ 4$ The translative element indicating vagueness is usually a relative that has (or approximates) the same form as the interrogative of the same category: Fr. qui (que vous soyez) 'who(ever you are)', Lat. qui(cumque), Gr. (hós)tis(poté), Eng. who(ever), Ger. wer (auch immer)..., Rus. kto ni. All these expressions have the same meaning: Eng. Whoever calls must be introduced at once, Fr. Il faut faire entrer quiconque se présentera (same meaning).

$\$ 5$ The translative element indicating generalization is the word designating the universal in the category of time in Greek, English, and German: Gr. (óstis) poté, Eng. (who so) ever, Ger. (wer auch) immer (cf. also Fr. quiconque < ( ${ }^{*} q u i q u$ ')onque $\left.(s)\right)$. This element is sometimes reinforced by a manner adverb: so in English, auch in German.

$\$ 6$ In Latin, the generalization is marked by agglutination of a relative - the relative expressing vagueness - with an element that contains the junctive of adjunction -que 'and': quicumque.

\$7 In French, the marker of generalization is the usual relative que. Given that an indeterminative element has the form of an interrogative (cf. above $\$ 4$ ) and this element often begins with the interrogative stem $q u$-, the result is that the translative expression of the generalized indeterminate clause often contains a repetition of the element $q u$-. Of these two qu-, the first marks vagueness, and the second generalization: Qui que vous soyez 'whoever you are', quoi que vous fassiez 'whatever you do', quelle que soit votre intention 'whatever the nature of your intention'. This process is reminiscent of the doubling form quisquis in Latin. This double qu- in French, while it is not always euphonic, has the advantage of being characteristic. It even occurs that the element appears three times: quelque riche que vous soyez 'however rich you are'.

$\$ 8$ In Russian, the generalization is marked by the use of the particle ni: Kto by to ni bylo 'whatever it is'.

$\$ 9$ These diverse processes permit different languages to express the categorical concession of generalized indeterminate clauses with the most diverse categories. 
\$10 The generalized indeterminative clause can belong to the noun category: Qui que tu sois, accueille-moi sous ton toit 'Whoever you are, take me in under your roof'.

$\$ 11$ French also utilizes the translative quiconque:

Quiconque a beaucoup vu

Peut avoir beaucoup retenu.
'Whoever has seen a lot

Can have retained a lot.'

(La Fontaine, Fables, 1, 8, L'Hirondelle et les petits oiseaux)

There is thus elliptical transfer, double transfer of the sort I $>$ A $>\mathrm{O}$ being reduced to $\mathrm{I}>>\mathrm{O}$.

\$12 Instead of Fr. quiconque, many foreigners find it convenient to employ an expression in French that has been translated from their language: ${ }^{*}$ chacun qui 'everyone who': *chacun qui a beaucoup vu... 'everyone who saw a lot.... This expression, without being entirely unintelligible for French speakers, nevertheless constitutes a grave error. It is the sort of error that a native French speaker never makes and it infallibly betrays the non-Francophone. Foreigners are delighted when they learn that nothing is simpler than the correct use of quiconque, which they have carefully avoided because grammars have succeeded at presenting the use of this word as a spectre. In fact, it suffices to formulate the sentence incorrectly with chacun qui, then to mechanically substitute in quiconque without changing anything else in the structure of the sentence.

$\$ 13$ The Latin translative of the generalized indeterminative clause for a noun is quicumque or quisquis: quicumque es or quisquis es 'whoever you are'.

$\$ 14$ When it is the second or third actant, the translative of the generalized indeterminative clause takes the mark of this actant in languages where it has a distinct form: Eng. He took his hat off to whomsoever he met.

$\$ 15$ If the noun does not designate a person, but rather a thing, the indeterminative element of the translative expression has the form of the interrogative that one employs for a thing, Fr. quoi que 'whatever':

Sans la langue, en un mot, l'auteur le plus divin

'Without the language, in a word, the most divine author

Est toujours, quoi qu'on fasse, un méchant écrivain. Is always, whatever he does, a horrible writer.'

(Boileau, Art Poétique, I, 161-162)

Quoi que vous disiez, ma décision est prise 'No matter what you say, I've made my decision', Eng. whatever: Whatever he asks, he is sure to get, Ger. Was er auch immer sagen mag,... 'Whatever he says ....'

$\$ 16$ French can also appeal to the translative malgré 'in spite of' constructed with the subjunctive: Malgré que j'en eusse, il me fallut bien sourire 'In spite of the fact that I had some, 
I had simply to smile' (G. Duhamel, Le jardin des bêtes sauvages), that is, etymologically (quelque) mauvais gré que j'en eusse '(some) bad taste that I had some', cf. Chapter 42, \$17) $\$ 17$ One will of course strive in French not to confuse the translative quoi que 'whatever' (two words) of the generalized indeterminative clause designating things with the translative quoique 'although' (one word, cf. Chapter 260) of the concessive clause: J'irai voir Alfred, quoique je ne le connaisse pas 'I will go see Alfred, even though I do not know him'. $\$ 18$ In the adjective category, the generalized indeterminative is marked in French by the translative quelque (...que) 'whichever' (one word) if one is dealing with an attributive adjective and by the translative quel que 'whichever' (two words) if one is dealing with a predicative adjective: Quelques decisions que vous preniez, vous vous en repentirez 'Whichever decisions you take, you will regret taking them'; Quelle que soit ton opinion, tu m'approuveras 'Whatever your opinion is, you will agree with me'.

$\$ 19$ In Latin, the translative of the generalized indeterminative adjective is quicumque 'whichever': Quaecumque fortuna erat, patiebatur 'Whatever his fate was, he bore it'.

$\$ 20$ If one is dealing with an adjective of quality, Latin employs the translative qualiscumque 'however', and if one is dealing with an adjective of quantity, the translative is quantuscumque 'however much': Illud quod est, qualecumque est, probat 'Whatever appears, whatever its quality, he accepts it' (Cicero, Brutus, 193); Totum hoc, quantumcumque est..., totum est... tuum 'All this glory, however much it is, belongs entirely to you' (Cicero, Pro Marcello, 2, 7).

\$21 In German, the translative expression of a generalized indeterminative clause transferred to a quality adjective is was es auch immer für ein 'whatever', which corresponds to the interrogative adjective was für ein 'what kind of': was er auch immer für Gründe haben mag 'whatever his reasons are'.

$\$ 22$ The translative expression that introduces a generalized indeterminative clause transferred to a temporal adverb is rare across languages. One generally manages to substitute the translative of the generalized indeterminate adjective for it (cf. below, $\$ 17$ ): Quel que soit le moment où l'on va chez lui, il est toujours sorti 'Whenever the moment when one shows up at his place, he is always out'. However, the translative Rus. kogda $n i$ is often employed in this way: Kogda ni zaidës' 'Whenever the moment when one goes to him, he is always drunk'.

\$23 In English, the translative expression which(so)ever of generalized indeterminate adjectives, which corresponds to the formula given above (cf. $\$ 4$ and 5), is often supplanted by the translative expression of generalized determinate nouns denoting a thing whatever: Whatever news you get, let us know at once; for any reason whatever.

$\$ 24$ The translative expressions that introduce a generalized indeterminate expression transferred to a locative adverb are of the sort où que 'wherever' in French: Où que tu ailles, je te suivrai 'Wherever you go, I will follow you'; D’ò̀ que tu viennes, dis-le moi 'Wherever you come from, tell me it'. 
\$25 In other languages, the translatives of generalized indeterminate expressions of place are of the following sort:

\begin{tabular}{lll}
\hline $\begin{array}{l}\text { Greek } \\
\text { English }\end{array}$ & $\begin{array}{l}\text { opothen dépote } \\
\text { wherever }\end{array}$ & $\begin{array}{l}\text { opothen dépote 'from wherever' } \\
\text { Wherever you go, let me go with you. }\end{array}$ \\
German & wo auch immer & $\begin{array}{l}\text { Wo ich ihn auch immer treffen kann... } \\
\text { 'wherever I can find him' }\end{array}$ \\
Russian & $\begin{array}{l}\text { otkyda ni } \\
\text { (otkole ni) }\end{array}$ & $\begin{array}{l}\text { Otkole ni voz'mis', na vstreču mos' } \mathrm{ka} \mathrm{im} \\
\text { 'Coming out from nowhere, a pug }(\mathrm{dog}) \text { came to meet them.' } \\
\text { (Krylov, Fables, The elephant and the pug }(\mathrm{dog}) \text { ). }\end{array}$ \\
\hline
\end{tabular}

\$26 The translative expressions that introduce generalized indeterminative clauses that have been transferred to a manner adverb are of the sort Fr. comment que 'however': ${ }^{311}$ Comment que tu t'y prennes, tu auras du mal à reussir 'However you behave, you will have difficulty succeeding.

\$27 The corresponding translative expression is wie auch immer in German and in Russian it is kak ni: Kak ni toropis', ne uspeeš' 'Even if you hurry, you won't manage.'

\$28 Translative expressions that introduce generalized indeterminative clauses that have been transferred to a quantity adverb are in general quite poorly represented in languages. However, one finds the quite common skol'ko ni 'however much' in Russian: Skol'ko ni dumaj, luces xleba-soli ne pridumaeš' 'However much one racks one's brain, one cannot imagine better hospitality'.

\$29 If one is dealing with an adverb of quantity subordinate to an adjective, the translative expression in French is quelque... que, pour... que 'however':

Quelque riches que soient vos parents, leur fortune n'est pas inépuisable.

...scènes... que l'historien souhaiterait de rapporter dans l'ordre, avec toute la précision et la concision souhaitable, pour difficile que ce soit. (G. Duhamel, La Nuit de la Saint-Jean, p. 263)
'However rich your parents are, their fortune is not infinite:'

'...scenes... that the historian would wish to put back in order, with the desired complete precision and concision, however difficult it is.'

\$30 In most languages, even in Latin, generalized indeterminative clauses appear in the indicative: Lat. Quaecumque fortuna erat patiebatur 'Whatever his fate was, he bore it' (cf. above, \$19). Yet French generally puts the clause in the subjunctive like it does a concessive clause (cf. Chapter 260, \$7): Qui que vous soyez 'whoever you are'; quoi que vous fassiez

311. First editors' note: comment que is an idiomatic expression that Littré already described as "dated" (Dictionnaire, t. I, p. 683, first column, low on the page). He only cites an example taken from P. L. Courrier. 
'whatever you do'; quelle que soit votre intention 'whatever your intention is'; quelque riche que vous soyez 'however rich you are'. However, the translative quiconque is constructed with the indicative, as with Lat. quicumque.

$\$ 31$ Russian can also sometimes form generalized indeterminative clauses with the imperative, which represents a former optative of Indo-European: Otkuda ni voz' mic' 'departing from somewhere or other'.

\section{Chapter 266. Structural and semantic aspects of subordinate clauses}

\$1 The value of subordination is essentially structural, whereas subordination has only secondary semantic value. The essential aspect of subordination is that there is a structural connection, but the meaning of the connection - that is, its semantic value - is in fact incidental. The semantic value of the connection remains practically the same when the structural relationship between the governor and the subordinate is reversed.

\$2 Thus concerning meaning, one says indifferently Il me dit qu'il fait beau 'He told me that the weather is nice' or Il fait beau qu'il me dit 'The weather is nice, which he told me', lit. 'The weather is nice that he told me'. Yet only the first structure is correct in French, whereas the second is familiar and neglected. But the two are semantically almost the same.

\$3 This is proof of the independence of semantics from structure, a fact that we have already considered (cf. Chapter $20, \$ 17$ ), and further, it is proof of the inversely related hierarchical importance of semantics and structure (cf. Chapter 21, §8).

$\$ 4$ Facts of this type are encountered in French more often than one imagines, not only in colloquial language, which is very much overlooked, but also in familiar style:

Ça ramène. «Ton pot!» qu'ils lui jetaient

(Céline, Mort à credit, p. 21).

- Donne moi mon chapeau!

- Mais non...

- Mon chapeau, que je te dis!

(Marcel Aymé, La jument verte, p. 190)

En achetant mes souliers neufs...

trotteront-ils sur le pavé de Paris?

que je me disais

(Mme Chéron de la Bruyère, L'Epée du

Donjon, Hachette, 1903, Bibl. Rose, p. 142)

Marco, que je lui ai fait alors, cherche M. Gail

(M. Génin, Marco et Tonino, IX, Magasin d'Education

et de Récréation, 1881, I, p. 273)
'It causes a fuss. "Your pot!"

(that) they said to him'

'- Give me my hat!

- But no...

- My hat, (that) I tell you!'

'Buying my new shoes..

will they pound the pavement of Paris?

(that) I was saying to myself.'

'Marco, (that) I then put to him, look for M. Gail' 
\$5 From this manner of speaking, a new construction has developed that is increasingly frequent in colloquial French. This construction involves the interruption of a report of the words of a third person using the expression Qu'il dit!, lit. 'That he says!'. This expression of skepticism is now a true adverbial of doubt that lets one know that the reported speech should not be taken as a gospel of truth: Alfred s'est conduit courageusement! - Qu'il dit! 'Alfred was behaving courageously - That (is what) he says!.

$\$ 6$ In English, it frequently occurs that no marker indicates the subordination of one of the two clauses to the other. In such cases, one can hesitate because it is not clear which clause is the governor: Two thirds of army officers once were GIs, report says. In this sort of expression, which is very frequent in journalistic style in English, in particular in the titles of articles, it is difficult to determine the meaning of the connection, that is, it is difficult to distinguish governing from subordinate clause. The only thing that is certain is that there is a connection between the two clauses, since if one were dealing with two independent clauses, the second would be of the type that is inserted and the verbal index of the first actant would be uttered after the verb (cf. above $\$ 4$ ): Two-thirds of army officers were once GIs, says report.

$\$ 7$ The ability to reverse the structural positions of the governing and the subordinate clause is available not only for actantial subordinate clauses, but also for circumstantial subordinate clauses. Hence with circumstantial subordinate clauses of time, one can also say the following in French: Il nous fallut repartir, alors que nous étions à peine arrivés 'We had to depart again, even though we had hardly arrived' and Nous étions à peine arrivés, $q u$ 'il nous fallut repartir 'We had hardly arrived, when (lit. that) we had to depart again'. Likewise, one will also even say Je savais tout cela, dès que notre séance fut levée 'I knew all hat as soon as our meeting was over' and Notre séance n'était pas plutôt levée, que je savais tout cela 'Our meeting had just ended when (lit. that) I knew all that'.

$\$ 8$ Similarly, one will also say with hypothetical subordinate clauses Je ne serais pas autrement surpris, s'il apparaissait à la dernière minute 'I would not otherwise be surprised if he appeared at the last minute' as well as Il apparaîtrait à la derniere minute, que je n'en serais pas autrement supris 'He would appear at the last minute, which (lit. that) would not otherwise surprise me' (J. Verne, Around the world in 80 days, XXXVI).

$\$ 9$ The independence of semantics from structure and the inverse relationship of their importance (cf. above, Chapter 3 and Chapter 21, \$8), permits French to utilize the essential adjectival subordinate clause in an original way: to call attention to the antecedent. Hence French places a syntactic accent of insistence on the antecedent. The languages that have an accent of intensity use it instead, which is then generally noted in orthography by the spacing of characters [or uppercase]: Fr. C'est mon père qui l'a dit 'It was my father who said that' cf. Ger. Mein Vater hat es gesagt 'MY FATHER said it.' Further: C'est lui qui m'a ravi l'amitié de mon père 'It is him who took from me the friendship of my father' (Racine). 
$\$ 10$ The inverse hierarchical importance of semantics and structure offers the speaker a means to insidiously hide pointed remarks in the ultimate folds of a subordinate clause, where they seem to pass unnoticed structurally, pointed remarks to which the speaker attaches the greatest semantic importance. The adjectival clause that contains a point of subordinate irony is always an accessory adjectival subordinate clause, since if it were an essential adjectival subordinate clause, the ironic remark would not find enough of a hiding place. The trick is precisely to use an accessory means to present an idea that is not accessory. $^{312}$

$\$ 11$ The subordinate irony is all the more powerful if it hides under a most benign structural appearance, and it often approaches insolence, e.g. a jab put in a report by one of the most spiritual French diplomats: Le colonel N..., dont l'esprit naturellement rigide n'a pas été assoupli par le métier militaire, m'assurait hier que... 'The colonel, whose naturally rigid mind was not softened by the military profession, assured me yesterday that....

$\$ 12$ Subordinate irony is one of Edmond About's favorite stylistic measures, one of the most spirited French writers:

Ce diable d'homme, qui devait me couper le cou à la fin du mois, m'inspirait quasiment du respect.

(E. About, Le Roi des Montagnes, IV, p. 129)

Ma figure lui avait plu dès le premier coup d'œel. Je lui rappelais un frère cadet qu'il avait perdu en cour d'assises. (Ibid, VI, p. 219)
'This devil of a man, who had to cut my neck at the end of the month, almost inspired respect in me.'

'My appearance made him cry at first sight. I reminded him of a fellow cadet that he had lost in the crown court.'

$\$ 13$ Anatole France and Abel Hermant also readily employ subordinate irony:

Les Romains aimaient la guerre, dit

M. Goubin qui évitait soigneusement les paradoxes.

(A. France, Sur la Pierre Blanche, p. 368, in Euvres completes,

t. XIII, Calmann-Lévy, 1948).

M. de la Guit'hardière, que n'aime pas les vaincus, n'hésita pas à exprimer des sentiments russophiles.

(Abel Hermant, Les Grands Bourgeois, I).
'The Romans loved war, said

M. Goubin, who carefully avoided paradoxes.'

'Mr. de la Guit'hardière, who does not like the defeated, did not hesitate to express pro-Russian sentiments.'

312. We thus cannot be completely satisfied with A. Moufflet, who, without getting to the bottom of the matter and who abuses an appearance, writes that, according to a formula that in my opinion is lacking nuance, "the main clause is generally the expression of the main idea", Contre le massacre de la language française, I, 1930, p. 239. 


\section{Chapter 267. Advancement of the subordinate clause}

\$1 The independence of structural and semantic aspects and their inverse hierarchical importance have the effect of favoring the advancement of the subordinate clause at the expense of the governing clause.

\$2 In particular, they permit French to renew its primary interrogative stock by way of a secondary system of reinforced interrogatives resting etymologically on subordination that is hardly sensed today (cf. Chapter $84, \$ 16$ ). Hence, by way of connective elliptical transfer, these interrogatives can serve as markers of direct interrogation exactly like primary interrogatives (cf. Stemma 353).

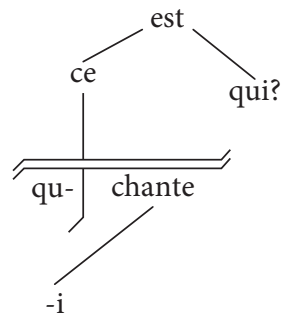

Stemma 353

$\$ 3$ As a matter of fact, these secondary interrogatives are the reinforced interrogatives that we have already discussed in the area of standard interrogatives (cf. Chapter 81 and Chapter $84, \$ 16$ ). We overlooked the real nature of these secondary interrogatives because we had not yet properly studied transfer.

$\$ 4$ The mechanism that leads to their structure - at least form the etymological point of view - consists of expressing the interrogative sentence in the form of a subordinate clause, the fixed antecent of which is included in the connective elliptical transfer.

\$5 This antecedent is the demonstrative pronoun ce 'that', which is the first actant of the verb être 'be' (cf. Chapter 67, and Chapter 207, \$3). The verb is itself fixed and included in the connective elliptical transfer.

$\$ 6$ Take the connected direct question in the sentence Alfred est-il venu? 'Has Alfred come?' as an example (cf. Chapter $84, \$ 9$ ), where the marker of interrogation is the inversion of the verb with the anontive index of the first actant. This primary index can be replaced by the secondary index est-ce que: Est-ce qu'Alfred est venu? 'Has Alfred come?' (cf. Chapter 84, \$16).

$\$ 7$ In this expression, the source of transfer is the independent clause Alfred est venu 'Alfred has come'. The translative que 'that' ensures the transfer of the verb est 'is' to a subordinate actant. The verb est is contained in the interrogative governor est-ce, where interrogation is marked by inversion of the verb with the index of the first actant (cf. Chapter $84, \$ 9$ ). 
$\$ 8$ But the analysis of this structure is purely etymological. In fact, the governing clause est-ce and the translative que are merged by way of connective elliptical transfer in the single fixed interrogative word est-ce que, which remains unanalyzed by speakers who pronounce it [eska] (cf. Chapter 84, \$18)].

$\$ 9$ The same fixed interrogative est-ce que helps the formation of secondary nuclear interrogatives.

\$10 Thus the circumstantial primary interrogatives où, quand, comment 'where, when, how' are strongly in competition in French with the secondary interrogative groups où est-ce que, quand est-ce que, comment est-ce que 'where, when, how'. Although in refined French one encounters Où allez-vous? 'Where are you going?', Quand viendrez-vous? 'When are you coming?', Comment allez-vous? 'How are you doing?', one prefers Où est-ce que vous allez? 'Where are you going', Quand est-ce que vous viendrez? 'When are you coming?', Comment est-ce que vous allez? 'How are you doing?' in spoken French (cf. Chapter 81, \$5), even with the ellipsis of est-ce in popular French: Où que tu l'as mise, ma belle œuvre? 'Where did you put it, my nice work?' (Céline, Mort à Crédit, p. 18).

$\$ 11$ Whereas the antecedent in the preceding cases is the pure translative and therefore the invariable element que 'that', secondary interrogative actants are formed etymologically by way of a transferred clause of the sort I > A, which is subordinated to these actants and which has the relative pronoun as its marker. The relative pronoun has a double value, both translative and connective, and it is therefore variable:

\begin{tabular}{|c|c|}
\hline Primary interrogatives & Secondary interrogatives \\
\hline $\begin{array}{l}\text { Qui chante? } \\
\text { 'Who is singing?' }\end{array}$ & $\begin{array}{l}\text { Qui est-ce qui chante? } \\
\text { 'Who is singing?' }\end{array}$ \\
\hline $\begin{array}{l}\text { Qui voyez-vous? } \\
\text { 'Who do you see?' }\end{array}$ & $\begin{array}{l}\text { Qui est-ce que vous voyez? } \\
\text { 'Who do you see?' }\end{array}$ \\
\hline $\begin{array}{l}\text { À qui donnez-vous ce livre? } \\
\text { 'To whom are you giving this book?' }\end{array}$ & $\begin{array}{l}\text { A qui est-ce que vous donnez ce livre? } \\
\text { 'To whom are you giving this book?' }\end{array}$ \\
\hline
\end{tabular}

$\$ 12$ We have already seen (cf. Chapter $81, \$ 9 f f$ ) the enrichment that occurs by way of the interrogative composed of the joint resources of the primary interrogative and the relative pronoun (cf. Chapter 81, \$7ff.).

$\$ 13$ Due to the influence of a desire for insistence (cf. Chapter 266, \$9), independent clauses tend to become subordinate clauses. In time, one gained the ability to express all independent clauses as subordinate clauses, initiating these clauses with que 'that'. Instead of saying, je suis, one was hence led to say moi que je sui, lit 'Me that I am...' or que je suis 'That I am...'.

$\$ 14$ This matter is very clear in Low Breton, where the most banal independent clauses are normally constructed as subordinate clauses: Me a zo... 'I am', lit. 'Me that I am..., Me a lavar 'I speak', Per a garan 'I love Peter', lit. 'Peter that I love him'. 
\$15 A number of French dialects appear to be based on a substratum, where this manner of expressing oneself was common. These dialects seem to have thus adopted, or have rather conserved, this manner of constructing sentences of the substratum, this substratum being visible underneath its neo-Latin exterior. This phenomenon is striking in the dialects of the Gascon or Béarnese type, where it has the effect of substituting the conjunction que 'that' for the personal indices $j e, t u$, $i l$, the conjunction being thus charged with the value of a personal index: Gascon que souy 'I am', probably understood originally as * (moi) que (je) suis '(me) that (I) am'; Béarnese que souy (same meaning), Lou baylet ques lhebat 'The servant got up', probably originally understood as 'the servant that he got up'.

$\$ 16$ Hence this analysis is also probably applicable to the genesis of the conditional translative que si 'if', and perhaps also to its Latin prototype quod si: Fr. Que si le ciel daigne favoriser mes voux, rien ne manquera à votre félicité 'If the heaven deigns to favor my wishes, nothing will be lacking to my felicity' (cf. Bescherelle, Dictionnaire National, see si).

$\$ 17$ Finally, the range of French translatives is enriched with novel nuances by transforming an adverb contained in a clause into a subordinating element by way of que. The translative même que lit. 'even that' thus arose in colloquial and avant-garde French. This translative même que does not really express anything different than the simple même inside the clause:

Comment!... tu ne reconnaissais pas le cadeau que tu m'avais payé à ma fête, même que tu m'as donné une grande pièce blanche et qu'on t'en a rendu deux petites. (Murger, Le Sabot Rouge, X), same meaning as tu as même donné une grande pièce blanche...

...il s'entêtait à allumer leur fourneau sur le carré, même que, le samedi d'auparavant, mademoiselle Remanjou... était descendue à temps pour empêcher le petit Linguerlot d'avoir le corps tout brûlé (Zola, L'Assommoir, II), same meaning as le samedi d'auparavant, mademoiselle Remanjou était même descendue à temps pour empêcher...
'What!... you did not recognize the gift that you bought for me. You even gave me a large white coin, and two little ones were given back to you'

'...he persisted in lighting their stove on the square. The previous Saturday, Ms. Remanjou had even descended in time to avoid the burning of the small Linguerlot' 


\section{Second-degree transfer, multiple transfer}

\section{Chapter 268. Multiple transfer}

$\$ 1$ Like first-degree transfer, second-degree transfer can take part in cases of multiple transfer.

\$2 However, it is worth noticing that multiple transfer never contains more than a single instance of second-degree transfer.

\$3 This fact is easily understood when one acknowledges that second-degree transfer contains a change in syntactic level by definition (cf. above chapter 164, 114 and 15 and Chapter 239, \$10) and that the number of changes in level cannot multiply indefinitely without endangering the cohesion of the syntactic edifice. The economy of the sentence would risk becoming too complex, making the sentence unintelligible.

$\$ 4$ Most often, an instance of second-degree transfer as part of multiple transfer is the first (but the last on the spoken chain in French and in languages that have the same structure).

$\$ 5$ The matter is easily explained. Second-degree transfer, which is secondary, most often comes after first-degree transfer, which is primary. Since it is more recent and hence stronger, it is normal for second-degree transfer to occupy the most conspicuous position on the spoken chain.

$\$ 6$ However, it can occur that a unique instance of second-degree transfer within a case of multiple transfer occurs second, third, or even last. We will encounter examples of this sort with cases of triple (cf. Chapter 270, \$3, 4, 5 and 7) and quadruple (cf. Chapter 271, $\$ 2)$ transfer.

$\$ 7$ We are going to examine multiple transfer containing an instance of second-degree transfer, and we will do so adopting the same principles of classification as for instances of multiple transfer (cf. above Chapter 229, \$2).

\section{Chapter 269. Double transfer}

\$1 Type I >> A > O; Mark 1, 2. 
1 (I >> A) Second-degree transfer of the independent clause met un frein à la fureur des flots to an adjective marked by the translative qui 'that'.

$2(\mathrm{~A}>\mathrm{O})$ First-degree transfer of the adjective thus obtained to a substantive marked by the retranslative celui 'the one'.

Likewise:

Ceux de qui la conduite offre le plus à rire,

Sont toujours, sur autrui, les premiers à médire.

(Molière, Tartuffe, I, 1)

Le vent redouble ses efforts

Et fait si bien qu'il déracine

Celui de qui la tête au ciel était voisine

Et dont les pieds touchaient à l'empire des morts.

(La Fontaine, Fables, I, 22, Le chêne et le roseau)
'The ones whose behavior offers the most to laugh at Are always the first ones to speak ill of others.'

'The wind redoubles its efforts

And does so well that it uproots

The one whose head was close to heaven

\section{$\$ 2$ Type I >> A > O; Mark 1, 2 .}

Fr. J'approuve ce que vous faites 'I approve of what you do.' This type is for objects, whereas the type in Celui qui met un frein à la fureur des flots 'The one who breaks the furor of the streams' (cf. above $\$ 1$ ) is for persons.

$1 \mathrm{I}>>$ A) Second-degree transfer of the independent clause Fr. vous faites 'you do' to an adjective marked by the translative $q u$-contained in the relative pronoun que 'that'.

$2(\mathrm{~A}>\mathrm{O})$ First-degree transfer of the adjective thus obtained to a substantive marked by the retranslative $c e$ 'that'.

Likewise:

Ce qu'on donne aux méchants, Toujours on le regrette.

(La Fontaine, Fables, II, 7,

La lice et sa compagne)

Et chacun croit fort aisément

Ce qu'il craint et ce qu'il desire.

(La Fontaine, Fables, XI, 6,

Le loup et le renard)

Je regarde ce que je perds Et ne vois point ce qui me reste. (Molière, Psyché, II, 1)

A quo id accepimus, quo ceteris opitulari possemus. (Cicero, Pro Archia, I)
'What one gives to the fox, Always one regrets it.'

'And each believes very easily

What he fears and what he desires.

'I examine what I lose

And I do not see what I still have.,

lit. '...what is left for me.'

'The one from whom we have the means to support others.'

$\$ 3$ Type I >> A > O; Mark 1 .

Lat. qui venit'(the one) who is coming. 
1 (I >>A) Second-degree transfer of the independent clause venit to an adjective marked by the translative qui 'who'.

$2(\mathrm{~A}>\mathrm{O})$ Unmarked first-degree transfer of the adjective thus obtained to a noun.

Traditional grammar teaches in such cases that the antecedent is implicit. However, pretending that a given word is not in the sentence distorts reality. We have already indicated (cf. above Chapter 27, \$10) what one should think about implicit words. Likewise: qui post eos fuerunt 'their successors', lit. 'who are after them' (Cicero, De finibus, IV, 3, 7), Zeno et qui ab eo sunt 'Zenon and his disciples', lit. 'Zenon and who are of/from him', Aristoteles, deinde eum qui secuti sunt 'Aristotle, then his followers', lit. 'Aristotle, then who follow' (Cicero, Tusculan Disputations, II, 3, 9).

$\$ 4$ In imitation of Latin, French sometimes employs a clause introduced by qui transferred to a noun: Qui veut voyager loin ménage sa monture 'Whoever wants to travel far takes care with his mount' (Racine, Les Plaideurs, I, 1). The resulting noun of double transfer (I >> A $>\mathrm{O}$ ) can be the first actant of a verb that undergoes I > E transfer (cf. above Chapter 206, $\$ 8$ ): jouer à qui perd gagne, lit. 'play to who loses wins', rivaliser à qui courra le plus vite, lit. 'rival to who runs the fastest'.

$\$ 5$ Type I > A > O; Mark 1.

Lat. Sunt qui id sciant '(There) are (people) who know that'.

1 (I >>A) Second-degree transfer of the independent clause id sciunt '(they) know that' to an adjective marked by the translative qui with a consecutive nuance (cf. above Chapter 261, \$6) marked by the subjunctive.

$2(\mathrm{~A}>\mathrm{O})$ Unmarked first-degree transfer of the adjective thus obtained to a substantive.

$\$ 6$ Type I >> E > O; Mark 1.

Fr. (Je vous demande) où vous allez '(I ask you) where you are going'.

1 (I > E) Second-degree transfer of the independent interrogative clause Où allezvous? 'Where are you going?' (direct question, marked by inversion) to an adverb (indirect question, that is, subordinate) marked by the suppression of this marker.

$2(\mathrm{E}>\mathrm{O}) \quad$ Unmarked first-degree transfer of the adverb thus obtained to a noun.

$\$ 7$ The change via transfer of a direct question: Je vous demande: Où allez-vous? 'I ask you: Where are you going?' to an indirect question Je vous demande où vous allez 'I ask you where you are going' has the consequence that où with interrogative value (in an independent clause) changes to a relative (in the subordinate clause). In this regard, it is easy to understand why the relative element has the same form as the interrogative element in many languages, since it stems from the interrogative element.

$\$ 8$ Transfer of the sort I > E > O can have elliptical transfer of the sort I > O as an equivalent. In this respect, Malblanc observed that French "frequently condenses an entire 
German clause in a noun": ${ }^{313}$ Ger. Lehren, wie man vorsichtig sein muss 'teach how one has to be careful' $\leftrightarrow$ Fr. enseigner la prudence 'teach prudence'.

$\$ 9$ What is valid for the translation of a German text to French is also valid for that of a Latin text: Firmissimum hoc adferri videtur cur deos esse credamus $\leftrightarrow$ Eng. Here, it seems to me, is the strongest proof that one can identify the existence of the Gods (Cicero, Tusculan Disputations, I, 13, 30). ${ }^{314}$

\$10 Marking the same notion, Italian readily employs the repeated imperative: Ponza, ponza, non fu buono di scriver la lettera 'Even if he put forth effort (lit. Make effort, make effort), he did not succeed at writing his letter' (A. Pézard, Grammaire italienne, p. 214).

\$11 When elliptical transfer (I $>>0$ ) obtains for double transfer $(\mathrm{I}>>\mathrm{E}>\mathrm{O})$, it can occur as in the case of ordinary I $>>\mathrm{O}$ transfer - that the first actant of the subordinate clause appears (by way of anticipation) as the second actant of the governing clause (cf. above Chapter 242, \$31). Hence one encounters Lat. Nam sanguinem, bilem, pituitam, ossa, nervos, enas ... videor posse dicere unde concreta et quo modo facta sint, lit. 'Indeed, I believe I can say blood, bile, phlegma, bones, nerves, veins... where (they) come from and in which manner (they) were made' (Cicero, Tusculan Disputations, I, 24, 56) instead of Nam sanguis, bilis, pituita, ossa, etc... unde concreta et quo modo facta sint ... videor posse dicere 'Indeed, I believe I can say where blood, bile, phlegma, bones, nerves, veins... come from and in which manner (they) were made.' ${ }^{315}$

\$12 Type I >> O > A; Mark 1, 2.

Sp. con la diferencia de que en el otoño los dias son los que van acortándose, al paso que crecen las noches 'with the difference (of) that in autumn the days get shorter, whereas the nights grow longer'.

1 ( I >> O) Second-degree transfer of the independent clause en el otoño...acortándose 'in autumn...' to a substantive marked by the translative que.

$2(\mathrm{O}>\mathrm{A})$ First-degree transfer of the noun thus obtained to an adjective marked by the translative (preposition) de: de que en el otoño... 'that in autumn...'

\$13 Type I > > E > A; Mark 1, 2 .

Fr. (colloquial speech) des souvenirs de quand j'étais enfant 'souvenirs from when I was a child'.

313. Malblanc, Stylistique comparée du français et de l'allemand, Paris, 1963, \$170, 171, 244. One finds an abundance of examples here.

314. Cf. Riemann \& Goelzer, Grammaire latine complète, 1912, p. 55. One finds plenty of other examples here.

315. Riemann \& Ernout, Syntax latine, 1935, p. 317. 
1 (I >>E) Second-degree transfer of the independent clause j'étais enfant 'I was a child' to an adverb marked by the translative quand 'when': quand j'étais enfant 'when I was a child'.

2 (E > A) First-degree transfer of the adverb thus obtained to an adjective marked by the translative (preposition) de 'from': de quand j'étais enfant 'from when I was a child?.

$\$ 14$ Type I >> E > A; Mark 1 .

Fr. la ville où vous allez 'the town where you are going.

1 (I >> E) Second-degree transfer of the independent clause vous allez 'you go' to an adverb marked by the translative où 'where': où vous allez 'where you are going.

2 (E >> A) Unmarked first-degree transfer of the adverb thus obtained to an adjective. $\$ 15$ Type I > E > A; Mark 1.

Fr. une femme très comme il faut 'a fine upstanding woman', lit. 'a woman very like it should be'.

1 (I >> E) Second-degree transfer of the independent clause il faut 'it should be' to a subordinate comparative clause (cf. above Chapter 263, \$13) marked by the translative comme 'like' (cf. above, Chapter 263, \$14): comme il faut 'like it should be'.

2 (E $>$ A) Unmarked first-degree transfer of the adverb thus obtained to an adjective. $\$ 16$ Type I >> O > E; Mark 1, 2.

Fr. Avant que le coq chante, tu me renieras trois fois 'Before the rooster crows, you will renounce me three times' (cf. above, Chapter 255, \$15).

1 (I >> O) Second-degree transfer of the independent clause le coq chante 'the rooster crows' to a subordinate nominal clause by way of the translative que 'that': que le coq chante 'that the rooster crows'.

$2(\mathrm{O}>\mathrm{E})$ First-degree transfer of the noun thus obtained to an adverb by means of the translative (preposition) avant 'before': avant que le coq chante 'before the rooster crows'.

$\$ 17$ This type of double transfer (cf. above Chapter $255, \$ 18$ ), which is marked by a double translative (the two elements that appear adjacent on the spoken chain in the order preposition + conjunction que) is frequent in French. For this reason, the majority of conjunctions of subordination, which are merely translatives of second degree, are in reality conjunctive expressions composed of a preposition followed by a conjunction of subordination que: parce que 'because', tandis que 'whereas', alors que 'when', depuis que 'since', tant que 'while', dès que 'as soon as', après que 'after', à moins que 'unless' (cf. Chapter 254, \$18), sans que 'without', pourvu que 'provided that' (cf. above Chapter 258, \$28), etc. 
\$18 Type I >> O > E; Mark 1, 2.

Ger. nachdem er gestorben war 'after he died' (cf. Chapter 255, \$14).

1 ( $>>$ O) Second-degree transfer of the independent clause er war gestorben 'he died' to a substantive marked by the article das contained in nachdem (cf. Chapter 255, $\$ 14$ and H. Paul, Deutsches Wörterbuch, see dass 13, p. 106).

$2(\mathrm{O}>\mathrm{E})$ Transfer of the substantive thus obtained to a temporal adverb marked by the translative preposition nach and the dative contained in nachdem.

$\$ 19$ The German translative nachdem is also encountered with the meaning 'according to', for example after the translative je and with ellipsis of the main clause with suspension of the target, e.g. je nachdem 'depending on' (cf. Fr. C'est selon 'It depends', lit. 'It is according (to ....)').

\$20 The dative dem of the article das, which has become the translative dass (cf. Chapter $241, \$ 17)$, is also found in indem 'by', seitdem 'since', and trotzdem 'despite'; Ger. Man verwöhnt die Kinder indem man immer ihren Willen tut 'One spoils the children by always doing what they want'; Indem uns der Arme dankte, so konnte er kaum seine Tränen zurückhalten 'The poor man could hardly hold back his tears as he thanked us' (Malblanc, loc. cit., p. 98).

\$21 The preceding examples show that the double transfer of second degree in German with the translative indem 'by' ( $>>\mathrm{O}>\mathrm{E}$ ) is practically equivalent to the double transfer of the first degree that constitutes the French gerundive (I > A > E) (cf. Chapter 224, $\$ 11$ and 12), which is easily understood, since in both cases the transfer occurs with the same source I and ends with the same target E.

\section{Chapter 270. Triple transfer}

\$1 Type I >> A > O > O Mark 1, 2, 3 .

Fr. Malheur à ceux qui remuent le fond d'une nation 'Woe to the ones who shake the foundation of a nation' (Rivarol).

1 (I >> A) Second-degree transfer of the verb remuent 'move' to an adjective qui remuent 'who move' marked by the translative element $q u$ - contained in the relative pronoun qui 'who'.

$2(\mathrm{~A}>\mathrm{O})$ First-degree transfer of the adjective thus obtained to a noun marked by the retranslative ceux: ceux qui remuent 'the ones who move'.

$3(\mathrm{O}>\mathrm{O})$ Subcategory transfer of the noun thus obtained to a third actant marked by the translative (preposition) $\dot{a}$ 'to': à ceux qui remuent 'to the ones who move'. 
\$2 Type I >> A > O > O Mark 1, 2, 3 .

Basque dunak 'the ones who have' cf. Euskaldunak 'the Basques', for euskara dunak 'the ones who have the Basque language' (euskal is the form taken by euskara 'Basque language' in composition).

1 (I >>A) Transfer of the verb duen 'he has' to the adjective dun marked by the relative suffix $-n$.

$2(\mathrm{~A}>\mathrm{O})$ Transfer of the preceding adjective to a substantive marked by the postposed article - $a$ : duna.

$3(\mathrm{O}>\mathrm{O})$ Subcategory transfer of the preceding singular noun to a plural noun marked by the substitution of $-a k$, the nominative plural of the article, for $-a$ : dunak.

$\$ 3$ Type I > I >> A > O; Mark 1, 2, 3 .

Fr. celui qui est venu 'the one who has come'.

1 (I > I) Subcategory transfer of first degree of the verb vient 'comes' to its anterior present form est venu 'has come' marked by the auxiliary est 'is'.

2 (I > A) Second-degree transfer of the verb est venu to an adjective marked by the translative element $q u$ - contained in the translative qui 'that'.

$3(\mathrm{~A}>\mathrm{O}) \quad$ First-degree transfer of the adjective thus obtained to a substantive marked by the retranslative celui 'the one'.

$\$ 4$ Type I > I >> A > O; Mark 1, 2, 3 .

Fr. Quiconque a beaucoup vu 'Whoever has seen a lot' (La Fontaine, cf. above Chapter 265, $\$ 11)$.

1 (I > I) Subcategory transfer of the verb voit 'sees' to its anterior present form $a v u$ 'has seen' marked by the auxiliary $a$ 'has'.

2 (I >>A) Second-degree transfer of the verb $a v u$ 'has seen' to an adjective marked by the elliptical translative quiconque 'whoever' (cf. Chapter 265, \$11).

3 (A > O) First-degree transfer of the preceding adjective to a substantive marked by the same translative.

$\$ 5$ Type I > I > A > O; Mark 1, 2.

Sp. Quien no ha visto a Sevilla, no ha visto a maravilla 'Whoever has not seen Sevilla, has not seen a wonder'.

1 (I > I) First-degree subcategory transfer of the verb $v e$ 'he sees' to its anterior present form ha visto 'he has seen' marked by the auxiliary ha 'has'.

2 (I >> A) Second-degree transfer of the verb thus obtained to an adjective marked by the translative quien 'whoever'.

$3(\mathrm{~A}>\mathrm{O})$ Unmarked first-degree transfer of the preceding adjective quien ha visto 'whoever has seen' to a noun. 
$\$ 6$ Type I >> A > O > A; Marked 1,2,3.

Fr. L'harmonie la plus douce est le son de la voix de celle que l'on aime 'The sweetest harmony is the sound of the voice of the one who one loves' (La Bruyère).

1 (I >> A) Second-degree transfer of the verb aime 'loves' to the adjective que (l'on) aime marked by the translative element $q u$-contained in the relative pronoun que.

$2(\mathrm{~A}>\mathrm{O})$ First-degree transfer of the adjective thus obtained to a substantive marked by the retranslative celle: celle que l'on aime 'the one who one loves'.

$3(\mathrm{O}>\mathrm{A})$ First-degree transfer of the noun thus obtained to an adjective that is subordinate to the noun voix 'voice', which is marked by the translative de 'of': de celle que l'on aime 'of the one who one loves'.

$\$ 7$ Type I > A > I >> A; Mark 1, 2, 3 .

Fr. un enfant qui est intelligent 'a child who is intelligent'.

1 (I > A) Etymological transfer of the Latin verb intelligit 'he understands' to an adjective marked by the particle of concomitance -ens: intelligens 'comprehending', fixed in Fr. intelligent.

2 (A > I) Transfer of the adjective intelligent to a verb marked by the auxiliary verb est; est intelligent.

3 (I >> A) Second-degree transfer of the verb thus obtained to an adjective by way of the translative element qu-contained in the relative pronoun qui: qui est intelligent 'who is intelligent'.

$\$ 8$ It is clear that this long transfer does not end with a different semantic result than that of the simple transfer I > A, since the effect of A > I transfer (marked by the translative auxiliary est) and of I >> A transfer (marked by the translative qui), because they are opposites, can only neutralize each other. This is why one generally says quite simply un enfant intelligent 'an intelligent child'.

$\$ 9$ Types I >> A > O > E; Mark 1, 2, 3.

Fr. Vois par ce que je suis ce qu'autrefois je fus 'See by what I am now what I was earlier' (Delille, Enéide, V).

1 (I >> A) Second-degree transfer of the independent clause je suis 'I am' to an adjective marked by the translative element $q u$-contained in the relative pronoun que: qu je suis 'that I am'.

$2(\mathrm{~A}>\mathrm{O})$ First-degree transfer of the adjective thus obtained to a noun, marked by the retranslative ce: ce que je suis 'what I am'.

$3(\mathrm{O}>\mathrm{E})$ First-degree transfer of the noun thus obtained to an adverb of manner, marked by the translative (preposition) par: par ce que je suis 'by what I am? 
Likewise: Fr. en ce qui me concerne 'in what concerns me'.

\$10 Transfer of an independent clause to a causal clause evoked by the translative parce que (cf. Chapter $256, \$ 3$ ) is nothing other than a semantically elliptical form (I >> E) of transfer of the sort I >> A > O > E (cf. Chapter 270, \$9).

\$11 The difference between the causal transfer I > E and the triple transfer examined above $(\$ 9)$ is so strongly sensed by French speakers, who have a feel for their language, that they were compelled to mark it in orthography, where par ce que (j'ai fait) 'by what (I did)' (I >> A > O > E) in three words (cf. Chapter 270, \$9) is distinguished from causal parce que (je l'ai fait) 'because (I did it)' (I >>E) in two words. The number of words marked by orthography is inspired by the number of underlying facts of transfer.

\$12 Type I >> A > O > E; Mark 1, 3 .

Gr. ex ohû gégona 'since I exist'.

1 (I >> A) Second-degree transfer of the verb gégona 'I was created / I am' to an adjective marked by the translative element contained in the relative pronoun gégona.

$2(\mathrm{~A}>\mathrm{O})$ First-degree transfer without a marker of the adjective thus obtained to a masculine noun expressing time (khrónos).

$3(\mathrm{O}>\mathrm{E}) \quad$ First-degree transfer of the noun thus obtained to a temporal adverb (duration), marked by the genitive reinforced by the translative (preposition) ex 'since': ex oh û gégona 'since I exist'.

Likewise: Gr. aph' ohû 'since' (conjunction), en hôi 'since (the time) when', eph' ồs 'under which (conditions)': Ohi parà Lakedaimoniōn hékontes ếlegon eph' oîs hétoimoi eîen tēn eirếnēn poieîsthai Lakedaimónioi (Lysias) 'The messengers from Sparta are saying under which conditions they were ready to conclude peace'.

\$13 Type I >> A > I > A; Mark 1, 2, 3 .

Lat. Hoc ad id quod propositum est non est necessarium 'It's not necessary on my behalf' (Cicero, Orator, 20, 68).

1 (I >>A) Second-degree transfer of the verb proponit 'proposes' to an adjective marked by the passive anterior participle propositum.

2 (A > I) First-degree transfer of the adjective thus obtained to a verb marked by the verb est: est propositum 'is proposed'.

3 ( $>$ A) First-degree reversive transfer of the verb thus obtained to an adjective marked by the translative element $q u$ - contained in the relative pronoun quod, lit. 'which is proposed'. 


\section{Chapter 271. Quadruple, quintuple, and sextuple transfer}

\section{Quadruple transfer}

\$1 Type $\mathrm{I}>>\mathrm{A}>\mathrm{O}>\mathrm{A}>\mathrm{O}$; Mark 1, 2, 3 .

This type is represented by Fr. J'en ai (du fin et) du bien râpé. 'I have fine and well ground (tobacco)' (J'ai du bon tabac 'I have good tobacco', popular song, cf. Chapter 229, §7).

1 (I >> A) Second-degree transfer of the verb je rape 'I grind' to an adjective marked by the anterior participle râpé.

$2(\mathrm{~A}>\mathrm{O})$ First-degree transfer of the adjective thus obtained to a noun, marked by the definite article le contained in the contracted article $d u$ : le bien râpé 'the well ground'.

$3(\mathrm{O}>\mathrm{A})$ Transfer of the noun thus obtained to an adjective, marked by the translative (preposition) de contained in the contracted article $d u$ : du bien râpé 'some well ground'

$4(\mathrm{~A}>\mathrm{O})$ Transfer without a marker (partitive article, cf. Chapter 229, \$7) of the adjective thus obtained to a noun.

\$2 Type $\mathrm{E}>\mathrm{A}>\mathrm{I}>>\mathrm{A}>\mathrm{O}$; Mark 2, 3 .

Fr. Le vrai Chrétien doit savoir pardonner à ses ennemis et qui plus est les aimer 'A true Christian must know to forgive his enemies and what is more, to love them'.

1 ( $\mathrm{E}>\mathrm{A}) \quad$ Unmarked first-degree transfer of the adverb plus 'more' to an adjective.

$2(\mathrm{~A}>\mathrm{I}) \quad$ First-degree transfer of the adjective thus obtained to a verb, marked by the verb est: plus est 'is more'.

3 (I >> A) Second-degree transfer of the verb thus obtained to an adjective, marked by the translative element $q u$-contained in the relative pronoun qui: qui plus est 'what is more'.

$4(\mathrm{~A}>\mathrm{O})$ Unmarked first-degree transfer of the adjective thus obtained to a noun in anaphoric connection with pardonner 'forgive'.

$\$ 3$ Type I $>>$ A $>$ O > A > E; Mark 1, 2, 3, 4 .

\begin{tabular}{cc}
\hline Apprenez que tout flatteur & Learn that every flatterer \\
Vit aux dépens de celui & Lives off the one \\
qui l'écoute & who listens to him.
\end{tabular}

(La Fontaine, Fables, I, 2, Le corbeau et le renard)

1 (I >> A) Second-degree transfer of the verb écoute 'listen' to an adjective, marked by the translative element $q u$-contained in the relative pronoun qui: qui (l') écoute 'who listens (to him)'.

$2(\mathrm{~A}>\mathrm{O})$ First-degree transfer of the adjective thus obtained to a noun, marked by the retranslative celui: celui qui l'écoute 'the one who hears it'. 
$3(\mathrm{O}>\mathrm{A})$ First-degree reversive transfer of the noun thus obtained to an adjective, marked by the translative (preposition) de: de celui qui l'écoute 'of the one who hears it?.

4 (A > E) First-degree transfer of the adjective thus obtained to an adverb, marked by the prepositive expression obtained by elliptical transfer: aux dépens de at the expense of'

\section{Quintuple transfer}

$\$ 4$ Type I > A > O > A > E; Mark 1, 2, 3, 4, 5 .

Fr. aux dépens de celui qui l'a écouté 'at the expense of the one who has listened to him'

1 (I > I) First-degree subcategory transfer of the verb écoute 'listen' to its anterior present form, marked by the auxiliary verb $a$ : a écouté 'has listened.

2 (I > A) Second-degree transfer of the verb thus obtained a écouté to an adjective, marked by the translative element qu-contained in the pronoun qui: qui $\left(l^{\prime}\right)$ a écouté 'who has listened (to him)'.

$3(\mathrm{~A}>\mathrm{O})$ First-degree transfer of the adjective thus obtained to a noun, marked by the retranslative celui: celui qui l'a écouté 'the one who has listened to him'.

$4(\mathrm{O}>\mathrm{A})$ Reversive first-degree transfer of the noun thus obtained to an adjective, marked by the translative preposition de: de celui qui l'a écouté 'of the one who has listened to him?

5 (A > E) First-degree transfer of the adjective thus obtained to an adverb, marked by the prepositive expression obtained by elliptical transfer aux dépens de at the expense of'.

\section{Sextuple transfer}

$\$ 5$ Type I >> E > A > O > A > I > I; Mark 1, (2), 3, 4, 5, 6 .

Fr. Mademoiselle va être à la fois d'un comme il faut et d'un troublant 'Ms. is going to be both so upstanding and so sexually disturbing' (Henri Lavedan, Viveurs, act IV, p. 29).

1 (I >> E) Second-degree transfer of the verb il faut 'must' to an adverb, marked by the translative comme: comme il faut, lit. 'as it should be', that is 'upstanding'.

2 (E > A) Unmarked first-degree transfer of the adverb thus obtained to an adjective (cf. Chapter 197, \$2).

$3(\mathrm{~A}>\mathrm{O}) \quad$ First-degree transfer of the adjective thus obtained to a substantive marked by the indefinite article un: un comme il faut, lit. 'one as it should be'

$4(\mathrm{O}>\mathrm{A})$ Reversive first-degree transfer of the noun thus obtained to an adjective, marked by the translative (preposition) de: d'un comme il faut, lit. 'of one as it should be', that is 'so upstanding. 
5 (A > I) First-degree transfer of the adjective thus obtained to a verb, marked by the verb est: est d'un comme il faut 'is so upstanding'.

6 (I $>$ I) First-degree subcategory transfer of the verb thus obtained to its future form, marked by the auxiliary va: va être d'un comme il faut 'will be so upstanding.

$\$ 6$ We have not encountered cases of multiple transfer containing an instance of seconddegree transfer composed of more than six component transfers, but that does not mean that they do not exist (cf. Chapter 238, \$4). 


\section{BOOK F}

\section{Applications}

\section{Chapter 272. The complete stemma}

\$1 If we make use of all the possibilities that the stemmatization of a sentence offers us for graphically representing its infinite structural complexities, we end up with stemmas of a complexity that we have essentially not produced so far during the course of this book.

$\$ 2$ However, in addition to the partial and fragmentary stemmas that we have used to represent this or that particular part of structural syntax, it is possible, at least theoretically, to conceive of a complete stemma that takes into account all the structural elements encountered in a sentence, or at least to approach this ideal.

$\$ 3$ The completeness of such a stemma can be envisioned from a qualitative and a quantitative point of view.

$\$ 4$ Qualitatively, the complete stemma would be such that it accounts for all the structural particularities of the sentence, that is, it would include both the connections of simple sentences and the complications due to junction or transfer.

$\$ 5$ From a practical standpoint, we have hardly had the opportunity to present stemmas of this nature, the desire for clarity of exposition having motivated us to not complicate the exposition with superfluous facts.

$\$ 6$ Furthermore, it would have been poor methodology of exposition to take account of the facts of junction or transfer in the first part, which examined just the simple sentence, or to have overloaded the exposition with facts about the one type of structure, be it junction (see the second part) or transfer (see the third part), with facts about the other type.

\$7 But that does not mean that these complications do not exist. Quite to the contrary, they are the rule, and if the theoretical exposition of the facts of structural syntax has to ensure that it does not mix disparate facts, reality forces us to mix the facts belonging to various areas, since reality presents us with facts that are nine times out of ten completely mixed.

$\$ 8$ Hence the facts of transfer are subject to the principle of junction in the same measure as the facts of the simple connection. We will see numerous examples of this with the few sentences above (cf. Chapter 135, \$9) for which we will give the complete stemmas below. $\$ 9$ Quantitatively, we have always remained with a single sentence.

\$10 But in reality, language does not present itself to us in a succession of isolated sentences. The norm is rather a sequence of sentences that express ideas that are interrelated 
and form an organized whole in order to express a more or less complex thought, either orally or in writing.

\$11 In everyday language, oral interventions can be brief. But it is generally not easy to be as laconic as Cambronne, ${ }^{316}$ and every orator knows the difficulty of expressing a somewhat complex thought in concise terms. The complete stemma of an unending conversation or of a long discourse contains all the stemmas of its constituent sentences.

$\$ 12$ Likewise, written works can be of any length. A quatrain is brief, unlike an epic poem in twelve songs. A theater piece of five acts necessarily contains a large enough number of sentences. The complete stemma of a work of this sort contains the constituent stemmas of all the sentences of which it is constituted.

$\$ 13$ One is thus quickly confronted in practice with the extreme dimensions of the complete stemma. We will therefore be content below to produce the stemmas of some short pieces (fables, epigrams).

$\$ 14$ As soon as a complete stemma is constituted by multiple sentences relating to a process involving more than one actant, it becomes almost fatal when it contains dashed connections indicating anaphoric reference, the complex interaction of these connections showing the structure of the envisioned piece and its economy.

\$15 Hence in The cicada and the ant (La Fontaine, Fables, I, 10), the dashed line of the anaphor referring to the cicada, which begins with the first word of the fable (cf. Chapter $42, \$ 16$ ), quickly becomes intertwined with that of the ant, the other character in the scene, the latter dominating at the end of the fable. In the middle, the two dashed lines freely cross over each other (cf. Stemma 354): 317

La cigale, ayant chanté
Tout l'été
Se trouva fort dépourvue
Quand la bise fut venue:
Pas un seul petit morceau
De mouche ou de vermisseau.
Elle alla crier famine
Chez la fourmi sa voisine;
La priant de lui prêter
Quelques grains pour subsister
Jusqu'à la saison nouvelle.

La cigale, ayant chanté Tout l'été

Se trouva fort dépourvue Quand la bise fut venue:

Pas un seul petit morceau

De mouche ou de vermisseau.

Elle alla crier famine

Chez la fourmi sa voisine;

Lupriant de lui prêter

Jusqu'à la saison nouvelle.
'The cicada having sung
The entire summer
Found itself without means
When the North wind came:
Not a single small bite
Of fly or worm.
She went to cry famine
To the ant her neighbor;
Asking of her to lend
A few grains for subsistence
Until the new season.

316. Translators' note: Cambronne was Napoléon's general. At the battle of Waterloo, Cambronne, who was commanding the last battalion, is supposed to have answered to the British asking him to surrender: “Merde!”, lit. 'Shit!', that is, 'Go to hell!'. This reply became famous and is known as le mot de Cambronne 'the word of Cambronne'. It is, for instance, repeated in Victor Hugo's account of Waterloo in his novel Les Misérables.

317. The reader can find the stemmas 354, 355, 356, 357, 358, 360, 361, 363, 364, 365, 366 grouped immediately after chapter 275 below. 
"Je vous paierai, lui dit-elle, Avant l'oût, foi d'animal, Intérêt et principal.» La fourmi n'est pas prêteuse: C'est là son moindre défaut. "Que faisiez-vous au temps chaud?» Dit-elle à cette emprunteuse. - «Nuit et jour à tout venant Je chantais, ne vous déplaise.» - «Vous chantiez? J'en suis fort aise; Eh bien! dansez maintenant.»
"I will pay you, she told her,

Before August, on my creed,

Interest and principal."

The ant is not unselfish:

That is her lesser fault.

"What did you do when it was warm?"

She said to the beggar.

"Night and day to all comers

I sang, even if it doesn't please you."

- "You sang? I am very happy about it;

Well then! Dance now." '

(La Fontaine, Fables, I, 1, La cigale et la fourmi)

$\$ 16$ In Le vase brisé 'The broken vase' by Sully Prudhomme, the interplay of dashed anaphor lines is more subtle. At first, anaphoric reference points to the cracked vase, which is the only character in the poem up to the point where it is imperceptibly and very skillfully replaced by the broken heart, which the cracked vase symbolizes (cf. Stemma 355).

\begin{abstract}
Le vase où meurt cette verveine D'un coup d'éventail fut fêlé; Le coup dut l'efleurer à peine, Aucun bruit ne l'a révélé.

Mais la légère meurtrissure, Mordant le cristal chaque jour, D'une marche invisible et sure En a fait lentement le tour.
\end{abstract}

Son eau fraîche a fui goutte à goutte, Le suc des fleurs s'est épuisé, Personne encore ne s'en doute,

N'y touchez pas, il est brisé Souvent aussi la main qu'on aime, Effleurant le cour, le meurtrit Puis le cour se fend de lui-même, La fleur de son amour périt.

Toujours intact aux yeux du monde, Il sent croître et pleurer tout bas Sa blessure fine et profonde; Il est brisé, n'y touchez pas.

\author{
'The vase where this vervain is perishing \\ Was cracked from a fan's tap; \\ The tap hardly grazed it, \\ No sound did it make. \\ But the light bruise, \\ Pecking at the crystal every day, \\ By an invisible and constant pace \\ Has slowly reached around.
}

Its fresh water has leaked drop by drop

The sap of the flowers has petered out,

Nobody is still in doubt,

Don't touch it, it is broken.

Often also the hand that one loves,

Touching the heart, bruises it;

Then the heart becomes cracked,

The flower of its love perishes.

Always intact to the eyes of the world,

It feels its fine and deep wound

Growing and weeping quietly;

It is broken, don't touch it.

(Sully Prudhomme, Le vase brisé 'The broken vase')

$\$ 17$ Furthermore, the complete stemma of a discourse or of a written work, while it might be a curiosity, is hardly of practical interest. One will therefore rarely choose to employ the complete stemma in common usage.

$\$ 18$ While the microscope would be useless and encumbering if one wanted to use it to obtain facts about any subject in daily life in great magnification, it is indispensable for the up-close study of strictly limited elements. So too the stemma; its role is just to permit one to account for the details of sentence structure, not for the entire edifice that sentences 
permit one to construct. In a word, it would be completely counterproductive to use what is essentially a microscope as a telescope.

\section{Chapter 273. Using the stemma for the study of style}

$\$ 1$ Whether complete or not, the stemma has the advantage of permitting one to explicitly acknowledge the characteristics of style that are contained implicitly in a given passage and that native speakers instinctively sense, these speakers having a feel for the nuances of their mother tongue.

\$2 Thus the stemma permits one to clarify the exact nature of the resources that the syntactic structure of a given language puts at the disposal of the writer, and of the stylistic processes, which can enrich the writer's art by their judicious use.

$\$ 3$ This is why French and many other languages can take varied effects and very expressive processes of style from the use of reversive transfer (cf. Chapter 196).

$\$ 4$ The independence of structural means from semantic means (cf. Chapter 20, \$17) is also the base of effects that have stylistic value, and the structural mechanisms of these effects can be brought to light by the stemma.

$\$ 5$ We have already seen (cf. Chapter $266, \$ 2 \mathrm{ff}$.) that this independence can lead to opposite means of expression belonging to various registers, from the most rigorous and elevated style to the lowest vulgarism (cf. ibid., $\$ 3$ and 4 ).

$\$ 6$ It also permits one to explain the mechanism of a stylistic effect as refined as subordinate irony (cf. Chapter 266, \$10) used by some of our best authors very effectively (cf. Chapter ibid., $\$ 11$ and 12).

\$7 Finally, it has permitted French to recast primary interrogatives as secondary interrogatives (cf. Chapter $81, \S 1$, and Chapter 267), which are stylistically less refined, but more popular, more expressive, and very easy to use (cf. Chapter $81, \$ 2-5$ ). This development constitutes undeniable progress for the language because it presents the inappreciable advantage of clarity, leaving no room for ambiguity (cf. Chapter $81, \$ 6 f f$.).

$\$ 8$ In addition to mechanisms allowing one to focus on details, the stemma permits one to see the general layout of the sentence clearly.

$\$ 9$ From this point of view, one can distinguish between two main types of sentences, rhetorical sentences and short sentences. The two chapters that follow are devoted to each of these two types of sentence.

\section{Chapter 274. Rhetorical sentences}

\$1 Rhetorical sentences are generally those of primitive languages.

$\$ 2$ They arise from the conscious application of mechanisms of style used by the masters of oratory who shed light on oratory efficacy. 
$\$ 3$ Since simple and primitive people have an innate taste and naive admiration for complicated sentences - which they themselves are incapable of producing - the rhetorical sentence can take on dimensions that are quite vast.

$\$ 4$ The sentence thus expanded ends up a periodic sentence, which is the primary artistic form that the Greeks and Latins used.

$\$ 5$ The classical periodic sentence presents, following monuments as the model, an architecture the fundamental structure of which is easy to recognize using stemmas.

$\$ 6$ This architecture is essentially constituted by the opposition of two parts that correspond to each other more or less symmetrically. The masters of classical rhetoric distinguished between these parts using the terms protasis (etymologically 'put forward') and apodosis (etymologically 'give back'), the two following each other on the spoken chain.

$\$ 7$ We have already seen - regarding the conditional sentence (cf. Chapter 257, \$19ff.) - the advantage of adopting this excellent terminology, which itself has unfortunately fallen into disfavor due to the unfounded criticisms that afflict many of the classical disciplines.

$\$ 8$ As is the case in particular in conditional sentences, the protasis is generally a subordinate clause, and the apodosis is generally the main clause that governs the protasis.

$\$ 9$ This is what is produced in the two classical periodic sentences, the one Greek and the other Latin, which we now cite below as examples.

$\$ 10$ In the Greek periodic sentence, the protasis extends through tôu haliéos 'the fisherman', and the apodosis begins with ohútō kaì sú 'now you likewise':

\begin{tabular}{|c|c|}
\hline 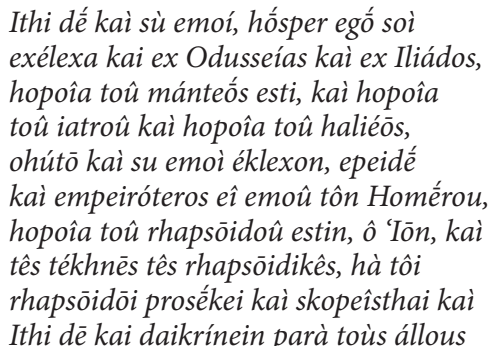 & $\begin{array}{l}\text { 'Come now, you do for me what I } \\
\text { have done for you. From both the Odyssey } \\
\text { and Iliad, I picked out for you the passages } \\
\text { belonging to the doctor, the diviner, and } \\
\text { the fisherman; now you likewise, since } \\
\text { you are better versed than I in Homer, } \\
\text { pick out for me the sort of passages, Ion, } \\
\text { that concern the rhapsode and the rhapsode's } \\
\text { art, the passages it befits the rhapsode, } \\
\text { above all other men, to examine and to judge.' }\end{array}$ \\
\hline
\end{tabular}

(Plato, Ion, 539 d-e, cf. Stemma 356)

11 One can see with this Greek example - as shown by Stemma 356, which represents its structural economy - that one is dealing with a sophisticated and well-organized sentence architecture, with complex developments through finely nuanced exprimendes (cf. Chapter 16). The result is inevitably a quite long sentence.

$\$ 12$ In the following Latin periodic sentence, the protasis extends through studiis and the apodosis begins with deducebatur: 
Ergo apud majores nostros juvenis ille, qui foro et eloquentiae parabatur, imbutus iam domestica disciplina, refertus honestis studiis deducebatur a patre vel a propinquis ad eum oratorem, qui principem in civitate locum obtinebat.
'And among our ancestors, that young man who was being readied for forensic oratory, already molded by firm upbringing at home and filled with liberal studies, was taken by his father or by relatives to some orator who held a ranking position in the commonwealth.'

(Tacitus, Dialogue on Orators, 34, cf. Stemma 357)

$\$ 13$ In the history of French, the Renaissance and the return to the models of classical antiquity that the Renaissance emphasized explains the favor enjoyed by the Greco-Latin periodic sentence among classical writers.

$\$ 14$ The periodic sentence triumphs in the oratory art of Bossuet, from whom we take the following example, where the dividing line between the protasis and the apodosis is marked by a semi-colon in punctuation.

De même qu'on voit un grand fleuve
qui retient encore, coulant dans la
plaine, cette force violente et impétueuse
qu'il avait acquis aux montagnes d'où
il tire son origine; ainsi cette vertu
céleste, qui est contenue dans les écrits
de Saint Paul, même dans cette simplicité
de style, conserve toute la vigueur qu'elle
apporte du ciel, d'où elle descend.

'Just as one sees a great river that still
maintains, as it flows in the plain,
the violent and raging force that it
acquired in the mountains from
whence it has its origin; thus the celestial
virtue contained in the writings of Saint
Paul, even in this simplicity of style,
conserves all the vigor that it brings
from the heavens, from whence it descends.'

(Bossuet, Panégyrique de Saint Paul, cf. Stemma 358)

\section{Chapter 275. Short sentences}

\$1 The Greco-Latin periodic sentence, since it is by nature long and heavy, is poorly suited to French. The sentence of Old French was, in contrast, much simpler, more fractious, and as a consequence, shorter. Only under the classical influence of the Renaissance has French learned, with difficulty, to handle the scholarly periodic sentence.

\$2 On the other hand, long sentences, when they are employed by mediocre writers, necessarily lead to pitfalls that threaten the periodic sentence. These pitfalls induce pompous, swollen, artificial, and even affected style. Even French quickly had to become weary of the periodic sentence, which certainly influenced it but which was unfamiliar to it. French tended to prefer, due to a more or less atavistic taste, the unaffected simple sentence, the secret of which Old French had found by natural inclination.

$\$ 3$ This was the linguistic work of the 18th century and, in particular, of the powerful mind of Voltaire, whose spiritual and incisive style contributed significantly to the triumph of 
the short sentence and to the undermining of the solid position enjoyed by the classical periodic sentence.

$\$ 4$ As an example of the short sentence, we cite Voltaire's famous epigram:

L'autre jour, au fond d'un vallon, Un serpent pique Jean Fréron. Que pensez-vous qu'il arriva? Ce fut le serpent qui creva.
The other day, at the bottom of a valley, A snake bit Jean Fréron. What do you think happened? It was the snake that died.

(Voltaire)
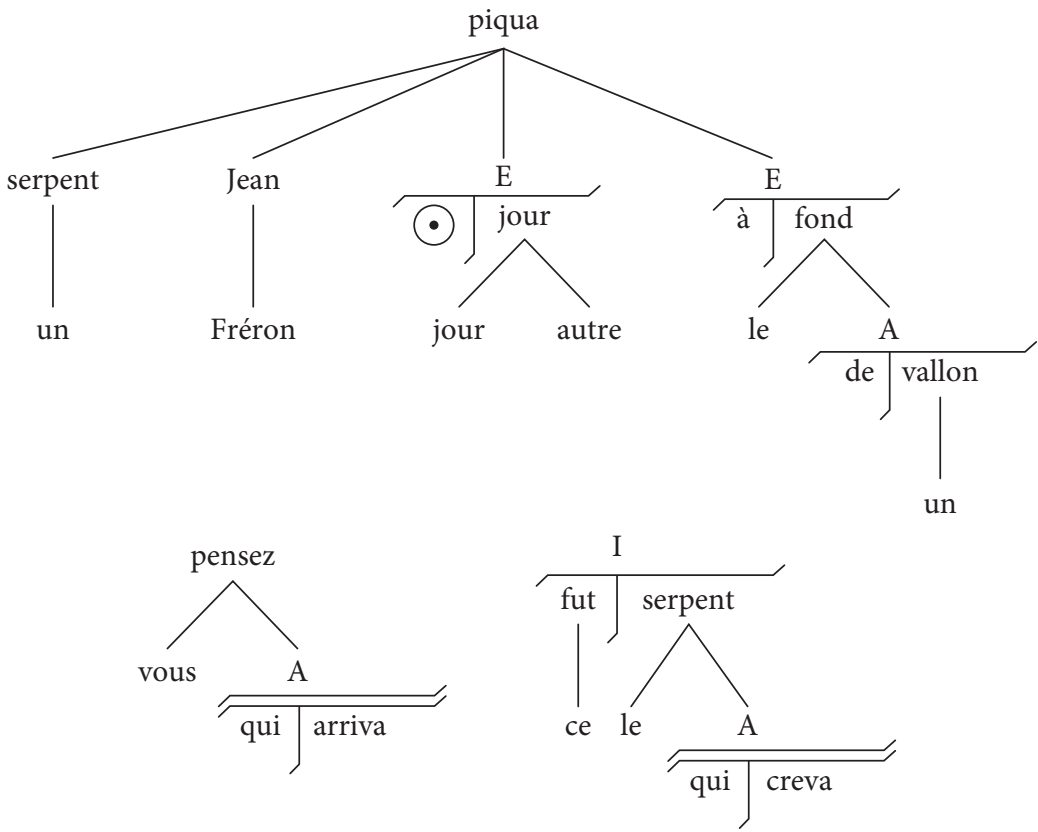

Stemma $359^{318}$

318. Translators' note: The interrogative word que? 'what?' is missing from the stemma of Que pensez-vous qu'il arriva? 'What do you think happened?'. Moreover, this piece of stemma shows qui arriva instead of qu'il arriva, which could suggest that Tesnière hesitated to analyze this sentence as Que pensez-vous qui arriva?, which is more colloquial, but also possible and synonymous. Both sentences are very complex, combining "unbounded dependencies", an impersonal construction, and the so-called qui-qui alternation. Tesnière may have hesitated between two solutions, with que? as a dependent of pesez or of arriva. 
$\$ 5$ But if French has adopted the short sentence that corresponds so well to its genius, this has not occurred without much trial and error, which itself is explained by the variety of innate dispositions of its various writers.

$\$ 6$ The sentences of Corneille fit instinctively into the mold of the Greco-Latin sentence. They were simply long. Further, the stemmas that they furnish are quite expansive. Such is the case in the first stanzas of Polyeucte, the final two octosyllables of which reproduce the classical style, a protasis followed by an apodosis:

Source délicieuse, en misères féconde,

Que voulez-vous de moi, flatteuses voluptés?

Honteux attachements de la chair et du monde,

Que ne me quittez-vous, quand je vous ai quittés

Allez, honneurs, plaisirs, qui me livrez la guerre,

Toute votre félicité

Sujette à l'instabilité,

En moins de rien tombe par terre;

Et comme elle a l'éclat du verre,

Elle en a la fragilité
Delicious spring, fertile in misfortune

What do you want of me, voluptuous pleasures?

Shameful affections of the flesh and the world,

Why do you not leave me, when I left you

Go, honors, pleasures, which do battle with me,

All your felicity,

Prone to instability,

In next to no time, fall down;

And as it has brightness of glass,

It has the fragility of it.

(Corneille, Polyeucte, IV, 2, cf. Stemma 360)

\$7 The same remark is valid for the first stanzas of Cid:

Percé jusque au fond du cour

D'une atteinte imprévue aussi bien que mortelle,

Misérable vengeur d'une juste querelle,

Et malheureux object d'une injuste rigueur,

Je demeure immobile, et mon âme abattue

Cède au coup qui me tue.

Si près de voir mon feu recompensé,

O Dieu, l'étrange peine!

En cet affront mon père est l'offensé,

Et l'offenseur le père de Chimène!
'Pierced to the bottom of the heart

By an unexpected attack as well as mortal,

Miserable avenger of a just quarrel,

And unlucky objet of an unjust rigor

I remain immobile, and my soul weakens

Ceding to the blow that kills me.

So close to see my fire rewarded,

O God, the strange punishment!

In this affront my father is the offended one,

And the offender (is) Chimène's father!'

(Corneille, Le Cid, I, 6, cf. Stemma 361)

$\$ 8$ The sentence of Racine, in contrast, is quite brief, as the words that he prefers are usually monosyllabic. One is familiar with this famous monosyllabic verse in Phèdre, which locates 13 words in two feet: Le jour n'est pas plus pur que le fond de mon cœur 'The day is not more pure than the base of my heart' (Racine, Phèdre, IV, 2; cf. Stemma 362). 


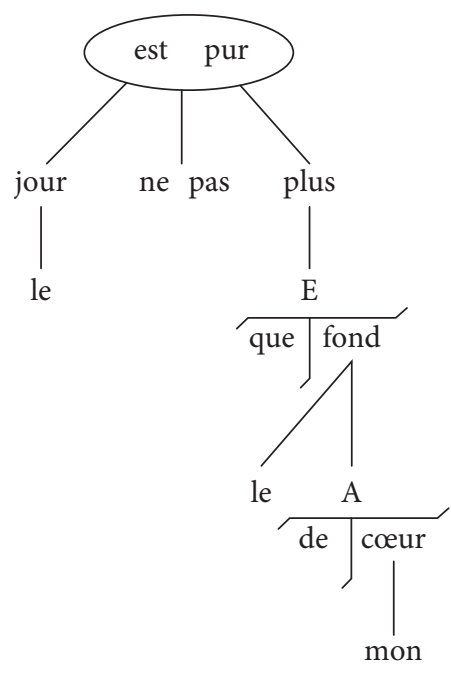

\section{Stemma 362}

$\$ 9$ Further, whereas Corneille always tends to get caught up in long and sonorous sentences that are often convoluted, Racine suffers more from the contrary tendency. He does not manage to lengthen his sentences and thus endows them with the allure of the periodic sentence only by joining them and by repeating the terms to permit his poetic fervor to gain its élan. This style, which one could call wheezy, is particularly clear at the start of poems, when the inspiration of the poet has not yet been awakened. The beginning of Athalie furnishes a good example of this:

Oui, je viens dans son temple adorer l'Eternel, Je viens, selon l'usage antique et solennel, Célébrer avec vous la fameuse journée Où sur le mont Sina la loi nous fut donnée.
'I come into his temple to worship the Eternal I come, following ancient and solemn custom, To celebrate with you the famous day When on M. Sinai, the law was given to us.'

(Racine, Athalie, I, 1; cf. Stemma 363)

$\$ 10$ But if the start of the Racine's sentence is visibly difficult and if he does not at first accomplish the beautiful classical declamation, this does not prevent him from reaching the most beautiful poetic maneuvers as soon as he has taken off:

Promettez sur ce livre, et devant ces témoins,

Que Dieu fera toujours le premier de vos soins;

Que, sévère aux méchants, et des bons le refuge,
Promise on this book, and before these witnesses,

That God will always be the foremost of your concerns;

That, severe to the wicked, and the refuge of the good, 
Entre le pauvre et vous, vous prendrez

Dieu pour juge,

Vous souvenant, mon fils, que, caché sous celin,

Comme eux vous fûtes pauvre, et comme eux orphelin.
Between the poor and you, you will take God as judge,

Reminding yourself, my son, that under this garment,

Like them you were poor, and like them you were orphaned.

(Racine, Athalie, IV, 3, cf. Stemma 364)

\$11 The art with which one can, without apparent effort, arrive at the expansion of a sentence that is by nature short has been brought to its apogee by Victor Hugo, who has given French poesy some of its most beautiful lyric:

Tout reposait dans Ur et dans
Jérimadeth;
Les astres émaillaient le ciel profond et
sombre;
Le croissant fin et clair parmi ces fleurs
de l'ombre
Brillait à Occident, et Ruth se
demandait,

Immobile, ouvrant l'œil à moitié sous ses voiles,

Quel dieu, quel moissonneur de l'éternel été

Avait, en s'en allant, négligemment jeté

Cette faucille d'or dans le champ des étoiles.
'Everything resting in Ur and in Jerimadeth;

The stars studded the sky deep and dark;

The thin and clear crescent among these flowers of shadow

Shone to the Occident, and Ruth asked herself,

Immobile, opening an eye by half under her veil

What god, what reaper of eternal summer

Had, going away, carelessly discarded

This golden sickle in the field of stars.'

(Victor Hugo, Booz endormi, cf. Stemma 365)

$\$ 12$ The degree of perfection that artistic work can reach, even in prose, is magnificently illustrated by the ease of style of Anatole France, whose works serve as a model. Although his sentences are quite brief, they are not limited, nor do they suffer from any apparent pokiness:

J'aime à regarder de ma fenêtre la Seine et ses quais par ces matins d'un gris tendre qui donnent aux choses une douceur infinite. J'ai contemplé le ciel d'azur qui répand sur la baie de Naples sa sérénité lumineuse. Mais notre ciel de Paris est plus animé, plus bienveillant et plus spirituel. Il sourit, menace, caresse, s'attriste et s'égaie comme un regard humain.
'I love to view from my window the Seine and its wharfs on these mornings of a tender grey that grants infinite gentleness to things. I have contemplated the azure sky that extends its luminous serenity over the bay of Naples. But our Paris sky is more animate, more benevolent, and more spiritual. It laughs, menaces, caresses, saddens, and rejoices like human expression.'

(Anatole France, Le crime de Sylvestre Bonnard, IV, June 4th, cf. Stemma 366)

$\$ 13$ These few examples show the usefulness of the stemma for the scientific study of style and the precision and progress its systematic use can give to theoreticians of sentence aesthetics. 

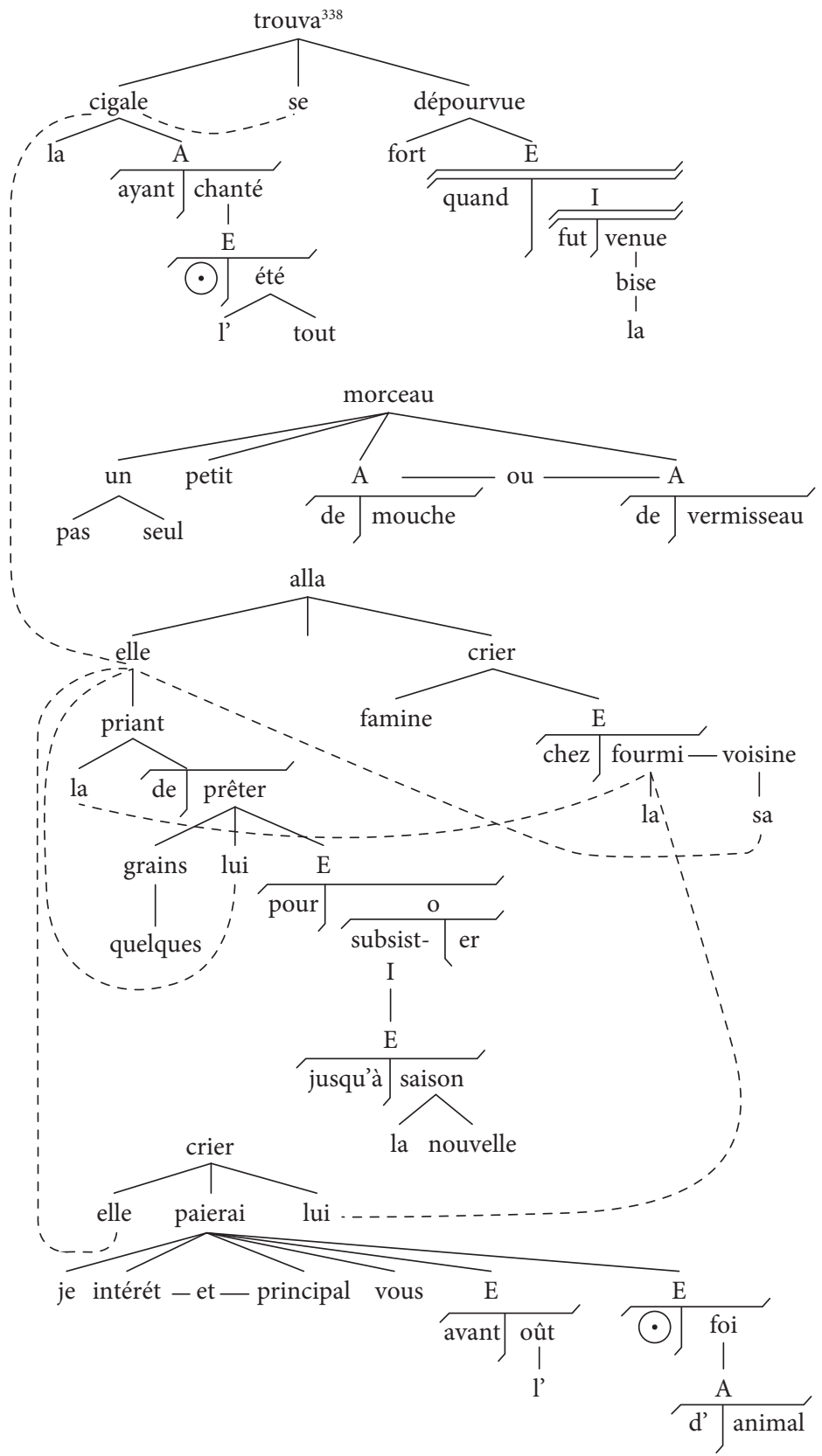

Stemma 354

(Continued)

319. Translators' note: This stemma and the stemmas that follow contained numerous errors in the original edition. We have corrected many of these errors. Others remain. 

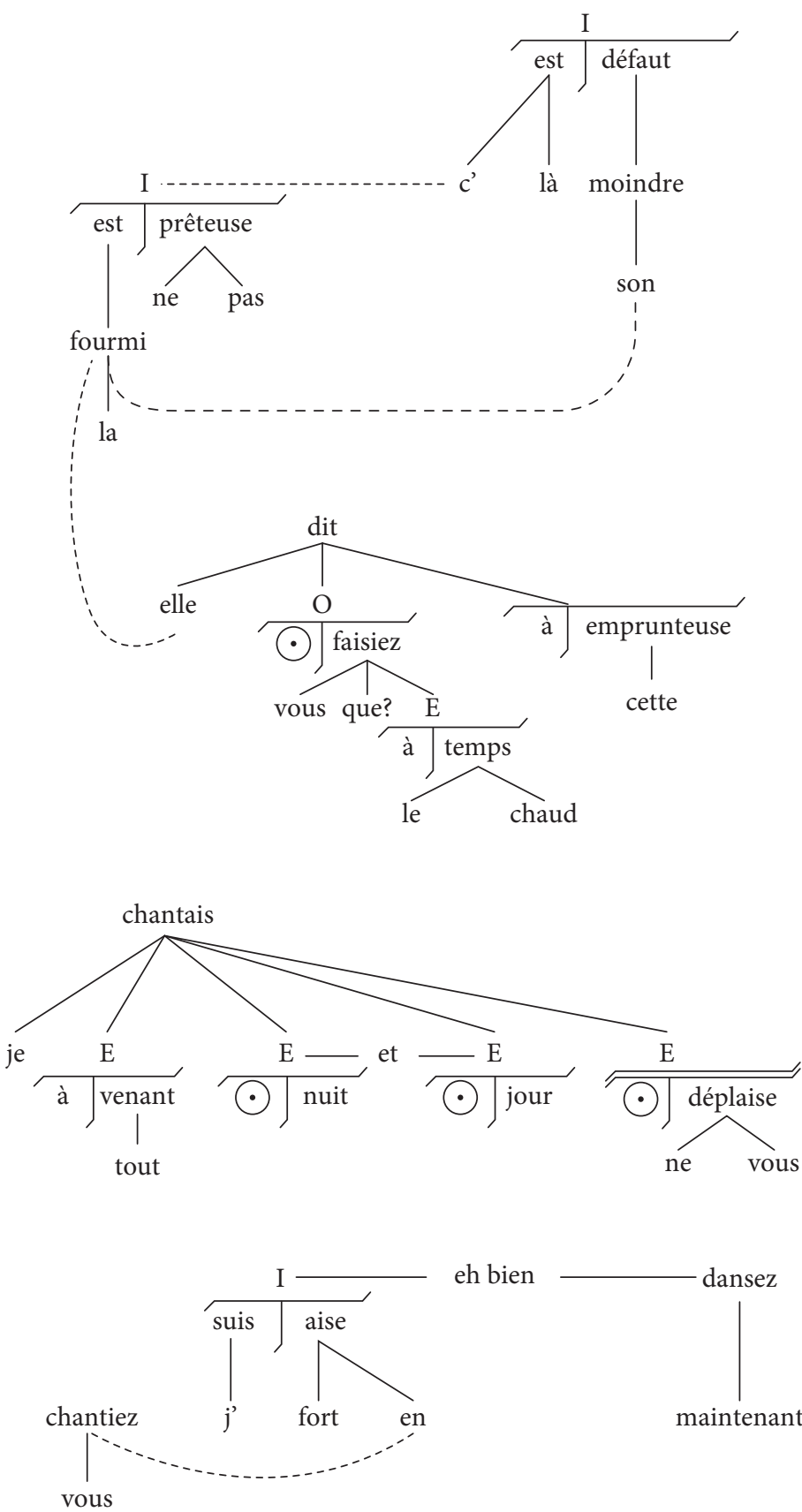


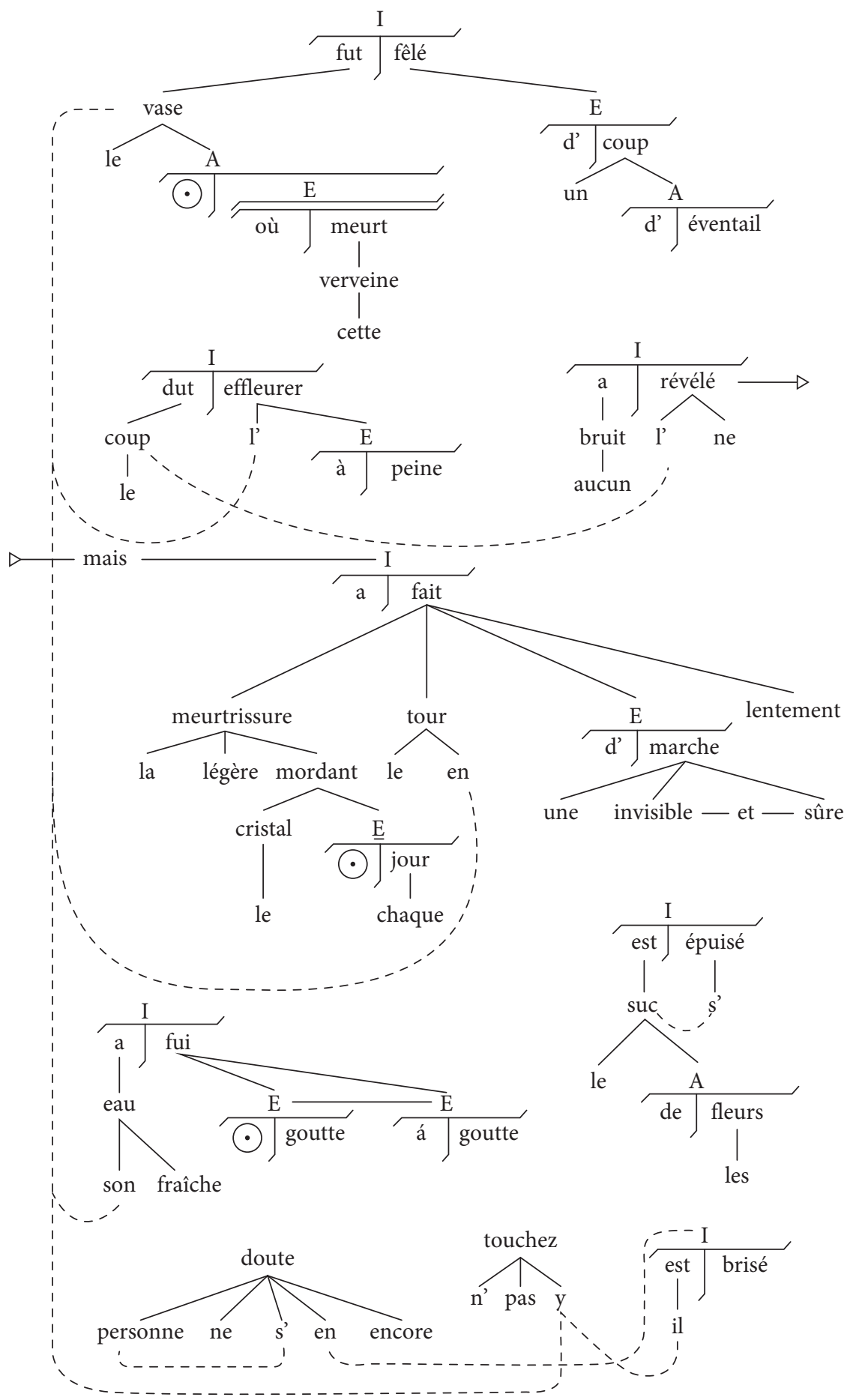




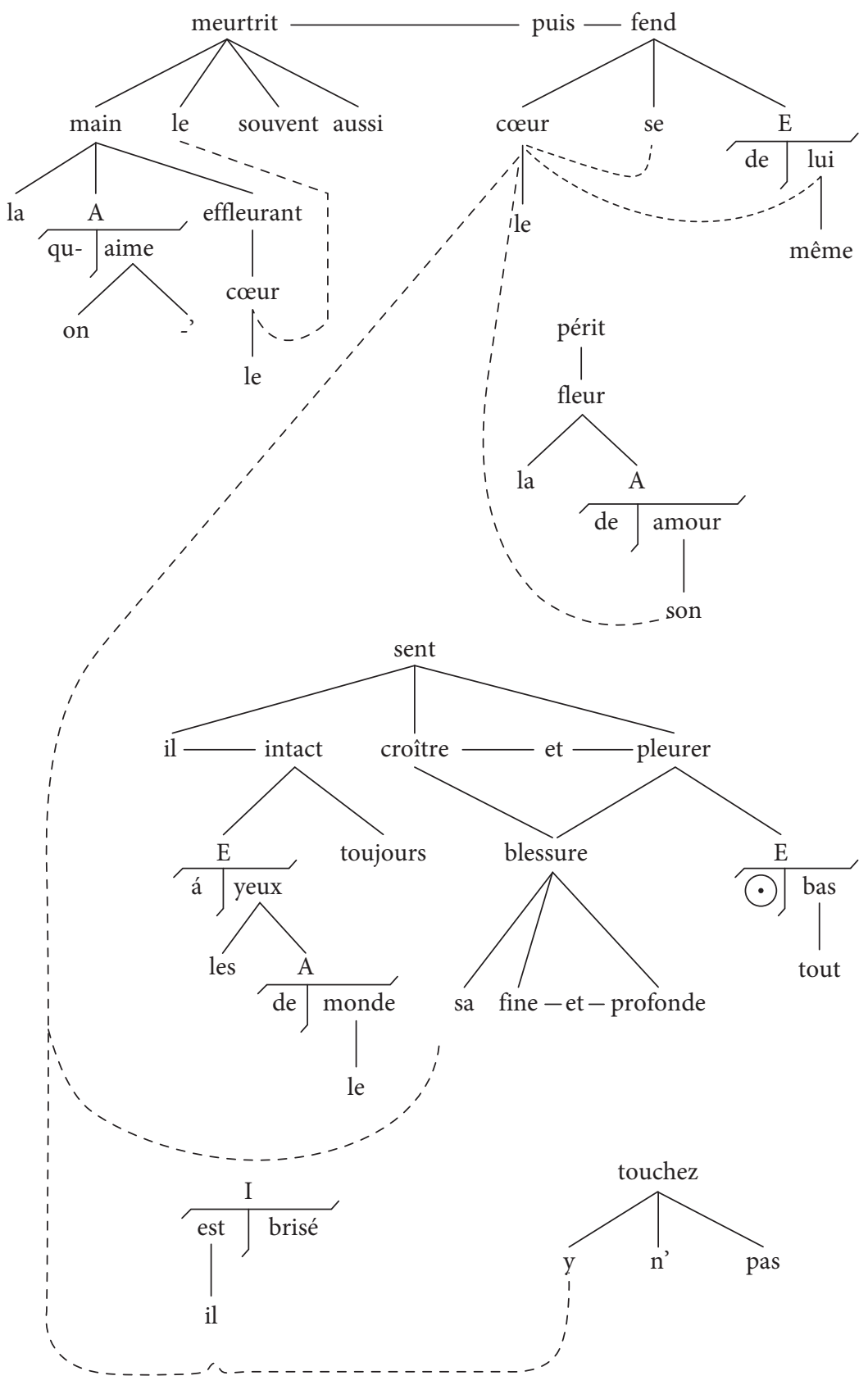

Stemma 355b 


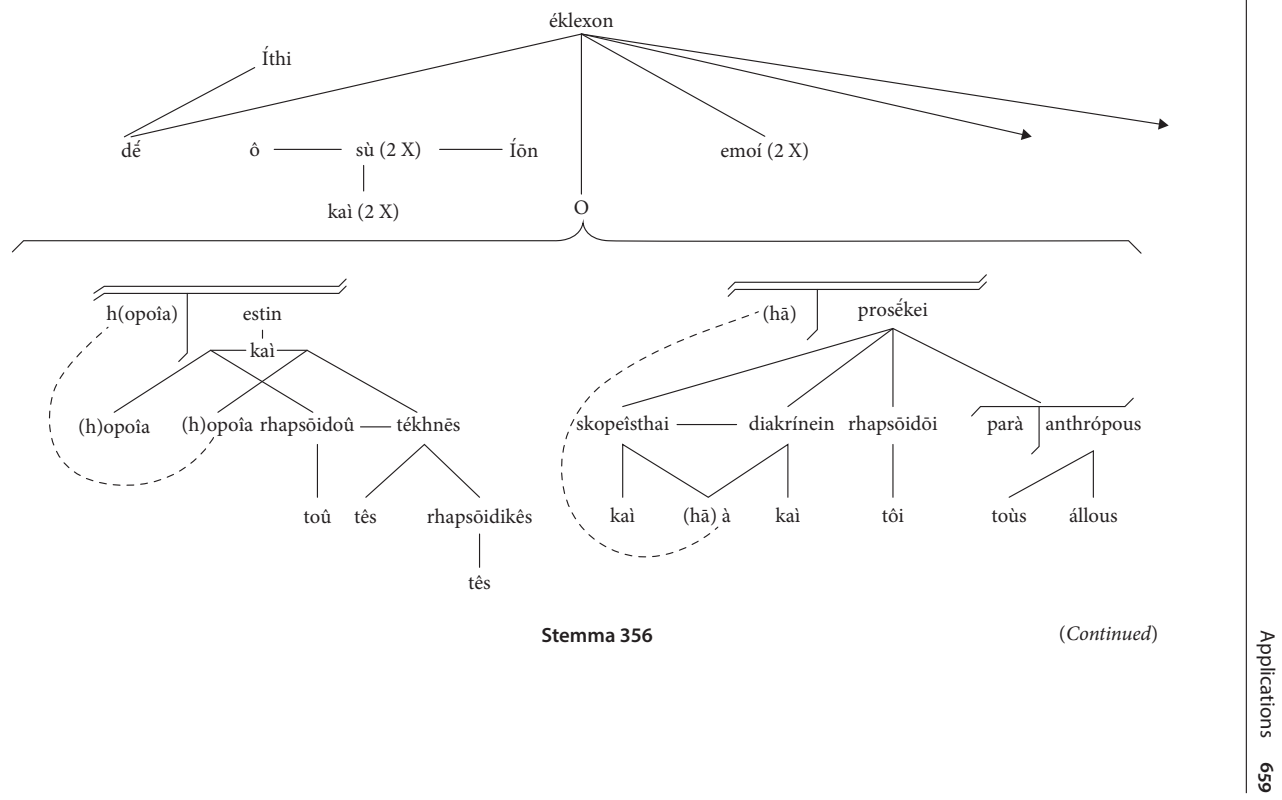




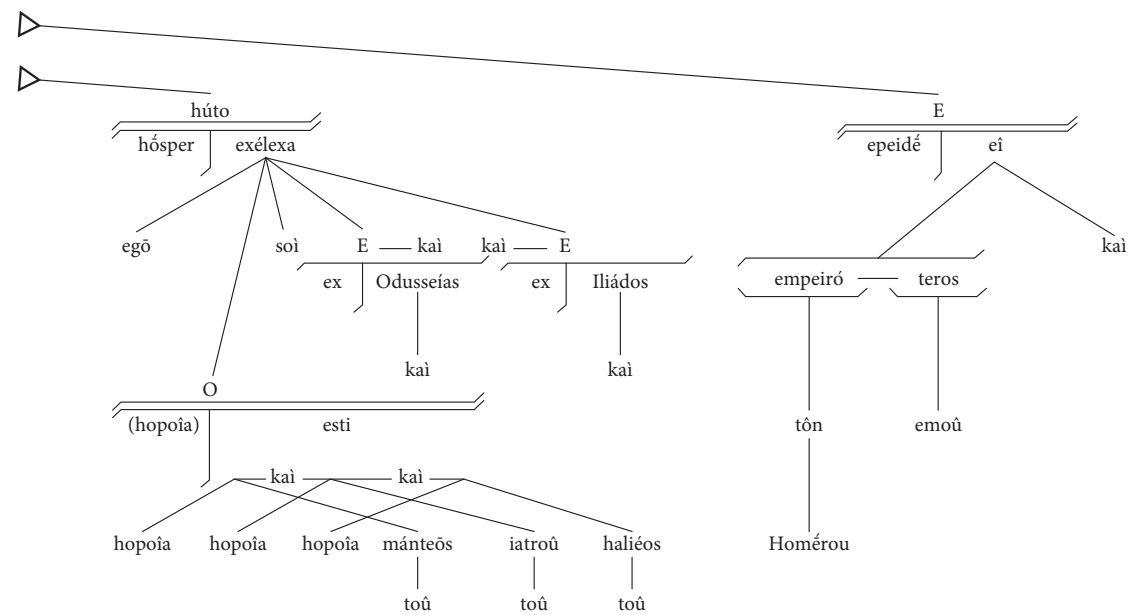

Stemma 356 


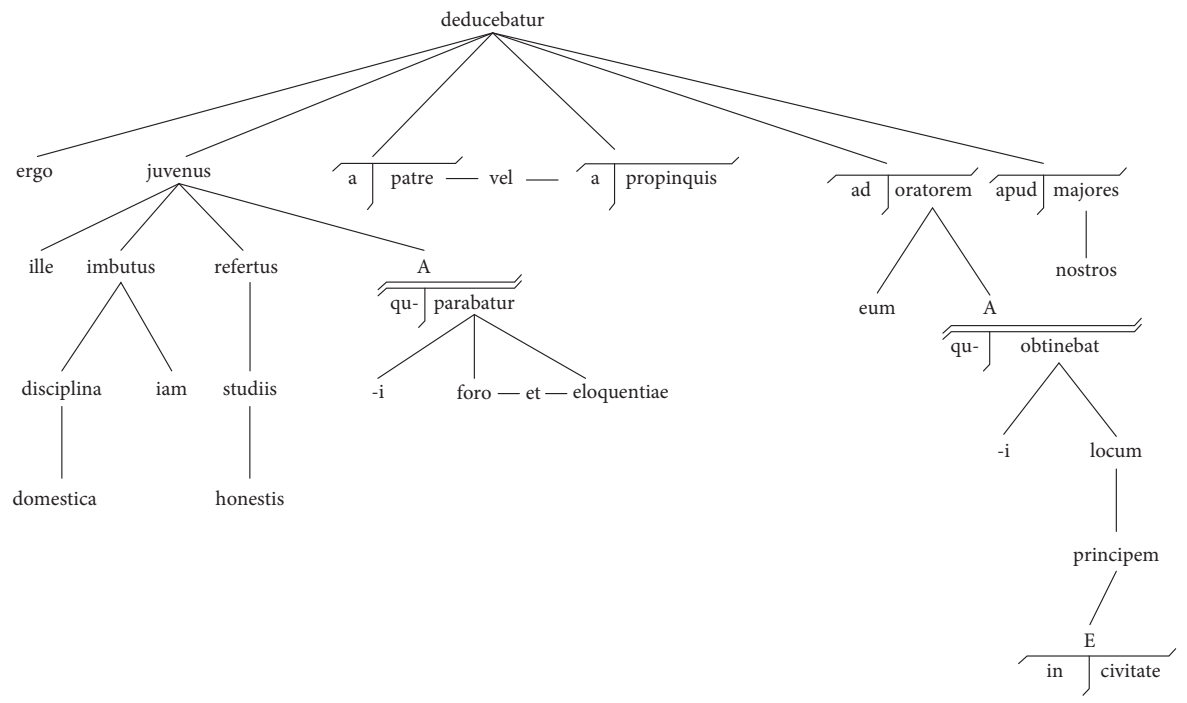

Stemma 357 


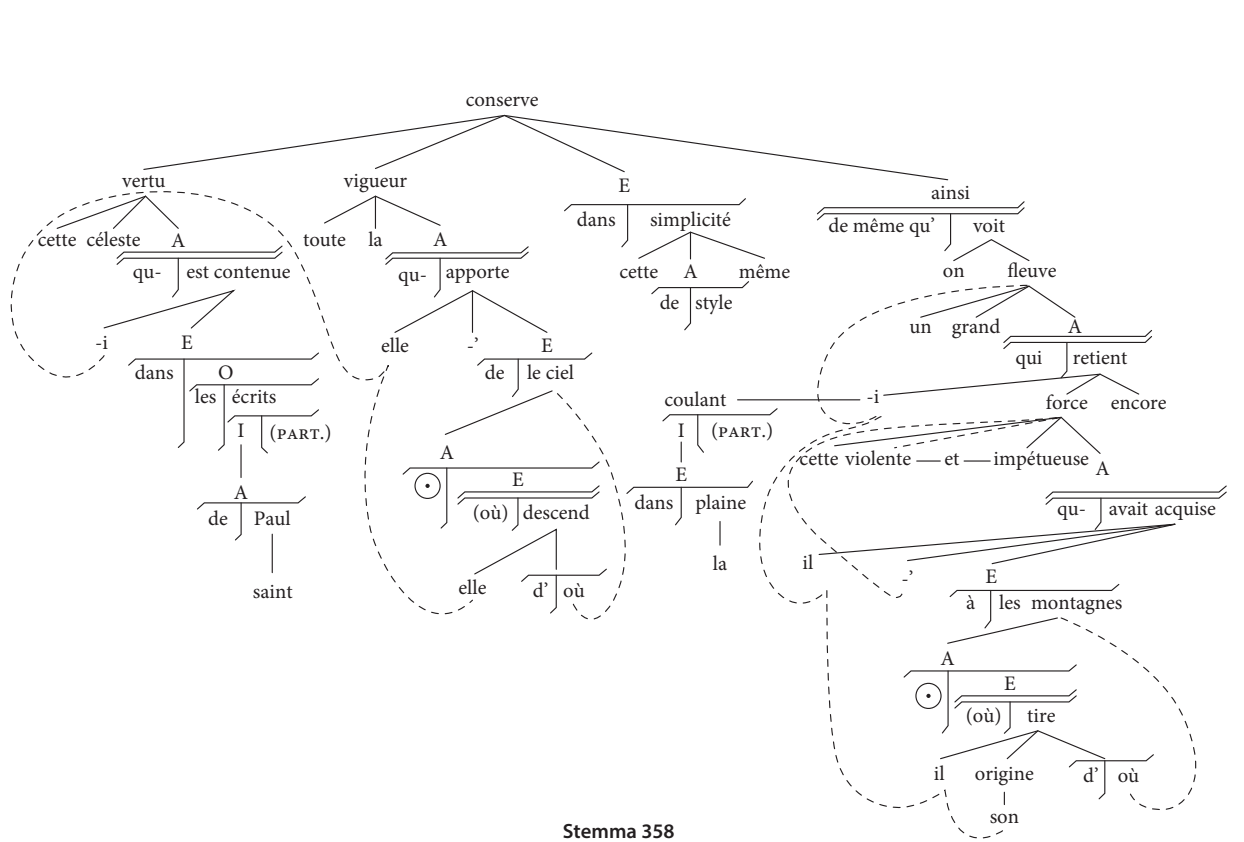




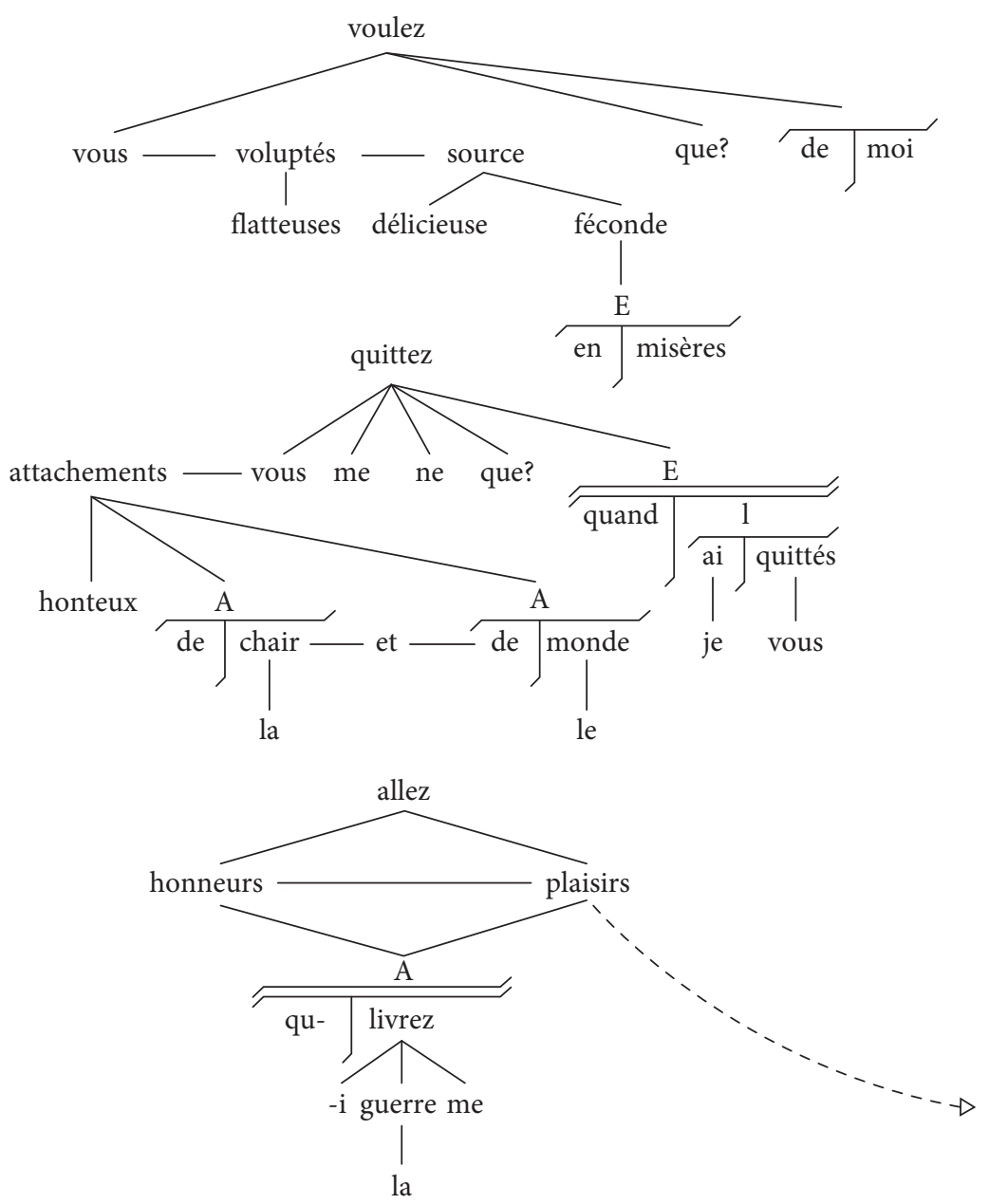

Stemma 360a

(Continued) 


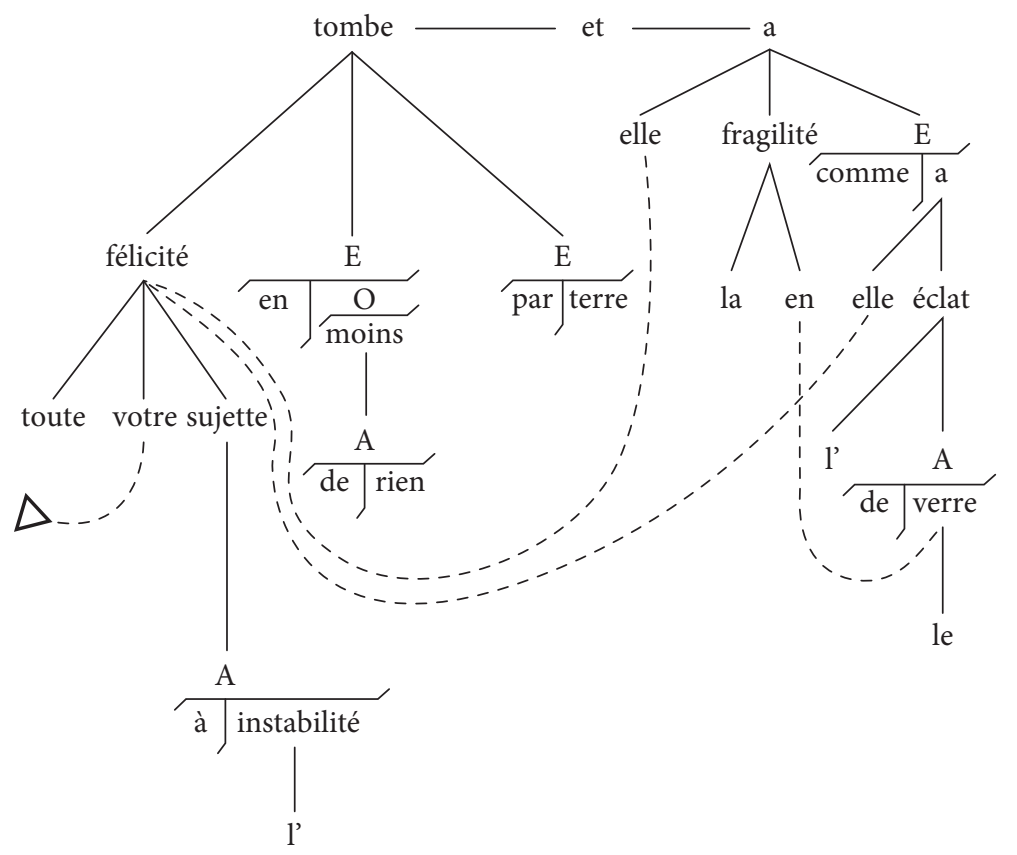

Stemma 360b 


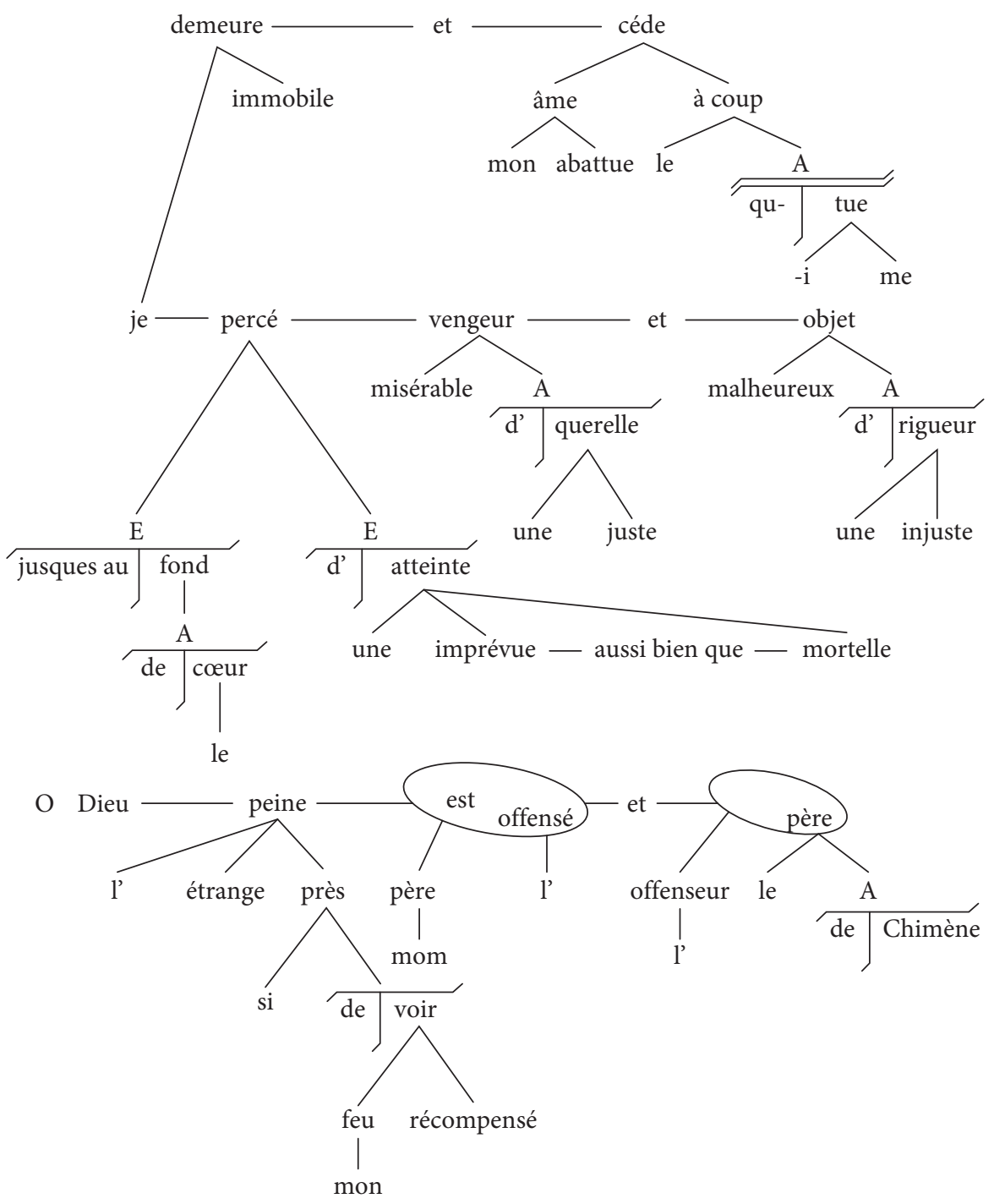

Stemma 361 


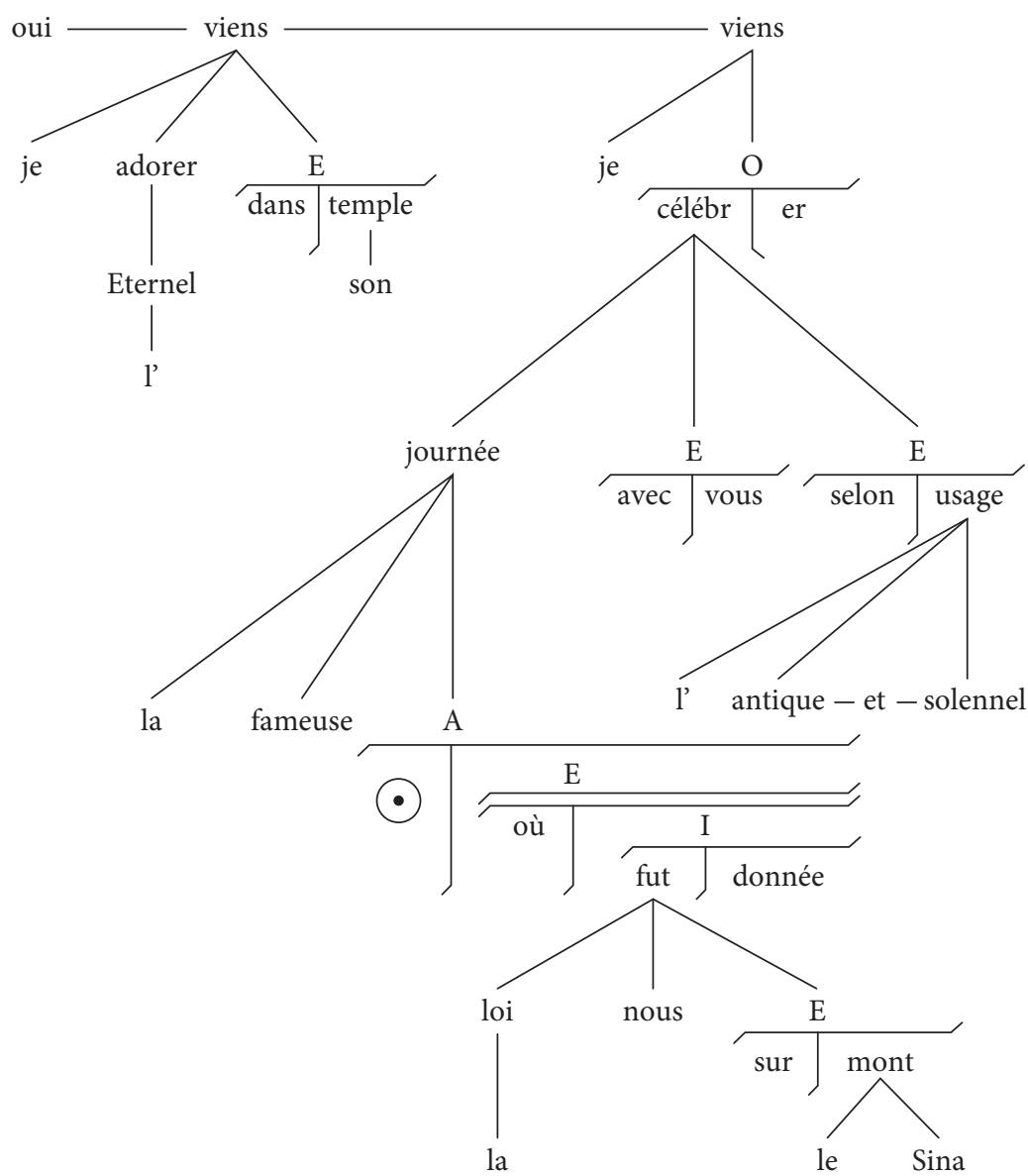

Stemma 363 


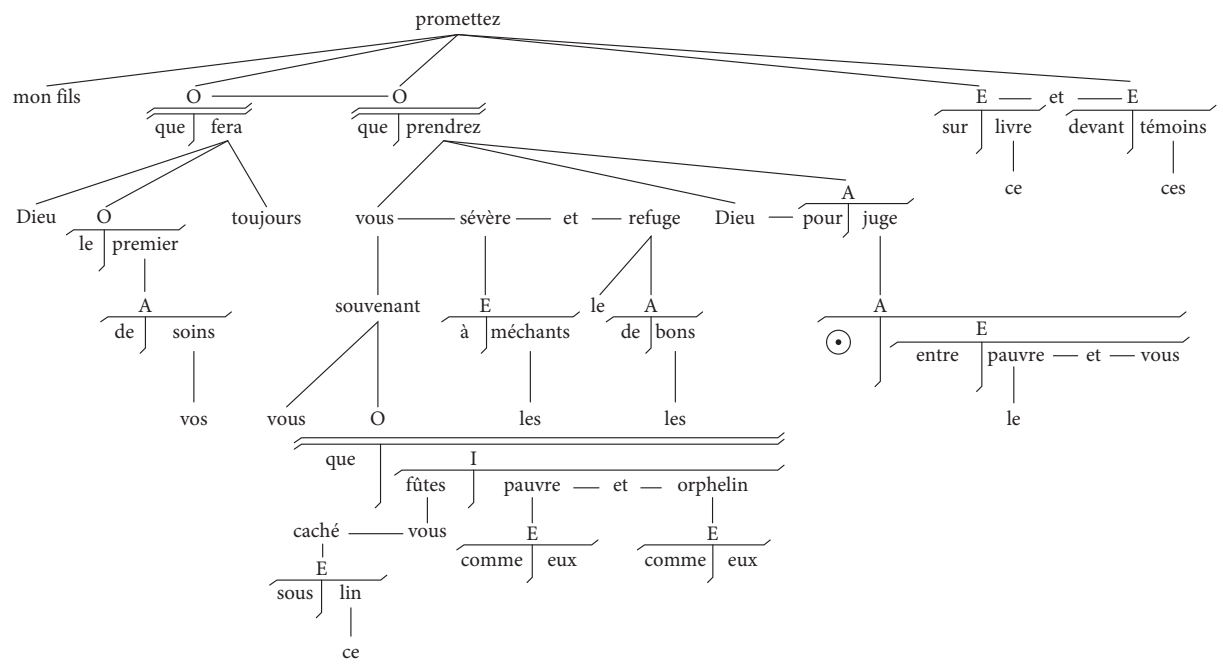

Stemma 364 

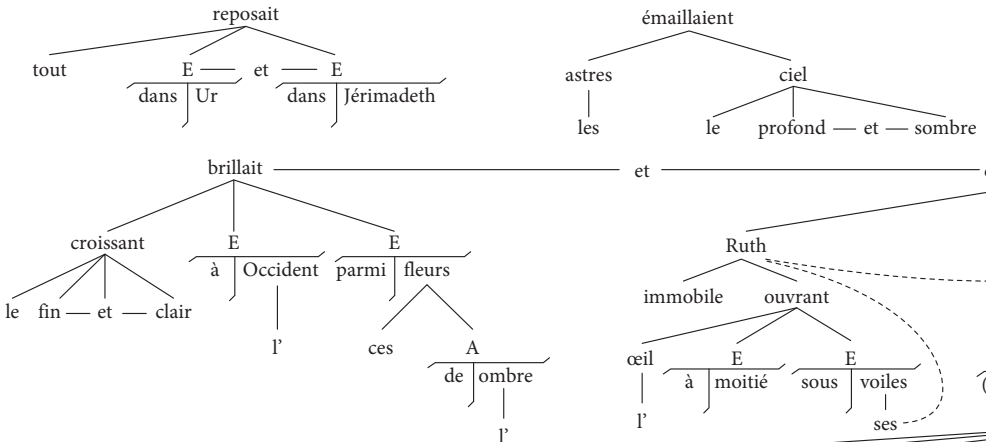

- demandait

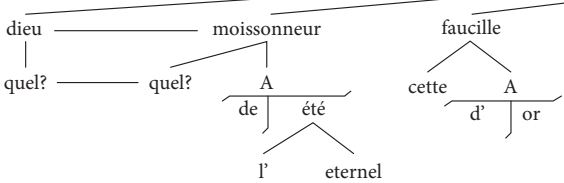

négligemment
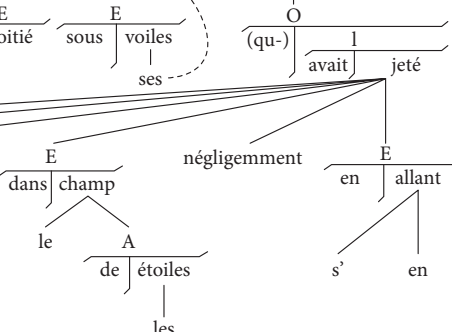

Stemma 365 

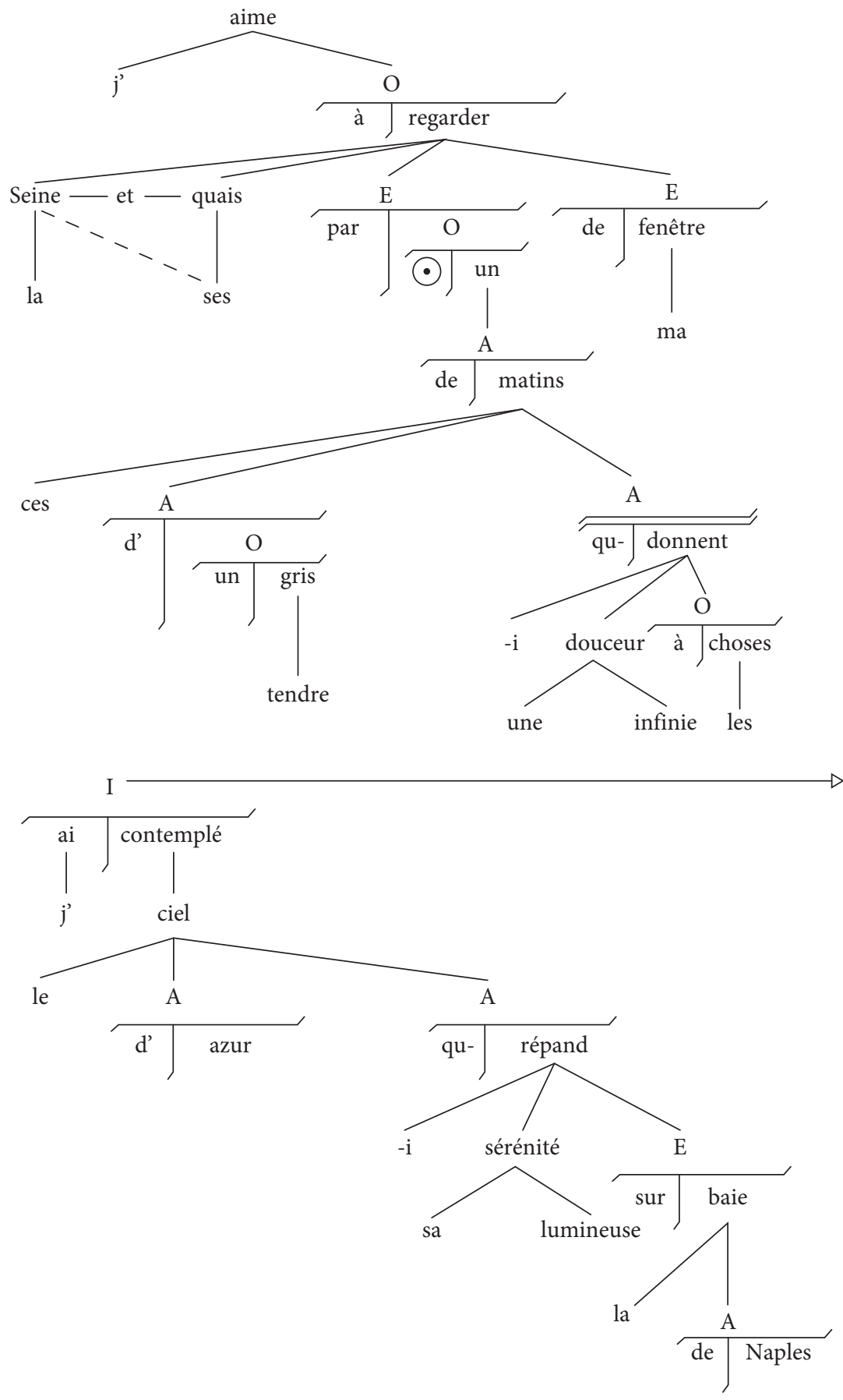

Stemma 366

(Continued) 


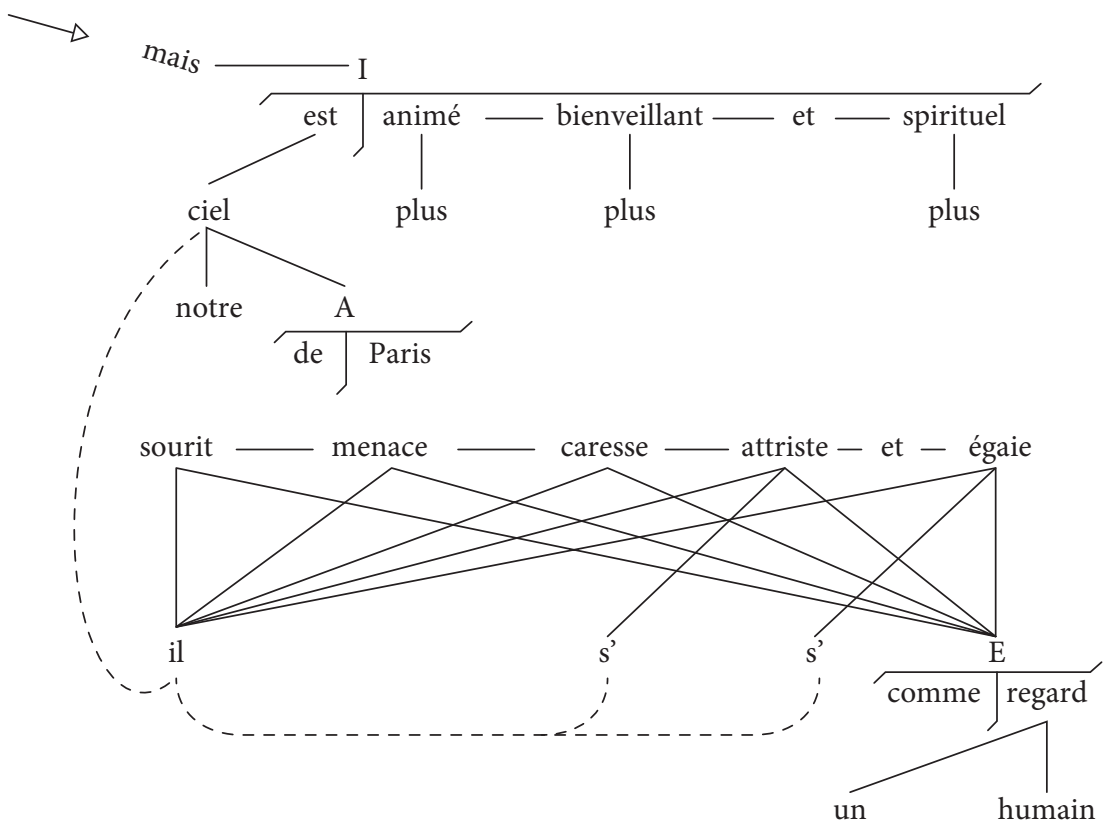

Stemma 366

\section{Chapter 276. Pedagogical directions}

\$1 Experience has demonstrated that the doctrine presented above is more accessible to children and to students who have not yet received any instruction than the ones who have received traditional education.

\$2 The latter, who do not forget what they already know, can do no more than to superimpose the new concepts over those that they have already acquired. They can hence benefit fully from the simplifications that the current doctrine offers. The new doctrine requires from them, at least at first, some extra effort, which is quickly compensated by a clearer vision and deeper understanding of the mechanisms of the sentence.

$\$ 3$ This is not only true for children and students, but also even for adults and teachers. The more one has become used to traditional grammar, the more difficult it is to overcome its influence, regardless of how defective this influence is. This is a completely natural phenomenon, and it requires that the resistance to the advocated novelties be expected more from teachers than from students.

$\$ 4$ Moreover, one must not lose site of the fact that in the areas where the doctrine presented above takes the opposing view of traditional doctrine, the modifications that it necessitates in order to justify its legitimacy will be considered heresy in relation to 
traditional and official teachings. Further, it would be dangerous to forget that students often prepare for tests and competitions where only official doctrine is acknowledged.

$\$ 5$ These considerations suffice to indicate the prudence, subtlety, and tact that the doctrine presented above requires if it is to be employed. Each teacher has to judge the particular circumstances in which he finds himself and decide accordingly the extent to which the new doctrine can be introduced. Practical experience, which has already been accumulated in the classrooms of primary education in the region of Montpellier, has shown that this measure is quite large.

$\$ 6$ What has been said is valid above all for the new terminology that has been proposed. Restoring the unity of numerous disparate facts, the terminology has, in itself, the effect of simplifying traditional terminology considerably. It uncovers the deep identity of disparate facts.

$\$ 7$ But as long as traditional terminology remains, the students have to learn both terminologies, and the simplification of understanding achieved will come at the cost of a minor augmentation in the number of terms to remember.

$\$ 8$ However, the two terminologies do not contradict each other in general. In many areas, teachers will be motivated to conserve, at least for a while, traditional terminology with those students who have already become accustomed to it.

$\$ 9$ The students will lose the advantage of rapidly seizing the entirety of mechanisms of the sentence, but they will gain insofar as they will not be completely disoriented by terminology that is completely new to them.

$\$ 10$ Experienced teachers will know to fluidly pass with subtlety from the one terminology to the other, without ever forgetting the official nomenclature that must be cited for exams, where the other terminology would probably not be understood (cf. above \$4).

$\$ 11$ Experience has shown that the combination of the two terminologies, when it is imposed, does not present large difficulties and is perfectly feasible.

$\$ 12$ Certain somewhat erudite terms can be replaced advantageously for the littlest children by terms that are more accessible to their young minds. Hence in the classroom of an elementary course where the method of graphic representation using stemmas has been introduced, the teacher who is pedagogically informed will not employ the word "stemma", but rather will invite the students to "draw the sentence".

$\$ 13$ The proposed doctrine, and above all the graphic method of representation that is its inseparable corollary, has the essential goal of capturing the sentence in all its variety and living complexity. The class that that becomes inspired by this doctrine and method will hence remain lively above all.

$\$ 14$ Certainly the necessity of a certain unity will motivate one to codify the procedures of stemmatic representation in concrete ways. But one should never forget that the stemma is a means of comprehension, not the goal in itself. 
\$15 While taking care to remove unhelpful contrasts, one will thus take great care to leave the stemma with all its subtlety and all its ability to model the infinite variety of sentences, and one will first and foremost guard against the ossification of stemmas under ridged forms that would quickly render instruction sterile. One must never lose sight of the fact that the stemma's only purpose is to get one to clearly understand the structure and organization of the sentence. From this point of view, a drawing that is, although somewhat unorthodox, insightful and hence demonstrates an understanding of the architecture of a given sentence has more educative value than the mechanical application and thoughtless memorization of a graphic formula. Above all, the stemma should remain intelligent.

$\$ 16$ On the other hand, the class must be active. That is, the stemma must not be imposed on the children as dogmatic truth. One must, in contrast, lead the children to arrive at the stemma on their own. To this end, one sends one of the students to the chalkboard, has her write the linear sentence, and encourages her to contemplate the sentence and to deduce the appropriate stemma. One should not prescribe an analysis that the children can discover for themselves.

$\$ 17$ It is due to this condition alone that the stemma will become a personal and lively means of grammatical expression. And in addition, the stemmatic representations have the advantage of showing clearly the opposition between linear order, represented by the sentence written from left to right on the chalkboard, and structural order, represented by the stemma on the chalkboard.

\$18 In order to apply the same procedure with an entire class, it is necessary to utilize the hand-held slates. One teacher who has acquired pedagogical experience with the method of graphic representation has drawn attention to the practical advantages of this manner of teaching in his report. While the one student works at the chalkboard, the others have to construct the stemma on their slates. Given a signal, the students then all raise their slates, showing them to the teacher. With a single glance, the teacher sees immediately whether the class as a whole has understood and who those are who have not yet comprehended.

$\$ 19$ Another remark that has been made is that while the children are always impatient to construct the stemmas, their attention slackens if the stemmas are always of the same form, that is, if one is dealing with stemmas the virtual versions of which are identical.

$\$ 20$ The teachers should introduce minor variants into the sentences that they place in front of the children. These variants will have, without hiding the essential facts that they are attempting to draw attention to, the effect of generating interest among the students and maintaining their attention.

\$21 In addition, variants of this nature will have the advantage of nipping in the bud the laziness that would be generated if one were to rely on the absolute uniformity of the stemmas in order to not have to contemplate the task at hand. 
\$22 Thus conceived, the stemma can not only be a tool that leads to insights into grammatical structure, but it can also be a means of rapid and effective control. The student who has produced a satisfactory stemmatic representation that is somewhat complex will have the proof that he really understood. This proof is infinitely more conclusive than the pedantic and too often empty verbiage that the classic means of grammatical and logical analysis place at the student's disposal. One can well imagine that these two instruments of torture could be replaced by simple stemmatic analysis (cf. Chapter $3, \S 13$ ), which would serve its purpose much better than the barbaric procedures that we expect from them.

\$23 It is also easy to imagine the incommensurable service that the stemmatic method could deliver to lexicography. Instead of presenting vocabulary facts in an order that is more or less alphabetical, dictionaries would gain clarity and would be easier to use, with a greater chance that one finds what one is looking for (one knows how rare success in this area actually is!), if they presented the material in stemmatic order (cf. Chapter $122, \$ 9$ and $\$ 10)$. For example, it would be easy to have one entry for all those cases where two nuclei would normally receive a separate entry each, one for the governor and one for the subordinate. Take the expression avoir le droit 'have the right': should one look under the entry for the governor avoir 'have' or under the entry for the subordinate droit 'right'? If one agrees about this matter, one would avoid long searches in two spots. Of course once the principle is established, it would have to be generalized and equally valid, for example, for expressions containing a noun and an adjective, the latter being subordinate to the former: bon droit 'good right' [cf. à bon droit 'with good reason, legitimately'].

$\$ 24$ It seems that there would be interest to classify all the expressions with the subordinates, since, the subordinates being more varied, organization would be split between more numerous articles in such a manner that each of these articles would be shorter and the whole would become briefer. Just as avoir le droit 'have the right' would have to be located under droit 'right', bon droit 'good right' would have to appear in the article bon 'good' (cf. Chapter 122, \$9 and 10).

$\$ 25$ The method of exposition of the advocated doctrine will be constituted essentially by the order in which the facts are presented.

$\$ 26$ It goes without saying that the theoretical order, which is logical and founded in reason and which has been presented in the preceding pages, is not suited in practice for the instruction to children.

\$27 Certainly the good pedagogical principle to respect should be one of increasing complexity. One should begin with the simplest sentences and stemmas.

\$28 From a certain moment, it is possible to develop the acquired scheme in different directions. It would thus be tactless to exhaust one of these directions, as was done in the theoretic exposition above, before passing to the others. 
\$29 From a practical standpoint, one has to push in all directions little by little, passing from one direction to another constantly, in a manner that grows the size of the circle by adding increasingly more complicated facts, which are arranged around the simple central schema. In a word, one begins by establishing a simple sentence, then by packing the snowball bigger.

\$30 To this effect, the teacher, when preparing for class, has merely to organize the symbolic stemmas, which provide the framework for his course, in the order of increasing complexity. With a bit of practice, the teacher will be in a position to rely on his imagination and to improvise as many examples in class as are necessary to convey the notion at hand.

\$31 The teacher will often be led to modify his plan according to the needs of the class and to the challenges of the sentence with which he begins. He will quickly recognize that his teachings will be all the more effective if he can better accommodate the needs of his students, and that his role is to direct, not to paralyze.

$\$ 32$ From this point of view, it will be necessary to contemplate the following principle: The teacher proposes, the student disposes. While of course maintaining his authority and supervision, the teacher will sometimes be better off following the course of interest suggested by the students, this interest being at times so difficult to arouse otherwise that one should profit from its presence when it does arise.

$\$ 33$ From a practical standpoint, the teacher will see that he rarely has to point to the problems. He will, rather, merely have to wait for these problems to become apparent to the students. He will then seize the opportunity to explain the problems. He will take care to answer the questions later that the students cannot answer for themselves when they first arise.

\section{Chapter 277. The program for the study of structural syntax}

$\$ 1$ Structural syntax encompasses all of grammar. It would therefore be a pedagogical error to attempt to teach it all at once. As for traditional grammar, one has to present the material in little doses, assuring that the one notion is perfectly understood and solidly acquired before passing to the next.

\$2 From here one must follow the necessity of a program that bears an order that has been adapted best to the acquisition of the principles of structural syntax in the classroom. One will find a sketch below of a program corresponding to a typical progression. ${ }^{320}$

320. This program has been established thanks to the kind aid of many teachers of primary and superior primary instruction: Madamoiselle Paravisol, former professor at the Ecole Normale 
\$3 The material to be taught has been divided into six successive stages. A preliminary table (cf. below \$6) furnishes the correspondence of these stages to the levels of elementary school, secondary school, and centers of professional education.

$\$ 4$ However, since the Diplôme d'Etudes Primaires Préparatoires Diploma of primary preparatory studies has the effect of skimming the primary schools after the intermediate courses to the benefit of secondary schools, the classes of the second cycle that replace the former superior courses are now lagging more behind than the classes of the corresponding secondary cycle. One has to heed the shift to see the limited possibilities of teaching grammar in the second cycle. The questions foreseen will be examined with much circumspection. The most difficult questions can be carefully placed to the side.

$\$ 5$ Finally, we indicate only the new areas that are to be explored at each stage. It is quite evident that this does not prevent teachers from returning to earlier concepts in order to promote acquisition and expand comprehension.

\section{$\$ 6$ Table of class ages}

\begin{tabular}{|c|c|c|c|c|}
\hline $\begin{array}{l}\text { Establishments } \\
\text { of primary } \\
\text { instruction }\end{array}$ & $\begin{array}{l}\text { Establishments } \\
\text { of secondary } \\
\text { instruction }\end{array}$ & $\begin{array}{l}\text { Centers of } \\
\text { professional } \\
\text { training }\end{array}$ & $\begin{array}{l}\text { Age } \\
\text { of } \\
\text { children }\end{array}$ & Stage \\
\hline Elementary course & $\begin{array}{l}\text { Dixième [2th grade] } \\
\text { Neuvième [3th grade] }\end{array}$ & \multirow{2}{*}{ First year } & $\begin{array}{l}7-8 \\
8-9\end{array}$ & $\begin{array}{l}\text { First } \\
\text { Second }\end{array}$ \\
\hline Intermediate course & $\begin{array}{l}\text { Huitième [4th grade] } \\
\text { Septième [5th grade] }\end{array}$ & & $\begin{array}{l}9-10 \\
10-11\end{array}$ & $\begin{array}{l}\text { Third } \\
\text { Fourth }\end{array}$ \\
\hline $\begin{array}{l}\text { Second cycle } \\
\text { 1st year } \\
\text { 2nd year }\end{array}$ & $\begin{array}{l}\text { Sixième [6th grade] } \\
\text { Cinquième [7th grade] }\end{array}$ & Second year & $\begin{array}{l}11-12 \\
12-14\end{array}$ & $\begin{array}{l}\text { Fifth } \\
\text { Sixth }\end{array}$ \\
\hline
\end{tabular}

d'Institutrices [Normal school, that is High school for primary school teachers-to-be] in Montpellier, Mademoiselle Touret, professor with the Institut de Formation Professionnelle d'Institutrices in Montpellier, Mademoiselle Champsaur, former primary school teacher at the appended school of the Ecole Normale d'Institutrices in Montpellier, and Monsieur Hortala, primary school teacher at the Ecole d'Application de Montpellier. These teachers all receive my gratitude for their precious advice, that, since they are taken from a deep knowledge of the children and from great pedagogical competence and are remarkably consistent together, have served as the basis for the elaboration of the program above. 


\section{PROGRAM}

\$7 First stage.

\section{The stemma:}

Sentences with one actant, with two actants, with three actants.

Attributive adjective.

$\$ 8$ Second stage.

\section{The circumstant:}

Nucleus. - Twin nucleus. - Compound tenses. - Predicative adjective.

Junctions with junctives. - Junctives. - Triangles. - Diamonds.

$\$ 9$ Third stage.

\section{The connection:}

Adverbs subordinated to adjectives.

Types of words. - Full words and empty words. - Base quadrilateral.

Symbols. - Symbolic stemma.

Junction without a junctive.

SYMBOL of transfer. - Some simple first-degree transfers of the sort

$\mathrm{O}>\mathrm{A}$ and $\mathrm{O}>\mathrm{E}$.

$\$ 10$ Fourth stage.

Valency and actants. - Active, passive, reflexive, and reciprocal voices.

Sentence words.

Sentences with two actants and linear inversion.

Verbs without actants.

Apposition. - Apostrophe.

Plexus.

Transfer with a translative. - Source, target, and translative.

Simple first-degree transfer of the sort A $>$ O, I $>$ O, and I $>$ A: pronoun, infinitive, and participle.

Simple transfer of second degree of the sort I >> O: complement clauses.

Transfer of the sort I >> E (temporal clause with 'when' alone).

Transfer of the sort I >> A. - Antecedent. - Agreement of the participle. ${ }^{321}$

\$11 Fifth stage.

Anaphora and anaphoric words.

Sentence words.

321. Translators' note: Of course this program was initially designed and tested on Frenchspeaking students, for whom participle agreement is a source of great difficulty - the rules vary depending on whether the participle follows the auxiliary être 'be' or avoir 'have'. Details aside, the program Tesnière suggests here is applicable to many other languages. 
Comparative sentences. - Bifid sentences.

I > A and I > E transfer: verbal adjective and gerundive.

Attenuated transfer: article and personal index.

Fixed transfer: derivation and composition.

Transfer without a translative.

Second-degree transfer. - Classification of subordinate clauses.

Transfer of the sort I >> A. - The relative clause. - Its complex nature. -

Accessory and essential relative clauses.

Transfer of the sort I >> E (conditional subordinate clauses with 'if' alone).

$\$ 12$ Sixth stage.

Inserted clauses.

Nuclear and connective questions and negations.

Double bifidities. - Restricted bearing.

Complex first-degree transfer: inverse, double, multiple transfers.

Simple second-degree transfer of the sort I >> O. - Direct and indirect

speech - Direct and indirect questions.

Multiple second-degree transfer.

Transfer of sentence words.

Variation in the number of actants. - Factitive voice. - Recessive voice. - Inherently or accidentally reflexive verbs. ${ }^{322}$

\section{Chapter 278. Conclusion}

\$1 Having arrived at the end of this work, the author feels some anxiety concerning the retrospective antinomy between the voluminous proportions that his book has grown to and the demands of the material covered.

$\$ 2$ Is it indeed not a mockery to have invited the reader to read what the author can only call the elements of structural syntax, whereby a volume containing almost 700 pages and 300 chapters is demanded of the reader?

$\$ 3$ Nothing is more consistent with reality than this latter observation. The author is the first to have recognized this disappointing situation.

$\$ 4$ It is unfortunately true that despite the length of his work and the exposition of the facts upon which the structural doctrine, which he wanted to separate from these facts, rests, the work is lamentably incomplete.

$\$ 5$ If the author wanted to produce an excuse for the reader, he would seek it in the actual extent of the subject which he has had the temerity to attack.

322. Translators' note: English has very few inherently reflexive verbs. An English-oriented program could have a chapter on phrasal verbs instead. 
$\$ 6$ In principle, no language has been excluded from the exposition, and while nothing has been scrutinized with the detail that it deserves and that the author desired, this situation is not because some languages were not a priori as of much interest to him as other languages, but rather because his information did not, despite the efforts of an entire existence, allow for the analysis of the prodigious diversity of the linguistic material that he wanted to consider. It is evident that the syntactic facts examined represent only a small part of the facts that one finds in the languages of the world.

$\$ 7$ One should also note that, even if one is a linguist, one cannot be a specialist in every language that one has considered in the course of general linguistic study.

$\$ 8$ The author also asks of the reader that he be granted patience concerning the facts that may not - despite the author's devotion to his work - stand up to the specialist's scrutiny.

$\$ 9$ This is due to the fact that there is some antinomy between the specialist's and the generalist's principles. The more languages the generalist's work considers, the more value it has. But it is also crucial that the greater the number of languages he examines, the less his work can specialize on any one of the languages considered. The reader would do well to acknowledge that everything that the work can gain because of the extent of the horizon of the linguist, it would necessarily lose in the detail of his specialization.

$\$ 10$ On the other hand, the author has in principle not wanted to acknowledge any limitation of the facts of structural syntax, and he has loyally committed himself to including these facts in his exposition, whatever their nature and whatever the syntactic system of the language from which they are taken.

$\$ 11$ Yet while he has had to observe, with great regret, the material impossibility of mastering the structure of several thousand idioms that are spoken on our planet and of which he could learn sufficiently only a small minority, he is all the more obliged to humbly acknowledge his incapacity to exhaustively examine all the facts of structural syntax presented to him by even just one single language.

$\$ 12$ Therefore he wishes arduously to find successors among his readers who will continue his work and who can bring the ambitious project to a good end, a project that the limits of human capabilities have prohibited the author from fully realizing. ${ }^{323}$

\$13 The hope arises that among those who continue the work, there will be some Pic de la Mirandole who is capable of suitably discussing de omni re scibili about every knowable thing' and de quibusdam alliis 'about some other things' in syntax. ${ }^{324}$

323. Translators' note: $:$.

324. Translators' note: Giovanni Pico della Mirandola (1463-1494), Italian humanist, synthesized the main philosophical and religious doctrines of his time. Pascal criticized him and his syncretism in Les Pensées, by alluding to those who pretend to discuss "de omni re scibili" (which was Pico's motto). 
$\$ 14$ But the complication and the diversity of the given facts of linguistics, as with every science, hardly permit modern man to hope for the hatching of such a rare bird, since modern man has, through his rough contact with reality, learned to be less presumptuous than his ancestors from the Renaissance. One can nevertheless hope that the structural typology of language will be established successfully due to the combined efforts of the best linguistic minds.

\$15 Insofar as the author has succeeded at adding his stone to the future edifice of structural syntax, he should be allowed to pass on to his successors, who he hopes are on the same path upon which he himself has embarked, certain recommendations that he considers essential.

\$16 As with every scientist who at the decline of his existence reflects on the evolution that he has experienced since his youth, the linguist is motivated to say or think: "If only I had known when I started with linguistics what I know now!” The linguist should be permitted to emphasize for those who will eventually continue the work the apodosis that might follow the melancholic protasis. He will be happy if this apodosis can be valued as an important piece of advice.

$\$ 17$ Moreover, the author must say that he also does not regret all the various areas in which he has been engaged. In particular, he retains an appreciative memory of those of his teachers in linguistics who, in building their linguistic self-examination in the same way as the author today, produced the following insight to his benefit: "Truly practice the languages that you speak and maintain knowledge of, this knowledge not being limited to just book knowledge. Speak foreign languages!” The author believes himself to have followed this excellent advice, insofar as he has devoted a large amount of his efforts to acquiring foreign languages with the direct method, which he has even applied to his study of ancient languages to the extent that it is possible. ${ }^{325}$

$\$ 18$ But there are linguistic ambitions that the necessities of his university duties have not permitted him to realize and of which he believes he must take the effort to make his eventual successors aware.

$\$ 19$ The limitations that syntacticians of general syntax run up against sooner or later are due to a large extent to the fact that the linguists who are susceptible to arriving at this general view of syntax are mostly specialists in a single language, and in general, in a single Indo-European language: Timeo hominem unius linguae 'I fear the man of one language'.

\$20 Their linguistic, and in particular, their syntactic horizon is hence narrow from the outset in a manner that is very inconvenient. The linguistic horizon of the linguist who studies only French is, with only very rare exceptions, confined only to French. This limited horizon often does not even provide the means of understanding the true syntactic originality of French. The

325. Cf. Lucien Tesnière, Pour prononcer le grec et le latin 'In order to pronounce Greek and Latin', Paris, Didier, 1941. 
Romanist is too often stopped by a curtain of linguistic iron as soon as he breaks out of the Roman and Latin world. The Germanist hardly departs from the Germanic world in which he is confined. The Indo-Europeanist himself, who is certainly keen on Indo-European, too often tends to see only a minority of facts that can be attributed to Indo-European, despite the great variety of languages with which he operates. Too deliberately he overlooks all the facts that arise from an evolution according to a non-European typology.

\$21 One cannot overemphasize that young linguists who desire to produce a general syntax should not forego an opportunity to increase their linguistic horizon, and to open their syntactic curiosity early on by giving all their attention on every occasion to "non-native" facts of syntax.

$\$ 22$ The author, who himself has had this constant preoccupation, cannot say enough about what his training in the syntax of languages owes to the study of languages such as Low Breton and Coptic, typologically so irregular in comparison to what we are accustomed to seeing in orthodox linguistics. These two languages, citing only them, have delivered syntactic observations infinitely more fertile than the Slavic languages, which form the center of his university career, but which have not generated much syntactic interest for him, since they are, at least from a syntactic perspective, often no more than a mildly interesting reflection of Indo-European typology.

\$23 Among the languages to which he has always been drawn from a syntactic point of view and which have always counted as the promised land into which he has never, despite his desire, been granted the right of entry, the author recommends that his eventual successors study languages that are different from the ones commonly taught in France, for instance Basque and Georgian, to which it would probably be necessary to add the Caucasian languages and the languages of the Red-Skins in America.

$\$ 24$ The syntactician who began, for example, with the study of Basque in his youth, who has acquired practical familiarity of this language, who has adapted to the Basque typology, which is so different from that of French, and who truly thinks in Basque, has thus gained the ability to confront the typology of French at every opportunity. Basque is a very old language and one can even presume that it is one of the last surviving representatives of a typology that is perhaps based on a "pre-logical" mentality, that is, on a manner of thinking and of structuring the sentence that has been replaced today by a mentality and a typology that is totally different.

$\$ 25$ One sees immediately all the advantages that there would be for the syntactician who is capable of operating with both typologies at the same time and who can thus systematically establish a direct comparison between them.

$\$ 26$ This is, all told, the happiness that the author wishes to his successors. He regrets not having been in a position himself to realize fully his project due to the demands of his university career and professional obligations that he carries and that have not left him enough time to devote himself completely to syntax. He apologizes to his readers for the brevity of human existence: Ars longa, vita brevis 'Art is long, life is short'. 


\section{Index of Terms}

\section{A}

A. See adjective, A-E-I-O

ablative $68,105,108,292,356$, $361,471,476,513-514,517$, 537-540, 546

ablative absolute 517, 539

absolutive 186, 192

accent 125-126, 155, 168-169, 387, $455-456,534,555,628$

accusative $68,107-108,158,163$, $166,244,258-259,274$, $425-427,438-439,538,574$

actant 71, 97-98, 100-108, $118-125,164-167,169-172$, 199-200, 239-245, 255-264, 273-275, 277-283, 288-297, 574-576

duplicated first $345-346,357$

first 100-106, 128-130, 132-139,

154-160, 241-245,

253-254, 257-258,

262-264, 266, 292-300,

$352-357,429-432,437-439$

new 261-264, 267, 296

projection of 169-174, 207

second 102-108, 128-131,

136-139, 157-158, 199-201,

241-245, 257-260,

262-264, 288-292,

$360-362,554-556,590-591$

second passive 104-105, 108

single 101, 241-242, 247, 258, $261,267,275,289,327,352$

third 102-105, 109, 121,

$128-129,131,138-139$,

157-159, 171, 258, 262-264, 288-294, 575

actants, inversion of $288-292$, 294-295

actant structure $263,267,271$, 278, 282, 288-294, 296-297, 299

adherence 29 adjectival 98, 182, 303, 371, 373, $506,508,516,566-567$, $572,574-577,587-589$ accessory 568, 629 essential 566, 628-629

adjective

attributive 62, 139-142, $145-147,149-151,155,176$, $180,182,368,461-462$, 587,590

circumstantial 62, 397, 449, 451-452

comparative $537,545,548$

demonstrative $64,84,488$

descriptive 415, 418, 444, 446-447

determinative 109, 418-419

general $61,418,454-456$

interrogative 194, 419, 625

nominal $367,379,407,415$, 418-419

numeral 63, 417-418, 481

personal 62-64

of personal relation $396-397$, $576,578,581$

possessive $63-64,82,84$, 139, 248-249, 253-254, 396-397, 419, 450, $576-577,581,588$

predicative $40-41,72,145$, 150-155, 157, 164, 179-180, $184,241,269,520,522$

qualitative $62,139,396-397$, 409, 411, 448, 476-478, $487,489,505-507,578$

of quality 625

of quantity 625

of quiddity $421,452-455,457$

relational 62,396

relative $84,486,505,534,589$

specific 415,420

subordinate $302-303,319,456$

transferred $380,415,478$

adjective category 396-397, 400,625

adjective-verbs 151, 480 adjunct. See circumstant adposition. See preposition, adverb postposition

causal $473,513,517,600$ goal 600,617

of location $306,374,396,532$

locative $67,305,458,467,470$, $506,513,546,595,625$

of manner $305,467,476,478$, $515,620,623,626,640$ quantity $185,216,421,428$, $473,503,510,622,626$

of quiddity $70-71,121,305$

relational 67,72

resultative $71,286,310,468$, 478,522

temporal 67, 305-307, 392, $467,472,541,595,597$, $599,625,638,641$

adverbial 71-72, 94-95, 182, $186-189,313-314,379$, $467,469,477,506,516$, 532

locution 72, 95, 153, 188, 379, $506,547,554$

adversative $317,335-336$, 340-341

A-E-I-O 57,325

affix 126, 130-131, 271. See also prefix, suffix

agent. See counter-subject agentive 259, 408, 497, 501 agglutinated 20-21, 39, 41, 113, 115, 117, 130-131, 413, 469, 519-520, 584, 586-587

agglutinating 21, 23-25, 39, $51-52,133,382$

agglutination 20-21, 24-25, 52, 130-131, 133-136, 138, $143,219-220,382-383$, $476-477,519,594-595$

degree of $21,24-25$ agreement 13-14, 30, 134, 136, $140,153,167,182,521,526$, 578-579, 590-591

gender 172,527

grammatical 13-14

number $163,578,590$

object $136-137$

participle 521, 589-590, 676 anacoluthon 82 
anaphor 79-85, 90, 131, 171-172, 211-213, 215, 254, 358-359, $570-571,580,584,588$ anaphora $78,80,82-83,358$, 360,676

anaphoreme 571,584 anaphoric $78-85,90-92,132$, $134,165-166,169-172$, $358-360,486,488,570-$ $581,583-589,646-647$

anontive $111-117,128,131,134-$ $138,165,171,200,209$, 240, 248-254, 437, 441

antecedent $79-80,315,455,552-$ $553,570,579,587-591$, 594-595, 600-601, 628, $630-631,635$

anticausative 577

antinomic 334-335

antiontive 111-117, 131-134, 136, $138,157,165-166,200$, 248-250, 252-253, 331, 401,520

aorist $69-70,72$

apocope 167

apodosis 605-606, 610-611, 649-650, 652, 679

apostrophe $143,160-161$, $165-167,174,676$

apposition 159-164, 166, $174,302,328,431,455$, 460-461, 491, 676

argument. See actant aspect 9, 42, 66, 68-70, 72, 88, $141,146,167,255,436$, 595-596

imperfective 69,436

inchoative $66,69-70,596$

perfective 69-70, 404

semelfactive 597

terminative 70,596

atonic 126, 155, 169

attraction 579, 620

attribute $77,117,145-146,160-$ $162,164,173-174,183-184$, $367-368,427-428,432$, 459-460, 471

attribution 104-105, 293

attributional 62, 64

attributive $62,139-142,145-147$, 149-151, 155-156, 161-162, $180,182,342-343$, 461-462, 587, 590

autonomous 20, 49-52, 131, 148-149, 251, 383, 385,
398-400, 406, 409,

413,476

autonomy of syntax 27-28

autoontive 111-117, 126, 131, 134, $157,165,184,248-252,331$, $401,423,578$

auxiliary 70-71, 114-115, 155, 245-246, 266, 268-269, 402-403, 519-521, 540-542, 589-591, 612, 639

causative 263-264, 266, 268-269, 299

auxiliated $40,124,155,210$, $245,266,268,295,402$, 480,519

\section{B}

bifid 349-352, 354, 356-358, 677

bifidity $351-354,356,358$

double 352-353

bifurcation 17

breaks (see also intonation)

$$
\text { 18-21, } 29
$$

\section{C}

case. See nominative, accusative, dative, etc.

category $41-43,70-73,75-77$, 286-287, 368-369, 371, $385-387,392-393,396-$ $398,400-402,412-413$, 439-441

adverb 481, 540, 595

general 53, 60, 396

grammatical 41-43, 286, 368, 406, 552

source $393,412-413,480,485$

verbal $398,437,440-441$

causal 297, 299, 316-317, 338-339, 473, 477, 513, 540, 572, 599-604, 614-617, 641

causative 261-274, 283-284, 292, 295-297, 299-301, 338,387

centrifugal $15-17,25-26,118$, 141-142, 144-145, 147$148,179,185,207-209$

centripetal 15, 17, 25-26, 141-142, $147-148,151$

change of location $286,311-312$

circumstant 97-98, 118-124, 129, 161-162, 171-172, 179-182, 259-260, 292-294, 305-306, 356-357, $575-577,581-582$ causal 297, 299, 540, 602

circumstantial $62,64,161-163$, 396-397, 449, 451-452, 568, 572-573, 586-587, $593,595,599-600$

manner 595,620

clause $315-317,424-427,438-440$, $551-558,561-563,565-568$, 574-579, 584-591, $593-594,602-626$, $628-632,634-638$

actantial 555, 599

adjectival $389,570,572$, 574-575, 577-578, 588, 590-591, 629

causal 316-317, 595, 599-604, $610,614-617,641$

circumstantial 72, 555, 593, $595,599-600,616$

comparative 621-622

complement 137, 253, 554,676

concessive $317,614-616,623$, 625-626

conditioned 605-607, 609-611, 613

See also apodosis conditioning 605-612

See also protasis conjectural 611-613 consecutive $586,616-617$ final 586, 600, 617-619 generalized indeterminative $623-627$ governing 187-188, 552-554, $561,566,568,579,593$, $602-605,614,616-617$, 630,636

governing governing $584-585$ hypothetical comparative 613-614 independent 434-435, $439,508,552-554,556$, $562-563,566,593,628$, $631,634-638,640-641$ infinitive $184,424-427,432$, 434-436, 438-440, 461-462

modal 600, 619-621

participle 461-462

relative $\operatorname{Lxxx}, 19,495,521$, 570, 586-587, 591, 677 subordinate conditioning 606, 608 suppositional 611-613 
transferred 557, 570, 593, 600,631

clitic. See personal index

color adjective 410-411, 447, 473,534

Colorless green ideas sleep furiously 35

comparative 186, 192, 226, 281, 306-307, 356-358, $510,537,545,548,613-614$, 621-622

comparative grammar 5,27 , 31, 297

comparison $354-358$

element of 354, 356-357

complement 37, 103, 105, $121-122,181,184,258,278$, $382,388,554,559$

object 105,554

complementizer. See transfer (deverbal)

composite $20,47,52,85-89,143$, $269,271,332,404,478$

concessive $161,316-317,335,540$, $568,573,614-616,623$, 625-626

concomitance $86,88,640$. See also secution

concomitant 246, 436, 459, 463-465, 479, 497-498, $515-516,547,596$

condition 72, 161

conditional LXXIX, 435-436, 459, $563,572,594,603-605$, $610-613,632,649,677$

conjectural 434-435, 459, 611-613

conjugation $43-44,65,115,128$, 132-133, 135-138, 148, 271, 401, 408

object $135-138$

personal 132-133, 135, 401

subject $136-137$

conjunction $44-45,73,75,325$, 358-359, 391, 556, 600, $602,632,637,641$

coordinate $75,325,391$

subordinate $75,325,391,413$ conjunctive $375,462,518,602$, $611,618,621,637$

connection 4-9, 12-14, 36-39, 78-83, 159-160, 164-166, 169-171, 205-211, 344$347,358-362,373-374$, $376-378$ anaphoric 78-83, 91, 132, 146, 166, 169-171, 207, 578, $585,589,642$

inferior $7,13,164,173,378$, 422, 427, 429, 437-439, $461,465,551$

semantic 36-38, 78, 80, 83, $85,155,159,169$, 358-360, 557

structural 5, 12-14, 17, 21, $36,38,78,156,169,360$, 556-557, 627

superior 139, 164, 173, 378, 422, 429, 437-438, 461, 465

connections, hierarchy of $7-8$, 19, 36

connective 203-207, 210-212, 214-218, 225, 227-228, 230, 232-234, 360, 525-526, 561-562, 564-565, 630-631

consecutive $338-341,586$, 602-603, 616-617, 620, 635

constitutive $39,48-53,74,325$,

content $403,413,623$

categorical $53-54$

semantic 47-48, 53-54, 66, 74, 89-91, 138, 201, 285, 296, 308, 402, 405

coordinate $75,316,319,321,323$, $325,391,557$

coordination $222,316,330$, 358-359, 555. See also junction

coped $342-344,350$

copula 154,429

correlative 578

counter-subject 105, 108, 295

D

dashed line. See anaphor line dative 109, 121, 158, 164, 181, 259, 451, 506, 509-510, 512, 514,638

declension $43,110,512-513,518$ demonstrative $50,59,64,84$, $88,90,134,137,571,573$, 575,579

dependency. See connection dependency tree. See stemma dependent. See subordinate deponent 279 derivation $149,377,380,383$, 387-388, 404, 407, 410, $496,506,549,677$

derivative $64,148,269$

diachronic 21-22

diathesis 104, 243-244, 247, 274, 278, 294, 431-432, 459, 498,552

active 104, 243-245, 247, 295,459

causative 261, 270, 296

passive 104, 243, 245-247, 264, 278-279, 295, 459, 466

recessive $261,274-275$, 278-281

reciprocal 243,255

reflexive $243,248,255,265$, $275,277,279$

discordantial 224-231, 234-235, 419

disjunction 563, 580, 583-584, 588

disjunctive 334,563

dislocation (left, right). See projection of actants

dissociated 40, 50, 53, 65, 70, 155-156, 159, 225, 309, $378,403,480$

divalent 239, 247, 256, 258-260, $262,264,267,271-275$, $277,280-283,292$

double-trigger 224, 229-231, 234 doubling 269, 623

dressed 307, 342-344, 350, 355, $460,509,512$

dual 116, 377

duplication 6, 101-102, 326-327, $343,345,347,349$, $356-358,360$

duration 10, 69, 86, 306, $470-472,516,596$, 604,641

\section{E}

E. See adverb, A-E-I-O ellipsis 157, 415, 490, 504, 507, $522-527,579,631,638$ elliptical 522-523, 525-526, $533-534,538,559,621$, 624, 630-631, 635-636, 639, 641, 643

English hypotaxis $318-320$ English preposition 398-399 English second actant 294, 304 ergative 106, 572 
est-ce 24, 198, 200-201, 206, 209, $454,563,630-631$

etymological 50, 376-377, 379-381, 392, 399, 410, $493,503-504,515,525$, $630-631,640$

etymologically $39,181-182,292$, 412, 418-419, 486, 493, $503,547,625,630-631,649$

etymology $39,50,94,252$, $278,359,380-381,400$, 409-410, 421, 424, 469, 474,476

exclamation $162,184,215-216$ exclamative $89,122-123,152,177$, 215-216

expressed form 28-30, 33-34

exprimende 28-30, 285, 301-303, 305, 313, 315-316, 319-320, 365

semantic 305, 319-320 extension 60-62, 74, 77, 229, 441 extra-nuclear 329, 375, 393

\section{F}

factitive 261, 268, 270, 274, 284, 287, 295-297, 677

finite verb. See verb forclusive 224-231, 234-235 form

compound 149, 232, 252, 410, $447,457,473,591$

contracted 531, 537, 539-540, $542-544,549,621$

personal $78,440,518$ formula $371,379-380,389$, 396, 486, 492, 494-496, 503-505, 507-510, $518-519,545-546,548$

French adjective $143,182,287$, 358,466

French adverb 182, 306, 335, 503

French circumstant 293-294, 314

French first actant 289-290, 298-299

French imperfect $85-86$

French personal index 49, 133

French preposition 48, 312, 523, 537

French second actant 291, 298-300

French sentence 15, 53, 131, 246, 255, 290, 294, 315, 362,570
French suffix 409, 466

frozen (see also derivation)

89-90, 128, 131-132,

$376-378,380,386-387$,

406-407, 409-410, 412,

function $518-519,537-538,540$

junctive 73,75

nodal $32,38,40$

semantic $38,40-41,46,50$, $155,403,480$

syntactic 224, 388, 398

translative $38,73,75-76,471$

\section{G}

gapping. See anacatadidymic

gender 112, 114, 135, 137, 140, $161,163,172-173,447$, $463-464,489-493,520$

feminine $380,489,492,504$ masculine $417,489-490$

neuter 42,172

nominal categories of 463,589

genealogical 9, 21-23, 25

genealogical classification 21 , 23,25

genitive 445-446, 448-452, 454, 486, 494-495, 504, 506, $514,517,526,540,576-577$

genitive absolute 517,540

German adverb 306, 308

German circumstant 294, 298

German first actant 294, 298-299

German particle 310, 312-313

German preposition 287 , 382,448

German sentence 16, 122-124, 290, 301, 308, 422, 563

German suffix 149, 476 gerundive $303,305,310,413,479$, $515-516,535,538,620,677$ glossogenetic hypothesis 134 governor $5-7,12-13,15,32$, $36-37,345,356-357,360$, 438-439, 492-494, $513-514,566$

\section{H}

haplology 522-523

head-final. See centripetal head-initial. See centrifugal hypostasis 159 hypotaxis $316-319,321-323,573$

hypothetical 572, 604, $610-614,628$

I

I. See verb, A-E-I-O idiom 386, 611, 615. See also frozen, locution

illogical 340, 591, 606

imperative 70-71, 92-93, 129-130, 157, 161, 165-167, 250, 286, 306, 313, $433-434,442-443$

imperfect LXXIX, 86-88, 133-134, $199,611,613$

imperfective 69-70, 72, 404-405, 436-437, 596

impersonal 48, 133, 240, 282, $437,511,516$

inchoative $66,69-70,72,596$ incorporated 126, 134, 137-138, $157,164,169-170,280$, $358,410,620$

index 76-78, 106, 125-127, $129-133,135-138,169-170$, 173, 266, 281-284, 383, 400-402, 491, 581

agglutinated 130-131

nominal $77,398,400-401$

personal 50, 52, 54-55, 76-78, $126,128-130,132-136$, $138-139,157,383-384$, $400-401,632$

reflexive $248,266,284,292$ indicative LXXIX, 76, 136, 416, 422-423, 433-434, $442-444,596,604-606$, $611,615-617,626-627$

inessive 514,518

infectum 105, 436, 613

infinitive 57, 246-247, 398, 421-424, 427-442, 458-459, 465-466, $510-513,541-544,551-552$, 559-560, 615-616

passive 57,431 inflection 167, 269-270, 387, 579 innere Sprachform 5, 59 insertion 556-557

instigator 261-262, $266-267,297$

intension 60-62 intention 221, 267, 617-618 interior form $27-28,43,581$ 
interjection $44-45,88-89$, $92-93,167,433$

interrogative 59-61, 63, 122-124, 191-212, 214-217, 419, 561-565, 601, 618, $622-625,630-631,635$

binuclear 201-203 connective 203-205, 207, 210, $214-216,562,564-565$

indirect 562-565

indirect nuclear 564-565

nuclear 193, 196-197, 203-205, 209, 215, 564

intonation 168, 204-207, 210

intransitive $66-67,241,247$, 271-273

intra-nuclear 329, 376, 393, 483,527

introspective method 30-32, 88,204

invariable $51-52,132-133$, $182-183,375,377,402,413$, $463,474-475,570-572$, $579-581,590$

inversion 100, 107,123, 130, 204, 207, 209-210, 245, 247, 289-291, 294, 422, $563-565,630$

irony $89,177,220,271,382$, 629,648

subordinate 629,648

\section{J}

junction 75, 95-96, 325-331, 333, $335,341-343,349,351-361$, $365,595,645,676$

anaphoric 358,360

total 349-350

junctive $73-75,222-223,325$, 328-330, 332-341, 354, $359,391,573,616$, 623,676

antinomic 334-335

of sentences 334-335

of words 325,334

\section{L}

language

agglutinating $23-24$

centrifugal $15,17,26,118$, 207-209

centripetal 15-17, 26, 118, 207 interior form of $5,28,43$ target 285, 289, 295 languages, history of $20-21,23$ Latin grammars 182, 246, 365, 471,573

Latin loanword 422, 498

Latin parataxis $318-320$

Latin preposition 68, 523, 537

Latin suffix 111, 408

Latin syntax 14-15, 46, 387

Le silence vertébral indispose la voile licite 35,37

liaison 143-144, 297, 573

limitative 228-229

line 10-11, 37-39, 69, 72, 121, 149-150, 155-157, 160, 328, $344,353,416$

anaphor $78,155,157$

connection 5-6, 8, 39, 150, 157, 160, 205, 209, $344-347,349,401$

junction $328,344-345,347$, 349

linear 10-18, 21, 27-29, 41, 44, 288, 332, 334, 371-372, $375,483-484,672$

linearization $15,25,141$ loanword 410, 422, 493, 533 locution $87-88,95,153,188,192$, $336-337,378-379,469$, $474,506,547,554$

logic Lxxix, 33, 35, 41, 45, 60, 98, $100,213,242,335,338$

logically $18,26,124,241,326,554$

M

manner, adverb of 72,307

marker 29-31, 277-280, 383-385, 445-447, 457-458, 471$474,477-479,484-490$, 494-496, 503-510, 562-565, 606-609

analytical 245,300 causative 272,283 double $485-486,502$ external 270, 556 of hypothetical meaning 612-613

interrogative 46, 206-207, 608

morphological 28-30, 32, 34, 73, 75-76, 261, 276, 295, $323,371,384-385,604$

negative 217-218, 220-221, 231 passive 278-279

reflexive $251,274,279$ synthetic 269

zero 29, 273, 279, 385

masculine $42,46,110,112,115$, $134-135,143,164,200$, $416-417,422,489-493$

meaning 28-29, 33-37, 140-144, 245-247, 259-261, 268$272,275-276,340-342$, 402-404, 566-568, $575-577,611-615$

metataxis 285-289, 291, 293-295, 297-301, 303, 305, 307, $309,313,315-317,321,323$

mitigated 17, 25-26, 142, 179

mononuclear 202

monovalent 260, 272-274, 276, $278-282,327$

mood LXXIX, 432-435, 440, 444, 459, 462, 551-552, 604-606, 609, 611, 617, 620

impersonal 240, 246, 459

marked 434-435

personal 240, 246, 462, 479, 514,518

See also indicative, subjunctive, etc.

morpheme 40, 46, 403

morphological 27-30, 32-34, $73,75-77,136,245-246$, $276-277,323,369$, 384-385, 406, 604-605

morphology 27-29, 33, 103, $136,143,245,365$, $385,398,404-406$, 437,605

multiple wh-question. See interrogative (binuclear)

\section{$\mathbf{N}$}

ne. See discordantial negation 90, 191-193, 195, 197, 211-213, 215, 217, 219, 221-237, 300-301, 309, 333-334

anticipating 221

connective 217-218, 232-233, 236

double 232-233, 235

double-trigger 224, 229-231, 234

impermeable 232, 235-237

marker of $217-218,220,231$

nuclear 217-218, 232-233, 236 
permeable 235

negation raising. See negation (anticipating)

negative $213,232-234$

semi- 232,236

negative concord. See negation (double-trigger)

negative polarity. See negative (semi-)

node 6-9, 38-40, 94-95,

97-100, 139-140,

159-162, 172-174, 301-302,

327-330, 342-347,

$377-378,555-556$

adjectival 94, 178, 183, 186, 327

adverbial 94, 184, 186

central $7,9,15,94-95$,

98-99, 195, 218-220, 286,

435, 508

governing 301-302, 309, 343,390

governing verbal 347,565

noun $54,99,149,159-160$, 173-174, 176

sentence 17,54

structural 13, 38, 40, 480

subordinate 301-302, 321, 334, 342,347

verbal 94, 97-100, 165-166, 169-170, 344, 346-347, $353,390,407,551-552$, $555-556,561-562$

nodes

connected 304, 347, 349

hierarchy of $7,178,184-185$

nominal 94-95, 114-115,

139-140, 154-156, 159-161,

$174-178,423,426-427$,

437-442, 462-464,

495-496, 555-556

nominal forms 59, 109, 115, 176, $217,246,303,306$

nominative 106, 152, 166-169, 244, 248, 385, 432, 439, $469,472,572,574$

non-reflexive 248-249, 254, 276

noun $54-57,61-63,138-153$, $159-167,415-425,437-$ 442, 444-459, 467-475, 488-498, 530-537, 539-549, 635-643

abstract 302-304, 313, 409, 501 action $135,379,407-408,424$, $428,465,501,511$

central $160-161,176-178$ common $60-61$

compound 144, 147-148

general 59-61, 64, 194

general personal 63,74

governing 147-148, 302-304,

$367,454,462,508$

masculine $57,144,641$

neuter 395,541

particular 59-61, 64, 194

personal reflexive 248 , 251, 277

proper $60-61,76,137,384$, 387,490

reflexive $251-252$

subordinate $148-149,450,594$

transferred $385,393,407$, 446, 448-449, 473, 501, $525-526$

true $59,109,144,386$, 429-430, 442, 512, 555

nuance

circumstantial 161-162, 572-573, 586

semantic 301, 334-335, 381-382, 404-405

nuclear 192-198, 202-206, 208-210, 214-218, 227-228, 232-234, 329, $375-376,393,524-527$, $564-565,618$

binuclear 201-203

multinuclear 202

nucleus $38-41,48-50,73-75$, 192-194, 203, 210-212, 215-218, 236-237, 329, 373-379, 391-393, 523-527

central 220, 225

dissociated 40, 50, 65, 70, 155-156, 159, 403, 480

empty 194, 197, 210, 212, 214-215, 217

governing 525, 527

single $234,525,549$

nucleus circle 39, 50, 155, 329,

number $353,377-378,484$

cardinal 63,481

ordinal 102,481

\section{0}

O. See noun, A-E-I-O

object 101, 103, 105, 107, 135-138, $246-247,272,276$, $385-387,410-411,447,552$ oblique $128-132,268,385,387$, $469,472,577$

oblique indices, block of 129, 131 optative 221, 433-434, 565, 611,627

order

broken 14, 17

centrifugal $15,17,145,148$

centripetal 15, 17, 143-144, 185

dynamic 43-44

linear 11-18, 27, 29, 44, 288, $372,375,484,585,672$

reverse 143,610

static $43-44$

structural 9, 11-15, 17, 44, 288, 585,672

orthography $20-21,77-78$, 130, 143, 377, 464, 497, 501, $534,537,555-556,641$

\section{$\mathbf{P}$}

parataxis $316-323,556,569,573$ parenthetical $358-360$ participle 163-164, 195-196, 458-466, 497, 500-501, 514-515, 517-521, 535-540, $542,544,591,676$

active 246,465

active anterior 246,521

anterior 92, 245-246, 303, 459, 463-464, 466, 498-500, 516-517, 520-521, 589-591, 593

concomitant 246,459 , $463-465,497-498$, 515,547

former anterior $181,466,540$ past $15,245-246,403,408$, $459,463,473$

present 111, 247, 303, 376-377, $459,463,615$

partitive 143-144, 495, 531, 542,642

part of speech. See type of word passive 104-105, 243-247, 255, $258,264-265,278-279$, 281-282, 294-295, 403, 431-433, 459, 465-466

impersonal 71, 278-279, 282 pedagogical LXXXI, 16, 59, 95, $103,123,312,422,563$, $670,672-675$

pedagogy LXXXI, 32, 44 perfective $69-70,72,87,105-106$, $110,404,436-437$ 
perfectum 436,613

periodic 649-651, 653

permeable $235-236$

person

first 77, 109-112, 422

See also autoontive

second 83, 109-112, 434

See also antiontive

third 55, 83, 101, 109-112, 249, 422,628

See also anontive

personal $60-64,76-78,112-113$, $115-117,125-126,128-139$, 248-249, 251, 383-384, 400-401, 437-440, $570-576$

phonetics 22, 27, 126, 408, 419, 522

pidgin 219

plane 9, 28-30, 33-36, 41-42, $48,50,83,285,288,369$, 371,458

logical 41

semantic $33-36,42,48,50$, 285

structural 33-36, 48, 396

plexus 344-345, 347, 676

plural 55, 63, 115-116, 137-138, $167,172-173,248-249$, 251-252, 255, 327, $440-441,521$

poet 4, 11, 299, 444, 516-517, 653 poetic 16, 223, 501-502, 653

poetical 14 poetry $4,11,167$

polar question. See interogative (connective)

position

first $123,145,207,422,563$

second 123,422

postposition 106, 381-384, 391, 398, 468-469, $474,485,506,512,514$, 575-576, 608

predicate $8,98-99,150$, $152-161,173-174,184,361$, $460-461$

predicate-argument relation. See connection (semantic)

predicative $40-41,145,150-157$, $164,179-180,184,259$, $269,480,520,522,590$

prefix 39, 106, 111, 126, 133, 219-220, 268-272, $382-383,485$ preposition 106-109, 185-189, $365-367,381-384,447-$ 450, 467-469, 474-476, 502-507, 509-510, 529$539,541-549,636-638$

translative $479,638,643$ preterit 114-115, 270, 521, 612 preverb 20, 72, 251, 256, 259, 271-272, 403-405

primacy of syntax 29 projection of actants 169-174, 569

projectivity. See order (broken) pronoun 44-45, 59, 109, 126, 216, 413, 418-420, 426, $530,570-571,576-577,584$

affix 130-131

demonstrative 137, 171, 426, $571,573,575,630$

indefinite 53,330

personal $76,78,84,109,116$, 126, 401, 571-572, 574, $576,578,588$

See also personal noun relative $79-80,84,504-505$, 569-579, 581, 584, 586-589, 616, 621, 631, 640,642

protasis 599, 605-606, 610-611, $649-650,652$

psychological 35, 41, 110-111, $239,433,523,615$

Q

quality $36,60,62,64-65,150$, $152,155-158,161-162$, $186-187,356-358,411,625$

question $67-72,79,191-209$, 211-215, 223-225, 227, 229-231, 259-260, 561-562, 564, 606-607, 635

direct 564,635

indirect 561, 564, 635

quiddity $70-72,121,305,421$, $452-455,457$

R

recessive 252, 261, 274-284, 292, $498,577,677$

reciprocal 137, 243-244, 255-256, $266,431-432,676$

reflexive 137, 244, 248-255, 257, 265-266, 275-279, 281, $284,292,676$ relation

circumstantial 84, 396-397, 449

personal 63, 84, 396-397, 449,581

relative $79-80,84,199-200$, 504-506, 569-579, 581, $583-589,591,620-621$, $623,631,638-642$

relative clause. See subordinate clause (adjectival)

relative clause

non-restrictive. See subordinate clause (accessory adjectival)

restrictive. See subordinate clause (essential adjectival)

relativizer. See transfereme repetition $71,86,204,211,333$, 380, 452, 495, 533-534, 559,623

retransfer $485,500,594$ retranslative 487-488, 495, 500, 533, 542, 634, 638-640, 642-643

reversive $392-393,485-486$, 489-490, 493-494, 502505, 519, 530, 539-540, $542,544,546-549,643$

rhetorical $648-649$

right node raising. See sentence (catadidymic)

root LXXIX-LXXX, 39, 110, 143, 149, 266, 269-270, 280, $339,379,409,498$

verbal 266,280

Russian verb 309, 315

\section{$\mathbf{S}$}

Saxon genitive $365,449,589$ sebja, non-abridged personal noun $249,277-278$

secution 435-436, 479, 595-596, 606-607, 613

anterior 598, 613

posterior $597-598$

semanteme 40, 46, 403

semantic dependency. See connection (semantic)

semi-negative 232, 236

sentence

adjectival 94-95, 183-184

adverbial 94-95, 98, 186-187, 189,467 
anacatadidymic 353-354

anadidymic $351-352$

bifid 349-352, 356, 677

catadidymic 351

classical periodic 649,651

comparative $357-358,677$

complete 91,150

conditional 603-605, 610-611, 649

declarative 196-197, 203, 206, 215

first $80,157,335$

host $359-360$

hypothetical $610-613$

inserted $358-360$

interrogative $129,152,195$, 202, 212, 422, 630

negative $192,223,601$

nominal 94-95, 114, 151, $174-178,183,427,429$, 462,508

parenthetical 359-360

periodic 649-650, 653

predicate 151,154

rhetorical 648-649

short 90, 648, 650-652

simple 95, 97-99, 101, 103, 105, 107, 109, 111, 113, 325-326, 390, 645

verbal $94-95,97-98,154$

virtual 56,58

sentence word 88-93, 444, 461, 479-480, 500, 554, 594, $606,676-677$

affirmative 90, 554, 594

command 92-93

emotive 93,480

imperative 92-93

logical 92-93

negative 554,594

sequence $10-12,14-15,17,19,21$, 29-30, 144-145, 170, 172,

$174,559,587-588$

linear $12,14-15,17,21,120,588$

shod 342-344

signified. See exprimende signifier. See expressed form

source $371-373,376,378$, 381-383, 389-390, 393, 396-397, 402-403, 443-445, 473, 483-486, 500-501 source of transfer 409, 484, 493, 539,630

spoken chain 10-15, 18-21, 29,

129, 170-172, 225 ,

227-229, 236-237,

371-373, 584-586, 588, 594

stemma 5-9, 11-18, 34-42,

46-51, 56-58, 97-104,

106-109, 118-121,

$155-161,341-355,372-376$,

645-673

abbreviated 156

complete $645-647$

dressed 343,350

expanded 156, 159

real $57-58,372$

symbolic $57-58,98,302,674$, 676

virtual $57-58$

stemmatic representation 36 , $102,155,245,353,484$, 592, 671-673

stripping. See sentence (catadidymic)

structure, syntactic 35, 111, 390, $423,444,503,562,648$

subcategorization. See valency

subcategory 67-68, 402-405, 440, 480-481, 495-496, $518,529-530,537,539,595$, 638-639, 643-644

subject $6-8,98-101,103$, 105-107, 133-137, 242, 244, 281-282, 291-293, 311-312, $357-359,554$

subject-predicate opposition $98-100$

subjunctive $433-434,551,560$, $563,565,602,611,615-617$, $619-620,624,626,635$

subordinate $145-151,184-188$, 301-304, 389-392, 426-429, 450-451, $551-559,561-563,565-570$, 574-577, 584-590, 626-631

immediate 98, 100, 122, 124-125, 401

subordinate clause 184, 187-188, 508-509, 551-558, 561, $563,565-568,574-577$, 584-589, 593, 605, 627-631 accessory adjectival 566, 568, 629,677

adjectival 508, 566-568, $575-577,587-589,628-629$

causal 600, 602, 614

essential adjectival 566-567, 628-629

governing $584-587$

subordination 5, 200, 313, 316, $321,323,557,562,565$, 627-628, 630, 637

conjunction of $512,593,637$

subordinator $122-123,422,563$

subsidiary $48-52,74,126$, 403-404, 413

substantive. See noun

suffix 148-149, 251-252, 270-272, $382-384,406-409$, 437-438, 448-450, 476-477, 481, 485-486, 518,533

adjectival 392, 445, 506, 532 derivational $185,380,383,385$, 409, 444, 458, 501, 534, $537,545,548$

personal 437, 439

possessive $54-55,437-439$, 450-451

translative 440, 462 superlative. See absolutive superlative 192, 452, 494. See also absolutive

supposition 221, 610-612 symbols LXXIX, 56-58, 74, 90, $371-374,376,381,481$, $483,491,552,570$

syntactic structure $111,390,423$, $444,503,562,648$

synthetic 245-246, 268-270, 273, $275,295-296,358,406$, 479, $577-578$

\section{T}

target $285,371-373,378,383-384$, 389-391, 393, 396-397, 412-413, 445-446, $472-473,480,483-486$

of transfer 421

target category $76,393,396-397$, $412-413,480,485$

tense, lxxix 40, 42, 69-70, $86-87,102,114,402-403$, 
435-436, 606-607, 611,613

compound 20, 40, 114, 402-403, 519, 551, 590,676

future past 459

past 70, 86-87, 613

posterior past 436,604

present 606, 611

present past 611-612

tetravalent 259-260, 263-264

traditional grammar 59, 61-63, 75, 78-79, 92, 100-101, 103-104, 109, 240-241, $243,407,551$

transfer 325-326, 368-393, 396-401, 410-413, 418-421, 444-452, 466-469, 471-481, 483-498, 500-515, $517-549,551-560$

adjectival 412, 445-446, 455,457

adverbial 412, 467, 509 attenuated 398-399, 471, 677 cascading 389,569 component 528-529, 549, 644 connective elliptical 525 , $630-631$

deadjectival 371, 412, 415 deadverbial 371, 412 denominal 371, 412, 447 deverbal 371, 412, 516, 519, 569 direct 420-421, 501, 506, 523 double 391-392, 483-491, 493-496, 500, 502-510, 514-516, 518-519, 522-524, $528,538,594-597,635-638$

effect $398,400-401$

elliptical 523, 525-526, $533-534,559,621,624$, 635-636, 643 etymological 503-504, 640 first-degree 423-427, 439, 461-463, 507-509, $513,551-552,558-559$, 593-594, 598, 621-622, 633-634, 636-644

first-degree subcategory 548, $639,643-644$

fixed 498, 501, 537, 539, 545, $547-548,677$ formal 393-394, 396, 444

frozen $380,386-387,407$, 409-410, 412, 537-538

functional 405, 412

graphic representation of 371,374

inverse $389,455-456,492$, 504

marker-less 410-411

marker of $75,381,384,391$, $410-411,445,529,608$

multiple 392, 483, 485, 487, 489, 491, 493, 495, $527-529,549,633$, 643-644

nominal 412, 415, 496, 502,519

novonuclear 393

quadruple $392,542,546,642$ reversive $392-393,485-486$, 489-490, 493-494, 502-505, 519, 524, 530, $539,542,544,546-549$

second-degree 390-391, 425-427, 439-440, 551-555, 557, 559-561, 565, $569,593-595,597-601$, $619-623,633-644$

sextuple 548, 642-643

subcategory 440, 480-481, $485,495-496,518$, 529-530, 539, 543, 546, 638-639

triple $412,527-529,533,536$, $540,546,600,638,641$

transféré. See target

transfereme 571, 584-585

transférende. See source

transitive 66-67, 232, 243-244, $256,264-265,272-273$

translation $162-163,213,215$, 250, 285-286, 288-299, 325-326, 367, 370, 381, $385,497-498$

translative $73-77,371-373$, $381-385,396-402$, 484-488, 558-563, $570-573,575-581$, 593-603, 607-619, $621-627,634-643$

second-degree 391 translocality 68 transvaluation $473,475,503,533$, $539,543,546,621$

trivalent $239,256,258-260$, 262-264, 273-274, 280-281, 292

type of sentence $127,150,153$, $178,298,612,648$

type of word $44-46,57,62$, $77,88,124-125,305$, $312,368-369,382,385$, 390-391

\section{V}

valency $239-241,243,245$, 247, 249, 251, 259-261, 263-265, 267-269, 273-275, 279-281, 353

new 267-269, 273

value, semantic 79, 104-105, $134,266,273,277,282$, $335,380,396,404-405$, 627

verb

of action $65-67,106,241,407$, 409,520

auxiliary $65,74-75,119$, 155-156, 159, 204, 402-403, 519, 521, 590, 640,643

causative 267, 292, 295-297, 299

divalent 247, 256, 258-259, $264,267,273-274$, 280-283

monovalent 241-242, 247, $256,258,260,267,270$, $273-275,277-282$

nominal 40, 154-155, 427, 462, $480,520,539$

non-causative $264,269,272$

reflexive 248, 251, 266, $276-277,279,677$

of state $65-67,106,241,269$, 502,520

tetravalent 259-260

transitive 243

virtual $53,56-58,83,99,157,164$, $166,244,672$

voice $138,239,243-244,265,275$, 292, 295-296, 471, 477, $513,640,677$

middle 138 
See also diathesis

VP-coordination. See sentence (anadidymic)

\section{W}

wh-question. See interrogative (nuclear)

word

composite $20,47,52,85,87$, 89,404

constitutive $48-52,325$ content $368,375,381,396$, 400, 403

empty $46-48,51-53,61,63$, $73-76,79,83,85,211-212$, 403-404, 473, 475-476

full $46,48,50-52,56,73,76$, $79,86-87,94,404,473$, $475-476$

function 395

See also word (empty)

general negative 217,227 impermeable negative 235-236

incomplete sentence 91,132 , 554, 566

invariable $51-52$

limitative 228-229

negative $232,235-237$

permeable negative $235-236$

subsidiary 48-52, 126

word order 565. See also order (linear) 


\section{Index of Languages}

\section{A}

Albanian 423, 560, 583

Alemannic 131

Algonquian 116

Alsacian 48

American 26

Amerindian 116, 173

Arabic 26, 110-113, 141, 199-200, $207,332,422,442,569,597$

Armenian 22, 118, 142, 207, 332,558

Austronesian 26, 116, 179

Avestan 378

\section{B}

Baltic 249, 251, 424

Bantu 26, 172-173

Basque 65, 70, 106, 118, 207, $219,254,332,381,418,422$, $427,440,450-451,462-463$, $468,477,486,514,518$, 533,679

Béarnese 184, 208, 632

Bengali 560

Berber 65

Breton 128, 130, 133, 142, 210, 229, 252, 256, 383-384, 418, 420, 478, 487, 491, 562, 564, $569,582,590$

Breton, Low 154, 249, 252, 282, 332,631

Brythonic 142, 210

Bulgarian 114, 405, 423, 560

\section{C}

Caucasian 22, 26, 381, 679

Celtic 26, 141, 145, 282, 418, 582

Chinese 24, 26, 46, 52, 107, 118, $132,142,147,208,219$, 329,603

Chinook 173

Chuvash 118, 142, 150, 207, 220, 469,597

Coptic 147, 679

Cornish 210

Creole 117
Czech 114-115, 169, 219, 250-251, $341,450,558,562,564,583$

D

Dacian 560

Danish 245, 252, 254, 410, 478

Dravidian 24, 26, 116

Dutch 142, 207, 220, 332, 478, 493

E

Egyptian, Ancient 55, 141, 147, 219

Elamite 26

Eng., 21, 24, 46, 51-52, 70, 107-109, 117-118, 179, 229, 232, 240-241, 243, 245, 271, 275, 279, 288-289, 294-295, 301-303, 308, 321, 332-333, $335-336,358,361,379,388$, 392, 409-410, 418, 428, 436, 438, 442, 445-450, 457, 468, 481, 486, 493, 498, 519-520, 557, 569-570, 577, 607, 609, $615,623-624,636$

English LxxxI, 15, 26, 51, 64, 68, 71, 76, 81, 106-108, $113,116,125,127,133,140$, 142, 144-145, 152, 154, 161, 163, 170, 194, 196, 199, 201, 204-207, 210, 212-213, 216-218, 220, 223, 232, 236, 241, 245, 247-249, 254, 257-258, 273, 275, 280, 286, 288-290, 292-293, 295, 299, 301-304, 318, 321, 323, 332, $335-337,355-356,358,365$, $370,381,385,398-401,408$, $410,418,426-427,438,445$, $447,449,457,473,476,481$, 492, 504, 506, 509, 537, 553, $558,562,565,572,575-576$, 580, 589-590, 597-599, 601, $607-608,612,620,622-623$, 625-626, 628, 677

English, Old 409, 450, 580, 622

Eskimo 141, 148, 248, 254, 511, 597
Esperanto 57, 149

European 47, 57, 95, 97, 112, 126, 154, 195, 218, 264, 381, 400, $468,557,569,571,584,607$, 619-20

F

Finnish 210, 219

Finno-Ugric 142, 381

Flemish 154

Frankish 410

French, Old 50, 87, 144, 444, 521,650

\section{G}

Gascon 130, 184, 632

Georgian 22, 106, 118, 254, 272, $332,468,477,558,574,679$

Ger., 16, 20, 34, 46-47,

51-52, 63-67, 70-72, 90, 95, 107-109, 119, 134, 140, 149, $152-153,179,189,222,229$, 232, 240, 245, 247, 252, 257, 263, 270, 273-275, 279, 281, 286-289, 293-294, 297-299, 302, 306-310, 312, 315, 321, $336,338,403,405,407-409$, 412, 418, 424, 428, 431, 434, 436, 441, 444-445, 448-450, 470, 472, 474, 479, 481, 488, $498,507,513,516,519-520$, $522,526,544,557,563,569$, 577, 593, 597, 599-600, 607-610, 615, 623-624, 628, 636,638

German LXXX-LXXXI, 16, 26, $42,64,66,68,71-72,81,103$, $107,117,122,125,131,142$, 146-149, 152, 154-155, 164, 188-189, 194, 207, 211, 216, 218-221, 223, 231-232, 236, 241, 245, 248-249, 252, 254, 259, 268, 270-273, 278-279, 286, 288-289, 293-299, 301-302, 305-308, 310-313, 318, 321-322, 332, 336-337, $339,341,359,381-382$, 399-400, 407-409, 411, 
418, 422, 430, 433, 441-442, 447-448, 451, 455, 458, 469, $472-473,478,480-481$, 486, 488, 492, 498, 507, 512, $517,519-520,522,536,551$, $553,555,558-559,563,565$, 574-576, 578, 590, 597-602, 607-608, 611-612, 616, 619, $622-623,625-626,638$

German, Middle High 90, 231, 409, 498, 583

German, Old High 231, 410, 579

Germanic 26, 48, 71, 131, 145,

149, 201, 231, 251, 268, 270-271, 316, 318, 408-410, 447-450, 476, 498, 579, 590, $607,615,679$

Gothic 149, 231, 409, 579, 583

Gr., 69, 72, 106-107, 109, 134, 138, $140,158,162,167,181,217$, $237,246,274,316,333,410$, $418,425,434,439,441,445$, 448-450, 468, 470-471, 496, $498,510,513,515,520,526$, 529, 533, 537, 541, 546, 551, $561,571,573,575,577,589$, $615,623,641$

Greek 5, 26, 69-70, 103, 107-108, 110-112, 138, 147-148, 152, $156,162-163,167-168,174$, 188, 195-196, 201-202, 218, $233,236-237,240,242,248$, 258, 269, 280, 295, 332, 334, $381,387,399,405,410-411$, 418, 421-422, 426-428, 430-431, 433-435, 438-439, 441, 445-446, 448, 450, 458-461, 470, 472, 477, 486, 494, 496, 498, 500, 506-507, 509-510, 512, 514, 517, 537, $540,558,561,563,565,573$, $575,579,589,600,611,613$, $616,622-623,649$

\section{H}

Hamitic 112

Heb., 107, 109, 452

Hebrew 26, 110, 130, 134, 199-200, $265,270,422,451-452$

Hungarian 54, 57, 136-138, 381, $384,451,468$

\section{I}

Indo-European 22, 24, 138, 152, $246,252,269-271,280,282$,
$333,379-380,387,428,463$, $466,498,571,627,679$

Iranian 581,583

Irish 282, 455, 583

It., $118,130,449,454,457,476$, $488,520,607$

Italian $22,26,57,117,127-128,130$, $138,141,154,183,218,229$, 234, 277, 332, 354, 400, 408, 434, 454, 457, 479, 488, 492, $537,545,554,558,582,591$, $596,601,608,622,636,678$

Italo-celtic 282

J

Japanese 26, 213, 477

\section{K}

Kabyle 112-13

Khasi 25, 113

Khoekhoe 26, 116

Komi 118, 142, 150-151, 332, 469

Korean 26

\section{L}

Lat., $10,39,45-47,63,65-67$, $72,74-75,77,87,90,94$, 104-107, 109, 118, 121, 134, $146,149,158,161-163$, 165-167, 181, 194, 200, 208, $232-233,236-237,240,244$, 246, 252-254, 256, 258, 270, 274, 278, 287, 289, 291, 294-295, 307, 329, 333, 356, $358,361,379,381-382,385$, 398, 405, 408-409, 412, 419, 424-427, 436, 438-439, 441, 444-446, 448-450, 468-471, 480, 497-499, $506,513-515,520,526,531$, 537-538, 546-547, 551, 560, $563,569-573,575,578-579$, 586-589, 596, 598-599, $607,609-610,615,620,623$, $626-627,634-636,641$

Latin $26,39,45-46,50,57$, $67-68,77-78,87,103,105$, 107-108, 110, 118, 121-122, $133-135,151,154,162-163$, 166-167, 181-183, 201-202, 208, 212, 218-219, 221, 232-233, 236, 244, 246-248, $253,259,263,268-269,273$, 278-279, 282, 288-295, 297-300, 302-306, 308-309,
312, 318-321, 330, 332-333,

$355,358,365,379-381,383$,

$387,398-399,406,418$,

421-422, 424-427, 430, $432-436,438-439,442,446$, $448,450,454-455,457,461$, 465-466, 469, 471-472, 477, 479-480, 494, 498, 504, 506-507, 513-514, 517, 523-524, 535, 537-539, 541, 548, 551, 559-561, 563, 565, 573, 576-579, 584, 586-587, 589-590, 596, 598-599, 602-603, 608, 611, 613-617, $620,622-626,635,649$

archaic 450

Latin, Medieval 409-10

Latvian 66, 118, 142, 154, 208-209, 219, 251-252, 332, $398,424,470,477,561$

Lithuanian 118, 142, 207, 558

M

Malagasy 116

Malaysian 26, 116

Manchu 116

Maori 116, 179

Mari 82, 118, 142, 220, 332, 455, $469,561,581,589$

Mongolian 142

Munda 116

\section{N}

Norwegian $251-252,580$

\section{0}

Occitan 138, 154, 178, 184, 220, $241,253,273,400,493,508$, $554,582,591,601$

\section{$\mathbf{P}$}

Papuan 26, 116

Persian 445, 449, 583

Polish 24, 115, 118, 154, 169, 219, $251,341,520$

Polynesian 24, 26

Portuguese 440, 449, 591, 593

Provençal 154, 280, 582

\section{R}

Romani 118, 142, 158-159, 219, $269,558,561,574,586-587$, 597

Romanian 107, 118, 141, 207, 341, $478,558,560,582,591,593$ 
Rus., 64, 66, 69, 72, 90, 107, $109,118,134,146,179,208$, 213-214, 221, 229, 247, 252, $256,270,274,287,291,298$, 301, 306, 323, 336-337, 340, $382,408,416,424,432$, 448-449, 469-470, 472, 519, $521,526,532,577,595,607$, 609,623

Russian 8, 11, 22, 24, 26, 48, 63-64, 68-69, 103, 107-108, $114,118,126,142,151-152$, $154,156,158,167,174,201$, 205-208, 211-213, 218-221, $223,235-236,244,248-250$, 254, 277-278, 287, 291-292, 295-301, 305-306, 309, $312,314-315,318,321,323$, $331-332,336-338,340-341$, 395, 403-405, 408, 416, 436, $445,449-450,458-459$, 468, 471-472, 479, 506, $512,520,553,558,561-562$, $564,574-578,595,597,600$, 608-609, 612-615, 617, $622-623,626-627,629$

\section{S}

Samoan 132, 141, 147, 179, 468, 597 Sanskrit 110-112, 138, 168, 246, 270, 378, 402, 410, 412, 422, $428,434,558,571$
Scandinavian 142, 249, 251-252, 279, 298, 399, 410,580

Semitic 24, 26, 110, 112, 133-134, $199,265,422,452,582$

Serbian 128, 169, 424, 520, 558, $560,562,564,578$

Serbo-Croatian 114, 127, 154, 169, 202, 219, 332, 412, 454

Sino-Tibetan 24, 26

Sioux 116

Slavic 26, 28, 42, 48, 57, 68-69, $86,108,114-115,126,169$, 201, 236, 249, 251, 270, 318, 339-341, 399, 403, 405, 408, 412, 424, 448, 450, 472, $520-521,534,560,562,564$, $578,583,590,679$

Slavic, Old 270, 412

Slavic, western 251

Slovenian 270, 272, 341, 469, $520,560,574,583,615$

Somali 116

Sp., 107, 130, 141, 207, 408, 449, 454, 457, 468, 476, 486, 591, 636,639

Spanish $26,57,107,117,127,130$, $141,154,184,219,277,332$, 400, 454, 456-457, 487, 555, $558,582,591,593$

Subiya 141, 172-173, 597

Sumerian 26
T

Tasmanian 26

Tatar 142, 150, 220, 249, 381, 468,561

Tibetan 24, 26, 116

Tocharian 282

Tongan 173

Tuareg 65-66, 113

Tungusic 116, 142

Turk., 4, 432

Turkish 17, 24, 41, 55, 115, 142, 150, 220, 249, 265, 279, 331, $381,427,430-431,437-438$, 440, 450-451, 462, 468, 477, 486, 506, 508-509, $512-513,558,575,582$, 597,608

U

Udmurt 118, 142, 150, 249, 469, 561

Ukranian 118, 154

Umbrian 282

Ural-Altaic 22, 24, 26, 150, 468, 477

V

Vietnamese 24

w

Welsh 210, 418, 582

White Russian 118, 154 



\section{Index of Linguists}

\section{A}

Aristotle 98, 574, 635

\section{B}

Bach, Adolf 451, 583

Bally, Charles 10, 28, 149, 257, 279, 386, 388, 421, 475, 556

Basset, A. and Picard A. 112

Beaulieux, Léon 423

Benvéniste, Émile 79, 107, 111-112, 135, 169, 173, 240, $378,387,421,528,434,463$, 581-584

Bescherelle, Louis-Nicolas 500, 505, 632

Bloch, O. 3

Boas, Franz 173, 394

Boyer and Speranski 405

Bopp, Franz 5, 23, 27

Brockelmann, C. 452

Brøndal, V. 28

Brunot, Ferdinand 28, 35,242, $386,500,591-592,617$

\section{C}

Condillac, Étienne Bonnot de 35

Couroyer, Bernard 444

Cousin, Jean 57, 99, 139-141, 143, 171, 389-390, 446

Cuendet, Georges 579-584

\section{D}

Damourette, Jacques LxxIx, 40, 46, 110-112, 224, 226, 275, 500

Dauzat, A. 388, 491, 589

Deny, Jean 257, 279, 294

Desmouliez, André 527

\section{$\mathbf{F}$}

Finck, Franz Nikolaus 117, 254, 329, 333, 451

Fourquet, Jean LxxxI-LXxxII, 122

Franz Nikolaus 87
G

Gaffiot, Félix 527

Galichet, Georges 36, 56, 104, 110, 239, 276

Gèze, Louis 36, 440, 462, 518

Gottsched, Johann 98

Gougenheim, Georges 253, 284, $387,452,593$

Guillaume, Gustave $387-388$

Guitter, H. 117

H

Hanoteau, Adolphe 66, 113

Hatzfeld, Darmesteter \& Thomas 88, 442

Heidelberg, Winter \& Paris 25, 257

Hovelacque, Abel 25

Humbert, Jean 28, 237

Humboldt, Wilhelm von 5, 8, $12,23-25,27,59$

\section{J}

Jakobson, Roman 278, 331

Jeanjaquet, J. 89

Juret, A. $28,203,387-388$

K

Kluge, Friedrich \& Alfred Götze 442

Kravtchenko-Dobelmann, Suzanne 582

Krjučkov and Svetliev 8

Kuryłowicz 388

L

Laborde, P. 184

Lafitte, Pierre 254, 418, 422, 440, $462,514,518$

Lamouche, Léon 241, 253, 274, 400, 554, 582, 591

Le Baut, Louis 204-205

Littré, Emile 88, 500, 626

Luick, Karl 622
M

Malblanc, Alfred 64, 66, 71, 297, 299, 301, 305-306, 321-322, 516, 635-636

Marot 591

Marouzeau, Jules 23

Marr, M. 11

Meillet, Antoine 5, 23-24, $27-28,43,64,115,282,560$

Miklosich 560

Morhof, Daniel Georg 98

Mossé, Fernand 231, 583, 589

Moufflet, André 69, 103, 227, 230, 496, 500, 577, 581, 619,629

Müller, Friedrich 23

$\mathbf{P}$

Paul, Hermann 231

Pézard, André 622, 636

Pichon, Edouard Lxxix, 40, 46, 110-112, 224, 226, 275, 500

Port-Royal 35, 98

Porzig 387

Pott 23-24

Przyluski, J. 24

Q

Quintilian 192

R

Riemann \& Ernout 538, 579, 586, 636

Riemann \& Goelzer 299, 303-304, 458, 636

S

Saussure, Ferdinand de 10, 34, 534

Sauvageot, Aurélien 3

Schlegel, Friedrich 23

Schmidt, K. E. 446

Schmidt, P. W. 25

Sjoestedt, Jonval L. 455

Slotty, M. 388 
Sommerfelt, Alfred 145, 609

Steinthal, Heymann 24-25

Straumann, Heinrich 258

\section{$\mathbf{T}$}

Tesnière, Lucien LXXIX-LXXXII, $6,15-16,37,56,62,136$, $265-266,370,565-566$

Touzard, Jules 265
Trager, Georges 278, 331

U

Ušakov, Smirnova, and Ščeptova 8

V

Vaillant, André Lxxv, 106, 135, $154,454,560,572$
Vendryes, Joseph 5, 18, 45, 282, 455,572

w

Wilbois, Joseph 603-604 Wundt, Wilhelm 35

Z

Zamenhof, Ludwik Lejzer 149 


\section{Index of Citations}

\section{A}

About, Edmond 216, 588, 629

Achard,Marcel 599

Amiel, Denys 183, 187

Armont P \& L. Marchand 175

Augier, Émile 188

Aymé, Marcel 127, 188, 445, 543, 599, 627

\section{B}

Balzac, Honoré de 129, 228

Barrès, Maurice 494

Baschet, Roger 489

Bazin, René 178, 567

Beauplan, Robert de 454

Bernard, Jean-Jacques 544

Bertrand, Louis 456

Bible, Acts of the Apostles 357

Bible, Exodus 444

Bible, Genesis 17, 395

Bible, Matthew 130, 153, 598

Boileau, Nicolas 139, 157, 501, 510, 516, 624

Boschet, Roger 394

Bossuet, Jacques-Bénigne 16, $88,274,587,650$

Bouniol, Bathild 494

Brillat-Savarin, Jean 156, 622

Brontë, Charlotte 144

Byron 393, 575

\section{C}

Caesar 274, 318, 379, 424, 561, $569,587,589$

Céline, Louis-Ferdinand 153, $177,230,328,518,627,631$

Chaine, Pierre 581

Chamfort 354

Chancel, Jules 455

Chanson de Roland 50, 444, 521

Chateaubriand, FrançoisRené 129, 357

Chénier, Marie-Joseph 515, 576

Chéron de la Bruyère, LouiseMarguerite 178, 184, 627

Cicero 158, 162, 299-300, 304, 308-309, 318-320, 426, $448-449,586-587,634-636$

Combarnous, Gaston 184

Comtesse de Ségur 226
Corneille, Pierre 84, 165, 175, $329,359,429,521,652-653$

D

D’Avenel, George 222

Darcy, Paul 330

Daudet, Léon 174, 394, 612

De Boufflers, Stanislas 129

Delille, Jacques 640

Demosthenes 439

De Sauvages, Pierre-Augustin (abbot) 493

Descartes, René 615

Deschamps, François 176, 188

Destouches, Phillippe

Néricault 461, 602

Dickens, Charles 127, 361, 572

Du Bellay, Joachim 153

Duhamel, George 330, 454, 467, 625-626

Dumas, Alexandre 80, 94, 187, $355,361,453,511,533-534,542$, 618-619

E

Euripides 233

\section{F}

Fabre, Jean-Henri 34, 176, 530

Faguet, Émile 588

Flaubert, Gustave 178, 389

Fléchier, Valentin Esprit 617

Florian, Jean-Pierre Claris de 337

Fourcade, Georges 117

France, Anatole 373, 629, 654

\section{G}

Genevray 503

Génin, M., 627

Gide, André 589

Goethe, Johan Wolfgang 5, 16, $117,135,337,522,608$

Gogol, Nikolai 221, 301, 622

\section{H}

Haraucourt, Edmond 428, 430

Hebel, Johan Peter 131

Heine, Heinrich 16

Hermant, Abel 629

Hervieu, Paul 490, 535
Homer 333, 410-411, 649

Hugo, Victor 16, 24, 178, 460

J

Jean-Jacques Bernard 171, 531

Jonval, M. L. Sjoestedt 455

K

Krylov, Ivan 626

L

La Bruyère, Jean de $84-85,178$, $184,573,627,640$

La Fontaine, Jean de 178 , 327-328, 350-354, 358-359, $460,508,517,531$, $556-557,634$

La Harpe, Jean-François de 180, 488

Lamartine, Alphonse de 456, 515

Langer, František 341

La Petite Illustration 536

La Rochefoucauld, François de 129,566

Larousse (dictionary), 245, 262, 379, 417

Las Cases, Comte de 81, 336

Laveaux, Jean Charles 85

Lavedan, Henri $153,175,177,183$, $187,216,454,461,496,503$

Lavergne, Julie 226

Le Franc de Pompignan 120,

Le Matin 153

Le Monde 388, 491, 589

Lermontov, Mikhail 340

Lester, P. \& L. Millot 184

Lichtenberger, André 187,

$453-455,493,535,539$

Livy $303,308,586-587$

Lysias 641

M

Marguerite, Paul 82

Martet, Jean 600

Martin du Gard, Roger 177, 232, 284, 341, 456, 618

Maupassant, Guy de 89, 171, 209, 284, 453, 487, 618, 621

Mauriac, François 395 
Maurois, A., 517

Meilhac \& Halévy 171, 175, 465

Mencken, Henry Louis 495

Meunier, Mario 411

Midi Libre 235, 247, 330, 533

Mistral, Frédéric 508, 582

Molière 139, 165, 175-176, 234, 393-394, 511, 515, 558, 560,634

Montaigne, Michel de 600

Morand, Paul 417

Murger, Henry 128, 164, 632

Musset, Alfred de 332, 355, 357,501

\section{N}

Nadaud, Gustave 354

Nepos, Cornelius 287, 356, 586

Nibelungenlied 583

Nodier, Charles 235, 475, 504

Noé, Yvon 211

0

Ovid 596, 611

\section{$\mathbf{P}$}

Paris-Soir 454, 506

Pascal 170, 678
Péguy, Charles 463

Perrault, Charles 241

Phaedrus 293, 333, 427, 432, 471, 539, 546, 572, 598

Plato 163, 237, 649

Pompadour, Madame de 176, 548

Prudhomme, Sully 647

Pushkin, Alexander 213, 223

$\mathbf{R}$

Racine 82, 84, 497, 500, 505, 609, $628,633,635,652-654$

Régnier, Henri de 81, 177, 188

Rivarol, Antoine de 638

Rostand, Edmond 429

Rouget, de l'Isle 429

\section{S}

Sallust 588

Sand, George 269, 356, 588, 608

Sarment, Jean 457

Say, Jean-Baptiste 84,340

Schiller, Friedrich 5, 164, 578

Shakespeare 175

Sion, Jules 246

Stahl, P.-J., 256, 532

Stolz, Mme de 268
Storm, Theodor 480

Sudermann, Hermann 117

Suetonius 162

T

Tapié, Victor-Lucien 153

Terence 609

Tolstoy, Leo 221, 437

Tristan, l'Hermite 572

Turgenev, Ivan 287, 309, 395

V

Vauvenargues, Luc de 5, 332

Vergil 244, 450

Verne, Jules 504

Verneuil, Louis $176,183,186-187$, 352

Villon, François 457

Voltaire 84, 395, 500-501, 650-651

\section{$\mathbf{X}$}

Xenophon 163

\section{Z}

Zola, Émile 70, 165, 188, 284, $334,443,446,455,546,554$

Župančič, Oton 4 
This volume appears now finally in English, sixty years after the death of its author, Lucien Tesnière. It has been translated from the French original into German, Spanish, Italian, and Russian, and now at long last into English as well. The volume contains a comprehensive approach to the syntax of natural languages, an approach that is foundational for an entire stream in the modern study of syntax and grammar. This stream is known today as dependency grammar (DG). Drawing examples from dozens of languages, many of which he was proficient in, Tesnière presents insightful analyses of numerous phenomena of syntax. Among the highlights are the concepts of valency and head-initial vs. head-final languages. These concepts are now taken for granted by most modern theories of syntax, even by phrase structure grammars, which represent, in a sense, the opposite sort of approach to syntax from what Tesnière was advocating.

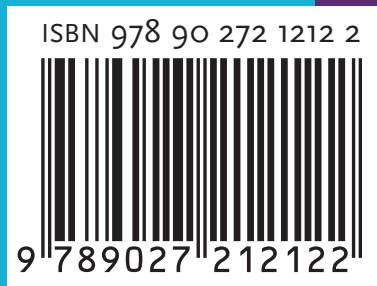

\section{John Benjamins Publishing Company}

